


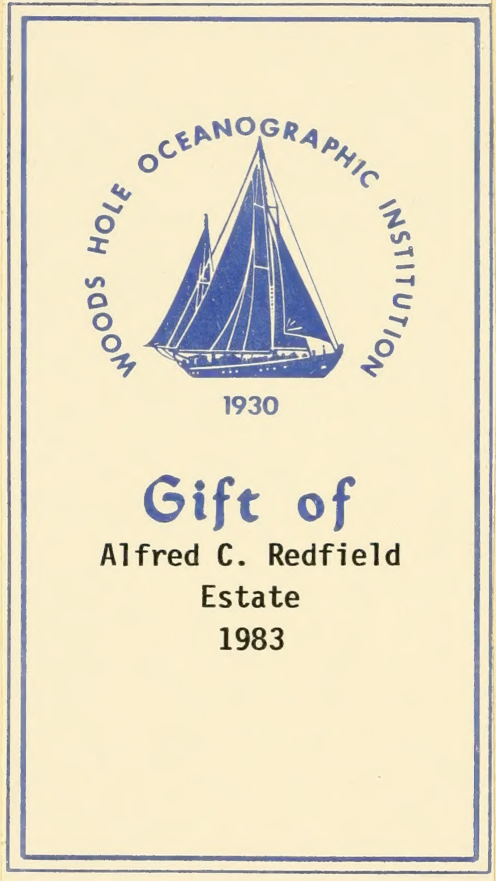



Cepuechoffier 

BAROMETRIC PRESSURE 



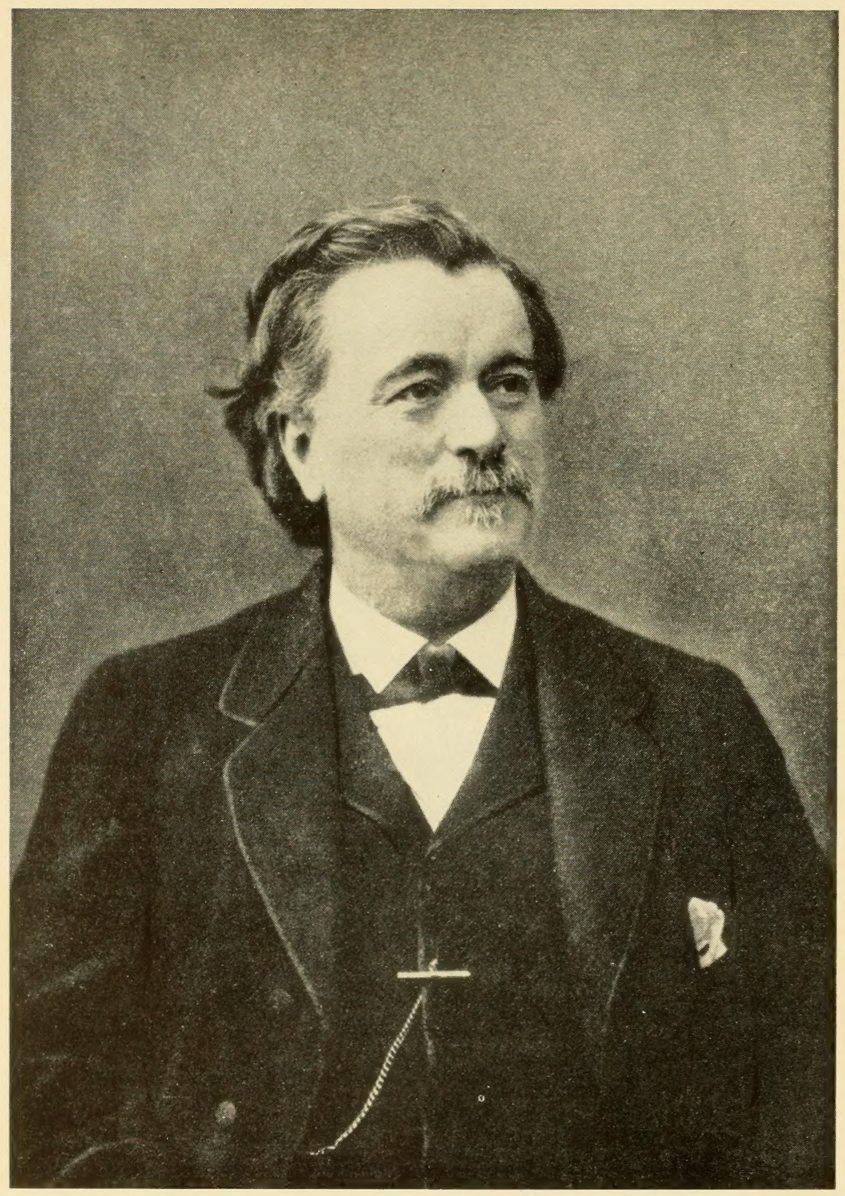

PAUL BERT

Born October 17, 1833. Died November 11, 1886. 


\title{
BAROMETRIC PRESSURE
}

\section{Researches In Experimental Physiology}

\author{
BY \\ PAUL BERT
}

\begin{abstract}
Translated from the French by
MARY ALICE HITCHCOCK, M.A.

Formerly Professor of Romance Languages at the University of Akron
\end{abstract}

and

FRED A, HITCHCOCK, Ph.D.

Associate Professor of Physiology at

The Ohio State University

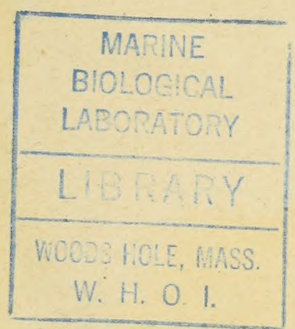

COLLEGE BOOK COMPANY

COLUMBUS, OHIO 
Copyright 1943

By

COLLEGE BOOK COMPANY

F. C. Long, Proprietor

THE F. J. HEER PRINTING COMPANY

Columbus, Ohio

1943 


\section{FOREWORD}

It can be said of Paul Bert as it has been of Vesalius, Harvey and Boyle, that the full significance of his work could not be fully appreciated until long after his death; but it is tragic that the chaos of a far-flung war was required to bring Bert's work into its full meaning and perspective. At a time when altitude physiologists and flight surgeons are being feverishly trained by all countries at war, it becomes of first importance to English-speaking peoples that the great classic of altitude physiology should be made available in the English language. Copies of the original French edition are exceedingly rare, and one therefore cannot praise too warmly the industry of Professor and Mrs. Hitchcock in preparing the English rendering, and the patriotic foresight of the publishers in thus making the text available to the flying personnel of our Armed Forces. That such a task could be accomplished in the midst of war is of itself gratifying, for it bears evidence that our perspectives and our scholarly traditions are being maintained and will survive during these years of stress and fury. As Professor Sigerist recently remarked in reviewing Howard Adelmann's translation of Fabricius, "Today when everyone thinks in military terms I would like to stress that the publication of such a book at such a time also represents a victory equally important to the capture of a strategic hill and more endurable. One can have full confidence in the future of a nation which in the midst of a bloody war possesses the intellectual and technical resources to produce such a document of scholarship."

The details of Bert's life are not widely known and it seems appropriate here to give a brief sketch of his meteoric career. Among his contemporaries Bert was probably better known for his pioneer studies on skin grafting-work that did much toward fostering the specialty of plastic surgery during the war of 1870-than he was for his studies in altitude physiology. Indeed in a notice published 
in the Lancet on November 20,1886, shortly after his death, there is no mention of La pression barométrique and little to suggest that Bert was a great physiologist.

Born at Auxerre on October 17, 1833, Paul Bert received his early education in the Department of Yonne. He had chosen engineering for his profession and had entered the Collège de St. Barbe with a view to preparing for the polytechnic school. He was dissuaded from this in favor of the law and passed his bar examinations successfully. But he soon found the law boring to his inquisitive mind and, for the third time, modified his course of study on becoming acquainted with Gratiolet, the Director of the Anatomical Museum in Paris. He eventually obtained his M.D. degree in 1863 at the age of thirty. During his years at Paris he had come under the influence of Claude Bernard in whose laboratory he served as an assistant. Bernard recognized his ingenious mind and predicted a brilliant future. His thesis, published in 1866 , on the grafting of animal tissues, attracted wide notice, and it won for Bert in 1865 the prize in experimental physiology offered by the Académie des Sciences. After teaching zoology for several years at the Faculté des Sciences at Bordeaux, he was appointed in December 1869 as Bernard's successor to the Chair of Physiology at the Faculté des Sciences at Paris. Bernard at the time occupied two chairs, one at the Sorbonne, the other at the Faculté, and he resigned the latter to make place for his brilliant pupil.

During the last two years of the Second Empire, Paul Bert made himself conspicuous in the political world by his uncompromising republicanism and at the fall of the Napoleonic dynasty in 1870 , he was rewarded by Gambetta with the Préfecture du Nord. Elected Deputy in 1871, he became noted for his constant opposition to religious congregation, which led eventually to the decrees of expulsion against the Jesuits, Dominicans and other orders. He was insistent that the state schools should be taught not by nuns and friars, but by non-sectarian personnel. In 1881 he was made Minister of Public Instruction in Gambetta's famous Grand Ministère, but he fell with his chief after an ephemeral exercise of power.

Following the death of Gambetta, Bert's political influence was on the wane and he returned to his scientific pursuits, obtaining a vacant chair in the Académie des Sciences. At the beginning of the year, the attention of the French Government was forcibly drawn to the highly unsatisfactory state of affairs in French Indo-China's Province of Tongking, and it decided to send out a Resident General vested with special powers to effect a thorough reorganization. 
Paul Bert was chosen for the post since he had always supported the French colonial policy, and he departed for the East in February, 1886. He was enormously active during his first five months at Hanoi and did much to effect a complete reorganization of the Tongking government; but in November he became suddenly ill and died of dysentery on November 11th, at the early age of fifty-three.

Paul Bert's activities had turned to altitude physiology about 1869 as a result of his friendship with a Dr. Jourdanet who had become interested in mountain sickness through personal experience while travelling in Mexico. Jourdanet was a wealthy patron of the arts and sciences, and he gave Bert the essential financial support for altitude studies, making it possible for him to develop several low-pressure chambers for man and animal. In the course of his investigations, Bert had sponsored an ascent in a balloon, Zenith, in which various determinations were to be made of the constitution of the upper air (April 15, 1875). This ill-fated expedition was undertaken by three balloon enthusiasts, MM. Sivel, Crocé-Spinelli, and the only survivor of the expedition, Gaston Tissandier. The account of the trip may be given in Tissandier's words:

"I now come to the fateful moments when we were overcome by the terrible action of reduced pressure. At 22,900 feet . . . torpor had seized me. I wrote nevertheless ... though I have no clear recollection of writing. We are rising. Crocé is panting. Sivel shuts his eyes. Crocé also shuts his eyes. . . . At 24,600 feet the condition of torpor that overcomes one is extraordinary. Body and mind become feebler. . . There is no suffering. On the contrary, one feels an inward joy. There is no thought of the dangerous position; one rises and is glad to be rising. I soon felt myself so weak that I could not even turn my head to look at my companions. . . . I wished to call out that we were now at 26,000 feet, but my tongue was paralyzed. All at once I shut my eyes and fell down powerless and lost all further memory."

The fatalities on the Zenith were due, in some measure, to competitive braggadocio, for the English balloonist, Glaisher, in 1862 had ascended to 24,000 feet and the Tissandier expedition wished to cutdo him. They had little notion of the dangers, nor were they aware of the peril of the fixation of ideas that develops under low oxygen tension.

Paul Bert began to work actively on respiratory problems early in the seventies, and in 1874 published a preliminary monograph of 167 pages entitled: Recherches expírimentales sur l'influence que les modifications dans la pression baromítrique exercent sur les phínomènes de la vie. This is taken up in part with a description of his admirably constructed low-pressure chamber. In 1878 he published 
the book here translated which has become one of the great landmarks of physiology-a book which stands as the very cornerstone of modern altitude physiology, La pression baromćtrique. Recherches de physiologie expírimentale, containing 1178 pages and 89 text figures. The first 522 pages deal with the history of altitude physiology up to that date; and if Paul Bert did nothing else, we should be lastingly in his debt for this masterly historical presentation-a model, be it said, for any student wishing to write in the field of medical history. The second part, occupying 518 pages, contains experimental protocols; the third and final part, which runs to 118 pages, contains his résumé and conclusions, and is again a model of concise, orderly and logical scientific presentation.

What precisely did Bert prove? There had been sharp divergence of opinion whether mountain sickness was due to diminution of barometric pressure per se, or to diminution of oxygen pressure. Bert performed critical experiments, keeping the absolute pressure of oxygen constant while lowering the total atmospheric pressure, repeating them time and again both in animals and man. By so coing he proved beyond all doubt that the principal symptoms of altitude sickness arise from reduced partial pressure of oxygen and not from diminution of total pressure. He thus applied for the first time to human respiration Dalton's concept of partial pressure which has become the basis of all subsequent work in the field of altitude physiology.

In one of his vivid lectures on the history of physiology, Sir Michael Foster said that science travels in circles: the concept followed yesterday may be dropped today and rediscovered tomorrow. One of those who did not accept Paul Bert's conclusions was that picturesque physiologist of Italy, Angelo Mosso, who maintained that at altitude one breathed so deeply that carbonic acid was lost with resulting alkalosis, and that oxygen-want played only a small part in mountain sickness, the major symptoms being due to "acapnia"-loss of carbon dioxide. Few in this century, save Yandell Henderson, have paid due attention to Mosso and acapnia, but we are coming once again to heed what he said. More is known now about acid-base relationships in blood and tissues. The carotid sinus reflexes have also been discovered. When blood of low oxygen saturation reaches the carotid sinus, a reflex increase in depth and frequency of respiration occurs. The partial pressure of oxygen is a primary and determining stimulus as Bert maintained; but under conditions of low oxygen tension, hyperventilation of serious proportions may occur, and we have reason 
to believe that pilots in the higher altitude ranges may in some circumstances hyperventilate to such an extent as to bring on tetany and even loss of consciousness.

Thus the pendulum swings; and if we wish to gain perspective for tomorrow, we look to the past and to the work of men like Robert Boyle, Paul Bert and Angelo Mosso who give us courage and inspiration to face the future.

Yale University,

John F. Fulton.

August 15, 1943. 



\section{TRANSLATORS' NOTE}

In his preface Paul Bert comments on his use of direct quotations in the historical part of this book in the following words, "In my bibliographic research I have repeatedly seen the affirmations of an author changed to negations by a series of translations and analyses." Again in a footnote on Chapter II he calls attention to the fact that a passage which he quotes from the French translation of the account of the balloon flights of Glaisher and Coxwell did not occur in the English text and adds, "Can it have been added by a fanciful translator? Traduttore, traditore" (translator, traitor). This evident distrust of our author for translators has been constantly in our minds and our translation is, therefore, somewhat more literal than it might otherwise have been. This policy has resulted in the use of certain words and expressions that are old fashioned; for example, we have used the word hematosis to mean arterialization of blood and we have retained the expression carbonic acid, even where our author is obviously referring to carbon dioxide.

In only two respects have we departed from the plan followed in the French edition. First, the footnotes, instead of being placed at the bottom of the page on which the reference occurs, have been grouped together and put at the end of the several chapters. This method is made mandatory by the mechanics of modern type setting, and also greatly improves the appearance of the page. Second, we have added an index. In the French edition there was no index and the detailed table of contents together with the list of illustrations was placed at the end of the book. In the English edition these have been moved to the front of the book and the index put at the end.

We wish to acknowledge our indebtedness and express our gratitude to the John Crerar Library of Chicago for the uninterrupted use of a copy of the original French edition of La Pression Barométrique over a period of more than two years. Coples of the book 
were also loaned us for shorter periods by the Library of Congress and by the Aero-Medical Laboratory at Wright Field. Photographic copies of the illustrations in the original edition from which the plates for the present volume were prepared were furnished us by the staff of the Wright Field Aero-Medical Laboratory. We are grateful to Colonel Otis O. Benson, Jr., who arranged to have this done.

Various agencies of the Ohio State University were of considerable assistance in a number of ways. Funds to help defray the cost of clerical assistance were furnished by President Bevis, and by the Graduate School upon the recommendation of Dean Alpheus Smith. The staff of the library furnished assistance whenever called upon, and Mr. Oscar Thomas and Mr. John B. Fullen of the Alumni Office were of great assistance in a variety of ways; we are especially grateful to them both.

Finally, we want to thank Professor John F. Fulton of Yale University not only for the preparation of the foreword, but also for his enthusiastic support and valuable advice throughout the entire project, and Mr. F. C. Long of the College Book Company, without whose vision and faith in Paul Bert the publication of the complete translation would have been impossible.

It is with some hesitation that we turn the manuscript over to the printer. It contains errors and imperfections. Many of these could be corrected by further revision, but such revision takes time and in the present state of the world it seems desirable to make Paul Bert's classic work available to the many English speaking investigators in the field of aviation medicine with as little delay as possible. We have therefore foregone further revision and polishing. We know nothing would please Paul Bert more than the knowledge that his work had been of use to the Allied Nations in their struggle to free his beloved country from the shackles of its traditional enemy. Paul Bert was a liberal, a humanitarian, and a loyal patriot, as well as an outstanding scientist. During the months that we have worked on the translation of his great book our admiration and respect for him have grown. It is our sincere hope that we have made none of his affirmations negations and that we have been translators without being traitors.

$$
\begin{array}{r}
\text { M. A. H. } \\
\text { F. A. H. }
\end{array}
$$




\section{TO DOCTOR JOURDANET}

My dear Colleague:

It is to you that I owe, not only the first idea of this work, but also the material means to execute it, which are so difficult to collect. I have been very happy to see physiological experimentation on one of the most important points of my study confirm entirely the theory which your intelligence had deduced from numerous pathological observations collected on the high Mexican plateaux. For all these reasons I should dedicate this book to you, and I do so with the greater pleasure because you are one of those persons who would make gratitude easy to even the most thankless natures.

PAUL Bert. 



\section{PREFACE}

No one doubts the considerable influence which changes in barometric pressure can exercise on living beings; we are even inclined to exaggerate its importance. If the barometric column rises or falls some millimeters, nervous or asthmatic people experience favorable or painful symptoms which they attribute to the heaviness or the lightness of the air. If this were really the cause, a walk from the banks of the Seine to the top of the Butte Montmartre or the converse should produce similar results in the same people.

But outside this group of data, to which I shall return in a moment, many remain which present a much greater interest, and which deserve to be studied with perseverance.

Are we dealing with increase in pressure? When, in the shafts of a mine or in the caissons intended to become the piers of a bridge, workmen are protected against the invasion of the water by air compressed by powerful machines to several atmospheres, they experience strange and sometimes dangerous symptoms during or after their stay in compressed air. Likewise divers who gather pearls, sponges, or coral, or attempt the salvage of sunken ships, furnished with diving apparatus and breathing an air whose pressure is proportional to the depth they reach, are frequently stricken by paralysis or death. On the other hand, medicine, making use of observations that are already old, has attempted with considerable success to make use of the influence of air at suitably low pressures, since the time of Junod, Pravaz, and Tabarié.

Are we dealing with decrease in pressure? We can mention first the symptoms which threaten aeronauts when their ascent brings them to heights above 4000 meters: nausea, vertigo, hemorrhage, syncope; then the phenomena which have been known much longer by all those who have attempted the ascent of mountains of over 3000 to 4000 meters, mountain sickness, about whose cause 
so many strange hypotheses have been suggested. Finally we find here data of a much greater importance. It is no longer a matter of a few workmen, a few invalids, or a few tourists, but of whole populations which normally and regularly live, construct cities, group themselves as peoples, in these lofty places where painful and sometimes unendurable sensations await the traveler.

We feel that here our problem affects not only the hygiene of peoples, but also to a certain point, their history and politics. In the Himalayas, in the Cordillera of the Andes, populous cities are built at heights greater than that of our Mont-Blanc, where no one completely escapes mountain sickness; in Mexico, thousands of men live on the plateaux of Anahuac, at an average height of 2000 meters; the great civilizations of the Mayas and the Nahuas had their maximum of development between 2000 and 4000 meters above sea level.

The reader can see by this brief survey in what important points the question affects the experimentation to which I have conscientiously devoted myself. It will consequently seem natural that such phenomena have given rise to numerous publications by doctors or travelers; but he will no doubt be surprised that so little has been attempted in laboratory experimentation to explain their cause. The simplest idea apparently would have been to construct apparatuses permitting one to reproduce changes in barometric pressure, isolating them from secondary conditions, uncontrolled variables, which inevitably accompany them in the state of nature, and to examine the immediate results of these changes on man and on animals. Now very little has been done in this direction. On the other hand, we shall find incomplete observations, pretentious dissertations, and probable or absurd explanations in great number.

My purpose has been to fill this considerable gap, and to solve these important problems by a purely experimental method.

In taking my position thus on solid ground, I had to set aside systematically three kinds of questions which could not be attacked in the laboratory, and for which consequently absolute conditions of proof could not be collected; that is: daily variations of the barometer, therapeutic applications and acclimatization in lefty places.

I do not regret the first question, which does not seem to me even to belong to our subject of study. Slight modifications in air pressure revealed by the barometric column in a given place are accompanied by too many other meteorological phenomena (hygrometric, electric, etc.) for anyone to determine the part, certainly very small, which they play in the condition of certain invalids. 
As to the other two questions, I have made great use of data given by authors who have discussed these topics, and I think that my own studies will not be without value in guiding physicians and hygienists in the midst of the innumerable difficulties which these questions involve. But I have not handled them directly, not only because of my medical incompetence, not only because laboratory experiments on birds, dogs, or even men could hardly settle them, but also for a special and rather personal reason.

Eight years ago, when Dr. Jourdanet, well known for his remarkable studies on the climatology of Mexico and for his theory of the anoxemia of altitudes, offered-with a generosity for which I hope the results of my work might be worthy recompense-to put at my disposal all the material means required by the researches whose importance and difficulty I had publicly indicated ${ }^{1}$ in 1868, a sort of tacit agreement was established between us. I was to limit myself to studying experimentally in the laboratory by means of my instruments the modifications which changes in barometric pressure would produce in the vital manifestations of animals or plants. Whatever the extent of my experimental equipment, these changes evidently could not be of long duration, so that if they were to produce convincing results, it was absolutely necessary that they should be extensive. Besides, this is the peculiar characteristic of laboratory experiments.

M. Jourdanet properly reserved for himself the study of the effects produced by slight variations in barometric pressure, acting either for a rather brief time upon invalids-a test the exquisite delicacy of which will always terrify experimenters a little-or for years upon the same individuals, or for centuries upon successive generations, joining their effect to those of so many causes known or unknown; dangerous problems, but very likely to fascinate a wise and eager spirit, aided by an eloquent pen.

We both accomplished our tasks; two years ago, M. Jourdanet published his fine book, Influence of Air Pressure on the Life of Man: Altitude Climates and Mountain Climates."

As for me, delayed by efforts outside the field of science, too often called from my laboratory by important civic duties, it is not until today that I present the properly arranged results of my long researches.

The present book which, if I am not mistaken, holds interest not only for physiologists, but also for physicians, engineers, and even travelers, is divided into three parts: history, experiments, conclusions. 
I have given the greatest pains to editing the history. I have tried to collect all that has been written on the subject of my study. It seemed to me that it would be very interesting for the reader to have thus before him all the pieces of evidence, with infinite variety of narration, frequent contradiction, and often instructive repetitions. I thought it best to give the actual works of the authors quoted: I distrusted even the most conscientious analyses; in my bibliographic research I have repeatedly seen the affirmations of an author changed to negation by a series of translations and analyses. Besides, summarizing and analytical chapters rest the mind of the reader; but each of the facts given there finds its proof in the preceding extracts.

In the second part my personal experiments are recorded. The titles of the chapters show the order in which I planned their exposition. A glance at the table of contents indicates that after studying directly the influence of changes in barometric pressure, I have devoted a few chapters to new researches on the physiolngical action of carbonic acid, on asphyxia, and on blood gases. The reader will see in perusing these chapters that I have not wandered as far from my subject as this mere statement of topics might imply; the numerous references to this part of my book that J. make in my conclusions give evident proof of this fact.

In reporting my experiments, which number about 670 , I have used the enumerative method; all those which seem to me interesting have been reported at length. This method has two advantages: first, it furnishes proof of all the conclusions, and second, it sometimes permits the reader to find in the account of the experiments what the author did not see there himself. Summaries added to each chapter facilitate rapid perusal of the results obtained. Finally I call attention to the fact that on each point the experiments are listed according to their date of performance; one can thus take account of observations which escaped attention at the beginning of the research, of improvements made by the experimenter, and consequently of the constantly lessening number of causes of errors.

Finally the third part is entitled: Recent Data, Summary and Conclusions. I first discuss the history which in the first part I carried down only to my own work. Then I draw conclusions from my whole series of researches. It will be seen that here my agreement with M. Jourdanet could not be carried out literally, and that I could not keep from trespassing somewhat on the domain reserved for him.

The third and last chapter, whose title is General Conclusions, 
contains only three pages. May this temperance in the summary bring me pardon for the eleven hundred and fifty pages which I thought necessary in order to bring the reader to this point! I leave to others the delicate task of deciding whether this antithesis deserves criticism or praise. I shall merely remind the reader, pleading at last extenuating circumstances, that since the Institute did me the honor in 1875 , on the recommendation of the Academy of Sciences, of bestowing upon my work the grand biennial prize, ${ }^{3}$ it seemed to me that it was my duty to spare myself neither time nor trouble to make the publication of my work more worthy of this great award.

Before finishing this preface, I must thank M. Gréhant and M. Dastre, my assistants in the chair of physiology of the Faculty of Sciences, Dr. Jolyet, assistant director of the laboratory, and M. Paul Regnard, assistant in the course, who aided me in my research with affectionate devotion.

$\mathrm{P}: \mathrm{B}$

October, 1877.

1 See my Lessons on the Comparative Physiology of Respiration; Paris, 1870, pages 121-130.

2 Paris. G. Masson. 1875. Second edition. 1876.

3 This award of the first order is given every other year, according to the terms of the constitutional decree, "to the work or discovery which has made the greatest contribution to th honor or the service of the country" in the last ten years, in rotation for each of the branches of human learning represented by the five classes of the Institute.

The triennial prize, by the decree of April 14, 1855, was decreed to M. Fizeau, in 1856; it was triennial only once, and by the decree of December 22,1860 , at the request of the Institute, it became biennial, and since then the awards have been as follows:

To Thiers (Académie française), 1861.

To Jules Oppert (Académie des inscriptions et belles-lettres), 1863,

To Wurtz (Académie des sciences), 1865.

To Felicien David (Académie des beaux-arts), 1867.

To Henri Martin (Académie des sciences morales et politiques), 1869.

To Guizot (Académie française), 18i1:

To Mariette-Bey (Académie des inscriptions et belles-lettres), 1873.

To Paul Bert (Académie des sciences), 1875.

To Chapu (Académie des beaux-arts), 1877.-(Editor's note.) 



\title{
TABLE OF CONTENTS
}

\author{
First PART
}

HISTORICAL

Title I. Diminished pressure

Preliminary chapter: the lofty regions of the globe

Europe _..... 6

Asia _... 10

America

Africa

Islands _. 15

Summary _. 16

Eternal snows

Living organisms 18

First chapter. Mountain journeys

1. South America

The Conquerors. Acosta. De Herrera. Frezier. Bouguer. La Condamine. Don Ulloa. A. von Humboldt. Wars of Independence. S. Haigh. Miers. Caldcleugh. Schmidtmeyer. Brand. De la Touanne. Temple. Bollaert. D'Orbigny. Poeppig. Boussingault. Meyers. Ch. Darwin. Smyth and Lowe. Arch. Smith. Cl. Gay. Von Tschudi. De Castelnau. Weddell. De Saint-Cricq. Gillis. Lloyd. Grandidier. Burmeister. Markham. Martin de Moussy. Mateo Paz Soldan. Guilbert. Pellegrino Strobel. Focke and Mossbach. Pissis. Wisse. J. Rémy. Steubel.

2. Central and North America

Wafer. Dollfus and 'de Montserrat. Burkhardt. Elliotson. Glennie. Gros. Truqui and Craveri. Laverriere. Sciẹtific Commission of Mexico. Von Muller. Fremont. Gunnison. Hines. Williamson. Coleman.

3. Etna Bembo. Filoteo. Fazello. Borelli. Riedesel. Demeunier. Houel. Delon. Dolomier. Spallanzani. Ferrara. De Gourbillon. De Forbin. De Sayve. 
4. Peak of Teneriffe

R. Boyle. Edens. Feuillee. Glas. Riche and Blavier. Von Humboldt. Cordier. L. de Buch. Dumont d'Urville. Le Guillou. Ch. Sainte-Claire Deville. Itier. Madame Murray.

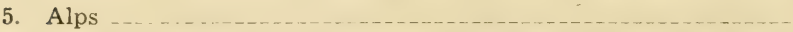

Bourrit. Laborde. De Saussure. Beaufoy. Forneret and Dortheren. De Lusy. Van Rensselaer. Hamel. Clissold. Clark and Sherwill. Hawes and Fellowes. Auldjo. Meyer. Parrot. Vincent and Zumstein. Molinatti. Hugi. H. Cloquet. Martin Barry. Atkins. Mademoiselle d'Angeville. Desor. G. Studer. Spitaler. Forbes. Lepileur. Bravais. Martins. Chomel and Crozet. Tyndall. Tyndall and Frankland. Pitschner. Piachaud. Lortet and Marcet. Durier. A. Tissandier. Hardy. Tuckett. Kennedy. C. Grove. Visconti. Gamard. Joanne. Ormsby. H. Russell.

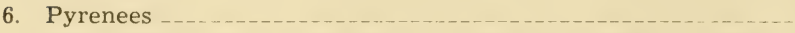

Rob. Boyle. Dralet. Ramond. Arbassiere. Cordier and Neergaard. Parrot. De Franqueville. Russell-Killough. Le Mulahacen.

7. Caucasus. Armenia. Persia

Engelhardt and Parrot. Kupffer. Sjorgrun. Radde. Douglas Freshfield. Gardiner.

Rob. Boyle. Tournefort. Parrot. Chodzko. Radde and Sievers. Hamilton.

Taylor Thomson. R. F. Thomson.

8. Central Asia

Marco-Polo. Hiouen. Tsang. Chinese Itinerary. Missionaries. S. Turner. Th. Hardwicke. Moorcroft. Fraser. Webb. Gérard Brothers. Johnson. V. Jacquemont. Wood. Burnes. Father Huc. Hoffmeister. Th. Thomson. Dalton Hooker. Robertson. Mistress Hervey. Oliver. Cheetam. Semenof. Schlagintweit Brothers. Godwin-Austin. The Pundits. The Mirza. Hayward. Faiz Buksh. Henderson. Hume. Drew.

9. Africa . 161

Burton. Mann. Rebmann. De Decken. New.

10. Volcanoes of the Pacific

Low. Brooke. Braddel. Rutherford Alcock. Gubbins. Jeffreys. Byron. D. Douglas. Loenenstern. Wilkes.

Chapter II. Balloon Ascensions

Charles and Robert. Leullier-Duché. Testu-Brissy. Blanchard. De Lalande. Robertson. Garnerin. Zambeccari. Biot and GayLussac. Andreoli. Beaufoy and Sadler. Madame Blanchard. Eug. Robertson. Green. Comaschi. Hobard. Barral and Bixio. Welsh. Glaisher. Crocé-Spinelli and Sivel. Simons.

Chapter III. Theories and Experiments

Acosta. Fr. Bacon. Academy del Cimento. Van Musschenbroeck. Robert Boyle. Huyghens and Papin. Beale. Veratti. Cigna. Darwin. Borelli. Bouguer. Ulloa. Haller. De Luc. Bourrit. 
De Saussure. Fodéré. Hallé and Nysten. Courtois. Legallois. Dralet. Gondret. Fraser. Govan. Gerard Brothers. Hodgson. H. Cloquet. Clissold. Roulin. J. Davy. Rostan. Cunningham. Burdach. Poeppig. Boussingault. De Humboldt. Junod. Magendie. Favre. Barry. Martins. Rey. Tschudi. A. Smith. Hill. Maissiat. Flechner. Brachet. Castel. Vierordt. Lepileur. A. Vogt. Father Huc. Przevalski. Pravaz. Payerne. Marchal de Calvi. Speer. Mayer-Ahrens. Lombard. Valentin. Heusinger. Giraud-Teulon. F. Hoppe. Fernet. Longet. Gavarret. Duval. Lombard. Martins. Guilbert. Jourdanet. His discussions with Coindet. Cavaroz. Tardieu. Foley. Liguistin. Leroy de Méricourt. Gavarret. A. Dumas. Scoutetten. Kaufman. Coindet. Gavarret. Von Vivenot. Flemeing. Bouchard. Beclard. Hudson. Piachaud. Lortet. Marcet. Forel. Clifford-Albutt. Dufour. Javelle. Tyndall. Durier. Russell-Killough. Mistress Hervey. Henderson. Drew. Burton. Hunt. Jaccard. Armieux. Gosse. Jourdanet. The Academy of Medicine in 1875. Virlet d'Aoust.

Chapter IV. Summary and Criticisms

1. Conditions of the appearance of mountain sickness____ 315

2. Symptoms of mountain sickness _ 328

3. Theoretical explanations

Pestilential exhalations. Electricity. Lack of oxygen in the air. Fatigue, cold. Theories of M. Lortet and M. Dufour. Lessening of the weight supported by the body. Escape of blood gases. Expansion of intestinal gases. Relaxing of the coxo-femoral articulation. Other mechanical actions. Excess of carbonic acid in the blood. Theory of de Saussure and Martins. Theory of M. Jourdanet.

Title II. Increased Pressures

Chapter I. High pressures

1. Diving bells

Sturmius. Halley. Spalding. Brizé-Fradin. Hamel. Colladon.

2. Apparatuses constructed in the Triger method Papin. Triger. Trouessart. De la Gournerie. Blavier. Pol and Watelle. Comte. Bouhy. Brunel. Cezanne. Regnauld. Babington and Cuthbert. Francois, Bucquoy. Foley. Nail. Hermel. Limousin. Bayssellance. Gallard. Triger. Barella. Eads. Bauer. Malézieux. Unpublished information.

3. Divers with suits

Borelli. Halley. Leroy de Méricourt. Denayrouze. Gal. Sampadarios.

Chapter II. Low pressures.

Junod. Tabarié. Pravaz. Milliet. Sandahl. Tutschek. G. Lange. Vivenot. Freud. Elsasser. Panum. G. Liebig. Mayer. Marc. 
Chapter III. Theoretical Explanations and Experiments

Borelli. Musschenbroeck. Haller. Achard. Brizé-Fradin. Hallé and Nysten. Poiseuille. Maissiat. Hervier and Saint-Lager. Pravaz. Pol and Watelle. A. Guérard. Milliet. Eug. Bertin. Hoppe. Francois. Bucquoy. Hermel. Foley. Caffe. Babington and Cuthbert. Sandahl. Tutschek. Vivenot. G. Lange. Elsasser. Panum. G. Liebig. Gavarret. Leroy de Méricourt. Bouchard. Gal.

Chapter IV. Summary and Criticisms

1. Physiological action of compressed air.

A. Phenomena due to compression.

B. Phenomena due to decompression.

2. Theoretical explanations.

A. Phenomena due to compression.

Physico-mechanical explanations. Chemical explanations.

B. Phenomena due to decompression.

\section{Second Part \\ EXPERIMENTS}

Chapter I. Chemical conditions of the death of animals subjected to different barometric pressures in closed vessels

Subchapter 1. Pressures below one atmosphere___ 507

1. Experimental set-up__ 507

2. Experiments 513

A. Experiments on birds____ 513

B. Experiments on mammals

C. Experiments on cold-blooded animals

3. Conclusions 552

Subchapter 2. Pressures above one atmosphere___ 552

1. Experimental set-up $\quad 552$

2. Experiments $\quad 555$

A. Compressions with ordinary air

B. Superoxygenated air; pressures between one and two atmospheres

C. Compressed air at very high pressures. Lethal action of oxygen 565

D. Compression with air of low oxygen content $\quad 570$

E. Compression with superoxygenated air____ 571

F. Compression with ordinary air; elimination of carbonic acid ...... 574

3. Conclusions _.. 577

Subchapter 3. Summary and conclusions _._. 578 
Chapter II. Gases contained in the blood at different barometric pressures

Subchapter 1. Operative methods and experimental discussion

Subchapter 2. Blood gases under pressures less than one atmosphere

594

1. Experimental set-up

594

2. Experiments

600

Subchapter 3. Blood gases under pressures greater than one atmosphere

615

1. Experimental set-up

615

2. Experiments

618

Subchapter 4. Blood gases in asphyxia compared to decreased pressure

Subchapter 5. The quantity of oxygen which the blood taken from the vessels can absorb at different barometric pressures

1. Pressures lower than one atmosphere

2. Pressures greater than one atmosphere

Chapter III. Phenomena presented by animals subjected to pressures less than one atmosphere

Subchapter 1. Symptoms of decompression

1. Respiration

2. Circulation

3. Digestion

4. Nervous and muscular effects 673

5. Nutrition 675

Chemical phenomena of respiration. Urinary excretion.

Sugar of the liver and blood, glycosuria. Temperature. Development.

6. Lower limit of pressure

7. Death

Subchapter 2. Comparison of the phenomena of decompression with those of asphyxia in closed vessels

Subchapter 3. Means of warding off the symptoms caused by decompression

Chapter IV. Action of compressed air on animals

Subchapter 1. Toxic action of oxygen at high tension

2. The diminution of oxidations caused by oxygen poisoning

3. Aquatic or invertebrate animals

Subchapter 2. Action of compressed air at low pressures

1. Short stay in compressed air

A. Experiments made upon myself 
B. Production of urea; experiments on dogs

764

C. Chemical phenomena of respiration 765

D. Pulmonary capacity___ 768

E. Intra-pulmonary pressure____ 771

F. Arterial pressure _._ 773

2. Prolonged stay in compressed air 775

Chapter V. Influence of changes in barometric pressure on plant life 780

Subchapter 1. Pressures less than one atmosphere_______ 782

1. Germination _ 782

2. Vegetation _- 787

Subchapter 2. Pressures above one atmosphere 788

1. Germination _- 788

A. High pressures with air of low oxygen content ___ 792

B. Normal pressure; superoxygenated air_______ 793

2. Vegetation

C. Low pressures; superoxygenated air____ 794

Subchapter 3. Summary 798

Chapter VI. Action of changes in barometric pressure on ferments, poisons, viruses, and anatomical elements_____ 799

Subchapter 1. Fermentations by organisms_______ 800

1. Putrefaction

A. Meat _. 800

B. Blood _- 817

C. Eggs _- 819

2. Coagulation of milk____ 820

3. Alteration of the urine

4. Brewer's yeast___________ 826

5. Wine ferments_______ 827

6. Molds _._. 831

Subchapter 2. Diastatic fermentations

1. Saliva and diastase

2. Pepsin

3. Inversive ferment of yeast

4. Myrosin - 838

5. Emulsin _- 839

Subchapter 3. Action of oxygen at high tension upon anatomical elements _... 839

Subchapter 4. Use of oxygen at high tension as an experimental method _. 842

1. Dry rot of fruit

2. Ripening of fruits

3. Venoms

4. Viruses __. 846 
A. Vaccine _.... 846

B. Glanders _.__ 847

C. Anthrax _.__ 847

Subchapter 5. Summary _... 849

Chapter VII. Effects of sudden changes in barometric pressure ____-_ 852

Subchapter 1. Effects of sudden increases in pressure _._._._. 852

Subchapter 2. Effects of sudden decreases in pressure beginning with one atmosphere

Subchapter 3. Effect of sudden decrease in pressure beginning with several atmospheres_______ 859

1. Decompression without interruption

A. Experiments on sparrows ___ 859

B. Experiments on rats

C. Experiments on rabbits _.__ 861

D. Experiments on cats

E. Experiments on dogs

2. Slow decompression in several stages___________ 874

3. Summary and conclusions from the preceding experiments 878

Subchapter 4. Prophylaxis and treatment of the symptoms of sudden decompression

Subchapter 5. Summary _._. 895

Chapter VIII. Various questions___. 896

Subchapter 1. Action of carbonic acid on living beings______ 896

1. Lethal tension of carbonic acid in ambient air_______ 896

2. Lethal concentration of carbonic acid in the blood_____ 899

3. Accumulation of carbonic acid in the tissues _........ 910

4. Symptoms and mechanism of carbonic acid poisoning _... 914

5. Action of carbonic acid on lower living beings _._____._ 924

6. Summary and conclusions ____________ 927

Subchapter 2. Asphyxia _........ 928

Subchapter 3. Observations on the gases of the blood_..._... 935

Third PaRT

RECENT DATA, SUMMARY AND CONCLUSIONS

Chapter I. Decreased pressure_______._. 949

Subchapter 1. Observations, theories, and recent discussions___- 949 Bouchut. Chabert. Dufour. Forel. Thorpe. Tempest Anderson. Calberla. Ward. Vacher. Crocé-Spinelli, Sivel and G. Tissandier. Stoliczka. Campana. Jourdanet. 
Subchapter 2. Summary and practical applications

1. Aeronauts

2. Mountain travellers

3. Dwellers in high places

4. Animal and plant life at high elevations

5. Medical applications

Chapter II. Increased pressure 1009

Subchapter 1. Observations, theories, and recent discussions 1009

1. High pressures 1009

Guichard. Heiberg.

2. Low pressures. Medical apparatuses 1014 J. Pravaz. G. Liebig. Leonid Simonoff.

Subchapter 2. Summary and practical applications

1. High pressures

2. Low pressures

3. Sudden decompression _..._. 1027

4. Practical applications. Therapeutics and hygiene_...... 1027

5. Conclusion from the point of view of general natural history 1032

Chapter III. General conclusions 1036

Addenda I. Relations between heights and barometric pressures 1039

II. The new work of Dr. Mermod 1041

Index 


\section{LIST OF ILLUSTRATIONS}

PAGE

Fig. 1. Lortet. Respiratory tracing taken at Lyons (200 meters)

Fig. 2. Lortet. Respiratory tracing taken at the summit of Mont Blanc (4810 meters), after resting an hour

Fig. 3. Cupelain: Chamounix (1000 meters)

Fig. 4. Grands-Mulets (3000 meters) at midnight, half an hour before starting

Fig. 5. Summit of Mont Blanc (4810 meters)

Fig. 6. The construction of a bridge pier by the use of caissons

Fig. 7. Diver equipped with the Denayrouze regulator, complete suit

Fig. 8. Diver equipped with the Denayrouze regulator, helmet removed

Fig. 9. The aerotherapeutic establishment of Dr. Carlo Fornanini at Milan

Fig. 9. bis. Respiratory modifications in compressed air

Fig. 10. Circulatory modifications in compressed air

Fig. 11. Circulatory modifications in compressed air

Fig. 12. Circulatory modifications in compressed air

Fig. 13. Circulatory modifications in compressed air

Fig. 14. Circulatory modifications in compressed air

Fig. 15. Apparatus with four plates for experiments on decreased pressure

Fig. 16. Mercury pump set up for the extraction of the gases of the blood

Fig. 17. Composition of confined air which has become lethal at pressures below one atmosphere

Fig. 18. Variations in the tension of the oxygen contained in compressed air which has become lethal at various pressures less than one atmosphere.

Fig. 19. Relations between the oxygen tension, duration of life, and capacity of vessels

Fig. 20. Cylindrical glass apparatus for high pressures (25 atmospheres) set up for superoxygenated air

Fig. 21. Confined air which has become lethal under pressure 
Fig. 22. Confined air which has become lethal under pressures from 20 centimeters to 24 atmospheres

Fig. 23. Graduated syringe for the extraction of blood

Fig. 24. Mercury pump set up for the extraction of the gases of the blood

Fig. 25. Small mercury reservoir

Fig. 26. Bellows for artificial respiration

Fig. 27. Large apparatus for the study of low pressures

Fig. 28. Dog prepared to be placed in the cylinders of Fig. 27, and for the extraction of blood under decreased pressure

Fig. 29. Different forms of cannulae for the extraction of blood under decreased pressure

Fig. 30. Extraction of the blood of an animal under decreased pressure

Fig. 31. Decrease of the quantities of $\mathrm{O}_{2}$ and $\mathrm{CO}_{2}$ contained in the arterial blood, when the barometric pressure is diminished

Fig. 32. Percentage decrease of the $\mathrm{O}_{2}$ and the $\mathrm{CO}_{2}$ of the arterial blood when the barometric pressure is diminished

Fig. 33. Large compressed air apparatus, cylinder of sheet steel capable of withstanding a pressure of 12 atmospheres

Fig. 34. Extraction of blood from an animal placed in compressed air

Fig. 35. Variations of the gases of the blood at pressures above one atmosphere

Fig. 36. Increase of the oxygen of the arterial blood from 0 to 10 atmospheres and from 0 to 26 atmospheres

Fig. 37. Dog breathing air from a rubber bag

Fig. 38. Variations of the gases of the blood and the oxygen of the air in asphyxia in closed vessels, when the carbonic acid is absorbed

Fig. 39. Variations in the gases of the blood in asphyxia compared to decreased pressure

Fig. 40. Decrease of the gases of the arterial blood and the venous blood when the tension of oxygen breathed decreases

Fig. 41. Flask arranged for saturating blood with oxygen under different decompressions

Fig. 42. Water motor shaking the flask containing the blood to be saturated with oxygen

Fig. 43. Capacity of the blood for absorbing oxygen at pressures below one atmosphere

Fig. 44. Apparatus to bring blood into contact with the air at a specified decrease in pressure

Fig. 45. Apparatus for saturating blood with air at high pressures

Fig. 46. Oxygen capacity of the blood from a vacuum to 18 atmospheres of air

Fig. 47. Modification of the number of respiratory movements under the influence of decompression. (Dogs, rabbits)

Fig. 48. Same (Guinea pig, Experiment CCXXVII) 
Fig. 49. Simultaneous modifications of the number of respiratory movements $\mathrm{R}$ and pulse $\mathrm{P}$ under the influence of decompression; (Cat, Experiment CCXXI)

Fig. 50. Same (Dog, Experiment CCXVIII) _... 671

Fig. 51. Same (Dog, Experiment CCXVII) ___ 671

Fig. 52. Consumption of oxygen and production of carbonic acid at different pressures

Fig. 53. Asphyxia without carbonic acid

Fig. 54. Maxima and minima of cardiac pressure in asphyxia without carbonic acid

Fig. 55. Bird in air progressively rarefied and oxygenated

Fig. 56. Respiration of superoxygenated air expanded by decrease of pressure

Fig. 57. Sudden modifications in the pulse rate by intermittent respiration of superoxygenated air

Fig. 58. Modifications in the pulse rate, during decompression, resulting from the continuous respiration of oxygen (Experiment CCLVI)

Fig. 59. Same (Experiment CCLVII)

Fig. 60. Dogs poisoned by oxygen

Fig. 61. Dog during tonic convulsions of oxygen poisoning

Fig. 62. Apparatus of M. Jourdanet for the therapeutic use of compressed or expanded air.

Fig. 63. Gas meter for the measurement of the respiratory movements

Fig. 64. Apparatus with double valve for the study of respiration

Fig. 65. Apparatus for the chemical study of the respiration of an animal kept for any specified time in air of constant composition

Fig. 66. Apparatus for the observation of variations in the intrapulmonary air tension

Fig. 67. Variations of the intra-thoracic tension. Normal pressure

Fig. 68. Same. Compressed air

Fig. 69. Tension of the blood in the femoral artery. Normal pressure

Fig. 70. Same. Compressed air._._.

Fig. 71. Tension of the blood in the carotid artery. Normal pressure

Fig. 72. Same. Compressed air

Fig. 73. Same. Normal pressure

Fig. 74. Oxygen consumption and carbonic acid production by a piece of meat in an atmosphere of constant oxygen content

Fig. 75. Death by carbonic acid; changes in the air of the bag (Experiment DCXV)

Fig. 76. Death by carbonic acid; changes in the composition of the gases of the blood, the respiration, and the circulation (Experiment DCXV) 
Fig. 77. Death by carbonic acid; relation of the respiration and the circulation to the carbonic acid content of the blood (Experiment DCXV)

Fig. 78. Death by carbonic acid; last respiratory movements (Experiment DCXV)

Fig. 79. Death by asphyxia in a closed vessel; gases of the air (Experiment DCXL) _ 932

Fig. 80. Same; gases of the blood (Experiment DCXXXIV)___ 932

Fig. 81. Relation between the oxygen content of the air and that of the blood - 933

Fig. 82. Pulse at the Riffel Pass (2780 meters), during an attack of mountain sickness _....... 955

Fig. 83. Pulse at the Sattel-Tolle (4300 meters) 955

Fig. 84. Pulse at the Riffel (2569 meters), rest on the return trip _ 956

Fig. 85. Pulse at Morges (380 meters), absolute repose__ 956

Fig. 86. The basket of the Zenith at a high altitude 966

Fig. 87. Diagram of the high altitude ascension on April 15, 1875__ 970

Fig. 88. Portrait of Sivel 972

Fig. 89. Portrait of Crocé-Spinelli 973 
Part I

\section{H I S T O R I C A L}




\section{Title I}

\section{DIMINISHED PRESSURE}

\section{Preliminary Chapter THE LOFTY REGIONS OF THE EARTH}

The effects produced upon the organism by a great and sudden decrease in the barometric pressure can be observed in three different cases: mountain journeys, balloon ascensions, and experiments under pneumatic bells.

These last two methods were absolutely unknown to the ancients. Galileo, as everyone knows, was the first to have a clear idea of the pressure of the air; it was not until 1640 that Toricelli invented the barometer, or until 1650 that Otto de Guéricke invented the pneumatic machine. In 1648, at the suggestion of our great Pascal, Périer made at Puy-de-Dòme the memorable experiment in which he saw the height of the barometric column decrease in proportion to the increase of the altitude of the place where it was observed.

For balloons, the discovery is still more recent. The first hot air balloon which carried aloft Pilattre du Rozier and the Marquis d'Arlandes, ascended from Paris November 22, 1783; a few days after, December 1, Charles made an ascension with the hydrogen balloon which he had just invented. This balloon, however, was not able to carry the observers high enough for the decrease of pressure to make its effect felt upon them. In fact, the experiment proved that this effect is not clearly evident in a balloon below an altitude of 5,000 or 6,000 meters. Consequently, among the thousands of ascents which followed that of Charles and Robert, only a very small number can be of interest to us in our particular purpose and therefore be reported in this historical review. 
As to the third condition, the ascent of high mountains, at first glance it seems astonishing to have to state that the ancient authors have left us no precise information permitting us to believe that they noted, during the ascent of lofty mountains, any physiological symptoms worthy of attracting attention. ${ }^{1}$

In fact, in the part of the world known to the ancients, there are mountains of considerable height. At its extreme eastern limits, ${ }^{2}$ Mount Ararat and the chief peaks of the Caucasus raise their heads covered with eternal snow more than 5,000 meters above sea level; the chains of Liban and Taurus contain many peaks more than 2,500 or even 3,000 meters high; the famous Mount Argaeus reaches a height of 3,840 meters; among the hills of Hemus and Rhodope, some rise to 3,000 meters; Mount Athos is 1,975 meters high, Parnassus 2,470, Taygetus 2,400, and it is at 2,975 meters, on the towering brow of Olympus, that the poets placed the abode of the gods. Mount Etna (3,310 meters) for two thousand five hundred years has been threatening the Greek cities settled at its feet. The Phenicians and the Carthaginians, whose daring had established colonies as far away as the Fortunate Isles, knew the smoking peak of Teneriffe (3,715 meters). Finally, the Pyrenees and the Alps were insufficient barriers against the armies of Carthage and Rome.

The reason for the silence of the authors is easily found. As von Humboldt very correctly said, the ancients feared mountains much more than they admired them. They spoke of them only with fear, with a secret horror; the magnificent spectacles they offer to the gaze did not affect them; the emotions they arouse, the noble ideas they inspire were unknown to the ancients. Love of the picturesque is a very modern sentiment; the ancients, and even our ancestors up to the last century, would have regarded with an astonishment mingled with disdain our intrepid climbers of the Alps. Polybius first passed through the Alpine valleys; the highest mountains, Mont Blanc, Monte Rosa, the Jungfrau, have no names in the classical languages.

The only mountain which the ancients climbed without being forced to is Etna. Seneca requests his friend Lucilius Junior to climb to the top of the volcano in his honor (Letter 79); these excursions were frequent in the time of Strabo, ${ }^{3}$ and according to a poem attributed today to this same Lucilius, priests burned incense on the edge of the crater to appease the gods; the emperor Hadrian, who was a great traveller, conceived the idea of climbing to the top of Etna to see the sunrise. None of these accounts speak of physiological symptoms; but we shall see that at the height of 
this volcano they are slight, attack only part of the travellers, and might be confused with the ordinary effects of fatigue. The same thing is true in crossing the Pyrenees and the Alps. The passes of the Pyrenees, through which regular communications were established between Gaul and Hispania, are hardly 1,500 meters high. Whatever opinion one has about the site of the passage of Hannibal, either at the Little Saint-Bernard (2,160 meters), or the pass of Mount Viso (2,700 meters), or Mount Cenis (2,080 meters), or in the valley of Beaufort between Albert-Ville and Chamounix, the heights reached were not very great. Augustus had two roads made through the passes of the Great Saint-Bernard (2,490 meters) and the Little Saint-Bernard, ${ }^{4}$ and King Cottus, his contemporary, cut the road of Mount Cenis. In the Middle Ages, the Simplon (2,020 meters) and the Great Saint-Bernard were much frequented; chroniclers have left us descriptions of these journeys or these expeditions in which the terrible difficulties of the roads, the excessive fatigue, and the cold explain sufficiently the pitiful state of the travelers, many of them, like Elfrid, archbishop of Canterbury, perished in the snow.

To attract the attention of the travellers to physiological symptoms they would have had to make more lofty ascents, and to have suffered discomforts evidently unexplainable by ordinary causes. The lofty summits of the Alps presented the necessary conditions, as we shall see; but since their ascents offered no practical interest, they were undertaken only toward the end of the last century. But twenty years after the discovery of America, the conquest of Mexico and Peru and military expeditions across the Cordilleras brought the Spaniards into conditions where the symptoms of decompression appeared definitely. So attention was soon attracted to them, and they were noted in ascents where they are neither great nor constant, like those of Etna and the Peak of Teneriffe. However, our Alps for a long time still remained unexplored; though the important cities and the rich valleys of Switzerland attracted many travelers, no one had the idea of climbing these dangerous peaks covered with snow, peopled with strange beings, ${ }^{5}$ and about which the most gloomy tales were told. It was not until the second half of the eighteenth century that people decided to admire them and that the idea of reaching their summits germinated in a few minds. It was the scientific point of view that guided the first ascents. In the account of his ascents de Saussure noted with keen alertness the symptoms brought on by a stay in rarified air. Since then, similar observations are numerous. Still 
more recently, officers, scholars, and English travelers have carried their explorations into the loftiest regions of the Himalayas. Their accounts, added to those of men who have ascended the Alps and of travellers in America, which have become more numerous, have familiarized physicians with the symptoms of mountain sickness.

In the following pages I shall report most of the interesting facts collected thus by eyewitnesses, often from their own personal observation. But in this preliminary chapter I should like to recall to the memory of the reader the different mountain regions in which the traveller is exposed to distress in consequence of the decrease of pressure. This simple enumeration will show him the practical importance of the question which we shall discuss here, that is, the manifestation by acute and violent symptoms of the effect of decreased pressure.

Rarely does mountain sickness appear with marked intensity in our temperate regions below an altitude of 3,500 meters. In the tropics, one must mount to more than 4,000 meters to experience it definitely in ordinary conditions. We shall return to these limits and take account of the different circumstances which hasten or delay the symptoms, I mean by that, cause them to appear at a lower or higher altitude. For the moment, these approximate heights serve as a basis for the review we intend to make.

Europe. Let us take Europe first; the Alps, the Pyrenees, and the Caucasus are almost the only mountain chains which offer us peaks high enough for their ascent to cause any other ill consequences than the weariness and the dangers customary in mountains.

Let us first examine the Alps. This enormous mass of mountains which includes in a curved line two hundred leagues long innumerable peaks laden with eternal snows, descends rapidly on the south to the low plains of Lombardy, while on the north it slopes more slowly towards the high plateaux of Wurtemberg, Bavaria, and Bohemia, interrupted by secondary mountains.

The heart of the system is formed by the group of Saint-Gothard, whose waters flow at the same time through the Rhine into the North Sea, through the Rhone into the Mediterranean, and through the Tessin into the Adriatic; and yet this region is one of the least elevated of the Central Alps. It is immediately dominated on the north by Galenstock (3800 meters) and Tödi (3600 meters); on the east, by the group surrounding the Little Saint-Bernard, among others the Rheinwaldhorn (3400 meters); on the west, by the enormous mass of the glaciers of the Bernese Alps, in the midst of 
which rise the Jungfrau (4170 meters), the Aletschhorn (4200 meters), the Schreckhorn (4080 meters), the Brietsch (3950 meters), the Monk (4100 meters), and the Finsteraarhorn (4270 meters). Advancing toward the east, we see Mount.Bernin (4050 meters) and Mount della Disgrazia (3680 meters) separating the valley of the Valteline, in which flows the Adda, from that of the Engadine, in which the Inn conducts by the Danube to the Black Sea the waters brought to it from numerous peaks more than 3000 meters high, such as the Piz d'Err (3390 meters), the Piz Linard (3410 meters), the Piz Languard (3270 meters), etc. On the other bank of the Adda, the Tyrolese Alps display still loftier peaks; the Adamello (3560 meters), the Wildspitze (3770 meters), the Venediger (3675 meters), the Gros-Glockner (3890 meters), and especially the Orteler (3920 meters).

But it is towards the west and on the left bank of the Rhone that the giants of the Alps rise. First, around the Simplon (3200 meters), are Monte-Leone (3560 meters), the Fletschhorn (4020 meters), and the Weismies (4030 meters); then the base of Monte Rosa, with its three surmounting peaks; the Dome du Mischabel (4550 meters), the Matterhorn or Mount Cervin (4480 meters), and Monte Rosa itself, the highest peak of which, the Pointe de Dufour, rises to 4640 meters. Next come the Dent-Blanche (4360 meters), the Weisshorn (4510 meters), the Grand Combin (4320 meters), and farther to the west Mont Blanc (4810 meters), which, surrounded by numerous almost inaccessible pinnacles, dominates all the other mountains of Europe.

Beyond, the chain drops rapidly, although it still displays a few lofty summits, such as Mount Iseran (4045 meters), Mount Cenis (3620 meters), the Vanoise (3860 meters), in the Graies Alps; Mount Viso (3840 meters), Mount Olan (4215 meters), in the Cottian Alps; Mount Pelvoux (3955 meters), the Pointe des Ecrins (4100 meters), the Grandes Rousses (3475 meters), in the Alps of Dauphiné. The Maritime Alps are still less lofty; finally come the Apennines, the highest peak of which, Monte Corvo, in the Abruzzi, is only 2910 meters high. But beside these giants, what an appearance the Capitol makes with its 47 meters above sea level!

At the end of the chain, a rather high mountain, Mount Alto (1080 meters), faces Sicily, the hilly soil of which, like that of Sardinia, has no peaks reaching 2000 meters. Above all these secondary mountains the crater of Etna rises to 3310 meters.

Among these high peaks, these abrupt pinnacles, which are climbed only by those inspired by love of science, a taste for grand 
views, or merely vanity, depressions called cols allow many travellers at certain points to cross the principal chain from Switzerland or France to Italy. These passes are generally very high. The best known and the highest are: in the Maritime Alps, the passes of Tende (1870 meters), of Longet (3150 meters), of the Argentière (1905 meters), and of Maurin (2980 meters) ; in the Cottian Alps, the passes of Traversette (2995 meters), of the Agnello (2700 meters), of Sayse (3360 meters), of Mount Genèvre (1850 meters) ; in the Graies Alps, the pass of Mount Cenis (2080 meters), and of the Little Saint-Bernard (2160 meters); in the Pennine Alps, the pass of the Grand Saint-Bernard (2490 meters), that of the Geant (3360 meters), of the Seigne (2530 meters), the pass of Balme (2200 meters), the pass of Saint-Théodule (3320 meters) ; in the Helvetian Alps, the Simplon pass (2020 meters), the pass of Gemmi (2300 meters), the pass of Grimsel (2160 meters), that of the Fourca (2460 meters), of the Saint-Gothard (2110 meters), of Bernardin (2060 meters), etc. The road of the Valteline, the highest carriage road in Europe, crosses the pass of Stelvio at 2810 meters, going from the basin of the Po to that of the Danube.

Along the Adriatic, the Alps continue by the mountains of Croatia, Montenegro, and Serbia, with the Balkans at the north and on the south the Rhodope mountains and the chain of Pindus which gives birth to the hills of Greece. In these very hilly regions, the summits of which are however not very high, we need mention only the Dormitor (2260 meters) in Herzegovina, the Kom (2290 meters) in Montenegro, the Kriwosta (2440 meters) in Roumania; then the giant of the Rhodope mountains, the Rilo Dagh (2815 meters), and finally the mountains of Greece of which we have already spoken.

The Danube, which receives the waters of the north slope of the Alps, rises in the mountain group of the Black Forest, in which there are a few peaks of moderate height; after running towards the east, it encounters the chain of the Carpathians, in which there are such peaks as the Tatra (2655 meters), the Gailuripi (2925 meters), the Ruska-Poyana (3020 meters), and which pushes it towards the south.

The mountains of the interior of France have no interest for us from the standpoint of our present purpose, since the highest, Mount Dore, is only 1890 meters high; the little chain which crosses Corsica is more interesting; its highest point, Mount Cinto, rises to 2710 meters.

But the Pyrenees, in a length of 150 kilometers and a maximum 
width of 120 kilometers, have a large number of peaks which, although they do not have the imposing mass or the height of the Alpine groups, are nevertheless important for our purpose. In the eastern Pyrenees there are first the Canigou (2785 meters), then the Puigmal (2910 meters) and the Corlitte (2920 meters), dominating on each side the pass of the Perche (1620 meters); finally from this pass to the valley of Aran, on a very lofty crest, a series of peaks reach a height of 2800 meters, the highest of which is the Montcalm (3090 meters).

Beyond the valley, the western Pyrenees begin with the group of the Maladetta, which contains their highest point, the peak of Nethou (3405 meters). This is the center of the Pyrenees group, which in a length of some hundred kilometers contains a great number of summits rising above 3000 meters: the peak of Perdighera (3220 meters), the cylinder of Marboré (3330 meters), Mount Perdu (3350 meters), Vignemale (3300 meters), Marmuré (2950 meters), the southern peak of Ossau (2885 meters); and to the north of the principal chain, the peak Campvieil (3175 meters), and the southern peak of Bigorre (2880 meters), on which a meteorological observatory has just been established. The passes or ports of this region also attain a considerable height: port of Viella (2455 meters), port of Vénasque (2420 meters); the lowest is the port of Gavarnie (2280 meters), the highest is the Portillon (3045 meters).

Towards the west, the chain drops rapidly; then, the Pyrenees proper give way to the Cantabric Mountains, which extend to the end of Galicia. In this whole extent, only a few summits rise above 2000 meters. In the rest of Spain, the Sierra Guadarrama and the Sierra de Gredos, which dominate Madrid and pour upon it the dreaded wind of the mountains, rise at certain points to more than 3000 meters; finally along the sea, at the highest point of the Sierra Nevada, the twin summits of the peak of Veleta (3470 meters) and the Cerro de Mulhacen (3555 meters) surpass the highest of the Pyrenees.

In the rest of Europe, there are no mountains which can attract our attention. Ben Nevis, the highest mountain in the British Isles, is only 1330 meters high; in Iceland, Orafa Jokul is 1950 meters; in the Scandinavian Alps, the highest mountains are Sneehätten (2300 meters), Skagstölstinder (2450 meters), and YmesFeldj (2600 meters); in the Ural Mountains, there are no peaks reaching the height of 2000 meters; the highest, Töll-pos-Is, is only 1680 meters. 
Asia. But on the borders of Europe and Asia, a considerable chain, the Caucasus, extending from the Caspian to the Black Sea, bordering on the north upon plains, and on the south upon the mountainous regions of Armenia whose ramifications we shall follow presently, is crowned by peaks which leave far below them the Pyrenees and the Alps themselves. Peaks of 3000 to 4000 meters are numerous there and they are dominated by Kasbek (5030 meters), Kaschtantan (5220 meters) and Elbruz, to which the legend fastens Prometheus (5620 meters). Only one carriage road crosses the chain at the foot of Kasbek, by the Caucasian gates of the ancients, at a height of more than 3000 meters.

At the south of the Caucasian chain, in the hilly territory of Armenia there rise a series of peaks, some of which reach the height of 4000 meters: Alagos (4090 meters), Kapudschich (3920 meters); above them towers the Grand Ararat (5155 meters). From this group there extends towards the southwest the chain of the Taurus, which contains several summits more than 3000 meters high, the highest of which are Metdesis (3570 meters) and Mount Argea (3840 meters); in the Liban, a fork of the Taurus, the highest summit, Dor-el-Chodib, is only 3065 meters high. At the south, the mountains of Kurdistan, with Dschehil (4550 meters); to the southeast, the Elburs mountains, with Sawalan (4810 meters) and Demavend (5620 meters), dominate the vast plains of Iran.

The center of Asia displays an orographic system much more complex and masses of mountains much more imposing. The traveler who goes up the Ganges sees rising on his right, from Boutan to Cashmere, over a stretch of more than 600 leagues, the formidable range of the Himalayas; from between the parallel lesser chains descend innumerable tributaries of the great Indian river. In this range are found the highest mountains in the world; the ridge reaches an average height of 5000 to 6000 meters; we can count by the hundred summits of more than 6000 meters; peaks less than 7000 meters high are generally marked scornfully on the English maps by mere numbers, and it seems as if mountains do not deserve to have a name unless they reach a height of 8000 meters.

We shall mention: in Boutan, Dalla (7030 meters), the Oodoo Mountains (7540 meters), Chamalari (7300 meters); in Sikkim, Mount Doukia (7070 meters) and Kantschin-Janja (8580 meters); this latter yields only to Gaurisankar or Mount Everest in Nepal, the highest mountain on earth, which raises its summit to the prodigious height of 8840 meters; we should gain this height by heap- 
ing the Jungfrau (4170 meters) upon Monte Rosa (4640 meters); it is more than seven times the height of Vesuvius (1190 meters). Also in Nepal, Jangmar (7930 meters), Djibjibia (8020 meters), Jassa (8135 meters), Marschiadi (8080 meters), Barathor (7950 meters), and finally Dawalaghiri (8185 meters), long considered the highest of all, but now known to be surpassed by Guarisankar.

Then the Himalayan chain opens to allow the passage of the Setledj, which carries to the Indus the waters of the northern slope and those of the sacred lake of Manasarovar (4650 meters). Beyond, it ends in the extraordinary maze of the mountains of Cashmere, in the midst of which opens the delightful valley of Srinagar, the "earthly paradise" of the Hindus.

At their eastern end, the Himalayas are joined to the Langtan Mountains, the heart of chains of relatively moderate height, which form the high relief of China and Indo-China.

The Himalayas thus form, on their southern slope, the gigantic talus of a high mountain plateau, as it were. This is Tibet, which over an immense extent rises above 3000 meters, and whose waters, collected in the Brahmapoutra, flow first towards the east, then, encountering the mountains of China, turn to the southwest, to join those of the Ganges. On the north, this plateau is bounded by the chain of Kuen-Loun; its western extremity is traversed by the chain of Karakorum, the summits of which rival those of the Himalayas, such as Dapsang (8620 meters), Diamer (8130 meters), and Gusherbrum (8040 meters).

Passes, the elevation of which naturally increases as the highest ridges are approached, permit a crossing of the foothills of these principal chains, and finally of the chains themselves. Many of these passes, which are much travelled, are at a height of more than 5000 meters; the famous pass of Karakorum is 5650 meters high; the Yangi-Diwan Pass, one of the routes from Cashmere io Khotan across the Kuen-Loun chain, is 5820 meters high; the highest " of all in the British Empire, the pass of Parang, has an elevation of 5835 meters.

The traveler who climbs the steps of this sort of gigantic stairway descends between them much less than he has ascended; thus he reaches a vast desolate plateau; this is the Pamir (visited in the thirteenth century by Marco Polo), or the Bam-i-Dunya, that is, the roof of the world, whose average altitude is more than 4500 meters. On the east, this roof slopes down to the lofty plains of upper Tartary, and its waters, through the river Tarim, are lost in 
the desert of Gobi. Towards the west, they collect in the Oxus which carries them to the Lake of Aral.

Other chains, of a considerable absolute elevation, rise above these high plateaux. On the northeast, Thian-Schan, whose culminating point is Bogda-Oola, borders the great desert, and joins Altai and the mountainous ridge which separates the basin of the Arctic Ocean from that of the Pacific. To the southwest, HindouKouch, which prolongs Karakorum and is fully as high at-the beginning, joins the chain of Elburs by the mountains of Korassan. To the south, Soliman-Kouch stretches along the river Indus.

America. The orographic system of America forms a striking contrast to that of Asia. Here there is no central group from which diverging chains extend, like so many gigantic arms. On the contrary, a ridge, certain summits of which are dominated only by those of the Himalayas, stretches along the shores of the Pacific Ocean from Patagonia to Alaska. In the part farthest toward the south, the Cordillera is simple and of moderate height; but towards the north its average elevation gradually increases and reaches two maximum points, in Bolivia and at the Equator. At the same time, while its western side remains consistently abrupt, so that mountains 6000 meters high are sometimes less than 20 leagues from the sea, there appear on the eastern side foothills whose size constantly increases, so that in Bolivia there is a group 100 to 150 leagues wide with an average height of 4000 meters, in which there stand out particularly two parallel chains bounding the lofty valley of the lake of Titicaca (3915 meters). These two chains, with their intermediate valley cut by knots, where rise the Marañon and the Ucayali, on which are built La Paz, Puno, Cuzco, Quito, and other cities, first drop, spreading out to the knot of Pasco, then rise again and reach their highest point just at the Equator. Here the eastern ridge forks in its turn and ends at the sea, by the chain of Venezuela and the Nevada of Santa-Marta, whose principal summit, the Horqueta (5500 meters), rises almost on the edge of the sea of the Antilles.

The western Cordillera, considerably reduced in height, next forms the isthmus of Panama, stretches along the Pacific in Central America, rises again, and spreads out in Mexico. Thence extend, as in South America, two great parallel chains, this time much farther from each other, and much less lofty. On the east, the ridge of the mountains of New Mexico, of the Rocky Mountains, of the Mountains of the Chipways, separates the waters of the Atlantic from those of the Pacific. The western chain remains near 
the ocean, and is interrupted in its course to allow free passage for the Colorado and the Columbia.

Along the immense extent of this mountainous ridge rise mountains, mostly volcanic, of prodigious height. Canon Bourrit seems to us extremely impertinent when he maintains that "compared to the Swiss Alps, these mountains of South America are only dwarfs mounted on great pedestals"; ${ }^{7}$ there is, however, a basis of truth in what he says and this is interesting for our purpose.

Precisely at the equator, from the terraces of the city of Quito, the astonished eye beholds eleven volcanic mountains covered with eternal snows. Some, like Cayambe (5950 meters), Iliniza (5250 meters), Chimborazo (6420 meters), are now extinct; others, like Pichincha (4860 meters), Antisana (5880 meters), and Cotopaxi (5945 meters), still send forth smoke or flames. Chimborazo has long been considered the highest peak of the Andes; that is a mistake. Higher still are Aconcagua (6835 meters) in the Andes of Chile, and especially Illimani (7310 meters) and Sorate (7560 meters), which border on Lake Titicaca.

A host of mountains, such as Tolima (5525 meters) and Puracé (5185 meters) in Colombia; Cotocachi (4950 meters), Sangay (5044 meters), Sinchalagua (5200 meters), Tunguragua (5020 meters), Llanganati (5395 meters), Altar (5240 meters), Sara-urcu (5140 meters), in the Republic of Ecuador; Misti (6100 meters), Chipicani (6180 meters), Jachura (5180 meters), Tacora (5700 meters), Parinacota (6330 meters), Nevado Vilcanota (5360 meters), Lirima (7470 meters), in Peru; Sahama (7015 meters), the peak of Farinacobo (6714 meters), Gualatieri (6690 meters), Cerro de Potosi (6620 meters), Atacama (5300 meters), Coolo (6870 meters), Soololo (6795 meters), Quenuta (6870 meters), and Pomarape (6580 meters) in Bolivia; Nevada de Famatina (5820 meters), in the Argentine Republic; Cerro del Plomo (5435 meters), Cima del Mercedario (6800 meters), Juncal (5960 meters), Tupungato (6180 meters), Maypu (5385 meters), San José (6100 meters) in Chile, are far higher than the Alps or even the Caucasus. ${ }^{8}$

The passes crossed by travelers going from the Pacific coast to the great cities of the Cordillera or directly to the basins of the Orinoco, the Amazon, or the La Plata, always reach at their highest points altitudes capable of affecting the organism. The great road which the Incas had constructed from Cuzco to Quito crosses the pass of the knot of Assuay at 4735 meters; from Potosi to La Paz, the traveler remains constantly at heights of 4000 meters and more; the post-house of Talapolco is at an altitude of 4190 meters. In 
the Republic of Ecuador, the passes through which one can go from Quito to the sea are above 4000 meters; the road from Lima to Pasco passes at Alto de Lachagual at a height of 4710 meters; that from Lima to Tarina, at 4800 meters. In Peru, the pass of Vilcanota, between Cuzco and the sea, is at a height of 4425 meters; the road from Arequipa to Puno passes at 4750 meters; the posthouse of Ancomarca, between Arica and La Paz, is 4330 meters high; the pass of Qualillas 4420 meters high, that of Tacora 4390 meters, and that of Chullunquiani 4620 meters high. Finally, of the two railroads which cross the Cordillera, the one which goes from Puerta Mejia to Lake Titicaca has its highest point at Crucero (4460 meters); thence it proceeds to Cuzco, remaining at a height between 3500 and 4300 meters; the one last constructed, between Callao and Oroya, passes at a height of 4760 meters, through a tunnel which had to be excavated at almost the height of Mont Blanc.

But the road most frequented by travelers till now in going from one ocean to the other, was the one which crosses the Andes from Mendoza to Santiago. It runs from Buenos Aires to Valparaiso (417 leagues), and from either of these points gives easy access by sea to other ports of the Atlantic or Pacific. There are four passes, which are, from north to south: that of "Los Patos," from Cordova to San Juan, long abandoned; that of Cumbre of Uspallata, more frequented (3920 meters); and that of Portillo, which requires the crossing of two passes, one of which has an altitude of not less than 4360 meters. Finally, the last, which is the lowest in the Andes in Chile, that of Planchon, which goes straight to the port of Conception, reaches the altitude of 2500 meters.

Over the long extent of Central America, the Cordillera remains at an average height; among the innumerable volcanoes with which it bristles, that of Acatenango (4150 meters) in Guatemala, alone exceeds 4000 meters.

The city of Mexico, like the city of Quito, is surrounded by mountains: Coluca (4580 meters), Ixtaccihualt (4790 meters), Chicle, over which Robertson junior passed in a balloon, and Popocatepetl (5420 meters). Citlaltepetl or the peak of Orizaba (5400 meters) is about 60 leagues away.

In the Rocky Mountains we should note particularly Uncompahgre Peak (4430 meters); Pike's Peak, on the summit of which (4340 meters) a meteorological observatory has just been installed; Mount Lincoln (4300 meters) ; Long's Peak (4310 meters) and Fremont Peak (4130 meters), between which the great railroad from 
New York to San Francisco passes at an altitude of 2500 meters; side by side, Mount Brown (4850 meters) and Mount Hooker (5100 meters). The mountains along the Pacific make way for the Oregon between the Sierra Nevada in California, the highest summits of which are Mount Whitney (4500 meters), Mount Tyndall (4380 meters), and Mount Shasta (4400 meters), and the chain of the Cascades, with Mount Baker (3390 meters), Mount Hood (3420 meters), and Mount Rainier (4400 meters) as the highest peaks.

At the northern end, on the very shore of the ocean, rise the highest peaks in North America, Mount Fairweather (4620 meters) and Mount Saint-Elias (5440 meters). Finally, in Alaska, the volcano Gorjaloja ends the immense American chain, which has stretched for more than 4500 leagues.

Africa. Africa is far from possessing chains of mountains which can compare with the Himalayas, the Andes, or even the Alps. And yet the belt of mountains at a short distance from the sea, which surrounds the vast plateaux of the interior, rises at different points to considerable heights. The Atlas range, which in French and Tunisian possessions never reaches 3000 meters, exceeds this height sometimes in Morocco, where Mount Miltsin measures 3470 meters. In Abyssinia, the circle of mountains around Gondar and Lake Zana rises at certain points to 4425 meters (Abba-Jaret), even to 4620 meters (Raz-Daschan); the pass of Buhait is 4520 meters high. On the shore of the Atlantic, the peak of Fernando-Po rises to 3260 meters, and opposite it, the Kamerun Mountains, perhaps

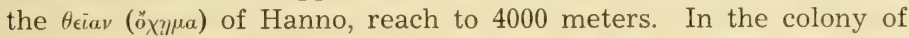
Natal, the chain of Drakenberg displays summits more than 3000 meters high: Cathkin Peak (3150 meters). Finally, almost on the equator, near the shore of the Indian Ocean, the Kenia mountains are 5000 meters high, and Kilimandjaro raises its crest, clothed in perpetual snow, to 6110 meters. Let us add that in the interior a lofty mountain has been noted, the peaks of which are more than 3000 meters high; it is Alantika, which is connected to the Kamerun Mountains.

Islands. The islands, which remain to be discussed, contain only a small number of mountains the height of which is great enough for their ascent to bring on physiological disturbances. The highest point of the Australian Alps, Mount Kosciusko, is only 2190 meters high. But in New Zealand, several exceed 3000 meters, and the giant of the southern island, Mount Cook, is 3770 meters high. New Guinea contains several volcanic mountains which are no less lofty than those of New Zealand; the Owen Stanley range, the highest, 
measures 4020 meters; but I object to including among them this Mount Hercules, 10,929 meters high, the discovery of which an English captain, M. Lawson, very recently announced, and on which he claims to have ascended to 8435 meters. In the island of Hawaii, among several still active volcanoes, Mauna Loa is 4250 meters high, and Mauna Kea 4195; on the neighboring island of Maui, Mauna Haleakala reaches an altitude of 3110 meters. The innumerable volcanoes which form the island of Java also have lofty summits; Gounong-Simeron measures 3300 meters, Semeroe 3730 meters. In Sumatra, I will mention Indrapura (3870 meters) and Dempo (3300 meters); in Borneo, Kini Ballu (4175 meters). The mountainous ridge of Formosa has summits of 3000 to 4000 meters. In Japan, among other lofty mountains, the volcano Fujiyama, the "Unequalled Mountain," with its height of 4320 meters dominates the roadstead of Yeddo. Finally, at the South Pole, the lofty volcanoes of Victoria Land, Erebus (3800 meters), Melbourne (4500 meters), and on the north Polar Circle, those of Kamchatka, the highest of which is Klioutchef (4805 meters), end this volcanic girdle which edges the Pacific Ocean on all its circumference, American or Asiatic.

On the island of Ceylon, the peak to which the pilgrims come to worship the Cri-Pada, the print of the foot of Buddha or Adam, rises only to 2420 meters. The mountains of Madagascar reach 3350 meters, at their highest point, Ankaratra. Piton de Neige, on Réunion, measures 3070 meters. Finally, mention of the volcanoes of Teneriffe (3715 meters) and of Etna (3310 meters) ends this long list of all the places on earth the elevation of which is great enough for an ascent of them to cause physiological disturbances the severity of which necessarily attracts the attention of travelers.

Summary. All of the foregoing can be summarized rapidly in a striking form. Let us suppose that the quantity of water on the earth should increase enough so that the sea level would rise 3000 meters. What would remain, emerging above an almost limitless ocean?

The largest stretch of land would be formed by the high plateaux of Thibet, Vokan, and Pamir, from which would rise numerous mountains 4000 to 5000 meters high; its area would be two or three times that of France. From it would diverge series of islands which would mark the chains of Thian-Shang, Indou-kouch, and Soleiman, and the mountains of Yunam and China.

At the other end of a terrestrial diameter, a long strip extending from the equator to the Tropic of Capricorn, spreading out at its 
two ends and particularly towards the south, in the region corresponding to Bolivia, would be prolonged towards the south and the north by strings of lofty islands, crowded against each other; that is all that would be left of the Andes.

The plateau of Armenia, separated from the emerging crests of the Caucasus, would form the last bit of land, much smaller than the other two, which would be flanked by a few summits of the Taurus and the Elburs mountains.

Then the region of the Alps would have become a complicated archipelago, with innumerable isles and islets, Oberland, Grisons, the main range of Monte Rosa and that of Mont Blanc. Of the Pyrenees there would remain only a few peaks near the Maladetta. Mulahacen and Etna alone would be the only others still emerging in Europe.

In Africa, there would be only the Abyssinian crescent and isolated points: a few islands in the Moroccan Atlas, the Peak of Teneriffe, that of Fernando-Po, the Kamerun Mountains, Kilimandjaro and Kenia, some peaks of the Drakenberg, and Ankaratra in Madagascar.

North America would still have left above the waters a certain number of summits belonging to the volcanoes of Guatemala and Mexico, to the Rocky Mountains, to the Cascades, and the Sierra Nevada; further to the north, Mount Saint Elias and the volcanoes of Alaska, facing those of Kamchatka. Finally, of Oceania which would have disappeared there would remain only the volcanoes of the southern lands, New Zealand, Haiti, New Guinea, the islands of the East Indies, Formosa and Japan.

These are the regions, thus reduced in surface, the study of which conicerns us here. The survey we have made of them shows that these mountains differ from each other greatly, not only in their height, but also in their general character. Some rise rapidly, with a single rush, so to speak, to their full height; this is the type, for example, of the mountains of the islands and those of the western slope of the Cordillera of the Andes. In others, the strata are heaped progressively upon each other, and summits of prodigious height do not seem, because of their high bases, to equal isolated peaks which they really surpass. In the third part of this book, we shall show that these different orographic characteristics are very important in our study.

Eternal Snows. The latitude of these mountains has an equal importance. In fact, it is closely connected with the question of 
temperature. Now the line at which the eternal snows begin corresponds very accurately with the temperature.

In our Alps and Pyrenees, about $43^{\circ}-47^{\circ}$ north latitude, this line is a little above 2700 meters; on Etna ( $38^{\circ}$ lat. N.) it rises to 2900 meters. In the main mountain ranges of the center of Asia, of Pamir $\left(40^{\circ}\right.$ lat. N.), in the mountains of Boutan (27 lat. N.), it varies between the enormous heights of 4000 to 6000 meters, higher, naturally, in the regions nearest the equator, and also, curiously enough, on mountain slopes facing north; on Gaurisankar, the snow begins at 5300 meters towards the north, whereas towards the south it begins at 4900 meters; the chain of Karakorum is at certain points bare of snow up to 6500 meters (Schlagintweit). In Abyssinia ( $13^{\circ}$ lat. N.) the line is about 4300 meters, and on Kilimandjaro ( $3^{\circ}$ lat. S.) it is a little more than 5000 meters. The Cordillera, in its long extent from south to north, does not lend itself to an average estimate. At the equator, the volcanoes around Quito have the line of eternal snow at about 4800 meters. Speaking generally, this snow line is lower as the distance from the equator becomes greater; at Popocatepetl $\left(19^{\circ}\right.$ lat. N.), it is only 4300 meters. But in the Andes of Bolivia, and especially in the mountains which edge Lake Titicaca on the west $\left(16^{\circ}\right.$ lat. S.), it rises considerably up to 6000 meters: much above the level in the mountains of the east, where it is about 4800 meters. In the Andes of the Chilean shore, on the volcano Corcobado (2290 meters), in $43^{\circ}$ lat. S., that is, at the same distance from the equator as Maladetta, it is only 1800 meters. On Mount Hooker ( $52^{\circ}$ lat. N.) it is 2600 meters, on Mount Elias ( $60^{\circ}$ lat. N.) 1500 meters, and on B̈̈renBerg (2096 meters) on the island of Jan Mayen ( $71^{\circ}$ lat. N.) at only 400 meters. On Tierra del Fuego, on Mount Sarmiento. (2075 meters), in $54^{\circ}$ lat. S., the line is at 1100 meters, much lower than on Mount Elias, which, however, is much nearer the pole.

Living Organisms. The extent of vegetation varies in altitude with the snow line, which perpetually limits it. Whereas in our Alps the timber line is at about 1800 meters, in the tropical Andes the grapevine, the cinchonas, and the oaks extend up to 3000 meters. In the Himalayas, the limit is higher yet, because apricot trees are cultivated at an altitude of more than 3000 meters, and birches and poplars grow up to an elevation of 4200 meters.

Animals naturally follow vegetation; birds conform to this rule, and if on the sides of Chimborazo the condors sometimes soar at the prodigious height of 7000 meters, that is because 2000 to 3000 
meters lower, pastures stocked with llamas, ostriches, etc., assure them abundant food.

Human dwellings obey the same law. In central Europe, only a few villages are at a greater altitude than 1500 meters; the highest in the Pyrenees, Porté, is at an altitude of 1625 meters; SaintVéran, in the Upper Alps, and Soglio, in the Rhetian Alps, are 2050 meters high. Above that height, there are only a few chalets unoccupied in winter. The monastery of Saint Gothard is at an altitude of 2090 meters, that of Bernina at 2300 meters; the highest of the summer pastures to which the Alpine shepherds go is that of Fluhalpe, at 2550 meters, and we know that a sufficient number of monks can be kept at the monastery of the Grand Saint Bernard (2470 meters) only by means of the double attraction of heavenly rewards and fat Italian prebends promised to the monks after some years of painful sojourn on the mountain.

In the Rocky Mountains, Central City is at an elevation of 3460 meters on the side of Long's Peak ( $40^{\circ}$ lat. N.).

In the Andes, not only villages but also populous cities are built in large numbers in lofty places. Mexico City is at 2290 meters, Santa Fé de Bogota at 2560 meters, Quito with its 60,000 inhabitants at 2910 meters, Cuzco at 3470 meters, Micuipampa at 3620 meters, La Paz at 3720 meters, Puno at 3920 meters, Tacora at 4170 meters; Potosi, which formerly had more than 100,000 inhabitants, is at 4165 meters, Oruro at 4090 meters, Torata at 4175 meters, Portugalete at 4290 meters, Cerro de Pasco at 4350 meters; in Peru and Bolivia, the larger part of the population lives above 3000 meters. ${ }^{9}$ Villages and dairy farms are at still higher levels. The mines of Chouta are operated at 4480 meters, those of Huancavelica at 4655 meters, those of Villacota at 5042 meters (Pissiz). The posthouse of Rumihuani, on Illimani, is at 4740 meters. The railroad from Arequipa to Puno, as we have seen, crosses the Cordillera at an elevation of 4460 meters, and that from Callao to Oroya at its highest point has a tunnel at 4760 meters; now these gigantic feats required the prolonged sojourn of a great number of workmen.

In the Himalayas, man has established his dwelling at heights just as astonishing. According to the Schlagintweit brothers, the capital of Little Thibet, Leh, is built at 3505 meters; in the same country, Muglab and Kibar, cities built of stone, are at 4150 and 4220 meters; the village of Chushul, highest in the Himalayas among those which are inhabited all year long, is at 4390 meters; the Buddhist monastery of Hanle, in Ladak, is at 4610 meters; about twenty lamas live there. The villages inhabited only during the 
summer are frequently situated between 4500 and 4900 meters; Norbu, for instance, is at 4860 meters. In summer, the herds feed in pastures as high as 5000 meters, like that of Larsa, at 4980 meters. ${ }^{10}$ On the high plateaux of Vokhan and Pamir, the Kirghiz bring their yaks and sheep to the elevation of 4700 meters. The Mirza sent by M. Montgomerie to Thibet even mentions a village, Thok-Djalank, at the extraordinary height of 4980 meters.

The Andes and the Himalayas include the only two regions of the earth where populations numbering millions of souls live regularly above 3000 meters. On the lofty plateaux of Mexico, the regions inhabited by a great number of men are as low as about 2000 meters; in Abyssinia, they are lower yet; Gondar is at 2220 meters and the village of Endschetkab, which seems to be the highest in Abyssinia, at 2960 meters.

About the same thing is true of the mountain dwellers in Armenia: Ispahan is situated at 1340 meters, Erzeroum at 1860 meters and Kars at 1900 meters. In Europe, as we have seen, the level is still lower.

Men who live at these heights are certainly in conditions very different from those encountered at sea level. At 5500 meters, a liter of air weighs exactly half as much as at sea level; at 3300 meters, a third less; at 2300 meters, a quarter less. Are these special conditions helpful or harmful to the material or intellectual development of man? I shall try to discuss this question in the third part of this book. I must remind my readers, furthermore, that slow, progressive influences, which the sojourn in lofty mountains may exert on successive generations, will be given little attention. For these important questions in hygiene and politics, I refer my readers to the noteworthy book of M. Jourdanet. In this work, and especially in the part devoted to the discussion of historical records, I shall deal only with sudden and evident symptoms caused in men and animals by an abrupt and considerable change in altitude and consequently in barometric pressure. And so in the following pages I shall refer to the accounts of travellers, generally telling their own experiences.

I have divided this historical part into three distinct chapters. The first contains the reports of which I have just spoken; I have classified them by orographic regions and listed them chronologically. I certainly do not claim that this list is absolutely complete; but I think I have omitted nothing that is really interesting.

In the second chapter the accounts of aeronauts are reported. Finally, in the third I have arranged the laboratory experiments, 
carried out with the purpose of studying the effect of diminished pressure, the theoretical interpretations which various physiolo-. gists have given a priori of the symptoms observed in mountain ascents, and finally the explanations suggested by the travelers themselves, with the popular opinions about these strange illnesses. Of course in this chapter I stop at the discussions which my own researches have aroused; my purpose is to show the state of knowledge when I began my experiments. Finally, the last chapter summarizes both all the data observed and all the theories suggested.

${ }^{1}$ See, however, in Chapter III, the quotation from Bacon.

${ }^{2}$ The altitudes which I give in this general review were taken generally from the last edition of Stieler's Hand-Atlas. Those which I did not find in this atlas were taken, for Europe, from the Orographie of Brugnière; for France, from the Géographie of M. Levasseur; for South America, from the works of Pentland and M. Pissiz. I used also the information furnished by the recent work of Berghaus (Höhentafel von 100 Gebirgsgruppen aus allen Erdtheilen, Geogr. Jahrbuch. 1874). My intended purpose evidently does not require absolute precision; therefore I did not hesitate to use some rather old documents; for the same reason, I omitted the units in the altitude figures.

${ }^{3}$ Strabo, Geography, Book VI, Chap. III, Section IX.

"Ibid., Book IV, Chap. VI, Section IV.

${ }^{5}$ See Schuechzer, Oúpєóıфoıт $\eta$ s Helviticus. Lugd. Bat., 1725.

${ }^{\circ}$ Harcourt, On the Himalayan valleys: Kooloo, Lahoul and Spiti. Journal of the royal geogr. soc., Vol. LXI, p. 245-257; 1871.

${ }^{7}$ Nouvelle description des glacières et des glaciers des Alpes, second edition, Vol. II, p. 87. Geneva, 1785.

${ }^{8}$ Besides the sources indicated above in a note, for these altitudes I borrowed frequently from Klöden, Handbuch der Erdkunde, Berlin, 1869, and from Stein, edition of Wappens: Handbuch der Geographie, Leipzig, 1863-70.

${ }^{9}$ Jourdanet, Influence de la pression de l'air sur la vie de l'homme, Vol. I, p. 108. Paris, 1875.

${ }^{10}$ Schlagintweit, Results of a scientific mission to India and High Asia in 1854-1858. 3 vol. 1861-1863; Vol. II, p. 477. 


\section{Chapter I MOUNTAIN JOURNEYS}

1. South America.

It is to the accounts of travellers who followed.the first American conquerors that we owe our knowledge of the discomforts that attack man when he reaches a certain height on a mountain side. To gain this elementary information, science had to wait until Cortez attacked Mexico in 1519 and until Pizarro, twenty-five years later, took Quito and conquered Chile and Peru. And yet the conquerors themselves gave little heed to the increase of suffering brought them by an unknown disease; at least their historians do not mention it. In the account of the two expeditions which by order of Cortez ascended to the crater of Popocatepetl (5420 meters) in 1519 and 1522, the details of the second of winich were told by Herrera, ${ }^{1}$ mountain sickness is not very clearly indicated.

The companions of Francis Pizarro (62 horsemen and 102 footsoldiers), in the daring march which took them in October, 1532, from the Pacific coast to Cuzco, the heart of the empire of the Incas, had to cross the lofty passes of the Cordillera of the Andes through a thousand perils. The historian, Xeres, ${ }^{2}$ who is the narrator of this marvellous expedition, speaks only of "the great cold experienced on these heights". However, they were below the region of perpetual snow; the ground was covered with a plant like the "esparto corto" (page 65). Ferdinand Pizarro, sent by his brother from Caxamalca to Parcama and Xauxa, on March 3, 1533, passed over "a very steep mountain of snow, into which the horses sank up to their bellies" (page 157); but mentioned no special com- plaint.

In 1534, Pedro de Alvarado with 500 men and 225 horses undertook the conquest of Peru; disembarking at Cape San Francisco, he 
reached the road from Cuzco to Quito at a point south of Ambato; it is evident then that he crossed the Andes near Chimborazo. He must have ascended to an altitude of more than 4800 meters, since he was in the midst of snows; the sufferings of his army were terrible:

There died (according to Herrera) fifteen Spaniards and six women, several negroes and two thousand Indians. When they issued from the snow, their faces were death-like. Several Indians who escaped lost their toes and even their feet; some were blind.

The great expedition of Don Diego d'Almargo, in the conquest of Chile, had still more terrible results. Leaving Cuzco in 1535, he tried to cross the mountain, in spite of his captains. The Inca Garcilasso de la Vega ${ }^{3}$ has given a touching account of the sufferings of the army.

As the land they entered was so wild, suffering soon resulted: for a few days after, they found strange obstacles in the road they took. The first was that they could not walk on account of the snow ... the second, that food began to fail ... and the third, that, according to the calculation of the cosmographers and the astrologers, since the mountains raised their summits into the middle regions of the air, the temperature was so low, because everything there is covered with snow, particularly in such a season as our adventurers had chosen, namely, winter when the days are the shortest and coldest of the year, that many Spaniards, Negroes, Indians, and horses were frozen and benumbed. But the Indians, though lightly clad, had the best of it. Of the 15,000 of them, more than 10,000 died and more than 150 of the Spaniards , ...

It was probably in the lofty regions of Tacora, on the road between $\mathrm{La} \mathrm{Paz}$ and Arica, that this expedition took place, so unfortunately undertaken in the middle of the southern winter.

In $1541,{ }^{4}$ shortly after the death of Pizarro, four Spaniards, wino were part of an expedition which had left Asuncion at the order of Irala, went to Lima, passing by Potosi and Cuzco. An envoy of the governor of Peru had made the same journey; "Miguel Ruedo and Ahaic were so exhausted by the hardships of the journey," says Ulrich Schmidel, who accompanied the expedition, "that they were obliged to stop at Potosi" (page 222).

These accounts, as we see, give as explanation of the sufferings and disasters only fatigue, lack of food, and cold. The Jesuit father Acosta, ${ }^{5}$ who travelled in South America about the end of the sixteenth century, was the first to note the special distress due to a special cause, the air of lofty places. Let us add that he gave a striking description of it. 
From the translation printed in Paris in 1596 by Robert Renault Cauxois, I copy the most interesting part of his account.

In certain parts of the Indies, the air and the wind blowing there dizzy men, not less but more than at sea ....

In Peru there is a high mountain called Pariacaca, and having heard tell of the variation it caused, I went there, prepared the best I could according to the information given by those called Vaquianos or experts; but in spite of all my preparation, when I began to mount the stairs, as they call the highest part of this mountain, I was suddenly attacked and surprised by an illness so deadly and strange, that I was almost on the point of falling from my horse to the ground, and although there were several in our company, each hastened his step without waiting for his companion so that he might leave this evil spot quickly. Being left alone then with an Indian, whom I asked to help me sit on my horse, I was seized by such a spasm of panting and vomiting that I thought I should give up the ghost. After vomiting food, phlegm, and bile, one yellow and the other green, I next threw up blood, so that I felt such distress in my stomach that I can say if it had lasted I am sure I would have died. That lasted only three or four hours until we had descended pretty low and had reached a temperature more suited to nature, at which point our companions, about fourteen or fifteen in number, were very much exhausted, some of them asked for confession on the road, thinking they were really going to die, others dismounted and were wrecked with vomiting and diarrhea; I was told that in the past some had lost their lives from this distress. I saw a man lying on the ground in a passion, crying out with the rage and pain caused him by this passage of the Pariacaca. But usually it does no important harm, except this annoying and disagreeable trouble as long as it lasts. And it is not only the pass of Mount Pariacaca that has this characteristic, but also this whole chain of mountains, which extends more than five hundred leagues; no matter where one crosses it, he feels this strange distress, although it is worse in some places than in others, and worse in passes up from the seashore than in those from the plains. I myself crossed it, besides by Pariacaca, by Lucanas and Soras, and in another place by Colleguas, and in another by Cauanas, that is, by four different places in my various comings and goings, and always in this place, I felt this dizziness and distress that I have mentioned, although never as much as the first time at Pariacaca, and all who have passed that way have had the same experience. . . .

Not only men feel this distress, the animals do too, and sometimes stop so that no spur can make them advance. For my part, I believe that this place is one of the highest spots on earth.

This whole chain of mountains is practically deserted, without any villages or habitations of men, so that one can hardly find little houses or retreats to lodge travellers at night. There are no animals either, good or bad, except maybe a few vicunas, which are the sheep of the country, which have a strange and marvellous characteristic, which I shall mention in the proper place. The grass is often burned and blackened by the wind I mentioned, and this desert lasts through the 
twenty-five or thirty leagues of the pass, and in extent stretches more than five hundred leagues, as I said (page 87).

After he had made this description, and we will admit that exactness could not have been joined to picturesqueness more skilfully, Acosta discusses the cause of these symptoms which he says he experienced in four other crossings of the great Cordillera. We shall report in a chapter devoted to a summary of theoretical explanations the ideas of this reverend gentleman, ideas which are really marvellous for insight and clearness.

It is hard to determine the exact point at which Acosta crossed; Pariacaca is a name that has disappeared in Peru as well as in Ecuador. It is almost certain that it was below the snow line, for his account, so exact and so detailed, does not speak of the snow; its height above sea level was therefore probably 4500 meters at the most.

It is very strange to see that after describing so admirably and after explaining the painful sensations he had experienced while crossing the lofty mountains, Acosta does not consider them as accounting for the disasters undergone by the Spanish armies. Yet he knew them very well; he speaks of them; but here his clearness of mind seems to abandon him.

There are other deserts or uninhabited places, which in Peru they call Punas (to speak of the second point which we promised) where the quality of the air cuts body and life from men without their feeling it. In the past the Spaniards travelled from Peru to the kingdom of Chile across the mountain; today they usually go by sea, and sometimes along the coast; and although this route is tiresome and inconvenient, there is never as much danger there as on the mountain road, in which there are plains in passing through which several men have died and perished, and others have escaped with great luck, and some of them were maimed. In this place there blows a little wind which is not too strong or violent. But it is so penetrating that men fall dead of it almost without feeling it, or maybe their fingers and toes are left there; which may seem a fabulous tale, and yet it is a true thing. I knew and long frequented General Hierosme Costilla, former administrator of Cusco, who had lost three or four toes, which had fallen off when he passed through the deserts of Chile, because they had been attacked and penetrated by this little wind, and when he happened to look at them, they were all dead and fell off of their own accord without giving him any pain, just as a rotten apple falls from the tree. This captain related that of a good army which he had led through this place the preceding years, since the discovery of this kingdom of Almagro, a great part of the men remained there dead, and that he saw their bodies stretched out on the desert, without any bad odor or decay. . . . No doubt this is a kind of cold so penetrating that it extinguishes the vital heat by cutting off its power; and also because it 
is very cold, it does not corrupt or cause decay in dead bodies, because putrefaction proceeds from warmth and humidity (page 89).

A celebrated Spanish historian, who wrote shortly after Acosta, Antonio d'Herrera, took up the ideas of the learned Jesuit, and, without quoting him, copied almost in full the passages which we have just put before our readers. ${ }^{6}$ But it is evident that he could not include the whole of the explanation of Acosta; at least it would be useless to include here his chapter: Reasons why it is so dangerous to pass through the "Puertos Nevados" which lead to Chile, and the passes of the province of Quito through which Belalcazar and Alvarado crossed with their armies.

A century and a half passed without the historians and the travellers speaking of the physiological symptoms which Acosta had noted. The "Lettres Edifiantes", 7 in which there are so many details, generally childish but sometimes interesting, do not allude to them, although their writers were evidently several times in the same conditions as their predecessor. My researches in the authors of the seventeenth century have revealed nothing pertinent to our subject.

But a document published at the beginning of the eighteenth century shows us that in the Andes it had been known for a long time that at certain points more or less severe symptoms attack men and animals. We even find in this document an explanation which recurs up to the present. A Frenchman, Frezier, ${ }^{8}$ visited the coasts of Chile and Peru from 1712 to 1714; he speaks at length of the rich mines in the interior of the country, and after discussing the origin of the metals, he adds:

It is certain that strong exhalations issue constantly from the mines; the Spaniards who live above them are obliged to drink very frequently Mate, the grass of Paraguay, to moisten their lungs, and thus prevent a sort of suffocation. Even the mules which pass through these places, although they are much less rugged and steep than others along which the mules run, are obliged to rest almost every moment to regain breath. But these exhalations are much more evident within; they are so powerful over bodies not accustomed to them that a man who enters for a moment comes out as if crippled. . . . The Spaniards call this illness Quebrantahuessos, that is, it breaks the bones (page $150)$.

Frezier had no opportunity to make personal observations. But a few years later, in 1736, three French Academicians, Bouguer, La Condamine, and Godin, went to Peru to measure a degree of the meridian there. It was at the time of this celebrated expedition that the symptoms of decompression were first studied and dis- 
cussed scientifically. In one of their trips, Bouguer and La Conclamine remained three weeks on Pichincha, at an altitude of about 4860 meters. There they experienced discomforts which Bouguer" describes in the following terms:

We were all at first considerably inconvenienced by the keenness of the air; those of us who had more sensitive lungs felt the difference more and were subject to slight hemorrhages, which no doubt came from the fact that the atmosphere, since its weight was less, did not by its compression help the vessels sufficiently to retain the blood, which, however, was still capable of the same action. Personally I did not notice that this inconvenience increased much when we happened later to ascend higher; perhaps because I was already acclimated, or perhaps also because the cold prevents the expansion of the air from being as great as it would be otherwise. Several of us, when we were ascending, fell fainting and were seized by vomiting; but these

symptoms were more the result of fatigue than of the difficulty of breathing ..... We sometimes felt a very severe cold, when the thermometer indicated only a moderate degree (page 261).

Bouguer then expounds a hypothesis of which we shall speak in the third chapter; according to him, the symptoms experienced are due in part to fatigue, in part to a sort of scurvy.

In the two volumes which La Condamine ${ }^{10}$ devotes to the account of his journey, and which are anyway half filled by his violent disputes with Bouguer, I could find only the following passage referring to his stay on Pichincha:

Don Antoine d'Ulloa, while ascending with us, fell in a faint, and had to be carried to a nearby cave ... Personally I felt no difficulty in breathing. As to the affections which $\mathrm{M}$. Bouguer mentions and which apparently refer to the tendency to bleed from the gums, with which I was then inconvenienced, I think it should not be attributed to the cold of Pichincha, since I felt nothing like it in other places of equal altitude, and since the same symptom attacked me again five years after at Cotchesqui, the climate of which is temperate. (Vol. I, p. 35.)

But the most circumstantial and exact information is furnished us by Don Ulloa, a young naval officer whom the Spanish government had sent to protect the French mission, and who later played a great part in his nation. His accounts ${ }^{11}$ give at the same time the story of the symptoms experienced temporarily by mountain climbers, and those which are the consequence of a stay of several months in certain regions of the Cordillera of the Andes. Here also for the first time we find suggested the services which a sojourn in lofty altitudes can render to therapeutics:

Those who are not accustomed to frequenting these places are also exposed to another discomfort, besides the cold of which we have just 
spoken; it is the Mareo of the Puna; and it is rare that they are not attacked by it. It is a disease quite like that which one feels at sea: it displays all the symptoms of it and follows the same course. The head whirls; one feels very hot; and painful nausea comes on, followed by bilious vomiting. Strength fails, the body weakens, fever appears; and the only comfort one finds is in vomiting. Some people are even so weakened that they would cause anxiety, if it were not certain that the-trouble was nothing but this Mareo. That lasts usually one or two days, after which health is restored. This inconvenience is greater or less according to the natural constitution of the person; but few escape. When anyone has felt it once, it is extraordinary that he should be attacked by it again in passing by Puna or coming from low countries or any country in which there is a high temperature (page 116)....

There is also observed in these climates another symptom to which animals are subject. As soon as they pass from the plains to these eminences or Punas, as from countries where there are dwellings to the summits which surround them, breathing becomes so difficult for them, that in spite of the different pauses they make to get their breath, they fall and die there (page 118).

Ulloa then discusses the different explanations suggested in his time to account for these phenomena, and energetically rejects the idea of toxic emanations due to minerals buried in the earth, an idea which is current even today among the common people and even in the educated classes of Bolivia and Chile. Then he adds:

The men who have recently come to this climate also experience something similar to what I said about animals; while walking, they feel a suffocating and very painful fatigue, which forces them to rest a long time; that happens to them even in the flat lands; now there can be no other cause for this phenomenon than the keenness of the air; but as the lungs become accustomed to this atmosphere, the discomfort lessens. However, they still experience some difficulty in breathing when they wish to climb some slope; this is inevitable, but is not felt in other countries where the atmosphere has a regular density.

This lightness of the air is favorable to those who have become asthmatic in a denser air. This asthma is known by the name of ahogos or suffocation; it is rather common there; that is why those who are attacked by it in the low countries go up into the mountains; although they do not entirely recover there, they live there nevertheless without pain: on the contrary, those who became so in high altitudes are well in the lowlands; so change of air is a certain alleviation in this sort of disease. The science of medicine might profit by these experiences, sending the patients of one country into another, although elsewhere there is not so great a difference of altitude.

Difficulty of breathing is noted also to a certain degree in the highlands of the province of Quito, but it is less painful there: no doubt that is because one of these countries is on the equator, or nearly so, whereas the other is remote from it. The conclusion is that the Punas or summits of Peru are less cold and the air less cutting than in the 
other countries. But it is well to note that what has been said of Guancavelica is general for all the lands extending towards the south.

That these details may be better understood, I shall observe here that what is called Punas in Peru, is named Paramo in the kingdom of Quito (page 120).

It was in the last year of the eighteenth century that the illustrious Alexander von Humboldt undertook that great expedition into South America, which was the source of so many important discoveries in the history of man, the physics of the earth, and natural history. ${ }^{12}$ In 1802 he made a stay on the lofty plateau of Quito, overlooked by the gigantic peaks of Pichincha, Cotopaxi, Chimborazo, and Antisana.

In March and in June 1802, he made ascents which have become famous of the last two volcanoes; he immediately gave a brief account of them in two letters, written the same day; I quote from them passages which are interesting from our point of view.

The first is addressed to Citizen Delambre; ${ }^{13}$ it relates particularly the ascent of Chimborazo:

It was believed till now in Quito that 2470 fathoms was the greatest height at which men could resist the rarity of the air. In the month of March 1802, we passed a few days in the great plains which surround the volcano of Antisana, at a height of 2107 fathoms, where cattle, when chased, often vomit blood ..... On May 16, we explored a path on the snow, a gentle slope on which we climbed to 2773 fathoms. The air there contained 0.218 of oxygen ... the Reamur thermometer stood at only $+13^{\circ}$; it was not cold at all, but blood issued from our lips and eyes. (P. 174.)

In the expedition which I made June 23,1862 , to Chimborazo, we proved that with patience one can endure a greater rarefaction of the air. We crossed 500 fathoms higher than La Condamine at the Corazon, and we carried instruments on Chimborazo to 3031 fathoms, seeing the mercury drop in the barometer to 13 inches, 11.2 lines; the thermometer stood at $1.3^{\circ}$ above zero. Our lips bled again. Our Indians abandoned us again as usual. Citizen Bompland and M. Montufar, son of the Marquis de Selvalegre, of Quito, were the only ones who were resistant. We all felt a discomfort, a weakness, a desire to vomit, which certainly arises as much from the lack of oxygen in these regions as from the rarity of the air. I found only 0.20 of oxygen at this immense height. (P. 175.)

The other letter is addressed to his brother, Wilhelm von Humboldt; in it, more than in the preceding letter, he speaks of the ascent of the volcano Antisana: ${ }^{14}$

On our journey to the volcano of Antisana, the weather was so favorable that we ascended to the height of 2773 fathoms. At this alti- 
tude the barometer fell to 14 inches, 7 lines, and the rarity of the air made blood issue from our lips, our gums, and even our eyes; we felt an extreme weakness, and one of those who accompanied us on this journey fainted. ... .

We succeeded in approaching to about 250 fathoms from the summit of the immense column of Chimborazo. ... We mounted to a height of 3031 fathoms, and we felt inconvenienced in the same manner as on the summit of Antisana. Even two or three days after our return to the plain, we continued to feel a discomfort which we could attribute only to the effect of the air in these lofty regions, an analysis of which gave us 20 per cent of oxygen. (P. 329.)

Thirty-five years later, ${ }^{15}$ von Humboldt returned with details about the account of these ascents. He dwells particularly upon the physiological symptoms, and develops some very interesting theories in this regard.

June 22, 1802, he was in the plain of Tapia, at an altitude of 2890 meters. The first part of the ascent had no particular interest for our purpose:

At an elevation of 15,600 feet, all the Indians but one abandoned us. . . They claimed that they suffered far more than we did. There were only four of us left then: M. Bonpland, . . . M. Carlos Montufar, ... a half-breed from San Juan, a nearby village, and I. (P. 413.) . . .

We all began by degrees to be very uncomfortable (they were then at a height of about 5,000 meters). The desire to vomit was accompanied by fits of dizziness and was much more painful than the difficulty of breathing. The half-breed from San Juan, a poor and sturdy peasant, who had wished to follow us to the end out of the kindness of his heart and not from any selfish interest, suffered more than we did. Our gums and lips bled. The conjunctiva of the eyes in all of us without exception was bloodshot. These symptoms of extravasation in the eyes and of a discharge of blood from the gums and lips did not disturb us, because we were acquainted with them from many examples. In Europe, M. Zumstein began to bleed at a much lower elevation, on Monte Rosa. ${ }^{16}$ (P. 417.) ...

Once, on the volcano of Pichincha, I felt, without any bleeding, such a violent pain in my stomach, accompanied by vertigo, that my companions found me stretched out unconscious on the ground. The altitude was only 13,800 feet $(4480 \mathrm{~m}$.), and consequently not important. But on Antisana, at the great height of 17,022 feet (5527 m.), Don Carlos Montufar bled profusely from the gums. All these phenomena vary greatly, according to the age, the constitution, the delicacy of the skin, and the previous muscular efforts which one has made; however, they are for each individual a sort of measure of the rarefaction of the air and the altitude he has reached. According to my observations, they appear in the Andes in white men, when the barometer stands between 14 inches and 15 inches 10 lines. (P. 418.)

We shall see later what successive opinions, and considerably 
different ones, the illustrious naturalist held about the explanation of these various phenomena.

But before going on to other accounts, I should include here a fragment of one of the works of Humboldt, ${ }^{17}$ in which he gives information full of interest for the subject of our study about the usual habitat of the condor and the maximum height to which it rises:

The region which one may consider the habitual sojourn of the condor begins at a height equal to that of Etna, and includes layers of the air from 1,600 to 3,000 fathoms above sea level. The largest specimens found in the chain of the Andes of Quito have a wing-spread of 14 feet, and the smallest only 8 feet. By these dimensions and by the visual angle at which this bird appeared sometimes perpendiculariy above our heads, one may judge to what prodigious height it rises when the sky is clear. Seen, for example, at a visual angle of four minutes, he would be at a perpendicular distance of 1,146 fathoms. The cavern (machay) of Antisana, situated opposite the mountain of Chuesolongo, and from which we took the measurement for the soaring bird, is 2,493 fathoms above the level of the Great Ocean. So the absolute height which the condor attained was 3,639 fathoms; there the barometer is hardly twelve inches high. It is a very remarkable physiological phenomenon that this same bird, which for hours soars in circles in regions where the air is so rarefied, suddenly swoops down to the seashore, for instance, along the western slope of the volcano of Pichincha, and thus in a few instants passes through all climates, as it were. At a height of 3,600 fathoms, the aerial and membranous sacs of the condor, which were filled in lower regions, must be extraordinarily inflated. Sixty years ago Ulloa expressed his surprise that the vulture of the Andes could soar at a height where the air pressure was only 14 inches. It was believed then, on the basis of experiments made. with the pneumatic machine, that no animal could live in a medium so rare. As I have already stated, on Chimborazo I saw the barometer drop to 13 inches 11.2 lines. My friend, M. Gay-Lussac, breathed for a quarter of an hour in air the pressure of which was only 0.3288 meters. At such great heights, in general man finds himself in a very painful state of asthenia. On the contrary, in the condor the act of respiration appears to take place with equal ease in media in which the pressure varies from 12 to 28 inches. Of all living beings, this is certainly the one which can at will rise furthest from the surface of the earth. I say at will, because small insects are carried still higher by ascending currents. Probably the height reached by the condor is greater than we found by the calculation given. I remember that on Cotopaxi, in the plain of Suniguaicu, covered with pumice stones, and at an elevation of 2,263 fathoms above sea level, I saw this bird at such a height that it seemed only a black dot. What is the smallest angle at which objects dimly lighted can be distinguished? The weakening of the rays of light by their passage through the layers of air has a great effect upon the minimum of this angle. The transparency of mountain air is so great at the equator, that in the province of Quito, as I have shown 
elsewhere, the poncho or white cloak of a person on horseback can be seen with the naked eye at a horizontal distance of 14,022 fathoms, and consequently at an angle of 13 seconds. (P. 78.)

The revolutions by which the Spanish colonies of America shook off the yoke of the mother country resulted in the crossing by troops of several thousands of men of certain passes of the Andes usually frequented by only a few travellers. The stay in rarefied air certainly brought an increase of suffering to these little armies; but the historians seem to have paid but little attention to it, preoccupied as they are by the natural effect of the cold, the lack of food, and the excessive fatigue.

Early in the year 1817, General Saint-Martin, at the head of 3000 Independents, invaded Chile by the difficult pass which leads from Mendoza to Santa Rosa, the highest point of which has an elevation of more than 4300 meters.

The expedition (says M. Gustave Hubbard ${ }^{19}$ ) presented such great difficulties that the troops from Santiago and the governor of Chile refused to give credence to such a dangerous attempt . . . A great number of men perished from cold in the rarefied and frigid atmosphere through which they had to pass .... When the army left Mendoza it had 9,281 mules; only 4,300 were left on the other side of the Andes, and out of 1,600 horses only 500 survived. (Vol. I, p. 346.)

The army which Bolivar led against Morillo in June 1819 from Venezuela to New Grenada, across the Andes of Colombia encountered the same difficulties. The Englishmen who formed a considerable part of his expeditionary forces died in great numbers. The celebrated historian Gervinus says in this reference: ${ }^{19}$

The way is unmistakably marked by the bones of numerous victims who die during these crossings. . . . In fact, those who, overcome by weariness and cold, abandon themselves to the peculiar drowsiness to which the traveller in lofty places becomes an easy prey fall into a numbness which takes their strength from them (emparamados irom paramos, a name given to the highest plateaux) and delivers them over to death without any hope of rescue (page 88).

Upper and lower Peru also witnessed such expeditions. In 1821, the Spanish viceroy La Serna, forced to abandon Lima, retreated across the Cordillera, and established himself in the high valley of Jauja. Thence his troops often descended to attack the Independents, until Bolivar undertook against them the campaign which ended in the battle of Ayacucho (1824), and the whole of which was carried on at a height of more than 3000 meters. It was at a still greater height, 4500 meters, that General Santa Cruz defeated the Spaniards in 1822 on the slopes on Pichincha. 
The Spanish writer Torrente, ${ }^{20}$ in his history of the SpanishAmerican revolution, is correct in attributing to the altitude a considerable share in the sufferings of the armies during these marches at high altitude:

When one crosses the Cordillera of the Andes of Peru, one usually suffers from two maladies: spasms and nausea. The latter is more common, especially for those who come from the low, hot land along the coast. The keenness of the air in this atmosphere hampers respiration and makes it very laborious, increases the pulse rate, speeds up the circulation, produces intense headaches, and causes the blood vessels to swell quickly, and the unfortunate victim to perish, with an issue of blood from the mouth, the eyes, and the nostrils. It is true suffocation which attacks animals also if their burdens are increased or their pace hastened ever so little. The losses of the small army of the viceroy La Serna were greater during the retreat from Lima to Jauja, because a large number of his soldiers were still convalescing.

The author adds, repeating popular superstitions:

It seems that the veins of precious metals and antimony which run through the territory of Peru are the cause of this atmospheric combination which is so injurious to health. What would tend to prove it is the fact that its effects are much less noticeable on points of greater altitude, such as certain parts of the Cordillera of Chile, the Sierra of Pichincha, and other mountains of Quito.

This nausea is known in the country by the name of Soroche, and it is experienced even in certain low lying villages, situated in metalliferous localities. (Vol. III, p. 164 and 169, note.)

We have seen Saint-Martin crossing the Cordillera from Mendoza to Santiago, thus carrying out an expedition which Manuel de Almagro ${ }^{21}$ considers "as far more difficult and worthy of admiration than that of Bonaparte at the Grand Saint-Bernard, which has been much exaggerated"' (p. 34). This route, as we have said, is the one usually followed by travellers who wish to cross America. Two passes exist, one by Cumbre (3920 meters), the other by Portillo (4360 meters). The former is more frequented. Most accounts mention the symptoms of decompression; but on this road they are usually not serious.

However, Samuel Haigh, ${ }^{22}$ who ventured into the passes of Cumbre from Mendoza to Santiago during the austral winter of 1818, felt them considerably. A snow storm which assailed him compelled him to take refuge with his companions at a hill where the "casucha" of Las Vacas offered them a shelter:

While climbing the hill on which it is built, (he says) I was attacked for the first time by the puna or soroche. This is an illness peculiar, I think, to high mountains; it is the result of the extreme 
rarefaction of the air which therefore causes difficulty in breathing. Three times I was forced to lie down on the ground before reaching the top of the hill, and I experienced shortness of breath with pain and oppression in the chest and a sensation of nausea. The puna attacks some persons so severely that blood issues from their mouths and nostrils.

However, I must say, our sufferings really began. (P. 104.)

But all are not equally affected, especially when, as usually happens in the favorable season, the journey is made on muleback. Miers, ${ }^{23}$ who crossed in May 1819, explains this very well:

Those who wish to undertake this journey will be dismayed by the accounts of the difficulties caused by the puna, a name given to the sensation of short and difficult respiration, which often attacks us when we ascend into rarefied air. This is the terror and the subject of conversation of all who have crossed the Cordillera, who tell you that they escaped these terrifying symptoms only by eating a great many onions, and by tasting no alcoholic liquors, except wine, which is considered the antidote of the puna. These precautions, however, are not necessary, for very few persons who make the ascent on horseback experience this discomfort, except those who have a lung ailment; but many of those who have climbed Cumbre on foot, overexerting themselves in driving the mules, have been affected. I do not think that anyone would suffer much from the puna unless he overexerted himself. I have twice ascended and descended Cumbre on foot without being affected. Moreover neither my wife nor my child, only six months old, felt the least difficulty in breathing with the thermometer at $35^{\circ} \mathrm{F}$. and the barometer at 19 and $1 / 8$ inches, although we might have expected that in a child of this age with such delicate lungs one would first observe modifications in respiration, even though they were due only to excessive rarefaction of the air. (Vol. I, p. 321.)

The account of the Scotchman Caldcleugh ${ }^{24}$ is particularly interesting, because this traveller crossed the Andes twice in opposite directions. The first time, March 17, 1820, in very bad weather, a snowstorm, he crossed by Portillo and Piuquenes, going from Mendoza to San Jose. He does not mention any symptoms. (Vol. I, p. 285-323.)

But on June 2 of the following year, while going from the Punta of San Luis to Cordova (Argentine Republic), he crossed at a much lower point, the Sierra of Cordova. He stopped at a little hut at an elevation of 3200 meters and passed the night there. The next day, ascent of the pass:

The snow was frozen hard. . . Two of the peons suffered severely from an illness called puna, which attacked them shortly after we had left the hut. This illness seemed to me to consist of heavings of the diaphragm, accompanied by great exhaustion and loss of spirits. Those attacked by it lie down, give themselves up, and often die before reaching the descent. Great quantities of garlic and onion are con- 
sidered specific against this condition. But the surest treatment is to take the patients as quickly as possible to a less lofty place. It has been commonly noted that those of the peons who are old and addicted to bad habits suffer more from the puna than the others, and this note applied perfectly to the two whom I had to send back. One of them was extremely sick, and the other under whose care he departed was slightly affected. At present I do not know whether he managed to cross the valley.

Shortly afterwards they reached the summit, at an elevation of 3840 meters. He suffered no personal distress.

Schmidtmeyer, ${ }^{25}$ in the account of his crossing the Cordilleras from east to west by the volcano of Cumbre, speaks of no physiological symptom. But at the end of the book, he fills this gap:

I should have spoken sooner of this exhaustion accompanied by difficulty in breathing which one experiences when crossing the range; I often heard it spoken of in Chile. But we remained on muleback up to the highest point of the pass, which we therefore reached without the slightest effort. One of our men, however, suffered from it considerably, but I do not know whether it was an extreme case. Usually, on the high peaks of the Andes, one experiences great difficulty in moving; that is the opposite of what happens on other mountains. (P. 349.)

Proctor ${ }^{26}$ (1824), Head ${ }^{27}$ (1825), who followed the same route, in the same direction, make absolutely no mention of the puna. Lister Maw, ${ }^{28}$ who in Noyember 1827 left Truxillo (Peru) for the basin of the Amazon, does not speak either of the effect of the pressure, except at Contumasa (2190 meters), where he says poetically:

The rarity of the atmosphere tended greatly to raise our spirits.

But Lieutenant Brand ${ }^{29}$ is more explicit; he mentions these symptoms, and even tries to explain them, but without having experienced them himself, and yet he made his first journey from Mendoza to Santiago over Cumbre in the midst of the austral winter (August 22, 1827). He had to endure terrible cold, even down to $15^{\circ}$ below zero.

August 22, he ascended Cumbre; the thermometer stood at $34^{\circ}$ F.:

As I had often heard of the puna, or difficulty in breathing, from travellers who complained of it bitterly, I gave particular heed to it; I cannot say that I felt any more inconvenience than would have happened to me if I undertook such labor, so long continued, even if I had not been at this elevation. I suffered only from a very acute thirst, which the snow aggravated instead of satisfying. . . But I do not intend to contradict what has been said of the puna, which has assailed many travellers severely. (P. 147.) ... 
On my return across the Andes, in December, 1827, I saw that the mules stopped frequently to breathe, especially when climbing Cumbre, where they stopped at each zigzag, as if they suffered from pain in the lungs, and, like Acosta, I found that neither shouts nor blows could make them advance until it suited them. But that is not peculiar to Cumbre or to the other mountains of the Cordillera, for mules often stop thus, as if they felt pain in their lungs.

It happened likewise to the peons, who suddenly, while walking, stopped, shouted "puna, puna" and then continued ascending. It seemed as if they knew the places where this would happen to them when on foot, for they frequently said: "Here there is much puna." I can attribute this only to the existence in these places of minerals which alter the air more or less, whence comes their effect upon the lungs. (P. 149.)

The French officer De la Touanne, ${ }^{30}$ who took part in the expedition of Bougainville, and who followed the same route as Brand, was so severely attacked as to fall on the ground; he crossed the pass January 29, 1826.

I estimated that the point where we were is at least 2,000 fathoms high. . . . The air is very much rarefied at this elevation; I had dismounted from my mule, letting him go ahead with the caravan, and I was examining some stones at the right and the left of the path. When I afterwards wished to increase my pace to overtake my travelling companions, respiration suddenly failed me; I fell down, my chest oppressed and breathing with difficulty. A peon had to bring me my mule; and from these slight symptoms I could judge what the arrieros and the travellers who have to cross this pass in bad weather must suffer. (P. 50.)

After this testimony from travellers who only crossed the mountain, here is what is said by an English engineer, Ed. Temple, ${ }^{31}$ who lived for a year 1826-1827, at Potosi (4165 meters), where he was employed in the exploitation of the rich mines of that country:

While walking, I often experienced that difficulty in breathing which is caused by the extreme rarity of the air, and to which even the natives and the animals are subject. The royal sport of horse racing cannot take place here, for the horses seem to suffer more from the zorochi than men do; I have often heard that they fall and die, if they are hurried when they are climbing a hill. (Vol. I, p. 296.)

I shall also quote the passages in which the English traveller Bollaert, ${ }^{32}$ who in the month of June, 1827, ascended the mountain Tata Jachura (5180 meters), describes the sufferings he experienced during the ascent.

We had slight nosebleeds, buzzings in the ears, headache, dimness of vision, and our bodies were numbed by cold, all of which were caused by the puna or soroche, that is, the expansion and cold of the atmosphere. (P. 121.) 
I now come to the important journey of d'Orbigny ${ }^{33}$ and the interesting description he gives of mountain sickness.

In his first journey, he is going from Arica to La Paz:

May 21, 1830, I reached the point where the ravine of Palca joins another dry ravine. ... There I left vegetation and humidity. . . .

Soon I began to mount the side of Cachun, and on its summit I felt at the same time as the first effects of the rarefaction of the air a very keen cold, due to the elevation. (Vol. II, p. 377.) . . .

The slope became still steeper. ... I felt more and more the severe effects of the rarefaction of the air, a very violent headache and a great difficulty in breathing; my arrieros, their mules, and even my dog, my faithful Cachirulo; were forced to stop every twenty or thirty meters, tormented like me by the soroche....

Whenever one feels the illness due to the rarefaction of the air, the natives say that he has the soroche. They fail to recognize the real cause, the great elevation above sea level, and attribute it to mineral emanations from antimony, called in Spanish soroche. It is this suffering, this difficulty in breathing in the very lofty parts of the Cordilleras that has given them the name of puna brava. Some travellers use for the Peruvian Cordilleras the word Paramo, not used in the country, and which does not take the place of the word Puna, meaning a lofty plateau, dry and deprived of trees.

$\Lambda$ fter many fatigues, we reached the top of the last slope; I was at last on the crest of the Cordillera. (P. 378.) . . Ever since my arrival at the summit of the Cordillera, I had been suffering terribly trom the rarefaction of the air. I felt frightful pains in my temples; I had nausea like that produced by seasickness, I breathed with difficulty. At the least movement, I felt violent palpitations and general discomfort, added to an exhaustion which all my efforts failed to overcome. I had very strong proof of what habit can do. While I was suffering thus, I saw two natives, sent as couriers, nimbly and easily climbing on foot places incomparably higher than those in which I was in order to shorten their journey. ... Yet they were at an elevation equal to that of Mont Blanc. In the evening I had a severe hemorrhage from the nose which relieved me a little; yet I passed a night which was all the more terrible because I was without shelter, exposed to a keen and cutting cold which froze all the water in the neighborhood. (P. 380.) ...

May 23. I still felt the effects of the rarefaction of the air; headache and palpitation of the heart did not leave me a moment of repose. ... My muleteers told me that a few months before a Spaniard who was taking the same route as they was so much affected by the rarefaction of the air that the very first day he experienced very alarming symptoms, and being unable to continue, he died the following night, without being able to get the least relief. They mentioned many other instances in which the travellers whom they accompanied had suffered atrociously from what they call the soroche. (P. 387.) ...

May 24. As I descended I breathed more easily, and I hoped that before the day ended at least a part of the discomfort I felt from the rarefaction of the air would cease. (P. 390.) 


\section{May 29, d'Orbigny arrived at La Paz (3720 meters) :}

As I had felt much better when I had descended from the western plateau to the Bolivian plateau, I expected to feel no more effects from the rarefaction of the air; but in the city of La Paz it was far different. At night I felt as if I were suffocating in my room. I could not climb the steeply sloping streets without being stopped every ten paces by palpitations and lack of breath. If I talked with animation, suddenly speech failed me; when invited to several houses to take part in a general entertainment, I could not waltz twice around without stopping, suffocated by the same symptoms; and I almost died one day when I tried to walk to Los Obragos, a village one league away, to reach which I had to climb a very steep slope.

This discomfort lasted during the whole of my first stay in La Paz. Persons born in the country feel no effects at all. All assured me that one finally gets acclimated, and I myself had the proof of this on my return three years later. However, I should advise persons with weak lungs not to subject themselves to this test, which gave me the most pain in all my travels. (P. 404.)

However the acclimatization of which d'Orbigny boasts was not as complete as one might think. It is true that in the account of his second stay in 1832 at Potosi, Oruro, and La Paz he does not mention any symptoms (Vol. III, p. 283 et seq.); but he returns to the subject when he tells of certain ascents:

I had to stop (July 5, 1832), whike I was going from Cochabamba to the country of the Moxos, beside a frozen lake nearly 5000 meters above sea level. We felt the excessive cold all the more because we had no shelter, and the air was so rarefied that I could hardly breathe. (Vol. III, p. 176.) . . . The next day, on the way down, . . . with the region of the clouds, vegetation began; up to that time I had felt an oppression in my chest, so I cannot express the pleasure I felt when I began to breathe more freely a less rarefied air (P. 117.)

A German traveller, Ed. Poeppig, discusses the subject at greater length; he was staying at Cerro de Pasco (4350 meters) :

The new-comer to Cerro de Pasco is subject to serious inconveniences; walking, even on level ground, tires him extraordinarily; in streets sloping upward, respiration becomes short and painful, he is seized by headaches, by afflux of blood to the lungs, certain signs that he will not be able to escape the attacks of the puna any more than other foreigners. In vain does he try to brace himself energetically against the sickness; it conquers him and triumphs over the strongest wills. Just as during a violent attack of seasickness, the spirits are depressed, the senses blunted, disgust and hypochondrial discouragement transform the most robust, the most animated, the most courageous in a surprising manner. The physical sufferings, when the attacks of this sickness begin, are more painful and more varied than in the usual forms of seasickness. When the puna (also called Veta, Sorocho, 
or Mareo) is felt only moderately, the patient complains of a difficulty in breathing, which compels him to stop after about ten steps, and he tries in vain by deeper inhalations and a greater expansion of the chest to draw more of the life-giving element into his lungs. He feels as if he were shut up in a room without air, and the distressing sensation is increased by the failure of all his attempts to conquer his loss of strength: The feet can hardly support the body, the knees bend, and every opportunity to rest, no matter how frequent, even after only a few steps, is welcorne. It is a torment to climb streets sloping upward, and while he heaves himself painfully towards home, it is a real joy to find a doorway, a corner where he can stop and lean against something, burdened as he feels. The distress lessens only during absolute repose; but the conviction of the absolute necessity of the illness, the incapacity for any intellectual effort, and the sense of loss of precious time bring on ill humor and discouragement, so that a vigorous man acts like a little child.

Those who are most seriously affected by this illness are often seized with syncopes, symptoms of an afflux of blood to the head and the lungs, with an indefinable distress; and without fever, even with a feeling of inner chill, with hands and feet numb, their pulse beats at the rate of 108 to 120 times per minute. The unconquerable fatigue, the tendency to sleep are far from bringing on refreshing drowsiness, so that they cannot find repose. In fact, night brings the strongest feelings of suffocation, it is a real martyrdom; unable to endure a prostrate position any longer, the unhappy patient seeks comfort beside the scanty fire which hardly keeps alive in the fireplace, at the risk of breathing air laden with coal fumes. The eyes are so weak that one can hardly read; in some, moreover, slight headaches appear, whereas in others there predominate discomforts and disorders of the digestive organs which resemble seasickness, from which, however, the puna is distinguished by its course as well as by its causes.

When this painful stage is nearly over, often very distressing critical symptoms appear. After 6 or 7 days, the violent symptoms usually ameliorate in those who have strong lungs and a good constitution; otherwise, weeks may pass before the patient improves. An eruption of urticaria appears over his whole body, or is limited to the lips, on which it causes scabs, bleeding, or unendurable pain. . . . In persons with thin skin and fair complexion, blood may issue from the skin without any wound, so that while the puna lasts, many dare not shave. In spite of the severity of the symptoms, there are hardly any cases in which they have caused death, and there is no danger except for those with weak lungs and especially those with heart disorders. (Vol. II, p. 84.)

Poeppig then explains the reactions of different temperaments and different races, and gives therapeutic advice; he admits a certain degree of acclimatization for Europeans.

He next states that the residents of the country, even those born there, are not absolutely immune to the illness, especially when the nights are cold. The Indians have a sort of immunity. Beasts of 
burden have symptoms like those of men; dogs feel no effects; cats are scarce in Cerro and in lofty places, and their young are hard to raise; hens do not lay there and seldom brood.

The account ${ }^{35}$ given by M. Boussingault of the ascent of Chimborazo, made December 16, 1831, is in strange contrast with what we have just reported. We have seen that d'Orbigny was seriously attacked by mountain sickness at about the height of 3700 meters; Poeppig has described to us the sufferings of Europeans who have come to Cerro de Pasco (4350 meters); now M. Boussingault and Colonel Hall, his companion, climb nearly to the summit of Chimborazo (to 6004 meters) and report almost no serious discomfort.

M. Boussingault left Rio Bamba, where he had been staying for some time, December 14, 1838. He was accompanied by Colonel Hall, with whom he had already made ascents of Antisana and Cotopaxi. December 14, they slept at the farm of Chimborazo (3800 meters), which they left on December 15 at seven o'clock in the morning, guided by an Indian from the farm. When they had reached the height of Mont Blanc, the breathing of the mules was hasty and panting:

It was noon. We were walking slowly, and as we were advancing upon the snow, the difficulty of breathing while we were walking became more and more noticeable; we easily regained strength by stopping every eight or ten steps, without sitting down. At equal heights, I think I have observed that it is more difficult to breathe on the snow than on rocks; I shall attempt later to give an explanation of this. (P. 155.)

This first attempt failed; the snow, which had become too deep, checked the progress of the travellers, who sank in it up to their waists; they went back down to the farm.

The next day, they started at seven o'clock by another route, the one followed by Humboldt, and ascended on muleback to 4945 meters. There they had to dismount, since the mules could no longer carry their weight; it was a quarter of eleven. The two travellers continued to ascend on foot.

We stopped to breathe every six or eight steps, but without sitting down. . . But as soon as we reached a snowy surface, the heat of the sun became suffocating, our respiration was painful, and consequently our pauses for rest became more frequent, more necessary.

We kept absolute silence during our advance, since experience had taught me that nothing was as exhausting as conversation at this height; and during our halts, if we exchanged a few words, it was almost in a whisper. It is largely to this precaution that I attribute 
the health which I have consistently enjoyed during my ascents of volcanoes. This wholesome precaution I imposed despotically, so to speak, upon those who accompanied me, and on Antisana an Indian who broke the rule by calling at the top of his lungs to Colonel Hall, who had strayed from us while we were passing through a cloud, was attacked by vertigo and had a slight hemorrhage. (P. 159.)

They finally reached the foot of a peak of trachyte which barred their way; it was a quarter of one, the height reached was 5680 meters, the thermometer stood at 4 degrees, and the air was very full of moisture, a condition which is constant on the glaciers of the Andes, according to M. Boussingault. Finally, after a rather long rest, after studying the terrain carefully, they once more began their climb:

We were already beginning to feel more than we ever had the effect of the rarefaction of the air; we were compelled to stop every two or three steps, and often even to lie down for a few seconds. When once seated, we recovered immediately; our sufferings occurred only while we were moving. (P. 250.)

Finally they arrived at a height of 6004 meters, an elevation which no one had yet reached; however this was not quite the summit of Chimborazo:

After a few moments of rest, we were entirely recovered from our fatigue; none of us felt the symptoms experienced by most of those who have ascended lofty mountains. Three-quarters of an hour after our arrival, my pulse rate, and that of Colonel Hall too, was 106 per minute; we were thirsty, we were evidently in a slightly feverish condition, but it was not at all painful. (P. 251.)

The rarefaction of the air generally produces very marked effects in persons who climb high mountains. ... As for us, we had, it is true, experienced difficulty in breathing and extreme fatigue while walking, but the symptoms ceased with the motion; when we were resting, we thought we were in a normal condition. Perhaps the mildness of the symptoms produced in us by the rarefaction of the air should be attributed to our prolonged stay in the lofty towns of the Andes.

When one has seen the bustling in cities like Bogota, Micuipampa, Potosi, and still others, at an altitude of 2600 and 4000 meters; when at Quito, at an elevation of 3000 meters, one has witnessed the strength and prodigious activity of the toreadors; when one has seen young and delicate women dancing all night long in localities almost as high as Mont Blanc, where the famous de Saussure could hardly find enough strength to consult his instruments, and where his vigorous mountaineers fell fainting while digging a hole in the snow; finally, when one remembers that a celebrated battle, that of Pichincha, took place at a height nearly that of Monte Rosa, one must admit that man can 
become accustomed to breathing the rarefied air of the highest mountains. (P. 245.)

But a German traveller, Dr. Meyers,": who in his journey around the world from 1830 to 1832 stayed for some time in Peru and in April, 1831, made the ascent of the volcano of Arequipa (5640 meters), speaks of mountain sickness in terms which recall the description of Poeppig:

At two o'clock in the afternoon we reached the summit of the mountain; my strength was exhausted, and we were suffering from the painful illness called sorocho. Little by little the symptoms of a nervous or feverish state from which we had been suffering during the whole ascent had increased. Respiration took place with increasing difficulty, and gradually vertigo appeared, nausea, vomiting, then nosebleed and fainting; in this condition we were forced to lie down on the ground, but rest restored our strength and permitted us to walk on again.

The illness from which we were suffering deserves to be studied here; all travellers have heard of it, as soon as they have set foot on the coast of this country, expressing the intention of travelling in the mountains. In Peru they call it sorocho, and in Quito mareo de Puna or Puna. It appears under different forms. One of its symptoms, which is found both in the lower regions and on the summit of the Cordilleras, is a sensation of difficulty in breathing at the least effort. If one is on horseback, he feels no effect of the sort; but there appears at different degrees of intensity a sort of half-feverish condition, which is evidenced by burning heat over the whole body, headaches, dryness of the tongue, a burning thirst, and loss of appetite. The pulse rate rises to 100 or 110 at the slightest movement. The face reddens, the skin cracks in different places so that blood issues; at the same time a general fatigue appears. That is the usual condition, the first test of those who make ascents, whether in Quito, Peru, Chile, the mountains of Asia or even the highest of those in our Europe. . . .

This feverish condition is made worse by exertion and also by the influence of the violent, dry and cold winds which are so common in the Cordillera; the well-informed residents of this country attribute this illness to these winds. . . The burning effect of the sun in lofty places also helps to aggravate these symptoms ... it is a factor in the headaches and the half-feverish condition. There are some persons who attribute the illness to exhalations from the metallic veins and deposits of sulphur so common on the summit of the Cordilleras.

The sorocho has been compared to seasickness, and it has even been said that those who are not subject to the latter are spared by the former. That seems to us a mistake. The half-feverish condition which we described previously is the basis of this illness, and when it becomes worse, it brings on the characteristic symptoms of diseases of the brain, the respiratory organs, and the digestive organs. One of these three organs is always particularly affected, so that different forms of the illness result. When the chest is particularly affected, difficulty in 
breathing is added to the general fever; a sensation of weight in the chest appears, and the respiratory rate, like the pulse rate, increases; then come lacerations of the lungs, symptoms of choking, and even hemorrhages, a very rare phenomenon. . . .

The death which has been observed in beasts of burden came, in our opinion, from suffocation; we ourselves, in ascending the volcano of Arequipa, experienced such respiratory difficulties that we had to stop every ten steps. Loaded animals, which are not allowed to do so, go on until they drop. In other cases, the illness attacks the digestive organs in particular, and then there appear nausea, qualms, extreme weakness, and finally vomiting, which gives a little relief. Affections of the brain are much more dangerous; they are also characterized by nausea and syncope, by a peculiar condition resembling drunkenness, and even by madness.

In general it is admitted that at great heights the pulse rate is more rapid; that is because respiration itself has become much more rapid in a rarefied air. But neither respiration nor circulation is accelerated if one keeps perfectly quiet; several times, on the plateau of Tacora, after sleeping our pulse rate was no more than 70 or 72 per minute, whereas a few hours later the mere act of riding made it rise to 100 and 110 . (P. 34 et seq.)

They reached the summit of the mountain in a state of absolute exhaustion, and descended in a feverish condition which had not completely disappeared the next day. (P. 38.)

The account of the illustrious naturalist Charles Darwin "is agrees perfectly with what we reported above in regard to the Chilean Cordillera. On May 20, 1835, he crossed the Andes, going from Santiago to Mendoza through the pass of Portillo (4360 meters) :

About noon we began the tiresome ascent of Peuquenes, and then for the first time we felt some slight difficulty in breathing. The mules stopped every fifty steps, and the poor brave animals, after a few seconds, started again of one accord. Shortness of breath in rarefied air is called by the Chileans puna; and they have very ridiculous ideas about its cause. Some say: all the waters here have the puna; others: where there is snow, there is the puna; which no doubt is true. It is considered a sort of disease, and they showed me crosses on the graves of people who had died "punado." Except in regard to people who had lung or heart diseases, I think that these ideas are mistaken. No doubt at these elevations a very sick man will experience greater difficulty in breathing than others, and if he dies, this may have been the cause.

The only sensation I felt was a slight oppression in the head and chest; this sensation is similar to what one feels when he leaves a warm room and exposes himself to icy air. There was much imagination in this; for, having found fossil shells on the highest peak, I forgot the puna completely in my joy. But certainly fatigue from walking is extreme, and breathing becomes deep and laborious. I cannot understand how Humboldt and others could have ascended to an elevation of 19,000 feet; beyond doubt a residence of some months in the lofty region of 
Quito had fortified their constitutions against such fatigue. However I was told that at Potosi (about 13,000 feet) foreigners do not become accustomed to the atmosphere until they have dwelt there a whole year. The natives all recommend onions for the puna ... as for me, I found nothing equal to fossil shells! (Vol. III, p. 393.)

The English officers Smyth and Lowe, ${ }^{38}$ who undertook a journey in 1834 to find a navigable passage to the Atlantic by way of the Pachitea, the Ucayali, and the Amazon, crossed the Cordillera much nearer the equator. They left Lima September 20, 1834. September 25, a little beyond Pucachaca, the illness attacked them:

The air became very cold ... we began to feel what is commonly called the veta or marea (seasickness), which consists of an acute pain through the temples and the lower and back part of the head, and which completely prostrates those attacked by it. . . (P. 25.)

They reached Cerro de Pasco September 28:

Because of the altitude, and especially while we were ascending, we felt a difficulty in breathing which oppresses the lungs, especially in new-comers; but after some time, the lungs become accustomed to the condition of the atmosphere, and this illness disappears. (P. 42.)

Moreover, these facts were so well known in the mountainous regions of South America, that in 1842 a Scotch physician, Archibald Smith, ${ }^{39}$ summarized in the following words the notes he had collected during a journey to Peru:

Veta, Soroche, la Puna, Mareo de la Cordillera. A headache with throbbing and a painful sensation of fullness in the temples, combined with a great oppression and tension of the lungs, and frequently with stomach disorders, are the symptoms usually felt during the first days when crossing the Cordilleras or staying in Cerro de Pasco. If one walks quickly, especially if one climbs a hill, he feels extreme fullness in the chest, the temporal arteries throb violently, and headaches come on. If one tries to run, these symptoms appear immediately, and he is glad to stop and regain breath. Breathing a frosty air, July 3 at midnight, in a miserable hut in the pass of Tucto ( 4855 meters), gave me an excruciating sensation along the tracheal artery; until I began the descent, I constantly felt afraid that some blood vessel had opened in my lungs ... On another occasion, on another route ... my breathing was panting and difficult.

Many young persons become accustomed to the effects of the rarefied air, so that they have headaches and dyspnea only during strenuous exercise. Some persons, on the contrary, and especially the plethoric, cannot cross the Cordillera or live in Cerro de Pasco without headaches and respiratory difficulties; when they cross the Cordillera, traveling over these lofty and icy plains which the natives call Puna, they are very likely to suffer from epistaxis. (Vol. LVII, p. 356; 1842.) 
The evidence of the French botanist Claude Gay ${ }^{40}$ is no less conclusive. Now the authority of this scientist is great, since for nearly fifteen years, from 1828 to 1842, he explored the Cordillera of the Andes. He expresses himself thus:

I left Lima (1841)... . After a march of four days, we crossed the first Cordillera by the pass of Tingo, 4815 meters above the level of the sea. There we felt a strange discomfort, the result of the great rarefaction of the air, known in America by the name of soroche, pouno, etc. It can very well be compared to real seasickness; there are the same symptoms, the same distress, headaches, vomiting, and such prostration that it almost makes life a burden, and kept me from going to consult my barometers and thermometers, which were only two paces from me. ...

This illness lasted some time; but subsequently I finally became accustomed to this rarity of the air, and I could take magnetic readings at an elevation of 4685 meters and carry out several other tasks of terrestrial physics without being noticeably inconvenienced. (P. 28.) ...

The Indians of Cuzco ..., although constantly at an elevation of 10,000 to 14,000 feet, are not at all inconvenienced by the great rarity of the air; they walk and talk with as much ease as we do in the low plains: and so there are found in these regions the loftiest towns and cities in the world; Ocoruco at 4232 meters, Condoroma at 4343 . There are some post-houses, for example, that of Rumihuani, which are at an elevation of 4685 meters, and shepherds' houses at 4778 meters, that is, almost the height of Mont Blanc. (P. 33.)

The celebrated German traveller J. J. von Tschudi ${ }^{41}$ gives an almost complete monograph on this subject.

At the great altitudes to which the Cordillera rises, the effect of the rarefied air upon the organism is seriously felt; it is evidenced especially by a condition of extraordinary fatigue and great difficulty in breathing. The natives call this effect Puna or Soroche, the Spanish Creoles call it Mareo or Veta, and attribute it to metallic emanations, especially those of antimony, which plays a very important part in their physics and metallurgy.

The first symptoms of the Veta usually appear at a height of 12,600 feet, and consist of vertigo, buzzing in the ears, and disturbances of vision, accompanied by violent headaches and nausea. These symptoms attack horsemen, but not so much as those on foot, it is true. The higher one ascends, the more these symptoms increase, and to them is added exhaustion of the legs so great that one can hardly move, with very painful respiration and violent palpitations. Complete rest checks these symptoms for an instant, but at the slightest movement they instantly reappear, and are often accompanied then by fainting fits and vomiting. The capillary vessels of the conjunctiva, the lips, and the nose burst, and blood issues in drops. The respiratory and digestive mucous membranes are the seat of similar symptoms; diarrhea and the spitting of blood are the evidence of the Veta in its worst form. 
One can compare this disease approximately to seasickness (whence its name of Mareo); but it alone produces respiratory distress. It is not unusual to see these symptoms become so serious that they cause the death of travellers. In 1839 at Pachachaca I met an officer who was carrying dispatches from Lima to Cuzco, but who, one year, while crossing at the Piedra parada, died in consequence of pulmonary and intestinal hemorrhages caused by the Veta. All residents on the seacoast and the Europeans who are crossing the high Cordilleras for the first time feel this illness which is usually not persistent in healthy persons, but which attacks severely those who are weak, nervous, with diseases of the lungs or heart, and also the plethoric and the obese. A German trader from Lima, a very corpulent man, who had gone to Cerro de Pasco on business, at the end of a few hours had to leave the city rapidly, and descend into the valley to escape the Puna.

By a long stay in these lofty regions, the organism becomes accustomed to this effect of rarefied air. Vigorous Europeans can even climb the highest mountains nimbly and move about there as freely as on the coast. I had the Veta only twice, but very severely; once on a lofty plateau, and once on the mountain of Antaichahua. The first time I crossed the Cordillera, I did not feel the least inconvenience, and I was able, getting off my tired horse, to walk a long way without feeling symptoms of the Veta, so that I thought I was completely immune to it. ...

The Indians of the mountains, who have been living since childhood in this rarefied air, are not subject to the Veta. . . . The physicians of Lima are accustomed to send to the mountains persons who suffer from prostration, so that the pure air may give them back their strength; but there they are attacked by the Veta most severely, and often lose their lives in the Cordillera . . . .

The Puna seems to have a worse effect upon certain domestic animals than upon man himself. This is particularly true of cats; these animals cannot live above an altitude of 13,000 feet. They have often been brought to lofty villages, but always in vain, for after a few days they were seized by terrible convulsions like those of epilepsy to which they succumb. . . . These sick cats do not try to bite, or to run away. .. . In this country they are called azorochados and are given antimony. The delicate breeds of dogs are also affected, but not so seriously.

Travellers in the Cordilleras are also subject to symptoms known by the name of Surumpe. . . These are eye affections due to the effect of the reflection of the sun on the snow. (Vol. II, p. 66 et seq.)

In his ascent of the Cordillera, Tschudi for the first time saw horses attacked by the veta, at the elevation of about 4000 meters:

First they walk more slowly, stop frequently, tremble all over, and are prostrated. The higher they ascend, the harder they tremble, and the oftener they fall. If they are not unsaddled, if they are not allowed to rest completely, they lie down on the ground. The arrieros bleed an animal in this condition in four places: at the end of the tail, on the palate, on the two ears; they often cut their ears and tail half-off and split their nostrils to the width of several inches. This last method 
seems to me to be rather useful, because the animals can then breathe a larger quantity of air. As a preventive garlic is placed in their nostrils. Mules and donkeys suffer less from the Veta, probably because they know better how to rest. Horses born on the Sierra are almost immune to these symptoms. (Vol. II, p. 32.)

A very striking episode in the account of Tschudi is the story of his twenty-four hour stay in the icy Puna of Peru, at an average elevation of 4300 meters:

I was beginning to climb the mountain vigorously when I felt the dangerous effect of the rarefied air; while I was walking I experienced an unknown distress. In order to breathe I had to remain quiet; even then I could hardly succeed; if I tried to walk, an indescribable anguish seized me. I heard my heart beating against my ribs; my breathing was short and interrupted; there was an enormous weight upon my chest. My lips were blue, swollen, cracked; the capillaries of the conjunctiva burst and a few drops of blood issued. My senses were strangely blunted; sight, hearing, touch, were altered; before my eyes there floated a thick cloud, grayish, often reddish, and I shed bloody tears. I felt as if I were between life and death; my head whirled, my senses failed, and I stretched out trembling on the ground. In truth, if the most precious riches, if immortal glory had awaited me some hundreds of steps higher, it would have been physically and mentally impossible for me merely to stretch out my hand towards them.

For some time I remained lying on the ground in this half-fainting condition, then I recovered a little, hoisted myself painfully on my mule, and I succeeded in going on. (Vol. II, p. 152.)

The accounts given by de Castelnau ${ }^{\ddagger 2}$ are no less explicit, and contain many interesting details:

Our stay in September, 1845, at Chuquisaca, a city of some 11,000 to 12,000 souls (Bolivian Republic), was rather gloomy. . . Most of my companions were also affected by the soroche, an illness caused by the rarefaction of the air at high altitudes (according to the observations of M. Pentland, Chuquisaca is 9343 English feet (2847 meters) above sea level): it is especially while climbing the uneven streets that one feels this painful sensation of suffocation; dogs, horses, and beasts of burden are equally subject to it there, and I have seen some beasts of burden from whose nostrils blood was dripping. In this case, muleteers usually make them swallow cloves of garlic. Animals have often died from such symptoms; this is especially true of horses. No matter how little they are urged on, they try to overcome the distress they feel, and sometimes fall dead in the streets; mules, on the contrary, stop of themselves and start only when they are rested, in spite of the ill treatment to which an unwise master may subject them. (Vol. III, p. 317.)

At La Paz (3717 meters), de Castelnau attended a bull fight:

Unfortunately (he says) the bulls of La Paz, raised on the frozen plains of the Puna, and which besides probably had the soroche, which, 
by the way, is terrible in this city; these bulls, I say, showed energy only in fleeing before base toreadors on foot who tried to hold them back by pulling their tails. The angry people rushed into the arena, and by dint of tormenting these unhappy animals, finally obtained the desired result, that is, the death of two or three Indians. (P. 376.)

One of the travelling companions of Castelnau, Weddell, climbed the volcano of Arequipa in October, 1847. He expresses thus the sufferings which he felt on this ascent:

The difficulty in breathing which our animals experienced compelled us to renounce their assistance. . . In advancing we had to tack, and even so we could not advance ten steps without stopping, so as to let the oppression which had seized upon our lungs pass. As we mounted higher, not only did this oppression increase, forcing us to make longer pauses, but weariness of the limbs was also added: a symptom more distressing than the soroche, because a halt was not enough to check it ....

The last strength of my companion was exhausted and he had to leave me. Alone I continued my journey, panting; . . . I could hardly advance more than two or three meters without stopping to get my breath. (P. 449.)

In May, 1846, de Castelnau left Lima for Cuzco. He therefore had to cross high mountains. At the pass of Vinda (4720 meters), the soroche attacked him very severely:

Vegetation, even the stunted thistles, disappeared. M. d'Osery complained bitterly of the soroche, and he was forced to pause constantly, as was Florentino. Here this disease is called veta, and people believe that it is due to the presence of veins of antimony. . . .

Hardly had we reached the little settlement of Casacancha when as I dismounted I was attacked by the soroche, the effects of which I had not felt until then; I vomited bile abundantly, and felt all of the symptoms of seasickness to which I am very subject.

When in the morning, after a very bad night, I wished to mount, I felt the absolute impossibility of it. M. d'Osery could hardly drag himself along; Florentino, a former sailor, was stretched out on the ground; little Catana alone was playing as usual, and seemed to feel no effects of the soroche. At last, understanding how indispensable it was to reach less inhospitable regions, we succeeded in mounting in the afternoon; but after going less than one league, we literally fell at the door of a farmhouse, where we were well treated. (Vol. IV, p. 194) ...

The altitude of Cerro de Pasco is estimated at 13,673 English feet (4166 meters) . . In spite of the burning rays of the sun, one is chilled as soon as he is in the shade, and he is constantly under the painful effect of the soroche. . . The climate is so fatal that priests try to keep their pastorate for only three or four years, in spite of its enormous benefices. . . The population, in 1845 , was 18,000 souls . . . It is only to the silver mines that this population is due. . . Barley will not go to seed there. (P. 196.) 
De Castelnau, after a few days, made an excursion to a nearby cavern, situated at a height of 4400 meters, in which he found the bones of prehistoric animals, among others a sort of armadillo (probably a glyptodon):

We were suffering frightfully (he says) from the soroche, the stifling from which forced us to rest constantly; even the Indians seemed affected by it.

A French tourist with a picturesque account, M. de Saint-Cricq, who published his travels under the pseudonym of Paul Marcoy, ${ }^{4.3}$ felt similar symptoms while he was going from Arequipa to Puno. He had passed the night at the post-house of Apo (no date):

After an hour's walking, which had raised us some hundreds of meters, I began to feel a general discomfort which I attributed to the insufficiency of the atmospheric pressure. This phenomenon, which the mountain Quechuas call soroche, and to which they are immune, gifted as they are by nature with lungs a third more capacious than those of Europeans, is attributed by them to poisonous gases produced by antimony, (in Quechua soroche), even in places where this metal does not exist. A contraction of the diaphragm, dull pains in the dorsal region, twinges in the head, nausea and vertigo are forerunners of this strange disease, which are sometimes followed by syncope. But I did not go that far. My guide, warned of what I was feeling by my livid pallor and by my efforts to remain in the saddle, gave me a clove of garlic, urging me to crunch it. . . I obeyed ... but the antidote ... having produced no effect, my Esculapius advised me to give myself several blows with my fist on my nose, and since this would cause a hemorrhage, it should bring prompt relief; but this method seemed to me much too heroic, and I preferred to nibble a second clove.of garlic...

About twenty minutes passed, and whether the remedy began to work or whether my lungs by degrees became accustomed to this thin air, I felt my discomfort passing away. (Vol. I, p. 76.)

Lieutenant Gillis, ${ }^{4+}$ of the English Navy, gives similar information, collected, it is true, second hand, but summarized in a very intelligent fashion.

In the first part of his work, devoted to the geographical description of Chile, the author speaks of the routes from Santiago to Mendoza, and especially of the Piuquenes route:

Very few travellers reach its summit (13,189 feet above sea level) without feeling respiratory troubles; and the poor mules suffer almost as much as their masters. In Chile, this illness is called puna, in Peru, veta, soroche, or mareo, indifferently by the natives and the Creoles. The latter, in their ignorance of its real cause, attribute it to exhalations of metallic veins, so common in the Andes. With variations in different cases, the disease produces extraordinary fatigue, prostration, vertigo, temporary blindness, and nausea, quite frequently ac- 
companied by hemorrhages from the nostrils and the eyes. Not all persons are subject to this effect, and it is clear that certain constitutions are more sensitive to it. The muleteers recommend garlic and onions as specifics. (Vol. I, p. 6.)

The Englishman Lloyd ${ }^{4 \pi}$ who crossed the great Sierra of Illimani, expresses himself as follows:

Except for the disease called soroche, which is an affection of the lungs that is painful and often dangerous, caused by the extreme rarefaction of the air at this great altitude, almost no illness is known, except colds and dropsy. (P. 260.)

The French botanist Weddell, ${ }^{46}$ whose sufferings when he was accompanying de Castelnau we have already reported, returned to Eolivia later. Coming from Arica, he had crossed the chain of the Cordillera without noteworthy symptoms, and after he had been in La Paz nearly two months, he had had no trouble; but on June 22, 1851, while he was botanizing, he wished to climb a steep slope rapidly; he was suddenly attacked:

I can hardly express my sufferings from the soroche (he says), in this ascent which demanded of me gymnastic efforts which I was far from expecting. The fact remains that when I had reached the top of the precipice with my flowers, and was stretched out exhausted and panting on the ground, I swore, but a little late, that I would not be caught that way again. During the first few moments following my climb, I thought only of getting my breath which seemed on the point of leaving me, and a few minutes afterwards, when I thought of examining my pulse, its rate was still 160 per minute. I do not think I have ever felt greater oppression than during this unexpected botanizing expedition. From that day I felt a physical discomfort which I could not account for, and I foresaw that I was going to be ill. (P. 187.)

He was, in fact, and very seriously.

Except on this occasion, Weddell pays very little attention to the soroche, although in many passages of his account we recognize suggestions of it, sometimes in men, sometimes in domestic animals. I find nothing to quote but this interesting remark about the Indian postillions, who always proceed at a run, on the road from $\mathrm{La} \mathrm{Paz}$ to Puno:

They never seem out of breath (he says), whereas in this same country, a European can hardly run ten steps without being obliged to stop. (P. 547.)

As you will perceive, there is a very great difference between this statement and those made by travellers on the Himalaya; the Indian coolies, they tell us, are often sicker than the Europeans 
themselves. Weddell is not the only one to note this; the Grandidier brothers were also struck by it. ${ }^{47}$

August 1, 1858, these travellers left Arequipa for Cuzco:

Here one experiences (says E. Grandidier in his account) a distress unknown to tourists in the old world, that is, the soroche; the traveller who crosses the Cordillera feels pains all through his body; he has pain in his kidneys, in his head, his limbs feel as if they were broken, blood even gushes sometimes from his nose, eyes or ears. This general distress is due, not to the presence of antimony, as has been said without reason, but to the rarefaction of the air and the failure of breath. The soroche has even caused the death of some more susceptible persons. Mules are also subject to the effects of the soroche, and I have heard many examples of these animals dying in consequence of the rarefaction of the air. (P. 56.)

And further on, while going from Paucartambo to Puno, their attention was directed to the natives on foot:

The Indian follows the horseman on foot, always running without ever losing breath, however speedy the horse, and however high the mountains. The swiftness with which the Indian runs long distances surprises the European all the more because he cannot, like the native, overcome the oppression caused by the rarefaction of the air and run at this altitude without falling immediately. (P. 194.)

In December, the two brothers arrived at La Paz:

The road down to La Paz is wide and well kept; but the slope is so steep that one can only walk his horse down. This descent is about a league long, and it takes at least an hour to get to the city. A very much longer time is needed to climb it, because of the difficulty in breathing which the mules experience while ascending; nevertheless I was assured that the Indians mount it running and playing the llute: they are not subject to the soroche, and in this way they are like the llama, whose breathing apparatus is adapted to the Cordillera on which it lives. (P. 225.)

The European who has recently arrived in La Paz feels the effects of a violent soroche; while he is walking through the town, he is forced to stop often to get his breath, so great is the difficulty of breathing and the oppression in the chest. The rarefaction of the air comes from the great elevation of La Paz above sea level; this elevation is 3730 meters. (P. 227.)

We have similar accounts from the German traveller Burmeister, ${ }^{48}$ who in the first part of March, 1860, was in the Cordillera, about latitude $28^{\circ} \mathrm{S}$., and longitude $72^{\circ} \mathrm{W}$. However, he speaks of these symptoms only by hearsay; moreover, the maximum altitude to which he ascended was 14,000 feet:

During my journey (he says) I never suffered from what is called 
the Puna, that is, the sickness which usually occurs on high mountains and which consists of difficulties in breathing, nausea, prostration, vertigo, and other symptoms. Only at first, when I entered the gorges near Estanzuela, I felt a heaviness in my head, as if I were going to have vertigo; but I had no other symptoms. . . . Probably I have been protected by the weakness of my constitution; for strong and portly people are more easily attacked by the Puna than those who are thin, spare, or weak.

The symptoms of the same disease appear in animals, and particularly in horses, on the lofty paths of the mountains; they are characterized particularly by trembling of the limbs and violent hemorrhages, which, however, do not become fatal. Many horses, and especially the best, fall down on the ground on journeys in the mountains. The natives call this disease the Trembladera; they claim that in the mountains there are places where it is particularly likely to attack passing animals; they pointed out one in the Aconquija Sierra, the position of which, however, I could not determine.

The Englishman Markham, ${ }^{49}$ who in 1860 made a journey to Peru for the purpose of studying cinchona trees and finding a way of introducing them into the Indies, gives information of the same sort:

On the heights of the Cordillera, men and animals are subject to a very painful disease, caused by the rarefaction of the air, and which the Peruvians call sorochi. I had been ill at Arequipa, so that I was probably predisposed to the attack of the sorochi, which affected me violently. Before reaching Apo (May, 1860), an excruciating headache, accompanied by acute suffering and pains in the lower part of the neck, made me very ill, and these symptoms grew worse during the night passed in the post house of Apo, so that at three o'clock in the morning, when we set out again, I was unable to mount my mule without assistance. (P. 89.)

In the official description of the Argentine Confederation, Dr. Martin de Moussy, ${ }^{5.1}$ who had dwelt for ten years in the basin of the Plata, gives a detailed description of the American form of mountain sickness:

The name of puna is given to this painful sensation, this distress in breathing which some persons experience when they are at great heights. This sensation is certainly due to the rarefaction of the air, for, at 4200 meters, the general altitude of the plateau, the barometric column falls on the average to 0.46 meters ... and it is impossible that such an enormous difference in the atmospheric pressure should not produce a profound impression upon the animal constitution. Furthermore, this impression varies in different persons; some have difficulty in breathing, others suffer from cephalagia, a sort of headache, and a complete loss of appetite. Many feel no ill effects; but when they try to walk, almost everyone feels unusual fatigue. 
As to the puna properly so-called, the difficulty in breathing, it is not peculiar to the great heights of the Cordillera; there are certain places of no great altitude where it is felt much more than in others. We ourselves experienced it at the town of Molinos, which is at an altitude of only 1970 meters, and in a valley surrounded by granitic mountains about which there is nothing peculiar. We cannot discover a cause for this peculiarity, which also exists at different points of the Andes in Bolivia.

Animals also experience this difficulty in breathing in their first crossings of the Cordilleras; but they become acclimated rather quickly and their vigor is so great that mules in good condition and reasonably loaded never weaken on ordinary journeys. (Vol. I, p. 217.)

Mateo Paz Soldan also gives a description of the soroche in his Geography of Peru: ${ }^{51}$

Cerro de Pasco is situated on a slope 4352 meters above sea level. ... The climate of this city is very cold, the temperature averages $44^{\circ}$ $\mathrm{F}$. by day and $34^{\circ}$ by night, during the months from July to October, a season during which a great quantity of hail and snow falls. Sometimes the thermometer falls to $30^{\circ}$ and $28^{\circ}$ in August and September; water boils at $180^{\circ}$. Storms, hail, and snow make this country uninhabitable from the month of October on. Strangers there are subject to the Soroche, an oppression in the chest, which in this country is called veta, and which is the result of the rarefaction of the atmosphere, in so lofty a region ... . Former miners are subject to a great many diseases and infirmities. . . . If this country did not possess mines of inexhaustible richness, it would be absolutely impossible to live here. (P. 172.)

About this period there appeared in the form of a thesis maintained before the Faculty of Medicine of Paris a remarkable work by a young doctor, Ch. Guilbert, ${ }^{52}$ who, attacked by consumption, went to $\mathrm{La} \mathrm{Paz}$ and there found the cure or at least a considerable amelioration of his dangerous disease. I shall quote the whole of his very concise description of the soroche:

The soroche or the disease of the puna begins in two different ways: some immediately have difficulty in breathing, and that has attracted greatest attention of the observers; in others, and in my opinion this is the largest number, nervous symptoms appear first. There are even some travellers who have no difficulty at all in breathing.

The same difference is found in the duration of these two classes of symptoms. Whereas the nervous phenomena last only 12 to 48 hours, difficulty in breathing and circulation sometimes persists for several months.

The nervous system is therefore often the first affected, and reacts upon the digestive and the locomotive systems. One first feels nausea, accompanied by very significant spitting. . . . At the same time there comes a very violent headache, compared to a ring of iron which binds the temples tightly. ... After the nausea, vomiting appears, often 
very painful, which increases the pain in the head. One also experiences vertigo, buzzing in the ears, sometimes drowsiness ....

Another phenomenon is muscular fatigue. . . This difficulty in muscular contraction is experienced even on horseback, and to such an extent that persons who are unable to move have to be taken down from their horses. But after the first few days, this great fatigue disappears completely after a very short rest. In the cities, new-comers are easily recognized; they stop for a few seconds every 40 or 50 steps.

Respiration and circulation are speeded up in proportion to the elevation. The dyspnea is extreme, the inspirations very frequent. ... The heart-beats are stronger, more numerous; at the least effort one is attacked by violent palpitations which continue when he is riding as well as when he is walking. Even at night, one is often awakened with a start by strong palpitations in the midst of the calmest sleep. . .

The beating of the arteries is stronger, that of the intra-cranial arteries very painful, the pulse is vibrating, almost as in aortic insufficiency. A rather frequent symptom is a nasal, buccal, or pulmonary hemorrhage; hemorrhages from the gastro-intestinal mucous membrane are rare. ... But when one becomes used to the rarefied air, when equilibrium is established, and when the different systems are in harmony with the surrounding medium, hemorrhages are no more frequent than anywhere else... An important symptom is the tendency to syncope, and so one must be very careful about bleeding the patient . . . .

The nervous symptoms are the first to disappear; the headache lasts hardly 12 to 24 hours; the nausea and vomiting no longer . . . The third or fourth day, appetite revives a little; as soon as the patient can take a little nourishment, the heaviness in the head disappears in its turn, and there remain only the difficulty of respiration and the rapidity of the heart-beats, palpitations occurring at the least effort, and making the lack of breath still worse. Later, when equilibrium has been established, little by little all these symptoms disappear, generally at the end of a few weeks, and one becomes perfectly acclimated to these lofty regions.

So Guilbert thinks that one can become perfectly acclimated to lofty regions. He recalls the words of M. Boussingault, which we quoted above, and adds:

Pichincha is 4996 meters high; the Bolivian general Santa Cruz defeated the Spaniards there in 1822. Two years after, at Ayacucho, a village situated at about the same height, the Colombian general Sucre defeated the viceroy La Serna....

At Corocoro (4430 meters) I saw very bloody bull-fights. These bulls, nimble and wild, might have given pleasure to the travellers mentioned by Lombard, ${ }^{53}$ who saw at La Paz bulls which were gentle and unable to make the least effort without vomiting; these were bulls which had recently been brought to the mountains and which were affected by the soroche, which attacks animals as well as men. ... It is very rare to cross the Cordilleras without witnessing the sickness of some beast of burden, attacked by the soroche; it is hastily unloaded, rubbed, and after a moment of rest, allowed to follow at liberty. 
In the special chapter I shall give the very eclectic mixture of theoretical explanations which Guilbert accepts.

The Italian professor Pellegrino Strobel, ${ }^{, 4}$ who crossed the different passes between Santiago and Mendoza, was lucky enough not to be affected by the soroche; it is true that he seems not to have mounted very high:

After what M. de Moussy wrote and what my friends had told me, I expected to experience on Planchon one of the sensations described under the name of puna. But-I do not know whether I should say happily or unhappily-neither here at 3000 meters above the Pacific, nor on Cumbre of Uspallata at about 4000 meters nor in any other part of the secondary chains of the Andes, was it granted me to feel the slightest difference in respiration or appetite, still less any headaches and other pathological symptoms or physiological phenomena; and yet on account of the weakness of my constitution and the narrowness of my chest, it seems as if I should have suffered from it more than anyone else. I must therefore admit that the puna does not depend solely upon the rarefaction of the air, but also upon other concomitant causes, which appear to be wholly unknown. (P. 25.)

However two German travellers, Focke and Mossbach, ${ }^{55}$ who speak from their own experience, declare that often men and beasts become ill at still lower altitudes:

Starting at an altitude of 10,000 feet, one feels the beginning of mountain sickness, that is, a stunning headache; it is the Sorocho, which attacks also beasts of burden. They refuse to go on, and to cure them, they are bled under the tongue. (P. 391.)

Finally, I have the statement of a high official of the Peruvian government, an intelligent man, that having gone to Perina-Cota (4800 meters) near Guayaquiri, he saw his mules become ill at an altitude of 3000 meters; out of 40 mules, 16 had to be unloaded. Some of his companions had nosebleed. During a stay of two weeks at this great height, he experienced regularly, about three o'clock in the morning, a feeling of suffocation which awakened him; the least movement then increased it considerably; these symptoms lessened during the day. The Indians who accompanied him suffered from the same illness. Even today, the generally accepted explanation is poisoning by metallic emanations; they try to check its effects by garlic sachets.

I also learned from this gentleman that while the railroad tunnel from Lima was being bored, at an altitude of about 4800 meters, all the workmen had been affected, even the most robust. I am sorry not to have been able to get written details of the phenomena observed during the execution of this extraordinary 
work. It is finished now, and already the locomotive conveys the travellers up to regions which formerly they could not reach without the most strenuous efforts. Strangely enough, nevertheless a certain number of them became ill. In a letter addressed this very year to one of my friends, there is this very characteristic passage:

A special train came for us at Callao, took us up Reinar to Lima, then from there into the Andes, climbing by successive planes to an altitude of 3450 meters. . . . We thus journeyed 130 kilometers. . . The temperature had fallen, the rarefaction of the air was such that many persons could not accompany us to the end. They felt extreme oppression and their eyes were bloodshot.

It would be very desirable to have careful observations made on this railroad and on the Titicaca railroad too; it would be very easy for the professors of the Faculty of Medicine of Lima to do so.

I shall finish these quotations from the principal general descriptions of mountain sickness in the Cordillera of the Andes by copying a very interesting letter written by $\mathrm{M}$. Pissis to Dr. Coignard, who asked him at my request for information which his great experience in the mountains made very valuable to me. The learned geographer in this letter describes very vividly the symptoms which he felt, but he does not venture upon any explanation:

Paris, March 17, 1874.

\section{Dear Doctor:}

Here are the observations which you requested of me upon the physiological effects of the rarefaction of the air on lofty mountains. The general effects are headaches, nausea, great difficulty in breathing and a contraction in the region of the false ribs, as if one were tightly squeezed by a belt. These symptoms vary greatly, however, according to the age and the constitution of the patients; when I crossed the pass of Tacora (bar. $463 \mathrm{~mm}$.) a negress eighteen to twenty years old, very sturdy, was extremely ill, she had a profuse nasal hemorrhage, whereas her mistress, a woman of about fifty years, of weak constitution, was hardly affected; the same difference is observed in animals; the strongest horses are the most likely to die. Nasal hemorrhages are frequent in them also. After one has lived a certain time in lofty regions, these effects are no longer felt; the residents of Oruro in Bolivia, at 3,796 meters (average barometric pressure $492 \mathrm{~mm}$.) live as if they were on the seashore; the Indians run leagues without getting tired, and after a year's residence, I easily climbed fairly high mountains, which would have been impossible at my arrival.

The highest point where I saw permanent dwellings are the mines of Villacote in the province of Chayauta; their altitude is 5,042 meters and the atmospheric pressure $421 \mathrm{~mm}$. The Indians work there as they do elsewhere, but they get tired more easily when it snows, for it never rains in these regions; the workmen, even those in the depths of the mines, are ill, and yet the decrease in pressure when it storms is 
hardly 4 or 5 millimeters. The alpacas and the vicunas live in herds at these heights, the condors fly far above, and I have found a few turtledoves there. Although accustomed to the pressure of Oruro, when I went to these mines, I was always ill, with nausea, headache and difficulty in breathing, and I could not walk eight or ten steps without having to stop to get my breath. The manager, who has lived there for two years, could walk a little further, but always had difficulty in breathing. At a height of 4,000 meters, the rarefaction of the air has only a passing effect upon the health, the residents of Oruro and Potosi become very old, and lung diseases are unknown there; the residents are generally thin, very active, but have little strength, which perhaps is partly due to their almost exclusively vegetable diet.

In Chile, the highest point I reached was on the side of Aconcagua at an altitude of 5,832 meters; the summit has an elevation of 6,834 meters. At the point where I stopped, the barometer reading was $382 \mathrm{~mm}$.; I was very sick and it was impossible for me to climb higher; my eyes were badly bloodshot; all objects, even the snow, seemed red to me, and even with my glasses of very dark blue glass, I had great difficulty in reading my barometer. On the way down, at about 5,000 meters, all these symptoms disappeared.

In my numerous stops in the region of the Andes, I often saw condors wheeling about the sides of the highest mountains, but never soaring above their summits; but one should not be hasty in drawing a conclusion from that fact; for the heights they reach are so great that they appear only as little black dots; if there were any at the height of the summit of Aconcagua, they would certainly be invisible, even if one were at an elevation of 5,000 meters, that is, higher than Mont Blanc. At 4,000 meters one finds in the Andes of Chile guanacos, swans, ducks, turtledoves, and even humming birds.

\section{A. Pissis.}

If travellers who limited themselves to crossing the passes of the Cordillera or stopping on the lofty inhabited plateaux of Bolivia and Peru have experienced such symptoms, one may suppose that those who purposely attempted the ascent of the mountains which tower above the average level of the chain have experienced even more. However this is not always true. We have seen that Humboldt and Boussingault suffered much less on Chimborazo than other travellers at Cerro de Pasco or even La Paz. Other examples are no less strange.

For instance, on January 14, 1845, Wisse ${ }^{56}$ descended into the crater of Rucu-Pichincha to the depth of "four times the highest pyramid of Egypt", and climbed back; he does not mention any physiological symptom.

We shall discuss these differences later. They are so great that certain travellers go so far as to deny that mountain sickness exists, because they never experienced it, and there reappear the explana- 
tions about poisonous air, which both the Indians of the Andes and those of the Himalaya have accepted.

The most remarkable account I know, in this respect, is that of the French traveller Jules Rémy, "iT who made the ascent of Pichincha (4860 meters) on October 2, 1856. The weather was magnificent, it was warm on the summit of the mountain, where numerous humming birds were buzzing about. Rémy felt no distress.

My breathing is free, easy, excellent, and I feel no symptoms of distress, a fact worth noting, for it confirms my preceding observations, although contradicting those of other travellers who had stated that at these altitudes the decrease of the atmospheric column causes serious symptoms in different organs.

Only on Cerro de Pasco, a mountain in Peru, celebrated for the silver mines operated there, are the morbid symptoms manifested in the animal organism constant and universal, so far as we know. There one is infallibly attacked by a strange disease, the soroche. . . .

But if it is noted that Cerro de Pasco is only about 10,000 feet above the ocean, and that after one has walked seven or eight leagues, normal health is suddenly restored, although one is then at a much greater altitude, one is compelled to admit that atmospheric pressure is not the cause of the soroche, which perhaps should be attributed to emanations from the ground.

However, if one reads carefully this very account of J. Rémy, he finds in it indications of the harmful effect of the altitude; but their slight importance had escaped our traveller.

He displayed the same immunity in the ascent which, on November 3,1856 , took him to the summit of Chimborazo; ${ }^{58}$ naturally his negative conclusions were greatly reenforced here. The camp of the night before was made at an altitude of 4700 meters, a little below perpetual snow:

The climb continued to be so steep that soon, under the weight of fatigue, we were obliged to stop frequently to get our breath; then thirst became extreme. . . . But we felt no symptom of discomfort or of any morbid affection, mentioned by most of the travellers who have ascended high mountains.

As soon as we had stopped walking for a few seconds, even without sitting down, we went on with new ardor, with a sort of fury inspired in us by the sight of the summit so near us. It seemed evident to us, from this new experience which confirmed so many preceding ones, that at these altitudes the atmospheric column is still sufficient not to hamper respiration, and that the short breath and organic symptoms of which complaint is generally made by those who reach considerable altitudes must be attributed to some other cause.

Having continued their journey in the midst of clouds, the two travellers thought, after observing the boiling point of water, that 
they had reached the summit of Chimborazo, which they estimated to be an altitude of 6543 meters.

But not everyone is so lucky. In a recent journey, Stuebel, ${ }^{\text {;9 }}$ while warning the reader against certain exaggerations, confesses that he suffered considerably in the ascent of Cotopaxi.

On February 8, 1873, at seven o'clock in the morning, the travellers started from an altitude of 3615 meters; at two o'clock, they were at a height of 4498 meters. Without great difficulties, they reached the summit of the volcano of Tunguragua (4927 meters), without being tired and "without suffering headache." (P. 273.)

March 8, ascent of Cotopaxi (5943 meters, temperature $3.5^{\circ}$ ) starting from the Saint-Elie farm:

Some of my people had gone on in advance, others had stayed behind. They were tired, had become a little timid, and complained of headache. ... The arenal has a slope of $35^{\circ}$; it wears down the strength, so that one must summon all his moral energy not to fall just as one is reaching his goal. ... It took us twenty-eight minutes for each hundred meters. (P. 282.) ...

We began to descend. . . . I found little by little all my men; one had remained 50 meters from the edge of the crater, unable to reach the goal so near at hand; the others 400 meters away, and most of the muleteers much lower. Like me, all were suffering from a very violent headache. Only one felt no effects and was not fatigued; he was carrying my barometer, which, however, is pretty heavy. One muleteer did not get above a height of 5,600 meters. I could testify that the vomiting is the effect of the air of these great heights, but not of a passing weakness of the stomach.

But neither in this ascent nor in the preceding ones, did I see blood issuing from the noses, mouths, and ears of my people. These are circumstances upon which other travellers like to dwell. Certainly it must seem strange that M. Reiss and I mentioned no case of the sort. Now we reached a height of 6,000 meters three times, and 5,000 meters several other times, an altitude to which few travellers have ascended. We have always taken with us a certain number of men of different races.... The scientific result of these ascents, in which man reaches the summits only by using all his strength, will always be of slight importance. (P. 285.)

\section{Central and North America.}

Central America. The republics of Central America contain no peaks the elevation of which is comparable to those of the grand Cordillera. So it was with great surprise that I found in the tales of an English navigator of the seventeenth century, Wafer, ${ }^{60}$ a very definite mention of mountain sickness.

Wafer took part in the expedition of Dampier, and was one of the troop who tried to cross the Isthmus of Darien, in 1681. He was 
severely wounded, and with four other Englishmen fell into the hands of Indians, who, after various adventures, restored him to liberty. They then left the vicinity of the southern sea for the ocean to the north:

We crossed (he says) several very high mountains, but the last one was the highest of all; it took us four days to ascend it, although there were some low spots here and there. As soon as we had reached the summit, I felt that my head was whirling strangely; I told this to my companions and the Indians, who answered that they were all in the same condition. Apparently the illness came from the great height of this mountain and the thinness of the air. ... Our vertigo left us as we descended. (P. 174.)

It should be noted that Wafer and his companions, even the Indians themselves, his guides, were in a state of fatigue which was near complete exhaustion. But in spite of this added circumstance, the importance of which we shall see later, I cannot account for the condition in which Wafer must have been when he says that he veered enough towards the northwest to reach Chiriqui (3430 meters), or further yet, Pico Blanco (3600 meters), which is nearer the sea to the north.

The only explorers who, in modern times, ascended the highest volcanoes of Central America, MM. A. Dollfus and deMontserrat, ${ }^{61}$ never mention in their detailed and interesting accounts the special illness of great heights; yet they knew it, having experienced it, as we shall see later, in their journey to Popocatepetl.

The high inhabited plateaux of Mexico have caused similar observations, and we shall see, in the chapter devoted to the analysis of theoretical explanations given by authors, that it was in regard to these plateaux that the discussion which was most fruitful for the topic of this book arose. I shall copy here two interesting quotations relating to symptoms observed in animals:

Horses and mules in Mexico (says Burkhardt) ${ }^{62}$ are subject to a disease which is little or not at all known in Europe. If while the sun is hot they are driven to great efforts or to rapid and continuous movement, they are often seized by palpitations and an acceleration of the pulse and circulation so great that they have strong convulsions over their whole bodies.

Profuse bleeding is the only remedy against this disease, which the Mexicans call asoleado. ... So before buying a horse or mule, the purchaser takes care to make the animal gallop a little, and then to notice whether palpitations in the withers give evidence of the disease. Animals often fall, as a result of this affection, if they are compelled to work uninterruptedly. (Vol. I, p. 63.) 
I borrow the other quotation from Heusinger, ${ }^{6 ; 3}$ who took it from Elliotson:

M. Lyell says that the Englishmen who own mines on the plateau of Mexico, at an elevation of 9,000 feet above the sea, took greyhounds there to hunt hares; but they could not endure hunting in the rarefied air, they were out of breath before reaching the game. On the contrary, their young born in this place are not affected by the rarefied air; they hunt and overtake the game as well as the best greyhounds in England. (Vol. I, p. 260.)

But I must not forget that my chief interest here is not the somewhat chronic and vague symptoms which follow the prolonged residence on rather moderate heights, but those which suddenly attack travellers who are ascending very lofty mountains.

From this standpoint, among the mountains whose height is above the limit at which appear physiological symptoms due to the altitude, Popocatepetl (5420 meters) should be particularly mentioned.

Since the time (1519) when the brave Ordaz ascended it at the command of Hernando Cortez, and as reward for his courage received the authorization to bear a volcano on his coat of arms, and when a second Spanish expedition was sent by the same conqueror to get sulphur there (1522), ${ }^{64}$ no mountain climber had trod the summit of the giant of Mexican mountains. The first European to ascend it is the English lieutenant, W. Glennie, April 20, 1827.

The sensations experienced by M. Glennie (says the secretary of the Geological Society in the extract he gives of a letter from this traveller $)^{65}$ are those already described by travellers to great heights, that is, prostration, respiratory difficulties and headache, this last symptom appearing first at the elevation of 16,895 feet (5147 meters). It was found that tobacco and alcoholic liquors produced an extraordinarily rapid effect upon the sensorium.

A few years later, April 27, 1834, Baron Gros, ${ }^{66}$ attached to the French Legation in Mexico, made the ascent in his turn.

When he had reached the limit of vegetation, he cried:

We began to feel that we are no longer in the sphere where it is possible to live. Respiration is hampered; a sort of melancholy which is not without charm seizes us. (P. 50.)

He passed the night at this height. Before lying down, the travellers mounted a little higher "to accustom our lungs somewhat by degrees to breathing an air so unfitted for them." (P. 51.) 
The next morning, Gros and his six companions set out again:

We walked one behind the other, our alpenstocks in our hands. . . We proceeded very slowly, and were forced to stop every fifteen paces to get our breath. The flask of sweetened water was very useful to me; for being obliged to breathe with my mouth open, my throat became so dry that it was painful. (P. 53.)

At 9 o'clock, we had reached the Pico del Fraile. ... Our guides through superstitious fear refused to go on .... The oppression which I felt was less severe than I had feared, and my pulse rate was only 120 per minute. (P. 54.)

The travellers continued their journey alone, finding the instruments which they had to carry "terribly heavy." To get a rest, they ate lunch:

But only a little; it would be unwise at this height to eat a little too much or to drink any alcoholic liquor, for the nervous system is excited thereby inconceivably. (P. 55.) ...

At noon, we had reached the summit of perpendicular rocks; but our strength began to fail, and every 10 paces we were forced to make a long pause to breathe and to permit the circulation of the blood io grow somewhat slower.

We had to shout to be heard at a distance of twenty paces. The air is so thin at this height, that I tried in vain to whistle, and M. Egerton had great difficulty in drawing a few notes from a cornet which he had brought with him.

At half past two, M. de Geroult was on the highest point of the volcano. He leaped with joy. (P. 57.)

We were exhausted. I had a violent headache and a strong pressure on the temples; my pulse rate was 145 per minute, and 108 after I had rested a little; but I felt hardly more distress than on Pico del Fraile. All four of us were frightfully pale; our lips were a livid blue, and our eyes were sunken in their orbits; and so, when we were resting on the rocks, our arms above our heads, or when we were lying on the sand, with our eyes closed and our mouths open, and under our crape masks so that we could breathe more easily, we looked like corpses .... We saw three crows fly 200 feet above us. (P. 67.) . . .

A great many attempts have been made to ascend to the summit of the volcano; almost all have failed for different reasons. Some travellers, when they had reached a certain height, vomited blood, which compelled them to give up their undertaking. However, in 1825 and 1830, some Englishmen reached the crater. M. W. Glennie is the first, I think, to have seen it. (P. 68.)

The travellers went down again and passed the night in the same place as the night before:

We were too tired and especially too excited to sleep well. When I was awake, I could talk of nothing but the crater, and if I succeeded in getting to sleep, I was climbing up there all over again, the oppression came on again, and I was awakened with a start. (P. 64.) 
MM. Truqui and Craveri, in their ascent in September, 1855, were more fortunate:

I ought to say (remarks one of them) ${ }^{67}$ that we experienced almost no difficulty in breathing during the ascent; at least, we thought that if we did feel any oppression, it should be attributed only to the fatigue of a long and difficult climb. (P. 316.)

In January, 1857, under the guidance of M. Laverriere, Director of the School of Agriculture of Mexico, a scientific ascent of Popocatapetl was made, and this expedition was part of a series of researches on the natural history of Mexico undertaken with the most praiseworthy ardor by the government of General Comonfort.

M. Laverriere in his notes and memoranda collected the data which were of physiological interest in this ascent which was so fruitful from the standpoint of physics and geography. I am quoting in full his communication, for which I thank him sincerely:

Among the tasks which had devolved upon us was the ascent of Popocatepetl, situated southeast of the city of Mexico. I expected to begin our operations by this ascent, because the season at that time seemed to me particularly favorable.

In fact, all who before us had attempted the ascent of Popocatepetl had failed or had only partially succeeded. Forgetting the latitude and the peculiarities of the climate of Mexico, they had made their attempts at times when such explorations are made in Europe, that is, spring or summer. I thought, on the contrary, that our expedition should be made in winter, a period when the atmosphere in Mexico is perfectly transparent and suitable for observations, and when, because of a relatively lower temperature, the snows which cover the upper part of the cone occupy a greater surface on its slopes, which lessens the distance to be traversed in the deep and unstable sands which cover them, while furnishing by their hardness a firmer footing for the traveller.

Consequently our little caravan, composed of Dr. Sonntag, astronomical engineer, a major-domo, two students from the School of Agriculture, and three servants, left Mexico (2278 meters) on Saturday, January 17,1857 , in very hot weather; on January 18 passed through Chalco situated on the lake of the same name; on January 19 through Amecameca (2493 meters), and entered the vast pine forests which cover the first foothills of the volcano, reaching the ranch of Tlamacas (3899 meters) on the evening of January 20.

The ranch of Tlamacas, situated at the foot of the north slope of the volcano, is composed of a few cabins in which the sulphur occasionally brought from the interior of the crater is refined. It occupies a clearing near the timberline, and near it are found several varieties of pines, noteworthy for their hardiness, the excellence of their timber, and the abundance of their resin, and capable of being acclimatized in Europe.

We passed the night in this spot. At six o'clock in the evening the 
thermometer stood at $-0.3^{\circ} \mathrm{C}$, and $-2^{\circ} \mathrm{C}$. an hour later. In spite of a good fire and our blankets, our sleep was uneasy and rested us but little; the Indians, on the contrary, slept like logs, and the next day they were up early, in good health and spirits, while we were stretching our limbs and looking surly.

Wednesday, January 21, at five o'clock in the morning, everyone mounted and set out in silence; the Indians followed on foot. The cold was so penetrating that in spite of our thick garments we vied with each other in shivering. A quarter of an hour afterwards, we left the wood and approached the sandy stretch, going straight towards the steep slope of the volcano. The horses sank up to their hocks, going on slowly and painfully. Soon we had to stop frequently to let them breathe, for the air was so stinging and the path so steep that they could hardly get their breath.

At half past eight we reached La Cruz (4290 meters). The horses were worn out, covered with sweat, panting. We dismounted and sent them back to Tlacamas. Numbed by the cold, we rested a little while on the sand warmed by the sun whose heat began to be scorching.

At nine o'clock, each one started out, his alpenstock in his hand, following our Indian guide, Angel, who with his feet wrapped in some rags, led the way with a step remarkably easy compared with ours.

We followed him with difficulty, in spite of the care we had taken to lighten our garments and footgear as much as possible. Soon we reached a strip of ice which precedes the snow. It was crossed without too many difficulties, thanks to the notches cut with an axe by an Indian sent on ahead with orders to blaze a trail up to the summit of the volcano.

At the line of perpetual snow (4400 meters on the slope at this season of the year) I began to feel acute fatigue. I was wet with sweat, my breath was short and hurried, and it seemed to me as if enormous weights were fastened to my feet. Near me, a Mexican from Amecameca, named Saturnino Perez, who wanted to accompany us, was climbing with a stronger step; but his pale face, his bluish lips, his wild eyes, the contraction of his mouth, and the dilation of his nostrils showed plainly enough the effects of the altitude upon his constitution, hardy and robust though it was. The slope was steep, it is true; but as the snow was packed, we experienced less difficulty in advancing than if we had been on sand or ice. Only the air was so thin, so dry, so cold, that this advantage was more than compensated.

Soon, since our strength failed, we had to halt, a very short halt, for the cold seized us straightway. Every forty or fifty steps we were forced to stop for a minute or two. Our lungs seemed to refuse to act; they hardly had the strength to raise the chest, which collapsed heavily after each inspiration.

At 300 or 400 meters from the summit, there was a moment of hesitation, of prostration. Although so near, our goal seemed still enormously far away. The extremely steep grade, the metallic glare of the snow, the rarity of the air caused me inexpressible weakness. So I had to collect all my energy, appeal to all my reasoning power, and think of my responsibility in particular to find strength to go on. 
Finally, thanks to a supreme effort, we reached the edge of the crater ( 5280 meters; temperature $-2^{\circ}$ C.) through an opening to which I gave the name of Silicco Breach, in honor of the judicious minister who had sent us. It was half past one in the afternoon, and the part of our ascent which had been made on foot had required no less than four hours and a half.

Within the crater, as soon as we had passed its edge, there was an inner slope towards the south, composed of sand and rock fragments. We dropped down upon it like inert masses, hardly conscious. My first sensation was that of inexpressible comfort. But this comfort lasted only a short time. The sand which at first I had found warm soon seemed unendurably cold to me. Moreover as the sun was beginning to descend, a cold little thin wind rose. I was soon shivering. To cheer myself, I wanted to eat, to drink a few gulps of an excellent sherry wine which our good Indians had brought. But since my throat was tight, I could not swallow the food, and the sight of it was distasteful. Instead of the strengthening effect expected, the wine produced a very different effect; no doubt because of a perversion of taste, I thought I had swallowed a stiff brandy, a regular fiery draught which literally burned my entrails. At the same time, and in spite of my weariness, a strange agitation seized me; it was a feeling of uneasiness, of distress, which would not allow me to rest. And yet, when I wanted to move, my strength betrayed me and almost refused me service. However, I found strength to climb back to the edge of the crater where I eagerly seized some snow to quench a little the burning thirst which tormented me.

This agitation nevertheless passed away a little and my strength returned for a few hours. But in the evening, and especially during the night which we passed huddled against each other under a shelf of rock, a feverish condition seized me; my head on fire, piercing cold in my limbs, a pulse of 120 to 130 , unendurable uneasiness, increased even more by the dull mutterings in the abyss beside us. It was a night I shall never forget. And therefore the dawn was greeted with joy, and after making observations according to our instructions, the signal for return was given; we left the volcano at ten o'clock and three hours afterwards, we were back at the ranch of Tlacamas, which we had left thirty hours before.

The Scientific Committee ${ }^{68}$ which accompanied our unfortunate Mexican expedition also made this ascent April 23, 1865; the sufferings were quite endurable:

The line of perpetual snow begins at a height of about 4300 meters above sea level.

Here everyone dismounts, and climbs over the snow, zigzagging a little. ... When one has ascended about 100 meters, he begins to feel great difficulty in breathing, his lungs are oppressed, and every step, every movement of his body makes him pant; he hạs to stop every twenty steps to get his breath, and there are certain constitutions which cannot endure the discomfort, although it is not very serious.

The reflection of the sun on the snow is blinding; it is wise to pro- 
vide oneself with colored glasses and veils so as not to add to fatigue and breathlessness the vertigo which would no doubt be caused by this immense winding-sheet of snow which surrounds one.

We could note, moreover, that the physical sufferings attendant upon such an ascent have been much exaggerated; none of us had hemorrhages of any sort. . . .

The Indians, used to this ascent, can carry an arroba (11 kilos) and they ascend very rapidly. ...

We reached the summit of the volcano (the summit reached by the travellers is the Espinazo del Diablo (5247 meters), and not the true summit, the Pico Mayor (5450 meters). . . . The last steps are rather difficult; the rarefaction of the air, becoming greater and greater, adds still more to the difficulty of the ascent . . . .

Hardly had we reached the summit than the difficulty in breathing which afflicted us ceased to be felt, and our lungs were not oppressed as long as we were resting. However, all of us could observe a certain excitement, which increased in some of us to the point of a violent headache; this excitement can be compared almost to a slight state of intoxication; the blood circulates rapidly, and the pulse rate rises to nearly one hundred per minute. (P. 194.)

Besides Popocatepetl, in Mexico there is only the peak of Orizaba (5400 meters) the ascent of which can bring on discomforts and even symptoms. This happened to Von Muller ${ }^{1: 3}$ and his companions, September 2, 1856.

The travellers passed the night at 3000 Spanish feet from the summit:

The consequence of a stay in such rarefied air were soon strongly felt by all of us. Our respiration had become much deeper and more rapid, a natural result of the diminished quantity of oxygen reaching our lungs at each inspiration of this thin air. We all had violent headaches with feverish tendency. These symptoms could not surprise us, because we were at an elevation greater than that of Mont Blanc. ... Although we were lying close together, with furs and rugs over us, we were all shivering with cold and fever. The temperature was below freezing. (P. 278.)

\section{The next day they wished to complete the ascent:}

The climb was extremely steep, so that in 25 steps, we mounted no more than 8 to 10 feet: besides we had to stop after these 25 steps ....

None of us had nosebleed or such symptoms during the ascent; but we had severe congestion of blood in the head so that the whites of our eyes were deep red. . . . All had violent headaches, and shook terribly with fever. (P. 282.)

A large company of American, English, and Mexican travellers, including artists, engineers, and mere tourists, tried to reach the summit of this peak in 1866. They did not succeed either. They were much distressed by symptoms of which one of the company in 
the New Orleans Picayune gave a very picturesque and very strangely worded account. Although I am quoting it, I do not hesitate to say that it seems to me greatly exaggerated; I shall add, along with the editor of the Alpine Journal, that I am not sure that I have always understood what the author meant, ${ }^{70}$ in his obscure and bombastic style:

At first they sang and whistled while they climbed; but these noisy demonstrations soon ceased. Respiration became difficult. . . . Up to about 2000 feet from the summit, the members of the company were strung out at a great distance from each other. At that time, some became weak and fell. Blood began to issue from their ears and noses; their faces were so swollen that old friends knew each other only by their garments. A few continued to climb some thousand feet, lay down, went to sleep on the snow or the black dust, and awoke panting. The artists, laden with their instruments, felt greatly the painful effects of the atmosphere; with one accord they turned around and went back down to the place where our companions who had no ambition and poor endowment of lungs had stopped. ... The engineers and the others lay down; they were stumbling as they walked, incapable of will or action, and calling to those who were ahead. Had it not been for the continual struggle to cling to life, the distress in breathing, and the constant loss of blood, one would have thought he was asleep and dreaming in a hollow in the snow or a gorge filled with ashes. We were then at an elevation of about 16,000 feet. . . General S. went on towards the summit. In spite of the claims of the natives, it is doubtful that anyone ever went as far as we did. During the war with Mexico, 20 years ago at the most, an officer tried to reach the summit; but he fell paralyzed, at the height of 15,000 feet. His comrades went no further, and at this point planted a standard the staff of which is still there.

Two-thirds of our company were out of sight; only three, besides the terrified guides, went on. Blood issued from our ears, nostrils, and mouths, and the veins stood out on our foreheads like dark lines; our progress was more and more uncertain, the slope steeper and more dangerous . . Colonel C. . completely exhausted, talked incoherently like an intoxicated man.

A stone which broke the shoulder of General S. . . compelled them to retreat, at about 500 feet from the summit.

North America. As we have seen, North America in many places has peaks lofty enough for travellers to experience on them the symptoms of mountain sickness. But the hardy explorers of the banks of the Colorado, the Oregon (Columbia), and the upper Missouri, gave little heed to scientific and picturesque ascents. On the other hand, the engineers and the officers whom the government of the United States sent repeatedly to the Far West generally were satisfied with making trigonometric abstracts, and journeyed 
only over the passes, the elevation of which rarely reaches 3000 meters.

However, Colonel Frémont, in his account of his expedition to the Rocky Mountains of Oregon, gives us an interesting observation. ${ }^{i 1}$

August 13,1842 , in latitude $42^{\circ} \mathrm{N}$., the travellers made the ascent of a lofty peak, and were suddenly extremely weary. The barometer stood at 20.522 inches, the altitude was reckoned at about 10,000 feet (3050 meters); the temperature was only $50^{\circ} \mathrm{F}$.; they stopped to camp:

I was seized shortly after (says Frémont) by violent headache and vomiting which lasted almost all night. These symptoms were probably caused by excessive fatigue, the lack of food, and also, to a certain degree, by the rarefaction of the air. ...

The next day two of our men were sick and lay down upon the rock; at that time I was seized by headache and vomiting, as on the day before, so that I was unable to go any further; M. Preuss had reached his limit, too; the thermometer stood at $50^{\circ}$, the barometer at 19.401 inches. (P. 67.)

August 15. . . The barometer dropped to 18.293 and the thermometer to $44^{\circ}$; we were at an elevation of 13,570 feet (4130 meters); at this great height we saw a solitary bee flying ... This is probably the highest peak of the Rocky Mountains.

Our careful method of advancing slowly had spared my strength; and with the exception of a slight tendency to headache, I felt no signs of the discomfort of the day before. (P. 70.)

The mountain discussed here is marked on the maps by the name of Frémont's Peak (4130 meters), in the State of Wyoming.

In the following journey, made in 1943-44, the American expedition crossed the Sierra Nevada in California at a height of 9300 feet, February 20 (ibid. p. 235) ; June 18, 1844, it reached the sources of the Arkansas, at a height of 11,200 feet (3413 meters) (P. 285) ; in neither case does the account indicate physiological symptoms.

I found a similar account in the immense scientific publication of the expedition organized for determining the route of the transcontinental railroad.

September 12, 1853, Captain Gunnison, ${ }^{72}$ topographical engineer, ascended Mount Creek, near Fork Lake in Colorado:

The agreeable and inspiring effect of the pure air of the mountains at this elevation, a favorite theme for the eloquence of trappers and scouts, manifested itself in our men by shouts of noisy joy. But the violent physical exercise soon made them breathless; and while climbing the hills, our animals were soon completely exhausted, if they did not stop often to get their breath; but a few moments of rest gave them back their strength and vigor. (P. 53.) 
And yet they were only at a height of 8559 feet (2610 meters); barometer $564 \mathrm{~mm}$., temperature $17.5^{\circ}$.

September 2, they had passed the highest point of their journey, 10,032 feet (3056 meters), at the pass of Coochetopa, in Colorado; they complained of no symptoms. (P. 47.)

The Reverend Hines ${ }^{73}$ made the ascent of Mount Hood in Oregon with three companions, July 24, 1866. It was not without trouble, as he says energetically:

We had only about 700 feet to go, but it taxed our sinews for two hours to climb them. The sun was shining again, and the sweat was dripping from our brows; but as we approached the summit, fatigue seemed to disappear, and it was with a feeling of triumph that we trod the summit of the highest mountain in North America. (P. 83.)

Hines was wrong on this last point; Williamson, ${ }^{74}$ who climbed Mount Hood again in 1867, found its height to be only 3420 meters; it is then not the highest of the Cascades, much less of North America.

More recently, a very well-known English mountaineer, M. Coleman, ascended mountains as high as or even higher than Mount Hood.

In August, 1868, he climbed Mount Baker (3390 meters)..$^{75}$ In his account he speaks oniy of sulphurous exhalations from which he and his companions suffered; one of them was seized by vomiting (P. 365). In August, 1870, ascent of Mount Rainier (4400 meters),$^{76}$ on the summit of which he passed the night, warming himself at the crevasses of the volcano, but much inconvenienced by their exhalations: here too, no physiological trouble. But that proves nothing, for we shall see, when we speak of the Alps, that professional mountaineers today seem to make it a point of honor never to speak of the sufferings of mountain sickness.

\section{Etna.}

In the preliminary chapter, I reminded the reader that the ancients had frequently made the ascent of Etna (3313 meters); but they have left us no record that might make us think that they felt any extraordinary symptoms. The authors of the Middle Ages, who followed their steps, and told of their own journeys, are no more explicit than the ancients.

Pietro Bembo, ${ }^{i \pi}$ who in 1494 made the ascent with his friend Angelo Chabriele, does not even speak of his fatigue in his celebrated dialogue with his son. In 1540 and 1545, Filoteo climbed Etna with several of his friends: he says nothing definite. ${ }^{78}$ Thomas 
Fazello ${ }^{79}$ gives a few more details in the account of his ascent of the 6th "of the Kalends of August", 1541; however he mentions nothing but an extreme fatigue:

We had to climb on foot the crest of the mountain; the ascent was very arduous; here, the roughness of the soil, there, deep sand delayed us, our feet sliding backwards; in fact, the difficulties were so great that although the climb was not more than 50 steps, it took us a good two hours, and reaching the summit at last, panting and dripping with sweat, we lay down on the ground. (Decas I, liber II, caput IV; vol. I, P. 116.)

But a century later, in 1671, the illustrious doctor-mathematician Borelli, ${ }^{80}$ whose attention had been aroused by the accounts of travellers in South America, notes symptoms which he indicates clearly:

Among the noteworthy observations which I made at the summit of Etna in the year 1671, there is an unexpected effect due to the rarefaction of the air. There, in fact, moderate movements ... brought on such lassitude, that young and robust men had to rest, to sit down, and to regain their strength by breathing frequently. (P. 242.)

Then he tries to explain these symptoms; we shall see that he gave successively two different theories for them. But the sensations which he had noted have not been experienced by all travellers, and we see beginning here a series of apparent contradictions, of which we shall mention numerous examples, even from our own times.

In fact, Riedesel, ${ }^{81}$ in the account of his journey to Sicily, relates his ascent of May 1, 1767, and he adds:

I did not find, as various travellers say, that the air was so rarefied and thin as to check or at least to hamper the breathing greatly; which may depend, besides, upon the conformation and constitution of the chest and the lungs of each subject who tries it. (P. 132.)

Demeunier, ${ }^{82}$ Houell, ${ }^{83}$ who made the same ascent at about the same time, do not mention observing any symptom. "Delon, ${ }^{84}$ when he reached the summit of Etna, cried out enthusiastically:

An ethereal air which crushes him, startles his being, and makes him realize an existence which warns man that he is out of the region to which his organs chain him. He is impressed by his rashness. . . .

I leave to the reader the task of deciding whether this ranting expresses any physiological phenomenon, and omitting other testimony quite as unimportant, I come to the account of Dolomieu, ${ }^{85}$ who on June 22, 1781, made the ascent of Etna; the celebrated 
mineralogist was very severely affected, and his guide still more than he:

The cold was cutting . . . often breath failed me, and I was forced to stop short to get my breath, and to prevent strong palpitations which I felt in the pulmonary arteries. . . My guide constantly called to me to walk more slowly, and when I reached the plain, near the Tower of the Philosopher, ${ }^{\mathrm{se}}$ he told me that he could go no further, that he felt very ill, and in fact, a moment afterwards, he fell unconscious, the pallor of death on his face, and in a most pitiful state. ... A few drops of wine made him revive a little; but he was very weak and like a man about to die. (P. 98.)

Dolomieu continued his journey alone and reached the crater without mentioning any real sufferings in his account; he speaks only of his fatigue.

The report left us by Spallanzani of his ascent on September 3, 1788 , is interesting particularly because of the record he gives of the remarks of travellers who preceded him:

The rarefaction of the air on the summit of Etna did not produce upon me the same effects as those experienced by some of the travellers who had preceded me. Chevalier Hamilton (September 26, 1769) felt his respiration hampered by the great thinness of the air; Count Borch (October 16, 1776) was still more distressed; "the rarefaction of the air on this mountain (he says) is very great, so great that the air is hardly suited for breathing." Riedesel (1767), on the contrary, felt no effects, or hardly any, as we see by this sentence: "I did not perceive that the air was so rarefied as several travellers state, nor so thin as to prevent breathing, or even to hamper respiration very much." Brydone (May 27, 1770) does not mention it, and I concluded from his silence that the thinness of the air did not tire him much.

As for me, my servant, and my two guides, the air gave us no trouble. The difficulty of climbing ... made our respiration painful and hurried, it is true; but after we had reached the summit, after resting a little, we soon regained our strength, and even while walking, we had no further difficulty in breathing. (P. 272.) ${ }^{37}$

The illustrious physiologist did not show his usual acuteness there; he could not distinguish, as Borelli had done one hundred years before, between the effects of walking and those in a resting condition, and whatever he says, we can easily see that the air gave him real, though slight, disturbances.

Ferrara, ${ }^{88}$ in his description of Etna, goes farther. According to him, not only did the ascent cause no distress, but he breathed with greater ease in this pure air:

The lessened density of the air, no less than its extreme purity; produced a full and free respiration. ... We felt none of those symp- 
toms which certain travellers say they experienced on the summit of Etna; those symptoms must have been an effect of their poor physical condition. We all felt very well. In his balloon, at the height of 21,482 feet, Gay-Lussac was in good shape. (P. 21.)

The French traveller De Gourbillon, ${ }^{89}$ who made the ascent October 10, 1819, felt no effects himself; but that was not true of his travelling companions:

M. Wilson experienced strange symptoms; his face, naturally ruddy, was wan and pale, almost entirely livid. Though younger and more nimble, and though he had not suffered as much from the volcanic exhalations, which had produced upon the latter and even upon the guide an effect like that of seasickness, my other travelling companion seemed neither fresher nor less distressed. . . Lazarus, when he left the tomb, was no paler. (P. 436.)

Likewise, Count de Forbin, ${ }^{90}$ who mounted to the crater the following year, was in very bad condition:

I was hardly halfway from the Tower of the Philosopher to the summit, and already I was thoroughly disheartened. The rarefaction of the air made breathing difficult; later, the oppression became very great, it acted so much upon one of our travelling companions that he fainted. He was revived, and summoning all our strength, we reached the highest crest of the crater after an hour and a half.

Never in my life had I felt such fatigue; . . . my first impression was that I was like an invalid, prostrated, distressed by the terrors of a feverish brain .... Weariness of the senses and excitement of the imagination reduced us to a state nearly like delirium. (P. 173.)

About the same time, A. de Sayve made this ascent. The results of it were told in a very interesting manner by $\mathrm{H}$. Cloquet, who made use of it to prove the effect of great heights upon the organism. He reported it to the Société Philomathique in the following words: ${ }^{91}$

In the month of January, 1820, M. H. Cloquet published some details about the medical topography of Mont St. Bernard, and ideas about the effect which a stay on the towering crests of lofty mountains has upon man...

In spite of these data, a celebrated author of our time, M. Ferrara, thought that only persons in poor health were inconvenienced while ascending to the summit of Etna, in Sicily. A careful observer, $\mathbf{M}$. Auguste de Sayve, visited this famous place in the month of May, 1821, and disagrees with the learned M. Ferrara in this point. Here are the principal results of the observations which he made, and $\mathbf{M}$. Cloquet considers that these results support what he has said . . .

At the snow limit is the little plain called Piano del frumento, at the beginning of which are the ruins ... known by the name of the Tower of the Philosopher ... Even before reaching this point, M. de 
Sayve felt that he was breathing with difficulty; in spite of the cold, he felt very acute thirst; however, a little rest restored his strength.

But the scene was to be changed ... The route passes by a hut of refuge, which is at the foot of the cone, and which is the highest building in all Europe $(9,200$ feet) . . . From there up to the summit there is only an absolutely bare cone, 1,300 feet high.

As our traveller climbed this cone of the crater, he felt his distress increase, and was obliged to stop at nearly every step. He felt extraordinary weakness in all his limbs; he was nauseated, and thinking that he had left the element suited to his physical nature, he tried, he says, to inhale a little air, but could not succeed at this critical moment; and yet he.was perfectly healthy when he began his ascent; his passage through the region of snow had tired him very little; the symptoms he felt can therefore be attributed only to the rarefaction of the air.

M. Aubert-du-Petit-Thouars . . . told the author that he had felt similar symptoms, especially a weakness in the stomach, when he climbed the mountain in the Ile de Bourbon, known as the Benard.

M. Cloquet, moreover, himself experienced symptoms of this sort, when he reached a certain height in the Alps ....

M. de Sayve had with him a companion who was much more severely affected; and we know that the unfortunate Dolomieu, in the same ascent, was also attacked by symptoms like those which we have just mentioned... .

These different symptoms are quite varied and appear sooner in some persons than in others; but they cannot be attributed to fatigue, which never has such consequences in mountains of an elevation less than 1,000 fathoms.

Moreover, they appear alike in animals and men.

I shall not give more quotations. More recent authors show the same differences in power of observation, and most of them say nothing about physiological disturbances. What I have reported is enough to show that Etna is, if I may use this term, a limited mountain, in the ascent of which many persons experience no painful symptom, whereas others are more or less ill. Since the first symptoms of distress are exactly those of excessive fatigue, the difficulties of the ascent of the cone are consequently enough to explain everything, in the opinion of most of the travellers; some think the cause of the oppression is the poisonous exhalations coming from the volcano through the innumerable fissures in the ground. It is not surprising, then, that before verification of the disease peculiar to mountains, in the main range of the Andes, nothing unusual was noted in ascents of Etna.

\section{Peak of Teneriffe.}

Discovered again in the fourteenth century by French navigators, the Canary Islands were conquered in the fifteenth century 
by the Spaniards. But for a long time no one dared attempt the ascent of the volcano, the summit of which seemed all the higher because its foot is at sea level.

The strangest and most exaggerated estimates were made of its height. According to Th. Nicols, ${ }^{92}$ it was not less than 15 leagues; Riccioli and Kircher estimated it at ten Italian miles; in reality, it is 3716 meters.

The first account of its ascent ${ }^{93}$ that we have found is that of a journey made in 1652 by some "notable merchants and men of great esteem"; they were considerably affected by the rarefied air:

At six o'clock in the morning 'we began to ascend the Peak . . . Some of our company became very weak and sick, and were attacked by diarrhea, vomiting, and feverish trembling . . . One of us was so ill that he could go no further. (P. 201.)

The celebrated Robert Boyle ${ }^{94}$ reported a similar account, in which the effect of the expanded air is confused with that of emanations from the earth, as often happens in ascents of volcanoes:

One day I asked an intelligent man who had lived for several years in Teneriffe whether he had climbed to the summit of the Peak, and what sensations he had had. He replied that he had tried, that several of his companions had completed the ascent, but that the thin air and the sulphurous exhalations had made himself and a few others so sick that they halted far below the summit. The effect of these vapors was such that his skin became pale yellow, and his hair was bleached. (P. 2039.)

Not all travellers experienced the same effects, and, as usual, those who were free from distress were led to deny what their less fortunate predecessors reported.

Edens ${ }^{95}$ who ascended the Peak in 1715, expresses himself as follows:

What has been said about the difficulty of breathing on the summit of the Peak seems wrong; we breathed as easily up there as we did below; we had our lunch there. (P. 186.)

Father Feuillée ${ }^{96}$ made the ascent of the Peak on July 31, 1724; he says nothing of interest to us.

G. Glas ${ }^{97}$ was less fortunate:

We reached the foot of the cone (he says in fact) ... Although the distance is hardly a half mile, we were forced to stop forty times, I think, to get our breath, and when we had reached the summit, it was a quarter of an hour before we had recovered. (P. 255.)

The same thing was true of the scientists whom Labillardière ${ }^{98}$ had taken with him on his journey in search of La Pérouse: 
Citizens Riche and Blavier (he says) had undertaken the ascent of the Peak one day after us (Labillardière, who made the ascent October 17, 1791, speaks of no painful sensation); but these two naturalists did not succeed in climbing to the summit; they were still far from it when they spat blood, since their lungs could not become accustomed to the rarefied air, and they were forced to give up their undertaking. (Vol. I, p. 27.)

\section{It is true that, according to Bory Saint-Vincent, ${ }^{99}$}

Riche was in very poor health and had very weak lungs . . . . He died as a result of his journey, soon after his return to France. (P. 182.)

Von Humboldt ${ }^{100}$ (ascent of June 21, 1799) says absolutely nothing of physiological disturbances.

The celebrated geologist Cordier, ${ }^{101}$ who ascended the Peak April 16, 1803, discusses these disturbances, but only to deny them, or practically so:

What has been said of the keenness of the cold, ... and the difficulty of breathing on the Peak is not correct. Moreover, I have already proved several times that the opinion generally held in this respect is more than exaggerated; I assure you that the cold was quite endurable ... that the rarity of the air did not inconvenience us at all, although it forced us to halt quite frequently as we approached the summit. (P. 61.)

The illustrious Léopold de Buch, in the accounts of his ascents of May 18 and 27, 1815, ${ }^{102}$ does not give them a more important place:

The ascent becomes more difficult after the Estancia de los Ingleses . . . In spite of that, the difficulties are not comparable to those of an ascent to the summit of one of the snow covered peaks, of the Alps .... When we reached the crater, we suddenly saw appearing opposite us Mme. Hammond, a Scotch lady, with her travelling companions. She was the first woman ever to ascend to the summit. (P. 4.)

May 27 we again ascended the Peak. (P. 5.)

The account of Dumont d'Urville ${ }^{103}$ is very interesting in its brevity. He passed the night, in June, 1826, at the Estancia de los Ingleses:

The air was very pure (he says) and I felt none of these violent disturbances and these suffocating sensations experienced by different travellers. M. Quoy alone had pains in the stomach, and M. Gaimard slept all night without any trouble ... The next day, as we approached the Pain-de-Sucre, we were obliged to stop frequently to get our breath .... We lunched gayly on the crest of the Piton. (P. 37.) 
At the time of his second journey, in October, 1837, the officers of the Astrolabe and the Zélée made the ascent of the Peak. Dumont d'Urville ${ }^{104}$ reports their sensations in these words:

In agreement with my observations in 1826, MM. Dumoulin and Coupvent noted ... . the numbness of the extremities of the body. During the night, the thermometer dropped to $-0.5^{\circ}$. MM. Dubouzet, Dumoulin, and Coupvent, especially the latter, felt severe headaches. (P. 32.)

The surgeon, Le Guillou, ${ }^{105}$ reporting the same ascent, says:

Several of our comrades were afflicted by a strange symptom; they had copious nosebleeds, and we were forced to stop a few moments. (P. 29.)

On September 18, 1842, ascent of M. Charles Sainte-Claire Deville; ${ }^{106}$ he does not say a word about physiological disturbances.

Itier, ${ }^{107}$ who climbed the Peak December 28, 1843, gives more importance than his predecessors to the sufferings he felt:

We left the Estancia d'Ariba (3104 meters), and mounted on foot the sort of path which winds between two flows of obsidian; walking is painful among these fragments of pumice stone mingled with ashes which give under the foot; besides, the sun began to affect us, and the effect of the rarefaction of the air soon added to the fatigue of our effort. My heart throbbed violently, and the arteries of my brain shared in this distress; the headache it caused forced me to stop frequently; my companion, less accustomed to mountains than I, felt these effects much more than I did; he stopped every ten steps, suffocating, exhausted. (Vol. I, p. 28.)

I shall quote finally the account reported from the notes of a traveller by Madame Elizabeth Murray, an English artist, ${ }^{108}$ of an ascent of the Peak, made in August, by four Englishmen and an American:

To pass the night, we made our bivouac at the Estancia de los Ingleses, at a height of 9933 feet. (Vol. II, p. 20.) . . . .

One of us was seized by extreme weakness, shivering, and violent headache; we covered him with rugs, lighted a good fire, and the heat, added to the effects of a little liquor, partially revived him. (P. 121.)

It was late, and we stretched ourselves on the ground, wrapped in our rugs. Shortly after, my companion on the right rose and complained bitterly of extreme cold, pains, and distress in his stomach. We placed him near the fire, and gave him warm water and brandy.

$\mathrm{He}$ began to be well enough to permit us to sleep when my neighbor on the left was attacked, then treated in the same way. Both suffered severely from the symptoms well known to ocean voyagers; these symptoms are not rare on the Peak; they are sometimes attributed to sulphurous exhalations, but I think that they are 
caused instead by the rarity of the air. At any rate, we smelled no odor of sulphur.

Of the four of us, my American friend and I were the only ones who felt no discomfort. (P. 123.) ......

Before arriving at the Rambleta (11,680 feet), many of us suffered more or less from difficulty in breathing. One of my companions, in particular, could not take more than eight to ten steps without stopping, thus forcing us to wait for him. (P. 126.) . . . .

After a great many halts to regain our breath, we reached the summit. (P. 128.)

We went back by the "Mal Pais", the descent of which was as disagreeable as the ascent, except that our respiration was much freer. (P. 136.)

In summary, the Peak of Teneriffe is, like Etna, a limited mountain, in the ascent of which many travellers feel no great effects, those who are ill being only slightly affected.

\section{Alps.}

It is not until the end of the last century that ascents were made in the Alps to heights sufficient to bring on physiological disturbances. Until the time of Canon Bourrit and the illustrious De Saussure, only a few chamois hunters had ventured above the line of perpetual snow. The main peak of Mont Blanc, today traversed in all directions every year by hundreds of tourists, bore the significant name of the Accursed Mountains; in the seventeenth century, the Bishop of Annecy, Jean d'Aranthon, ${ }^{109}$ came to exorcise its glaciers, which withdrew submissively after his benediction. Of the rival summits of Monte Rosa and the Jungfrau, there was no question. The principal passes had been frequented since the days of the Romans; many armies had crossed them; the hospice of the Grand Saint-Bernard was founded at the end of the tenth century, but no one had thought of risking his life in the ascent of one of the innumerable summits which tower above the beautiful Alpine valleys: in 1740, the first Englishmen arrived at Montanvert!

However, it was well known that travellers suffered sometimes, in crossing the Alps, from pulmonary disturbances. Haller considers them, as we shall see in the chapter devoted to the discussion of theoretical explanations; he even speaks of hemoptyses observed by Scheuchzer: "ut in primis in J. Sch. triste exemplum exstat". ${ }^{110}$ I could not secure the work of this German geographer; ${ }^{111}$ but according to Meyer-Ahrens, ${ }^{112}$ he must have experienced only the oppression and threats (Vorboten) of hemorrhage.

The first traveller who has given us an account of personal disagreeable sensations, the second to make the ascent, today so com- 
mon, of Buet (3110 meters) is the Canon Bourrit.113 At this moderate height, he experienced strange symptoms:

In 1776, I left Geneva with the purpose of ascending Buet; it was the second time that I had climbed this mountain; . . . . I was in good physical condition .... All three of us reached the summit feeling very well .... After ten minutes of peaceful halt, I felt a numbness in my arms and legs, and soon I had not the strength to force myself out of this condition; I was already unconscious when my companions removed me; they carried me down to the first rocks of the glacier....

The next year, . . . . I went there in very fine weather; . . . . I began to sketch, and told my guide to hold my parasol over me. After 15 minutes, I noticed that he was not holding it well; . . . and you can imagine my surprise when I saw this man as white as snow .... and his eyes almost motionless; I made the utmost haste to get him away from this baneful summit . . . Finally, in $1777, \ldots$. M. Saint-Ours . . . witnessed a similar attack on the summit of Buet .... (Vol. II, p. 94.)

Bourrit, however, seems to have been quite subject to syncopes; he reports two others, one on the glacier of Buet, while he was walking (Vol. III, P. 198), the other during his attempt to ascend Mont Blanc, September 11, 1784 (Vol. III, P. 300 and 304).

At a still lower elevation, at the monastery of the Grand SaintBernard (2430 meters), a traveller of the same period, Laborde, felt similar symptoms, although considerably less severe:

The sky was clear when we reached the monastery of the Grand Saint-Bernard (July 30, 1777).

It would be difficult to express the different sensations which one feels at the same time; the first that is noticeable is an attack caused by difficulty in breathing; it seemed as if the lungs did not have their usual elasticity and lacked the capacity to hold the air inspired; the difference between the air one breathes at such a height must be very evident to those who are used only to air of the plains; it is more rarified and purer because it is less filled with vapors (Lecture on the natural history of Switzerland, P. VIII).

These few quotations bring us to the celebrated accounts of De Saussure; the sufferings experienced at elevations which are very low compared with Mont Blanc, the ascent of which he dared to attempt and carry out, bring out still more the bravery which he displayed in this intrepid undertaking. Canon Bourrit, when he said, as we shall see in Chapter III, that it would be difficult, if nor impossible to live long on the summit of Mont Blanc, only translated, in a somewhat modified form, an opinion universally held by mountaineers.

De Saussure, when he ascended Mont Blanc, had prepared for it 
by numerous expeditions made every year on lofty mountains. Now at fairly moderate heights he had already felt symptoms, which had attracted his attention. In the account of his ascent of Buet, made July 13, 1778, in the company of Pictet, he gives ${ }^{115}$ a very clear indication of it:

The rarity of the air, as soon as one passes the elevation of 1300 to 1400 fathoms above sea level, produces very strange effects upon the body.

One of these effects is that muscular strength is exhausted very quickly. (Vol. I, p. 482.) . . . .

Another effect of this thin air is the drowsiness it produces. As soon as one has rested for a few moments at these great heights, he feels his strength entirely restored, as I have said; even the impression of the former fatigue seems wholly effaced; and yet in a few moments one sees all who are not busy, falling asleep, in spite of the wind, the cold, and the sun, and often in very uncomfortable positions. Of course fatigue, even on the plains, produces sleep; but not so suddenly, especially when it seems to have entirely disappeared, as it does on the mountains, as soon as one has rested a few moments.

These effects of the thinness of the air seemed to me quite universal; some persons are less subject to it; the dwellers on the Alps, for example, who are accustomed to living and working in this thin air, seem less affected by it; but they do not entirely escape its effect. The guides, who on the lower slopes of the mountains can climb for hours at a time without stopping, have to pause to get their breath every 100 or 200 steps, as soon as they are at an elevation of 1400 or 1500 fathoms, and as soon as they have halted for a few moments, they too fall asleep with surprising promptness. One of our guides, whom we had standing on the top of Buet with a parasol in his hand so that the magnetometer might be in the shade while M. Trembley observed it, kept falling asleep constantly in spite of the efforts which we made and which he made himself to struggle against this drowsiness. And on my first trip to Buet, Pierre Simon, who had crept into a snow crevasse to shelter himself from a cold north wind which distressed us greatly, went sound asleep there. But there are constitutions which this rarity of the air affects still more severely. One sees men, very sturdy elsewhere, consistently attacked at a certain elevation by nausea, vomiting, and even fainting, followed by an almost lethargic sleep. And all these symptoms cease although fatigue continues as soon as they have reached a denser air in the descent.

Fortunately for the progress of physics, M. Pictet is not so seriously affected by the thinness of the air; however, he is more affected than the average man, for although he is very strong, very nimble, and well trained in climbing mountains, he is always attacked by a sort of distress, a. slight nausea, and an absolute loathing of food, as soon as he reaches the elevation of 1400 fathoms above sea level. As for me, I feel no effect other than being obliged to rest very 
frequently, when I ascend steep slopes at these great heights. I tested this again in my last trip to Buet. While we were climbing the slope covered with soft snow which crowns the mountain, I absolutely had to stop every fifty steps, and M. Pictet, more sensitive than I to this effect of the rarity of the air, counted his steps without telling me, and found that he could not take more than forty without getting his breath. (P. 483-85.)

But that was nothing compared to what he was to observe in his trip to Mont Blanc. Already several attempts had been made to reach the summit of this colossal mountain. De Saussure recorded for us the account of these vain attempts, and it is clear that the physiological symptoms experienced by those who made these attempts had much to do with their failure:

$\$ 1103$. In 1775, four guides from Chamounix tried to reach the summit by the mountain of La Cote . . . Everything seemed to promise them perfect success; . . . . but the reflection of the sun upon the snow and the stagnation of the air in a great valley of snow which seemed to lead them directly to the crest of the mountain gave them a feeling of suffocating heat, as they said, and at the same time gave them such distaste for the provisions with which they were supplied, that, worn out with lack of food and weariness, they retraced their steps. (Vol. II, p. 550.)

$\$ 1104$. In 1783 , three other guides made the same attempt by the same route. They passed the night at the top of the mountain La Cote, crossed the glacier, and followed the same valley of snow. They were already fairly high and were advancing courageously, when one of them, the most daring and sturdy of the three, was seized almost suddenly by an absolutely unconquerable desire to sleep; he wanted the other two to leave him and go on without him; but they could not consent to abandon him and leave him sleeping on the snow, convinced that he would die of sunstroke; they gave up their attempt and returned to Chamounix. For this need of sleep, produced by the rarity of the air, ceased, as soon as he was in a denser atmosphere in the descent .... The heat gave them all great distress; they had no appetite; the wine and the food which they took with them had no attraction for them.

September 13, 1785, De Saussure himself attempted the ascent with M. Bourrit and his son. He slept at the hut (1422 fathoms) :

\$1112. M. Bourrit and his son even more than he were a little affected by the rarity of the air; they did not digest their dinner well, and could eat no supper. As for me, since the thin air inconveniences me only when I am exercising violently in it, I passed an excellent night there.

The next day, he mounted to an elevation of 1900 fathoms; the snow stopped him.

But the ascent of Mont Blanc had become a dominating idea in 
him. The next year, he commissioned Pierre Balmat to construct a hut at the foot of one of the crests of the needle of Gouté, so that he might rest there before trying next to mount to the summit of Mont Blanc:

\$1963. In executing this project, Pierre Balmat, Marie Coutet, and another guide, June 9, 1786, . . . reached the summit of the needle of Gouté, after having all of them been extremely ill from fatigue and the rarity of the air. (Vol. IV, p. 138.)

It was in consequence of this trip that Jacques Balmat, who had rejoined his compatriots and who passed the night on the mountain, found the route to Mont Blanc by the Corridor:

$\S 1965$. This route had already been tried but had been discarded because of a strange prejudice. As it follows a sort of valley between eminences, it was imagined that it was too warm and had too little air .... Fatigue and the rarity of the air caused in those who made the first attempts this prostration of which I have often spoken; they attributed this distress to the heat and the stagnation of the air, and tried to reach the crest only by uncovered and isolated ridges.

The people of Chamounix also believed that sleep at these great heights would be fatal; but the test which Jacques Balmat made by passing the night there dissipated this fear. (Vol. IV. p. 140.)

It seems as if the account given by De Saussure of the discovery of Jacques Balmat is not exactly correct. The illustrious physicist of Geneva seems to have been led astray by his favorite guides, who, jealous of Balmat, attributed to chance what was the fruit of long and persistent research. The interesting works of M. Ch. Durier have cast some light on this point. At any rate, June 10, 1786, Jacques Balmat, having found the true route, after several nights passed on the mountain, descended to Chamounix almost dying of fatigue and cold. Being attended by Dr. Paccard, he informed him of his discovery and proposed to share the glory of it with him by making the ascent with him. Paccard accepted, and on August 9, 1786, a human foot for the first time trod the summit of the highest mountain of Europe. Dr. Paccard had been exhausted by fatigue and no doubt also by the rarefaction of the air so that he stopped on the way and lay down; Balmat ascended alone, then returned to seek his companion, half carried him to the crest, and took him back down blinded by the snow.

Unfortunately I have not been able to get an authentic account of this memorable ascent. That of Alexandre Dumas (Impressions de voyage en Suisse, Chap. $\mathrm{X}$ ), much less inexact than one would expect, cannot, however, be trusted in physiological matters. But what has been said and written about this journey shows that the 
two companions, especially Dr. Paccard, suffered keenly from the rarefaction of the air.

At the news of the success, De Saussure, who had promised a prize to the person who should find the true way, though hoping to use it first himself, made haste to organize a new expedition. But judging that the season was too advanced, he had to put off until the following year the realization of a desire which had interested him deeply for so many years.

August 1, 1787, he left Chamounix, accompanied by a servant and eighteen guides. He slept under the tent on the summit of the mountain La Cote.

The evening of the second day of the ascent, he reached the little plateau; the barometer registered 17 inches 10 lines. They made preparations to pass the night (1995 fathoms): ${ }^{116}$

\$1962. There (says De Saussure) my guides first began to examine the place in which we were to pass the night; but they very quickly felt the effect of the rarity of the air. These sturdy men, for whom the seven or eight hours of walking which we had just done were absolutely nothing, had hardly lifted five or six shovelfuls of snow when they found it absolutely impossible to continue; they had to relieve each other constantly .... .

I myself, who am so accustomed to the air of the mountains, who feel better in this air than in that of the plain, was completely exhausted while examining my meteorological instruments. (Vol. IV, p. 144.)

The next day they continued to ascend, and reached "the cliff which forms the left shoulder of the crest of Mont Blanc":

\$1985. When I began this ascent, I was already quite out of breath from the rarity of the air .... The kind of fatigue which results from the rarity of the air is absolutely unconquerable; when it is at its height, the most terrible danger would not make you take a single step further. (P. 165.)

Soon they were no more than 150 fathoms in elevation from the summit of Mont Blanc:

\$1988. I therefore hoped to reach the crest in less than three quarters of an hour; but the rarity of the air gave me more trouble than I could have believed. At last I was obliged to stop for breath every fifteen or sixteen steps; I usually did so standing, leaning on my alpenstock, but about once out of every three times I had to sit down. This need of rest was absolutely unconquerable; if I tried to overcome it, my legs refused to move, I felt the beginning of a faint, and was seized by dizziness quite independent of the effect of light, because the double crape which covered my face protected my eyes perfectly. Since it was with keen regret that I saw thus passing the time which I hoped to devote to my experiments on the summit, 
I made different tests to shorten this rest; I tried, for example, not to continue to the end of my strength, and to stop an instant every four or five steps, but I gained nothing; I was obliged, after fifteen or sixteen steps, to take a rest as long as if I had made them consecutively; and this was very noteworthy, that the greatest distress is not felt until eight or ten seconds after one has stopped walking. The only thing that did me any good and increased my strength was the cold air of the wind from the north; when as I climbed I had my face turned in that direction, and swallowed great mouthfuls of the air coming from it, I could take twenty-five or twenty-six steps without stopping. (P. 171.)

At last the highest crest was reached:

\$1991. I now had to make the observations and experiments, which alone gave some value to this journey; and I was terribly afraid that I should be abie to do only a small part of what I had planned. For I had already found, even on the plateau where we had slept, that every observation made carefully tires one in this thin air, and that is because, without realizing it, one holds his breath; and since there one must compensate for the rarity of the air by the frequency of his breathing, this suspension caused definite distress; I was obliged to rest and to pant after observing any instrument as after making a steep ascent. (P. 175.)

\section{What De Saussure had foreseen happened:}

$\S 1965$. When I had to get to work to set out the instruments and observe them, I was constantly forced to interrupt my work and devote myself entirely to breathing ... .

When I remained perfectly quiet, I felt only slight distress, a little tendency to nausea.

But when I took pains, or when I fixed my attention for a few moments consecutively, and especially when I compressed my chest by stooping, I had to rest and pant for two or three minutes. My guides experienced similar sensations. They had no appetite. (P. 147.)

$\$ 2021$. Some could not endure all these kinds of sufferings, and descended first to reach a milder air. (P. 208.)

Farther on, De Saussure makes a very accurate statement, which explains many exaggerations and many doubts:

$\$ 2021$. I observed a rather curious fact, that for some individuals there are perfectly.marked limits, where for them the rarity of the air becomes absolutely unendurable. I have often taken with me peasants, elsewhere very robust, who at a certain height were suddenly so affected that they absolutely could not ascend higher; and neither rest, nor cordials, nor the keenest desire to reach the crest of the mountain could make them pass this limit. They were attacked, some by palpitations, others by vomiting, others by faints, others by a violent fever, and all these symptoms disappeared as soon as they breathed a denser air. I have seen persons, but only a few, whom these symptoms forced to stop at eight hundred fathoms above sea 
level; others at twelve hundred, several at fifteen and sixteen hundred; as for me, like most of the dwellers on the Alps, I do not begin to be noticeably affected until at nineteen hundred fathoms; but above this limit, the best trained men begin to suffer when they hurry a little. (P. 209.)

Finally they had to descend; from eleven o'clock to half-past three, De Saussure remained on the summit, and he was sorry to leave, because, he says, and I call the attention of the reader to this extremely important remark:

\$2021. Although I had not wasted a single moment, in these four hours and a half I could not make all the experiments which I had frequently finished in less than three hours at sea level . . . But I kept the well founded hope of finishing, on the col du Géant, what I had not done, and what probably no one will ever do, on Mont Blanc. (P. 210.)

The descent was accomplished successfully and without great fatigue:

As the movement one makes while descending does not compress the diaphragm, it does not hamper respiration, and one does not suffer from the rarity of the air.

The example of the illustrious physicist was soon followed. Seven days after his famous ascent, the English colonel Beaufoy ${ }^{117}$ in his turn reached the summit of the giant of the Alps. It was not without keen sufferings, as the following extracts from his account prove.

Leaving Chamounix August 8, 1787, he slept with his ten guides at the hut built in 1786 by the orders and at the expense of M. de Saussure. The first physiological phenomenon which the colonel mentions is thirst:

Our thirst, since we had reached the upper regions of the air, had become unendurable. Hardly had I drunk when my mouth was dry. Although I was drinking constantly, the quantity of my urine was very small; its color was very dark. The guides were similarly affected; they did not wish to taste wine ... .

The rarity of the air soon began to give me a violent headache; to my great surprise, I also felt a keen sensation of pain just above my knees....

When we were within .150 fathoms (270 meters) of the summit, the harmful effects of the rarity of the air was evident in all of us; an almost irresistible desire to sleep possessed us. My energy had left me; indifferent to everything, I thought only of lying down on the ground; at other times, I regretted this expedition, and when I was almost at the summit, I thought of descending, without doing it however. Many of my guides were in the most pitiful condition; exhausted 
by excessive vomiting, they seemed to have lost both strength of body and strength of mind. But shame came to our assistance. I drank the last pint of water and felt refreshed. Yet the pain of my knees had so increased, that every 20 or 30 steps I had to stop until its acuteness had diminished. My lungs did their duty with difficulty, and my heart throbbed with violent palpitations. Finally, however, but with a sort of apathy which barred joy, we reached the summit. Six of my guides and my servants immediately threw themselves down with their faces against the ground and went to sleep. I envied their repose.

The colonel suffered greatly from the reflection of the sun upon the snow; he had neither veil nor glasses.

Some weeks later, De Saussure, in his ascent of Mont Cenis, September 28, 1787, again made very interesting remarks from the physiological point of view:

\$1280. At our departure from the summit, where we had stayed for two hours, I counted by my watch with a second-hand the pulse rate of all those who composed our little caravan, and counted it again on our arrival at the post-house of Mont Cenis:

J. B. Borot, guide, above 112 , below 100

B. Boch, guide above 112 , below 96

J. Tour, guide above 80 , below 88

Tètu, my servant, above 104, below 100 My son above 108 , Myself above 112 , below 100 above $104 \frac{2}{3}$ below $98 \% \frac{1}{3}$

It will be noted that Joseph Tour was the only one whose pulse rate was higher at the foot of the mountain than at the top; that for my son, the number was the same, and that the other four had a more rapid rate on the summit, so that the average gives six beats per minute more above than below, with a difference of about 4 inches 2 lines in the height of the barometer. There is this also to be noted that after I counted the pulse rate on the mountain after a stay amounting to a rest of at least two hours for the guides; whereas on the plain, as they wished to leave, I had to count it a few minutes after our arrival.

What is still more remarkable is that when I separate those who were nauseated (three of the four guides, whose names De Saussure does not give, were nearly sick on the summit) from those who remained well, I find that the average difference was $9 \frac{1 / 3}{3}$ for the first, and only $2 \frac{2}{3}$ for the second. This observation confirms what I have always believed, namely, that this discomfort partly resembles a sort of fever, produced by the frequency of the breathing, which quickens the circulation of the blood. And as for me, if my pulse was a dozen beats more above than below, even though I felt no discomfort, that is because I did not rest a single moment; I was at work continually during these two hours; if I had rested like those 
who were ill, I am sure that my pulse rate would have dropped several beats. (Vol. III, p. 85.)

The following year, he went with his son to stay on the col du Géant (3360 meters) from July 3 to July 19, 1788; this trip, which filled the guides with terror, was undertaken with the purpose of attempting experiments which, on Mont Blanc, "the shortness of the time and the discomfort caused by the rarity of the air prevented me from carrying out." (Vol. IV, p. 217.) One whole very interesting chapter is devoted to Observations Relating to Physiology:

\$2105. It was interesting to note what effect upon our bodies would be caused by a prolonged stay in an air as rarified as that which we were breathing on the Col du Geant. It must be recalled that the average height of the barometer was, during our stay, about 19 inches, that is, 9 inches lower than at sea level, and that therefore the density of the air there was nearly one third less.

M. Odier, a doctor in medicine, very eager for the progress of his profession, had given me some questions which were to serve as text for my observations.

\$2106. To determine precisely the degree of animal heat. During the morning of July 17, at a moment when I was very calm, and without having made any violent movement, I placed under my tongue a small mercury thermometer keeping my mouth closed, and at the same time I observed this thermometer with a magnifying glass. It was at $291 / 2$, and registered the same degree under the same circumstances on the plain.

To count the number of inspirations and expirations which a man in repose and not forewarned makes in a minute, and also the relation of this number to that of the pulse rate. Under the same circumstances as those of the preceding paragraph, at first I found 75 heart beats for each inspiration and as many for each expiration. But another time, taking a larger number, which for that very reason deserves greater confidence, I found that I made 10 inspirations and expirations in 35 seconds, which amounts to 17 per minute, and that my pulse rate was also 79 per minute.

\$2107. To try to inspire deeply enough to stop the pulse in the left wrist, supposing that the same individual can do so on the plain.

July 19, when I arose, seated on my pallet, I succeeded in stopping the pulse of the left wrist, prolonging the inspiration for ten seconds; immediately I repeated the test, and the pulse stopped at the fifteenth second; the third time, at the thirty-fifth second the pulse was still resisting when I was forced to catch my breath. When I made the same test standing, I could not stop my pulse; but it is true that I could prolong the inspiration only for 32 seconds. Therefore this test appears, at least for me, not susceptible of regular comparison.

\$2108. To count the pulse in a perfectly vertical position; if the 
difference is greater than on the plain, it is a proof that the air of ' lofty mountains increases the irritability of the heart.

July 18 , in the afternoon, having taken a short nap on my pallet on the ground, in a horizontal position, my pulse rate in this same position was 83 per minute. I then arose, and while standing, my rate was 88 ; but suspecting that the effort which I had made in rising might have contributed to this acceleration, I rested a few instants, and then my pulse rate was only 82 .

\$2109. To determine by comparison whether the inspiration can be held as long on the mountain as on the plain.

In section 2104 I reported the attempts I had made on the mountain. I then forgot to repeat them on the plain on my return, and since then, my constitution has been so much affected by fatigues and illnesses, that the comparative tests I might make would give no result on which one could reason.

To determine, if it is possible comparatively, the proportion of the urine to the amount drunk. We lacked the necessary facilities to make comparisons.

$\$ 2110$. To verify particularly whether the effects of the rarified air appear suddenly or gradually.

It appeared to us that the general effects were almost the same during our whole stay. When we arrived, we were all more out of breath than we should have been after making an ascent equal to that on a less lofty mountain on the last day. On the following days, the discomfort was far from increasing; our companions, my son, and I thought that we were becoming accustomed to this air: however, when we gave attention to it, and especially when we made efforts for this purpose, we found that if one ran, if he remained in an uncomfortable attitude, and particularly in a position in which the chest was compressed, one was much more out of breath than on the plain, and in an increasing progression; so that, from moment to moment, it became more difficult, and at last even impossible to keep up these efforts.

\$2111. As our observations forced us to remain in the open air almost all day, I had advised my son and my servant always to keep a piece of crape over the face, as I did myself. My servant thought that he could do without it, but his whole face, and particularly his lips, swelled, which made him hideous, and which was accompanied by very painful cracking of the skin. That made my son think that perhaps the action of the sun produced a liberation of air which caused this swelling.

To see whether this air would appear outside, he had this same young man hold his hands in water in the sun; they were immediately covered with little bubbles; he wiped them, then when he put them back in the water, more bubbles appeared; he wiped them a second time, and dipped them for the third time; but then there were no more bubbles to be seen. We concluded from that, that the bubbles which we had seen at first were only air adhering to the surface of the skin.

2212. It seemed to us that in general our nerves were more irritable, that we were more subject to impatience, and even to 
impulses of anger; our tempers were noticeably worse; hunger appeared more disturbing and more imperious; but on the other hand our appetites were more easily satisfied and digestion seemed to take place more rapidly than on the plain. Moreover, it seemed to my son and me that in our work and our observations relating to physics, our minds were noticeably freer, more active and less easily tired, I will even say more inventive, than on the plain, and I hope our readers will find the proof of it in the report of our occupations during these seventeen days. (Vol. IV; p. 315-318.)

In his trip around Monte Rosa he also describes the distress felt by animals. On August 14, 1789, he was on the glacier of Mont Cervin (glacier Saint-Théodule) :

2220. The mules, which were sinking in the snow up to their girths, were unloaded; yet it was very hard for them to go on, they were panting, obliged to stop for breath, as soon as they had made a few steps. However the grade was not very steep, and the three or four hours of walking which they had had could not have tired them ... . but it was the rarity of the air which affected them; they experienced all that we had experienced when we ascended Mont Blanc . . . . The breathing of these poor animals was extremely painful, and at the very moments when they were stopping for breath, they panted with such distress that they uttered a kind of plaintive cry which I had never heard, even when they were very weary. It is true that I had never travelled with mules at so great an elevation .... . we were then 1,736 fathoms above sea level. (Vol. IV, p. 380.)

Canon Bourrit, whose vain attempts had preceded the expedition of De Saussure, made the ascent of Mont Blanc in 1788, accompanied by Woodley and Camper. I have not found any complete description of this trip. But we owe to him a few details of a somewhat later expedition, made August 11, 1802, by Forneret and Dortheren:

The rarity of the air (he says) ${ }^{118}$ added to the difficulty of walking; their chests felt lacerated, and they told me that nothing on earth would induce them to undertake such an attempt again. (P. 431.)

On July 14, 1809, the first ascent of Mont Blanc by a woman, Marie Paradis, a maid-servant at Chamounix. She was so exhausted at about the elevation of 4600 meters, that the guides who accompanied her were forced to hold her up and carry her to the crest.

From 1809 to 1816, only one ascent (Rodaz, 1812) about which we have no information.

A German officer, Count de Lusy, left Chamounix September 14, 1816, to ascend Mont Blanc; he had eight guides with him. From 
the German pamphlet of Hamel, from which I shall quote presently, since I was unable to secure the account of Lusy, ${ }_{119}^{19}$ I borrow the references to the serious symptoms which attacked them:

Near the summit, some of the travellers felt nausea and a strong desire to sleep; three bled from the nose and one from the mouth; that did not stop Count Lusy. (P. 36.)

August 4, 1818, Count Malazesky, a Pole, ${ }^{120}$ then van Rensselaer of New York on July 11, 1819, also undertook this difficult enterprise. The report of the latter, although quite detailed, ${ }^{121}$ contains no suggestion of any interesting physiological fact; his companions and he experienced only a great acceleration of respiration and pulse accompanied by loss of appetite.

Then, in 1820 , Dr. Hamel, ${ }^{122}$ court counselor of His Majesty the Emperor of all the Russias, made the ascent in the company of Colonel Anderson. His trip was interrupted near the summit by a terrible catastrophe, which took the lives of three guides, dragged down in an avalanche.

He first made on August 3 an unsuccessful attempt:

We started from Saint-Gervais and passed the night at PierreRonde, sheltered by a few rocks.

The next day at 11:30 we reached the summit of the Dome du Goùté ....

It was on this two hour march that for the first time I experienced the effect of the rarified air upon my strength. It was absolutely impossible for me to take more than forty steps without stopping about two minutes to get my breath; and when I reached the summit of the Dôme $(2,200$ fathoms), I felt so exhausted that I should have needed at least a half-hour's rest if I were to be able to go on to the crest of Mont Blanc. After I had made my calculations, I found that it would be absolutely impossible to go to the summit and come back down the needles of the Goite before night; I therefore decided to retrace my steps. (P. 306.)

August 16, he once more began the ascent, this time starting from Chamounix. The travellers, accompanied by twelve guides, passed the night at the Grands-Mulets. In spite of his guides, who were alarmed by the poor condition of the newly fallen snow, Hamel wished to go on the next day; at half-past eight in the morning, they were on the last large plateau:

No one was ill. And yet for some time we had been feeling the effect of the rarity of the air; my pulse rate was 128 per minute, and I was thirsty all the time. Our guides suggested that we should lunch here, for higher up, they said, no one has any appetite.... Each of us ate his half-chicken with pleasure. ${ }^{123} \ldots$.

We had reached the elevation of 2,300 fathoms . . . No one was 
talking, for at this height even talking fatigues one, and the air transmits the sound feebly. I was still the last, and I was taking about twelve consecutive steps; then, leaning on my alpenstock, I stopped to take fifteen inspirations. I found that in this way I could advance without becoming exhausted. Wearing green glasses and with a crape veil over my face, my eyes were fixed on my steps, which I was counting, when suddenly I felt the snow give way under my feet ....

The whole sheet of snow slid from under the travellers, and three of the guides disappeared forever in an immense crevasse.

After this fatal experience, no one had ventured upon this undertaking "dangerous as well as useless", when F. Clissold tried again successfully, on August 18, 1822. In his first rather brief account, ${ }^{124}$ he limits himself to saying that all the guides, except one, were "more or less affected by the rarity of the air".

The detailed account which he published later ${ }^{125}$ is much more explicit; it even contains very unusual theoretical ideas which we shall report in the proper place.

It is strange to have to state that this stranger who was making his first trip to the Alps endured the decreased pressure better than the guides, almost all of whom had already ascended to the summit of Mont Blanc:

We were not far from the Grands Mulets (he says) when the man who was fastened to my rope untied himself, being absolutely exhausted. I then had myself tied between two others; shortly afterwards, a second one stayed behind, and finally all, except Favret (one of the six guides) and myself, had to stop from weariness and a difficulty in breathing which they attributed to the rarity of the air; a little rest soon revived them. At two o'clock, we reached the Grand Plateau. Marie Coutet, who could hardly breathe (he had already ascended Mont Blanc five times) was surprised at my fine condition. (P. 146.)

They slept in a little excavation of the Rocher Rouge (4490 meters) and suffered greatly from the cold. The next day, at dawn, they set out for the summit:

Favret and I were the only ones who were comfortable, especially in breathing. As for the others, some were stretched out flat on the snow, others paused standing up, bent forward with their heads hanging, finding it easier to breathe in this position. For my part, I have felt much more fatigue in other trips and on much less lofty mountains than I felt in ascending Mont Blanc; it is true that I was walking more quickly then. My pulse rate did rise from 100 to 150 per minute, but my circulation always quickens to this degree when I climb a steep grade, so that all in all I experienced nothing particular or new to me. (P. 149.) 
The account of the trip of Dr. Clark and Captain Sherwill $1 \%$ contains very interesting details. They ascended Mont Blanc August 25, 1825; leaving Chamounix at seven o'clock in the morning, they reached the summit the next day at five minutes past three:

When they reached the Grand-Plateau, M. Clark was exhausted, Captain Sherwill was greatly nauseated and oppressed .... Simon, one of the guides, complained of headache ....

On the summit of Mont Blanc, M. Clark found breathing difficult, even when he refrained entirely from moving. He felt in his chest a sensation like that which precedes hemoptysia, a disease to which he was quite subject in his youth. However he did not spit blood on the summit of Mont Blanc. One of the guides who had accidentally received a blow on the nose lost a little blood, which seemed darker in color than usual. Both M. Clark and Captain Sherwill suffered from violent headache; their faces were pale and drawn. The captain spoke of a singular sensation which he had felt near the summit: it seemed to him as if his body had an extraordinary elasticity and lightness, as if his feet hardly touched the ground. The guides were, in general, very tired and complained of headache.

In 1827, July 24, another ascent by Hawes and Fellowes, ${ }^{127}$ accompanied by ten guides. The night was passed at the GrandsMulets $\left(-5^{\circ}\right)$.

During the ascent of the Dome du Gôté, they began to feel the effects of the great elevation, the headache increased as they advanced; the veins swelled, the pulse was strong and rapid ....

At a thousand feet from the summit, the travellers had nose-bleed, and nearly every one spat blood; these symptoms were extraordinarily severe in M. Felowes, who was very delicate; but M. Hawes, short, sturdy, and robust, resisted better. Their breathing was strangely affected; they could not take more than six or eight steps without stopping. Two guides, completely worn out, were sick and vomited much blood. Moreover, every one had the skin of his face cracked and lost blood within. The cold was intense ....

By resting, though for only a short time, the travellers reached the crest of Mont Blanc at 2:20. (P. 267.)

The same year, a Scotch traveller, Auldjo, made the same ascent on August 9. Not having been able to get the original account which he published, I am borrowing a summary of it from the work of M. Lepileur, whom I shall mention again soon:

M. Auldjo says that he did not begin to feel the effects of the rarefaction of the air until he had reached an elevation of about 4,200 meters; he was then attacked by oppression and difficulty in breathing. His pulse became frequent; he felt thirst and a fullness of the veins of his head, but no headache when he was quiet. Most of his guides suffered in the same way and to the same degree. As 
he mounted, he was more exhausted, the oppression increased, a violent headache appeared, as did strong 'palpitations, general lassitude, and a pain in the knee and the muscles of the thigh, which made movement of the legs difficult. About the elevation of 4,570 meters, he had a strong desire to sleep, and was completely exhausted, down-hearted, and discouraged; his guides had to force him to leave the rocks of the Petits-Mulets. The rest of the ascent was extremely painful for him; they had to hoist him by a rope along the last grade. As soon as he had begun to feel ill effects, neither he nor his guides, took more than fifteen or twenty consecutive steps. While climbing the last hundred meters, the most robust and daring guide, he says, was exhausted after three or four steps, and forced to stop to get his breath. He suffered much from the cold on the side where the sun did not strike. Finally, after climbing the last twenty meters with a little less discomfort, he reached the crest, where he fell deeply asleep immediately. He was awakened after a quarter of an hour; he was better, the headache and the pain in the legs had stopped, but he was shivering and thirsty; his pulse was frequent, his breathing difficult, although the oppression had lessened. He could not eat; the sight and the smell of food nauseated him .... (P. 20.)

Mountain excursions became numerous; it was not only Mont Blanc that the travellers, who had become "tourists", aimed at. A German Swiss, Meyer, ${ }^{128}$ who published the account of his excursions in 1812, gave his attention to physiological symptoms; he found that they had been greatly exaggerated:

All that De Saussure reports on the effects of the atmosphere in lofty elevations upon the animal organism has no general foundation; there are still a great many things which are hypothetical. For instance, at an absolute elevation of 10,000 to 12,000 feet and more above sea level, not one of us was drowsy or in a feverish state, or vomited or fainted, symptoms about which some travellers who reached very lofty summits have said a great deal ....

Who could deny that when one is climbing, the pulse rate becomes almost immediately twice as frequent as it was before? If one walks then at a slow pace long enough to recover, the pulse will quickly return to the same rate as on the plain or in the valleys.... I had the opportunity to note that the fainting of one of our guides near the summit of the Jungfrau had been brought on largely by the great efforts he made in ascending, and partly also by the fear inspired in him by the danger he was running. None of us felt anything of the sort when we were descending. (P. 30.)

Let us note the fainting of the guide, whatever the explanation given may be. Let us add that at lower elevations than those reached by Meyer, Dr. Parrot, a celebrated mountaineer, experienced a strange symptom which he attributes, it is true, to the heat, but in which the decrease of pressure seems to me to play 
an important part. He reports in the following words this symptom which happened to him September 18: ${ }^{129}$

I had been for two hours on the western edge of the glacier of Lesa, at the height of 3436 meters; the heat was such that my eyes began to grow red, and I felt a frontal headache with such drowsiness and fatigue that I had great trouble in observing my barometer suitably; I found no relief for this condition except in lying down on the ground. (P. 386.)

The first ascent of Monte Rosa took place August 5, 1819; it was made by two men who lived in the neighborhood, Vincent, superintendent of the mines of Indren, and Delapierre, inspector of forests, better known by the German translation of his name, Zumstein.

In the first journey, no physiological disturbance was mentioned. But the second, which is reported with details in the Mémoires de l'Académie de Turin (vol. XXV, p. 230-252; 1820), furnishes some interesting references. At first, in the night which the mountaineers passed at the foot of the last ridges in the hut of the Mineurs, which was occupied two months, "the highest in Europe" (1681 fathoms), Zumstein "felt a certain oppression in his chest which prevented him from closing his eyes all night. "Perhaps," he added prudently, "this excitement was caused only by the keen impatience for the morrow" (P. 237). When they were near the summit, as the daring travellers were crossing a dangerous ridge on steps cut in the ice, "the man who was second in line grew pale and tottering leaned towards the slope at the left (P. 241)"; rubbing him with snow restored him. On the summit, after a certain time for rest, the pulse rate of Vincent was 80 , that of Zumstein 101, that of one of the guides 104, and that of the sportsman who was sick 77, which naturally surprised Zumstein.

At last they reached the top of the Vincent pyramid (4210 meters) :

They had little appetite, but a burning thirst. Vincent had already felt discomfort while he was ascending, and Zumstein, as he stooped to pick up some silvery butterflies which were lying half dead on the snow, had an attack of dizziness, which fortunately soon disappeared. (Anal. de Briquet, p. 16.)

On July 31,1820 , they repeated their ascent, in the company of the engineer Molinatti, and passed the night almost at the very summit of the mountain, at an elevation of 13,128 feet:

In the middle of the night, Zumstein was awakened by palpitations which choked him; he got up to seek recovery and was soon better. 
The next morning, they continued to climb:

M. Molinatti, exhausted by the rarity of the air, was forced to stop constantly, whereas MM. Vincent seemed to have wings, eager as they were to reach the summit first; Zumstein, about fifty steps behind, followed them panting, but soon overtook them.

Thus they reached the summit of Zumstein's Point (4560 meters), and descended without trouble.

The other ascents of Zumstein, in 1821 and 1822, had no incidents which would interest us. ${ }^{130}$

We note, therefore, in this ascent, evident physiological disturbances, although less than those which the travellers to Mont Blanc had reported.

Much less still are those observed by Hugi, ${ }^{131}$ who goes so far as to deny even the acceleration of the pulse rate on lofty places, which seems rather strange.

The greatest elevation reached by this traveller and his companions was the Finsteraarhorn (4275 meters):

At these elevations I never failed (he says) to observe the pulse rate, the respiratory rate, and the temperature of the body. The results were constant; that is, in these respects heights and planes show the same results, when neither effort, nor fatigue, nor fear are involved. I am omitting the table of observations. Wahren alone, who is noted for his vigor all through the Oberland, felt a little nausea on the point of the Finsteraarhorn. While he was working at the Pyramid, he twice lost power of vision, so that he was forced to sit down. (P. 218.)

On the opposite side, Hipp. Cloquet ${ }^{132}$ states that the symptoms of decompression are often felt, even at the low elevation of the Grand Saint-Bernard:

The rarefaction of the air .... causes in the organs of respiration an alteration strange enough to be mentioned. Persons with a strong constitution and with lungs in perfect condition experience a certain pleasure in breathing an air as cool as it is pure and light; on the contrary, those who lack these advantages, and especially those who are asthmatic, experience a marked distress and an extreme difficulty in breathing, when they visit the monastery and its surroundings. At the Saint-Bernard travellers have been seen to be asphyxiated, so to speak, for want of air, and to fall in a faint, without any other known cause, and this happens often to weak and delicate persons. At the beginning of the syncope, the pulse rate is very high; but the greater the strength of the lungs, the less is this acceleration in the pulse rate.

It is also to the rarity of the air that we should perhaps attribute a strange phenomenon presented by the observation of wounds in this place. Their cicatrization requires double or even triple the time it 
would take on the plain for its entire completion .... The same thing has been observed on all high mountains. (P. 33.)

The accounts of travellers on Mont Blanc are always most characteristic in reference to mountain sickness. After Auldjo, an interval of seven years had elapsed, during which only one ascent (Wilbraham, August 3, 1830) had taken place. But September 17, 1834, Dr. Martin Barry ${ }^{133}$ made a scientific ascent the account of which is very interesting.

He mentioned physiological disturbances only above the Grand Plateau:

We had then reached an elevation at which I was to verify the statements of previous travellers about the exhaustion brought on by the slightest effort in a much rarefied atmosphere. I did not experence such discomforts before reaching this point, and I did not see any in my guides. I could take only a small number of steps at a time, and those were short and slow. Two or three deep inspirations were enough at each step to revive me; but when I started again, the exhaustion returned as before. I felt an indifference which was not overcome by the sight of the summit so close at hand. I even had a slight fainting fit, and was forced to sit down for a few minutes; but a little wine revived me....

After a few minutes rest at the summit, the weakness, exhaustion and indifference disappeared ..... (P. 112.)

The account of the ascent of Count de Tilly, which took place a fortnight after that of Barry, contains so many mistakes and confusions that we cannot give our time to it. But the following year, an Englishman, Atkins, ${ }^{134}$ reached the summit with two companions, Hedringen and Pedwel, without counting the guides, and observed interesting data.

His ascent took place August 23, 1837. He begins by making excuses as if for a foolish action. The first symptoms are not reported by him until on the Grand-Plateau:

I was forced (he says) to stop every ten steps to get my breath and rest my legs. I suffered from thirst and from deathly languor. From time to time I swallowed a mouthful of vinegar, to moderate the thirst which devoured my entrails, and I often had nosebleed.

Coutet was not free from distress and Jolliquet could not hold his head straight. Some of those who were ahead dragged themselves this way and that, others raised themselves, then fell down again. At the foot of the wall of La Cote lay a man stretched out at full length and motionless. I cannot say whether this was one of the guides, but he finally rejoined us....

At last, after a terrible ascent, after having been forced to stop every two minutes to breathe, we reached the summit . . . It was $7^{\circ}$ below zero (P. 36.) . . . . 
The little dog which accompanied us had to struggle against sleep as soon as we had passed the Grand-Plateau, and every time we stopped, it tried to lie down at our feet, finding the snow cold. It showed more than one sign of surprise, often casting wild eyes around it. Sometimes it made an effort to run very fast, and sometimes fell down exhausted. As for its appetite, the chicken bones we gave it disappeared with astonishing speed, but it did not appear to suffer from thirst ....

Hedringer, wishing to have the glory of being the first to set foot on the crest, began to run, but he had hardly taken a few steps, when from exhaustion he stretched himself out stiffly on the snow for two or three minutes, enduring cruel pains. He felt the consequences of his mistaken ardor as long as we remained on the summit (P. 56) . .

Our breathing became more and more free as we descended, and we felt so light that we hardly seemed to touch the ground (P. 59).

After that time, the ascents of Mont Blanc became more numerous. From that of Atkins to the celebrated expedition of Bravais, Lepileur and Martins, in 1844, there were 17; but I can hardly call any of them interesting except that of Mlle. d'Angeville (September 4,1838 ), who had to be almost carried to the summit.

Dr. Rey ${ }^{13}$ in the following words reports the symptoms felt by this daring woman:

I learned from Mlle. Dangeville that in her usual condition her pulse beats 58 to 60 times per minute, very soft and very regular. When she left Chamounix for the ascent, it was already 64 and increasing, emotion was beginning: at the Grands-Mulets, it was 70 and irregular, although she felt better, mentally and physically. On the grade which is above the Grand-Plateau, where she began to feel a little tired and sleepy, she counted 136 beats at unequal intervals, that is, much more than double the number in her ordinary condition. When she had reached a place called the Mur de la Cotte, near the last crest, she felt a sort of agony, caused by an excessive need for sleep, and she cannot tell how high this extraordinary acceleration rose during her severe attack, but five minutes after she reached the summit, the pulse of the noble and intrepid French woman had already dropped to 108 (p. 341).

Now let us consider the other mountains.

The celebrated naturalist Desor, ${ }^{136}$ in the report of numerous excursions with a prolonged stay in lofty places which he made in the company of the illustrious Agassiz, is surprised at feeling and observing no physiological disturbance; he is especially struck by it at the time of his ascent of the Jungfrau (4170 meters) in 1841:

I must confess that while we were on the summit, and also during the ascent, we experienced none of those symptoms, such as nausea, nosebleed, buzzing in the ears, acceleration of the pulse, and many 
other discomforts, to which most of those who have made the ascent of Mont Blanc say that they were prey. Should we attribute it to the difference of 500 meters between the height of Mont Blanc and that of the Jungfrau? Or should we seek the cause of it in the habit we had formed during several weeks of living at an elevation of more than 2,590 meters? But we should note that M. Duchatelier, who had been in the mountains only a few days, was not ill either. Without claiming to decide this question, which belongs more particularly to the realm of physiology, I am, however, inclined to think that there is a little exaggeration in all that has been told us on this subject. Perhaps also a few travellers have been deceived by their imaginations, like the students of medicine who every day think themselves attacked by the disease the symptoms of which the professor has just set forth to them. Some German physiologists, if I am not mistaken, even claim to have observed the most extraordinary symptoms on mountains only a few thousand feet high. (P. 409).

He refers again ${ }^{137}$ to this immunity in reference to his ascent of the Schreckhorn, or rather the Lauteraarhorn (4030 meters), August 8, 1842:

I should note that no one of us experienced the least discomfort either on the summit, or on the ascent, or on the descent, so that in this respect I can fully confirm what I said elsewhere about the socalled ill effects of lofty regions.

And yet to this absolute conclusion we can oppose the following fact from Desor's ${ }^{138}$ own accounts:

We had been travelling thus for a quarter of an hour when suddenly our friend Nicolet shouted to us that he could do no more. He experienced that complete fatigue by which one is attacked sometimes in the lofty Alps, but which passes very quickly if one rests a moment .... "I feel sure," he said, "that I shall never reach Zermatt alive" .... (P. 342.)

The travellers were only at the foot of Mont Cervin.

Gottlieb Studer ${ }^{139}$ ascended the Jungfrau August 13, 1842; he felt no discomfort either and gives a strange reason for it:

We perceived none of the symptoms which at such great heights travellers have often attributed to the rarefaction of the air; yet we must note that in such a long ascent, for three long hours, the chest can rest.... (P. 313).

On the opposite extreme, another tourist, Spitaler, ${ }^{140}$ who with several companions made unimportant ascents, certainly exaggerated the sufferings experienced. So, in regard to the "Venetian" on Pinzgau, a mountain of 3675 meters, he makes the following lamentable picture: 
We needed to breathe more frequently and all our muscles acted painfully; the heart beats and the pulse doubled or even tripled; the pulse was soft and weak, difficulty in breathing amounted to anguish, and stopped one of us a few hundred steps from the summit; another, returning, had a slight pulmonary hemorrhage; the secretion of the kidneys was strangely lessened .... no one was troubled by perspiration, but thirst was very great. The temperature was $+2^{\circ}$ to $+6^{\circ}$ $\mathrm{R}$...-On the plain we should not have been cold, but at an elevation of 9,000 feet a painful sensation of cold seized us; our skin was flabby, our faces aged; the strength of the muscles was greatly lessened, and out of forty, only twenty-six reached the summit.

The evidence of the celebrated English physicist, Principal Forbes, is much more valuable and much more exact. Forbes ${ }^{141}$ speaks of the symptoms of mountain sickness in reference to his expedition to the col du Géant (3360 meters), April 23, 1842, on which he noted that one of his guides was slightly affected:

We were about a thousand feet from the summit, when Couttet felt his respiration a little affected, but not severely. That is a very common symptom, which depends greatly on the state of the health. I hardly felt it from here to the summit. But in 1841 , I was definitely affected at a lower level, when ascending the Jungfrau. The guides say that these variations depend upon the state of the air; and David Couttet assured me that on different days, he and his father had at the same time felt difficulty in breathing at a very moderate height. (P. 224).

After all these travellers, naturalists or mere tourists, who spoke only incidentally of physiological symptoms, we come to a scientific expedition which has justly remained famous, the first on Mont Blanc since De Saussure, one of the members of which, Dr. Lepileur, was especially charged to observe himself and his companions from the physiological point of view. And so the report ${ }^{142}$ which he makes of this ascent deserves to be analyzed here at considerable length.

But before beginning the report itself, M. Lepileur, who was a frequenter of mountains, says that in his excursions previous to the ascent of Mont Blanc, he experienced or observed a certain number of interesting phenomena, particularly because of the moderate heights at.which they appeared:

While I was going from Martigny to the Grand Saint-Bernard, in September 1832, I saw my brother and two of my friends display most of the symptoms of mountain sickness; one of them, a young man twenty-six years old, was seized by general discomfort, fatigue, breathlessness, and palpitations, one hour before reaching the monastery, and soon he could not walk without being supported and without making frequent halts at equal intervals. When he reached the 
monastery, he went to bed, without being able to take anything but a little tea; he suffered all night from a discomfort which he compared to that of fever; the next morning he still felt oppression, and hastened to descend to Martigny. Of the two others, one was thirty years old, and my brother seventeen: they had very little discomfort during the last half-hour of the ascent; but although they were not very tired when they arrived, they had not the slightest appetite, and even the sight and the smell of food disgusted them. During the night they recovered completely; on the next day, they were able to ascend to one of the crests to the south of the monastery, and to go back down to Martigny on foot. The fatigue of this day's efforts also took away their appetite that evening, as it did that of another of our companions, who had felt no effects at the Saint-Bernard; but then it was only fatigue, there was no trace of the discomfort which they had felt the night before.

In the month of June, 1835, while I was climbing the slope of snow which extends below Château Pictet on Buet, at a height of about 3,000 meters, I felt my strength fail, it was very hard for me to go on. One of my friends who accompanied me had already been suffering for nearly a half-hour from fatigue in the legs and knees. $\mathrm{He}$ made frequent halts. As for me, I could not take more than 160 consecutive steps.

A little chocolate which I ate restored me almost completely; however I was still obliged to stop from time to time, although I was much less exhausted. From Chàteau Pictet to the crest of Buet the slope is very gentle, and I felt no lassitude while mounting it.

In the month of July of the same year, I was climbing with a guide on the point of rock which towers above the Saint-Théodule pass on the north; about sixty meters below the crest, I perceived that the guide stopped frequently; soon it was impossible for him to take more than eight to ten steps without stopping for breath. He was a robust man and in the prime of life, so that I could not believe that the weight of my sack which he was carrying was enough to weary him to this extent; seeing him pant, turn pale, and nearly fall in a faint, I told him to take a little rest; he would not admit his distress at first, but finally was compelled to sit down, a cold sweat ran down his face, he was exhausted. I had him eat a little bread and chocolate, which, with a ten minute rest, quite restored him. The elevation at which we were was hardly one hundred and fifty meters above the Saint-Théodule pass, that is, 3,560 meters, but I had noted when we left Zermatt about midnight that the guide was drunk, and that is what had made him so susceptible to the rarefaction oi the air.

Two days after, while climbing the Breithorn, at the east-southeast of the Saint-Théodule pass, one of my guides found it impossible to climb higher than the last plateau (about 3,900 meters); this man was sixty years old and was afflicted by a double inguinal hernia. Another guide of the same age panted greatly while climbing the terminal cone of the Breithorn (4,100 meters), the grade of which is very steep. The other two guides, men of thirty to thirty-five years, felt no more distress than I. The next year, making the same excur- 
sion with one of my friends, I was suddenly seized by unconquerable sleepiness as I was crossing the vast plateau south of the Breithorn, where a guide had had to stop the year before. I was sleeping as I walked, no matter what efforts I made to stay awake; one of the two guides had the same experience, the other and my travelling companion felt nothing of the sort. As we returned to the Saint-Théodule pass (3,410 meters), after a light meal taken with good appetite, we all slept in the sunshine for about an hour. When he awoke, my travelling companion was nauseated and vomited what he had eaten an hour before. I must note that the second night before, we had slept little and badly, and that after a walk of eight hours, we had had only three quarters of an hour of sleep on the night before our excursion. Several times, in Paris, I have found myself thus overpowered by sleep so that I slept and even dreamed while I was walking. Moreover, none of us felt any other discomfort during this excursion.

In July, 1844, while climbing the slope of the Couvercle, at an elevation of about 2,500 meters, I felt a distress and a difficulty in climbing like that I had experienced in 1835 on Buet. This condition lasted about twenty minutes. I was not forced to stop, but I suffered, and my strength seemed much lessened; at last, without any perceptible cause, for I continued to ascend, the discomfort suddenly ceased, I could climb without trouble the height of about 150 meters, which separated the point where I was from the Jardin. When I reached the Jardin, I ate with considerable satisfaction; but I was soon satisfied. Dr. Noel de Mussy, one of my companions on this walk, who was in the mountains for the first time, was only a little out of breath; at the Jardin, he ate with a good appetite. And yet, in the evening, while we were returning, he was much more tired than I. Another traveller who accompanied us felt no distress.

Finally, in the month of September, M. Camille Bravais, who ascended with me to the rock of the Echelle, when we had reached an elevation of about 2,300 meters, had to stop every twenty steps to get his breath. It is true that M. C. Bravais, affected no doubt by a slight hypertrophy of the heart, was never able to climb a steep grade without experiencing severe palpitations. (P. 33 et seq. of the separate printing.)

Now let us turn to the ascents of Mont Blanc. In the first attempt with MM. Bravais and Martins, July 30, 1844, they experienced some effects on the Grand-Plateau (3911 meters), where they set up their tents for the night, and beyond which they could not go: distaste for food, diarrhea, prostration. M. Lepileur was seized by violent shivering, recurring eight or ten times an hour; M. Martins had a similar attack. They had helped their guides in setting up their tent, and had become much fatigued.

August 7, all three set out again, and camped at the GrandPlateau: the shivering attacked M. Lepileur there again; M. Martins was quite ill, Bravais felt nothing but an irresistible desire 
to sleep at the Grandes-Montées (3800 meters). The face of one of the guides was cyanosed, which M. Lepileur attributes to the cold. On the descent, M. Martins had a slight hematuria.

August 28, third journey; departure from Chamounix at midnight:

The ascent went very well up to about 3,100 meters. There, Tournier felt ill, lost courage entirely and was forced to descend. He was pale, his face was bathed with sweat, and he could hardly climb even a few steps, although his burden had been taken from him and although we were on a rather gentle slope. He attributed this failure of his strength to the fact that the day before, not expecting to make the ascent, he had worn himself out at a painful task. His distress ceased as soon as he was two or three hundred meters lower.

At 3,600 meters, I felt no ill effects as long as I walked slowly; but when I wanted to ascend quickly, as for example, to rejoin my travelling companions, after having paused a moment, I felt discomfort. M. Bravais suffered much from cold feet for several hours. Several times he had been obliged to stop, and we had reestablished circulation in him by slapping the dorsal side of his toes with our hands ....

At the Petit-Plateau, I ate, at first with repugnance, then with pleasure, when a little food had stimulated the stomach. We all took a little wine; that was always what helped us most . . . .

M. Bravais again, this time like the two others, became very sleepy about the elevation of the Petit-Plateau (3,800 meters).

When we reached the Grand-Plateau, he was a little tired and so was I. M. Martins was not. Cachat and Ambroise Couttet were exhausted. As soon as they had halted, they lay down on the snow in the sunshine, and remained there for three or four hours, without being able to help us at all. Ambroise Couttet felt nausea besides all afternoon. As soon as he tried to stand up, he was threatened with syncope. The others helped us set up the observation instruments and clear our tent which the snow had three quarters buried on the north-east side. This labor did not tire us at all, and we were no more out of breath than the first time at Chamounix, when we had set up the tent ourselves for practice and to show the guides how it ought to be done.

None of us had as much appetite as in the valley. M. Bravais had very little; M. Martins and I had none at all. However, I felt no distaste for the fresh food which we had brought. Three hours after our arrival, when I took off my crape mask which hindered me in making my observations, I felt the beginning of a headache which stopped as soon as I put my mask back on. When I gave careful attention to the observation of some instrument, when, for example, I read a thermometer placed on the snow, and in general whenever I was in a position in which respiration was hampered, I felt a slight sensation of nausea which lasted hardly one or two seconds; the instant before and the instant after, I had no discomfort at all. MM. Martins and Bravais noticed the same effect in themselves. With that 
exception, we were very well, gay, and full of confidence. We noted this slight discomfort only to be rigorously exact.

A. Simon almost fainted while I was feeling his pulse. He was standing, and just had time to lie down on the snow to avoid a complete loss of consciousness. After our arrival, he had been busy clearing the tent and setting out our camping equipment without feeling any discomfort; however, this time he was not quite as well as the others. After some time he recovered and even ate with appetite. In the evening, everyone was well; our two invalids had recovered from their fatigue; I slept at night, although very uncomfortable because I could not stretch out my legs. I also felt some rheumatic pains in my right knee, toward the inner edge of the kneecap, and a little neuralgia on the outer side of the left thigh. M. Bravais made observations until midnight. August 29, at four o'clock in the morning, I made the first observation. I was rested and felt quite strong, but I had no appetite; the only food I cared to eat was a few raisins; the provisions, which had been thoroughly frozen for a month, and especially the meat, filled me with disgust. About six o'clock, M. Bravais and I took a little bread and wine. The first hours of the morning were passed in making observations and a few experiments, during which we were standing, coming and going on the soft snow. At ten minutes past ten, we started for the summit.

The crossing of the Grand-Plateau was painful because of the snow into which we sank up to the calf. I did not feel as strong as in the morning, but I felt no distress. I perspired abundantly while crossing the Grand-Plateau and during the first half-hour of the ascent. Our hands and feet were very cold, those of $M$. Bravais particularly. M. Martins lost his breath a little more and a little more quickly than we did. Up to the foot of the upper Rochers Rouges, about 4,400 meters, I had no discomfort of any sort; we took 350 or 400 steps consecutively without stopping for breath; but when we reached this number, we felt the need of resting for a few moments. The grade which we were climbing, measured with a geologist's compass, was, at the elevation of 4,300 meters, $42^{\circ}$, and the slope of our course was $16^{\circ}$.

About 4,400 meters, I began to feel after ten or twelve steps a little fatigue with pain like that of lumbago in the legs and knees. I counted my steps again, we were still taking one hundred between halts; but the last twenty were very painful to me. This pain in the legs stopped as soon as I halted, and the first steps I took after that were very easy. I began to be very anxious that the grade should become easier. A quarter of an hour before we reached the top of the upper Rochers Rouges it did become less steep. About this height (4,500 meters) I perspired a little, but it lasted only a few moments. After a short pause, we continued the ascent; a little before the top of the upper Rochers Rouges, I had begun to feel an undefinable discomfort when I was walking; I had neither headache nor palpitations, once or twice I felt a few throbs in the carotids, no doubt because I had made a few steps more quickly than the others. I was not nauseated either, but I felt a general discomfort, a sort of exhaustion. I was weak and it seemed to me that I had just enough strength 
to carry out the motions of locomotion for a certain time and then it would be all over; in a word, I was like a man who, at the end of a long day of walking, perfectly exhausted, feels that he can reach a point not very far away, but that he must give up going any further. I could walk only with my head lowered and my chin nearly touching the sternum. This was the attitude of us all, and when we were getting our breath, it was also with the neck stretched out and the body leaning forward during the first seconds. Clissold had observed the same thing. I felt a slight desire to sleep several times and yawned occasionally. What added greatly to the discomfort was a rather keen thirst or rather a dryness and a sticky condition of the mouth; a little snow melted on the tongue while I chewed a raisin quenched the thirst for a few moments. This uncomfortable condition developed gradually, and it was quite endurable when at about 4,560 meters a violent wind from the northwest struck us. At once we felt as if our hands, our faces, and the part of our heads which the head covering did not protect were freezing. The side of the body which the wind blew upon was also very cold, especially in MM. Bravais and Martins, whose clothing was rather thin. As we were climbing in a zigzag, when we had the wind in our faces during a squall, I experienced then in the highest degree the sensation which I described in connection with our first ascent to the Grand-Plateau. It was in vain that I covered my nose and my mouth with my hand, stooped, turned aside my head; I could not breathe any more than if I had been under water. I felt the distress of asphyxia, my head whirled, and I felt slightly nauseated. When I turned my back to the squall, it seemed as if the wind made a vacuum around me, and I had difficulty in breathing. I was the only one to feel this effect of the wind, both on the first and on the third trip. This increase of discomfort lasted without stopping for a quarter of an hour or twenty minutes, I asked myself whether I could reach the summit, I felt sure that I should succeed; but I had to use all the mental strength I possessed to actuate my physical powers. Sometimes too I advanced mechanically, without thinking, so to speak. No one talked, everyone, like me, had but one thought, that of advancing a few steps more. So the distance one iraverses between the Rochers Rouges and the summit, although it took us nearly two hours to cover it, did not leave many details in my memory, and returns to me as a vague recollection, rather painful and very short, no doubt because of its uniformity. The same thing was true for MM. Bravais and Martins, for we were all three surprised when we had to admit from our notes that it took us nearly two hours to go from the Rochers Rouges to the summit. We remembered only two or three incidents of this ascent, which, although painful, was however made without interruption and without the excessive fatigue and exhaustion experienced by some travellers. It is, I think, to the blank left in the memory by this part of the ascent to Mont Blanc that we should attribute the mistakes and the confusions so frequent in the accounts of travellers when they speak of this passage.

When we halted, after two or three seconds I was in perfect condition; I felt no discomfort except a slight thirst and cold feet and hands. We did not find, as De Saussure observed in himself, that 
the distress caused by walking reached its highest point after the first eight or ten seconds of the halt.

During the last quarter hour of the ascent, the slope was gentler and the wind blew less violently. These two causes, added to the joy I felt when I saw the summit only a short distance away, lessened my distress greatly. M. Bravais suffered only from the cold. We had already realized that of the three of us it was he who felt the effects of the rarified air least. M. Martins was the one who suffered most from it. He was very much out of breath, had palpitations, throbbing in the carotids, and a little headache; he felt a general fatigue, and took fewer steps than we did. When he reached the summit, he thought he was still a half hour away from it, and felt keen joy when he found he was there. None of us felt pain or fatigue or anything extraordinary in the coxofemoral articulation while we were walsing; in general, we felt no fatigue in the muscles of the thigh. MM. Bravais and Martins had a little in the right anterior muscle only.

Between the Rochers Rouges (4,500 meters) and the PetitsMulets (4,660 meters), we first took eighty steps without stopping for breath, then this number was lessened to seventy, and finally to thirty-five or forty steps between the Petits-Mulets and the summit. However, as we came near the highest point, since the grade was very moderate, we made one or two stretches longer than the others. At about forty meters from the summit, M. Bravais wanted to see how many steps he could take climbing as quickly as possible and in the direction of the great slope. He had to stop after thirty-two steps; he felt, he said, that when he stopped, he could have taken two or three more, perhaps four, but that it would have been quite impossible for him to go beyond that.

During the ascent, none of the guides or porters seemed affected; two of them were a little more fatigued than the others; they were Frasserand, who the day before had been rather fatigued when we reached the Grand-Plateau, and A. Couttet, who had been ill there all afternoon. Our two guides and the porter Simon seemed able to take more steps than we were. Several times they stopped only because they were asked to. M. Bravais and I reached the summit at the same time; M. Martins joined us there a few minutes afterwards..

For eight or ten minutes I had keen pain in my feet, caused by the change from intense cold to warmth. I was also rather drowsy shortly after we arrived and when the pain in my feet had stopped. I lay down on the snow where I remained five minutes, but without being able to sleep. Then I got up, the desire for sleep disappeared, and during the whole time we spent on the summit I felt absolutely no painful sensation, except a little cold the last hour. I had no appetite, although the idea of eating caused me no disgust. M. Bravais was also very well; only from time to time he felt the slight nausea which M. Martins and I had observed in ourselves the day before on the Grand-Plateau. He had an appetite and ate some biscuits and a few prunes. Shortly after our arrival at the summit, he and I each drank about a third of a glass of brandy. This liquor seemed to us delicious and very mild, to our great surprise; it did us much good, and gave us strength without causing the excitation 
usually produced by alcohol. We also drank a little wine, during the first two hours of our stay on the summit. A moment after he reached the crest, M. Martins was attacked by nausea, and vomited some seeds of raisins which he had eaten an hour before. Vomiting relieved him. He compared his illness to seasickness. When he lay down, he had no trouble, but moving about and standing brought back the nausea. An hour afterwards, he was better; after two hours, the sickness was completely gone. He drank a little wine, but did not wish to eat. The six men we had with us ate hardly anything, but they drank about two bottles of wine and half a bottle of brandy. All were in perfect health; only two were evidently fatigued, although they would not admit it ....

We could walk without any difficulty on an almost horizontal plane; but as soon as we had to climb, we were affected by panting and general lassitude....

There was a white coating on the tongues of all of us, but less in the guides than in us, and their appetites were not, like ours, completely or almost completely wanting. (P. 44-54.)

After a few hours of observations, they descended to the GrandPlateau; M. Martins was attacked by panting, palpitations, and throbbing in the carotids, so that he had to sit down. During the night, M. Lepileur felt violent sciatic neuralgia on the left side. His appetite did not return until the next day when he reached the altitude of 3000 meters while returning to Chamounix; during the whole day, he had eaten only a small piece of bread dipped in a little wine. He sent fresh provisions to Martins and Bravais, who had remained on the Grand-Plateau; they received them with great pleasure and made a good meal; however, what five of them ate would hardly have equalled the ration of one man in the valley.

The urine of all of them was scanty and dark.

The work of M. Lepileur is finished by a series of tables indicating the pulse rate of himself, Martins, and three guides from Servoz or Chamounix to the summit of Mont Blanc. He summarizes it as follows:

The increase of the pulse rate is a constant result, when one is ascending, beginning with a certain elevation, .... which may vary with the individual . . . My pulse was less frequent at Chamounix (60) than at Paris $(67.25) ; \ldots$ the contrary was true of M. Martins .... The ratio of frequency between Chamounix and the summit is: for M. Martins 0.82 ; for me 0.68 ; for Muguier 0.67 ; for Couttet 0.60 ; for Simond 0.61. (P. 77-80.)

M. Martins ${ }^{143}$ much later narrated the same journey; his recollections agree with those of M. Lepileur:

On the Grand-Plateau the guides began to clear snow off the tent. 
This work was painful; each of them had hardly removed a few shovelfuls when he stopped to breathe; a hidden distress was revealed on every face; appetites were gone. Auguste Simon, the tallest, the strongest, the most daring of the guides, collapsed upon the snow, and almost fainted while Dr. Lepileur was feeling his pulse; it was the effect of the rarefaction of the air added to fatigue and insomnia, from which all of us suffered more or less. We were then about 4000 meters above sea level, and there are few men who are not inconvenienced at 3000 meters. I am not surprised that in this ascent we felt the effects of the rarefaction of the air, which we had hardly noticed in the two previous ascents. Never had we mounted so quickly from Chamounix to the Grand-Plateau; starting from 1040 meters above sea level, after ten and a half hours of walking we were at an elevation of 3930 meters; that is a difference in level of 2890 meters, traversed in less than a half day. All discomfort disappeared when we ceased moving. (P. 25 of the separate printing.)

The next day, they finished the ascent:

The rarefaction of the air .... compelled us to walk slowly; every twenty steps we stopped breathless ....

We were reaching the goal, but we were walking slowly, our heads lowered, our chests heaving, like a procession of invalids. The effect of the rarefaction of the air was felt painfully: the column paused constantly. Bravais wishes to find out how long he could continue climbing as quickly as possible; he stopped at the thirtysecond step without being able to take one more. At last at a quarter of two we reached the long desired summit. (P. 27.)

The account of the ascent of July 19, 1859, made by MM. Chomel $^{144}$ and Crozet, has also given us interesting observations; they followed a route different from the usual one, from the beaten path, we may say, so frequent have journeys to Mont Blanc become:

There comes at last the cap of Mont Blanc, which, in spite of its slight elevation above the Mer de Glace, nevertheless requires two more tedious hours of ascent. During this last stretch, the lack of air makes every movement of the body painful, and one must make superhuman efforts to resist palpitations, sleep, and fainting ....

Only a few feet now separate us from this long-desired summit. Our self-respect spurs us on, and rising from the snow on which we were stretched, we cover the rest of the way at a run ....

And here we are on the summit of the giant of the Alps. The first impression .... was, alas! a dizziness and contractions of the stomach which made us reel.

The celebrated English physicist Tyndall ${ }^{145}$ is one of the most ardent mountaineers in the Alps. Every year sees him planting his alpenstock on some new summit. And it is not only with a scientific purpose that he runs thus the greatest dangers; it is not 
only the great spectacles of nature which attract him and thrill him; he too seems gripped by this passion for climbing for the sake of climbing, which, though it had its origin in England, is making progress today in our own country. But his evidence has all the more value for these different reasons.

August 12, 1857, Tyndall made his first ascent of Mont Blanc, in the company of MM. Hirst and Huxley. The latter had to stop at the Grands-Mulets.

When he reached the Derniers Rochers, Tyndall felt exhausted. The guide Simond cried at every halt: "Oh, how my knees hurt!"

I lay down upon a bed composed of granite and snow, and went to sleep immediately.

But my companion soon awakened me: "You frightened me," he said, "I have been listening for several minutes, and I have not heard you breathe once."

We got up then, it was half past two .... To the feeling of fatigue we had felt till then was added a new phenomenon, palpitations. We were constantly subject to them, and sometimes they became so severe as to cause some apprehension. I counted the number of steps that I could take without stopping and found it to be fifteen or twenty. At each halt my heart beat hard enough to be heard as I was leaning on my alpenstock, and its subsiding was the signal for a new advance. My breath was short, but easy and unhampered. I tried to find out whether the articulation of the thigh was relaxed because of the decreased pressure, but I could not be sure ... .

After we had passed the Derniers Rochers, we struggled on with the stoical indifference of men who are carrying out a duty without bothering about the results. At last a ray of hope began to brighten our spirits; the summit was visible, Simond showed more energy . . . . at half past three I clasped hands over the summit. (P. 80.)

The account of the second ascent, made September 12, 1858, merely alludes briefly to the fatigues of the mountains. (p. 189.)

In 1859, an ascent still more important and very profitable for science. Tyndall, Frankland, and nine guides passed a night on the summit of Mont Blanc; they stayed there about twenty hours: ${ }^{146}$

We did not suffer from the cold, although we had no fire and the snow was at a temperature of $-15^{\circ} \mathrm{C}$. But we were all ill. I was sick when I left Chamounix . . . I I had frequently conquered my discomfort on previous occasions, and I hoped for the same thing this time. But I was absolutely disappointed; my illness was more deeply rooted than usual, and it grew worse during the whole ascent. But the next morning I was stronger, whereas the opposite was true for several of my companions. (P. 54.)

The same year, a German, Dr. Pitschner, ${ }^{147}$ made a remarkable ascent of this same mountain; he was very seriously affected: 
At six o'clock in the morning, we were in the Corridor $(3,990$ meters); the thermometer marked $-8^{\circ} \mathrm{C}$. We had hardly been there five minutes when a strong desire to sleep seized us, and conquered me completely. My respiration was very painful; my eyes blinked, I had buzzings in my ears, headache, nausea; soon I vomited repeatedly; Balmat was as much affected as I, and his desire to sleep was so great that he lay down on the snow, and I immediately let myself fall beside him.

"I cannot go any further without sleeping a half-hour", I said to Balmat .... I fell into a lethargic sleep, interrupted by smothering spells, which finally seemed dangerous to Balmat; and so he began to stir me and shake me, without being able to awaken me. Fifteen minutes passed. His shouts awoke me, and he said to me: "You cannot stay here any longer, you must go on". Perspiration covered my face; I rubbed my face with snow, and after a score of deep breaths, I felt better....

From my sensations on the glacier, it is evident that the effect of mountain air was evidenced in me very definitely; it produces dangerous congestions....

On our return, at three o'clock in the afternoon, the same symptoms appeared in the same place, but with much less intensity: headache, nausea, vomiting.

The expedition of Dr. Piachaud, ${ }^{148}$ July 26, 1864, gave results just as interesting. The author gave heed to the physiological phenomena experienced by his companions and himself, and "attributed to the rarity of the air":

The chief symptom (he says) is the oppression, which hardly exists when one is resting, but which appears as soon as one starts walking, then stops again when one halts. From it there results the necessity of increasing the number of inspirations, and thence such a fatigue that one is forced to halt every twenty or twenty-five steps. This fatigue, moreover, is not like that one feels as the result of a long walk; it is not the legs which are chiefly affected; it takes possession of the whole system; there is a sort of general depression both mental and physical. I should add that this peculiar condition is observed only during the ascent, for once I had reached the summit and during the descent, I felt nothing of the sort. Another noteworthy effect of the rarity of the air is sleepiness, which I could hardly resist; I felt that if I had stretched out on the snow, or if I had been alone, I should have gone to sleep immediately. I do not think that this drowsiness can be attributed to the cold, for on the summit, where the cold was very keen, I was wide awake.

I also experienced very slight vertigo, but I mention it only to omit nothing. As for nausea, vomiting, fainting, hemorrhages, none of us was affected by any of them; our guides, of whom I asked information on these different points, told me that they had never observed hemorrhages. As to oppression, which is the symptom most frequently observed, I should say that it is far from being absolute, for of the six of us, I am the only one who felt it very definitely; the guides 
did not complain of it and M. Loppé could run when he got near the summit. (P. 86.)

Examination of the pulse rate gave the following results:

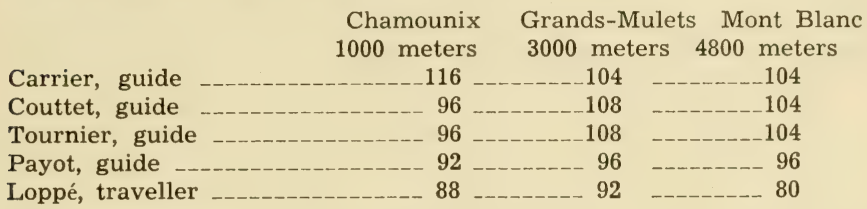

I now come to the two ascents of Mont Blanc which were noteworthy from the standpoint that interests us because for the first time the whole combination of physiological phenomena was studied with the precision instruments used in laboratories. Disturbances of circulation and respiration were thus determined in the conditions which the present exactness of physiological research demands. Besides, these observations serve as a basis for an entirely new theory of mountain sickness, which will be discussed in its proper place.

M. Lortet ${ }^{149}$ begins with a rapid historical survey of the symptoms felt by the most celebrated travellers. Then, before beginning the account of his journey, he lets escape the precious confession of an incredulity of which I have often heard Alpine travellers boast, even those who had made the most difficult ascents:

However, in spite of so many data and proofs reported by these distinguished men worthy of credence, I had been a little incredulous and I could not help believing that imagination played a great part in the production of these phenomena. On the main range of Monte Rosa I had often ascended heights of more than 4300 meters without any difficulty and without the least discomfort, and I could not believe that 500 meters more were enough to affect an organism which had stood the test very well up to this altitude. Now I am forced to admit it, I have been convinced de visu, and even a little at my expense, of the very real existence of symptoms which, above this altitude, attack anyone who breathes and particularly anyone who moves in this rarified air. (P. 11.)

He then comes to the account of his first ascent with Dr. Marcet, August 16, 1869. I copy the important points of his description, which is remarkable for its exactness and moderation:

Up to the Grands-Mulets (3050 meters), where we arrived at 3 o'clock to pass the night, we were well; no one felt the least discomfort; we all had excellent appetites; but already our instruments announced serious disturbance of circulation, respiration, and especially calorification. (heat production) 
The night at the Grands-Mulets was horrible . . . At half-past two we set out.

\section{At daybreak they reached the Grand-Plateau (3932 meters) :}

We stopped a moment to breathe... . The guides took a little nourishment; but it was completely impossible for me to swallow a single mouthful, although I still felt quite well.

We climbed very slowly; we all felt an inclination to sleep which was very difficult to struggle against and an intense occipital headache, thirst and dryness of the throat, only a few palpitations, but a wretched pulse which varied between 160 to 172 per minute.

When we reached the ridge, we were all tired, and it seemed to me that it would be completely impossible for me to go further. None of us vomited, but almost all of us were nauseated. Like those who are attacked by seasickness, I was completely indifferent about myself and the others, and I wanted only one thing, to remain motionless. The Englishmen who were following us seemed even more affected than we were; one of them was obliged to stop and soon retraced his steps.

\section{At last they reached the summit of Mont Blanc:}

I no longer felt any kind of illness, but the breathlessness was extreme as soon as I wished to take a few steps rapidly. The least movement caused me disagreeable palpitations. One of my companions, who had felt no ill effect until then, was attacked suddenly, as soon as he had reached the summit, by dizziness and almost constant vomiting which did not cease until he reached the Grand-Plateau on the way down. His stomach was empty, so that he vomited only glairy and bilious matter with very painful efforts. Nothing succeeded in stopping this stomach trouble; only one thing seemed to relieve his condition at all, that was small fragments of pure ice which he managed to swallow from time to time. His pulse was very uneven, very wretched, and the thermometer placed under his tongue hardly went above $+32^{\circ}$ !

The sun was warm, the atmosphere fairly calm, so it was with surprise that $I$ observed that the temperature of the air was $-9^{\circ}$.

We remained at the summit nearly two hours to make the experiments of which I shall speak later. While I was resting, I felt quite well, although it was impossible for me to take the least nourishment. (P. 16.)

The second ascent went much better. The night at the GrandsMulets was good; magnificent weather made the walking easy:

We felt almost no discomfort except a leaden sleepiness while we were climbing the slope which leads to the Dome. I have never felt anything like it, and I am sure that I slept while I was walking. But when I reached the ridge, the cold air and rubbing my forehead with snow removed this congestion.

I felt much better than on the first ascent. I even had an appetite and could eat some morsels with pleasure. However, breathlessness 
at the slightest movement was still intense. One of our companions experienced great nausea, complete lack of appetite, but did not vomit. (P. 18.)

After this general description, M. Lortet passes to the analysis of the disturbances in the various functions. And at the beginning he is careful to say:

Hardly noticeable while going from Lyons to Chamounix, that is, passing from a height of 200 meters to an altitude of 1000 meters, their disturbance is, on the contrary, very appreciable from Chamounix to the Grands-Mulets (from 1050 to 3050 meters), still plainer from the Grands-Mulets (3050 meters) to the Grand-Plateau (3932 meters); finally this change becomes very great from the GrandPlateau to the Bosses-du-Dromadaire (4556 meters), and at the summit of the Calotte of Mont Blanc (4810 meters).

We shall therefore review the variations undergone by the respiration, the circulation, and the inner temperature of the body, taken under the tongue at different altitudes, either while walking, or after a suitable period of rest. (P. 20.)

Respiration: From Chamounix to the Grand-Plateau (from 1050 to 3952 meters) disturbances of respiration are slight in those who know how to walk in the mountains, who keep their heads lowered to lessen the laryngial orifice, who breathe with their mouths closed, being careful to suck an inert object, such as a hazelnut or a little piece of quartz, which considerably increases salivation and prevents the drying out of the air passages. From Chamounix to the GrandPlateau, the number of respiratory movements is hardly changed; while at rest, we find twenty-four per minute, as in Lyons and in Chamounix; but from the Grand-Plateau to the Bosses-du-Dromadaire and to the summit, we find thirty-six movements per minute. The breathing is very short and very difficult, even when one remains quiet; it seems as if the muscles are stiffened and the ribs are held in a vise. At the summit, the slightest movement brings on panting; but after two hours of rest these discomforts disappear little by little. Respiration drops to twenty-five per minute, but it still remains painful. (P. 20.)

M. Lortet studied the changes in the amplitude of his respiration with the anapnograph of Bergeon and Kastus; the two tracings below give a very complete idea of them; in both, the area GFED represents the inspiration, the area DCBA, the expiration. Comparing the tracing of Figure 1, taken at Lyons, with the following, taken at the summit of Mont Blanc, after a rest of an hour and a half, we see that the quantity of air inspired and expired at the summit of Mont Blanc is much less than at Lyons.

Circulation: During the ascent, although progress is excessively slow, the circulation is accelerated extraordinarily. At Lyons, when $\mathrm{I}$ am resting and fasting, my average pulse rate is sixty-four per 
minute. While I was climbing from Chamounix to Mont Blanc, it increased progressively, following the altitudes, to $80,108,116,128$, 136; and finally, while I was climbing the last ridge which leads from

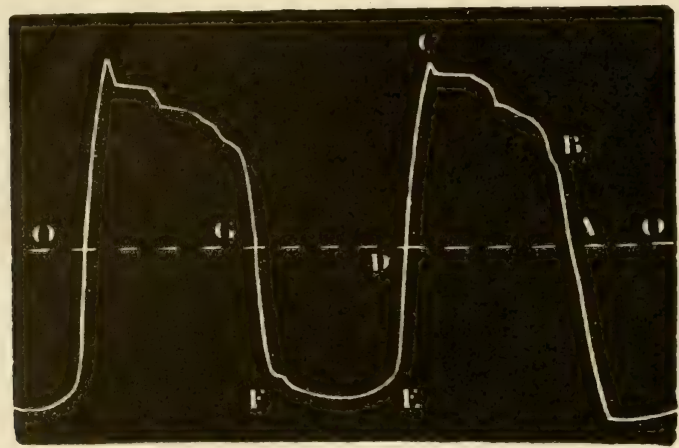

Fig. 1-Lortet. Respiratory tracing taken at Lyons $(200 \mathrm{~m}$.

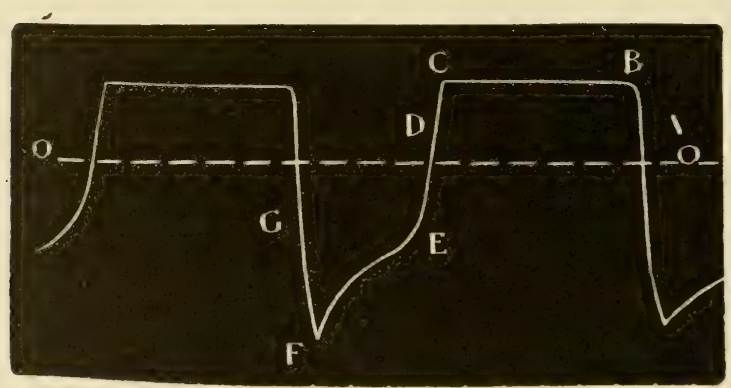

Fig. 2-Lortet. Respiratory tracing taken at the top of Mont Blanc (4810 m.) after an hour's rest.

the Bosses-du-Dromadaire to the summit, to 160 and sometimes more. These ridges, it is true, are very steep, they have a grade of forty-five to fifty degrees; but slowness of the walking is very great. One generally takes thirty-two steps per minute and often much less when steps have to be cut constantly. The pulse is feverish, hasty, and weak. It is plain that the artery is almost empty. The slightest pressure stops the current in the blood-vessel. The blood must pass very rapidly in the lungs, and this rapidity increases still more the insufficient oxygenation which has already resulted from the rarefaction of the air. It does not have time to receive the oxygen adequately, and neither does it have time to give off its carbonic acid entirely. Above 
the elevation of 4500 meters, the veins of the hands, the forearms, and the temples are distended. The face is pale with slight cyanosis, and everyone, even the guides acclimated to these lofty regions feel a heaviness in the head and a drowsiness which are often very painful, due probably to a venous stasis in the brain or to a failure of oxygenation of the blood.

Even after two hours of complete rest at the summit and fasting, the pulse always remains between 90 and 108 beats per minute. (P. 23.)

We reproduce as very interesting examples the following sphygmographic tracings (Figs. 3, 4, 5) which, made by $M$. Chauveau of Lyons at the time of his ascent in 1866, give all neces-

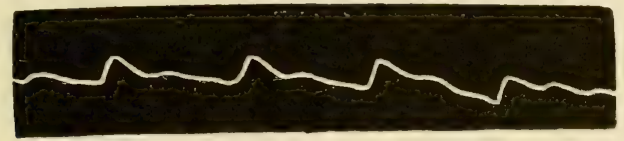

Fig. 3-Cupelain; at Chamounix (1000 m.)

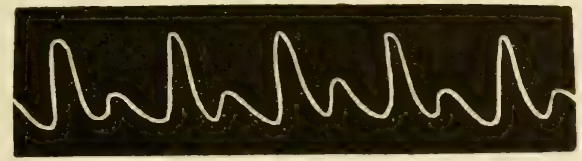

Fig. 4-Cupelain; at the Grands Mulets $(3000 \mathrm{~m}$.) at midnight, one halfhour before starting.

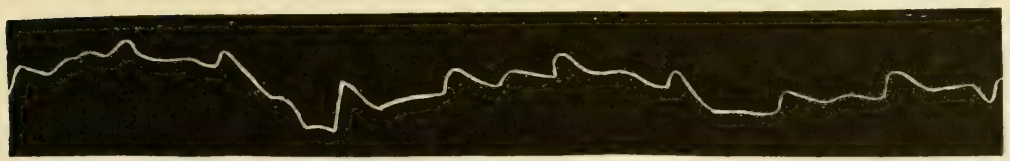

Fig. 5-Cupelain; top of Mont Blanc (4810 m.)

sary proofs of accuracy. The guide Cupelain, who was the subject, is a very vigorous young man, who seems not to suffer from mountain sickness at all.

For M. Lortet, who does suffer from it, the changes were still more considerable.

Temperature. We now come to the subject to which M. Lortet gave most attention, and which serves as a basis for his theory of mountain sickness. I continue to quote verbatim:

The thermometer was placed under the tongue, the buccal orifice being always closed hermetically, and respiration going on only 
through the nose.... The instrument was always left in place for at least fifteen minutes. (P. 31.)

Fasting, while walking continues, the decrease of the temperature is, according to M. Lortet, almost proportional to the altitude at which one is. This is shown by the following table.

Lortet: Temperature

$\begin{array}{ccc}\text { First } & \text { Second } & \text { Temperature } \\ \text { Ascent } & \text { Ascent } & \text { of the air }\end{array}$

Places

Chamounix

Cascade du Dard

Chalet de la Para

Pierre-Pointue
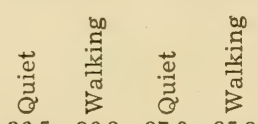

First Second

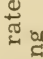

Ascent Ascent 2 ,

Grands-Mulets

Grand-Plateau

Bosse du Dromadaire

$$
1050
$$

36.5

36.3

1500

1605

2049

36.4

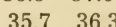

35.3

+10 .

$+12.4$

$34.3+11.2+13.470$

3050

36.6

34.8

36.3

34.2

$+11.8+13.6 \quad 80$

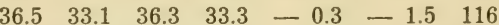

$\begin{array}{lllllllll}3932 & 35.3 & 32.8 & 36.7 & 32.5 & -8.2 & -6.4 & 128\end{array}$

Summit of Mont

Blanc

4556

36.4

$32.2 \quad 36.7$

$32.3-10.3-4.2136$

$\begin{array}{llllllll}4810 & 36.3 & 32.0 & 36.6 & 31.0 & -9.1 & -3.4 & 172\end{array}$

So during the muscular efforts of the ascent, the temperature of the body may drop four or five degrees, when one mounts from 1050 to 4810 meters. As soon as one stops for a few minutes, the temperature rises quickly to nearly its normal figure ....

Since my return to Lyons, I have observed that when one ascends rapidly one of the numerous stairways that lead to Fourvieres or the Croix Rouge, there is regularly a drop in temperature which varies almost always from three to seven tenths of a degree. (P. 32.)

It is to this drop in temperature of the body that M. Lortet attributes all the symptoms of mountain sickness. In Chapter III we shall give this theory and the objections it has aroused.

The same day when MM. Lortet and Marcet suffered so severely during the ascent, M. Ch. Durier ${ }^{150}$ followed them, walking, so to speak, in their footsteps. Strangely enough, neither he nor his companions felt any symptoms:

There were three of us, three companions of very different temperament; one was a lad fifteen years old, the youngest travellerat least that I know of-ever to ascend Mont Blanc. Well! None of us felt the slightest discomfort, not even breathlessness. (P. 66.)

Why this difference in impression? M. Durier asks himself. And to this question he gives an answer full of acuteness, of which we shall make use later. 
I shall end the review of the principal ascents of Mont Blanc with that of M. Albert Tissandier:151 it is particularly interesting because its author, being an aeronaut, could compare his sensations with those he felt in a balloon; he had no uncomfortable sensations:

At the height of 4400 meters, respiration began to be somewhat painful and panting, but I endured the effect of the rarefaction of the air without very much trouble. My two guides looked at me at that time, and told me that often, at that altitude, travellers have a peculiar color; sometimes their vision grows dim and their strength fails; then they have to be hoisted up with great difficulty or else descend, depending upon the energy the traveller possesses.

I should have been very sorry to be obliged to descend. In a balloon I have reached altitudes almost equal to that of Mont Blanc without being inconvenienced; but a mountain ascent, slow and painful, is not at all like the ascent one makes so quickly and easily in the basket of a balloon.

The ascent of Mont Blanc, so much feared before the daring attempt of Jacques Balmat, and which the sufferings of De Saussure and then the accident of Dr. Hamel had invested with a terrifying renown, has in our time become frequent, almost common. In 1873, sixty travellers ascended to the summit of the giant of the Alps, among them seven women and a lad of fourteen, the youngest who has ever made the ascent, named Horace de Saussure. Since the time of the illustrious ancestor of this brave lad, I have counted on the list still incomplete given by M. Besançon, ${ }^{152}$ which goes to the end of 1873,828 ascents, 27 of which were made by women. The last, made by an Englishwoman, Mrs. Straton, shows remarkable courage; it took place January 31,1876 ; on the summit the lady found a temperature of -24 degrees. But the large majority of these expeditions offer no scientific interest; they are mere tourist excursions, often managed very imprudently. Mont Blanc, of which the professional "mountaineers" speak with a certain disdain, seems to avenge itself; there have been more serious accidents upon it than in all the rest of the Alps. One of these disasters, the most terrible of all, perhaps has some relation to our subject. September 6, 1870, nine guides and three travellers reached the summit of Mont Blanc; they could not get down, and died the next day in the snow. In the pocket of one of them, M. Beau, ${ }^{153}$ was found a paper giving an account of their sufferings:

We passed the night in a cavern dug in the snow, a very uncomfortable shelter; I was sick all night. 
Most of those who have made recent ascents of Mont Blanc, the accounts of which have been preserved for us by the Alpine clubs, say nothing of mountain sickness. They go on at length about the preparations for the departure, the petty incidents of the journey, the joys of the return, but maintain complete silence about the physiological phenomena. And what I say of Mont Blanc is true of all the other ascents, even of mountains rivaling it in height. I have gone over, page by page, the journals of the English, Swiss, Italian, Austrian, and French Alpine clubs; I have patiently read hundreds of monotonous accounts, and have found very few data relating to our study; I shall mention them chronologically. August 13, 1857, M. Hardy ${ }^{154}$ made the ascent of the Finsteraarhorn (4275 meters) :

Wellig (inn-keeper of Eggischhorn), considering himself insulted by our jokes, went on ahead to reach the summit first. But hardly had he taken a hundred steps, when he fell as if some one had shot him. Ellis, who was walking behind him, thought that he was resting, and walked quietly up to him; but when I came, I perceived that it was more serious. His eyes were turned up, his mouth open, and he looked strangely like a fish. I did not know what to do; but Cruz adopted a queer mode of treatment .... He raised him to a seated posture and shook him so vigorously backward and forward, that after a few vibrations he revived from his faint, got up, and went to join Fortunatus. (P. 299.)

Perhaps we may hesitate to attribute this sudden syncope to mountain sickness; but in the narrative of Tuckett, ${ }^{155}$ the doubt is not possible.

The matter in question is an ascent on Grivola (3960 meters). made in June 1859; an avalanche threatened to carry away the travellers:

Chabot, one of the guides, complained of painful sensations in the chest and stomach, loss of appetite, vertigo, nausea, headache, resulting partly from fear and fatigue, and partly also, perhaps, due to the rarity of the air, for we had reached the height of 12,028 feet (3665 meters). (P. 297.)

In my opinion, in spite of the complication of a somewhat exaggerated consumption of alcoholic beverages, the influence of rarified air is incontestable again in the following observation ${ }^{156}$ :

A young Englishman about twenty-four years old, a regular picture of health and strength, passed the Weissthor by Macugnagna. $\mathrm{He}$ was not much accustomed to difficult ascents ... . and to give himself strength drank brandy and water frequently. The result was soon seen. The guides had to pull him along with ropes, in a state of 
complete exhaustion.... In fact, as he told me, he has no notion of the way in which he overcame the difficulties and reached the summit; he was in an inert stupor the whole time. (P. 349.)

M. Kennedy, ${ }^{157}$ one of the most daring and one of the first men to make ascents in the Alps, was himself attacked in one of his expeditions, not the first, far from it, nor the most difficult, nor the highest; he was climbing the Dent-Blanche (4365 meters) and was still far, from the summit:

An extraordinary weight seemed to be loaded on me, hampering my movements. My legs, although I did not feel fatigued, refused to act with their usual vigor, and I was left far behind; but the pure and rarified air which blew over us and the sight of the peak of the DentBlanche began to revive me. (P. 36.)

In certain accounts, it is only incidentally, as if buried in a sentence, that we see the symptoms of mountain sickness appearing:

Guides and travellers were exhausted, stopping often for breath ${ }^{15.8}$ .... (P. 107.)

In other cases they are more clearly indicated, even described.

The snow was hard, it was necessary to cut steps, and more ${ }^{359}$ than once the travellers had to stop to get their breath. (P. 166.)

In 1864, Craufurd Grove ${ }^{160}$ ascended to Studer-joch (3260 meters); too great speed in walking made travellers and guides ill:

Perru, who was afraid of avalanches, made us walk at a pace unusual in the Alps, which quickly produced signs of distress in the whole group; . . . . but the robust son of Zermatt gave no heed, and slackened his pace only when the outraged laws of respiration claimed their rights and compelled him to stop completely to get his breath ... We reached the summit; but our joy was greatly lessened by the fact that we were almost all ill. Some of us who had relaxed beside Italian lakes from the hard work of the mountaineer had eaten figs and grapes in excess. The result of this diet, while we were walking on the ice, was too painful to be described. The guides were in a hardly less pitiful condition; they had drunk Grimsel brandy the night before. (P. 368.)

The account of the ascent of Monte Rosa by Visconti, ${ }^{161}$ in August, 1864, is still clearer and more interesting:

The rarefaction of the air inconvenienced us greatly, either because of the difficulty in breathing or because of the decrease of atmosphere pressure on the blood-vessels. For these reasons and because of the steepness of the grades, our legs and lungs tired quickly; but a few moments of rest restored their strength rapidly ... 
Just before we reached the summit (4640 meters), we met the English travellers coming down. One of them was pale and disturbed; he told me that the rarefaction of the air had caused frequent vomiting which had weakened him; in addition, he was dizzy. I merely felt a weakness of the stomach with frequent nausea. (P. 160.)

Last I shall report an observation made by M. Gamard, ${ }^{162}$ during his ascent of the Jungfrau (4170 meters), August 24, 1874, which we shall discuss later:

We were buried in the very side of the mountain; air failed us, and as we noticed on Monte Rosa and Mont Blanc, it is not at the summit that we suffer from this rarefaction, but in spots which the wind does not reach.

At half past nine, we rested again; we were at an altitude of about 3750 meters. (P. 216.)

But, I repeat, observations of this sort are extremely rare. Ball does not say a word about mountain sickness in his useful work entitled Suggestions for Alpine Travellers, ${ }^{163}$ in which he enumerates the dangers of ascents and the principal observations of physics and natural history which can be made there.

Does this mean that everything has changed since the time of De Saussure, and that today one can safely make ascents which then were painful and difficult? In this hypothesis, however strange it may appear at first thought, there is a portion of truth, the amount of which we shall discuss later. But to make sure that the immunity is anything but general and complete, we need only question carefully those who make ascents, even those who in their accounts do not mention physiological disturbances, even those who deny the existence of such disturbances. Moreover, M. Joanne, who has read and seen and heard so much, summarizes perfectly in his excellent guidebook to Switzerland ${ }^{164}$ all common knowledge on this point:

The lightness and the great rarity of the air in the Alps, and the energy with which it speeds up evaporation cause at certain altitudes very noticeable physiological phenomena, such as considerable decrease or loss of appetite, distaste for food, nausea, drowsiness, panting, headache, fainting, etc.; some of these symptoms even compel certain individuals to turn back at once, as soon as they have reached an altitude of 3000 meters; at about 3400 meters, mules are so out of breath that they utter a sort of plaintive cry. However strength returns, in such a case, as quickly and apparently as completely as it was exhausted. Mere cessation of movement seems, in the short space of three or four minutes, to restore it so perfectly that when one starts walking again, one no longer feels any fatigue. (P. 93.) 
But if these symptoms are so frequent, why not speak of them, or at least why not mention them in accounts which are often so prolix and loaded with uninteresting details?

In the first place, we must confess, their importance and severity have been so exaggerated that travellers affected only by panting and palpitations are willing to deny even the reality of an illness which they dreaded so much in advance. In this connection, I found an interesting indication in the account of ascents made in August, 1859, of Grivola (3960 meters) by M. Ormsby. ${ }^{165}$ He was climbing the "chimney" in a very dangerous position when he had a very strange dizzy feeling, and he adds:

I had read so many terrible stories of the strange effects of the rarified air on man at great altitudes that I began to be very nervous ... It was the moment to be attacked by apoplexy, catalepsy, bleeding from the eyes or some other of the terrible symptoms. (P. 333.)

In the second place, most of the tourists whose narrations fill the Alpine journals have hardly any scientific interests in their ascents; they climb for the sake of climbing, or seeing, or often of telling that they have climbed and seen. It is generally this last feeling which dictates their accounts, and that is why one sees them every year seeking some horn, spitze, or joch, hitherto inaccessible or merely forgotten: a virginity often hard to conquer, the sterile conquest of which they will dispute.

Finally, a point of honor has intervened; they are almost as afraid of being ridiculed for mountain sickness as they are for seasickness. Formerly, they sought its symptoms in themselves, they liked to boast of having experienced them, as they would have boasted of a mysterious danger they had risked; today they refuse to observe them, especially to admit them; sometimes they deny them.

One of the travellers of our period who are most experienced in mountain climbing, Count Henry Russell, ${ }^{166}$ expresses himself on this point with the greatest clearness and authority:

I regret to state that some of the most important authorities of the Alpine Club have gone so far as to deny completely a thing like the painful phenomenon known in all countries by the name of "mountain sickness", or they declare it an exception, an effect of fatigue, of exhaustion. It is true that very favored lungs can go to very high altitudes and continue to breathe comfortably. Likewise, there are travellers who are immune to seasickness, and we can therefore deny this sickness as well as the other. Mountain sickness is an ailment which has been felt all over the earth (even in the tropics), in the 
Andes, on the Altai, on the Himalayas .... everywhere. No animal is immune to it, at a certain height; and as for me, I confess humbly that I can hardly breathe on the summit of Mont Blanc; in fact, we were all sick, more or less, including the guides. On the Calotte, where the slope is very gentle, not one of us could take more than thirty-four steps without pausing a long time. And that was not fatigue, because in two hours we were descending to the GrandsMulets, in very good health and full of vigor. (P. 243.)

How few "mountaineers" and "Alpinists" will have courage to make a similar confession!

\section{The Pyrenees.}

Since the highest mountains of the Pyrenees do not attain 3500 meters, the symptoms due to decreased pressure can be felt there only under exceptional conditions. So travellers generally do not mention this subject, and when they speak of it, it is usually to declare that they have had no such experiences.

The first author to mention physiological phenomena observed in the Pyrenees is Robert Boyle ${ }^{167}$ but he gives only second-hand information:

A gentleman of learning had made the ascent of the peak of Midi in the month of September. I asked him whether he had found the air on the summit as plentiful for breathing as that belew. He said no, that he was forced to breathe more frequently and less deeply than usual. And as I thought that perhaps that came from the movement, I asked him whether this difficulty had ceased after his arrival at the summit; he answered: "Yes, evidently, for we could not have remained several hours on this summit with such difficulty in breathing." (P. 2039).

During the eighteenth century, a fairly large number of ascents were made, for scientific reasons, on different mountains of the Pyrenees, and those not the least lofty. The book of Dralet ${ }^{168}$ gives an interesting summary of the data formerly observed:

The artists who were employed in 1700 in constructing on Canigou a pyramid for determining the meridian felt no symptom. MM. Vidal and Reboul passed three days and three nights on the summit of the peak of Midi of Bigorre without any inconvenience; I have always been immune, and so have my travelling companions, not only on this same peak, but also on the loftiest ridges which separate France from Spain ... However some travellers have been affected in the Pyrenees, even at moderate heights. In 1741, M. Plantade, celebrated astronomer of Languedoc, died at the age of 70 beside his quadrant, on the Hourquette des Cinq-Ours (1244) fathoms. Count Dolomieu, in August, 1782, almost met the same fate; he was attacked by a violent fever which kept him from reaching the summit of the peak "; 
M. de Puymaurin and M. Lapeyrouse, his travelling companions, were for an instant almost without pulse. M. Dusaulx, before reaching the plateau of the peak of Midi, felt dizziness and a sort of weakness, without his companions experiencing any such symptoms. These facts seem to prove, according to the opinion of M. de Saussure, that nature has fixed for the constitution of each person the altitude to which he can ascend without discomfort and without danger. But it should be noted that certain travellers have been affected at a moderate height, although accustomed to climbing very high mountains without any trouble. (Vol. I, p. 38.)

After that time, the traveller and naturalist Ramond made the first ascent of Mont Perdu (3350 meters). His very interesting account ${ }^{170}$ gives proof of very uncommon sagacity; at least he does not deny what he was fortunate enough not to feel:

We were breathing without difficulty this light air which was no longer sufficient for the respiration of many others. I have seen vigorous men forced to stop at much lower elevations ... Here we felt nothing of the sort; only the condition of the pulse indicated a change independent of the excitement of the trip: rest did not quiet it. As long as we remained on the summit, it was small, dry, difficult, and quickened in the ratio of 5 to 4 ; this fever, which is nervous, announced plainly the illness which we should have felt at a greater elevation; but at the point where we were affected by it, it produced an effect just the opposite of that which a degree more would have produced. Far from causing exhaustion, it seemed as if it aided my physical powers and raised my spirits. I am convinced that we often owe to it this nimbleness of limb, this acuteness of the senses, this activity of thought which suddenly dispel the prostration of fatigue and the apprehension of danger; perhaps we need not seek elsewhere the secret of the enthusiasm which permeates the accounts of all who have mounted above ordinary heights. (P. 84.)

Likewise Arbanère ${ }^{171}$ declares that on the summit of Mont Perdu in 1821 he:

Experienced no effect of the rarefaction of the air, that distress, that anxiety, that nausea which often cause prostration at such a height. (Vol. II, p. 85.)

On Vendemiaire 11, in the year XI, Cordier and Néergaard made the ascent of the Maladetta. One of them was seriously affected; here is the account the celebrated geologist gives of this complication: ${ }^{172}$

Shortly afterwards, the ridge became wholly impassable and we had to go out upon the glacier. We were then at a height of about 3000 meters. M. Néergaard was so distressed by nausea and dizziness, caused by the rarity of the air, that it was absolutely impossible for him to go any further. I will note, by the way, that mountain sickness 
almost always attacks the small number of persons whom a natural or accidental tendency makes subject to it, at the height of 2600 to 3000 meters, immediately above the timber line. (P. 266.)

Cordier and his guide continued on the way and reached the summit without seeming to have experienced any unpleasant symptoms; at least the account gives no signs of any.

A traveller of whom we have already spoken, who made numerous ascents, particularly in the Pyrenees, Parrot, ${ }^{173}$ gave special attention to the variations in his pulse at different heights. I reproduce his important observations:

My pulse rate on the summit of Mont Perdu was 110, and a few days before, in my first attempt to climb this mountain, it was 100 . Upon the Maladetta, it was 103 , and some days before, at Bagnères de Luchon (628 meters), it was only 70 . These variations are in a regular ratio with those of the height; they agree with the observations which I have already made on my pulse on different mountains. So my pulse rate, which is 70 at sea level, rises to 75 at a height of 1000 meters, 82 at 1500 meters, 90 at 2000 meters, 95 at 2500 meters, 100 at 3000 meters, 105 at 3500 meters, 110 at 4000 meters. (P. 216.)

After him, I have hardly anything else to quote but the account of M. de Franqueville, ${ }^{17 t}$ who was the first to ascend the highest peak of the Pyrenees, the peak of Néthou (3400 meters).

The ascent took place July 18 and 19, 1842. The travellers reached the glacier of Néthou, very near the goal of their ascent:

We were all expecting to feel some of the symptoms due to the rarefaction of the air, which generally add still more to the difficulties of great ascents. However this did not occur. But after making a few steps on the glacier, M. de Tchihatcheff was attacked by nausea so violent that he was forced to stop from time to time and lie down on the snow. A few moments of rest revived him completely, and permitted him to go on. As for the rest of us, neither the guides nor I felt anything special. We did not even have to struggle against this lassitude, this distress which are so painful and which so often accompany, they say, the presence of man in these lofty regions which were not made for him.

Here ends all related to our subject that we have been able to find in the narratives of mountaineers in the Pyrenees. A strange document shows us that nothing important ever attracted their attention. Count Russell-Killough, who knows the Pyrenees so marvellously, has published a collection of ascents of the peak of Néthou, from the one which we have just mentioned up to 1868 . In this interval, there were about two hundred, including nearly a thousand persons, twenty-two of whom were ladies. 
The book, which contains the personal notes of each tourist, shows absolutely nothing, except the general vanity of motives which impelled so many persons to this painful ascent. Physiological symptoms are not even mentioned. Count Russell alone (August 24, 1863) says: "no spitting of blood". (P. 50.)

Finally, I will quote in this section a few observations ${ }^{176}$ made in an ascent of Mulahacen, the highest peak of the Sierra Nevada of Spain; they contain the outline of a strange theory:

The effects produced by the rarity of the air upon the lungs and the body were not felt as long as we remained on the mules. But now that we had to make muscular efforts, a greater shift of energy is necessary than in a dense atmosphere. The equilibrium of the air, which supports the bones as the water does for fishes, fails, and the muscles are forced to lift a greater weight; hence exhaustion. (P. 157).

\section{The Caucasus, Armenia, Persia.}

Caucasus. The ascents of the lofty summits of the Caucasus are quite recent. Klaproth, ${ }^{177}$ in the account of his journey to Mount Caucasus and Georgia, made in 1807-1808, said:

No one has ascended Elbrouz; and the Caucasians think that no one can reach its summit without special permission from God. (Vol. I, p. 131).

A very serious attempt to ascend to the summit of Kasbek or Mquinvari (5030 meters) was made September 17, 1812, by Engelhard and Parrot. ${ }^{178}$

The two travellers camped at the line of perpetual snow; Parrot alone undertook the ascent to the summit. He had to surmount the usual mountain difficulties; but, he adds:

The most annoying thing to me was a strange lassitude which forced me to rest every fifty steps; it arose less from oppression of the chest than from a complete weakness of the muscles which seized me suddenly, and which soon passed when I stopped for only a half-minute. It was generally followed by a strange and agreeable sensation, as if I were in a new element, to which my body, made for the stronger pressure of the lower regions, was superior in strength. An inevitable consequence of the extremely rarified air which surrounded us was the acceleration of the pulse and the respiration; but distress and vertigo troubled neither me nor my companions. In return, I observed in them and myself a weakening of several sense organs; we were obliged to talk very loud to make each other hear; we had difficulty in talking, not because respiration failed us, but because our tongues had lost their flexibility; even the eye seemed less active, and one would have said that an inner cause prevented it from seeing distinctly and at a great distance. (P. 302.) 
Parrot was forced to stop at an elevation of 2168 fathoms; he passed the night with his companions, but had to descend the next day without having reached the summit, which he estimates has a height of 2400 fathoms.

In 1829, a military and scientific expedition approached Mount Elbrouz (5620 meters); Kupffer ${ }^{179}$ and the other scientists who were in the party resolved to attempt the ascent of the giant of the Caucasus.

July 22, 1829, they reached the line of perpetual snow upon its sides:

We were forced to stop at nearly every step. The air is so rarified that respiration is no longer able to restore the strength that one has lost; the blood is in violent movement and causes inflammation in the weakest parts .... All my senses were blunted, my head whirled, I felt from time to time an indefinable dejection which I could not control .... We were then at a height of 14,000 feet above sea level. (P. 33.)

However they had not reached the altitude of Monte Rosa; they could go no higher, but one of their guides ascended to the summit.

Sjogrun, ${ }^{180}$ who, May 26, 1836, made the ascent of "the highest mountain of the Caucasus" (his account is not clear, but I think he means Kasbek), says absolutely nothing of physiological disturbances.

But Radde, ${ }^{181}$ although his ascent of Elbrouz August 10, 1865, was not completed because of bad weather, shows clearly in his account the effect of rarefied air:

Before us rose, all white, the summit of the mountain. A strong west wind had risen. We stopped a certain time; weariness and dizziness painfully affected my two companions and myself; we likewise experienced a strange weakness of the knees, which soon checked all our movements ....

We stopped more and more often; dizziness and weakness of the knees increased; horrible fatigue (entsetzlich) weighed me down.

We had reached a height of 14,925 feet (4557 meters). (P. 102.)

In their journey, in 1868, Douglas W. Freshfield, Moore and Tucker, ${ }^{182}$ accompanied by a guide from Chamounix, Fr. Devouassoud, with whom they had made ascents in the Alps, made the two difficult ascents of Kasbek and Elbrouz.

July 1, ascent of Kasbek; night passed at a height of 3300 meters; except for the excessive fatigue which forced one of them to lie down and nearly prevented another from reaching the summit, our travellers notice nothing to interest us. 
July 31, ascent of Elbrouz; they complain only of the cold.

Gardiner, Grove, Walker and Knubel ${ }^{183}$ ascended to the summit of Elbrouz July 28, 1874. July 27, they camped at a height of 11,300 feet, and the next day reached the summit:

Everyone suffered from the rarity of the air. In 1868, not one felt its effects; the peak ascended then was probably that of the east; but the difference in height, if there is any, is too slight to explain the immunity of the former expedition.

It is probably the journey of Douglas Freshfield and others that is referred to here.

In the same publication is a second account, by Gardiner, ${ }^{184}$ of the same ascent:

After we left the col, no serious difficulty appeared. However Grove, Knubel and I suffered more or less in breathing, which forced us to stop often; we also had what I have heard a Swiss guide call "a blow in the knees". Walker had the nosebleed, but no other symptom. (P. 119.)

Armenia. The plateau of Armenia, which over a vast expanse has an average altitude of over 3000 meters, is dominated by the double summit of Ararat, which was well known by the ancients and of which the books of the Bible speak, as everyone knows.

But if Noah, according to the legend, could easily descend from the summit to which the waters had carried him-which, if they had covered the lofty Ararat, would have left above them only its neighbors Elbrouz and Demavend with the highest peaks of the Andes and the Himalayas,--the ascent of the holy mountain offers quite serious difficulties. However, Pierre Bergeron, a Parisian, in his treatise on the Tartars, ${ }^{185}$ gives us the following curious information:

Elmacin, an Arabian historian, relates that when the emperor Heraclius was making war in Persia, and passed by the city of Themanin, built, they say, by Noah on leaving the Ark, curiosity urged him to ascend this mountain (Ararat, which is the Taur, as the Scriptures call it, and the Greeks call it Periarde; today, it is Chielder), to see whether he could find any remains of this vessel. Haiton says also that in his time there were a few pieces left. (P. 66.)

It is also to Robert Boyle ${ }^{186}$ that we owe the first account of an ascent of Ararat, with mention of the discomforts produced by a stay in so lofty a place:

Having met an ecclesiastic who had ascended the lofty mountains of Armenia (on one of which, because of its great height, the people of the country say that the Ark came to rest), I asked him whether 
he had had any difficulty in breathing on the summits .... He answered that he had not been able to reach the tops of these mountains because of the snow; that, however, he had noticed that he was obliged to breathe more frequently.

I asked him whether this difficulty seemed to him accidental or peculiar to him; but he assured me that it was general on lofty places and was commonly observed.

This same ecclesiastic felt similar respiratory symptoms when he made the ascent of a mountain in the Cévennes. (P. 2038.)

The celebrated botanist Tournefort, who attempted the ascent on August 11, 1701, could not go even to the snow line:

One (he says) complained that he could not breathe; as for me, I had never been so afraid that some lymph vessel would burst in my body. (Vol. II, P. 316.)

The first complete ascent of which we have a record is the one made in 1829 by Parrot, the learned traveller whom we have quoted so often already; he had to make three attempts.

September $12,{ }^{188}$ he ascended only to 3850 meters (p. 130); September 18, he reached 5000 meters (p. 146). Finally, September 26 , he passed the night at 4300 meters; he complains only of a feeling of fatigue and a tendency to sleep (P. 156.) The next day, departure for the summit:

We had to leave one of our peasants sick at camp. Two others, over-tired by the ascent of the glaciers, lay down on the ground, then went back down. Without letting ourselves be discouraged, we continued on our way. (P. 157).

The rest of their account shows that their fatigue was extreme; but no other symptom is noted. At a quarter past three, they reached the summit: "My first desire and my first pleasure was rest", says Parrot. (P. 159.)

The difficulties with which popular opinion surrounded an ascent which seemed a trifle sacrilegious caused this circumstantial and credible account of Parrot to be called in question. But a few years later other explorers, Avtonomoff, ${ }^{189}$ August 5, 1834, Behrens, ${ }^{190}$ July 20 and August 9, 1835, Abich, ${ }^{191}$ July 29, 1845, proved its exactness. I could not get the complete account of these ascents, and the reports of them given by the journals of geography do not mention any physiological disturbance.

But that proves nothing, for they are equally silent when they discuss ${ }^{192}$ the celebrated ascent of the Russian Colonel Chodzko, and yet it appears from a communication the learned geodesist sent me that these disturbances were anything but negligible. 
Here is the account as it was given me in a letter written in French by General Chodzko: I quote it in full, thanking my eminent correspondent sincerely for his kindness. The expedition included five officers and sixty soldiers:

The ascent began July 31 (August 11), 1850. From August 4 (16) to August 6 (18), we remained in our tents at the foot of the summit of Mount Ararat. August 5 (17), during the night, sheltered under perpendicular cliffs, we remained from eight to eleven o'clock in the evening in the midst of electrically charged clouds. The lightning flashes which one sees from below crossing the clouds like mere thin ribbons had enormous dimensions; the thunder roared at the very instant when the flash appeared; it was like the fire of a volley of cannons. After a storm of three hours, a very loud clap of thunder detached a part of the cliff, which fell with a crash.

After the thunder storm was over, hurricanes of snow came on. It was a very difficult task for us to unroll and stretch a little higher two little canvas tents, under which we remained from the 16 th to the 19th of August. August 18, after reaching the summit, we set up there a cross painted black. Two tents were pitched in holes dug in the snow. August 19, the observations of the zenithal distances were begun (Ararat was observed from 122 trigonometric points); they were finished after a fashion on the morning of August 24. We set out at noon, and descended rapidly.

As for physiological symptoms, my head was very heavy; it seemed to me as if an iron ring pressed my skull above the ears. We had to walk very slowly in order to breathe easily. At night, when we were sleeping wrapped up in pelisses, if the cold penetrating through them awakened us, the movements we made to pull them around us cut off our breathing. The third day my head became lighter; but it was still impossible to walk quickly.

In their journey to Armenia, Raddé and Sievers made some fairly lofty ascents, among them one of a mountain near the lake of Chara-Gol, July 28, 1871:

At an altitude of about 12,300 feet (says Raddé) ${ }^{193} \mathrm{I}$ had to stop. My respiration was difficult, my knees were absolutely broken. I began to be feverish .... Sievers climbed bravely on. I remained lying down completely apathetic, for two hours, awaiting his return. At the end of about two hours, he returned, as sick as I, completely exhausted and broken. (P. 177.)

Among the numerous travellers who have traversed Asia Minor in all directions, I find only one, Hamilton, ${ }^{194}$ who made the ascent of Argaeus (3840 meters), July 30, 1837. He says absolutely nothing of physiological disturbances.

Persia. But I have found two accounts of ascents of the extinct volcano of Demavend (5620 meters), near Teheran. 
September 8,1837 , Taylor Thomson ${ }^{195}$ camped on the mountain side at an elevation of 2000 meters. The next morning, he set out:

I had not been climbing more than an hour, when two of my men refused to go any further .... I kept on with the other two, but one of them complained so bitterly of headache and palpitations that I had to let him go back. By entreaties and threats I kept the other as far as the crater: the cold was extreme .... The temperature was $56^{\circ} \mathrm{F}$., the barometer stood at 15.05 inches ... . which corresponds to 14,700 feet (4480 meters).

The other ascent was made July 24 and 25, 1858, by members of the different European missions to Teheran. The English attaché, R. F. Thomson, has given a detailed account of it. ${ }^{196}$

On July 24, camp was made for the night at the village of Rina (3920 meters); the thermometer registered $0^{\circ}$ centigrade. On the morning of July 25, they set out early:

The ascent of this part of the mountain brought on great fatigue especially on account of the rarefaction of the air which began to affect our lungs....

The last part of the ascent of Bamshi Bend was extremely painful because of the rarefaction of the air. We felt nausea and violent headache and a great difficulty in breathing, even while resting. M. de Saint-Questin, of the French mission, and M. Castelli, a Sardinian, who accompanied us, were affected like us. When we had rested a little and were less tired, we began our observations. They indicated the enormous height of 21,520 feet (6560 meters). ${ }^{107}$

We remained at the summit about an hour and a half. (P. 15.)

\section{Central Asia.}

In the last half of the thirteenth century, a famous trav'eller, Marco Polo, ${ }^{198}$ was the first European to penetrate into the lofty regions of the plateaux of Central Asia. The celebrated Venetian, no doubt, as has been proved by the testimony of those who followed his steps five hundred and fifty years afterwards, must have felt the phenomena of which we shall soon give many descriptions, and must have observed their effects upon his companions and his beasts of burden; but his account gives no suggestion of it:

Always one rides through mountains, and mounts so high that it is said that this is the highest spot in all the world. (P. 130.) . . .

No flying fowl is there, because of height and cold. And I tell you that fire, through this great cold, is not so bright nor so warm as in other places, nor can it cook viands so well. (P. 133.)

This place, the highest in the world, is, as the English traveller 
Wood showed later, the plateau of Pamir, at an altitude of 4700 meters.

Chinese travellers, still earlier, had visited these lofty places. For instance, the pilgrim Fa-Hian ${ }^{199}$ in the year 399 crossed the pass of Karakorum (5690 meters). Also the celebrated HiouenThsang ${ }^{200}$ coming from China found "a series of mountains and valleys and peaks of prodigious height. He crossed black mountains." (P. 55.) M. Stanislas Julien declares that this means the passes of Hindou-Kouch and the plateau of Pamir. But in the very brief reports left us there is no mention of physiological observations.

The description "of the provinces Wei and Zzang" of Western China, which, published in Chinese in the year 1792, has been translated into French by Klaproth ${ }^{201}$, contains some indications which, as we shall see later, evidently refer to the symptoms of decompression.

In mentioning disturbances whiç affect travellers in these lands of lofty mountains, the Chinese author speaks of:

Heat of the body, headaches, and other diseases peculiar to the climate. (P. 23.)

Later, in an itinerary remarkable for the accuracy in distances and the abundance of details, he mentions the influence of poisonous plants, which we shall soon see playing a great part in the narratives of travellers; here, it is rhubarb which is blamed:

Leaving Djedo, one travels from mountains to mountains; they extend a long way, but they are not very high. Rhubarb is abundant there; it exhales a very strong odor which annoys the traveller very much. (P. 188.)

Finally, after plants, come exhalations from the ground:

Further to the west of Djaya, one crosses a great snowy mountain; the road is very steep. The accumulated snow looks like silvery vapor. The mist which the mountain exhales penetrates the body and makes the Chinese sick. (P. 210.) . . .

From Lang Thang Keou, one follows the valley, ascending ...

The frozen snow makes the road slippery and very dangerous. There are also pestilential exhalations there. (P. 217.)

During the seventeenth and eighteenth centuries, some European travellers, missionaries, merchants, soldiers, or adventurers, visited the lofty regions of Central Asia, either in the Chinese Empire, or in that of the Grand Mogul.

Only in one account, that of the Portuguese Jesuit Antonio 
d'Andrada, ${ }^{202}$ have I found clear indication of symptoms which one can attribute to the effect of the air of lofty places. This missionary had the courage to cross the Himalayas almost alone on his way from Cashmere to Tibet:

There begins a region of lofty mountains which one cannot cross in less than 20 days. There is nothing there but rocks almost always covered with snow ....

Partly from disease and partly from a certain pestilential exhalation from the ground, suddenly one feels a violent inward revulsion which kills in a quarter of an hour. I attribute these sudden deaths to the cessation of natural warmth which is checked by the great cold, and especially to poor food. (P. 13.)

But as for him and his two companions, he complains only of the extreme cold, partial freezing, numbness of hands and feet, and "loss of appetite" (P. 16), the only symptom which one can attribute to decreased pressure. However they had passed through very lofty regions, since they "reached the summits of all those mountains where lies the lake whence issue the river Ganges and another which waters the lands of Tibet" (P. 16). It is evidently Lake Manasarowar that d'Andrada means.

Dr. Bernier, ${ }^{293}$ who in March, 1663, followed the Grand Mogul Aureng-Zeb from Lahore to Cashmere, had to cross a lofty mountain, still covered with snow; but he speaks only of the cold, and alludes only to the difficulties of the trip in speaking of the journeys of the merchants who go to Kashgar and Tibet across the lofty ranges.

The accounts of Father Verbiest, ${ }^{204}$ who in 1683 accompanied the Emperor of China into Eastern Tartary, and those of Father Gerbillon, ${ }^{205}$ from 1688 to 1698 , mention no sufferings.

In October, 1714, Father H. Desideri left Lahore for Cashmere, "across the Caucasus", as the Himalayas were called for a long time. May 17, 1715, he undertook the terrible journey through Tibet, and reached Ladak June 25. Among his discomforts he mentions only fatigue, cold, wild winds, and the reflection of the sun upon the snow. ${ }^{206}$

In the second half of the eighteenth century the political relations of the English with Boutan and Tibet begin. In 1774, Bogle was sent to the Grand Lama by the governor of India; J. Stewart, ${ }^{207}$ who has narrated his journey, makes no allusion to the effect of the mountains.

In 1783, Samuel Turner ${ }^{208}$ was entrusted with the same mission. He crossed the high passes of Boutan, and stayed several months 
in Tibet. He frequently lays stress upon the extraordinary height of these regions and upon the cold and parching winds prevalent there. The only observation that can be referred to the harmful effect of altitude is the following; Turner was then at the foot of Chumalari:

When we had dismounted at Terma, I felt a violent headache, which urged me to throw myself upon a rug; ... . I was in pain and did not wish to talk. (Vol. I, p. 312.) . . . .

I attributed this headache, which gave me great pain, to the change of climate. (P. 314.)

Captain Thomas Hardwicke ${ }^{209}$ in 1796 made a journey to Srinagar in Little Tibet, during which he seems to have mounted to fairly great heights; but he mentions no symptoms that one can attribute to mountain sickness.

But with the celebrated journey of Moorcroft "1" who in 1812 crossed the Himalayas to reach Lake Manasarowar, begins a new era, so to speak. After that, all the narratives of travellers will contain clearly and often with details evidence of the sufferings which altitude added to fatigue and cold.

He left May 26, but it was not until June 4 that one finds in his journal the indication of a special distress:

Toward the end of this day (he says) I found that my respiration quickened proportionately to the difficulties of the ascent, and I was often compelled to stop and wait until the beating of my heart grew calm. My companion had been suffering from this oppression for three days, but $I$ had not felt it at all until then. (P. 397.)

Moorcroft does not specify the height which he had then reached; he only speaks of a village named Niti where he made his camp then. After a few days, he wished from there to make the ascent of the neighboring mountains:

On the morning of June 26, I set out. The ascent was very painful because of the great difficulty in breathing; of five persons, only one was capable of accompanying me .... I could not take more than five or six steps without stopping to breathe ... Having suddenly turned my back to the wind, I felt a sensation of fullness in my head, with vertigo and threats of apoplexy; and so I quickly lay down on the ground. Shortly afterwards, my panting slackened, the beating of my heart became less violent, and I could rise. But in spite of precautions in walking, I was twice attacked by the same symptoms, so that it seemed wise to me to give up ascending higher.

The imperious necessity of stopping to breathe every four or five steps was felt only while I was climbing. When the violent action of the heart was lessened by rest, the difficulty in breathing disappeared. It did not appear during the descent, even when I ran; but several 
times at our camp, just as I was going to sleep, I was aroused by this sensation ... Although I experienced neither excessive cold nor heat, my hands, my neck, and my face were red, the skin was sensitive, and blood oozed from my lips, which had never before happened to me. (P. 408.)

He refers repeatedly to the oppression which precedes sleep:

June 30 , at sun-rise, the thermometer registered $46^{\circ} \mathrm{F}$. . . . I awoke very early, and at once was seized with difficulty in breathing and great oppression in the heart, symptoms which disappeared after a few deep inspirations. As I was going to sleep again, the smothering reappeared, and respiration became very uneasy; however, as soon as the air had grown warm, this distress lessened. (P. 412.) . . . .

In the evening, although overcome by need of sleep, it was impossible for me to fall asleep because of the smothering which came on immediately, and which nothing but a few deep breaths could quiet. (P. 415.)

July 3, Moorcroft reached Daba. The rest of his journey did not expose him to mountain sickness, on the cause and nature of which he did not venture any hypothesis.

In 1819, Moorcroft, in the company of Trebeck, began a long expedition which was to end in 1825 with the death of the two travellers. In the publication by Wilson ${ }^{211}$ of the results of this journey, I have found nothing relating to mountain sickness. In telling of his crossing of the pass of Chang-La, the highest he had yet crossed, Moorcroft complained only of terrible cold (Vol. I, P. 428). At the pass of Parang-La, the altitude of which he estimates as about 19,000 feet, he says only:

My horse was so unable to walk, before reaching the summit, that I had to dismount and leave him to his fate. (Vol. II, p. 54.)

Three years after the first journey of Moorcroft, Fraser,"1" who accompanied the political agent sent to the army of General Martindale, went up the banks of the Jumna in 1815. He crossed the mountains from Jumnotree to Gangotree by very lofty passes, the height of which he does not give.

On July 16 for the first time there appear in his narrative symptoms which one may attribute to mountain sickness:

We were much annoyed by the coolies (he says) ..... It was very difficult to start them moving, and they sat down after a few steps, although their burdens had been greatly lightened in preparation for the difficulties of the march. They told us that they were attacked by the Serân, or poisonous air coming from the flowers which covered the ground (primroses, polyanthus, heather); and although their condition was perhaps partly due to drink and excesses, 
and although something must also be attributed to laziness, their general appearance indicated something more. When they stopped, they threw their burdens on the ground, and lay down sick; generally they went to sleep immediately, and very few thought of eating first; they told us that the next day's stage would be still harder. (P. 440.)

In fact, the next day, the sufferings increased:

It was exceedingly cold . . . Many of the Mewatees and Goorkhas were almost unable to go on, each one complaining of the bis, or poisoned wind. I thought then that this supposed poison was nothing but the effect of the rarefaction of the air due to our great altitude, which makes it insufficient for our breathing; it cannot distend our lungs; I have been brought to this belief by my own sensations. I was obliged to make tremendous efforts to continue, and could hardly find strength enough to walk. I experienced great respiratory oppression, as if I lacked air. We certainly could not have endured that very long ....

At last we reached the summit of Bumsooroo-ke-Ghat, where there was nothing but moss and lichens... As soon as one of those who complained of oppression lay down, he went to sleep, but it did not seem wise to let him do so. Eating a few mouthfuls helped a little, but nothing did much good, and no one was free from this general weakness. This was the highest point of our journey. (P. 442.)

From there we had to execute a series of ascents and descents ... along a path which was very difficult and painful on account of the snow and rolling stones; we were cruelly tormented by difficulty in breathing, until we reached Chaiah-ke-Kanta. (P. 444.)

They were not at the end of their sufferings. The next day, they had to make new ascents:

We were troubled by the difficulty of the terrain, the poor condition of the road, and above all, by the artificial fatigue due to the oppression which we all felt most severely. (P. 449.)

When we reached the high gorge of Bamsooroo, no one escaped the baneful influence. It was strange to see those who had laughed at their companions give themselves up, some to fatigue, others to sickness, in spite of their efforts to hide it from the others. I think that I escaped longer than anyone else; and yet, after passing this gorge, a few steps upward seemed to me an impossible labor, and even while I was passing over level places, my knees trembled under me, and I experienced stomachic nausea. The symptoms produced are quite varied; some persons suffer from violent headaches; others have pain in the chest, with oppression; others have nausea and vomiting; many are overwhelmed with drowsiness and fall asleep even while they are walking.

But what proved that all of this was the effect of our great altitude is that when we descended and reached the region of vegetation, all these violent symptoms, all these sufferings diminished and disappeared. (P. 459.) 
In 1816,1817 , and 1818, Captain Webb made vain attempts to cross the Himalayas, and see again the sacred lake of Manasarowar; the Tartars stopped him on the way. His observations were published in an interesting article in the Quarterly Review; ${ }^{213}$ some of them interest us particularly:

Without raising the least doubt (says the editor who reviews Webb's letters) in regard to the difficulty in breathing experienced by M. Moorcroft in his ascent of Ghaut, we shall call attention to the fact that higher ascents have often been made without any such effect, which seems to indicate that these effects depend greatly upon the state of the health. Captain Webb, however, confirms these claims, not only by the evidence of his own sensations, but by that of the mountaineers themselves, who experience them as much as strangers do, and he assures us that neither horses nor yaks are immune to them. The natives call this illness Bis-kee-huwa, that is, poisoned air, and attribute it to the emanations from certain flowers; it appears when one is walking or when one is tired.

"Everyone", says our traveller, "complained of loss of appetite for several days after our arrival at Nitee. As for me, I felt exactly the sensations which precede an attack of fever, with great oppression and exaggerated action of the heart and viscera. But one of those who accompanied me suffered one of those attacks to which the residents of Boutan are subject, at the beginning of the season, and which they consider as directly produced by the Bis-kee-huwa. He had gone down to the river's edge at the close of day, and when he wished to climb back up, he lost the use of his legs and even lost consciousness; however, he still retained some feeling, but to me he looked like a man struck by apoplexy. His extremities were cold, and after vainly trying to revive him by friction and by the application of warm stones on his hands and on the soles of his feet for several hours, I decided to give him an emetic; a great quantity of foam was thrown up, and in two or three days he recovered completely. I think that this secretion of foam is an effect peculiar to the inhalation of toxic vapors. (P. 420.)"

At about this same time the brothers Gerard began the celebrated series of journeys across the Himalayas.

In 1817 (August 27 to October 14) first journey of Captain Alexandre Gérard, from Soobathoo to Rarung and return. He was accompanied part of the way by Dr. Govan, of whom we shall speak later. His account was published for the first time from his travelling notes by Lloyd in $1841^{214}$ (P. 191-267). There is no mention of mountain sickness in it.

The next year he set out again, this time accompanied by Dr. J. G. Gérard, his brother. They went from Soobathoo to Shipke, and returned to Soobathoo (September 22-November 22, 1818). 
From the simple notes which they published ${ }^{215}$ I extract that which concerns our subject:

October 2. Our tent is pitched at an altitude of 15,095 feet; on the pass which separates Choara from Koonawur, there is only scanty grass and a little moss .... During the night which we pass there we all feel violent headaches, probably due to the rarefaction of the air, but which the natives attribute to a toxic plant which grows abundantly at great heights. (P. 366.)

October 7, crossing of the pass of Toongrung (13,729 feet), no effect noted; October 12, the same, at 13,518 feet, at the pass which separates Koonawur from Chinese land. October 16, camp at 14,900 feet, and October 18, ascent of a peak rising to 19,411 feet (5915 meters) :

Violent headaches, hardly permitting us to make any efforts .... The natives refused to go on .... To tell the truth, we ourselves could no longer walk, so severe were our headaches, with general weakness, and keen pains in the ears and chest .... The thermometer did not fall below $22^{\circ} \mathrm{F}$. . . and yet because of the wind, my hands were so numb that I had to rub them for a quarter of an hour before being able to use them ....

The travellers who cross the pass of Gangtung consider it extremely difficult: they are covered with garments to defend them against the excessive cold, and they complain of terrible pains in the head and ears; goats, sheep, and men often die there. (P. 377.)

October 24, the pass of Hungrung (14,837 feet); October 25, the pass of Roonung (14,508 feet); no indication. November 22, return to Soobathoo.

Alexandre Gérard soon set out on a new journey. This time, he intended, if possible, to go up to the sources of the Setlej, one of the tributaries of the Indus, which comes from Lake Manasarowar. The narrative of this journey forms the second volume of a work published in London in $1840 .^{216}$ It had already been published in a shorter form in a scientific journal of Edinburgh, in 1826 and $1827 .^{217}$ Both accounts are extremely chary of descriptions and particularly of the physiological type. I quote from the volume published in London.

The journey began June 6, 1821; Al. Gérard set out from the land of Rol, at an altitude of 9000 to 10,000 feet. At the summit of the pass of Shatool, at 15,555 feet (4738 meters), where we shall see that his brother was to suffer so greatly, he merely says:

June 9. We slept very little, because of headaches and difficulty in breathing. (P. 15.) 


\section{At the pass of Boorendo:}

June 16. As usually happens at these altitudes, we hardly slept at all, worn out by headaches and an extreme difficulty in breathing. (P. 37.)

At the pass of Keoobrung, 18,313 feet, he is a little more explicit:

June 24. I felt great difficulty in breathing, and great weakness, but no headache, although my followers suffered from the acceleration of circulation noted by M. Moorcroft: the temperature was $46^{\circ}$.

August 30, he made the ascent of the pass of Manerung at the enormous height of 18,612 feet (5671 meters).

We were ascending the mountain very slowly; respiration was difficult and we were almost exhausted at every step. The crest of the pass was not visible, and we did not know when our troubles would end: the road ascended at an angle of $30^{\circ} \ldots .$.

Our situation was different from anything we had experienced before; it cannot be described. Long before we reached the summit, our respiration became panting and oppressed, and we were forced to sit down after a few steps; even then we could hardly inhale a sufficient quantity of air. The slightest movement was accompanied by weakness and mental prostration. We suffered thus for two miles; the last half-mile was in perpetual snow. At the summit, the barometer registered 15.300 inches, the thermometer $36^{\circ} \mathrm{F}$. . . .

Several of my followers could not cross the pass on account of headaches. The length and the difficulty of the ascent, the rarity of the atmosphere, the rigor of the climate, although it was summer, make this pass dangerous to the sturdiest persons. (P. 240.)

September 29, he had reached Kotgurh, the end of the journey. In the first volume of the work published by Lloyd, there is a letter from Dr. Gérard, narrating his journey to the passes of Shatool and Boorendo, with the purpose of determining the line of perpetual snow. It is dated from Lake Charamace, at 13,800 feet, August 18, 1822.

At the height of 15,000 feet, the same symptoms attacked him and his travelling companions:

I cannot describe the extreme fatigue which the last 500 feet caused us. Distressed, sick, we could not use our arms to break off a piece of stone with a blow of the hammer. Respiration was free, but insufficient, our legs could hardly support us, and our faces were drawn as if we were going to have the fever ....

All my people were in a wretched condition, I suffered from headache, and everyone was complaining. (P. 308.)

It was August 9, they reached the summit of the pass of Boorendo, at more than 15,500 feet, the thermometer standing at $37^{\circ}$ : 
During the descent, I felt again the symptoms of headache, and they did not leave me until after noon; I went out to get flowers, but I was obliged to return to camp (12,800 feet). I awoke at daybreak, unrefreshed by sleep. I had the same feeling of weakness and languor as on the ascent, but not so bad. (P. 315) . . .

My visit had removed my doubts on the phenomena of new snow in the passes in July and August, and I had hardly any reason to doubt the strange tales of the dwellers at the foot of the mountain about the symptoms which sometimes attack travellers crossing it. They say that the phenomena of drowsiness and weakness are much more to be feared in the rainy season .... .

The people who live at the foot of the mountain and who breathe in a very much rarified air, or who are accustomed to climbing their steep slopes suffer much less than those who inhabit a lower zone in a denser atmosphere; but they know these effects very well, and describe their sensations with ingenious and very interesting simplicity ....

Between Koonawur (where the people seem born to live and die in inaccessible regions) and the Indian slope of the mountains, we travelled for a long time on the crests of mountains, at a positive elevation of 16,000 feet: I met every day a crowd of people laden with grain; they were walking slowly, stopping often to get their breath, and they seemed to suffer from a uniform oppression. I have not ascertained whether they are subject to an illness like the one I experienced, and yet it must be so, and it is undeniable that above a certain height, the effects of the rarified air upon the functions of animal life are permanent and that neither habit nor constitution can conquer them. (P. 320.) . . .

Sandy and I, in our excursion to the peak 19,500 feet high, although unable to take a dozen steps without being exhausted, and finally being hardly able to move at all, nevertheless were better than the villagers who accompanied us, and who live at the altitude of 12,000 feet. In the interior of the country, where the ground is very high, the most dangerous symptoms appear while crossing the mountains. Between Ladak and Yarkand, an intelligent servant of $M$. Moorcroft told me of the fatal consequences of lack of precaution. He says that the passage of the highest range should be made fasting, and recommends frequent doses of an emetic during the journey. He told me the story of a Russian merchant in good health, who was going from Ladak to Lee to see M. Moorcroft, and who died while crossing one of the passes because he ate a good meal before starting. Death, in such a case, should be attributed to the drowsiness brought on by the cold and the extreme rarity of the air which predisposes to inactivity and leads the traveller to his last sleep. (P. 325.)

I took a little walk over the cliffs, but the sensation of fullness in my head forced me to return. Since I arrived here, I have been more or less affected by headaches, particularly violent at night; the pain was not like that of ordinary headaches, but as if an overwhelming weight (a dead weight) was attached to all sides of the head, pushing it in different directions. Tea relieved me, but only for a short time. (P. 325.) 
I suffered greatly at night from headache and from a sort of drowsiness, such as occurs in drunkenness. I have never felt such evident proof of the existence of an agency dangerous to the principles of animal life, and although I suffered much more in the pass of Boorendo, in 1818, the illness did not last day after day, as it did here. All my servants were also affected, some by nausea, others by headache; they were not all equally affected, but we could judge that that was only a matter of chance; we should merely say that the natural conditions of energy and action are not always the same....

The extremes of the barometer here were from 17.055 inches to 17.160 inches; those of the thermometer from $41.5^{\circ} \mathrm{F}$. to $53^{\circ}$; which gives the pass of Shadool an elevation of 15,500 feet. (P. 326.)

Captain Al. Gérard, moreover, has left us in a special chapter of a posthumous work, ${ }^{218}$ a summary of the data which he observed in his numerous excursions:

On lofty mountains, a depression of spirits and a weakness of body, accompanied by cruel headaches, fullness in the brain, oppression of the chest, difficulty in breathing, with pain in the ears from time to time, affect everyone more or less. All these symptoms result from the rarefaction of the air, and of this I have had numerous proofs, having visited thirty-seven places at different times, between 14,000 and 19,400 feet, and thirteen times my camp was pitched above 15,000 feet. It should be noted that the people of Koonawur and the Tartars estimate the altitude of the passes by the difficulty in breathing which they experience when they make the ascents of them.

However it should be noted that the difficulty in breathing does not affect everyone equally or at the same time; it certainly depends largely on the state of health. When I was not well, I suffered from headache at 13,000 feet, whereas in good health I felt no effects at 16,000 feet. At Boorendo (15,000 feet) I was very cold, and experienced, even when resting, a greater suffocation than ever happened to me at 19,000 feet, while I was walking.

Any fatigue, but especially the ascent of hills, increases these symptoms: from 17,000 to 19,000 feet, the headaches are constant, and no one can take more than a half-dozen steps without resting.

When one camps above 16,000 feet (4875 meters), the difficulty in breathing is really terrible, and often for whole hours I thought I was going to suffocate.

Persons who have not made such journeys can hardly imagine how much time it takes to cover a distance of twelve or fourteen miles in lofty places. I have gone thirty-four miles on foot in lands which would be called mountainous by those who do not know the difficult parts of Koonawur, with more ease and in less time than I could walk twelve miles in these lofty regions. An ascent of 5000 or 6000 feet is not rare, and when the elevation is more than 14,000 feet, every mile, even when the road is good, requires at least twice as much time as at the height of 7000 to 8000 feet. The prostration of mind and body experienced on lofty mountains affects everyone 
more or less, and one of my friends was more wearied by an ascent and a descent of 5000 feet, in a total walk of nine miles on lofty ground than in going from Nahun to Soobathoo, which is 45 miles. (P. 57-59.)

The observations of Captain Hodgson who, in 1817, went to the sources of the Ganges and one of its principal tributaries, the Jumna, deserve to be quoted for the same reason: ${ }^{219}$

We experienced a great difficulty in breathing and that peculiar sensation, constant at great elevations where there is no verdure, which I have never felt anywhere as severely as on fields of snow, even when I ascended higher....

The mercury stood at 18.854 inches, at a temperature of $53^{\circ} \mathrm{F}$. so that the altitude was 12,914 feet (3935 meters). (P. 111.)

It was May 30; the travellers had reached the source of the Ganges.

These countries were visited ten years afterwards by Captain Johnson, whose account ${ }^{20}$ gives data identical with those of his predecessors. Moreover, the dangerous effect of lofty places is well known to the people of the country.

In fact, July 1 and 2, 1827, Johnson made the ascent of the peak of Tazigand or Pendjeoul:

The natives, learning of M. Johnson's plan, tried in vain to persuade him to abandon it by exaggerated accounts of the innumerable difficulties which it presented and of the dangers of the bis or poisoned wind which blows over the snow. (P. 160.)

Moreover, a fact which deserves mention and of which we shall subsequently find many examples, the people dwelling in the country suffer much more than the Europeans:

On July 2, Captain Johnson occupied the same ground as that where Dr. Gérard had made his barometric calculations at a height of 19,411 feet ( 5915 meters) above sea level . . .

The natives who had guided him there found breathing very difficult; they stretched out on the snow, holding their necks in both hands, and the Sepoy nassir, who was the only one to reach the greatest height, complained a great deal also. It is surprising that our compatriots felt no distress. They occasionally experienced difficulty in breathing; but they had blisters on the hands and feet and momentary blindness from the glare on the snow. (P. 162.)

The French traveller Jacquemont seems to disagree with the statements of all his predecessors. At least, he declares that he felt no symptoms at heights often equal or superior to those at which the English travellers suffered so greatly. This difference 
made such an impression on him that he reported ${ }^{221}$ it to the professors of the Museum of Natural History, and tried to explain it:

Kurnaul, February 1, 1831

Several English travellers have crossed the pass of Bouroune (about 15,000 feet), and all complain of the headaches and nausea they experienced there. I have gone through much higher places, because I camped three times above 16,000 feet, and on my way to Beckhur, I had to cross passes at an altitude of more than 18,000 feet. I have never felt any of the painful symptoms of which all travellers on lofty mountains complain, and I have never observed them in even one of the numerous companions of my excursions. I lived seven months in the Himalayas; I have ascended from their feet to their summits; at the time of my journey to Beckhur, four times I ascended to an altitude of 6000 meters, and for almost two months I almost never went below 3000 meters; then I camped at 4000 meters after a stay at 5000 meters. When the ascent is so gradual, the lungs easily become accustomed to working freely in an atmosphere which gradually becomes more rarified. It is a very considerable change of level in a short time that affects them and produces the oppression mentioned by Saussure and all who ascended Mont Blanc after him, long before they reached the summit. (P. 53.)

The interesting notes he left, which were published after his death, ${ }^{222}$ contain very interesting observations on this subject, to which he had given particular attention:

May 16, 1830, I reached an altitude of 3927 meters . . . . This was the first time I had ascended to so great a height; it exceeds that at which the effects of the rarefaction of the air begin to be felt painfully in the Alps. I did not feel them at all; I was no more out of breath than I should have been at the lowest level, if I climbed equal grades with the same speed.

I saw no real symptoms in any of the people who followed me; no panting, nor drowsiness, nor nausea.

It seems to me that in the temperate climates, on parallels like those of the Alps and the Pyrenees, one feels them sooner than on mountains nearer the equator. If this statement stands out uniformly in the testimony of travellers, it is hard to explain. The effect, if it depends solely on the atmospheric rarefaction, should be the same at the same altitude in all the regions of the earth, or even greater in the tropical countries where the temperature rarifies the air more at the same elevation. (P. 101.)

Jacquemont refers repeatedly to this harmlessness of the heights of the Himalayas compared to the bad effects in the Alps; in the following passage he even offers an explanation of it which has some foundation:

I crossed the pass of Rounang, at an elevation of more than 4267 meters, three times, on horseback. 
This elevation is higher than that at which travellers claim to have begun to feel the effects of the rarefaction of the air in the Alps and the Pyrenees. I did not feel them at all. Perhaps the breathlessness from which Saussure and his guides and all those who followed his steps on Mont Blanc since then suffered was only the result of a long and difficult march on exceedingly steep slopes. Perhaps if one could be carried from Chamounix to the summit of Mont Blanc, one would escape the illness which is generally attributed to the rarefaction of the air at its crest. The Gérard brothers, who are undeniably the foremost travellers in Alpine regions, constantly complain of excessive fatigue and violent headaches on all the passes they crossed, between 4572 and 5791 meters; and this painful condition continued as long as they remained at these heights, where they camped several times. From that fact it would seem that this illness was not merely the passing effect of fatigue caused by a long climb, but really an effect of the atmospheric condition ....

The elevation of Mont Blanc is 3780 meters above Chamounix, which is only about 1036 meters above sea level. The ascent is made in thirty hours. There is an enormous change in atmospheric pressure in which one is immersed, and in a very short time. So sudden a transition, independent of the fatigue involved in making it, can definitely affect the respiratory organs. Here, on the contrary, for more than three months, I have been living at an elevation on the average 1829 meters above sea level, and for the last month, at 2743 meters, an altitude at which I feel none of the effects of the rarefaction of the air. When I ascend to an absolute elevation of 4572 meters, I pass through a vertical difference of only 1829 meters, half of that which exists between Mont Blanc and Chamounix, and I have no sensation which I can refer to a respiratory disturbance. Finally, the proof that the annoying symptoms felt by travellers on the summit of the Alps or on the passes of the Himalayas would vanish in time, and that their lungs would find enough oxygen in an air which has lost half its density, is the existence of the farm of Antisana in the Andes, which M. von Humboldt told us about, at an elevation of about 4114 meters, where a family lives, plows, and works. There is no doubt that the lake of Manasarowar exceeds this height by 305 to $457^{22.3}$ meters, and yet there are dwellings on its banks, and pilgrims go round it in a seven day journey. M. Gérard himself proves very satisfactorily that a considerable portion of the high country, in which the Kanaweri merchants travel in going from Shipki or Skialkur to Garou (Gortope), is above 4877 meters in elevation, and yet these merchants do not complain there of symptoms by which we see them attacked when crossing passes often at a lower altitude; whence I conclude that in the latter case it is from the fatigue of the journey that they suffer, laden as they are, whereas in the lofty plains of Chinese Tartary, they walk empty-handed on an almost level road.

I myself have felt at an elevation of 4000 meters some of the symptoms in question, that is, fatigue and headache. But I have hardly ever mounted to this height without being exposed to a furious wind, and whatever precaution I took against its cold, I was always chilled, and 
this acting first in me upon the digestive tract, caused a disturbance in the digestion, of which the headaches were evidently the consequence. (P. 259.)

The following observations corroborate the first explanation given by Jacquemont:

August 11, 1830, I reached the altitude of 5486 meters on the pass of Gantong; at the summit, I felt absolutely no difficulty in breathing, as long as I remained motionless, carried by my horse, but when I tried to walk on an almost level road, fatigue and panting appeared promptly. And yet I saw my servants, to reach the summit of ihe pass, walk several hundred steps on very moderate slopes of snow, without stopping to get their breath; only one was sick. (P. 288.) ...

August 16, at the pass of Kioubrong (5581 meters), the same immunity; I ascended there rapidly over a very gentle slope, and walked quickly for more than an hour, without feeling any special lassitude caused by the elevation, no pains of the head or ears, no tendency to sleepiness, in a word, nothing particular, perhaps, but a slight panting; and in fact, after a few minutes rest, my pulse rate was 82. (P. 297.)

The limit of perpetual snow in this region of the Himalayas is hardly below 6000 meters, according to Jacquemont.

Finally, Jacquemont wished to fix clearly the conditions of the problem by a personal experience:

I had ridden on horseback to Kioubrongghauti, and since the experiment which I had made there of walking rapidly for an hour in a place with an altitude of 5600 meters, after reaching it without any fatigue, left me without doubt as to the cause of the strange symptoms experienced by travellers who ascend to the summit of Mont Blanc, I wished to climb the pass of Gantong on foot, to see whether the walk, which was prolonged but prolonged moderately for only five hours and very slowly, with numerous intervals of rest, on slopes which are really very steep, but whose vertical height did not exceed 1000 meters, would reduce me to the state of exhaustion described by $M$. Gerard as the immediate consequence of the slightest movement, as soon as one reaches the absolute elevation of 4572 meters. That was just the level of my starting point.

Stimulated at the beginning of my walk by the morning chill, sustained beside by the freshness of the wind, preoccupied by interest in the objects which I saw at every step, often stopped by them, and taking care after walking three hours to eat a light lunch to ward off any feeling of hunger, which, I have found, always produces in me in lofty places an extreme weakness and headaches, I arrived without weariness, and almost without perceiving it, at the summit of the pass of Gantong, at an elevation of 5576 meters. (P. 302.)

But if Victor Jacquemont was almost free from any acute symptom, and did not see any appearing in his travelling com- 
panions and his beasts of burden, it is far from being true that all travellers have enjoyed the same immunity.

In fact, in the annals of Berghaus, for March, 1832, we find the following quotation, relating to a passage of the Himalayas on the border of Sutlej; the name of the traveller is not mentioned:

At an elevation of 15,000 feet, respiration becomes difficult; the traveller feels great lassitude, vertigo, headaches and unquenchable thirst. It is impossible to describe the sensations produced by extreme rarefaction of the air; one constantly feels as if he were smothering; respiration accelerates in a very painful manner, the elasticity of the skin diminishes. The highest ${ }^{224}$ point of the pass is at an elevation of 16,500 feet. (P. 547.)

Moreover, Lieutenant J. Wood, ${ }^{225}$ who made a journey to the sources of the Oxus in 1836, 1837, and 1838, gives numerous and interesting details on this subject.

February 20, the expedition reached the plateau of Pamir, the altitude of which is 15,600 feet, the mountains surrounding it rising 3000 or 4000 feet higher; the party was at the sources of the Oxus, on the shore of a frozen lake:

We began to break the ice to sound the depth of the lake. The ice was $21 / 2$ feet thick, and because of the great rarity of the air, a few strokes with the picks exhausted us so much that we had to lie down on the snow to get our breath. (P. 360.) ...

Fifty steps at full speed set us to panting. In fact, exercise brought on pain in the lungs and a general exhaustion which did not improve for several hours.

Some of us suffered from vertigo and headaches, but except for these various phenomena, I felt nothing and saw nothing in the others which resembled the sufferings experienced by travellers in the ascent of Mont Blanc. In the latter case, the transition from dense air to rarified air is so sudden that the circulation does not have time to adapt itself to the difference in pressure, so its speed increases in some of the most sensitive organs of the body. The ascent of Pamir, on the contrary, was so gradual that it required "extrinsic" circumstances to remind us of the considerable altitude which we had reached.

The effects of the great elevation had, however, been proved to me some time before in a manner for which I had not been prepared. One evening, in Badakhshan, as I was sitting reading by the fire, I had the idea of feeling my pulse, and its rapid and wild beating aroused my attention. I imagined that I had been attacked by a violent fever, and I used the precautionary measures which Dr. Lord had prescribed when he left. The next day, my pulse was as rapid as on the day before, and yet I felt in excellent health. I thought then of examining the pulse of my companions, and to my great surprise I found that theirs were more rapid than mine. The cause of this increase in circulatory activity was evident to me at once; and when 
we next went toward Wakhan, I counted the pulse of my companions every time I recorded the boiling point of water.

The changes in the pulse thus form a sort of living barometer, by means of which a man accustomed to examining himself can, at great altitudes, estimate roughly the elevation.

On Pamir, the pulse rate gave the following figures:

Myself 110

124

Gholam Hussein, Munshi

Omer-Allah, muleteer 114

Gaffer, servant 124

Scotland fat

Dowd, servant Jasulmeere fat Afghanistan _....... thin Peshawuree _._.___ thin

The elevation of the snow line in this region is above 17,000 feet (5180 meters). (P. 352.)

Lieutenant Wood was accompanied for part of his journey by Al. Burnes, an envoy to Caboul. October 19, 1837, two others of their companions, Lieutenant Leech and Dr. Lord, went to reconnoiter and cross a pass of Hindu-Koush, going to Caboul. The pass is about 15,000 feet high; the snows would soon render it impassable; the ascent was easy. However, says Burnes: 226

The horses were in a very pitiful condition, and they had to dismount and walk. No one had any symptoms, but the natives informed them that they themselves were frequently attacked at this point by vertigo, faintness, and vomiting. (P. 152.)

Some years later, a French traveller, who travelled over not the Himalayas, but the much less lofty regions of Upper Tartary, made a pitiful story of his sufferings. It is true that one must be on his guard against the statements of Father Huc, ${ }^{227}$ whose credulous simplicity is almost boundless. Nevertheless, the vivid picture which he has left us of the sensations experienced during the passage over Bourhan-Bota, a mountain the height of which he does not give, and which seems to be situated about longitude $95^{\circ} \mathrm{E}$. and latitude $40^{\circ} \mathrm{N}$., deserves to be reproduced here. The day of the ascent is not specified, nor is the temperature of the air:

We prepared to cross Bourhan-Bota, a mountain famous for the pestilential vapors in which, they say, it is continually enveloped....

Soon the horses refuse to carry their riders, and everyone proceeds on foot slowly. Gradually all faces grow pale, nausea comes on, and legs refuse to function; one lies down on the ground, then gets up and makes a few steps more; then one lies down again, and this is the miserable fashion in which one climbs this famous Bourhan-Bota. Good heavens! What wretchedness! One feels his strength broken, his head whirls, all members seem to be disjointed, one feels illness exactly like seasickness, and in spite of that, one must save enough 
energy, not only to drag himself along, but also to beat energetically the animals which constantly lie down and refuse to go on. A part of the group, as a matter of prudence, stopped half-way, in a depression where the pestilential vapors were less thick, they said; the rest, also out of prudence, exerted all their powers to get through with it and not die from asphyxia, in the midst of this air laden with carbonic acid. (P. 256.)

The travellers whose accounts I shall now mention agree much better with what the Gérard brothers said than with the extreme statements of Jacquemont and Father Huc.

July 14, 1845, Hoffmeister ${ }^{228}$ reached the highest point of his journey, the pass of Lama-Kaga (Thibet) at the elevation of 15,355 English feet; the temperature was $-50^{\circ}$ Réaumur; the snow was falling:

About an hour and a helf passed before our first coolies arrived with our baggage. They were in a very sorry state, and were suffering, as well as our interpreter $M$. Brown, from headaches which they described as unbearable. Loss of strength, pains, and nausea are the symptoms of this illness which they call here Bies (poison) or Mundara. It attacks travellers thus at the line of perpetual snow. In the coolies it appeared halfway up the pass. As a remedy against it they use a sort of paste made of little sour apricots and their seeds. (P. 242.)

In the account of Dr. Th. Thomson, ${ }^{229}$ it was not only the coolies, but the European traveller himself, who was affected by the altitude.

September 6, 1847, Thomson and his attendants camped at an altitude of 14,800 feet, and on the 7 th, they ascended to 17,000 feet (5180 meters) :

The whole day long I had never been free of a violent headache, evidently caused by the great elevation. Rest relieved it, but it reappeared at the slightest movement. It lasted all evening, as long as I was awake, and I still had it on the morning of the 8th, when I got up at daybreak to prepare for the journey ....

The ascent next day was extremely steep and difficult. The act of raising one's body was very tiring, and the last few hundred yards were covered only after several pauses .... I reached the summit of the pass of Parang at a quarter of eight in the morning; I was at an elevation of 18,500 feet ( 5640 meters); the temperature was $28^{\circ}$ .... the snow was frozen ... the wind blew violently .... We descended without fatigue .... (P. 135.)

After living a year in these lofty regions, Dr. Thomson reconnoitered towards the north, as far as the celebrated pass of Karakorum, at a height of 18,604 feet (5670 meters). There again, his 
symptoms reappeared, or to speak more exactly, they became so intense that he was compelled to make special mention of them:

August 19, 1848. During these three days of ascent, I suffered greatly from the effects of the rarefaction of the air, being constantly tormented by a painful headache which the least exercise aggravated ... The temperature of the air was $50^{\circ} \mathrm{F}$.

The botanist Dalton Hooker is still more explicit. ${ }^{2: 30}$

At the height of 16,000 feet, while ascending the pass of Kanglachem, December 2, 1848, in eastern Nepal, Hooker experienced difficulty in breathing, great lassitude, vertigo and headache. (Vol. I, p. 247.)

Some days afterwards, on the mountain of Nango, at a height of 15,000 feet:

I found it quite impossible to remain composed because of the increase of the pains in my forehead, lassitude, and oppression. (P. 252.)

July 25,1849 , crossing of the pass of Kongra-Lama $(15,741$ feet) :

After two hours, I was chilled and stiff, and was suffering from headache and vertigo due to the elevation. (Vol. II, p. 82.)

September 18, ascent of the pass of Sebolah (17,517 feet):

I took the pulse rate of eight persons after a rest of two hours; it varied from 80 to 112 , mine being 104 . As usual at these altitudes, everyone was suffering with vertigo and headaches. (P. 142.)

October 15, night passed at an elevation of 17,000 feet:

My coolies were in good health; but those of Campbell were in a very sad condition of pain and fatigue; their faces were swollen and their pulses rapid; some were practically insensible with symptoms of weak cerebral pressure; the latter were especially the Ghorkas (natives of Nepal). I have never experienced bleeding from the nose, ears, lips, or eyes, and have never seen such symptoms in my companions on such occasions; nor have I met any recent traveller who has experienced them. Dr. Thomson has noted this too, and when we were together in Switzerland, we learned from A. Balmat, Fr. Cartet, and other guides of experience on Mont Blanc that they had never witnessed these symptoms, nor the darkening of the skin, so frequently mentioned by Alpine travellers. (P. 160.) ....

October 17. It is quite surprising to see that Turner nowhere alludes to difficulty in breathing, and speaks only in one place of headache, even at this great elevation. That is probably because he was always on horseback. When I was riding, I never felt any disturbance in my breathing, my head, or my stomach, even at 18,300 feet (5580 meters). (P. 167.)

We see that it is while they are crossing passes that travellers feel symptoms; ascents, properly so-called, of isolated mountains 
are, in fact, extremely rare. However here is one, in which Captain Robertson, ${ }^{231}$ in October, 1851, reached the summit of Sumeru-Parbut, at a height which he estimates as about 20,000 feet (6100 meters). The preceding night was passed at nearly 4000 meters:

The next morning, we left our tent at ten minutes past eight, and at thirty-five minutes past one reached a sloping glacier. At this point, vision and respiration became very painful for Lieutenant Sandilands and several of our guides . . . .

Sandilands reached a spot half an hour's distance from the summit, where he was so affected by the rarefaction of the air that it was physically impossible for him to go any further; he therefore turned back, with the only Rajput who had followed him thus far, the others having abandoned him long before; my Brahmin, a handsome young man of strong constitution, who came with me to the summit, apparently felt no effects, but when we reached our tent again, he could eat nothing. As for me, my eyes were painful, and my respiration and my vital force were affected, but yet I had enough energy and physical force left to climb still higher. On my return to my tent, my appetite was not affected at all, and I ate a hearty supper.

But the most interesting accounts I have found in my reading are certainly those published by Mistress Hervey. And that is easy to understand; a simple tourist, not heeding politics or geography, or science, she gives special attention to everything relating to her health and the little incidents of her journey, which she tells obligingly in all their details. Besides, since she has rather a weak constitution, she seems to be easily affected at rather low levels.

So it is to mountain sickness that we must attribute part of the following symptoms, although the elevation is very moderate:

June 25. We halted (after crossing the pass of Rotung $(11,000$ feet, 3350 meters) in Lahoul) ... Captain $H$. came to say good evening to me in my tent about nine o'clock, and noticed that I was very pale, and that my face and hands were cold and clammy. I was then very sick; I was delirious; I was nauseated, my hands and feet were icy cold. Convulsions came on and I frothed at the mouth. I stretched myself on the ground, and remained there in great distress; they gave me two doses of Luce water, and put my feet in water which, though it was boiling hot, could hardly restore the circulation. Yesterday I was sick all day and unable to get up; my pulse rate was not less than 108. I am better this morning, but my pulse rate is still very high, although less irregular.

Captain $H$. declares that this sudden illness is due to the rarity of the air of the pass .... If I am already affected thus, what will happen at 16,000 or 17,000 feet? (Vol. I, p. 117.) 
But if doubt is possible in this case, it certainly is not in the following quotations. July 6, crossing of the pass of Bara-Lacha; Mistress Hervey was very ill:

I had severe pains in my legs, and felt extreme lassitude, long before reaching the summit of the pass; but I made a violent effort to overcome these sensations, and succeeded in riding to the summit. As soon as we dismounted, a terrible, splitting headache attacked me. Before reaching Yûnnumscutschoo, I had suffered from nausea and felt as if my head were going to split. The principal sensations were a very painful and very intense throbbing in my temples, violent nausea, pains in my legs, and a lassitude amounting to prostration. No one else was sick in the camp, except Ghaussie, who had a bad headache.

I could not get to sleep at night before one or two o'clock, and was awakened by the throbbing of my heart, so violent that I felt serious fears about it. My pulse was galloping, my head was burning and my temples throbbed, and I was wretchedly nauseated. We did not set out until late the next morning, and if I had not felt better, we could not have moved at all. Captain $\mathrm{H}$. told me that he had had a bad headache during the night, that he had felt tired and ill, but that nevertheless he had not suffered as much this time as the last time he had crossed the pass, for then he had had the same sensations as I ....

The pass of Bara-Lacha is, I think, between 16,000 and 17,000 feet above sea level, according to Captain Cunningham. (Vol. I, p. 133.)

Mistress Hervey then relates that the natives of the country attribute all these symptoms to the effect of a poisonous plant; but this time, the plant is a kind of moss. We shall quote this passage in Chapter III.

The next day, the road, which still ran along at great heights, several times forced the travellers to ascend small hills:

As we ascended (says Mrs. Hervey) I noticed a great many poisonous mosses, two or three species of which were growing on bare rocks.

I had a terrible headache, and was shivering with a return of the terrible "pass sickness" or, as the natives say, from being "boittee luggeea", that is, affected by the plants.

Tomorrow we shall ascend the Lòng-Illâchée Joth (or pass), and descend it, which promises to me a fine day of bôttee. (Vol. I, p. 139.)

And in fact, when she reached Rokchin (Ladak) the next day, Mistress Hervey declared that she was so sick and so weak that she could not write. July 9 , after a night's rest, she could hardly write and had to remain lying down. Two of her servants were 
very sick. Captain $H$. suffered during the night from a violent headache. (P. 142.)

July 11, passage of a place the height of which Mistress Hervey estimates at about 17,000 feet:

I had a worse headache than usual with a terrible oppression of the chest. It is true that since the crossing of the pass of Bara-Lacha, I have constantly suffered greatly from the effects of the rarity of the air; a constant headache, and, especially during the night, a painful pulmonary discomfort, and a very annoying acceleration of the movements of the heart. I had hardly an hour of continuous sleep; I had to sit down on my bed, as I could not breathe when I was lying down. These lofty regions do not suit my lungs. (P. 152.)

The following night, camp at 14,800 feet on the banks of Lake Chôômorêêree:

I am now afraid of the night, because, far from sleeping, I suffer terribly. Yesterday, it was really very painful; besides a cruel headache, I suffered from great oppression in the chest, and my heart went at a railroad pace, when I moved even an inch in my bed. (P. 153.)

These sufferings were so great that they decided her to change her route a little, to avoid great heights (P. 162). And yet, July 16, when she reached the foot of the pass of Tunglund, she wrote:

We saw much poisonous bootie today on the road. I was wretchedly sick all night. About eleven o'clock in the evening, the respiratory oppression and the suffocation became so unendurable that I had to sit up on my bed to get my breath a little. (P. 169.)

The next day, ascent of the pass (between 16,000 and 17,000 feet) :

The odious moss of which I have spoken so often covered the pass, and long before I reached the summit, I had a most violent headache. But I had no nausea, perhaps because the pass is very easy. (P. 171.)

July 19 of the following year, in spite of her continued residence in the lofty regions of Little Thibet, Mistress Hervey was not acclimated, for, as she crossed the pass of Brarmoorj in Wurdwun (from 15,000 to 16,000 feet), she said:

I suffered from an absolutely unendurable headache, which kept constantly increasing; but I did not have the nausea which I always felt on all the passes of Ladak. (Vol. II, p. 298.)

And August 5, 1851, while crossing the pass of Hânnoo (between 15,500 and 16,000 feet), in Ladak, a pass of rather easy access, she suffered horribly; it is true that she was already ill. She said the next day: 
I have crossed many passes, but until today I had never experienced the terrible sensations which almost made me crazy before I was halfway and long after I had left the great heights. My sufferings might have been aggravated by my illness, but in any case, they were crushing. I lay down on the ground at Dorâ, more dead than alive, and my servants made me a tent of blankets. I was in such a state of prostration that not only was I unable to rise, but I could not bear to be carried in a "dhoolie" . . . . A violent headache, unbearable nausea, hasty palpitations, and the inability to breathe deeply, such were the symptoms of the well known boitie, which attacked me more severely than ever before I reached the summit of the pass. I am sure that if I had stirred about for a quarter of an hour during these horrible sensations, some blood vessel would have broken and I should have died on the spot. Just speaking was a painful exercise, which brought on copious hemoptysis and increased my pulse rate far beyond 100 per minute. I was terribly nauseated, and the exhausting power of this distress can be compared only with the nausea of seasickness. I was also very wretched and my sufferings were intense yesterday. Even today I cannot breathe without pain, and my heart beats violently and irregularly; I have not yet forgotten the rarified atmosphere of the pass of Hânnoo.

As they werc carrying me yesterday about a half-mile from the summit, Ghaussie called my attention to one of my servants, who was lying unconscious on the snow. They woke him easily, but he refused to move, saying that his head "was going to split in two." After a slight struggle between humanity and strongly rooted prejudices, for the sick man was a sweeper, the lowest class of servants, I sent him my own pony to carry him; if he had been left there, he would certainly have died during the night.

While I am speaking of the illness on this pass as a case of bôstie, I must confess that I did not see a single plant of the particular kind of moss, which, in the passes of Ladak and Lahoul, are considered as poisoning the wind and causing the painful illness which I have described.

One of my servants from Cashmere was the only other person among my attendants to be affected; distress in high altitudes is therefore not a rule without exception. (Vol. II, p. 367-370.)

And the next day, as she set out from Scheerebookhchun, she wrote:

I shall travel by moonlight, for I have been so sick all day that I have had very little desire to move. If I let myself be governed by the painful sensations which have tried me so much, I should not start now, but that might be impolitic. In my opinion there is nothing like exercise to overcome our little bodily and mental troubles.

I must practice what I preach, and ride horseback this morning, sending my dhoolie on ahead. (P. 378.)

She set out at sunrise, and went on horseback to Kulatsey.

I was then so sick and so exhausted that, not finding my dhoolie there, I lay down on my shawl on the ground for several hours. At 
last, towards evening, another dhoolie was ready, and I could get into it ... I have not recovered from the effects of the rarified air on the pass of Hânnoo. My heart beats violently and irregularly, and when I breathe, I have severe pains in my chest. My distaste for nourishment is so great that I can hardly touch any food all day long. (P. 378.)

August 14, crossing a sort of a pass, near Ghia:

I have suffered from a very painful headache, but have felt no nausea, although I recognized my old enemy, the bôtie, the fatal moss of Ladak-Oôjar. When I walked fifty steps to pluck a flower, the throbbing of my heart increased terribly, and repeated doses of digitalis have not quieted its hasty and violent beating. I do not know any sensation that is more alarming and more painful than this exaggerated action of the heart. None of my servants felt any ill effects ....

I reached Zurra at sunrise. I am completely prostrated by my splitting headache, although I have escaped nausea, and that is the only consolation I have in my sufferings. (P. 397.)

August 18, camp at Chôomorêêree, at a height of 14,794 feet (4510 meters) :

I passed a miserable night, and this morning I am sick and exhausted. I had to remain thus half the night, absolutely incapable of breathing in a horizontal position; my heart beat violently with terrifying palpitations. I was really afraid of dying in the dark . . .

In the evening, we camped at an elevation of nearly 15,000 feet. I have the greatest difficulty in breathing, my chest seems loaded with an enormous weight which oppresses me painfully. These distressing sensations increase at nightfall. (Vol. III, p. 13.)

August 20, camp at the foot of the pass of Parung, at about 17,000 feet (5180 meters) :

A terrible height in which to pass the night under a tent, when one suffers from the rarity of the air as I do. Oppression in the chest, extreme difficulty of respiration, frequent spitting of blood have left me no rest during the last sixteen hours .... The cold is intense ....

At daybreak, I feel better, although I cannot breathe freely, and although the slightest movement distresses me ... My head has almost recovered, and since my courage has returned, I have decided to cross the pass .... To go on horseback is impossible, to walk is impossible too; I am riding a yak. (P. 19.)

Strange thing, that although this pass is the highest our travelling lady has crossed, she has little trouble there; no nausea, only a slight headache (P. 26). Moorcroft estimates it as at 19,000 feet (5790 meters), and Mistress Hervey goes to 20,000 feet (6095 meters). She is naturally amazed at this result: 
It is curious (she says) to note the different effects of the different passes. Although the painful sensations observed undeniably result from the rarity of the air, it is certain that the illness is not proportional to the elevation. On the passes of Bara Lacha and Hannoo, I was wretchedly sick, beyond all description, and on the pass of Pàrung, 3000 or 4000 feet higher, I had no nausea, hardly a headache. I had difficulty in breathing, but that seems to me a secondary matter.

I am far from being able to give a satisfactory reason for this difference. I have crossed so many passes that I have had many opportunities to note how little relation there is between the "pass sickness" and the elevation, of course, beyond 13,000 or 14,000 feet. The "Bischk-ke-Bôttie", or poisonous plant, covered the ground many miles around Tâtung. (P. 33.)

The journeys of Captain Oliver ${ }^{233}$ in the Himalayas also offer an account of impressions connected with our topic. In July, 1859, he crossed the pass of Roopung, at about 15,500 feet (4720 meters) :

We camped at the lower line of perpetual snow, at 14,000 feet above sea level. It was very cold ... . .

We set out the next morning over the snow .... The summit of the pass appeared in a wild and desolate scene. But I heeded if little, being occupied with myself, for the rarefaction of the air was acting upon me. I suffered from a painful shortness of breath, and soon I had to stop every two or three steps. The snow was soft, which made walking still more difficult ... I finally reached the last slope, a bank of snow 50 feet high and very steep ... But at the moment I was so completely exhausted that I was quite unable to cross it without assistance. However, after a short halt, I made a desperate effort, and somehow or other I reached the summit, where I stretched myself out on the ground, absolutely exhausted. (P. 84.) . . . .

This pass is much frequented by the Tartars who bring borax and wool to the Indian markets. They suffer greatly, however, from the rarefaction of the air, but attribute its symptoms to a poisonous plant, a fabulous plant, which, according to them, grows at great elevations.

They are also subject to violent attacks of colic in the passes .... One of my Sikhs was attacked by it; he lay down on the summit, groaning, and declaring that he was going to die; thirty drops of laudanum restored him. (P. 85.)

The same year, another traveller, Cheetam, ${ }^{234}$ took the road from Simla to Srinagar; August 17, 1859, he crossed the pass of Lunga-Lacha at 16,750 feet (5100 meters) :

I then had my first experience of the harmful effects which greatly rarified air, bad weather, and fatigue produce at great elevations.

Vertigo, violent headache, and nausea, such are the characteristic sensations, to which is agreeably added a feeling of intense exhaustion, a profound physical and mental depression. Happily, in 
me this pleasing complication lasted only a few hours, in the middle of the day, and again intermittently. I noticed that invariably I was better when descending the hills than when ascending them; and that there was a sort of connection between the appearances of the sun and my lucid intervals.

The sufferings of my Cashmere servant and the merchants of Caubul were evidently much more continual and acute than mine, particularly because of a general disturbance of which they had been complaining since the day before, at the pass of Bara Lacha.

It was impossible to destroy their absolute belief that all these symptoms were due to the poisonous exhalations from a mysterious plant, the "dewaighas" or "medical herb", which they are sure grows in these regions, although they have never been able to find any ....

The man from Cashmere was sick two days. P. 137.)

A few days after, crossing of a still higher pass, that of Tunglung, which has an altitude of 17,750 feet (5410 meters). The night camp was made at Larsa, at 16,400 feet:

The ascent of the 1350 feet which we had to climb was very rugged; the slightest effort in this rarified air made our breathing very painful. (P. 141.)

The account of Semenof ${ }^{235}$ is interesting in that it relates to the first journeys made in the high regions of the Celestial Mountains. June 25, 1857, after camping at an altitude of 7500 feet, he crossed the pass of Zauku. There thousands of carcasses of camels, horses, oxen, and dogs are to be seen:

The horse of M. Kosharof broke down .... mine slipped, cut itself deeply, and died at once; two of the horses of the Cossacks were so exhausted that they could not go on .... The guide assured us that it was so difficult to breathe at the summit of the Zauku Pass that it would be impossible to live there more than an hour and a half. (P. 364.)

We see, in this statement of the guide, an example of the exaggerations usual in all countries where very lofty places are the exception. Unfortunately, Semenof does not give the altitude of the pass of Zauku.

But no one could treat this question with more authority than the Schlagintweit brothers, whose expeditions in the lofty regions of Asia are among the most important journeys of this century, and the most fruitful from the point of view of geography, history, and the natural sciences.

They have devoted a section, in the official account of their journey, ${ }^{236}$ to the history of the symptoms of decompression. In it we see that they mounted to the greatest height ever attained by 
man in mountain ascents, that is, to 6882 meters, on the sides of Ibi-Gamin, August 19, 1855.

Here is the summary of their highest ascents:

On some very lofty plateaux which serve as pastures, a temporary dwelling for a few months was established at an altitude of about 16,500 feet (5030 meters); it is at this height, probably the highest of the sort in the world, that the shepherds of Thibet pitch their tents and even build permanent dwellings.

From personal experience we can say that for ten or twelve days, man can remain considerably above this altitude, perhaps not without distress, but positively without any very serious consequences. In our explorations of the glacier of Ibi-Gamin, from the 13th to the 23rd of August, 1855, we camped for ten full days, in the company of eight men who were our attendants, at really extraordinary elevations. During this time, our camp was pitched at 16,642 feet (5070 meters) at the lowest. The highest point was 19,326 feet (5890 meters); that is the highest elevation at which we passed the night. Another time, we camped at 19,094 feet, later at 18,300, and the rest of the time, between 18,000 and 17,000 feet $\ldots$.

One day we crossed a pass at 20,459 feet (6230 meters), and three days before, August 19, 1855, we had climbed on the sides of Ibi-Gamin to the height of 22,259 feet (6882 meters). So far as we know, that is the greatest height to which anyone has ascended in the mountains ....

On the peak of Sassar, August 3, 1856, we reached a height of 20,120 feet. Before us, the brothers Alexandre and James Gerard ascended to 19,411 feet on the peak in Spiti, October $18,1818 \ldots \ldots$

So far as the symptoms to be considered in acclimatization are concerned, we can speak from our personal experience. When we crossed passes at an elevation of 17,500 to 18,000 feet for the first time, we first felt serious symptoms. A few days after, when we had traversed the highest points and passed several nights at these altitudes, we were almost completely free from these disagreeable symptoms, even at the elevation of 19,000 feet. What the consequence of a longer stay in these lofty regions would have been, we cannot say. But we consider it very likely that a longer residence would have had serious effects on the health ....

The effect of the altitude varies with the individual. A healthy man is likely to suffer less. The difference in race is not particularly important. Our Hindu servants, who accompanied us to the highest points, suffered from the cold more than the Thibetans, their comrades, but they did not feel the effects of the decrease in atmospheric pressure more.

For most people, the influence of the altitude begins to appear at 16,500 feet, the elevation of the highest pastures. Our camels and our horses were very definitely suffering at about 17,500 feet.

The symptoms produced by the rarefaction are: headache; difficulty in breathing; oppression in the chest, which may go so far as to bring on the spitting of blood, and very rarely slight nasal hemorr- 
hages; we never saw blood issue from the lips and the ears; loss of appetite and often nausea; muscular weakness, with a general prostration and dejection. All these symptoms disappear almost simultaneously, in a healthy man, upon return to lower elevations. The effects mentioned are not perceptibly increased by cold, but wind has a very harmful effect on the symptoms experienced. As this was a new phenomenon to us, and as it had not been mentioned by our predecessors, we observed it carefully, and noted circumstances in which fatigue was not a factor. On the plateaux of Karakorum, it frequently happened even to those who were asleep under the tent in rather sheltered places to be awakened during the night by a feeling of oppression which must be attributed to a breeze, even a gentle one. which had arisen during the hours of repose. When we were busy with observations, we took little or no physical exercise, sometimes for thirty-six hours, and our servants even less than we did. And it often happened, in elevations which did not exceed 17,000 feet, that the afternoon or evening wind made us so ill that we lost all taste for food; we did not even think of preparing dinner. In the morning, when the wind was not blowing, appetite generally returned, we were not as ill in the morning as in the evening; this was evidently partly because the strong winds rose usually in the second part of the day.

The effects of diminished pressure are considerably aggravated by fatigue. It is surprising how exhausted one becomes; even the act of speaking is a labor, one heeds neither comfort nor danger. Often our servants, even those who had served us as guides, let themselves fall on the snow, declaring that they would rather die at once than take another step. From simple motives of humanity, we were often obliged to intervene in their behalf and tear them by force from the stupor into which they had fallen, whereas we ourselves were hardly in a better condition of energy. (Vol. II, p. 481-485.)

The observations of more recent travellers agree completely with what we have just reported. We must even note that, since the existence of discomforts on lofty passes is today well known to everyone, travellers often do not speak of them, or merely allude to them in a few words.

So Captain Godwin-Austen, ${ }^{237}$ who explored the glaciers of Karakorum, in 1860 made the ascent of Bianchu (16,000 feet) and Gommathaumigo (17,500 feet) without speaking of any symptom.

In his journey of 1861 , he first climbed Boorje-La (15,878 feet); his pulse rate was 138 , and that of one of his men 104, and he mentions no other symptom (P. 23.) But while he was ascending a peak of 18,342 feet ( 5590 meters) on August 10 (this is the highest ascent he made) he reports that "many men became ill, had violent headaches, and lay down on the ground." (P. 34.)

And in addition, in the account ${ }^{2: 38}$ of the long and important journeys made by two young Brahmins, two brothers, whom the English government sent to visit regions in which Europeans can 
hardly set foot without risking their lives, there is no mention of the symptoms of decompression. And yet the two "Pundits" certainly visited many lofty places, since they crossed the Himalayas in Nepal, at the foot of Dhawalaghiri, followed the course of the Brahmapoutra from Lhasa to Lake Manasarowar, and pushed on as far as Gartokh. But since they were exclusively interested in geography and politics, they did not heed phenomena which are universally known, or at least they did not think they should give space to them in their narrative.

Since this native expedition gave excellent results, a few years afterwards, the Trigonometrical Survey sent an employe, the Mirza, whose journey M. Montgomerie ${ }^{239}$ has related, across Hindu-Kush and Pamir to Turkestan. In this account there are a few details which refer to our subject.

In January, 1869, the Mirza reached Lunghar, in the steppes of Pamir:

The whole company, when they reached Lunghar (12,200 feet), suffered greatly from the Dum, as the Mirza calls it, that is, shortness of breath, etc., the usual effect of great altitudes. The natives generally consider it to be produced by a bad wind; some of the men became almost insensible, but soon recovered when the Mirza had them eat some dry fruits and sugar. (P. 158.)

At the pass of Chichik-Dawan (15,000 feet) they suffered greatly; all felt extreme difficulty in breathing, which the Mirza tried in vain to overcome with his sugar candy and dried fruits. (P. 165.)

At the same time, an English traveller, Hayward, ${ }^{240}$ was also making his way towards Kashgar, but through Little Thibet, across the enormous chain of Karakorum. He too is extremely chary of observations relating to the rarefaction of the air.

The journey lasted from October, 1868, to June, 1869. Crossing of the pass of Masimik, at an altitude of 18,500 feet (5640 meters) :

It presents no difficulties, is very easy, but loaded horses are slightly affected there by the rarefaction of the air. (P. 36.)

Crossing of the pass of Chang-Lang at 18,839 feet (5740 meters) (p. 38) ; ascent of a peak of 19,500 feet (p. 43), of another of 19,000 feet (p. 55-58), without any physiological observation; he merely says:

The chief difficulty at the Chang Lang pass is the distress of loaded animals, as a result of the elevation and the rarefaction of the air. (P. 126.) 
The following year, in 1870, the "Munschi" Faiz Buksh, leaving Peshawar in the Upper Punjab, set out for Kashgar, trying, like so many other more or less clearly official envoys, to open these new ways by which the commerce, the diplomatic influence, and perhaps the arms of England strive to penetrate western Turkestan.

His account ${ }^{241}$ is very rich in details which interest us. $\mathrm{He}$ lays particular stress on Pamir:

Pamir has been given the name of Bam-i-Dunya (roof of the world) because of its height. Its great elevation is proved by the absence of trees and the scarcity of birds; grass grows there only in the summer. The air there is greatly rarified, so that breathing is difficult for men and beasts. This difficulty is called tunk by the people of Badakhshan and Wakhan, and ais by the Mogols. The liver and the stomach are irritated. Travellers suffer from headache, and blood flows from their noses. In people of weak constitution, the face, hands, and feet swell. The colder it is, the more marked these symptoms are. The natives use acid, dried apricots, and plums as remedies. At night, if one does not have his head two feet higher than his legs, respiration is hampered during sleep. These symptoms appear whether one is afoot or on horseback.

I am thirty-four years old. On one of the peaks of Pamir, my pulse rate was 89 per minute; I had a headache, with irritation of the liver and stomach; once I had the nosebleed. One of my servants, named Kadir, a native of Peshawur, aged twenty-seven, had an attack of fever, with difficulty in breathing, irritation of the liver, and swelling of the face and extremities; his pulse rate was 99. Another, named Mehra, a native of Ghizni, aged twenty, felt only slight difficulty in breathing; his pulse rate was 75 . Over-feeding increases the difficulty of breathing. (P. 470) ....

Between Ak Tash and Sarkol is a lofty peak named Shindi Kotal, the summit of which is always covered with snow; we felt more difficulty in breathing there than on Pamir.... Three days' journey after Sarkol is a lofty peak called Yam Bolak, the summit of which is always covered with snow; we experienced great difficulty in breathing there also. (P. 472.)

The expedition led by Forsyth the same year from Lahore to Yarkand, through Ladak, had to cross successively the Himalayas and Karakorum. The account which Henderson ${ }^{242}$ gives of it frequently indicates the observation of symptoms due to the rarefaction of the air.

June 27, 1870, crossing of the Namyika Pass, in Ladak:

Although the summit of this pass has an elevation of only 12,000 feet, several of our men had great difficulty in breathing, which continued for several hours after we had reached our camp at Karbu, 600 feet lower; some of our men could not even sleep during the night for this reason. (P. 46.) 
July 10, crossing of the pass of Chang-La, from the basin of the Indus to that of Shyok, one of its tributaries, at 18,000 feet (5485 meters); little snow:

It was the first time that almost everyone in camp suffered from the rarity of the air. The following observations, made after a halfhour's rest at the summit, may seem interesting:

Mercury barometer 15.73. Thermometer $61^{\circ} \mathrm{F}$. Water boiling at $181^{\circ} \mathrm{F}$.

I walked to the summit

M. Forsyth, who was on horseback

Pulse

80

100

M. Shaw, who was on horseback

Mullik Kutub Deen, of Punjab, on horseback

A Hindu of Punjab, on foot

A Thibetan, on foot

\section{4}

92

93

78

Several travellers told me that they and their companions had suffered more while crossing this pass than on others which were higher. We camped for the night near a little lake of sweet water, at 300 feet below the summit of the pass. The painful symptoms caused by the rarity of the air did not disappear until the next day, when we were at a much lower altitude. As for me, even at 19,600 feet, I have never felt great discomfort; mine amounted only to a certain shortness of breath after any exercise, and awakening during the night with a feeling of suffocation which disappeared usually after a few deep inspirations. But in several of our men the symptoms were very serious, and even alarming sometimes. They consisted of intense headaches, with great prostration of body and mind, constant nausea, and such an irritation of the stomach that even a spoonful of water was not tolerated. A great irritability of disposition was another marked symptom; in some cases the lips became blue; in M. Shaw, a clinical thermometer showed a temperature which had fallen 1 or 2 degrees in comparison with that of the preceding days. Having with me a certain quantity of chlorate of potash, I gave a strong solution of it to the patients, rather to please them than in the hope of relieving them. However, it seemed to have a good effect, but why? I should not dare to make a guess. I do not doubt that these symptoms of the lofty mountains are merely temporary and that custom would end them, as it does seasickness. They become much more intense when one makes an ascent when he is already at a great height.

July 11, we camped 500 feet below the pass. There the headaches and nausea stopped quickly. (P. 56 et seq.)

July 20, crossing of the pass of Cayley, a newly discovered pass, easy of access, which is about 5900 meters high; through it one goes from the basin of the Indus to the plateaux of Yarkand; there was no snow. The travellers found several butterflies there. They do not speak of any physiological disturbance. 
July 21, camp on high desert plains, at an altitude of 5000 meters; they suffered much from the wind:

Travellers are frequently killed by this wind, which is sometimes so cold that it checks the vitality very quickly. Men and horses suffered much here from the rarity of the air. Several of our men lay down on the plain, completely exhausted, and could not reach our camp until the next day; some horses which fell were abandoned to their unhappy fate. (P. 77.)

They remained several days on these lofty plateaux, and in reference to this, the narrator adds:

There are a number of observations which I greatly regret not having made while we were at these heights, and among them changes caused in the pulse, respiration, and body temperature. My travelling companions offered to submit to the boredom of having their temperature taken and their pulse counted at determined times, but I found that I already had too many irons in the fire. The few scattered observations which I made had no great value, but they prove clearly that, in me at least, altitude has only a slight effect, as the following figures show. I should say that numerous observations made on my companions gave similar results:

Temperature Pulse Respir. under tongue

Ordinarily 24 98.2

At Sakte, seated for several hours, 12,900 feet, July 9 $90 \quad 25$

98.3

Summit of Chang-La; 18,000 feet (5485 meters), July 10, after walking to the summit 80 26

Lak Zung, more than 17,500 feet; July 24 (P. 79.)

97.8

The second part of the book is devoted to natural history. The ornithology is edited by A. O. Hume. I am quoting from it interesting observations on the habitat of birds at great altitudes:

One of the points which seemed most striking to me in the observations of Dr. Henderson is the ease with which birds seem to live at great altitudes. Our friend the Cuckoo swings on the pendent branches of the birches, uttering his joyous song at an elevation of 11,000 feet, while snow covers the ground. The Lapwing seems at home at 18,000 feet ( 5485 meters), the "Kashmir Dipper", which lives above 13,000 feet, seeks for insects in half-frozen torrents; the "Guldenstadt's Redstart" hops carefree in the snow at 17,800 feet; the Montifringilla haematopygia seems to live permanently between 14,000 and 17,000 feet, and the "Adams' Finch" is common at 13,000 feet. The long-beaked tufted Lark is in places from 12,000 to 15,000 feet, while the Mongolian "Dottrel" and the "Ruddy Shieldrake" live at 16,000 feet, and the brown-headed "Gull" at 15,000. (P. 163.) 
I shall end this long series of quotations with an extract from the work which Fr. Drew ${ }^{243}$ recently devoted to the geography of Jumnoo and Cashmere.

In the description of the lofty valleys of Ladak, Drew begins with that of Rupshu, the average elevation of which is from 14,000 to 15,000 feet ( 4270 to 4570 meters); the line of perpetual snow there is at about 20,000 feet. A wretched tribe, of one hundred tents, lives there, the Rupshu Champas. In a special section the author discussed the influence of the rarified air:

At great elevations, in addition to the oppression and the shortness of breath, one feels headaches and nausea, as happens at the beginning of fever or seasickness, but with no modification in the temperature of the body. In some persons, at high levels, vomiting occurs, but has no serious consequences, and the patient recovers when he descends to lower regions, provided however, that the organs are not diseased; rarity of the air generally reveals lesions of the lungs or heart.

The elevation at which these symptoms are observed varies in a peculiar way, and it is not easy to find the cause of these inequalities. The condition of the health has a great deal to do with it; a man in good condition can endure a much higher elevation than a man who is not accustomed to exercise. That is evident first when one exerts himself a little more than usual, as in running or climbing some hill; under these conditions, in persons who live above 6,000 feet the symptoms usually appear at 11,000 or 12,000 feet. At 14,000 and 15,000 feet, there sometimes appears what may be called an attack of shortness of breath, even when one is resting. The first time I visited Rupshu, that happened to me during the night, when I had been in bed about a half-hour; but after a week, I overcame this tendency, and since then I have not felt any difficulty in breathing while I was resting, even when I camped 2,000 or 3,000 feet higher. Likewise I knew a native of Punjab, unused to muscular labor, it is true, who had an attack at 11,000 feet.

But although one can become accustomed to the rarity of the air to a certain extent, and not feel it at all, the slightest effort will bring on its effects. At 15,000 feet, climbing the gentlest slope makes one more breathless than scrambling up a very steep hill at a lower altitude. Talking or walking, even on a level, soon produces breathlessness. When one is at great elevations-and here every thousand feet make a great change-climbing a slope is a painful labor. I have crossed a pass at an elevation of 19,500 feet which lower would have caused no trouble; and yet at every 50 or 60 steps, I was absolutely forced to stop, panting, to get my breath; but yet I did not feel any headache or other painful symptom; acclimatization to the mountains for a month or two permitted me to sleep under these conditions. (P. 291.) 


\section{Africa.}

Atlas.-Several summits of the Atlas in Morocco, which were 11,000 to 12,000 feet high, were visited by Dr. Hookes, ${ }^{244}$ in 1871 ; he does not mention any symptoms.

Kamerun Mountains.-The first ascent was made December 22, 1861 , by Burton. In the account ${ }^{245}$ of it which he published immediately he mentions some strange discomforts which should very probably be explained by the influence of the altitude:

While I was ascending the volcano, I was so tired that I could not keep my eyes open; I felt a distress which seemed to me to be due to fever. I was obliged to rest, I slept an hour, and at four o'clock I was able to make this ascent. (P. 79.)

The general account ${ }^{246}$ which he published later of his journeys to the Kamerun Mountains and Fernando Po is no more definite:

M. Saker then complained of complete deafness. The burning heat removed all sensation. Perhaps it was aided by the rarefaction of the air. However we were not surprised at suffering so little in the course of our ascent from the discomforts of which so many travellers to Mont Blanc and in the Rocky Mountains complain. (Vol. II, p. 121.)

We must note that they were then only at 7000 feet; but the next day they finished the ascent of the great Peak:

As we approached the summit, the difficulties of the ascent increased. Kharah dropped on the ground, almost fainting under the rays of a burning sun, and was forced to remain there. At half-past one, I reached the summit of the peak. (P. 155.)

January 13, 1862, another ascent by MM. Calvo, Saker, and Mann (P. 162-181). No symptom noted.

But in the account of it published by Mann, ${ }^{247}$ he declares that "he was sick on the Albert Peak and compelled to descend" (P. 23).

Finally, January 29, 1862, ascent of Burton. He camped at 10,187 feet, and reached the cinder cone of Mount Albert:

I noted again the complete absence of any suffering due to the thinness of the air. The altitude is considerable, but not sufficient, it appears, to cause the hemorrhages from the ears and lips experienced by von Humboldt in the Andes, or the sufferings of M. GayLussac in his balloon. (Abeokuta, Vol. II, p. 198.)

Kilimandjaro.-May 11, 1844, Rebmann ${ }^{248}$ saw Kilimandjaro covered with snow. The mountain is "inaccessible, the natives say, because of the evil spirits which had killed a great many of those who had attempted to ascend it." (P. 276.) 
So he could not attempt an ascent.

In 1861, Baron de Decken reached an elevation on the sides of the immense mountain which Thornton, ${ }^{249}$ his companion, estimated as 22,814 feet (6952 meters).

November 27, 1862, he was able to ascend high enough to feel some discomfort. Dr. Kersten, ${ }^{2 \pi 0}$ who accompanied him, reports that they stopped at 4223 meters, because of the cold, before reaching the snow line:

The ascent (he says) continued to be fairly difficult, and we were often forced to stop short. Anamouri, one of the men whom we had hired, was also indisposed. (P. 36.)

Baron de Decken ${ }^{250}$ expresses himself more definitely on the effect of the altitude:

When I had reached a height of 4225 meters about quarter past eleven, I stopped, as I was forced to do, since my servants could go no further without danger of pains in the chest. Dr. Kersten also felt the effects of the rarified air. (P. 49.)

And last, October 30, 1871, New ${ }^{251}$ ascended Kilimandjaro to the snow line:

My men abanảoned me, complaining of the cold. I continued with Tofiki alone. All went well for an hour and a half; but then Tofiki collapsed, hardly able to speak. He urged me to go on, telling me that he would wait for me, but that he would die if I did not return. I went as far as the ice, broke off some pieces of it, and descended at once.

Yes, snow in Africa, he cried with enthusiasm! What ideas this undeniable evidence must have given the learned editor of the Nouvelles annales des Voyages who, in 1849, denied that Rebmann could have seen snow on Kilimandjaro.

10. Volcanoes of the Pacific.

Borneo.-The highest peak of this vast island appears to be Kini-Ballu, the height of which (4175 meters) is almost that of Jungfrau.

The first attempt to ascend was made March 11, 1851, by Low. ${ }^{252}$ He did not get above 2850 meters, and considered that the summit, which he estimates at 13,000 or 14,000 feet, is "inaccessible for any one without wings."

And yet, in April, 1858, he reached the summit, accompanied by M. Spencer Saint-John. The latter felt the effects of the rarified air very slightly, as his account shows: 
During the ascent (says Spencer) ${ }^{253}$ I suffered slightly from shortness of breath and felt some sluggishness in moving. But hardly had I reached the summit when the symptoms left me, and it seemed to me that I was lighter, that I could float in the air.

The thermometer at the summit registered $62^{\circ} \mathrm{F}$. (Vol. I, p. 271.)

In June, 1858, second ascent of the same traveller. This time, he did not say a word about physiological symptoms.

In another part of the island, another English explorer, Brooke, ${ }^{354}$ ascended Tabalau Indu in March, 1858. It is difficult not to attribute to the altitude a part of the causes of this ikak of which the natives speak and which one of his companions experienced:

The climb was hard; the heat was excessive; every step seemed the last one could make.... We reached the summit and rested there with satisfaction. Poor $\mathrm{X}$... was in great distress and lay down on his back, while some of his servants went to seek "the friend of the traveller", a very abundant root, from which they squeeze a cool liquid with a slight taste of wood. It is a great mistake to drink, for one has constant thirst, and is attacked by what the natives call "ikak", a painful oppression in the chest, with difficulty in breathing. (P. 305.)

Malacca.-In his ascent of Mount Ophir, Braddel ${ }^{255}$ experienced some discomfort:

When I was near the summit, I had a violent headache and severe throbbing in my temples; I bathed my brow with brandy, which relieved me .... But I felt a peculiar fatigue and stretched out on the ground. (P. 87.)

Japan.-The first ascent of Fuji-yama of which I have found an account was made in 1860 by Rutherford Alcock. ${ }^{-56}$ He estimates at 14,177 feet (4320 meters) the height of this volcano which has been extinct since 1707. It took him eight hours to reach the summit; and he definitely felt the effect of rarefaction of the air:

The second half of the ascent was much more difficult .... The air became very rare and evidently affected respiration .... It took more than one hour of struggling, stopping frequently to breathe and to rest our legs and our backs, which pained us; when we reached the top, we were absolutely at the end of our strength. The temperature was $54^{\circ}$ F. (P. 344.)

Gubbins, ${ }^{257}$ who ascended the volcano August 10, 1872, complains only of fatigue. But Jeffreys, ${ }^{2.58}$ whose ascent was on May 4, 1874, mentions clearly real symptoms of decompression, attacking even the natives: 
As we were painfully climbing, a strong desire to sleep seized us, and the coolies could not resist it when we stopped. One of them was even unable to go on and we had to leave him on the way. We ended the ascent with great difficulty, and reached the summit at noon exactly. (P. 172.)

Kamschatka.-The only known ascent of the highest volcano of Kamschatka, Klioutchef (4805 meters), was made by Erman, ${ }^{259}$ September 10, 1829. He does not mention any physiological disturbance.

Hawaii.-June 15, 1825, for the first time Europeans ascended Mauna Kea, the "White Mountain" (4195 meters); they were a missionary and some officers of the English vessel Blonde. The commander Byron ${ }^{260}$ says in narrating this expedition:

The lieutenant and the purser were so overcome by sleep that they lay down on the bare rocks to rest.

Lord Byron in his turn ascended June 27; but he speaks of no discomfort.

January 12, 1834, ascent of Mauna Kea by David Douglas, ${ }^{* 61}$ and January 29, of Mauna Loa, "the Great Mountain" (4250 meters): no mention of physiological disturbances. Same silence on the part of Loevenstern, ${ }^{262}$ who ascended Mauna Loa in January, 1839. Anyway, his account contains only a few lines.

The great expedition which the government of the United States sent around the world under the command of Wilkes made a long stay in Hawaii. From December 21, 1840, to January 13,1841 , Wilkes and several of his officers camped on the side of Mauna Loa; several times they reached its highest point. It was not with impunity that they lived thus for three weeks at such heights; while they were ascending, they suffered severely:

The thermometer had dropped to $18^{\circ}$, and many of our men were severely affected by mountain sickness, with headache and fever, so that they were unable to do anything. I myself suffered greatly from it, with violent throbbing in my temples, and short, painful, and distressing breathing. (P. 149.)

Officers, sailors, and natives reached with countless difficulties the foot of the terminal crater, at 13,440 feet (4095 meters). The next morning, their distress was somewhat abated. The camp was kept at this great height for three weeks, and the detailed account of the geodetic and physical operations in which they were engaged shows that they suffered frequently from mountain sickness: 
Everyone experienced it more or less. Dr. Judd remarked that in the natives the symptoms were ordinarily colics, vomiting, and diarrhea; one or two were affected by the spitting of blood, some had fever and chills. Almost all of us had yellowish skin, headache, and vertigo, some had asthma and rheumatism ....

Dr. Judd also found that patients were very hungry without being able to eat. During the day, the least exercise increased the pulse rate of all of us by 30 to 40 . (P. 177.)

Since that time, I have found in the accounts of the travellers 264 who have ascended the volcanoes of Hawaii or Maui no mention of physiological distress.

1 See Jourdanet, Influcnce de la pression do lair sur la vie de l'homme. Paris, 1875. Vol. I, p. 212 .

"Relation z'éridique de la conquete du Pérou: in Callection de voyages pour servir à lhistoire de la décoúcerte de l.Amcrique by Ternaux-Compans, Vol. IV, Paris, 1837.

"Histoire des guerres civiles des Espagnols duns les Indes. Translation of Baudoin, $\mathrm{D}$. 200. Paris, 1650. (The original work was published in Cordova in 1613.) Book II, Chap. XX. Vol. I

${ }^{4}$ Histoire céritable dun Vovage curicur dans l'Amérique, from 1534 to 1554 . In the Ternaux-Compans collection, $\mathrm{Vol} \mathrm{V}$.

5 Acosta (José de) Historia Natural y' Moral de las Indias: en que se trata de cosas notables del Cielo de los elementos metaless, plantas, $y$ animales, etc. (Seville, 1590)

'Historia general de los Hechos de los Castcllanos en las islas y tierra firme del mar Occano. Madrid, 1615. Decada V, Pook X. Chap. V, Vol. III, p. 29, I.

${ }^{7}$ New edition, Vol, VI, VII, VIII, IX. Paris, 1 isi.

8 Relation du vovage de la mer du Sud aux cotes du Chily et du Pérou, made during the years 1712, 1713, and 1714. Paris, 1716.

${ }^{0}$ Relation abrégée du voyage fait au Pérou, far $M . M$. de l. Académie rovale des sciences, pour mesurer les degrés du weridien aur environs de léquateur, et en conclure le figure de la terre. Mémoires de l'Académie des sciences de Paris, 1744, p. 249-297.

10 Journal du voyage fait par l'ordre du Roi, à l'équateur. 2 vol., Paris, 1751

11 Mémoires philosophiques, historiques, phvsiques, concernant la découverte de l'Amérique.

French translation, Vol. I, 1787.

${ }_{12}$ Voyage aux régions équinoxiales du nouveau continent, fait en 1799-1804. Paris, 1814.

${ }^{13}$ Lettre de $M$. Humboldt adresséc att citoyen Delambre. datée de Lima, Nozember 25.

Ann. du Muséum d'histoire naturelle. Vol. II. p. 170-180, year XI (1803).

${ }^{14}$ Extrait de plusieurs iettres dc $M$. de Humboldt, Ann. du Muséum, Vol. II, p. 322-337, year $\mathrm{XI}(1 \mathrm{SO} 3)$.

15 Von Humboldt (Alexander). Notice sur deur tentatives d'ascension au Chimborazo. Annals of Chemistry; second series: Vol. LXIX, p. 401-431; 1838 . Translated by Eyries from the Jalirbuch de Schumacher for 1837 .

${ }^{16} \mathrm{I}$ could not find this statement in Zumstein's accounts.

1i Tableaux de la nature, translated by Eyriès. Paris, 18:8, Vol. II

18 Histoire contemporaine de lEspagne. 2 vol. Paris, 1869.

1 Gervinus, Histoire du dix-ncurième siècle, Minssen translation, Vol. VII. Paris, 1865.

20 Historia della Rerolncion histano-americana. Marlid, 1830.

${ }_{21}$ Corta descricion de los viages hechos en America por la Comision cientifica mandada por el Gobicrno Fspanol. durante los anos 1862, 1866. Madrid, 1866.

22 Shetclies of Buenos-Ayres, Chilc, and Peru. London, 1831.

${ }^{23}$ Travels in Chile and la Plata. 2 vol. London, 1826.

24 Traicls in South America, during the years 1819-20-21. 2 vol. London, 1825.

25 Trazels into Chile arer the Andes, in the vears 1820 and 1821. London, 1824.

${ }^{20}$ Narrative of a journey across the Cordillera of the Andes, in the years 1823 and 1824. London, 18:4.

${ }_{27}$ Rougi notes taken during some ratid journey's across the Pampas and anong the

Andes. London, 1828

28 Journal of a passage from the Pacific to the Atlantic. London, 1829.

Nournal of a royaae to Peru. London. 1828.

30 Itinéraire de Valparaiso à Buenes-Avres, published in the second volume of the Journal de nariaation autour du glrbe, of Bougainville. Paris, 1837. 1830.

Tarapaca, and route of Chile by the coast of the Desert of Atacama. Journal of the Rovat Geographical Socict». London, vol. XXI. n. 99.130; 1851.

${ }_{33}$ D'Orbigny, Vovaqe dans l'Amérique méridionale, made during the years 1826-1833, 7 vol. Paris, $1835-1847$.

"34 Reise in Chile, Peru, und auf dem Amazonenstrome, während der Jahre 1\$27-1833, 2 vol. Leipzig, 1836.

${ }_{25}$ Ascension an Climborazo, made December 16, 1831. Ann. de chim., second series, vol. LVIII. D. $150-180 ; 1835$.

Reise "m die Erde. in den Jahren 1830-32. Berlin 1835, rol. II.

${ }^{37}$ Narrative of the royages of Adrenture and Beagle; 1826-1836, third volume; Journal and remarks. London, 1832-1836. 
38 Narrative of a journey from Lima to Para. London, 1836.

30 Practical obscriation on the diseases of Peru, described as they occur on the Coast and in the Sierra. Edinburgh Med, and Sura. Journal, vol, LIV, LVI, LVII, LVIII, 1839. 1841. 1812,1843 .

* Fragment d'un vojage daus le Chile et au Cusco. Bull. de la Soc. de géogr. Second series, vol. XIX, p. $15-57 ;$; 843.

¿11 Peru, Reiseskizzen aus den Jahren 1838-184?. 2 vol. Saint-Gallen, 1846.

¿Expédition dans les parties centrales de l'Amérique du Sud. Hist. du voyage, vol. III and vol. IV. Paris, 1851.

${ }_{43}$ Vovage à traźers l'Amérique du Sud, de l'Ocćan Pacifique à locean Atlantique. Paris. 2 vol., 1869.

i4 The U. S. nazal astronomical Expedition to the southern Hemisphere during the years 1819 - 185(?) 2 Chile, Philadelphia, 18.59.

4. Report of a journey across the. Andes, between Cochabamba and Chimore. J. of the royal geographical Society, vol. XXIV, p. 259-265; 1854.

troyage dans le nord de la Bolivie et les parties voisines du Pérou. Paris, 1853.

${ }_{47}$ Vovage dans l'Amérique du Sud, Péron et Bolizic. Paris, 1861.

48 Reise durch die La Plata-Staaten, ausucfuirt in den Jahren 1857-1860.

49. Traiels in Peru and India. London, 1862. 1860-64.

*) Description géographique et statistique de la confédération argentine. 3 vol. Paris.

5i Mouqueron's translation. Paris, 1863.

52 De la phthisie pulmonare dans ses rapports ą́ce l'altitude et az'ec les races au Pérou et en Bolizic. Du soroche ou mal des montagnes. Thesis of I'aris, 1862.

53 The reference is to Castelnau.

54 Relazione della gita da curico nel Chili a san Raphacl nella Pampa del sur (febraio 1866). Parma, 1869.

${ }_{55}$ Reise über die Cordilleren von Arica bis Santa-Cruz. Extrait in Petermann's Mittheilungen, Vol. XI; 1865.

56 Exploration du cratère du Rucu-Pichincha. Noù̃, ann. des voyages, Vol. CVII, p. $106.112 ; 1845$

si Ascension du Pichincha. Châlons- sur-Marne, 1858.

58 Rémy (Jules) et Brenchley, Asccusion du Chimborazo. Nouv. ann. des voyages, Vol. CIIII, p. 230-238; 1857 .

59 Vovages au Chimborazo, à l'Altar, et ascension au Tunguragua, letter of April 18.1873. Bull. de la Soc. de geogr., sixth series, vol. VII, 0. $258-295 ; 1875$.

to Journey of M. Wafer, in which is found the description of the isthmus of America: inserted in volume IV of the Voyage aur terres. Australes, of G. Dampier. Rouen, 1715.

${ }_{61}$ Voyage géographique aux républiques de Guatemala et de San Salvador. Paris. 1868. "s2 Aufenthalt und Reisen in Merico in den Jahren 1825 bis 1834. Stuttgart, 1856.

63 Recherches de Pathologie comparée. Cassel, 1853.

64 Jourdanet, Pression de l'air, vol. I, p. $21 ?$.

$65 \mathrm{~L}$. W. Glennie, The ascent of Popocatapetl (sic.). Proceedings of the geolog. Soc. of London, vol, I, D. $75 ; 1834$.

* Gros (baron), Ascension au sommet du Popocatepetl. Letter of May 15, 1834. Nouz: ann. des voyages, vol. LXIV, $44-68,183 t$.

fit Ascension du volcan du Popocatepctl (mountain of smoke) in September, $1856 . \quad N o u v$. ann. des zoyages, vol. CLIII, p. 304-317; $15-57$.

ss Récit d'une ascension du Popocatepetl, by MM. A. Dollfus, de Montserrat and Pavie.

Archires de la Commission scientifique dis Mexique, vol. II, p, 187-201. Paris, 1866.

${ }^{69}$ Reisen in den Vereinigten Staaten, Canada und Mexico. Leipzig, 1864.

70. Attempted ascent of Orizaba. Alpine journal, vol. III, p. 210-214. London, 1867.

"Report of the exploration to the Rocky Mountains in the vear 1842. Washington. 1845.

$\pi^{2}$ Reports of explorations and surieys to ascertain the most practicable and economical

route for a railroad from the Mississippi River to the Pacific Ocean. Vol. II. Washington, 1855. 1867 .

73 Ascent of Mount Hood. Extract in Proced. of the Roy. Geogr. Soc. vol. III, p. 81-84;

${ }^{74}$ Petermann's Mittheil., vol. XIV, p. $151 ; 1868$.

7. Monntaineering on the Pacific. Alpine journal, vol. V, p. 357-367. London, 1872.

76 Ibid., vol VI, 192-193; 1874.

77 Opere, vol. 4. Venet, 1729

7 . Aetnac topographia; in Thesaurus antiq. sicul. Lugd. Bat., 1728.

79 De Rebus siculis. Catane, 1749.

sn De motu animalium. Pars altera. Rome, 1681

s1 Voyage dans la Sicile et dans la grande Grèce, addressed by the author to his friend.

M. Winckelmann; translated from the German (without author's name). Lausanne, 1733.

82 Voyage en Sicile et à Malthe, vol. I, p. 225. Amsterdam, 1775.

1784.

${ }^{83}$ Voyage pittoresque des isles de Sicile, de Malthe, et de Lipari, vol. II, p. 103. Paris.

84 Voyage en Sicile. Paris, 1788.

85 Relation d un voyage fait depuis peu sur ce volcan: in Voyage pittoresque ou description du royaume de Naples et de Sicile, by the abbé Saint-Non. Fourth volume, p. 91-104. Paris, 1785. se Built by Empedocles, according to the legend. (See Fazello, loc. cit., vol. I, p.

87 Voyages dans les deux Siciles, translated by G. Toscan, Vol. I, Paris, year VIII.

8. Descrizione dell' Etna. Palermo, 1818.

s'Voyage critique à l'Etna, en 1819, vol. I. Paris, 1820.

90 Souvenirs de la Sicile. Paris, $18 \cdot 3$.

1 Note sur les cffets physiologiques de la raréfaction de l'air à de grandes hauteurs. Soc. philomatique, p. 120-122; 1822 .

"In the midst of it is seen a very steep, round mountain which they call Pico de Teithe, the tonography of which is as follows: its peak is very steep and includes 15 leagues, which amount to more than 45 English miles." Description des Canaries, by the Englishman Nicols or Midnal; in Traité de la navigation, by Pierre Bergeron, preface to Vovages faits en Asic dans les douzicme, treizième, quatorzic̀me at quinzième siécles, vol. I, p. 119. La Haye, 1735. 
93 A Relation if the Pico Ténériffe receiced from some considerable merchants and men worthy of credit, who went to the top of it. History of the Royal Society of London, by Th. Sprat, third edition. London, 1722, p. 200-213.

94 Philos. Transac., Sept. 12, 1670. Vol. XXIX, p. 317-325, 1717.

${ }_{95}$ An account of $a$ journey from the port of Oratain in the Island of Teneriff, to the top of the Pic in August 1715. Mem. of the Royal Soc. of London, second edition, vol. V1, p. 172-177. London, $17+5$.

Memoirs of the Academy of Sciences of Paris for 1746, p. 140-142.

${ }_{97}$ The History of the Discovery and Conquest of the Canary Islands. London, 1764.

selation d'un voyage à la recherche de la Perouse, made by order of the Constitutional Assembly, during the years 1791-1792 and during the first and second years of the French Republic. Paris, year VIII.

${ }_{99}$ Essais sur les isles Fortunées et l'antique Atlantide. Paris, Germinal, year XI

1000 loyage aux régions équinoxiales du nouveau continent, vol. I, p. 123-145. Paris, 1814.

101 Lettre aü citoyen Derilliers fils. Journal de phys., de chim. et d'hist. nat., vol. LVII.

p. $55-63 ; 1803$.

${ }_{102}$ Description physique des iles Canarics. Translated by Boulanger. Paris, 1836.

103 l oyage de l:Astrolabe, made during the years 1826-27-20-29. Histoire du voyage, vol,

I; Paris, 1830

10t Voyage au Pole Sud, vol. I. Paris, 1841 .

105 Voyage around the world of the Astrolabe and the Zélée, under the command of Dumont d'Urville. Paris, 184?

p. $6.5-79$.

1we Voyage géologique aux Antilles et aux iles de Ténériffe et de Fogo. Paris, 1848; vol. I,

ivi Jownal diun royage en Chine in 1843, 18t5, 1846. Paris, 1848, 3 vol.

1us Sitteen years of an artist's life in Morocco, Spain, and the Canary Islands, 2 vol.

London, 1859.

109' lie de Jean d.Aranthon éreque d'Alex, de 1600 à 1695; Lyons, 1767. Quoted in the

Guide - itineraire du Mont-Blanc, of V. Payot. Geneva, 1869; p. 161.

${ }^{110}$ Elementa physiologiae, vol. III, p. 197. Lauzanne, 1761.

111 Disquisitiones physicae de meteoris aqueis. Pars prima. Tiguri, 1786. ${ }^{112}$ Die Bergkrankheit. Lejpzig, 1854, p. 71.

1785 .

${ }^{113}$ Nonvelle description des glacières et glaciers des Alpes, second edition. Geneva, 3 vol.;

114 Tableaux topographiques, etc. . . . . de la Suisse, vol. I. Paris, 1780.

115 Voyages dans les Alpes, 4 vol. Geneva; 1is6-1796.

110 The exact height is 3655 meters.

11 Narrative of a journey from the -illage of Chamouni, in Switzerland, to the summit of

Mount Blanc, undertaken on. Aug. 8, 17si. Thomson's. Annals of Philosophy, vol. 1X, p. 97-103: 1817 .

${ }^{113}$ Letter from M. Bourrit to the ellitor of the Bibliothèqu britanuique. Biblioth. brit. de Genize, vol. XX, p. 429-433; 1802 .

${ }^{11}$ Vovage au Mont-Blanc. Vienna, Gerold Company.

131 Bibliothicque unizersclle de Gené̃e, vol. IX, p. 84-89, 1818

1* Notice sur un volage au sommet du mont Blanc, ibid., vol. XIV, p. 219-234, 1820.

12 Relation de deux tentatices récentes pour monter sur le mont Blanc. Bibliothèaue universelle de Genère, vol. XIV. 13. 301-323; 1824. Hamel has since published a more detailed account of his journey, with historical notes, under the title of Beschreibung zweier Reisen auf den Mont-Blanc. Vienna, 1s21.

1:3 Hamel makes a mistake here; he was still about 700 meters from the summit (Lepileur). 124 Notice sur une nourelle ascension au mont Blanc. Biblioth. univ. de Genèze, vol. XXI, 1). $68.75,1822$.

${ }_{125}$ Détails dune ascension au sommet du mont Blanc, Ibid, vol. XXIII, p. 137-155 and $232-244, \quad 3823$.

${ }_{126} \mathrm{D}$. Clark and Capt. Sherwill, Quelques détails sur leur expédition au mont Blanc. Biblioth. univ. de Genève, vol. XXX, p. 245-246, 1825.

${ }_{127}$ Ascension du mont Blanc en 1827 . Nour, ann. des royages, vol. XI. p. 265-269, 1828.

${ }^{125}$ Reise auf die Eisgebirge des kantons Bern und Ersteigung ihrer höchstergipfel in sommer 1812. Aarau, 1813.

${ }_{12} \mathrm{Dr}$. Parrot. Ueber die Schnecgränze anf der mittaglichen seite des Rosagebürges und barometrische Messungen. Schweiggers journal für chemie und ply sik, vol. XIX, p. $36 i-423,1817$.

${ }_{130}$ They are told verbatim in the Bibliotheque unizerselle, vol. XXVIII, p. 66-77, 1825. Zumstein's notes were published in Vienna in $1 \$ 24$, by Baron von Welden, in a book entitled: Der Monte Rose. which I could not procure. I am borrowing the preceding details from an article published by M. Briquet under the title of Ascnsions aux pics du mont Rose. (Bibl. univ.. vol. XII, p. 1-47; 1861.)

${ }_{131}$ Naturhistorische Alpenreise. Solothurn, 183n.

13: Apercu sur la topographie médicale de l'hospice du mont Saint-Bernard. Nouveau journal de Med.. Chim. Pharm. etc. vol. VII, p. 29-37; 1820.

${ }_{133}$ Ascent to the summit of mont Blanc, Sept. 16-18, 1834. Edinburgh new philos. journal.

vol. XVIII, p. 106-120; 1835 .

1838. Ascension au mont Blanc, translated from the English by Jourdan. Geneva, London,

135 Influence on the human body of ascents of high mountains, Rer'ue médicale, 1842; vol.

IV, p. $321-344$

${ }_{136}$ Excursions et séjours dans les glaciers et les hautes régions des Alpes, of M. Agassiz and his travelling companions. Neufchatel, Paris, 1844.

137 Rev'ue suisse. Neufchâtel, June, 1843.

138 Journal d'une course faite aux glaciers du mont Rose et du mont Cervin. Biblioth. univ. de Genere, Second series, vol. XXVII, 1840.

139. Ausflug nach dem Aletsch Eismeer und Ersteioung der Junafrau $(416 \pi \mathrm{m}$.). Quoted in crtenso in Matériaux pour l'etude des glaciers, hy Dollfus-Ausset. vol. IV. 1864 .

$1+0$ Beobachtungen über den Einfluss der i'erdunnte Luft und des stärken Sonnenliclites auf hoher Gebirgen, etc. Osterreich. med. Johrb. N. Folge, vol. XXXII; 1843. 
141 Travcls through the Alps of Sar'oy-Edinburgh, 1843.

15: Mém. sur les phénomenes physiologiques, observed on ascending to a certain height in the Alus, Revue mèdicale, 1845, vol. II.

${ }_{143}$ Deux ascensions scicntifiques au mont Blanc.-Revue des Deux-Mondes, number of March 15,1865 .

${ }_{144}$ Ascension du mont Blanc par la routc de Saint-Germain-les Bains.-Noui'. ann. des voy., vol. CLXIII, p. 358-362, 18.59.

145 Tyndall, The glaciers of the Alps.-London, 1860.

$1 * 6$ Hours of exercise in the Alps.-Second edition.-London, 1871.

$1+$ Der mont Blanc. Darstellung der Besteigung desselben am 31 juli, 1,u. 2 August 1859. -Berlin, 1860 .

1:8 Une ascension au mont Blane en 1864. Bibl. univ. de Genève, fifth series, vol. XXIII.

p. $66-106,1865$.

${ }_{149}^{106}$ Deux ascensions au mont Blanc en 1869; Recherches physiologiques sur de mal des montagnes (Lyon mèdical, 1869.)

150 Histoire du mont Blanc. Paris, 1873.

151 Ascension du mont Blanc. La Nature, Oct. 10, 1 sit.

${ }^{152}$ Le mont Blanc et Chamounix. Geneva, no date.

153 Alpine journal, vol. V, p. 189.-London, 1872.

154 Ascent of the Finsterraar-horn.-Peaks, Passes and Glaciers.-London, 1859, p. 283-308.

$155 \mathrm{~A}$ night bivouac on the Grivola.-Peaks, Passes, and Glaciers.-second series, vol. II.London, 1862.

${ }_{156}$ Schweitzer. The Breithorn (3735) ascension in 1861.-Peaks, Passes, and Glaciers.-

Second series, vol. 1.-London, 1862.

157 Ascent of the Dent Blanche (June 9, 1862). The Alpine Journal, vol. I.-London, 1864.

158 Stephen (Leslie), The Jungfrau-joch and Viescher-joch. Alp. journ., vol. I.-London.

1864.

${ }_{159}$ Reg. Somerled Macdonald, Passage of the Roththal Sattel (August, 1864). Alp. journ.,

vol. II.-London, 1866 .

${ }_{100}$ The Studer-Joch. Alp. journ., vol. I,-London, 1864

101 Ascension al monte Rosa nell' agosto 1864. Bulletino del Club alpino italiano, vol. VI, p. $157-163 ; 18: 3$.

1:3 Ascension de la Jungfrau; Annuaire du Club alpin francais, first year, 18i4, p. 211-219.

-Paris, 1875

163 Peaks, Passes, and Glaciers, p. 482-509.-London, 1859

164 Paris, fifth edition; 1874.

10s Ascent of the Grivola.-Peaks, Passes and Glaciers.-Second series, vol. II.-London, 1862. ${ }_{106}$ On Mountains, and on Mountaineering in general. Alpine journal, vol. V, p. 241-248, 1872. 167 Philosoplical transactions, Sept. 12, $16 i 0$.

10s Description des Pyrćnées, 2 vol,-Paris, 1813.

$109 \mathrm{He}$ even spat blood, according to Gondret (Mèm. concernant les effets de la pression

atm. sur le corps humain; Paris, 1819. (P. 44.)

${ }_{170}$ Vojage au sommet du mont Perdu.-Ann. du Muséum d'historie naturelle, vol. 111. 1804. 171 Tableau des Pyrénèes francaises, 2 vol.-Paris, 1828.

17 Rapport fait au Counseil des mines sur un voyage à la Maladetta, par la zallee de

Bagnères-de-Luchon.-Journal des Mines, Messidor, year XII, vol. XVI, p. 249-282; 1804.

${ }_{173}$ Ueber die Beschleunigung des menschlichen Pulses nach Maaszgabe der Erhöhung des

Standpunkets uber der Meeresfläche.-Frorieps Notizen, vol. X; 1825.

174 Voyage à la Maladetta.--Paris, 1845.

175 Recueil des ascensions au pic du Néthou, from 1842 (first ascension) to 1868.-Bull. de

la Société Ramond, 1872, p. 15-24, 193-198; and 1573, p. 49-58.

${ }^{16}$ Ford, A Hand-Book for traz'ellers in Spain-London, 1847.

177 Voviage au mont Caucase et en Géorgie.-Paris, 1823.

178 Voyage à la vallée du Terek. N. Ann. des Voyages, vol. LI, p. 273-324; 1831.

179 Voyage dans les environs du nont Elbrous dans le Caucase, undertaken in 1829.-Report

marle to the Imperial Academy of Sciences of St. Petersburg.- St. Petersburg, 1830.

180 Voyage dans les rallées centrales du Cancase, fait en 1836 et 1837.-N. Ann. des Voyages,

vol. CXVIII, p. 276-328, 1848.

181 Reisen und Forschungen im Kaukasus, 1865,--Peterm. Mitth, vol. XIII, 1867.

18: Journey in the Caucasus, and Ascent of Kasbek and Elbruz.-The journ. of the roval

neogr. Society vol. XXXIX, p. 50-76; London, 1869.-Itinerary of a Tour in the Caucasus;

Alpine Journal, vol. IV, p. 160-166; London, 1870. - The Caucasus, by C. Tucker (Ibid. 421-425.) 183 Itinerary of a Tour in the Cancasus made by F. Gardiner, F. C. Grove, A. W. Moore

and 1 Walker, with Peter Knubel of St. Niklaus.-Alp. Journal, vol. VII, p. 100-103; London, 1874. ist An ascent of Elbruz.-Alpine Journal, vol. VII, p. 113-124; London, 1875.

sss $V$ l ovages faits en Asie, dans les XII, III, XIV, et XV siecles.-The Hague, 1735. 186 Philosoplical transactions, Sept. 12, $16 \pi 0$.

${ }^{187}$ Relation d'un voyage du Levant, 2 vol.-Paris, 1717. 188 Reize zum Ararat.-Berlin, 1834.

183 Magazin fur die Litteratur des Auslandes; 1835, no. 34.

190 Gazette russe de l'Académie: 1\$3s, nos. 21, 23.

191 Journal le Caucase; 1846 , nos. $1,57$.

102 Journal le Caucase; 1850, no. 50,-Translated in Nour'. Ann. des Voyages, vol. CXXX. p. $334-349 ; 1851$

${ }_{133}$ Reisen im Armenischen Hochland in Sommer 1871.-Second part: West.-Peterman's Mittheilungen, 1873.

${ }^{194}$ Notice d'un voyage dans l.Asic-Mincure, faite en $1837 .-N$. Ann. des Voyages, vol.

LXXXI, p. $153-196 ; 1839$.

${ }_{195}$ An Account of the Ascent of Mount Demazend, near Tehran, in September, 1837.-

Journ. of the $R$. geograph. Soc., vol. VIII, p. 109; 1838.

100 R. Thompson and I.ord Schomberg H. Kerr, Journey through the Mountainous Dis. tricts. North of the Elbruz, and Ascent of Demacend, in Persia.-Proccedings of the royal geouraph. Soc, vol. III, p. 2-18; 1859.

${ }_{147}$ Great mistake; the height of Demavend is 5620 meters. 
198. Le live de Marco Polo, citoyen de Venise, drawn up in French at his dictation, in 1e98, by Rusticien de Pise.-Published by Pauthier. Paris, 1865.

${ }_{19 y}$ Purdon, On the Trigonometrical Survey and Plysical Configuration of the valley of Kashmir. $-J$. of R. Geogr. S., vol. XXXI, p. 14-30; 1861.

${ }_{200}$ Memoires sur les contrées occidentales, translated from the Sanskrit into Chinese, in the Year 648, by Hiouen-Thsang, and from the Chinese into French by Stanilas Julien, vol I. Paris, 1857.

201 Klaproth, Description $d u$ Thibet, translated from the Chinese-Paris, 1831

32 Voyages au Thibet; translated by Parraud and Billescoq.-Paris, year IV.

? Voyages de Fr. Bernier, vol. II, letter IX.-Amsterdam, 1699.

204205 Description de la Chine of P. du Halde, vol. IV-Paris, 1735.

206 Letter of April 16, 1710. Lettres édifiantes. New edition, vol. VII, p. 430-435.-Paris, 1781.

p. $465.492 ; 1777$.

2us ; 17i7.

309 A Journey to Sirinagur. - Asiatic researches, vol. VI, p. 309-381; 1801.

21 A Journey to Lake Manasarovara in Un-dés, a Province of Little Tibet. Asiatic re. scarches, vol. XII, p. $37-534$-Calcutta, 1816.

${ }_{211}$ Travels in the Himalayan provinces of Hindustan and the Penjab; in Kunduz and Bokhara: 2 vol.-London, 1851.

ai: Journal of a Tour through Part of the snowy Range of the Himalaya mountains, and to the sources of the Riners Jumna and Ganges.-London, 1820. This journal was published in abridged form in the Asiatic rescarches, vol. XIII, p. 170-249.-Calcutta, 1820.

${ }_{213}$ Vol. XXII, p. 415-430.-London, 1820.

214 Account of Koonawur, in the Himalaya.-London, 1811.

n5 First part: journey out. Account of pait of a journey through the Himalaya mountains.-The Edinb. Philos. journal, vol. X, p. 295-305; 1824. - Second part, journey back. Journal of an Excursion through the Himalaya mountains, from Shipke to the Frontiers of Chinea. Tantary.-The Edinb. Journal of Scicuce, vol. I, p. 41-51 and p. 215-244; 1824 . These two articles are reprinted in the Journal of the Asiatic Society of Bengal, vol. XI, p. 363-391: 1842. My quotation is taken from this publication.

2w Lloyd: Narrative of a journev from Caunpoor to the Boorendo pass, with Capt. Alex. Gerard's account of an attempt to penetrate by Bekken to Garoo and the Lake of Manasarowara. -London, 2 vol. 1840.

${ }_{217}$ Al Gérard, Account of a Surev of the valley of the Setlej River, in the Himalaya

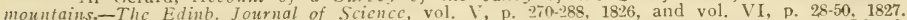
21. Acconnt of Koonazur in the Himalaya. Published after his death by G. Lloyd. London, 1841.

${ }_{219}$ Jeurnal of a Survey to the Heads of the Rivers Ganges and Jumma.Asiatic researches, vol. XIV, P. 60-152.-Calcutta, 1822.

"zo i ovage par les monts Himalaya aux sources du Djenna et de là aur frontières de l'cmpire chinois: d'aviril en Oct. 1827.-N. Ann. des Voyages, vol. LXVII, p. 127-188, 1835.

-21 Corresfondance inédite, vol. II, 1867.--Lettre à MM. les. Professeurs Administrateurs du Muséum, à Paris.

${ }_{232}$ Voyage dans l'Inde, pendant les années 1828 à 1852.-Paris, vol. II, 1841.

223 The lake is at an altitude of 4650 meters. 204 Berghaus Annalen, vol. V.-Berlin, 1832.

"25 A personal narrative of a journey to the source of the River Oxus, in the years 1836.

1837 , 1838 .-London, 1840

226 Cabool; in the years 1836, 3-8.-London, 1842.

Paris, 1850

zen Briefe aus Indien.-Braunschweig, 1847.

${ }^{29}$ Western Himalay and Tibet; a narrative of a journey through the mountains of

Northern India, during the years 184-48.-London, 1852.

:30 Himalavan journal; or notes of a Naturalist, 2 vol.-London, 1854.

$309 ; 1556$

231 Asconsion du Sumeru-Parbut (Himalaya).-N. Ann. des Voyages, vol. CLII, p. 303-

23: The adicntures of a Lady in Tartary, Thibet, China and Kashmir.-London, 3 vol., 1853.

${ }^{233}$ Trips in the Himalaya.-Alpine Journal, vol. IV, p. 73-93; London, 1870.

${ }_{234}$ The Tibctan Route from Simla to Srinagar.-Alpine Journal, vol. III, p. 118-153:

London, 1867

${ }^{235}$ First ascent of the Tian-Shan or Celestial mountains, and visit to the Upper Course of

the Jaxartes or Syr-Daria, in 1857. -The Journal of the roy. geogr. Soc.; vol. XXXI, p. 356$36 ; ; 1: 61$.

${ }_{236}$ Schlagintweit (Hermann, Adolph and Robert de), Results of a scientific mission to India and High .4sia, 1854-1858; 4 vol.-Leipzig and London, 1861-1866. ${ }_{237}$ On the Glacicrs of the Mustakh Range. - The Journal of the royal geogr. Society, vol.

XXXIV, p. 19-55; London, 1864. 23s Reisen und Aufnahmen zzveier Punditen (gebildeter Indier) in Tibet; 1865 bis 1866.-Petermann's Mittheilungen; vol. XIV, p. 233-243; $276-290,1868$.

${ }_{239}$ Report of "the Mirza's" Exploration from Canbul to Kashgar.-The Journ. of the roy. geogr. Soc., vol. XLI, p. 132-192; 1871.

240 Joirney from Leh to Yarkand and Kashgar, and Exploration of the sources of the

Yarkand Ricer.-The Journal of the roy. geogr. Soc., vol. XL, p. 33-166; 1870.

${ }^{31}$ Journey from Peshawar to Kashgar and Yarkand in Eastern Turkestan.-The Tourn. of the roy. geogr. Soc., vol. XLII, p. 448-473; 1872.

$2 \$ 2$ Henderson and Hume, Lahore to Yarkand. Incidents of the route and natural history

of the countries traversed by the Expedition of $18 \% 0$, under T. D. Forsyth.-London, 1876. ${ }^{243}$ The Jumbo and Kashmir territories, a geographical account. London, 1875. 244 Letters to S. Roderick Murchison giving an account of his Ascent of the Atlas.Procesd. of the rov. geogr. Socicty, vol. XV, p. 212; 1871. ${ }_{245}$ Relation d'une ascension aux monts Cameron (Afrique occidentale). Translated in $N$. Ann. des voyages; vol. III, p. $71-107 ; 1863$. 
245. Abeolituta.-London, 2 vol., 1863.

${ }^{31}$ Forschungen an der Westhuste $\tau$ 'on Africa.-Petermann's Mittheilungen, vol. XI:

$1665 ;$ p. $22-26$

D. Journal d'une excursion au Djagga, le pay's des nciges de l'Afrique orientale. $-N$. Ann. des Voy : vol. CXXi1, D. 257-307. 1849.

$24:$ Notes on a journey to Kilimandjaro, made in company of the Baron von der Decken. -The Journal of the $R$, geog. Soc.; vol. XXXV, p. 15-21; 1865.

20 Ascension du Kilinandjaro, dans l'intérieur de l'Afrique orientale. $N$. Ann. des Voyages; 1864 , vol. I. p. 28.

251 Alpine Jaurnal; vol. Vi, p. 51-52.-London, 1874, issue of April, 1872.

Notes of an ascent of the mountain Kina-Balow. (The Journal of the Indian Archipelago. Vol. VI, p. 1-17).-Singapore, 1852

is 2 Life in the forests of the far East. 2 vol.-London, 1862.

$25 \mathrm{Ten}$ years in Sarazuk.--London, 1866.

255 Notes of a Trip to the interior from Malacca. The Journal of the Indian Archipelugo, vol. Vi, p. 73-104.-Singapore, 1853

$\mathbf{x}$ Narrative of a journey in the interior of Japan, in 1860-The Journ. of the R. Geograph.

Soc., vol. XXXI, p. 321-356; 1861

${ }_{257}$ Ascent of Fuji-Yana. Proceedings of the Royal Geogr. Soc., vol. XVII, 1873; $0.78-79$ इs Ascent of Fuji-Yama in the Snow. Proceedings of the Royal Geogr. Soc., March 18i5: p. $169-173$.

250 Reise um die Erde, in die Jahren 18:8; 29 und 30.--Historique, third vol., p. 363 et seq. 280 loyage of H. M.S. Blonde to the Sandwich Islands in the years 182t-1825.-London, 1826. ${ }^{281}$ Extract from a private Letter addressed to Captain Sabine.-Journal of the R. Geograph. Soc., vol. IV, p. 333-344.-London, 1834.

mi2 Apercu d un vilyage autour du monde. Bull. de la Soc. de. Geogr., Second Series, vol,

XVI, p, 166-177, 1841

283 Narrative of the United States Explorina Expedition during the years 1838, 39, 40, 41. 42, vol. IV.-Philadelphia, 1844.

zti Sawkins, On the Iolcanic Mountain of Hawaii. Journ. of the Roy. Geogr. Soc., vol, XXV, p. 191-194; 1855. Robert Haskell. On a I'isit to the Recent Eruption of Manna Loa. Hazeait. The American journal of science and arts. Second series, vol. XXVIII; 1859, p. 66-71. - Wilmot, Our Journal in the Pacific, London, 1873. 


\section{Chapter II \\ BALLOON ASCENSIONS}

At the end of the 18th century, the remarkable discovery of the Montgolfier brothers introduced a new element into the question of decompression. In this case, the traveller no longer climbs laboriously and slowly to the regions where rarefied aid can act upon his organism; he is carried there without fatigue and with great speed.

We are not interested in the montgolfiers, or hot-air balloons, since ordinarily they can mount only to very moderate heights. We shall simply note that the first aeronauts, Pilatre du Rozier and the Marquis d'Arlandes, made an ascent November 21, 1783, and crossed Paris in a montgolfier.

But the history of gas balloons is rich in data applicable to our subject.

The first of December in this same year of 1783 , the physicist Charles, who had just invented the hydrogen balloon, tested his invention under conditions much more stirring and dangerous than the two brave aeronauts just mentioned. This ascension, as we know, was divided into two periods: Charles, who left the Tuileries at 1:45, landed at 3:30 in the plain of Nesles; he let his companion Robert get out of the basket; then, lightened, his balloon rose again with extraordinary speed. In less than ten minutes he rose over 1500 fathoms; the barometer stopped at 18 inches, 10 lines.

The story $^{1}$ of the clever physicist, filled with justifiable enthusiasm, shows him as "questioning his sensation, listening to himself live, and having no disagreeable feeling in the first moment." But soon:

In the midst of the inexpressible rapture of this contemplative ecstasy, I was recalled to myself by a very extraordinary pain in the interior of my right ear and in the maxillary glands; I attributed 
it to the expansion of the air contained in the cellular tissue of the organ, as well as to the cold of the surrounding air .... I put on a woolen hood which was at my feet; but the pain vanished only when I reached the ground.

This marvellous invention thrilled the whole world; the most ardent illusions about the practical utility of balloons were cherished. Among the strange ideas produced by these experiments in which man took possession of the air for the first time, one of the most curious is that which, less than a year after the first ascent, inspired a thesis sustained in 1784 before the Faculty of Medicine of Montpellier. Louis Leullier-Duché, its author, ${ }^{2}$ had the idea of using balloon ascension as a treatment of diseases.

"The effect," he said, "will be triple: motion, cold, change of air."

He insists especially upon this last point:

The essential part of air is for man the dephlogisticated air (oxygen). Now in what proportion is it united with the phlogistic in the different regions of the atmosphere? Chemists have not determined. But as the phlogistic is lighter, there must be more of it at a very great height .... The neighborhood of the earth is the proper region of the dephlogisticated air. But we cannot doubt that it is polluted there by different emanations of volatile bodies. And so, in that part of the atmosphere which is the region of dephlogisticated air, the latter is purer the further we go from the surface of the earth. Moreover, as it is colder, the dephlogisticated air is accumulated and condensed there.

Leullier-Duché attributes the strongest curative virtues to oxygen, and considers that it acts even on generation and death:

Births at Montpellier coincide with the spring months and deaths with the autumn months; during the spring, the atmosphere is more laden with dephlogisticated air which the growth of plants produces, and during autumn their putrefaction releases a greater quantity of inflammable or phlogistic air (he refers to nitrogen by this double name).

Leullier-Duché then proposes to use balloons in the treatment of intermittent, pestilential, or nervous fevers, rickets, scurvy, hysteria, chlorosis, melancholy, slow healing sores, etc.

We have seen that the inventor of the hydrogen balloon, in the first and only ascent which he made, experienced painful sensations when he had risen rapidly to a height of about 3000 meters. It was simply a matter of the expansion of the gases of the middle ear, gases which on account of the speed of the ascent had not had time to escape by the Eustachian tube. More serious symptoms were soon to be observed. 
On the 12th of Brumaire in the year VII (see the Moniteur, p. 173), Testu-Brissy, mounted on a horse, rose to a considerable height.

In a little book," "dedicated to childhood", a curious engraving represents him on horseback on a platform supported by a cylindrical balloon. After some details about the ascent of the adventurous aeronaut, the author, who says she knew him, declares that:

The purpose of the scientist was attained; he discovered that at a degree of elevation where he himself was not at all affected, the blood of large quadrupeds, apparently less fluid than that of man, was forced out of the arteries and ran out through the nose and ears. Satisfied with this observation, he descended from the considerable height to which he had risen, and gave account of his expedition to the Institute with modest simplicity. (P. 95.)

One can hardly attach much importance to this tale.

Two years after the ascent of Charles, Blanchard, an aeronaut who died poor and obscure after enjoying prodigious popularity, whose statement, it is true, cannot carry much weight, claimed to have risen November 20, 1785, from Ghent, to a height of 32,000 feet $(10,400$ meters $)$ :

I rose with a rupture of equilibrium of 35 pounds .... In less than two minutes, I was more than 4500 feet from the earth . . . . The expansion of the inflammable air was such .... that I mounted to an incredible height, which according to the record of my instrument was 32,000 feet from the earth . . . .

I sailed in the immensity of the air at the mercy of the winds, experiencing a cold which no mortal ever felt in the severest climates. Nature grew languid, I felt a numbness, prelude of a dangerous sleep, when rising in spite of my lack of strength, I called upon my courage, entered my balloon, and with the handle of my flag.... I broke the lower pole in pieces. (P. 7.)

The result of this maneuver was a rapid fall, which ended happily after a series of curious incidents.

Blanchard announced his ascent briefly in a letter," addressed to the Journal de Paris. It is evident that he mounted very high; but his observation or his calculation was certainly wrong.

The astronomer de Lalande, who also dabbled in aerostatics, appeared quite doubtful. He wrote to ${ }^{6}$ the publishers of this curious extract to refute the assertions of the vain aeronaut: 


\section{Gentlemen:}

Probably a mistake slipped into the article which you published on the fifth of this month in regard to the ascent of M. Blanchard, made November 21 near Ghent; it says that he rose to 32,000 feet, which would make 5333 fathoms; the greatest height reached hitherto is 2434 fathoms, and the great expansion of the air would probably make it impossible to rise to or to breathe at a height which is more than double that ... . At 2430 fathoms height the barometer is at only 16 inches. M. de la Condamine observed it at 15 inches 11 lines, but no man has seen it lower. If one could rise to 5441 fathoms, the barometer would stand at only 8 inches, and it is probable that hemorrhage and death would soon be the result.

De Lalande.

There follows a table given by de Lalande, indicating the relations between the barometric pressure and the altitude:

$\begin{array}{lrrr}27 \text { inches } & 158 \text { fathoms } & 12 \text { inches } & 3679 \text { fathoms } \\ . & . & 11 \text { inches } & 4057 \text { fathoms } \\ 16 \text { inches } & 2430 \text { fathoms } & 10 \text { inches } & 4472 \text { fathoms } \\ 15 \text { inches } & 2710 \text { fathoms } & 8 \text { inches } & 4929 \text { fathoms } \\ 14 \text { inches } & 3010 \text { fathoms } & 7 \text { inches } & 5441 \text { fathoms } \\ 13 \text { inches } & 3332 \text { fathoms } & \end{array}$

By the way, Lalande reproduces this table in the Yearbook of the Bureau of Longitudes for the year 1805, then he adds:

The last numbers will probably be eternally useless; human beings will never see the barometer at 11 inches, unless, by artificial means, they succeed in giving air to the lungs and lessening the pressure of the inner air. (P. 94.)

In the Yearbook of 1806, the remark about the impossibility of reaching 11 inches is suppressed. The only statement is:

The last numbers are probably useless: M. Gay-Lussac went only to 3584 fathoms. (P. 99.)

Prudent correction, for 11 inches correspond according to Lalande to 4057 fathoms (7907 meters), a height far surpassed since then, as we shall see, by Glaisher and Coxwell and by Gaston Tissandier.

But let us return to Blanchard; he did not consider himself conquered, and replied haughtily in the Journal de Paris: ${ }^{7}$

\section{Gentlemen:}

If I have not replied sooner to the letter written you by $M$. de Lalande about a so-called error in regard to my ascent at Ghent, in which I say I rose to the height of 32,000 feet, it is not for want of material; I shall not reply even today, intending to discuss his opin- 
ion at greater length in the collection of journals of my ascents which I intend to give the public. The nature of your paper, gentlemen, would not permit me so long a discussion.

M. de la Condamine, says my illustrious antagonist, is the only man who has observed the barometer at the lowest level, and he observed it, he adds, at 15 inches 11 lines. It would be of no use to remind him that I said that I had seen it at 14 inches in my ascent from Lille with the Chevalier de l'Epinard, and lower yet in England, because, words not being proofs, he would be just as incredulous in the matter. Knowing all M. de Lalande's superiority, I shall take care to contend with him only with victorious arms; and as facts sometimes give the lie to the most careful calculations, I limit myself now to inviting him, as I have just done in a personal letter, to do me the honor of accompanying me in my next ascent; he will then be convinced that the best arguments have no effect against the certainty of a fact.

Yours, etc.

Blanchard,

Citizen of Calais, pensioner of the King.

We know that de Lalande replied to the challenge.

One should read in the Journal de Paris, ${ }^{8}$ his curious correspondence with Blanchard on this subject. On the 8th of Thermidor in the year VII, they both ascended with the famous flotilla of five balloons invented by the celebrated aeronaut. They hoped, by making use of currents, to go as far as Gotha "to see with delight" said Lalande, "a prince and a princess who, by their learning and their zeal for the sciences, give an example to everyone"; but alas! one of the balloons burst, and the astronomer and the citizen of Calais fell ingloriously into the Bois de Boulogne.

But let us drop stories lacking precision and perhaps truth. We enter the domain of scientific attempts with the remarkable ascents of Robertson and, soon after, of Gay-Lussac.

The most important ascent of the French physicist Robertson ${ }^{9}$ took place at Hamburg, July 18, 1803. He started at 9 o'clock in the morning, accompanied by M. Lhoest, his colleague and compatriot; the barometer marked 28 inches, the Réamur thermometer $16^{\circ}$ :

During the different tests with which we were busied, we felt an uneasiness, a general discomfort; the buzzing in the ears from which we had for some time been suffering increased still more as the barometer dropped below 13 inches. The pain we felt was something like that which one feels when he plunges his head below water. Our chests seemed expanded and lacked resilience, my pulse was hurried; that of M. Lhoest was less so: like mine, his lips were swollen, his eyes bloodshot; all the veins were rounded out and stood up in relief on my hands. The blood had rushed to my head so much that I noticed that my hat seemed too small. The cold increased 
considerably; the thermometer then dropped quickly to $2^{\circ}$, and stopped at $51 / 2^{\circ}$ below freezing, while the barometer stood at 12 and $4 / 100$ inches. Hardly was I in this atmosphere when the discomfort increased; I was in a mental and physical apathy; we could hardly ward off the sleep which we feared like death. Distrusting my strength, and fearing that my companion would succumb to sleep, I had fastened a cord to my thigh and to his; the ends of this cord were in our hands. It was in this state, not much adapted to delicate experiments, that I had to begin the observations that I was planning. (Vol. I, p. 70) ....

At this elevation, our state was that of indifference: there, the physicist is no longer sensitive to the glory and the passion of discoveries; the very danger which results from the slightest negligence in this journey hardly interests him; it is only by the aid of a little fortifying wine that he succeeds in finding intervals of mental clarity and power.

As I wish to omit nothing that can cast light on the functions of the animal economy and the operations of nature at this elevation, I ought to mention that when the barometer was still at 12 inches, my companion offered me bread: I made vain efforts to swallow it, but never could succeed. If one considers carefully the state of the surrounding atmosphere, the great rarity of which offered only a slight resistance to my expanding chest; if one considers the small quantity of oxygen contained in the gas in which I was floating, one can believe that my stomach, already filled by a denser gas which was impoverished by the loss of oxygen, was in no state to receive solid food and still less to digest it. I must add that the natural excretions were checked in my friend and myself during the five hours of the journey, and that they were not resumed until three hours after our return to earth .....

Seventh experiment. I had taken along two birds: at the moment of the experiment I found one of them dead, no doubt on account of the rarefaction of the air; the other seemed drowsy. After placing him on the edge of the basket, I tried to frighten him to make him take flight: he beat his wings, but did not leave his place; then I left him to himself, and he fell perpendicularly with extreme speed. There is no doubt that birds could not support themselves at this elevation. (P. 76) ... .

One can estimate the height of the balloon, taking account of all the corrections, at 3679 fathoms (7170 meters). ${ }^{10}$ (P. 83.)

The number of March 16, 1876, of the journal Les Mondes says on this subject:

If, in one passage of his account, Robertson says that he mounted to 7170 meters, in another he says only 7075 ; calculating by the present tables of the Yearbook of the Bureau of Longitudes on the data of temperature and pressure registered by Robertson, we find only 6881 meters for the maximum height. (Ch. Boissay.)

Robertson sent the account of his ascent and of the experiments in physics which he performed during it to the Galvanic 
Society; a report ${ }^{11}$ was made from which we extract the following passage:

We have known for a long time that an animal cannot pass with impunity from an atmosphere to which he is accustomed to one much denser or much rarer. In the first case, he suffers from the weight of the outer air, which has an excessive pressure; in the second case, the liquids or elastic fluids which are part of his system, since they are undergoing less than the usual pressure, expand and stretch the surrounding tissues. In both cases, the effects are almost the same, uneasiness, general discomfort, buzzing in the ears, and often hemorrhages; the experiment of the diver's bell long ago indicated to us what would happen to aeronauts. Our colleague and his travelling companion experienced these effects with great intensity; their lips were swollen, their eyes bloodshot; the rounded veins stood out in relief on their hands, and-a very astonishing fact-they both displayed a reddish brown complexion which surprised those who had seen them before their ascent.

This distension of the blood vessels, in their farthest ramifications, must necessarily produce a hindrance, a constraint in all the muscular movements; and it is mainly to this cause that I think we should attribute the vain efforts made by our colleague to swallow the bread which his companion gave him when they were still at a height marked by 12 inches on the barometer. (Mém., Vol. I, page 106.)

An aeronaut who was celebrated for being the first to descend from a balloon in a parachute (October 29, 1797), Jacques Garnerin, tried to take from his rival Robertson the honor of the highest ascent. As the following extract from the Journal de Paris ${ }^{13}$ proves, he claimed to have risen to 4200 fathoms (8186 meters).

In the interest of the sciences and the arts, which barbarians have mutilated, M. Garnerin writes from St. Petersburg to Paris the account of the aerial journey which he undertook at Moscow the third of last October, in which he rose exactly to the height of 4200 fathoms, without having experienced any symptom other than hemorrhage of the nose, and a little discomfort from the cold. Happy opportunity to entertain the public with his quarrels with M. Robertson, whom he calls "the aeronaut of Hamburg", and whose powers of observation and whose truth he questions! "I rose," says M. Garnerin, "521 fathoms higher than the aeronaut of Hamburg, and I did not notice that matter lost weight, nor did I see the sun without brilliancy, nor the sky without azure. I felt neither an extraordinary apathy, nor difficulty in swallowing, nor a desire to sleep, etc. . . . "

Nothing seems less authentic than the statement of Garnerin; the data which we shall presently report show that at the height which he says he reached he would have experienced very serious physiological disturbances. 
In this same year, a very dramatic ascent took place at Bologna.

Count Fr. Zambeccari, of Bologna, Dr. Grasetti, of Rome, and Pascal Andreoli, of Ancona, left during the night of the 7th-8th of October, 1803. They had spent the day in inflating their balloon, which measured 14,000 cubic feet, and intended to start the next day; but they had to hurry on account of the rioting and shouts of the populace of Bologna. The balloon rose with extreme rapidity, and they soon reached such a height that Zambeccari and Grasetti, overcome by the cold and exhausted by a series of vomiting, fell into a sort of torpor accompanied by a profound sleep. The brief account, inserted in the Annales de Gilbert, ${ }^{1}$ tells their sufferings and misfortune as follows:

Andreoli, who had retained use of his senses, could not read the barometer because the candle which they had brought in a lantern had gone out. About 2:30 in the morning, the balloon began io descend, and Andreoli heard distinctly the noise of waves breaking on the coast of Romagna. He awoke his companions .... . The basket and the balloon fell into the Adriatic Sea with such force that the water dashed up around them to the height of a man. The aeronauts, covered with water, in great haste threw out a bag of sand, their instruments, and all that the basket contained.

Then the balloon again rushed rapidly into the air. They traversed three strata of clouds, and their clothes were covered with a thick layer of ice; the air was so rarefied that they could hardly hear each other. About three o'clock the balloon descended again.

The melancholy German pamphleteer Kotzebue, ${ }^{14}$ during his journey to Italy, called on Zambeccari, this man "whose eyes are thoughts". The daring aeronaut gave him a detailed account of this terrible ascension of October 7-8, in which he nearly perished:

I rose at midnight .... Suddenly we mounted with inconceivable speed.

We could observe the barometer only by lantern light, and that very imperfectly. The unendurable cold which reigns in the region to which we had risen, the exhaustion I felt from lack of food for 24 hours, the grief. which overwhelmed my soul, this whole combination caused complete torpor and I fell on the bottom of the basket in a sort of sleep like death. The same thing happened to my companion Grasetti. Andreoli was the only one who remained awake and well, no doubt because his stomach was full and he had drunk rum abundantly. In fact, he too had suffered greatly from the cold, which was excessive, and for a long time made vain efforts to awaken me. Finally he succeeded in getting me to my feet, but my ideas were confused; I asked him, as if I had been dreaming: "What's the news? Where are we going? What time is it? What is the direction of the wind?"

It was two o'clock. The compass was ruined, consequently it was 
useless to us; the candle in our lantern could not burn in an air so rarefied, its light grew dimmer and dimmer, and finally went out. (Vol. IV, p. 301-303.)

They then fell into the sea; then having thrown out everything in their basket, they rose again:

With such rapidity, to such a prodigious height, that we could hardly hear each other even when we shouted; I was sick and vomited considerably. Grasetti had the nose-bleed; we both had short respiration and an oppression in our chests. As we were wet to the bone when the balloon took us into the higher strata, the cold seized us rapidly and we were covered in an instant with a layer of ice. I cannot explain why the moon, which was in its last quarter, was in a line parallel with us, and seemed red as blood. After rushing through these immense regions for a half-hour and being carried to an immeasurable height, the balloon began to descend slowly, and we fell once more into the sea; it was about four o'clock in the morning. (Vol. IV, p. 305.)

The unfortunate aeronauts fell into the Adriatic and remained there, the playthings of the winds and the waves, until 8 o'clock, when a bark picked them up, not without great difficulties. Their feet and hands were frozen, and Zambeccari had to have three fingers amputated.

The following year on June 30 , Robertson ${ }^{15}$ made a new ascent, accompanied by the Russian physicist Sacharoff; but their barometer went to only 22 inches and they had no special experiences.

This same year of 1804, two young physicists, Biot and GayLussac, ${ }^{16}$ were given by the Institut de France a scientific mission in the air. They were particularly to investigate variations of magnetic power, which de Saussure thought he had observed on the col du Géant.

The two scientists left on the 6th of Fructidor, at ten o'clock in the morning, from the garden of the Conservatoire des Arts. As they did not rise above 4000 meters in a temperature of $+10^{\circ}$, they felt no serious physiological disturbances. So they said only a few words on this subject:

We observed the animals which we had taken along; they did not seem to suffer from the rarity of the air; however the barometer stood at 20 inches 8 lines, which gives a height of 2622 meters. A violet bee, which we freed, took flight very quickly and buzzing left us ....

Our pulses were very fast; that of Gay-Lussac, which is ordinarily 62 per minute, was 80 ; mine, which is usually 89 , was 111 . This acceleration then was felt by us both in about the same proportion. 
However, our respiration was not at all affected; we felt no discomfort, and our situation seemed to us extremely agreeable . . . .

We observed our animals at all heights; they did not seem to suffer at all. As for us, we felt no effect, except this acceleration of the pulse rate of which I have already spoken.

There follows the account of what happened to a greenfinch and a pigeon, freed at 3400 meters; the pigeon opened its wings and let itself fall describing circles like the large birds of prey.

Gay-Lussac ${ }^{17}$ started alone some days after, and rose much higher than the first time. The symptoms of a physiological nature were quite endurable; he speaks of them thus:

When I had reached the highest point of my ascent, 7016 meters above sea level, my respiration was noticeably hampered; but I was still far from experiencing such severe discomfort as to wish to descend. My pulse and respiratory rate were much accelerated; and so, breathing very frequently in a very dry air, I was not surprised to find my throat so dry that it was painful for me to swallow bread . . .

These are all the inconveniences I experienced. (P. 89.)

In regard to this account Robertson made an observation which is interesting because it shows what cause he assigns to the phenomena which he experienced himself:

I do not think that there is a professor of physics who has not spoken to his hearers of the weight of the column of air which corresponds to the body surface of a man, and who has not shown that this enormous weight is made imperceptible to the body by the equilibrium established between the pressure of the outer air and the reaction of the elastic fluids which are part of its inner system. There is none who has not demonstrated what the effects of the rupture of this equilibrium would be. (Mem., vol. I, p. 107.)

But nothing justified Robertson in drawing from these remarks the strange conclusion which follows:

I do not think that $M$. Biot has changed all that. No one can refuse to conclude that the effects experienced by $\mathbf{M}$. Lhoest and myself, then by M. Sacharoff, are anything but very reasonable; while those experienced by MM. Biot and Gay-Lussac are so contrary to ours that they need to be explained. Now the only explanation possible is that these aeronauts did not rise high enough or that they rose so slowly that there was no rupture of equilibrium for them, otherwise one cannot see what could have kept them from experiencing the effects which are the inevitable consequences. (Mem., vol. I, p. 108.)

This doubt unnecessarily cast upon the truth of the observations of scholars like Biot and Gay-Lussac should have had just 
reprisals, and it had much to do with the undeserved discredit which has since fallen upon the statements of Robertson.

The ascent of Gay-Lussac had a well deserved fame. But people went too far in passing over in complete silence those which had preceded it. Robertson complained justly that the role which he himself had previously played had not been recognized:

M. Biot printed in his treatise on physics and repeats in his courses in the Collège de France that M. Gay-Lussac rose to the greatest height that man had reached up to that time. This assertion, though false, is believed by the youth of today, because I have no one who can say every year to some hundreds of auditors that I had risen to 3630 fathoms more than a year before the ascent of Gay-Lussac; and the time will soon come when no one will know or remember that, before the ascent of MM. Biot and Gay-Lussac, I had made one like it, and like theirs, in the interest of science, but during which the air of those high regions had been less hospitable to me than to those gentlemen. (Mém., vol. I, p. 117.)

A few years after, in August, 1808, Andreoli, one of the companions of the unfortunate Zambeccari, rose from Padua, and reached, if we are to believe him, a height much greater than that which his predecessors had attained. The correspondent of the Journal de Paris, ${ }^{18}$ who tells the story, seems to give little credence to the account of the Italian aeronaut, a really very extraordinary account, in which we do not know whether to be more astonished at the ascent or the descent of the daring and lucky aeronauts:

Italy. Padua, April 23, 1808.

M. Andreoli undertook yesterday in this city an aerostatic journey, which was not very lucky and the account of which arouses unpleasant doubts among well-informed people as to the veracity of the physicist. According to this really curious story, which people in Paris may perhaps ridicule, M. Andreoli, accompanied by M. Brioschi, rose at 3:30 in the afternoon, in the presence of a great number of spectators. The barometer having dropped to 15 inches (to 15 inches! Are they quite sure of what they say, and do they know how prodigiously rarefied the air should be and really is at that height? And in that case, how would the two travellers have breathed?) at this elevation, Brioschi began to feel extraordinary palpitations, without, however, noticing any painful change in his breathing: the barometer dropping next to 12 , he felt himself overcome by a gentle sleep, which soon became a real lethargy (they do not say how M. Andreoli felt, and how he resisted the powerful narcotic which overcame his companion). The balloon kept rising and when the barometer was at about 9 inches (that is, a height much greater than that of the highest of the Cordilleras) Andreoli perceived that it was completely expanded and that he could not move his left hand. The mercury, continuing to descend, registered $8 \frac{1}{2}$ inches. Then the balloon exploded with a loud 
report and began to descend rapidly (I believe it), and then $M$. Brioschi awoke (not without terror). The fall took place at the castle of Engança, not far from the tomb of Petrarch and the city of Acqua, 12 miles from Padua; and the most marvellous thing about this story, which was so marvellous from end to end, is that the travellers, no doubt protected by a geni out of the Thousand and One Nights, did not experience the slightest harm, not even the least scratch. Surely that is a miracle which should disconcert all the calculations of ordinary physicists. However it may be, the travellers took post horses, and reached Padua at 8:30 to receive congratulations which such a prodigious success deserved on every score.

I should note here that the celebrated English aeronaut, M. Glaisher, ${ }^{19}$ seems disposed to give credence to these extraordinary data; he calls attention to the fact that Andreoli, accustomed to ascents, suffered much less than his companion. And as to the possibility of surviving such a terrible fall, he discusses it with authority and admits it without great hesitation. (P. 161.)

August 29, 1811, two Englishmen, Beaufoy and Sadler, ${ }^{20}$ made an ascent in which they did not rise above 6000 feet, and which holds no interest for us except the sensation felt by Beaufoy "of a slight pressure in the ears and a little deafness", and especially the strange explanation of it which the traveller gives: he attributes this effect to "the dampness resulting from not wearing a hat during the trip." (P. 296.)

April 26, 1812, the widow of Blanchard, who was to die so miserably July 6, 1819, on a roof in the Rue de Provence, made an ascent at Turin in which she claimed to have risen to a very great height. The Journal de Paris ${ }^{21}$ gave an account of it in the following words:

She had taken a barometer with her .... At 15 inches 6 lines, the cold was icy; at 14 inches 1 line, Mme. Blanchard said she had experienced a lessening of the cold; at 12 inches 11 lines, she felt a palpitation of the artery near the outer angle of the left eye and a sort of trembling of the lower lid of the same eye. At 12 inches 3 lines, she had a severe nosebleed.

A few minutes later, the barometer marked 10 inches 3 lines, which was its lowest point . . . This indicates that the highest elevation of Mme. Blanchard was 3900 fathoms (7600 meters); at this height the cold was unbearable, the Réaumur thermometer was $17^{\circ}$ below freezing ....

The color of the sky was almost black .... The sun did not have its usual rays and its diameter seemed much smaller than when observed from the earth. A moment after these observations, the thermometer dropped another degree, and Mme. Blanchard, almost stiff with cold, decided to descend. 
Robertson expressed some doubts about the exactness of Mme. Blanchard's barometric readings. The note he sent to the Journal de Paris ${ }^{2:}$ contains details about the sufferings which he and Lhoest had experienced in their ascent of July 1803, which are not included in the account we quoted above:

The elevation to which you state that Mme. Blanchard rose lately at Turin must surprise your readers all the more as it must be regarded as the last degree of human temerity .... First I must admit that I think it impossible for anyone, with an aerostat of 20 feet diameter, which Mme. Blanchard ordinarily uses, to rise high enough to make the mercury drop to 10 inches ....

When one reaches the elevation of 3600 fathoms, one yields gradually and unconsciously to a lethargic sleep; the mental faculties succumb long before the physical faculties. First one has no memory, no cares for the present or the future; one forgets to supervise the aerostat; soon a soft and gentle sleep, which one cannot resist, lulls all the members and holds the aeronaut in a complete asphyxia, which no doubt is fatal if it is prolonged ....

In July, 1803, I made an ascent at Hamburg with M. Lhoest . . . . The barometer dropped to 12 inches and some lines (while we were still in possession of our faculties). The sky seemed to us to be brown; the sun lacked brilliance; we could gaze at it without being dazzled; we had a slight hemorrhage, and experienced all that Mme. Blanchard has just mentioned. We succumbed to sleep in this ascent; but the lower part of the balloon.... released the gas which was driven out by expansion. We roused from this torpor simultaneously and suddenly, without being able to tell what had happened, except that there had been a break in the continuity of our ideas.

Eugène Robertson, ${ }^{23}$ one of the sons of the celebrated aeronaut, rose on October 16, 1826, from Castle Garden in New York, to 21,000 feet (6400 meters), ${ }^{24}$ in a balloon of 16,000 cubic feet, inflated with hydrogen:

Respiration was painful and difficult, the faculties were blunted, the cold unbearable, especially in the hands. (Therm. at $21^{\circ} \mathrm{F}$.)

February 12,1835 , this same aeronaut " 5 rose from Mexico to a height of 5928 meters. He examined from close at hand the crater of the former volcano the Chicle and rose "above a nursery of mountains."

The famous English aeronaut Green, who made, according to Glaisher, ${ }^{26}$ more than fourteen hundred ascents, certainly rose several times to great heights; but he seems to have been rather careless about exact measurements, and his figures show evidence of great exaggeration.

One of his ascents, which took place in 1821, is curious because 
of the nature of the gas with which he inflated his balloon; he used oxide of carbon which took him to 11,000 feet. ${ }^{27}$ But this does not concern our subject.

April 20, 1831, Dr. Forster ${ }^{28}$ with Green made a balloon trip which did not exceed an elevation of 6000 feet, a height at which they remained for four hours. Their physiological observations referred only to the phenomena of deafness which attack mountain travellers and aeronauts. Forster considers them as having very different causes in the two cases, due in the first to a feeling of fullness in the ears, and in the second to a real weakening of the hearing.

The extravagant exaggeration of Green's statements begins to appear in a note of the publisher of Froriep's Notizen, ${ }^{29}$ which reports naively that Green had made 226 ascents, in which he had several times gone above 6000 fathoms, without experiencing difficulty in breathing.

The story which Green ${ }^{30}$ himself gave of the catastrophe by which, September 27, 1836, his companion Cocking lost his life, indicates a height which perhaps should not be considered accurate. We know that Green played a very sorry role in this mad adventure. Cocking had made a parachute wrong side out, the absurdity of which no one could doubt; Green consented nevertheless to take it along. The unhappy Cocking unfastened his parachute just as the balloon reached the height of 5000 feet; he fell like a stone. At the same time, the balloon, freed of his weight, darted upward to great heights:

We rose then with such rapidity that we were almost suffocated; with great difficulty I controlled my senses enough to observe the barometer; but M. Spencer observed that the mercury stopped at 13.20 , which gives an elevation of 24,384 feet (7430 meters), or about $4 \frac{1}{4}$ miles.

But that is nothing beside what he told of an ascent made with Rusch; the pathologist Henle ${ }^{31}$ reports this prodigious statement as a very simple thing, and without making any comment:

In his balloon ascents, Green says he never experienced any acceleration of the pulse or of the respiration, except when he rose rapidly after throwing out ballast.

In 1838 he rose with Rusch to the height of 27,136 feet (8268 meters), where he saw the mercury drop to 10.32 inches; he passed through the first 11,000 feet (3350 meters) in 7 minutes, without any inconvenience except those mentioned above. (P. 386.)

Tall tales are useless! An Italian aeronaut claimed to have 
surpassed even the fabulous height that the English balloonist said he had reached. We read, in fact, in the Proceedings of the Academy of Sciences of Paris: ${ }^{32}$

M. Bonafoux writes that on the occasion of the marriage feast of the hereditary Prince of Savoy, M. Comaschi made a balloon ascent at Turin, in which, if there was no mistake in the barometer readings, M. Comaschi rose to 9474 meters above sea level; but the difference in temperature would seem to indicate a lesser height.

The story of Hobard, if it does not give information of great precision, at least appears credible; it is inserted in the Courrier français of October 9, 1835:

August 17, 1835, an aeronaut, M. Hobard, ran the greatest risks in an ascent which he made at Lynchburg, in Virginia; he mounted at seven o'clock in the evening, and in less than an hour landed about 13 leagues from the city. M. Hobard in his account says that a few minutes after his departure he lost sight of the earth completely. At half past seven he made his last observation and judged that he was more than a league high. He saw then two meteors, one in the north and the other in the west; the latter seemed to be approaching rapidly, but it disappeared suddenly, to the great satisfaction of M. Hobard, who feared that it would set his balloon on fire. Shortly after, a squall seized the balloon and whirled it aloft to a height which the aeronaut estimated as not less than 26,000 feet (7925 meters), judging by the difficulty of breathing and the entire loss of hearing. He wished to let gas escape by opening the valve; but not being able to hear, he could not judge, as usual, the escape of the gas by the noise it makes as it issues. He saw nevertheless that the balloon was not deflating much, and he feared it would burst; he feared also that some of his veins would burst, since the rarefaction of the air had made them dilate greatly. The first of his fears was soon realized. Without entirely bursting, the balloon split above and rapidly deflating descended with great speed. Happily for M. Hobard, the fall of the balloon was broken by a young fir whose flexible trunk protected him from the terrible shock he would have experienced. However he was thrown out of the basket and considerably bruised, but what were a few contusions in comparison with the cruel death he expected! M. Hobard based his estimate that his greatest elevation was 26,000 feet on the fact that the rarefied air had affected his organs in a more painful way than was experienced by aeronauts who had risen to 25,000 feet, the maximum height hitherto reached in balloon ascensions.

We must refer to the memorable ascent of MM. Barral and Bixio, July 27, 1850, to find scientific certainty and precision. But from our point of view, this ascent, so useful to meteorology, has only moderate interest. In fact, under the influence of a barometric pressure of $315 \mathrm{~mm}$., corresponding to a height of 7016 meters, in 
spite of a temperature of $39^{\circ}$ below zero, the two brave travellers experienced no physiological symptom which attracted their attention: "Our respiration", they merely said, "was not at all affected." 33

Two years later, ascents no less important from the scientific point of view were made in England by M. Welsh: ${ }^{34}$

In July, 1852, the Committee of the Kew Observatory decided to institute a series of balloon ascensions for the study of the meteorological and physical phenomena which require the presence of an observer in the upper strata of the atmosphere. (P. 311.)

J. Welsh, who took Nicklin as companion, was charged with the scientific part; the control of the balloon was entrusted to the celebrated aeronaut Green. The first ascent took place August 17, the aeronauts rose to 19,510 feet (5945 meters); in the second (August 26), they rose only to 19,100 feet (5820 meters); and in the third, only to 12,640 feet (3850 meters). But on November 10 , in one hour they reached 22,930 feet (6987 meters) and remained more than 10 minutes above 20,000 feet; the descent took place with extraordinary rapidity:

At this height, much greater than all the others we had reached previously, the effects of lowered pressure began to be felt more. M. Green and I experienced very great difficulty in breathing, with increased panting and fatigue after the slightest exercise. (P. 320.)

At much lower elevations still, a celebrated English meteorologist, M. Glaisher, noted considerable modifications in respiration and circulation.

The ascents of M. Glaisher constitute the finest series of aerial journeys ever undertaken with a scientific purpose. Some of them took him to very great heights, and one will forever remain famous, that in which he nearly died from the decompression. I am quoting from Voyages aériens ${ }^{35}$ the following data which have a bearing on our subject.

The first ascent took place June 30, 1862; Glaisher and his balloon engineer Coxwell reached 8000 meters:

Between the heights of 4700 and 5900 meters, the thermometer marks $6^{\circ}$ above zero. . . The palpitations of my heart are beginning to become apparent, and my breathing is no less disturbed, my hands are growing blue, and my pulse rate, becoming feverish, is 100 beats per minute.

At 6168 meters, we are in a stratum at zero degrees ... my pulse is growing still quicker, and I have increasing difficulty in reading the instruments; I feel a general discomfort, like seasickness, 
although the balloon is not rolling or pitching ... The blue of the sky has become purer. (P. 47.)

The English edition of the work quoted above, ${ }^{36}$ which $M$. Glaisher published in 1871, gives quite a different account of the symptoms experienced by the learned aeronaut. In the first place, the date of this ascent is given as July 17 instead of June 30:

At the height of 18,844 feet ( 5740 meters), my pulse beat 100 times a minute; at 19,435 feet (5920 meters), I noted the beating of my heart; the ticking of the chronometer seemed very noisy and my respiration began to be affected; my pulse was still faster, and I read the instruments with growing difficulty; the palpitations of the heart were violent. My hands and my lips were a deep bluish color, but not my face.... At 21,792 feet (6640 meters) I felt a sort of seasickness, although the balloon did not roll or pitch; I was so sick that I was unable to examine the instruments.... The sky seemed a very dark blue. (P. 44.)

Second Ascent, August 18, 1862. The travellers reached 7100 meters, the highest point of the ascent:

I felt the pulse of $\mathrm{M}$. Coxwell, ${ }^{37}$ which was only 90 per minute, whereas mine was increasing rapidly. From 100 it went to 107 and then to 110 , without that of my companion changing appreciably .... As we descended we heard another clap of thunder roaring in the clouds which we were rapidly approaching. Is it the increasing speed of our descent that oppresses me? Is it the electric tension whose increase disturbs the hidden sources of life? . . . I d do not know, but I experience a sudden distress, a sort of nervous trembling. Happily, after a minute of anguish, a wonderful spectacle helps me triumph over this fleeting swoon. (Voyages aćriens, p. 57.)

At last came the famous ascent of September 5, 1862; it is the third. The ascent from Wolverhampton took place at 1:03 in a temperature of $+15^{\circ}$. At $1: 34$, the aeronauts had reached an altitude of about 5200 meters; the temperature is $-9^{\circ}$; there no longer is water vapor in the air. The first physiological disturbances then appear:

At $1: 34$, I noticed that M. Coxwell began to be out of breath, which is not surprising, because he was constantly occupied with managing the balloon....

At 1:39, we reached the height of 6437 meters (the altitude of Chimborazo) .... We threw out sand .... ten minutes were enough for us to rise to the height of Dawalagiri; the temperature had fallen to $-18.9^{\circ} \ldots$.

Up to this time I had taken my observations without difficulty, whereas M. Coxwell, who was obliged to move about in his duties, seemed weary. At 1:51, the barometer marked 11.05 inches. We found out later, by comparison with the standard barometer of Lord Wrottes- 
ley, that we should lessen this figure by a quarter of an inch. About 1: 52 , the dry bulb thermometer registered $-5^{\circ}$. Soon I could not see the column of mercury in the wet bulb thermometer, or the hands of a watch, or the fixed divisions of any of my instruments. I asked M. Coxwell to help me get the figures which escaped me, but, because of the rotation of the balloon, which had not ceased since we left the earth, the cord of the valve was tangled. M. Coxwell had to leave the basket and climb on the ring to untangle it. I observed the barometer; I saw that it registered 10 inches, and that it was falling rapidly. Its real height, taking care to subtract the quarter of an inch, was 9 and $3 / 4$ inches, which indicated a height of 29,000 feet ( 8838 meters). Shortly afterwards, I leaned on the table with my right arm, which had had its full strength an instant before; but, when I wanted to use it, I saw that it was no longer able to render me any service. It must have lost its power instantaneously. I tried to use my left arm, and found that it too was paralyzed. Then I tried to move my body, and succeeded to a certain degree; but it seemed to me that I no longer had any limbs; I tried once more to read the barometer, and while I was making this attempt, my head fell on my left shoulder. I stirred and moved my body again; but I could not succeed in raising my arms. I lifted my head but only for an instant; it fell once more.

My back was leaning on the rim of the basket and my head in one of its angles. In this position I had my eyes fixed on M. Coxwell, who was in the ring. When I succeeded in sitting up, I was completely master of the movements of my spine, and certainly still had great control over those of my neck, although I had lost command of my arms and my legs; but the paralysis had made new progress. Suddenly I felt incapable of making any movement. I vaguely saw $M$. Coxwell in the ring, and I tried to speak to him, but could not move my powerless tongue. In an instant, thick darkness seized upon me; the optic nerve had suddenly lost all power. I still was perfectly conscious and my brain was as active as while I am writing these lines. I thought that I was asphyxiated, that I should make no more experiments, and that death would seize me unless we descended rapidly. Other thoughts were rushing into my mind when I suddenly lost all consciousness, as when one falls asleep.

My last observation took place at 1:54, at 29,000 feet. I suppose that one or two minutes passed, before my eyes ceased to see the little divisions of the thermometers, and that about the same time elapsed before my faint. Everything leads me to believe that at 1:57 I lapsed into a sleep which might have been eternal. I was not able to move when I heard the words temperature and observation. I perceived that M. Coxwell was speaking to me and that he was trying to awaken me; hearing and consciousness had then returned to me. I then heard him speak louder, but I could not see him; it was much more impossible to answer him or make a movement. He was saying to me: "Try now, try." Then I vaguely saw the instruments and soon afterwards surrounding objects. I rose and looked around me, as if I were coming from a feverish sleep, which exhausted instead of resting one. "I fainted", I said to M. Coxwell. "Certainly," he answered, "and I nearly fainted too." I then pulled up my legs, which were 
extended straight out, and took up a pencil to continue observations. M. Coxwell told me that he had lost the use of his hands, which had become black and on which I poured brandy.

He added that, while he had been in the ring, he had been seized by an extreme cold and that icicles hung around the orifice of the balloon, like a terrible candelabrum, worthy of the polar seas. When he tried to descend from the ring, he could no longer use his hands, and was forced to let himself slide on his elbows to get back into the basket, where I was stretched out. He thought, seeing me on my back, that I was resting, and spoke to me without getting an answer. My face was serene and tranquil, without that anxiety which he had noticed before climbing into the ring.

Seeing that my arms and my head were hanging down, $M$. Coxwell understood that I had fainted. He tried to approach me, but could not, feeling unconsciousness overcome him too. Then he wanted to open the valve, but, having lost the use of his hand, could not manage it. He could not have succeeded in controlling our course, if he had not had the idea of seizing the cord between his teeth ${ }^{38}$ and pulling it two or three times by shaking his head violently.

I resumed my observations at 2:07, and the first figures that I registered were $292 \mathrm{~mm}$. for the barometer and 18 degrees for the thermometer. I suppose that 3 or 4 minutes passed from the moment when I heard the first words of M. Coxwell to the moment when I began again to read my chronometer and my other instruments. If this is so, I returned to life at 2:04, and was completely unconscious for seven minutes. (P. 59-64) ....

I felt no unpleasant result from my faint . . . . I walked eight or nine miles after we had landed as easily as if nothing had happened to me ....

I made my last observation at 8838 meters. [That is within two meters of the height of the highest peak on the surface of the earth, the Gaourichnaka of Nepal, at the foot of which the Brahmin pilgrims who are seeking Nirvana come to die; ${ }^{39}$ one may say that no human being ever could drag himself to this height following uneven terrestrial surface, and in spite of their courage the brothers Schlagintweit did not aspire to mount there. However, I might have continued my observations there, if the continued ascent of the balloon had not taken me higher, where life is still more difficult.] When ${ }^{40}$ I fainted, we were ascending at the enormous speed of 305 meters per minute, and when I resumed my observations, we were descending at a speed of 610 meters, double our speed of ascent; this circumstance permits me to calculate with a certain exactness the height to which we had really risen. (Voyages aériens, p. 65.)

Calculations based both on the ascensional speed of the balloon and on the temperature marked by a minimum thermometer have led M. Glaisher to judge that the balloon had reached the height of about 11,000 meters. The results of this calculation are, we must say, evidently erroneous. We are surprised to see a scientist of this caliber suppose that the balloon had a uniform speed in 
ascending and descending, and solve by equations of the first degree a problem which evidently depends on the second.

Everything leads us to believe that the balloon soon stopped and soared for some minutes before descending.

I should mention a little experiment that is rather interesting:

We had taken with us six pigeons to toss into the air successively at sufficient heights. We threw out the first at 4807 meters; he spread out his wings but could not support himself and fell like a leaf of paper.

The second, which was thrown out at 6437 meters, did not let itself fall so easily; it whirled about, flying vigorously. Probably it turned completely about each time it dived in spite of itself. Perhaps by yielding to this strange waltz it found a way to resist the terrible suction.

The third was thrown out before reaching the level of 8048 meters. It fell like a stone and disappeared rapidly. We kept the three pigeons left for the descent, but we found that one of them was dead in its cage and another was hardly better. When I took it from its cage, it refused to fly away. Only after a quarter of an hour of rest did it begin to peck at a bit of pink ribbon which was around its neck. It was a carrier pigeon which, when once recovered, flew with great rapidity in the direction of Wolverhampton. (P. 67) ...

Of all the pigeons thrown out during the journey, only one returned to Wolverhampton, during Sunday (the fifth of September was a Friday).

M. Glaisher made several more ascents in which he mounted above 7000 meters (April 10, 1863, to 7300 meters; ${ }^{41}$ June 26, 1863, to 7100 meters); in his accounts he says nothing at all of physiological disturbances.

But he summarizes, in a separate section, the observations of this sort which he made in these different ascents; I quote from the English edition in which it is much fuller and more interesting than in Voyages aériens:

The number of heart beats per minute increases with the altitude, as does the number of inspirations: my pulse was generally 76 before starting, about 90 at 10,000 feet, about 100 at 20,000 feet, and 110 at greater heights; but the increase in the height is not the only element on which the rate depends; the state of health has much to do with it, as does the temperament of the different individuals.

The same thing is true of the color of the face; at 10,000 feet, certain persons are of a flaming purplish red, while others are hardly affected. At 17,000 feet, my lips were blue; at 19,000 feet, my hands and my lips were a deep blue; at a height of four miles, one could hear my heart beat and my respiration was much affected; at 29,000 feet, I became unconscious. From all observations one may conclude that the effects of great heights are felt by everyone, but vary in the same individual according to circumstances. (P. 92.) 
M. Glaisher states that one soon becomes accustomed to the influence of rarefied air, and cites his own experience in this regard. He expresses hopes on this subject that show both keen imagination and scientific understanding:

The diminution of pressure .... should act in a very special way on persons who are journeying in the air for the first time. I can make this statement from my own personal experience, which certainly has some value, for I have not always been able to ascend without ill consequences to a height which ordinarily produces great distress, and generally brings on discoloration of the hands and face. I recall having caused great astonishment in a group of scientists by stating that I was accustomed to rising to very lofty altitudes 'without turning blue. I am really convinced that I have become acclimated to the effects of the rarefied air found at six kilometers from the surface of the earth, and I flatter myself that I can breathe freely in these strata high above sea level. I even have no doubt that this acclimatization can be sufficiently developed to exercise a considerable influence on the scientific use of balloons. At eight or ten kilometers I have tested upon M. Coxwell and myself the limits of our ability to live in rarefied air. Frequent trials would increase this height, and I am certain that it could be extended even more if one used artificial means to aid respiration. Certainly human lungs would find up there their Columns of Hercules, but I do not hesitate to declare that these impassable boundaries are still very far from the regions I have reached. (Voyages aériens, P. 9.)

The learned meteorologist of Greenwich, in another passage of his work, again refers to the future he predicts for ascents to great heights; he expresses with unusual vigor his unlimited confidence in the fruitful efforts of science. We shall show in the rest of this work that these hopes have not been disappointed:

As I have already explained in the introduction, I do not doubt that some one will succeed in making observations in regions which I could not attain without fainting. I am persuaded that a day will come when aeronauts will surpass me just as I exceeded the height of Barral and Bixio, who in their turn reached altitudes higher than Sakaroff and Gay-Lussac. I certainly shall not take it upon myself io set the limits of human activity and indicate the point, if it exists, where nature says to the aeronauts: "You shall go no further." (Voyages aériens, p. 67.)

For about ten years, there has been no ascent to a great height, and in the scientific ascents to moderate heights, the aeronauts, preoccupied with important problems of meteorology and physics, neglected completely the physiological phenomena whose slight modifications could not be observed without having great attention devoted to them. 
We must turn to the ascents organized by the Society of Aerial Navigation to find facts that interest us. The first among them, although it did not pass above 4600 meters, gave Dr. Pétard, one of the travellers, very interesting physiological observations. He begins by listing briefly the temperaments of his travelling companions:

M. Crocé-Spinelli is blond, of a lymphatic temperament, nervous, he is ordinarily inclined to attacks of bronchitis.

M. Pénaud is chestnut-haired, of a lymphatic temperament, and he is disposed towards rheumatism.

M. Jobert is very dark, of an athletic constitution with biliososanguine disposition.

M. Sivel is dark, of a sanguine disposition; he is very strong, and, furthermore, not sensitive to aeronautic influences because of the great number of ascents he has made.

Finally, I am dark and of a sanguine disposition. (P. 118.)

The balloon rose to a height of 4600 meters $(429 \mathrm{~mm}$.), where the aeronauts found a temperature of -7 degrees after having passed through a layer at -20 degrees:

I could (says M. Pétard) observe that the earth below appeared like a basin, and this illusion makes the hills seem very low and the ravines very shallow.

The second phenomenon to be observed is the oppression displayed by M. Crocé-Spinelli, at about 3500 meters. I remind you that M. Crocé-Spinelli is predisposed to bronchitis. M. Pénaud also experienced oppression, but to a much less degree than M. Crocé-Spinelli. The other passengers felt none.

We next observed the buzzing in the ears which M. Pénaud mentioned first at a height of about 2700 meters.

We were all affected at about the same time and in the same way, but with very marked differences in the intensity of the impression. For M. Crocé-Spinelli it passed to a state of keen pain, and so persistent that in the train, during our return, he still complained of pains in his ears.

M. Crocé-Spinelli said that in him the buzzing and later the acuteness of the pain appeared only during the rapid descents, that is, when the outer pressure exceeded that of the ear. In me, this buzzing was perceptible whenever we had a rapid descent or ascent of some extent, that is, whenever the equilibrium between the inner and the outer pressure in the ear was broken .... Not only did the sounds seem weakened, but they also appeared to come from far away. (P. 119.)

The following observations were made above 4000 meters:

By aid of the buccal thermometer of M. Sainte-Claire Deville and that of Celsius, I observed a slight drop in the animal temperature, which varied in the experiments made from $35.02^{\circ}$ to $35.07^{\circ}$. The 
acceleration of the respiratory rhythm and of the arterial circulation, very noticeable in all, was in very different proportions in the different subjects. M. Jobert, whose respiratory rate is normally only 10 , had a rise to 20 ; his pulse, normal at 100 , reached a maximum of only 130 . That of M. Pénaud rose from 68 to 104 , the respiratory rate from 25 to 45 . M. Crocé-Spinelli: normal pulse, 72 ; maximum pulse, 116 , at an altitude of 3500 meters. At 500 meters it was only 86 . The number of inspirations went from 40 to 64 . M. Sivel: normal pulse, 80 ; maximum, 108; respiration went from 25 to 40 . Dr. Pétard: normal pulse, 87; maximum, 110; normal respiration, 26; maximum, 35.

These data show that the increase in inspirations reached an average of $8 / 5$ of the normal value, but that the increase in pulse rate varied according to the temperaments. While this increase was from 7 to 11 for lymphatic temperaments, it was from 10 to 13 for sanguine temperaments.

I could not observe, by the pneumo-dynamometer, any appreciable difference in the expansion of the lungs.

The pulse was generally full and regular; but it was not possible to make graphs of it, since we were not able to use sphygmographs on account of the drop in temperature, which made exposure of the skin painful. (P. 120.) ...

We felt a sensation of peculiar well-being impossible to describe, although it was expressed by words and mien.

The two celebrated ascents to great height (7300 meters and 8600 meters) carried out by my regretted colleagues Crocé-Spinelli and Sivel, having been undertaken after the first publication of the results of my researches, their account will naturally be placed in the third part of this book.

In conclusion, I shall merely quote an account of an English aeronaut, Simons, who on July 9, 1874, started from Cremorne Garden, in London, taking Groof, the Flying Man, with his complicated apparatus suspended under the basket.

The balloon contained 27,000 cubic feet; at 1000 feet, Groof disengaged himself, and falling head first, was dashed upon the ground. Groof and his machine weighed 130 kilograms:

I looked over the edge of the basket (says Simons), but I was rising so rapidly that I lost consciousness until I was over Victoria Park. ${ }^{42}$

But I hasten to add that we should not have too great confidence in the ascents of Simons, who certainly deviated from the truth in his replies during the inquest on this painful event.

1 Manuscript preserved in the Library of the Institute, under the title of Second Mémoire de $M$. Charles sur l'Aérostatique, 1784. See also L'Art de voyager dans les airs ou les ballons. specifying the means of making aerostatic spheres, following the method of MM. de Montgolfier and the procedures of MM. Charles and Robert. Paris, 1784, without an author's name (by Piroux, according to the Dictionnare des. Anonymes de Barbier).

De. Aerostatum usu medicinae applicando. Thèses de Montpellier, 1784. 
${ }^{3} \mathrm{Mme}$. $\mathrm{B}^{* * *}$, horn de $\mathrm{V}^{* * * *}$, The Olympic Circus, cti. followed by the Acronautic Horse of M. Testu-Brissy, Paris. 1817.

4 Relation du scizieme z'ovanc aérien de M. Blanchard, dedicated to S.A.S. Mgr. le prince de Ligne; br. in 4 of 17 p. Ghent, 1786.

Journal de Paris, Necember 5, tisi.

7 January 5, 1786i. p. 18

: Ibid., December 20, 17es: 11. 1Ififi.

816 th and 20th Messidor and 10th Thermidor, in the year VII.

9 Robertson, Rélation adresséc au président de l'Acad. imp. de Saint-Pétersb., in his Mémoires récréatifs, scientitiques et anecdotiques, 2 vols. Paris, 1810.

${ }_{10} \mathrm{It}$ is, therefore, by an error that all authors, without exception, have attributed a height of 74 io meters to the ascent of Robertson.

11 By Izarn (See the Moniteur universel, January 25, 1804)

12 January 20, 1804; year XII, vol. I, D. 73.

${ }_{13}$ Abenteuer des Grafe $Z$. . bei einer nachtlichen Luftfahrt. Gilbert's Annalen der Physik, vol. XVI, p. 205-2019; 1804.

if Souźenirs d'un rovage en Lizonie, à Rome et à Naples, faisant suite aux Sourenirs de

Paris. Translated from the German. Paris, 4 vol.. $18^{\prime} 6$

15. Ascension de Robertson et Sacharoff, June 30, 1804. Annales de Chimie, vol. LII, D. 121

(Report of Robertson). Philosophical Magasine, 1805; vol. XXI, p. 193 (Report of Sacharoff).

16 Account of an aerostatic journey made br. M.M. Gay-Lussac and Biot; read to the class of mathematical and physical sciences of the Institut National, the 9th of Fructidor, in the year XII Moniteur Universel, of the 12th of Fructidor in the year XII (August 30, 1804.)

17 Account of a balloon journey made by M. Gay-Lussac the 29 th of Fructidor, in the year

XII. Ann. de Chimie, vol. LII. p. 75-91, year XIII.

is September 9,1508 , 1 , blaisher, Flammarion, IV. de Fonvielle and G. Tissandier. 2nd edition. London, $18 i 1$.

Biblioth. britann., vol. LVII, p. 286-300; 1814.

21 May 8, 1812.

$=$ Mav 16, 1812 .

23 Silliman's American Journal, vol. XII, p. 161-168; 1827.

\# The work of Roch (Essai sur les Voyages aériens d'Eug. Robertson; Paris, 1831), says 3533 fathoms (6856 meters).

${ }_{25}$ Relation du premier voyage aérostatique érecuté dans la République mericaine. Paris. 1835 .

2n Les Voyages aériens. Paris, 1870, p. 27.

"Einiges über die Luftreize des H. Green in London am Krönungstage des Königs.

Frorien's Notizen, vol. 1, p. 71 ; 182.2. See also: Ibid, vol. V, p. 202.)

* Bericht über cine Luftschiffarht. Ibid, vol, XXXII, p. 49; 1831.

29 Neue Froriet's Notizen, vol. I, D. 8; 1837 .

3. T.etter to the Standard. July, 18:7.

"Handbuch der rationnellen Pathologie. Vol. II, 2nd. part; 1851.

$32 \mathrm{Vol}$ XIV p. 921; 184?

33 Journal d'un voyage aéronautique fait le $2 \tau$ juillet 1850 . Cpt. $R$. Acad. des sc., vol. XXYI, D. $126 ; 1850$.

ai An account of Meteorolosical Observations in four Balloon Ascents, made under the direction of the Kew Ohservatory Committee of the British Association for the advancement of science, by John Welch. Philosophical Transactions, vol. CXLIII, p. 311-347; 1553.

35 Glaisher, Flammerion, de Fonvielle, G. Tissandier, Voyages aériens, Paris, 1870.

an Travels in the Air, 2nd ed. London, 1871. first.

$37 \mathrm{Mr}$. Coxwell was an aeronaut by professicn; the ascent of June 30 was Mr. Glaisher's

as The nossibility of opening a balloon valve thus, even for a man in full possession of his powers, has been absolutely denied by a professional aeronaut, M. Duté-Poitevin ( Aéronaute of April 1s.6, p. 105). I should call attention to the fact that $M$. Glaisher never considered V. Coxwell a scientific crllaborator.

39 In the diagram which accompanies this account, a diagram the original of which. drawn hy M. (ilaisher himself. I have had in my possession, the last certain observation of height is ahout 8100 meters; the temperature was $-30.6^{\circ}$.

40 The passage between brackets does not exist in the English text. Can it have been added

by a fanciful translator? Traduttore, traditore.

${ }^{41}$ This is the number in the English edition and diagram. Voyages aéricus gives $780 \times$ meters.

42 The journal, the Aeronaut, number of August, 1874. 


\section{Chapter III}

\section{THEORETICAL EXPLANATIONS AND EXPERIMENTS}

In the present chapter, we shall review the manifold explanations given by different authors, travellers, physicians, and physiologists of the symptoms the varied descriptions of which we have given in the preceding chapters. We shall add the reports of the few experiments made in laboratories to throw light on these obscure problems. This will be only an exposition of theories; criticisms will come in the following chapter.

We shall follow here a strictly chronological order, since the proposed explanations would naturally show the effects of current physiological theories.

The first traveller to describe mountain sickness is, as we have seen, the Jesuit Acosta; ${ }^{1}$ he gave an explanation of it which we quote in full, and which is admirable for its shrewdness, the soundness of its views, and its clearness of expression. On the one hand, he specifies the real cause, and on the other, he rejects in advance a mistaken hypothesis:

There is no doubt (he says) that the cause of this distress and strange affliction is the wind, or the air current there, because the chief and best remedy to be found is to close the nose, the ears and the mouth as tightly as possible, and to cover oneself with garments, especially the stomach, since the air is so thin and penetrating that it pierces the very vitals ....

By this I am convinced that the element of the air is in this place so thin and so delicate that it is not proportioned to human breathing, which requires it denser and more temperate ....

On passes of the Nevada mountains and others of Europe which I have seen, no matter how cold the air there may be, nevertheless this cold does not take away the appetite to eat; on the contrary, it awakens it and does not cause vomiting in the stomach. In the Indies .... it happens at the same place even when the sun is warm, 
which makes me think that the distress one feels from it comes irom the quality of the air one breathes there. (P. 87.)

When one thinks that these lines were written at the end of the sixteenth century, three hundred years before Lavoisier and Priestley, by a man whose specialty was not the study of the chemical and natural sciences, one is filled with admiration for the great astuteness of the learned Jesuit and the unusual accuracy of the expressions he uses. Let us remember also that the pneumatic machine had not been invented, and that Torricelli had not yet been born, when Acosta said that "the element of the air is in this place so thin and so delicate that it is not proportioned to human breathing".

It is interesting to compare the explanations of Acosta with what the celebrated Francis Bacon " wrote thirty years later on the same subject, in his Novum organum (appeared in 1620). If I am not mistaken, the comparison is not to the advantage of the learned chancellor of Verulam:

The rays of the sun produce no heat in what is called the middle region of the air; which is explained well enough in the schools by saying that this region is not near enough to the sun from which the rays emanate, nor to the earth which reflects them. To support this explanation, we may cite the summits of mountains (unless their elevation is not great) where perpetual snows lie. In fact, certain travellers have noticed that there is no snow on the summit of the Peak of Teneriffe, nor on the Andes of Peru, whereas the sides of these mountains are covered with it up to a certain height. It is stated, moreover, that at these extreme heights the air is not cold, but merely rare and sharp; that is why on the Andes it attacks and injures the eyes and the stomach, which cannot keep food down. The ancients had already noted that on the summit of Olympus the air was so rare that to climb to it one must take with him sponges wet with vinegar and water, and often place them on the nostrils and the mouth, since the air, because of its rarity, did not suffice for respiration. It is added that on this same summit, where neither rain nor snow. fell, and where the wind never blew, there reigned such a calm that when sacrificers had traced with their fingers characters on the altar of Jupiter with ashes of the victims, these impressions remained quite intact until the following year. Even today the travellers who ascend to the summit of the Peak of Teneriffe make their ascent by night and not by day; immediately after sunrise, their guides urge them to descend without delay, apparently because of the danger caused by breathing an air so rare and asphyxiating.

In fact, it was not until a half century after Acosta, that Torricelli invented the barometer, and Otto de Guéricke the pneumatic pump. After that, laboratory experiments could go 
on simultaneously with observations made by travellers. But strangely enough, for a long time physicists tried exclusively to study the effect of a vacuum, that is, the total lack of air. They did not inquire what would happen from a sojourn in air which was merely rarefied; for them, it seems, only two possibilities existed: to have air or to have no air. And yet, by a strange contradiction, many of them, trying to find out why animals which are kept in closed vessels die, were convinced that it was because of "the decrease in the elasticity of the air". Very strange! They did not investigate experimentally to see what would happen to animals which were subjected to such a decrease from the very outset; after the famous experiments of Pascal on the Puy-deDome (September 22, 1648), they were not surprised to see animals continuing to live, which, on the mountains, were subjected to a decrease in the elasticity of the air enormously greater than that which accompanies asphyxia in closed vessels.

At any rate, the members of the famous Academy del Cimento: tell us that:

As soon as Torricelli first advised the experiment with mercury, he began to think also how he would imprison different animals in a vacuum, so as to observe in them movement, flight, respiration, and all the other phenomena which could be observed. But being without the instruments necessary for this sort of experiment, he did the best he could. For the small and delicate animals were overwhelmed by the mercury, through which they had to climb upward, when next the vessel was overturned and they were plunged into the other mercury. And they were then quite or almost dead, so that one could not tell whether they were injured more by the mercury which suffocated them or by the lack of air. (P. 46.)

As for them, they tell in their memoirs for the year 1667 the numerous experiments they made on animals, using barometric tubes, the large chamber of which was closed by a bladder.

These animals were leeches, snails, insects of different sorts, reptiles, and birds. The experiments give with remarkable exactness the different symptoms displayed by these animals which were subjected instantaneously to an almost perfect vacuum. The physicists of Florence noticed besides that, in fish placed in the vacuum, the "air bladder" deflated and the fish then remained at the bottom of the water; in consequence, they performed curious experiments, thanks to which they discovered the "little vent-hole" through which the air escapes when it is expanded by the effect of the diminution of pressure.

We do not find in this account any very definite theoretical 
explanation of the effect of the vacuum. It appears, however, that for the academicians of the Cimento, a vacuum acts simply by the removal of air. Furthermore, their translator and commentator van Musschenbroeck explains it very clearly when he says:

If we wish to know exactly how long a little bird can do without air, let him be plunged under water; for then he cannot breathe air, and he is immediately in a situation similar to a vacuum.

These notes of van Musschenbroeck ${ }^{4}$ also contain a very curious description of the phenomena presented by an animal subjected to the action of a vacuum, with an interpretation of the causes of death, an extremely interesting interpretation, although it savors of the false ideas of the epoch about the pulmonary circulation:

We shut a rabbit in a glass receiver, and by means of the pneumatic pump drew out all the air; the animal at first was uneasy, sought air, swelled up all over; its eyes protruded, it defecated, sought a way out all around the vessel, sat up hardly breathing, grew weak and fell in convulsions, lay down on its side, and finally died; all these things happened in half a minute, after the pump began to work and rapidly removed all the air from the vessel: the whole body of the animal lost its air and was deflated; then when we opened the chest, we found the lungs small, collapsed, solid, heavier than water. The whole body of the animal swells in the vacuum because the ventricle and the intestines contain much air, which, when it is no longer compressed by the outer weight of the atmosphere, expands in all directions as a result of its elasticity and distends the abdomen. But the blood and the other humors have elastic air mingled with their.parts, which then, not being compressed, expands, recovers its elasticity and distends all the vessels, so that all the body of the animal must swell in all parts, especially the eyes, the humors of which contain much of this air; experimentation has taught me this, as I have tried to prove in my dissertation De aeris existentia in omnibus animalium humoribus.

Moreover, the animal enclosed in a vacuum cannot inhale air into its lungs, and although it tries to expand its chest, and often repeats this expansion, nevertheless nothing enters from the outer part of the lungs into the air vessels or vesicles. That is why the contractile force natural to all fibres compresses the vesicles; the lungs collapse, become denser, and specifically heavier than water; but whereas the vesicles attached to the extremities of the tracheal artery are compressed, the circulation of the blood is hampered in the arteries and the veins which surround the whole vesicular surface in abundance, and in those which are situated in the interstices left around each vesicle. But in this adult animal, the blood of the whole body, pumped out by the right ventricle of the heart, must pass through the vessels of the lungs into the left auricle and ventricle, so that from there it can be pumped out into the parts of the body. When the vesicles of the lungs are contracted and compressed in the vacuum, the blood vessels 
are also compressed, nothing passes from the right ventricle of the heart into the left, the blood is not pumped to the brain, the cerebellum, or the other parts of the body, and the circulation of the blood, upon which life depended, is ended. But before the circulation of the blood ceases entirely in the lungs, the air which is mixed with the blood escapes from the interstices, collects, grows rarefied, is pumped to the brain, causes obstructions here and there; hence comes the disorganized secretion of animal spirits in the brain, and hence their irregular influence upon the muscles of the body, which is the cause of the convulsions, and delays death. I do not doubt that all animals whose heart has two ventricles and is not pierced by an oval hole would die in a vacuum with the symptoms which I have reported ... .

The animals which have an oval hole opened in the heart live a long time in a vacuum, and die only because of thirst, hunger, etc. (P. 55.)

And so, in the opinion of the celebrated professor of Leyden, the death of animals subjected to a vacuum occurred as a result of a stoppage of the circulation of the blood, a stoppage due to the collapse of the lungs from which the vacuum had removed all the air; furthermore, the gases which escaped from the blood obstructed the vessels, especially in the brain:

They say (adds Musschenbroeck) that birds endure rarefied air more easily and with less inconvenience than land animals, because they are used to breathing a rarer air when they fly high: however, they cannot endure an air three-quarters rarefied; that is why they can rise only to a certain height in the atmosphere and not to all kinds of heights: these animals are uneasy in a rarer air, because this air can hardly, by its elasticity, expand the vesicles of the lungs unless the chest is expanded by very great force; and this is the cause of the uneasiness felt by the men who have climbed to the summits of the high mountains of Armenia, Savoy, the Pyrenees, and Teneriffe, where the air is much rarer than that which is near the surface of the earth. (P. 57.)

In France, the Academy of Sciences thought at first of making experiments with "the machine of M. Guéricke of Magdebourg"; but the only one which its Memoirs ${ }^{5}$ have reported to us dealt with a gudgeon which, after the action of the vacuum, fell to the bottom of the water, "its bladder being emptied".

However, in England, one of the most remarkable experimenting physicists of the seventeenth century, Robert Boyle, ${ }^{6}$ had undertaken very interesting researches on the life of animals subjected to a vacuum. He used the pneumatic pump. His experiments, published in 1670 in the Philosophical Transactions, surely antedate this epoch considerably since some of them are quoted in 
the memoir mentioned above of the Physicists of Florence, printed in 1667.

This noteworthy work is divided into several parts:

In the First, Boyle questions whether aquatic birds, which can remain for some time under water "because of the peculiar structure of certain vessels which they have around the heart", could sustain better than other animals the lack of air in a pneumatic machine. And, after an experiment made on a duck, he replies in the negative.

In the Second and the Third, Boyle reports the results of experiments made on snakes and frogs, which sustained the vacuum for a long time.

In the Fourth, he says that he experimented on new-born kittens, and that he was astonished to see that these animals held out three times longer than older animals of the same size could have done.

Part V. Experiment to find out the volume of air contained in the pores of water.

Parts VI and VII. On the effect of the vacuum upon oysters, crabs, and a gudgeon.

Part VIII. Experiment on a bird and a frog enclosed in the pneumatic machine, both having the abdomen opened.

Part IX. Experiment on the heart of an eel.

Part X. Comparison of the time it takes to kill animals in water and in the pneumatic machine.

In Part XI, Boyle reports the sufferings of which Acosta complained in his trip over Pariacaca, and he declares that he had heard similar reports from travellers who made the ascent of Mount Ararat, the Peak of Midi, the Peak of Teneriffe, and even the Cévennes. In Chapter I we quoted these different observations. He asks himself in this regard

Whether the difficulty of breathing which certain persons experienced on the heights of Pariacaca, and perhaps on some other very lofty mountains, comes solely from the lack of elasticity in the air in these high places; whether we should not attribute it, at least in part, to certain penetrating vapors with which the air may be laden in places. (P. 42.)

Part XII. Effects produced upon an animal by the alternate rarefaction and condensation of the same air.

Part XIII contains the account of a very remarkable experiment, which Magnus was to repeat, more than a century and a half afterwards: 
The blood of a lamb or a sheep was brought me still warm from the slaughterhouse, where care had been taken to break the fibers to prevent coagulation. This blood I placed in a glass vessel with a wide opening, and put the vessel in a receiver; the air was immediately pumped out very carefully; but the effect of this operation was not so prompt or so apparent, especially at the beginning, as I should have expected it to be in so spirituous a liquid; however, after a long delay, we saw that the most subtle parts of the blood appeared through the more viscous parts, and formed bubbles, some of which were as large as big beans or nutmegs; sometimes the expansion was so strong, that the blood boiled up out of the glass vessel, of which, however, it hardly occupied a quarter at the beginning of the experiment. (P. 46.)

Robert Boyle drew air in the same way from other organic liquids and all the soft parts. And he explains with keen sagacity the purpose of these experiments; he wished to find out

What, joined to the failure of respiration, could contribute to the death of animals in the vacuum of the pneumatic machine; as a matter of fact, it appears that the bubbles which, when the ambient air is removed, form in the blood, the other liquids, and the soft parts of the body, can by their number and their expansion in some places swell and in others contract the vessels which carry blood and nourishment into the whole body, especially the smallest of these vessels, can choke passages or change their shape, and finally stop or disturb circulation in a thousand ways. Add to that the irritation caused in the nerves and the membraneous parts by forcible distentions; an irritation which produces convulsions and causes death more quickly than simple lack of air would have done. This formation of bubbles takes place even in the smallest parts of the body, for I have seen a very apparent bubble moving from side to side in the aqueous humor of the eye of a viper at the time when this animal seemed violently distressed in the receiver from which the air had been exhausted. (P. 47.)

In Part XIV there is reported a very fine experiment, by which Boyle shows that animals become accustomed to the effect of the rarefaction of the air, and suffer less from it in successive experiments.

Part XV. Experiment which shows that air can preserve its elasticity while ceasing to be suitable for respiration.

Part XVI. On the use of air for causing the escape of exhalations from the body. air.

Part XVII. Ability of the slug and the leech to endure lack of

Part XVIII. Trial of the vacuum upon certain crawling insects.

Part XIX. Winged insects enclosed in a vacuum.

Part XX. On the need of air for motion shown by ants and mites.

In another work, ${ }^{7}$ the celebrated physicist again dwells upon the experiment relating to the bubbles of air which escape from 
organic liquids placed in a vacuum, and he is led to ascribe to the escape of these bubbles an important part in the symptoms due to decreased pressures:

When I recall how our machine (the pneumatic machine) brings out air invisibly held in the pores not only of the water, but also of the blood, serum, bile, urine, and other liquids of the human body; when I reflect that (as I have shown experimentally elsewhere) the pressure of the atmosphere and the elasticity of the air act upon liquids and upon bodies immersed in these liquids, and upon bodies directly exposed to the air, I am inclined to believe that simple changes of the atmosphere from the point of view of weight can, in some cases, have a perceptible influence even on the state of health or sickness of man. When the ambient air, for example, suddenly becomes lighter than before or than usual, the spiritual or airy particles, which are contained in abundance in the blood, naturally will swell this liquid, being able thus to distend the large vessels, and change considerably the speed of the circulation of the blood in the capillary arteries and the veins. That through this alteration several changes can occur in the body will not seem improbable to those who know, in general, how important the rhythm of the circulation of the blood is, although, as to its special effects, I leave them to the speculation of the physicians.

These experiments were repeated, and varied in different ways by all the physicists of this time: Stairs, Derham, Huyghens, Papin, du Hamel, etc.

I shall quote an extract of the work written in collaboration by Huyghens and Papin; this passage is remarkable for the wholly mechanical explanation given in it of the cause of the death of animals placed in a vacuum in the pneumatic machine.

According to Huyghens and Papin, ${ }^{8}$ warm-blooded animals never revive when they have been placed in a perfect vacuum. They then add:

M. Guide, who has often dissected these animals which we killed by a vacuum, has observed among other facts that their lungs sink in water, and he maintains that the solidity or density of the lungs of animals which have died thus in a vacuum results from the fact that the blood, carried into the lungs by the arterial vein, presses with such violence upon the bronchi of the tracheal artery, that it forces the air out of them and brings together the walls of these collapsed conduits, as if they had been glued together; but, for my part, I do not believe that the blood of the arterial vein can compress the bronchi in this way, because the blood has its own vessels which contain it and prevent it from compressing others. . .

It is therefore more probable that if the lungs are compressed, it is done by the pleura which can be distended within the chest as the skin is distended on the exterior; but the lungs need not be 
compressed in a vacuum to sink in water; for I have several times placed in a vacuum pieces of lungs and whole lungs, and they remained extremely inflated while in the vacuum; but as soon as air was admitted to the receiver, they became flat and red and sank when placed in water. (P. 150.)

Finally, before leaving this fruitful epoch, I think I should reproduce here a very curious plan of experiments suggested to the English physicist Beale ${ }^{9}$ by his celebrated compatriot Boyle:

It would be, I think, very important to see the effects produced on plants placed in Mr. Boyle's air-pump, and likewise on cherryblossoms, etc.

The distinguished $\mathrm{Mr}$. Boyle suggests that in the approaching season I should see:

1. Whether seeds germinate in the vacuum receiver;

2. Whether lack of air is harmful to sensitive plants;

3 . Whether grafting pear buds on spina cervina (the only vegetable purgative known in England) will give the pears purgative qualities.

4. Whether the eggs of silkworms will hatch in the receiver when the season has arrived.

I should, besides, investigate whether aquatic plants live in water from which the air has been removed by the pump ... . .

One of these experiments was carried out on lettuce seeds. Those which had been planted in open air measured 11/2 inches in height after a week, the others had not sprouted; but they germinated when air was admitted.

We shall not dwell longer on these attempts which, as we have noted, relate almost exclusively to the effect of an almost complete vacuum. Except for a few experiments of Boyle and Musschenbroek, air that is merely rarified is, in fact, not considered in them at all.

And yet, as we have seen, these physicists tried to find in these experiments explanations for the physiological disturbances experienced by travellers who ascend high mountains. This interest is shown also in a curious passage in the History ${ }^{10}$ of the Academy of Sciences for 1705; it shows at the same time how many uncertainties then assailed the minds of the physicists themselves on the question of measuring altitudes by the barometer:

There is some reason to believe that the air expanded in a tube is not quite of the same nature as air at the top of a mountain. If one puts lukewarm water in the vacuum machine, it boils very hard as soon as half of the air has been pumped out, because that which was naturally mixed with this water, and which had already been warmed a little, when it is freed of half the weight which pressed 
on it, tends to escape entirely. Hence M. Mariotte has conjectured that if one was at an elevation where the weight of the atmosphere was diminished by half, the blood, much warmer than lukewarm water and still full of air, would boil, so that it could no longer circulate, and we must admit that the conjecture was well founded. However, MM. Cassini and Maraldi, who have ascended to altitudes where, according to their calculation, the weight of the atmosphere was almost a half less, felt no distress caused by the rarefaction of the air. Many persons who have been still higher felt no more than they.

I do not need to go to great lengths to show the mistake of the writer in regard to the height of the mountains which Cassini and Maraldi ascended. A few lines above, he said himself that "the barometer hardly drops 5 or 6 inches on the highest mountains where observations have been made".

Later, the Italian physicists once more took up the study of these important problems. Veratti, an academician of Bologna, made numerous experiments ${ }^{11}$ on this subject. He begins by recalling that two very different explanations have been given for the death of animals in the vacuum:

According to the clever Borelli, this death occurs because, when the outer air is removed, the air contained in the blood and the humors is greatly rarefied and distends the vessels beyond the endurance of the animal. According to this idea we must conclude that in the blood and the other liquids a sort of effervescence is caused which rarefies them and slows their movement, that the nerves are compressed by it and the course of the animal spirits checked, which necessarily brings on the death of the animal ....

M. Musschenbroeck ... thinks that the cause of this phenomenon lies in the lungs. He thinks that the pulmonary vesicles, when they receive no more outer air, contract more than is natural .... which causes the vessels to be cramped and the blood to be stopped in them .... (See above the opinion of Musschenbroeck and that of Guideus.)

Veratti, having placed quails in the vacuum, found that their lungs floated after death. The lungs of rats and rabbits floated also, but those of kittens a week old did not. He concludes from this:

That Musschenbroeck and Guideus had either used in their experiment new-born animals, in which the oval hole was not yet closed, and whose lungs could not expand sufficiently to become specifically lighter than water; .... or that they left the animals in the vacuum for too long a time after their death; .... or that the air in the receiver was perhaps more rarefied in the experiments of these physicists ... . who were not careful about specifying the degree of rarefaction which they used .... As for him, he merely rarefied the air to the point necessary to kill the animals....

The lungs, he says in conclusion, are heavier than water only in 
case they have been kept in the vacuum for some time after the death of the animal. That proves that this death should not be attributed to the contraction of the lungs .... Perhaps the lungs do not become denser in the vacuum, and seem so when they are withdrawn only on account of the pressure of the outer air, which then begins to act upon them. Besides, when all the other parts of the body swell in the vacuum, it is not clear why the lungs should be the only exception.

We see that Veratti is far from being satisfied with the result of the experiments of the Dutch physicists. However, he does not take sides definitely, although he is inclined towards the opinion of Borelli.

In another memoir ${ }^{12}$ which he devotes to the study of asphyxia in closed vessels, he makes an observation, mistaken to be sure, which shows how complex these questions seemed to him:

None of the animals which die in the receivers (confined air) have convulsions, as always happen to those which die under the receiver of the pneumatic machine; which proves that the cause which kills animals in confined air is very different from that which kills them in a vacuum.

We are really much surprised to see, after that, that in the explanation of the death of the enclosed animals he gives an important role to "the destruction of the elasticity of the air, proved by his experiments", that is, to a decrease in pressure of a few millimeters of mercury.

Another Italian, J. Fr. Cigna, ${ }^{13}$ shortly after, carried on research of the same type on death in closed vessels. But he was the first to have the idea of studying what would happen to animals kept until death in closed receivers, in air of different degrees of rarefaction.

He used a bottle containing "about 50 pounds of water". In it he placed a sparrow, then pumped out the air in two minutes to a decompression of 16 inches, 10 lines:

The animal vomited at the beginning, went through a few convulsions, then seemed in fairly good condition for a few instants. Its respiration at first was shallow and rapid; it became still more so afterwards; soon it was rapid and deep, and finally deep and slow; then came convulsions which ended its life. The mercury had risen little by little in the siphon, so that at the time of the animal's death its height had increased about $4 \frac{1}{2}$ lines. Counting from the moment when communication of the tube with the pump had been cut off, the sparrow had lived 35 minutes....

After washing the bottle, I placed another sparrow in it; I pumped out the air so that the mercury rose in the siphon only to 13 inches, 5 lines, and I cut off the communication of the bottles with the pump. 
As on the first time, all these operations were carried out within two minutes after the sparrow had been inserted. This animal showed the same symptoms as the first. It lived 70 minutes; at its death, the mercury had risen 7 lines above the point at which it stood at the beginning.

Finally I placed a third sparrow in the bottle, without having rarified the air (the height of the mercury was then 27 inches, 6 lines). The symptoms were the same with the exception of the convulsions. The animal lived three hours and a half. At the time of its death, the mercury had risen in the siphon about 1 inch and $1 \frac{1 / 2}{2}$ lines.

In these experiments, the quantities of enclosed air were to each other as the numbers $128,169,330$, and consequently almost as $3,4,8$. The duration of life of the sparrows was as the numbers $35,70,210$, and almost as 1, 2, 6; whence it follows first that in airs of different density, it does not correspond to the quantity of air, but increases in greater proportion than the quantity of air when its density is greater, and consequently, that the same quantity of air supports the life of the animals longer when it is condensed than when it is rarefied. (P. 165.)

From these experiments Cigna draws the following conclusion:

A rarefied air is not harmful to the life of animals from its rarity, but because it is altered sooner than when it is denser; for in such an air, the animals breathe at first without difficulty; their respiration becomes labored only by degrees, and in proportion to the capacity of the receiver; in a word, everything goes on just as in an air with its natural density. If the air were harmful on account of its rarity, it would be equally harmful no matter what the capacity of the receiver might be. (P. 166.)

And to prove it, he performs a double experiment, in which two sparrows were subjected to the same very low pressure (from $91 / 2$ to $71 / 2$ inches), one in a closed bottle, the other in a receiver in which he renewed the air frequently. The first died, whereas the second was "full of health" after more than a half-hour:

I conclude from this experiment (he says) that an air, extremely rarefied under the pneumatic receiver, is capable of maintaining respiration and life, provided it is renewed, and that is why animals endure the condensation of enclosed air much better than an equal rarefaction; that is also why a flame burns and animals live on the highest mountains, although the air there is extremely rarefied, whereas they soon die under a receiver in which the air has been rarefied to the same degree. (P. 167.)

But I call particular attention to the remarkable explanation which Cigna gives for the harmlessness (which he certainly exaggerates greatly) of air which is rarefied and renewed:

It is obvious that the air needs only to be dense enough to expand the lungs by its pressure; now to expand the lungs, this pressure 
needs only to be able to overcome the resistance which the contractile power of these organs opposes to it, for there is no thoracic air to increase this resistance, and this pressure hardly exceeds that of two inches of mercury; whence it follows that an air, even when extremely rarefied, still exerts sufficient pressure for the mechanism of respiration.

So he reaches this opinion that "the suffocation of animals kept in closed vessels is the work of vapors". But following him in this path would lead us astray from our subject.

We shall return to travellers who have ascended lofty mountains; but we should first report the interesting experiments of the poet-naturalist Darwin ${ }^{14}$ and the curious theoretical conclusions which he draws from them; we shall return to these explanations later.

The author asks himself whether there really exist in the blood elastic vapors of some sort or other, which could cause "lunar and equinoctial maladies" to be attributed to variations of the atmospheric pressure:

The truth of this opinion (he says) seems to be demonstrated by the following experiment: Four ounces of blood are drawn from the vein of the arm and immediately placed in the reservoir of an airpump: when the air is removed, the blood begins to froth and rise in bubbles so as to occupy ten times its original volume.

But that reasoning is mistaken, says Darwin. If, in an animal which has just been killed, a certain length of a vessel full of blood is isolated between two ligatures, and this fragment is placed in a vessel full of water, under the receiver of the pump, it remains at the bottom of the water when a vacuum has been made, without rising or swelling, as it should do if it really contained air:

So a great change is produced in the blood drawn from the vein by the introduction of atmospheric air .... Therefore a cupping-glass applied to a living animal brings out no froth, as happens in a vacuum.

It is, therefore, probable that animals can undergo great variations in pressure without inconvenience ... Some persons who have ascended lofty mountains report that they have spat blood; but that has never been noted in animals placed in the pneumatic machine, where the decrease in pressure was greater than occurs on the highest mountains. This blood-spitting was therefore an incidental disturbance, or was the result of the violent exercise of the ascent.

We have seen, quoted above by Veratti, the explanation at first given by Borelli of the symptoms of decompression, which he himself had experienced when he ascended Etna; he thought they were the result of a sort "of effervescence which might occur in the 
blood and the other humors". But Borelli did not continue long in this opinion, and, absorbed exclusively by his theory of effort, he narrowed the question greatly: ${ }^{15}$

I then perceived that this distress was not produced by the excessive rarity of the air or by any corruption of its qualities, since, when we were sitting down or were on horseback, naturally breathing the same air, we felt no more oppression than on the seashore. I have given a solution of this problem in my Meteorology ${ }^{16}$ of the Fires of Etna; but when I reflect upon it, I cannot remain in this opinion, and I now come to a more probable explanation of it. (P. 242.)

Borelli then reminds the reader that he has shown why a fatiguing labor necessarily brings on panting. He will now show why locomotion in rarefied air cannot take place without great fatigue, whence comes the difficulty in breathing. (It is his proposition CXXIII.)

A labor can become fatiguing for two reasons: first, if the resistance increases; second, if the strength lessens ...

The air contained in the chest, as I have said, helps the effort of the muscles, compressing by its elasticity the air- and blood-vessels. Therefore, when the air is very much rarefied, although it is compressed by the thorax as the dense air was, it acts less upon the vessels, and consequently aids the muscles less . . . . Therefore, in rarefied air the same work will require greater effort, since the strength is lessened, whence comes the lassitude, which was to be demonstrated. (P. 243.)

Bouguer ${ }^{17}$ does not display any greater astuteness; the wellknown fact that under certain circumstances the symptoms attack only those on foot and not horsemen makes him attribute them to fatigue; for more serious cases, he resorts to the cold:

What proves this irrefutably is that one is never exposed to this illness when one is on horseback or when he has once reached the summit, where the air, however, is even rarer. I do not deny that this great rarity hastens lassitude and contributes toward increasing exhaustion, for respiration becomes extremely painful; however little one exerts himself, he is all out of breath at the slightest movement; but nothing of the sort takes place as long as one remains inactive. . .

We passed three weeks (August, 1737) on the summit of Pichincha; the cold there was so keen that one of us began to feel some scorbutic symptoms, and the Indians and the other servants whom we had engaged in the country had violent colic: they passed blood, and some were forced to descend; but when once we were camped on the edge of the cliff, their illness was always the result of the severity of the cold to which they were not accustomed, without the rarity of the air seeming to be the cause of it, at least, not the immediate or near cause: I investigated this the more carefully because I knew that most of the 
travellers had been deceived in this, because they did not distinguish sufficiently between the different effects. (P. 262.)

However, Bouguer gives some importance to the decrease in the weight of the air:

The slight hemorrhages no doubt resulted from the fact that the atmosphere, having less weight, was not of enough assistance by its compression to help the vessels restrain the blood, which, for its part, was still capable of the same action. (P. 261.)

Ulloa, ${ }^{18}$ who in other regions of the Cordillera had seen "riders as sick as those on foot", could not assume, as Bouguer had done, that fatigue was the principal cause of the symptoms. So he does not even mention this hypothesis. But he triumphantly discusses that of the cold.

The idea of the rarity of the air occurred to him, but one circumstance puzzled him, which puzzled many others, namely, that these symptoms do not appear in the lofty regions near Quito:

Certainly one cannot attribute this distress to the cold, for if that was the only cause, this illness would be common in all cold countries. It must therefore come from the properties of the air, either its lightness or some other quality which we do not know. This illness does not appear in the lofty regions of Quito, the altitude of which is as great as that of Peru, for it is different from the sickness which we call paramarse: at least no one has experienced it when the matter was being considered, so that no one has spoken of it, whereas it is very common in the lands lying before these regions. We should note also that those who are likely to vomit at sea are also so inclined on the Punas, whereas those on whom the sea makes no impression do not experience this distress on these peaks either. Something of the sort is felt on the lofty mountains of Europe and other mountain chains; it is peculiar to delicate persons, but these symptoms are not so noticeable or so serious or even so general as in the regions of America. That which is felt in Europe comes only from the rarity of the air and from the cold on these heights, two circumstances which might well produce some ill effect. (P. 117.)

Then, in regard to the symptoms noted in beasts of burden, Ulloa reports, but only to oppose it, the opinion common in his time and even today almost universally accepted in these regions of South America, that these symptoms are the result of poisoning by metallic emanations from the ground. And yet he cannot keep from believing in some foreign substance permeating the air:

The inhabitants of these regions say that it is because the animals are then passing over mines, for they claim that the mountains are full of minerals, from which are emitted through the pores of the earth 
molecules of antimony, sulphur, arsenic, and others, to which they attribute these symptoms.

But the objection may be raised that if this opinion were well founded, the men who ride on these animals would experience the same distress when they have stopped, which is not the case. We must therefore believe that it is due only to the extreme rarity of the air, which is filled, moreover, with some foreign body disseminated in it, although this foreign substance does not come from the pores of the earth. We may also say that it is not probable that there are minerals enclosed within all these peaks where the symptoms occur, since we see no outer sign revealing them; if it were so, there would be no mountain or slope in these chains, covering several hundred leagues, in which one would not find some mineral. (P. 116.)

Ulloa also says a few words about symptoms which are much less serious, but which his successors did not always have the sagacity to distinguish, as he did, from mountain sickness:

The dry, rare air causes such dryness that the epidermis, and especially the skin covering the lips, chaps and cracks; this causes pain, and soon blood issues from them; the hands become rough and scaly: this roughness is particularly noticeable on the joints and upper part of the fingers, the scales are thicker there than elsewhere, and they take on a darkish color which is not removed by lotions. These affections are called chugno, a term which the natives use for anything that is wrinkled and hardened by the cold. (P. 111.)

All these data were known to the illustrious Haller, who reviews them briefly in the third volume ${ }^{19}$ of his immense work, and tries to explain them with the data of the physics, chemistry, and physiology of his time. The mechanical influence of the pressure of the air seems to him absolutely predominant. In his discussion, he utters this very strange idea, already suggested by Cigna, that the air of altitudes would act on the organism in a less painful manner than that which was rarefied to the same desree under the pneumatic bell-jars:

The air (he says) weighs upon the body of man from all sides and different authors estimate this weight at variable amounts from 31,144 to 42,340 pounds. Children are more compressed proportionately than adults, since the surface of their bodies diminishes less than the mass.

All of this varies in the same locality, because the mercury of the barometer rises or falls about three inches, and thence come differences which have been estimated at from 3062 to 3982 pounds. The variation is much greater if we compare the air of the highest mountains to that of the deepest coal mines ... In this case, it may go from 36,292 to 19,281 pounds (according to La Condamine, it would be only 17,000 pounds on the top of Chimborazo, which is an inaccessible peak anyway). And this difference appears even much greater, if in- 
stead of a man we consider a fish living in submarine depths as great as 400 fathoms ... We should then reach a pressure of $2,272,000$ pounds.

The English academicians did not doubt that a man can live at a depth of 200 fathoms. (P. 191.) ...

The effects of this pressure on the human body cannot fail to be great; we see that when we place animals under the pneumatic bell.

The body is subjected to the pressure which presses the bloodvessels, the muscles, and the soft parts against the bones. And since in the humors of the body, in the air passages, in fact, everywhere, there is air kept in a small volume by the pressure, when this pressure is removed, the animal swells up all over, from the expansion of the lungs, the intestines, and the air contained in the vessels and even in the cell meshes. (P. 192.) ...

But there is a great difference between air rarefied by vapors or that rarefied by the removal of a part of itself, and that air which is lighter because of the altitude and its distance from the center of the earth. In the latter, in fact, although it has lost half its weight, respiration takes place without difficulty; this I experienced on the mountains Jugo and Furca. (Haller quotes Cassini, Bouguer, etc.)

And one can even live a long time at these heights ... I agree with Arbuthnot, who teaches that a sudden shift to rarefied air is hard to endure at first, but that one can become accustomed to it. Perhaps that is the reason why birds endure rarefied air more easily than other animals (Derham). It is easy to understand, in fact, that the pressure upon our humors and our vessels will increase in proportion as the outer air becomes denser, and vice versa. (P. 193.) ...

We easily understand the disadvantages of rarefied air; we shall see that it cannot inflate the lungs completely. Since the pressure no longer sustains the vessels of the body, they resist the heart less and are more easily ruptured. In a very much rarefied air, the danger is increased by the expansion of the air contained in our humors. Light air, which does not fully inflate the lungs, makes the passage of the blood in these organs more difficult, and allowing less blood to reach the left heart in a given time, removes from it the stimulus which urges it to contract. (P. 196.) . .

In rarefied air, strength is diminished. In our Alps, those who have lung ailments die when they are in lofty places, especially if it is warm there, for cold moderates the ill effects of rarefied air. The sturdy mountaineers of the Alps carry enormous burdens in lofty places.

The fever, prostration, slight hemorrhages and hemoptysis, an unfortunate example of which one can find in Scheuchzer, ${ }^{2 a}$ which symptoms certain travellers have experienced while passing through the mountains, I attribute rather to the fatigue of the ascent and to the strain on the respiratory powers. In fact, travellers who are resting or are on horseback have no such symptoms. (P. 197.)

So, according to the celebrated Swiss physiologist, the effect of the rarefied air has as its principal causes the lessening of weight pressing upon the surface of the body, the dilation of the superficial 
blood-vessels, and the increased difficulty of the passage of the blood through the lungs. We shall return, in the next chapter, to the value of these theories which it would be premature to discuss at present.

According to the account of Haller, we see that travellers in the Alps had already experienced painful effects of the decrease of barometric pressure. However, no explorers had yet trodden the summits of any of the giants of the Alps, Mont Blanc, Monte Rosa, nor the Jungfrau, which rise to an elevation of more than 4000 meters. Below this level, even slight symptoms are rather rare. The Genevan physicist de Luc ${ }^{21}$ is surprised at that, when he considers the great decrease in the weight of the air supported by the body; he draws from it a very reasonable conclusion about the effect on the health which certain physicians attribute to barometric changes:

We were very comfortable near the little rocks to which we had descended (the Buet glacier, barometer 19 inches, 6 lines; 9355 feet above sea level) ... We were surprised that we perceived the difference in the density of the air only through our instruments, that no discomfort or disagreeable sensation warned us that the air we were breathing was nearly a third less dense than that of the plain, that the weight of the atmosphere upon our bodies was one hundred quintals less without any disturbance of the inner equilibrium. What a marvelous machine this is, which adapts itself to such great variations in the very causes of its principal movements, without their ceasing to be regular!

I cannot refrain from saying in this regard how much mistaken certain doctors were who attributed to the difference in the weight or the density of the air the changes experienced by certain persons when the barometer falls, and who undertook to explain them by the lack of equilibrium between the inner and the outer air, or by the effect which a more or less dense air can produce upon the movements of the heart and the lungs.

If these variations had a perceptible effect upon our organs, what would become of those chamois hunters who pass every day from the depths of the valleys to the summits of mountains equally high ... Even asthmatic persons are not affected by them; at least I was on the mountain of Salève with one of my friends who feared this effect and did not experience it. (P. 328.)

We have seen that Canon Bourrit, in his ascent of Buet, was less fortunate than de Luc; the accounts of de Saussure and Pictet show, moreover, that this mountain, in spite of its moderate height, is one of those on which travellers are most easily affected in the ascent. In this connection, Bourrit ${ }^{22}$ makes a strange remark about the difference in density, at an equal altitude, between the air of 
the Alps, which makes one ill, and that of the Cordilleras, "where one feels no effect":

I have noted that these symptoms can be avoided by walking ... a means of renewing the air in the lungs and maintaining their activity.

I know that it would be difficult, not to say impossible, to live a long time on Mont Blanc... .

From all these circumstances we must conclude that the air which we breathe on the high Alps is much rarer than that of the Cordilleras at the same height, because the latter are beneath the equator, and for that very reason they are more impregnated with heavy and dense vapors. (Vol. II, p. 98.)

If this idea seems very strange to us today, what shall we say about that of d'Arcet,,$^{23}$ who first denies mountain sickness (he had ascended only the peak of Midi) and then asks himself whether the air of lofty regions is really rarer than that of the plains!

As to the difficulty in breathing which it has been thought was sometimes felt on lofty mountains, and which we have never experienced, I think that it may come from the oppression which one feels when, heated and weary with the ascent, he reaches a very open and very lofty summit. There, he is suddenly struck by a cold and keen air ...

No matter how tired one is, when one reaches the top of a lofty mountain, he is promptly refreshed; he feels nimbler, lighter; the face is pale and the flesh less ruddy. In a word, what one feels then has nothing in common with, or rather it is the opposite of, the effects produced upon living beings by an air which is too expanded and too rare. (P. 123.)

He next discusses the observations of Bouguer and La Condamine, and says in conclusion:

I urge physicists who have the opportunity to attempt new experiments, if it is possible, to ascertain whether at certain heights the air really becomes rare and expands to such a degree that animals cannot ascend there without suffocating as they do in a vacuum; whether this more or less great density is the only cause of the rising and the variations of the mercury in the barometer.

De Saussure, ${ }^{24}$ in the first volume of his great work, after telling of his sufferings from mountain sickness during his ascent of Buet, tries to find the reason for them. It is strange that he alludes to the real explanation, although only to oppose it, which the recent discoveries of Priestley and Lavoisier permitted him to glimpse:

559.-We cannot attribute the exhaustion of muscular strength to fatigue alone, as M. Bouguer thought. A fatigued man, on the plain or on mountains of moderate height, is rarely so exhausted that he 
absolutely cannot continue; whereas, on a lofty mountain, one is sometimes so exhausted that, to avoid most imminent danger, he would literally not take four steps more, perhaps not even one step. For if one persists in making efforts, he is attacked by palpitations and such rapid and hard throbbing in all the arteries that he would fall in a faint if he increased the palpitations still more by continuing to ascend.

However, and this forms the second characteristic of this strange kind of fatigue, the strength is restored as quickly, and apparently as completely, as it was exhausted. Mere cessation of movement, even if one does not sit down, and in the short space of three or four minutes, seems to restore the strength so perfectly that when one starts walking again, he is convinced that he will ascend even to the summit of the mountain all in one breath. Now on the plain, a fatigue as great as that of which we have been speaking does not pass away so quickly.

560.-One would be tempted to ascribe these effects to the difficulty in breathing; it seems natural to believe that this rare and light air does not expand the lungs sufficiently, and that the organs of respiration are tired by the efforts they make to supply it, or that, since the duty of this vital function is not completely carried out, and since the blood, according to the theory of M. Priestley, is not sufficiently supplied with its phlogiston, the whole animal economy is disturbed by it.

But what persuades me that this is not the real reason for these effects is that one feels fatigued, but not at all oppressed; if the painful action of climbing a steep slope makes the respiration shorter and more difficult, this inconvenience is felt on low as well as on high mountains, and yet does not produce in us, when we climb these low mountains, the effect which we experience on those which are very lofty; moreover, on the latter, when one is quiet, he breathes with the greatest ease. Finally, and this consideration appears to me conclusive, if it was imperfect respiration which produced this prostration, how could a few instants of rest taken while breathing this same air seem to restore the strength so completely?

561.-I am inclined to believe instead that these effects should be attributed to the relaxing of the vessels caused by the decrease of the compressing power of the air.

Because we are accustomed to living compressed by the weight of the atmosphere, we hardly think of the action of this weight and its effect upon the animal economy. However, if one reflects that at sea level every part of the surface of our body is laden with the weight of a column of mercury 28 inches high, that a single inch of this fluid exerts upon a surface one foot square a pressure equivalent to 78 pounds, 11 ounces, 40 grains, marc weight; that consequently 28 inches exert on this same surface the pressure of 2203 pounds, 6 ounces; and that therefore, reckoning ten square feet of surface for a man of average height, as is usually done, the total mass of weight which compresses the body of this man is equivalent to 22,033 pounds, 12 ounces; if we consider what must result from the action of this weight, we shall see that it must compact all parts of our body, that it binds them together, so to speak, that it compresses the vessels, that 
it adds to the elastic power of the arteries, that it condenses the walls of these same vessels, and resists the transudation of the more subtle parts, the nervous fluid, for example, and that for all these reasons it must contribute to the muscular strength.

If then one were suddenly transported from sea level merely to the altitude of 1250 fathoms, where the weight of the air lifts only about 21 inches of mercury, the action of the atmosphere upon our body would be lessened one quarter, or 5508 pounds, 7 ounces; consequently all the effects of this action would be considerably lessened, and the muscular powers would necessarily suffer from it. The vessels, in particular, would exert very much less pressure upon the fluids which they contain; and for that very reason they would interfere less with the acceleration which muscular movement tends to give to the whole mass of our liquids.

And so in lofty regions where the vessels are only slightly compressed by the pressure of the atmosphere, the efforts one makes in climbing a steep slope must accelerate the movement of the blood much more than in low lands, where the compression of the vessels resists this acceleration. From that, no doubt, result the rapid throbbing of all the arteries and the palpitations which attack one on lofty mountains, and which make one fall unconscious if he persists in moving with too much speed.

But also, through an effect of this same relaxing of the vessels, since they react weakly upon the blood, as soon as one ceases moving, the acceleration which had been produced by this movement ceases of itself shortly, whereas if the vessels were greatly strained, their elasticity would have perpetuated this acceleration, long after its cause had ceased to act. That is the characteristic of weak beings, they are easily moved, and quieted too; whereas strong beings, hard to set in motion, are also harder to quiet. When, therefore, the vessels are relaxed by the decrease of the air pressure, a few moments of rest are enough to establish order and calmness in the circulation, and by the slackening of this circulation to give a feeling of inner coolness, which, aided by the coolness of the air which one breathes in these lofty regions, brings complete calmness, and persuades one that the fatigue has completely vanished. As to the drowsiness, I think that it is the effect of the vascular relaxation, and especially that of the brain. At least this seems to me the most probable reason for these facts: I leave judgment of it to the professional physiologists. (Vol. I, p. 482-488.)

And so to de Saussure it is the decrease of the pressure exerted by the air upon the cutaneous vessels which, by lessening their resistance to the heart impulses, causes the circulatory acceleration and consequently all the symptoms which he observed and experienced. But, after his celebrated ascent of Mont Blanc, he adds to this explanation reflections of a value in much greater harmony with the wisdom of his lofty intellect:

1965.-If we consider after all (he says) that the barometer at that height stood at only sixteen inches and one line, and that there- 
fore the air had hardly more than half of its usual density, we shall understand that the lack of density had to be compensated by frequency of inspirations. Now this frequency accelerated the movement of the blood, all the more because the arteries were no longer compressed from without by a pressure equal to what they usually experience; and so we all had fever. (Vol. IV, p. 147.)

He returns a little later to this explanation and draws conclusions from it. He likewise refutes the theory of Bouguer:

2021.-Of all our organs, the one which is most affected by the rarity of the air is that of respiration. We know that to maintain life, especially that of warm-blooded animals, a specified quantity of air must pass through their lungs in a given time. If then the air they breathe is twice as rare, their inspirations must be twice as frequent, so that the volume may compensate for the rarity. It is this forced acceleration of respiration which is the cause of the fatigue and the distress which one experiences at these great heights. For at the same time that respiration accelerates, the circulation accelerates also. I had often noticed this on lofty peaks, but I wished to make an exact test of it on Mont Blanc; and so that the effect of the motion of walking might not be confused with that of the rarity of the air, I did not make my test until we had remained quiet or nearly quiet for four hours on the summit of the mountain. Then the pulse rate of Pierre Balmat was 98 per minute; that of Têtu, my servant, 112, and mine, 100. At Chamounix, also after resting, the same men, in the same order, had pulse rates of $49,60,72$.

While there, we were all in a state of fever which explains both the thirst which tormented us and our aversion to wine, strong liquor, and even all kinds of food...

However, when we remained perfectly quiet, we had no definite discomfort. And that is the fact which made Bouguer think that the symptoms which one experiences in this air come only from fatigue, for he agrees with me on all the data . . .

It seems evident to me that in explaining these data, the learned academician made a mistake, confusing the effects of the rarity of the air with those of weariness. Weariness does not produce the effects of the rarity of the air. Often, in my youth, when I returned from some long mountain trip, I felt weary to the point of not being able to stand up any longer; in the state which Homer expressed so energetically by saying that the limbs are dissolved by fatigue, and yet I felt no nausea or faintness, and I desired restoratives, far from feeling a dislike for them. Moreover, although these academicians often experienced great fatigue in the course of their long and painful labors, nevertheless, to ascend Pichincha, which is particularly mentioned, they started from Quito, which is at an elevation of 1400 or 1500 fathoms, and they went still higher on horseback. They therefore had only 300 or 400 fathoms to make on foot, which could hardly produce a fatigue capable of causing the symptoms which Bouguer describes. Therefore the same muscular movement which would have produced only moderate weariness without any symptoms in a dense air pro- 
duces in a very rare air an acceleration in respiration and circulation, from which there results distress which is unendurable to certain temperaments. (Vol. I, p. 207-209.)

But the first interpretation accepted by de Saussure, the decrease of the weight sustained, had success much above its deserts, whereas the second, which contains, as we shall see, a part of the truth, remained much less widely known.

Some years after him, the physiologist ${ }^{25}$ Fodéré underlined his mistake, so to speak, comparing the hemorrhages from decreased pressure to those which follow the application of cupping-glasses:

The atmospheric pressure keeps the vessels from being too forcibly distended by the liquids which they contain and by the elastic force of the air abundant there ... If this pressure is removed, or if its intensity is merely lessened, the parts undergo considerable swelling and hemorrhages; we have common examples of it ... in suction, in the operation of cupping-glasses, in the hemorrhages of travellers who ascend to the summits of lofty mountains; in the heaviness, distention and discomfort which we experience whenever the air is lighter. (P. 220.)

Hallé and Nysten ${ }^{26}$ share this opinion and express it with the greatest clearness. For them, in the first place, the chief effect is due to the removal of the weight of the atmosphere:

Whenever one places an animal under the receiver of the pneumatic machine, or when one mounts rapidly to considerable heights, then not only the sudden expansion of the free elastic fluids, proportional to the rapid decrease of the atmospheric pressure, but also the tendency to expansion which exists in the animal liquids themselves, especially in the elastic fluids which they hold in solution, may be the cause of several striking results, such as a feeling of general discomfort, etc.

However, after describing the phenomena presented by travellers and balloonists, the authors seem to relegate their entirely mechanical explanation to a secondary place, for they add:

These effects are easily accounted for. On account of the decrease in the density of the air there is a lessened quantity in the same volume. This air, therefore, is less adequate for the combinations which it must experience in the act of respiration; consequently, so that in rarefied air these combinations may take place conformably to the purpose of nature, one must breathe proportionately with greater rapidity. This is the cause of this hasty and panting respiration and consequently of the acceleration of the pulse rate which results from it. We even comprehend that at much greater heights the rarefaction of the air would be such that acceleration of the respiration would 
not suffice to bring to the lungs the quantity of air necessary for the maintenance of life, and that life would finally be extinguished, as it is in asphyxia, for lack of the principal agent of respiration. Death in this case might be preceded by various phenomena unrelated to respiration, such as emphysema and different hemorrhages due entirely to the great expansion of all parts of the body.

Here again we find, applied to respiration, the explanation already given by de Saussure; as to hemorrhages, Hallé and Nysten persist in attributing them to the decrease of the weight sustained by the body.

The same combination of explanations is expressed with greater clearness and moderation in the thesis of Courtois: ${ }^{27}$

Most of these phenomena depend at the same time upon changes which occur in the weight of the air and upon the varying quantity of oxygen which this fluid contains in the same volume, depending upon whether it is condensed or rarefied; thus chemical phenomena complicate those which depend upon the weight of the air. (P. 17.)

At the same epoch there appeared a remarkable work, which deserved more attention from physiologists, and which nevertheless remained almost completely unknown, at least in the part which interests us. I must even confess, not without some embarrassment, that I did not know of its existence until I was doing bibliographic research necessary for the preparation of the first part of this work, after all my experiments had been completed.

In his researches on animal heat, Legallois ${ }^{28}$ was led to compare the variations in temperature of warm-blooded animals with the quantity of oxygen which they absorb in a given time. Among the causes which might act upon this absorption, he considers the rarefaction of the air, as a means "of lessening the quantity of oxygen contained in the air in which the animal is confined". Legallois kept the animals in closed vessels (the manometer, as he calls it, measured 41 liters) during the whole experiment; he has nowhere specified the degree of decompression to which he had subjected them, but it is easy to conclude from his accounts that he never reached a half-atmosphere. I summarize in the following table the results of his experiments; the comparative test, made for each animal at normal pressure, lasted the same time, of course: 
$\begin{array}{cc}\text { Oxygen } & \text { Change in } \\ \text { Carbonic } & \text { body }\end{array}$

1. Rabbit, normal pressure $\quad 7.05 \quad 6.16+0.2^{\circ}$

Rabbit, rarefied air $\quad 6.43 \quad 5.02 \quad-2 .^{\circ}$

2. Rabbit, normal pressure

Rabbit, rarefied air $\quad 5.97 \quad 4.56 \quad-2.2^{\circ}$

3. Rabbit, normal pressure $\ldots$

Rabbit, rarefied air $\quad 9.96 \quad 7.60 \quad-1.3^{\circ}$

4. Cat, normal pressure

Cat, rarefied air $6.93 \quad-4.2^{\circ}$

5. Cat, normal pressure $\quad 8.52 \quad 6.20 \quad-3^{\circ}$

Cat, rarefied air $\quad 7.66 \quad 6.12 \quad 7 .^{\circ}$

6. Dog, normal pressure $-1.7^{\circ}$

Dog, rarefied air $\ldots 10.91 \quad 9.112^{\circ}$

7. Dog, normal pressure

Dog, rarefied air

8. Guinea pig, normal pressure $\quad 8.49 \quad 6.27-0.4^{\circ}$

Guinea pig, rarefied air $\quad \begin{array}{lll}6.37 & -26^{\circ}\end{array}$

9. Guinea pig, normal pressure
Guinea pig, rarefied air

Legallois draws from these experiments, in reference to the subject which interests us here, the following conclusion, which shows admirable sagacity:

Since the mere rarefaction of the air, carried far enough to lower the barometer less than 30 centimeters, is enough to chill the animal which breathes it, the result is that the cold experienced on lofty mountains does not depend solely on the coldness of the atmosphere, and that it has in addition an inner cause, which acts through respiration. (P. 59.)

What a contrast between these clear experiments, these precise conclusions and the confused mass of so-called explanations which, in that same year, Dralet ${ }^{29}$ gave both of the discomforts and the improved conditions experienced on lofty places!

The air on mountains of moderate height is more healthful than that on the plains ... If we consider, moreover, that the pressure of the atmosphere is less as we ascend, we shall not be surprised that the dwellers on the plain are in better health on the Pyrenees, eat with more appetite, and that the elasticity of their lungs gains new strength there.

But the man who is approaching the region of snow will not find an air so favorable to the animal economy; since vegetation, according to the observation of M. Ramond, is practically absent from these wild spots, the nitrogen is not absorbed by the organs of plants, and lessens the wholesomeness of the air by its abundance.

MM. Vidal and Reboul have proved that the quantity of vital air in the atmosphere at the summit of the peak of Midi in Bigorre was about 
one-fourth less than in the valley. Moreover, as the weight of the atmosphere decreases in proportion to the height of its strata, when a man has reached the summit of a lofty mountain, all the parts of his body, since they no longer receive sufficient pressure from the surrounding air, must yield to the heat which expands them in seeking its equilibrium in the surrounding bodies. The result is relaxation in the fibre, softening in the solid parts, and excess of fluidity in the liquids.

So persons who travel on lofty mountains are subject to hemorrhages, vomiting, and fainting; but these symptoms rarely appear unless one ascends to 2000 fathoms above sea level. (Vol. I, p. 36.)

Gondret ${ }^{30}$ was no more fortunate when he tried to give "an explanation, if not complete, at least satisfactory", of the symptoms observed during mountain ascents. This is what he says:

The decrease of the weight of the column of air and the elasticity of our organs explain the turgidness of the body, the expansion of the vessels and fluids, and consequently the hemorrhages.

The lungs, accustomed to 18 or 20 regular inspirations and expirations per minute, suddenly forced to multiplied movements in order to absorb the same quantity of air, are extraordinarily hasty in their labor.

The heart immediately feels the effect of the hasty action of the lungs; the result is an accelerated pulse rate and lipothymies.

When the two effects which the heart and the lungs exert on the brain are thus accelerated, we can imagine the changes that take place in this organ, and consequently in its functions; it is to these changes that we can attribute the vertigo, dizziness, syncope, and all the disorders which follow.

The differences noted in different individuals in the intensity of the symptoms are the result of idiosyncrasy. (P. 40.)

However, we must admit that he was the first to have the idea of applying rarefied air to therapeutics. From the very evident effect exerted upon us by changes in the barometric pressure, he derives this suggestion:

Perhaps chambers may be constructed in such a way that, by the help of the pneumatic pump, we may introduce into them a more or less dense air, according to the requirements of the case. (P. 45.)

The rest of the volume is devoted exclusively to the study of the effect of cupping-glasses, simple or combined with scarification.

The English travellers who, at the beginning of this century, journeyed over the lofty regions of India, introduced a new element into the explanation of mountain sickness. According to their stories, the natives of these countries attribute the disturbances which attack strangers and the natives themselves to the effect of 
a poisoned wind; generally, the emanations of certain plants are supposed to give these toxic qualities to the air.

Fraser ${ }^{31}$ is the first to give us this curious information; we must admit that he makes haste to reject this explanation, and for an excellent reason:

I did not suspect that the altitude could affect the strength and the lungs so severely, and yet it was the only cause, no matter how difficult the ascent; for in that respect we had had days before that were at least as bad; and although we were told that the air was poisoned by the odor of flowers, and although there were indeed a profusion of them during the first part of our journey, most of them had no odor, and we could not perceive any in the air. More than that, we were particularly distressed when we reached the lofty gorge of Bamsooroo, where there was no vegetation, and consequently no perfume of flowers. (P. 449.)

Dr. Govan, ${ }^{32}$ who accompanied Captain Al. Gérard on his first journey in 1817, reports the same tradition, without giving it any more credence. But much astonished by the lack of proportion already noted by travellers between the altitude and the intensity of the symptoms, he has the peculiar idea of having electricity play an active part in these phenomena:

On the highest peaks of the mountains of Choor there first appear the juniper-tree, the alpine rhododendron, and the tall aconite, the toxic effects of which, when it is used internally, are well known, and seem to have given rise to the belief common among the natives that it poisons the surrounding air; I can find no basis for this opinion, except that in the lofty places in which this beautiful plant grows, travellers often, but not always, experience disagreeable symptoms, usually attributed to the expansion of the air.

If the symptoms considered by eminent naturalists as resulting from this expansion should really be ascribed to it, why are they not proportional to the elevation and the rarefaction, and why do these symptoms not invariably appear when the elevation and rarefaction reach a certain degree?

On two occasions I passed the night at elevations more than 14,000 feet above the line of perpetual snow; I crossed the Rol-Pass (much above 15,000 feet), accompanied by 40 native soldiers, without anyone of us experiencing these painful symptoms. Now, in the same places, and even at lower elevations, they have been observed in other ascents and predicted in advance by the natives.

All of this seems to indicate that these symptoms result from less general atmospheric circumstances, such as the electric force, which, in the case of such lofty conductors, must be in a state of constant fluctuation. (P. 282.)

Captain Al. Gérard, ${ }^{33}$ in the account of his journey of 1818 , also mentions poisonous plants: 
I should note that the inhabitants of Koonawur estimate the height of mountains by the difficulty in breathing during the ascent of them, which difficulty they attribute to a poisonous plant; but in spite of our search in each village, we found no one who ever knew this plant, and judging by our experience, we are inclined to attribute these effects to the rarefaction of the atmosphere, for we have experienced them at elevations where there was no more vegetation. (P. 49.)

He alludes again to this hypothesis in his book on the country of Koonawur, ${ }^{34}$ but always to reject it:

Travellers crossing these ranges attribute these painful effects to the influence of poisonous plants; but better informed persons, who customarily pass over these heights where there is no vegetation, know very well that they are produced entirely by the altitude. ( $P$. 37.)

But in narrating his expedition and his stay at the pass of Shatool (4830 meters), Dr. Gérard ${ }^{35}$ does not give any heed to the explanation of the natives. He suffered greatly, as the account which we reported above proves, and naturally sought the cause of his distress, but without success; but in the meantime, he opposed the skepticism of those who for some reason experienced no symptoms:

There I had a lesson which I shall never forget, and I am sure that a man of a more plethoric constitution would have died from apoplectic suffocation. The blood left my extremities, and the pressure on the surface of the body was so diminished in that rarefied air that the blood rushed to the head and produced vertigo. (P. 308.)

The cause of the symptoms is not very easily seen, and these extraordinary indications of loss of strength, distress, and mental weakness are not satisfactorily explained, and although we cannot hesitate to attribute the principal and immediate cause of them to the rarity of the air, or, more exactly, to the diminished pressure, by which the balance of the circulation is destroyed, nevertheless, the effects are so capricious and irregular that they can hardly agree with the idea of a constant cause. This leads travellers even to deny the existence of the symptoms, and those who have by chance resisted this effect while crossing the mountains remain firm in their conviction; but I know that you will believe my reports, although you had only a headache on Boorendo. I too passed the night here without any symptom, except weakness. (P. 320.) ...

As respiration cannot take place in a vacuum, we must consider that, at the elevation of 18,480 feet ( 5630 meters), the air is nearly half exhausted, and as the whole can have only the sum of the effects of its parts, the progressive action here becomes an arithmetical series, reducible to an experiment in physics, in which the piston strokes of a pneumatic pump seem to draw the hand placed over the opening 
more and more, until the greater pressure is so much more than the lower pressure as to be unendurable to the experimenter. At 18,480 feet, the barometer stands on the average, at 15 inches, so that we then breathe an air only half as dense as that at sea level; who could be surprised at the effects observed? (P. 323.)

Captain Hodgson, ${ }^{36}$ who in his turn reports the statements of the natives, seems not far from believing them himself:

The mountaineers, who know nothing of the rarefaction of the air, attribute their weakness to the exhalations of harmful plants, and I think that they are right, for a sort of unwholesome effluvium was exhaled by them here as well as on the heights below the snowy peaks which I crossed last year on Setlej; although, on the highest snow, the complaint was not of weakness, but of the impossibility of walking for some time without stopping to breathe. (P. 111.)

We shall see later, by the testimony of recent travellers, that this idea of wind poisoned by plants is today quite popular in Upper Asia.

If now we return to our Alps, about this same time we find Hipp. Cloquet ${ }^{37}$ republishing the mechanical explanation:

The pressure of the air, which weighs constantly upon us from all sides ... seems necessary to the maintenance of the equilibrium between the living solids and the humors which circulate or float within them; it counterbalances the elastic force of the fluids of our bodies; and since this pressure is considerably diminished here, it is not surprising that the equilibrium is ruptured. (P. 36.)

Dr. Hamel, ${ }^{38}$ when he undertook the fatal expedition on Mont Blanc in 1820, had planned to make experiments there; one of his plans gives evidence of a remarkable sagacity and shows very definite and very scientific hypothetical views about the cause and the effects of rarefied air:

I had prepared a flask of lime water to see whether, at the summit, the expired air was laden with carbon in the same proportion as in the regions where at every inspiration about one-third more oxygen enters with the same volume of atmospheric air. I also planned to extract, on the summit, the blood of some animal, to see by its color whether it had been sufficiently decarbonated in the lungs.

The account of the ascent of Mont Blanc carried out by Clissold ${ }^{39}$ in 1882 brings us to an explanation which had not appeared up to that time, and which might serve as type for that physiology of probabilities which has done such harm to science.

In the first place, Clissold attributes the symptoms observed to the smaller quantity of oxygen contained in the same volume of air, which compels respiration to be deep and hasty. 
On the other hand, since muscular energy in general is diminished, the lungs expand less, and compensation must be made by greater frequency of inspirations. Then the editor of the Bibliothèque universelle adds:

Clissold here suggests, without developing it, one of the causes to which we should be tempted to attribute the greatest influence upon one of the effects noted; we mean the expansion undergone by the air enclosed in the abdominal cavity, as one rises in the atmosphere; this expansion, by raising the diaphragm, lessens by so much the capacity of the thoracic cavity, and does not permit the lungs to expand as much as usual, until, by certain slow communications with the exterior, equilibrium between the abdominal and thoracic cavities is established again, and the latter regains its ordinary capacity.

The French naturalist Roulin, ${ }^{40}$ who spent several years in Bolivia, in 1826 sent to Magendie a letter containing observations on the pulse rate, made on the same persons at Guaduas (average pressure $718 \mathrm{~mm}$.) and at Santa-Fé-de-Bogota (560 mm.; 2643 meters above sea level). They show a slight increase in the pulse rate in the latter place. The difference is rather slight, and $\mathrm{M}$. Roulin concludes from this:

According to that, we may assume that the effects felt when one ascends lofty mountains and attributed entirely to the decrease of pressure, when they are not due to cold or the fatigue of the ascent, must be considered chiefly as nervous phenomena.

And yet, a few pages farther on, the author adds:

The difficulty in breathing which I felt on the plateau of Bogota was at first attributed to the state of my health; but I observed that several persons, who had recently arrived on the plateau, also complained of this difficulty.

It is evidently rather because of the name of their author than because of their own importance that I have quoted these observations; they are anything but conclusive.

It is also from the standpoint of curiosity that I report here the conclusions from a work of John Davy ${ }^{41}$ upon the gases of the liquids and the solids of the body; it is a real step backward from what Robert Boyle and Darwin had taught us. But the reader may judge from that the hesitations between which the minds of physiologists drifted.

J. Davy carried out numerous experiments with the purpose of finding out whether the liquids or the solids contain gases which the pneumatic pump can extract. The results obtained were always negative, and he concluded from that that there are no free gases 
in the blood, which, moreover, would be "unchemical" and incompatible with life, for at the slightest increase in temperature or decrease in pressure, nothing could prevent the escape of these gases.

It is curious to see, a few years afterwards, a celebrated French physician, Rostan, ${ }^{42}$ appeal to the very influence of these gases, though vaguely, it is true, to explain the symptoms of decompression. He mingles with his discussion the mistaken ideas, which we have already met and which we shall often find again, about the part played by the decrease of the weight sustained by the body:

If one places a living animal in a vacuum, the air within, having nothing to resist it, expands, the animal swells up and dies ... It is the pressure of the air which keeps the fluids in the vessels of animals and prevents them from escaping. When the barometer drops a few degrees, the fluids press towards the periphery; there is difficulty in breathing, disturbance of the circulation, and congestion towards the head. (P. 340.)

About this same time there appeared an English memoir which at least had the merit of originality, in the sense of oddness. Cunningham, ${ }^{43}$ as Govan had already done, makes electricity play a principal part, thus explaining the unknown by the unknown; but he adds a strange idea; that there is a radical difference between the effects of the ascent of mountains in the two hemispheres:

Apoplectic symptoms characterize the distress of travellers on Mont Blanc, whereas in the southern hemisphere the threatening symptoms are all those which accompany syncope...

The first have been attributed to the great rarefaction of the air which permits the soft parts of the human body to expand as a result of the reduction in the pressure exerted upon them; but since a similar elevation in the Andes produces effects of an opposite nature, we should seek to explain the latter by other causes than the rarefaction of the air.

\section{This cause the author finds in electricity,}

Which occupies, in the northern hemisphere, the upper part of the body, and, in the southern hemisphere, the lower part, and thus tends to draw the blood towards the head in the former, and towards the feet in the second ... which also explains why the distress is relieved by the horizontal position.

We think it useless to continue any farther, and we shall also report without comment the few lines which Burdach, ${ }^{44}$ in his immense encyclopedia, devotes to the effects of a decrease in pressure upon the organism; we see clearly by what he says that he 
attributes them to the lack of the support of the air upon the blood vessels:

The pressure of the atmosphere (he says) upon the human body is equal to a weight of 30,000 to 36,000 pounds; it keeps the mechanical arrangements of the organism in their normal state, and gives considerable help to the circulation, restraining the flow of the blood towards the surface... Symptoms caused by congestions in various organs have sometimes been noted on lofty mountains, where the air is greatly rarefied. (P. 325.)

One of the great difficulties always encountered by authors is the lack of proportion between the severity of the symptoms and the elevation which the travellers have reached, and that not only in different hemispheres, but in the same country, on the same chain of mountains.

That is why the German Poeppig, ${ }^{45}$ who gave such a complete description of the mountain sickness of the Andes, cannot make up his mind that the cause of it is the decrease of the atmospheric pressurē:

The idea that the Puna, the Veta, does not depend upon the rarefaction of the air, but upon a change in its composition, finds support in the observation that the illness is not always in proportion to the elevation of a place above sea level. The cabin of Casacaucha is nearly at the same level as Cerro de Pasco, the pass of Viuda is a thousand feet higher, and I have never felt the slightest distress there. (Vol. II, p. 84.)

M. Boussingault ${ }^{46}$ also was struck by these variations; but bolder than Poeppig, he seeks an explanation of them:

In all the excursions I undertook in the Cordilleras, I always felt, at an equal height, an infinitely more painful sensation when I was climbing a slope covered with snow than when I was mounting over bare rock; we suffered much more in scaling Cotopaxi than in ascending Chimborazo. On Cotopaxi we were constantly mounting over snow.

The Indians of Antisana assured us also that they felt stifled (ahogo) when they walked for a long time over a snowy plain; and I confess that after considering carefully the discomforts to which de Saussure and his guides were exposed when they bivouacked on Mont Blanc, at the moderate height of 3888 meters, I am disposed to attribute them at least in part to the still unknown effect of snow. In fact, their bivouac did not even reach the elevation of the cities of Calamarca and Potosi.

In the lofty mountains of Peru, in the Andes of Quito, the travellers and the mules which carry them sometimes suddenly experience a very great difficulty in breathing; we are told that animals have been seen to fall in a state very like asphyxia. This phenomenon is 
not invariable, and, in many cases, it seems independent of the effects caused by the rarefaction of the air. It is observed particularly when abundant snows cover the mountains and the weather is calm.

Perhaps this is the place to note that de Saussure was relieved of the distress he felt on Mont Blanc when a light north wind arose. In America, the name soroche is given to this meteorological state of the air, which affects the organs of respiration so greatly. Soroche, in the language of the American miners, means pyrites; this name shows plainly enough that this phenomenon was attributed to subterranean exhalations. The thing is not impossible, but it is more natural to see in the soroche an effect of the snow.

The suffocation which I felt several times myself while I was mounting over snow, when it was struck by rays of the sun, made me think that air which was evidently foul might escape from it as an effect of the heat. What supported me in this strange idea was a former experiment of de Saussure, in which he thought he observed that the air which escaped from the pores of the snow contained much less oxygen than the atmosphere. The air subjected to examination had been collected in the interstices of the snow on the col du Géant. Analysis of it was made by Sennebier, by nitrous gas and in comparison with the air of Geneva. (P. 167.)

M. Boussingault then repeats the experiment of Sennebier with the snow which he had taken from Chimborazo. Ordinary analysis gave him only $16 \%$ of oxygen. But the celebrated chemist himself declares that objection may "strictly" be made to his method; since the snow had melted in the bottle, the air, in the presence of water only slightly aerated, might have given it part of its oxygen. Evidently that depends upon the quantity of air in proportion to the quantity of water, a proportion which is not given in the work from which we quote.

But later, M. Boussingault, having taken up this question again, ${ }^{47}$ showed that the apparent lack of oxygen in the air contained in the pores of the snow results from the fact that the oxygen is dissolved in greater proportion than the nitrogen in the water of fusion. There is nothing left then of his first hypothesis.

These contradictory results, due to the improvement of methods of chemical analysis, remind us of the different opinions expressed in 1804 and 1837 upon the same subject by the illustrious von Humboldt.

In the letters which he wrote to his brother and Delambre, immediately after his ascents of Antisana and Chimborazo, von Humboldt declared that in his opinion

The distress, the weakness, and the desire to vomit certainly came as much from the lack oxygen in these regions as from the rarity of the air. He had found only 0.20 of oxygen at 3031 fathoms, on Chimborazo. (P, 175.) ${ }^{48}$ 
And yet, it appears from his letter to his brother ${ }^{49}$ that the same symptoms attacked him on the summit of Antisana, where, however, analysis showed them the normal proportion of 0.218 of oxygen in the air.

But when, in $1837,,^{50}$ he refers to the details of his account, he no longer speaks of the chemical composition of the air, but only of the lessened quantity of oxygen in the same volume; furthermore, he introduces into science a new explanation of the fatigue on mountains, an unsatisfactory explanation, which, however, was long accepted without contradiction:

According to the present state of eudiometry, the air seems as rich in oxygen in these lofty regions as in the lower regions; but in this rarefied air, since the barometric pressure is less than half what we are ordinarily exposed to on the plains, a smaller quantity of oxygen is received by the blood at each aspiration, and we understand perfectly why a general feeling of weakness would result. This is not the place to inquire why this asthenia, on the mountains as in vertigo, usually causes uneasiness and a desire to vomit, nor is it the place to demonstrate that the issue of blood or bleeding from the lips, the gums, and the eyes, not experienced by everyone at such great heights, can by no means be explained satisfactorily by the progressive removal of a mechanical counterweight which compresses the vascular system. It would be better to examine the probability of the effect of a lessened air pressure upon weariness when the legs are moving in regions where the atmosphere is greatly rarefied; since, according to the memorable discovery of two clever scholars, MM. Guillaume and Edouard Weber, the leg, attached ${ }^{51}$ to the body, is supported when it moves, only by the pressure of the atmospheric air. (P. 419.)

If M. Gay-Lussac, who on September 16, 1804, reached the prodigious height of 21,600 feet, which consequently was between that of Chimborazo and Illimani, did not suffer from bleeding, perhaps that should be attributed to the absence of all muscular movement. (P. 418.)

About this time, a French physician, Dr. Junod, ${ }^{52}$ conceived and carried out the idea, already glimpsed by Gondret, of lowering the pressure artificially in apparatuses large enough to accommodate a man.

M. Junod had been led to make his experiments by the effects he felt from the expanded air in the Alps, in the Pyrenees, and on Mount Etna. His apparatus consisted of a copper sphere 1.30 meters in diameter, in which a man could sit:

When a person is placed in the interior of the receiver, and the natural pressure of the air is lessened one-quarter, this is what one observes:

1. The membrane of the tympanum is distended, which causes a 
rather uncomfortable sensation, which disappears as equilibrium is reestablished;

2. Respiration is hampered: the inspirations are short and frequent after 15 or 20 minutes. A true dyspnea follows this difficulty in breathing;

3. The pulse is full, easily depressed, frequent; all kinds of superficial vessels are in a state of manifest turgescence. The eyelids and the lips are distended by the superabundance of fluids. Not infrequently hemorrhages occur, with a tendency to syncope. The skin is the seat of distressing heat and its functions are increased;

4. The slackened formation of blood, the expansion, more or less great, of the gases which circulate with the blood, and the superabundance of this liquid in the different classes of superficial vessels, explain well enough the failure of innervation which is characterized by lack of energy and a complete apathy;

5. The salivary and renal glands secrete their fluids less abundantly, and this effect seems to extend over the whole glandular system;

6. The weight of the body seems to diminish perceptibly.

The memoir ends with the description of the large cuppingglasses and of some pathological cases treated with them. To the application of this method of treatment, to which he has given the name of hémospasie, M. Junod has devoted his efforts since that time. $^{53}$ It really has no connection with our subject, since it concerns a rupture of the equilibrium of pressure between different points on the body, by the application of a partial vacuum on one or several members. Magendie first made this evident in the report ${ }^{54}$ which he was requested to present to the Academy of Sciences upon the work of M. Junod.

The celebrated physiologist first reviews the history of cuppingglasses, which date from the time of the Egyptians, and passes to the barometric chambers of M. Junod by a transition which shows that, in spite of himself, he still compares them with these cupping-glasses:

These apparatuses (he says, in fact) were constructed with the purpose of varying, upward or downward, the pressure which the body of man sustains through the extent of its cutaneous and pulmonary surfaces ...

It is by acting upon the two surfaces at the same time that this apparatus differs from those which were devised in England by MM. Murray and Clanny; these apparatuses last mentioned act exclusively upon the skin, the lungs having free communication with the outer air, through a separate tube. ${ }^{65}$

Then, to come to the part of M. Junod's work which has some interest for us, Magendie quotes the report of the phenomena pre- 
sented by a man subjected to the action of compressed or expanded air; we have just taken from the original memoir what relates to this last point.

We regret to add that Magendie did not display much foresight when he said:

From a medical point of view, these apparatuses as yet do not seem to offer any application... That is not true, however, of those which M. Junod designs to use for rarifying or compressing the air around members.

It is not surprising to note that after these discouraging remarks M. Junod gave up the use of expanded air as a general medium, and limited himself to improving ${ }^{56}$ the large cuppingglasses which bear his name, a very powerful therapeutic agent which has very unjustly been neglected by physicians. But through a strange confusion, explanations which were very appropriate when it was a matter of the local rarefaction by the large cuppingglasses continued to be applied to the general action of decreased pressure. As an example of this mistake, I shall quote the remarks of Dr. H. Favre: ${ }^{57}$

The principles upon which the Junod method rests are very simple:

M. Junod, born in the Alps, had himself felt the difference in pressure as one ascends or descends in the mountains. He resumed the experiments of de Saussure and Gay-Lussac with the most laudable discernment.

If one ascends to the summit of Mont Blanc, or rises in a balloon to a height of 7000 meters, he feels remarkable effects, resulting solely from the lack of pressure exerted at these heights by the more and more rarefied atmosphere.

Artificially, we know how, by making a vacuum, to rarefy the air, that is, to lessen the pressure on a circumscribed area. If we are dealing with a living body, certain effects produced by an ascent in the atmosphere will then appear: such is the purpose of homospasie; Dr. Junod attains it by the creation of his large cupping-glass. (P. 7.)

Returning now to mountain travellers, we find again the series of mistaken preconceptions and apparent contradictions which we have already noted. The difficulty of explaining the facts brings many of these travellers to deny them. An example of these theoretical protests is furnished us by the editor of the Bibliothique universelle of Geneva, who reviewed the account of the ascent of Mont Blanc by Dr. Barry:

The circumstances observed by M. Barry are so unimportant that they confirm us in the opinion that fatigue plays a greater part than 
the rarity of the air or the supposed influence of snow ... We can assert that these are the same sensations felt by ordinary travellers when they approach the summit of any mountain whatsoever.

I beg the reader to refer to the actual words of Barry, which I quoted previously (See page 95); he will find, I hope, in them a proof of the necessity of verbatim quotations.

It is interesting to note that M. Martins, ${ }^{59}$ who was later to become so sick on Mont Blanc as if by a kind of punishment for his skepticism, at that time shared these sentiments. Accounts of mountain sickness left him very incredulous:

As for us (he says), occupied night and day with our observations, we also tried to test our sensations to find out whether this lofty habitation (2680 meters) had any physiological effect upon our organs. But it was in vain ... Since my sojourn there, I have read again all the accounts of ascents of Mont Blanc, from de Saussure to Mlle. d'Angeville, and the sensations felt by these travellers can be explained very easily by fatigue... .

Of course the air of the mountains is more rarefied, but it is also more alive ... The liveliness of the air, added to its rarity, refreshes the traveller and doubles his powers; for the chemical composition is the same. (P. 213.)

I confess that I am surprised that a man with so clear and so perspicacious a mind could have used such expressions. What do the words "a more alive air" mean? The Swiss peasants who saw the celebrated professor of Montpellier collecting air in balloons and sending it to Paris, and who thought that he would make some illustrious patient breathe it, shook their heads and said: "Our air will be dead when it gets there." We see that essentially they thought like M. Martins.

Dr. Rey, ${ }^{60}$ whose work is often quoted, and who, without seeming ever to have made an ascent, wrote a dogmatic article about mountain sickness, reaches the theoretical explanation after an enumerative description. He sees, and in this he does not have the merit of invention, that rarefied air is the cause of all these symptoms:

It is neither the fatigue which removes the power of breathing, nor the difficulty of breathing, nor an incomplete respiration which cause the exhaustion, as has sometimes been said; it is the decrease in the density of the air...

These effects are due to the relaxation of the fibre caused by the decrease of the compressing power of the air, the explanation of which follows. (P. 334.)

The usual calculation on the difference in the weight sustained by the body at different altitudes follows. At the Saint Bernard 
pass, "the action of the atmosphere is diminished one quarter or 5500 pounds, which expands the vessels in a similar proportion". Then, to the explanations "furnished by science" Rey adds one, which I cannot help finding rather queer:

We can hardly climb to the top of a very lofty tower without making frequent pauses on the way, and usually we reach the top only with great effort. Certainly that is not because of the rarefaction of the air, nor even because of weariness. Is it not because we have had to lift our legs many times consecutively, by a law quite different from that of walking and much harder to obey? In fact, all the muscles of our organs of locomotion, set to work at the same time by an ascensional movement to the continuity of which they are not accustomed, experience from it a fatigue which forces us to pause frequently, which increases as long as we continue to mount, but which ceases as soon as we have reached the top and does not return while we are taking the same way downward. Well, that which takes place in a man climbing a stairway he experiences with greater reason on the side of a rugged mountain, because here there is a combination of a long walk on trails often requiring violent and unaccustomed use of muscular powers and a great rarefaction of the atmospheric air. If we could wind around Mont Blanc and reach its crest by a gradual slope as we wind around the Saint Gothard or the Simplon pass, it would no longer be necessary to make the unnatural movement of the legs, members which become heavier to raise in proportion to the contraction of the column of the air, and consequently we should no longer feel this distress which we mistake for fatigue. (P. 335.)

Tschudi, ${ }^{61}$ the celebrated. German traveller whose complete description of the mountain sickness in the Cordillera of the Andes we have already quoted, explains the extreme weariness of the lower limbs which one experiences in ascending, like von Humboldt and the Weber brothers:

Since the head of the femur, according to the researches of Weber, is held in its cavity by atmospheric pressure, when this pressure diminishes, a continuous muscular contraction must replace it. (Vol. II, p. 66.)

He then reports, but without seeming to believe it, the explanation given by the Indians about metallic emanations:

There are places where it is known that the Veta is more severe than elsewhere, and they are sometimes lower than others where it is much less evident, so that it does not seem to be caused entirely by the rarefied air, but also by some unknown climatic influence. Usually these places are rich in minerals, whence comes the general belief of the Peruvians that these effects are due to metallic emanations.

Dr. Archibald Smith ${ }^{62}$ does not consider these differences; but 
he gives some very strange information about the symptoms of the Veta and their possible causes:

The inhabitants of the coast, when they climb the chain of the Andes, feel their respiration oppressed in places where the Indians do not experience this distress, because of the much greater development of their respiratory organs ....

The pulse accelerates and the lungs act much more rapidly than normally. Their free play is hindered, however, by the accumulation of blood and a considerable degree of congestion, resulting, in my opinion, on the one hand from the lessened atmospheric pressure, which causes an expansion of the fluids in circulation, and on the other hand from the resistance of the cutaneous and pulmonary capillaries enlarged by the cold.

The result of this is that strangers to these climates are very subject to stomach disturbances, dyspnea, apoplexy, or other hemorrhages when they cross the passes of the Cordilleras ... Cats which have been taken to the snow line and have been well-fed are very subject to sudden death ... I have heard that at Cerro de Pasco a terrier suddenly fell dead, probably from apoplexy, while he was jumping with joy and caressing his master. (P. 356.)

An English traveller, Hill, ${ }^{63}$ who was quite sick while crossing the Andes, and who saw two children stricken with the soroche so violently that they "were almost lifeless in the arms of their father", lays stress upon the effect of different temperaments in reference to the severity of the illness:

The illness, in its most serious form, is accompanied by very alarming symptoms and is generally fatal; in a traveller of a plethoric constitution it is usually very serious; it is characterized then by vertigo, weakness of vision and hearing, and very often by a flow of blood from the eyes, the nose, and the lips and by violent headaches and vomiting: But in thin travellers, not very strong in constitution, it is more likely to cause fits of weakness, accompanied by the spitting of blood. In persons who enjoy good health, vomiting is one of the most frequent symptoms, and the others generally consist of lassitude and difficulty in breathing, such as appeared in my companions and myself. (P. 68.)

Coming to the causes of the symptoms, he repeats, without seeming to attach real importance to it, the opinion of the natives about metallic emanations:

This illness has been noted to be more common in the provinces where metals abound; so the general opinion among the natives is that it owes its appearance or its increase of violence to the metallic exhalations which are supposed to saturate the atmosphere of those regions. This opinion is undeniably based on the fact that the disease particularly attacks prospectors for metals, men who are usually not 
accustomed to the air of the mountains, and who endure great fatigue.

We can hardly doubt that, whatever the form under which it presents itself, its appearance is due to the decrease in the weight of the air, whose effect everyone feels in very lofty places. (P. 69.)

Hill does not hesitate to declare that animals can become almost completely acclimated to lofty places:

The effects of the rarefied air are not limited to man; they exert equal, if not greater, action upon the other animals of creation. The horses and the mules of the plains cannot cover the same distance in a given time on the mountains as on the plain; they are not capable of carrying as heavy burdens on the Sierra as in the climates in which they are accustomed to living.

However, these animals, when they have been taken to considerable heights and are well cared for, become acclimated, in most cases, after a few months, and they become fit to do almost the same work as animals born in these lofty regions. (P. 69.)

The physiologists continued, nevertheless, but without great success, to seek for the causes of these symptoms noted, explained, or denied by travellers. One of them, M. Maissiat, ${ }^{64}$ whom his profound knowledge of physics has often inspired to better result, taking up an explanation which we have already seen mentioned by Clissold, in 1822, gives an important part to the abdominal gases, expanded by the decrease in pressure:

Their pressure stimulates the diaphragm and regulates the frequency of its contractions; therefore, the circulation is linked with the production of the intestinal gases. (P. 253.) . . . . .

If the pressure enveloping the animal diminishes, there will be acceleration of the circulation and respiration and congestion of the skin, and if the pressure continues to diminish, delirium or even death may result; since the pressure of the abdominal gases increases in its effects proportional to the decrease in the outer pressure, these gases expand and distend the entire abdomen even to the point of rupture, if the drop in external pressure is very rapid ....

The accelerated circulation and respiration tend to speed up the abdominal action, and thus to restore equilibrium and quiet regularity. (P. 254.)

The German physician, Flechner, ${ }^{65}$ reports an opinion quite contrary to that of Boussingault and von Humboldt upon the composition of the air of lofty places; he opposes it, it is true, and prefers the last idea suggested by de Saussure. I quote from the review in Schmidt's Jahrbuch:

According to the general opinion, the air in the mountains is richer in oxygen, from which inflammatory diseases result... . 
Flechner has found that that is not correct . . . But if, in lofty places, the air is rarer while the composition remains the same, the oxygen will weigh less: it will furnish less oxygen to the blood. The light of the sun has no effect.

All the rest of the work is devoted to considerations of the diseases which are prevalent in the mountains.

The professor of Lyons, Brachet ${ }^{66}$ in the special work which he devoted to our subject, begins by repeating the common idea of the decrease of the weight sustained by the body when the air expands:

A column of air which raises the barometer only to $13 \frac{1}{2}$ inches must exert upon the body and all the surfaces with which it is in contact an infinitely smaller pressure, the effects of which we can compare to those of the immense cupping-glass of Dr. Junod and which we might, consequently, consider as a sort of suction. The capillaries, which are less compressed, must therefore react less energetically upon the blood and the other liquids which circulate through them; they must therefore be distended and congested by a sort of stasis . . . .

The rarefaction of the air explains very well the difficulty and trouble in breathing, but it does not explain the panting and the extreme prostration which the slightest movement causes.

To explain this new element, Brachet, who has just fallen into so strange an error in physics, expresses the most suitable ideas:

The panting (he says) results from the darker blood which reaches the lungs and does not find, in the rarified air which enters there, a sufficient quantity of oxygen to revitalize it quickly enough. The lassitude results from the fact that the blood, which is therefore not well aerated, no longer gives the muscles the normal stimulus which they need to contract.

This view, which is so simple, so clear, and, let us add in advance, so true, did not end the controversy, however.

In fact, a few months afterwards, Castel, ${ }^{67}$ a member of the Academy of Medicine, discussing the question theoretically, expresses himself on the subject in the vaguest terms; no doubt, for him, the physiological phenomena observed on lofty mountains are due to the decrease of atmospheric pressure, but, he adds:

Not that this pressure is, as certain authors have maintained, the immediate agent in the movement of the blood in the most remote arterial ramifications and the veins, but it exerts a direct and constant influence upon contractility, of which the flow of animal liquids is never independent. The contractility is checked to a degree proportional to the amount of decrease of atmospheric pressure:

Finally, in this same year, the celebrated German physiologist Vierordt ${ }^{68}$ made a certain number of experiments upon the effect 
of slightly expanded air upon respiration. He gives no information about the manner in which he carried on his experiments, which dealt only with pressures included between 340 and 330 lines of Paris (767 and $744 \mathrm{~mm}$.).

Their chief purpose was to find out whether variations in pressure have an effect on the exhalation of carbonic acid; their results are not very clear, in spite of the profusion of tabelles in which they are expressed and the wealth of decimals of doubtful derivation which accompany each number. All conclusions based on these experiments would seem to me extremely rash. Besides, the slight barometric oscillations within the limits of which they are kept prevent them from having any interest for us.

It was also at this same period that M. Lepileur's ${ }^{69}$ memoir appeared, the interesting narrative of which we have quoted in the proper place and in considerable detail (See page 98 et seq.). This work is not only rich in precise and shrewd observations, but it also contains theoretical views, the importance of which deserves our full attention. M. Lepileur first gives credit to the explanations of de Saussure and those of Brachet; but they do not satisfy him:

The phenomena relating to hematosis do not seem to us the only causes of the panting and lassitude on lofty mountains ....

One gradually becomes used to the rarefied air so that he no longer feels its effect. If it depended only on the more or less complete stimulation of the muscles by a blood which is more or less arterial, would this fatigue be accompanied by pains of back and limbs, and would it be likely to disappear thus through habit in so short a time?

We should be tempted to consider this painful fatigue as resulting chiefly from the congestion of blood taking place in the muscles during their action, in proportion to their efforts, and the whole group of phenomena due to the rarefaction of the air seems to us to agree fairly well with this idea. The more active the circulation is, the more easily congested the organs are. Now the pulse, without losing strength, becomes considerably more rapid when one is ascending a mountain, and the tendency to congestions is completely demonstrated by the facts which we have given .... When one remains motionless, equilibrium is maintained .... but as soon as one begins to move, the contracted limbs become the seat of a congestion which occurs with a rapidity proportional to the increase in the speed of the circulation. (P. 62-64 of the separate printing.)

Beside the congestion of blood in the muscles, which, according to him, explains the lassitude, M. Lepileur places exertion, which would explain the nausea, the impending syncope, and the headache: 
During exertion, there is a stasis of blood in the capillaries and congestion in the brain, the lungs, and the muscles. When one makes a series of almost uninterrupted efforts, .... when one runs up a stairway, .... vision is dimmed, vertigo occurs, a painful fatigue is felt in the limbs, and muscular strength fails. But if one stops to get his breath before the effects of the cerebral and pulmonary congestion have reached this point, the blood then flows back towards the heart, the face grows pale, and a well defined sensation of fainting is felt; sometimes the syncope occurs even when one has not taken care to place himself immediately in a horizontal position ....

If now we consider the phenomena observed in the organism at great heights, we find exactly the same course and the same signs. Except that the rarefaction of the air, by making respiration more frequent and the panting more rapid, necessarily hastens the rest of the ordinary effects of exertion ....

The slight hemorrhages of the gums, the imminence of hemoptysis, and the epistaxis are explained by the congestion, as a result of exertion ....

As to the distress in the stomach, must we not consider the gradual expansion of the intestinal gases under a constantly decreasing pressure of the atmosphere as contributing greatly to this phenomenon and to those which accompany it? .... And yet we have not observed any increase in the volume of the abdomen. (P. 65-68.)

We see that M. Lepileur considers that everything is explained by congestions of the muscles and the nervous centers, due to exertion and increased by the panting, about the cause of which he says absolutely nothing.

It appeared very difficult, after so complete and detailed an observation, to deny the harmful effect of altitude under certain circumstances. And so, following the account of his ascent of the Wetterhorn (3707 meters), on August 31, 1845, A. Vogt ${ }^{70}$ protests against denials which are at least unwise; moreover, he tries to explain them, but he is not very successful in this attempt:

We see (he says) in the narratives of travellers who have climbed lofty mountains strange contradictions; some mention frequent and more or less serious disturbances, others deny them completely. It seems to me that three factors act upon the human organism at great altitudes:

1) The decrease of weight of the atmosphere and the consequent expansion of the air; 2) the dryness of the air; and 3 ) the light reflected from the stretches of snow.

Martins, Barry, Agassiz, Desor, Escher von der Linth, etc., who felt no symptoms, blame the imagination of their predecessors. I can contradict them on one point. During the night which we passed at the Aaresattel, I was astonished at the rapidity of my breathing; my respiratory rate was twice as great as on the plain, although I did not feel the slightest discomfort. 
It is natural for one to breathe more air in a rarefied atmosphere, in order to bring the same quantity of oxygen to the blood, since in a given volume of air there is less weight of it than on the plain. If there are many mountain climbers who have not noticed this phenomenon, that is because the diminished atmospheric pressure is a great help in the expansion of the thoracic cavity, and thereby makes respiration easier.

Father Huc ${ }^{71}$ is not a skeptic, far from it. His well-known credulity even robs his accounts of much authority. Nothing is so strange as this simplicity which very lightly borrows the language and the aid of science. In fact, he adopts absolutely the idea of poisonous emanations or vapors; but, more daring than his predecessors, he even specifies the nature of them, and considers that they are formed of carbonic acid:

The mountain Bourhan-Bota has this very strange peculiarity, that the harmful gas exists only on the part that faces east and north; on the other side, the air is pure and quite respirable; it seems that these poisonous vapors are nothing but carbonic acid gas. The people attached to the embassy told us that when it was windy, the vapors were hardly noticeable, but that they were very dangerous when the weather was calm and serene. Since carbonic acid gas is known to be heavier than atmospheric air, it must condense on the surface of the ground and remain there until a great agitation of the air sets it in motion, scatters it through the atmosphere, and neutralizes its effects. When we crossed Bourhan-Bota, the weather was quite calm. We noticed that when we were lying down on the ground, we breathed with much more difficulty; if, on the contrary, we mounted our horses, the influence of the gas was hardly felt. Because of the presence of carbonic acid, it was very difficult to light a fire, the argals burned without flame, shedding much smoke. However, it is impossible for us to tell how this gas was formed and whence it came....

A terrible quantity of snow fell during the night; those who, on the day before, had not dared to keep on, joined us in the course of the morning; they told us that they had finished the ascent of the mountain with ease because the snow had dispelled the vapors. (P. 265.)

These regions, so rarely explored, were crossed in 1873 by Captain Przevalski. ${ }^{72}$ He rejects absolutely the explanation which we have just reported:

The great elevation of northern Thibet causes marked difficulty in breathing, especially if one walks quickly; then come vertigo, trembling in the legs, and even vomiting. The fuel of the country (argal) is hard to burn because of the rarefaction of the air and the rarity of the oxygen.

The missionary Huc explains the same phenomena, which he observed on the mountain of Burchan-buda, by emanations of carbonic 
gas; but that is a mistake, for many Mongols from Tsaidam remain there during the summer with their cattle, which would not be possible if asphyxiating gases escaped there .... Father Huc should not be believed when he speaks of the harmful gases of Burchan-buda. (P. 174.)

Dr. Pravaz, ${ }^{73}$ a physician of Lyons, a few years before, had founded an establishment in which he used a stay in compressed air for the treatment of different diseases. The book which he devoted in 1850 to the exposition of the data which he had observed contains, in its first part, interesting remarks on the different causes of mountain sickness:

1. Respiration is mechanically restrained in its extent by the lack of elasticity of the atmosphere, which presses upon the interior of the lungs and by itself causes their development when the thorax expands through the effort of the inspirating muscles.

2. This function is insufficient for hematosis, because the oxygen, or the vivifying principle of the blood, is present in too small an absolute quantity in the volume of air introduced by each movement of the inspiration, in addition to the fact that the lack of pressure makes the quantity of this gas dissolved in the blood less abundant.

3. The arterial circulation is accelerated as a result of the rapidity of the respiratory movements caused by the instinct of self-preservation, while the capillary circulation slackens, because the recall of the venous blood to the right cavities of the heart has become less energetic on account of the decrease of the constriction exerted on the periphery of the organs. (P. 57.)

Farther on, while discussing at length these congestions of the mucous membranes which have attracted so much attention from the observers, he explains them by saying:

One of the motors of the venous circulation, and consequently of the capillary circulation, namely, the atmospheric pressure, decreases as one rises above sea level. The greater the altitude, the less active will the recall of the blood into the right cavities of the heart be, and the greater tendency will the blood have to congest the parts where aspiration is ordinarily most effective. We may then compare the action of the heart with that of a pump working in a medium where the air is very much rarefied, and which can draw water only at a depth much less than under the ordinary pressure of the atmosphere....

Hence the tendency to hemorrhages and apoplexy on lofty mountains.

Mountain sickness presents another symptom which no one has tried to explain physiologically. It is evidently produced by a disturbance of the circulation in the portal vein system; it is characterized, in fact, like congestions of the liver and the abdominal viscera, by vomiting, cramps in the stomach, and intestinal pains. (P. 82.) 
As to the differences presented by different individuals with reference to the altitude at which mountain sickness attacks them, Pravaz finds reason for that in the inequality of "the resistance of their tissues and in the vital contractility of their lungs". The sudden appearance of symptoms, a suddenness which our author exaggerates, is due to the fact that "in an almost indivisible moment, the atmospheric pressure becomes less than the reaction of the lung, and ceases to be able to struggle successfully against it. ... The decrease of the quantity of oxygen contained in the air breathed would not be great enough to explain this fact, for this decrease . . . could bring on dyspnea only gradually". (P. 76.)

Be that as it may in regard to this last restriction, up to that time the alternative explanation given by de Saussure had been accepted without dispute, an explanation which tends to attribute the discomforts of decompression chiefly to the insufficient quantity of oxygen which the respiratory acts bring into the lungs. But in 1851, Payerne ${ }^{74}$ an engineer who gave much attention to divingbells, raised an objection to this hypothesis, the worth of which we shall discuss later:

Upon the highest summits ever ascended, the pressure is equal at least to $32 \mathrm{~cm}$. of mercury. The air there contains still $125 \mathrm{gm}$. of oxygen per cubic meter, or $100 \mathrm{gm}$. per 800 liters which a man. breathes per hour. Now experiments, the accuracy of which no one could question, have recently shown that a man while resting converts only $50 \mathrm{gm}$. of oxygen into carbonic acid. Assuming that while at work he would convert 5 and even $10 \mathrm{gm}$. more, he will be far from lacking it in a place where the barometer stands at 32 centimeters ....

The weariness and the panting in lofty places therefore do not seem to me to come from an insufficiency of oxygen, but from the rupture of the equilibrium between the tension of the fluids contained in our organs and that of the ambient air, no matter in which direction the rupture operates.

The authors who followed Payerne seemed not to have known of his objections. Marchal de Calvi, ${ }^{75}$ among others, reproduces purely and simply the former explanation; this is shown by the extract from his work, published by the Proceedings; this extract we quote in full:

The author thinks that he can conclude from the experiments reported in this Note that the variations in the atmospheric pressure are far from exerting the influence attributed to them. According to him, the mistake comes from the fact that in most cases which have been considered, when there is a decrease in pressure on the surface 
of the body, there is at the same time rarefaction of the air entering our lungs, and consequently decrease in the quantity of oxygen necessary for the normal accomplishment of hematosis.

In 1853, Speer, ${ }^{76}$ an English physician, published a special work on the nature and causes of mountain sickness. He begins by telling that he himself, on the main peak of Mont Blanc, began to feel the following symptoms when he had reached 9000 feet:

Congestion in the head, throbbing of the carotids, palpitations of the heart, distaste for food. At 10,000 feet, he felt a constriction of the chest, and shortly after, the taste of blood in his mouth, which was caused by a slight exudation from the gums.

He then reviews the different explanations suggested, dwelling on that of Brachet, which he finds "too exclusive". To his mind, the great fatigue of the muscles is caused by "the congestion of blood which follows their repeated contractions", and as for the other symptoms of mountain sickness, they are due chiefly to "the irregularity of the circulation, with congestion of the brain and the abdominal viscera".

The following conclusions indicate clearly the author's line of thought:

Mountain sickness is characterized by the following symptoms, the union of all of which, however, is only rarely seen, if ever, in the same person: vertigo, headache, drowsiness, dyspnea, constriction of the chest, palpitations, tendency to syncope, oozing of blood from the mucous surfaces, increased rapidity of the pulse, anorexia, nausea and vomiting, thirst, feverish tongue, muscular pains, sensation of extreme weakness in the lower limbs, general prostration.

These symptoms should be attributed to three causes: gradually increasing congestion of the deep portions of the circulatory apparatus; increase of venous plethora of the blood; loss of equilibrium between the outer air and that of the gases present in the intestine.

These determining causes of mountain sickness are themselves the result of the considerable and rapid change in the pressure and the temperature of the atmosphere.

The next year, Dr. Conrad Meyer-Ahrens, ${ }^{i 7}$ a physician at Zurich, devoted to the study of the symptoms of decompression a long work far more important than that of Speer.

This memoir is composed of two parts; in the first (p. 1-99) the narratives of a great many travellers are reported with details; the second summarizes the symptomatology (p. 99-123) and indicates the etiology ( $\mathrm{p} .123-136)$, the prophylaxis and treatment ( $\mathrm{p}$. 136-139) of mountain sickness.

In the preceding chapters, we have given all the data quoted 
by Meyer-Ahrens and many others besides; since this part of his work contains no personal observation, I shall not speak of it. But from the part devoted to symptomatology, I extract a very good summary of the symptoms from which mountain travellers have suffered in different degrees:

The principal symptoms or at least those which occur oftenest in man are: discomfort, distaste for food, especially distaste for wine (however, the contrary has sometimes been noted), intense thirst (especially for water, which quenches the thirst best), nausea, vomiting; accelerated and panting respiration; dyspnea, acceleration of the pulse, throbbing of the large arteries and the temples; violent palpitations, oppression, anxiety, asphyxia; vertigo, headache, tendency to syncope; unconquerable desire for sleep, though the sleep does not refresh but is disturbed by anguish; finally, astonishing and very strange muscular fatigue. These symptoms do not always appear all together.... Others are observed, although less frequently, such as pulmonary, renal, and intestinal hemorrhages (in animals also); vomiting of blood; oozing of blood from the mucous membrane of the lips and the skin (due merely to the desiccation of these membranes), blunting of sensory perceptions and the intelligence, impatience, irritability, . . . f finally, buzzing in the ears. (Pages 100-101.)

But the chapter most interesting to us is that on etiology. I quote here the principal passages:

All that we have just said about the etiology of mountain sickness shows: 1) that it appears at varying altitudes; 2) that meteorological conditions, temporary or general personal characteristics, and the speed of walking vary the altitude at which one is attacked and the severity and number of the symptoms.

When one sees the appearance of mountain sickness correspond to varying altitudes, he asks himself what circumstances depending upon the altitude are capable of causing the phenomena which constitute it. In my opinion, the principal role belongs to the decrease of the absolute quantity of oxygen in the rarefied air, the rapidity of evaporation, and the intense action of light, direct or reflected from the snow, whereas the direct action of the decrease of pressure should be placed in the second rank. I find the immediate causes of mountain sickness in the changes made in the composition and the formation of the blood by the decrease in oxygen and the exaggerated evaporation, changes to which are added others due to the action of light on the cerebral functions, an action which affects the preparation of the blood liquid.

These suppositions permit us to include-if we also take into account individual constitutions-all the phenomena of mountain sickness, without needing to appeal to the direct action of the decrease in the weight of the air. This explains the acceleration of the respiratory movements and the circulation, the congestions, the hemorrhages, the functional disturbances of the brain and the extraordinary fatigue of which almost all travellers complain. We see too why mountain 
sickness attacks not only travellers on foot, but also horsemen; why the former are stricken much more severely (twice as severely, according to Tschudi); why exertion aggravates it; why it disappears when the traveller stops walking for a moment and reappears immediately when he starts again; why, however, just as horsemen themselves feel its painful symptoms, so at very great heights rest does not completely free travellers from it (de Saussure, A. Vogt); why walking on a level at great heights is often accompanied by distress which increases when one walks more quickly or begins to climb; why aeronauts are not exempt from disturbances of respiration and circulation; why patients stricken by the disease of the Puna are advised to sit quietly in rooms which are warm and well closed, etc. (Pages 131-133.) ... .

Other phenomena can in part be attributed to the immediate action of the diminished pressure, as, for example, the strange sensation of lightness of which many travellers speak, the violent beating of the heart, qualms, nausea, vomiting, and oppression. In fact, the lessened pressure of the air, by lowering resistances, aids rapid walking, respiratory movements, and the action of the heart, while at the same time it tends to increase the volume of gases contained in the intestinal canal; so that distention of the stomach and the crowding upward of the diaphragm may bring on nausea and oppression. But these phenomena of direct action may be relegated to the second rank, as I have already said. (P. 134.)

We know, from the experiments of the Webers, that the great lassitude of mountain travellers is due to a direct action of the diminished atmospheric pressure; but we must understand that not only the large muscles, those that move the large bones and hold them in their articulations, become weary, but the same thing is also true of the small muscles, like those of the tongue and the larynx (Parrot and Hamel); a phenomenon which must be general and keep increasing, as A. Vogt asserts, if it is the consequence of the decrease in pressure, and that really does happen. Here too, we must make allowance for individual peculiarities. (P. 135.)

So, in the eyes of Meyer-Ahrens, the immediate causes of mountain sickness are, in the first place, the decrease in the absolute quantity of oxygen in the rarefied air; then come the rapidity of evaporation, the intense action of the light, the increase in volume of the intestinal gases, and a weakening of the coxo-femoral articulation.

Dr. Lombard, ${ }^{78}$ who almost at the same time wrote for the Bibliothèque de Genève excellent articles which he soon afterwards collected and published in a brochure, returns purely and simply to the two old explanations of de Saussure: diminution of weight sustained, diminution of the quantity of oxygen contained in the same volume of air; then the theory of the Webers appears again: 
There is a very important element in mountain climates; it is a lessened atmospheric pressure and consequently an air which is less dense, as well as a decrease in the quantity of oxygen which is necessary to maintain life by means of respiration. To these last two circumstances are due in great part the phenomena observed on lofty mountains, and to these two I wish to call the attention of my readers for a few moments.

If we question physics, we shall see that the total weight of the atmosphere represents as many times one hundred three kilograms as there are square decimeters on the surface of our body, so that, depending upon the height of different persons, the total weight sustained by our organs will vary between fifteen and twenty thousand kilograms. If then we leave a country more or less near sea level for a higher elevation, our bodies will sustain a pressure which will diminish in proportion to the increase in altitude. We can understand what a shock it must be to our organs when the enormous weight to which they are usually subjected is diminished by a sixth, a quarter, and even a third, as is noted on the Righi, the Saint Bernard, or the summit of Mont Blanc. And if we add to this decrease in pressure the no less important change which takes place in the density of the air, and consequently in the quantity of oxygen, we shall not find it difficult to explain the various disturbances which occur in the respiration, the circulation, the locomotion, and the digestive processes of those who climb the lofty peaks of our Alps, or dwell there for a time.

In the appearance of the symptoms of which we are speaking, what part is played by a low pressure, and what part by an insufficient quantity of oxygen? That question is hard to answer, since both respiration and circulation should be equally modified under these two influences and should react on the muscular strength; on the other hand, now that recent researches have shown that the head of the femur is kept in the cotyloid cavity by means of the atmospheric pressure, it is clear that a decrease in the weight of the air should make movements more difficult; so that we reach the conclusion that the phenomena produced in living bodies, transported to great heights, are the result of the two meteorological conditions of which we have just spoken: a decreased pressure and a smaller quantity of oxygen. (P. 273.)

But shortly after this, M. Giraud-Teulon, a French physician who was very competent in matters relating to physics, completely exposed the fundamental error upon which M. Lombard, along with so many others, was relying.

Long before this, Valentin, ${ }^{i: 1}$ calculating the amount of the changes in the weight of the atmosphere on the surface of the human body at different heights above sea level, and admitting that organic matters are compressible to the same degree as water, had shown that: 
For one atmosphere of added pressure, the decrease of volume would be about 0.2 of a cubic inch, that is, $1 / 22522$ of the total volume of the body.

We see then that the volume of a man who was on the summit of Mont Blanc and let himself slide down would contract only seven one-hundred-thousandths. (Vol. I, p. 84.)

However, this clear demonstration of the lack of importance of changes in pressure considered from the mechanical point of view had not kept a very eminent author, Heusinger, ${ }^{80}$ from repeating with many details the explanation carelessly approved by so many travellers:

The pressure of the atmosphere upon the body diminishes .... At sea level, it has been calculated that an adult man would sustain a pressure equal to 33,893 pounds; if he ascends to the height of Mont Blanc, the pressure will be only 19,334 pounds . . . The bones will no longer be held in their articulations with the same strength, the muscles will have to exert greater force, fatigue therefore will be greater, .... the blood will be held with less force in the vessels, it will have a tendency to transude and to form hemorrhages where the walls are thin enough, and the blood will accumulate in the less contractible organs, where the capillary vessels can be expanded more easily, for example, in the mucous membrances, the lungs, and the brain; there will be congestion in these organs; the heart, which has fewer obstacles to overcome, will contract more often and the pulse will become more frequent. (Vol. I, p. 252.)

We must note that to this erroneous cause a number of others are added, which are more or less justified, according to the vagaries of the eclectic method. First come evaporation due to decreased pressure and dryness, lower temperature, the action of the rays of the sun, which is stronger and "penetrates the body more deeply, and irritates the eyes, the brain, and the spinal cord", then electricity, "probably stronger and less often negative", and finally the lessened quantity of oxygen in the rarefied air, which "counterbalances the frequency of the respiration and the circulation".

To return to the mechanical explanation, it was absolutely demolished by the work of M. Giraud-Teulon, and we are surprised that after such a thorough refutation, it has appeared again in books and even in the academies.

M. Giraud-Teulon ${ }^{81}$ first lays down two principles which have been too much forgotten by physicians and physiologists, before and after him: 
1. All pressures exerted by the ambient atmosphere upon the human body naturally oppose each other and balance each other perfectly.

2. The force exerted by the weight of the atmosphere is, moreover, counterbalanced by the incompressibility of the liquids with which all our organs are imbued, and by the tension of the gases and vapors in the splanchnic cavities and interstices. Thus the skin is placed between two forces which strive in opposite directions and cause an equilibrium.

Then he asks himself:

Whence comes the difference (a difference, the nature of which he unfortunately does not explain) observed between the corpse and the living body in the reaction of the two to outer pressure? Should we attribute it entirely to the difference in temperatures? But the temperature of the human body is not high enough to give a tension of more than 3 or 4 centimeters of mercury to the vapors of the liquids which it contains. Should it be attributed to the gases dissolved in these liquids? But the experiments of Magnus prove that if their quantity, merely for some of them, reaches proportions sufficient to carry the tension of the liquids containing them to a figure which equals or surpasses the atmospheric pressure, their action and their reaction, with reference to the atmosphere, would be purely physical. Now Magnus has shown, on the contrary, that the gases dissolved in the blood are retained there by quite other forces than simple pressure. For it is not enough to raise the temperature or to lower the outer tension, even to just a few centimeters, to expel the gases dissolved in the liquids of the body; it requires the presence of other gases for which the blood has a greater affinity than for the normal gases which it contains. Where then shall we find the inner force which balances the ambient pressure? In the study of the laws of circulation and pressure in the great vascular systems.

The author then shows that, in the living animal, because of the circulation of the blood, the tissues are always in a state of tension which he estimates at from 8 to 15 millimeters of mercury. Since this tension is constant, the result is, he says:

That the organic system of the living being is never endangered by even a great variation, if it is gradual, of the outer pressure and that the circulation would continue as it was before the variation. And this explains the data collected by M. Poiseuille and by M. Tingu, in regard to the continuation of the vital functions, in spite of a considerable increase of the ambient pressure.

The dangerous power of the gases of the blood, freed by the decrease of pressure, a hypothesis which Robert Boyle was the first to express and which M. Giraud-Teulon strongly opposed, as we have just seen, found an able defender in Felix Hoppe. ${ }^{82}$ The work of this chemist is of a purely experimental type; it was 
undertaken with the purpose of explaining the symptoms which attack laborers working in compressed air; and as everyone has observed that these symptoms occur at the moment of decompression, Hoppe hoped to find their cause by studying death in rarefied air. Here first is the summary of his experiments:

A rat was subjected to a rapid decrease of pressure. Convulsions occurred at about $50 \mathrm{~mm}$. of mercury ... a and death between 40 and $50 \mathrm{~mm}$. On opening the thorax, ... there could be seen through the walls of the vena cava, and the right auricle and ventricle, a considerable quantity of gas which could be released by puncture ....

In a cat . . . . which died at about $40 \mathrm{~mm}$., . . . . I found about 0.3 cubic centimeters of air in the vena cava and the right cavities of the heart; there were a few bubbles of air in the left auricle. The veins and the right heart were full of blood, the left heart almost empty; the blood was completely liquid, the arteries contracted spontaneously, the ventricles only under stimulation; the lungs were empty of air and healthy; there was no rupture of vessels; the brain was normal ....

Two swallows died .... at a pressure between 125 and $120 \mathrm{~mm}$; I found a few small bubbles of air in their blood .....

In birds as in mammals, the blood of the left heart was bright red, and consequently still contained oxygen ....

Two frogs taken to the point of complete collapse were opened; there was no gas in their hearts ... A slow-worm taken to a pressure of $22 \mathrm{~mm}$. swelled and remained motionless; then, a few minutes after being returned to normal pressure, it seemed as well as before.

\section{Summarizing:}

1. Birds die long before the point of effervescence of their blood; mammals die at a pressure hardly above this point; amphibians do not die even below this point;

2. In warm-blooded animals, gas escapes in the interior of the vessels as a result of rapid decrease of pressure. This is not true of amphibians.

F. Hoppe then asks himself whether death should be attributed to this escape of the gases of the blood, or to the lack of oxygen in the blood. It is very difficult to answer this question, he says: "For, in the autopsy, the arterial blood is still bright red, and very different from the blood of animals dying of asphyxia" (P. $67)$; an observation which is accurate, but due to an experimental error which we shall demonstrate later. At any rate, the sudden death seems to him to be certainly due to the obstruction of the vessel by the gases liberated:

The heart exerts upon its contents a pressure of $100 \mathrm{~mm}$; if the air in the large venous trunks has a pressure of only $50 \mathrm{~mm}$., it must 
be compressed a third of its volume to enter the arteries; the result is a great slackening of the circulation. If this slackening, joined to the small quantity of oxygen contained in the blood and the unequal power of the right and the left heart, can cause death, it can be only an instantaneous death. This death can be caused only by the obstruction of the capillaries of the lungs by bubbles of air, whence comes the stoppage of the circulation.

He does not limit himself to this theoretical demonstration, and tries to prove experimentally that it is not the lack of oxygen, but the decrease of the pressure which kills animals placed under the belljar of the pneumatic machine. To make this proof, he uses a method which, long before I knew the work of Hoppe, one of the last I found in my bibliographical research, I frequently used, and from which, as will be seen, I have drawn conclusions diametrically opposite to his. It will be interesting to discuss the reason for these differences; but this is not the place to do so.

At any rate, Hoppe said to himself: if it is the decrease of pressure which brings death, and not the lack of oxygen, death will necessarily occur at the same pressure, even if pure oxygen is used:

A guinea pig fell in convulsions at $77 \mathrm{~mm}$; pure oxygen was admitted into the bell, and it rose at once. When the pressure had been lowered again, it experienced the same symptoms at $75 \mathrm{~mm}$; second admission of oxygen, third lowering of pressure: symptoms at 75 $\mathrm{mm}$; another admission of oxygen, collapse at $75 \mathrm{~mm}$. Returi to normal pressure; the animal survived. (P. 69.) . . . .

So the symptoms of sudden asphyxia came at the same pressure, whether the animal was in air or in oxygen.

From this he draws the definite conclusion that the cause of death lies in the appearance of free gases; the moment of their escape varies with "the pressure, the temperature of the animal, the power of absorption and the affinity of the blood for gases, and the quantity of blood corpuscles".

The important researches of $\mathrm{M}$. Fernet ${ }^{83}$ this same year brought to the question a new element which, during later discussions of the cause of mountain sickness, seemed to support mistaken theories.

Ever since the early experiments of Robert Boyle, it had been known that gases in considerable quantities are present in the blood. More recent chemists, particularly Magnus ${ }^{8 t}$ in 1837, had shown that oxygen forms a very large proportion of the gases. From these experiments physiologists had been led to conclude that respiration is only a simple exchange of gases between the 
carbonic acid of the blood and the oxygen of the air, an exchange regulated by the laws of physics. ${ }^{85}$.

The work of M. Fernet made them change their minds. This physicist, by a series of experiments carried on with unusual shrewdness, showed that carbonic acid and oxygen are kept in the blood chiefly by a chemical affinity. The method of demonstration which he used is directly connected with our subject, since he utilized the effect of changes in the barometric pressure.

The method used by M. Fernet involved removing from the blood the gases which it contained, agitating it in closed vessels, with oxygen or carbonic acid under various pressures, and measuring the quantity of gas which it absorbed under these different conditions.

He thus showed that:

The volumes of oxygen chemically absorbed and independent of the pressure have a relative value so great that these experiments are immediately distinguished thereby from those which relate to saline solutions and even to serum. Not only is the progress of the phenomenon almost completely freed from the law of simple solution, but the volumes absorbed seem from the very first to be independent of the pressure, since the volume, when chemically combined, is almost five times as great as the volume when dissolved under atmospheric pressure. (P. 209.) ... .

In respiration, the oxygen of the air exerts a pressure which amounts to only one-fifth of the pressure of the atmosphere, so the volume dissolved in the blood of the respiratory apparatus must be reduced in the same proportion. The volume of oxygen absorbed in the state of combination by the corpuscles will then become about twenty-five times as great as the volume which actually enters the serum in the state of true solution. (P. 211.)

From this well established fact, in his actual experimental conditions, M. Fernet thought he could draw the following conclusion:

This is the explanation of this result, already verified by a great many observations, that the absorption of oxygen is practically the same, on the summits of mountain and on the plains, whatever the atmospheric pressure; however, observation, here agreeing with theory, has already noted slight differences corresponding to differences in pressure; but they can be demonstrated only by measuring methods capable of great accuracy. (P. 211.)

We should make reservations about this conclusion, which does not seem to us to be included in the experimental premises. But we shall see that certain physiologists let themselves be drawn far beyond that. In this number is Longet. 
Longet ${ }^{86}$ rapidly reviews the observations of mountain travellers and aeronauts; he lists the different explanations which they have given of the symptoms felt. He agrees that sudden changes in the pressure can decrease the oxygenation of the blood, because:

A certain lapse of time is always necessary for the equilibrium between the gases of the blood and the outer gases to be completely established, and also for the more active movements of respiration to be put in harmony with the new conditions, so that the lungs absorb, in a given time, almost the same quantity of oxygen as the normal state requires. (First edition, p. 474; third edition, p. 560.)

But if one stays a long time, a complete equilibrium is established. In fact, he says:

If, at each breath, the mountain dweller necessarily draws less oxygen into his lungs than the plain dweller does, he compensates for that by more frequent inspirations, so that, after all, in both of them the same quantity of oxygen can be absorbed in the same time. (First edition, p. 475; third edition, p. 561.)

And farther on, speaking of the oxygen of the blood, he writes this quite explicit passage:

We know that the quantity in weight of a gas dissolved in water is always proportional to the outer pressure; applying this law to the case in question, we would reach this conclusion that the blood of dwellers in regions where the atmospheric pressure is hardly 0.380 meters would contain one-half less oxygen than the blood of dwellers by the seashore, where this pressure is 0.760 meters; but no doubt the preceding law does not apply here, because some chemical affinity interferes. (Third edition, p. 592; first edition, p. 493.)

That was also the opinion of M. Gavarret, ${ }^{87}$ who, in 1855 , expressed himself as follows:

It would be false to say that the absorption of oxygen by venous blood is a purely physical fact; everything proves, on the contrary, that chemical forces play an important part in this fixation of oxygen. If, in fact, its absorption was a simple physical solution, while the outer pressure remained the same, the quantity of oxygen absorbed should increase in direct ratio to the proportion of this gas in the air breathed by the animal; now the experiments of Lavoisier had already shown and those of M. Regnault had proved indisputably, that however great is its proportion in the artificial atmospheres created around the animals, the consumption of oxygen remains the same. In the second place, if the composition of the air remains the same, the ponderable quantity of oxygen dissolved physically by a liquid varies proportionately to the outer pressure. In the hypothesis that the phenomenon took place entirely through physical forces, the mass of oxygen absorbed by the residents of cities situated on the 
lofty plateaux of the New World would necessarily be reduced to very small proportions; the animals which live permanently at the dairy farm of Antisana, where the barometer stands at only 47 centimeters, would absorb a weight of oxygen less than two-thirds as much as they consume at sea level. Such a variation in so important a function would certainly cause great changes in their mode of existence, which surely would not have escaped observation. If the oxygenation of the blood in the pulmonary capillaries was a purely physical fact, in birds of lofty flight which pass instantly from the surface of the earth to the highest regions of the atmosphere, the consumption of oxygen would undergo variations too sudden and too extensive not to endanger seriously the lives of these animals. (P. 262.)

Moreover, in 1868, in his third edition, Longet borrowed this last objection from M. Gavarret, and added to the passage which I quoted above the following remark:

How can we admit that observers would not have been struck by the profound changes which such variations would not fail to produce in the mode of existence of these populations?

After that, is it not strange to see that when M. Jourdanet, as an "observer", noted "these variations in the mode of existence of the populations of lofty places", his conclusions were rejected by an exception drawn from the fact that by virtue of chemical laws oxygen cannot be removed from the blood by decrease of pressure?

In 1858 there appeared the second edition of the book of M. Lombard, ${ }^{88}$ of which we have already spoken; in announcing it, the editor of the Bibliothèque Universelle, Dr. Duval, ${ }^{, 9}$ expresses himself in these characteristic terms:

The researches on mountain sickness have been completed and better coordinated; perhaps the author made the possible symptoms of the digestive functions at an altitude of 1300 to 2000 meters seem a little too common. Many tourists will state that at that height they feel neither lack of appetite, nor nausea, nor vomiting, but on the contrary, an excellent and hearty appetite; some will also deny this distaste for wine and alcoholic liquors which would be experienced under the same circumstances; but that is only a question of a few meters more or less, and the reality of the symptoms described is none the less constant at an elevation which varies with the individual. De Saussure, who did not begin to be perceptibly affected until he had reached a height of 3800 meters, may pass as an exception.

As for M. Lombard, he thinks much less of the direct effect of the diminished weight of the air; he also brings up the objection of Payerne, but none the less he gives great importance to the les- 
sened quantity of oxygen contained in expanded air, of equal volume:

MM. Barral and Bixio, .... in spite of the fact that more than 9000 kilos were taken from the pressure to which their bodies were accustomed, felt no very pronounced sensation .... On the other hand, workmen in diving bells endure a double, triple, or even quadruple pressure without serious change in the functioning of the organs; and by this we are naturally led to consider the differences of atmospheric pressure as less important than one would be inclined to think from the purely scientific point of view.

On the other hand, we have recognized that as one ascends heights, the air becomes less dense and consequently contains less oxygen, so that the respiration must be more frequent and more complete to bring into the lungs the quantity necessary for the oxygenation of the blood. From this physiological necessity there must result a considerable difficulty in breathing and consequently in the circulation also; and this we see in the dwellers in the lofty regions of our globe.

Yet we must not believe that the rarefied air of our mountains does not contain a sufficient proportion of oxygen to maintain life; experiments made on the quantity of oxygen necessary for respiration have, in fact, shown that a man at rest in one hour converts 50 grams into carbonic acid, and if we add five or even ten grams for the increase produced by movement or work, we shall see that, assuming that the stay is in a place where the barometer stands at only $315 \mathrm{~mm}$. (7000 meters), the air still contains 100 grams of oxygen in the 800 liters that a man breathes per hour. So that we see definitely that, even at great heights, the atmosphere can furnish man a sufficient quantity of oxygen to sustain breathing.

Does it follow, nevertheless, that this great decrease in an element so essential to life has no effect upon our principal functions? We do not think so, quite to the contrary; it is visibly evident that the withdrawal of a considerable portion of oxygen must make respiration incomplete and react upon the other vital functions which, like the circulation, are very intimately associated with respiration.

But even that is not all; when an incompletely oxygenated blood reaches the different organs, such as the brain and the muscular system, it is evident that their functions will experience a disturbance proportionate to the incompleteness of the oxygenation; so that one must attribute to the decrease of oxygen a considerable portion of the disturbances which occur in innervation and motility. (P. 47.)

M. Lombard then admits in part the explanation which the Weber brothers had given and which von Humboldt had accepted in regard to the role of the pressure on the cotyloid cavities.

Among the symptoms experienced by travellers attacked by mountain sickness, the sensation of extreme cold is neither the least strange nor the least painful. M. Ch. Martins, ${ }^{n 0}$ who had felt it in his ascent of Mont Blanc in the company of Bravais and M. Lepileur, made a special study of this physiological cold, an 
expression which indicates, in the mind of the learned professor of Montpellier, not a drop in the body temperature, but the sensation of cold which may be produced by various causes.

After studying these causes in a man at sea level, M. Martins declares that others exist in the mountains. Some act indirectly by changing the temperature of the air to which the sun gives less heat as a result of its decreased density, and which receives very little heat from the much reduced contact surfaces of the ground. Let us add that its constant renewal does not give it time to become warm, and that the expansion of ascending currents tends to chill it. Other causes act directly upon the living body.

First is the power of radiation, which is twice as great on the Grand-Plateau of Mont Blanc as at Chamounix; next, pulmonary and cutaneous evaporation, stimulated by the low pressure, by the wind which blows almost constantly in lofty regions, and by the dryness of the air; finally, on lofty summits, the contact with a frozen soil. These are the physical causes which tend to chill the body. After explaining them in detail, M. Martins next comes to the physiological causes of the chill, which are peculiar to high mountains.

Here we quote verbatim:

Everyone knows that, at elevations which vary according to the individual from 2000 to 4000 meters, one begins to feel painful sensations, namely: extreme panting accompanied by headache, desire to sleep, nausea, and great lassitude. This is the phenomenon called mountain sickness, a complex result of fatigue, abrupt decrease in pressure, and especially the rarefaction of the air. Physiologists consider that man draws into his lungs in an ordinary inspiration on the average a half-liter of air; the oxygen of this half-liter of air combines with the blood. At sea level, at a pressure of $760 \mathrm{~mm}$. of mercury, a half-liter of air weighs $0.65 \mathrm{gm}$. and contains in weight $0.16 \mathrm{gm}$. of oxygen; at a decreased pressure, $475 \mathrm{~mm}$. for example, to which we were subjected for three days at the Grand-Plateau, the volume of air inspired is still the same; but its weight differs, for it is reduced to $0.40 \mathrm{gm}$., and the oxygen contained by this half-liter of air is only $0.10 \mathrm{gm}$., and on the summit of Mont Blanc, at a pressure of $420 \mathrm{~mm}$., only $0.09 \mathrm{gm}$. . . .

The oxygen of the blood and consequently the heat production are therefore less than at sea level merely because the quantity of oxygen drawn into the lungs is much smaller. Respiration is less perfect, just as it is in foul air in which the proportion of oxygen is lower than in normal air. This entirely physical cause had already been pointed out by Halle, Lombard, and Pravaz junior. Like them, I attribute to it the symptoms of panting which are noted in rapid ascents on lofty mountains.

The objection that on lofty mountains the number of inspirations 
compensates for the lessened proportion of oxygen in the air inspired is not valid. Anyone who has himself experienced the short and hasty inspirations, without proper expansion of the thorax, which accompany the breathlessness during and immediately after an ascent, realizes that these hasty inspirations cannot have the calorific effect of regular inspirations. So panting ceases the moment one stops walking, and a regular respiration, more frequent than on the plain, partly compensates for the lessened quantity of oxygen; I say partly, for to make complete compensation, on the Grand-Plateau, for example, the number of inspirations would be to the number on the plain as 8 is to 5 , that is, proportional to the quantities of oxygen inspired. Now that is not the case; panting, in a state of rest, certainly does not add one-third more. The lessened oxygenation of the blood is therefore not counterbalanced by the frequency of the inspirations, and becomes a physiological cause of cold which is peculiar to lofty regions, and probably the principal one of all those causes which bring on the symptoms known under the name of mountain sickness.

This explanation, we see, is only the one already envisioned by de Saussure; we see also that M. Martins is much less optimistic than Longet, who asserted that on the mountains one could make up for the lessened oxygen content of the inspirations by their number.

The same ideas also occur to the mind of Guilbert, ${ }^{91}$ when he gives an account of the soroche of the Cordilleras:

Upon the plateau of the Cordilleras, the air contains only $3 / 5$ of the quantity of oxygen which it contains at 0.76 . When one ascends, he reaches colder and colder regions, where man must produce more heat, to maintain his normal temperature. To expedite combustion, he needs a greater quantity of oxygen, and the air contains less. Here are two causes working in the same direction, which are sufficient to explain the disturbance of the respiration and the circulation.

The experiments of Magnus have shown the presence of free gases in the state of solution in the blood. The tension of these gases increases as the pressure diminishes. Then these gases exert a pressure against the walls of the vessels in which they circulate with the blood, and distend them; hence come compression of the brain, and consequently violent pains in the head, etc. . . . Perhaps too hematosis is incomplete; in this case, it could claim part of the effect on the nervous system; the blood, which has lost part of its stimulating qualities, could no longer be a sufficient stimulus; hence the tendency to syncope, etc.

The decrease of the atmospheric pressure also explains the hemorrhages. The free gases of the blood press against the walls of the vessels; a moment may come when these walls, unable to resist. longer, are ruptured and let the blood escape .....

The action of the heart is no longer counterbalanced by the atmospheric pressure, and the result is a stasis of blood in the capillaries which are therefore distended. This phenomenon is evident, 
in the face and the hands, and especially in the conjunctiva. The same thing must take place in the capillaries of the lungs, and the exaggerated contraction of the heart also has a share in causing the difficulty in breathing.

Let us note, in addition, that Guilbert adopts the explanation of the Weber brothers in regard to the connection between decompression and the firmness of the articulation of the head of the femur.

Finally I shall report the conclusions of Guilbert with reference to pulmonary phthisis. This disease is very common on the Pacific coast, except among the Indians. But in the Cordillera, according to this physician, one observes:

1. The absence of phthisis among the natives, without any racial distinction;

2. Curability by a prolonged sojourn, and in such a proportion that this curability cannot be considered as the exception;

3. The constantly delaying effect of the climate upon the progress of the disease in those who cannot be definitely cured, and the not infrequent remissions.

In the year 1861 the first book of M. Jourdanet ${ }^{92}$ appeared. This work had a double merit; first, by actual observation, he recognized certain signs of harmful effect from prolonged sojourn in lofty places, although no one before him had suspected it; second, by his explanation, he revived for science the idea glimpsed by Pravaz, but rejected through the work of M. Fernet, of a lessened solubility of the oxygen in the blood, in consequence of a diminished barometric pressure. The true doctrine is completely expressed in this volume. In the beginning, M. Jourdanet takes up and develops the calculations of M. Martins:

The barometric pressure of Mexico is $585 \mathrm{~mm}$. Consequently a liter of air weighing, at sea level, 13 decigrams, weighs only about $1 \mathrm{gram}$ in this capital. In both cases, oxygen figures in the proportion of $23.01 \%$. That gives us 299 milligrams as the weight of a liter of oxygen at sea level, whereas this figure is reduced to 230 milligrams for the altitude of Mexico.

Let us declare then a difference of 69 milligrams per liter to the disadvantage of this locality.

Admitting now as correct the calculation which rated at 16 the number of inspirations made by a man per minute, we observe that the consumption of air is 8 liters in this interval of time, and consequently is 480 liters in an hour. But we have already noted for Mexico a loss of oxygen of 69 milligrams per liter. It is therefore indisputable that in this capital one loses the benefit of 33 grams per hour or 794 grams of oxygen per day. (P. 65.) 
After explaining thus the chief condition of the physico-physiological problem, M. Jourdanet states that the ardor of the sun on the heights of Anahuac must also act to diminish considerably the density of the strata of air near the ground, and consequently the intrapulmonary gaseous endosmosis.

When this has been established, he shrewdly compares respiration in a pure air, but under low pressure, with respiration in air with low oxygen content, but at normal pressure. Then answering the objection taken from the work of MM. Regnault and Reiset by M. Gavarret, an objection which had just found new strength in the experiments of M. Fernet, he comments with reason that if the chemical combination of the oxygen and the blood was absolutely independent of pressure, one should live with ease not only at the lowest barometric pressures, but also in air with very low oxygen content, which no one will admit:

According to the opinion of M. Gavarret himself, the solubility of oxygen in the blood is diminished when the quantity of oxygen inspired is lessened. It is therefore indisputable that, however effective and necessary the affinity of the corpuscles for oxygen in the act of respiratory endosmosis may otherwise be, the mere fact of the rarefaction of this gas lessens the absorption of it at high altitudes and thus causes real disturbance in the phenomena of respiration. (P. 69.)

M. Jourdanet then adds the following interesting observation:

If the convictions which we have just expressed were to be shown inaccurate in the results, compensation for the rarefaction and the lightness of the atmosphere in Mexico would have to be made by deep inspirations and by a respiration which in general was more active than at sea level. It is commonly believed that this is the case and this opinion is based upon the observation furnished by persons who make a rapid ascent in the atmosphere or who make only a short stay at high altitudes. It is completely erroneous. The truth is that those who dwell at great elevations breathe less quickly than men whose abode is near sea level. The rarity of the air, as we shall see later, produces apathy of the muscular system. The chest also feels its effects. I have often surprised the functions in the very act by counting the respiratory movements of persons who were unaware of it and who were in a state of complete repose. I almost always noted a decrease in the number of expansions of the chest. Sometimes, fairly often, in fact, one forgets to breathe and is forced to make up for lost time by taking deep inspirations. (P. 76.) . . . .

But this respiration, so calm in absolute repose, easily gains amplitude under the influence of movement. (P. 87.)

The consequences of this decreased absorption of oxygen are easily foreseen. The first is a decreased activity in the production 
of animal heat, at the very time when, on account of the altitude, this production should be increased.

In fact, our author says very fittingly:

Prudent Nature at sea level has established laws which assist, through the atmosphere, these variations in the production of human heat. For in winter the cold air is denser, and contains a greater part of the vivifying principle in a certain volume. The warmth of summer, on the contrary, by expanding the atmosphere, gives the lungs a proportion of oxygen in keeping with the small amount of heat which the body must produce. Thus the source, from which we draw the elements of our respiration, itself varies in a certain measure, which, at sea level, is a kindness of Providence.

This is not true at high elevations, where the density of the air, lessened by the decrease of the barometric pressure, is no longer proportionate to the temperature surrounding us, but to the altitude which we have reached. And note particularly this extremely important fact: whereas at sea level the exterior causes which chill us take care to give us the means of combatting this drop in temperature, in Mexico, on the contrary, the decrease of pressure which produces cold in the air alters the source of heat for us by compelling us to breathe a rarefied atmosphere. So that, on the one hand, the increased expansibility of the air and the easier evaporation chill us constantly, while, on the other hand, the increased rarity of oxygen refuses us the normal means of calorification.

Upon these data, so clear and so exact, the physiological peculiarity of altitudes rests entirely. (P. 83.)

It is, therefore, not surprising to see that:

Persons in a state of repose chill very easily. Their lower limbs are almost never warm. Muscular exercise would stimulate the circulation and the respiratory movements; but the blood, deprived of oxygen, produces apathy of the muscles and makes one prefer repose. Here then appears the result of the experiment made by M. Becquerel upon the muscle fiber which loses its contractility and becomes enervated when it lacks contact with the arterial blood. (P. 86.)

Here M. Jourdanet meets the phenomenon described by all mountain travellers, of exaggerated fatigue, pain in the thighs, and heaviness of the lower limbs; he protests energetically against the explanation of the Weber brothers, which was accepted by von Humboldt and almost all later authors, although this explanation, to use his apt expression, "does not bear careful examination":

In fact, if we estimate in square centimeters the surface on the plane of opening of the cotyloid cavity, the diameter of which is 54 millimeters, we get a result of 22.89 square centimeters, which, multiplied by 1003 grams, a weight equivalent to a square centimeter of surface, give us 23,645 grams, to represent the real weight in the cavity of the joint. If we remember that many travellers have felt 
the muscular fatigue which we are discussing when they had hardly gone beyond a fourth of the atmospheric pressure, we shall see that this phenomenon appeared when the thigh was still supported by a weight of $17 \mathrm{kil}$. $734 \mathrm{gm}$. We do not understand why a member, which may weigh at most 15 pounds, would have so little respect for the 21 pounds surplus which it would drag along in its fall. (P. 89.) The real reason, according to $M$. Jourdanet, is expressed thus:

This phenomenon appears when the blood, incompletely oxygenated, causes the contractile power of the muscular fiber to be considerably diminished. The abdominal member then refuses to carry out its normal functions and warns by pain that the task is beyond its powers. The same thing would happen to the other muscles of the body, if one required of them the exaggerated efforts which ascent demands from the muscles of the thigh. (P. 89.)

\section{Summarizing:}

The symptoms of the famous mountain sickness: vertigo, swooning, vomiting, - what do they amount to but cerebral anemia, for want of the stimulus of arterial oxygen; congestion of the venous system, and especially the portal vein and the liver; but, above all, enervation of the muscular fiber for the same reason.

Always and everywhere: lack of the normal quantity of oxygen in the circulation of the arterial blood. (P. 90.)

Most of the book is devoted, as its title indicates, to the study of the diseases of Mexico. Everywhere there M. Jourdanet finds predominant the effect of this anemia of a special type, "result of an imperfect respiratory endosmosis". It is indeed, as he says clearly in his subsequent works, this strange syndrome which, awakening his medical shrewdness, caused him to reflect upon the conditions harmful to respiration and metabolism presented by a prolonged sojourn on the lofty plateaux of Anahuac.

I shall merely quote the following passage because it offers a sort of summary of this remarkable work, and because we find in it a part given to the pressure as a mechanical agent, simply assisting its chemical action:

We have already seen the blood, feebly welcomed and lazily expelled by the nervous centers, congesting the brain and the spinal cord of weak persons, already injured by the climate. We shall mention the disturbances of more than one sort of the alimentary canal, several of which are due to the circulatory slackening and to the capillary congestions of the intestinal venous system. The uterus has attracted our attention by phenomena of the same nature. We shall take the opportunity to say here that pulmonary congestions are frequent in Mexico and too often are fatal. Finally, more frequently than all the other organs, the liver imbibes blood and from this source draws countless symptoms, the unfortunate consequences of which are frequently reckoned among the causes of death. 
And so, beyond any doubt, altitude favors venous stases. When they are superficial, one cannot deny that the decrease of the air pressure acts in a purely mechanical sense towards this result. The superficial capillary networks, deprived of their natural external support, expand with an ease in proportion to the decrease in the weight. If to this first cause you add a blood not sufficiently stimulating for the arteries and too abundant in general for the veins, you reach the etiological trinity: lessened external adjuvant, organic sluggishness, general congestion of the venous system; a trinity the effects of which will be directed by turns to different parts of the organism, depending upon where the disturbances in innervation have previously prepared for them. (P. 254.)

Two years later, there appeared a long memoir by the same author. ${ }^{93}$

The mere title of this second work, The Anemia of Altitudes, indicates the idea of M. Jourdanet: in his opinion, "the dwellers at great elevations, above 2000 meters, are generally anemic", and this condition is particularly evident to the eyes of the practitioner by the syndrome. And yet the chemical analysis of the blood strangely contradicts what the clinical observation revealed:

In 1849 , while I was in Puebla, I wished to ascertain by analytical examination of the blood whether the proportion of corpuscles was reduced. I made my first investigation on a young man twenty-five years old whom I knew to be suffering from gastralgias and vertigo. He fell from his horse, and the consequences of this fall made bleeding necessary. My analytical tests were made on blood obtained in these circumstances. They showed me that the proportion of corpuscles was $151 / 1000$. I repeated my experiments upon four young women who were bled following accidents. Their pallor, their general prostration, and their nervous condition showed that they were suffering from chloro-anemia, although auscultation revealed no arterial murmur. Their blood furnished the normal proportions of corpuscles. (P. 8.)

What is the explanation of this apparent contradiction? It is that:

The principal duty of the blood corpuscles is to serve as aid to the real agent of our life. When their proportion is reduced in the blood, it is no doubt correct to say that the sickness is the result of the decrease in corpuscles; but we would fix the immediate cause of the symptoms of the disease more accurately if we attributed its existence to the decrease in oxygen. I think I am more justified in expressing myself in this way because if, in the case of anemia, we call attention, as it is natural to do, to the reduced proportion of this gas in circulation, we see several causes which may produce this circulatory anomaly, without finding it necessary to explain it by a decrease in the number of corpuscles. That, exactly, is the case in the anemia of altitudes. (P. 10.) 
M. Jourdanet summarizes his opinion in the following propositions:

1. The corpuscles and the barometric pressure regulate the quantity of oxygen in the blood;

2. Disturbances in either of these two forces must necessarily affect hematosis;

3. Since oxygen is the chief vital agent, its decrease for lack of corpuscles causes the weakness of anemic patients; its decrease in the blood for lack of pressure must produce the same result;

4. For this reason persons breathing the atmosphere of great elevations must have their health affected in the same way as those suffering with anemia at lower levels;

5. The anoxemia of altitudes is therefore analogous to the hypocorpuscular anemia of the sea level. (P. 21.)

Since plethoric persons have a large proportion of corpuscles in their blood, it is not surprising, as M. Jourdanet says, to see them often:

Climbing the rugged sides of Popocateptl and at an altitude of 17,700 feet imbibing the complete elements of life, whereas their travelling companions, of less sturdy constitution, succumbed to mountain sickness. (P. 22.)

Then making a more detailed study of the chief phenomenon, the general trend of which he indicated previously, and taking into account the experiments of Magnus and M. Fernet and his own, M. Jourdanet reaches the remarkable conclusions which we give verbatim:

1. From 76 to 65 centimeters, partial vacuum acts only upon the part of the gases of the blood which is held in true solution;

2. Under the influence of this first barometric decompression, the release of carbonic acid is mush greater than the loss of oxygen, the result of which is greater freedom of action for the oxygen;

3. It is possible then that, since a moderate elevation does not noticeably decrease the quantity of the oxygen in the blood, whereas it removes a considerable portion of carbonic acid, it may act upon man with a tonic and strengthening effect;

4. As to the portion of oxygen which a weak affinity allows us to consider as being held by chemical action, its escape from the blood results from lowered barometric pressure only when the pressure approaches 60 centimeters;

5. We therefore should consider that the quantity of oxygen in the blood is seriously diminished beginning in the neighborhood of this limit, and it is then that the anemia of altitudes begins;

6. We can therefore understand that a moderate altitude may be a powerful means of curing anemia, whereas this same disease is a natural consequence of sojourn at a considerable altitude. (P. 37.) 
Finally, in 1864 , a third ${ }^{94}$ work repeats with new developments the ideas expressed in the works from which I have just taken numerous quotations. However, I cannot refrain from extracting from one of his chapters on mountain sickness his clear explanation of this syndrome, an explanation in which we need to make no important change for the conclusions of the present book:

A man who rapidly ascends to a very lofty point is deprived of a certain quantity of oxygen from which he was accustomed to receive a stimulating effect necessary for the full exercise of his strength. Certainly, what is left him after his ascent is still capable of maintaining life and even the regular action of the functions. But man cannot endure without temporary symptoms a sudden reduction which lessens the resources from which the nervous system is accustomed to draw its power. The muscular fibers also refuse to perform their task when their oxygen supply is decreased. We then see appearing those phenomena which hemorrhages have made familiar to us. As a result of the loss of blood, the organism, we know, suddenly loses an important part of its normal stimulus; the patient has vertigo, his muscles weaken, nausea attacks him, and the more nearly vertical his position is, the more quickly he is seized by syncope . . .

The weakness produced by bleeding is evidently the consequence of a sudden lack of oxygen through the loss of a certain quantity of corpuscles, just as mountain sickness results from a more direct withdrawal of the same gas. So that, beyond a doubt, an ascent beyond 3000 meters amounts to a barometric disoxygenation of the blood, just as a bleeding is a disoxygenation of the blood through the lack of corpuscles. (P. 92.)

These works soon stirred up a controversy which was very bitter. A French expeditionary corps had just been sent to Mexico, and the conclusions of M. Jourdanet were anything but encouraging for those who dreamed of the establishment of a Latin empire supported by a French colony established on the lofty plateaux of Anahuac.

Michel Levy, then director of the School of Military Medicine and Surgery, was aroused and thought he should open a sort of investigation of the accuracy of the data given by M. Jourdanet; Dr. L. Coindet, head of the medical service of the second division of the French army, agreed to take charge of this investigation.

The first letter sent by this observer to his hierarchic chief censured the statement of M. Jourdanet about the slackening of the respiratory movement:

A statement (said Michel Levy) which contradicts the opinion accepted hitherto that, under the influence of reduced atmospheric pressure, respiration is accelerated to compensate by the number of 
inspirations for the diminished quantity of oxygen in the same volume of air. ${ }^{95}$

In this document, L. Coindet ${ }^{96}$ reports the results of 1500 observations made on Mexicans and Frenchmen on the high plateaux, in which he counted the number of respiratory movements. I give here the summary of his tables:

Below 16 inspirations per minute
16 inspirations
Above 16 inspirations
General average of inspirations per minute
In the presence of this mass of data (adds our author), doubt is
no longer possible, and it is certain that those dwelling here do not
breathe less quickly than men whose dwelling is 2277 meters lower.
Farther on, Coindet declares:
That, independently of the greater activity of the respiration, the
inspirations are generally ample, deep, and profound, and-that all the
more because they are less numerous.

He then states, without having made any exact measurement of this point, however:

That thus equilibrium is always established, and that the function constantly tends to adapt itself to the rarefaction and lightness of the atmosphere.

Then, in a very sudden decision, which seems to indicate on the part of our author a very great desire to be easily convinced, Coindet does not hesitate to draw at once this important conclusion from these observations on the respiratory rhythm:

That what has been written in regard to the insufficiency of the oxygenation of the blood at great altitudes, as a consequence of an alleged slowing of the respiration, should be considered unfounded ... It may very well be that the so-called Mexican anemia is merely the yellowish complexion characteristic of the natives!

Next come observations on the pulse rate and the comparative measurements of the chest capacity of Frenchmen and Mexicans. We shall return to the second of these later. In regard to the pulse:

I have felt it repeatedly (says Coindet) without any prejudice, and I have even counted the heartbeats, which agreed with those of the arteries.

In short, he finds as the average pulse rate, 76.216 for Frenchmen, and 80.24 for Mexicans. 
The second letter" treats of "acclimatization on the heights of Mexico"; it contains only a summarizing description of the races of Mexico and a little meteorological information. However, I quote the following passage, which is rather interesting:

After crossing Cumbre, when we reached an elevation above 2000 meters, first respiration and circulation, and afterwards absorption, exhalation, and metabolism underwent noticeable changes. We perceived a tendency of the fluids of the body to move towards the periphery, the result of which was derangement of the circulation, various congestions, cerebral, pulmonary, and nasal hemorrhages, several examples of which I have given; difficulty in breathing, which made us pant; general discomfort, which made us consider the weather heavy, although it was really lighter; difficulty in moving and greater fatigue, and these symptoms were particularly marked in the men of the 95th of the line, who had not remained long at Orizaba, like us, and who had been transferred rather suddenly from sea level to a fairly high elevation. Little by little, the organism of everyone, at first in conflict with a medium for which it had not been created, adapted itself progressively to this medium, and today, after a ten month sojourn on Anahuac, it has been so transformed that it resembles that of the Indian. (P. 817.)

The third letter ${ }^{98}$ is much more important to us. In it is the report of the analyses made in the laboratory of the School of Mines of Mexico under the supervision of Professor Murfi, with the purpose of measuring the quantity of carbonic acid formed in a given time by dwellers on the lofty plateaux. Twenty-five persons, 10 of whom were French, 10 Indians or half-breeds, and 5 Mexicans of European origin, were the subjects. The average results, for the French, for example, are given in the following table:

Number of inspirations per minute

Pulse rate _- 78.2

Quantity of air expired in one minute _-_ 5.90 liters

Average percentage of carbonic acid per minute__________ 4.24

If we set aside the discussion which Coindet gives about the petty differences of details noted among the representatives of the different races on whom he experimented, we find that these observations inspired the following reflections in him:

The average quantity of air expired per minute according to $\mathrm{M}$. Dumas is 5.3 liters at sea level; here generally we have about 6 liters, when once the man is acclimated. This is logical, for since the air of altitudes contains in a given volume less oxygen at a barometric pressure of 0.58 or 0.59 meters than at 0.76 meters a greater quantity of this air must be absorbed to compensate for the difference: this is attained by a more active respiration; so that the air which is drawn into 
the lungs and exhaled from them is always about a third of a liter for each inspiration and each expiration.

While the air expired by man at sea level contains from 3 to 5 parts of carbonic acid per 100, our experiments show that on Anahuac the average is just as high, since it is 4.36 for 25 subjects.

It has been shown by 103 observations made at sea level by MM. Brunner and Valentin that the quantity of carbonic acid contained in the expired air is $4.267 \%$. M. Vierordt, ${ }^{99}$ who made nearly 600 experiments on this subject, reached nearly the same results. The expired air contains on the average $4.336 \%$.

Our average does not differ from the latter, if we take into account the decrease in atmospheric pressure which, as is well known (?), increases a little the proportion of carbonic acid exhaled.

We are not surprised, after this long enumeration of data, to see Coindet cry out with an accent of triumph:

Absorption of oxygen, exhalation of carbonic acid constitute two connected expressions, from the chemical point of view. On the other hand, modification in the qualities of the expired air and the corresponding changes in the composition of the blood are the two terms of the physico-chemical problem of respiration.

There can be no doubt then about what one should think of the alleged insufficiency of the oxygenation of the blood at high elevations.

The Gazette hebdomadaire contains another series of letters addressed by Coindet to Michel Levy, ${ }^{100}$ under the general title: "Statistical Studies of Mexico", devoted to pathology, meteorology, etc.; they only rarely treat questions which are purely physiological. We see that for this physician everything is settled by his preceding researches, and that it is quite proved, as he says frequently, that at high elevations man compensates exactly, by the number and amplitude of the respiratory movements, for the loss in oxygen caused by the lessened density of the air; so that equilibrium is regularly maintained. I can find to be quoted verbatim only the following passage, in which our author's opinion about the cause of mountain sickness is shown.

June 5,1863 , (he says) in the company of Dr. Laval, I ascended almost to the summit of Iztaccihuatl (4686 meters) . . . . Our mouths and throats were dry; our legs were exhausted; our respiration was panting, hasty, deep, often broken; our pulse, which was small, had a rate of 128. But we did not yet feel the distress, headache, or nausea, which constitutes mountain sickness, in which, by the way, acceleration of the circulation no doubt plays a great part by its congestive effect.

M. Jourdanet did not fail to answer the letters which contradicted his physiological and medical statements on almost all points and which gave the impression that there could be nothing 
accurate "in a book", these are the very words of Coindet, "so opposed, I am proud to say, to all I have written". Without discussing what relates to pathology, we shall go straight to the convincing reply which $M$. Jourdanet ${ }^{101}$ made in opposition, not to the data reported by Coindet, but to the conclusions which this doctor drew from them:

M. Coindet states that the respiration is not merely accelerated, but that it is ample, deep, profound. Now what do this amplitude, this depth, and this profundity amount to? We find the definite measure of them in the passage of his correspondence in which we see that 25 subjects gave an average of 6 liters of air breathed per minute, in 20 respirations. That is therefore an average of 30 centiliters of air for each respiratory movement. It is evident that this volume of air represents only a very moderate thoracic amplitude ...

Our colleague is no more fortunate when he states that, on the great elevations of Anahuac, more air passes into the lungs in a given time than at sea level; for the 6 liters which he collected in the subjects of his observations are not above the very ordinary average furnished by men from 20 to 30 years old at the pressure of 76 centimeters. And we should also note that, considering the rarefaction of the air of Mexico, these 6 liters weigh only 6 grams, instead of 7.8 grams, the weight of the same volume of air at sea level ....

So, according to M. Coindet himself, at an altitude of 2277 meters, respiration is not ampler, or deeper, or more active than at sea level. (P. 150.)

The reply appears incontrovertible on this phase of the question. The chemical considerations remain.

Here M. Jourdanet criticizes an obscurity in Coindet's wording, which no doubt has already impressed our readers, but which makes the reading of the different observations contained in the memoir itself quite incomprehensible. In the table reproduced above, we have copied verbatim these words: Average percentage of carbonic acid per minute: 4.24. What does this information mean? Does it refer to a percentage calculated in volume or in weight? This question is asked in regard to each of the observations.

We are quite surprised (M. Jourdanet says naturally) at the obscurity which reigns in the report of M. Coindet. Let us take, for example, the first experiment:

"H. Staines . . . Number of inspirations per minute 22; number of liters of air in one minute 6.4 ; carbonic acid $4.64 \%$."

Considering these 6.4 liters of air breathed by the subject of the experiments, we cannot help thinking that the $4.64 \%$ of carbonic acid indicates the proportional quantity of this gas in volume also. But further on (Gaz., 1864, p. 36, first column), these figures are repeated under the heading: Weight per 100 of carbonic acid expired in one minute. Evidently the wording is not clear. 
We repeat with M. Jourdanet: Evidently the wording is not clear; but an important circumstance throws complete light on it. It is the comparison which Coindet makes between the figure he obtained and those of Vierordt, Brunner, and Valentin. These physiologists very certainly meant the percentage in volume, and Coindet could not have been confused about that, because the passage we copied above is the word for word reproduction of a new paragraph of the deservedly popular book of M. Béclard, ${ }^{102}$ from which only the words "percent in volume" have been left out. To M. Coindet, then, the matter concerns a proportion in volume, and his own experiments would show, if this were the case, a considerable decrease in the intra-organic combustions on the Mexican plateau, since, the quantity (in volume) of carbonic acid exhaled there being the same as at sea level, the quantity in weight would evidently be much lower, in a proportion measured by the very decrease of the atmospheric pressure.

But here is another thing. M. Jourdanet, who was then in Mexico, desirous of settling this doubtful question, asked M. Murfi, "true author of these analyses", and obtained from him an answer showing clearly that:

The experiments of the College of Mines gave an average of 4 grams and 51 centigrams of carbonic acid per 100 liters of air expired, measured at a temperature of 14 degrees and at a pressure of 58 centimeters.

The contradiction is glaring: Coindet specified volumes, M. Murfi states that it is a matter of weights, and M. Jourdanet, naturally giving more credence to the statements of the Mexican chemist, draws from them a really crushing conclusion for his adversary:

It is therefore unquestionable (he says) that the subjects of the experiments of the College of Mines produced 4.51 grams of carbonic acid per 100 liters of expired air. On the other hand, the report of M. Coindet, agreeing in this with the statement of M. Murf, says that the quantity of expired air was on the average 6 liters per minute. Who can doubt then that if 4.51 grams of carbonic acid correspond to 100 liters of air, the 6 liters expired by the subjects of the experiments contained 27 centigrams. It is therefore certain that the quite undeniable result of the respiratory proportion of the College of Mines was that the subjects from twenty to thirty years old produced 27 centigrams of carbonic acid per minute, that is, 16 grams and 20 centigrams per hour.

The conclusions of M. Coindet do not agree with these figures; for not only did these alarming figures not authorize him to say that respiration in Mexico is identical with that at sea level, but they 
indicate a danger which would justly make one fear sojourn in lofty Anahuac; since, according to these experiments, the carbonated respiratory combustions would not be half there what they are at sea level. The analyses of the College of Mines therefore leave us in great anxiety. I notified my colleagues of the Society of Medicine of Mexico, who were sufficiently affected by them to vote new surveys. (P. 151.)

To this undeniable conclusion, Coindet ${ }^{103}$ tried to reply in his turn. Let us set aside the mere assertions and the digressions of acrimonious polemics, although they are numerous, and come to the root of the matter, the contradiction which we revealed above:

M. Michel Levy (he says) and the members of the Society of Medicine of Mexico know the reply which I made to the statements of M. Jourdanet. I proved that the volume 3.90 per 100 of air at a temperature of 14 degrees and a pressure of 58 , which was given me by the weight 4.51 per 100 of air also at a temperature of 14 degrees and a pressure of 58, furnished, because of the greater quantity of air expired (6 liters instead of 5.3 Dumas), 295.13 grams of carbon consumed in 24 hours, or 12.30 grams in one hour, and we know the averages established at sea level by MM. Dumas, Andral, Gavarret, Valentin, Brunner, Vierordt, etc. It is quite certain, I assert, that my subjects would not have expired more than 3.3 liters of air at sea level.

I confess for my part that I do not understand this very well, and it would have been desirable that Coindet should copy in his letter the proofs which he had sent to M. Michel Levy. First, let us note that this time the 4.51 are no longer for him a measure ${ }^{10+}$ of volume, as that resulted evidently from the new paragraph which we mentioned, but a measure of weight; it is, as M. Murfi said, the weight of carbonic acid contained in 100 liters of air expired at $14^{\circ}$ and $58 \mathrm{~cm}$. But from that point, the reasoning and the calculation of M. Jourdanet are unassailable. If 6 liters of air per minute pass through the lungs, that makes 360 liters in an hour, containing $360 \times 4.51$ grams $=16.23$ grams of carbonic acid. The researches of Andral and Gavarret ${ }^{105}$ give an average, between the ages of 20 and 40, of 12.2 grams of carbon consumed, which corresponds to 44.07 grams of carbonic acid. The difference is enormous, so enormous that, for my part, I think that there is a fundamental error in the analyses which are the basis of his reasoning.

Let us see now what Coindet's reasoning is. And first, let us note that he takes a strange cross-road: "I have proved", he says, "that the volume 3.90 per 100 of air at a temperature of 14 degrees and a pressure of 58 , which was given me by the weight 4.51 per 100 of air also at a temperature of 14 degrees and a pressure of $58 \ldots$. 
These are painful and useless calculations; why change a weight into volume to find again a quantity in weight? Let us, however, make them again, because, if their apparent result is favorable, we shall find considerable errors in them.

A liter of carbonic acid at $0^{\circ}$ and $76 \mathrm{~cm}$. of pressure weighs 1.966 grams. Therefore, 4.51 grams of this gas represent under these conditions of temperature and pressure $\frac{4.51}{1.966}$ liters, and at $58 \mathrm{~cm}$. 4.51 liters x 76,

$1.966 \times 58$ and at $14^{\circ} \frac{4.51 \text { liters } \times 76(273+14)}{1.966 \times 58 \times 273}=3.160$ liters.

So the expired air contained in volume $3.16 \%$ of carbonic acid, and not 3.90 as Coindet said, so that all his subsequent results are decidedly wrong.

Better still: accepting the figure of $3.90 \%$ (a proportion, which, by the way, does not vary, as Coindet seems to think, with the pressure and the temperature) we get final results very different from those he records. In fact, the men whom he observed breathed per hour 360 liters of air, which consequently contained, according to him, $360 \times 3.9$ liters $=14.04$ liters of carbonic acid, at $14^{\circ}$ and $58 \mathrm{~cm}$., representing at $76 \mathrm{~cm}$. and $0^{\prime}$,

$$
\frac{14.04 \text { liters } \times 58 \times 273}{76(273+14)}
$$

Now since 1 liter weighs 1.966 grams, we would have for the production per hour only 1.966 grams x $10.19=20.03$ grams; and as there is a weight of $27.68 \%$ of carbon in carbonic acid, the weight of the carbon consumed per hour would be

$$
\frac{1.966 \text { grams } \times 10.19 \times 27.68}{100}=5.54 \text { grams; }
$$

which is far from the 12.30 grams announced by Coindet.

On the contrary, the calculation of M. Jourdanet here finds a complete verification by counter-proof. In fact, it results from what we have just said that really, according to the experiments of Coindet, his men exhaled per hour

360 liters x $3.16=11.376$ liters

of carbonic acid, representing at $76 \mathrm{~cm}$. and $0^{\circ}, 8.258$ liters, which weigh 16.23 grams, a number exactly like the one we found before according to M. Jourdanet. 
It is for the reader to decide whether, after such a surprising argument, one should jeer, as Coindet did, at the "competency" of the man who very courteously criticized his mistake. At any rate, we can now easily evaluate the following conclusions, which he boldly ${ }^{106}$ formulated:

4. The average of the carbonic acid expired on Anahuac, with diet and conditions equal, is not lower than at sea level.

6. The quantity of oxygen circulating in the blood is the same at high elevations as at sea level; and with similar and equally satisfactory hygienic conditions, the efficacy of hematosis is the same also.

17. Under ordinary conditions, residence in Anahuac does not seem to lessen permanently and injuriously the total of the gases which circulate in the human body.

As for me, I do not hesitate to say that in the work of Coindet nothing justifies this last conclusion, and everything in it contradicts the first two. To tell the whole truth, I confess that I cannot accept as accurate even the analyses which are the foundation of them; there must be some mistake in the experimental method or in its application. I shall merely say that the quantity of air upon which the analysis was based was much too small; M. Murfi had the respiratory movements carried on in his apparatus for a half-minute; Andral and Gavarret had them continued from 8 to 13 minutes. Furthermore, no one took care to collect the air which passed through the nostrils. However disposed I am to think that in Anahuac the intensity of the organic combustions is really lessened, I refuse to believe that it is one-half less, as would be demonstrated if we considered as accurate the figures furnished by the work of Coindet himself. To sum it up, from the point of view of the chemical phenomena of respiration, there is absolutely nothing left of this work.

One of the surgeons of the Mexican expedition, M. Cavaroz, ${ }^{10 i}$ shortly afterwards published a memoir, the observations and conclusions of which are exactly like what M. Jourdanet had already said.

He first made a great many measurements on French soldiers and found that at an altitude of 1712 meters the general average of respirations was $19 \% 3$ and the pulse rate $651 / 4$ :

He first draws this conclusion that: on the lofty plateaux of Anahuac, there is established in the European a supplementary respiration, intended to compensate by the number of respiratory movements for the loss of oxygen for hematosis resulting from the rarefaction of the atmosphere .... 
But, he soon adds, we need to know whether this compensation is complete, and whether, after all, there is no loss of oxygen, and whether the hematosis is as normal and perfect as at sea level. I do not think so, for according to the average ratio of 18 respirations for 67 heartbeats, the number of heartbeats for $19 \frac{2}{3}$ respirations should be $67 \frac{1}{2}$. It is only $651 / 4$; therefore there is a loss of $2 \frac{1 / 4}{4}$ heartbeats; therefore the circulation is slackening to a certain degree, and the physiological condition is disturbed.

The rest of the work of M. Cavaroz contains observations tending to prove that on the lofty plateaux the European loses his liveliness and strength, and that if he falls ill, he rapidly passes into a state of prostration. So, in his opinion, perfect acclimatization is by no means proved. The resemblance between these ideas and those of M. Jourdanet is quite striking.

However, no one has paid any attention to it, and henceforth authors will speak of no one but Coindet, and we must confess that without exception they will side with him against M. Jourdanet, which proves, among other things, that it is much easier to read conclusions than to discuss a memoir.

So in the article Air which M. A. Tardieu ${ }^{10}$ wrote for the Dictionary of Practical Medicine and Surgery, the learned hygienist devotes a page to the study of the physiological effects of rarefied air. It is filled by a rapid review of the ideas of M. Jourdanet and the works of Coindet; I take from it these characteristic lines:

After what has just been said, we see what we should think of the alleged insufficiency of oxygenation of the blood at high altitudes.

Moreover, M. Tardieu gives no explanation.

The article Altitudes which M. Leroy de Méricourt wrote for the Dictionnaire Encyclopedique two years after deserves the same reproach. But before discussing it, I must say a few words about a very odd book, published in 1863 by Dr. Foley. ${ }^{109}$

When we come to the study of compressed air, we shall have to give a lengthy review of it. We shall see that in the opinion of this physician, the compression exerted by the air plays the principal part: "When one enters the caissons", he says, "he is flattened." He naturally brings the same preoccupation of a mechanical type to the study of mountain sickness:

A traveller climbs a mountain. The higher he ascends, the weaker he feels, and the more his subcutaneous veins distend. He finally becomes ill. Why?

The periphery of his body is no longer compressed. A comparative vacuum has been formed around it. The blood has accumulated there. The brain has therefore failed. The aeronaut has fainted. (P. 63.) 
Let us add that farther on M. Foley declares that nausea, cramps, etc., are the sign of "insufficient hematosis".

In his opinion, it is the presence of the air sacs which saves the bird from the symptoms of decompression; the shocks ${ }^{\circ}$ with which he would be threatened on his return as workmen are when they leave the caissons (see later, Title II, Chapter III) are spared him because of the elastic tension of the gases contained in the sacs. For that, the bird that is mounting needs only to close its beak and its nostrils; but perhaps we may be permitted to ask how it can breathe then.

A distinguished veterinarian, M. Liguistin, ${ }^{110}$ who was in command of this service during the Mexican expedition, found himself confronted with the same problems as the military physicians. $\mathrm{He}$ seems not to have known of the heated discussion the principal points of which we have just summarized:

"In his opinion, moreover, the effect of the decrease in the density of the air is very well known." (Vol. III, p. 583.)

As to symptoms observed in animals, he states that the respiratory disturbances noted by doctors seem not to have attacked beasts of burden:

Would the large solipeds bear more easily than men the effect of an air with low oxygen content? Would the lymphatic temperament with which they are endowed explain sufficiently the less urgent need of a denser air? However we know very well, and have already said so, that the atmospheric pressure most favorable to animals is also that found at sea level and in places of moderate elevation, where the mercury column registers about 76 centimeters on the barometer; that, if we place a living animal in a vacuum, the air within it, no longer meeting any resistance, expands, the animal is distended and dies; that it is the air pressure which keeps the fluids in the vessels of animals and prevents them from escaping. Therefore, when the barometer drops a few degrees, the blood must evidently flow towards the periphery; then we observe difficulty and acceleration of respiration, slackening of the circulation, weariness, prostration, and lack of interest. If in this situation our animals were endowed with the power of speech, they would probably tell us, as men do, that the weather is heavy, thus taking the effect for the cause, for we know that the rarer the air is, the lighter it is. It is unnecessary to explain why the respiration is more hasty. We know well enough that, since the air necessary for life is extremely rare, the respiratory acts must be more frequent to produce the same result. It is still more unnecessary to add that when the air becomes rarer, one might die of asphyxia. In a rarified air, thoracic inflammations and hemorrhages must necessarily prevail. And yet we have not observed this, and that is why we think that we are authorized to assert that the reduced atmospheric pressure on the lofty plateaux of Mexico does not have 
the peculiar influence upon our animals which we have observed in men living in the same medium. We mention the effect of the rarefaction of the air only in explaining the exaggerated distention accompanying the numerous indigestions observed in our horses and mules during the period of the siege. (Vol. III, p. 658.)

In a special work, this same veterinary gives an account of a series of very unusual symptoms, observed in the animals of the expeditionary corps, in the crossing of Rio-Frio (3300 meters).

The animal passes from health to sickness without any preliminary symptoms. The system is in a state of general tension, especially the muscular system. The eyes are fixed, wild, brilliant, the face contracted and the pupil dilated. The hind limbs and the whole hindquarters are the seat of spasmodic movements which are very definite and easily detectable. The muscles of the stifle and the thigh display partial quiverings.

The mouth is filled with a white, foamy, and very abundant saliva. The jaws are in a state of permanent contractility. There is certainly an over-stimulation of the salivary glands. There is a manifest desire to vomit. Frequent efforts with belching are easily observed. The belly is not distended. There are a few slight colics shown by a little uneasiness, but the animals do not lie down, aroused instinctively by the desire to urinate or defecate. The genito-urinary system is over-stimulated: there is a stubborn and painful erection of the penis. The conjunctiva is in its natural state and shows no very perceptible changes; it is moist and very slightly bloodshot. The capillary blood system is not visibly changed. The heartbeats are strong and tumultuous. One can see at a distance, without resorting to auscultation, the hasty movements of diastole and systole, and can count the throbs of this organ by looking from behind the knee; . . . and yet, strangely enough, the state of the pulse is not appreciably modified in its normal rhythm.

The nostrils are dilated. The expired air is hot; respiration is accelerated. The inspiration is shallow and the expiration deep. The respiratory muscles are contracted and tense, and the flanks, drawn upward, are separated by extremely pronounced projections. They rise and fall up to twenty or twenty-five times per minute.

There is rather general prostration of the nervous system than evident over-stimulation of the brain.

The symptoms which we have just listed continue for several hours without increasing and then disappear evidently as the effect of suitable measures. (Vol. IV, p. 258.)

This strange series of symptoms apparently so dangerous, which, however, never brought on any serious consequences, suggested to M. Liguistin the idea of poisoning. Not all of his colleagues shared his opinion; "some explained the symptoms in question by blaming chiefly the rarefaction of the air, slow asphyxia ..." 
M. Liguistin himself realized that this element might have an important etiological part:

Certainly there is no doubt (he says himself) that at the season when we crossed Rio-Frio, the period of great heat, that a considerable increase in the temperature, causing evident rarefaction of the air, added to an elevation of 3302 meters above sea level, and producing by this altitude a decrease of $3 \frac{1}{2}$ kilometers in the height of the atmospheric column, had the immediate result of decreasing considerably the quantity of respirable air and producing symptoms characteristic of such causes. We should have liked to be able to prove this physical point by the barometer, during the different conditions of the atmosphere; for that alone would have furnished the real explanation of the swelling of the abdomen frequently appearing in the animals of the expeditionary corps during our crossing of Rio-Frio. However, although this rarefaction was not demonstrated experimentally, its existence is nevertheless undeniable.

in Mexico City, observation showed that the atmospheric pressure was only 58 degrees. We may therefore estimate it for Rio-Frio at approximately 55 or 56 , which would cause a decrease of 20 degrees from normal atmospheric pressure. Is it illogical to suppose, after that, that animals cannot be placed for even an instant in such a medium without their organism feeling some effects of it? Evidently not; and we were all the distressed, but not surprised, witnesses of the harmful effect which so rarefied an atmosphere can produce upon the health of large solipeds; I mean this second pathological scene, which appeared again more definitely at Rio-Frio, and which brought a moment of turmoil and confusion (indigestion with distention). (Vol. IV, p. 262.)

In short, M. Liguistin persists in the idea of poisoning, the harmlessness of which he explains by the partial neutralization produced by other plants simultaneously ingested. By searching in the vicinity, they found a sort of scilla, to which they attributed the symptoms. Experiments made with the leaves suspected gave, however, only one interesting result: the firm refusal of the horses to taste them, even after a fast of 48 hours. As for poisoning obtained by aqueous extract, ingested in the animals by force, they by no means resemble the symptoms observed during the crossing of Rio-Frio. Whence we conclude, in direct opposition to our author, that these symptoms were due exclusively to the rarefied air.

I now come to the article of M. Leroy de Méricourt, ${ }^{111}$ an article to which the name and the special qualifications of its author gave much credit, and which is still quoted constantly.

However, it does not contain any personal observation, and the only really original idea in it is due to Professor Gavarret; but it gives, in an elegant style, a summary of the data previously 
observed and the theories put forth. The most interesting part consists of a very harsh criticism of the works and opinions of M. Jourdanet, whom he considers completely vanquished by Coindet. According to him:

The proportion of carbonic acid in the air expired, as indicating the activity of hematosis on altitudes of more than 2000 meters, showed that the average exhalation of this gas is not less than it is at sea level.

We have already shown what one should think of this assertion, to which the very figures of Coindet would give much too complete a contradiction, in our opinion.

Then, finding the comparison made by M. Jourdanet between mountain sickness and bleeding, and expressed in these striking and accurate terms: "An ascent above 3000 meters is a barometric disoxygenation of the blood, just as a bleeding in a corpuscular disoxygenation", M. Leroy de Méricourt finds nothing better to say about it than to qualify it as strange:

Moreover, (he says) a priori, the objection may be raised against M. Jourdanet that the absorption of oxygen by the venous blood is not a purely physical fact, the result of a simple solution, but that chemical forces play an important part in this fixation of oxygen.

I was very desirous of reporting this opinion because it shows well what the sentiment of the most learned and the best authorities was in 1866 . We must, in fact, wait for the theory expressed by M. Jourdanet, the accuracy of which I have demonstrated experimentally, to be considered soon as a thing so simple and evident that everyone will claim to be its originator, or at least will refuse it any merit of originality.

I now come to the passage penned by M. Gavarret.

After reviewing a few principles of elementary physics, the learned professor of the Faculty of Paris continues in these words:

When he ascends a lofty mountain on foot, man accomplishes a quantity of mechanical labor which varies with the weight of his body, the height of the ascent, the nature and the disposition of the ground on which he walks. To the mechanical force which he thus expends there corresponds a consumption of a determined quantity of the organic materials of his blood, the combustion of which produces no thermic effect. Independently of the quantity of heat necessary for the maintenance of his own temperature, the respiratory combustions must therefore furnish the calorific equivalent of the mechanical force expended during the ascent. To understand thoroughly the consequences of this forced increase of the respiratory activity, let us give our attention to a specific example. 
An adult man, of good constitution, weighing 75 kilograms, has ascended, on foot, to an altitude of 2000 meters on the side of a mountain. He has thus accomplished a useful work of 150,000 kilograms, representing 353 units of heat, the thermic effect of which is zero, since they are transformed entirely into mechanical force, and which are furnished by the respiratory combustions. Since eight tenths of this transformed heat comes from the combustion of carbon, the creation of the mechanical force corresponding to the useful work accomplished during the ascent requires the production of 65 liters of carbonic acid, above 22 liters of this gas which the man forms per hour in his general capillaries to maintain his own temperature. The consequences of the production of so great a quantity of carbonic acid in the body are apparent. The consumption of the organic materials of the blood is excessive, and the powers are rapidly exhausted. The respiratory and circulatory movements are considerably accelerated, on one hand to render possible the absorption of all the oxygen necessary for such active combustions, and on the other hand to rid the blood of such a proportion of dissolved carbonic acid. When the pace is slow, the force expended in a given time is slight, and the functional disturbances are not great.

But if the ascent is rapid, the exhalation of gas, though very much activated, is not enough to maintain the normal composition of the blood, which remains saturated with carbonic acid; then respiration becomes uneasy; the dyspnea is extreme, and is accompanied by headache, vertigo, and drowsiness ..... We easily understand why a halt of a few instants is enough to dissipate all these symptoms.

As soon as the man is resting, the expenditure of energy ceases, the activity of the respiratory combustions drops rapidly to the degree strictly necessary for the maintenance of his temperature, the utilization of oxygen is only 22 liters per hour, the blood is very quickly freed of the excess of carbonic acid which it contains, and all the disturbances of the respiratory and circulatory functions disappear at the same time....

As a result of these considerations, we think that we are authorized to say that the larger part of the functional disturbances characteristic of mountain sickness should be attributed to a true intoxication by carbonic acid dissolved in too great proportions in the blood. To express our ideas completely, we shall add that an intoxication of the same sort, the inevitable result of too great an expenditure of energy, is one of the principal causes of the serious symptoms observed in overdriven animals.

This interesting and original theory, supported by indisputable calculations and the great authority of the learned professor of medical physics, should gain great success and be epoch-making in science. Henceforth, all will vie with each other in repeating it; already Dr. Aug. Dumas ${ }^{112}$ has been the first to do so in his inaugural thesis.

But the theory of M. Gavarret does not satisfy him; he accepts and supports with well-made calculations the theories of the 
Weber brothers on the tendency of the head of the femur to separate from the cotyloid cavity in expanded air. The objections of M. Jourdanet do not affect him, as we see. That is because he does not consider the work of this learned physician very important; in his opinion, Coindet has completely refuted such erroneous statements:

What becomes then (he cries) of the alleged insufficiency of oxygenation of the blood at high altitudes? and what shall we say of all the theories which M. Jourdanet has based upon this idea?

As to the headache, vertigo, and loss of consciousness experienced by von Humboldt and other travellers, Dumas explains them "in a wholly mechanical manner"; to tell the truth, he merely copies an explanation already given by Pravaz:

Barry has shown that at each expiration, the course of the blood is slackened in the jugular veins. Therefore it is easy to understand that, in a person who has reached the summit of a lofty mountain, where his hampered respiration forces his thorax to make hasty movements, his venous blood experiences a stasis in the jugular veins and even flows backward, possibly causing a congestion of the nervous centers and all the symptoms which result from that.

M. Scoutetten, ${ }^{113}$ whose work appeared the next year, is satisfied with copying the principal parts of the article Altitudes, and particularly the quotation from M. Gavarret, whose opinion he adopts wholly.

As he seems besides to attach much importance to the variations of the weight sustained by the human body under different barometric pressures, he took the trouble to draw up a long table in which are listed the amounts of this weight in all the mineral water spas.

We learn from this that a man who sustains 15,345 kilograms at sea level is relieved of 406 kilograms at Vichy, of 1015 at Saint Gervais, of 1905 at Mont Dore, and 2744 at Cauterets, the highest of the spas.

Is it among such ideas that an author takes his stand whose Proceeding for 1867 publish a note which is not conspicuous for clarity? I do not know and leave the reader the task of deciding: ${ }^{114}$

M. Kaufmann submits to the judgment of the Academy a memoir on the mechanical effect of the air upon certain physiological functions in which it does not usually play a part.

To ascertain, the author says, the mechanical effect exerted upon different parts of the organism by the pressure of the air, I began experiments to measure the air; some in which I measured the 
changes produced in different physiological or pathological states by variations in the weight of the atmosphere; others in which I produced these variations artificially. Those whose results I am submitting to the Academy today refer to the different periods of generation in mammals from conception to the time of delivery.

In the book which he published at the time of his return to France, Coindet ${ }^{115}$ returns to the question of the quantity of carbonic acid formed by men who live on the lofty plateaux. Evidently he felt ill at ease on this ground, for in a work of two volumes, containing more than 650 pages, he devotes only 5 to this important subject. And yet what could be more convincing in favor of his point than to dwell upon this demonstration that the intra-organic combustions are as active at high altitudes as at sea level? Anoxemia, against which he was battling, would be completely disproved. I confess that at first I expected to find new experiments in this book; there are none, and the explanation of the data is infinitely less complete and detailed in it than in the letters addressed to Michel Levy.

This is soon explained, for first we record a valuable confession; "I was mistaken", says Coindet (Vol. II, p. 90), "when I formerly wrote weight instead of volume." There is a point gained, and, as I had shown when I recalled the passage copied by Beclard, the notorious $4.51 \%$ in 1864 represented to Coindet a proportion in volume, although he said the opposite in his 1865 letter. But then, if there is $4.51 \%$ of carbonic acid in volume in the air, since the subjects were breathing at the rate of 6 liters per minute, or 360 liters per hour, that makes in one hour 360 liters $\times 4.51=16.23$ liters of carbonic acid expired.

Since we are working at $14^{\circ}$ and at 58 centimeters, this volume corresponds, at $0^{\circ}$ and $76 \mathrm{~cm}$., to 11.77 liters; and as a liter weighs 1.966 grams, the production of carbonic acid per hour would be 23.14 grams, giving 6.40 grams of carbon consumed. Once more we are far from the 12.30 grams announced triumphantly by Coindet. .

But he thinks better of it:

We must not lose sight of the fact (he says) that $4.52 \%$ in volume, the average amount of carbonic acid exhaled in one minute, has been removed from an air at a temperature of $14^{\circ}$, and a pressure of $58 \mathrm{~cm}$, brought to a temperature of $0^{\circ}$, and a pressume of $76 \mathrm{~cm}$. ... so that 6.125 liters, average amount of air expired in one minute, disregarding the Frenchmen who had lately arrived and were not acclimated, give us 367.55 liters in one hour...

When the average of $4.52 \%$ of carbonic acid exhaled in one minute is accepted, we can establish the following proportion: 
$100: 4.52:: 367.55: \mathrm{x}=16.62$ liters of carbonic acid per hour.

At sea level, 1.85 liters of carbonic acid contain 1 gram of carbon, which gives us 9 grams very approximately consumed in one hour...

This figure is quite different from the 12.30 grams of the first work. And yet how was it obtained? First by taking the quantity of air expired from 6 liters to 6.125 liters; then by declaring that in the calculations the air was reduced to $0^{\circ}$ and $76 \mathrm{~cm}$.; but Coindet forgets that he said exactly the opposite before:

I have proved that the volume $3.90 \%$ of air at $14^{\circ}$ and $58 \mathrm{~cm}$. furnished me by the weight (let us not forget that now it is the volume) 4.51 of air also at $14^{\circ}$ and $58 \mathrm{~cm} . \ldots$.

In another passage, he is no less explicit:

Since the quantity of air expired per minute, as admitted by M. Dumas, is 5.3 liters at sea level, in Mexico City . . . we have about 6 liters. This was logical, for since the air at high altitudes contains less oxygen in a given volume, a greater quantity of this air had io be absorbed to make up the difference.

It is not therefore, in our opinion, 9 grams, but 6.40 grams of carbon consumed in an hour that are given by the figures of Coindet himself. But even with 9 grams, we must realize that we are far below the average figure of 12.2 grams found by Andral and Gavarret. Coindet cannot conceal it, but he does not seem at all disturbed by it:

Our average of 9 grams (he says calmly), lower than that found by some authors, does not cause us, for reasons given above, to consider the respiratory combustions of carbon as perceptibly lower on the lofty plateaux than they are at lower levels.

What are these reasons then? First, we see, is that

Our creoles were students in the School of Mines, on the day before their final examination for the year, sitting studying all day long, and under these circumstances the expired air has undergone little change;

And second, that

The Indians had an insufficient diet and used alcohol habitually; And third, that

There were losses through the nostrils!

I think it would be useless to continue. I can only repeat what I said above: from the chemical point of view, there is nothing, absolutely nothing, left of the work of Coindet; and as the experiments which we have just shown to be so unsatisfactory are the 
basis of his whole physiological argument, we see that his position is untenable.

I should certainly not have spent so much time on a work which has had far too much publicity, if it was not still quoted as an authority by persons who preferred to trust to its peremptory conclusions rather than to make the painful analysis through the meanderings of which we have led our readers. And the latter have had the opportunity to see that even if the a priori assertions and the statements of conclusions are clear, the experiments themselves and the calculations based on them contain only obscurity, confusion, or error.

M. Gavarret ${ }^{116}$ did not adhere to the theory which we reported above, and which he had given in the form of advice to M. Leroy de Méricourt. When he wrote the article Atmosphere for the Dictionnaire Encyclopídique, he was led to investigate the effects of decreased pressure, without the addition of fatigue, exertion, and the production of carbonic acid imposed by mountain ascents. Reaching the study of causes, as an experienced physicist, he first opposes the opinion that the lessening of the weight sustained by the body may have some effect; he properly invokes against this error the principle of the incompressibility of liquids, and consequently of the body. But in giving his attention to this point, strangely enough, he returns to the ideas of Robert Boyle:

The disturbance which accompanies the decrease of the barometric column is really the effect of the pressures from within outward exerted by the vapors and the gases imprisoned with the body .... We must fix our attention upon the gases of the blood which, under the effect of a considerable and very rapid drop of the barometric column, may cause serious symptoms. The blood, in fact, contains oxygen, nitrogen, and carbonic acid in the state of simple solution. When the outer pressure diminishes, these gases tend to separate from the blood, push the walls of the vessels from within outwards, and distend the pulmonary and general capillaries, the walls of which may be ruptured because of their thinness and lack of resistance. Such is the mechanism of the production of hemorrhages, sometimes slight and temporary as their determining cause when they appear on external surfaces, sometimes serious and even fatal, when they have the interior of some vital organ as their seat. (P. 153.)

But M. Gavarret makes haste to apply a proper restriction to this:

Symptoms of this sort may no doubt be produced in persons who are very rapidly moved to great altitudes; but that is not the case with travellers who gradually ascend from sea level to the highest plateaux on earth. In the latter, the laws of physics governing gases and their solubility .... reestablish harmony .... (P. 154.) 
In other words, the explanation given by the learned professor can be applied, according to him, only to laboratory experiments performed on animals; mountain climbers and aeronauts are not amenable to it.

The argument brought by M. Gavarret against the part which so many authors had given to the decrease of the weight sustained by the body seemed to have exposed this error; the important experiments of Rudolph von Vivenot ${ }^{117}$ seemed, on the other hand, to give it new authority. In fact, the Viennese physician proved very clearly that in rarefied air the depth of the respirations and the respiratory capacity diminish considerably.

These experiments were made at the Johannisberg establishment, in the apparatuses set up by Dr. Lange; some had as their purpose the study of compressed air, and those we shall discuss later; the others, of which we shall speak now, related to rarified air.

When we take into account the altitude of Johannisberg, where the average height of the barometer is $742 \mathrm{~mm}$., we see that if the decompression reached in the apparatus was $318 \mathrm{~mm}$., the actual pressure was $424 \mathrm{~mm}$., which corresponds to an altitude of 4470 meters above sea level.

Under these conditions, as I said a moment ago, the amplitude of the respirations diminished considerably:

Dr. Lange and Dr. Mittermaier, whose pulmonary capacity shortly before at normal pressure had been $3942 \mathrm{cc}$. and $4237 \mathrm{cc}$., could only with the greatest efforts expire $3448 \mathrm{cc}$. and $3842 \mathrm{cc}$, of air which was admitted to the receivers of the spirometer. Their respiratory capacity therefore had diminished $494 \mathrm{cc}$. and $394 \mathrm{cc}$. respectively. On an average, we can deduce from the above figures as a normal average respiratory capacity $4090 \mathrm{cc}$., as respiration in rarefied air 3646 cc., consequently as average decrease of pulmonary capacity 444 cc., to which we must add that these $3646 \mathrm{cc}$. of rarefied air represent only 2084 cc. of normal air. (P. 7 of the separate printing.)

The frequency of the respirations has considerably increased, working inversely:

The number of respirations rose in me from $14-15$ to 18 ; in M. de G. . . ., from 17 to 21, and at another time, from 17-18 to 19 ; in Dr. Lange, from 15 to 21; in Dr. Mittermaier, from 7.5 to 9.5 per minute. As to the consecutive duration of this effect, it could not be noted, because no observations were made following the experiments in rarefied air. (P. 11.)...

As to the depth and rhythm of respiration in rarefied air, an increase in the depth of the inspirations is noted. This, then, is the first case in which the effect of rarefied air seems to agree with that 
of compressed air, although the causes are opposite. Whereas in compressed air there is a deeper inspiration spontaneously, as a mechanical effect of the increase in pressure, it is, on the contrary, the need of getting air, which, since it cannot be satisfied in rarefied air by normal inspirations, necessarily produces deep and forced inspirations. One experiences at the same time a feeling of uneasiness, oppression, during which the inspiration is especially difficult, because, even in atmospheric air, it requires more energy than the expiration, whereas the latter, in rarefied air, is made more easily and more quickly. (P. 16.)

Vivenot also made observations on the pulse rate. It rose from 78 to 80 in Dr. M., from 73 to 82 in Dr. L., from 61 to 76 in M. de G., from 80 to 105 in Vivenot himself.

A veterinarian of the Royal Corps of English Engineers, Flemeing, ${ }^{118}$ published in 1867 a work in which he reports a fairly large number of travellers' observations, and at the head of which he expresses his theoretical opinion about the effect of decompression:

If the pressure is reduced artificially, as when one climbs a mountain or ascends in a balloon, one notes the same phenomena as in fish taken from the water.

The body swells, the inner fluids distend the tissues outwards, exerting a vigorous pressure on them, burst the vessels, and often cause hemorrhages.

Rarefied air contains less oxygen in a given volume, so that respiration, being incomplete, is accelerated to compensate for this deficiency; the inspirations are proportionately more numerous; the heart contracts vigorously and more frequently, the blood circulates with difficulty, the lungs are congested, the blood vessels are distended, and aneurisms are formed. (P. 9.)

In summary, according to Flemeing, the effect of altitude can be produced in several ways:

1. By the decrease of the atmospheric pressure: the muscles and the articulations tend to relax, the blood stops or transudes through the walls of the vessels, especially the mucous membrane of the air passages, the lungs, and the brain envelopes.

2. By cutaneous and pulmonary evaporation ....

3. The frequency of the circulation and the respiration is counterbalanced, or better, caused by the small quantities of oxygen which the inspired air contains.

4. The lowered temperature ....

5. The more powerful rays of the sun .... which cause irritation of the eyes, the brain, and the spinal cord. (P. 12.)

M. Bouchard, in his noteworthy thesis on the pathogeny of hemorrhages, ${ }^{119}$ is led to express his opinion about the cause of the symptoms, noted both in persons subjected to a considerable 
decrease of pressure and in workmen who are being decompressed when they leave the caissons of bridge piers. In his opinion, as we shall see at the proper time, hemorrhages are due partly to the escape in the vessels of the carbonic acid of the blood, which has been stored up there in exaggerated proportions during the compression.

Decompression by ascent would produce the same effect; and if hemorrhages have been noted particularly in mountain climbers, the theory which he suggests may explain the difference in these effects:

The man who rises in an aerostat performs practically no work except that required by the respiratory movements. The man who climbs a lofty mountain, on the contrary, makes a considerable muscular expenditure and must load his blood with carbonic acid. Is it not, moreover, to this accumulation of carbonic acid in the blood that certain authors attribute this peculiar dizzy state called mountain sickness? (P. 102.)

Errors are hardy. It is strange to note that in spite of the authoritative answer made by M. Jourdanet to the theory of the Weber brothers, it continues to be taught almost universally. M. Beclard, ${ }^{120}$ in the last edition of a book which should be in the hands of all students, says, in fact:

When man rises in the air, climbing very high mountains on foot, as the rarefaction of the air increases, he experiences a very peculiar feeling. It seems to him that his limbs are heavier; the lower limbs especially soon become the seat of a fatigue which urges him to rest. Hardly has he stopped an instant when this fatigue disappears to reappear after a short time; and so on. This is what happens; the atmospheric pressure is no longer sufficient by itself to keep the head of the femur firmly against the cotyloid cavity, and thus counterbalance the weight of the lower limb, and muscular effort must keep the limb in its articular relations. This unusual muscular effort is promptly followed by need of rest for the muscles . . . .

This effect is felt even when the differences in pressure of the barometric column are not very great. When the barometer falls, since the muscles have to move heavier organs, we say that the weather is heavy, although in reality the pressure exerted upon the surface of the body by the atmospheric column is less. Likewise, when the barometer rises, movements are made more easily. ( $P$. 697.)

As to the symptoms of decompression other than heaviness of the limbs, M. Beclard attributes no importance to them when the transitions are made rather slowly:

At Potosi (4000 meters), at Deba (5000 meters) . . . the functions of metabolism, respiration, and circulation of the mountain dwellers 
go on as in dwellers on the plains, and they are in just as good health ....

Men and animals therefore can endure very considerable variations in pressure without disturbance of the functions of life. It is true that, since the density of the air is lessened, the air drawn into the lungs contains in each inspiration less oxygen than on the plain in the same volume; but the movements of respiration harmonize with these new conditions. Moreover, pressure is still exerted in all directions, the air penetrates all the open cavities (alimentary canal, respiratory passages), the gases of the blood are put in equilibrium of tension with the atmospheric air, and the normal conditions of gaseous exchange are not altered in the lungs.

The variations in the pressure of the atmospheric medium in mountain ascents or in balloon ascensions are not likely either to cause painful symptoms in regard to metabolism.

But this is not true when the decompression takes place rapidly, as happens in aerostatic ascensions:

Then a certain time is needed for the equilibrium between the inner gases and the outer gases to be established. When the ascension has been to a considerable altitude, sometimes there appears a difficulty in breathing, suffocations (from expansion of the intestinal gases which press upon the lungs, crowding the diaphragm upwards) and local hemorrhages in the mucous membranes (probably from.sudden expansion of the gases contained in the vessels, and from rupture of the capillaries). (P. 696.)

Beside the ideas of physicians with theories we should place the opinion expressed by mountain climbers. After the theories and the discussions which we have just reported, it is somewhat surprising to see certain travellers almost deny the effect of decompression.

For instance, Hudson, ${ }^{121}$ who scorning "the easy beaten path which usually leads to Mont Blanc," ascended the mountain by a new route, starting from Saint Gervais, states that:

If one is careful to save his strength, he can cross the highest summits without experiencing any serious inconvenience. Several persons have complained of discomfort experienced at great heights, nausea, drowsiness, bleeding from the nose, the eyes and the ears, and I do not doubt that such symptoms are possible; but my long training in mountain journeys has proved to me that they should be attributed only to fatigue, to which no doubt may be added cold and the rarity of the air, or rather the unusual precautions required by these two circumstances. In fact, there were five of us in the group, and thanks solely to care not to get tired, none of us had an instant of discomfort; the same thing was true at the time of my ascent of Monte Rosa. (P. 85.)

Dr. Piachaud, ${ }^{122}$ whose interesting observations we have already 
summarized, made during his ascent of Mont Blanc in 1864, also attributes to fatigue alone the disturbances of circulation and respiration; according to him, the drowsiness is due to cold, the muscular fatigue to the cause indicated by Brachet, and the heaviness of the lower muscles to the cause specified by Weber and von Humboldt.

But these not very original estimations have hardly any importance beside the new and very ingenious theory advanced by Dr. Lortet. ${ }^{123}$ We have reported at length the observations made with all the precision required by modern physiological research by this learned physician during his ascent of Mont Blanc. The discovery to which he gives most importance is the decrease of the body temperature during the act of ascent. In his opinion, this is the true cause of the symptoms experienced, and to explain it, M. Lortet relies upon the elementary notions of the mechanical theory of heat:

In a state of rest and fasting, man burns the materials of his blood, and the heat developed is wholly employed in maintaining his temperature constant in the midst of atmospheric variations. On the plain and during moderate mechanical work, the intensity of the respiratory combustions, as $\mathbf{M}$. Gavarret has shown, increases proportionately to the expenditure of energy. There is a transformation of heat into mechanical energy, but because of the density of the air and the quantity of oxygen inspired, there is enough heat formed to make up for this expenditure.

In the mountains, especially at great altitudes and on very steep snowy slopes, where the mechanical work of the ascent is great, an enormous quantity of heat is needed to be transformed into muscular energy. This expenditure of energy uses up more heat than the organism can furnish, hence the perceptible chilling of the body and the frequent halts which must be made so that one can gain warmth. Although the body is burning hot, although it is often covered with perspiration, it becomes chilled during the ascent, because it uses up too much heat and because the respiratory combustion cannot furnish a sufficient quantity of it because the air lacks density; because of the rarefaction of the air, at each inspiration less oxygen enters the lungs at a great height than on the plain. (P. 33.)

M. Lortet then shows, by a simple calculation, that while he is ascending 1000 meters, a man weighing 75 kilograms would find that the temperature of his body would drop $2.3^{\circ}$, if he furnished no restorative heat. Hence he draws this conclusion that the drop of $4^{\circ}$ to $5^{\circ}$, which he noted in ascending to 3800 meters, is quite natural and within the limits indicated by his theory:

Let us take, for example, a human body weighing 75 kilograms, and let us assume that during the ascent no combustion repairs the 
loss of heat undergone; let us assume also that all the mechanical work is usefully employed, that is, that none of it is lost in slipping, false steps, etc.

When the body has been raised 1000 meters, the quantity of work accomplished will be represented by $75 \times 1000$ or 75,000 kilogrammeters.

As the mechanical equivalent of heat is 425 kilogram-meters for each unit of heat, to get the quantity of heat absorbed during this work of ascent of 1000 meters, we shall have $\frac{75,000}{425}=176$ units of

heat. If we assume that the specific heat of the human body is equal to that of water, that is, equal to 1 , and if we represent this specific heat by $\mathrm{C}$; if we call the drop in body temperature $\mathrm{X}$, we shall have: quantity of heat lost by the body $75(\mathrm{C}+\mathrm{X})$ or $176=75 \mathrm{x}$, whence $\mathrm{X}=\frac{176}{75}$, or $\mathrm{X}=2.3$

Therefore the drop in body temperature resulting from the heat absorbed by a work of 75,000 kilogram-meters, performed in an ascent of 1000 meters, would be $2.3^{\circ}$ centigrade, assuming that no combustion repaired, at least in part, this loss of heat. But it is evident that in reality this combustion exists and that a part of the heat expended is restored while it is being absorbed. But we have seen, by the study which we have made of the respiratory and circulatory disturbances, how much this combustion is hampered at a certain altitude, and how incomplete it is.

Furthermore, it is evident also that all the energy expended is far from being useful because of false steps and the softness of the snow. The quantity of heat used must therefore be enormous, and the drop in temperature must be great and hard to meet by respiratory combustion.

We see then, when these different elements of the problem are well considered, that this drop of four and some tenths degrees centigrade, in the ascent of Mont Blanc, is not at all extraordinary because this figure gives one and some tenths degrees centigrade for each thousand meters of elevation, a quantity which is very near the $2.3^{\circ}$ centigrade given us by the physical theory, when we do not take into account the respiratory combustions. (P. 36.)

However, when one is digesting, there is almost no drop in temperature, probably because of the acceleration of the circulation, either general or capillary, and perhaps also because of an extremely rapid absorption of alimentary material. This explains the practical habit of the guides of giving out food about every two hours. Unfortunately, above 4500 meters, distaste for food is so great that it is almost impossible to swallow a few mouthfuls. (P. 37.)

To this chief cause others are added, which M. Lortet stresses. First:

The rapidity of the circulation is another cause of the drop in 
temperature, since the blood does not have time to become suitably oxygenated in the pulmonary vesicles. (P. 34.)

In addition, as M. Gavarret has shown:

The creation of mechanical energy corresponding to useful work, accomplished during the ascent, requires the production of 65 liters of carbonic acid above the 22 liters of this gas which man forms per hour in his capillaries to maintain his temperature. The consequences of the production of so great a quantity of carbonic acid in the body are apparent.

At a great height, the respiratory and circulatory movements are accelerated not only to make possible the absorption of an adequate quantity of oxygen, but also to free the blood of the carbonic acid which it holds in solution. But this exhalation of gas, though very active, is not sufficient to maintain the normal composition of the blood, which remains supersaturated with carbonic acid; hence the occipital headache, the nausea, an irresistible drowsiness, and a still greater drop in temperature, from which travellers and guides usually suffer above 4000 to 4500 meters. (P. 35.)

And he concludes by saying:

The symptoms known by the name of mountain sickness are due chiefly to the great chilling of the body, and perhaps also to a corruption of the blood by carbonic acid. (P. 37.)

M. Lortet was accompanied on his ascent by an English physician, Dr. W. Marcet, ${ }^{1 * 4}$ who made the same experiments, and gave an account of them in a special work.

The observations were made with a thermometer placed in the mouth, without pausing in the ascent, because:

The pause in the progress upward, however short its duration, was nevertheless enough to permit the body to produce heat momentarily to replace that which had been expended during the act of ascent.

The results which M. W. Marcet reached are identical with those of M. Lortet:

1. The temperature of the human body in a state of rest does not seem usually to be less at great heights than at sea level.

2. The temperature of the body invariably tends to drop during the act of ascent. The amount of this drop depends almost exclusively upon the time of the last meal. This drop is due to the muscular movements and not to the effect of rarified air .... A rapid ascent of only 328 meters was enough to cause a drop of $1.4^{\circ}$.

3. The general discomfort, particularly the nausea, often experienced at great elevations, is accompanied by a considerable drop in body temperature. It is the result of the fact that the body has become unable, because of the physiological circumstances in which it is placed, to replace the heat which it has expended during the act of ascent. 
And so, according to M. Lortet and M. Marcet, who expresses himself even more definitely than his travelling companion, there is a considerable drop in body temperature, and this drop is due "not to an effect of the rarified air", but to the muscular movement, to the transformation of heat into work.

But these physiologists found in M. Forel an adversary worthy of them.

The excellent work of the professor of Lausanne is divided into three parts published, one in 1871, the last two in 1874. It was undertaken first as a criticism of the memoirs of MM. Marcet and Lortet. M. Forel ${ }^{125}$ begins with very just criticisms of the use of the buccal thermometer, as an indicator of the real temperature of the body. I copy here his observations, to the complete accuracy of which I can testify in many circumstances:

First, it is very difficult to keep the lips hermetically closed for a sufficient timè, and only after a rather large number of attempts and experiments could I become completely enough accustomed to it so that I could be sure that not even one bubble of air was admitted during the experiment. What is difficult in a state of repose becomes unendurable while one is climbing, when one begins to pant, when all the openings together are not enough to admit a sufficient quantity of air into our lungs, especially when the rarefaction of the air demands imperiously a larger volume than we need on the plain so that our system may be supplied with enough oxygen; then it is regular torture to close for ten minutes the mouths which we should like to be able to enlarge, and the experiment becomes terribly painful.

Another difficulty is to keep the thermometer exactly under the tongue, and as much as possible always in the same place. The tongue is very flexible and fairly docile; it can, if need be, surround the bulb of the thermometer closely enough not to permit contact with the air of the mouth; but the thing is very difficult, as one can convince himself before a mirror, and what is difficult when one is at rest becomes almost impossible under the painful conditions of the experiment.

Now if any portion of the surface of the bulb is in contact with the air of the mouth, the results are greatly modified. In fact, the buccal cavity is not closed at the back, the opening of the palate permits a constant mixture of the air contained in the mouth and the air which circulates with violent impetuosity in the canal of the pharynx; even if there is no current of air in the buccal cavity properly socalled, this mixing necessarily takes place, and in proportions which are greater, as the current of air in the pharynx is more violent and the differences of temperature and humidity between the pharyngeal air and the buccal air are greater. In our conditions of experimentation on lofty mountains we are as unfavorably placed as possible from this point of view. The respiration is panting in a very dry and very cold air. The mixing of air must necessarily increase in amount with the altitude and with the muscular movements which accelerate the respiration. 
The cold air drawn into the mouth might perhaps be warmed quickly enough not to cause very considerable changes in temperature: but as this air is very dry, there is evaporation of a certain quantity of saliva, and therefore a chilling and a lowering of the temperature. (P. 12.)

Besides this quite general criticism, M. Forel rightly considers one of the statements of MM. Lortet and Marcet strange and inexplicable, unless we admit a serious mistake in the observation:

Both say, in fact, that they had to observe the temperature while walking, during the very act of ascent, for as soon as they stopped, or merely slackened the speed of their progress, the thermometer, relatively very low during the ascent, rose almost suddenly to the normal body temperature... .

Now the human body cannot grow warm so instantaneously. If the temperature is assumed to be $35^{\circ}$, if the body weighs 60 kilograms, 60 calories must be produced for the temperature to rise to $36^{\circ}$... Helmholtz estimates the production of heat of a man weighing 60 kilograms at 1.5 calories per minute; it would therefore take 40 minutes to produce the 60 calories .... which is very far from the instantaneousness described by Lortet and Marcet. (P. 15.)

The first part of M. Forel's work ends with conclusions from which I take the two following, which are the most important:

1. The act of ascent normally produces an increase in body temperature of some tenths of a degree;

I reserve my opinion in regard to the effect of ascent upon the heat production of the body in the condition known by the name of mountain sickness. (P. 28.) ${ }^{128}$

These conclusions appear again at the end of the second part, in which physicians and physiologists will read with the greatest interest experiments investigating very exactly the determination of the temperature in different parts of the body (hand, armpit, groin, mouth, auditory canal, urine, rectum).

The third part is subsequent to the publication in the Annals of the Natural Sciences of my Memoir, the results of which M. Forel approves. In it is an anecdote which is very interesting from the point of view of the theory which I have formulated, and the accuracy of which the present work will show, I hope, to those who are the hardest to convince; I shall relate it in the third part of this work.

Finally, M. Forel ends with a detailed account of an ascent of Monte Rosa in which he experienced mountain sickness, although only slightly. On this occasion he makes this remark,-which explains both certain exaggerations and certain doubts-namely, that attention given to observation of the symptoms one feels dispels 
mental depression and lessens fatigue. This is true of danger as well as of scientific interest; no one suffers from mountain sickness on dangerous passes.

On this ascent, M. Forel noted that his temperature was always increased by walking, even above 4000 meters; he himself is surprised at that, considering the very pronounced state of anoxemia in which he must have been. But as he was not seriously affected, he merely states the fact, and, true to his prudent method, still reserves the case of ascent during an established state of mountain sickness.

These conclusions were corroborated by the researches of an English physiologist who did much research on variations in temperature of the body in health and in sickness.

Clifford-Allbutt ${ }^{127}$ made a series of ascents, one of them on Mont Blanc in very bad weather, to study the effects of walking and climbing on the temperature of the body. It was measured under the tongue during the act of walking, the maximum thermometer remaining in place for 15 or 20 minutes.

From his observations he draws the conclusion that muscular exercise tends to raise the temperature.

I copy one of his tables, the most interesting one, since it relates to the passage from the Grands-Mulets to Mont Blanc:

August 18, 1870.

$1: 30$ in the morning. At the Grands-Mulets, before rising _-_- $97.5^{\circ} \mathrm{F}$.

$3: 30$ in the morning. Ascent begun at 3 o'clock________ 97.7

5:00 in the morning. On the Grand-Plateau. Terrible weather 98.0

$7: 30$ in the morning. I began to descend at 7 o'clock ______ 98.5

8:30 in the morning. Arriving at the Grands-Mulets_______- 98.5

9:15 in the morning. At the hotel in Chamounix, in bed ____ 97.6

I should note, however, that the day before, when he reached the Grands-Mulets, his temperature suddenly dropped to $95.5^{\circ}$, and rose to $98.5^{\circ}$ after a 10 minute rest. August 20, at Chamounix, in bed, Allbutt's temperature was $95.4^{\circ}$.

Another English physiologist, C. Handfield Jones, ${ }^{128}$ attributed the sphygmographic records of $\mathrm{M}_{i}$. Lortet to exhaustion from fatigue.

The discussions between MM. Lortet and Forel again attracted the attention of physicians and physiologists to mountain sickness, especially in Switzerland. And so M. Dufour, ${ }^{129}$ in his turn, suggests in regard to this difficult subject a very noteworthy theory, which shows thorough acquaintance with the recent advances of science. 
In the session of the Diablerets section of the Swiss Alpine Club, on January 27, he expressed the idea

That the somewhat undefined unhealthy state called mountain sickness results from the absence in the blood of the ternary elements which are used in combustion. (P. 72.)

M. Dufour is especially struck by the contrast between travellers and aeronauts, since the latter are in good condition at elevations which the former cannot reach without serious symptoms:

If the mere rarefaction of the air were injurious to health, how much more seriously affected Glaisher and Coxwell should have been, who in 25 minutes rose from about sea level to the level of the summit of Mont Blanc!

Besides, when aeronauts finally experience pathological symptoms, these symptoms do not at all resemble those of mountain sickness. M. Glaisher gives a description which resembles a paralysis of sensitivity and movement extending regularly from the extremities to the center. Is this paralysis produced by a stoppage or a slackening of the circulation, or is it a direct effect upon innervation? We cannot tell. The fact that M. Coxwell's hands were blue for a moment seems to support the first hypothesis, whereas the fact that M. Glaisher lost the use of the retina, while his mental powers were still intact, would rather support the second.

At any rate, and this is the point which is important to us, the pathological symptoms come very late, and when they do come, they are not the symptoms of mountain sickness.

We are therefore led to consider muscular work as the principal factor in the production of mountain sickness, and if the rarefaction of the air makes some contribution to it, it is through the combustion which the work requires. (P. 76.)

M. Dufour thinks that inanition produced by work is the principal cause of mountain sickness. He says that he experienced the symptoms of it on the plain after great muscular efforts:

M. Dufour experienced several symptoms of mountain sickness, including nausea, when he was mounting from the bottom of the mines of Freiberg in a shaft and by vertical ladders. He had walked in the mine for about three hours, and had eaten nothing; the distress attacked him while he was ascending, and was still 50 or 60 meters below the surface of the ground. In covering this short vertical distance, he had to rest two or three times.

Likewise in an ascent of Pilate, after too rapid a walk from Hergiswyl, he was seized by extreme prostration, throbbing in the neck, headache, and dyspnea. At that moment, feeling mechanically in the pocket of his coat, he found a morsel of bread which he put into his mouth. After taking five minutes to get enough saliva to moisten his bread, he swallowed it. A few minutes afterwards, the symptoms of distress disappeared as if by magic, and he was able to ascend very easily the remaining 100 or 200 meters. (P. 76.) 
Then basing his conclusion on recent physiological data, he considered that the work of ascent uses up the reserve of ternary materials contained in the blood and the tissues, and results in the muscular exhaustion.

I shall quote this noteworthy passage verbatim:

It is probable that during the first hours of the ascent, the muscular work consumes the non-nitrogenous substances immediately available either in the muscular substance or in the blood.

What replacement can compensate for the effect of so great an expenditure? It can take place in only two ways: either the chyliferous vessels bring into the circulatory stream new elements supplied by the digestion, or the organism absorbs and draws again into the circulation the elements of the subcutaneous adipose tissue. This last point is so certain that working hard and eating little is a means of getting thin that is well known to everybody. The first of these replacements can be made quite quickly; the second, if we judge by the phenomena of absorption which we often witness, can take place only much more slowly.

It is probable that the absorption of the adipose tissue to be used as a combustible in the work of ascent is a phenomenon too slow to compensate satisfactorily for the expenditure caused by the work of someone ascending without stopping.

Therefore a moment must come whes, if the climber does not eat, the available combustible material keeps diminishing and can be only partly replaced by absorption. This effect will be produced most easily when after work of several hours the climber approaches a steep grade which he wishes to climb too quickly, so that there is a still greater disproportion between the work performed and the time used in performing it. (P. 77.)

Therefore, according to M. Dufour, it is very easy to explain:

a. The importance of rest, because during rest there is no expenditure whereas replacement continues.

b. The fact that after rest, the quantity of work easily performed is obviously proportional to the duration of the rest; for the same reason as above.

c. The fact that, to anyone who has mountain sickness, any new effort, such as stooping or using the arms, becomes painful. (See H.-B. de Saussure.)

d. The fact that mountain sickness seems to attack plump persons more than thin persons, because the former produce, on an equal ascent, a much larger number of kilogram-meters of work. The fact that they have in the adipose tissue a deposit of combustible material is without importance here, for very thin persons always have a sufficient adipose membrane to supply the work of ascent as it generally appears.

f. Finally, the fact that a means of avoiding mountain sickness is to eat often, that is, to furnish materials not by way of resorption, but by way of digestion and absorption. (P. 78.) 
Then he draws from his theory this logical conclusion:

We are therefore led to seek a combustible food easy to digest and absorb, to avoid mountain sickness.

M. Dufour thinks that sugar syrup or better, glucose syrup would fulfill these conditions. In fact, the fats, which are the best combustible material, require a certain time for digestion and may not be digested in time to satisfy an immediate need; the feculae must be transformed into sugar, glucose syrup then would be the food which would reach the circulation most easily. (P. 78.)

The discussion aroused by the important theory presented by M. Dufour brought a very interesting communication from IM. Javelle, ${ }^{130}$ president of the Diablerets section of the Swiss Alpine Club.

The narratives which it contains show, as we have already noted, that persons attacked by mountain sickness, even very seriously, often find that their illness disappears immediately when dangers appear or when a very intense application of mind becomes necessary.

They prove besides that these illnesses are much more frequent than is generally supposed, and make a satisfactory reply to certain skeptics who did not hesitate to jeer at what they call the exaggerations of M. de Saussure.

Let us note that M. Javelle has had great experience on high peaks, and that he has made nearly 200 ascents of 5000 to 15,000 feet, very often in the company of 10 to 20 young men:

Mountain sickness very frequently appears in the medium region of the Alps, between 5000 and 10,000 feet, that is, at an elevation where the air is sufficient for the needs of respiration, and where one can hardly consider intoxication from excess carbonic acid as an explanation for it. At 14,000 or 15,000 feet, the illness experienced by even the sturdiest mountaineers differs in several characteristics.

Mountain sickness affects particularly persons who are unaccustomed to the mountains, and especially those who lead a sedentary life. Those who are anemic rarely escape it. Novices who begin with a difficult ascent are very likely to pay tribute to it. (P. 136.)

This illness appears especially on soft snow, turf, slopes covered with landslides where walking is difficult, in small valleys and on long slopes, in general, everywhere that walking is both tiresome and monotonous.

It very rarely appears during the climbing of cliffs or on ridges, very rarely too on difficult or dangerous expeditions.

An interesting conversation or merely a careful observation of the landscape often wards it off.

M. Javelle has noted that young men who made the expeditions without interest or rivalry and merely to accompany their companions were most often affected by it. (P. 13.) 
The editor of the Bulletin summarizes the discussions which arose about the etiology of mountain sickness among the members of the Swiss Alpine Club in this odd sentence:

The principal factors are need of food, the intensity and rapidity of the work, and the mental characteristics. We cannot remove completely from the list of causes the rarefaction of the air and intoxication by carbonic acid. The question, which has a certain interest, therefore still offers some unknown quantities to be found. (P. 140.)

Moreover, the following passage, taken from the celebrated physicist and daring mountain climber Tyndall, also gives interesting information on this subject:

It is not a good idea to begin these ascents without having eaten and it is not good to eat heartily. One must eat a little here and there, as the need appears. But left to itself, the stomach inevitably falls ill, and the energy of the system is rapidly exhausted. If the illness brings on distaste for food, vomiting may ensue and the stomach be conquered. A little food is enough to restore it. The strongest guides and the sturdiest porters are sometimes reduced to this extremity. "Sie mussen sich zwingen". The guides attribute these caprices of the stomach to the great elevation of the air. Perhaps that is one of the causes, but I am inclined to think that something is likewise due to movement,--the continuous action of the muscles on the diaphragm. The conditions under which the journey is made and those which have preceded it also deserve much attention. One sleeps little or not at all; the morning meal is taken at an unusual hour; and if the start is to be made from a cave or a hut instead of a hotel bed, there is a serious aggravation of bad conditions. It cannot be the slight difference in height between Mont Blanc and Monte Rosa that makes the effects of their ascents so different. It is because, for the first, one makes his coffee of the melted snow of the Grands-Mulets, and has a bare plank for his bed; whereas for the other, he enjoys the inn of the Riffel, very comfortable in comparison. Milk and a crust of bread are all I need to sustain my strength and ward off mountain sickness. (P. 304.)

These very wise remarks have been made by many travellers. The degree of fatigue preceding the ascent is an element the importance of which is well known today. The same thing is true of the habit of walking and of living in the mountains. The following observations of M. Durier ${ }^{132}$ in this regard deserve our approval. We have told earlier how, by a strange coincidence, M. Durier and his companions, who suffered no ill effects from the decompression, ascended Mont Blanc just behind MM. Lortet and Marcet, whose symptoms we have given. M. Durier explains this difference in the following words:

In general, the physiologists who have studied the effects of mountain sickness upon themselves tear themselves from work in their labo- 
ratory and rush to Chamounix; on the first favorable day, they attempt the ascent. Well! I think that they are making their experiment under conditions which are not very scientific. The ascent of Mont Blanc is, after all, very difficult. It requires previous exercise and training. These scholars are likely to confuse the effects of unusual fatigue which finds their muscles unprepared, with those of a rarefied atmosphere. (P. 63.) .... .

It is under these conditions that MM. Marcet of Geneva and Lortet of Lyons made their ascent .... We were in the fourth week of a journey on foot, during which, without resting even one day, we had crossed some of the highest passes of the Alps. (P. 66.)

Finally M. Russell Killough, ${ }^{133}$ whose very astute replies to the skeptics who deny mountain sickness I have mentioned, is less fortunate in regard to theoretical explanations. He revives, without the slightest proof to support him, either from experiments or reasoning, the hypothesis of the injurious effect of snow:

I am ready to agree that altitude is not exclusively the cause of these sufferings. I think, and others have thought before me, that snow is an important factor in the question, because as soon as one touches terra firma, he is relieved. Have we not all observed that on glaciers the air has a metallic taste, like water from melted snow, that it seems polluted, as if the ice and snow poisoned it with their emanations? Why in the tropics, where one walks on grass at an altitude of 18,000 feet, are nausea and the desire to sleep, this sort of somnambulism, felt only at much greater heights than in Europe?

At any rate, whatever the cause may be, this peculiar sickness cannot be denied, and man cannot live at certain altitudes any more than in the depths of the ocean. (P. 244.)

If we pass from the Alps to the Himalayas, we see modern travellers giving us in their narratives testimony that even in our days the sicknesses of great elevations are attributed by the natives to the influence of plants which are supposed to poison the air frum a distance.

Mistress Hervey ${ }^{134}$ refers to it repeatedly:

These extraordinary attacks on passes of great altitude are attributed by the natives to what they call Bischk-Ke-Hawa (Bischk, poison; Hawa, wind) or poisoned wind. They believe that the wind becomes poisoned because it blows over certain plants of the group of mosses, which grow abundantly on the high mountains of Tartary, and are found where vegetation ceases. From the summit of Bara Lacha to Yunnumscutchoo, I saw thousands of them. They have very small yellow flowers, and are of different species. A more scientific explanation of this peculiar illness attributes it to the great rarity of the air at these extreme altitudes. (Vol. I, p. 133.)

We even see, in several parts of her narrative, and we have quoted some very strange ones in this connection, that she is not 
always very sure of the superiority of "the more scientific explanation".

Henderson ${ }^{135}$ also speaks of plants; only it is not a kind of moss, but an artemisia:

Before reaching camp, many of our followers complained of headache, and I found several of the Thibetan shepherds lying by the road, in a state of complete prostration. When I asked them what was the matter, they placed one hand on their foreheads, and with the other tore up a piece of a strong-smelling artemisia, making signs that this plant was the cause of their sufferings. On several of the passes, this artemisia has an extremely powerful odor, and all the baggage, the horses and the men coming from Yarkand are tainted with it. Even mutton has this odor.

Drew ${ }^{1: 6}$ does not limit himself to mentioning this prejudice and refuting it authoritatively, he looks at the question itself, and does not inquire why one is sick, which seems to him very simple, but how one can resist the dangerous effect of expanded air:

In the valleys of Rupsku, water boils at about $187^{\circ} \mathrm{F}$., which corresponds to a barometric elevation of 17.8 inches; so that the quantity of air-and oxygen-drawn into our lungs by an ordinary inspiration is only $7 / 12$ of the amount that enters at sea level. How do the Champas (tribes which occupy the high plains of Rupsku, to the southeast) compensate for this loss? I cannot tell exactly; I think, first, that there is less wear and tear on the tissues in their bodies than in the tribes which live in lower and warmer regions; they take less muscular exercise than the peoples of the surrounding lands; it is true that they are good walkers, but they think little of this quality and do not wish to carry burdens. Watching over flocks is not an occupation which causes the muscles to act vigorously. But that cannot explain everything; there must be some compensating habit which makes them capable of absorbing a large volume of this rarified air; probably, without realizing it, they breathe more deeply.

In us, this oxygen compensation tends to take place by a simple and direct means. Respiration becomes more rapid and more deep; there is an effort to increase both the number of inspirations and the capacity of each of them. The intensity of this effect increases every time one mounts a little when one is already above the level where ordinary respiration is sufficient. (P. 290.)

The natives commonly attribute these harmful effects of rarified air to plants which, in their opinion, have the power of poisoning the air. Some of the plants which grow at high altitudes exhale an odor when they are crushed, and it is to them that the discomforts are attributed. The onion, so much abused, which grows wild at great heights, is often blamed. But an easy reply to this error is that the effects are most marked at elevations where these plants, and all other vegetation have disappeared. (P. 292.) 
These ideas are far more definite and certain than those of Captain Burton ${ }^{137}$ about the origin of mountain sickness:

Some tried to explain our immunity to mountain sickness or the puna on the Grand-Pic, by the existence of a wind blowing violently and steadily from the east, which brought to our lungs the quantity of oxygen necessary for their consumption. I think, however, that this sickness must be, like seasickness, a disorder of the liver or the stomach, often aggravated by stimulants and by violent and sudden exercise. (Vol. II, p. 121.)

The celebrated African traveller quotes seriously in this connection a passage from a work which I could not procure, which contains, I think, one of the most comical ideas ever expressed on this difficult subject:

According to Dr. J. Hunt (Acclimatisation of Man) Europeans cannot live long at a great elevation in the northern hemisphere; the natives of the south can .... "This difference between the north and the south hemisphere, he says, is caused by the difference of the attraction to the North Pole. In the northern hemisphere the ascent of a high mountain causes a rush of blood to the head; in the southern, it is attracted to the feet: and hence the cause of the discomforts experienced in the ascent of a mountain in the first hemisphere."

I shall end this long series of quotations by reporting almost entirely two very interesting accounts, which we owe to the pens of very distinguished physicians, and in which there is a discussion of the effects of altitudes insufficient to produce mountain sickness, but sufficient to cause physiological changes which have proved useful to therapeutics.

The first is by Dr. Jaccoud, ${ }^{138}$ and is devoted to the study, from the medical standpoint, of the spa of Saint Moritz, in the Upper Engadine.

The greatest variations of the barometer at the baths are included between 599 and 627 millimeters. The altitude of the village of Saint Moritz is 1855 meters above sea level. On the vast plateau of the Engadine the climate is much more clement than at corresponding elevations in the rest of Switzerland.

In the adult who is in good health, the first effects of altitude are shown by an increase of appetite noticeable the first day, which keeps equal with a proportional increase of digestive and assimilative power ....

The parallel superactivity of the digestive functions and of metabolism is shown, on the one hand, by the ease and speed of digestion, in spite of the increase of the ingesta; on the other hand, by changes in proportion between the adipose tissue and the muscular tissue. . The first decreases considerably as a result of a prolonged sojourn in the 
Upper Engadine, whereas the muscles gain a preponderant development shown by increase of strength and motor capacity ....

The decrease of the atmospheric pressure causes the acceleration of the heart beats; in myself, I noted an increase varying from 12 to 18 in the number of radial pulsations; moreover, the circulation in general is considerably modified, in that there is a strong flow of blood to the periphery; the cutaneous capillaries are turgescent, and the teguments take on a violet red color found in the upper mucous membranes, especially those of the mouth and tongue; if the sojourn continues for several weeks, the predominance of the peripheral circulation produces a deeper pigmentation of the skin; as this phenomenon is more marked in regions usually exposed to the action of the sun, one might think that this is merely a pigmentation by solar irradiation; but the same modification occurs on parts protected by clothing, and its real cause is thereby clearly demonstrated. In a few cases, rarer than one would suppose $a$ priori, instances of slight epistaxis also show the change in the distribution of the blood.

The constant rush of blood to the periphery keeps the viscera in a state of relative anemia, which, in proportion to its degree, is revealed only by favorable phenomena; the cerebro-spinal functions are more active and easy, the head is free and light, the locomotor power is increased, respiration is noticeably eased, although its mode is greatly changed, as we shall see in an instant. These organic changes awaken in the person who undergoes them the feeling of new strength, which he judges by comparison with his usual condition; he feels well and gay, he has a vim justified by the real increase of his capacity for physical work. (P. 31.)

The rarefaction of the air at the altitude of Saint Moritz produces in the respiratory function two changes which are the point of departure of important modifications. The frequency of the respiration is increased, the average number of my inspirations in Paris, at rest, is 15 per minute; it is 19 to 20 in the Engadine; while it is more frequent, the respiration is deeper, or rather, more ample; the reason is that in this rarified medium a greater capacity and inspiratory absorption are needed to maintain in the pulmonary apparatus the quantity of air necessary for the regular execution of the operations of hematosis and metabolism in a state of superactivity. The slight increase in the number of inspirations could not produce this result; it can come only from a greater pulmonary expansion, which puts to work certain regions of the lungs which I call lazy, because, under ordinary conditions, they take only a very slight part in the inspiratory expansion; these regions are the upper parts of the organs. But since the atmospheric pressure is lowered, this more complete participation of the lungs in the inspiratory act necessarily involves an increase in action of the muscular forces which control the expansion of the thorax; and this combination of subordinate conditions, all produced by the change in pressure of the respirable medium, results finally in systematic and constant gymnastics of the respiratory apparatus, which are kept up without fatigue at the maximum of functional activity.

And thus, by active intervention of the organs of respiration, there 
are produced effects analogous to those which they undergo passively under the influence of compressed air; in rarified air, the inspiratory absorption becomes complete by means of active use of muscular powers; in compressed air, the increased inspiratory absorption is the result of an increased pressure, to which the lungs, and the lungs alone, yield passively. This comparison, which seems to me interesting, sufficiently establishes the superiority of the first condition, in regard to the development and regular exercise of the pulmonary functions. (P. 34.)

And so increase in the number and amplitude of the respiratory movements, with the purpose of compensating for the oxygen deficit due to the decreased weight of the air, the acceleration of the heart beats, and the rush of blood to the periphery of the body are, in M. Jaccoud's opinion, the effects on the organism of a decompression of 15 to 16 centimeters.

Dr. Armieux, ${ }^{159}$ of whom I still have to speak, examined carefully the soldiers under his medical care at the thermal spa of Baréges (1270 meters).

He begins by calculating the decrease in the weight of the air sustained by a man's body at the elevation of Baréges; it is about 220 kilograms; "this decrease," he says, "is very perceptible; one is more agile and vigorous (p. 7)".

Finally, at Baréges, considering the density of the air, there is a deficit in the quantity of oxygen admitted to the lungs of 22.56 grams per hour and 541.44 grams per day.

But here is the really original part of the work of M. Armieux:

May 4, 1867, at Toulouse, I measured the chests of 90 hospital attendants, who were to be sent to Baréges. The chest circumference, taken horizontally at the level of the nipples, gave me an average of 871 millimeters, at rest, and 905 millimeters in the greatest amplitude obtained by a deep inspiration.

These men reached Baréges May 15, they did not take the thermal cure, and the subsequent observations showed only the effect of the hygienic medium.

June 27, that is, after 43 days of residence, their chests measured again gave averages of 888 millimeters in circumference at rest and 917 millimeters in the maximum expansion; the increase of circumference then was on the average, in the first case, 17 millimeters, in the second 12 millimeters.

September 17, after a sojourn of four months at Baréges, the same subjects, given a new measurement, furnished the following average results: 900 millimeters at rest and 930 millimeters in maximum expansion; there was a new average increase of 12 or 13 millimeters over the measurements of the month of June, and a total progressive increase, after four months, of 25 millimeters in expansion, and 32.9 millimeters at rest.

It is therefore indisputable that the chests of these soldiers in- 
creased in capacity, in four months, in a rather large proportion, as a result of their removal to a place the altitude of which is 1100 meters higher than that in which they had formerly lived....

To get a more direct proof, in 1868, we made an experiment which confirmed the former one, taking care to get the exact weight of the subjects so as to compare their total material gain with the increase in volume of the chest.

We also wished this time to keep an account of the changes made in the pulse rate and the respiratory movements by removal to high altitudes.

We subjected fourteen hospital attendants to a close observation, before their departure for Baréges and after thirty-five days of residence there.

The following table gives the details and the averages of our observations:

\begin{tabular}{|c|c|c|c|c|c|c|c|c|c|}
\hline \multirow[b]{2}{*}{ Age } & \multirow[b]{2}{*}{$\begin{array}{l}\text { Height } \\
\text { meters }\end{array}$} & \multicolumn{4}{|c|}{$\begin{array}{c}\text { Toulouse } \\
\text { May } 7,1868\end{array}$} & \multicolumn{4}{|c|}{$\begin{array}{c}\text { Baréges } \\
\text { June } 18,1868\end{array}$} \\
\hline & & $\begin{array}{l}\text { Weight } \\
\text { kilos }\end{array}$ & Chest & Pulse & enes. & $\begin{array}{l}\text { Weight } \\
\text { kilos }\end{array}$ & Chest & Pulse & Res. \\
\hline 22 & 1.620 & 62.100 & 91c. & 86 & 20 & 64.5 & 98 & 85 & 19 \\
\hline 23 & 1.590 & 62 & 86 & 76 & 16 & 61 & 87 & 80 & 20 \\
\hline 19 & 1.567 & 56 & 80 & 70 & 17 & 57 & 82 & 64 & 20 \\
\hline 23 & 1.620 & 63.100 & 85 & 80 & 18 & 65 & 88 & 70 & 22 \\
\hline 31 & 1.650 & 63 & 88 & 74 & 17 & 64 & 90 & 68 & 20 \\
\hline 19 & 1.615 & 52 & 76 & 72 & 18 & 56.5 & 81 & 75 & 21 \\
\hline 23 & 1.6 & 64 & 86 & 80 & 20 & 67 & 89 & 70 & 22 \\
\hline 23 & 1.630 & 60 & 89 & 82 & 21 & 61 & 89 & 80 & 22 \\
\hline 23 & 1.610 & 59.9 & 86 & 90 & 18 & 60 & 86 & 88 & 22 \\
\hline 24 & 1. & 60 & 84 & 75 & 20 & 59.5 & 88 & 65 & 20 \\
\hline 20 & 1.610 & 57 & 85 & 74 & 18 & 58 & 86 & 70 & 19 \\
\hline 49 & 1.640 & 59.5 & 81 & 72 & 19 & 59.7 & 83 & 68 & 20 \\
\hline 23 & 1.585 & 64 & 90 & 80 & 18 & 66.5 & 91 & 80 & 20 \\
\hline 36 & 1.610 & 59 & 86 & 80 & 21 & 60 & 89 & 74 & 23 \\
\hline \multicolumn{2}{|c|}{ Totals } & 841.6 & 1191 & 1091 & 261 & 859 & 1227 & 1037 & 290 \\
\hline \multirow{2}{*}{\multicolumn{2}{|c|}{$\begin{array}{l}\text { Average } \\
\text { Av, at Baréges }\end{array}$}} & 60.114 & 85.70 & 77.92 & 18.64 & 61.4 & 87.64 & 74.07 & 20.70 \\
\hline & & 61.400 & 87.64 & 74.07 & 20.70 & & & & \\
\hline \multicolumn{2}{|c|}{$\begin{array}{l}\text { Av. at Baréges } \\
\text { Av. at Toulouse }\end{array}$} & 60.114 & 85.70 & 77.92 & 18.64 & & & & \\
\hline \multicolumn{2}{|c|}{ Inc. at Baréges } & 1.286 & 1.94 & - & 2.06 & & & & \\
\hline \multicolumn{2}{|c|}{ Dec. at Baréges } & - & - & 3.85 & - & & & & \\
\hline
\end{tabular}

We see by this table that the increase in weight is, on the average, 1 kilogram and 286 grams, varying from 1 to 4 kilograms in 12 of these soldiers, and showing a slight decrease in two of them, whereas the increase in the volume of the chest is, on the average, nearly two centimeters, which is relatively greater; this increase went as high as 7 centimeters in the first subject; finally, it is general and exists even in those who lost weight, which is decisive. 
For the sake of completeness, I copy here a passage which concerns the composition of the gases of the blood, although it contains unexplainable mistakes, and although I understand neither its purpose nor its results; but it is interesting to show by a very recent example how many unknown quantities and obscurities these questions contain, even in the minds of the most learned physicians:

Besides the phenomena which we have just reported, there are produced as a result of the decrease of atmospheric pressure an expansion and a greater tension of the gases contained in the blood vessels. The venous blood contains per liter:

Oxygen
Nitrogen 11 cubic centimeters
Carbonic acid 15 cubic centimeters
Total $\quad 51$ cubic centimeters

The arterial blood contains per liter:

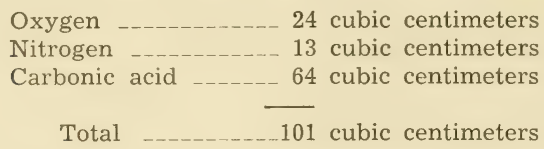

For M. Schoeuffele who studied the question at Baréges, these figures become at the pressure of 65 centimeters: 94.780 for the venous blood and 119.640 for the arterial blood; the increase in volume of the intra-vascular gas would therefore be on the average $11.25 \%$ at the altitude of Baréges.

M. Armieux ends his work with the following conclusions:

The experiments which I have just reported show that persons who go to Baréges experience, as effects of the altitude:

1. A considerable increase of the thoracic capacity to compensate for the oxygen deficit;

2. An increase in weight, which shows greater metabolic activity;

3. An increase of respiratory movements;

4. A decrease in the pulse rate;

5. A lack of correlation between the two relations of the respiration and the circulation;

6. An expansion of the gases contained physiologically in the blood vessels, as a result of decreased atmospheric pressure;

7. A greater tendency toward diaphoresis for the same reason.

This considerable increase of the thoracic capacity, observed by M. Armieux in soldiers subjected continuously to the influence of low barometric pressure recalls what was said long before by 
d'Orbigny, ${ }^{1+0}$ in speaking of a Peruviain tribe, the Quichuas, who live in the lofty regions of the Cordillera:

Their bodies are more bulky in the Quichuas than in the other nations of the mountains; we can describe them as characteristic. The Quichuas have very broad and square shoulders, their chests are extremely capacious, very bulging, and longer than usual, which makes the trunk larger; the normal ratio of respective length of the trunk with the extremities does not seem to be the same in the Quichuas as in our European races, and differs equally from that of the other American branches. (Vol. I, p. 226.)

And the celebrated traveller, struck at the same time by this thoracic amplitude, the habitat of this tribe, and its immunity to the soroche, tries to determine the anatomical fact and to connect it theoretically with the conditions of life of these Indians.

Let us return to the causes which produce in the Quichuas the great volume we have observed: many researches have made us attribute it to the influence of the lofty regions in which they live and to the modifications resulting from the extreme expansion of the air. The plateaux on which they dwell are always included between the limits of 7500 to 15,000 feet, or from 2500 to 5000 meters above sea level; the air there is so rarified that a greater quantity is required than at sea level for man to find the elements of life in it. Since the lungs need, because of the great volume necessary and their greater expansion during the inspiration, a larger cavity than in the lowlands, from infancy and during the whole period of growth, this cavity receives a great development, quite independent of that of the other parts.

We wished to ascertain whether, as we should have assumed a priori, the lungs themselves had not undergone considerable modifications, as a result of their greater tension. Living in the city of La Paz, which is 3717 meters above sea level, and learning that at the hospital there were always Indians from very populous plateaux of still greater elevation (3900 to 4400 meters), we took advantage of the kindness of our compatriot M. Bernier, physician of this hospital; we asked him to permit us to make the autopsy of the cadavers of some of these Indians of the higher regions, and, as we expected, we found with him that the lungs had extraordinary dimensions, as the outer form of the chest indicated. (M. Burnier showed us, besides, that the lungs seemed to be divided into cells much more numerous than usual. Since this fact seemed to us strange and hard to believe, we asked M. Burnier to repeat these observations on a larger number of subjects; and when, after a few years, we saw this well informed physician again, he confirmed it once more completely.) We noted that the cells are larger than those of the lungs which we had dissected in France; a condition which was necessary to increase the surface in contact with the ambient atmosphere. In summary, we discavered: 1 . that the cells are more expanded; 2 . that their expansion increases considerably the volume of the lungs; 3 . that conse- 
quently the lungs need a larger cavity to contain them; 4. that therefore the chest has a greater capacity than in the normal condition; 5. that this great development of the chest lengthens the trunk a little beyond the ordinary proportions, almost out of harmony with the length of the extremities, which have remained as they would have been, if the chest had retained its natural dimensions. (Vol. I, p. 267.)

Thse anatomical observations are so interesting that the Society of Anthropology discussed them among the Ethnological and Medical Questions Relating to Peru, and suggested in 1861 that travellers verify them.

In a scholarly report, M. Gosse senior, ${ }^{141}$ states that "up to the present, the assertions of d'Orbigny have not been verified by any traveller" (p. 107). He even mentions a fact which would seem to prove that this is a racial characteristic independent of the environment, since:

The descendants of the mountaineers settled in a colony by the Incas on the seashore near Cobija would have retained up to the present, as an effect of heredity, the special physical constitution, said to have been acquired in the atmosphere of the lofty plateaux. (P. 108.)

The same. year, M. Jourdanet, ${ }^{142}$ speaking of the Indians of Mexico, said:

The Indian, whom we may consider as positively acclimated, has a chest the amplitude of which exceeds the proportions which we should expect from his short stature. And so he performs work which might well surprise us in any country . . . . His vast chest makes him comfortable in the midst of this thin air. (P. 98.)

On this point also he was contradicted by Coindet. ${ }^{143}$ According to this observer, for a series of Frenchmen whose average height was 1.678 meters, the thoracic circumference on the level of the nipples was 92.450 centimeters, whereas in the Mexicans, in an average height of 1.620 meters, it fell to 89.048 centimeters. But the English traveller Forbes confirmed the observations of d'Orbigny and M. Jourdanet:

M. D. Forbes, says M. Darwin, ${ }^{1+4}$ who carefully measured a great number of Aymaras, living at an altitude included between 10,000 and 15,000 feet, told me that they differ very greatly from the men of all other races he has seen in the circumference and the length of their bodies.

Finally, in his last book, M. Jourdanet ${ }^{145}$ gives specific data, saying:

I have the abstract of a great number of observations which do not admit the least doubt. They justify me in stating that with an average height of 160 to 165 centimeters, the Indians of Anahuac have 
a sternum $227 \mathrm{~mm}$. long, with a thoracic circumference of $895 \mathrm{~mm}$, measured immediately above the nipples.

On the other hand, my researches permit me to state in a general way that to find the same chest dimensions in the Creoles, the height had to increase from 168 to 173 centimeters. (Vol. I, p. 317.)

So the point is really not so much an unusually large thoracic capacity as a shorter height, or, to speak more exactly, lower limbs which are shorter in proportion to the height of the trunk.

But let us return to the inquiries of Dr. Gosse.

M. Gosse follows his shrewd observations on this interesting point by a questionnaire on mountain sickness, which I think it best to quote here verbatim:

The study of the influence exerted by the rarefied air of high altitudes in the Peruvian Andes upon the physiological constitution of their inhabitants naturally leads us to the study of symptoms produced by this cause in persons foreign to the plateaux, who are exposed to it imprudently or too suddenly, and of the measures which are used to combat the symptoms or at least to moderate their effects.

If the symptoms observed in our European Alps, to which the name of mountain sickness has been given, are limited in general to extreme breathlessness, accompanied by headache, throbbing of the carotids, palpitations, nausea, disturbance of the digestive functions, great lassitude and sometimes syncope, the symptoms appearing in the Andes of Peru, known by the names of soroche, mareo, or veta, reached such violence, they say, that they deserve the attention of physicians who are explorers, all the more because sufficient analysis has not yet been made, in this connection, of the mechanism of the action, usually combined, of the decrease of the oxygen in the air and of the atmospheric pressure, of the eventual drop in temperature caused by easier radiation of heat, of the absence of humidity, and especially of the unnatural strain on the muscles, and because, as explanation of the anomalies, there has been a tendency to suspect the existence in Peru of special unknown causes, which would not be found elsewhere.

Observations carefully made and new records thoroughly verified would end doubts and reconcile opinions. With this purpose we are propounding the following questions:

1. What are the characteristic symptoms of the soroche of the Peruvian Andes, with reference to the nervous, circulatory, pulmonary, or muscular systems?

2. What is the normal sequence of these symptoms, in the commonest cases, and which are the predominating ones?

3. Are there premonitory symptoms of the acute attack, and what are they?

4. Is a tendency to nasal, labial, pulmonary, ocular, cutaneous, etc., hemorrhages noted frequently at very great elevations?

5. Are a congested condition of the cornea and erythema of the face observed, in the absence of reflected light from the snow?

6. Does the skin take on a livid or cyanosed shade at an eleva- 
tion which cannot be less than 3800 meters, but which, in the latitude of Peru, must be the line of perpetual snow? If this phenomenon appears, is it only temporary during the ascent, or does it persist after the summit has been reached?

7. When the dwellers on the heights descend to the plains and toward sea level, do they experience a disturbance in their functions, and of what does this disturbance consist?

8. Is a mental disturbance corresponding to the physical disturbance, or discouragement, or irritability of temper often observed?

9. Are the symptoms of the soroche the same on the eastern and western slopes of the Andes, whatever the exposure of the places where they are observed?

10. Do they occur only at the line of eternal snow, as certain authors maintain, or do the Peruvian and Bolivian Andes furnish verified exceptions to this rule?

11. Do strangers to the plateaux of the Andes experience the soroche when they reach high elevations on the Cordillera on horseback? And when they feel the attacks, did muscular efforts usually precede the disturbance of the organs of circulation and respiration?

12. Do the effects of the soroche differ with age and sex?

13. Do they vary with idiosyncrasies, and what are the idiosyncrasies which predispose to it or retard it?

14. What is the effect exerted upon its production or its symptoms by the seasons, the prevailing winds, or storms?

15. What is the effect of the cold in the places where the soroche appears? Specify the average temperature of these places and the absolute temperature at the time the symptoms appeared.

16. What is the effect of dryness or humidity?

17. Is it proved that the absolute altitude in the atmosphere is not enough to explain certain local anomalies? And if this is an actual fact, seek out the probable causes of these anomalies, either in the atmospheric conditions of the time or the locality, or in the telluric conditions, especially in the nature of emanations which may rise from the ground. Study in this connection the conformation of these localities which might favor the continued presence of water and atmospheric humidity, their nearness to ore-bearing regions, which might exhale mineral, harmful, arsenical, or other vapors. Do not neglect occasional conditions in which individuals may be placed.

18. Does the acclimatization of strangers in relation to the soroche take place more or less quickly, and what are the conditions which favor or delay it? Does this acclimatization have a lasting or merely temporary effect? Do the negroes have more difficulty in becoming acclimatized than the whites? And if the opportunity offers, it would be interesting to make a series of experiments to ascertain the normal pulse rate of the inhabitants of the plateaux, Indians, negroes, and whites; taking care to repeat them on a great number of healthy persons of both sexes, adults of verified age, and to make these experiments at rest, standing and lying down, at a certain distance from mealtime, and to note the outer temperature of the season, hot or cold.

19. If the symptoms of the soroche appear in animals, what are their characteristics in the different animals and what are the condi- 
tions which give rise to them? Especially what are the causes which give rise to the disease of mules known by the name of trembladera? Are the domestic llamas and those used as beasts of burden equally subject to this disease?

20. Is the mortality of certain animals (cats, for example), caused by their sojourn in very lofty places, an established fact or not? And if the fact is established, what are the symptoms which precede death, and what are the probable causes of this mortaltiy?

21. Are there means of awarding off the soroche, and if there are, what are they? Has anyone tried, for example, in Peru, as in Styria and the Tyrol, the ingestion of small doses of arsenic to prevent the fatigue of the ascent of mountains? Study particularly in this connection the effects of the plant known as cuca or coca, either chewed or taken in an infusion, which they say has a remarkable prophylactic power.

22. What are the means employed with the greatest success in checking or lessening the symptoms produced by the soroche, either in man or in the animals? (P. 113-117.)

As I said at the beginning of this first part of my work, I shall not discuss in this historical section any researches which rely upon the results of my own investigations or which oppose my conclusions. My discussion of them will naturally take place in the third part.

And for this reason I shall say nothing of the book recently published by $\mathrm{M}$. Jourdanet, ${ }^{146}$ in which he repeats, develops, and supports by new proofs taken from the study of altitudes over the whole earth the opinions suggested to him by observation of the diseases of Upper Mexico. I shall borrow from this immense, work only the account of an important experiment in which appears the first attempt made to study chemically the degree of the anoxemia:

I decided to devote myself to this work of analysis about the end of 1864. I found assistance-very worthy of special mention in this book-in the laboratory and the cooperation of M. Romuald Zamora, a Spanish gentleman, who studied the sciences in his hours of leisure. I analyzed the blood of three rabbits by means of carbonic oxide, following the specifications given by $\mathrm{M}$. Claude Bernard. I found an average of oxygen which was very low, but not enough to justify one in feeling authorized to make really legitimate general conclusions. I also felt hesitant because of a consideration which I thought exceedingly important; namely, that one could always ask himself whether these same animals would not have given this same quantity of oxygen at lower levels. In fact, differences in amount found in my previous analyses of blood prove that the proportion of this gas is an individual peculiarity, at least within certain limits. It seemed to me after that, that this interesting point cannot be indisputably decided without a double analysis of the blood of the same animal, drawn first at normal 
pressure, and second, at a more or less pronounced decompression. Therefore I again put off till a better time the realization of my wishes. (Vol. I, p. 181.)

These wishes I had the good fortune to realize, thanks to the generous assistance of my learned colleague. And we shall see that I succeeded in proving how closely his anticipations agreed with the truth. But for this demonstration, I refer the reader to the second part of my book.

In the third part he will find the detailed history of the latest aeronautic ascensions to great heights, and particularly of the one which had so fatal an end. We shall then specify definitely the causes of this disaster and draw from it the lessons it contains. Limiting ourselves to the subject of the present chapter, we shall say that the interpretations, given by the different scientific journals and others, of the causes of the death of Sivel and CrocéSpinelli are merely those whose discussion fills the preceding pages. There is nothing new in them which deserves to be noted here, and all these ideas had already been given by authorities of greater weight.

We shall except only the short discussion which arose on this subject within the Academy of Medicine. We see that, in the opinion of MM. Woillez, Mialhe, and Colin, the diminution of the weight sustained by the body again plays the principal part; in spite of the elementary principles of physics of which M. GiraudTeulon, M. Gavarret and many others have already reminded them, they still harp on the theory of the universal cupping-glass. But M. Colin adds to that a hypothesis which alone would deserve the honor of repetition, for it had been only very briefly suggested by a few former authors, and M. Maissiat did not go so far as to give it such importance. In his opinion, the escape of gases into the intestine and the expansion of these gases by the decrease in pressure played the chief part in the fatal ending. Here is the passage in full:

M. Larrey: The ingenious experiments of M. Woillez and the new researches he has made on the spiroscope would no doubt lead him to the physiological study of respiratory phenomena at different altitudes, and then to the hygienic prophylaxis of the violent disturbances of this important function, under other influences. We should also decide upon therapeutic measures, when asphyxia, for example, is imminent and causes complex symptoms which rapidly become fatal, through sudden rarefaction of the air or through the progressive diminution of the air pressure. Finally, it would be desirable to determine and check the measures by which artificial respiration could 
be established, for instance in the diving bell, comparable, in this respect, to the basket of the aerostat.

The fatal disaster which has just startled the world of science and the two victims of which were buried this very day urges me to make this suggestion to the Academy, even if it is only a digression useful, perhaps, to the interesting communication of M. Woillez.

M. Woillez: I cannot give an opinion here on so important a matter; but it seems to me that it is not only a question of respiration; we must particularly take into consideration the decrease in the atmospheric pressure for which the oxygen they had taken along could give no help.

M. Colin: Since the question of the balloon has been brought up, I should like to give my opinion of the causes of the death of the aeronauts. Certainly these causes are multiple, especially those connected with the decrease of pressure; some are already indicated by the conditions in which the aeronauts were.

Two had lunched and they are dead; the other was fasting and he survived. The escape of gases into the digestive tract of the first two might have played a great part in the progress of asphyxia. We know that this escape is very great in ruminants following the eating of green fodder, and that it may, at ordinary pressure, produce sudden death by asphyxia by immobilizing the diaphragm. No doubt this escape is more limited in man: but it increases as a result of illness and indigestion, and then, since the expansion of the gases increases as the pressure decreases, the diaphragm is soon vigorously crowded upward; its movements become very limited and finally become impossible. We know that at a certain moment, when the traveller is climbing high mountains, he is seized by lassitude, his arms and legs are worn out; the muscles, irrigated by a blood which is imperfectly oxygenated, lose their energy. The diaphragm shares in this fatigue, and finally becomes inert, especially if it is crowded back by the expansion of the gases of the stomach.

I know very well that aeronauts need to fortify themselves against becoming chilled, and that fasting does not warm them, but they can arrange their meals in such a way as to complete digestion before starting, and replace fermentable food by respiratory food, by liquids which stimulate and develop heat.

Observations made on the victims and the survivor show clearly the chief cause of the symptoms. This cause is not, whatever M. Bert may say, the lack of oxygen, for in the experiments the animals do not die with the proportion of this gas which may be in the air at 7000 or 8000 meters. It is the decrease of pressure, as M. Woillez has just said, which produces the serious symptoms, the hemorrhages in the respiratory passages, the circulatory disturbances, etc.

M. Blot: M. Colin's last words seem to me to contradict what he said at the beginning. So he explains death first by the compression of the diaphragm and the lungs under the influence of the expansion of the intestinal gases, and finally attributes it to the decrease in pressure.

As to the comparison between the herbivores and man, it seems to me very debatable. 
M. Colin: I am surprised that M. Blot sees the slightest contradiction in my words. I said that the symptoms and death in ascensions are due to several causes, among others the compression of the diaphragm by the gases of the digestive tract and the decrease of pressure on the tissues and the vessels resulting in pulmonary, nasal, and other hemorrhages. Each of these causes has a part in the effect; far from excluding each other, they are linked together.

M. Mialhe: I agree with M. Woillez that the decrease of the atmospheric pressure was the principal cause of death, but I cannot accept the idea of M. Colin that one should not eat before making a balloon ascension. Man is not a ruminant, and things do not go on within him just as they do in the herbivores.

M. Colin: What! Does man then have privileges in regard to digestion? Does the stomach function otherwise in the abdomen of man than in the abdomen of an animal? The dog which has eaten meat and bread has in his stomach much gas which one can measure by ligating the aesophagus and the pylorus. Why would not these same foods also produce gases in the stomach of man? Have not the digestive process and the fermentations uniform characteristics in species so closely related?

I shall express myself later upon this question of the intestinal gases; but now, seeing the importance which M. Colin seems to attribute to it, I cannot refrain from one remark: the desire of contradicting must be a very strong passion in some persons, since it has led a physiologist of this rank to say such strange things.

The last document which I shall submit to my readers is perhaps still stranger. If there are some among them, as I fear, who think that, in giving the history of mountain sickness, I have displayed an excessive wealth of quotations and descriptions, they will, no doubt, pardon me for this imposition when they consider that in 1875, before the Geographical Society, before the Academy of Sciences itself, the very existence of mountain sickness was denied, a denial which depends upon the strangest of methods, or rather which is the very absence of scientific method, because it takes into account only the circumstances in which the travellers felt no symptoms during their ascents.

The first communication from M. Virlet d'Aoust on this subject is dated May 19, 1875. The official Proceedings i48 of the Geographical Society narrates it in the following words:

M. Virlet d'Aoust, on the occasion of the recent disaster of the Zenith, made a communication about the effects of the rarefaction of the air in the region of lofty mountains. In an ascent of Popocatepetl, at an altitude of 4500 meters, he felt no other discomfort than a fatigue more pronounced than on the plains. There are numerous examples in the Andes of inhabited places at an altitude of 2000 and 3000 meters. Mexico City is at an elevation of 2300 meters. 
A discussion took place in regard to the influence of atmospheric pressure on human life.

MM. Antoine d'Abbadie, Maunoir, de Charencey, and de Puydt took part in it. The last mentioned for two years travelled through the valleys of the Andes, in Ecuador and Bolivia, living at altitudes of 4800 meters, always keeping his health and vigor. M. l'abbé Durand confirmed this statement, according to M. Stuebel, who made an ascent of Chimborazo two years ago. (P. 552.)

We can see by the account of Stuebel's ascent which we have given into what an exaggeration M. l'abbé Durand has fallen. But without discussing this for the moment, it is interesting to reproduce at greater length the arguments presented by M. Virlet d'Aoust and his learned colleagues, according to an authorized journal, the Explorateur: ${ }^{149}$

M. Virlet d'Aoust, on the occasion of the lamentable disaster to the Zenith, which cost the lives of two young scientists, MM. CrocéSpinelli and Sivel, recalled the circumstances of his ascent of Popocatepetl, in April 1853, with the purpose of emphasizing the considerable differences which exist between ascents of mountains and vertical balloon ascensions in the atmosphere.

When one rises in the air by means of a balloon, says M. Virlet d'Aoust, he finds himself successively plunged in layers of air, if not of different compositions, at least of different densities, in which, however, the carbonic acid must diminish in proportion because of its greater specific weight. This kind of ascension, moreover, is made too rapidly for the organs of human life to have time to undergo sufficient changes to make the successive differences in atmospheric pressure endurable.

When one scales a mountain on foot, the layers of air have exactly the same composition as on the plain, for these layers, though becoming thinner, rise in currents from below up to the highest summits. The result is that any experiment which has for its sole purpose the determination of differences in the composition of the air at different heights should be carried out vertically in a balloon and not in a mountain ascent.

The ascent of Popocatepetl (the smoking mountain) by M. Virlet d'Aoust involved numerous companions, and was, so to speak, an international expedition. The United States, England, Mexico, Germany, Belgium, Switzerland, Italy, and France were represented.

Although the plain and the city of Mexico have an elevation of about 2300 meters above sea level, life there is very comfortable; public health is perfect and free from any endemic disease. The travellers halted at the foot of the cone at an elevation of more than 4000 meters; they had reached this spot on horseback without the least inconvenience and without feeling the slightest effect of the rarefaction of the air. The difficult part was the ascent of the cone, a regular sugar loaf, which had to be climbed on foot. That requires four hours of very difficult walking, although the descent is made in less than a half-hour. Neither M. Virlet d'Aoust nor his companions experienced 
any discomfort except that resulting from a somewhat accelerated respiration, and a little more heaviness in the limbs ....

From these experiments M. Virlet d'Aoust has drawn the conclusion that the so-called mountain sickness is merely great fatigue resulting principally from heaviness due to the decrease of the layer of air which surrounds the traveller and which supports him in the lower regions ....

M. d'Abbadie asked the author whether a distress manifested by dizziness and vomiting did not appear on lofty peaks. M. Virlet d'Aoust stated that he felt nothing of the sort nor did his travelling companions. M. de Puydt said that he had crossed the highest peaks of the Andes, from the equator to the sixth degree, north latitude; that he had reached altitudes of 4800 meters and that he had never felt any of these fatigues; and yet he had travelled more than 450 leagues in the Andes. M. l'abbe Durand supported this opinion, recalling the official ascent of the great volcanoes ordered by the government of Ecuador. Finally, M. Maunoir said that the effect of ascents, even in the mountains, must vary with the health conditions and the constitution of the traveller. (P. 401.)

M. Virlet d'Aoust ${ }^{150}$ returned to this subject in the session of July 7 ; he still followed the same strange method:

M. Virlet d'Aoust, resuming the subject studied in a former session, that is, the effect of the rarefaction of the air in the higher regions of the atmosphere, reported an ascent of the volcano of Arequipa or Misti, the altitude of which is 5650 meters, during which the travellers were not at all inconvenienced (Reference to the Bulletin). (P. 107.)

\section{The Explorateur of July 15, 1875, is much more explicit: ${ }^{171}$}

Mountain sickness. In support of what he had previously said, on the occasion of his ascents of Popocatepetl and Ixtaccihuatl, in reference to the so-called mountain sickness, M. Virlet d'Aoust reported another ascent, that of the volcano Misti, more often designated by the name of the volcano of Arequipa, in Peru, which led to the same conclusions. Dr. J. T. Coates, of the United States, who made the ascent, left Arequipa September 22, and camped for the night at the foot of the mountain, situated 30 miles northeast of this city. The next day very early, accompanied by three guides and furnished with two aneroid barometers, he undertook the ascent. The little caravan could travel on horseback at first; but after an hour, since the grade became too steep and the difficulties kept increasing as they advanced, they had to continue on foot.

After ten hours of difficult walking, at half-past six in the evening, they finally reached the summit of the volcano, without having experienced hemorrhages, or difficulties in breathing, or nausea, or headaches, or any other of those painful sensations which, it is claimed, should be felt by persons who venture in the mountains to altitudes of more than 3000 meters ....

Finally, M. Virlet d'Aoust thought he should mention another still 
higher ascent which might have taken place in New Guinea. Several journals announced recently that the Englishman, Captain Lawson, had discovered in this huge isle of the ocean a mountain called Mount Hercules, which has an altitude of 10,929 meters above sea level, that is, 1262 meters more than Mount Everest, in the Himalayan chain, hitherto considered the highest point of the whole world. The Explorateur has suggested that the welcome to this alleged discovery should be given with certain reservations. At any rate, according to his story, when Captain Lawson attempted the ascent of Mount Hercules, he could ascend only to the height of 8435 meters, that is, an altitude almost equal to that reached by the balloon Zenith in its last and fatal ascension; but at this height, blood issued from his eyes and ears, and he nearly died as a result of the rarefaction of the air. This statement, like the discovery of a mountain claimed to be the highest in the world and yet so late in recognition, requires confirmation. (P. 65.)

Nothing has confirmed this last account, which no one, unless he is exceedingly credulous, could believe. But I will not continue; the following chapter will contain the critical discussions.

1 Loc, cit., Chap IX,-Sevilla, 1590.

Novum organum, Book II, 11. Translation by Lorquet, p. 85.

3 Rclation de divers phénomènes arrizés dans le vuide, ${ }_{a}^{a}$ des animaux qu'on $y$ avoit enfermes.-Collect. acad., foreign part, vol. I, p. 46-61.

${ }_{4}^{4} \mathrm{I}$ do not know their exact date. Musschenbroeck lived from 1692 to 1761; the volume of the Collection academique in which they are included appeared in 1755 .

5 Expérience du Vuide.-Histoire de $l$.Acad. des sciences de Paris, 1668; vol. I, D. 45.Collect. acad., French part, vol. I, p. 23.

6 Boyle, R., New Pncumatical experiments about Respiration. Philos. Transact., vol. V, p. 2011-2058, 16-0.--Extracted and translated: Collect, acad., foreign part, Vol. VI, p. 23-59; 1761.

3 - 4 , Experiment concerning an Effect of the varying Weight of the Atmosphere upon some Bodies in the Water.-Philosoph. Transact., VII, 1672; P. 5156.

${ }_{8}$ Huyghens and Papin, Some Experiments touching Animals, made in the Air-pump.Philosoph. Transact., X, p. 542-543.-Extracted and translated, Collect. acad., foreign part, vol. VI, p. 143-155.

$\mathrm{p}_{3}$ To try the Effects of the Pneumatick Engine exhausted in Plants, Seeds, Eggs of Silkworms. Philosohth. Transact., vol. II, D. 424-4.25; 1667 .

10 Sur la raréfaction et la condensation de l'air.-Hist. de l'Acad. des sc. de Paris, year 1705, p. 15; and Collect. acad., French part, vol. II, p. 181.

i1 Sur la mort des animaur dans le vuide, Acad. des sc. de Bologne.-Coll. acad., foreign part, vol. X, p. 53; 17i-3.

${ }_{12}$ Sur la mort de quelques espèces d'oiseaux et de grenouilles dans un air, renfermé. Acad. des sc. de. Bologne.-Collect. acad., foreign part, vol. X, p. 313-321.

${ }_{13}$ S Soc. roy. des sc. de Turin, vol. II, years $1760-1761$; p. 168 .-Collect. acad., foreign part, vol, XIII. p. $158-1 \times 4: 1779$.

${ }_{14}$ Darwin. Experiments on Animal Fluids in the exhausted Reccirer.-Philos. Trans., vol, LXIV, p. $344-349,1774$

${ }_{15}$ De Motu Animalium, Pars altera.--Rome, 1681 .

${ }^{18}$ I could not procure this book. But probably this solution is the one which Veratti quoted and which we have just mentioned.

${ }^{17}$ Loc. cit.: Relation abrégée, etc.. 1744.

is Loc. cit.: Mémoires philosopliques, $178 \overline{\text { T }}$.

19 Elementa Physiologiae corporis humani. Lausonne, 1761

20 De metcoris aqueis, p. to. I could not procure this work.

${ }^{21}$ Recherches sur les modificatians de l'atmosthère, vol. II-Geneva, $17 i 2$.

22 Loc. cit: : Nourelle description, etc., 1785

2 Discours en forme de dissertation sur l'état actuel des montagnes des Pyrenées.Paris, $17 i 6$.

${ }^{44}$ Voyage dans les Alpes.-Geneva, 4 vol. in $4^{\circ}: 1786$ to 1796.

${ }_{25}$ Essai de Physiologie positive appliquée spécialcment à la médicine pratique, vol. I.Avignon, 1806

23 Art. Air, Dict. des Sc. médi., vol. I, P. 248; Paris, 1812

${ }_{2 \pi}$ Des effets de la pesanteur de l'air sur lhomme consideré dans l'état de santé.-Thèses de Paris: 1813 .

2a Deuxième Mémoire sur la chaleur animale; 1813. Oenvres de Legallois, avec des notcs de M. Pariset, vol. II-Paris, 1830.

29 Description des Pyrénées, 2 vol.-Paris, 1813

30 Mémoirc concernant les effets de la pression atmosphérique sur le corps humain, et l'application de la ventouse dans différents ordres de maladie.-Paris, 1819. 
${ }^{31}$ Loc. cit.: Journal of a Tour, etc.; 1820.

32 Additional Observations on the Natural History and Physical Geography of the Himalayah Mountains, between the River-Beds of the Jumna and the Sutlej.-The Edinburgh Journal of Science, conducted by D. Brewster, vol. II, P. 277-287, 1825. Read before the Royal Society of Edinburgh, December 10, 1824.

${ }^{33}$ Loc. cit.: The Edinb. Journal of Science, vol. I; 1824

34 Loc. cit.: Account of Koonaziur, etc.-London, 1811.

${ }^{35}$ Loc. cit.: Narratice of a journey, etc.; vol. I.-London, 1840.

3i. Loc. cit.: Asiatic Research, vol. XlV; 18*2.

37 Loc. cit.: Nouveau Journal de médecine, vul. VII; 1 kno.

av Lec: cit.: Bibl. uniz:, vol. XTV; 1820.

30 Loc. cit.: Bibl. univ., vol. XXIII; 1823.

40 Observations sur la vitesse du pouls à différents degrès de pression atmosph-Journ. de Phy'siol. de Magendie, vol VI, p. 1-13; 1826.

${ }^{41}$ On the Effects of removing Atmospheric Pressure from the fluids and solids of the human Body. Transactions of the Medico-Chirurgical Society of Edinburgh, vol. III, p. 448-458; 1829.

42 Dictionnaire de Médecine, article Atmosphère, vol. IV; 1833.

${ }^{43}$ Effects of Mountain Elevation upon the human Body.-London, Med. Gaz., vol. XIV, p. 207,$520 ; 1834$.

${ }^{44}$ Traité de Physiologie, Jourdan translation, vol. VI; 1837.

${ }^{45}$ Loc. cit.: Reise in Chile, etc.; 1836.

${ }^{46}$ Loc. cit.: Ann. de Chimie, Second series, vol. LVIII, 1835. 47 Sur la composition de l'air qui se trouve dans les pores do la neige. Ann. de Chim. et
de Phys., Third series, vol. I, p. $351-360$; 1811 .

4s Loc. cit.: Lettre à Delambre. Ann. du Musenm; vol. II; 1805.

49 Loc. cit.: Ibid.

${ }^{50}$ Loc. cit.: Ann. de Chimie, Second series; vol. LXIX; 1838.

51 The fact that atmospheric pressure is the real cause of the maintenance of articular adherences was discovered by the French physiologist Bérard, something not generally known. Guérard, who bore witness to it, expressed himself as follows:

"Long before the work of these physiologists was known in France, M. Bérard, in a competition for the Central Board (about 1828 or 1829), had had printed, according to the practice at that time, a series of propositions upon which the argument was based. One of these proposition was worded as follows: Atmospheric pressure can aid or hamper disjointing, according to circumstances. M. Bérard quoted an experiment which he had devised, and which consisted of removins all the muscles which hold the thigh to the pelvis and of cutting the capsular ligament. When the leg was pulled, the adherence of the head of the femur to the cotyloid cavity under the effect of the weight was sufficient so that the body could be dragged on the ground without the two parts of the articulation separating." (Ann. d'hyg. publiquc et de med. lég. Second series, vol. I, 1854, p. 304.)

What we really owe to the German plysiologists is the mistaken application they have made of this truth to the theory of walking.

52 Recherches sur les effets physiologignes et thérapeutiques de la compression et de la raréfaction de l'air, tant sur le corps que sur les membres isolés. Ann. gén. de Méd., Second series, vol. IX, p. 157-172: $1 \leqslant 35$.

${ }^{53}$ De l Hémospasic.-Recueil de Mémoires sur les effets thérapeutiques de cotte méthode de traitement.-Paris, 1550 .

54 Rapport sur un Mémoirc ajant pour titre: De la Condensation et de la Raréfaction de l'Air, apérécs sur, toute l'habitude du corps ou sur les membres seulcment, consid récs sous leuts rapperts thérapentiques, par M. Th. Junod, M. D.-Cpt. R. Acad. des Sc., vol. I, p 60$65 ; 1835$.

${ }^{55}$ In fact, that is what Clanny himself says: "It is interesting to note that at the same time Sir James Murray of Dublin. Th. Jumod of Strassburg, and I invented a similar apparatus, for the purpose of lessening the pressure of the atmosphere on the surface of the body, with. out anything having been published previously in any journal." (Researches of M. Junod into the physiological and therap. effects of compression and rarefaction. The Lancet, 1835-36: vol.
II, p. 359.)

Clanny and Murray had invented only the great cupping-glass.-Apparatus for re. moving the Pressure of the Atmosphere from the Body or Limbs. The Lancet, 1831-35: vol. I. p. $804-805$

${ }_{56}^{5}$ Junod, Traité théorique et pratique de l'hémospasie.-Paris, 1875.

${ }_{57}$ Considérations sur les effets thérapeutiques de l'hemospasie, d'après les observations recueillies en Algérie par T. Junod.-Paris, 1858 .

${ }_{58}$ Bibl. univ. de Genere, Second series, vol. V, p. 151; 1836.

59 Ascension au Faulhorn. Revue médicale, 1841, vol. IV.

${ }^{60}$ Loc. cit.: Influence, etc.-Revue médicale, 1812, vol. IV.

61 Loc. cit.: Peru, Reiseskizzen, etc.; 1846.

¿2 Loc. cit.: Practical observations, etc.; vol. LVII, 1812.

${ }^{83}$ Voyages au Pérou et à Mexico, vol. I, I am borrowing this quotation from Flemeing, Ringuet translation; loc. cit., De l'influence, etc.-Périgueux, 1869.

${ }^{64}$ Etudes de Physique animale.-Paris, 1813.

os Betrachtung der Gebirosluft und der Lebensweise der Gebirasbewohner in Bezun ihres

Einflusses auf Blutbercitung und auf das Vorkommen gcreisser Krankhcitsformen. Oesterr. Med. Jahrb., vol. XXIII.-Analyse in Schmidt's Jalwb., vol. XXXIII, p. 298, 1842.

6i: Notes sur les Causes de la lassitude et de läanhélation dans les ascensions sur les montagnes les plus clevées.-Rev. Med., 1844, vol. III, p. 356-368.

${ }_{67}$ Sur la Cause des phénomènes physiologiques que l'on trouve quand on s'élìve à une certaine hauteur dans les montagnes.-Cpt. R. Ac. des Sc., vol. XX, p. 1501; 1845. ${ }_{\text {es }}$ Physiologic des Atmens.-Karlsruhe, 1845, p. 81-89.

60 Loc. cit., Mém. sur les phén. phisiol.; 1845.

70 Allegemeine Zeitung Missellen: Ersteigung des Wetterhorns, reproduit in extenso dans Dolfus-Ausset, loc. cit.. Matériaux, etc., vol. IV, p. 117.429.

${ }^{11}$ Loc. cit.: Souvenirs, etc., vol. II, 1850. 
${ }^{2}$ Esplorazioni di N.-M. Przeralski nella Mongolia orientale e sulle falde N.-E del Tibet

(1871-1873). Cosmos di Guido Cora, vol. II, p. 14-19, 164-175 and 261-277.-Turin, 1874.

73 Essai sur l'Emploi de lair comprimé.-Paris-Lyons, 1850.

${ }^{74}$ Observations tendant à démontrer que, dans les ascensions sur les hautes montagnes, la lassitude et lanhelation éprouv és par la plupart des explorateurs nont pas pour cause une insuffisance d'oxygène dans l'air respiré. Cpt. R. Acad. des Sc.., vol. XXXIII, p. 198; 1851.

${ }_{75}$ Note sur les Effets de la diminution de la pression atmosphérique sur les animaux.

Cpt. R. Acad des Sc., vol. XX XVII, D, 863; 1853

${ }_{76} \mathrm{On}$ the Nature and Causes of the physiological phenomena comprised in the term

"Mountain Sickness" more especially as experienced among the Hiaher Alps.-Assoc. Med.

Journ., 1853, D. 49 and 80 .

it Die Bergkrankheit, oder der Einfluss des Ersteigens grosser Hohen auf den thierischen

Organismus.-Leipzig, 1854 ; in octavo, 140 p.

${ }_{7 s}$ Des Climats de montagne considérés au foint de rue medical.-Arch des Sc. phys. et nat.

de Genève, vol. XXXII, p. 265-306; 1856.

${ }^{79}$ Lehrbuch der Physiologie des Menschen. Brannschateig, 1844.

so Recherches de Pathologie comparée. Cassel. 1553.

81 Mémoire sur la pression atmosphérique dans ses rapports avec l'organisme vivant.

Cpt. R. Acad. des Sc., vol. XLIV, p. $233 ; 1857$.

${ }_{52}$ Ueber den Einfluss, welchen der Hechsel des Lufidruckes auf las Blut ausïbt. Mül-

ler's Archiv.; 1857, p. 63-73.

${ }_{33}$ Du rôle dés principaur éléments du sang dans l'absorption ou le dégagenent des gaz de

la respiration. Ann. des Sc. Natur. Fourth series; Zool., vol. VIII, p. 125; 185 .

st Ueber dic in Blute enthaltcnen Gase: Sauerstiff. Stickstoff und Kohlensaüre. Poggen-

dorff's Annalen, 18:37; translated in Ann. des Sc. nat., Zooi. Seco nd series, vol. VIII, p. 79;

$18: 37$.

1845 .

${ }^{85}$ For the development of this view see: Vierordt. Physiologie des Athmens.-Karlsruhe.

86 Traité de Physiologie.-Paris, First edition. vol, I, 1857; Third edition, vol. I, 1868.

$\$ \mathrm{De}$ la chaleur produite par les êtres zizants.-Paris. 185.5.

${ }^{8}$ Climats de montagne, etc., Second erlition, isis.

${ }^{89}$ Bibl. univ de Genere, Fifth series, vol. II, p. 64i, 1858.

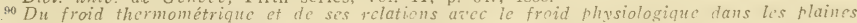

et sur les montagnes. Mem. de l.Acad. des Sc. de Montpellier, vol, IV, 1859.

${ }_{1}$ Loc. cit. De la phthisis, etc., 1810 ?

92 Les Altitudes de l'Amérique tropicale comparées au niveau des mers, au point de i'ue de la constitution medicale.-Paris, 1861.

${ }^{3}$ De l'Anémie des Altutudes et de l.Ancmie on général, dans ses rapports ấec la pression

de l'atmosphére.-Paris, 1863.

${ }^{94}$ Le Mexique et l.Amérique tropicale: climat, hygiéne et maladies-Paris, 1864.

95 Gazette hebd. de med et de chir.. 1663 , D. . . .

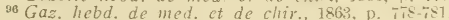

97 Gaz. hebd., 1663, $817-521$.

${ }^{93}$ Gaz. hebd, 1864, p. 33-37.

99 The average of the intra-pulmonary air circulation for Vierordt was exactly 6 liters, that

is, equal to that observed by Cointet.

100 Gaz. hebd., 1864, p. 234, 265, 371, 450, 545, 579, 674.

101 Gaz. hebd., 1865, p. $145-151$.

${ }^{102}$ Traité élémentaire de Physiolngie, chap. IV, Section 138.

103 Gaz. hebd.. 1865 , p. $467-470$.

104 This figure is relative to experiments made on Indians. (Gaz. hibd.. 1864, p. 36.)

105 Recherches sur la quant d'ac carb. exlalé par le poumon dans l'espáce humaine. Cot.

R. Acad. des. Sc., vol. XVI, p. 113, 1843.

${ }^{106}$ Gazette hebdomadaire, 1865 , p. 468

${ }_{10} \mathrm{De}$ la Respiration sur les hauts platcaur de l'Anahuac.-Rec. de Mém. de méd. milit.

Third series, vol. XIV, D. 512-516, I8fis

${ }^{108}$ Article Air from the Diction de Méd. et de Chir. pratiques.-Paris, 1864

${ }^{109}$ Du Travail dans l'air comprimé.-Paris, 3863.

${ }^{110}$ Considérations aánérales sur les maladies principalcs qui ont reané sur les chevaux et

mulcts du corps expéditionnaire due Mexique pendant la période de 1862 à 1863.-Journal de médecine vétérinaire militaire, vol. III, March, April, May, 1865; vol. IV, June, July, August, 1865 .

111 Article Altitudes from the Dictionnaire encyclopédique des Sciences médicales.-Paris.

$1 \leqslant 66$.

112 Etude de queloues-unes des rariations que l'altitude fait sentir a l'air ambiant et de

l'infusence de ces c'ariations sur l'homme. These de Paris 1866.

${ }^{113}$ Influence de l'altitude des lieux sur les fonctions physiologiques.-Paris, 1867.

114 Kaufmann, Cpt. R de l Acad des Sciences, vol. LXV, D. 317, 1867.

${ }^{115}$ Le Merique considéré au point de vue medico-chirurgical.-Paris, vol. I, 1867; vol. II.

1868. 111-164.

${ }^{116}$ Article Atmosphere. Dictionn. encyclopédique des Sciences medicales.-Paris, 1867; p.

${ }_{i i}$ De l Infuence de la compressian et de la raréfaction de l'air sur les actes mécaniques de la respiration. Thierry-Mieg translation.-Gaz. méd. de Paris, 1868.

${ }_{11}$ De l'Infuence de la pression atmosph. et de lialtitude sur la santé et les maladies de l'homme et des animaux. Ringuet translation.-Perigueux, 1869.

${ }_{119}$ Théses $d u$ Concours d'agréation.-Paris, 1869.

1870.

120 Traité élementaire de physiologie, Book II, Chap. I, Section 244, Sixth edition; Paris.

121 Une Ascension au mont Blanc. Bibl. uniz., Fourth series, vol. XXX1, p. 79-95, 1856.

122 Loc. cit.: Bibl. uniz.; 1865.

${ }^{123}$ Loc. cit.: Deux ascensions, etc.; 1869. 
124 Observations sur la température du corps humain à différentes altitudes à l'etat du repos et pendant l'acte de l'ascension. Bibl. univ'. de Genève, Arch. des Sc. phys. et nat.; Fifth series, vol. XXXVI, p. 247-289, 1869.

125 Expèriences sur la température du corps humain dans l'acte de l'ascension des montagnes.-Extract from Bullctin de la Societé médicale de la Suisse Romande, First series, Geneva and Bâle, 1871; Second and Third series, 1874.

126 In his ascents M. Forel had not yet gone beyond la Cima di Jazzi (3818 meters).

${ }_{12 \pi}$ The effect of exercise on the bodily temperature.-Journal of Anat. and Physiol., Second series, vol. VII, p. 160-119, November, $15 i 2$.

${ }_{123}$ Observations on the Effects of Exercise on the Temperature and Circulation. Proceed. of the Roy. Soc., XXI, p. 3i4, 18i2-73. $72-79$.

129 Sur le Mal des Montagnes.-Bullet. de la Soc. méd. de la Suisse Romande, 1874, p.

${ }^{130}$ Sur le Mal des montagnes.-Bull. de la Soc. méd. ae la Suisse Romande, 18it, p. 136140.

1:31 Tyndall, Hours of Excrcise in the Alps, Second edition.--I.ondon, 1Ni1.

132 Histoire du mont Blanc,-Paris, $18 i 3$.

${ }^{133}$ Loc. cit.: On mountains, etc., $18 i 2$.

134 Loc. cit.: The adventures, etc, 1853.

135 Loc. cit.: Lahore to Yarkand, etc., $18 \% 3$.

130 Loc. cit. The Jumnoo, etc., 1875.

137 Abeokuta.-London; 2 vol., 1863.

${ }_{133}$ La Station médicale de Saint-Moritz (Engaline).-Paris, 1si3.

139 Effets physiologiques du climat et des eaux de Baréges. $M e ́ m$. de l'Acad. des. Sc.

Inscr. et Belles Lettres de Toulouse, Seventh series, vol. II', p. 214-23I, Isi3.

${ }^{140} L$ homme américain, 2 vol.-Paris, 1839.

Paris, 1861.

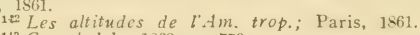

${ }_{1+3}$ Gaz. hebd.; 1863, p. 779.

1*4 Descendance de l'homme, vol. I, p. 330.

145 Influence de la pression de l'air; Paris, 1875.

140 Influence de la pression de l'air sur la vie de l'homme, 2 vol.-Paris, 185. 469.471

${ }_{147}$ Bulletin de l Académie de médecine. Séance du 20 ariril 1875, Second series, vol. IV, p.

iis Bull. de la Soc. de Géogr. Sixth series, Vol. IX. 1st5.

149 First year, first volume.-Paris, 1875.

15i) Bull. de la Soc de Géog., Sixth series, vol. X

151 First year, second volume.-Paris, 1875. 


\section{Chapter IV SUMMARY AND CRITICISMS}

The time has come to summarize the long series of observations, experiments, and theories, the details of which we have just related. After placing before the eyes of the reader nearly all that has been written about the effect of decreased atmospheric pressure, by the laborious but certain method of word for word quotations, we should now simplify his task by condensing all these varied assertions, often redundant and sometimes contradictory.

We must, moreover, subject to careful examination the explanations suggested, opposed, or eclectically collected by travellers, physicians, physiologists, and physicists, who have considered in its various aspects this question, which is apparently so complex, but really so simple, as we shall show. In this part of my task I shall, of course, set aside the arguments drawn from my own experiments. It is by ideas previously known that I hope to prove that at the time when I began my researches, there existed in science no theory-I do not say demonstrated, for that is evidentwhich could sustain thorough criticism. Even the truth, when it was found, was mingled with so many errors or was so unfurnished with proofs that it could not force its clear evidence upon rebellious minds. Now anyone is right only when he can prove to everyone that he is right: "To keep on answering," Voltaire said, "is to prove that no answer has been given."

The present chapter is naturally divided into three parts: the conditions under which mountain sickness appears, the summary of the symptoms which constitute it, the careful examination of the theories suggested to explain it.

1. Conditions Under Which Mountain Sickness Appears.

The most general fact emerging from our study is that when 
men and animals ascend to great heights above sea level, they always finally experience a series of more or less serious symptoms, the combination of which constitutes mountain sickness.

The very existence of these symptoms, however, has been denied, as we have seen; but these denials, which are rash and unscientific generalizations upon a few isolated cases, do not merit our attention here.

The first striking fact, when we examine the series of data which we have collected, is the difference in altitude at which the dangerous symptoms appear, depending upon whether we are dealing with mountain journeys or balloon ascensions. Whereas in the first case travellers often become ill at about 3000 meters, and almost never mount above a height of 5000 meters without serious suffering, Gay-Lussac, Barral and Bixio, and M. Glaisher felt only a few slight disturbances at 7000 meters. In a moment, we shall easily find the reason for this enormous difference.

On earth as in the air, the severity of the symptoms keeps increasing with the altitude; but in its ascending progress, it follows a law of progression, not of proportion. Up to 3000 meters, a traveller who set out from the level of the valley, 1000 meters for example, will be warned of the decrease of pressure only by a slight increase in pulse and respiratory rates; from 3000 meters to 4000 meters, the symptoms increase considerably in intensity; above that, each ascent of a few hundred meters is marked by a progressively increasing aggravation of them, and a moment comes when it is harder to climb 50 meters than it was to ascend 500 meters at the beginning of the journey. It is not surprising, therefore, to see, as Captain Gérard reported, mountaineers of Koonawur, accustomed to observing sensations of this sort, estimate the altitude of the point which they have reached by the difficulty in breathing experienced there.

The altitude at which the symptoms of mountain sickness appear varies considerably in the different regions of the earth. We have seen that in the Pyrenees serious symptoms appear only near the highest summits, that is, above 3000 meters and then they are very rare. At the same level in the Alps the accounts of travellers begin to indicate some disturbances; they are rather customary between 3500 and 4000 meters; above that, their existence constitutes a rule from which far fewer persons escape than the editors of the Alpine Clubs would have us believe. Etna, with its 3313 meters, is in this respect, as we have said, a limited mountain, as is the Peak of Teneriffe (3716 meters). In the Caucasus and the mountains of Armenia the level at which almost everyone 
is severely attacked seems a little higher than in the Alps; on the volcanoes of the Pacific, which exceed 4000 meters, the sickness is hardly worse than on the Peak of Teneriffe; the same thing is true of the Kamerun Mountains, and on Kilimandjaro, New reached an altitude of about 5000 meters without serious distress; in North America, Frémont and his companions were ill at about 3500 meters; but in Mexico one must mount above 4500 meters, to experience perceptible discomforts; they are not always very serious even on the summit of Popocatepetl (5420 meters). The long mountain chain of South America cannot be crossed at any point from Chile to Colombia without inflicting the terrible puna upon most of the travellers. But it seems that these sufferings do not appear at a completely uniform height; whereas on the passes of Santiago in Chile many are sick below 4000 meters, and almost all foreigners are severely attacked at La Paz (3720 meters), and even a.t Chuquisaca (2845 meters), and all at Cerro de Pasco (4350 meters), the ascent of the mountains near Quito causes almost no symptoms up to 5000 meters, and a thousand meters more present no unsurmountable difficulties from the physiological point of view.

The immense mountains of central Asia may be compared to the Andes of Upper Peru from the standpoint of the line where mountain sickness appears. Passes less than 4500 meters high are crossed without serious sufferings; there are some more than 5500 meters high which are considerably frequented; several travellers have reached 6000 meters, and the Schlagintweit brothers ascended to the prodigious height of 6882 meters on the sides of Ibi-Gamin.

These inequalities, from our standpoint, among the different mountainous regions of the earth, stand out among the multitude of facts which we have listed; but one can easily find numerous exceptions to these general rules. Indeed, and this is not the least interesting fact revealed to us by these multiple observations, we see that in the same region of the earth, in the same mountain chain, certain definite places are particularly feared by travellers and natives; and these places are not always the highest, far from it. This peculiarity is noted even in the ascent of a given mountain; for instance, the Couloir of Mont Blanc, where symptoms often appear which disappear on the summit. In a word, and these facts have been noted particularly in the Andes and the Himalayas, the intensity of the symptoms is not always in proportion to the altitude reached. This was the origin of strange hypotheses imagined by the natives, to which travellers too often gave credence; 
and thence came also the belief in metallic emanations, mephitic gases issuing from the ground, and fatal exhalations from different plants.

But, barring these very interesting exceptions which we shall try to explain in another part of this work, the differences in average height at which serious symptoms appear according to the parts of the world in which they are observed are in a remarkable agreement with differences in the altitude of the line of perpetual snow, when we consider them as a whole. The summary which we inserted earlier (see page 16) on this latter subject facilitates this comparison for the reader. But we must not go so far as to believe, as some travellers have done, that a direct relation, almost of cause and effect, exists between these two distinct orders of phenomena. Very evidently, no one has ever complained of mountain sickness in the polar regions, where the lowest hills are eternally covered with snow. But without having recourse to this reductio ad absurdum, we see that in our Alps it is almost always 500 meters at least above the line of melting where physiological disturbances appear with sufficient intensity to attract attention. The same thing is true upon the volcanoes of Ecuador and Mexico, the Rocky Mountains, and many other points. On the contrary, on the Bolivian Andes and still more on the Himalayas, the narratives previously published show us that travellers may be very sick when they are treading terra firma, and are still quite far from the zone of perpetual snow. But it is no less true to say that, in a general way, the higher the line of perpetual snow, the later will travellers in their ascent be threatened with the symptoms which we have so often described.

Besides these irregularities due to exterior circumstances, there are some which depend upon the idiosyncracies of the travellers who are subjected to the effect of decompression.

Indeed, in the same region, on the same mountain, we see travellers sometimes complaining of severe sufferings, sometimes rejoicing or expressing surprise at having felt almost no distress. On the pass of Cumbre of Uspallata, most of those who are crossing the Andes are attacked by the puna; Samuel Haigh, Schmidtmeyer, and many others have testified to it: but we have seen that Miers, Brand, Strobel, etc. escaped it entirely. Whereas von Humboldt and Bonpland were very sick in their ascents of Chimborazo, M. Boussingault and Colonel Hall, who ascended higher than they, experienced only slight symptoms, and M. Jules Rémy, who says that he reached the summit, states that he felt no symptom of illness, On Popocatepetl, Bacon Gros and his six companions, and 
later M. Laverrière, complained of real distress; MM. Turqui and Craveri, M. Virlet d'Aoust declare that they were completely spared, while the Scientific Commission of Mexico was a little less favored.

These differences are still more striking on less lofty mountains. Riche and Blavier, when attacked by hemoptysis, gave up climbing the summit of the Peak of Teneriffe, which von Humboldt, Léopold de Buch, Elie de Beaumont, ${ }^{1}$ and so many others reached without trouble. On Etna, Count de Forbin and A. de Sayve suffered greatly, whereas Spallanzani was unaffected, and Ferraro claimed to feel better than on the plain.

The same thing is true of the Alps. In the hundreds of ascents of which its summit was the goal, Mont Blanc has given us the most contradictory results. De Saussure, Beaufoy, Clark and Sherwill, Hawes and Fellowes, Bravais, Martins and Lepileur, attest to violent distress, which they conquered only by prodigies of energy ; on the contrary, Clissold, Piachaud, and Albert Tissandier were hardly ill at all. I have heard "Alpinists" of repute state that they had experienced absolutely nothing unusual in this ascent which was formerly so much dreaded. By a striking contrast, Laborde, the brother of M. Lepileur, etc. were ill when they ascended merely to the Grand Saint Bernard (2490 meters); Spitaler and his companions relate the most painful details about their ascent to Venediger (3675 meters), when Desor and Gottlieb Studer affirm that they felt absolutely nothing when they ascended the Jungfrau (4170 meters). In Armenia, Radde lay down exhausted at 3700 meters, whereas daring travellers almost with impunity trod the summits of neighboring mountains of far greater height, Elbrouz (5620 meters), Kasbek (5030 meters), and Ararat (5155 meters). More than that, in 1868, Freshfield, Moore, and Tucker made the ascent of Kasbek without any suffering; in 1874, mountaineers who were no less experienced, Gardiner, Grove, Walker, and Knubel suffered considerably on the same ascent. I shall not mention other examples. We need only refer to what we have said in the preceding chapters to find, among so many observations, examples of inequalities no less great noted in the Pyrenees, the Himalayas, and other mountainous regions.

These differences are especially striking when they appear in travellers who, in apparently similar conditions of health, hygiene, and previous training, make the same ascent simultaneously. On Pichincha, Ulloa fell fainting; La Condamine felt no difficulty in breathing. While ascending Cotopaxi (5943 meters), one of Steubel's muleteers was so sick that he could not go beyond 5600 
meters; another felt absolutely nothing. On Mount Etna, de Gourbillon felt nothing, whereas his companion Wilson suffered greatly. In the ascent of the Finsteraarhorn (4275 meters), Hugi was in very good condition, as were his companions, except one of the sturdiest guides of the Oberland, who had vertigo and nausea. On the glacier of the Maladetta, Néergaard stopped, unable to continue an ascent which the celebrated geologist Cordier finished without any trouble. MM. Lortet and Durier ascended Mont Blanc on the same day; the accounts of their sensations are as dissimilar as possible. At 5300 meters, Crocé-Spinelli in his balloon was seized with evident oppression; his travelling companions said that they experienced nothing.

But that is not all; the same person, in conditions which seem to him identical, making the same ascent on two different occasions, does not always have the same sensations. On his first ascent of Buet, Canon Bourrit fell unconscious; the next year, he had no special experience. On the Breithorn (4100 meters), M. Lepileur, in 1875, felt no discomfort, whereas the following year he was seized there by an unconquerable drowsiness. There is a similar lack of agreement in the three ascents of Mont Blanc by M. Tyndall, and the two by M. Lortet. Observations made on the guides are still more conclusive.

We must also note that while certain persons seem extremely sensitive to the effects of ascents, others without any complaint pass beyond the level where the great majority of travellers are attacked by the usual symptoms. We saw that Dr. Martin de Moussy had felt the puna at 1970 meters, whereas Jules Remy could ascend almost with impunity to the summit of Chimborazo (6420 meters). Victor Jacquemont seemed particularly immune in this respect, as we can see from the excerpts from his letters. Moreover, these facts are well known to all mountaineers; it is known that certain guides are unable to follow "their gentlemen" beyond a certain level, and travellers who were daring and tireless on mountains of the second rank have had to renounce reaching the highest summits of the Alps.

The numerous ascents, the narratives of which we have given, definitely differ then from one another in regard to mountain sickness, first, for reasons which seem to depend upon the mountain itself, and second, for reasons which depend upon the travellers; the latter may be constant or only transitory. The extremes of these differences may vary between 1500 meters (M. Javelle) and 6000 meters; that explains, without justifying them, the thoughtless denials which we have so often recorded. 
We should now apply ourselves particularly to the study of influences of a transitory nature, and by analyzing, in a more detailed manner, the narratives quoted find out whether it is possible to explain these differences by certain conditions of environment, by circumstances in which the travellers are placed by chance, or by this combination of intrinsic conditions peculiar to each of us, some of which may be measured, others more or less unknown and designated by the general expressions of constitution and idiosyncracy. This is the place to investigate the effect of habit and acclimatization and to take into account the race to which the traveller belongs.

In this last connection, the results observed seem quite contradictory: whereas d'Orbigny, Poeppig, Tschudi, de Saint-Cricq, Weddell, the Grandidier brothers, etc., note with astonishment the immunity of the Indians who run beside their mules without showing the least distress, we find, in von Humboldt's ascent of Chimborazo, a half-breed born in the lofty places suffering more than the Europeans; likewise the peons of Caldcleugh, Brand, and Steubel were sick when the travellers themselves felt almost no effects; and yet, in a general way, it is clear that in the Andes the Indians are much more resistant to the effects of mountain sickness than the Europeans are.

I must quote in this connection a passage from an interesting letter written me by a French engineer, M. E. Roy, former assistant director of the School of Arts and Trades of Lima, who often visited the lofty regions of the Andes:

The native Indian race is strong and vigorous; nature or the effect of a kind of atavism has endowed it with a powerful respiratory apparatus which permits it, probably by the respiration of a larger quantity of air, to find the oxygen equivalent necessary for its existence and for the maintenance of a good constitution. The Indian of these high plateaux is thick-set, with an enormous torso and pelvis and relatively short legs; he is a walker of the first rank. Shod with his double woolen socks and his moccasins, he will walk 50 kilometers, without wincing, in his mountains and provided he has coca leaves to chew, he will make this distance in one stretch. For him and his llamas, a straight line is the shortest distance between two points: he does not try to wind around the valleys to go from one to another, he goes straight ahead, unless the mountain side is impassible; that shows you how necessary it is that he should breathe freely.

Conversely, when these mountaineers go down to the seashore, they cannot perform any hard work, as they do in their mountains; many contract diseases of the lungs. At the school of which I was assistant director, many of the young men coming from these lofty regions had to return to their native air for this reason before finishing their studies, because the work of the shop was too hard for them. 
The opposite seems to be true in the narratives of travellers in central Asia. Fraser complains bitterly of his coolies. According to Dr. Gérard (page 137), the inhabitants of Koonawur, born on the lofty plateaux, are as sick as the travellers. Johnston relates that whereas the natives who accompanied him on the peak of Tazigand breathed with the greatest difficulty, he and his English companions felt no ill effects (page 139). Oliver Cheetam, Godwin Austen, and Henderson tell similar experiences. To the Schiagintweit brothers, the difference in races seems of little importance. Drew saw a native of Punjab sick at 11,000 feet (3300 meters). So Indians, even those born in mountainous regions, seem at least as sensitive as Europeans to the effects of ascents.

The same is true in Africa in the ascents of the Kamarun Mountains and Kilimandjaro; likewise in Hawaii on Mauna Loa, the natives were attacked by mountain sickness before the European travellers, and more severely than they.

But it should be stated at once that the natives and the Europeans were not, during these journeys, in identical conditions, either of clothing, or food, or exertion.

If natives belonging to races which seem, according to the expression of Dr. Gérard, "born to live and die in inaccessible regions", are attacked by mountain sickness, the same thing should be true, for an even stronger reason, of the people of European races living in lofty places. All the accounts of Chapter I show, in fact, that the porters and the guides become ill as quickly and as seriously as the travellers, when the latter have already become used to exercise in the mountains. Sometimes even, the former become ill first; the account of Dolomieu (page 71) is quite characteristic. The slight advantage which they show, on the average, is rather quickly acquired by people of the plains whom wanderlust urges into the mountains.

Another proof, and that not the least striking, of the slight importance of acclimatization in lofty places is drawn from the intensity with which the disease attacks domestic animals. All the accounts of travellers in the Andes and the Himalayas are rich in melancholy details of the pitiful condition of the mules or the horses which are carrying burdens; the latter often die; camels are no better off; the mules of de Saussure uttered plaintive cries on the glacier of Saint-Théodule; the wild cattle themselves, when they are hunted, often vomit blood, von Humboldt says, and we have seen what a sorry picture they made sometimes, according to de Castelnau, in bull fights. Dogs are also severely attacked, and have difficulty in running. Cats particularly seem to possess 
excessive susceptibility, since, according to Poeppig and Tschudi, they cannot live above 4000 meters (pages 40, 46). However, we must note that, in the opinion of Tschudi and Elliotson, animals born on the mountains are not as sick as the others.

But it must be admitted that all of this relates to imported domestic animals. The native species seem very comfortable at the greatest heights; only Captain Webb saw yaks attacked by the sickness (page 134); llamas seem completely immune, and in the free state graze at altitudes of more than 4000 meters. Since the time of Ulloa, everyone has been struck with astonishment at the sight of condors soaring habitually at 4000 or 5000 meters, and sometimes above 7000 meters; in the Himalayas, the lapwings and other sparrows live at altitudes of more than 5000 meters.

Here we are dealing with one of the most interesting points of this birdseye view of the subject. The influence of habit or custom on mountain sickness is undeniable; but its conditions have been both exaggerated and poorly determined.

On the testimony of d'Orbigny, Poeppig, Gay, Tschudi, and Guilbert, one can become quite accustomed to living in the lofty regions of the Andes, and the often unendurable distress which attacks the European in the early part of his sojourn gradually disappears. "In the streets", says Guilbert, "it is easy to distinguish the newcomers; every forty or fifty steps they stop for a few seconds" (page 54). Analogous effects have been noted on our European mountains; a novice who, when newly arrived from the plains, is sick at a low altitude, can later make much higher ascents with impunity. But we must not think that this immunity is absolute; a fairly great change in level or peculiar circumstances may suddenly bring on the sickness that had disappeared; we shall find the proof of that in the accounts of M. Weddell, M. Pissis and d'Orbigny himself. In a word, the same thing is true of arrival in the mountains as of all sudden changes to which we may be subjected; the passage of a certain time permits the reestablishment of the equilibrium which was shaken for an instant, and which slower transitions would have left unaltered.

We shall try later to determine the nature and the importance of the conditions changed by the act of ascent; but even now we can assert the reality of habit or, as we usually say, acclimatization to lofty places.

But here, as we cannot repeat too often, we are dealing only with the violent and sudden symptoms of mountain sickness, in a word; we have no intention of plunging into the delicate and complex study (in which the means of demonstration are the more 
numerous as they are less convincing) of real acclimatization, in lofty regions, of successive generations tending towards the formation of a race.

With certain reservations, for it seems to be proved that certain persons cannot become accustomed to sojourn in lofty places, we simply state that a traveller who has been in the mountains for some time will feel no unusual sensations at a level where at first he was ill; that his descendants, if he founds a family there, will preserve his relative immunity; that the race thus formed will enjoy the same advantages, so that the traveller who is a newcomer will be surprised. But with the reservation already made that there is nothing absolute in this.

We must also have an understanding in the matter of habit. Indeed, as we shall say in a moment, fatigue plays a great part in the intensity of mountain sickness. One of the consequences of prolonged exercise in the mountains is a lessened tendency to fatigue. The same thing is true of this special gymnastics as of all others; one finally contracts only the muscles, only the muscular bundles indispensable for the movement one seeks to make; one brings them only to the degree of contraction which is precisely necessary; in a word, one reduces the expenditure of energy to a minimum. Moreover, the muscles, and no doubt the nerves also, more frequently stimulated to action, from which a more active local circulation constantly removes the wastes, can suffice for a greater dynamic storage and expenditure, become, as we say, stronger, and, for the same work, give the sensation of fatigue in a much lessened degree.

And therefore one fits himself for acclimatization on the heights by the simple gymnastic exercise of moderate ascents, with which the professional "Alpinists" always take care to preface their feats of lofty altitudes. For failure to comply with this rule, the most energetic often pay a forfeit. One of the members of the Austrian Alpine Club, very familiar with the lofty summits of the Alps, who boasted to me that he had felt no symptoms on Monte Rosa or Mont Blanc, confessed that he had been very ill one day because he had made an ascent of 2500 meters, coming from a sedentary life with no transition. That is one of the reasons why the moderate mountains of the valley of Chamounix, Buet and sometimes even Brévent (2525 meters), cause illness in travellers coming from Geneva; it is also this lack of training which explains the frequency of the symptoms of mountain sickness in the ascent of Mont Blanc, when that of Monte Rosa is much less feared in this regard; it is because the former ascent is often made 
by novices or even by "mountaineers" who have experience, but who a few days before were living in the atmosphere of London or Paris, whereas usually no one attempts Monte Rosa without a series of preliminary exercises which have disciplined the locomotor apparatus.

Examples of the effect of fatigue are numerous in the very accounts which we have quoted.

While listing the symptoms of mountain sickness, we must dwell on the fact of its aggravation by exercise, even the most moderate. Here, we should simply mention the cases in which it appears only under the influence of fatigue, and we may even say a passing fatigue, due to violent exercise. I myself have felt rather serious symptoms because I climbed a hill about a kilometer long at a quick step, on the road to the Grand Saint Bernard at an elevation not above 1500 meters. It is to the effect of fatigue, of burdens borne on the backs of men, that we should chielly attribute the violent symptoms which sometimes attack the peons of the Andes and especially the coolies of the Himalayas pefore the European travellers are affected.

The latter, moreover, usually allow themselves to be borne quietly along on the backs of horses, mules, or yaks. We have mentioned many cases in which the sickness attacked them suddenly, as soon as they dismounted to walk beside their animals. If they are walking on difficult footing or on new snow into which the body sinks, the fatigue is increased and with it the intensity of the symptoms.

If, as travellers usually do, we apply the word fatigue not only to the result of exaggerated muscular contractions but also to the effect of other exhausting causes, this factor of mountain sickness takes on still more importance. So insomnia and lack of rest and comfort are not to be neglected. On their second ascent of Mont Blanc, MM. Lortet and Marcet were much less ill than on the first; they had passed a good night at the Grands-Mulets. Most of the symptoms, when one is climbing this mountain, are partially caused by the fact that the resting place, the hut of the Grands-Mulets, is very poorly furnished; on the contrary, on Monte Rosa there is the inn of the Riffelberg, where one rests comfortably, and where one can stay several days at an elevation of 2570 meters.

To fatigue and insomnia we must add insufficient or poor food. The guides are unanimous in urging one to eat little, but often and substantially. A bad condition of the stomach or the intestine infallibly brings on the symptoms long before the usual level. 
Guides have frequently become ill at a fairly low level, because they had been drunk the night before; peons who have bad habits suffer more from the puna than the others, says Caldcleugh (page 35).

The following are the principal circumstances, variable and accidental, which may affect the intensity of mountain sickness: lack of acclimatization, lack of training, fatigue, insomnia, poor food, and temporary ill health. Different constitutions seem unevenly affected. According to most of the travellers, according to A. Smith (page 44), Tschudi (page 46), Burmeister (page 52), and Pissis (page 56), the plethoric and also the aged or very weak persons are especially affected. It is not rare to see persons apparently frail, but bilious or nervous, make with impunity ascents on which corpulent people fail. We may say that they have less weight to carry, which is important, especially when they are walking in the snow, into which they sink less; besides, their pulmonary surface is, like that of children, greater in proportion to their weight, but whatever the explanation is, the fact is commonly observed.

The state of ill health, for whatever cause, likewise predisposes one to be sick sooner. "When I was not well", said Al. Gérard, "I was sick at 13,000 feet, but in good health I felt no effects at 16,000 feet" (page 138).

An effect of general nature is that of cold, which predisposes to mountain sickness. As we have seen, it usually appears in the region of perpetual snow, and in intertropical lands it recedes with the snow line to enormous heights. All travellers agree in declaring that when the icy wind of high places rises, it makes the symptoms unendurable, and may bring on death; this fact was first noted in the Andes by Acosta (page 25).

If then to the fatigue of walking and of burdens borne we add insufficient food, the privations of poverty, and clothing insufficient to keep out the cold, we find united all the causes which may increase the intensity of mountain sickness. These causes, not to mention bad habits, combine to attack the unfortunate Indian coolies and also, though to a less degree, the peons of the Andes; that is enough to explain the violence with which they ordinarily suffer from the puna or the bies, to use their expressions.

If now we refer to the differences mentioned at the beginning of this section among the different mountains in regard to the height at which the symptoms usually appear, we can explain them in part by the observations which have just been abstracted.

If in the tropics mountain sickness hardly ever appears below 
4500 meters, whereas in our Alps it is not rare a thousand meters lower, temperature certainly has much to do with this considerable irregularity; as I remarked a moment ago, the zone of eternal snow is almost the same as that in which the symptoms appear. If the city of Cerro de Pasco is so much dreaded by all travellers, that is because its icy climate increases the severity of the symptoms caused by the altitude. Evidently it is to their position on the equator that the immense mountains which surround Quito owe is part the relative immunity enjoyed by the persons who ascend them. At Quito, says Jameson, ${ }^{2}$ the average temperature is about $14^{\circ}$; the thermometer fluctuates between $18^{\circ}$ and $8^{\circ}$.

But this element is not the only one. There is a great difference, judging by what we said before, between a mountain situated on the shore of the ocean, like the Peak of Teneriffe (3715 meters), for example, and another of the same height in the main range of our Alps, Iike Galenstock (3800 meters). To make the ascent of the former, in fact, the traveller starts from sea level, and in one stretch covers a considerable vertical height; in the case of the second, the distance to be traversed is lessened by at least 1000 meters. In the latter case, the transition is infinitely slower. Moreover, one cannot even approach the foot of the Alps without having had a sort of acclimatization with muscular training, instead of merely disembarking at the foot of the Peak or Etna. And so on these mountains of moderate height, in spite of the high temperature of their region, symptoms are still more frequent than on mountains of similar height in the Alps.

For the same reason, in addition to their situation in the torrid zone, Chimborazo, Antisana, Cotopaxi, etc. cause only moderate symptoms; the city of Quito, which is at their feet, and from which one starts after a longer or shorter sojourn, is situated at an altitude of 2910 meters, so that there remains a vertical ascent of only 1950 meters to the summit of Pichincha; and so here we recall the irreverent comparison of Canon Bourrit (page 13).

The reader may convince himself, by reviewing the journeys across the Andes (pages 22-59), that the symptoms are much more general and much more severe among travellers going from the Pacific to the Atlantic, than among those going in the opposite direction. In my opinion, the explanation of this apparent peculiarity lies partly in the fact that from the coast of Chile the ascent is extremely steep, whereas it is slow and progressive for the traveller going from the east to the west.

The considerable height to which one must ascend in the Himalayas before being attacked by mountain sickness may be due to 
the same cause. In the enormous range in which the Indus, the Bramapoutra, and the Ganges rise, one reaches the dangerous passes only after he has walked for a long time over hilly territory, the strata of which, rising higher and higher, gradually prepare him for the effects of the lofty heights. The transitions there are very slow; the dreaded symptoms should appear very late, and this actually happens.

But of course this great effect must be reconciled with climatic conditions and other causes of variations which we have already noted. It seems to us that, except for a few cases which are still hard to interpret and upon which the discussion of theories suggested will cast some light, the strange irregularities which we mentioned at the beginning of this section can almost all be explained satisfactorily.

\section{Symptoms of Mountain Sickness.}

Mountain sickness, the veta, puna, mareo, or soroche of the South Americans, the bis, tunk, dum, mundara, seran, or ais of the mountaineers of central Asia, the ikak of the natives of Borneo, is composed, at its maximum intensity, of a group of dangerous symptoms, which affect at the same time all the great physiological functions: innervation, locomotion, circulation, respiration, and digestion. We shall first summarize them in accordance with the preceding accounts, assigning them to each of these divisions of natural phenomena.

Digestion. Exaggerated thirst, distaste not only for eating, but even for the sight and smell of food, lack of flavor in liquids, nausea, and vomiting have been noted by almost all travellers. One eats very little on lofty mountains; Martins and Bravais, with three guides, made a good meal on the rations for one man. As for violent symptoms, nothing is more striking than the description given by Acosta: "After vomiting food, phlegm, and bile, one yellow and the other green, I even threw up blood" (page 24). The modest euphemism of English travellers about "heavings of the diaphragm" and "distress in the stomach" give glimpses of the picture energetically drawn by the old Jesuit. In the narratives of the first chapter, we shall find it difficult to make a selection among the many descriptions. Sometimes the stomach becomes so sensitive that it cannot endure a spoonful of water (page 158).

Diarrhea has been noted, probably as a result of the spurts of bile injected into the intestine during the efforts to vomit. "My companions were exhausted with vomiting and defecating", Acosta 
also says (page 24). However we must say that in some cases it seems to be due simply to the cold, to wet feet, etc.

The combination of these phenomena is always that which has most astonished and terrified the travellers; to these phenomena is due the old comparison which has given its significant name to mountain sickness, mareo.

Secretions. Secretory disturbances are not very important; their relation of effect to cause with the act of ascent is far from demonstrated. If there is an exaggerated flow of perspiration, the violent exercise and the direct action of the rays of the sun are sufficient explanation for that. The decrease in urinary secretion may be the consequence of the same causes, but several travellers see in it the direct effect of lofty regions. Besides, no exact measurement has been taken, nor has any chemical analysis been made.

Respiration. Respiration which is more frequent, shorter, then difficult, broken, and uneasy has been experienced and noted by everyone. Oppression is often accompanied by pains in the chest. This, along with exaggerated fatigue, is the first manifestation of mountain sickness. Animals are not immune. We have seen what importance has been attached to the increased respiratory rate by the theorists who have considered the question; we shall return to it in a moment.

The observations of M. Lortet (page 111) have fixed the modifications in the respiratory rhythm caused by the altitude: the amplitude decreases if the number increases. Vivenot in his apparatuses has also noted this (page 280).

As to the consequences, in regard to respiration, of a permanent sojourn in lofty places, the data reported seem to contradict these results. To quote only the most recent authors, M. Jaccoud states that the number and the amplitude of the respirations increase on the Engadine (page 297). Drew also finds "the respiration more rapid and more ample" (page 295). M. Armieux reaches the same result in regard to number; moreover, he reports an increased respiratory capacity in the hospital attendants at Baréges. Everyone seems to agree on the question of frequency; but that of amplitude requires additional research. The same thing is true, for greater reason, if we take up the question of races (page 301).

Circulation. The acceleration of the pulse, though it has not been noted by all travellers, like the digestive and respiratory disturbances, is no less constant. One can verify this, even though no feeling of discomfort attracts the attention. While I was making the very modest ascent of Nivolet (1558 meters) near Chambéry (269 meters), my pulse rate and that of all the other persons who 
composed our little caravan rose by 4 to 8 ; it was counted, of course, after a long rest. Lieutenant Wood only by chance noticed the extraordinary rapidity of his pulse, so that he thought he was feverish (page 143).

When the difference in level is very great, the acceleration becomes considerable. Moreover it is, as de Saussure said (page 85), in proportion to the intensity of the distress experienced. The extraordinary rates of 130 and 140 are not very rare on lofty mountains: "My heart", says Mistress Hervey, "was going a railroad pace". (page 149). Parrot tried to establish a sort of ratio, which might have served as a measure of the height, between his pulse rate and the altitude reached (page 122). The table published by Lortet (page 114) is very interesting in this regard; but such a regularity is far from being general. At great heights, the acceleration of the pulse becomes unendurable; it is accompanied by buzzing in the ears, throbbing in the carotids and temples, and more or less violent palpitations which become terrifying. This acceleration does not seem to be controlled by the use of digitalis (page 151).

This modification is not transitory; it continues through the whole sojourn in lofty places. It is regrettable that exact observations on this point are extremely rare. So I think I should quote here those which were recently published by M. Mermod.

M. Mermod" counted his own pulse rate repeatedly at the three stopping places of Erlangen (323 meters), Lausanne (614 meters), and Sainte-Croix (1090 meters); the sojourn in each of these places lasted several months. These observations were made with meticulous care, and all necessary precautions were taken so that the causes of error might be less than the variations, evidently very slight, which the circulation might show under equally slight differences in altitude. The average of 900 observations made at Erlangen was 62.76 heart beats, that of 577 observations made at Lausanne was 66.68 , and that of 333 observations at Sainte. Croix 68.87. The increase of the number with the altitude was noted at all hours of the day.

M. Jaccoud (see page 297) also observed on the Engadine a persistent acceleration of his own pulse rate.

I should, however, mention on the opposite side the observations of Dr. Armieux (page 299), who found an average decrease of 3.85 heart beats from Toulouse (200 meters) at Baréges (1270 meters).

The frequency does not show the only modification in the pulse. Its strength is greatly diminished, it becomes irregular, very 
plainly dicrotic, and is progressively smaller and more easily depressed. The tracings made by $\mathrm{M}$. Lortet during the ascent of INont Blanc (see page 112) are very clear in this regard. The arterial tension decreases considerably.

Other observers, on the contrary, have found the pulse full, strong, "vibrating," says Guilbert, "as in aortic insufficiency" (see page 54). According to Junod, who experimented in closed vessels, it is full, depressible, frequent (page 229). Without losing strength, says M. Lepileur, the pulse increases in rapidity considerably (page 236).

The venous system displays no less striking phenomena; fullness of the blood vessels, congestion of the skin, the lips, and the conjunctiva; face violet or reddish, swollen; lips blue and swollen.

Then sometimes the picture suddenly changes completely; the face becomes pale; syncope seems imminent. Sometimes it actually appears, going as far as complete loss of consciousness. Upright posture is very likely to bring it on (see pages 79,106 ).

The most terrifying, if not the most serious, of the circulatory disturbances is hemorrhage; it appears less frequently than is generally said; in order of frequency, we note first nasal and pulmonary hemorrhages, then hemorrhages from the eyes, the lips, the ears, and the intestines; finally, M. Martins experienced a slight hematuria. Mlle. Dangeville found that her menstrual period was considerably advanced; but the violent exercise might explain that.

These losses of blood have been observed in animals, especially horses and cattle. I mention in passing the important observation of Dr. Clark, who remarked that the blood coming from the nose was "darker than usual" (page 91).

Locomotion. The heaviness of the lower limbs, the "blow on the knees", a fatigue which the efforts made do not explain, are among the first signs of mountain sickness. We have seen in numerous quotations that at a certain height it becomes impossible for the sturdiest walkers to take more than a few steps without stopping. And this is a matter of altitude, not of the ordinary difficulties of mountain journeys. "I made 34 miles on foot," says Captain Gérard, "through country which would be called mountainous by those who do not know the difficult parts of Koonawur, more easily and quickly than I could walk 12 miles in these lofty regions. When the altitude is more than 14,000 feet, every mile, even when the road is good, requires at least twice as much time as at the height of 7000 to 8000 feet" (see page 138). 
It is not only walking that becomes painful. The slightest weight wearies the shoulders; a task, moderate in ordinary regions, cannot be carried out in the mountains without real sufferings, sometimes dangers. "We could not use our arms," said Dr. Gérard (page 136), "to break off a piece of rock with a stroke of the hammer." Hamel says that "even talking tires one" (page 90). And the Schlagintweit brothers, who make the same observation, add that "one heeds neither comfort nor danger" (page 155).

I have found convulsions mentioned only in the narratives of Mistress Hervey (page 147) and, in spite of the disrespect of the connection, in the horses whose story is reported by Liguistin (page 272). But in both cases there is perhaps some other cause in addition to the effect of lofty places.

Innervation. At the head of this category come the headaches, which are so violent and unendurable, compared to "an iron ring compressing the temples" (Guilbert), as if "the head were going to split in two" (Mrs. Hervey), of which travellers in the Himalayas complain in particular.

The sensory modifications, and especially the mental depression, have been noticed much less than the preceding symptoms. However, rather frequent mention is made of buzzing in the ears and a blunting of hearing and taste. The weakening of hearing is explained by the lessened intensity of noises transmitted by the thin air. Mention is more rarely made of sight, although we have quoted examples of travellers whose sight failed or who complained of dazzled or dimmed vision, etc. (see pages 94, 147). Loss of consciousness, total swooning as a result of syncope, they say, is also mentioned. But only an unwilling report is given of what Captain Gérard frankly called "mental depression" (page 138), and Henderson called "great prostration of body and mind" (page 158).

And yet when we read travellers' accounts carefully, we almost always find the manifest trace of it. Many disguise it under the name of drowsiness; there is no hesitancy about speaking openly of a desire to sleep which sometimes becomes unconquerable; but we do not admit so willingly that the senses are dulled, the intellect weakened, the energy lessened, that the mind like the body is invaded by extreme indolence, or, by a strange reaction, thrown into unhealthy exaggerations.

Count de Forbin, however, declares (page 72) that he was "enfeebled, agitated by the terrors of a feverish brain. Weariness of the senses, exaltation of the imagination cast one into a state of near-delirium." Henderson also speaks, and de Saussure had 
done the same long before him, of a great excitability of temper. On the other hand, de Saussure admits that he did not work with much zest on the summit of Mont Blanc. M. Lepileur goes further and relates (page 103) that he and his companions journeyed mechanically, without thinking, so to speak, He attributes to this mental prostration the contradictions which he notes in the accounts of mountain climbers who preceded him. As for me, who have read hundreds of accounts of ascents, in the collections of Alpine clubs of all nations, I cannot help thinking that their monotony, their lack of real interest, the want of more than average thoughts which characterizes almost all of them, result largely from the unconscious state of mental depression of their authors, caused by the sojourn in lofty places. The average account of ascents to lower levels is infinitely more interesting, richer in outside observations and evidences of intellectual activity; gymnastic feats and culinary preoccupations are much less in evidence in all cases.

Aeronauts have noted similar facts, that is, slow depression leading to indifference and sleep: "The mental powers fail before the physical powers. First one loses memory and care. He forgets to give heed to the balloon; soon a slow and gentle sleep lulls all the members" (Robertson, page 183). In other cases, there is a strange excitement. Finally, at great heights, the aeronaut, even in the most complete physical calm, is suddenly struck by complete insensibility. That happens to Zambeccari and M. Glaisher.

Such are the grievous symptoms produced by the influence of lofty places. At the beginning, a sensation of inexplicable fatigue, short respiration, rapid panting, violent and hasty palpitations; distaste for food; then, buzzing in the ears, respiratory distress, dizziness, vertigo, weakness constantly increasing, nausea, vomiting, drowsiness; finally, prostration, dimming of the vision, various hemorrhages, diarrhea, and loss of consciousness. Such is the ascending series of symptoms, in proportion to the altitude reached Among all the accounts which we have collected, which picture vividly all these distresses, in my opinion, there is none which is more vivid and complete than that of Tschudi, falling unconscious on the ground, in the icy Puna of Peru (see page 47).

Even death, an immediate death, may be the result of these serious symptoms. We have given some instances of this in the Andes (see pages 25, 33, 37, 43) and in the Himalayas (page 137). And it is not only men who may succumb; animals, cats, dogs, camels, mules and horses in particular, die still oftener.

The intensity of these symptoms is considerably aggravsted 
by walking, running, any expenditure of energy. We have had many examples of this: one of the best guides of the Oberland (page 94), whom a rather strenuous effort twice makes blind; the traveller Weddell, till then immune to the soroche, who is stricken after a rapid excursion (page 48); de la Touanne, falling on the ground almost unconscious, because he wished to go faster suddenly (page 36); d'Orbigny, who, thinking himself acclimated, was compelled to stop every time he waltzed (page 38 ); Hedringer falling on the snow, because he wished to run to the summit of Mont Blanc (page 96); an inhabitant of the Alpine mountains, who, trying to outstrip his companions, rolls over "as if some one had shot him" (page 116). Travellers say that it is to the eagerness of the horses, which spring forward under the spur, that their frequent deaths are due, whereas the mules, patient and obstinate, survive because they refuse to quicken their pace. It is walking uphill which especially fatigues and exhausts.

This fatal effect of muscular activity is felt at all altitudes. But in regions of moderate elevation rest is sufficient to dissipate its effects and restore complete calmness. And that is perhaps the most peculiar characteristic of mountain sickness. To the uneasiness of the traveller, to his extreme fatigue, to his grievous distress, there succeeds an unexpected comfort, as soon as he stops, sits down, or particularly lies down: his heart regains its rhyfhm, respiration becomes regular, a feeling of energy returns, all as if by enchantment; so that after a few minutes, astonished both by these unknown discomforts and this sudden cure, the inexperienced traveller confidently resumes his climbing. But soon he is again attacked and conquered.

On loftier mountains, rest, even rest in a horizontal position, even if it dissipates the most violent symptoms, does not, however, restore calmness. Palpitations, suffocations, trouble, or prevent sleep. Sometimes a strange symptom appears; cluring the night, at dawn especially, sudden respiratory distress awakens the sleeper with a start (see pages $39,54,55,132,149,155,158,160$ ). A few deep inspirations restore calmness; probably it is a consequence of this forgetting to breathe of which de Saussure had spoken (page 83); imminent asphyxia awakens the sleeper suddenly.

Such is the series of symptoms which, in different degrees, at different altitudes, attack mountain climbers and aeronauts. It seems that there is no great difference, except in intensity, between the symptoms observed in the different mountainous regions. Although the symptoms which we have described appear sooner in our Alps than in the Andes and the Himalayas, they 
never reach there the dangerous severity which threatens the lives of travellers and their guides, even natives, in the other regions. That is because the height of Mont Blanc (4810 meters) is the maximum which one can reach in our Europe, and because one remains there only a few hours at the most. Conditions in the Himalayas are far different, because there one remains for a long time on plateaux at an altitude of more than 4000 meters, crossing almost every day passes which reach an elevation of 5000 to 5500 meters.

A harmful influence whose dangerous effects many travellers have mentioned is that of the wind. "There blows in this place," says Acosta, whom I must constantly quote, "a little wind which is not too strong or violent. But it is so penetrating that men fall dead from it, almost without perceiving it" (page 25). M. Lepileur also suffered from the wind to a much less dangerous degree (page 103). The Schlagintweit brothers also complain of it very bitterly (page 155), and Henderson claims that it often kills travellers (page 159).

Many narratives agree in stating that the symptoms are particularly severe at points on the mountain where the air is renewed with greater difficulty. Should this irregularity be attributed to the heating of this air, expanded by the sun? Or to the tediousness of walking in these monotonous passages? The observations of M. Javelle and M. Forel tend to support this latter hypothesis. They state, in fact, that mountain sickness disappears in dangerous spots (page 289) and also as a result of attentive observation of the landscape or oneself (page 292).

It would not be very interesting to dwell on the medications used by the natives against the symptoms of mountain sickness. They generally agree in forbidding alcoholic beverages; in America, they praise bleeding, especially for animals. In the Andes protective powers are attributed to garlic or onion placed in the nostrils of the animals; in the Himalayas, acid and dried fruits are used. Almost everywhere it is recommended that one should eat little and often. M. Dufour declares that he dispelled an already violent attack of mountain sickness merely by eating a piece of bread (page 290).

\section{Theoretical Explanations.}

We may divide into two great categories the hypotheses and the theories put forward to explain mountain sickness: some of them, by far the most interesting, try to settle the mechanical, physical, or chemical role of the diminished atmospheric pressure; 
the others, the most peculiar ones, seek the cause of the symptoms in something other than the fall of the barometer. We shall begin with the latter.

Pestilential exhalations. The explanations which put forward pestilential exhalations, either from the ground or from toxic plants, must be given a moment of our time.

They have their origin in the absolute ignorance of the native peoples about the very existence of an atmosphere. Therefore the Indians and the Tartars of the Himalayas, the Redskins of the Andes and their successors, almost as uncivilized as they, did not hesitate to attribute the symptoms which struck them and their domestic animals to some mysterious poisoning. In the Andes, the frequent presence of metallic ores and the evident effect of mountain sickness upon the unfortunate miners gave rise to the belief that there issued from buried metals, and particularly from antimony, "which plays," says Tschudi, "an important part in their physics and metallurgy," emanations dangerous to all those who passed over their veins. Hence the name soroche, which means both antimony and mountain sickness.

In central Asia, the idea of exhalations from the earth also occurred to the people, especially towards China; we saw that Father Huc did not hesitate, with his usual credulity, to declare that the symptoms of Bourhan-Bota were due to carbonic acid from the ground (page 238).

Volcanic mountains, like Etna, the Peak of Teneriffe, the mountains of North America, because of deleterious vapors which rise from certain crevasses, have caused among travellers a much more pardonable confusion between the effect of the altitude and that of the mephitic gases; we have seen examples of it.

All through the Himalayas, the mountaineers do not hesitate to attribute the distress from which they suffer to volatile poisons emanating from flowers or plants. Generally the narratives of the travellers limit themselves to these vague expressions; but when they are more exact, the strangest divergences appear.

The Chinese author whom we quoted (page 129) gives rhubarb as the cause. When Fraser's coolies complain of the seran and blame the flowers which cover the ground, he looks around him and finds primroses, heather, and polyanthus (page 132). For Mistress Hervey, whose distress we have narrated, it is a sort of moss. the bôttee, which the natives show her as the cause of all her troubles (page 148). They could not show Cheetam the dewaighas, the mysterious and toxic plant (page 153). Henderson reports that they blamed artemisia (page 295), and Drew, the onion (page 295). 
These hypotheses, natural product of the ignorance of the natives, have sometimes been accepted by European travellers. They served as an easy explanation of this curious fact that the intensity of the symptoms is not regularly proportional to the altitude, and that at certain points, sometimes of moderate elevation, almost everyone is sick. It is especially travellers in the Andes who believe in emanations from the ground. Some of them would say, like the peons of Brand: "There is much puna here" (page 36).

However, very few admit their credulity clearly; they are satisfied with saying that there are "accompanying causes, which are unknown, and which act with the rarefaction of the air" (page 55); that "the atmospheric pressure is not included in the causes of the soroche, which should perhaps be attributed to emanations from the ground" (page 58).

Asiatic travellers have been more prudent. Hodgson alone allows one to glimpse a certain credulity (page 223); but all the others refuse to admit intoxication by plants; those who have deigned to take note of it declare formally that frequently the symptoms appear where there is no vegetation, not even moss: from Fraser to Mistress Hervey and Drew, they all agree on this point.

To tell the truth, these hypotheses do not need any other refutation. Moreover, the identity of the morbid symptoms attributed now to antimony, now to vapors from the earth, elsewhere to emanations from undetermined plants, is enough to show that they have a single cause, which is closely connected with the elevation above sea level.

Electricity. When people do not know what else to say, they are very likely to invoke electricity as the cause. Dr. Govan did this (page 221): "These phenomena," he says, "depend upon atmospheric circumstances, less general than the decrease in pressure, like the electric power which must be in a state of constant fluctuation in the presence of such lofty conductors." For Heusinger (page 245), electricity must act, for it is stronger and less often negative. But these authors were outdone by Dr. Cunningham, who declared that "in the northern hemisphere, the electricity attracts the blood to the head, and in the southern hemisphere, to the feet .... from which mountain sickness results, which explains why this illness is cured by the horizontal position" (page 225). The strangest thing is that this strange doctrine has found votaries (page 296).

Lack of oxygen in the air. It is the unevenness of the effect of the altitude, according to the regions, which has suggested all these 
peculiar explanations. Truthworthy, even eminent men have not escaped this need of seeking elsewhere than in the effect of diminished pressure the cause of the distress experienced.

Certain persons believed that they had found this cause in a special weakening of the air or, to speak more exactly, in its diminished oxygen content. That was the opinion of von Humboldt (page 30 ), who said that he found only $20 \%$ of oxygen on Chimborazo, and attributed a great effect to this difference.

M. Boussingault, struck by the fact that mountain sickness hardly ever occurs until perpetual snow has been reached, took up an old idea of de Saussure, who had maintained that the air released from the pores of the snow contains less oxygen than free air; he made an analysis which gave only $16 \%$ of oxygen, and then he attributed the suffocation which he had experienced to this foul air. freed by the action of the solar rays (page 227). By this reckoning, one should experience mountain sickness on plains covered with snow, in a fine January sun. Other travellers (page 294), without other objection, accepted this hypothesis, which the celebrated chemist himself finally admitted was mistaken.

Fatigue, cold. These are two causes frequently hailed, not as adjuvants, which would be correct, but as the principal or even the sole cause. It is the warhorse of those who deny mountain sickness: "We can assert," says one of them, "that these are the same sensations experienced by ordinary travellers when they approach the summit of any mountain" (page 231). "What proves indisputably that these symptoms are due to fatigue," says Bouguer, "is that no one was ever affected by them when he was on horseback, or when he had once reached the summit, where the air, however, was still thinner" (page 208).

We must admit that at first glance and for slight symptoms confusion is possible. Hasty respiration, dyspnea, circulatory acceleration, palpitations, even vertigo, and heaviness of the limbs are the result of any exercise which is somewhat tiring and prolonged. But we need only glance at the numerous data reported above to find in them the proof that there really is a special influence in lofty places: the symptoms appear, as we have seen, even during rest and sleep. Moreover, Acosta had very early refuted these errors (page 24), as did de Saussure (pages 213, 216).

Yet it is still fatigue, though of a special type. which Rey invokes (page 232). M. Lepileur's ideas (page 237) are evidently of the same sort; this learned physician in his explanation of the fatigue gives overwhelming importance to "the congestion 
of blood taking place in the muscles during their action." As to the other phenomena, they are the result of congestions of the lungs or the brain, caused by the constant repetition of efforts made during the act of climbing. Moreover, "the rarefaction of the air, making respiration more frequent and panting more rapid. necessarily hastens the rest of the ordinary effects of effort." But how does the rarefaction of the air make panting more rapid? That is what M. Lepileur does not tell us.

Theories of $M$. Lortet and $M$. Dufour. Here now are two very important theories, which show a thorough knowledge of the most difficult questions of physiology. Their place is indicated here because they are, in a word, only a scientific form of the common charges against fatigue and cold.

In the opinion of M. Lortet, the body temperature of man diminishes when he expends the enormous quantity of work necessary to raise the weight of his body to a great height. We have reported in full the data secured by Lortet (page 114) and the theoretical conclusions which he draws from them (page 286). Unfortunately, as MM. Forel (page 288) and Clifford-Allbutt (page 289) have shown, the very observations of the French physiologist were wrong: the temperature of the body always rises as a result of the act of ascent, as in the case of all violent gymnastics.

Even referring to the figures of M. Lortet, who maintains that from Chamounix to the Grands-Mulets the temperature dropped $2^{\circ}$, and that at Chamounix the act of walking cooled the body $1.7^{\circ}$, serious symptoms should follow the slightest exercise at these elevations, where, however, mountain sickness has never been observed. Moreover, according to him, rest should restore the normal temperature almost instantaneously but it is far from dispelling all the symptoms.

We must say, however, that M. Forel, never having had mountain sickness, could not take his temperature in this special condition; we might still say, until proved wrong, that he would find it lowered in this case. But even if it were so, it would still have to be admitted that another element besides work must be involved, and that altitude is this element.

We shall soon discuss the theories about insufficient oxygenation due to decreased pressure. If we introduced this new factor into Lortet's theory, we should be led to think that since the work of ascent requires an increased combustion, and since the proportion of oxygen is too small, heat would be transformed into motion, resulting in a drop of temperature and consequently, general disturbances. But this drop would have to be proved, and Lortet's 
observations are evidently tainted with causes of error which vitiate them as sources of proof: even the experiments of Legallois (page 218), notable as they are, cannot be used in his favor, since they deal with confined air.

The theory of M. Dufour (page 291) is also independent of the idea of altitude. In his opinion, mountain sickness is the consequence pure and simple of fatigue, which results from the exhaustion of the ternary materials stored in the muscles; and so he states that he experienced the symptoms even on the plain, after great fatigue. It cannot be merely the rarefaction of the air, he says, which makes one ill on the summit of Mont Blanc, because aeronauts had to reach 7000 and 8000 meters to experience serious disturbances; moreover, these disturbances do not at all resemble those produced on the mountain.

We leave to the reader the task of weighing the value of this last statement, and as for the comparison of mountain sickness to simple fatigue, we shall merely ask why it has never been made by tourists, who, not without great fatigue, walk all day in mountains less than 2000 meters high. At least they have never confused the lasting weariness which they experience in the evening with the sudden "blow on the knees" which exhausts the limbs and disappears after a few minutes rest; nor have they confused the breathlessness and the acceleration of the pulse due to a laborious or rapid walk with the dyspnea, the palpitations, and the total exhaustion which, at an elevation of 4000 meters, often halts the traveller after a few steps. There is, therefore, something besides the exhaustion of the ternary materials, and this something is the altitude reached, or, to speak more clearly, the diminished pressure. This objection is evidently applied to the ideas of Bouguer, Lepileur, and Lortet, as well as to the theory of Dufour.

We now come to the theories which involve the decrease in atmospheric pressure. Laboratory experiments had shown that animals placed under the bell of the pneumatic machine became ill, even died, when the pressure was lowered sufficiently, and the conclusion had been drawn that the lowered air pressure on lofty mountains was probably the chief cause of the symptoms. But how does it act? Here the theories become numerous.

Decrease of the weight sustained by the body. One of the first which entered the minds of travellers may be summarized thus: At normal pressure, each square centimeter of our bodies sustains a weight of 1.03 kilograms, or, for the entire surface, a number which should be 18,000 kilograms for a man of average height. We do not feel this enormous weight which would crush us, the 
authors say, thanks to the inner tension of the fluids of the body which counteract it; but if it diminishes, immediately this tension, which nothing now checks, will urge the fluids to the periphery, will fill the skin with blood, will swell it, will congest it, and by rupturing the blood vessels will cause hemorrhages: it will be the same as if the body were plunged into an immense cupping-glass. Now this is what happens when one rises in the air: at an elevation of 3300 meters, 5000 kilograms will have been removed; at 5500 meters, half of the total weight, that is, 9000 kilograms. Why should one be surprised at the serious disturbances which occur then?

This is the theory approved by the large majority of those who have considered the question, particularly, we must say, travellers and physicians. We find it suggested for the first time in a few words by Bouguer (page 209). Haller develops it at length (page 210 ); it is true that, recalling a strange idea of Cigna (page 206), he declared that there is a great difference between "air rarified by the removal of a part of it and that which is lighter because of the elevation. . In the latter, although it has lost half its weight, respiration takes place without difficulty." That is no stranger, at any rate, than to see Bourrit maintain that at an equal elevation, "the air of the Alps is rarer than that of the Cordilleras" page 213). De Saussure accepted completely the theory of the "relaxing of the vessels produced by the decrease of the compressing force of the air" (page 215). It was this illustrious physicist who expressed it most clearly. It was also accepted by Fodére (page 217), Hallé and Nysten (page 217), Gondret (page 220), Dr. Gérard (page 222), Hipp. Cloquet (page 223), Burdach (page 225), Rey (page 231), Brachet (page 235), Lombard (page 243), Heusinger (page 245), Foley (page 270), Scoutetten (page 276); we mention only the chief advocates.

We see that this theory has the support of the most eminent names. It is really painful to have to reject it by a sort of preliminary question, as absolutely contrary to the laws of elementary physics. But long before me, MM. Giraud-Teulon (page 246) and Gavarret (page 279) had called upon the principle of the incompressibility of liquids to combat this error. Valentin (page 244) had even calculated that the removal of a half-atmosphere would increase the volume of the body only about three hundred-thousandths. It is quite evident that all pressures or decompressions balance each other, immediately counteract each other, when they are applied to the whole body, since it is composed entirely of 
liquids and solids. If there is decreased pressure on the surface of the skin, on the outer wall of the blood vessels, the decrease is absolutely equal on their inner wall, and there is no change in the state of equilibrium.

It is really strange that anyone could have thought seriously that by going to Cauterets he would be relieved of 2744 kilograms (page 276), and that Gay-Lussac should have felt 10,000 kilograms removed from his shoulders in a few minutes. If the liquids of the organism were really thus held by the outer pressure, a few centimeters decrease in pressure would produce the most terrible disturbances. It is the comparison with the cupping-glass which has caused the error: they forgot that in the cupping-glass it is the effect of the pressure on the rest of the body which causes the swelling, the congestion, and the local hemorrhages.

Escape of the gases of the blood. The physicists, most of whom escaped the erroneous hypothesis which we have just discussed, were better inspired when they gave an important role to the escape of the gases of the blood, as an effect of the diminisher pressure. Robert Boyle had been the first (page 201) to see that all the liquids of the body, blood, urine, bile, humors of the eye, release bubbles of gas, when they are placed in the vacuum. From it he drew the conclusion that in animals which die under these conditions, death may be, "besides the failure of respiration," the result of the formation of these bubbles, which "check or disturb the circulation in a thousand ways." He even thought that, at the time of slight variations of the barometer, it is "the spirituous or airy particles which, held in abundance in the blood as a whole, naturally expand the liquid, thus being able to distend the large vessels and change considerably the speed of the circulation of the blood in the capillaries and the veins."

Borelli had the same idea and attributed to a sort of effervescence of the blood the symptoms which he had experienced on Mount Etna (page 207); but he soon gave up this idea (page 208), to which, however, there rallied Musschenbroeck (page 198), author of a dissertation De aeris existentia in omnibus animalium humoribus, Veratti (page 204), Rostan (page 225), F. Hoppe, who made experiments upon animals to verify it (page 248), Guilbert (page 254), and finally Gavarret (page 279).

The escape or the tendency to escape of the gases of the blood has been used especially to explain the circulatory acceleration and the hemorrhages. "When the outer pressure diminishes," says M. Gavarret, "these gases tend to escape from the blood, force the walls of the vessels from within outward and distend the pul- 
monary and general capillaries, the walls of which, since they are thin and lack resistance, may be ruptured. Such is the mechanism of the production of hemorrhages.'

Indeed it seems settled, in spite of the objections of Ch. Darwin (page 207), John Davy (page 224), and M. Giraud-Teulon (page 246), that at a sufficiently low pressure, gases escape from the blood of living animals placed under the pneumatic bell; F. Hoppe did not even hesitate to conclude that the death of the animals under these conditions is due to this release of gases. But nothing in the experiments yet known proves that the escape takes place at pressures which coincide with mountain sickness, nor that the tendency to escape can bring on the disturbances for which it is blamed. No comparison can be made between an animal brought in a few minutes to a fatal decompression and a traveller who takes six hours to ascend vertically 2000 meters. If the gases were partial cause of the symptoms, aeronauts, who undergo enormous changes in pressure with great rapidity, would be the first to be stricken, and we know that that is not the case.

Expansion of intestinal gases. The idea that the decrease of pressure must expand the intestinal gases is evidently not wrong from the standpoint of physics; but that is far from justifying the conclusion that this increase in volume is the cause or one of the causes of mountain sickness. However, Clissold (page 224) considered that it must hamper respiration and circulation considerably. M. Lepileur (page 237) and Speer (page 241) also tend to attribute some effect to it; M. Maissiat is more positive: "The intestinal gases, gaining volume, distend all, to the point of rupture" (page 234). The learned physicist reasoned as if the intestine was a closed swimming bladder, and he forgot the double communication with the exterior, which, in practice, permits no distention. The same thing is true of M. Colin, who sees a cause of death in "the forcing back of the diaphragm by the expansion of the gas" ipage 307).

Loosening of the coxo-femoral articulation. It is under the patronage of the illustrious von Humboldt (page 228) that there appeared this odd explanation of the extreme fatigue and the heaviness of the lower limbs which appear in lofty ascents. It has since been accepted by many writers: Tschudi (page 232), Meyer-Ahrens (page 243), Lombard (page 252), and Guilbert (page 255).

It is undeniable, as Brard (page 312 ) has shown, that the surface of the cotyloid cavity is sufficient to permit the atmospheric pressure to support the weight of the leg, when all the soft parts 
have been cut away. According to M. Jourdanet, the pressure thus exerted would be equivalent to about 23 kilograms. We have seen how this author proved, by calculations based on the surface of the cotyloid cavity, that at the time when the weariness of the lower limb appears, the atmospheric pressure is still capable of supporting a weight double that of this member (page 257).

Dr. Faraboeuf, at my request, consented to make precise measurements upon a human cadaver. Here are the results which he gave me:

Man of forty-eight years, weighing 52.5 kilograms; height 1.65 meters, 0.85 meters in the lower limb; well proportioned, thin, but still apparently muscular.

Diameter of the cotyloid cavity_____ $51.5 \mathrm{~mm}$.

Surface 20.8 sq. $\mathrm{cm}$.

Weight of the atmosphere on this surface $21.4 \mathrm{k}$.

Weight of the lower limb disarticulated in the fold of the buttock and the groin $6.3 \mathrm{k}$.

Weight of the lower limb deprived of the muscles which are inserted into the pelvis

5. $\mathrm{k}$.

So the atmospheric pressure is capable by itself of supporting a weight four times greater than that of the lower limb deprived of the muscles which support themselves by their connection to the pelvis. We should therefore have to go to a fourth of an atmosphere, that is, a pressure of $19 \mathrm{~cm}$. to cancel the support furnished by the weight of the air. Evidently then the cause suggested by von Humboldt has no connection with the fatigue which appears on Mont Blanc at a pressure of $41 \mathrm{~cm}$., at which point the atmosphere still represents 11.5 kilograms.

Very certainly the effect of the pressure upon the firmness of the articulations has been exaggerated; setting aside this exaggeration, von Humboldt has not drawn the really logical conclusion from the principle which he thought correct. It is not a greater muscular fatigue which should occur, and it should not be limited to the muscles of the thigh; the danger for the traveller in regions where the atmospheric pressure is lessened is dislocations, and in all the articulations; but in spite of the unusual exertions which ascents entail, no such symptom has ever been noted.

Other mechanical effects of decreased pressure. Borelli attributed the fatigue to the presence in the thorax of expanded air which "no longer aids," he says, "the effort of the muscles, compressing by its elasticity the air and blood vessels." It is not easy to see clearly what the learned physician-mathematician meant. But there is some truth in what we may suppose to have been his thought. If, in the phenomenon of effort, the chest walls, as M. J. 
Cloquet ${ }^{4}$ has shown, are immobilized in a certain state of expansion, because an equilibrium has been established between the pressure of the expiratory muscles and the elasticity of the intrapulmonary gases which the closed glottis prevents from escaping, the original density of these gases should be important. If they are rarefied, the state of equilibrium will occur only with a stronger contraction, or a smaller expansion of the thorax, and this situation may be unfavorable to the phenomena of maximum effort,. But the effect, in any case, should not be of great importance.

Musschenbroeck had given a very ingenious explanation of the death of animals in a vacuum. He had found their lungs "small, flabby, solid (page 198), specifically heavier than water," and he had considered that the death is the result of the stoppage of the circulation which this collapse should produce; the same fact was noted by the Dutch physiologists (page 202), who interpreted it a little differently. But these explanations cannot, however, be applied to disturbances and death in an air which is much rarefied but still far from a perfect vacuum. Cigna long ago commented that respiration should continue under these conditions, as long as "the air is dense enough to expand the lungs by its pressure"; but for that, it is sufficient "that this pressure should overcome the resistance offered by the contractile force of the lungs, for there is no thoracic air to increase this resistance, and this pressure hardly exceeds that of two inches of mercury" (page 207).

It could not be better stated, and Cigna was replying in advance, without knowing it, to those who would later give an important part in mountain sickness to the tendency of the lungs to retract under a lessened density of the intra-pulmonary air. Their force, that is, their elasticity, is equal to only a few centimeters of mercury, as Cigna had said. Therefore only under a still lower pressure could the lungs separate from the thorax wall, making a vacuum in the pleura. The supposed effect is therefore absolutely nil.

Pravaz fell into a similar error when he said that "in mountain air, respiration is mechanically restrained in its extent by the lack of elasticity in the atmosphere which presses the interior of the Iungs" (page 239). His opinion is subject to the same objections. But at least it has some appearance of probability, whereas I cannot understand what made A. Vogt say that "the diminished atmospheric pressure assists greatly in the expansion of the thoracic cavity, and thereby facilitates respiration" (page 237). 
The learned physician of Lyons seems to me no better inspired when he ascribes to the diminished pressure the venous congestions, because "the return of the blood to the right cavities of the heart will be less active." His comparison of the heart to "a pump operating in a medium in which the air is greatly rarefied, and which could bring up water only from a much lessened depth" (page 239) is not at all valid; no one believes now in the active, sucking expansion of the heart.

In conclusion, we shall quote a more accurate idea of the same author in regard to the recall of the venous blood by pulmonary expansion. One might think that the force of this recall should be decreased by the decrease in pressure. And yet, when we think it over, we see that there is no proof there: the return of the blood of the large venous trunks towards the heart takes place because of the difference between the tension of the outer air and that of the air which enters the lungs and expands there, since, as we proved long ago, ${ }^{5}$ in no animal can the opening of the glottis suffice for the capacity of the respiratory pump. It would still have to be demonstrated that this difference, the negative pressure of the Germans, is less in rarefied air than in normal air, of which we are by no means sure, and which is not even probable.

Excess of carbonic acid in the blood. We have reported with all the discussion it deserves the strange theory of M. Gavarret (page 275), explaining mountain sickness by a real poisoning by carbonic acid. According to the learned professor, the act of ascent would require such an increase of organic combustion that the carbonic acid which is the product of it could not be expelled quickly enough, in spite of the increase in the number of respiratory movements and heart beats. The result would be a storing up which brings symptoms of poisoning; and also the improve-ment which immediately follows rest, during which the excess of gas is expelled.

This theory was accepted by M. Leroy de Méricourt, M. Aug. Dumas, M. Scoutetten, M. Lortet (page 286), and many modern authors.

I do not dwell upon the difference between the symptoms of mountain sickness and those of poisoning by carbonic acid. But it is quite evident that the theory of M. Gavarret is open to the same objection which we used in disproving the theories involving fatigue and the theory of $M$. Lortet. It is clear, in fact, that the quantity of carbonic acid which must be produced in raising the body 1000 meters, for example, is independent of the altitude; so 
that there must be an excess of gas stored up, and consequently distress, just as much in ascending from Chamounix (1050 meter to the Pierre-Pointue (2040 meters) as in ascending from the Grand-Plateau (3930 meters) to the summit of Mont Blanc (4810 meters); yet that has never been observed. Furthermore, even at sea level, a task which is sufficiently energetic and prolonged should bring on the same result, and that is not the case. The necessary element, altitude, is not considered at all in this explanation.

As to the fact advanced, it in itself is far from proved. There is no proof that the carbonic acid, the formation of which is increased during the labor of ascent, can really be stored up in the blood. According to M. Gavarret himself, when a man lifts himself vertically 2000 meters, he forms 65 liters of carbonic acid, above the 22 liters which he produced per hour in his normal requirements. It will take him at least six hours to cover these 2000 meters. (MM. Lortet and Marcet took 8 hours to go from Chamounix (1050 meters) to the Grands-Mulets (3050 meters). We must then add 65 liters to the 132 liters formed during this time; in other words, the quantity of carbonic acid produced will have been increased by one third. Now it is very probable that the pulmonary excretion will have been sufficient to expel this small gaseous excess; the arterial blood, the nutritive blood, the impairing of which is so dangerous, is therefore probably not overladen with toxic gas. On the other hand, we know, from the experiments of M. Cl. Bernard, that one can safely inject into the venous system of an animal enormous quantities of carbonic acid, without producing symptoms, because of the rapidity and the energy of the pulmonary exhalation. And so nothing proves that there is an excess of carbonic acid in the arterial blood; nothing proves that this excess, if it exists, is capable in its actual proportions of causing symptoms; at any rate, these symptoms should appear at any altitude whatsover, and consequently have no connection with mountain sickness.

Theory of de Saussure and Martins. De Saussure noted, as we have reported (page 216), that, on the summit of Mont Blanc, "since the air had hardly more than half of its usual density, compensation had to be made for the lack of density by the frequency of inspirations. . . That," he said later, "is the cause of the fatigue which one experiences at these great heights. For, while the respiration is accelerating, so also is the circulation." The former view, however, was incomplete, or, rather, incompletely expressed. 
De Saussure gave one to believe, in fact, that the respiratory acceleration could compensate for the decreased density of the air. Now he certainly knew that that was not the case, and that on the summit of Mont Blanc neither the number nor the amplitude of the respirations doubled the pulmonary ventilation.

This explanation was accepted by all the authors who followed de Saussure. Hallé and Nysten (page 217), Courtois (page 218), Gondret (page 220), Clissold (page 223), von Humboldt (page 227), Brachet (page 235), Lepileur (page 236), A. Vogt (page 237), Pravaz (page 239), Marchal de Calvi (page 240), Meyer-Ahrens (page 243), Lombard (page 244), Longet (page 250), etc., reproduced it in different forms. Some were satisfied with speaking, as de Saussure had done, in a rather vague manner of the insufficient quantity of air brought into the lungs at great heights; others, making more definite statements, declare that, since less oxygen reaches the lungs in a given time, less of it must be absorbed by the blood, and hence the symptoms; some, like Longet, deny this conclusion, affirming that "the person who dwells on the mountains . . . . compensates by more frequent inspirations, so that . . . the same quantity of oxygen can be absorbed in the same time" (page 250).

M. Martins criticized this evident mistake; he declared that there must be a lessened oxygenation of the blood resulting from this insufficient pulmonary circulation, and hence "a physiological cause of cold peculiar to high altitudes, and probably the principal among all those causes which bring on the symptoms known by the name of mountain sickness" (page 254).

But we have revealed the fundamental objection which Payerne (page 240) raised against the theory of de Saussure. In his opinion, there is quite enough oxygen in the air, even on the summits of the highest mountains attained, to satisfy the needs of respiration and to meet the requirements of the combustions increased by the work of ascent.

Lombard alone (page 251) seems to be affected by the calculations of Payerne; he makes no objection to them, and admits that "even at altitudes of 7000 meters, the atmosphere can furnish man with a quantity of oxygen sufficient to maintain respiration" (page 252). Nevertheless he drew the conclusion "that an insufficiently oxygenated blood reaches the different organs . . This is the cause of a considerable part of the disturbances which occur in innervation and motility" (page 252).

In another part of this book, I shall discuss thoroughly the objection of Payerne, and I shall show how much truth it contains. 
But here I shall merely show that no one replied to it, and that consequently the theory of de Saussure, with the chemico-physiological commentaries with which it has been enriched, is now considerably damaged by it. If, even at 7000 meters, and without taking into account the respiratory acceleration, much more oxygen enters the lungs that is required by the organic combustions, why should not the blood take what it needs and what it can find there?

And first, as a fact and not as a theory, is the blood really "less thoroughly oxygenated," as Brachet said? It is interesting to note that Hamel was the only one to suggest performing an experiment to "extract, on the summit of Mont Blanc, the blood of some animal, and to see by its color whether it had been sufficiently decarbonized in the lungs" (page 223). Yet we must confess that the purple tinge of the lips and the conjunctiva furnished some basis for the statements of those who maintained that oxygenation was incomplete: when one of Clark's guides had the nosebleed, "his blood seemed darker than usual" (page 91).

Theory of $M$. Jourdanet. Some authors had glimpsed, as an explanation of this insufficiency of oxygenation, a cause other than the one which we have just been discussing. It was not merely the insufficient quantity of oxygen circulating in the lungs in a given time which they blamed; but, to borrow the actual words of Pravaz, "the lack of pressure which makes the solution of this gas in the blood less abundant" (page 239). This idea was clearly formulated only by Pravaz, in the passage which I have just quoted: no one adopted it afterwards. M. Gavarret opposed it energetically; the learned professor of the Faculté de Médecine of Paris declared "that the absorption of oxygen by the venous blood is not a purely physical fact, but that chemical forces play an important part in this fixation" (page 250). Moreover, if it were so, what would become of the people living at the dairy farm of Antisana, where the barometer stands at 47 centimeters, who would absorb "a weight of oxygen two thirds less than that consumed at sea level"? And Longet said a little later: "If the law of solutions applied, we should reach this conclusion, that the blood of those living in regions where the atmospheric pressure is hardly 0.380 meters would contain only half as much oxygen as the blood of those who live at sea level . . . But, of course, the preceding law does not have an application here" (page 250).

But the point here was to find out what did happen to these dwellers in lofty places, and the reasoning of the learned professors was a real vicious circle. Fortunately for them, the notable 
experiments of M. Fernet (page 249), carried out meanwhile, appeared to justify them completely, seeming to show that the volumes of oxygen absorbed by the blood are almost independent of the barometric pressure.

Everyone yielded then to these conclusions supported by experiments which give no opening for any objection of a purely physico-chemical type.

M. Jourdanet alone (page 256) did not declare himself convinced. He remarked shrewdly that no matter how great was the affinity of the corpuscles for oxygen in the respiratory act, there was no doubt that in an air with low oxygen content, the solubility of this gas in the blood would be less. It cannot be other wise in rarefied air, and the blood there must take up a lessened. and possibly an insufficient, quantity of oxygen. Join to that the decrease due to the cause of which de Saussure had spoken and to which M. Jourdanet attributes considerable importance, and you will become convinced, he thought, that on the mountains the blood has a lower oxygen content than at sea level; and this decrease in oxygen, although the number of blood corpuscles remains the same, produces the same dangerous effects as a decrease in the number of these corpuscles. Anoxemia is the pathological counterpart of anemia; thence comes this notable statement: "An ascent above 3000 meters is equivalent to a barometric disoxvgenation of the blood, as a bleeding is a corpuscular disoxygenation" (page 261). When the symptoms are carried to the extreme, as happens on lofty mountains, the violent symptoms which we have described are the result of the irrigation of the organs by a blood containing too little oxygen, incapable of stimulating and nourishing them. At lower altitudes, as on the Mexican plateau, the difference in the oxygen content is not great enough to bring on disturbances serious enough to attract attention, in the usual conditions of life. But if some illness is contracted, it will immediately take on a character so peculiar that an experienced physician will at once recognize in his patient a real anemic. This is the general thesis which M. Jourdanet has ardently sustained since 1861; he has supported it in the successive works, which we have already reviewed, with an astonishing number of personal observations and quotations in agreement with them.

To be sure, more or less definite statements had been made before his time, as we have seen, about insufficient absorption of oxygen, and even about blood incompletely oxygenated; but no one had connected the two causes which may produce a low oxygen content in the blood, or measured their importance, or shown 
their prevalence; no one seemed even to have supposed that they could act at moderate altitudes, where no violent symptom attracts the attention of the traveller or the physician; no one had followed their consequences and shown their dangerous effect under pathological conditions; and finally, no one had tried to discover what part they play in the hygiene of peoples inhabiting lofty places, what effect they produce upon their character, their customs, and their destiny.

If it is true to say that the discovery belongs, not to the one who has found the truth, as if by chance, and who has carelessly expressed it, but to him who, perceiving it in his turn, has felt its whole importance, has collected proofs to support it, has defended it against bitter attacks, even when they came from eminent authorities; who, in a word, has made a theory out of an isolated idea, it is to M. Jourdanet and not to de Saussure, Martins, Brachet, or Pravaz that we shall give the credit for having found the true explanation of the symptoms of decompression, as he already has the credit for having so clearly defined and described them by the name of anoxemia.

However, we must note here again that the basis of the theory rested only on reasoning and deductions, very well connected, to be sure, but not sufficient to establish complete proof to minds accustomed to the precision of scientific methods. It was necessary to make experimental proof of anoxemia and of its effect upon the production of the symptoms which appear in rarefied air. I had already said in 1869: "I cannot repeat too often that these are reasonings, likelihoods, probabilities at most. When shall we have the experimentation which will bring conviction? Who will do for the study of respiration, under decreased or increased pressure, what the King of Bavaria did when he furnished Pettenkofer with all the apparatus necessary for the study of the products of normal respiration?" 6

This appeal was heard. M. Jourdanet himself permitted me to subject to experimental test both his own theory and all those which deserved to be examined thus. The account of the experi. ments which I made with the help of the apparatuses which I had secured, thanks to him, will form the second part of this work.

And now in completing this review of the opinions suggested to explain mountain sickness, I have only to remind the reader in summary that many of them could not withstand the critical examination to which we subjected them; that others, whose accuracy is not very likely, are awaiting, for final judgment, experi- 
mental control; that still others, and among them the one which seems to us to have the firmest foundation, that of anoxemia, can bring conviction only by the aid of the supreme judge: experimentation.

1 Comptes rendus de l'Académie des sciences, vol, XX, p. 1502; 1845 .

2 Journey from Quito to Cayambe. Journel roy. geogr. Soc, vol. XXXI, p. 184-190, 1861.

3 Etude de l'Jnfuence de l'altitude sur la frégnence des battoncits du coeur. Bulletin de la Société vaudoise des sciences naturelles, vol. XIII, p. 391-399, 18 i3. 1820.

"De l'influence de l'effort sur les organes renfermés dans la cavité thoracique.-Paris.

${ }_{5} \mathrm{P}$. Bert, Lecons sur la physiologic de la respiration. Paris, 1870, p. 381-389.

'Lecons, etc., p. 129 


\section{Title II \\ INCREASED PRESSURE}

Nature offers no conditions where man and air-breathing living beings are subjected to the effect of a pressure greater than that exerted by the atmosphere at sea level. ${ }^{1}$ Only aquatic animals and plants endure pressures which may, in the depths of the ocean, be reckoned in hundreds of atmospheres.

The quest for minerals, especially coal, has compelled many laborers to live at depths where the normal pressure of $760 \mathrm{~mm}$. is increased by several centimeters of mercury. But the effect of this slight modification has never attracted the attention of observers, lost as it is, admitting that it is of some importance, in the host of peculiar and unfavorable conditions under which miners live (dampness, darkness, confinement, deleterious gases, dusts, etc.)

But since the sixteenth century, the progress of industry has caused men to work under pressures beyond four atmospheres. Diving bells, diving suits, and the caissons with compressed air invented by M. Triger have placed thousands of workmen in this modified medium. Serious symptoms have appeared, the number of which has terrified engineers and physicians.

However, the latter, struck by the strange and often favorable changes which a stay in compressed air causes in certain pathological conditions, had the idea of regulating the use of this new therapeutic agent. Apparatuses have been installed, which have been of service in making interesting physiological observations and useful medical applications.

In the following chapters, I shall report the data observed under the circumstances which I have just mentioned. A considerable difference will be noted among them, if they are considered as a whole. Divers and laborers in caissons are subjected to 
pressures which are sometimes enormous; attention has been attracted only to symptoms appearing when these pressures were very high; and finally, these symptoms are, as we shall see, the result, not of the compression itself, but of sudden decompression. In medical apparatuses, on the contrary, the pressure used has always been low, less than double normal pressure; the physiological observations have been made on the phenomena produced by the compressed air itself, and no symptom could be charged to the decompression, which was always very gradual.

I therefore had to divide into two chapters the report of such different data. A third is devoted to the account of the attempts made by various authors to explain the physiological changes and the more or less dangerous symptoms which attack the workmen. Finally, in the last chapter, I have summarized and discussed the data observed and the theories suggested, with the purpose of explaining them. 


\section{Chapter I \\ HIGH PRESSURE}

1. Diving bells.

At the beginning of the sixteenth century Sturmius invented the diving bell, which was to render such great services. It was simply a bell heavily weighted, which, full of air, was allowed to sink vertically in the water until it touched the bottom. The water penetrated the apparatus to a height which increased with the depth of the immersion: at ten meters, there was under the bell, in volume, half air and half water; at twenty meters, twothirds water and one third air, etc.; the workmen, who were ensconced up to that point on seats like shelves, got down from them to work under the worst conditions.

The inventor considered the harmful effect which the air compressed by the descent might exert upon them; to prevent it, says Panthot, ${ }^{1}$ he advised that air should be taken along in bottles which would afterwards be broken under the bell.

This procedure, which could not alter at all the tension of the air, was improved upon by Halley, with a purpose in greater harmony with the laws of physics. The English physician planned to drive out the water which encroached upon the workman and to renew the air which had been made foul by his respiration; he did so by letting down under the bell small barrels full of air, which the diver received and opened at will; the warm and foul air escaped from the top of the bell by means of a valve. Halley even found the means of permitting a diver to leave the bell, keeping in communication with the compressed air contained in it by mean of a tube and a helmet covering the head. (Brizé-Fradin, 2nd. S., pl. I.). This was the first idea of the diving suit.

Spalding made improvements of a purely mechanical type in Halley's apparatus; these improvements did not prevent him from meeting death in his own apparatus in 1785 . 
Brizé-Fradin, from whose work ${ }^{3}$ I have borrowed most of the preceding information, summarizes in the following words the disadvantages of the diving bell:

1. Keen and unendurable pain in the ear, due to the compression of the tympanic membrane;

2. Deterioration of the air by the breathing of the workmen, with asphyxia as the result;

3. Most physicists have found a third disadvantage; they believe that the elasticity of the air, acting in all directions and at all depths, compresses the blood vessels, and the arteries, and causes hemorrhages.

We may oppose to this statement unvarying data and direct experiments; let us listen to M. Halley:

"I myself was one of the five persons who dived to the depth of 18 meters, without being inconvenienced by it; we remained for an hour and a half; I could even have staid there longer, for there was nothing to prevent it."

This testimony of M. Halley could be seconded by that of all the divers. The pressure of the air under water, at a depth of 18 meters, does not cause blood-spitting; if one dived deeper, of course, he would find the limit where the compressed air could not be breathed. (P. 171)

And yet, adds Brizé-Fradin:

Noting the equal value of the water pressure and the compression of the air, it seems that the diver placed under the bell at a depth of 18 meters should be in a state of general collapse. (P. 173)

The Court Councilor of the Emperor of Russia, whose fatal ascent of Mont Blanc we have already reported, Dr. Hamel, ${ }^{4}$ descended in a diving bell installed by Rennie in the port of Howth, near Dublin; the depth of the water was about 30 feet. He felt no other inconvenience than violent pains in his ears, "as if some one were forcibly inserting a stick," which he checked by swallowing his saliva. From that the idea came to Hamel "that the divers' bell might serve as a remedy in cases of deafness resulting from the obstruction of the Eustachian tube."

In regard to the rest he merely says:

I expected to experience some painful effect upon respiration, resulting from the pressure of the air increased by the weight of almost a whole atmosphere; and yet I did not feel the least inconvenience in this respect.

The same year, Dr. Colladon ${ }^{5}$ descended in the same bell and to the same depth. He is a little more explicit:

We descended so silently that we did not perceive any movement of the bell; but as soon as it was immersed in the water, we felt in our ears and on our foreheads a sensation of pressure which kept 
increasing for several minutes. However, I did not experience any pains in the ears; but my companion was in such pain that we had to stop the descent for a few minutes. To remedy this distress, the workmen advised us to swallow our saliva, after closing the nostrils and the mouth tightly, and to hold our breath for a few instants, so that, by this exercise, the inner air might act upon the Eustachian tube. My companion got little relief from this procedure. When we began to move again, he was in great pain, he was pale, his lips had lost their color, one would have thought him nauseated. His prostration was due, no doubt, to the violence of the pain, added to a fear which he could not overcome. This experience produced the opposite effect upon me: I was in a state of excitement, as if I had drunk some alcoholic liquor, I had no pain, I merely experienced a strong pressure around my head, as if an iron ring had been fastened tightly about it. While I was talking with the workmen, I had some difficulty in hearing them; this difficulty in hearing became so great that for three or four minutes I did not hear them speaking; I did not even hear myself, although I was talking as loud as I could, and soon the noise caused by the violence of the current against the walls of the bell no longer reached my ear. (P. 6) ...

At last we reached the bottom of the sea, where every disagreeable sensation ceased almost entirely .... .

We breathed very easily during our whole visit under water . . . . Our pulse rate showed no change ..... .

As we rose again, our sensations were very different from those we had experienced as we descended; it seemed to us as if our heads were becoming much larger; that all our bones were on the point of separating. This discomfort did not last long. (P. 8.)

To these almost negative observations, Colladon adds two facts which are most interesting and which were the point of departure of important therapeutic applications:

None of the workmen become deaf; it would rather seem that in certain cases, the effect of the bell on the ears might serve as a remedy for deafness. One of the workmen, who had habitually breathed with great difficulty, was completely cured shortly after undertaking work in the bell. (P. 14.)

The diving bell today is completely abandoned. It has been replaced by caissons filled with compressed air by the Triger method.

Interesting attempts have been made repeatedly to invent submarine boats in which men would live either in compressed air or in air at normal pressure. These attempts began in the seventeenth century; Father Mersenne, the friend of Descartes, did not scorn to apply himself to the subject; more recently $R$. Fulton in the port of Brest made attempts which perhaps should have been encouraged; then came Payerne, whose submarine hydrostat operated with some success. In our own time, M. Villeroi, 
then Rear-Admiral Bourgeois invented cigar-boats which might be used in case of war. But since no observation of a physiological nature has been made with the help of these contrivances, and since I have no desire to write a history, no matter how short, of the industrial applications of compressed air, I now come without other transition to the numerous data relating to the digging of mine shafts and to the sinking of bridge piers by the Triger method.

\section{Apparatuses Constructed by the Triger Method.}

It is, in fact, to M. Triger, a French engineer, that we owe the valuable invention of the use of air compressed to high pressures for boring mine shafts and sinking bridge piers. It was a question of working in the grant of Haye-Longue (Maine-et-Loire) coalbearing strata covered with alluvial deposits over which flowed the waters of the Loire. It was impossible to drain off the water which seeped through and prevented them from extending the galleries: M. Triger conceived the simple but brilliant idea of driving it back and holding it by pumping compressed air in through the upper part of the shaft; protected by the drainage thus secured, workmen could stop the leaks by vaults of masonry.

M. Trouessart, whose report on this wonderful discovery we shall quote later, comments that Denis Papin had already had an idea of this sort, in 1691, and he quotes the following passage, which is indeed very noteworthy:

Fresh air could be injected constantly into the diving bell by means of a strong leather bellows furnished with valves, by a tube passing under the bell and opening into its upper part. And so, since the bell would always remain empty and rest entirely on the ground, the bottom in this place would be almost dry and one could work there just as if he were out of the water, and I have no doubt that it would save much expense when construction must be carried on under water. Moreover, in case the leather bellows were not strong enough to compress the air as much as would be necessary at great depths, one could always meet this difficulty by using pumps to compress the air.

But from this idea to the complete invention of M. Triger is a long way; in 1839, he solved the problem from a practical standpoint, and listed the numerous applications which would later be made of it.

The complete explanation of this invention is in a Memoir ${ }^{8}$ presented to the Academy of Sciences in 1841.

We naturally omit all details of the construction of the appara- 
tuses and come to the mention of physiological phenomena, not much considered, as we shall see, by the celebrated engineer.

An interesting fact appears at once; M. Triger wished to try upon himself the effect of compressed air. Now:

At the moment when the manometer had hardly risen to the height of 40 inches (total pressure), there was a report, and we were struck with icy cold and plunged into the most complete darkness, because of the instantaneous formation of a thick mist: a windowpane of the apparatus had burst.

This explosion had no other result that to cause us a great surprise.

M. Triger next mentions, ascribing them quite accurately to their cause, the pains in the ears that accompany compression and decompression. Then he adds, and this is all his Memoir contains on the subject which interests us:

At the pressure of three atmospheres, it is not possible to whistle in compressed air: but the power is lost only when one reaches this pressure.

In compressed air, everyone talks through his nose, and this becomes increasingly noticeable with increase in pressure.

The workmen have noticed that while they were climbing the ladders, they were less out of breath in compressed air than in free air.

I shall end with a rather interesting observation, which I was in a position to note personally: namely, that a miner, named Floc, who had been deaf since the siege of Antwerp, invariably heard more distinctly in compressed air than any of his comrades. (P. 892.)

Professor Trouessart, ${ }^{7}$ commissioned by the Industrial Society of Angers to investigate the practical results of the apparatus of M. Triger, gave an account of his researches in an interesting Memoir.

There is very little mention of physiology in it; however, we do find in it a few observations which deserve to be reported here, particularly because they were the first made on man at pressures of 3 atmospheres above the normal atmosphere:

It is with a certain apprehension, we admit, that one goes down for the first time into the apparatus to be subjected to a pressure of three atmospheres there. These 32,000 kilograms above the former pressure which you will have to endure are enough to terrify the stoutest shoulders.

First comes the description of the pains in the ears, which are thoroughly studied and explained:

A phenomenon which is more difficult to understand is that deaf persons not only hear better in compressed air than in free air, but that they hear better than persons whose ears are normal .... 
One of the strangest results is that one suddenly loses the power of whistling under the pressure of $2 \frac{3}{4}$ to 3 atmospheres.

The functions of nutrition, respiration and circulation do not seem perceptibly altered in compressed air. At the time of our first visit, we thought that we found an increase in the pulse rate of every one subjected to the experiment; but on our second visit, the result of a more accurate observation, made by a member with much experience in taking the pulse, was completely negative....

The respiration is neither slower nor faster. It seems that it is not more active and that the animal heat is not increased. The blood too gushes out under normal conditions. In a word, the most surprising thing is that there are very few changes in the vital functions. The workmen assert that they climb the ladder more easily and are less out of breath when they reach the top. This cannot result from the rather slight loss in their weight. Is it possible that they can hold their breath longer because of the greater density of the gas inhaled at each respiration? On the other hand, they maintain that they become much more tired when working in compressed air than in open air. We think that this is the result of the very great humidity of the atmosphere of the shafts, which hampers the insensible perspiration and promotes the more rapid secretion of sweat in those who have to exert their muscular powers in such a medium. Perhaps this humidity would also explain the somewhat severe pains in the articulations experienced by some workmen a few hours after leaving the shaft ....

We may conclude that there is no serious danger in staying several consecutive hours for several successive days in air compressed to 3 atmospheres.

Our author says nothing of the duration of the decompression; he seems, moreover, to pay more attention to "the passing from a low to a high pressure": he only says that they opened the cock gradually.

In a second communication to the Academy of Sciences, M. Triger ${ }^{8}$ repeats his former observations. He adds to them the following data:

Everyone talks through his nose and loses the power to whistle at 3 atmospheres. To ascertain the effect of compressed air on a stringed instrument, I had a violin taken down into the shaft and it was found that at the above pressure the sound lost at least half of its intensity.

Then comes the first suggestion of the rather serious symptoms of decompression:

I should say here that two workmen, after passing 7 consecutive hours in compressed air, experienced rather keen pains in the articulations, half an hour after leaving the shaft. The first complained of a very sharp pain in his left arm, and the second experienced a similar pain in his knees and left shoulder; rubbing with spirits of 
wine soon relieved this pain in both men; they kept on working the following days.

In 1846, M. de la Gournerie, ${ }^{9}$ getting his idea, he said, from an apparatus suggested in 1778 and approved by the Academy of Sciences in 1779 , used for the extraction of rocks in the channel of the port of Croisic a boat with a metal chamber open at the bottom, from which the water was expelled by compressed air.

He submerged it only 3 or 4 meters; it is not surprising then that

The workmen never found that the air pressure inconvenienced them. It merely gave them a slight discomfort in the ears for a few seconds.

The pulse rate is not noticeably increased. (P. 308.)

In the mines of Douchy (Nord) the method used by M. Triger on the banks of the Loire was first imitated. The difficulties were greater, because here it was not a matter of penetrating permeable sands with a sheet-iron tube 1.50 meters in diameter, but of digging a shaft 3 meters in diameter through limestone.

We shall shortly quote the important Memoir which the physicians Pol and Watelle devoted to the study of the symptoms which attacked numerous workmen in this undertaking. The first account of them was given by a report of the engineer Blavier, ${ }^{10}$ sent to examine this new invention.

He first mentions the pains in the ears and the inability to whistle. A certain effort must be made in speaking:

It seemed to us also that in the diatonic scale the voice lost a tone or a tone and a half in the upper notes without gaining in the lower ones.

He found no difference in the pulse rate before entering the apparatus and while within it:

If the effects of compressed air upon the animal organism do not appear during the whole time that one is subjected to it, at least during one shift of workmen, the same thing is not quite true if we try to consider subsequent effects .... Most of the workmen, although selected from the most robust and healthy, have frequently felt heaviness in the head or pains in the legs a few hours after leaving the caisson. Only one of them experienced complete paralysis of arms and legs for 12 hours. The superintendent of the mine assured us that the effects felt almost always coincided with some excess committed between shifts. (P. 361.)

However, Blavier himself, after being subjected to the total pressure of 2.6 to 3 atmospheres, was attacked by a fairly severe symptom: 
The day after our visit of December 5 , keen pains appeared in the left side, and we felt a rather severe painful discomfort for several days afterwards. Since a chill or some other cause not connected with the compressed air might have been acting, after we were quite free from these pains, December 28, we were anxious to try the experiment again, and when we left the shaft, we took the greatest precautions to protect ourself from any chill. In spite of these precautions, the next day, very noticeably at the same hour, that is, 20 hours after our exit from the medium of compressed air, we felt in the right side pains just like the former ones, which kept us numb for four or five days. (P. 362.)

We now come to the important Memoir, the first written by physicians about these symptoms, in which MM. Pol and Watelle ${ }^{11}$ recount the effects of compressed air upon the miners during the excavating at Avaleresse-la-Naville, at Lourches, in the grant of Douchy (Nord).

The authors took care to warn the reader that since their notes were made without any intention of publication, they made their observations without plan, without program, and gonsequently without system. But they thought, and with good reason, that their work would nevertheless present some interest and some utility.

During the exploitation, the total pressure rose to $4 \frac{1 / 4}{4}$ atmospheres. The compression was made in a quarter of an hour, the decompression in a half-hour; 64 workmen took part in the work; they usually stayed four hours consecutively in the apparatus, twice a day.

The authors described separately the physiological effects which they observed in themselves and the pathological effects experienced by the workmen:

1. Physiological effects: Pains in the tympanic membranes; slowing of the respiration and particularly a decrease in the amplitude of the thoracic expansion, which became hardly perceptible; slowing of the pulse, (from 70 to 55); increase of urinary secretion.

The authors also mention a "muscular sensation of a resistance to be overcome, as if the unusual density of the ambient atmosphere hindered movement; the inability to whistle, experienced above 3 atmospheres, is also attributed to an unexpected resistance, experienced by the muscles of the tongue in compressed air.

On the return and during the decompression, they experienced a keen sensation of cold, a kind of panting; the pulse rose to 85 .

Pathological effects. Taking the observations as a whole, we 
see that out of 64 men, 47 withstood the work fairly well; 25 had to be discharged; 2 died. Taking them in detail, we see that 14 felt slight symptoms, 16 more or less severe symptoms, sometimes even threatening life; 2 died.

On the other hand, 2 benefited by a certain improvement. One (First category, obs. I) was asthmatic, and breathed better in the shaft; the other (Third category, obs. 3) chloro-anemic, having had frequent blood-spitting, found that his oppression tlisappeared and his mucous membranes became redder:

We see dawning, (MM. Pol and Watelle said in this connection) without concealing the difficulties of application, a new resource of palliative therapeutics in the treatment of most dyspneas.

The universal rule without exceptions was that the symptoms appeared at the time of decompression:

The danger does not lie in entering a shaft containing compressed air; nor in remaining there a longer or shorter time; decompression alone is dangerous: pay only when leaving.

Let us see now what these more or less serious symptoms are. They are, first, pains in the eardrum, more or less severe and lasting, and M. Pol states that they can be checked much more quickly by blowing one's nose than by going through the motion of swallowing.

As for the other symptoms, as MM. Pol and Watelle had the good sense to give the complete observations, I think I cannot do better than to summarize each in a few words, following the order in which they presented them:

First Category. Workmen on the Job from the Beginning.

Observations. I. Asthmatic, breathes better in the shaft. On decompression, violent oppression with exaggerated circulatory reaction. Discharged.

II. Went up to $4 \frac{1}{2}$ atmospheres. Respiration hampered, decrease of appetite, indigestion, pains in the limbs. Stools dark. Lost much weight.

III. Same effects.

IV. Same.

V. Did well up to 3 atmospheres. After that, dizziness, muscular pains, cramps or general numbness, vomiting of dark matter. All this on the return to open air.

One day, an hour after leaving the shaft, having eaten, he complained of distress; when placed in bed, he lost consciousness. Pulse full and rapid, face congested, respiration short and stertorous; obscure sound everywhere, bronchial murmur, mucous râle; muscular resolution. Bled, purged, plastered. After four hours, return to consciousness. In three days, cured. Discharged. 
VI. Taken to $4^{1 / 4}$ atmospheres without accident. One evening, after going to bed apparently well, at 11 o'clock seized by muscular pains accompanied by contractions like tetanus spasms.

Skin cold, pulse small and slow, urine abundant and clear. Respiration uneasy; same results of auscultation as $\mathrm{V}$.

Baths at $32^{\circ}$ so aggravated the pains that the patient could not remain in them. Friction, strong sudation, quiet. Recovered next day, back at work.

VII. At a pressure of 3.3 ; cerebral disturbances, like intoxication with coma, hebetude, stuttering. Respiration accelerated, pulse rapid. Pupils dilated.

Two similar attacks, cured one in nine days, the other in fifteen. Continuance of double vision and vertigo, with deafness on one side. Discharged.

VIII. Presented an excessive form of twa common phenomena: 1. suppression of the functions of the skin and increase of the urinary secretion during the compression: 2. increased rapidity of the heart beats after decompression; his pulse rate rose from 58 to 130 .

IX to XVII. Nothing important to be noted.

XVIII. Healthy and vigorous. Experienced repeatedly keen pains in the limbs and chest. Respiratory disturbances increasing with the pressure, as well as the muscular pains which were very acute.

Was discharged. During the last days went down into the shaft without permission. Worked there without complaining; went out with his companions, washed himself like them, immediately fell unconscious and died in a quarter of an hour. Autopsy shows only obstruction of the lungs, congestion of the liver, the spleen and the kidneys; nothing in the brain except gritty congestion.

XIX. Violent oppression with dullness on percussion and bronchophony; rapid pulse, cold skin, continual cough; clonic contractions of the limbs; more sensitive after five hours of treatment.

Then, at another time, to these symptoms are added: dilation of the pupil, relaxing of the limbs, subdilerium, coma. Three bleedings in rapid succession; blood bright red on leaving the vein; cured. Discharged.

XX. Same symptoms as VII. Also remained deaf on one side, with vision much weakened. Discharged.

XXI. One day, sight affected and double, hearing gone; respiration hampered, cough frequent, pulse hard and galloping. Blood red, recovered.

XXIV and XXV. Nothing important.

XXVI. Usual thoracic and cerebral symptoms; recovered after profuse sweatings. (P. 250 to 259.)

Special Category of men who worked only one day and without preparation at 2.8 atmospheres.

Nine men left the shaft without making any complaint. But shortly afterwards, eight experienced very severe muscular pains, which disappeared during the night, except in one, in whom they persisted several days. 
Second Category. Workmen who worked only above 2.9 atmospheres.

I. No effect.

II. Only muscular pains in the left thigh, which yielded to cold water.

III, IV. Nothing.

V. Moderate muscular pains, but persisting from one shift to the next; recompression relieved them immediately.

VI. Nothing.

VII. 28 years old. Athletic. Pressure of 3.8 at the beginning. After 10 days, loss of consciousness, violent lockjaw. Rapid pulse.

Reddish bleeding eight hours afterwards, purging, blisters.

Two days after, consciousness suddenly returned: the patient opened his eyes, seemed to awaken from a dream, said a few astonished words.

Recovers, but remains extremely deaf.

Third Category. Workmen who began at 4.154 atmospheres.

I, II. Nothing.

III. Had previous hemoptysis. Improvement.

IV, V, VI. Nothing, except rather severe muscular pains.

VII. 40 years old. Very robust. Went down into the shaft only once. On coming out (decompression in twenty minutes) died almost immediately.

Autopsy held 36 hours after death: generalized subcutaneous emphysema (existed before putrefaction began, the authors note); nothing in the meninges, in the brain, or the cerebellum; congestion of the lungs with generalized darkish tint (underlined by the authors); blood fluid and dark in the heart; liver, spleen, and kidneys congested.

VIII. Nothing.

IX. Moderate muscular pains.

$\mathrm{X}$. At his first trial, very severe muscular pains, persisting for several days. Discharged.

XI. Same.

XII to XIX. Nothing, except insignificant muscular pains. However, they sustained the pressure of $4 \frac{1}{4}$ atmospheres for three months.

$\mathrm{XX}$. At his first trial, too rapid decompression. A few minutes after his leaving the lock-chamber, looked like a corpse: face pallid, icy cold, eyes dull, pupils enormously dilated, respiration uneasy; on listening to the heart, heard only a vague quivering; pulse imperceptible; perception gone; involuntary urination; dark vomit; complete loss of muscular power.

Warm bath, blankets, friction. After a half-hour, the pulse begins to be perceptible, the respiration is deeper, a little warmth appears in the body; the patient stammers disconnected words. During the night, hardly has warmth been reestablished when acute pains appear in the muscles; keen pains in the head, blindness and deafness; wretched pulse, 50 . 
Evident improvement two days afterwards; the patient sees vaguely. Vision remains weak and pupils are abnormally dilated.

XXI. At his first trial, too rapid decompression. Severe muscular pains persisting for six days.

XXII. At his first trial, too rapid decompression. Loss of consciousness, resolution of limbs; respiration embarrassed, pulse full, hard, 130.

Bleeding blood red, blistering; after four hours, consciousness returns. During the night, cramps and muscular pains of terrible violence.

Survives, but with great weakness of vision and extreme deafness. (P. 265-275.)

I shall now quote the description of the complication whicch attacked M. Pol himself, because it contains the account of a very strange symptom, upon the importance of which we shall dwell later. The pressure undergone had been 3.48 atmospheres:

At 11 o'clock, he reached his lodging; he felt keen pains in his left arm and shoulder; the walls of the thorax were also painful. It seemed to him that emphysema existed in these regions . . . About midnight, he had a few chills, followed by vomiting. He took a cup of tea and went to sleep; soon abundant sweat broke out. The next day, he was in his usual condition. (P. 250.)

In summary, the symptoms noted, at the time of decompression, are as follows:

Respiratory difficulties, which may go as far as anxiety;

Acceleration and hardness of the pulse;

Muscular pains which are often very severe: "none of the effects of decompression appeared so general; sole symptom in many cases, it is the initial symptom in almost all .... It is the first and the largest link in a chain which includes successively, by ascending order of severity and descending order of frequency, non-permanent or clonic spasm, resolution, and finally sideration" (P. 227) ;

Cerebral symptoms, dullness of intellect, loss of sensitivity and consciousness, coma. Deafness, blindness, very often permanent;

Finally, sudden death.

The reading of the observations abstracted above shows what a variety of form and intensity is presented by the symptoms, even for the same pressures, in different individuals, and sometimes in the same individual.

MM. Pol and Watelle noted that young men from 18 to 26 resisted much better than mature men; out of the 25 who were discharged, 19 were more than 40 years old, and 5 were more than 30 ; the other was 28 years old. 
These symptoms are attributed by the physicians of Douchy exclusively to pulmonary, hepatic, renal, or cerebral congestions. In the special chapter devoted to the enumeration of theoretical explanations, we shall see what theories of these pathological phenomena were given by MM. Pol and Watelle.

I have wished to review at length their important Memoir, the first study of high pressures to appear, not only because of the numerous interesting observations reported in it, but also because truths of great importance are clearly revealed by it:

1. "Compression, up to $4 \frac{1}{4}$ atmospheres, is not dangerous in itself; it is endured very well and infinitely better than a rarefaction which is proportionately much less." Only the return to normal pressure is dangerous; its danger is proportional both to the amount of the compression and the speed of the decompression: the decompression must therefore be very gradual;

2. In compressed air, the venous blood becomes bright red. This effect lasts a short time after return to normal pressure;

3 . We are "justified in hoping" that a sure and prompt means of relief would be to recompress immediately, then decompress very carefully;

4. Chlorotic or anemic persons and those who have respiratory difficulty will be benefited by a stay in air compressed to a variable degree.

During the work at Douchy, an explosion occurred at a time when the total pressure was 3.20 atmospheres. It was the subject of a report by M. Comte, ${ }^{12}$ chief engineer of the mines. Eight men were in the apparatus at the time; four were crushed to death; two others, after beginning to climb the ladder to leave the cylinder, let go of it, without anyone ever being able to find out why or how; a seventh workman felt no ill effects; the eighth, who was overtaken by the water, also managed to escape. In regard to him, M. Comte suggests a strange and interesting hypothesis, interesting because it shows how easily the best minds go astray in these questions:

Perhaps he found some help in rising above the water .... in the specific lightness given him by the compressed air with which certain parts of his body were still more or less filled. (P. 130.)

The new method quickly became general. Other shafts were sunk, and data similar to those reported by MM. Pol and Watelle were observed.

That happened, for instance, according to the report of Bouhy ${ }^{13}$ in the mine of Strépy-Bracquegnies (Belgium): 
At Strépy-Bracquegnies, all the laborers, except one, who worked in air compressed to 3.70 atmospheres, and from 4 to 5 hours conseutively, were attacked, after leaving the apparatus, by more or less acute pains ... These pains, the seat of which was chiefly in the articulations, such as the knees, the shoulders, and the joints of the arms, appeared in certain persons so severely that they sometimes went more than forty-eight hours without being able to sleep ... .

It was noted that some laborers who had had rather severe attacks and who had gone down to work were completely relieved of pain as soon as they were in compressed air, but that the pains came on again some time after they had left the apparatus.

Besides these effects, the author again mentions unpleasant stinging over the whole surface of the body and especially on the extremities.

But compressed air is used chiefly on the foundation of bridge piers, and it is under these conditions that hundreds of workmen are exposed to its effects every year. It is therefore of interest for us to explain briefly the mode of application of the Triger method in this particular case.

Figure 6 will permit us to be very brief in our explanations; it is a cross-section which we borrow from the memoir of Dr. Foley, which will be reviewed later.

A cast-iron tube MM composed of concentric rings fastened together by bolts $m$, and ending at the bottom of a widened chamber or "crinoline," is let down upon the bed of the river in the spot which the bridge pier is to occupy. It is topped at its upper end by a room with 3 compartments; the one in the middle, $\mathrm{F}$, is in constant communication with the cast-iron tube; a blowing machine, through a tube $\mathrm{G}$, constantly pumps into it air which is sufficiently compressed to drive all the water out of the cast-iron cylinder, and escape constantly bubbling all around; the bottom then becomes dry, as happens in a glass tube into which a child blows after immersing it in water.

Under these conditions, the workman who is coming to work opens the door of one of the lateral chambers, E, and closes it behind him, and by a cock communicating with the central chamber $\mathrm{F}$, equalizes the pressure of the air about him with that of the air in the cylinder. When this has been done, he easily opens the inner door, hitherto held shut by the pressure, and goes down to the bottom of the shaft by a ladder. There he works and fills with the earth which he digs out buckets which are hauled up and emptied outside. Does he wish to leave? He goes to the other lateral chamber $\mathrm{C}$ in which the air has remained under pressure, goes in, closes the door, and by a cock communicating with the 
exterior allows the excess of compressed air to escape. He can then easily open the outer door and leave the apparatus.

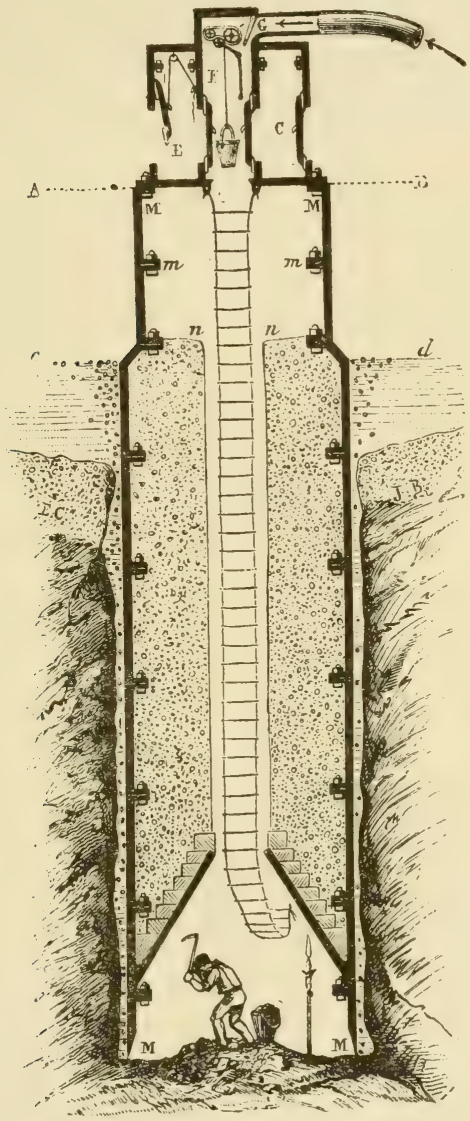

Fig. 6-(borrowed from the thesis of M. Foley). Diagram representing the construction of a bridge pier by caissons with compressed air.

As the work progresses and the excavation becomes deeper, the cast-iron tube sinks of its own weight and that of the masonry $n n$ in which it is loaded; then more cast-iron rings are superposed 
until the digging is finished; then there is nothing more to do but fill the whole cylinder with masonry and the pier is finished.

It is by this method, which is so simple and yet which is much more complicated in practice than the preceding description seems to indicate, that a great many bridges have. been constructed since 1851.

The idea of this application of his system of drainage to the foundation of bridge piers belongs to M. Triger ${ }^{14}$ himself. But this idea was not put into execution until 1851, by an English engineer Hughes, in the construction of the Rochester bridge over the Medway in the county of Kent.

An engineer of French descent, Brunel, constructed by this system the bridge of Chepstow, over the Wye (1849-1851) and that of Saltash (1854-1859); for the latter, the maximum depth reached was 26.68 meters below high water. Only in connection with this one did a fatal accident occur; a man died on leaving the cylinder in which he had remained a very short time. I could not get detailed information on these facts, however.

In 1856, M. Cézanne ${ }^{15}$ was charged with the construction of a bridge at Szegedin (Hungary), to permit the Austrian railroad from the south-east to cross the Theiss, a tributary of the Danube.

He used the system of caissons with compressed air. The work of excavating was "stopped at about 20 meters below high water, so as not to expose the men to the pressure of 3 atmospheres, beyond which work is very difficult." (P. 355)

A special section of the memoir of my regretted colleague is devoted to the study of the physiological effects of compressed air:

There are three phases to be distinguished: the entrance, the stay, and the exit.

When the cock admitting the air is opened, the ears are immediately attacked by a violent buzzing accompanied by pains the intensity of which varies with the individuals .... .

The stay at the bottom of the caisson, in a pressure of three atmospheres, may be prolonged for several hours without ill consequences; the tone of the voice is somewhat impaired, and the respiration hastened as if by rapid walking; if a cigarette is waved about, it burns with a flame; candles burn rapidly, but with smoky flame. .....

The time of exit, though not very painful for the great majority of individuals, is the most dangerous for the workmen .... Sometimes there is an issue of blood from the nose and the throat; some persons experience violent, but brief neuralgia; others have headaches and toothaches for several days . . . . .

Laborers who usually work in the caissons look ill; however, they resist the ill effects very well. (P. 369.) 
December 12, 1859, there was an explosion at a bridge pier at Bordeaux, and consequent instantaneous decompression; seven of the laborers working there felt no ill effects. Two were killed, but by purely mechanical causes.

M. P. Regnauld, ${ }^{16}$ who gave a report of the work, does not say at what pressure this accident took place, but we conclude from his Memoir that the caisson at that time had certainly been sunk more than 12.90 meters. (p. 82)

In 1859, the bridge of Kaffre-Azzyat was built over the Nile: the piers were excavated to a depth of 26 meters below the water. Five Arabs died from the effects of the pressure: one in the cage, as he was leaving, but before he had reached the open air; the pressure was 36 English pounds per square inch. ${ }^{17}$ The others felt ill in the caisson and died during the decompression; the pressure then was more than 30 pounds. Blood issued from their mouths, noses, and ears.

The Memoir of Babington and Cuthbert, ${ }^{18}$ from which I have borrowed the preceding data, is particularly devoted to the medical study of symptoms observed during the laying of the foundation of the bridge of Londonderry, in October, 1861.

The depth reached was 75 feet below water level:

The pressure sustained by the laborers was, at the maximum, 43 pounds per square inch, in all. They suffered from pains in the ears, headaches, pains in the legs, nosebleeds, and general distress. These symptoms increased greatly when the cocks were opened wide and the change in pressure was therefore too rapid ... . These symptoms appeared first when the men entered the compressed air; but they were much worse when the change was made from the caissons to the open air: serious, even fatal, symptoms appeared then.

I am copying in abridged form the six observations of the authors:

I. October 3, 1861. Man 28 years old, who had worked four hours under a pressure of 23 pounds; when he came out, he fell unconscious. Cold and livid; total insensibility, facial paralysis on the right side; strabismus of the right eye; pupils almost motionless; pulse 150, small and irregular; heart sounds hardly perceptible; respirations very irregular, 24 to 44 per minute; inspiration abrupt, expiration prolonged.

Bleeding: blood dark, viscous and sticky . . . . Died 24 hours after leaving the cylinder.

II. Case absolutely similar, occurred at the same time . . . . Died also in 24 hours.

III. 23 years old. When we visited him, he was completely prostrated, but was conscious, and complained of pains in his legs and thighs. Unable to walk, hands and feet cold and without sensation. 
Was seated with his feet in the fire, so that several of his toes were burned without his feeling the heat.

He had not become sick immediately, and as he had had pains in his legs for days before, he had not called the doctor until several hours after leaving the cylinder.

Two days afterwards he was cured except for his burns.

IV. Similar case. Hemoptysis. Cured.

V. 18 years old, October 3. Four hours under pressure; fell unconscious while being decompressed .... In a semi-comatose state, responded when stimulated and fell back into unconsciousness. The symptoms of coma passed in 18 hours; he was then totally paralyzed from the fourth rib. Retention of urine, loss of sensation, and other symptoms of diseases of the cervical medullary region.

Died in the hospital 162 days afterwards; never regained sensibility or movement.

VI. 30 years old. Identical symptoms; except that the paralysis began only with the eighth dorsal vertebra. Lived 30 days.

Many other cases of slight paralysis, muscular pains, and other nervous affections were also observed.

Unfortunately no autopsy could be made.

We shall see later the explanation which the two English physicians gave of these data.

In 1859, a work of the greatest importance, the bed of the piers of the bridge from Strassburg to Kehl, was carried out with the use of compressed air. Two interesting Memoirs, one more 'particularly pathological, the other more physiological, reported to us the sensations felt, the phenomena observed, and the symptoms which appeared. The first in date is that of Dr. Francois; ${ }^{19}$ we shall discuss that one first.

The author begins by describing briefly the apparatuses used in the construction of the bridge. One shift lasted four hours, and there were eight hours of rest between shifts. The total pressure rose to $3 \frac{1 / 2}{2}$ atmospheres. According to the rules, the decompression should have taken from 6 to 8 minutes up to 2 atmospheres; from 12 to 15 minutes up to 3 atmospheres; but the carelessness of the laborers almost always prevented strict carrying out of this rule.

Physiological effects. Easier, less frequent respiration; greater expansion of the chest, "which explains itself;" circulation accelerated during the compression, then slowing at the time of the return to open air; perceptible loss of weight, even in the workmen who had no pains.

The author does not give much time to these data, and says that they will be discussed in the work of M. Bucquoy which we shall review presently. 
Pathological effects. These are first earaches and inflammations of the ear, after which the hearing often remains much impaired.

Then pains in the muscles or the joints: there were 133 cases of this sort. They disappeared after a few days. Sometimes there was a rather evident local swelling, but without crepitation. In one of the cases, the left breast of one of the workmen suddenly swelled so as "to resemble the well-formed breast of a woman;" this painful swelling quickly yielded to the application of cuppingglasses with scarification. (P. 307.) In another case, the patient was left unable to use his left leg.

M. François also mentions as frequent the itching of the skin, fleas, as the workmen call it; it yields, he says, to washing with cool water.

He explains, by congestions about the lungs, the heart, the liver, and the spleen, some rather vague symptoms, in which suffocations, palpitations, etc. are involved; one of the patients, who was, moreover, subject to hemoptysis, died a few months afterwards.

Finally, the violent headache and the loss of consciousness are attributed to a cerebral congestion; these congestions began only after a quarter or a half an hour. In one of these cases, the workman, who left the caissons (3 atmospheres) without experiencing anything but a very uncomfortable prickling over the whole body, walked to the citadel with a nimble step; when he reached there, he fell as if struck by lightning: repeated bleedings, purgings, etc.; he recovered, except for a considerable weakness of the lower limbs for a rather long time.

This brings us to the description of some functional lesions of the spinal cord: retention of the urine, violent pains in the limbs, and, for one patient, paraplegia persisting on the left side; the pressure was 3 atmospheres.

Let us finally say that slight nasal and even pulmonary hemorrhages have sometimes been noted.

I mention only for the record a work of M. Willemin, ${ }^{20}$ which is only a simple report of that of M. François, all of whose conclusions the author seems to accept, for he does not give any attention to the theoretical explanations.

The thesis of M. Bucquoy ${ }^{21}$ is, on the contrary, an original work of real importance. His observations, as I have said, were made at the time of the construction of the bridge of Kehl.

At the beginning of his exposition we find a bit of information from which we shall perhaps later derive some profit, namely, that the air in the caissons in which the laborers were working 
contained on the average (six analyses at different periods) $2.37 \%$ of carbonic acid.

Reaching the study of the physiological phenomena, M. Bucquoy first describes the pains in the ears.

In regard to the circulation, he gives the following table:

$\begin{array}{cc}\text { Number } & \text { Pulse } \\ \text { of } & \text { in the }\end{array}$

Observations open air

$10 \quad 77.85$

$9 \quad 77.08$

$7 \quad 75.39$

$28 \quad 76.05$

$11 \quad 76.59$

$3 \quad 76.50$
Pulse

during the different periods of the compression

While the air was entering ___ 100.05

After a quarter hour stay ____ 90.12

After 25 minutes

After a half-hour _- 81.57

After 1 hour ___ 83.58

After 2 hours
Increase

22.20

13.04

11.41

5.32

6.99

7.00

So, in compressed air, the pulse rate is higher than in open air, and that is true for all degrees of pressure and especially up to $2 \frac{1}{2}$ atmospheres. M. Bucquoy, who states here that he disagrees with the authors who observed the patients, adds:

I have, nevertheless, one observation which seems to confirm what M. Pravaz says as to the sedative effect of compressed air. One of my friends, M. Ritter, who went down into the caissons with me in spite of a very high fever, found that his pulse fell from 95 to 75 after an hour's stay. (P. 24.)

The respiratory capacity also increases, as Pravaz had already said (see the following chapter); the following summarizing table gives the average measurement of this modification:

\begin{tabular}{ccc} 
Number of & Time & \multicolumn{2}{c}{ Respiratory capacit } \\
Observations $\quad$ when they were made & in cubic & centimet \\
103 & 10 minutes before entering the lockchamber & 2950 \\
103 & After a halfhour stay in compressed air --- & 3224 \\
103 & A quarterhour after return to open air & 3075 \\
10 & After three quarters of an hour & 3004 \\
10 & After 2 hours & 3000 \\
10 & After 10 hours & \\
10 & After 15 hours
\end{tabular}

So the increase, which is constant, and which, as other tables show, keeps growing up to 2 atmospheres, persists for a fairly long time after the decompression.

So M. Bucquoy adds with reason:

Showing that this effect is not passing, that it does not cease with the compression, my experiments make us anticipate the efficacy of treatments of compressed air for patients whose vital capacity is too small. (P. 29.) 
In regard to the general phenomena of metabolism, M. Bucquoy, after analysing all works preceding his and showing their contradictions, at least apparent, declares that he:

Is inclined to believe that in compressed air the respiratory combustions increase; but the bases on which they have tried to establish this idea lack solidity, and the question must be re-examined.

Dr. Foley ${ }^{22}$ has written an odd pamphlet on our subject, which is often quoted and praised. He had observed the symptoms of the caisson-workers at the time of the construction of the bridge of Argenteuil over the Seine in 1861; the maximum pressure had not gone above $3 \frac{1 / 2}{2}$ atmospheres. I shall begin by quoting a few of the most characteristic passages in which M. Foley describes and at the same time explains the phenomena experienced in compressed air:

In the caissons all sounds have a metallic tone which shakes your brain; and when one speaks, he makes the base of his skull vibrate as a trumpet would do.

Let us explain these phenomena. By flattening all of our mucous membrane which is exposed to the air, the compressed air makes our pharyngo-laryngial and bucco-nasal cavities larger and more sonorous through the bones.

Moreover, for the vibration, it gives to the edges of the larynx, the tongue, the lips, the soft palate, and even the nostrils, tensions which are greater in proportion to the increase in its density. We must therefore not be surprised that all these organs raise the pitch of the sounds which they produce .... Because of the weakness of our lips, we all lose the power to whistle in compressed air.

Some persons feel that taste and the sense of smell are weakened or entirely lost in compressed air.

The flattening of the mucous membrane which is exposed to the air, which makes impossible any hemorrhage of the respiratory tracts and cures suddenly (though not without pain) coryza and hoarseness, explains all these data perfectly. How could a withered, shrivelled organ collect any savors?

Our skin is more substantial than our mucous membrane; in spite of that the caissons affect it. Its papillae, like those of the nose and tongue, become less sensitive, and many workmen, whose hands, however, are very callous, find their sense of touch less sure in compressed air .... .

In this same medium, our pulse soon becomes filiform and even imperceptible. The venous pressure soon fails, our circulation flags, but our tissues do not become livid; the contrary is more likely to take place.

That is because the great tension of the air, favoring the combination of the oxygen with the blood, as with all the other combustibles, makes it so rich that it comes out of our veins as ruddy as out of our arteries. What loss of color would be possible with such a liquid? 
In compressed air, our pulmonary capacity increases, and the movements of our ribs lessen. The excessive pressure which dissolves the oxygen in our finest vasculo-sanguine ramifications makes the action of the thorax unnecessary, and for this reason, our coordinating nervous center reduces it to its minimum of amplitude.

Economy of strength and time, such is the law which the human spirit follows in the numerous combinations which it makes to keep us in harmony with the world, even when it is a matter of our vegetative life.

The laborers, when they are working in the caissons, feel fatigue less than in the open air, and do not become so breathless. Hunger seizes them quickly; they sweat a great deal and yet are never thirsty.

This is the reason for all these phenomena, which are contradictory only in appearance.

The absence of thirst, in spite of enormous loss by sweat, is the result of the great quantity of water which the compressed air holds in solution and forces into the organism.

The sweat is due to the assistance which our outer tegument never refuses to the lungs, especially in a warm atmosphere, when it is a matter of throwing off much of the muscular materials broken down by work.

Hunger results from the enormous consumption of our various tissues by the excess of oxygen which penetrates them and by the more energetic contractions of some of them.

The lessened breathlessness is caused by the circulatory slackening which brings back (towards the lungs, the liver, and the spleen) only a very little venous blood, since there is hardly any, to tell the truth.

Finally, the absence of fatigue results precisely from the richness of this same nourishing liquid, which unceasingly repairs our muscles at the same time that their own contractions destroy them.

In compressed air, our secretions are modified; those of the lungs and the skin increase considerably. Those of the alimentary canal, the kidneys and the liver, their converse in many circumstances, do not change, or rather, generally diminish. (P. 12 and 13.)

When leaving the compressed air, when no illness is to follow, one immediately has a feeling of comfort. It seems as if one breathes as if in spite of himself, that one's chest is full of air, and that one is lighter. That is because there is no longer the heavy weight upon you. (P. 17.)

Such are the effects produced by the passing action of compressed air. According to M. Foley, the workmen who are frequently subjected to it experience phenomena of another sort:

Any too long period of work within the caisson is divided into two stages: one of benefit, the other of organic loss . . . .

As long as the first lasts, the caisson worker has an increased appetite, leaves his work without fatigue, and returns to the open air more alert, more lively, and more eager than usual. He feels stronger and boasts of it with reason, for then the richness of his blood profits him. 
As soon as the second begins, the contrary takes place. The workman loses appetite, and, more and more, reaches his work as he leaves it, melancholy and tired. His skin becomes flabby, loses color, becomes almost clay-colored. The conjunctiva takes on a wine-colored hue. His gaze is dull. His face and body grow thin. Indecision, distaste for movement, stupor almost, appear in all his motions, and gradually the time comes when, outside the caisson, he seems to have lost strength; when the normal atmosphere is no longer sufficient to aerate his blood.

In the compressed air, all these painful symptoms disappear; unfortunately they reappear as soon as he goes out, and more and more quickly too. Soon even the excess pressure fails to revive him. $\mathrm{He}$ is then on the point of being able to regain the strength he loses, every time he works, only by the intervention of morbid phenomena. (P. 18.)

So much for the purely physiological phenomena. As for the symptoms, the fleas, or excruciating itching of the skin, hardly ever begin to appear before the pressure of 2.5 atmospheres; beyond 3 atmospheres, "everyone has them;" the muscular swellings (sheep) are frequent at about 3 atmospheres, as are the "synovial swellings;" but the joints themselves are attacked only later and more rarely. The muscle symptoms affect particularly those which have been tired by repeated contractions.

The number of days during which the laborers have worked in the caissons seems to M. Foley a very important consideration; under an almost equal pressure, the symptoms would become more and more frequent and severe the longer one worked.

No fatal ending or paralysis, however, has been observed at Argenteuil. The most serious symptoms are muscular pains, which, judging by the details of the observations, seem to have been of extreme violence.

M. Foley disagrees with all the other authors on two main points, which are of the highest practical importance. According to him, in the first place, when the workmen prolong their stay in the caissons beyond 12 hours, they come out without harm: that results, he says, from the fact that "the nervososanguine reaction is general" (p. 49); but this so-called explanation is of little importance.

In the second place, curiously enough, he considers that the speed of the decompression is of little importance. One minute per atmosphere of compression seems to him long enough:

For pressures above $3 \frac{1}{2}$ atmospheres (decompression in $2 \mathrm{~min}$ utes 30 seconds), would it be necessary to follow the same progression? I do not think so; two and a half minutes are a long while in an icy lock-chamber. (P. 56.) 
If one is to use these high pressures, M. Foley advises that the men be decompressed in "three minutes." Furthermore, he is so far from the idea that a rapid decompression can be dangerous, and so persuaded that it is merely a matter of chilling, that he summarizes his thought by this precept:

If the thick and icy mist which is sure to appear seems too penetrating to you, make haste! (P. 53.)

Constructing foundations by the use of compressed air was used in 1862 on the viaduct over the Scorff, at Lorient, and in 1864, on the bridge over which the railroad of Napoléon-Vendée crosses the Loire at Nantes. The chief engineer Croizette-Desnoyers, ${ }^{23}$ who gives the most minute details about the construction and the operation of the apparatuses set up by the Gouin Company, does not mention the condition of the workmen; he is satisfied with admitting that "at great depths, the system of laying foundations by the use of compressed air may injure the health of the workmen." (P. 392)

And yet serious accidents had occurred at the bridge over the Scorff.

The list of sick workmen, drawn up by Dr. Nail, contains 16 names; the accidents, all due to the compressed air, include: 1 case of deafness, 6 cases of pains in the joints, 1 of muscular pains, 6 cerebral congestions, 2 deaths.

The two deaths were not simultaneous. The first occurred March 17, 1862; the workman died "of asphyxia on leaving the caisson;" the second, June 3, in another pier; the medical note says: "died after four hours of cerebral congestion and asphyxia."

I could get no details about either the symptoms which preceded death or the results of the autopsies, if there were any, or even the pressure reached. I know only that the decompression was made regularly in 10 seconds and that the maximum excavation for the first pier was 18 meters, for the second only 12 meters.

There were, therefore, 8042 shifts of workmen, among whom there were only 16 accidents serious enough to be noted. Other workmen who were in the lock-chamber with the two victims experienced no symptoms.

This double disaster was the cause of a court summons against the company officials, accused of homicide by carelessness; they were acquitted by the court of Lorient (September 30,1862) and by the court of Rennes (December 11, 1862). The preambles of of the judgment and the decree are very interesting, because they 
reveal the vague ideas of the doctors about the real cause of the accidents, and these uncertainties inspired the acquittals given:

Another accident, followed by another court instance, took place at the bridge over the Scorff. M. Gallois, civil engineer, an agent of the company, who went down into the caissons May 12, 1862, on his return to open air was attacked by symptoms of paralysis "as a result of cerebro-spinal congestions, spells of dizziness, and nervous shocks," so that he had to be sent to a wateringplace; he died two years afterwards.

His request for damages was refused by the tribunal of the Seine (August 18, 1861); the Orleans company produced an opinion of M. Dufaure, which reveals, like the legal documents which I mentioned a moment ago, the uncertainties of medical science. The celebrated lawyer combats the opinion of Pol and Watelle about the necessity of making the decompression very slowly with that of M. Foley. The tribunal gave no decision as to the scientific question, but declared that Gallois had not received an order to go down into the caisson, and that consequently the company could not be held responsible.

Here is the condition in which Dr. Hermel, ${ }^{2+}$ a homeopathic physician living in Paris, found M. Gallois, who had him called in consultation a few days after the accident:

May 21, 1862, we were called in Paris in the case of M. Gallois, a civil engineer, aged 24. We found the patient suffering from incomplete paralysis of the lower limbs, permitting him neither to stand upright nor to walk without support; he could advance only in a very awkward manner, placing both hands on all the surrounding objects; the movements of his limbs were irregular, jerky, trembling; he dragged his feet; if he tried to stand upright, a violent trembling immediately shook his legs and forced him to sit down. After three or four steps, the same convulsive trembling stopped him, because it kept increasing and would have made him fall. Over his whole body cutaneous sensitivity was exaggerated, it was hyperesthesia, the skin was the seat of an annoying pruritus, without any trace of an eruption. The movements of the tongue were so difficult that the patient could not pronounce all the words distinctly. Both memory and ideas were confused. As a result of the suffocation, a frequent cough tired him when he talked and produced a profuse expectoration of mucus with the appearance of the white of an egg. Auscultation of the chest and percussion showed that the lungs, though permeable to air in their whole extent during deep inspirations, did not possess their full elasticity; one could hear, especially on the left side, the expansion of the pulmonary vesicles beginning and stopping suddenly before the movement of inspiration was finished. This expansion of the pulmonary vesicles was therefore incomplete, which hampered normal respiration. The abdominal functions were interrupted; the 
constipation could be overcome only by enemas; there was paralysis of the rectum. The bladder was also paralyzed; urination could take place only by use of the catheter. He had lost appetite, and the cough often caused vomiting.

Knowing the perfectly regular life of this young man, we asked him about the date and the mode of onset of this disease.

He told us that while he was employed at the railroad works at Lorient, he had gone down into a caisson under a pressure of three atmospheres (including the outer pressure), where he had remained three hours to check the progress of the work in the foundation of a pier. Three or four minutes after his exit, he felt an icy cold, sudden and penetrating, as a result of the enormous rarefaction of the air in proportion to the inner pressure. When he tried to wash his hands, he perceived that movements of the arms were impossible, he could not put his hands into the tub because he could not lift them higher than his waist.

Taken home by two men who supported him under the arms and placed his feet on the steps he had to descend, he went to bed; after four or five hours he wished to get up, but he was completely paralyzed. An energetic treatment was given him and made him able to come to Paris after a fashion. On the tenth day he was in the condition which we described abové.

For ten days we gave belladonna (twelfth) and bryonia, which checked the cough a little. June 2, we began to apply every other day the rheophores of an electro-galvanic machine over the hypogastrium, to overcome the paralysis of the bladder. After the third treatment, he began to urinate without the catheter, but the next day, he was forced to have recourse to it again. After the fourth treatment, he urinated voluntarily only during the day. After the fifth, the urine resumed its natural course. The constipation persisted. We electrified the walls of the abdomen and the anus. Defecation, although sometimes difficult, was reestablished about the eighth treatment. After the tenth treatment, the abdominal organs had gained strength and activity, especially on the left. The right leg was still dragging, and in certain positions it was still affected by convulsive trembling; he could not have stood up on one leg; he used a cane in walking.

In July, he went to the baths of Balaruc, from which he returned August 1. His condition was improved, but there was still a faltering in the right leg. The cough persisted, although not so bad; respiration was still incomplete. Soundness of speech, ideas, and memory was reestablished. He no longer experienced pruritus or hyperesthesia of the skin. Six more applications of electricity caused a great improvement in the movements; he could walk without support.

Today, January 12, that is, after eight months of treatment, he has at times tiring fits of coughing; his respiration is almost normal, he becomes breathless if he walks too far or too quickly. He walks without support, but there is still stiffness in the right leg, and we cannot say when he will be completely cured. (Vol. XVII, p. 198-200.)

Also in 1862, a bridge was constructed over the Adour, in Bayonne, in the construction of which the pressure had to be 
raised to more than 4 atmospheres. The civil engineer who supervised the work, M. Counord, twenty years old, who up to that time had felt no symptom, on December 31 , a few minutes after leaving the lock-chamber, in which the decompression had been made in 4 or 5 minutes, was attacked by vertigo, dizziness, and complete loss of consciousness. The pressure was 4 atmospheres, the length of the stay in compressed air was one hour; the day before, he had remained in the caisson for two hours. Three hours afterwards, when he regained consciousness, he was completely paralyzed in both sensation and movement in the lower limbs, with loss of sensation in the arms.

The detailed observation of the beginning of this strange case was given by Dr. Limousin, ${ }^{2 \pi}$ of Bergerac, who does not hesitate to attribute the symptoms to a hemorrhage of the spinal cord:

I called upon M. C., who had been brought from Bayonne to Bergerac, on January 12, 1863: complete paralysis of the lower limbs, involuntary excretion of the feces and urine, normal sensitivity everywhere, a little exaggerated in the lower limbs; if they were struck suddenly, or touched with a cold body, a sudden extension was produced. Intelligence normal. In the epigastrium and the hypochondria, pains which were checked by the application of morphine on the bare skin. Up to January 20 , two doses of cathartic were given; nothing new appeared except very painful convulsive movements of the abdomen.

January 28. Excruciating pains appeared yesterday in the belly; it is flaccid, pressure does not change it. The patient's condition is terrible: constant moaning, voice faint, cold sweat, face cadaverous, pulse imperceptible, 48. Dry cuppings, enemas with laudanum have no effect. I then prescribed 20 centigrams of extract of opium in four pills, one every hour.

On January 29, with the second pill, the pains stopped; the patient fell into a profound sleep; he awoke quite free from pain. In the first few days, a small erosion had formed on the sacrum, today there was a huge scab; the bittocks, and the lumbar region were dull red; the patient could lie only on his back.

February 20. The sore on the sacrum, sprinkled with gray cinchona bark, has shrunk to the size of a 5 franc piece; it is pink and granulated; painful contractions have yielded to the application of metallic armatures. Movements can be made by the paralyzed limbs; they are executed more freely on the right side; on the contrary, sensitivity is very dull on the right, and keener on the left side in the same parts; there are formications over the whole body; one day sight was entirely gone for a few instants; erections, rare at first, have become more frequent. Finally defecation and urination are voluntary.

It is hard to find a better example of medullary apoplexy: sudden attack, lesions of contractability, sensation, a special sense, and the eye; reflex movements caused by the slightest stimulus; great lowering of the vitality of the tissues, manifested by the rapid mortification of 
the regions sustaining the weight of the body; finally, erections not accompanied by any stimulus of the genital impulse. There was never any considerable sensitivity along the spine.

The improvement did not make very rapid progress. In May, 1870 , M. Counord took several steps without support; he still had very unusual reflex movements when his lower limbs were pinched; the sensitivity of the left leg was much diminished. I saw him again in May, 18'76; he could climb one flight of stairs with great difficulty and with the aid of an arm; formications in the upper limbs seemed to indicate a morbid action in the upper regions of the spinal cord; the functions of urination and defecation had become normal again.

A few days later, a terrible accident, in which three men died, saddened the Bayonne works; the caisson had burst, as happened at Douchy, and later at Chalonnes. The suggestion ${ }^{26}$ was made that the death of the workmen had been caused by the decompression; that is probably a mistake, as is shown by the following extract from a letter written me by the engineer Bayssellance, who was kind enough to make a little investigation of the matter, at my request:

The pier, being deeply imbedded in the sand, measured in all more than 30 meters from base to the water level. The inner pressure, therefore, was about $4 \frac{11}{4}$ atmospheres. The upper surface, not being constructed with a view to such a high pressure, buckled perceptibly: this buckling caused a deformation of the cast-iron cylinder of the equilibrium chamber. One of the bolts having yielded to the uneven tension, a shock was produced which made the whole upper part of the equilibrium chamber fly to pieces. The decompression in this small portion of the apparatus was therefore sudden; in the interior of the pier, the capacity of which was 200 to 300 cubic meters, it must have been more gradual, and brought a violent current of air upwards from below, bringing with it the planks and the sand of the resting stages.

According to the foreman, the results were quite different from what was reported. No man was killed by the change of pressure. Since the wet sand from the bottom was no longer restrained, it rose rapidly, reached and passed over one of the men who was climbing the ladder; he was found seventeen days afterwards when the caisson was being cleared out, clinging to the ladder rungs in the position of climbing. Another was carried away by the air current and found himself at the top without really knowing what had happened to him. Two others who were on the intermediary stages were carried up and crowded against the under side of the floor of the equilibrium chamber, and were almost suffocated, with their mouths full of sand; they were taken to the hospital, and died the next day, I think. Finally, five men who were in the equilibrium chamber itself 
were covered with sand, which even penetrated the skin, and remained for a few moments as if stupefied, but none of them was seriously ill.

This result does not agree with what had been told me; but $M$. Wolff was on his rounds at the moment of the accident; and $\mathbf{M}$. Counord was ill; it seems more certain to trust the version of a witness though it is almost the opposite. Moreover, this man was present at a similar accident, at the time of the construction of the bridge of Bordeaux; there too, no death was caused by the sudden decompression; two men only were killed by fragments of iron.

But if a sudden decompression of more than three atmospheres was not fatal, this change, though moderated by a stay of 4 or 5 minutes in the equilibrium chamber, was none the less dangerous in the long run. According to M. Counord, $90 \%$ of the workmen were ill, all attacked by violent pains in the joints, oppression, disturbance of vision, etc. The foreman whom I saw was attacked three times, and suffered greatly, but never more than a day. One morning, out of eleven men who were leaving, nine were seized with pains after a few moments.

Certainly it is not impossible that the decompression had something to do with the death of the two workmen who were buried in the wet sand; but that is not proved. The strangest thing in this observation is to see men experiencing almost no symptom after an instantaneous decompression from at least 4 atmospheres.

In 1865 , there was a similar foundation under the Louet, at Chalonnes (Maine-et-Loire), for the bridge of the line from Angers to Niort. A catastrophe as yet unexplained killed two workmen:

February 20, 1865, when pier number 2 had reached bed rock, at a depth of 14 meters below the low-water mark, when everything seemed finished, when the work-chamber was already filled with concrete, and when the caisson, like a chimney, was also filled up to a depth of 5 meters, suddenly a violent explosion occurred and half of the metal roof of the equilibrium chamber ${ }^{27}$ was hurled about 30 meters away. Two laborers, who were in the work-room, were crushed. No explanation for this terrible accident has yet been found. (Lectures on Bridges by M. Morandière)

It is probable that in this case, for some unknown reason, the tension of the compressed air had risen far above that required by the depth reached; the force of the explosion proves that.

I am endebted to Dr. Gallard for some interesting details about this distressing accident:

The death of the two workmen (this learned colleague writes me) was almost instantaneous, like a thunderbolt for one of them, a little slower for the second, who still breathed for a few seconds, but had already lost consciousness.

The autopsy (made by M. Gallard under bad conditions, after exhumation and previous autopsy by the physician of Chalonnes) 
showed numerous patches of interlobar and vesicular emphysema on the lungs of the two victims. There were besides numerous ecchymoses in spots under the pleura and the pericardium .... I seem to remember that the blood .... contained a few bubbles of gas .... The notes of the autopsy were lost by the physician of Angers to whom I had dictated them.

Should we attribute the death to the decompression? It is hard to decide, in view of an unsatisfactory autopsy and especially the fact which we reported above in discussing the bridge of Bayonne.

M. Triger was disturbed by the accidents caused by the application of his method, and sent to the Minister of Public Works a Memoir on this subject, which was submitted to the examination of MM. Combes, Hennezel, and Féline-Romany.

The report ${ }^{28}$ of these engineers, after briefly reviewing the works carried out by the Compagnie du Midi over the Tech, at Bordeaux and Bayonne; by the Compagnie de l'Ouest at Argenteuil, at Elbeuf and at Orival over the Seine, at Briollay over the Loire; by the Compagnie d'Orléans over the Scorff at Lorient, over the Louet at Chalonnes, and over the Loire at Nantes, states that:

The accidents to which laborers working in compressed air are exposed rarely endanger their lives, cause only rather short interruptions of work, and, especially, are very few, compared to the number of men passing through the lock-chambers in each job.

The diseases caused by these accidents can be prevented by the use of the means specified in the course of this report.

These means are the use of woolen garments in the lockchamber and a decompression for which no uniform rule could be given:

There is no rule to be observed other than the one which common sense indicates, namely, not to open the cock too quickly, for compression as well as for decompression, so as to give the organism time to place itself in equilibrium with the medium in which it is immersed.

M. Triger requires that the decompression last 7 minutes, and states that then the symptoms disappear completely. It seems to us that this time should vary with the constitution of the workman. (P. 125.)

The excavation of the shaft of a coal mine at Trazegnies, in Belgium, at about this same time, was the subject of a very interesting work by M. Barella. ${ }^{29}$

The total maximum pressure was $3 \frac{1 / 2}{2}$ atmospheres. The decompression was made in about 20 minutes.

According to M. Barella, in addition to pains in the ears one experiences: 
Dryness of the pharynx, a considerable decrease of the urinary secretion, a sensation of respiratory improvement, for it seemed to me that I had never breathed so freely, and so easily.

As for the pulse, we did not obtain a very definite result; however, in most of our workmen, it seemed to us that the rate had decreased by a few beats. (P. 598.)

The symptoms observed were:

1. In seven workmen, epistaxis, not serious;

2. In eleven workmen, pains in the thoracic and abdominal members, sometimes crushing, lancinating, excruciating.

3. Severe itching on the legs, unaccompanied by pain, a very frequent symptom. (P. 605.)

M. Barella calls attention to the fact that none of these symptoms occurred during the stay in compressed air; they were observed only when the workmen were leaving the apparatuses. Moreover, they began to appear only above 2.8 atmospheres.

M. Barella says that the little wounds which the laborers inflicted on themselves while at work did not bleed, "which is explained by the pressure on the cutaneous teguments."

A student at the School of Mines of Liége, who went down into the shaft April 15, experienced on his exit very serious symptoms, which he describes himself in the following words:

During the decompression, I felt a discomfort which I attributed to the cold.

After I had come out, when I wished to raise my right arm, I could not make it reach a definite point without making the effort two or three times. My sight was affected, and I saw my arm moving much as one perceives objects after he has whirled about several times.

The paralysis grew worse and it became impossible for me to move my arm which hung inert, I could not even make motions with my hand. The phenomenon was rather like that of an arm which has gone to sleep. It appeared progressively and in the same manner in my right leg.

They placed me on a bed, for I could not walk, I sank down. They rubbed me. I was dazzled and my eyes refused to serve me at all. I saw only at long intervals, and for a second at the most, then everything disappeared to reappear only after a few moments in the same way. My eyes were dull and glassy, they told me, and perceived only a white, vaporous light.

I recovered the use first of my leg, then of my arm; the instants during which I could see grew closer together, and I saw distinctly for longer periods.

Finally no symptom was left except a violent headache and the usual signs of a fit of indigestion. I threw up my food. My headache disappeared in the open air, and I went home, having nothing but fatigue to remind me of my former experiences. 
The friend who accompanied me, who had eaten the same meal as $I$, had no unusual sensation. (P. 612.)

Among the conclusions of M. Barella, we shall quote two:

1. It is best not to go beyond a pressure of three and a half atmospheres above normal pressure.

2. We may take as a standard of the duration of the decompression 10 minutes per atmosphere.

The others have only a purely medical interest: lymphatism, heart ailments, etc.

In America, the first bridge constructed by compressed air was over the Great Peedee River, for the railroad from Wilmington to Columbia and Augusta. I have found in my reading no information about this work from the point of view which interests us here.

In 1869, a truly gigantic work was undertaken at Saint Louis (United States). A bridge with two piers was built over the Mississippi. On the east pier, the depth reached was 33.70 meters below the usual water mark; it was a depth without precedent in the applications of the method, which was to be increased by the occasional floods of the river. The total pressure rose to 4.45 atmospheres. The total number of workmen employed there was 352 ; about 30 were seriously affected: 12 of these died.

Here is an extract from the report made by the chief engineer of the work, M. Eads: ${ }^{30}$

When the diepth of 60 feet was reached, some of the workmen were affected by muscular paralysis of the lower limbs. It was rarely painful, and went away in two or three days. As the caisson sank deeper, the paralysis went away more slowly. In some cases, the arms were affected, and more rarely the sphincters and the intestines. The patients also had much pain in the joints when the symptoms were very severe. Nine tenths of the patients felt no pain and got well very quickly.

The duration of the stay in the air chamber was gradually shortened from 4 hours to 3 , to 2 , and finally to 1 hour. The use of galvanic plates or rings seemed, in the opinion of the director of construction and the workmen, to give a remarkable immunity against attacks. Finally, they all had them. They were made of alternate rings of zinc and silver, and placed on the chest, the arms, the elbows, the waist, and under the soles of the feet. The acidity of the perspiration was sufficient to establish a galvanic current, and the opinion of those with the greatest experience in these matters was quite favorable to this remedy. Captain Eads is strongly inclined to believe it to be valuable.....

The engineers of the port, who very often visited the caisson, have never been ill.

Physicians have differed greatly about the cause of the symptoms. 
Some maintained that a slower return to normal pressure would have been less dangerous; others blamed too rapid compression for all the trouble. The fact that the workmen employed to operate the doors were never affected, although during the two hours of their work they were very frequently in extreme and alternating conditions of pressure - one moment at normal pressure, and 5 minutes afterwards sustaining a weight of 50 pounds per square inch of the surface of their bodies - would seem to prove that these two theories are wrong, and makes us believe that the real cause of danger lies in the long duration of the stay in this air where the body endures so great a pressure, and not in the rapid changes to which it is exposed .....

The transitions lasted from 3 to 4 minutes ......

Considering that thousands of persons, even delicate ladies, had visited the air chambers for a short time without harm, after the caisson had reached bed rock too, and that no serious symptom attacked the workmen after the reduction of the working time to 1 hour, M. Eads concluded that the real cause lay in the prolonged labor.... Too long a stay was invariably followed by paralysis. Dr. Jaminet, physician at the job, after staying one day for $23 / 4$ hours when the depth was 90 feet, was severely affected after returning home.

Dr. Bauer, ${ }^{31}$ surgeon at the City Hospital, to which were taken the 25 workmen affected during the laying of the foundation of the Saint Louis bridge, presenting what he calls "Bridge cases," gave some interesting information about the symptoms observed in these patients:

Respiration becomes more laborious, and the pulse more rapid at the beginning of the compression, which passes off rather quickly in persons who are in good health. The voice takes on a nasal tone which it retains even after leaving the compressed air.

When they leave, all the workmen are very pale and extremely weary, even to the point of stretching out on the ground. In others, one sees involuntary, choreic muscular contractions with bleeding from the nose and lungs.

In serious cases, there is paralysis in different degrees, from slight paresis to a complete loss of movement and sensation.

Very often, urination is rendered difficult or wholly impossible, so that the urine must be drawn with a catheter: it is often bloody. Respiration is not affected; fever rarely appears and then it brings on a fatal ending. Death occurs in a state of coma, with delirium, hiccuping, stertorous respiration, and muscular cramps; the pupils are dilated towards the end.... .

Among the patients observed, only a few were cured in the course of the first week; others remained under treatment for a month; four died. In the paralytics, there are found congestions of the cerebral and medullary meninges, edema of the arachnoid, softenings of the brain and the spinal cord without definite localization. In one case, the softening covered the anterior horns and lateral column the whole 
length of the spinal cord. Baumgarten found in this focus abundant cells of the neuroglia attacked by fatty degeneration.

The same facts were told by the chief engineer of bridges and highways, Malézieux, ${ }^{32}$ in his fine report on the public works of the United States of America in 1870. He copies verbatim (p. 91-93) the passage from the report of the engineer Eads which we quoted above.

M. Malézieux has also given details about the foundation of the bridge which was to connect New York to Brooklyn. At the time of his visit, they were only at the beginning of this work. But the plans were gigantic; the foundation caisson was 52.46 meters long by 31.11 meters wide, that is, more than 16 ares in area.

In the second Memoir, ${ }^{33} \mathrm{M}$. Malézieux gives the depth actually reached. The Brooklyn pier had a foundation 15 meters deep; the New York pier, 24 meters.

For the latter, steam-heating was installed in each of the airlocks, so as to prevent the chill produced by the sudden escape of the compressed air (p. 385.)

As to the physiological effects, M. Malézieux states:

That he has little to add to what he reported previously about the Saint Louis bridge. M. Roebling (that is the engineer and constructor), however, notes this fact, that the action of the lungs is changed involuntarily in compressed air; the number of times one breathes in a given time is reduced 30 to 50 per cent; which would indicate that the organism reacts against the introduction of oxygen in a proportion two or three times greater than in normal atmosphere.

The natural conclusion to be drawn from this observation is the one which M. Eads had made at Saint Louis; to shorten the duration of work in compressed air as the pressure increases. (P. 395.)

I shall quote in conclusion some information which I owe to the kindness of the managers of a great industrial company, which does a great deal of work on the foundations of bridges with the use of compressed air. These documents refer to works executed very recently outside France; a discretion the motives of which everyone will understand prevents me from giving more definitely the details of date and place.

First, here are general specifications about the manner in which the works were carried on, and which resulted in the accidents; these specifications come from the superintendent of the job himself:

1. At a depth of 20 to 22 meters, the shifts still lasted 8 hours, and our men were not too tired, none of them felt any ill effects from the pressure, they were merely inconvenienced by the evil odor of the mud and by the hot air, which, however, we took care to 
renew frequently through the hoisting-shaft; under this pressure of two atmospheres, the workmen underwent decompression in 4 or 5 minutes.

2. From 22 to 25 meters, the shifts lasted 4 hours; under this pressure, the men began to feel rather severe symptoms; the decompression took 10 minutes, the opening of the discharge cock was only 25 millimeters, then afterwards 18 millimeters.

3. From 25 to 28 meters, the workmen relieved each other every 3 hours, and were decompressed by means of a cock, the opening of which was reduced to $10 \mathrm{~mm}$; it took 16 to 17 minutes, and it was while working under this pressure, that our men were most fatigued; very often it happened that 4 out of 7 were affected by the pressure in their legs, heads, and stomachs; in others, the decompression caused paralysis of the bladder or of vision; some of these workmen experienced horrible sufferings for two or three days and then three or four days of convalescence before being able to go back to work; these were the ones most seriously affected; as for those who had lighter attacks, they also experienced great pain for twenty-four hours and then 1 or 2 days of inability to work. (July 22, 1875)

As a sequel to my letter of the $22 \mathrm{nd}$, I wish you to know that in the last four days we have had only two workmen affected by the pressure; only slightly, but enough to keep them from working; we still have in the hospital 2 workmen seriously affected by the pressure since the 21 st on coming off duty at 6 o'clock in the evening; they are paralyzed in the lower parts of their bodies, and their urine must be drawn by the catheter.

The decompression lasts on the average 18 minutes; the shifts work 3 hours. (July 28)

To continue my letter of the 28th of this month, I wish to inform you that a man named $R$, one of the two working in the excavation who were hospitalized as a result of the pressure, died today at half past twelve. The second workman is out of danger, the doctors think; he has recovered except that his legs are paralyzed, and they hope that this trouble will soon clear up.

The doctors claim that the death of $R$. is due to the pressure, which probably affected the spinal cord; this man had worked before in excavations with compressed air, but had never gone beyond 2.1 or 2.2 atmospheres. (July 30.)

The first of the two workmen who were seriously affected and whom we have just discussed returned to his home; we have had no further information about him.

As to the said R., his autopsy was performed. It resulted in noteworthy findings which Dr. L. describes in a letter addressed , the company, and a translation of which follows:

After opening the spinal canal, I found that at the height of the thoracic vertebrae the spinal cord was very soft; for some inches it was transformed into a soft, flowing mass, yellowish gray in color, which above and below merged into the healthy part. 
The cord in general was much congested, as was the brain, but I saw nothing else abnormal, there or in the other organs.

\section{Diving Suits.}

As we said when we began this chapter, the diving bell has been entirely abandoned for the diving suit, an apparatus which is infinitely simpler and less costly, and which allows each man to work by himself with a certain liberty.

I have no intention of going back to the origin of this invention although it is very recent; the French word itself scaphandre

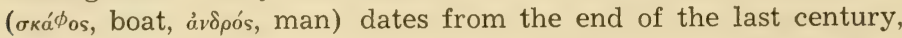
and was given to a simple life preserver. It is only during the last fifty years that Siebe of London, then M. Cabirol, and finally MM. Rouquayrol and Denayrouze have made a practical apparatus of it, easy to use in fishing for oysters, coral, pearls and sponges, in saving sunken objects, in cleaning and inspecting the hulls of ships, etc.

However, I cannot keep from mentioning a strange invention of Borelli, which had some connection with the diving suit and is interesting in the history of the theories of respiration; I borrow the description of this apparatus, very poorly planned because it did not provide for renewing the air for the diver, from BrizéFradin who quotes it without telling where the celebrated doctormathematician described his apparatus. He expresses himself in these words:

Borelli, inventor of the machine called diver's bladder, prefers it, for some reason or other, to Halley's bell. It is a globe of brass or copper about two feet in diameter, placed over the head of the diver; it is fastened to-a goat-skin garment made to fit the diver. In this globe are the tubes by which the circulation of the air is maintained; at his side the diver carries an air-pump, by means of which he can make himself heavier or lighter, as fishes do, compressing or expanding their air-bladder: in this way he thinks he can meet all the objections made in regard to other machines, and especially the objection in regard to lack of air, since the air which has been breathed is, according to him, deprived of its harmful qualities by circulation in the tubes. (P. 44.)

Let us recall that in Halley's diving bell a man could take several steps outside the bell and continue to breathe by means of a sort of helmet and a tube which ended in the air of the bell; he was therefore almost in the conditions of the modern diving suit. The principal part of the present apparatus (Fig. 7) consists of a heavy metal helmet, with glass portholes, which the diver places over his head; a tube which communicates with a compressing 
pump placed on the bank or on the deck of the boat furnishes him compressed air which escapes through orifices contrived for this purpose. The pressure to which the air breathed by the diver is

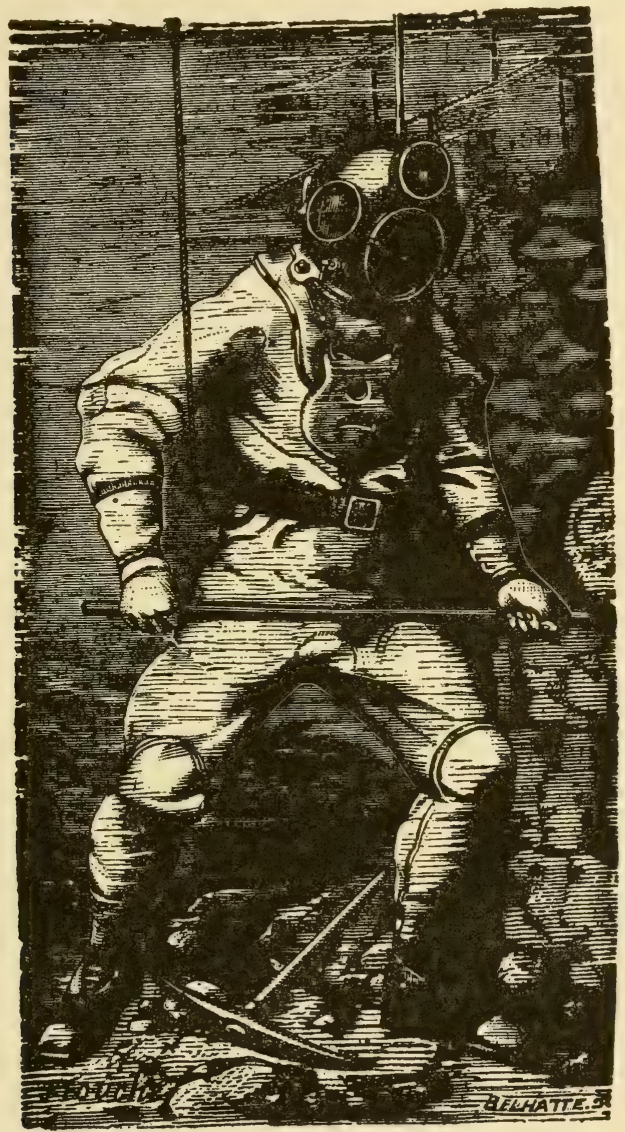

Fig. 7-Diver equipped with the Denayrouze regulator, complete suit.

subjected is therefore practically equal to that which the water exerts on the rest of his body. This condition absolutely must be met, as we shall see in the following part of this work, and very 
serious symptoms must have been the result, under certain circumstances, of forgetting this fundamental rule.

It is scrupulously observed in the apparatus of MM. Rouquayrol

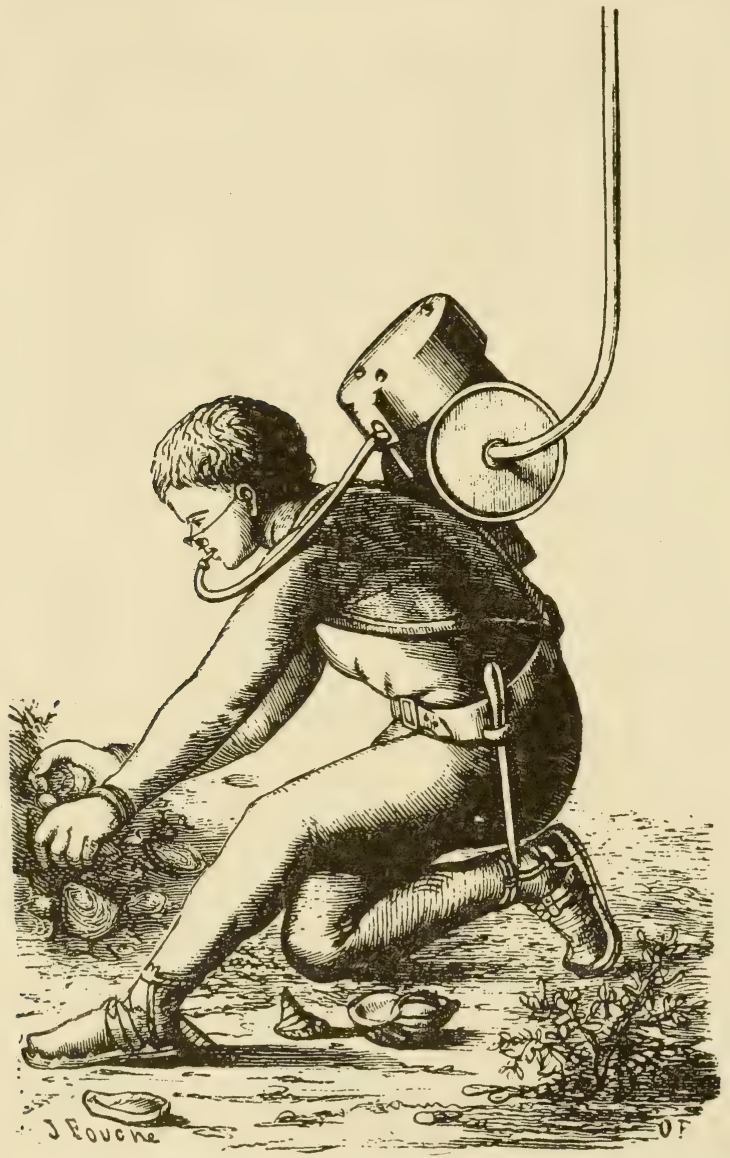

Fig. 8-Diver equipped with the Denayrouze regulator, helmet removed.

and Denayrouze. The diver dressed in their suit does not breathe directly the air furnished him by the pump; on his back there is a metal reservoir in which the compressed air is constantly 
stored up and from which, thanks to a very ingenious mechanism, it escapes only to meet the needs of the diver at the pressure absolutely necessary at the depth reached. When the reservoir is full, the diver can detach the tube which leads to the pump, and move about freely for a certain time. He can even, for work of short duration. remove the helmet and take in his mouth the tube which comes from the regulator (Fig. 8).

To return to the surface, the divers sometimes climb a rope ladder, and sometimes are hoisted on board by means of a rope fastened to the belt. In both cases, they hardly ever take more than one or two minutes to return to normal pressure.

The diving-suits are now used very frequently in all our seaports; but the depths reached are generally rather shallow and do not exceed 20 meters. They are also used considerably in the seas of the Archipelago for sponge-fishing. There, the depths reached are as much as 40 meters; I even have it from $M$. Denayrouze that divers have reached 48 meters; in that case the total pressure was therefore 5.8 atmospheres.

According to M. Leroy de Méricourt, divers with suits in the employ of English companies have ventured to the depth of 54 meters, the pressure therefore being 6.4 atmospheres.

It is not with impunity that such pressures have been endured, or to speak more exactly, it is not with impunity that divers have risen from such depths in a few minutes to the surface of the water. Many accidents have been reported, a large number of which have ended in death. Their frequency and their severity are such that the accounts telling us of them seem to scorn and omit whatever does not amount to paralysis or death. However, the financial returns are so great that the use of suits keeps increasing every year. They were introduced only about twelve years ago in the Archipelago, where their appearance caused regular riots in 1866; and in 1867, about a score of machines were operating in sponge-fishing. I have been told that today there are more than three hundred of them,- -and that the deaths have risen to about thirty per year!

The first document which informs us of these strange and dangerous accidents we owe to M. Leroy de Méricourt, ${ }^{34}$ and bears the date of 1869. This article is based, the author says, on information contained in an unpublished memoir of M. Aublé, agent of the Society for sponge fishing by means of the Rouquayrol and Denayrouze diving apparatuses:

During the 1867 cruise, no serious accident occurred among the men who were equipped with this apparatus for fishing. But in the 
same season, out of 24 men who used 12 suits of English manufacture, 10 died.

The lack of doctors at the fishing places and the difficulty of getting information from the fishermen of the Archipelago, who are of a very distrustful nature, did not allow us to determine, as would have been desirable, the nature of the symptoms which preceded the death of the 10 men we have just mentioned. We could learn only that three of them died suddenly as they were leaving their submarine work, and that others had languished from one to three months, paralyzed in their lower limbs and bladders. Because of the existence of paraplegia in the 7 divers who lived for a time, we may assume, up to a certain point, that this symptom must also have been present in the 3 who died rapidly.

What are the injuries which caused the death of these unfortunate fishermen during the cruise of 1867, and how can we explain the mechanism of their production? The lack of medical observations and especially of autopsies requires that we express an opinion on this subject only with considerable reserve. Paraplegia, it is true, is a symptom so characteristic and apparent that one does not need to be a physician to observe it. In one of the victims, a very daring young Greek diver, there was such a distention of the bladder that the father, in the hope of relieving this unfortunate young man, tried to catheterize him; he caused disturbances which were followed by a peritonitis which was soon fatal.

We shall see in Chapter III the explanation which M. Leroy de Méricourt suggests for these symptoms, which he attributes to medullary hemorrhages.

The rest of the note is devoted to very accurate remarks about the superiority of the Denayrouze apparatus and the necessity of a slow decompression:

Whereas the group of divers among whom the symptoms appeared reached the considerable depths of 45 to 54 meters and consequently endured pressures varying from $5 \frac{1 / 2}{2}$ to 6.4 atmospheres, M. Denayrouse with a prudence which does him honor, had given the order not to go beyond 35 meters, not to stay more than $2 \frac{112}{2}$ hours, per diver and per day, and finally to come up very slowly, taking one minute for each meter of depth. Moreover, the apparatus used offers greater safety than the diving suit: the air is given out in proportion to the needs of respiration, and at a pressure mathematically equal to that of the ambient medium.

But it was not possible to make the Greeks observe these strict precautions. The decompression to which M. Denayouze had assigned a duration of 15 minutes began to be made in one or two minutes again. The symptoms reappeared also. A private letter from M. Denayrouze, dated July 9, 1872, gives me the following information on this point: 
For 6 months, I have had about a hundred men diving at depths varying from 30 to 40 meters. 200 other foreign divers were working under my supervision under the same conditions. All these men were breathing air at the pressure of the ambient medium, about 4 or 5 atmospheres.

Five men died at these pressures, a great many others were attacked by different affections, the most frequent of which were paralyses of the lower limbs and the bladder, deafness, and finally anemia.

The men subjected to sudden decompressions were really more affected by the symptoms than the others. Those who died never expired at the bottom of the water, they came up complaining of inward pains, particularly of the heart, lay down in their boat, and died after a few hours.

July 19, 1872, a young doctor who in 1868 had made a cruise on board a boat bound for sponge fishing on the coast of Turkey, Alphonse Gal, ${ }^{35}$ sustained before the Faculty of Montpellier a very interesting thesis on the data which he had observed.

In the first part of his work, he discusses the modifications in the physiological functions caused by a stay in compressed air. Naturally I am reporting only the part of the observations which come from his experience.

Speaking first of respiration, he says:

It is impossible to use a spirometer in a diving suit; and it is rather difficult to appraise sensations of the type that we were studying. However, at pressures varying from 15 to 25 meters, I observed myself from the point of view of respiratory movements and I think that the expansion is less than in the normal state. No doubt the pulmonary capacity, which M. Bucquoy calls the vital capacity, increases, in the inspirations in which the lungs are called upon for their full strength; no doubt when one is making an experiment and tries to produce the fullest expansion, the results are better in the compressed air; no doubt also the patient subjected to the air treatment and quickly experiencing a sensation of well-being due to the greater efficiency of hematosis, instinctively takes deeper inspirations; but the diver, subjected to a pressure of 2,3 and 4 atmospheres, does not feel the necessity of increasing his pulmonary expansion, and like Foley, I believe in the action of the nervous centers in moderating the extent of the inspiration, since this extent has become useless because of the greater quantity of oxygen brought in contact with the capillaries of the pulmonary plexus in a volume which merely equals the normal volume.

And so in summary, for forced respirations the pulmonary capacity increases with the atmospheric pressure; but for ordinary inspirations, especially in a healthy man, this rule no longer holds, for one is more likely to observe-at least I think I noted it, especially at pressures of 2 to 3 atmospheres-a decrease in the pulmonary amplitude (P. 17).

In regard to the number of respiratory movements: 
For my part, I have been able to make a rather large number of observations on this point; when a diver was on the bottom a short distance from the boat, and when the sea was calm, I clearly saw the bubbles of air from each respiration coming to the surface. As one could see in the description of the regulating air bag, the diver with the Denayrouze suit breathes through his mouth air contained in a reservoir, and he expires also through the mouth. The air thus expired escapes through a valve which closes immediately after the expiration. The time separating two respiratory acts can therefore be measured in this way, and during this time the diver is under the normal conditions of work and does not know that he is being observed. I have thus been able to note individual differences, but within very narrow limits. The minimum number of respirations was 12; the maximum 30; but we should not think that the average is the number halfway between these two numbers. Taking all the observations I have made, the average is 18 , but it is too high and cannot give the normal number of inspirations in compressed air. In fact, every time I observed in a diver a respiratory rate higher than 20 , I am sure that this respiratory acceleration resulted from a chance cause (emotion, muscular effort, rapid walking, etc.). In many cases, after following the respiration of the diver for a few minutes, I saw it dropping little by little and finally getting below 20 .

In summary, the physiological modifications of the respiratory apparatus affect the extent and the rhythm of the movements. Let us add to what we have said on this subject that respiration is always very easy in compressed air. In this we agree with all who have carried on experiments under good conditions of ventilation. Under the water, whatever the depth, one breathes easily and freely (P. 19).

We have seen in divers that the respiratory movements increase in number as the men ascended the ladder and were consequently decompressed. A great part of this acceleration must no doubt be attributed to the very act of decompression, for the ascent is extremely easy for the divers; and because of the air contained in their suit, which expands as the ascent continues, they need rather to hold themselves down than to make efforts to ascend. But however great is the pressure undergone, this acceleration of the respiratory movements never goes as far as panting (P. 21.)

Let us turn to the circulation:

In diving suits, only inexact observations can be made in this regard; the pulse is very hard to take and there is no way of measuring exactly the time occupied in the observation. Nevertheless I tried to find the rhythm of my circulation, and I think that its rate never dropped.

We may say, without trying to explain it, that in compressed air, at pressures used by sponge divers, the circulatory rhythm does not seem altered.

This is not true of the amplitude of the pulsations; in this all experimenters, except Junod alone, agree. They all admit that in compressed air the pulse becomes filiform and sometimes imperceptible .... 
Evidently the superficial capillaries and the arteries which are nearest the skin are more subject to the effect of the outer pressure and their caliber lessens. If one goes into compressed air with a part of the mucous membrane or the outer tegument congested, the congestion quickly disappears. In the diving suit, in spite of rubber rings which clasp the wrists tightly, the hands are pallid. But although the quantity of blood in the periphery is diminished, the organs which by their position are less directly subjected to the action of the compressed air have a more abundant circulation. Since the lungs are under the same conditions as the skin, they must receive less blood than in the normal state. (P. 22-23)

If one returns from a higher pressure to normal pressure, the pulse rate accelerates, the pulse which was filiform regains its fullness, and if the difference in pressures was considerable, slight hemorrhages are sometimes observed.

The agreement of authors on this question is perfect. We were not able to follow the changes in the circulation during the act of decompression, but we noted by a great number of observations that at the moment of reaching the deck the pulse rate of the divers was almost always more than 80 per minute. Out of 240 observations we found it to be:

Below
From
From
From

Half an hour afterwards, 203 times the pulse had returned to nearly normal; 3 times it had fallen definitely below, and 34 times it was still between 75 and 80 .

Here, as in regard to respiration, we cannot attribute the acceleration of the rhythm to the act of ascent. As we have said, muscular fatigue is almost absent because of the expansion of the air in the suit and the slowness with which the diver ascends. (P. 24.)

The secretions furnish him with the following observations:

All authors, except MM. Foley and François, note a greater secretion of urine; I think that this opinion is correct. The divers whom I have observed could not remain more than an hour and a half subjected to a pressure of 20 meters of water without feeling the need of urinating; sometimes they even urinated in their suits. The increase of the salivary secretion was noted only by MM. Eugéne Bertin and Junod; as for me, I cannot form an opinion on this matter; in all the French divers and in myself the salivary secretion was more abundant than in the normal state; but the presence in the mouth of a rubber apparatus intended to admit air accounts satisfactorily for this phenomenon.

After this series of purely physiological observations, M. Gal reaches the study of dangers of high pressures. He divides the diseases which one may attribute to the effect of compressed air 
into two categories: diseases which begin suddenly, which never occur while the diver is in the compressed air, and which are the result of the decompression; and diseases with an insidious beginning, which must be directly connected with the action of the compressed air.

Diseases with a sudden beginning. In the first rank M. Gal places the "fleas":

This disorder disappears without any treatment and ends when a hypersecretion of perspiration occurs. (Foley, p. 33) Is it then because our divers were always covered with sweat when they reached the deck that I have never had the opportunity to observe it? That seems to me more than probable. (P. 33.)

Then come the muscular pains, the attacks of arthritis:

Among all these disorders, I have seen only extremely acute pains appearing suddenly, soon after the exit from the compressed air; affecting particularly the parts of the body in which muscular effort was longest exerted, generally the left deltoid in divers; almost always a little swelling in the part affected, but with no redness. These pains never lasted more than two days, and generally they disappeared after a few hours.

All the divers, except two named Thepot and Paugarn, experienced them repeatedly.

I have not listed any observations on this subject, because these disorders, which were always slight, showed me nothing abnormal, either in their course or in their ending. Rubbing with soothing balm or application of a poultice with laudanum always dispelled them.

Then pains and inflammation of the ears, of which M. Gal mentions some examples, and gastric disturbances, the cause of which lies perhaps in the nervous centers. A case of hemorrhage was observed, which offers this rare circumstance of having begun during the compression:

December 15, a man by the name of Feroc, 28 years old, a diver trained to the use of the suit, went down to a depth of 14 to 15 meters, stayed at the bottom three quarters of an hour and came up with a nosebleed which began while he was subjected to the pressure. His face was slightly flushed, his pulse was 70 . He told me that it was the third noseblood he had had, and that it always began on the bottom. Like the former ones, it stopped without treatment.

January 12, this same diver went down again for the first time since December 15, to a depth of 20 meters. Another hemorrhage under the same conditions; only the pulse was 90 a quarter of an hour after he came up, and an hour afterwards it was 70, weak and easily depressed. At the same time, an acute headache.

Stimulating friction; rest. The next day he was quite well. (P. 41)

In regard to serious symptoms, M. Gal observed only one para- 
plegia, which, strangely enough, began only twenty-four hours after the decompression. Here is the complete observation:

Quidelleur, 28 years old, given to drink. January 18, 1869, descent to a depth of 28 meters.

After staying on the bottom for an hour, he came up deaf in one ear; it was his first symptom, he had no pain, and merely noticed a buzzing, accompanied by deafness in the left ear.

January 19, he went to a depth of 16 meters, finished his shift of an hour and a half, and told me when he came up that his deafness disappeared at the bottom.

January 20 , he went down to a depth of 28 meters. That day, while four divers were in the sea, and among them Quidelleur, the ship made a complete turn around its anchor, and this accident resulted in rolling around the ship's chain the four air tubes and the four signal cords of the divers.

There was a moment of confusion, during which the signals could no longer be felt; and when Quidelleur reached the deck, he complained that at three different times he was raised from the bottom to a depth of about 10 meters, and each time he fell back suddenly, with great injury to his ears. In all, he remained for one hour at an actual pressure of 3.8 atmospheres; and he complained only of pains in his ears, especially the left one.

I had him rubbed with dry flannel, as was always done after a descent of more than 20 meters, and I noticed nothing abnormal about him.

On January 21, diving was interrupted all day, and Quidelleur like the other sailors worked at different jobs on board. In the evening at 5 o'clock, he came to take me on shore, and I noticed that he did not look well; when I inquired about it, he assured me that he had no pain except a little in his left ear. One hour afterwards, I was sent for; he was complaining of violent pains, without a definite location, extending over his whole body. I had great difficulty in making him talk, but his attitude showed me that the chief pain was in the abdomen. The patient was doubled over, all his members were bent against the front of his body. The pains were so great as to make him weep; he finally told me that the pain was as great as if someone were tearing open his belly and his chest. I noted no swelling and no redness of the skin. His pulse was 70 ; it was greatly depressed. The rather hasty respiration was jerky ....

At eleven o'clock in the morning (January 22), I was told that the patient was complaining again of not being able to urinate; I noted the presence of liquid in the bladder, and warned by this symptom, I tested for a lessening of sensitivity and motility. Both were weak in the lower limbs, without being entirely gone. The penis was in a semi-erection. The introduction of a catheter into the bladder gave a half-liter of urine. It flowed slowly; muscular contraction was not present; the bladder was paralyzed. The pulse was quite normal, the pains of the day before were gone, the respiration was good.

Friction on the spinal column and on the lower limbs with opodeldoc balm. Elder tea. 
January 23. The patient, less stiff, tried to rise, but his legs could not support him, although when he was in the hammock, he could move them as on the day before; lessened sensitivity.

Pulse 70, easily depressed. Respiration normal, no pains; the hearing which on the day before was rather weak on the left, had returned to normal.

I had plasters put on the lower limbs and along the spinal column. Elder tea. Catheterisms in the morning. Soup.

In the evening, the paralysis had gone; the patient urinated easily. Nothing new in his condition; he had not defecated since the day of the accident, that is, January 20.

January 24. Legs in the same condition; pulse and respiration normal. No movement of the bowels. The patient wished to eat ....

January 27. Slight improvement, movements of the lower limbs a little easier, although there was not much strength . . . .

From that day to January 30 , the improvement progressed very slowly; then suddenly, February 1, the patient came up on deck and one could hardly tell by his gait that his lower limbs were paralyzed.

During the following days, the improvement was maintained; the rectum alone was still paralyzed. There were no results unless enemas were used.

The patient was very intractable as long as his illness lasted; I could testify that he was of a very weak character, and that he was easily prostrated by pain.

I wanted to purge him the very first day; but in spite of all my persuasion, he would not consent.

Up to February 5, he did not defecate and suffered greatly from his constipation. I administered to him, without his knowing it, 80 centigrams of calomel in some milk; this purge brought on an evacuation which was the signal for his complete recovery. From that day, the rectum resumed its normal functions, and the health of this diver was excellent.

M. Gal gives three more observations of the same sort, the details of which he gathered himself, although he did not see the patients at the time of the accident. In the first case, death occurred as a result of the doctor's ignorance:

August 5, 1869, a man named Nicolas Theodoros was seized by paralysis of the lower limbs.

This diver had been fishing on the shores of Crete since the beginning of May, that is, for three months. He was a man of great height and at the same time of an enormous corpulence, due chiefly to the very considerable development of adipose tissue.

August 5, he was fishing near Sitia, and for a week he had been working in depths of twenty fathoms and more, that is, 30 to 35 meters. No serious symptom, no pain, gave him any warning, when August 5, a quarter of an hour after coming up from a depth of 37 meters, he was seized by complete paralysis of the lower limbs.

I learned from the Greeks who were diving from the same boat that he had remained on the bottom more than a half-hour, that he 
had been hoisted up, according to the bad habit of the Greeks, and that consequently the decompression had been very rapid.

He had taken off his diving clothes and was going to rest on the deck of his caique, when the illness began gradually by general discomfort, and soon he perceived that he could no longer move his legs, and that they were completely without sensation.

Unfortunately, at that time I was in Kanea, that is, more than a hundred miles from the place where this unhappy diver was. His boat went to the nearest point where they hoped to get help; that was at Sitia. There was there only an Italian physician completely ignorant of the symptoms which may appear in divers.

Finding no fever and no pain, he did not know what could be the cause of the illness and remained completely inactive. The death certificate which he gave to the comrades of the diver simply said that he died: From intestinal strangulation and constipation.

Although these words indicate that he had recognized the inability of the diver to urinate and defecate, he did not heed the first indication, did not catheterize the patient, and merely gave him a cathartic; he did not even do that until the eighth day of the illness, the day before he died.

To the paralysis, which had been painless at the beginning, soon were added the ordinary symptoms of paralysis of the bladder and the rectum, when the former is not emptied and the bowels are not kept open.

When I reached Sitia, August 16, the patient had been dead for two days, after terrible sufferings located in the abdomen and accompanied by a considerable increase in the volume of that part of the body. The information given me by his comrades was quite recent, and I am convinced that Theodoros succumbed to the paraplegia only from want of care. It will be seen by the observations which I shall give that when the paralysis reaches only the lower limbs, cure is quite frequent, or at least if the paralysis persists, the patients do not die, or at least die only after several months. (P. 48.)

In the other two cases, the paraplegia was half cured:

At Symi I saw two divers, Foti Kazi Foti and Yanni, who, during the cruise of 1867 , were both completely paralyzed in the lower part of their bodies. Both of them returned immediately to Symi, where they were attended by a doctor who had had his medical course at Paris, M. Migliorati. I had an opportunity to talk with him; unfortunately, he was very ill, in the last stages of pulmonary tuberculosis, and he could give me only a little information.

The two divers remained three months without being able to use their lower limbs; little by little, however, it became possible for them to make some movements; the paralysis of the bladder and the rectum disappeared first. M. Migliorati exhausted all the resources of therapeutics on them: friction, blisters, cupping-glasses with scarification, tincture of nux vomica rubbed in or given internally, etc. However, he did not try cauterization or faradization:

When I saw them, I noted that the paralytic lesion of the lower 
limbs still persisted; they had been ill for more than a year. However they were able to walk, provided that they used two sticks, but they did not need crutches. It was evident that it was difficult to them to lift their feet, and they did so only as much as was absolutely necessary.

I tested the sensitivity and found a marked weakening on both sides of tactile sensitivity, sensitivity to heat and cold, and sensitivity to pain.

All the other mechanisms and all the other functions were normal. I observed, however, a little anemia in Yanni, but it had no connection with the paralysis; in 1868, he had had obstinate intermittent fevers, from which he had recovered only a short time before I saw him.

The muscles of the lower limbs were not manifestly atrophied. These two men continued to use the diving suit. They resumed their work, one in the month of October, 1868, the other in the month of May, 1869, and they found that walking was easier in the water than in the open air.

In the month of January, 1870, their condition was unchanged. (P. 50.)

Next comes a series of 9 observations, in which 2 divers died very quickly, one after twenty-four hours, the other after three months, from the sequelae of paraplegia. The last five recovered more or less completely. I reproduce in full these observations, which are very brief:

I. June 23, 1868, at Navarin, Jorgieos Koutchouraki, who had gone down to a depth of 40 to 45 meters, remained on the bottom for a quarter of an hour. According to the custom of Greek divers, he had himself hoisted up after this time; he reached the deck of the boat in perfect health; a few minutes afterwards, he complained of dizziness, and fell upon the deck. Loss of speech and intelligence; face red; sudden death.

II. July 10, 1868, in the Greek Archipelago, Manolis Couloumaris, went down to a depth of 25 fathoms, that is, about 40 meters, and remained on the bottom about three-quarters of an hour. He then gave the signal agreed upon and was hoisted up. He had been on deck about a quarter of an hour, and, according to his comrades, he was squeezing out the sponges which he had brought up, when he was suddenly attacked by severe pains, and almost immediately by complete loss of consciousness. He rapidly succumbed.

III. June 15, 1869, on the coast of Bengasi, a man by the name of Joannis Xippas went down 20 fathoms, that is, 30 to 35 meters. This diver had gone down five days in succession, and several times each day, in depths always more than 30 meters, and until that time had felt no symptoms, except a little pain in his left arm. June 15, he had gone down for the second time when the attack came. Coming up after a stay of more than a half-hour, at first he did not seem ill, and went down to the deck of his caique to rest. Only an hour afterwards one of his comrades, going down to him, found him uncon- 
scious, his face red, his limbs completely inert and covered with cold sweat. They tried to warm him, but could not succeed.

They set sail for Alexandria, where they hoped to find help; but death came after 24 hours. The patient had remained all this time absolutely motionless. He had not defecated or urinated. Those present at his death stated that shortly before he died, he gave certain signs of consciousness and pain; but the paralysis of his limbs remained complete.

IV. July 1, 1869, on the coast of Rhodes, a man named Nicolas Roditis, who had been diving in a suit for about three months, came up from a depth of 35 to 40 meters. After a half-hour, he was seized by severe pains in the epigastric region, and at the same time perceived that he could no longer stand up. They took him to Rhodes, where he first consulted a quack, who had him put in an oven. He was not relieved, as one may well imagine; the pains in his stomach persisted; the paralysis of the lower part of his body was complete, and affected the legs, thighs, bladder, and rectum. To the pains of the epigastric region was added the tension of the belly; for three days he had not urinated or defecated, and then an Italian physician was summoned, who catheterized him at once and then tried to cure his paraplegia. They gave him various remedies and had him rubbed; but it was impossible to find out exactly what treatment was given him.

One month after the accident, he came to Calymnos, where Dr. Pélicanos attended him. At that time, he was completely paralyzed in the whole lower half of his body, both in motility and sensitivity. The bladder and the rectum shared in this paralysis.

Moreover, he had on the back and lower part of the trunk a large sore 14 by 15 centimeters. All the soft parts were ulcerated and the sacrum was bared. At the level of the two great trochanters, there were also two sores; one had destroyed the skin; in the other, the bone was tbared. Scab on the right calcaneum. Scab on the lower and outer part of the fifth left metatarsal and on the sole of the same foot. Excruciating pains in the region of the stomach; persistent constipation. The patient was very anemic.

He was first given syrup of lactate of iron, cinchona bark, old wine of Cyprus, and a diet as nourishing as possible. The sores were washed with a decoction of camomile and cinchona; they were dressed with aromatic wine. From time to time a cathartic with castor oil or jalap powder.

No improvement; the sores grew larger; a fever of the daily intermittent type, growing worse every evening, appeared. It was evidently hectic fever.

Appetite was almost wanting, the general condition grew worse; a gangrenous sore spread over the prepuce, and finally the patient succumbed in marasmus three months after his accident.

The paralysis of the bladder had disappeared one month before; but there had been no improvement in the motility and sensitivity of the lower limbs.

V. In the early part of September, 1868, a man named Nicolas Kardachi, on the coast of Bengazi, was seized by paralysis of the 
lower limbs, the bladder, and the rectum. He showed complete paralysis of movement, hyperesthesia of the skin, and severe pains from the region of the kidneys to the ends of the toes.

The disturbance had appeared very shortly after he had come up to the deck of his caique.

He was taken as quickly as possible to Calymnos, where he arrived five days after the beginning of his illness. He had not urinated or defecated; the bladder, which was much distended, caused him acute pain. Catheterization, the use of cathartics, and the application of a large blister to the spine in the region of the loins were the first measures used by Dr. Pélicanos.

The patient was wholly free from fever; his appetite was good; the regimen was tonic from the first.

The blister in the lumbar region was renewed, and motility returned little by little, at the same time as normal sensitivity. The paralysis of the bladder was the first to yield, and after a month and a half the patient could walk a little, dragging his feet. First he was given frictions along the spinal column with tincture of nux vomica, and then with the following liniment:

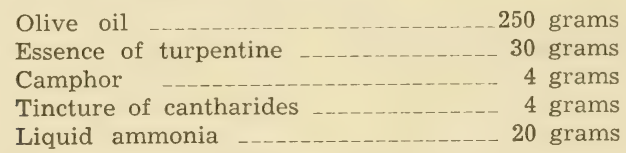

Dr. Pélicanos is well satisfied with the use of this last remedy; motility returned little by little, and at the end of three months the patient was perfectly cured.

VI. September, 1868. The history of this patient, named Nomikas Sissois, is exactly the same as that of the preceding one. Like him, he was attacked while fishing at Bengazi, at the end of the fishing season, in depths of 35 to 45 meters; he was slower in going to Calymnos, and the disease lasted longer, although he could walk, dragging himself about, at the end of a month.

The treatment was the same, the duration of the disease six months; and in January, 1870, that is, fifteen months after the beginning, there was only a slight hesitation in his gait. They tried with him an injection into the bladder of a dilute solution of sulphate of strychnine; but this measure did not give satisfactory results.

VII. In the month of August, 1869, on the coast of Crete, a man named Philippe Karantoni was paralyzed in his lower limbs after diving to a depth of 35 to 40 meters. The bladder and the rectum were not affected. They used as treatment only the stimulating liniment already indicated, and he was cured in two weeks.

VIII. In the month of September, 1869, in the Greek Archipelago, a man named Georges Ervloia was paralyzed in the whole lower part of his body; the bladder and the rectum were affected; the patient also had violent pains all through his body. He reached Calymnos the day after the beginning of his illness.

Catheterization, a cathartic, and the use of the stimulating liniment brought a complete cure in twenty days. 
IX. In the month of September, 1869, a man named Georgios Baboris was diving at Candia; he was slightly affected by paralysis. Treated at Megalo-Castro, he was very soon on his feet and only a slight weakness of his lower limbs remained.

After this interesting enumeration, M. Gal adds:

What we have just shown by these observations, the frequency of functional lesions of the spinal cord, appeared also in the ten divers who died in 1867. Only three died suddenly; the other seven dragged on a longer or shorter time. The latter were all paraplegic. I had another purpose in listing these observations, that is, to show that with precautions one can lessen the number of accidents considerably.

So in 1867 , there were in Greece 12 diving suits manned by 24 divers; there were ten deaths. The Greeks went down to depths of more than 45 meters, had themselves hoisted up rapidly when they wished to come up, and made a considerable number of dives during the day.

In 1868 , there were at least ten suits at Calymnos alone. They used 30 divers; there were two deaths, and two cases of paraplegia ending in recovery.

In 1869 , more than 15 suits, using more than 45 divers. Three deaths and three cases of paraplegia.

I could get these statistics only for the island of Calymnos; but one can see how much the number and the severity of the accidents diminished. The precaution of taking three divers for each suit, to lessen the daily work of each one, and a little greater care in regard to the depth were enough to bring about this result. A little book published in Greek by M. Denayrouze and distributed liberally among the divers has no doubt had its share in bringing about this improvement. (P. 56.)

And now we come to the second category of diseases observed among the divers. M. Gal calls them by the name of Diseases with gradual beginning; according to him, they are the multiple manifestations (emaciation, loss of strength) of a peculiar anemia:

Like Foley, we attribute the emaciation to the effect of the compressed air and what we have noted many times, that after several days of work, all the divers without exception showed evident symptoms of anemia, and a much more definite susceptibility to attacks of the diseases with a sudden beginning. It was then that almost all experienced more or less keen muscular pains, and that prudence required us to make them take a restorative rest. (P. 57.)

I owe to Dr. Sampadarios of Egina a series of interesting and unpublished observations which I copy without omitting anything; I am glad to be able to thank him here for his interesting communications:

Observation I. During the summer of 1866, they called me to attend one L. This man had for some time been diving in a suit in 
sponge fishing; he was forty years old. The day before, after he had come up from the bottom, he had fallen into a state of coma; when I saw him, he was in his last moments, his face puffed up and bluish, as if he were dying of asphyxia.

Observation II. In 1867, I observed another patient; he had gone down three times in one day to fish, he said; the third time, he had felt an oppression in his chest at the bottom of the sea, and he had hardly had time to give the signal to be raised. When he was in the boat, he had fallen into a state of coma, quite insensible, from which he had recovered after three hours. He then had dyspnea, complete paralysis of the lower limbs and the bladder, constipation, incomplete paralysis (paresis) of the upper limbs, on one side especially. The dyspnea had soon disappeared; they were forced to empty the bladder with a catheter. The progress of the patient had been followed for a month, there was an improvement, then they lost sight of him.

Observation III. N. B., attended by another colleague; for some months he had had a paralysis of the lower limbs and the bladder, with constipation; the urine was always drawn with a catheter. There was only a slight flexion of the coxofemoral articulation and that of the knee; more or less advanced paralysis of sensitivity. When the patient had been drawn up from the bottom, he remained for several hours in a state of coma; when he had recovered from this, he had dyspnea and his members were paralyzed.

Observation IV. N. A., a sturdy young man, aged 25, in good health till now; for some time he had been connected with a company of sponge fishermen, and he was diving in a suit. I had been summoned to attend him July 20,1870, and he told me that two days before, he had worked too long, because he had stayed, he said, for five hours on the bottom, collecting sponges, and consequently he had had a sort of fainting fit. However he had gone down again to work; but after working a half-hour, he felt ill, gave the signal to be drawn up, and was pulled up very quickly, as usual, when there is a sign of danger; the diving suit was also taken off him very quickly, and after that, he fell into a state of insensibility. He had felt a numbness of the limbs and dizziness, and his mouth foamed, he said. They had not called a doctor, because the divers had had such symptoms several times, and had recovered after several hours through the use of frictions and revulsives on the extremities. He too had recovered from this comatose state after five hours, after he had vomited several times; but for twenty-four hours he was dizzy whenever he opened his eyes; the lower limbs and the bladder were paralyzed. At the beginning there was also a sort of paresis of the upper limbs, which quickly disappeared, but the complete retention of the urine persisted, and that is why they called me on the third day.

I found the bladder rising as far as the navel; there was constipation and the lower limbs were paralyzed; on the right side there was complete paralysis of movement and sensitivity; on the left, sensitivity was partly present with weak flexion of the coxofemoral articulation; there was no other disturbance, no pain in the spinal column. We emptied the bladder with the catheter; the next day a purge with castor oil gave evacuations. We continued to catheterize the 
patient; finally, after twenty-one days, the patient could urinate without assistance. We should note that after the eighth catheterism a very severe attack of intermittent fever came on, for which we gave quinine, and which did not recur.

The paralysis of the limbs yielded also to stimulating frictions, and on the fortieth day the patient could walk with crutches. We gave him extract of nux vomica, pains appeared along the limbs, but no improvement resulted. Not knowing the nature of the illness, we gave a symptomatic treatment; we gave iodide of potassium internally.

October 24. The lower limbs were still weak, especially on the left, where we noted at the same time, in the leg and the foot, lack of sensitivity to pain and touch, and a moderate sensation of cold. On the right, where at the beginning there was complete paralysis of sensation and movement, the insensibility persisted only on the outer part of the back of the foot. The active movements were carried out well, except a weakness on the left at the tibio-tarsal articulation, especially in flexion. The passive movements were natural.

Examination by electricity (induction apparatus) found at the right the electrical contractility lessened in the muscles which depend upon the peroneal nerve. On the left, not only these, but also the tibial muscles showed lessened electrical contractility. The other muscles reacted well, like those of the belly.

We continued to faradize the skin and the muscles of the limbs and the belly. There was an improvement. For two hours after the faradization the patient felt that his movements were free, as if he were quite well.

November 28. Lack of sensitivity to pain, touch and cold on the left halfway along the thigh, even half of the penis, on the right only lack of sensitivity to pain and touch on the foot; weakness of the limbs, however, extension of the foot on the right was very incomplete. If the patient closed his eyes, he tottered and began to fall. Lack of coordination or irregularity of movements during walking, involuntary, convulsive contractions, through reflex action of the lower limbs, for example, from the bite of a flea on the buttocks or the loins. Sometimes retention of the urine, at other times, incontinence. We applied two cauteries on the spinal column, and gave him internally iodide of potassium.

December 10. Improvement, he wants to go away.

After my publications on this subject, in 1871, in the month of September, Dr. Cotsonopoulos, of Nauplia in Morea, published an observation, followed by an autopsy in the Greek Journal Asclepios (Esculapius), in which my observations are also published. I will make a translation of it for you.

D. N., aged 30 , a sailor in good health, strong, who had been working for a year with the English diving suit, was taken to the hospital of Nauplia on May 2. Six days before he had been working on the shore of the Argolic gulf, at a depth of 30 meters on a muddy bottom. When he was drawn up, he felt a pain in the loins and great numbness in the lower limbs, movement of which after an hour was wholly impossible. His companions rubbed him and cauterized his penis. 
A physician bled him before he entered the hospital and several times placed on his loins cupping-glasses, a blister sprinkled with strychnine, and cauteries with the cautery already there. When he entered the hospital, the paraplegia was complete; no movement of the lower limbs; no contraction even by electricity, they said; loss of sensitivity, even electrical sensitivity. The upper third of the thigh a little sensitive; the patient sometimes had spontaneously a burning sensation in the legs; paralysis of the bladder, sluggishness of the alimentary canal, the belly swollen: the bladder was emptied twice a day. Pressure on the spinal column was not painful. A painful erythema existed in the sacral region, that was the beginning of the gangrene of decubitus, which developed later. No fever. In the presence of such symptoms which came on suddenly with pain in the loins, a hemorrhage in the spinal column was assumed, and orders were given again for cupping-glasses and leeches on the anus, cathartics, and vinegar enemas, since the cathartics were not effective. There was a slight improvement: sensitivity increased a little on the upper part of the thighs, but soon the disease made progress; a cystitis developed with gangrene of decubitus, fever, chills, incontinence with retention, involuntary evacuations; finally, on account of the progress of the gangrene, the sacrum was wholly bared. During the last days of the sickness sores appeared on the heels.

Death occurred on the fortieth day from the beginning of the sickness. The patient had preserved his mental faculties intact up to the end.

Autopsy. There was some difficulty in getting the permission of the relatives for the autopsy. Dr. Jéanopoulos was present. The dorsal canal was opened and blood was found in quantity, half-coagulated, reddish-black, between the dura mater and the canal of the bone and extending from the first lumbar vertebra to the end of the meningeal sac. The outer surface of the dura mater, which was wet with blood, was reddish black and infiltrated with extravasated blood. Its inner surface after being sectioned was found to be whitish and slightly bloodshot. In the lower part of the subarachnoid cavity there also existed an effusion of dark red blood, half-coagulated in a fairly large quantity around the nerves forming the cauda equina. Having made incisions in different parts of the spinal cord, we found that a large part of the lumbar portion and the upper third of the thoracic portion had undergone the white softening to a considerable degree, because hardly was the pia mater cut or torn when the substance of the marrow flowed out, so to speak. The other parts of the marrow, even those which were situated between the softened parts, had the natural consistency; no congestion in either the marrow or the pia mater. Since the relatives of the patient had arrived, no examination was made of the other cavities; only the hypogastrium was opened for an examination of the bladder, the walls of which were much hypertrophied.

Such are the observations published in our country up to the present concerning this question.

If we analyze these different data, we see that death occurred in two manners: either immediately or by lesion of the spinal cord. 
When the nature of this disease has been determined, we shall know whether there are two different causes which produce these two kinds of morbid manifestations, or whether they are different degrees of one affection.

I shall merely remark that if one tried to explain these symptoms solely by the change in the atmospheric pressure, that would not be enough; because very certainly the disturbance of health began at the bottom of the sea. The fisherman felt ill and gave the signal to be hauled up. M. Cotsonopoulos mentions a case in which the diver was hauled up almost dead, and died after a few movements. The patient whom I attended also told me of a similar accident. I am not sure whether death came to my patient in the same way (observation I). These people say that they are sick when they work at a great depth for four or five hours, when there are wind and waves (and perhaps the pressure of the machine cannot be regulated then), and finally when they are too tired. It must be noted that when the diver gives the signal that he is ill, haste is made to draw him up very quickly, and to the first disturbance perhaps that of sudden decompression is added. When they go down to a depth greater than 30 meters, they cannot work there very long; the deeper they go, the shorter a time do they remain. Moreover, sometimes the pressure of the machine is not strong or regular enough, and the diver feels the column of water beginning to press the suit around his hands and feet; then he makes the signal agreed upon and air is sent him. It seems that they were working in our country, at least at first, with the English suit.

As for the persistent paraplegia, we see that it is a remnant of a disturbance which acted upon the whole organism (observations 2, 4), but which, not having caused death, leaves material disturbance only in the spinal cord, because we cannot accept the idea that this affection of the marrow alone caused death or that general state observed at the beginning. But what is the nature of this affection? M. Le Roy de Méricourt thinks that capillary hemorrhages occur in the spinal cord during the decompression. In our patient, (observation 4), we saw at the beginning a paraplegia, a complete failure of the functions of the spinal cord; a very great improvement occurred after a few days, and later we had the syndrome of myelitis. The seat of the affection must be in the thoracic portion, since the bladder and the rectum were more or less paralyzed, for when the lumbar region is affected, there is merely paralysis of the lower extremities.

The autopsy of the other patient showed us diffused softening of the spinal cord and a hemorrhage. But it is the softening of the cord, which did indeed affect the thoracic portion, which can explain the symptoms of paralysis of the bladder and the rectum, and not the hemorrhage which affected the lumbar portion. As for us, we think that the ecchymoses of the membranes are related to the gangrene of the sacrum. Let us say in addition that our patient had felt no pain, and pain would have been produced in case of hemorrhage of the membranes of the cord.

But how is this inflammation of the cord produced? Is it by cap- 
illary hemorrhages? Is it by expansion of the capillaries by gases and, as a consequence, by faulty metabolism (softening)?

\section{Microscopic examinations in men and animals may settle this question. \\ Samsoun (Turkey in Asia), June 6, 1875.}

${ }^{2}$ I quote this opinion of Panthot frem Brizé-Fradin, $p_{.}, 31$.

${ }^{3}$ La Chimie pneumatrque appliquée aux traz'aux sous l'eau. Paris, 1808.

4 Lettre au professeur Pictet sur la cloche du plongeur. Bibl. univ. de Genève, Vol. XIII. p. 230-234, 1820 .

5 Relation d'une descente en mer dans la cloche du plongeur. Paris, 1826.

- Triger, Mémoire sur un appareil à air comprimé, pour le percement des puits de mine et autres travaux, sous les caux et dans les sables submergés: Compt. rendus Acad. des sciences, Vol. XIII, p. $881-896,1811$.

7 Rapport sur les puits à air comprimé de M. Triger. Bull. de la Soc. indust. d'Angers et du départ. de Maine-et-Loire, 1815.

8 Lettre à M. Arago. Comptes rendus de l'Académie des sciences, Vol. XX, D. 445-449: 1845.

$\checkmark$ Mémoire sur l'extraction des roches de la passe d'entrée du port du Croisic. Ann. des ponts et chaussées, 184S, First semester, p. 261-315.

${ }^{10}$ Rapport sur le procédé suivi, à Douchy, pour trãeerser des nappes d'cau considérables. Ann. des mines, Fourth series, Vol. IX, p. 349-361; 1816.

11 Memoire sur les effets de la compression de air appliquée au creusement des puits à houille. Ann. d’hygiène publique et de medècine légale. Second series, Vol. I, D. 211-279: 1854. Memoir written at the end of the year 1S47, and presented to the Société de Douchy shortly after.

12 Rapport sur l'explosion d'un cylindre à air comprimé sur l'az'aleresse No. 7 , située dans la concession de Doucliv (Nord). Ann. des mines, Fourth series, Vol. II, p. 121-1+8, 1847.

${ }_{13}$ Creuscment à travers les sables mouvants d'un puits de la mine de Strépy-Bracquegnies.

Ann. des trav, publ. de Belgique, Vol. VII, 18\$8; quoted by Barella, p. 621.

14 Lettre à M. Arago. Comptes rendus de l'Academie des sciences, Vol. XX, p. 445, 1845

15 Notice sur le pont de la Theiss et sur les fondations tubulaires. Annales des ponts et chaussées, 18.59. First semester, p. 334-382.

16 Mémoire sur la construction du pont métallique sur la Garonne, a Bordeaux. Ann. des ponts et chaussées, 1867 , Second semester, p. $27-145$.

11 One atmosphere corresponds to 15 pounds per square inch.

$1 s$ Paralysis caused by working under compressed air in sinking the Foundations of Londonderry New Bridge. The Dublin quart. journal of medical science, Yrol. XXXVI, p. 312-318, 1863. ${ }_{19}$ Des effets de l'air comprimé sur les ouvriers travaillant dans les caissons seriant de base anx piles du pont du grand Rhin. Ann. d'hyg. publ. et de méd. lég., 1860, Second series. Vol. XIV, p. $289-319$.

${ }_{20}{ }^{\mathrm{D}}$ Remarques sur l'emploi de l'air comprimé dans les traĩanx d'art. Gaz. méd. de Stras. bourg, 1860 , p. 179.

${ }_{21}^{1}$ De l'air comprimé. Thèse de Strasbourg, 1861.

22 Du travail dans l'air comprimé. Paris, 1863.

${ }_{23}$ Memoire sur l'établisscment des travaux dans les terrains vaseur de Bretagne. Ann. des Ponts et Chaussées, 1864. First semester, p. 275-396.

${ }_{24}$ Symptoms produced by the use of caissons in underground and undersea works. Art Médical, Vol. XVI, n. 128-452, 1862; Vol. XVII, p. 27-48, 105-124, and 194-213. 1863.

${ }_{25}$. Action de lair comprimés apoplexie de la moelle épinière. Union médicale de la Gironde. 1863. ก. 269-270.

${ }_{26}$ Soc. des Sc. pliys, et nat. de Bordeaux, year 1874-1875. Minutes of the sessions, D. XX. 27 Weighing nearly $500 \mathrm{kil}$, says the report of the engineer Dubreil.

28 Ann, des Ponts et Chaussees, 1867, Second semester, p. 116-131.

${ }_{29}$ Du travail dans l'air comprimé. Observations recueillies à Trazegnies, lors de l'cnfonce. ment d'un nouveau puits hexiller. Bull. acad. de méd. de Belgique, Third series, Vol. II, D. 593-647, 1868 .

30 The effects of compressed air on the human body. The Med. Times and Gazette, Vol. II. p. 291-292, 1871 .

31 Pathological effects upon the brain and spinal cord of men exposed to the action of a largely increascd atmospheric pressure. St. Louis Med. and Surg. journ., May, 18io. Faxtract in Canstatt's Jahr., Vol. I, p. 178, 1870.

${ }_{32}$ Travar.r publics des Etats-Unis d'Amerique en $1 \$ 73$. Paris, $18 \%$.

33 Fondations d̀ l'air comprimé. Ann. des Ponts et Chanssées, 1874. First semester, p. 329402.

${ }^{34}$ Considérations sur l'hygiène des pecheurs d'éronges- Ann. d'hygiène publique et de médecine légale. Second series, Vol. XX.XI, D. 274-286, 1869.

${ }_{3}^{3}$ Des dangers du travail dans l'air comprimé ct des moyens de les prérenir. Thèses de Montpellier, 1872. 


\section{Chapter II}

\section{LOW PRESSURES}

The pressures discussed in this chapter have never reached one atmosphere above normal pressure. Workmen employed on the foundations of bridge piers, and divers in suits are evidently also subjected frequently to these moderate pressures; but since they do not experience any distress there (except pains in the ears at the beginning) and since they come from them with no ill effects, the attention of engineers or physicians has almost never been attracted to the phenomena which they might have observed under these conditions.

The case is quite different for the low pressures which physicians use frequently today for therapeutic purposes. Here, on the contrary, delicate observations, of a purely physiological order, have been accumulated, and a study has been made of the effect of slightly compressed air with the same care and following the same method as that of any medicinal substance: that is, on man in good health at first, then in different pathological cases.

To three French physicians, Junod of Paris, Tabarié of Montpellier, and Pravaz of Lyons, is due the honor of having introduced into therapeutics an agent the efficiency of which is noted every day by practitioners and the use of which will become, we are safe to state, more and more frequent. I do not wish to take sides in the quarrel which has arisen among them on the subject of priority of invention; as far as I can judge, it belongs to M. Junod; at least it is he who first had publications on this subject.

Today, the apparatuses intended for treatment by compressed air are fairly numerous. Establishments are now found: in France, two in Paris, others in Lyons, Montpellier, and Nice; in Germany, at Hanover, Stuttgart, Wiesbaden, Johannisberg, Reichenhall, and Ems; in Denmark, at Altona; in Sweden, at Stockholm; in Scot- 


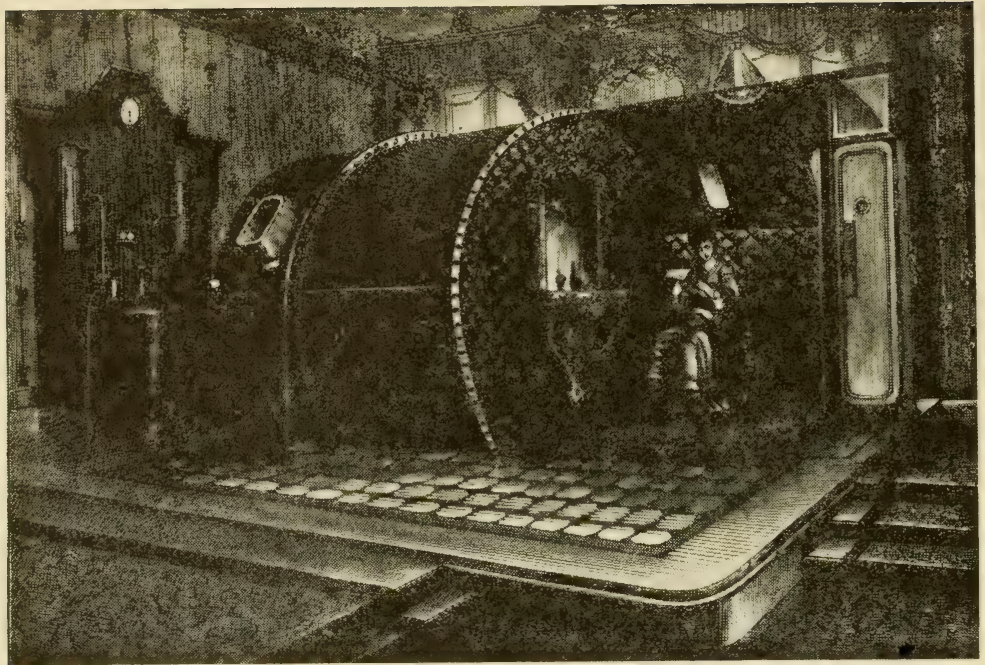

Fig. 9-The aerotherapeutic establishment of Dr. Carlo Fornanini, at Milan. Horizontal cylinder containing two chambers; the front wall of the chamber at the right has been removed.

land, at Ben Rhydding; in England, at London; in Italy, at Milan. Figure 9 represents the apparatus which Dr. Fornanini has installed in the last-mentioned city.

The various directors of these establishments have different opinions as to the pressure which should be used or rather as to the degree at which they should begin. There are some who approve of high pressures, 30 centimeters at least; in Paris, M. LevalPiquechef prefers to begin very moderately, 10 centimeters at the most. It is not for me to discuss these different points in practice; nor shall I give any time to the therapeutic applications of the method, limiting myself to saying once for all that its efficacy has been considered very great in emphysematous asthma, chronic bronchitis, chloro-anemia, and passive hemorrhage; it seems to be both tonic and sedative, to use the language of the School. ${ }^{1}$ (of Medicine)

Before listing the evidence collected by physiologists and physicians, I think I should report, according to Jaeger, ${ }^{2}$ the account of a catastrophe which made a great stir at the time, and in which workmen and physicians maintained that compressed air increased 
the sufferings of the victims, a point which is far from being proved, in my opinion.

February 28, 1812, at 11 o'clock in the morning a gallery of the coal mine of Beaujeu, near Leodium, was overrun by water; there were 127 workmen at a depth of 270 meters. Ninety of them were cut off at the end of a gallery, in compressed air "capable of holding water at 64 feet in a metallic tube, so that its density was double that of the atmosphere." They remained in this critical position for 7 days; only 70 survived:

As it was impossible for these unfortunate men to communicate with the rest of the gallery, they remained confined in a narrow space, deprived of air and everything. But their foreman Coffin and his son showed heroic courage ....

It was not possible to reach them before the seventh day. So, for seven days and as many nights, they were deprived of light and food, and exhausted by constant work. They suffered incredibly from hunger and thirst; respiration was difficult, and the candles went out for lack of air. They felt suffocating heat; their skin was dry and burning. They said that the enormous pressure of the air was very painful to them .... Some became mad, and the others had to aid them and protect themselves against them ....

In my opinion, the amazing density of the air was the cause of these phenomena. There is no doubt that the air produced more heat by its condensation, for, we know, condensation can produce fire .... And therefore the processes of combustion were so accelerated in the lungs that the sensation of heat can be explained. (P. 98.)

The first publication relating to symptoms experienced by men placed in compressed air was made by M. Junod. ${ }^{3}$ He reports his observations in the following words:

When we increase by one half the natural pressure of the atmosphere on the body of the man placed in the receiver, this is what we observe:

1. The membrane of the eardrum, pushed back towards the inner ear, becomes the seat of a rather unpleasant pressure. However, this sensation disappears as equilibrium is reestablished.

2. The respiratory movements go on with new ease, the capacity of the lungs for air seems to increase, the aspirations are deep and less frequent; after 15 minutes, one feels an agreeable warmth within the thorax, one would say that the pulmonary areolae, which for a long time had not known contact with the air, are expanding to receive it again, and the whole system with each inspiration drinks in increased life and strength.

3. Increase of the density of the air seem to modify the circulation considerably; the pulse has a tendency to become rapid; it is full and not easily depressed; the caliber of the superficial venous vessels 
lessens and may even be entirely obliterated; so that the blood, on its return towards the heart, follows the deep veins. If the caliber of the superficial vessels increases or diminishes because of the tension of the atmospheric elasticity, the same thing must be true in the pulmonary organs, which are under the same conditions in this respect; the inevitable result of this must be that when the pressure of the air is increased, the quantity of venous blood contained in the lungs must decrease; no doubt that is why a much greater quantity of air can be inhaled at each inspiration than at normal atmospheric pressure.

If the increasing density of the air lessens the caliber of the venous vessels, the necessary result must be that the blood flows in greater quantity in the arterial system, and towards the principal nervous centers, especially in the brain, which is protected from the direct pressure of the atmosphere by the resistance of the bony case in which it is contained. So the functions of the brain are activated, the imagination is lively, thoughts have a peculiar charm, and in some persons symptoms of intoxication are evident. This increase of innervation acts also upon the muscular system; movements are easier and more assured.

4. The functions of the alimentary canal are expedited: thirst is wanting;

5. The salivary and renal glands secrete their fluids abundantly. (P. 159.)

The report made by Magendie on the work of M. Junod, from which we quoted earlier (page 229) the part relating to the effect of decrease in atmospheric pressure, says nothing new on the subject, about either symptoms or theories.

It was not until 1838 that Tabarié ${ }^{*}$ published his researches, which, he said then, nevertheless dated back to a considerably earlier period.

His note shows that he had planned a series of very complex problems, since the processes which he had used included:

1. General compression of the air over the whole body;

2. Local compression over the limbs;

3. Local rarefaction over the limbs.

4. Alternate and local compression and rarefaction or oscillation on the limbs;

5. Rarefaction over the whole body except the head;

6. Use of alternate compressions and rarefactions over the whole body except the mouth, resulting in an artificial and complete respiration to be used in cases of asphyxia.

The rest of his note contains only a very short summary of applications of these different methods. It contains nothing definite either in regard to physiological phenomena or relating to the theoretical ideas he formed about the action of compressed air. 
But in a later work ${ }^{5}$ he is a little more explicit in the description of the phenomena.

The effect of compressed air, he says, is marked by two chief points:

1. Compressed air acts upon the circulation by slackening it; and while it lessens the number of heartbeats, it regularizes their rhythm.

These phenomena, which are hardly noticeable in a normal state of health and under the effect of short or incomplete experiments, become very marked in case of inflammatory or feverish diseases, provided that the experimental conditions are properly fulfilled and sufficiently maintained....

2. Compressed air does not affect general heat production as air with higher oxygen content would do; for far from stimulating this function, as has been supposed through analogy, it moderates it, and in certain cases even depresses it.

This fact, which I stated with some hesitancy in 1838, has been proved since then by new evidence. Not only does the use of the compressed air treatment develop no unusual heat within the thorax, but, on the contrary, it tends to produce a general sensation of cold, even when the temperature within the apparatuses is higher than that outside; and in some subjects in whom this chilly feeling is more marked, we note that it increases with the length and the degree of compression of the treatment.

Better results are obtained at moderate pressures ( $2 / 5$ of an atmosphere) than at higher degrees ( $2 / 3$ of an atmosphere).

However, Tabarié's note contains no theoretical explanation.

The first attempts of Pravaz to apply compressed air treatments to therapeutics date back to 1836 . In $1837,{ }^{6}$ he began to publish the result of his observations. He summarized his previous notes and memoirs in the work which we are taking as our guide. ${ }^{i}$

His apparatus measured 9 cubic meters. The pressure used was generally from $30 \mathrm{~cm}$. to $35 \mathrm{~cm}$. Pravaz describes as follows the phenomena displayed by the subjects of his experiments:

In most of the subjects of good constitution and in a healthy state, the arterial circulation does not show great modifications, no doubt because the respiration which was sufficient for hematosis under ordinary pressure keeps about the same rhythm in compressed air; but this is not true when there is a morbid acceleration of the pulse; then it drops considerably, except in a few exceptional cases which will be discussed later.

The congestion of the capillaries of the skin and the mucous membranes is evidently decreased by the increase in pressure exerted upon the periphery of the body. This effect becomes very apparent upon the surface to which a vesicant is applied or the conjunctiva, when the latter is red and inflamed.

The stimulation of the digestive organs, noted by MM. Colladon and Junod, is not always limited to producing a simple increase of 
appetite; sometimes this stimulation, after a certain time, reaches the point of causing a real bulimia, which forces one to discontinue or make less frequent the use of the compressed air treatment.

Among the secretions the increase of which has been mentioned by the authors whom I have just quoted, that of the urine displays, in quantity and nature, changes which seemed to me most remarkable; and that would naturally result from the greater activity brought to the metabolism of the tissues by a greater absorption of oxygen.

The feeling of easier, deeper respiration is not experienced in the same degree by all subjects placed in compressed air. Those who usually breathe deeply hardly notice it, but the same thing is not true of patients or valetudinarians attacked by a more or less pronounced dyspnea, either on account of an affection of the thoracic organs, or on account of a state of venous plethora; in general they experience a sensation of extraordinary well-being which would persuade them that they are cured, if it continued after the treatment. (P. 112.)

Another doctor of Lyons, Milliet, ${ }^{8}$ who had founded the establishment at Nice, a few years afterwards published observations which partly agree with those of Pravaz:

One of the most remarkable phenomena produced by increase in pressure of the air breathed is the considerable slackening of the circulation caused in most of the subjects. The circulatory rhythm drops 10, 15, and even 45 heartbeats .... In a woman 74 years old, suffering from a subacute catarrhal affection, the pulse, which had risen to 120 , fell to 60 and remained there. (P. 13.) ... .

In compressed air, the movements of inspiration slacken; they are repeated with less frequency in a given time to maintain regular pulmonary nutrition. (P. 15.)

However the new method of treatment had made progress; apparatuses had been installed at Stockholm, by Dr. Sandahl, ${ }^{9}$ who in 1862 reported the physiological phenomena which he had observed.

After indicating, discussing in detail, and explaining the usual pains in the ears, Sandahl comes to the respiratory and circulatory phenomena:

In 1454 observations, dealing with 75 persons, the respiratory movements were slowed in 1362 cases, including 64 persons; in only 11 persons, who took in all 102 treatments, was respiration more rapid than before....

In general, we find that the decrease in the number of respiratory movements not only comes during the treatment, but also lasts after the treatment....

The heartbeats also become slower.... So the pulse in the treatment where the air was compressed a half-atmosphere, dropped 9.94 beats on the average. 
Similar observations were made at Nice. Tutschek ${ }^{10}$ declares that the effect of compressed air is shown by:

1. Enlargement of the pulmonary alveoli; 2. decrease of the number of respirations; 3. slackening of the arterial circulation; 4. acceleration of the venous and capillary circulation; 5 . stimulation of organic expenditures and of assimilation, evidenced by greater excretion of carbonic acid and urea, and by hunger reaching the point of gluttony; 6. greater stimulation of the nervous system by a blood richer in oxygen, evidenced by activity of mind and a sensation of lightness of movement.

He does not give the pressure used. Everything leads us to think, moreover, that this summary of symptoms is merely borrowed from former authors; Tutschek made observations on only 3 healthy persons and 6 sick ones. In the former, the number of respirations decreased by 3 to 5 and that of the heartbeats by 0 to 10 ; the changes were greater in the invalids.

In Germany, Dr. G. Lange, physician at the spa of Johannisberg, had installed in this establishment an apparatus for the use of compressed air. In collaboration with Rudolph von Vivenot, he there made numerous observations which we shall discuss, and published a memoir, translated into French by M. Thierry-Mieg, about the results of his practice. The interesting extracts from this memoir will be better placed in the chapter devoted to the study of theoretical explanations.

I shall quote here only the summary which he gives of the phenomena observed in persons subjected to the action of compressed air:

Slackening of the respiration and the circulation; very probably, greater absorption of oxygen by the skin and the lungs; increase of exhalation of carbonic acid; decrease of cutaneous transpiration and pulmonary exhalation; increase of the urinary secretion, which eliminates more uric acid and less phosphate; improvement in hematosis and nutrition; increase in the energy of the muscular apparatus and in the vital capacity of the lungs. (P. 33.)

In 1860 von Vivenot began the series of his publications on the physiological and therapeutic effect of compressed air. His numerous notes and memoirs ${ }^{11}$ led him to write a lengthy work, ${ }^{12}$ which appeared in 1868; it is by far the most important work which has been published on this subject.

The larger part of his researches were made at the baths of Johannisberg. Since the altitude was fairly great, the average barometric pressure was only $741.17 \mathrm{~mm}$.; as the compression used rose to $318.07 \mathrm{~mm}$., the total pressure was $1060.24 \mathrm{~mm}$. This pres- 
sure was reached in the apparatus in 20 minutes; it stood there for 1 hour; 40 minutes were used for the return to normal pressure.

Respiration. The most important of Vivenot's memoirs is the one which he devoted to the study of the changes in the mechanical and chemical reactions of respiration. Since in his long wori he added to it only details of observation of moderate interest, I cannot do better than to reproduce the principal passages of the original work, published in 1865; it is a sort of analysis of Vivenot by Vivenot himself.

We shall, however, limit ourselves here to reporting the observations relating to changes in the respiratory rhythm and the pulmonary capacity; the chemical part, since it is much more closely connected with questions of theory, will be better placed in the following chapter:

If we examine a person first under normal pressure, then under compressed air, we may detect, by percussion, auscultation, and palpation, changes in the size and location of different organs, corresponding to the new conditions of pressure. If we have noted, under normal pressure, the position of the diaphragm and the upper limit of the liver corresponding to as deep an inspiration and expiration as possible, as well as the boundaries of the dullness of the heart, we find, in both cases, the diaphragm and the liver situated lower under compressed air; the drop is from $1 \frac{1 / 2}{2}$ to 2 centimeters under an increase of pressure of $3 / 7$ of an atmosphere; the dullness of the heart has become less extensive and has taken another form (that of a sickle, the convexity of which is turned towards the sternum). At the same time, the cardiac impulse seems less vigorous to a palpating finger, and the ear in auscultation finds the heart-sounds weaker, as if they were further away. There is sometimes produced in compressed air a mechanical expansion of the lungs, as a result of which the diaphragm and the liver are pushed down, while the anterior lobe of the left lung places itself above the corresponding half of the heart. For this reason the dullness of the heart diminishes, its form is changed, and the impulse and sounds of this organ seem weakened.

The increase in capacity of the lungs, shown by these facts, is demonstrated in another manner. In compressed air, the spirometer shows us a rather considerable increase of the respiratory capacity. The average of a great number of experiments, made during a stay of an hour and a half under the pressure of 1 and $3 / 7$ atmospheres, gave in me an increase of 108.07 cubic centimeters, in Dr. G. Lange 133.3, in Dr. Mittermaier (after a single experiment) 121.0 and in M. H. .y 99.2. Now since my pulmonary capacity on the average is 3425 cubic centimeters, that of Dr. Lange 3950 cc., that of Dr. Mittermaier 4159 cc., and that of M. H. .y 2910 cc., it follows that the increase in lung capacity was in me $1 / 31.7$, in Dr. Lange $1 / 29.7$, in Dr. Mittermaier $1 / 35.4$ and in M. H. .y $1 / 29.3$.

We see that these results do not differ perceptibly from each 
other and they indicate an average increase of pulmonary capacity equal to $1 / 31.5$ of the volume of the lungs, or $3.3 \%$. As the maximum of this increase, I found in myself $254 \mathrm{cc}$, in Dr. Lange 200 cc., in M. H. .y 223 cc., in M. R. 270 cc. and even $500 ; 686$ in a patient with emphysema, M. G., whose average respiratory capacity was 2268 cc., that is, about $2 / 9$ to $2 / 7$ of the total respiratory capacity.

The effect obtained, as we see, is doubled; on the one hand, we have in the same volume more atmospheric air, and on the other hand, our enlarged lungs are capable of receiving a greater volume of this compressed air. If then my average respiratory capacity is 3425 cc. under normal pressure, the same volume of compressed air at 1.37 atmospheres would represent by itself 4893 cc. of normal air. And as, under increased pressure, my lungs inspire an average of $108.1 \mathrm{cc}$. more, which is equivalent to $154.5 \mathrm{cc}$. of normal air which I inspire, then $3425+108.1 \mathrm{cc}$. $=3533.1 \mathrm{cc}$ of compressed air, it follows that the volume of air drawn in by the deepest inspiration under the effect of compression is equal to $5047.5 \mathrm{cc}$. of air at normal pressure...

Experimentation has proved that after a stay of $\mathbf{2}$ hours in compressed air, the pulmonary capacity, even under normal pressure, does not return to its original volume, but retains an increase which, in me, rose on the average to $50.53 \mathrm{cc}$, at the maximum to $183 \mathrm{cc}$; in $\mathrm{M}$. H. .y on the average to $57.6 \mathrm{cc}$., at the maximum to $124 \mathrm{cc}$. It next gave this interesting and astonishing result that the subsequent effect is not a passing effect, but that it is partly permanent, so that as a result of the use of compressed air for two hours every day, one enters the pneumatic apparatus with a pulmonary capacity which, naturally disregarding physiological variations, every day exceeds what it was the day before by 20 to $30 \mathrm{cc}$. For instance, from April 30 to September 19 inclusive, that is, in 143 days, after 122 treatments with compressed air taken during this time, my pulmonary capacity under normal pressure had risen successively from 3051 to $3794 \mathrm{cc}$. (under compressed air even to $3981 \mathrm{cc}$.), a figure which it had already attained August 12 after 91 air treatments, and at which it remained almost constantly. The vital capacity of the lungs therefore in me in three and a half months had made a progressive increase of $743 \mathrm{cc}$., that is, nearly a quarter of its original volume $(24 \%)$. A similar result was observed in other persons. In M. H. y, the respiratory capacity had risen after 11 days use of compressed air from $2900 \mathrm{cc}$. to $3085 \mathrm{cc}$; in M. de K., in 4 days, from 3252 cc. to 3664 cc.; in M. G., a patient with emphysema, in 17 days, from $2202 \mathrm{cc}$. to $2550 \mathrm{cc}$; the respiratory capacity of the latter had even reached $2836 \mathrm{cc}$. in compressed air.

A suspension, even for several days, showed no retrogressive effect, and three weeks after my last stay in compressed air, the spirometer showed that my respiratory capacity had remained at $3800 \mathrm{cc}$. Likewise percussion, by Professor Duchek, revealed after 3 weeks that the forcing downward of the diaphragm and the liver for 2 centimeters and the decrease of the dullness of the heart, matters discussed above, were maintained. 
It is quite evident that such changes in the pulmonary capacity must have some effect upon the sum total of the respiratory functions, and particularly upon the number, the depth, and the rhythm of the respirations.

The number first:

In my first experiments published several years ago, I had already found the number of inspirations diminished; my long present series of experiments has confirmed this result, as being constant, one may almost say. The decrease in the number of inspirations varies with the individual. On the average, it increases proportionately with the original number of respirations; in general, it is $3,2,1$, to $1 / 2$ respirations per minute. As a maximum, I have observed in two patients with emphysema, whose inspirations rose to 33 per minute, a decrease which was respectively 16 and 11 inspirations.

Upon the return to normal pressure, the number of inspirations increases again a little, but without reaching its original figure. In that also, the effect of the compressed air is not merely temporary, but has a somewhat permanent quality. This is more evident when we consider the frequency of the respiration in a longer series of observations. Then we note that the respiration is always less frequent the day after than on the day before. As it undergoes a new decrease as a result of each new treatment with compressed air, the result is this certain and constant fact that the continued use of compressed air lessens the frequency of the respiratory movements every day, up to a certain limit.

My own respiration, after three months of daily use of compressed air for two hours every day, had fallen from 20-16 per minute to 4.5 under normal pressure, and even to 3.4 in compressed air.

When it had reached this degree of slackening, it remained stationary during the subsequent experiments (still slackening a little under the influence of pressure) and even now, while I am writing these lines, although 5 months have passed since then, my respiration does not exceed the noteworthy figure of 5.4 inspirations per minute. The same result, though less remarkable, because the series of experiments was shorter, was noted in observations made on other people. In M. H. .y, the number of inspirations had fallen in 12 days successively from 21 to 16 and in compressed air to 13 per minute. In Dr. Lange, after 4 treatments taken in 11 days (in spite of interruptions of several days) from 19 to 16 , and in compressed air from 14 to 6 ; in M. G., an emphysematous patient, after 14 treatments taken in 19 days, from 20.5 to 15.5 ; in Dr. D., also emphysematous, from 33 , on the second day, to 18 , and in 5 days to 10.4 .

It is during the first days that the respiratory frequency lessens most noticeably and most promptly; later, the decrease becomes slower and the differences less great.

If we compare the result obtained as to the frequency of the respiration with the result given us by the spirometer, it will be difficult not to observe that there is between the two a well-founded relation, that the frequency of the inspirations is inversely propor- 
tional to their amplitude, so that while this amplitude increases, the frequency of the respiration diminishes. The increases of the capacity of the lungs, under the effect of compressed air, is the cause of the slackening of the respiration; or, in other words, the slackening of the respiration is an inevitable consequence of the increase of the pulmonary capacity, because the inspiration and expiration of a greater volume of air necessarily require more time.

Then the depth:

We could imagine three different methods as possible. A compensation might be established between the frequency and the depth of the inspirations by the fact that the amplitude of the respiration could be less than under normal pressure, since a greater quantity of air enters in the same volume, and the frequency of the respiration could nevertheless be reduced also; or, in the second place, the compensation could be established, for the same reasons, by less numerous inspirations, keeping the same amplitude. Finally, in the third place, there might be, in spite of the supplying of a greater quantity of air, as a consequence of the compression, a slowing down and an increase in depth of the inspirations. This last condition appeared a priori most probable if we took into account the increase in amplitude of the respiration, as we had observed it, and it should occur particularly in persons whose pulmonary capacity had been pathologically reduced.

To settle these questions, I used an apparatus constructed for the purpose, which could be attached around the thorax, and followed its movements of inspiration and expiration, the increase of the circumference of the thorax being indicated in millimeters by the separation of two movable needles. This greater or smaller increase in the thoracic circumference served to measure the greater or smaller depth of the inspirations. In each of the thirty-nine experiments made with this thoracometer, the depth and the number of the inspirations were noted for fifteen consecutive minutes, long enough for the effect of the will or a slight error of observation to be negligible. The experiments were always made comparatively in atmospheric air and in compressed air; and as the frequency of my inspirations was then from 7.67 to 4.40 per minute, from 115 to 66 observations were needed in each experiment, making a total of about 3000 numbers concerning the mobility of the thorax.

The measurement made as explained above justifies the statement that in me, on the first day of the experiment, the thoracic expansion, that is, the increase of the thoracic circumference produced by an ordinary inspiration was $12.39 \mathrm{~mm}$, at normal pressure, and at the beginning of the maximum pressure 15.68; after an hour of this same pressure 17.22; and at the end, under normal pressure 18.14, whereas the frequency of the inspirations had dropped from 7.67 to $6.07,5.80$, and even 5.60 ; there had been produced therefore under the influence of the compressed air a progressive decrease of frequency at the same time as a progressive increase in the depth of the inspirations, which continued even after ordinary pressure had been restored. The next day, the thoracic expansion under normal pressure was 14.92 ; the third day, 17.84 ; the fifth day, 18.98 ; a fort- 
night later it had risen to 21.86, while the number of inspirations under atmospheric pressure had dropped respectively from 7.67 to 7.07 , $6.40,6.53$, and 5.00 per minute, and the respiratory capacity on the contrary had risen from $3350 \mathrm{cc}$. to $3400,3474,3498$, and 3644 .

The experiments made on MM. de K. . . and Dr. M. . . gave the same result. In the latter, the frequency of the inspirations had fallen during a single experiment in compressed air from 7.6 to 6.5 per minute, whereas his thoracic expansion had risen from 19.28 to $23.02 \mathrm{~mm}$., and his respiratory capacity had likewise risen from 4159 to $4280 \mathrm{cc}$. This result proves that under the influence of compressed air the depth of the inspirations as well as the capacity of the lungs increase, whereas the frequency of the inspirations diminishes in inverse proportion.

The expansibility of the thorax, as it has been investigated up to the present, is only that which corresponds to an ordinary inspiration, not modified by the will, and as it is produced as an effect of the prolonged influence of the compressed air.

However, the modifications already noted suggest also a change in the conditions of the voluntary inspirations, and this change is to be verified by the increase of the total circumference and of the voluntary expansion of the thorax before and after the prolonged action of the compressed air. If the capacity of the lungs had really been increased, the last measurements should indicate an increase in the circumference of the thorax, not only during the greatest expirations, but also during the deepest inspirations; and if by a prolonged stay in compressed air the ease of a habitually more vigorous respiration had been gained, the maximum expansibility of the thorax should also have increased. This result is also verified by the figures. My thoracic circumference, which on April 30 after the deepest inspiration had been 85 centimeters, was 86.5 on September 1 ; and after the strongest expiration, it was $77 \mathrm{~cm}$. on April 30, and $78 \mathrm{~cm}$. on September 1 ; so that my pulmonary expansion was 8 centimeters on April 30 , and $8.5 \mathrm{~cm}$. on September 1 .

The general increase of the lung capacity, as it was indicated by the spirometer, and the increase of the vertical diameter of the lungs, as it was determined by percussion, receive an additional demonstration by the increase of the thoracic circumference.

Finally, the proportions of the respiratory periods:

The inspiration is made more easily, being favored by the increase of pressure, by the extensibility of the pulmonary tissue, and by the compressibility of the intestines, whereas more force is needed for the expiration so as to contract the lungs which are more distended and to expel the greater quantity of air expired. That is why the expiration is made with more difficulty and more slowly than in the normal state. While under atmospheric pressure the duration of the inspiration is to that of the expiration almost as $4: 3$, this ratio becomes in compressed air almost as $4: 6,4: 7$, and even $4: 8$ and $4: 11$.

However the resistance to the expiration finds partial compensation in the more powerful contraction of the abdominal muscles 
which the compression supports in their action. Through the effect of this contraction, the first half of the expiration is made quickly and energetically; but the second half is made so slowly and so imperceptibly that there is a sort of pause between the inspiration and the expiration. This pause which should in any case be added to the expiration and the length of which has been, according to my observations, from two to six seconds, is increasingly longer as the inspirations are fewer.

Vivenot has tried to express these different modifications of the respiratory rhythm by the following graph (Fig. 9), which I borrow from his long work (p. 251), and in which the solid line indicates the normal respirations, and the dotted line the respiration under compressed air, the whole during fifty-some seconds.

Circulation. The memoir published by Vivenot in 1865 in the archives of Virchow contains detailed information about the modifications in his pulse under the influence of compression. These explanations are accompanied by numerous graphs obtained by means of the sphygmograph of M. Marey; I reproduce here the most characteristic:

A rapid glance at the curves shown below reveals that under the influence of compressed air they undergo considerable modifications in their original forms; closer attention shows that all parts of

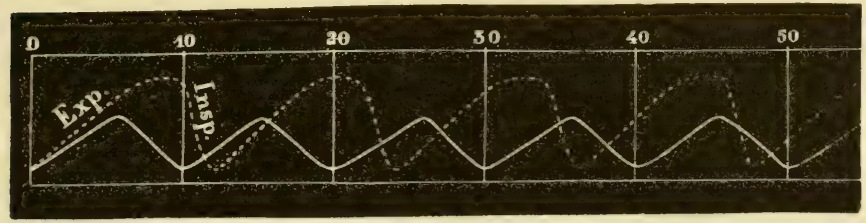

Fig. 9-(bis).

the curve are so essentially changed that their analysis requires careful dissection of separate segments of the curve.

We see that in all the curves without exception, under the influence of compressed air, the height of the curve decreases. The line of ascent, more or less abrupt originally, becomes more oblique; the apex seems more rounded, and because of the lessening of the amplitude, the line of descent, still less abrupt, finally is bent into the form of a wave which is more or less convex on the right. Because of the decrease in the height of the curve, the angle formed by the intersection of the ascending line and the descending line of the pulsation inscribed and which under normal atmospheric pressure measures about $45^{\circ}$ is considerably blunted; and also, because of the more oblique direction of the line of ascent, the apex of the top of the 
curve is further prolonged backward ... so that the curve as a whole assumes the form of the segment of a sphere.

The changes which we have just described are proportional to the strength of the air pressure and to the duration of the stay in compressed air and consequently are more marked and more pronounced as the air pressure is carried higher and the stay in the ap-

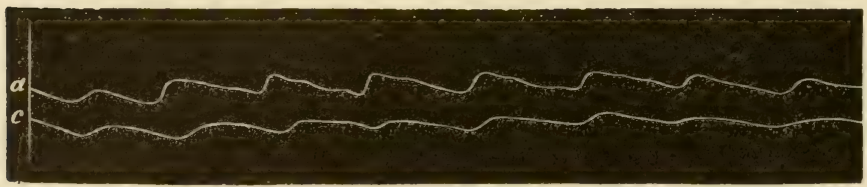

Fig. 10

paratus is lengthened. We find then that the indications produced after twenty minutes of maximum pressure, that is, the visible obliquity of the line of ascent, the shortening of the wave, the rounded flattening of the top, and the transformation of the wavy line of descent into a straight line or a simple convex line, after an hour and a half, that is, after an hour of exposure to the constant maximum pressure, take on a still more evident character, so that the tracing of the pulse finally presents, so to speak, only a straight line.

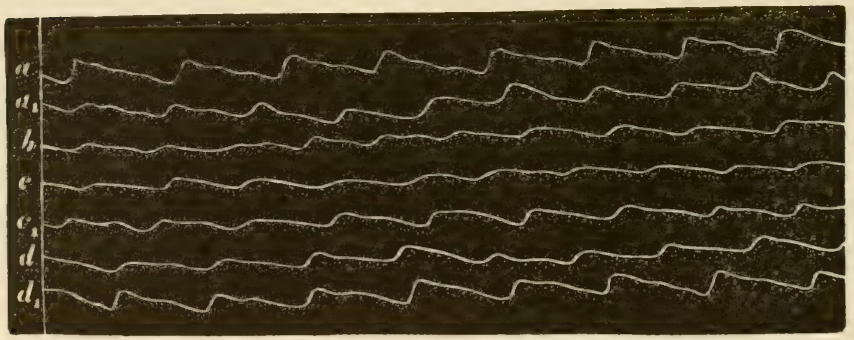

Fig. 11

In these four figures letter $a$ indicates the sphygmographic tracing obtained under normal pressure; $b$ is the tracing while the pressure is rising in the apparatus; $c$, during the period of constant compression; $d$, after return to normal pressure. Fig. 11, $a_{1}$ was taken while the pressure was increasing; $c_{1}$ while it was decreasing.

Upon return to normal atmospheric pressure, immediately after the treatment, the curve resumes its original form, or only partially returns to it, or, somewhat frequently, the change when it has once begun in the blood curve undergoes a downward movement. Figure 9 expresses all these different phases. 
In no case did I find this change in the curve lasting, but this effect, agreeing with.the results which we obtained for the pulse rate, in favorable cases is prolonged for a few hours. Curve $d$, in Figure 12, furnishes an example of a curve rising and regaining its original form, not immediately, but twenty minutes after the return to normal pressure.

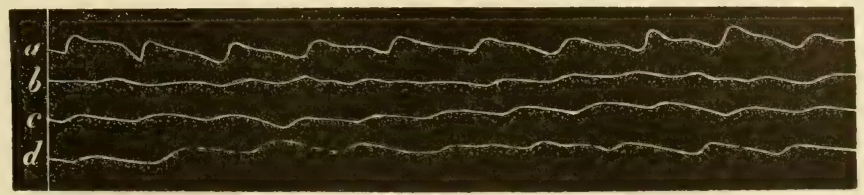

Fig. 12

To establish the truth of the assertion which we have already accepted, that the vestige, remaining after the treatment, of an effect upon the tracing has already disappeared after several hours, one may use curves obtained upon myself May 26, a day on which I had had two experimental treatments in compressed air. If we compare the curve obtained on that day before the first treatment, at eight o'clock in the morning (Fig. 12, a) with the corresponding

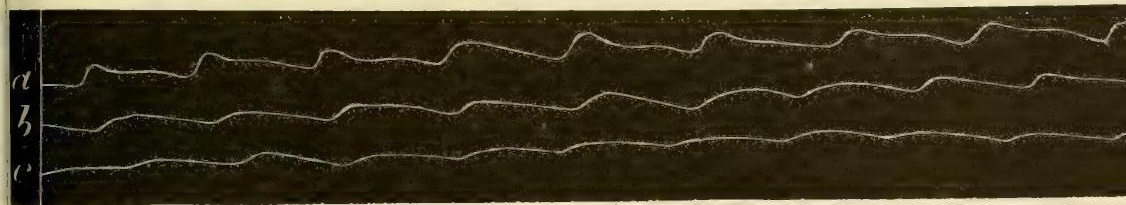

Fig. 13

curve of the second treatment, that is, taken at half-past two in the afternoon (Fig. 13, a), one can note no essential diflerence between these two pulse tracings. After this period of four hours and a half there is no perceptible sign of the effect still noticeable at ten o'clock on curve $b$ of Figure 13; still less should we expect to find the persistence of this effect from one day to another.

Now, to grasp the value of the differences so far found, we should picture the different elements of the curves as the expression of these changes.

The irregularity in the ascending line which coincides with the systole of the heart is produced by the blood wave expelled by the contraction of the heart, and this wave, tending to spread in all directions, partly urges on the blood current and partly exerts an excentric pressure upon the walls of the vessels which it stretches. The ascending part of the curve (line of ascent) therefore corresponds to the arterial diastole. The more easily the blood flows in the capillaries, 
the more quickly does it move in the arteries, and the more easily does the heart contract, since the blood pressure representing the resistance opposed to the systole of the heart becomes weaker. It is well known that every muscle contracts so much the more easily and quickly, in proportion as the execution of this movement requires less expenditure of energy. Consequently, in such a case, the arterial expansion will take place in so much less time; and if the time from the rise of the blood pressure to its maximum increase is very short, that will be expressed in the steepness of the ascending line of the curve; and if the period of time is so short that it cannot be measured, then the line of ascent will appear completely vertical, as is almost always the case in the normal state.

When, on the contrary, on the tracings made in compressed air we observe that the line of ascent is becoming oblique, we conclude that the resistance opposed to the blood wave produced by the systole of the heart has increased at the same time that the flow of blood is checked in the capillaries; that consequently the systole of the heart is less rapid, that the blood wave reaches the arteries slowly, and that consequently also the dilatation of the arteries does not take place suddenly, but progressively.

The apex of the curve which we do not wish to consider as a mathematical point, but as the convergence of the ascending and descending lines, shows us the moment when the artery, having reached the maximum of its dilatation by the blood distending it, resists by means of its own contractility the pressure of the blood which acts upon it, and by its contraction exerts a new impulse on the blood.

If the resistance which the blood wave meets in the arterial trunks at a distance from the heart decreases a little, then the flow of the blood in the direction of the current, from the heart to the periphery, becomes easy and rapid, and the pressure of the blood in the arteries decreases rapidly, and the arteries can contract rapidly. The more marked this tendency is, the more acute the apex of the tracing appears, as we can see, for example, in the normal pulse.

The contrary takes place in compressed air, and the original acute angle changes, as we have seen, into a more or less obtuse angle, and even into an arch, which takes place, if, on account of the considerable obliquity of the line of ascent, the highest vertical point intersects the middle of the curve.

Consequently the increase of resistance already expressed in the ascending part of the curve, by its obliquity under the influence of the compressed air, is communicated or transmitted also to the apex of the curve (p. 557-560)....

The descending wave of the curve of the pulse, which corresponds to the diastole of the heart, shows us the decrease of the blood pressure in the arteries, coinciding with the closing of the semilunar valves, and with the simultaneous flow from the large arteries into the capillaries, that is, the arteries gaining the victory in their struggle against the pressure of the blood, and by means of their elasticity, through the transformation of their expansive energy into active energy, contracting to the minimum limit of their caliber. The vary- 
ing appearance of the line of descent, according as it bends, becomes straight, or oblique, or convex, or falls perpendicularly, shows us how much more or less easily the blood passes through the capillaries. The tracings of the pulse taken at normal atmospheric pressure, before entering the compressed air (tracings I - XVII of Vivenot) show this more or less accentuated characteristic oscillation which the finger detects only in the most pronounced cases, which is called dicrotism, and which consists of two or, more often, three oscillations of the wave. (P. 562)

Whereas we have found polycrotism as a more or less marked peculiarity of the normal pulse at ordinary pressure, it appears from our curves that the compression of the air causes the polycrotism to disappear and transforms the wavy line of descent into an almost straight line or one which is more or less convex.

So we find the proof of a congestion of blood in the vessels and of a hindrance of the capillary circulation, in the descending line of the curve as well as in its ascending part and its apex.

Whereas, as Marey has shown and has proved by an example in a tracing made in a case of heart disease (Fig. 86 of Marey), the dicrotism is proportionately greater as the wave expelled by the ventricle is smaller in proportion to the caliber of the artery, we confirm, for our part, this proposition in regard to the dicrotism, because, as it appears from the preceding discussion, the arteries, which are compressed by the outer pressure and therefore convey very little blood, are nevertheless very full of blood in proportion to their lessened caliber.

Upon return to normal pressure, at once the original figure of the line of descent reappears, and the simply convex line resumes its previous polycrotism, or rather the form which has been produced persists for a time, one or two hours, and then yields and gradually regains its original appearance (See above, Fig. 9).

In our analysis of the pulse tracings we have hitherto omitted one circumstance, that is, the somewhat important change in the amplitude of the curve under the influence of compressed air.

For the sake of clarity, we have delayed analysis of it until we reached the subject of the energy of the pulse, better named the size of the pulse, which refers to the vertical height of the blood wave, that is, the maximum height, and which, according to Marey, is proportional to the energy of the pulsation. As we have concluded from the agreement in the tracing of the curves which we have collected for far, the amplitude of the pulse is lessened by the stay in compressed air, and often loses from $4 / 5$ to $5 / 6$ of its original height, so that the whole series of pulsations traced is often changed into a line in which the separate waves are hardly perceptible.

This decrease of amplitude is proportional to the compression of the air and to the length of the stay in the compressed air, and so the minimum amplitude is noted particularly at the end of the stay in the compressed air; it happens by exception that after the return to normal pressure the amplitude remains stationary, and returns to the normal state after a long stay under ordinary pressure. It is also exceptional to see the amplitude, after reaching its minimum, 
begin to rise gradually during the period of constant maximum pressure, without reaching its original height, however.

Moreover, the changes which the pulse undergoes here are explained by and are perceptible to the touch, because in most cases the pulse which is normal before the entrance into the pneumatic apparatus is almost imperceptible to the touch of the finger in compressed air; it is really the pulsus debilis. We should note in regard to this last point that the changes of the pulse described above in a pulsus longus, such as we have seen appear in the pneumatic apparatus, and which are observed in normal air pressure in certain morbid processes, such as aneurisms and embolisms, give a deceptive sensation to the finger, so that even when the vertical height of the pulse remains identical, as Marey observed (p. 243), the pulse will appear stronger in proportion as the blood wave is more gradual, which is expressed by the rise and fall of the blood pressure in the vessels; but since in our case, in compressed air, the decrease of the strength of the pulse indicated by touch is also confirmed by the decrease in vertical height of the tracing, the decrease of the strength of the pulse in itself must be considered certain.

We should now have to show the cause of this decrease of the strength of the pulse in compressed air, as it appears from our researches; we might well think first of the weakening of the action of the heart itself, and of the occasional circumstance of the decrease of the strength of the pulse in compressed air, a weakening which perhaps is caused by the rise in resistance, which the increase of the atmospheric pressure, compressing the whole of the peripheral vessels, produces in the arterial system; in support of this hypothesis we might mention data which I reported under other circumstances and in another place; in fact, inspection and palpation of the neart show its weaker impulse; auscultation of the heart gives an identical result, and the sound appears further away, so to speak.

However, these data in no way show and prove that a change has taken place in the strength of the heart impulse, for, on the one hand, we find it extremely difficult to get an almost certain and demonstrated proof of the changed intensity of the contraction of the heart, and, on the other hand, the weakening of the heart impulse and of the heart sounds, noted by sight, hand, and ear during the stay in compressed air, can be only apparent; and, as I have already shown in the dissertation mentioned above, can be only a simple effect of a displacement of the heart, caused by the compression of the air and connected with the increase of the capacity of the lungs and the passing of the anterior layer of the left lung in front of the heart. (P. 564$567)$.

So far we have discussed only the form of the isolated wave, without taking into account the combination of the successive waves, and yet this complex phenomenon requires some explanations.

Let us draw a line from the beginning to the end at the base of the wave or across its apex; we shall then have what Marey called a line of the whole (gemeinsame linie), which may give us some information about certain changes in the pressure of the blood and in the distention of the vessels. This line which, as we have said, varies 
according to certain changes in the attitude of the body, may display a total or partial change in its form and in its direction. The first case appears following a change of long duration in the blood pressure and in the distention of the vessel, and is evidenced by a considerable modification of the whole line in reference to the original form of the pulse, whereas a frequent change in blood pressure and vascular distension, such as takes place, for example, under the influence of an irregular respiration, finds expression in the more or less marked and more or less frequent incurvations in a series of rises and drops of the pulse line. Now since this line, according to Marey, indicates that an obstacle to the blood flow increases the distension in the arterial system at some point, we had to investigate whether that took place in compressed air because of the compression of the superficial vessels, and whether the obstacle or the difficulty recognized by us in the arterial circulation by the change in the line of ascent also produced a change in our line of the whole, and found its expression in its rise (oblique ascent of the whole line) in compressed air.

After preparing the instrument for this purpose, according to the rules established in our preceding experiments made with the use of the sphygmograph, and arranging things in such a way that the registering stylus should be placed just in the middle of the band of paper, at an equal distance from the upper and the lower edge, and after releasing the clockwork, I thus made in the open air a tracing of the pulse in the exact middle of the paper; but I did not have the same success with operations in compressed air. Although the instrument had not been lifted, and no change had been made in the attitude of the arm or the position of the instrument, the registering stylus under the influence of the compressed air moved from its original situation and rose; it even rose so high that it passed above the upper edge of the paper band, and it had to be lowered, by a slight movement of the hand, to the level of the paper so that a tracing could be obtained. By this experiment we demonstrated: for the radial artery a general rise of the blood tension and of the vascular distention independent of that which can be observed in an isolated pulsation.

As far as concerns the influence of the respiratory movements shown by the arched incurvations of the pulse line, it is slight and imperceptible enough to go unnoticed by superficial observation. It is very apparent only when one takes deep inspirations and when there is a difficulty in respiration.

In consequence of changes produced in the size of the thorax by the inspirations and expirations on the one hand, and, on the other, as a result of the rising and falling of the diaphragm, which alternately contracts and enlarges the abdominal cavity and the thoracic cavity, and of the consequent change in distention of the abdomen, a stronger pressure is produced alternately in the thoracic aorta and the abdominal aorta; the result is a variable distention in these vessels which is then communicated to the remote arteries.

And so, as I have shown elsewhere, under the influence of compressed air, we observe a slackening of the frequency of the respira- 
tion which, maintained by the daily repetition of this same influence of the pressure of the air, increases from day to day to a certain figure; moreover, the respiration is easier in compressed air; it becomes calmer and more complete; and thus certain respiratory disturbances are quieted. So whereas in the open air the influence of the respiration was shown in the curve of the pulse, in compressed air this influence should be weakened, that is, the curves and arches of the line of the pulse should, under this influence, lose frequency

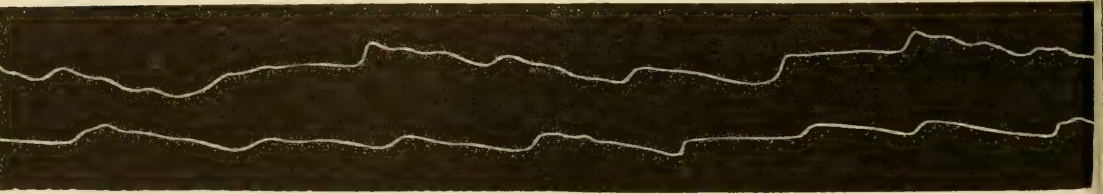

Fig. 14

and intensity, as, moreover, we can see in Figure 14, which, made May 1 on an emphysematous patient aged 44, in $a$ at normal pressure shows noticeable variations in the curves expressing the pulsations, which show great difficulty in respiration, whereas, under the influence of compressed air in $b$, the intensity of the curve has fallen so considerably that the pulse line almost becomes horizontal, and that at the same time there is a greater number of pulsations for one respiration than in $a$, and by this change the abatement of the previous respiratory difficulty is indicated.

The existence of this change in the respiratory curve under the influence of compressed air may be considered the rule, and we rarely find the opposite state. (P. 578-580.)

As to the number of pulsations, Vivenot summarizes in the following words 423 observations made upon himself:

In the morning between 6 and 7 o'clock, when I awoke, my pulse rate was 65.22 . After I had breakfasted in bed, this number rose to its maximum, 81.20; at the time of entering the pneumatic apparatus it was only 79.03. Under the influence of compressed air, it fell to between 75.43 and 71.66 ; on return to normal pressure it was still 72.41 , and in the course of the day my pulse did not rise to the figure given before my entering the apparatus.

This decrease in the pulse rate in compressed air was noted 375 times in my 423 observations; 18 times there was no change; 30 times, an increase in the pulse rate. (P. 532).

Vivenot observed that the congestion of the vessels of the conjunctiva disappeared wholly or partially through compression. The examination of the retina in a person who had been given atropine also showed him that the vessels of the eye are emptied of blood in compressed air.

Besides, he made five direct observations upon a tame white 
rabbit in regard to changes in the circulation in the ears and the conjunctiva. I copy the details which he gave on this subject, because they do not seem to me to justify the conclusions which he drew from them and which were accepted on his authority.

\section{I. (a). Normal pressure:}

The rabbit quiet and free. The ears erect, swollen with blood. The vessels of the conjunctiva congested. The iris and particularly the pupil very red.

(b). During the increase of pressure:

Vessels of the conjunctiva thinner and paler. Loss of color in the iris and the pupil.

(c). During the constant maximum pressure:

By transparency, the vessels of the ears empty of blood; the largest are hardly visible; shortly after, the ear is quite pale and limp and the vessels have completely disappeared.

(d). During the decrease of pressure:

The ear and the conjunctiva remain pale.

(e). Under normal pressure, immediately after treatment:

After the treatment, even an hour after, the ears are empty of blood, pale and limp.

II. (a). The vessels-of the ears are moderately congested.

(b). At the beginning, a greater congestion of the arteries and the veins of the ear; later the iris first grows pale and then loses its color.

(c). The ears remain pale; the iris is darker; the pupil redder.

III. (a). The vessels of the ears are moderately congested; the iris and the pupil are a beautiful red.

(b). Swelling of the vessels and particularly of the veins of the ears, the largest of which are dilated.

(c). At the beginning, no change noticeable in the color of the iris and the pupil. The vessels of the ear alternately grow pale suddenly and fill up again; however, some time afterward, they are definitely pale and remain empty of blood.

(d). The ears are still pale and limp.

(e). Some hours after the treatment, the ears are still quite empty of blood, pale, and limp.

IV. (a). Long before the treatment, the ears are rather empty of blood.

(b). The vessels of the ears are alternately congested and pale; finally they remain pale.

(c). Because of the darkness in the apparatus, the color of the pupil cannot be observed.

(d). The ears still pale.

(e). The pupil seems to become dark red. The ears are well filled with blood.

V. (a). The conjunctiva congested at isolated places. The vessels of the ear moderately congested.

(b). The congestion of the conjunctiva and the vessels of the ear partly disappears. 
(c). Vessels of the ear and the conjunctiva obliterated; the ears pale; sometimes congested in an instant. Because of the increasing darkness, the color of the pupil and that of the iris cannot be determined.

(d). The ear and the conjunctiva remain pale; finally, no vessel can be perceived. (P. 587).

So, Vivenot concluded, under the influence of compressed air the blood diminishes in the vessels of the periphery of the body.

After the details which I have just reported about the changes in the two great physiological functions of respiration and circulation, changes which are at the same time the most important and the easiest to verify, I think it will be sufficient to reproduce the summary which Vivenot himself gives of all his observations. Unfortunately, the statement of the data in it is so thoroughly mingled with the theoretical ideas which the author conceived to explain them that it would be impossible to separate them from each other; but the difficulties resulting from this confusion will be settled in reading the following chapter.

\section{Summary of the Physiological Phenomena.}

1. Impressions in the ear.

2. The change in the tone of the voice, the tones rise in pitch; the difficulty in pronunciation, the impossibility of whistling, sometimes slight stammering.

3. Smell, taste, and touch lose their keenness.

4. The negative pressure in the inspiration and the positive pressure in the expiration increase.

5. The convexity of the abdomen decreases because of the compression of the intestinal gases. fall.

6. For the same reason, the diaphragm and the base of the lungs

7. The lung, during inspiration as well as during expiration, comes around in front of the heart.

8. Thence comes the decrease of the cardiac impulse upon palpation and the faintness of its sounds upon auscultation.

9. The pulmonary vital capacity increases. At $3 / 7$ of compression, it is increased in a half-hour by $73.40 \mathrm{cc}$. on the average, and in $1 \frac{1}{2}$ hours by $105.27 \mathrm{cc}$, that is, $3.30 \%$ of their original dimensions.

10. On return to normal pressure, the increase in pulmonary capacity decreases, but the lungs do not regain exactly their original volume.

11. Repeated treatments bring every day an increase of the pulmonary capacity; more at the beginning than at the end. After $3 \frac{1}{2}$ months of air treatments my pulmonary vital capacity had become greater by $743 \mathrm{cc}$., that is, increased one quarter without any loss of the contractile power of the lungs. 
12. The changed activity of the diaphragm and the thorax persists after the end of the experiments.

13. These increases do not take place solely in extreme respirations; they are observed in the regular respiration, and the diaphrâgm then is also lower than in the normal state.

14. The respiration becomes less frequent. The number of the movements decreases by 1 to 4 per minute. This effect continues a little while after the return to normal air.

$15,16,17,18$. These sections repeat for frequency what was said about depth in 10 to 13 .

19. The inspiration is faster, the expiration slower; the first part of the latter is rather short, but the second becomes so slow that there seems to be a pause.

20. The proportion of carbonic acid contained in the expired air increases; a respiration with $3 / 7$ of an atmosphere above the normal contains on the average $22.26 \%$ more carbonic acid than at normal pressure.

21. This increase therefore is not in exact proportion to that of the pulmonary capacity, which is $3.3 \%$.

22. It takes place not only in exaggerated respiratory movements but also in quiet respiration.

23. Upon comparing this increase of carbonic acid with the decrease of respiratory frequency, we see that there is definitely a greater quantity of carbonic acid given off and consequently of oxygen absorbed.

24. The result of this is that after a series of treatments in compressed air, the venous blood appears brighter, the temperature of the body increases (from $0.1^{\circ}$ to $0.4^{\circ}$ ), the muscular energy is greater, hunger appears, and, in spite of a larger amount of food, the weight of the body lessens through emaciation; however, if the pressure is not too great and if one eats a great deal, one may, on the contrary, grow fat.

25. The pulse rate drops by 4 to 7 per minute; this decrease is still more marked when there was an abnormal acceleration.

26. On return to open air, the pulse resumes its normal rhythm.

27. However, when the frequency of the pulse was due to some respiratory difficulty, a permanent drop may be the result of treatment by compressed air.

28. The decrease of the frequency of the pulse seems to be the result of the purely mechanical action of the compressed air; the increased pressure on the surface of the boody increases the resistances met by the blood waves sent out by the systole of the heart; the systole then becomes more difficult, with the result of a decrease in the number of pulsations.

29. The curve of the radial pulse undergoes changes in form; its height lessens, the line of ascent is less steep, more oblique, the apex more rounded, the line of descent loses its wavy form and becomes straight or slightly convex. There is therefore a shrinkage of the vessels, and consequently of the quantity of blood which they contain, an increase in resistance to the systole of the heart, and a greater difficulty in the capillary circulation. 
30. On return to normal air, the tracing gradually regains its original form.

31. The radial pulse seems changed to the touch; it becomes small, filiform, almost imperceptible.

32-33. These sections relate to an experiment which will be reported in the following chapter.

34. The action of the heart in compressed air is not stronger; but we do not know whether it diminishes, although that is probable.

35. The sphygmographic curve, while the pressure is increasing, is above that obtained in normal air. There is, therefore, in this phase an increase in the total pressure of the blood, at least in the radial artery.

36. Experiments made on animals, on the pressure of the blood in the carotid artery, by means of the hemo-dynamometer gave no result. It is probable that when the air pressure has become constant, a new degree of equilibrium is reached, the action of the heart which has become less strong brings a decrease in the aortic system.

37. The decrease in caliber of the vessels of the conjunctiva, of the retina, and of the ears of rabbits, the loss of color in the pupil and the iris of white rabbits, the pallor of workmen who labor in compressed air, directly prove the ebbing of the blood from the periphery towards the center.

38. Thence come the decrease of the intra-ocular pressure, the contraction of the pupil, the lessened sensation of the pulse in the ear and the jaw, the decrease of the redness in the membrane of the tympanum, the improvement in cases of erysipelas, and finally the decrease in size of scrofulous strumae.

39. A manometer placed in the jugular vein showed that the venous pressure diminishes in compressed air. (Vivenot did not make any experiments on this; he depends upon an experiment of Panum, which he himself finds unsatisfactory and poorly carried out. (P. 414).

No direct experiments have been made in regard to the effect of compressed air upon the venous and lymphatic systems. But it is certain that it can only be stimulating; moreover, the negative pressure, which is increased, acts also on the heart and the large vessels.

40. The temperature in the armpit increases while the air is being compressed, it reaches its maximum with the compression. During the stage of constant pressure, there is also an increase of rectal temperature.

41. It is shown by our experiments that a part of the blood is driven back from the periphery of the body; the organism has therefore at its disposal a quantity of blood which must rush to the organs which are more deeply situated, such as the brain, the spinal cord, the muscles, the alimentary canal, the liver, the spleen, the kidneys, and the uterus. Thence result, for the brain, the heaviness of the head, the slight deafness, and the yawning; for the alimentary canal, the hunger and the increased rectal temperature; for the muscles, the increase of muscular energy and of the axillary temperature; for the 
kidneys, the greater quantity of urine. Those complex symptoms, in which the outer cold also has some influence, act only within physiological limits.

42. That is why the compression of the air causes no serious disturbance in the circulation of the blood, even when it is carried to $4 \frac{1}{2}$ atmospheres.

43. The same thing cannot be said of the stage of decompression, which, when it is too sudden, causes annoying and even very dangerous disturbances in the distribution of the blood.

44. The stay in compressed air is therefore less dangerous than the return to open air, which causes congestions, hemorrhages, pains and particularly disturbances of equilibrium of different sorts in the circulatory system, which, by the development of gas in the blood, may even cause a stoppage of the circulation and consequently a sudden death.

45. The means to be used in the case of these symptoms is a rapid return to compressed air. (Zur Kenntniss, etc. P. 489-495.)

The series of Vivenot's works attracted the attention of physiologists and physicians to the interesting symptoms which he was the first to note or which he described with more accuracy than the preceding authors. The publications followed each other rapidly.

Freud ${ }^{13}$ noted a considerable increase in his pulmonary capacity. After 30 air treatments, it had risen from 3100 cc. to $3600 \mathrm{cc}$; this increase still persisted $5 \frac{1}{2} 2$ months later. There were only four rèspirations per minute.

Elsässer, ${ }^{1+}$ who did his research in the apparatus of Gmelin, at Stuttgart, summarized the observations of his predecessors and his own in regard to the respiratory rhythm in the following statements:

1. The total value of the respiratory movements in a given time is diminished ... ; 2. The decrease affects partly the frequency, and partly the amplitude of the movements; the more nearly the frequency approaches the normal, the less deep the respirations are; if they are very rare, they become deeper; 3 . In very deep inspirations, a greater quantity of air enters the lungs than at normal pressure. (P. 26.)

Moreover, his memoir seems to be only a sort of summary of the former works of Vivenot. It is especially devoted to therapeutics.

But in the front rank of the authors who, after Vivenot, considered these questions, we must mention Professor Panum. The work of the Danish scientist is exclusively of a physiological nature. $^{15}$ We shall give it an important place in the following 
chapter; here, we shall mention only observations relating to the physico-mechanical phenomena of circulation and respiration.

Respiration. The first phenomenon discussed is the enlargement of the pulmonary cavity in compressed air:

Respiration is always deeper than at normal pressure. This effect often lasts for 24 hours or more and increases with the repetition of the air treatments. In one person whose inspiration, under normal pressure, amounted to 400 to $700 \mathrm{cc}$. (an average of $480 \mathrm{cc}$.), the first treatment of $35 \mathrm{~cm}$. raised it from 650 to $800 \mathrm{cc}$. (average $750 \mathrm{cc}$.); the second took it on the average to $900 \mathrm{cc}$.

The frequency of the movements had fallen from $13-14.5$ to 11.5 per minute. (P. 153)

Here, moreover, is a table which expresses the modifications shown by respiration in normal air and in compressed air, following different voluntary rhythms of respiration:

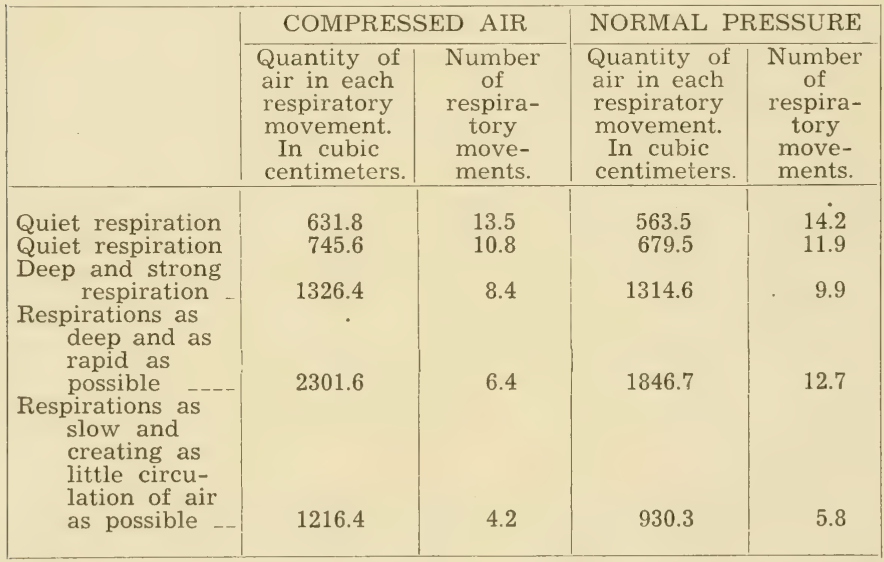

As for the respiratory rhythm properly so-called, Panum states that "the relative duration of the inspiration and the expiration is similar in compressed air and at normal pressure." And in support of this statement, which contradicts what we previously reported on the authority of Vivenot, he gives a tracing of respiratory movements directly recorded.

Circulation. Panum reports the observations of Vivenot and Sandhal, and admits the slowing down of the pulse. He tried to make experiments on two dogs to study the modifications of the manometric pressure of the heart; but they gave no result.

The decrease of the blood flow in the capillaries is proved, 
according to him, by the fact that a toothache disappeared in compressed air. However, observations on the conjunctiva and the ears of rabbits showed nothing definite; besides, he says, there are too many causes of complications. But what is the immediate cause of these modifications in the circulatory acts?

The decrease of the pulse and of the tension must be due to an effect on the heart action. Is this effect the result of respiratory changes? Does it depend on the pressure exerted on the muscles and the ganglia of the heart? Or on some other circumstance? I do not venture to give an authoritative opinion.

The work of G. von Liebig ${ }^{16}$ contains the account of the experiments made at Reichenhall in the apparatuses of the Mack brothers. The average pressure at Reichenhall is 72 to 73 centimeters; in the apparatuses it varied from 100 to 130 centimeters.

G. Liebig first observed, as did so many others, that respiration slackened in compressed air. In Kramer, one of the persons whom he observed, it fell from 10 to 7 per minute, and remained at this figure under normal pressure: but in the other, Mack, one of the proprietors of the establishment, who was accustomed to compressed air, the difference was only from 4.3 to 4.1 .

The respiratory amplitude was also modified in the first subject. It rose from 0.819 liters to 1.073 liters, and remained at 1.068 liters. But in the second, the change was only from 1.437 liters to 1.489 liters and we may consider it as non-existent.

Mayer ${ }^{17}$ made similar observations on a lady affected with dropsy and on himself:

He noted the usual phenomena. But (contrary to Vivenot) he found a constant slackening of the pulse, which he explains by increased circulatory resistances (increased pressure on the heart and the vessels); the respiration was also slowed down. The vital capacity of the lungs increased in a perceptible manner which seemed to be persistent. The increased combustion raised the temperature in the patient from $37.3^{\circ}$ to $37.7^{\circ}$.

The work of Marc ${ }^{18}$ is more interesting, although it deals only with an observation which Dr. Stachelhausen, who had been suffering from hemoptysis and emphysematous asthma for four years, made upon himself.

After treatment for a month, a considerable improvement was made; but I have no intention of dwelling on pathological details. The most striking detail of the observation is the marked change caused in the number of heart beats and of respiratory movements; I have summarized the author's figures in the following table: 


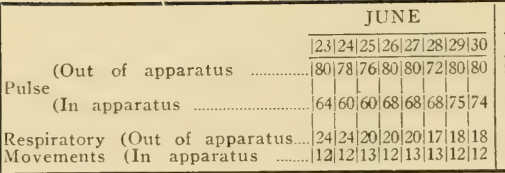

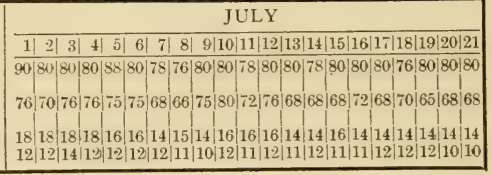

So two things are to be noted: first, the sudden decrease of the number of heart beats and of respiratory movements by the effect of compressed air; the decrease in the number of the latter, even in the open air, as long as the treatments were being given, whereas the pulse rate did not change.

The pulmonary capacity measured on the spirometer was increased $550 \mathrm{cc}$.

June 22, before the beginning of the treatments_____ 1450 cubic cent.

June 29, during the treatments 1600 cubic cent.

July 8, during the treatments 1800 cubic cent.

July 15 , during the treatments 1900 cubic cent.

July 21 , during the treatments 2000 cubic cent.

It is regrettable that Marc specified neither the degree of the air compression nor the length of time his patient stayed in the apparatus.

1 Here is a list of the chief works published on the therapeutic use of compressed air. I did not include those which I am quoting and analyzing in the present and the following chapter. This list shows the astonishing variety of ailments in which the new treatment has been tried:

Pravaz, Mém. sur l' emploi du bain d'air comprimé dans le traitement des affections tuber. culenses, des hémorrhagies capillaires et des surdités catarrliales. Acad. de Med. de Paris, Dec. 6, 1837, Cpt. $R$. Acad des Sciences, Vol. VII, p. 283, 1838.

Id., De l'influence de la respiration sur la santé et la vigueur de l'hopnme. Lyon, 1842.

Id., Mémoire sur l'emploi de la compression au moyen de l'air condense dans les hydarth. roses, et sur la possibilité de réduire certaines luxations spontanées de la hanche. Lyon, 1843.

Dubreuil, Bains d air comprimé. Marseille, 1848.

De la Prade, Rapport sur le memoire relatif aux bains d'air comprimé, in Essai sur l'emploi médical de l'air comprimé, par Pravaz. Lyon, 1850.

Poyser. On the treatment of chronic and other diseases by baths of compressed air. Association Med. Journal, September 9, 1853.

Devay, Du bain d'air comprimé dans les affections graves des organes respiratoires. Gazette hebd. $185 \overline{3}$.

Schütz, Briefliche Mittheilungen aus Nizza. Deutsche Klinik, February, 1857.

Bottini, Dell' aria compressa come agente terapeutico. Gazz. med. italiana, Stati Sardi, 1857. A. Simpson, Compressed air as a therapeutic agent. Edinburgh, 1857.

Haughton, On the use of the compressed air baths. Dublin, Hosp. Gaz.. 1858.

Pravaz fils, Des effets physiologiques et des applications thérapeutiques de lair comprimé. Lyon, 1859

Gindrod, The compressed air-bath, a therapeutical agent in various affections of the respiratory organs and other diseases. London, 1860.

Lippert (in Nizza), Ueber Paris nach Nizza, medicinishe Reiseskizze. Deutsche Klinik, October, 1861.

Trier, Om Bode $i$ fortoettet luft. Copenhagen, 1863.

G. Lange, Der pneumatische apparat. Vienna Med., Wochenschift, August, 1863.

Levinstein, Beobachtungen über die Einwirkung der verdichteten Luft bei Krankheiten der Respirations-und Circulations-Organe. Berl. Wochenschrift, 1864.

Freud, Der pneumatische apparat. Wirkung und Anwendung der comprimirten Luft in verschicdenen Krankheiten. Vienna, 1864.

Fischer, Errichtung eines Luft compression Apparates zu Hannover. 1864.

Josephson, Die therapeutische Auwendung der comprimirten Luft. Deutsche Klinik, 1864.

Levinstein. Grundzuge zur practischen Otiartie mit Berucksichtigung der neuesten therapeutischen Technik, etc. Berlin, 1865.

Smoler, Die Anwendung der comprimirten Luft in Krankheiten der Gchörorganes, Osterr. Zeists. f. pract. Heilkunde. Vienna, 1865.

Storch, Jagttagelser over Virkningen af comprimiret Luft ved behandlingen af Brysttidelser. meddelte fra Rasmussens medico-pneumatiske Austalt. Hospitals-Tidende VIII. Aarg. Copenhagen, 1865 . 
Sandahl, Nyare undersökningar och iakttagelscr rörande de fysiologiska och tcrapeutiska verkningarne af bad $i$ förtätad lift. Hygiea. Stockholm, 1865.

Id., Berättelse om den mediko-pncumatiska anstaltens verksamhet i Stockholm under arcn 1863 och, 1861. Stockholm. 1865.

Freud, Vortrag iiber der pneumatisch Apparat, und seine Wirkungen in Vienna Doctoren

colleg. Zeitsch f. pract. Heilk., 1865.

Bertin (Emile). Analyse de trois brochures sur l'air comprimé. Montpellier medical, 1866.

Kryszka, Der atmosphârische Druck. Voch. d. Zeitsch der K. K. Gesellsch. der Aerzte in

Wien, 1866 .

Pravaz fils, De l'application de l'air comprimé au traitment de la surdité catarrhale. Grenoble, 1866

Brunniche, Beretning on .4. Rasmussens medico-pneumatiske Anstalt i 1866 . Bibliotek for

Lager. Copenhagen, 1867

George v. Liebig, Der pneumatische Apparat zu Reichenhall und andere Fortschritte des

gen. Kurorts. Bayer, arztl, Intell. Blatt; 1867.

Id. Der pneumatische Apparat su Reichenhall während der Saison von 1867. Ibid., 1868.

Sandahl, Des bains dair comprimé. Court apercu de leurs effets physiologiques et thérapeutiques. Stockholm, 1867.

Roussaux, De l'aérothérapie. Thèse de Paris, 1868

Levinstein, Zur Casuistik der Anwendung der verdichteten Luft bei Lungcnkranken. Kisch's

Baln. Zeitung; 1868, Bd. II.

Gent, Emploi thérapeutique de l'air comprimé, Bull. Acad. de Méd., November 20, 1869.

Freud, On the effects of compressed air on the organism in general and especially upon diseased organs of respiration. New York Med. Gaz., February, 1871.

G. v. Liebig, Die Wirkung der crhörten Luftdrucks der pneumatischen Kammen auf de,

Menschen. Deutsche Klinik, 1872, No, 21 and 22.

Id., Ueber Blutcirculation in den Lungen und ihre Bezichungen zum Luftdruck. Arch. $f$.

klin. Med., June, 1872.

Runge, Zur Theorie der Wirkung der comprimirten Luft auf den Organismus. Wien. allg.

med. Zeit.; Vienna, 1868, Nos. 12 and 13.

Pundschu. Ueber den pnuematisch. Apparat als Kurmittel für Brustkranke. Vienna Medical

Press. Nos, 48 and 49 . Vienna, 1868.

Franchet, Du bain d'air comprimé. Thèses de Paris, 1875

Féréol, Applications thérapeutiques de l'air comprimé. Gaz. méd., 1875, p. 258.

Tractatus physico-medicus de atmosphera et acre atmospherico. Cologne, 1816.

3 Loc. cit. Arch. gén. de Méd.; Second series, Vol. IX. p. $15 \bar{i}-1721835$.

${ }^{4}$ Recherches sur les effets des zariaitons dans la pression atmospherique à la surface du corps. Cpt. R. Acad. des Sciences, Vol. VI, p. 896; 1838.

5 Sur l'action thérapeutique de l'air comprimé. Cpt. R. Acad. des Sc., Vol. XI, D. 26; 1840

6 See list of works on therapeutic use of compressed air in Note 1.

7 Essai sur l'emploi médical de l'air comprimé. Lyon-Paris, 1850.

8 De l'air comprimé comme agent thérafentique. Lyons, 1855 .

- Om verhningarne af färtatad luft pae den menskliga organismen, $i$ fysiologiskt och terapeutiskt hänseende. Medicinskt Archiv utgizet of Lärare vid Carolinska Institut et in Stockholm. Vol. I, Chap. I; p. 1-205; 1862. Since I was unable to procure the original memoir, I quote from the extensive analysis of it given by Von der Busch in Schmidt's Jahrbucher der Gesamm. ten Medicin, Vol. CXX, p. 172-180; 1863.

${ }_{10}$ Die comprimirte Luft als Heilmittel. Aerstl, Intell. B1. 18, 19. Extract in Canstatt's Jahr.,

1863; Vol. V, p. 135.

11 Uéber den Einfluss der veränderten Luftdruckes auf den menschlichen Organismus. Virchow's Archiv für pathol. Anat. und Physiol. und Klin. Medicin, Vol. XIX, Berlin, 1860, p. 492-521.

b. Ueber die therap. Anwendung der verdichteten Luft, und die Errichtung eines Luft Compressions Apparates in Wien. Wochenblatt der Zeits. der K. K. Gesellschaft der Acrite $z u$ Wien. Numbers of July 9,16 , and 23,1862

c. Licber die Aufstellung cines pneumatischen Apparates in Wien. Allgemeine Wiener Medic Zeit. Numbers of February 13 and $10,1863$.

d. Ueber der Einfluss der verstärkten und verminderten Luftdruckes auf der Mechanișmus und Chemismus der Respiration. Medic Jahrb, der Zeitsch, der $K . K$. Gesellschaft der Acrzte $z u$ Wien. May, 1865. Translated in part by Thierry-Mieg; Gaz. Med de Paris, 1868.

e. Ueber die Zunahme der Lungen capacität bei therapencischer Anwendung der verdichteten Luft. Virchow's Archiv. Vol. XXXIII: Berlin, 1865, p. 126-144.

$\mathrm{f}$ Ueber die Veränderungen im arteriellen Stromgebicte unter den Einfluss der verstärkten Luftdruckes. Virchow's Archiv. Vol. XXXIV; Berlin, 1865; p. 315-391. Translated by Lorain: Le Pouls, Paris, 1870.

g. Ueber die Veränderungn der Körperwärme unter den Einfluss der verstarkten Luft. druckes. Medicinische Jahrb. der Zeitsch. der K. K. Gesellsch. der Aerzte zu Wien. February. 1866.

h. Ueber Luftdruckcuren. Der Cursalon. Vienna, 1867, Nos, 6 and 7.

i. Beiträge zur pneumatischen Respirationstherapie; Allgem. Wien. med. Zeitung. Vienna, 1868.

12 Zur Kenntniss der physiblogischen Wirkungen und der therapeutischen Anwendung der verdichteten Luft. Erlangen, 1868; octavo of XII-626 pages.

${ }_{13}$ Erfahrungen iiber Auzendung der comprimirten Luft. Wiener Med. Press, 1866.

$14 \mathrm{Zur}$ Theorie der Lebenserscheinungen in comprimirten Luft. Stuttgart, 1866.

15 Panum's memoir appeared first in Danish, in 1866. I quote from the German translation published by the author himself: Untersuchungen über die pliysiologischen Wirkungen der comprimirten Luft. Pfluger's Archiv f. Physiologie; Vol. I, p. 125-165, 1868.

${ }_{16}$ Ueber das Athmen unter erhöhten Luftdruck. Zcitschrift $f$. Biologie; Vol. V, D. 1-27.

Munich, 1869

${ }_{17}$ Bericht uber eine Versuchs-Sitzung in comprimirten Luft. Petersburgh med. Zeitsch.,

XII, extract in Gurlt's und Hirsch's Jahr. 1870, Vol. I, p. 210.

13 Beiträge sur Erkenntniss der physiologischen und therapeutischen Wirkungen der

Bäder in comprimirten Luft. Berliner Klinische Wochenschrift, 1871, p. 249-251. 


\section{Chapter III \\ THEORETICAL EXPLANATIONS AND EXPERIMENTS}

Even if the experiments and the theories which we reviewed in speaking of the effect of diminished pressure were numerous, varied, contradictory, sometimes strange and almost incomprehensible, at least their purpose was to answer a single question: What is the cause of the symptoms of decompression? It is otherwise with those which we shall summarize in the present chapter, and their discussion will necessarily betray the confusion into which those who expressed them have fallen.

The data which we have hitherto reported show that in truth the phenomena displayed by persons subjected to the effect of compressed air are extremely varied and appear under conditions which can hardly be compared, perhaps are absolutely unlike. In fact, we must take account, at least when the compression has risen to a certain degree, not only of the phase of compression but also of that of decompression, the dangerous effects of which were soon shown by observations made by the workmen themselves. It was these effects which first attracted attention by their strangeness and their severity. The changes which the compressed air itself causes in the different physiological functions are not very great, within the limits hitherto observed, and to verify them attentive and sustained observation was required, aided by the instrumental resources used today by physiology and pathology. Some physicians have distinguished between the two classes of phenomena, and have tried to explain them by different reasons; but others have confused them in common theories, so that it would not be possible to subdivide this chapter, as personally we should like to do.

Let us add that laboratory experiments on animals have been 
much rarer than for decreased pressure. The reason is not hard to find; on the one hand, the problem seemed much less interesting, since it was not connected with questions of temporary or permanent habitat for man; on the other hand, the necessary instrumental apparatus is more complicated and more expensive, and the experiments entail some dangers.

The first author in whom I found theoretical suggestions about the manner in which compressed air should act on living beings is the physician-mathematician Borelli, who, in his celebrated treatise De motu Animalium, ${ }^{1}$ sets down the following proposition:

Prop. CXXV. Probable causes of the suffocation produced in different ways in air which is thick and too much condensed.

Following the knowledge of his time, Borelli here confuses the effect of compressed air with that of air laden with "ethereal, earthy, aqueous, oily, igneous, saline, etc., particles, as happens in the vapor of coal .... and in the cavern of Lake Agnanus Puteolis." ... However, he devotes a special section to the effect of "pure air, brought to the highest degree of compression, ut in folle lusorio sit;"

I will not deny (he says) that it might be dangerous to breathe, because the extremities near the bronchial tubes and the delicate Malpighian vesicles might be distended and torn by the excessive elasticity, from which dangerous disturbances might result. Moreover, the passage and circulation of the blood would be prevented by it, because the expiration could be made only with great difficulty because of the excessive resistance of the ambient air. (P. 246.)

Borelli made no experiments.

It is in the notes which van Musschenbroeck added to the translation of the Memoirs of the Academy del Cimento ${ }^{2}$ that we find the first indication of experiments made on animals subjected to the action of compressed air:

I shall first report (the Dutch physicist says) what happened to animals placed in air much denser than it is at about sea level. M. Stairs shut up a rat in air twice as dense; it lived for five hours; however, after five more hours, it died. But when he had put another rat in air much denser, he observed that it died suddenly. He reports that a fly, in compressed air which made the mercury rise sixty inches above its usual height, was in good condition the third day, and even flew about; but its other companions died.

M. Derham placed a sparrow in a receiver, in which he compressed the air; because it did not hold the air tightly, he repeated the compression from time to time; the sparrow lived for three hours; then, when set at liberty, it seemed to have suffered no harm. Next he put in a titmouse and a sparrow, he compressed the air twice as much; after an hour these birds were as well as when they were put in; then 
they began to pine, in two hours more they were sick, and three hours afterwards they died.

I also placed a duck in a receiver, in which I made the air three times denser than that of the atmosphere; however it remained gay for an hour, and seemed to have suffered no inconvenience.

I next shut in three perches and a trout with a great quantity of water together with some living earthworms; I made the air in the receiver three times denser; prolonging the experiment for six hours I observed the following things: the first hour all the little fishes swam very well, often took new air at the surface of the water, and yet did not eat any worms; after an hour, the trout seemed less lively, and was more quiet; half an hour afterwards it shook its fins, yet its back was turned upwards as in the natural state; the perches during this time were swimming gayly; five hours afterwards, the trout, still having its back turned upward and resting freeîy in the water, had died; one perch became more quiet; after the sixth hour, it also was near death, but was lying on the bottom with its back turned upward; then after I had opened the vessel and let the air out, the two perches were alive and very gay; but the two dead fish were floating lying on their backs; the worms all this time had lived under water, and being taken from it, they were quite sickly. This experiment was made November $10,1730$.

\section{I call attention to the interesting conclusions which Musschen-} broeck draws from the experiments which he has just reported:

It follows from these experiments that animals can live longer in compressed air than in natural air without its being renewed; for although the enclosed animals consume a little air, a portion of its elasticity is lessened; nevertheless, in compressed air there is enough air left, and the elasticity is great enough: so that in the inspiration the vesicles of the lungs expand well and easily, and the blood circulates very freely in the arteries and the veins of the lungs. However, animals finally die in this compressed air; but what is the cause of that? It is not the lack of air, it is not the loss of its elasticity; for the mercury shows by the index that there is still enough of it left. But they die because the exhalations from the body of the animal are harmful to its lungs, or to its life, or because something is consumed out of the air which is necessary to the maintenance of life, and which must be constantly mingled with the blood. This last idea, however, can hardly be well founded, because the celebrated $\mathbf{M}$. Boerhave has proved by irrefutable arguments that no air inspired into the lungs can pass from the vesicles into the blood vessels: that is why we must conclude that the particles which we exhale are harmful to us, and that those which issue from other animals are also harmful to them and act like a poison; and so we understand why divers shut up in a bell, a cask, or other vessel must always be refreshed with new air so that they may breathe comfortably; and why miners who work in deep mines are very uneasy if new air is not constantly sent them in the mines by means of blowers or some other ventilators. (P. 58.) 
Haller ${ }^{3}$ gave space in his physiology to experimental data and those already revealed by observation of diving bells; he explains them in the following manner:

If the air is much denser . . . . the blood, which flows in vessels which are themselves more compressed, undergoes more friction there; this air will inflate the lungs better, and will bring to the left heart the stimulus which will make it contract better ....

A condensed air is useful and increases the energies of the body. Animals have lived without discomfort in air reduced to a quarter and an eighth of its volume. Under the diving bell, in a denser air, one can live, and a slower respiration is sufficient. A rat lived longer in compressed air than in ordinary air....

Yet there are limits beyond which compressed air is harmful. That happens in the diving bell; in which, when the depth increases, the water enters and compresses the air again. Then respiration is hampered, the belly is compressed, the air enters the auditory meatus painfully, the arms are bound as if with a rope, the membrana tympani is sometimes broken, and blood issues from the ears and the nostrils; finally the heart experiences such resistances that the flow of the blood is almost checked, and some have died thus. A rat died in air reduced to a twentieth of its volume. (P. 194.)

Experiments similar to those of Stairs, Derham and Musschenbroeck were made at the beginning of this century by Achard, ${ }^{4}$ who reports them in the following words:

I have made some experiments on the germination of seeds in compressed air. The result is that the more compressed the air is, the more quickly do the seeds germinate; the difference is considerable. At the same time I made experiments on the length of life of animals in air condensed to different degrees, and I found that in air three times as dense as the atmosphere an animal lives, under circumstances otherwise similar, and in equal volumes of air, five times longer than in atmospheric air. It should be noted that when the air is suddenly compressed to a density about triple, the animal falls into a state of inactivity and lethargic sleep, which apparently is a consequence of the pressure exerted on the brain. After this state has lasted a longer or shorter time, the animal regains its natural activity, and then falls into a state of great uneasiness which increases gradually until death. It is also noteworthy that the animal economy feels no ill effect from this state of compression; I have kept birds for an hour in air reduced to one fourth of its volume, and then returned them to the open air; they were in very good condition and showed no sign of inconvenience. (P. 223.)

Brizé-Fradin, after writing the history of diving apparatuses, as we have seen, and after reporting the sensations experienced there, tries to explain these phenomena, and to form a clear idea of the situation in which the man breathing in compressed air is 
placed, from the physical and physiological points of view. The passage below is truly very interesting:

The diver is placed in a medium which compresses the whole system.

How does he get into equilibrium with these combined powers? How can he surmount them?

The logical solution is found in the characteristics and the properties of the vital force. It is necessary to consider in man what forms the essence of life, that is, this energy which often modifies the laws of nature, and reduces them to what they should be to constitute life; it is the primordial law of the action, the conservation and the harmony of organized beings.

Analysis does not permit us to resolve into its elements the nature of this vital force attributed to a subtle, invisible spirit; but it is enough that its existence should be proved by its properties, its constant relationships. (P. 176.)

To do justice to Brizé-Fradin we must say that he is not satisfied with this vague declaration, and that, not content with metaphysics, he tries to determine the effects of this vital force upon the diver:

The denser air, enclosed in the bell, brings to the lungs a greater quantity of oxygen; immediately a greater quantity of heat is produced there: this air, endowed with elastic force, rushes into the lungs; the respiratory organ, the walls of which touch the pleura on all sides, gains a greater capacity; the gas opens the angles which the vessels form there and makes the passage of the blood through them freer and easier; it increases the speed of the circulation, and multiplies in the fibers of the muscles these inner frictions which are powerful causes of heat. The levators and the intercostals contract quickly; the ribs rise; the diaphragm falls; not only is the equilibrium destroyed, but the elastic power of the air is repelled by this inner energy which raises the muscular contractility to the highest degree, and which follows the effects of the caloricity.

We know that the pressure of the air upon a surface is equal to a column of water thirty-one feet high; it has been calculated that the effect of the pressure, in a man of average height, is equal to a weight of 36,000 ; but this weight is counterbalanced by the vital force and by the reaction of the elastic fluids which are part of our organism. Since the variations of the atmosphere are successive, they affect us in a hardly perceptible way; but if a sudden change occurs, the rupture of equilibrium has a very marked effect upon the animal economy; if a man mounts to great heights, he experiences discomfort, fatigue, drowsiness: so if we wish to account for the difference between the effects of the weight of water and those of the elastic force of the compressed air at a depth of sixty feet, we must again resort to this force whose principle is unknown, but which changes and molifies the general laws, and puts into the class of demonstrated truths that which at first glance seemed hard to explain. (P. 177.) 
We see that his physiological attempt has been unsuccessful and that he must return to explain, not the symptoms, but the resistance of the diver to "this force whose principle is unknown, but which changes the general law." It was really useless then to take so much trouble to try to apply these laws.

Further on, mentioning the two principal inconveniences of the diving bell, the pains in the ears and the confinement of the air, Brizé-Fradin proposes as remedies:

1. To put cotton in the auditory canal, to imitate "the Creator, omniscient in his works, who distributed in the organ of hearing this cerumen which ... assists the harmony of the sound waves" (p. 131);

2. To bring oxygen into the bell by means of a force-pump "when the sea has been drained out of the bell by these airdrums"; but he recommends "that only exact quantities should be introduced, which should never exceed a tenth of the quantity of vital air .... for an excess would produce a harmful sensitivity and disturbance" (p. 183).

I mention only for the sake of the record the passage in which Hallé and Nysten ${ }^{5}$ speak of the effect of compressed air; in fact, they merely say:

In deep mines, the effects resulting from the compression of the air would be more wholesome than harmful, because of the increased quantity of air in the same volume. They would make respiration less frequent, because each inspiration would take effect upon a greater mass of this fluid.

The increase in the weight of the atmosphere should, it seems, produce less perceptible effects than its decrease, and the pressure which tends to compress all its parts seems less harmful to our organism than their excessive expansion.

For the same reason I report the opinion of Jaeger, ${ }^{6}$ who does not seem to base it on any direct observation:

Air compressed to a very high degree may cause sudden death, because it produces apoplexy with hemorrhage and prevents the return of the blood to the upper parts and the heart. (P. 97.)

The experiments of Poiseuille ${ }^{7}$ are much more important.

In the course of his researches, so conspicuous for the scientific spirit and the accuracy which he manifests in them, this author asks himself whether variations in pressure have an effect upon the circulation of the blood. To settle this important question, he uses a pneumatic object-holder composed of an unyielding box, 
furnished with glass plates, in which the pressure can be increased or diminished:

The animal prepared so that the capillary circulation can be seen is placed in the instrument, and the apparatus itself is placed under the object-glass of the microscope; then one can observe the changes which a greater or less ambient pressure can cause in the capillary circulation. In salamanders, frogs, their tadpoles, very young rats, and young mice, the arterial, capillary, and venous circulations showed no change when enduring pressure, even sudden pressure, at $2,3,4,6$, and 8 atmospheres, and conversely. Moreover, the circulation continued to go on with the same rhythm under a pressure of several centimeters of mercury in salamanders, frogs, and their tadpoles. Upon placing in the apparatus very young rats and very young mice (we know that mammals, during the first days of their lives, can remain a few hours without breathing), we could see by the perfect soundness of circulation in these animals then placed in a vacuum, how unfounded was the opinion of the physiologists who think that without atmospheric pressure circulation is not possible; but the atmospheric pressure and the respiratory movements in conjunction are the accessory causes of the flow of the blood, as M. Poiseuille demonstrated in one of his preceding memoirs.

Poiseuille, we see, considers at the time the effect of the increase and that of the decrease of pressure upon the rapidity of the circulation; he states that they are non-existent.

The explanations of M. Maissiat ${ }^{8}$ also tend to consider the two questions simultaneously. We saw, in Title I (page 234), that he thinks that the principal factor is the intestinal gases, the volume of which must change with the pressure of the air. After considering their expansion as speeding up circulation and respiration, and as forcing the blood to the skin, he adds:

Opposite effects and a return of the blood towards the vessels in deeper positions will be caused, if, on the contrary, the outer pressure on the animal increases; the effect will be medically sedative, soothing both the respiration and the circulation. (P. 254.)

A few years later, Hervier and St.-Lager, ${ }^{9}$ at the suggestion of Pravaz, made the first experiments attempted with the purpose of finding out whether the organic combustions are expedited during the stay in compressed air.

The authors reach the singular result formulated in the following conclusion, a result which they do not support by any figures; the method by which it is obtained and which gives not the quantity of carbonic acid exhaled, but only its proportion in the air expired, is, I must say, very faulty: ${ }^{10}$

The quantities of carbonic acid exhaled in compressed air rise 
above the proportions of the normal state up to the pressure of 773 thousandths; above this figure, the lungs exhale less carbonic acid than before.

And here is the rather vague explanation which they give for this contradiction:

At a low pressure, since the chemical effect dominates the mechanical influence, endosmosis finds in the conditions of pressure a circumstance favorable to the development of the respiratory functions without exosmosis being hampered by too strong a pressure .... and therefore a growing increase in the exhalation of carbonic acid follows. At a higher pressure the mechanical effect neutralizes and destroys the chemical influence, to the point of preventing gaseous exosmosis in the compressed air, without hindering the absorption of gases, however.

It is this storing of carbonic acid by the blood, under the influence of the compressed air, which would explain, according to our authors, how:

The baths of compressed air increase the exhalation of carbonic acid outside the bath; this effect, which persists for several hours after the treatment, is more perceptible two or three hours afterwards than immediately after the bath.

This would be owing to the fact that:

The abnormal expansion of the pulmonary vesicles, as an effect of a sufficiently strong pressure in compressed air, lessens the energy and elasticity of the respiratory organs .... whereas, when after the bath the mechanical influence suspends its action, the energy of the lungs soon returns to its normal state, and by means of the gaseous exosmosis which is no longer hampered, casts off in the form of carbonic acid all the oxygen which it had absorbed in the bath under the influence of endosmosis.

Pravaz, ${ }^{11}$ from whose book we have already quoted (page 415), after listing the favorable changes which the stay in compressed air brings to the exercise of several important physiological functions, finds that these considerable advantages have three causes of different types:

A. The amplitude of the inspirations is increased for two reasons:

1. If it is certain that, under the ordinary conditions of life, the inspiration is far from having the extent which the anatomical position of the thoracic walls would permit, we cannot doubt that in a great number of persons, and particularly in those who, because they lead a sedentary life, need only a moderate encounter with the atmosphere for the purpose of hematosis, the retractility of tissue has 
considerably reduced the maximum capacity which the lungs can attain under ordinary pressure, and consequently the usual expansion of the pectoral cavity; then is it not manifest that in increasing this pressure and thus raising to greater power the energy which struggles against the reaction of the lungs, we should extend the upper limit of its own development and consequently that of the expansion of the thoracic framework under the effort of the inspirator muscles, an effort which promptly loses its power when the tendency towards a vacuum, which takes place between the two pleura during the inspiration, passes a certain limit?

2. Since the increase of the atmospheric pressure has the effect of compressing the abdomen, of increasing the elasticity of the intestinal gases and consequently their reaction against the effort of the diaphragm, this muscle meets a more stable point of support and changes the usual mode of respiration, forcing the ribs and the sternum to take a greater part in the mechanism of this function. In fact, the expansion of the thoracic cavity vertically is thus diminished; but this reduction is more than compensated for by the expansion of the chest, following its antero-posterior and lateral diameters, and, far from being lessened, the volume of air admitted by each inspiration is increased. In fact, in the mode of respiration which takes place principally by the descent of the diaphragm, the capacity of the chest increases only according to the simple proportion of the successive vertical diameters, measured laterally, for the middle part of the diaphragm remains almost stationary; whereas in the costo-sternal respiration, the enlargement of this cavity takes place in the compound proportion of the product of the original horizontal diameters to the product of the same diameters expanded. (P. 11-12.)

B. Hematosis is expedited:

Is it, as is generally thought, because the compressed air contains in a given volume a greater absolute quantity of oxygen that it expedites and improves the oxygenation of blood? (P. 21.)

Pravaz then compares the recent experiments of MM. Regnault and Reiset with the former statements of Allen and Peppys, and he adds:

If, between these contradictory statements, one leaned towards the former, as guaranteed by experimenters with the reputation of greater exactness, one would not be puzzled for an explanation of how compressed air can give other results than pure oxygen, or oxygen merely offered in greater quantity for pulmonary absorption.

In fact, Lavoisier and MM. Regnault and Reiset collected their observations at ordinary pressure; now we know, on the authority of M. Biot, that the quantity in weight of gases dissolved in a liquid increases proportionately to the pressure which these gases support.

There is therefore in the action of compressed air on the organism an element other than the multiplication of the molecules of oxygen in a given volume; this element is a mechanical force greater than that which acts upon the gases under experimentation at the ordinary 
pressure of 0.76 meters; this difference between the conditions of absorption makes us anticipate a corresponding difference between the results given by an inspiration of pure oxygen and one of merely compressed air. (P. 23.)

Experimentation, according to him, confirms this idea of the theory. This experiment is the one of Hervier and St.-Lager (page 446), whose conclusions Pravaz accepts, and whose apparent contradictions he explains as follows:

The endosmosis of oxygen, which is the principal duty of respiration, is aided by all circumstances which increase the solubility of this gas in the blood; now the increase of atmospheric pressure is evidently included in these circumstances, according to the experiment reported by M. Biot; so in compressed air there must be a supersaturation of the venous blood by oxygen, but this phenomenon cannot manifest itself immediately by a greater exhalation of carbonic acid, for the exosmosis of this gas is kept down by the same mechanical force which increases the absorption of oxygen.

When the respiration is once more taking place in normal atmosphere, the superoxidation of the blood corpuscles which was produced during the compressed air bath necessarily gives rise to symptoms of vital exaltation and to the elimination in greater quantity of the gaseous product of the combustion of carbon, which has become more active because this gas is no longer subjected to the increased pressure which restrained its expansibility ....

Analogy leads us to think that the same thing is true of nitrogen as of oxygen. Has its increased absorption some advantage for metabolism? I am inclined to think so, judging by the observations of Regnault and Reiset upon the absorption of nitrogen from the air by animals in a state of inanition ... so that this gas .... would seem to be intended .... to supply the place, in a certain degree, of alimentation by the digestive organs. If one admitted this very plausible hypothesis, he would have a new datum to explain the good effects obtained by the use of the compressed air bath in cases where there is weakness of the digestive functions through debility. (P. 28.)

C. Compressed air aids the return of the venous blood to the heart.

Pravaz states first that compression decreases the number of arterial pulsations: he has even seen it reduced $2 / 5$, "especially when a feverish state existed previously." Then he stresses the fact that the suction "exerted by the right auricle and the thoracic cavity" is one of the most active causes of the venous circulation, and he adds:

The capillary system, as a result of the increase of the barometric pressure, must empty into the veins more easily, for not only has the peripheral action of the force which compresses this network and the veins into which it empties become more energetic, but also the 
tendency towards a vacuum produced in the pericardium and the mediastinum during the inspiration, and intended to assist the concentric effort of impulsion towards the heart, must be more pronounced. (P. 52.)

The book of Pravaz ends with the discussion of the favorable effect of compressed air in the treatment of phthisis, rickets, chlorosis, anemia, deafness, chronic congestions of the nervous centers, and different neuroses.

In explaining the numerous successes which he lists in this connection, Pravaz gives especial emphasis to the effect of the chemical reason of the superoxygenation of the blood, and the greater activity thus imparted to the phenomena of metabolism. But he likewise refers to the mechanical action, the pressure of the compressed air. So, in speaking of the cure of coxalgia by the compressed air bath, he says, in a work preceding the one from which we have just quoted: ${ }^{12}$

In compressed air, one can carry out the indicated compression of the swelling of the hip in the most uniform and harmless manner, because not only the articular head but also the capsule, which projects abnormally out of its adherences, is pushed inward from without. This compression, the force of which upon the area corresponding to the cotyloid cavity can be reckoned as twenty kilograms per atmosphere, must cause the absorption, at least partial, of the liquids which have escaped, as we see in cases of dropsy and hydrocephalus, when a more or less tight bandage is placed around the abdomen or the skull. (P. 8.)

Further on, mentioning the case of a girl cured by compressed air of a wryneck "due to cephalic hyperemia," he declares that the freeing of the cerebrum is due to the mechanical pressure:

The vacuum which is caused in the jugular veins during the inspiration and which draws thither the blood from the head and the spine tends to be filled more rapidly in proportion to the strength of the outer pressure; and on the other hand, the increase of this pressure must provide a greater obstacle to the ebbing movement which the expiration causes in the afferent vessels; then we cannot be surprised that the capillary system of the brain and the spinal cord, in communication with the veins subjected to a sort of suction which has become more vigorous than in the normal state, can free itself of the excess of blood which choked it. (P. 13.)

Pol and Watelle ${ }^{13}$ are the first authors who have tried to explain the symptoms of decompression, the time of which they had also been the first to determine definitely. They are the ones who reported to us this characteristic saying of the workmen: "Pay only when leaving." 
Let us note, in passing, as a sort of curiosity, the idea suggested by these authors that "the unaccustomed density of the compressed air would hamper walking," and that the difficulty in talking in the cylinders, which they had observed, would also result from "this unexpected resistance to muscular contractions instinctively gauged by habit." (P. 250.)

Now comes the explanation of the symptoms produced by decompression. The physicians of Douchy attempt, according to their expression, "to discover the meaning of the symptoms observed, and to determine, by interpreting them, the nosologic individuality which they characterize." Now they say:

This task is easy to accomplish, or rather it is already accomplished.

In fact, if we except the muscular pains, at least in the cases in which, being isolated, and unaccompanied by any indication of a disturbance of the nervous centers, they were probably produced by the impression upon the capillaries of this system of a blood with an excessive oxygen content;

If we also except the gastric symptoms, which have sometimes seemed purely sympathetic, and sometimes, in our opinion, have been caused by the very copious ingestion of the products of combustion, it seems very clear that they have always been above all the expression of a state of congestion of the brain and the lungs.

We shall not strive to demonstrate, with symptoms at hand, this proposition in regard to which the autopsy of Héraut admits no doubt, and which will gain an over-abundance of evidence from the results of a second autopsy.

Pulmonary and cerebral congestion is therefore the principal result of the compression of the air; it is its most important morbid result, the source from which the fundamental therapeutic indications are derived.

We purposely omit mention of the congestions of the liver, the spleen, and the kidneys, noted in the autopsy reported above, and which will be repeated in the following one; they were not revealed by symptoms, except that of the kidneys which caused excessive secretion. (P. 259.)

So the serious symptoms experienced by workmen are the consequence of visceral congestions. But what can be the cause of these congestions? The compression, they reply, as an agent of the mechanical class; at least, that is what is clearly expressed by the following passage:

Since, when the atmospheric pressure is much decreased, the blood flows towards the exterior and escapes from the capillaries, there should result from the compression of the air visceral congestions, deep hyperemias. For contrary influences, opposite effects: contraria contrariis. 
Thence comes this conclusion, as yet wholly theoretical, that if a constantly increasing pressure were exerted, we should see occurring to a degree at present indeterminable intra-organic hemorrhages, apoplexies, instead of the peripheral hemorrhages caused by the rarity of the air. (P. 272.)

But if it is the compression itself which causes the congestions, why is it that they display their dangerous effect only at the time of the decompression? Here is the odd reply made by the two physicians to this objection which might seem unanswerable:

Rasori thought that congestions are invariably venous, and that is beyond doubt when they are caused by an obstacle to the return of the blood. But is this also true when they are the result of an arterial afflux; would the circulatory stoppage which constitutes them be located exclusively in the venous capillaries then also; in a word, would the dark blood be the agent of the congestions under all circumstances, as the Italian physician thinks?

The observations of M. Andral do not contradict this opinion; on the contrary, they justify it, since the consequence is that the congested tissues, red in the first phase, which according to M. Dubois of Amiens is only an inflammatory stage preceding congestion, are brown in the second phase and black in the third.

Now let us admit by hypothesis that their harmful effect is due rather to the narcotic effect of the dark blood than to the compression resulting from an exaggerated supply, and it will follow that if the inspiration of an excess of oxygen should arterialize the venous blood, congestions, depending upon the quantum, should lose all or part of their harmful power.

Well, that is exactly what happened in our miners; on the one hand, congestion without any symptoms; on the other hand, brignt red venous blood.

And as a counter-test, when the agent of the redness was removed and its action destroyed or lessened to a certain degree, which took a variable time, serious symptoms occurred which might be fulminant.

So the congestions which result from the compression of the air do not reveal their existence as long as this compression is exerted. The compression consequently has its corrective within it.

The decompression in a way reveals the congestions; it lets them exert their full and complete effect; we might say that it makes them effective instead of latent and potential.

From that, we imagine that it must appear more dangerous in proportion to its speed, and that to make it harmless, probably one would need only to make it very slow, much slower than it has been at Louches most of the time. (P. 260.)

So the physicians of Douchy give to the superoxygenation of the blood a rôle which is surely strange, but very important. It is interesting to see, however, how vague an idea they had of the conditions which in compressed air cause this superoxygenation. 
In fact, speaking of the inspirations of oxygen which had formerly been attempted, they protest against any comparison between the use of this gas and that of compressed air:

Certainly it is a very different thing to breath pure oxygen, or even oxygenated air, and to breathe air which is merely compressed, without any quantitative modification of its elements, air in which the oxygen is still diluted with nitrogen in the natural proportions. (P. 269.)

The lengthy note which A. Guerard ${ }^{14}$ placed after the important memoir of Pol and Watelle in the Annales d'Hygiéne is only a compilation. It contains nothing new, either from the point of view of phenomena observed or from the point of view of physiological explanations. Only its author stresses, more than anyone had done up to that time, the enormous changes which the increase of pressure made in the weight supported by the body. He drew up a detailed table of them, from which, as a curiosity, we extract the following figures:

At 1 atmosphere the weight supported varies from 15,500 to $20,600 \mathrm{~kg}$. At $1 \frac{1 / 2}{2}$ atmosphere the weight supported varies from 23,250 to $30,400 \mathrm{~kg}$. At 2 atmospheres the weight supported varies from 31,000 to $41,200 \mathrm{~kg}$. At 3 atmosphere the weight supported varies from 46,500 to $60,800 \mathrm{~kg}$. At 4 atmospheres the weight supported varies from 62,000 to $82,400 \mathrm{~kg}$. At 5 atmospheres the weight supported varies from 77,500 to $103,000 \mathrm{~kg}$. At 6 atmosphere the weight supported varies from 93,000 to $123,600 \mathrm{~kg}$.

And he assumed that there were terrible extra weights, since at 5 atmospheres they would vary from 77,500 to 100,000 kilograms!

Guérard supposes besides that, under the influence of the pressure, the oxygen and the nitrogen are dissolved in the blood in greater quantity, and that the result is an increase of interstitial combustions, and consequent emaciation.

As to the muscular pains, he considers them as being of a rheumatic nature, and due to the chill which accompanies the decompression.

Then, admitting as general the greater facility of movement which Pol and Mathieu had thought they noted in some of the workmen in compressed air, he says:

It might be that the influence exerted on walking by the atmospheric pressure would be magnified by the increase of this pressure.

For the rest, he accepts the conclusions of $\mathrm{Pol}$ and Watelle and those of Pravaz.

With Dr. Milliet, ${ }^{15}$ we return to observations of a purely medical nature. In the opinion of this physician, the action of compressed 
air is exclusively physical; he protests against the idea of a chemical change in the respiratory acts; but, aside from this protest, he furnishes no clear idea:

When the organs of respiration are plunged, so to speak, into a more condensed atmosphere, the lungs will find in the same volume a considerably greater quantity of atmospheric air; after that, they will come in contact, at every inspiration, with a larger mass of atmospheric air .... What will be the result of this addition? This single effect, a greater ease of operation. (P. 15.)

This reduction of rhythm in the operation of the respiratory movements is purely physical, and in spite of the generally accepted ideas, it is certain that no chemical modification, either an increase or a decrease, is produced in the process of the oxidation of the blood. The air has not been changed in its chemical composition, and the laws which govern our organism have not ceased in their natural action.

So, whether the atmospheric air is rarified or condensed, there is no modification in the chemical action of respiration; there is only a physical effect upon the performance of this function. But the situation is very different if you change the chemical proportions of the gases of the air.

One of the effects of the use of compressed air is the increase of the secretions and of absorption. The nervous activity in the excretory and absorbent organs has seemed to me to be derived from the venous circulation, which is always more ample and more complete while the body is being subjected to a higher pressure. (P. 16.)

In 1855, there appeared the first edition of the book which Eugène Bertin, ${ }^{116}$ who was using the apparatuses installed at Montpellier by Tabarié, devotes to the study of the therapeutic use of compressed air. This work, as its title indicates, is of particular interest to physicians. Moreover, the author declares in the beginning of his book "that he will not discuss physiological considerations." And so we shall not pause long over it.

However, he summarizes his opinions in the following words:

Compressed air, to whatever degree the compression is carried, can be sustained without danger because of the equilibrium of pressure which is established in all parts of the body, exactly as in ordinary atmosphere.

Experimentation demonstrates that at a pressure carried far beyond the degree needed to cause all therapeutic effects, no modifications in the phenomena of life occur which might interfere with their regularity.

It is logical to admit that since the decrease of pressure can delay the return of the venous blood to the heart and thus promote stases in the capillary system, an increase of pressure should, on the contrary, facilitate this return and dissipate these congestions.

Respiration which is carried on in compressed air, because it 
brings the blood in contact with a greater quantity of the two constituent elements of the air in the same volume, must of necessity decarbonize a greater quantity of blood than under ordinary conditions. For the same reason, the part which the nitrogen may play in the body should also be more completely filled. Every inspiration therefore should have a more extensive effect in compressed air than in ordinary atmosphere: hence the necessity of less frequent inspirations to satisfy the customary needs; hence a decrease, often very great, in the action of the pulmonary organs, and the source of a rest which is so useful and yet so hard to secure in any other way for organs whose action must be incessant.

Because of relations uniting respiration with the heart beats, the slackening of the former must cause a similar change in the circulation; many data, moreover, permit us to attribute to compressed air a direct sedative effect on the circulatory system; under this double action, the slowness of the pulse becomes a permanent condition, not only during the continued use of compressed air baths. but even a long time after their discontinuance....

At the same time, the appetite increases, the digestive functions go on regularly, and therefore good nutrition, the undoubted source of an increase in the general strength, is assured ....

The secretions show few signs of the effect of compressed air. I have noted a perceptible increase of the saliva while the baths were being given. (P. 60.)

In his second edition, published in 1868, Eug. Bertin reproduces purely and simply (p. 97) the summary which we have just quoted. Moreover, if- we exclude the medical observations, much more numerous than in the first edition, we find very few changes from the original text.

The most important addition is the criticism of the opinion of Vivenot about the slowing of the heart rate. Bertin first remarks that he has rarely observed this decrease in the apparatus; on the contrary, he noted it after the bath, almost always several hours after, or even the next morning before the patient had risen. Often it does not exist at all. Finally, it is not proportionate to the pressure, he says, for then it would be enormous in caisson workers.

We saw above that Hoppe, ${ }^{17}$ in a notable work on the causes of the death of animals killed suddenly by rarified air, had found in their blood vessels bubbles of free air, to which, in his opinion, the death was due. He did not fail to apply to the symptoms of sudden decompression the observation which he had made:

If, after an animal has remained for some time in compressed air, the pressure is suddenly lowered, the lungs will not have time to allow the gases which have been freed in the large veins to escape. That is why sudden deaths, without anatomical lesions, have occurred in the coal mines of France. (P. 72.) 
We should note that Hoppe never made direct experiments on this point, and that he reasons only by analogy.

As to the effect of the compression itself, he says merely:

The increase of the air pressure must increase the capacity of the blood to absorb gases; the blood will then contain more oxygen, from which will result a greater production of heat and a decrease of the quantity of air breathed in a given time. The observation of Pravaz of a lessened quantity of carbonic acid excreted in compressed air is explained by the small volume of air used in his experiments. (P. 71.)

Dr. François,$^{18}$ after the account which we have quoted of the symptoms appearing in the workmen at the bridge of Kehl, inquires into their cause. He first rejects the opinion of Guérard about rheumatism, and one of the reasons he gives is that "the muscular pains disappear spontaneously if the workmen go back into the compressed air." The explanation which he gives of these pains is very strange:

They are (he says) the evident result of introduction into the tissues of compressed air, forced in by the blowing machines, and this air blends with the cellular tissue in its innermost parts, as, for exexample, mercury blends with hog's lard after a careful trituration, so that not a molecule of metal is perceptible to the naked eye.

This air, thus accumulated beyond measure in our tissues, must seek to establish an equilibrium with the ambient atmosphere at the time of leaving the compressed air, and the more hasty is this departure from the air chamber, the less gradual it is and the less prolonged is the elimination, the more pronounced the pathological effects must be, for the reason mentioned above.

He explicitly rejects, as Pol and Watelle had done, any comparison between superoxygenated air and compressed air:

We cannot agree that these pains are produced by the presence of an air with a higher oxygen content, as has been suggested; in fact, every atmosphere of compressed air contains, with all its other elements, only the same proportion of oxygen that it contains on the outside: it is not an excess of oxygen that is forced into the caissons, but rather an excess of atmospheric air.

We are therefore inclined to admit that the muscular pains are the result of a constant effect exerted upon the tissues by an excess of atmospheric air, an irritation sometimes rising to the most acute pain, when this air seeks too suddenly to find an equilibrium with a less dense medium. (P. 309.)

So much for the muscular pains. As to symptoms affecting the respiration, these are pulmonary congestions, M. François says: 
Their method of production is easily ascertained; in fact, we know that the increase of the pulmonary capacity is very great under the influence of compressed air; that the cells of the respiratory organs are considerably distended: at the time of leaving the caissons and especially after a hasty and poorly managed decompression, a vacuum is too quickly made in the thoracic cavity, and this vacuum must necessarily be replaced by a speedy afflux of blood and the other liquids; hence these congestions; hence also this spitting of blood, as a result of the rupture of vessels in the pulmonary parenchyma.

Therefore one may understand that full-blooded, plethoric persons are more subject to these affections than persons with lymphatic or nervous temperament.

The cerebral symptoms, examples of which we have mentioned, are also in his opinion the result of congestions. And here, M. François tries to explain why they appear exactly at the time of decompression:

It is undeniable that these cerebral congestions, like those of the pulmonary tissue, do not result from the same causes as congestions attacking persons in the course of ordinary life, in which they are produced generally by a stasis of venous blood occasioned by an obstacle to the return of the blood; at other times, but less frequently, they are the result of a great arterial impulse; but then there always occurs a subsequent stasis which may become harmful when the congested blood changes from red to dark and becomes a depressant, that is, when it becomes less and less rich in oxygen.

Is the same thing true in congestions produced by compressed air? Evidently not, for here there is no congestion as long as the increased atmospheric pressure lasts; then when the workman leaves the increased pressure, the excess of air contained in his body seeks to establish an equilibrium with the outer air; this tendency operates immoderately, as would be expected; hence, a surge of blood, but a red blood, towards the nervous center, a surge which sometimes is overpowering, especially if the decompression has not been made gradually and carefully, but which up to the present has not produced any fatal case.

In all cases, when the patient was bled, the blood issued from the vein very red; no dark blood has been observed in bleeding. (P. 313.)

Finally paraplegias, retention of urine, etc., would be due to medullary congestions produced by a similar cause.

It is likewise, as we said, upon the workmen employed at the bridge of Kehl that M. Bucquoy ${ }^{19}$ made his observations. His work is extremely noteworthy, especially from the point of view of physiological explanations.

He first discusses the increase in the quantity of oxygen contained by the blood. But the hypothesis which might have ap- 
peared very simple to Pravaz becomes strangely complicated after the work of M. Fernet. (See page 249.) M. Bucquoy, who dwells at length on the difference established by this physicist between the oxygen chemically combined in the corpuscles and the oxygen dissolved in the serum, says also:

It is to the oxygen in simple solution that the changes in hematosis observed in compressed air are due.

In fact, the blood corpuscles in compressed air do not absorb a greater proportion of oxygen than in the open air, because this proportion has been shown to be independent of the pressure.

On the other hand, the expenditure of oxygen which the blood must make for the benefit of the respiratory combustions is as great in compressed air as in open air, because these combustions are no less active there than under ordinary atmospheric pressure.

If then, in compressed air, the blood corpuscles supplied alone and without compensation all the oxygen necessary for the combustions, they would lose, as at ordinary pressure, a quantity of oxygen sufficient to cause their arterial color to disappear, and when they left the general capillaries, they would have the color of venous blood. Now this is not the case; the corpuscles of venous blood are bright red in the man who is subjected to compressed air.

This fact, important from the physiological point of view, can be explained in only two ways:

Either the blood corpuscles supply for the respiratory combustions under compressed air too small a portion of oxygen for their red color to be perceptibly altered; in this case, the complement of oxygen necessary for the combustions is taken directly from the portion of this gas which is in simple solution in the serum, the quantity of which, however, increases with the pressure.

Or the corpuscles furnish all the oxygen necessary for the combustions; in this second case, we are obliged to admit that they take it from the serum as they lose it, since their color is hardly altered; this hypothesis is the more probable.

However it may be, the portion of oxygen dissolved in the serum plays directly or indirectly an important part in the phenomena of hematosis which go on under pressures greater than that of the atmosphere. It is this portion of oxygen which alone can explain the redness of the venous blood always found by MM. Pol and Watelle, and by M. François too. It is wrong, therefore, that this portion of oxygen absorbed should now be neglected and that variations in pressure should be considered immaterial in regard to hematosis. (P. 50.)

After this noteworthy page, I am sorry to find the adoption, timid, it is true, and full of reservations, of the unsound theory of the physical compression of the outer tissues, and of the consequent ebbing of the blood into the interior of the body. Here is the way, very original I admit, in which M. Bucquoy words it: 
The increase in pressure of the ambient medium produces its maximum effect upon the tissues of the periphery. These tissues become more compact, but they resist the outer pressure to a certain degree, and neutralize a fraction of it. The remaining pressure compresses the layers lying below the first ones, but it meets a new resistance from them which decreases its intensity still more, and so on. In proportion as one goes from the surface towards the central parts, the tissues are less and less compacted, and the pressures more and more weakened. But the blood contained in the superficial tissues transmits the outer pressure to the whole mass of the blood, in all directions, to all depths, and almost equally. Consequently, in all parts of the body, the blood exerts against the walls of its vessels, from within outwards, and tending to expand them, a pressure almost equal to the pressure it sustains from without.

To resist this expansion of the vessels, each tissue has its own resistance and the fraction of outer pressure which has penetrated as far as that through the more superficial layers. The result is that the different tissues resist this expansion of the vessels very unequally, and that the deeper the tissues lie the greater is the expansion, because the outer pressure transmitted to the tissues by the tissues decreases with the depth. Consequently: expansion of the vessels in the deep tissues, where the pressure coming from the exterior is weak; decrease of the diameter of the vessels in the superficial layers where the outer pressure is strong; all that in a suitable measure so that equilibrium may be established everywhere. At each new increase of pressure, a similar effect is produced; a new distribution of blood and a new equilibrium are established. The total effect is a greater mass of blood in the tissues and the deep-lying organs; in a word, the visceral congestions and the hyperemias, which all the authors mention, appear. (P. 52.)

But M. Bucquoy finds solid ground again when he speaks of the painful effects of decompression. He does not have much trouble in managing the theories of Pol and Watelle on the slow effects of superoxygenation of the blood, and of Guérard on the rheumatic nature of the pains. Considering the question as a physicist, he says:

If one enters compressed air, the oxygen, carbonic acid, and nitrogen, held in simple solution in the blood, must increase with the pressure; and if the compression has lasted long enough, Dalton's Law requires that the quantity of each of these gases absorbed by the blood should be proportional to its pressure in the compressed air which one is breathing. Under ordinary conditions, the carbonic acid and nitrogen of the blood are not drawn in with the air inspired; they are engendered by the physical phenomena of life. Because of their origin, these two gases no doubt do not follow Dalton's Law strictly, but their ponderable quantity in the blood necessarily varies in the direction indicated by this law.

That being granted, what must happen when one leaves the compressed air apparatus? 
During and after the decompression, all the gases dissolved in excess in the blood, because of the compression of the air, will tend to escape from the blood with a force the amount of which will be greater in proportion to the increase in the pressure undergone, the stay in compressed air being equal. That is a necessary result of the laws of physics dealing with the solution of gases in liquids, and we have a common and frequent example of it in the speed and force with which the carbonic acid escapes from a charged water when the cork is removed from the bottle containing it. (P. 58.) . . . .

The particles of gas which have regained the aeriform state all through the blood system remain mechanically blended with the liquid molecules which held them in solution before; it follows that the blood becomes an expansible mixture which constantly struggles to distend these vessels and to increase in volume. The ultimate result is a general and more or less important turgescence of the blood vessels and a more or less threatening imminence of hemorrhages. And as the gases dissolved in excess separate from the humors as they do from the blood, a general tendency to emphysema will result.

Let us now attribute to the expansive power of the liberated gases a sufficient intensity, and it does not need to be great, if it is favored by individual peculiarities, and then the threat of hemorrhage and the tendency to emphysema will become facts. We shall have all the cases of hemorrhage and emphysema observed in ascents of lofty mountains, or in balloon journeys, or in compressed air apparatuses. (P. 59.)

Supported by this excellent basis of reasoning, M. Bucquoy easily explains the emphysemas observed at Douchy, the hemorrhages, and the muscular and articular pains, in regard to which he quotes the following very interesting observation:

One day when I was observing a workman who was having severe pain in one knee, I saw the dry cupping-glasses placed around the articulation falling off one after the other, although they had been carefully applied by the orderly, a very skillful man. They were replaced several times and remained in place only a certain time; the patient was then considerably relieved. The elimination of the free gases explains both the falling of the first cupping-glasses and the prompt disappearance of the pain through their repeated application. (P. 62.)

M. Bucquoy finally with good reason advises the engineers to take all precautions necessary to make the decompression sufficiently slow.

We reported above (page 379) the story of the patient of M. Hermel, ${ }^{20}$ who was seized by paralysis when he was leaving the caissons of the bridge piers of the Scorff, near Lorient. The author attempted, when he summarized the preceding observations, to explain the symptoms noted; we shall see that he is not very successful in his attempts. 
He first dwells at great length on the confinement to which the laborers working in the caissons are subjected. The carbonic acid which is produced there must, in his opinion, play a great part, and recalling the tinglings and the burning of the skin described by Herpin (of Metz) he thinks:

That this phenomenon might very well be the cause of the burning and itching of which the workmen complain and which MM. Pol, Mathieu, and François have noted, which the workmen call their fleas.

Likewise, the effects of the bath of carbonic acid which accelerates the circulation may give us the reason for the divergence of opinions which we have reported between MM. Pol, Mathieu, and Blavier, on the one hand, (the first two having observed a slowing down of the circulation in compressed air, the third having noticed no difference in three persons) and on the other hand, M. François, who noted a constant acceleration of the circulation. (Vol. XVI, p. 445.)

As to the redness of the venous blood, observed by Pol and Watelle, he refuses to accept their shrewd explanation. He repeats with François that "it is not an excess of oxygen which is sent into the caissons but an excess of atmospheric air." He even goes further:

As we have proved, the oxygen of the caissons was considerably diminished by the respiratory absorption and combustion; since the carbonic acid is a hindrance to hematosis, how could the venous blood be oxygenated? We must seek some other reason for the redness of the blood. The conditions of the medium which we are discussing give reason to assume the formation of carbon monoxide, which would explain this phenomenon. (P. 447.)

This carbon monoxide would be produced, according to our homeopathist, by respiration in air with a low oxygen content.

Such is the cause of the symptoms attacking the workmen:

Since the authors saw these symptoms appear only after decompression, they have attributed them all to this transition.

He then reaches the study of decompression; and he compares what takes place in workmen with the effects of ascent into the lofty regions of the atmosphere. There is a great difference, however, he says, namely:

As it is the normal pressure of the air which keeps the fluids in the vessels, it is rare that the hemorrhages which are frequent in ascents appear when the men leave the caissons. (Vol. XVII, p. 37.)

Besides, the effects are more serious than those of ascent because the compression is greater, because the decompression is more rapid, because it acts upon men in a manifestly morbid condition, 
and because this sort of rarefaction takes place in a confined air mingled with harmful gases.

In regard to the muscular pains, he rejects the explanation of Pol and Watelle:

Because we did not find that the blood absorbed a greater proportion of oxygen than normally. (P. 112.)

But we admit with François that the compression of the air forces a certain quantity of air into the tissues. This fact is demonstrated by the cases of subcutaneous emphysema. (P. 114.)

As to the serious symptoms, they are, in the opinion of M. Hermel, pulmonary, medullary, and cerebral congestions, which he explains by the rebound produced by decompression; moreover:

The decompression in itself (he says) does not produce all the symptoms noted; the compression of the air in the caissons and the harmful environment have much to do with it. (P. 203.)

The work of M. Foley ${ }^{21}$ is certainly the most original from the standpoint of theory of all those we have already found and summarized. Reading it is very stimulating, though not very easy; in it, in fact, are found not only the account and the explanation of the symptoms which attack the workmen in caissons, but also the theory of the respiration of birds in the lofty regions of the air, the operation of the swimming bladder in fishes, etc. Setting aside these questions, which concern us only indirectly, we find M. Foley trying to cast light on the inner cause of the symptoms which he has observed by a study, which is hard to understand, of metabolism, hematosis, and the physiology of the three nervous systems by means of which "man (plant, animal and soul) governs his multiple being."

An example will indicate the nature of these considerations and their conclusions. The author remarks that engineers go a long time before feeling the ill effects of compressed air:

That is because (he says) usually the former (engineers) nourish their spinal cord and consequently stimulate their whole being with memories, retained sensations, and because after that, to crush their senses is to favor (so to speak) their ordinary mode of life.

On the other hand, the second (workmen), forced to live and work from day to day, to fashion and expend stimulation from hour to hour (because they have never had time to accustom the primary source of our organic activity to retained impressions), can nourish their spines only with the materials of atmospheric contacts, always real, always positive, always immediate: the very materials which the excessive pressure prevents them from collecting. (P. 24.) 
I confess that I think I must give up the task of summarizing in a definite and intelligible statement the theories of M. Foley. Here are a few quotations which I try to coordinate so as to cast a little light on these obscurities of thought and style:

As soon as the workmen are in the compressed air, their blood becomes superoxygenated and their circulation tends toward its minimum. At the same time, their nervous reserve, already so low, . . . . falls still more.

However they work, or in other words, their muscles and their different mechanical organs, while being nourished by the blood, require stimulation from the spinal cord and plastic energy from their controlling ganglia; from this triple compound of brain, spinal, and sympathetic pulp; from this triple mixture of coordinating, vegetative, and stimulating substances, the sympathetic chain first decides the course of the blood, then regularizes it, and finally transforms it into human flesh.

How do the mechanical and metabolic governors, thus questioned, reply to their subjects?

But the spinal cord which no longer produces enough stimulation refuses to give any, perhaps even demands to have some back from the ganglia or plexus of the sympathetic chain! In their turn then, they refuse to give any to their subjects, which nevertheless continue to work, become empty of blood, then deteriorate, and finally are unable to continue to operate. (P. 27.)

So much for the phenomena caused by compression; now let us turn to the decompression:

We shall have the inverse of what the compression caused. (P. 44.)

Little by little, the blunted senses of the caisson-worker revive; little by little they send to the spinal cord more complete sensations; little by little the apparatus of the spinal cord regains its power. Little by little, it sends to the parts of the sympathetic chain, upon which have been made such strong demands, the stimulation which they need for their own recovery; and little by little, but in the final step, these controlling nerves give the order which will send the restorative tide to the muscles or other exhausted organs.

Finally this command is dispatched. It leaves like a thunderbolt. But generally too obedient to the principle (the reaction must equal the action), it almost always causes an arterial congestion, the degree and speed of which are proportional to its delay. (P. 28) ...

In summary, for the caisson-worker who has returned to open air, we need to fear only too strong a nervoso-circulatory reaction, a shock to the circulation in this excessively violent change. (P. 45.)

That is what M. Foley calls by the name of "post-caisson congestion."

"Thus," still according to M. Foley, "we have all the necessary keys to the understanding of the different morbid phenomena which may arise when one has left compressed air." (P. 29.) 
Here, for example, is the key to the discharge of blood which occurs rather frequently from the nose or mouth:

The mucous membrane, almost bloodless as long as the compressed air acts upon it, fills with blood as soon as the tension ceases, ruptures if it is too thin .... then, momentarily surprised, it recovers its normal thickness after a few painful oscillations. (P. 30.)

And now for the sensations of heat in the skin, and for the "painful, burning, intolerable itching, which forces one to scratch himself with both hands with impatience, uneasiness, fury, or delirium, which the workmen call fleas":

As soon as one enters the caissons, he is flattened; the arteries diminish in caliber, and there is abundant perspiration. By all these effects our skin empties and withers.

As soon as one leaves, on the contrary, merely through the mechanical power of its elastic fibers, this envelope expands. Unfortunately the retractility of their yellow coats keeps our nutritive vessels at their minimum diameter. The result is that a sort of vacuum forms around them.

Matters being thus situated, when the reaction begins, or in other words, when the blood waves become strong again, our arteries, which previously were isolated, yield easily, regain their former diameter, and even increase it. At the same time, our innumerable cutaneous papillae are considerably swollen by a superoxygenated blood. Then within the thickness of the skin the nerve meshes which are interwoven with our nutritive vessels, suddenly tugged about inordinately, cause cruel and lacerating pains, whereas on the surface of the skin any contact causes both itching and burning. It is all these simultaneous pains that cause the "fleas." (P. 33.)

Finally, the symptoms which attack "the muscles, then their synovial auxiliaries, aponeurotic or articular," are explained in the same way; they are tumefactions, as we have already seen (page 377 ) :

Are these swellings of a gaseous, hemorrhagic, or rheumatic nature, as has been stated? No!

The recompression which always dispels them immediately, the absence of crepitation, of rale, of any coloration under the skin, and of peregrination, and finally the excessive richness of the blood, which excludes any idea of excess fibrin, or, in other words, of an inflammatory malady, do not allow us to doubt. These are simply arterial congestions without extravasation. (P. 35.)

M. Foley does not hesitate to predict the brightest future for treatment by compressed air:

Make (he says) a sedan chair closing hermetically . . . . Attach to it a safety valve, a blower, and a manometer: in a word, arrange 
everything so that in this little chamber the air pressure may reach 2.5 atmospheres, at the most.

And certainly you will possess a piece of furniture which will allow you to relieve many asthmatic old men, to save many children attacked by croup, and also to cure many adults afflicted with congestional, toxicohemic diseases. (P. 135.)

Without discussing the value of these hopes, we must call the attention of the "realizers," as M. Foley calls them, to the fact that the construction of the apparatuses is considerably more complicated and more expensive than he seems to think.

M. Caffe ${ }^{22}$ was commissioned by the Société Médicale d'Emulation to investigate the work of M. Foley. He took advantage of the opportunity to study the effect of compressed air in his turn.

He first accepts the ideas of Dr. François about the mechanical effect of compressed air and about the "amalgamating" of the air and the tissues; he summarizes them in the following words:

M. François attributes the muscular and arthritic pains to the penetration into the tissues of compressed air, which becomes a cause of irritation, designated as "caisson pain"; abscesses sometimes follow. An experiment seems to confirm the opinion of M. François; at the time when the caissons were being sunk, when the oak timbers, which had been subjected to the compressed air, were removed from within the caissons, these bearns, when plunged into water, gave off considerable quantities of air bubbles.

The danger of cerebral congestions is likewise referred to the exit from the lock-chamber; when the blood has been freed from the pressure of the compressed air, it tends to establish an equilibrium with the outer air; it therefore is urged towards the nervous centers, brain, and spinal cord; even the urinary bladder loses its contractility. (Page 2.)

Then after reporting the observations and theories of M. Foley, he declares himself a very ardent partisan of his "sedan chair," and cries out enthusiastically:

We shall then possess an ingenious apparatus which will become a valuable therapeutic resource for the solace and prolongation of the life of many catarrhal and asthmatic old men, and for relieving pains so hard to witness and to endure in adults afficted with angina pectoris, who turn blue and suffocate while seeking the air which eludes them.

Without any effort of the imagination, but proceeding with the logic of data and reasoning, we can picture the hope of saving from imminent death the victims of the last stages of croup. The compressed air will depress and flatten the false membranes, and will restore free passage of the air in the respiratory tracts. Cerebral congestions and predispositions to apoplexy will be warded off as long as the nerve influx controls the circulation; perhaps we may even hope that typhus, 
glanders, and all diseases of a blood-poisoning nature will be cured, or at least considerably shortened in their course and checked in their severity by respiration in compressed air, which arterializes and oxygenates the blood without any effort; experiments can easily be carried out on animals.

The venom of the viper, the virus of the rabies, of smallpox, etc. perhaps will be neutralized locally some day, since they will encounter in compressed air a very rich, essentially vital blood, which will consequently refuse to serve as a vehicle for the poison, and they will therefore be annihilated on the spot. What physician does not know that contagious or transmissible diseases become so only when they encounter persons who are predisposed, and who therefore form a suitable breeding-ground for them? (P. 7.)

The English authors, Babington and Cuthbert, ${ }^{23}$ who were witnesses of the accidents at the bridge of Londonderry, tried like all their predecessors to explain them. They too were surprised to see that these symptoms occur exclusively in the phase of decompression:

The idea of a dangerous element in compressed air must be abandoned, because the workmen felt no ill effects during the period in the cylinder, which lasted 3 or 4 hours. All cases of serious sickness occurred when an excess pressure was removed more or less rapidly. It seems reasonable, in the absence of any other cause, to suppose that the sudden transition from compressed air to open air occasions all these serious symptoms.

But why does this change attack the nervous system? The brain and the spinal cord, encased in their bony cavities, and having their vessels protected thereby, cannot yield to the atmospheric pressure as easily as the more elastic parts. So when the workman is under an excessive pressure, if this pressure is removed from the surface, the brain cannot adapt itself to this change as rapidly as the other organs; the excess pressure on the brain and the spinal cord must be removed through the narrow passages by which the blood leaves these organs. The bony channels in which the blood vessels lie make this escape more difficult, and the excess pressure presses upon the delicate nervous parts rupturing the little vessels, and producing the series of dangerous symptoms which we have reported. (P. 318.)

Dr. Sandahl ${ }^{24}$ is very definite in his explanations. In his opinion, the physiological modifications observed are principally the result of an increase in the quantity of oxygen contained in the blood. The mechanical effect of the compression is exerted only through the medium, so to speak, of the dissolved gases:

The greater oxygen content of the compressed air naturally acts more energetically upon diseased lungs than upon healthy lungs. Let us assume that a healthy man makes 20 inspirations per minute, eacn absorbing 30 cubic inches of air; if his lungs become diseased, and 
then inspire only 20 cubic inches, he will have to make 30 respirations per minute to bring the same quantity of oxygen into his body. If he is given air with a half-atmosphere of compression, his lungs will make only 20 respirations, because 20 cubic inches of this compressed air will be equivalent to 30 of ordinary air.

If the total mass of blood in a healthy man passes through the lungs in 4 minutes and absorbs a certain quantity of oxygen there, in case the lungs are shrunk by disease, it will have to pass through more quickly to absorb the same quantity of oxygen, and for this reason there is a necessary increase in the pulse rate. If compression has made the oxygen content of the air greater in the same volume, the blood will obtain more oxygen from it, and the circulation will not need to be so rapid ....

An essential action of compressed air is its effect upon the free gases contained in the blood. The presence of these gases permits the mass of the blood to be compressed by the air, so that the vessels contract. This effect at first must be produced particularly upon the vessels on the surface of the body. The capillaries of the skin and the lungs will therefore contract ....

The increased production of carbonic acid in compressed air needs to be demonstrated by new researches ....

Since the compression brings more oxygen into the blood, we might expect to see the temperature of the body rise. But that did not take place under observations made with the greatest care .... Moreover, the slackening of the respiration and the circulation should compensate for the greater quantity of oxygen contained in the blood.

A discussion of the perspiration, urine, and nutrition follows, from which no definite conclusion is drawn.

Tutschek ${ }^{25}$ makes a more concise statement of similar opinions. In his opinion, the action of compressed air has two factors:

The increased mechanical pressure, which modifies the fiow of the blood; the increased oxygen content of the blood, which exerts a great influence upon the metabolism.

We now come to the works of Rudolph von Vivenot. ${ }^{26}$ The part describing the changes in the respiratory rhythm as a result of the stay in compressed air has been reported in the preceding chapter. (See page 420.) As to the explanation of the increase in the pulmonary capacity, Vivenot finds it in the following theory:

Although the increased pressure is exerted equally over all parts of the surface of the body, the effect produced by this pressure is by no means equal everywhere, because of differences in texture, consistency, and position of the different organs.

The pulmonary tissue, which is delicate and elastic and yields easily, will resist the increased pressure less at the base of the lungs, where it rests only on the intestines, which are very compressible, than at the thoracic walls, which are formed of firmer and more com- 
pact tissues. That explains the increase in the vertical diameter of the lungs and their displacement downward.

The modifications which the action of compressed air can cause in the gaseous exchanges of respiration were studied by Vivenot with a profusion of detail; the paramount importance of this phase of the question compels us to quote here a great part of his memoir of 1865 :

As a basis of observations, it was necessary to determine the quantity of carbonic acid exhaled in respiration, in order to see whether the quantity of oxygen absorbed and the quantity of oxygen consumed differ as a result of the compressed air.

A priori, one might expect an increase in the absolute and relative quantities of oxygen absorbed; in the absolute quantity, because of the increase of the pressure exerted upon the lungs, and also because of the previously mentioned increase of the pulmonary capacity; in the relative quantity, because the number of respirations is decreased, and because it has been proved that the carbonic acid exhaled, and sometimes also the oxygen absorbed, are in inverse proportion to the frequency of the respiration. (Vierordt)

Vivenot then describes the spirometer which he used, and into which "was exhaled the air coming from an expiration as strong as possible, but made without great effort":

If we are to have any confidence in the result, the expiration, as previous attempts have proved to us, must always be made in almost identical circumstances. That is why the greatest precautions have been taken, and experiments were made on inspirations as deep as possible, made at intervals of one hour and under absolutely similar conditions.

In my case, the volume of air was on the average $3,700 \mathrm{cc}$. The duration of the respiration was from 15 to 18 seconds. The first test was made one hour before entering the compressed air, that is, at eight o'clock in the morning; the figures obtained at that time are not important, since they were to serve only as a point of departure for the experiment. The second test was made at nine o'clock, immediately before entering the pneumatic apparatus; the third at ten o'clock, under the influence of compressed air, after one hour of compression; the fourth at eleven o'clock, at normal pressure, immediately after leaving the apparatus; the fifth and the sixth at noon and one o'clock, also at ordinary pressure.

Observations made in this way, daily, from August 26 to September 13 inclusive, gave the following figures, as quantities of carbonic acid expressed in grams, contained in each expiration, and corresponding quantities of carbon exhaled. 


\begin{tabular}{l|l|l|l|l|l|l}
\hline \multirow{2}{*}{$\begin{array}{l}\text { Observer, } \\
\text { Vivenot }\end{array}$} & \multicolumn{2}{|c|}{$\begin{array}{c}\text { Under normal } \\
\text { pressure }\end{array}$} & $\begin{array}{c}\text { Under } \\
\text { increased } \\
\text { pressure } \\
10\end{array}$ & \multicolumn{3}{|c|}{ Under normal pressure } \\
\cline { 2 - 7 } & $\begin{array}{c}8 \\
\text { o'clock }\end{array}$ & $\begin{array}{c}11 \\
\text { o'clock }\end{array}$ & Noon & o'clock \\
\hline $\begin{array}{l}\text { Quantity of car- } \\
\text { bonic acid con- } \\
\text { tained in one } \\
\begin{array}{l}\text { expiration ex- } \\
\text { pressed in grams }\end{array}\end{array}$ & 0.1983 & 0.2236 & 0.2676 & 0.2183 & 0.2177 & 0.2106 \\
$\begin{array}{l}\text { Quantity of car- } \\
\text { bon in one expir- }\end{array}$ & & & & & & \\
$\begin{array}{l}\text { ation expressed } \\
\text { in grams }\end{array}$ & 0.05408 & 0.06098 & 0.07298 & 0.05954 & 0.05937 & 0.05744 \\
\hline
\end{tabular}

This result evidently proves that one expiration in compressed air contains from 0.0440 to 0.0570 grams, on the average 0.050 grams, that is, 1/4.352 of carbonic acid more than at normal pressure.

The figures obtained for normal pressure (with the exception of the observation made at eight o'clock), the average of which is 0.2176 grams, show remarkable agreement; however, we cannot disregard a slight progressive decrease of carbonic acid from eleven o'clock, that is, after return to normal pressure, until noon or one o'clock. The maximum quantity of carbonic acid found in my case under normal pressure rose to 0.2890 , and in compressed air to 0.3215 grams.

The data obtained from other persons gave similar results. In M. H . . t an expiration of 3,000 cc. under ordinary pressure contained an average of 0.1305 grams of carbonic acid, but in compressed air 0.1735 , with an excess of 0.0430 grams, that is, $1 / 4.04$ of the total and normal quantity of carbonic acid. In Mlle. B., a single experiment made under normal pressure gave 0.138 grams for $3,000 \mathrm{cc}$. of air expired at normal pressure, and in compressed air 0.170 of carbonic acid, that is, an increase of 0.0320 , or $1 / 4.31$.

Starting with the idea that at the beginning of the stay in compressed air there was perhaps a greater quantity of oxygen absorbed than towards the end of the stay, as if the blood was saturated with oxygen, Dr. Lange made experiments upon himself, and modified my own method of experimentation. He determined the content of carbonic acid in his respiration immediately before the treatment, then he made another test after half an hour in the compressed air, that is, when the pressure was reaching its maximum, then after an hour of the continuous effect of this maximum pressure, that is, after a stay of an hour and a half in compressed air. For a quantity of 3950 cc. of expired air, he obtained the following results:

Observer,

Lange

Quantity of carbonic acid contained in one expiration expressed in grams.

Quantity of carbon in one expiration, expressed in grams.
Under normal On reaching After an hour pressure

0.2506 | maximum preshalf-hour). of maximum pressure (that is, after $1 \frac{1}{2}$ hrs.

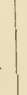


Here also therefore, on reaching the maximum pressure, after a half-hour in compressed air, there is an increase of the quantity of carbonic acid exhaled, similar to that observed in me. This increase was 0.0453 grams, that is, $1 / 5.53$. The absolute maximum in Dr. Lange, at normal pressure, was 0.3770 grams, and in compressed air 0.4345 grams. But we find here, after an hour of maximum pressure a decrease of 0.0295 grams in the carbonic acid exhaled.

However the figure obtained in the last place is doubtful, as was evidenced by tests made later, and that is explained by the fact that a part of the expired air was lost, because the rubber tubes had not been hermetically closed. Tests made afterwards by Dr. Lange gave the following figures, as the total quantity of carbonic acid exhaled in two ordinary expirations (of about 3000 to 4000 cubic centimeters) and also as the quantity of carbon eliminated:

\begin{tabular}{l|c|c|c}
\hline Observer Lange & $\begin{array}{c}\text { At normal } \\
\text { pressure }\end{array}$ & $\begin{array}{c}\text { On reaching maxi- } \\
\text { mum pressure } \\
\text { (after a half hour) }\end{array}$ & $\begin{array}{c}\text { After an hour } \\
\text { at maximum } \\
\text { pressure (after } \\
11 / 2 \text { hours) }\end{array}$ \\
\hline Carbonic acid__- & $0.2460 \mathrm{gm}$. & $0.2910 \mathrm{gm}$. & $0.2920 \mathrm{gm}$. \\
\hline Carbon & $0.06709 \mathrm{gm}$. & $0.07936 \mathrm{gm}$. & $0.07964 \mathrm{gm}$. \\
\hline
\end{tabular}

Which agrees with the results which I had obtained myself as increase in the quantity of carbonic acid exhaled in compressed air.

If now I compare the figures obtained from several persons, I find as the excess of the carbonic acid exhaled in compressed air, in comparison with the total quantity:

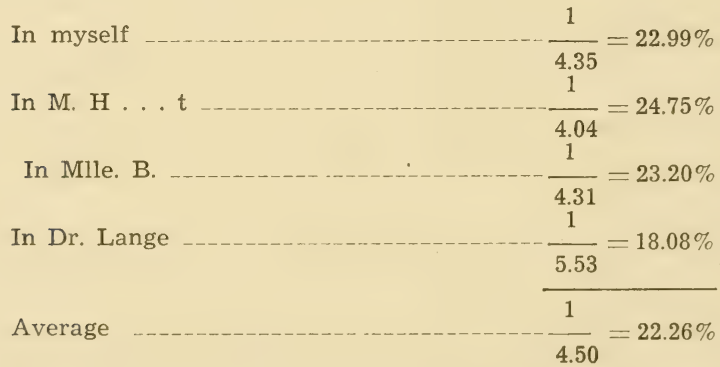

We should note here that the excess of carbonic acid expired in compressed air cannot be attributed to an increase in the quantity of carbonic acid which might have been contained in the pneumatic apparatus. A test of the air in the apparatus made by Dr. Lange after three persons had stayed there for two hours gave as an average of 4 experiments on $3,500 \mathrm{cc}$. of air 0.0391 grams of carbonic acid. The air of the waiting-room, where the spirometer was placed and where the tests described above of the carbonic acid expired under normal pressure were made, likewise gave, as an average of 4 tests on 3,500 cc. of air, 0.0392 grams of carbonic acid, that is, exactly the same quantity. 
So it is proved, in the opinion of Vivenot, that in one expiration there is more carbonic acid in compressed air than at normal pressure. But on the other hand, the respiratory capacity is greater in the first case than in the second. Is there a proportion between these two increases, and can one perhaps be considered as the result of the other? Vivenot replies to this question as follows:

If we compare the proportions of the quantities of carbonic acid exhaled under normal pressure and in compressed air and the respective proportions of increase of the pulmonary capacity, we find:

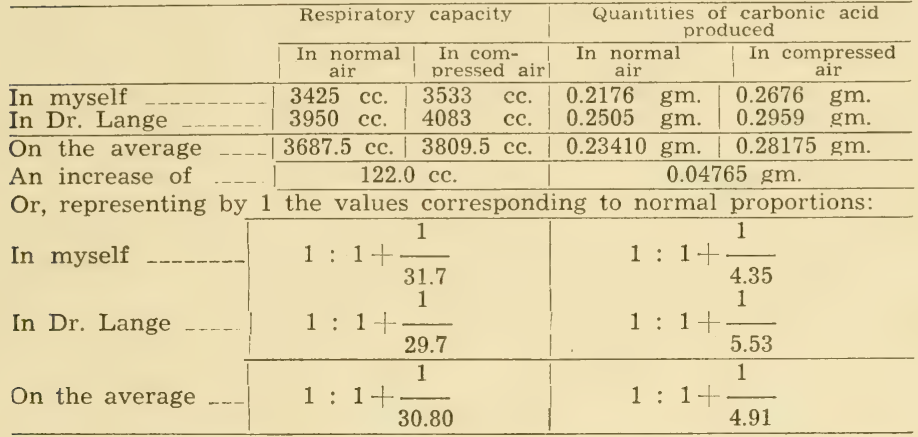

So, while the increase of the pulmonary capacity in compressed air rises to $1 / 30.80$, the quantity of carbonic acid exhaled has risen $1 / 4.91$. The ratio of the increases is therefore about $1: 6$. If I calculate what the quantity of carbonic acid exhaled would be, if the increase observed in the compressed air was proportional to the increase of the pulmonary capacity, I find the proportion 3687.5 cc.: $3809.5 \mathrm{cc} .=0.23410 \mathrm{gm}$. : $\mathrm{x}$, hence $\mathrm{x}=0.24197 \mathrm{gm}$. The increase calculated in this case is 0.00787 instead of $0.04765 \mathrm{gm}$. which the experiment gives.

This considerable difference between the calculation and the experiment shows clearly that the increase in the quantity of carbonic acid exhaled in compressed air is not proportional to the increase in pulmonary capacity, which can have only a small share in causing this increase. It would therefore seem permissible to state that the increase in the quantity of carbonic acid exhaled would be produced by the compression itself, acting partly according to Dalton's Law and causing a greater absorption of oxygen, under the direct influence of the compression on the one hand, and of the fact that the compressed air itself contains $3 / 7$ more oxygen in the same volume.

A calculation still had to be made of the total increase in the carbonic acid produced in a given time. To do this, Vivenot in his calculation takes into account both the number of respirations 
which he makes in one minute, and the quantity of carbonic acid contained in one expiration. He explains his method of procedure as follows:

The air exhaled by myself in one expiration contained, as was said above, 0.2176 grams under normal pressure, and 0.2676 grams of carbonic acid in compressed air. Now since at the time when the analyses were made (from August 26 to September 13) the average of my respirations was 4.15 in normal air and 3.76 per minute in compressed air, we can draw the following conclusion from this series of experiments:

\begin{tabular}{l|c|c|c|c}
\hline & $\begin{array}{c}\text { Quantity of carbonic } \\
\text { acid exhaled, expressed } \\
\text { in grams }\end{array}$ & \multicolumn{2}{|c}{$\begin{array}{c}\text { Quantity of carbon } \\
\text { consumed, expressed } \\
\text { in grams }\end{array}$} \\
\cline { 2 - 5 } & $\begin{array}{c}\text { Normal } \\
\text { pressure }\end{array}$ & Compressed & $\begin{array}{c}\text { Normal } \\
\text { Pressure }\end{array}$ & $\begin{array}{c}\text { Compressed } \\
\text { air }\end{array}$ \\
\hline In one minute & 0.903040 & 1.006176 & 0.24628 & 0.27441 \\
In one hour & 54.18240 & 60.37086 & 14.7770 & 16.4647 \\
In 24 hours & 1300.37760 & 1449.49350 & 354.6480 & 395.1528 \\
\hline
\end{tabular}

If we compare the figures obtained for normal air with those given by the most trustworthy authors, we find that the quantity of carbonic acid exhaled in one hour by persons from 20 to 28 years old has been estimated by Andral and Gavarret at 44.55 grams on the average and at 51.7 grams at the maximum, and by Valentin on the average at 39.146. Reduced to carbon, these figures, in the calculation of Andral and Gavarret, correspond to an average quantity per hour of 14.1 grams, and in that of Valentin, to 10.665 grams. Dumas specifies 10 grams as being the probable average consumption of carbon per hour, and 15 grams for men of exceptional strength

We see by this that figures obtained for myself at normal pressure, although my constitution is not very robust, correspond to the highest figures obtained by the authors, but that the results obtained in compressed air still exceed these quantities considerably. The calculation made for a stay of twenty-four hours in compressed air gives only an ideal result, because the stay in reality lasted only two hours per day, and therefore in this case one should take only the results of compressed air for two hours and add to them those of normal air for the 22 hours remaining. When we make the calculation in this way, we find as the real quantity of carbonic acid exhaled in 24 hours, after a daily treatment of two hours in compressed air, 1312.7539 grams, and as the corresponding quantity of carbon consumed during the same time 358.0234 grams. Whence it follows that even after this reduction the production of carbonic acid found by me still considerably exceeds that found by other observers under normal conditions.

The explanation of the high figures which I obtained at normal pressure lies in the fact that the analyses of the expired air could not be made at the time of the first treatments for lack of suitable apparatuses and reagents, and were made only after I had already taken more than a hundred treatments in compressed air. Whence it follows that in the figures obtained upon myself at normal pressure the effect of a prolonged use of compressed air is already a factor, that is, an 
increase in the quantity of carbonic acid; and analyses made before the beginning of my series of compressed air treatments would certainly have given a production of carbonic acid corresponding perfectly with that of the authors, that is, a smaller quantity.

The result then establishes indubitably as a fact that the direct effect of the compression of the air as well as the delayed effect of a daily two-hour treatment in compressed air, repeated for a certain time, produces a greater exhalation of carbonic acid, and consequently also an increase in the quantity of oxygen absorbed.

From this increase in the quantity of oxygen absorbed, which Vivenot considers proved, he draws general conclusions of the greatest importance:

Two facts which agree perfectly with what precedes are:

1. The greater need of nourishment which is shown as an effect of the compressed air by a noticeable increase of appetite, which I noted in myself and in others, and which is observed especially and without exception in laborers working in compressed air; 2. the very considerable increase in the urinary secretion, observed again in myself during this series of experiments and in several other persons, and evidenced especially in the first treatments with compressed air.

Therefore there is produced in the body a greater exchange of materials, and that also explains apparently contradictory results, observed by different authors.

There is an increase in the weight of the body, noted by several authors as a result of the stay in compressed air: for instance, J. Lange (of Utersen), who says he observed a weight increase of 5 kilograms in thirty-eight days (from 58 to 63 kilograms) in one person, and of 5 kilograms in 21 days in another. I can confirm this observation by what I noted in myself; for my weight had increased in four months (from April 30 to September 1) 31/2 pounds (from 127.5 to 130 pounds), which is all the more conclusive because it was in the middle of the warm season when, as is well known, the weight of the body usually decreases.

But on the other hand, there is one fact which cannot be disputed either, and that is the considerable decrease in weight of laborers working under a pressure of three to four atmospheres (in coal mines or in the construction of bridges). Sandahl has observed the same fact as a result of the therapeutic use of compressed air, so that this treatment has already been advised rather frequently as a means of combating obesity.

The apparent contradiction of these effects resulting from the increase of the air pressure, is explained by considering the connection between the need, the supply of materials, and the combustion. The need of increased nourishment is felt. If then the increase in appetite and the possibility of getting more food can not only counterbalance but even exceed the increased combustion of the materials of the blood (which will be the case with only a slight increase in pressure and relatively short daily treatments), an increase in the body weight will necessarily result. But if in the case of a combustion of carbon 
as great as that produced in laborers working six to eight hours a day under a pressure of three to four atmospheres, the replacement of the materials consumed cannot be made completely, combustion will necessarily take place at the expense of the body, which will cause loss of weight.

We have quoted above (page 423 et seq.) the most interesting parts of the long study made by Vivenot of the changes which compressed air causes in the circulation and particularly in the characteristics of the pulse.

He asked himself whether these changes in the form of the pulse can be explained by the direct, local action of the pressure on the arterial system. To get the answer to this question, he carried out the following experiment, in which he eliminates, he says, all the complex elements of the problem, in order to concentrate on "the contractility of the vessels and the pressure of the blood":

A rubber balloon with a tube about 50 centimeters long is filled with water, without being stretched, and the end of the tube is tied shut with a thread. The heart is represented by the balloon, the arteries by the tube, and the blood by the water.

A sphygmograph is placed over the tube. A weight falls regularly and always from the same height upon the balloon, representing in this way the impulse of the heart. Thus a sphygmographic tracing is obtained.

At normal pressure, this tracing displays the characteristic appearances of the normal pulse under these conditions: rapid, vertical ascent, acute apex, descent in the form of waves, all the signs of weak tension in the vessels.

If the apparatus is placed in compressed air, nothing else being changed, the curve of the sphygmograph is much altered. It then resembles very closely the tracing given by the pulse itself under compression. The line of ascent has become oblique, the apex has changed into a plateau, the height of the impulse is only half as great, and the polycrotism of the descending line has disappeared completely.

When the weight is allowed to fall from a greater height, so as to have a stronger pressure upon the artificial heart, the line of ascent will become straighter, the amplitude of the oscillation will increase, but there will be no polycrotism. If the apparatus remains a long time in compressed air, a few drops of liquid will escape near the ligature, a thing which never happens at normal pressure. At this time, the sphygmograph gives a tracing which is very similar to that obtained with the first impulse.

On return to normal air, the original curve appears again, except with a still steeper ascent and a more pronounced polycrotism. Zur Kenntniss, etc., P. 373-374.)

He concludes from this experiment and from the similarity of the tracings obtained both from the arteries and with his apparatus, in compressed air, that: 
The changes displayed by the curves in both cases have the same causes and result from a purely mechanical influence exerted by the increase of the pressure upon the elastic vessels filled with liquid.

The obliquity of the ascending line, which has become more pronounced in compressed air, indicates a greater resistance of the walls of the arteries to the impulse of the heart.

The lessened amplitude of the oscillation has two causes:

The diminution of the excursion of the arterial vessels, the diastole of which is less because of the increased resistance of the walls, and the systole is less because, on account of the pressure, the arteries contain more blood in proportion to their caliber, and cannot contract as much;

The decrease in volume of the arteries which, in compressed air, become smaller and contain less blood absolutely; which is shown clearly by the escape of the liquid from our apparatus after a long stay in compressed air....

Now there are compressed gases in the blood, which are liberated by the decrease in the air pressure, and which consequently are kept there by a high atmospheric pressure: and this is a reason why the mass of the blood, remaining constant, is reduced under high air pressure to the smallest volume possible ....

From these facts it follows that the action of the compressed air is exerted most strongly upon the peripheral vessels. (Ibid., p. 375.)

In the following chapter we shall see the value of this odd experiment, the only one which Vivenot performed in the course of his researches, and what importance the conclusions which he draws from it may have.

The ideas of G. Lange ${ }^{27}$ agree perfectly, as one might have expected, with those of his collaborator Vivenot. He adds, however, a few original explanations; this one, for example, which has reference to the decrease in the number of respiratory movements:

The need of breathing does not result from the influence exerted upon the outstretched spinal cord by a blood with a reduced oxygen content; it is the carbonic acid of the blood which produces this need, the intensity of which grows proportionately to the quantity of this acid which the blood contains. That is why every increase in the quantity of carbonic acid exhaled will decrease the need of breathing, and consequently the number of inspirations, unless a more active combustion of the blood restores an excess of carbonic acid equal or superior to the quantity exhaled.

The decrease in frequency of the respiratory movements would therefore be explained by a greater exhalation of carbonic acid in compressed air, at least during the stay under the bell and the time immediately following this stay. (P. 23.)

But G. Lange knows very well that this hypothesis, then agreeing with the theory of Brown-Séquard, cannot account for the per- 
manent slackening of the respiratory movements. So then he resorts to another kind of explanation:

I can explain this fact (he says) only by the unquestionable increase in the strength of the respiratory muscles, which can alone account also for the increase of the vital capacity of the lungs noticeable even at the first treatment.

Here he relies upon the conclusions of a memoir by J. Lange, ${ }^{28}$ which I could not procure:

Dr. J. L., in his work on the physiological and therapeutic effects of compressed air, concluded from a series of experiments, the accuracy of which I can vouch for, that in it the negative pressure increased considerably during the inspiration, and the positive pressure during the expiration. If then the respiratory muscles gain strength, we are justified in assuming that all the rest of the muscular apparatus shares in this increase of strength. This Dr. J. L. proved by a series of experiments, and he established it as a fact that if patients have been subjected to the effect of compressed air for some disease of the lungs, they feel their strength increasing after a few treatments, and muscular exercise becomes easier and less tiresome for them from day to day.

The same author says also: It is difficult, if not impossible, to measure this increase in strength. Experiments do not give us results of absolute quantity. They show us, however, that an increase in power of the whole muscular system is produced, and that it is fairly large....

The increase of muscular strength in compressed air may be considered a proof of the absorption of a greater quantity of oxygen. This absorption is carried on especially by the lungs, but partly also by the skin. Sandahl justly states that the skin has a respiratory power and that under the influence of a strong pressure, which promotes endosmosis, it would absorb more oxygen. (P. 27.)

G. Lange comes next to the slackening of the circulation, and quotes the explanation of Vivenot:

Could one not somehow explain (he says) the slackening of the pulse by the fact that the pressure exerted over so large a part of the capillary system and the small arteries makes the passage of the blood there more difficult?

The presence of free gases in the blood makes a compression possible, and the vessels, especially those which are situated on the surface, contract so much that sometimes even slight hyperemias disappear rapidly.

The observations relating to the effect of the compressed air on the functions of the nervous system are interesting enough to be quoted in full; we find again in their explanation the idea already suggested by different authors, and particularly by M. Junod 
(page 414), that the organs contained in the cranial cavity escape more or less completely the effect of the compression exerted on the rest of the body:

If more activity and clearness of mind are observed under increased atmospheric pressure, this phenomenon may be attributed to another cause than the rise of the barometer of an inch or an inch and a half, and we cannot draw any conclusion from it in favor of the increase of pressure. When Junod maintains that under a certain pressure the sphere of ideas enlarges, and that one becomes capable of writing verses, his claim seems extravagant to me. Moreover, my observations conflict with those of Dr. J. Lange. He says that under the influence of compressed air the central nervous system is stimulated in a peculiar way, that in particular the functions vested in the cerebral hemispheres are carried on with greater activity, that in many persons one observes more or less definitely an elasticity and brilliancy of mind which did not exist before. The patient subjected to the treatment is supposed to experience a mental well being, and his mind is clearer and freer. In addition, he thinks that he can consider these phenomena as constant effects of compressed air.

In my numerous observations, I have noted nothing of the sort. On the contrary, I have observed in myself and others a feeling of calmness, generally followed by a tendency to sleepiness.

Compressed air cannot act directly upon the organs contained in the cranial case, whereas all the other parts of the body undergo its effects: so one might assume that even a slight increase of the atmospheric pressure brings more blood to the brain. The tendency to sleepiness would also suggest such a conclusion. Dr. Vivenot conceived the idea of observing this increase of pressure by means of the dilatation of the pupil.

He placed in a spectacle frame a thread divided into milimeters, and measured by means of a concave mirror the size of the pupil before and during the treatment, using candles in both cases, in order to have equal lighting. Strangely enough, he most frequently observed a contraction of the orifice of the pupil, which must be attributed to a stimulation which, as I have already said, was not indicated in myself by any other sign. (P. 29.)

Let us quote also an interesting discussion of the changes in the lymphatic circulation:

An increase of appetite is usually observed in persons who have taken treatments of compressed air for some time. Some of them lose a little weight at the beginning, but soon their appearance improves and they gain weight. Dr. J. Lange gives the following explanation of this fact: The blood contained in the subclavian vein undergoes suction and therefore the lymph which comes from the thoracic canal would flow there more abundantly, and besides, the thoracic canal itself, which is hermetically inclosed in the chest, would also be subjected to negative pressure, and consequently the lymph contained in 
it would undergo a suction from which would result a stronger current and the presence in the canal of a greater quantity of lymph. Whether or not this explanation is true, I think that the weakness and emaciation caused by a disease of the respiratory organs should lessen as the cure proceeds, and that when the respiration is better, the appetite is improved. The emaciation at the beginning probably results from the greater absorption of oxygen, and the effects of this gas are no longer depressing when the appetite increases. (P. 31.)

The opinions of Elsässer ${ }^{29}$ are evidently only a reflection of those of Vivenot:

The effect of compressed air depends upon two principal factors:

1. The increased mechanical pressure (a) on the exterior surface of the body, (b) on the respiratory cavities; 2 . the greater quantity of oxygen and nitrogen breathed in a given volume.

The first factor shows its effect first on the gases contained in the body, then on the blood capillaries of the skin and the mucous membranes, the walls of which are flattened. The second will act upon the respiratory exchanges and movements. (P. 9.)

And farther on, developing these principles:

The pressure of an atmosphere and a half results in a compression of the tissues, a contraction of the diameter of the blood vessels; the supply of blood in the skin is diminished; slight cases of conjunctivitis are cured, blistered surfaces and the ears of white rabbits grow pale.

Similar changes are noted in the respiratory mucous membranes; they become more compact, thinner, less rich in liquids and blood. From this fact, cures of inflammation of the lungs, etc. result . . .

What is the result of this forcing back of the blood? Does it not cause interior congestions? Experience shows that the heart is not affected by it, but works more quietly; there is no cerebral congestion . . . ; but the increase of appetite, of urinary secretion, and of strength seems to be consistent with a greater quantity of blood.

The second factor, the greater quantity of oxygen, has been too much neglected hitherto ... . If, at normal pressure, a healthy man breathes 16 times per minute, and absorbs each time 30 cubic inches of air, he will have consumed 480 cubic inches in one minute. But under the pressure of $1 \frac{1}{2}$ atmospheres, these 480 cubic inches which he needs become 320 ; if he still breathes 16 times, each inspiration will include only 20 cubic inches; with 12 respirations, it will rise to 26.6 cubic inches; with 8 , to 40 cubic inches ..... If therefore the proportion thus calculated is not observed, more oxygen will be introduced into the lungs in a given time, which explains the statements of the authors about the greater absorption of oxygen, the increased hematosis, the stimulated organic combustion, etc. (P. 13-17.)

Panum,$^{30}$ in the work which we have already quoted (page 435), justly criticizes the method employed by Vivenot in measuring the quantity of carbonic acid produced in a given time: 
The enormous quantity of carbonic acid found by Vivenit (he says) results from making the expirations too strong; in fact, taking his figures, we find that the pulmonary ventilation for 24 hours at normal pressure is 21,111.2 liters, and in compressed air 19,745.5 (Panum in one experiment gets 1152 liters for himself at normal pressure). In respiration so greatly forced as that, he finds a production of carbonic acid of 1300 grams in normal air and of $1449.5 \mathrm{gm}$. in compressed air (Panum gets $816.2 \mathrm{gm}$. in himself).

As to him, he made his analyses on 60 or even 120 liters of air expired in a spirometer at different periods in the experiment. Moreover, he does not give very clear specifications of the manner in which he carried out this experiment; I can find only that the compression was 24 centimeters:

I have found no trace in my experiments of this increase in the production of carbonic acid after the air treatments, of which Vivenot speaks .... I consider the opinion of Vivenot a mistake, because his method had no solid basis and could not be used to estimate the quantity of air which passes regularly through the lungs in a given time, with quiet and natural respiration; his respiratory rhythm was forced, not natural ....

If we compare in. my tables the cases in which equal volumes of compressed air and normal air were breathed, we find that the quantity of carbonic acid exhaled has increased absolutely and relatively in compressed air. But if we compare the cases where there was the same volume of air, when reduced to the same pressure, breathed in free air or under the bell, we see that a little less carbonic acid was produced in the compressed air than at normal pressure. In other words, the quantity of carbonic acid exhaled increases during respiration in compressed air because of the increase in the mass of air which passes through the lungs, as a result of this pressure, but in a proportion a little less than the latter. (P. 143-146.)

But this is exactly the result which Vivenot reached, in spite of the faulty method which he had used. Panum is surprised at this agreement:

The experiments of Regnault and Reiset, in which the respiration of an air with greater oxygen content had not brought a greater excretion of carbonic acid, seemed to prove a priori that the same would be true in compressed air. Yet my results were the same as those of Vivenot, and were contrary to my expectation, which makes them all the more convincing.

What causes such a difference between the respiration in air with high oxygen content at normal pressure, and that in normal air at higher pressure?

We might ask whether it is the oxygen chemically united with the corpuscles of the blood, or that which is simply absorbed, which in one case oxidizes more energetically than in the other. If one breathes superoxygenated air at normal pressure. then the increased 
partial pressure also increases the proportion of oxygen in simple solution in the blood, whereas that which is in a state of chemical combination there very probably does not vary. This shows that it is not the oxygen simply dissolved, but the oxygen combined which produces the carbonic acid, since in the experiments of Regnault this production did not increase.

We can see likewise that the increase of oxidation and of carbonic acid production which we observed in compressed air is caused by the combined oxygen of the blood. (P. 147.)

Passing to another class of phenomena, the Danish physiologist studies the changes in the respiratory rhythm. We have quoted in the preceding chapter the data which he obtained. To explain the increase of the pulmonary capacity, he makes the following experiment:

I immerse under water in a flask a bladder half full of air; a second bladder provided with a tube is placed upon the first; the tube passes through a stopper which hermetically closes the flask, which therefore is full of water except for the space occupied by the bladders. The lower bladder represents the intestinal tube and its gases, the upper one represents the lungs with the trachea, the flask and the water representing the closed thoracic cavity. If this very simple apparatus is carried into compressed air, we see that the lower bladder decreases while the upper one increases in volume.

This result is not at all changed if we use a flask the bottom of which is replaced by an elastic membrane. The closed bladder behaves in the same way; but only a part of the space which it leaves free is filled by the upper bladder; the membrane at the bottom rises.

This shows that it is the compression of the air contained in the intestine which is the cause of the increase in the lung capacity and the greater lowering of the diaphragm.

The changes in the respiratory rhythm could not be explained, Panum says, by the increase in the oxygen of the blood, since this increase leads to apnea; now in apnea, not only the number but also the amplitude of the respiratory movements decrease. He also rejects the hypothesis accepted by Vivenot and G. Lange of an increase in the power of the inspirator muscles; he justly considers that these authors gave no proof of their assertion. In his opinion, it is the increase in the average capacity of the lungs, under the direct, mechanical influence of compressed air, which causes the deeper inspirations.

In regard to the changes in the pulse and the increase of the arterial pressure, Panum finds quite contrary to the laws of physics ("ganz unphysikalisch") the explanation of Vivenot, G. Lange, Sandahl and Elsässer, which attributes them to an alleged decrease 
in the volume of the blood, as a result of the decrease in volume, under the influence of the pressure, of the gases contained in it.

Finally, in reference to the symptoms of decompression, our author, though not having made any experiment on data of this kind, reaches this conclusion, that:

The morbid symptoms chiefly result from the fact that the air which has suddenly been liberated in the blood vessels is drawn along by the circulatory current, and forms embolic obstructions in different vascular regions. (P. 149.)

The chief purpose of G. von Liebig ${ }^{31}$ was to find whether the quantity of carbonic acid formed is the same in free air and in compressed air. He describes minutely the complicated apparatuses which he used; I shall merely say that the analysis of the air was made on the quantity expired in 15 minutes, by means of a solution of baryta proportioned by oxalic acid. It goes without saying that all the figures are accompanied by numerous decimals; but, to compensate for that, the author does not tell whether the subjects were put on a regular schedule, both of diet and of exercise, which, however, is far more important than discussions of the length of time one should shake the vessels to secure complete absorption of the carbonic acid.

The carbonic acid, the proportion of which was decided in eight experiments of which Kramer was the subject, really seems to have been decreased as a result of the compression. At normal pressure, first, the subject produced in 15 minutes, the first day $8.442 \mathrm{gm}$. of $\mathrm{CO}_{2}$, the second $7.955 \mathrm{gm}$; in the apparatus, successively, $7.614 \mathrm{gm}$., 7.784 gm., 7.747 gm., 7.136 gm.; finally, on return to open air, 7.791 $\mathrm{gm}$. and $7.287 \mathrm{gm}$., that is, an average of $8.198 \mathrm{gm}$. before the compression; $7.570 \mathrm{gm}$. during the compression; and $7.539 \mathrm{gm}$. after the compression. The decrease then was, during the compression, for 15 minutes, $0.628 \mathrm{gm}$., or in 24 hours, assuming that it would have remained the same, $60.3 \mathrm{gm}$.

G. Liebig, who blends in a common average the experiments in the open air, before and after the compression, reaches a difference of only 28 grams, which he declares to be within the order of physiological differences. I grant this willingly, even for the 60 grams, because he gives none of the indispensable information about the schedule of his subject: But then we must admit that of his numerous analyses nothing is left which could be useful to us on physiological ground, in spite of the accompaniment of discussions from the standpoint of physics about the effect of water vapor and of the slightly increased proportion of carbonic acid in 
compressed air over open air $(0.197 \%$ instead of $0.147 \%$, for example).

G. Liebig also takes up the explanation of the changes in the rhythmic phenomena of respiration.

In regard to the increase of pulmonary volume, he expresses himself as follows:

The barometric pressure acts at the same time upon the surface of the body and that of the lungs. As it rises, it opposes more vigorously the elasticity of the pulmonary tissue; this elasticity, which is equal to $35 \mathrm{~mm}$. of mercury, corresponds to $1 / 24$ of the pressure 720 $\mathrm{mm}$. (average pressure of Reichenhall), but is only $1 / 34$ of $1030 \mathrm{~mm}$. (pressure of the apparatus); so that in compressed air the contraction of the inspiratory muscles has less resistance to overcome. The diaphragm is also assisted in its action by the decrease in volume of the intestinal gases. The inspiration is therefore easier and stronger; for the same reasons the expiration is slightly delayed, so that one cannot breathe as quickly in compressed air as at ordinary pressure. The lungs also collapse less, so that their volume is greater in a state of repose. (P. 16.)

As for the increased capacity of the chest, which persists after the treatments are over, like G. Lange, he considers that to be the result of the helpful exercise undergone by the inspiratory muscles because of the new position of the thoracic cage in compressed air.

The authors still left to be mentioned were particularly interested in the symptoms of decompression.

M. Gavarret, ${ }^{32}$ in the article which we have already quoted (page 274), also discusses the symptoms affecting workmen:

The return to open air often produces buccal and nasal hemorrhages, which generally are not accompanied by any pain. In our opinion, these discharges of blood are the result of ruptures of capillaries caused by the tension of the gas with which the blood is supersaturated.

The changes caused in the cutaneous circulation at the time of the decompression seem to us sufficient to explain these symptoms. The blood, supersaturated with free gases at high tension, flows into the capillaries, distends them, twitches the innumerable nerve networks which surround them, and causes, depending upon the speed and the intensity of the vascular congestion, sometimes a simple sensation of heat, sometimes real pains. (P. 156.)

M. Leroy de Méricourt, ${ }^{33}$ after describing the paralyses which attack divers using the diving suit, explains them by saying:

We think that we may state that in these cases a lesion of the spinal cord is produced, and that this lesion must have been a hemorrhage. According to the seat and the severity of this hemorrhage, death 
occurred very quickly, as happened to three cases, or occurred only after a variable time, as in the other seven cases.

Then, after accepting this hypothesis, he asks himself what the cause of the spinal hemorrhage can be:

After due reflection (he answers himself), we are inclined to believe that it is the result of the exaggerated tension of the free gases, in solution in the blood, as a result of the high pressure to which the divers may be subjected. In the diving-suit, as we know, the man is completely isolated from the water by. a suit of strong impermeable fabric and a metal helmet fastened upon the collar of the suit. Air is admitted to this covering by means of a pump which communicates with it by means of a flexible tube ending at the back of the helmet. Nothing regulates the quantity or the pressure of the air pumped into the suit. Consequently, the workman often receives too much or too little air; he is compelled to remedy partially the difficulty in breathing which he experiences by being in constant communication with the pumptenders by means of signals consisting of a certain number of tugs given to a signal cord. Nevertheless, by means of this atmosphere which the man keeps around him, he can maintain his respiration and remain whole hours under water. But the greater the depth, and the more prolonged the stay, the more must the blood be laden with an excess of free gases in the state of solution. The lack of regulating mechanism for the pressure must often cause the atmosphere of the suit to be at a pressure greater than is necessary. From the point of view of physics, the man is really in the situation of a bottle of water which is charged with carbonic acid gas to obtain artificial Seltzer water.

When he rises to the surface, if the decompression is not gradual enough, the gases with which the blood is supersaturated tend to escape with effervescence. Now experimenters who make injections into the venous system of horses, for example, know that if they intentionally allow a small bubble of air to enter with the liquid injected, as soon as this bubble of air penetrates the cerebral circulation, the experimental animal falls as if struck by lightning. The effect, in this case, is only momentary, but if the quantity of bubbles of air admitted is great, death occurs very soon.

We have thought it best to quote in full this noteworthy passage which recalls what M. Bucquoy had already said (see page 459), and which contains in the form of a hypothesis an exact description of what really takes place, as we shall show in the second part of the present book. But by a strange inconsistency, which shows what influence the old ideas about the mechanical effect of the decompression had gained over the best intellects, M. Leroy de Méricourt, instead of adhering to the idea of intravascular gaseous obliterations, remains imbued with the hypothesis of hemorrhages, resulting from the forcing back of the blood. He then asks himself 
why "they occur in the special nervous center rather than in the cerebral mass," and he answers:

The cranial case and the vertebral column form two coverings which are equally incompressible; consequently, when the blood is driven from the entire surface of the body and the compressible splanchnic cavities, it must tend to congest the cerebro-spinal axis. The circulatory system of the spinal cord, compared to that of the brain, is infinitely richer, as the congestions show; finally, in the sponge fisherman, it is the legs which become most weary, because during his stay under water, he must constantly walk and climb up and down the rocks. Perhaps these are the causes which account for the fact that the spinal cord is the favorite seat for the symptoms. We give this explanation, of course, with the greatest circumspection.

M. Bouchard,,$^{34}$ in his study of the Pathogeny of Hemorrhages, includes the symptoms of compression and decompression, which he considers as due to abdominal, spinal, and cerebral congestions and hemorrhages. The manner in which he imagines they are produced is very interesting; it is borrowed, he says, from M. Marey:

When the compressed air makes its way into the lungs, there is no longer any tendency for a vacuum to be made in the chest, as in the case of naked divers; pulmonary congestions are no longer to be feared. However the abdomen is normally distended by gases; since the outer air does not enter the intestine, these gases are compressed and occupy a volume which is in inverse proportion to the intensity of the compression. The volume of the abdomen will become four times less, if the pressure is four atmospheres. Then the wall is everywhere crowded against the spinal column and thus forms an anterior concavity. But this wall is not inert; it tends to become straight again, through its tonicity and even its contractility, and consequently to lessen in the abdomen the pressure which had been counterbalanced by this pushing back of the wall; it acts like a huge cupping-glass, which would attempt to accumulate in the abdomen the blood from the other organs. And in fact, general anemia is produced.

This plethora of blood in the abdominal organs is not, however, the cause of hemorrhages, except perhaps in the spleen.

So much for the explanation of the visceral congestions during the compression. But at the time of the decompression, an inverse phenomenon would take place:

It is at the time of the decompression that the hemorrhages occur, at the moment when the intestinal gases, regaining their volume and distending the abdominal wall in the opposite direction, cause the organs of the belly to undergo a positive pressure which will drive out the blood stored in their interior, and direct it suddenly towards the other organs, the vessels of which, since they have lost their tonicity, .... . do not adapt themselves quickly to this sudden inroad. 
Then appear the cases of epistaxis and hemoptysis, sometimes passing or fatal apoplexies, accompanied in certain cases by temporary or permanent hemiplegias, and finally these fleeting or persisting paraplegias, which M. Barella observes in laborers working in caissons, and which, according to M. Leroy de Méricourt, would be one of the most common causes of death in sponge fishermen.

This explanation, however, does not satisfy M. Bouchard, who then quotes the ideas of MM. Rameaux and Bucquoy on the gases of the blood:

But this sudden congestion, at the time when the blood flows back from the abdomen towards the other organs, is perhaps not the only cause or the real cause of these hemorrhages, or at least of a certain number of them: of those, for example, which take place in the incompressible cavities, the skull and the spine. Another interpretation has been given, which seems probable. Gases are dissolved in liquids in proportion to their tension; the blood of a man who has remained for several hours under a pressure of four atmospheres should therefore contain a much greater proportion of carbonic acid than in the normal state; and this dissolved carbonic acid will return to the gaseous state as soon as the outer pressure lessens. If the decompression takes place slowly, the blood as it passes through the lungs, can release the surplus carbonic acid, and no symptom will appear; but if the decompression is sudden, the carbonic acid will tend to break out in gaseous form even into the vessels, and by its sudden expansion, or by the obliteration of small vessels in which it cannot circulate, will cause ruptures and extravasations. (P. 99.)

M. Bouchard applies this idea to the formation of painful muscular swellings, of which the authors whom we have previously quoted have spoken:

These swellings are not inflammatory, they are not exudates nor extravasations. They disappear immediately simply through return to compressed air, and are never followed by ecchymotic spots. When the swelling exists, it is not accompanied by throbbing or redness, so that we can hardly attribute it to an exaggerated arterial dilatation, as M. Foley has done. If it is true that muscular labor is an important source of carbonic acid, might we not assume that the muscles which have exercised most are laden with carbonic acid dissolved in the very tissue, and that, at the time of decompression, this acid is liberated in gaseous forms, and then is redissolved by a new compression? (P. 101.)

We now have to speak of an author who wrote after our first personal researches; but we place him here because he seems to have given little heed to the experiments which we had already published.

After reporting the data which he observed, the summary of 
which we gave in the first chapter (page 395, et seq.), M. Gal ${ }^{35}$ comes to the theoretical explanations, or, as he says, to the pathogeny of the diseases caused by work in compressed air.

He shrewdly distinguishes the cause of diseases with slow beginning from that of symptoms which come on suddenly. For the first, he accepts, he says, the explanation of M. Foley; but at least he has the undeniable merit of expressing it in a comprehensible form:

We have seen that the blood of the caisson worker and the diver is richly oxygenated, and it seems as if it would be hard for anemia to occur under such conditions. But on the other hand, we have seen that sensations perceived by the sense organs are much less distinct in compressed air; therefore the spinal cord and the brain, since they receive fewer stimuli, will produce less nervous energy, and the effect of the sympathetic system upon the metabolism of the tissues will be weaker than in the normal state.

As long as the workman has not exhausted his reserve of nervous influx, he will not suffer; the increase of his appetite will furnish/ his blood with the materials which it needs to consume its oxygen; but when he has exhausted his reserve, since production is less than the expenditure, the functions of the sympathetic system will be carried on imperfectly, and the patient will become mortally ill. Then he will be most subject to the other diseases with sudden beginning and immediate danger.

As for the other diseases, they are all "due to congestion." On that, says M. Gal, everyone is in agreement; but this is not the case when their method of production is to be explained.

On this point, he appears very eclectic. He considers as "possible," after my experiments, the opinion which attributes symptoms to a liberation of gas in the blood. But he prefers the explanation of M. Foley about:

The too violent reaction caused either by too sudden a decompression, or by the lack of reaction in places where it usually takes place, and where it is harmless, especially the skin. (P. 60.)

We confess that this is anything but clear. A little farther on he adds:

In regard to the divers who died suddenly, the opinion of M. Bucquoy and M. Leroy de Méricourt (he is referring to the effervescence of gas) is very probably true.

As for the other divers, who died sooner or later after the accident, they all had paraplegias. In all of them the lesion of the spinal cord had occurred suddenly, which one can connect only with a congestion, a hemorrhage in the substance of the spinal cord, or a compression by hemorrhage in the vertebral canal.

The cases of rapid cure observed and the invariability of double 
paraplegia make me incline towards congestion in most cases; but we have no proof that the gaseous tension did not sometimes cause hemorrhages.

Finally, in the case which we observed, in which paralysis began more than 24 hours after the last dive, we can see only a condition rather abnormal in divers, a passive congestion in which the effect of the gases of the blood cannot be admitted.

We have laid stress on severe congestions; all that we have said can be applied to all diseases of divers, depending on varying degrees of severity. The afflux of blood and perhaps the effect of the gases which it contains takes place at different points, and the severity of the attack depends upon the importance of the organ. The "fleas," the muscular and arthritic pains, the hemoptyses or nasal hemorrhages, the inflammations of the ear, and the visceral congestions are always the result of the same cause: a reaction of the blood which is too violent or badly directed, whether this reaction is due, as Foley thinks, to the nervous influence which revives during the decompression, or whether the action of the gases dissolved in the blood must be involved. (P. 60.)

From the practical and prophylactic point of view, like all the authors who preceded him (except M. Foley), M. Gal draws this conclusion that the decompression must be made slowly; he also makes the recommendation that the greater the depth reached, the shorter the time under water should be. Here, in fact, is the schedule followed under his supervision:

Up to 25 meters, even in uniform depths, the period of work under water was an hour and a half. From 25 to 30 meters, the time was reduced to one hour. From 30 to 35 meters, only a half-hour. Between 35 and 40 meters the divers stayed on the bottom only a quarter of an hour.

Our fishermen never went below 35 meters. The Greeks, who are more daring, went to 54 meters, in 1867.

At the same time that the length of the shift was decreasing, the time spent in the decompression was increasing. A half-minute per meter was the rule first established; but the fishermen were never willing to submit to it. They ascended at about 4 meters per minute. (P. 72.)

1 Pars altera. Rome, 1681

${ }^{2}$ Loc. cit. Collect. acad., foreign part, Vol. I, p. 46-61, 1755.

${ }^{3}$ Elementa physiologiae corporis humani, Vol. III, 1761. 1801.

4 Extrait d'une lettre de M. A. au citoyen Van Mons. Ann. de Chimie, Vol. XXXVII.

5 Article Air in the Dict. des Sc. méd. Vol. I, p. 248, 1812.

- Tractatus physico-medicus de atmosphera et aere atmospherico. Cologne, 1816.

${ }^{7}$ Recherches sur les causes $d u$ mouvement du sang dans les vaisseaux capillaires. $C$. $R$. Acad. des Sc.. Vol. I, p. 554-560, 1835. These different experiments are reported in detail in the memoir of this same author, included in Volume VII of the Memoires des savants étrangers.

${ }^{8}$ Etudes de physique animale. Paris, 1843. 168.

- Note sur la carbonométrie pulmonaire dans l'air comprimé. Gaz. med. de Lyon, 1849, p.

168. ${ }^{10}$ This method is explained in a previous work by the same authors, entitled: Recherches sur les quantités d'acide carbonique exhalé per le poumon à l'état de santé et de maladie. Ibid.. p. $39-50$.

${ }^{11}$ Loc. cit. Essai, etc.; 1850.

12 Loc. cit. See above, Title II, Chapter I, section 2. 
${ }^{13}$ Note sur les effets physiologiques et pathologiques de l'air comprimé. Ann. d'hyg. publ. et de méd. lég., 1854, Second series, Vol. I, p. 279-304.

${ }_{14}$ Loc, cit. De l'air comprimé, etc. Lyons, 1854.

15 Etude clinique de l'emploi et des effets du bain d'air comprimé dans le traitement des diverses maladies. Paris, 18.5.

${ }_{16}$ Loc. cit. Ueber dor Einfluss, etc. Müller's Arch., 1857.

17 Loc. cit. Des effets de l'air comprimé, etc.; $1 \$ 60$.

18 Loc. cit. De l'air comprimé; 1861.

19 Loc. cit. Des accidents, etc.; 1862, 1863.

${ }^{2}$ Loc. cit. Du trar'ail, etc.; 1863.

${ }^{21}$ Rapport sur le travail de $M$. Foley, lu à la Soc. méd. d'émulation de Paris, session of August $1,1863$.

${ }_{22}$ Loc. cit. Paralysis caused, etc.; 1863.

${ }^{23}$ Loc. cit. Ueber die Wirkungen, etc.; 1862.

24 Loc. cit. Die comprimirte Luft, etc.; 1863.

${ }^{25}$ Loc. cit. See the list of Vivenot's works, in Chapter II.

${ }^{29}$ Mittheilungen über die physiologischen Wirkungen und theropeutische Bedeutung der. comprimirten Luft. Wiesbaden, 1865. Translated from the German by Dr. Thierry-Mieg. Paris, 1867.

$2 \pi$ Ueber comprimirten Luft, ihre physioligischen Wirkungen and ihre therapeutische

Bedeutung. Göttingen, 1864.

${ }_{23}^{23}$ Loc. cit. Untersuchungen, etc.; 1868 .

${ }^{29}$ Loc. cit. Zur Theoric, etc.; 1866.

${ }^{30}$ Loc. cit. Ueber das Atlimen, etc.; 1869.

31 Loc. cit. Article Atmosphere; 1867.

32 Loc. cit. Considérations, etc. 1869.

${ }^{33} \mathrm{De}$ la Pathogénie des Hemorrhagics. Paris, 1869.

${ }^{34}$ Loc. cit. Des dangers, etc.; $18 \div 2$. 


\section{Chapter IV}

\section{SUMMARY AND CRITICAL COMMENTS}

I shall now summarize, as I did for decreased pressure, first the physiological symptoms brought on by the use of compressed air and the more or less serious conditions which have often followed it, and finally the theories which the authors have advanced to explain all these phenomena.

\section{Physiological effect of compressed air.}

It appears very clearly from the data given in Chapter I that the phenomena which are to be reported here are divided into two categories very different in their origin, and which we should, for fear of confusion, separate in the exposition, although the distinction has not always been made by the authors. Some, in fact, appear even during the compression, and are the result of the stay in compressed air; others occur only at the time of return to normal pressure; they are the result of the decompression, and their intensity is in proportion to the speed of the decompression and the degree of the compression. This differentiation, which was first suggested in a rather vague manner by $\mathrm{Pol}$ and Watelle, will govern our summary.

\section{A. Phenomena Due to Compression.}

Pains in the ears. Pains in the ears have been noted by all observers during the process of compression as well as during the decompression. All have given the exact explanation of them; they have shown that since the Eustachian tube, obstructed for different reasons, does not permit the compressed air to enter the tympanic cavity, the tympanic membrane is pushed back and distended, causing pains which may be unendurable. Sometimes it is even ruptured, as happened to M. Cézanne, at the bridge of Sgedezin. 
Similar symptoms, but less severe, accompany decompression. They can be checked by opening the tube, either by the movements of swallowing, or, and this is a more certain method, by making a strong expiration with the nose and mouth closed.

These repeated procedures result in reestablishing the permeability of the tube, the obliteration of which is a frequent cause of deafness; hence come, no doubt, the improvement in this infirmity which is often observed in compressed air, and the effectiveness of the treatment originated by Pravaz. But the question is complicated by the direct effect of the compressed air upon the mucous membranes, of which I shall speak presently.

Voice. The voice is impaired in compressed air: one talks through the nose, Triger says; it rises in pitch, and in this regard Vivenot made an exact observation upon a well-known woman singer who gained a half-tone in the apparatus. The act of whistling becomes impossible beginning with 3 atmospheres, as Triger had already noted; it even takes a certain effort to talk, according to Pol and Watelle. All of this is quite evidently due to the increased density of the air.

Respiration. It has been very definitely determined that the maximum respiratory capacity increases considerably during the stay in compressed air. The diaphragm and the base of the lungs drop; respiration therefore goes on in a certain constant state of enlargement of the thorax. No doubt that is one of the causes of the improvement in asthmatic patients, in whom pulmonary expansion then takes place more fully. This change, which increases with each of the first treatments, persists for a longer or shorter time after return to open air.

The frequency of the respiratory movements decreases considerably; everyone agrees on that; their amplitude increases in inverse proportion. But after all, a smaller volume of air under pressure passes through the lungs in a given time than of ordinary air. At least that seems to be the conclusion to be drawn from the figures of Vivenot and Panum; but it must be said that no direct experiment has been made, and that these conclusions have been drawn from calculations in which one had to take into account the amplitude of one or several respirations and the number of respiratory movements per minute: complex calculations strewn with causes of errors of a physiological order.

As to the rhythm itself, Vivenot and Panum contradict each other completely in their statements; however, the point is of little importance. 
Circulation. The decrease in the pulse rate is also a matter of general observation; M. Bucquoy alone (page 374) has made a contradictory statement. In highly compressed air, Pol and Watelle observed the rate to fall from 80 to 50 ; the change is especially great when there was an abnormal acceleration. On return to ordinary pressure, the usual rate is restored.

The pulse undergoes still other changes, in regard to which the tracings of Vivenot give us definite information (Fig. 10-13, pages 424,425$)$; its amplitude is much lessened, and it shows all the characteristics of exaggerated arterial tension.

No direct experiment has been made to measure in animals the changes in the blood pressure and the speed of the blood flow.

The capillary circulation is evidently much changed. The skin and the mucous membranes grow pale, especially when they were the seat of congestion or inflammation; in regard to this important point in therapeutics, the observations of physicians are more convincing than the experiments made by Vivenot on the ears of white rabbits.

The blood becomes a brilliant red in color; this has been observed particularly in caisson workers. The venous blood drawn from the arm, as Pol and Watelle were the first to note (page 367), looks as if it were arterial, a certain indication of the greater proportion of oxygen which it contains: according to these authors, this redness of the blood persists for some time.

Secretions. The only important observation which has been made concerns the increase in the urinary secretion; but no exact measurement has been taken, and no analysis of the urine has been made.

Some observers have spoken of the dryness of the skin, but it is difficult to get exact estimates on this point.

Nutrition. Very different estimates of the variations in the weight of the body have been made by different authors. The physicians of caisson workers and divers declare that there is a loss of weight; those who used compressed air with a therapeutic purpose consider that there is an increase in weight. Besides the fact that there may be a great difference in this regard between the effect of a pressure of 3 atmospheres and that of the pressure of a few centimeters of mercury, one can hardly compare caisson workers, men who are exhausted by their hard labor, who seek dangerous assistance in alcoholic beverages, and who are generally much undernourished, with subjects who are in excellent hygienic conditions and who can satisfy completely the increased appetite 
which a stay in the bells seems to produce. On this point then, it hardly seems possible to reach any conclusion.

The observations of Vivenot on an increase in body temperature, of from $0.1^{\circ}$ to $0.4^{\circ}$, do not seem to me at all convincing.

As to the production of carbonic acid in a given time, we shall speak of that in the next section.

Innervation. It is very difficult to see, in the accounts of the authors, any clear indications in regard to sensory functions. Taste and smell are disagreeably affected by the impurities in the air of the caissons, and the ear is affected by the distention of the tympanic membrane.

They do not agree in regard to the functions of the brain. Colladon (page 357 ) mentions a stimulation which resembles intoxication; M. Junod (page 414) states that "the functions of the brain are stimulated;" M. Foley, when he left the caissons, it is true, was attacked by an excessive cerebral excitation which made him "catch himself in the very act of babbling, in spite of all his efforts." J. Lange (page 477) states that constantly, even in the apparatus, "one experiences an activity and coolness of mind which did not exist before." On the opposite side, Dr. François says that especially at the beginning one feels a sort of drowsiness, and according to G. Lange, the only phenomenon which one can note is "a feeling of calmness generally followed by a desire to sleep."

\section{B. Phenomena Due to Decompression.}

Their severity depends, as we have said, upon two factors to which it is proportional: the degree of pressure reached, the speed of the decompression.

Up to 2 atmospheres, no symptom seems to appear in the workmen. Above that, there appear more and more frequently cutaneous itchings, "puces" (fleas), which finally cause very keen pains; they are much more common in caisson workers than in divers. Then come painful swellings of the muscles, particularly, according to the accurate note of M. Foley, of those muscles which worked hardest during the stay in compressed air; at the same time, periarticular pains. Not until the pressure is above 3 atmospheres do really serious symptoms occur: sensory disturbances, blindness, deafness, disturbances of locomotion and general sensitivity, especially paralysis of the lower limbs, the bladder, the rectum, and, much more rarely, the thoracic members; cerebral disturbances, loss of consciousness; finally, sudden death.

These symptoms do not appear until after a few minutes and 
sometimes a few hours after leaving the caissons or the diving suits; in one case observed by M. Gal, the paraplegia did not begin until twenty-four hours after the decompression had been made. The time given to decompression is, moreover, extremely variable; in divers, it takes place with a speed which the good advice of M. Denayrouze could not reduce; for the caisson workers, it was at most three or four minutes per atmosphere.

Slight disturbances, cutaneous, muscular, and articular pains always disappear in a rather short time. The same thing is often true of more serious symptoms, and even of loss of consciousness. But too frequently the paralyses of the lower limbs are persistent, and we have reported numerous observations which make a sad picture of these unhappy men whose sufferings death almost always ends after a period of variable length. In none of the cases which we reported was a paraplegia which lasted more than two days ever completely cured.

The irregularity between different persons in regard to the effects of decompression is one of the strangest circumstances revealed to us by this study. We have seen by many examples that, of several persons subjected to the same pressure and decompressed at the same rate, some remained absolutely immune, others had only slight symptoms, whereas one among them might be attacked severely. Similar variations occur in many other circumstances, even a mere departure from the ball shows similar irregularities. But the strange fact about the present case is that these symptoms are attributed, and justly, as we shall prove, to a purely physical cause, and physics should be the same for everyone. But the irregularity does not exist merely between different individuals; it exists in the same person, following circumstances not well determined. It is not rare to see a workman, hitherto spared, attacked when leaving a pressure the same as, sometimes even lower than, those the removal of which he had already endured without any ill effect. The commonplace and ready excuse of alcoholic or other excesses has often been advanced to explain these facts; but sometimes this explanation, which is not one at all from the standpoint of physics, was completely wanting. The only circumstance on which observers agree is the length of the stay in compressed air; the longer it is, the more are the symptoms to be feared, so that certain authors have concluded that the shifts, that is, the intervals of work in the caissons, should be made more numerous, without considering that the decompressions, which cause the symptoms, would thus be increased in number also. 
The rule to decompress slowly, aside from any theoretical idea, has been accepted by all authors and proclaimed by the workmen themselves, although in practice the intense cold which accompanies the decompression urges the latter to make haste. M. Foley alone seems not to consider it important, and, on the contrary, advises rapid decompression (page 377 ).

\section{Theoretical Explanations.}

Here again we must separate the symptoms observed during the stay in compressed air from the symptoms of decompression.

\section{A. Phenomena Due to Compression.}

Of course, there could be no question here of seeking elsewhere than in the compressed air the cause of the symptoms reported by experimenters or workmen; the strange hypotheses which we have discussed in regard to mountain sickness could not be suggested here. But this effect of compressed air was considered by some from the physico-mechanical point of view, by others from a purely chemical standpoint. I recall only for the record the so-called explanation given by Brizé-Fradin (page 444), which advances the theory of "vital force," and then has recourse to it to "change general laws" and settle things according to his desire.

Physico-mechanical Explanations. Let us set aside, first as really not worthy of discussion, the idea that air compressed to several atmospheres would hinder the movements of locomotion, and, second as too apparent, the effect of compressed air on the tympanic membrane, of which we have already spoken. We are first faced by the explanation which we have had to combat in speaking of decompression, that is, the difference in the weight sustained by the body.

We have quoted the calculations which Guérard took pains to make to show to what a crushing weight a man would be exposed who is working under a pressure of several atmospheres. So the workmen of the Kehl bridge would have had to sustain an additional weight of 54,000 kilograms. In fact, if, as we have already shown (page 341), elementary physics did not pass sentence on these ideas in the name of the incompressibility of liquids and solids, these figures alone should have warned the authors of the enormity of the error which they were committing. However, almost all have accepted this explanation; M. Foley expresses it in striking words: "As soon as one enters the caissons, one is flattened" (page 464). 
Almost all the authors, I repeat, even the shrewdest and the best qualified, even Pravaz, Bucquoy, Vivenot, etc., believe in the direct and mechanical effect of the pressure. What could draw such keen intellects into such an error? A very accurate observation, made by all observers: the pallor of the skin and the mucous membranes in workmen or experimenters, and especially in patients, when the mucous membrane was inflamed. In rarified air, we have seen, the veins and the superficial capillaries are filled, as if the blood was forced to the periphery; in compressed air, these vessels are emptied, as if the blood was forced back into the interior. Thence came, in the first case, the theory of the general cupping-glass; in the second, that of the crushing weight; "the compressed air," says M. Foley again, who frequently returns to this idea with singular energy, "everywhere flattens the mucous membrane which is exposed to the air" (page 375).

The other authors are generally more prudent; they feel embarrassed by physics, which protests against their theory. Nothing is more curious than the attempts of M. Bucquoy to escape from this contradiction; but his theory of pressure decreasing progressively from the skin to the deep tissues is not tenable (page 459). I also call attention to the ideas of M. Junod, G. Lange, and M. Leroy de Méricourt about the supposed forcing of the blood into the brain, due to the fact that since it is protected by the cranial case, the brain cannot be compressed directly like the rest of the body; these authors have forgotten that the pressure is applied instantaneously to the spinal cord and the brain by other paths than the blood vessels, so that there is equality of pressure in this organ as there is elsewhere, and the circulation of the blood in it cannot be changed at all.

But even if we can understand that the complexity of the conditions presented by the human body, considered as a whole, has drawn distinguished intellects into such astonishing physical errors, we can hardly explain why, when the question was reduced to its simplest terms, they did not immediately recognize what a mistake they were making. And yet we have seen Vivenot, with the aim of explaining the changes which a stay in compressed air causes in the form of the pulse, carry out the strange experiment reported above (page 474), and maintain that a pressure of a third of an atmosphere is enough to change the volume and the elastic reaction of a rubber ball filled with water.

I was curious enough to repeat this experiment, not to enlighten myself in regard to it, but to learn what could have given Vivenot 
graphic tracings different in normal air and in compressed air; from my attempts I concluded that very probably Vivenot had not closed his apparatus tightly, and that besides he had left air in it. We understand that it is absolutely useless to dwell on conclusions which are "ganz unphysikalisch," as Panum says very truly. The strangest part of the matter is that this experiment, so oddly conceived and so poorly carried out, has been accepted and praised on both sides of the Rhine. Vivenot has made an experiment! they said. And that is enough for many people; for there is a whole school of medicine, the followers of which, of course, have never frequented laboratories, for whom the word "experiment" answers for everything, like the "cream tart" of the comedy.

Pravaz did not fail to apply to compression the theory which we have already quoted (page 345) in regard to decompression. According to him, the blood is forced more energetically into the interior organs at the time of the inspiration in compressed air, because the exterior pressure acts more vigorously upon the venous system. But, as we have already said, it must be proved that in compressed air the intra-thoracic negative pressure is stronger than at one atmosphere. The conclusions of Vivenot say so, it is true, but I was unable to find the proof of it in his book.

Finally I shall mention the interesting theory developed by M. Bouchard (page 484). According to him, the abdominal wall, crowded in by the pressure on account of the decrease in volume of the intestinal gases, would tend to resume its shape through its elasticity, and thus would exert upon the abdominal organs a sort of suction, which would cause a storing up of the blood there: the result being visceral congestions and general anemia. For my part, I cannot accept this original idea; it is not only the abdominal wall which is pushed inward; the diaphragm is in the same situation, and we have seen that the vertical diameter of the chest increases. Now it seems to me impossible to admit that these muscular membranes present sufficient elasticity to resist the compression and thus act as a cupping-glass: on the contrary, they should, especially the diaphragm, yield to it very passively.

Nevertheless it is true that, for various reasons, the blood seems to be pushed back from the periphery towards the more deeply situated organs; the result is important modifications in the circulation and the metabolism of the different parts of the body, modifications which may have been of great therapeutic value, but from which the health may suffer, when they continue too long. 
Variations in the respiratory amplitude and rhythm have also been explained by the mechanical action of compressed air.

Some, like Pravaz, have thought that compressed air promotes pulmonary expansion, by opposing more energetically the elastic reaction of the tissues. That is the converse of the theory suggested in regard to decompression, the inexactness, or at least the great exaggeration, of which we have shown.

Others, with much better reason, have cited the effect of intestinal gases. In fact, they form the only part of the organism upon which the pressure of the air can act directly. Even though their volume cannot increase in the phase of rarefaction, as we have seen, because of the two orifices which allow an excess to escape so easily, it can and evidently must decrease following the Law of Mariotte, and indefinitely, as the outer air is more compressed. And this really does take place; caisson workmen, whom I have questioned, have told me that they were compelled, when once in the caissons, to pull up the buckle of their pantaloons because of the retraction of the belly.

Although this fact has been established, I cannot accept the conclusion which Pravaz draws from it (page 448), that the increased elasticity of these gases hampers the action of the diaphragm, and decreases the vertical expansion of the thorax, but increases the expansion of the chest in the other two directions. Besides the fact that this hypothesis hardly seems tenable, the measurements obtained directly by Vivenot by means of percussion and auscultation show that in compressed air the lungs drop lower than in the normal state.

To disclose the mechanism of the increase of the thoracic cavity, Panum performed an experiment which we reported above (page 480 ). It has only one defect, namely, that it was useless to make it; certainly, if we are given a tube closed at its ends by two membranes of unequal thickness, filled with water and containing besides a bladder full of air, if this apparatus is put under pressure, we shall see the bladder decrease in volume and the two membranes pushed into the tube in inverse proportion to their thickness. Very evidently something similar must take place in the abdomen, between the gases of the intestines on the one hand and the diaphragm and ventral wall on the other. The whole interest of the question lies in knowing in what proportions these lastmentioned organs tend to invade, pushing from without inward, the space which was occupied by the intestinal gases, now diminished in volume. But Panum's experiment says nothing about that. 
Chemical explanations. The idea that under a greater barometric pressure the blood, as it passes through the lungs, is lader with a greater proportion of oxygen, is a very natural idea, which was accepted by all the authors, up to the time of and including Brizé-Fradin (page 444). It found an obvious confirmation in the observation made by Pol and Watelle, François, Foley, and all the physicians who attended caisson workers, that the blood drawn from the veins during the compression, or even some time after the decompression, is red and arterial in color. The apparently contradictory experiments of M. Fernet (page 249) did not make much impression on the authors in the face of this very obvious fact. Only M. Bucquoy (page 459) tried to discuss them; in his opinion, it is only the dissolved oxygen whose proportion increases, because M. Fernet has proved that the blood corpuscles do not absorb a greater quantity of oxygen in compressed air than in free air. The other authors merely state that the blood is richer in oxygen, and draw from that all the conclusions which they think inspired by logic, a guide which one must always distrust in these complex matters.

For M. Foley, for example, "the hyperarterialization" of the blood cannot be doubted, and it results in "an enormous consumption of the different tissues, because of the excess of oxygen which penetrates them." But the existence of this increase in the intraorganic combustions would have to be proved.

But the experiments of MM. Regnault and Reiset, showing that animals which breathe in a medium with very high oxygen content do not absorb more of this gas and do not form more carbonic acid there than in ordinary air, showed that the idea of an increased chemical activity was not very probable. Pravaz, the only one who with Panum (page 480) seems to have understood the import of the objection, makes a rather unsatisfactory reply to it (page 448) in such a way as to compromise his reputation as a physicist a little. But he did have two of his pupils, Hervier and Saint-Lager, perform experiments tending to settle the difficulty directly.

We know what complicated conclusions (page 449) these experimenters reached when they tried to determine the modifications which a stay in compressed air makes in the excretion of carbonic acid and consequently in the consumption of oxygen. I shall not try to discuss them, because such researches are of value only because of the method employed; I have already stated that this method was extremely faulty. In so delicate a matter, in 
which one may assume that the differences will be very slight, it is indispensable to observe scrupulously both chemical precision and above all physiological exactness.

It is not the first one of these conditions which is missing, at least apparently, in the work of Vivenot. If we may believe his figures, the analysis he made of the carbonic acid contained in one expiration was exact down to the sixth decimal, and that by itself, I confess, would be enough to make me distrustful. Thus the quantity of carbonic acid exhaled in 24 hours at normal pressure being $1300.37760 \mathrm{gm}$., in compressed air it would be $1449.49350 \mathrm{gm}$. That seems very conclusive. But how were these figures obtained? By analyzing the product of one expiration "as strong as possible, but made without great efforts" at normal pressure, which gave $0.2176 \mathrm{gm}$. of carbonic acid, and of one expiration under compression, which gave $0.2676 \mathrm{gm}$; by taking into account the average number of respiratory movements per minute, which was 4.15 for the first case and 3.76 for the second; and finally, by multiplying the number thus found by 60 then by 24 .

As for me, I refuse to grant any sort of value to figures obtained by a method so absolutely contrary to what true precision, physiological precision, requires. To take as a basis one expiration, made at the rate of 3.76 respiratory movements per minute, certainly extraordinary conditions, is to expose oneself in the name of the experimental method to the severest criticisms. I do not hesitate to say, without going into the details of the experiments, without laying stress on the "rubber tubes not hermetically closed" (page 470), that all this part of Vivenot's work, in spite of his innumerable tabelles and his columns of figures in which the table of logarithms has "worked wonders," should be considered null and void.

This is also the opinion of Panum, who studied the same question, under conditions which are better, no doubt, but are still open to reproach. However, his experiments give evidence in the same direction, and tend to show that in compressed air there is more carbonic acid produced in a given time than at normal pressure.

I admit that to my mind this fact is not proved; a glance at the table published by Panum is enough to justify my doubts even about the results of his experiments; for we see that after all there are only four of them which are comparable and under normal conditions, and that of these four only one was made at ordinary pressure. Moreover, the respiration was carried on for only 10 
to 12 minutes; finally, nothing was said of the diet to which the subject of the experiments was limited.

The increase in the quantity of carbonic acid exhaled in compressed air, admitted without argument by Pravaz, M. Foley, and the German physiologists, led them to conclude that a greater quantity of oxygen was absorbed even during the compression. Hence a whole series of conclusions, already glimpsed by the earlier authors: nervous stimulation, muscular energy, combustion of the tissues are easily deduced from it. Hence the increase in the quantity of urine excreted (?), the slight rise in temperature (?), the insatiable appetite, which causes an increase in weight if it can be satisfied, and a loss of weight under opposite conditions. All that links up very well, one must admit; but the method which bases the accuracy of the premises upon their harmony with the conclusions is a very dangerous one: it never proves anything to the mind of an experimenter. Therefore I do not dwell upon these data, all the details of which I have given above.

\section{B. Phenomena Due to the Decompression.}

Physicians who have attended caisson workers and divers working in suits have been unanimous in attributing to congestions of the blood, sometimes going as far as hemorrhage, the symptoms following decompression: congestion of the lungs, the abdominal viscera, and particularly the encephalic and spinal nervous centers. But they have not clearly determined the method of producing these congestions, far from it.

$\mathrm{Pol}$ and Watelle believe that the congestion is produced during the very act of compression by the centripetal driving back of the blood; if it does not produce its effect then, it is because the superoxygenated blood has no harmful effect upon the organs. At the time of decompression, the blood loses oxygen, and the usual consequences of congestion appear (page 452). I confess I do not understand very well how the physicians of Douchy could reconcile their theory with the cases which they observed themselves in which the most serious symptoms existed at the exact time when the venous blood was brilliantly red.

M. Foley, in his explanation of the "post-caisson congestion," is so vague that I prefer to refer the reader to the word-for-word quotations which I made from his memoir (page 463). Babington and Cuthbert (page 466) do not express themselves much more clearly: in their opinion, the protection of the skull and the spinal column would prevent, at the time of the decompression, "the 
excess pressure on the brain and the spinal cord from escaping rather rapidly by the narrow passages through which the blood leaves these organs:" and hence the congestions, or rather the nervous compressions. This error in physics really does not deserve refutation.

On this subject M. Bouchard has conceived an idea worthy of attention. It might be the sudden expansion of the intestinal gases, originally compressed, which would suddenly expel the blood contained in the abdominal viscera, would drive it into the general circulation, and produce the congestions and the hemorrhages in the nervous organs (page 486). I confess that I cannot admit that an expansion of gas, in a canal open at both ends, when dealing with walls as extensible as the diaphragm and the abdominal muscles, can expel the blood from the liver, the spleen, etc., so violently as to produce such disturbances.

Another explanation of the symptoms of decompression has been suggested by M. Bucquoy, and prompted by the lectures of Professor Rameaux, of Strassburg (page 459). Under the effect of pressure, the gases of the blood would increase in quantity, the oxygen following Dalton's Law, the nitrogen and the carbonic acid following a lessened progression, "since they are not drawn in in the inspired air, but engendered by the physical phenomena of life." As a result, at the time of decompression, these gases tend to be liberated again, just as "the carbonic acid escapes from charged water, when the stopper is removed from the bottle containing it." And M. Bucquoy mentions, to support this hypothesis so probable in its general features, the emphysemas observed at Douchy, the cure of muscular swellings by recompression, and a very interesting observation which we have reported in full (page 460)

F. Hoppe, as we have seen, had already had the same idea; but he based it only on experiments made on decompression by the pneumatic machine, and brought no personal observation to support his hypothesis (page 455).

The idea of M. Bucquoy was accepted by M. François, who, however, seems not to have had a very clear understanding of it, because he speaks of "an amalgamation of the cellular tissue with the air from the blowers, like that of mercury with hog's lard" (page 456), and by all the authors who followed him, Vivenot (page 435), Panum (page 480), M. Gavarret (page 482), M. Leroy de Méricourt (page 483), etc.; M. Foley alone did not believe in it (page 463). M. Bouchard (page 484), M. Gal (page 486), and others 
admit both the visceral congestions and the escape of the free gases from the blood.

But no one has seen this escape, since no experiment has been made. And what are these free gases? The three gases of the blood and especially the oxygen, as M. Bucquoy indicates? Nothing proves it; how can we believe that the oxygen, which combines so easily with the tissues, can become gaseous again, and present a serious, unconquerable obstacle to the circulation of this blood which usually absorbs it so rapidly, and into which one can inject it in large quantities without danger? Then how does the gas act when it is freed? By obliterating the vessels? By causing hemorrhages? And how can it be that the symptoms are only the exception, even above four atmospheres? Could one not deny the truth of the hypothesis itself, by maintaining that, if it must be admitted, all the workmen decompressed at the same time should have their blood like the charged water which escapes from the uncorked bottle of which M. Bucquoy speaks, and should consequently be stricken simultaneously?

We see, although it is probable a priori, and true as stated in advance, the theory of free gases is far from being proved today. Even for those who expressed and supported it, it is mingled with other theories, and nothing very definite is evolved from the summary which we have just made. 


\section{Part II}

\section{EXPERIMENTS}


,

$$
\text { - }
$$




\section{Chapter I}

\section{CHEMICAL CONDITIONS OF THE IEEATH OF ANIMALS SUBJECTED TO DIFFERENT BAROMETIC PRESSURES IN CLOSED VESSELS}

The numerous researches I formerly made on the final composition of the air contained in closed vessels in which animals were kept till death ${ }^{1}$ decided me to begin the study of the influence exerted on living organisms by modifications in the barometric pressure, by analyzing the air which had become incapable of supporting life in consequence of confinement, when this air is subjected to pressures differing from the normal pressure.

A certain number of preliminary experiments, details of which it would be useless to give here, had already given me the idea that the principal, if not the sole cause of this influence, of which aeronauts on one hand and men in diving apparatus on the other present the most striking examples, was the different composition of the gases contained in the blood, as a result of the different pressures. It seemed, therefore, that the shortest and best way of settling the question would be to begin by installing and operating the apparatuses necessary for studying these gases of the blood. However, I gave up this idea, though it seemed the simplest, and determined to attack the problem by the indirect method of studying the confined air; for this I had two reasons. In the first place, I thought that I should thus find some new ideas on the question of asphyxia, in which I had long been interested; secondly, the problem which I was undertaking to solve seemed to me to present such apparent complexity that I thought it best not to go straight to what it seemed a priori should give me the general solution for fear of being too quickly satisfied, and letting escape certain elements which perhaps were very important. I hoped, if I may be 
permitted this comparison, that in going across lots instead of following the highway, I should find out something usefui and strange. The reader may judge whether my hope was deceived; I merely wish to clear myself in advance of the charge of lacking logic which might appear well founded, without daring nevertheless, in spite of my great desire to do so, to declare that this indirect, and as it were oblique approach should be in many cases adopted as the general method of research.

Now that this first question was given, I had to consider it from all its points of view, and they are numerous. I could first consider animals of the same species dying in closed receptacles under pressures higher or lower than the normal barometric pressure. I could next compare to each other animals of different species in similar barometric conditions. Finally, I must examine the action, under different pressures, of respirable media the chemical composition of which differed from that of atmospheric air, because this last consideration, applied to the theory of asphyxia, had given Claude Bernard. data of great interest.

I therefore adopted these various points of view, and I shall give an account successively of the results which experimentation gave me. I shall begin with the study of ordinary air and end with that of air of different composition, and in both cases I shall take up first decreased, then increased pressure. Each part of my research will furnish the text of individual discussions; but it is clear that general conclusions can be drawn only from their simultaneous study, since the different data will so complete each other and will be so intermeshed, so to speak, as to lead to a general result which even now I can state in this rather paradoxical form: pressure in its greatest variations, for example, from 10 centimeters of mercury to 20 atmospheres, when these variations are made with sufficient slowness, acts on living beings not as a direct, physical agent, but as a chemical agent changing the proportions of oxygen contained in the blood, and causing either asphyxia, when there is not enough of it, or toxic symptoms when there is too much. It is upon the demonstration of this truth that all the experimental data, the details of which I shall now give, converge. 


\section{Subchapter I \\ PRESSURES BELOW ONE ATMOSPHERE}

\section{Experimental Set-Ūp.}

The apparatus with which I made my experiments on the composition of the confined air in which animals die under pressures less than one atmosphere, is very simple.

On a table four glass discs are fixed, mounted on copper plates like those of pneumatic machines (Fig. 15) A, so that four experiments can be carried on side by side. Since the four parts of the apparatus are absolutely alike, only one need be described.

The disc is pierced in the center by an orifice through which passes a lead tube topped with a movable cap B, which will prevent the animal from being moved by the air suction. This tube leads to a cross-pipe CC', which communicates with a suction pump operated by a steam engine; a cock D permits or cuts off communication. Between the cock and the mouth $\mathrm{B}$ extends a long glass tube with two bends EFGH, which contains mercury. It is clear that when the bell-jar I is fixed on disc A and the suction pump is set in motion, the mercury will rise in the closed arm of the glass tube, and that the difference between the levels $n n$ ' measured on the divided rule $\mathrm{K}$ will show exactly the amount of decompression; $e$ is a bulb intended to hold the mercury which a piston stroke that was too strong might suck into the lead tubes. The bell-jar I ends in a neck closed with a rubber stopper through which pass a thermometer $\mathrm{L}$ and a cock $\mathrm{M}$; the lower extremity of the latter has a rubber tube, so that the air, which is extracted by the process I shall explain in a moment, comes from the middle of the bell-jar.

If these experiments are to give a satisfactory result, the apparatus must be hermetically sealed and must keep exactly the degree of vacuum to which it has been brought; the least opening, permitting a little air to enter, may be the cause of serious errors, as I found to my expense. To obtain the necessary hermetical sealing, I immersed in water all the cracks through which the air might enter. And therefore, the glass disc, on which the bell-jar is fastened by tallow as usual, is surrounded by a projecting circle of zinc $\mathrm{N}$, into which water is poured; likewise, rubber capsules $\mathrm{O}$ and $\mathrm{P}$ form a hydraulic seal for the adjusting of the cock $\mathrm{M}$ and the manometric tube $\mathrm{E}$; the cocks $\mathrm{D}$ and $\mathrm{Q}$ are immersed in water in the receptacle $R$ and the zinc gutter SS'. This device insures that, if the closing was not perfect, water would enter 
instead of air, which would be a danger signal and show the place where the apparatus was faulty.

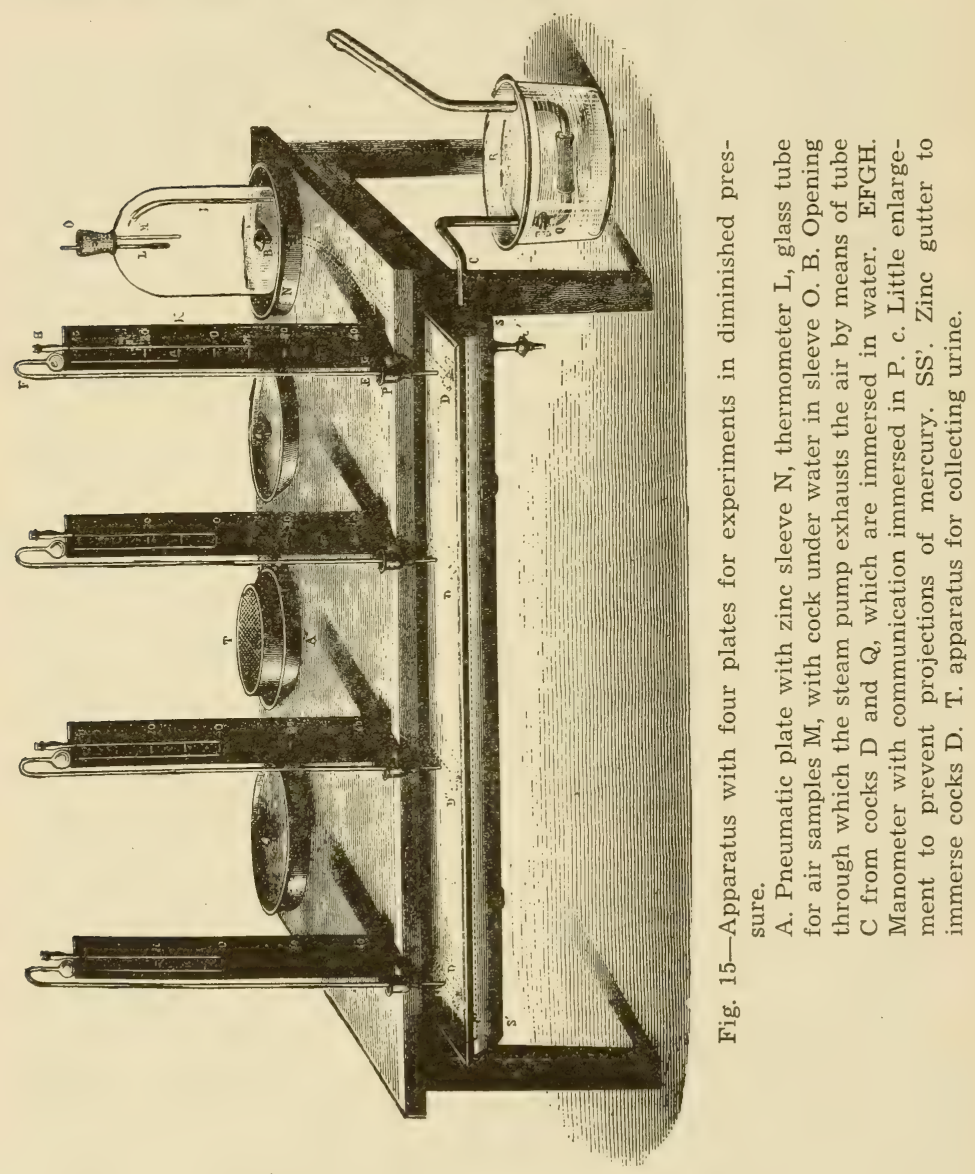

The animals placed under the bell-jar can be kept at a specified height by means of a screen $\mathrm{T}$, if it appears necessary.

When everything is ready, the pump is started, and the reader will easily understand how one can, by varying the opening of the cock M, diminish more or less rapidly the pressure in the 
bell-jar, while maintaining a current of pure air. This precaution, as will be seen later, permits animals to become accustomed to a certain degree to rather low pressures, which they seem unable to endure at first. When I needed diminutions of pressure which the pump could not give me, as soon as it stopped working, I closed cock D (cock M having been closed some time before) and put cock $M$ in communication with an ordinary air pump by a thick rubber tube, being able in this way to secure a vacuum of about $1 \mathrm{~cm}$. However, I rarely needed to resort to this procedure.

Now I must explain how I procured for analysis at a given moment, especially after the death of the animal, a certain quantity of the air contained in the bell-jar.

For this purpose I used the little model of mercury pump constructed by MM. Alvergniat. I think I should give here a description of this instrument which will be mentioned often in this work.

The mercury pump (Fig. 16) consists of a barometric tube whose chamber A forms a large bulb and has on top a cock R, which I shall discuss shortly, the cock being surmounted by a little mercury bowl C. The barometric tube is connected below by a very thick rubber tube with a reservoir $B$, whose capacity exceeds a little that of chamber A. This reservoir is fixed on a piece of wood which can slide up or down in a double groove by means of a system of gears whose arrangement the figure shows.

The whole operation of the apparatus really depends on the different positions of cock R. This is a three-way cock; the glass ring in which it turns communicates by three orifices with the barometric chamber, the mercury bowl, and the lateral tube leading to the exterior.

The cock itself is pierced by two channels meeting at right angles. It is easy to understand the significance of its different positions, which are represented above at the left in Figure 16. In 1 , all communication is cut off, and the barometric chamber is hermetically closed; in 2, communication is made between the chamber and the mercury bowl; in 3, communication between the chamber and the lateral tube.

This glass cock, when properly greased, keeps the vacuum perfectly. However, for fear that air bubbles, penetrating between the cock and its ring, should vitiate results, I had the whole enclosed in a jacket of iron and rubber, which is kept full of water.

The last detail of construction is the graduated rule, which allows the height of the mercury column to be measured, which is often useful; the whole apparatus is mounted on a wooden case 
equipped with casters and supporting screws and surrounded by ledges intended to catch the mercury which often falls and would be lost in considerable quantity during the different operations.

It is clear that by pouring mercury into reservoir B previously set at its highest point, and bringing cock $\mathrm{R}$ to position 2, one can expel the air contained in the barometric tube and its chamber

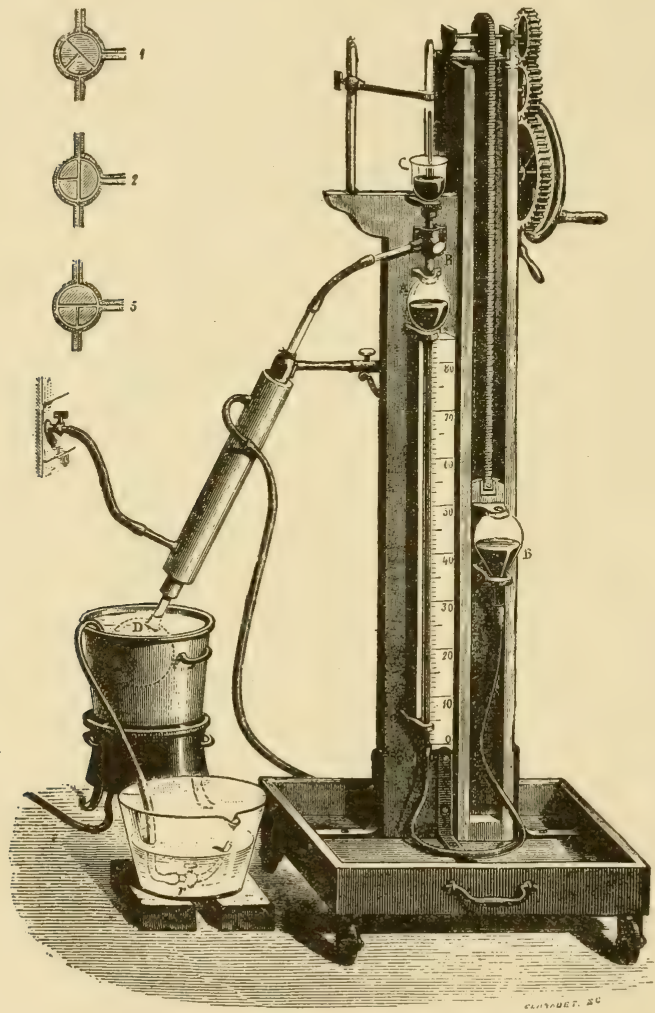

Fig. 16-Mercury pump set up for the extraction of the gases of the blood. A. Barometric chamber. B. Movable bulb, in communication with A by rubber and glass tube. C. Mercury bowl with graduated tube to collect gases. R. Three-way cock which can completely close the barometric ehamber (position 1), or connect A with $\mathrm{C}$ (position 2), or A with D (position 3): 
and replace it by mercury, which then rises into the bowl $C$. If then the cock $R$ is closed (position 1) and the reservoir $B$ is set at the bottom of the groove, the mercury will fall in the tube and remain at $76 \mathrm{~cm}$. above the level of reservoir $\mathrm{B}$; in other words, there will be a barometric vacuum in chamber $A$. If then cock $R$ is turned (position 3) to put this chamber in communication with the lateral tube which, in our figure, communicates with a system of sleeve and balloon serving only for the extraction of blood gases, a certain quantity of outside air is introduced, and the mercury descends in the barometric tube. When the cock is closed (position 1), a quantity of this air is imprisoned; and if any is needed for an analysis, one needs only to raise reservoir $B$ and shift cock $R$ to position 2, and the air driven out by the rising mercury passes through the little bowl $\mathrm{C}$ and enters the inverted tube which is ready to receive it.

The invention of the mercury pump is usually attributed to German technicians, and with the love of foreign advertising customary to us we often decorate this instrument with the name of "Geissler pump." The truth is that the invention belongs in principle to M. Regnault. Long ago this famous professor of the Collège de France invented a similar pump, equipped with a three-way cock, which is the most important part of the instrument. But instead of using a movable reservoir, since at that time rubber was seldom used in the construction of apparatuses, he put his barometric tube in communication with two reservoirs, one above and one below; this required, of course, a rather complicated system of tubes and cocks. But the principle was the same, and the addition of a rubber tube is certainly not of sufficient importance to make us forget the real inventor.

And now it is very simple to understand how this instrument can be applied to extracting the air contained in the bell-jars of the apparatus represented in Figure 15. The only thing necessary is to add to the lateral tube, which in Figure 16 communicates with the balloon D, a rubber tube which can sustain a vacuum, and which covers with its other end the cock $M$, which is at the top of the bell-jar in which the experimental animal is contained. When this cock has been closed and a vacuum has been made in chamber $A$, I put cock $R$ in position 3 so as to exhaust the air from the rubber tube $S$; then close cock $R$ (position 1 ), raise reservoir $\mathrm{B}$ as high as possible, place the cock in position 2, and the air passes out over the mercury in the bowl, over which the tube has not yet been inverted. When this procedure has been repeated 
two or three times, a complete vacuum has been made in the whole apparatus, including the rubber tube, as is proved by the sharp click of the mercury (the "mercury hammer") against the closed cock $R$, the force of which must be lessened by raising the reservoir carefully.

When this has been done, and when reservoir $B$ has been lowered as far as possible and cock $R$ has been placed in position 3 , I open the communicating cock between the bell-jar from which I wish to take an air sample and the rubber tube. Evidently, a certain quantity of air from the bell-jar rushes out and fills bulb A. As a precaution, I let out this air for fear that the vacuum has not been perfect in the lateral tube and the barometric chamber, and begin the same procedure again. But this time I invert over bowl $\mathrm{C}$ a graduated tube full of mercury, and the gas which has been compressed in chamber A as a result of raising reservoir B comes into the tube bubble by bubble through a passage carefully controlled in shifting from position 1 to position 2 of the cock. The gas thus collected can easily be removed for analysis.

The analysis is made over the mercury bowl by means of a solution of potash to absorb the carbonic acid, then by another solution of pyrogallic acid to absorb the oxygen. The differences of level, measured in the graduated tube, by a very simple calculation give the percentage composition of the gas. This method of analysis, extremely convenient and rapid when one is careful to shake the tube vigorously, especially after the introduction of the pyrogallic acid, seems to me superior to any other.

A German physiologist, who visited my laboratory one day, reproved me severely for measuring the differences of level without using a cathetometer; for not using the Bunsen method, by bubbles of potash and phosphorus, which gives more exact results; for not having deducted the value of the column of liquid, which lessens by two or three centimeters of water the tension of the air contained in the graduated tube; and for not having taken into account the small quantity of oxide of carbon which may be formed during the absorption of oxygen by the pyrogallate. I should not mention these petty criticisms here if they did not furnish a very characteristic example of a common mistake in method from the other side of the Rhine, which affected pedants would like to import into France. I have already had the opportunity to express my opinion of this useless and dangerous.search for false exactness. I mention - it in reference to the present analyses merely to state that the causes of errors pointed out affect only the third decimal, which I 
took care never to record. The reader will see, when I discuss the results of the experiments, how circumstances which it is impossible to foresee and very often impossible to explain can cause variations in the numbers furnished by the analyses in the first decimal or even in the units. Worrying about a third decimal would be silly.

These observations refer, of course, to all the gas analyses enumerated in the present work, whether of compressed or expanded air, gases extracted from the blood, etc.

2. Experiments.

A. Experiments on Birds.

These are much the most numerous.

Sparrows (house sparrow, Fringilla domestica, Lin. and mountain sparrow, Fringilla montana, Lin.) were chiefly used in these experiments and in those relating to increased pressure.

I will begin by giving details of experiments in which death in confined air took place at normal pressure. They will serve as comparison for the others.

Experiment I. March 21, temp. $15^{\circ}$. House sparrow, vigorous, weighing $31 \mathrm{gm}$. Placed on the mercury reservoir in a bell measuring 1 liter; a cork ring separates it from the mercury.

Entered at 1:40; died at 2:45; duration of life, 1 hour 5 minutes. Composition of lethal air : $\mathrm{O}=3.0 ; \mathrm{CO}_{2}=14.8$ t

Addition of oxygen remaining and carbonic acid formed:

$\mathrm{CO}_{2}+\mathrm{O}_{2}=17.8$

Proportion of carbonic acid formed to oxygen disappeared:

$\frac{\mathrm{CO} z}{\mathrm{O}_{2}}=\frac{14.8}{17.9}=0.82$

Experiment II. March 18. House sparrow.

Bell of 1.9 liters. Entered at 1:10, dead at 3:05. Final decompression results from absorption of $2.3 \mathrm{~cm}$. There is no bloody spot on the head.

Lethal air : $\mathrm{O}=4.2 ; \mathrm{CO}_{2} 14.6$

$\mathrm{CO}_{2}+\mathrm{O}_{2}=18.8 ; \frac{\mathrm{CO}_{2}}{\mathrm{O}_{2}}=0.87$

Experiment III. July 20; temp. $24^{\circ}$. House sparrow.

Bell of 1.3 liters. Entered at 3:15, normal pressure. Not dead at $6: 15$, dies about 7 .

Lethal air : $\mathrm{O}_{2} 3.3 ; \mathrm{CO}_{2} 16.0$

$\mathrm{CO}_{2}+\mathrm{O}_{2}=19.3 ; \frac{\mathrm{CO}_{2}}{\mathrm{O}_{2}}=0.86$ 
I now come to the experiments made with the apparatus pictured in Figure 15.

Experiment IV. March 24 , temp. $15^{\circ}$, pressure $75 \mathrm{~cm}$. House sparrow. Bell of 5 liters.

Entered at 2:04. Began current of air with steam engine, cock $\mathrm{M}$ being open. At 2:10, decompressed $10 \mathrm{~cm}$; at $2: 12,15 \mathrm{~cm}$; at $2: 14,20$ $\mathrm{cm}$; at $2: 17,25 \mathrm{~cm}$.; at $2: 20,30 \mathrm{~cm}$.

The cock is closed and the decompression continued. At 2:23, $32 \mathrm{~cm}$.; at 2:30, $40 \mathrm{~cm}$; at $2.37,52 \mathrm{~cm}$.; actual pressure $23 \mathrm{~cm}$.

Cock $D$ is then closed. The pressure is perfectly maintained at $23 \mathrm{~cm}$. with absorption of about 1 half-centimeter. The bird dies at $3: 55$, and therefore lived in 5 liters of air at $22.5 \mathrm{~cm}$., which represent about 1.4 liters at normal pressure, for 1 hour 35 minutes.

Composition of lethal air: $\mathrm{O}_{2} 10.3 ; \mathrm{CO}_{2} 7.5$.

$$
\mathrm{CO}_{2}+\mathrm{O}_{2}=17.8 ; \frac{\mathrm{CO}_{3}}{\mathrm{O}_{2}}=0.70 \text {. }
$$

Experiment $V$. March 25; temperature $15^{\circ}$; pressure $75 \mathrm{~cm}$. House sparrow. Bell of 3.200 liters.

Entered at 1:50; current of air. At 1:53; pressure down $10 \mathrm{~cm}$; at $1: 59,21 \mathrm{~cm}$; at $2: 02,33 \mathrm{~cm}$; at $2.05,45 \mathrm{~cm}$.; cocks closed: actual pressure $29 \mathrm{~cm}$.

Lethal air: $\mathrm{O}_{2} 9.3 ; \mathrm{CO}_{2} 11.2$.

$$
\mathrm{CO}_{2}+\mathrm{O}_{2}=20.5 ; \frac{\mathrm{CO}_{3}}{\mathrm{O}_{2}}=0.96
$$

Experiments VI to IX, simultaneous. May 6 ; temperature $16^{\circ}$; pressure $76.4 \mathrm{~cm}$. Vigorous male mountain sparrows.

VI. Bell of 2.5 liters.

Entered at 3:42. Left at normal pressure. At 6 o'clock, very sick; respiratory rate 128 ; at $6: 25$, respiratory rate 120 . Dies at 7:05. Lived three hours 23 minutes.

Lethal air: $\mathrm{O}_{2} 3.5 ; \mathrm{CO}_{2} 14.6$.

$$
\mathrm{CO}_{2}+\mathrm{O}_{2}=18.1 ; \frac{\mathrm{CO}_{3}}{\mathrm{O}_{2}}=0.84
$$

VII. Bell of 3.2 liters.

Entered at $3: 42$. Current of air; at $3: 55$, pressure down $6 \mathrm{~cm}$; at 4 o'clock, $16 \mathrm{~cm}$.; at 4:04, $21.4 \mathrm{~cm}$. Cocks closed. Actual pressure $55 \mathrm{~cm}$.

At $4: 19$, fairly calm, respiratory rate 120 ; at $5: 08$, respiratory rate 116 ; at 6 o'clock, respiratory rate 112 , does not seem sick; at 6:25, respiratory rate 108 , still well enough. Dies at 8:35.

Lived 4 hours 31 minutes, in 3.2 liters of air at $55 \mathrm{~cm}$., which represent 2.3 liters at $76 \mathrm{~cm}$.

Lethal air: $\mathrm{O}_{2} 4.5 ; \mathrm{CO}_{2} 14.4$.

$$
\mathrm{CO}_{2}+\mathrm{O}_{2}=18.9 ; \frac{\mathrm{CO}_{3}}{\mathrm{O}_{2}}=0.84
$$


VIII. Bell of 5 liters.

Entered at 3:42: current of air. At 3:55, pressure down $8 \mathrm{~cm}$; at 4 o'clock, $16 \mathrm{~cm}$; at 4:04, $19 \mathrm{~cm}$; at 4:07, $40 \mathrm{~cm}$. Actual pressure 36.4 cm. Cocks closed.

At $4: 19$, respiratory rate 150 , calm; at $5: 08$, respiratory rate 126 ; at 6 o'clock, very sick, respiratory rate 128 ; at $6: 25$, respiratory rate 150 ; dies at $7: 10$.

Lived 3 hours in 5 liters of air at $36.4 \mathrm{~cm}$., which represent 2.4 liters at $76 \mathrm{~cm}$.

Analysis lost.

IX. Bell of 11.5 liters.

Entered at 3:42: current of air. At 3:55, pressure down $14 \mathrm{~cm}$; at 4 o'clock, $29 \mathrm{~cm}$; at 4:04, $38 \mathrm{~cm}$; at 4:07, $52 \mathrm{~cm}$; at 4:11, $59 \mathrm{~cm}$. Cocks closed. Actual pressure $17.4 \mathrm{~cm}$.

Very sick afterwards. At $4: 19$, respiratory rate 140 ; at $4: 22$, dies with convulsions. Lived 11 minutes.

Lethal air: $\mathrm{O}_{2} 19.6 ; \mathrm{CO}_{2} 0.6$.

Experiments $X$ to $X I I$, simultaneous. May 11 ; temperature $16^{\circ}$; pressure $75.5 \mathrm{~cm}$.

X. Male mountain sparrow. Bell of 2.2 liters.

From $3: 20$ to $3: 22$ the pressure is dropped suddenly to $20 \mathrm{~cm}$. Immediately, collapse of bird, and death at $3: 24$, after convulsions. It was not thought necessary to take an air sample for analysis.

The left heart contains dark blood; no gas in the blood.

XI. House sparrow. Bell of 3.2 liters.

Brought from $3: 15$ to $3: 17$ to a pressure of $24.5 \mathrm{~cm}$. Collapses a moment, then recovers very well. Dies at 3:52. Lived 38 minutes in a bell the capacity of which, when reduced to a pressure of $76 \mathrm{~cm}$., represented 1.03 liters of air.

Lethal air: $\mathrm{O}_{2}$ 12.8; $\mathrm{CO}_{2} 6.2$.

$$
\mathrm{CO} 2+\mathrm{O}_{2}=19.0 ; \frac{\mathrm{CO}_{2}}{\mathrm{O}_{2}}=0.76
$$

XII. House sparrow. Bell of 4.6 liters.

Brought in a few minutes to a pressure of $34.3 \mathrm{~cm}$; hardly seems to notice it. Cocks closed at 3:09.

At 4:50, very sick, but still on its feet. Dead at 5:45. Lived 2 hours 34 minutes in a quantity of air representing 1.89 liters at $76 \mathrm{~cm}$.

Lethal air: $\mathrm{O}_{2} 8.2 ; \mathrm{CO}_{2} 10.8$.

$$
\mathrm{CO}_{2}+\mathrm{O}_{2}=19.0 ; \frac{\mathrm{CO}_{2}}{\mathrm{O}_{2}}=0.85
$$

Experiments XIII to $X V$, simultaneous. May 24; temperature $17^{\circ}$; pressure $76.5 \mathrm{~cm}$. House sparrows.

XIII. Bell of 2.5 liters.

Entered at 3:31: current of air. At 3:35, actual pressure $37 \mathrm{~cm}$ : cocks closed. The bird does not seem uncomfortable.

Dies at 5:20. Lived 1 hour 45 minutes in a quantity of air which repre- 
sents 1.22 liters of air at $76 \mathrm{~cm}$. Slight absorption of about $1 / 2 \mathrm{~cm}$. of mercury; the final pressure therefore is only $36.5 \mathrm{~cm}$.

Lethal air: $\mathrm{O}_{2} 7.2 ; \mathrm{CO}_{2} 11.5$.

$$
\mathrm{CO}_{2}+\mathrm{O}_{2}=18.7 ; \frac{\mathrm{CO}_{2}}{\mathrm{O}_{2}}=0.84 \text {. }
$$

XIV. Bell of 3.2 liters.

Begun at $3: 24$. At $3: 27$, actual pressure of $28.3 \mathrm{~cm}$; the bird does not fall; the cocks are closed.

Dies at 4:56. Lived 1 hour 30 minutes in a quantity of air corresponding to 1.19 liters; absorption of about $1 / 2 \mathrm{~cm}$; the actual pressure therefore is $27.8 \mathrm{~cm}$.

Lethal air: $\mathrm{O}_{2} 7.9 ; \mathrm{CO}=10.3$.

$$
\mathrm{CO}_{2}+\mathrm{O}_{2}=18.2 ; \frac{\mathrm{CO}_{2}}{\mathrm{O}_{2}}=0.79 \text {. }
$$

XV. Bell of 4.6 liters.

Begun at $3: 10$. At $3: 15$, drop in pressure of $51 \mathrm{~cm}$, the bird falls. At 3:17, drop of $55 \mathrm{~cm}$; cocks closed; actual pressure, $21.5 \mathrm{~cm}$.

At $3: 25$, the bird rises and appears much less uncomfortable. At $4: 42$, fairly violent convulsive struggling. Last movement at $4: 55$. Lived 1 hour 40 minutes in a quantity of air corresponding to 1.3 liters.

Lethal air: $\mathrm{O}=11.8 ; \mathrm{CO}: 7$.

$$
\mathrm{CO}_{2}+\mathrm{O}_{2}=18.8 ; \frac{\mathrm{CO}_{2}}{\mathrm{O}_{2}}=0.77 \text {. }
$$

Experiments XVI to XIX, simultaneous. May 31 ; temperature $19^{\circ}$. Pressure $75.8 \mathrm{~cm}$. Young, but vigorous sparrows.

XVI. Bell of 5 liters.

Begun at $3: 43$. At $3: 53$, the actual pressure is only $19.7 \mathrm{~cm}$. The cocks are closed.

The bird has remained motionless; but when the pressure has dropped 45 to $50 \mathrm{~cm}$; it becomes uneasy, then sick. At the moment when the cocks are closed, it seems likely to die soon. But about 4 o'clock it is considerably better.

Dead at 5:30. Lived 1 hour 45 minutes in a quantity of air corresponding to 1.30 liters.

At $5: 42$, the rectal temperature is $25.6^{\circ}$; there is no rigor mortis. At $5: 55$, the temperature is $22.8^{\circ}$ and there is rigor, which therefore came in less than 25 minutes.

Lethal air: $\mathrm{O}_{2}$ 12.9; $\mathrm{CO}_{2} 7.0$.

$$
\mathrm{CO}_{2}+\mathrm{O}_{2}=19.9 ; \frac{\mathrm{CO}_{2}}{\mathrm{O}_{2}}=0.87 \text {. }
$$

XVII. Bell of 4.6 liters.

Begun at $3: 45$. As soon as it was under the bell, the bird struggled continuously; the same thing was true during the first part of the 
decompression; at about a drop of $40 \mathrm{~cm}$., it grew calm, began to pant and grew sicker and sicker. At 3:53, the pressure was only $20.8 \mathrm{~cm}$. Cocks closed. The bird was very sick, struggled violently and convulsively, and died at $3: 55$, that is, in 2 minutes, in a quantity of air corresponding to 1.27 liters.

At $4: 15$, its rectal temperature was still $31.6^{\circ}$, and the rigor mortis was very pronounced.

Lethal air: $\mathrm{O}_{2} 20.5 ; \mathrm{CO}_{2} 0.3$.

XVIII. Bell of 3.2 liters.

Begun at $3: 47$. The bird struggled as did the preceding one, then grew calm at a drop of about $40 \mathrm{~cm}$. and immediately became quite sick. At 3:51, the pressure was only $27.8 \mathrm{~cm}$; cocks closed.

The bird was then very sick, and seized by vomiting. But he quickly recovered and was fairly well about 4 o'clock. At 6:30, died without convulsions. He therefore lived 2 hours in a quantity of air corresponding to 1.15 liters.

At $6: 42$, his rectal temperature was $21.4^{\circ}$; no rigor mortis. At $6: 45$, $21^{\circ}$; beginning rigor. At $6: 47$, that is, after 17 minutes, complete rigor; temperature $20.5^{\circ}$.

Lethal air: $\mathrm{O}_{2} 8.5 ; \mathrm{CO}_{2} 10.9$.

$$
\mathrm{CO} z+\mathrm{O} z=19.4 ; \frac{\mathrm{CO}}{\mathrm{O} z}=0.88 \text {. }
$$

XIX. To examine the natural course of the decrease of temperature and the onset of rigor mortis, at 5:07, I cut off the head of a sparrow like the preceding. The rectal temperature was $42.8^{\circ}$; the reflex movements disappeared immediately; the eye lacked sensitivity, although the beak still opened spontaneously several times. After 3 minutes, the temperature was $41.7^{\circ}$; after 15 minutes, $35.5^{\circ}$; after 23 minutes, $32.9^{\circ}$; after 38 minutes, $29.5^{\circ}$. At that time there was no rigor mortis yet.

Experiments $X X$ to $X X I V$, simultaneous. June 3 ; temperature $20^{\circ}$; pressure $76.3 \mathrm{~cm}$. House sparrows.

These experiments were made with the purpose of finding out whether the dimensions of the bells have a considerable effect upon the composition of the lethal air when the decompression is the same in all.

XX. Bell of 11.5 liters.

Begun at 2:51. At 2:57, the pressure is only $30.8 \mathrm{~cm}$. The sparrow has not struggled, he is hardly sick. Cocks closed.

At 3:05, he staggers and vomits, but recovers rather quickly; at 5:40, a little sick; at 9:30, very sick: air is extracted with the mercury pump, which decreases the pressure about $1.5 \mathrm{~cm}$. more; the bird's discomfort seems increased immediately.

Dies at 9:50; lived 6 hours 53 minutes in a bell the capacity of which, reduced to normal pressure, would represent 4.66 liters, or 1 hour 28 minutes per liter.

The rectal temperature, taken at $9: 55$, is $28.4^{\circ}$; there is no rigor mortis, but it is present at 10:05, the temperature being $26.7^{\circ}$. 
The air sample taken at $9: 30$ contained $\mathrm{O}=8.8 ; \mathrm{CO}=9.4$. The lethal air contained $\mathrm{O}_{2} 8.3 ; \mathrm{CO}_{2} 9.8$.

$\mathrm{CO}_{2}+\mathrm{O}_{2}=18.1 ; \frac{\mathrm{CO}_{2}}{\mathrm{O}_{2}}=0.78$.

XXI. Bell of 7 liters.

Begun at 2:51. At 2:55, pressure is $30.3 \mathrm{~cm}$. The bird, which has been struggling a good deal, is quite sick, and has difficulty in standing up. Cocks closed. At 5:25, very sick.

Dies at 7:20. It therefore lived 4 hours 25 minutes in a quantity of air corresponding to 2.79 liters, or 1 hour 34 minutes per liter.

At $7: 30$, its temperature is only $25^{\circ}$; no rigor; at $7: 40$, found stiff. Lethal air: $\mathrm{O}_{2} 8.2 ; \mathrm{CO}_{2} 10.1$.

$$
\mathrm{CO}^{2}+\mathrm{O}^{2}=18.3 ; \frac{\mathrm{CO}_{2}}{\mathrm{O}_{2}}=0.79 \text {. }
$$

XXII. Bell of 5 liters.

Begun at 2:47. Struggles a great deal. At 2:51, the pressure is only $26.1 \mathrm{~cm}$. The bird is very sick and crouched against the rim of the bell.

Dies at 2:53. At $3: 10$ is very stiff. Its temperature is $34.7^{\circ}$.

Lived 6 minutes. No air sample taken.

XXIII. Bell of 5 liters.

Begun at $3: 20$. Struggles a great deal. At $3: 24$, the pressure is $30.3 \mathrm{~cm}$; the bird does not seem sick; cocks closed. At 5:25, very sick. The time of death was not noted.

Lethal air: $\mathrm{O}=8.3 ; \mathrm{CO}=10.3$.

$$
\mathrm{CO} z+\mathrm{O} z=18.6 ; \frac{\mathrm{CO} z}{\mathrm{O}_{2}}=0.81 \text {. }
$$

XXIV. Bell of 2.5 liters.

Begun at 2:51. At 2:59, the pressure is $30.5 \mathrm{~cm}$. Struggled a great deal, vomits, but does not fall. Cocks closed.

About 3:05, a little struggling. Dies at 4:30.

At 4:50, temperature $27^{\circ}$; pronounced rigor. Lived 1 hour $31 \mathrm{~min}-$ utes in the bell the capacity of which corresponds to 1 liter.

Lethal air: $\mathrm{O}_{2} 10 ; \mathrm{CO}_{2} 10.4$.

$$
\mathrm{CO}_{2}+\mathrm{O}_{2}=20.4 ; \frac{\mathrm{CO}_{2}}{\mathrm{O}_{2}}=0.95 \text {. }
$$

The average of the four experiments in which the air was analyzed is for the pressure of $30.5 \mathrm{~cm}$.: $\mathrm{O}^{2} 8.7 ; \mathrm{CO}^{2} 10.1$.

Experiments $X X V$ to $X X V I I I$, simultaneous, made with the same purpose as the preceding ones. June 8 . Temperature $20.5^{\circ}$; pressure $76 \mathrm{~cm}$. House sparrows. 
XXV. Bell of 11.5 liters.

Begun at $3: 45$. At $3: 53$, the pressure is $24.2 \mathrm{~cm}$. Struggled; somewhat sick; lying down, yawns frequently; cock closed.

At 4:15, gets up on its feet; at 6 o'clock, in fair condition; at $7: 30$, somewhat sick; found dead at 9:30.

Therefore lived about 5 hours in a bell the capacity of which represents 3.66 liters; or about 1 hour 22 minutes per liter.

Lethal air: $\mathrm{O}=13.7 ; \mathrm{CO}=5.4$.

$\mathrm{CO}_{2}+\mathrm{O}_{2}=19.1 ; \frac{\mathrm{CO}_{z}}{\mathrm{O} z}=0.75$.

XXVI. Bell of 7 liters.

Begun at 4 o'clock. At $4: 10$, pressure of $24.2 \mathrm{~cm}$. Struggled a great deal; has convulsions and seems near death. Cocks closed.

At $4: 15$, gets up on its feet; at $4: 30$, very lively, struggles a good deal at 5 o'clock, becomes sick; at 6 o'clock, drowsy; at $6: 20$, dies after violent convulsive struggling.

Lived 2 hours 10 minutes, in a quantity of air corresponding to 2.22 liters; or 58 minutes per liter.

At $6: 32$, rectal temperature $30.3^{\circ}$, is not quite stiff; at $6: 45$, stiff, temperature $26.5^{\circ}$.

Lethal air: $\mathrm{O}_{2} 12.6 ; \mathrm{CO}_{2} 7.0$.

$$
\mathrm{CO}_{2}+\mathrm{O}_{2}=19.6 ; \frac{\mathrm{CO}_{2}}{\mathrm{O}_{2}}=0.84
$$

XXVII. Bell of 5 liters.

Begun at 4:15. At 4:21, reached a pressure of $24.2 \mathrm{~cm}$.; struggled at first, then grew calm at a pressure drop of about $42 \mathrm{~cm}$. as the preceding ones did; did not fall. Cocks closed.

At 4:22, staggers, vomits, crouches down; but soon gets up and seems fairly well.

At $5: 30$, very sick; at $6: 10$, dies. Lived 1 hour 50 minutes in a bell the capacity of which corresponds to 1.55 liters of air; or 1 hour 10 minutes per liter.

At 6:21, stiff; temperature $27.2^{\circ}$.

Lethal air: $\mathrm{O}_{3}$ 11.6; $\mathrm{CO}=7.8$.

$$
\mathrm{CO}_{2}+\mathrm{O}_{2}=19.4 ; \frac{\mathrm{CO}_{2}}{\mathrm{O}_{2}}=0.84 \text {. }
$$

XXVIII. Bell of 2.5 liters.

Begun at $4: 16$. At $4: 26$, the pressure is $24.2 \mathrm{~cm}$. Struggled, but does not seem in danger.

Dies at 5:30; lived 1 hour 4 minutes in a quantity of air corresponding to 0.79 liters; or 1 hour 21 minutes per liter.

At 5:50, found stiff; temperature $27.5^{\circ}$.

Lethal air $\mathrm{O}_{2}$ 12.6; $\mathrm{CO}_{2} 5.9$.

$\mathrm{CO}_{2}+\mathrm{O}_{2}=18.5 ; \frac{\mathrm{CO}_{2}}{\mathrm{O}_{2}}=0.71$.

Average of the four experiments: $\mathrm{O}_{2} 12.6 ; \mathrm{CO}_{2} 6.5$. 
Experiments XXIX to XXXII, simultaneous. June 10. Temperature $21^{\circ}$; pressure $75.5 \mathrm{~cm}$. House sparrows.

XXIX. Bell of 11.5 liters.

Begun at 2 o'clock. Struggles a great deal; at 2:08, a pressure drop of $40 \mathrm{~cm}$; grows calm for a moment, then struggles again. At 2:12, the pressure drop is $47 \mathrm{~cm}$; no longer moves; a little out of breath. At 2:16, drop of $55 \mathrm{~cm}$.; more out of breath, vomits. At 2:17, the pressure is only $17.5 \mathrm{~cm}$. Cocks closed.

The bird is breathing with great difficulty, and remains lying down. It dies with convulsions at $2: 20$, that is, after 3 minutes. The air hardly contains traces of carbonic acid.

XXX. Bell of 11.5 liters.

Begun at 2:45; struggles a good deal. At 2:50, the pressure is decreased $42 \mathrm{~cm}$; the bird grows calm; at 2:53, a decrease of $44 \mathrm{~cm}$.; staggers, vomits, but begins to struggle again. At 2:56, a decrease of $52 \mathrm{~cm}$; suffers greatly. At 3:05, a decrease of $56 \mathrm{~cm}$.; falls and seems about to die. A little air is admitted until the decrease is only 49 $\mathrm{cm}$. At $3: 08$, since the bird seems to have recovered fairly well, the decompression is resumed; at $3: 11$, a decrease of $58 \mathrm{~cm}$; convulsive struggling, death imminent; we return to a decrease of $49 \mathrm{~cm}$. At 3:16, fairly well recovered; at $3: 18$, a decrease of $56.5 \mathrm{~cm}$.; not too sick. Cocks closed.

At $3: 35$, the bird vomits; at $3: 55$, as it is not too sick, the decompression is carried to $57.5 \mathrm{~cm}$.; that is, an actual pressure of $18 \mathrm{~cm}$.; it immediately becomes uneasy, but death does not occur until 4:30.

Therefore it lived 1 hour 4 minutes in a quantity of air representing 2.70 liters; or 23 minutes per liter.

Lethal air: $\mathrm{O}_{2} 17.7 ; \mathrm{CO}_{2} 2.8$.

$\mathrm{CO}_{2}+\mathrm{O}=20.3 ; \frac{\mathrm{CO}_{2}}{\mathrm{O}_{2}}=0.87$.

XXXI. Bell of 1.9 liters.

Begun at $3: 35$. At $3: 45$, the pressure is $41.3 \mathrm{~cm}$. Cocks closed.

Dead at $5: 23$; at $5: 30$, rectal temperature $28^{\circ}$.

Lived 1 hour 45 minutes in a bell corresponding to 1.03 liters; or 1 hour 40 minutes per liter.

Lethal air: $\mathrm{O}_{2} 6.5 ; \mathrm{CO}_{2} 12.9$.

$\mathrm{CO}_{2}+\mathrm{O}_{2}=19.4 ; \frac{\mathrm{CO}_{2}}{\mathrm{O}_{2}}=0.89$.

XXXII. Bell of 1.5 liters.

Begun at $3: 35$. At $3: 45$, a pressure of $48.5 \mathrm{~cm}$. Closed.

Dead at 5:10. At 5:20, temperature $24.8^{\circ}$. Lived 1 hour $25 \mathrm{~min}$ utes; the capacity corresponded to 0.92 liters, or 1 hour 32 minutes per liter.

Lethal air: $\mathrm{O}_{2}$ 5.2; $\mathrm{CO}_{2} 14.1$.

$\mathrm{CO}_{2}+\mathrm{O}_{2}=19.3 ; \frac{\mathrm{CO}_{2}}{\mathrm{O}_{2}}=0.89$. 
Experiments $X X X I I I-X X X I V$, simultaneous. June 14. Temperature $22^{\circ}$; pressure $76.5 \mathrm{~cm}$. House sparrows.

XXXIII. Bell of 3.2 liters.

Begun at $4: 16$; moderate agitation. At $4: 21$, pressure decrease of $43 \mathrm{~cm}$; vomits, is tired; at $4: 22$, pressure is $23 \mathrm{~cm}$; very sick. Cocks closed.

At $4: 26$, still on its side; rises later. Dies at $5: 20$. At $5: 31$, temperature $32^{\circ}$, not stiff. At $5: 40,30.7^{\circ}$.

Lethal air: $\mathrm{O}_{2}$ 11.2; $\mathrm{CO}_{2} 7.6$.

$$
\mathrm{CO}_{2}+\mathrm{O}_{2}=18.8 ; \frac{\mathrm{CO}_{2}}{\mathrm{O}_{2}}=0.78 \text {. }
$$

XXXIV. Bell of 2.8 liters.

Begun at 4:19; moderate agitation. At $4: 25$; pressure of $25 \mathrm{~cm}$; vomits. Cocks closed.

Not so sick as the preceding bird. At 4:27, pressure dropped to $24.5 \mathrm{~cm}$.; panting hard. At 5:27, dies with convulsions. At 5:40, the temperature is $31.6^{\circ}$; at $5: 52$, it is $29.4^{\circ}$. Lived 1 hour 2 minutes in the equivalent of 0.9 liter of air; or 1 hour 7 minutes per liter.

Lethal air: $\mathrm{O}_{2} 11.3 ; \mathrm{CO}_{2} 8.1$.

$$
\mathrm{CO}=\mathrm{O} 2=19.4 ; \frac{\mathrm{CO}_{2}}{\mathrm{O}_{2}}=0.84 \text {. }
$$

Experiments $X X X V-X X X V I$, simultaneous. July 26. Temperature $22^{\circ}$; pressure $76 \mathrm{~cm}$. House sparrows.

XXXV. Bell of 2.25 liters.

Brought in a few minutes to a pressure of $55 \mathrm{~cm}$. Cocks closed at $1: 45$.

Dead at $3: 25$. Therefore lived 1 hour 40 minutes in a bell the capacity of which represented 1.6 liters at normal pressure; or 1 hour 3 minutes per liter. At 3:33, rectal temperature $28^{\circ}$.

Lethal air $\mathrm{O}_{2} 4.6 ; \mathrm{CO}_{2} 13.4$.

$$
\mathrm{CO} 2+\mathrm{O}_{2}=18.0 ; \frac{\mathrm{CO}_{2}}{\mathrm{O}_{2}}=0.81 \text {. }
$$

XXXVI. Bell of 3.2 liters.

Brought to a pressure of $47 \mathrm{~cm}$. Cocks closed at 2 o'clock. Dead at $3: 53$. Lived 1 hour 53 minutes in a capacity equivalent to 2 liters; or 57 minutes per liter.

At 4 o'clock, rectal temperature $27^{\circ}$.

Lethal air: $\mathrm{O}_{2} 5.5 ; \mathrm{CO}_{2} 12.4$.

$$
\mathrm{CO} z+\mathrm{O} z=17.9 ; \frac{\mathrm{CO}_{2}}{\mathrm{O}_{2}}=0.80 \text {. }
$$

Experiment $X X X V I I$. March 18. Pressure $76 \mathrm{~cm}$.

House sparrow, placed at 1:45 under a bell of 3.2 liters. The pressure is lowered to $38 \mathrm{~cm}$. Dead at $3: 15$. A few spots in the cranial 
diploe, in the occipital region. Lived 1 hour 30 minutes in the equivalent of 1.6 liters of air, or 56 minutes per liter.

Lethal air: $\mathrm{O}_{2} 8.2 ; \mathrm{CO}_{2} 11.6$.

$$
\mathrm{CO}_{2}+\mathrm{O}_{2}=19.8 ; \frac{\mathrm{CO}_{2}}{\mathrm{O}_{2}}=0.91 \text {. }
$$

I have purposely given in the preceding pages an account of a great number of experiments so as to show what is indefinitely variable in the phenomena and at the same time what stands out as general in this variety, which defies both deceptive averages and sham precision of decimals. Certainly, when a sparrow dies under a bell at a certain pressure, the air of this bell has a composition which the best methods of modern chemistry could perhaps permit us to determine to about one ten-thousandth. But what would be the use of this precision when our experiments show us that another sparrow exactly like the first, placed in apparently identical conditions, dies with a composition of ambient air which may differ from the first by 4 or 5 tenths of oxygen or carbonic acid, or even more? It is evidently better to multiply experiments to try to find the explanation of these differences and to adhere to convenient methods of analysis which permit one to work rapidly.

But the height of absurdity-and this, unfortunately, is found rather frequently in German work-is to claim to give to these other methods an appearance of precision which they do not possess, carrying calculations to the second and third decimal and even resorting to a table of logarithms to get more decimals. This charlatanism of decimals which leads one to claim exactness for the thousandths in a number which is wrong beyond the units, is an illusion which must be avoided. Let us make our criticism specific by applying it to the present case.

Let us imagine, in a tube graduated to tenths of cubic centimeters, inverted over the mercury bowl, our usual gaseous mixture of nitrogen, oxygen, and carbonic acid. To avoid taking account in the first determination of a convex mercurial meniscus and in the other two of a concave aqueous meniscus, I first introduce into the tube some drops of pure water, and try to determine the level. Now admitting that the greatest precautions have been taken, it is impossible to estimate the height of the liquid column with a closer approximation than five hundredths. Let us suppose that I have found that it is between $25.3 \mathrm{cc}$. and $25.4 \mathrm{cc}$; but I cannot be sure whether it is $25.32 \mathrm{cc}$. or $25.37 \mathrm{cc}$., for example. I now add the potash, shake it vigorously and repeatedly, and again plunge the tube into the mercury to bring it to its original temperature. 
Again I make a supposition: the present level will be, let us say, between $20.2 \mathrm{cc}$. and $20.3 \mathrm{cc}$. and I must choose between $20.23 \mathrm{cc}$. and 20.28 cc. According to whether I take my meniscus level higher or lower-and we know how difficult the estimate is for a colorless liquid, without mentioning the fact that the meniscus of pure water in a tube which is necessarily rather dirty is not the same as the meniscus of a potash solution which wets the glass perfectly,-there will have disappeared in an average quantity of $25.35 \mathrm{cc}$. either $5.04 \mathrm{cc}$. or $5.14 \mathrm{cc}$. of carbonic acid, which gives for the percentage composition in the first case 19.88 cc. per 100 $(25.35: 100=5.04 \mathrm{cc} .: \mathrm{x}=19.88)$; and in the second case, $20.27 \mathrm{cc}$. per $100(25.35: 100=5.14$ cc. : $\mathrm{x}=20.27)$.

That is, without taking into account the cause of error due to the operation itself, which here involves the second decimal, my analysis, though made as well as possible by the volumetric method, exposes me to an error which in this present case may equal $0.39 \mathrm{cc}$. In other words, the first decimal can and must be constantly vitiated in the necessary speed of the analyses.

It is with this consideration that we must examine all the results of our analyses; and therefore no one will reproach me for having prudently stopped at this figure which indicates exactly the degree of precision which one can expect from this volumetric method of analysis, any more than for not having used other methods, when the experimental differences, over which we have no control, are at least of the same order, as I said above.

With these reservations, let us examine the results of the experiments which, in order to shorten tiresome reading, I have grouped in a summarizing table, arranging them in the order of the pressures.

If we examine Column 8 , which gives the proportion of oxygen remaining in the air which has become irrespirable, we see that the numbers which it contains increase proportionately as the pressure diminishes. This rule, however, has apparent exceptions, as the table shows. But if we consider the results given by the analyses of air which has become incapable of supporting life made at the same pressure, we see that the exceptions mentioned are of the same order as the differences which separated the results of these analyses. Thus at normal pressure, the proportion of oxygen remaining varied between 3.0 and 4.2 per cent; similarly at $24.2 \mathrm{~cm}$., it varies between 11.6 and 13.7 per cent.

The general tendency of the phenomenon is shown still more clearly in the curve represented by O, Figure 17. Here the pres- 
sures are measured on the axis of the abscissae, in increasing order, and the quantities of oxygen are represented on that of the ordinates. We shall see presently that this curve, if we set aside the

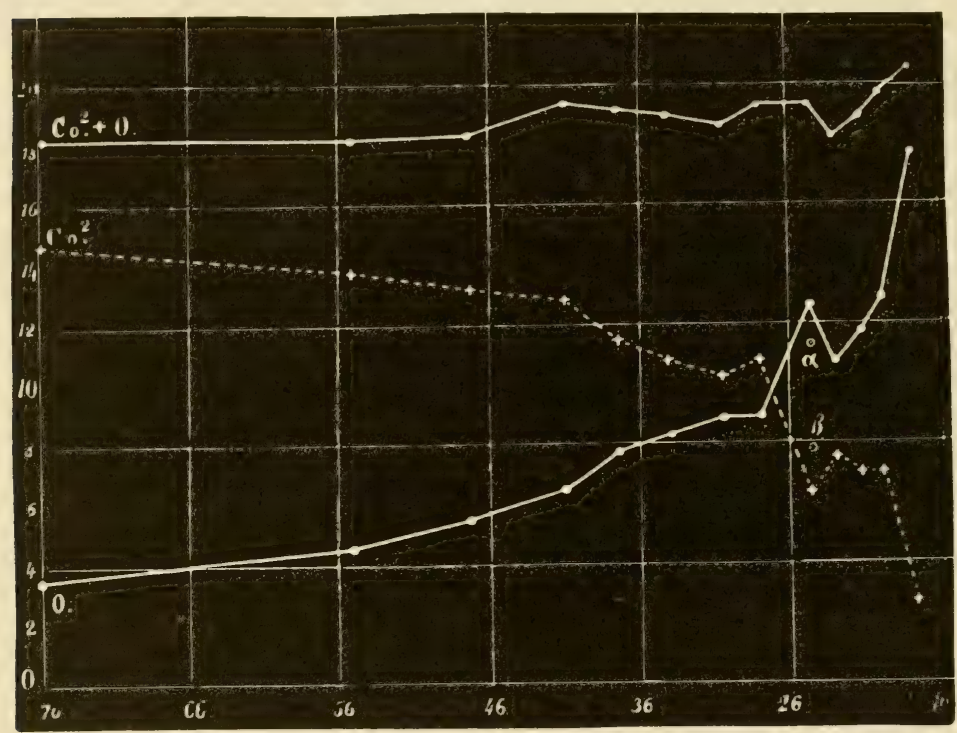

Fig. 17-Composition of confined air which has become lethal at pressures below 1 atmosphere. O. Proportions of oxygen remaining. $\mathrm{CO}^{2}$. Proportions of carbonic acid. $\mathrm{CO}^{3}+\mathrm{O}$. Sum of oxygen consumed and carbonic acid formed.

little irregularities of which we have spoken, takes a precise geometric form, which is exactly a branch of a hyperbola.

The proportion of carbonic acid produced naturally follows an opposite course, as is shown by curve $\mathrm{CO}_{2}$, which represents its modifications.

Therefore, the weaker the pressure, the less the confined air needs to be altered in its chemical composition to become irrespirable. At very low pressures it becomes irrespirable even though perfectly pure, for a reason which we shall give presently. But the general fact which we have just mentioned is enough to show that the carbonic acid given off in the confined space plays no part in the death, since its proportion decreases progressively 
Table $\mathbf{I}$

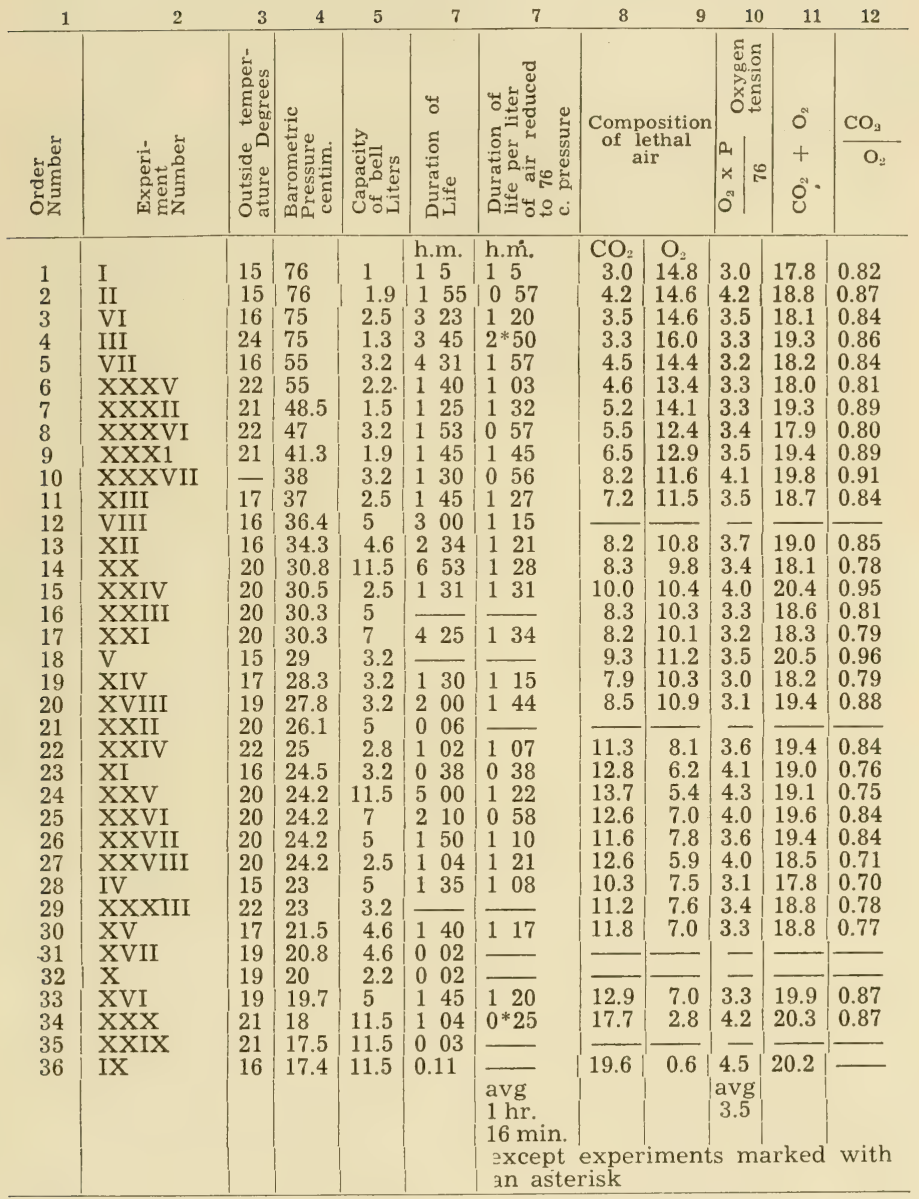

to minimum amounts. Furthermore, direct experiments, in which this acid was largely absorbed by a solution of potash as rapidly as it was formed, have shown that the composition of the lethal air, from the point of view of its oxygen content, was not changed at all. It is this content, or rather this lack of oxygen which is the cause of death, and which we must consider carefully. 
It really seems very difficult at first glance to attribute death to a lack of oxygen in experiments where 12, 15, or 17 per cent of it remained in the air. But this difficulty disappears after sufficient reflection.

Indeed, we know that when a bird dies at normal pressure in confined air, this death is due (for the most part, at least; we shall give a longer explanation later) to a lack of oxygen, or to speak more exactly, to the too weak proportion, and more exactly still, to the too weak tension of this gas in the ambient atmosphere. This tension can be expressed at normal pressure precisely by the figure which indicates the percentage. One may say, for example, that at one atmosphere the tension of the oxygen of ordinary air is 20.9; and likewise that the tension of the oxygen of confined air which has become lethal varies somewhere between 3 and 4 per cent.

According to this, the tension of oxygen at a pressure lower than one atmosphere will evidently be represented by a number obtained by multiplying the percentage by the proportion of this pressure to normal pressure, both expressed for greater simplicity in centimeters of mercury. Thus the pressure of the oxygen of ordinary air at $30 \mathrm{~cm}$. of pressure will be represented by the number $20.9 \times \frac{30}{76}=8.2$.

Applying now this simple calculation, whose formula is $\mathrm{O}_{2} \times \mathrm{P}$ 76

given in Column 10. We see that at whatever pressure our birds were placed, their death came when the pressure of the oxygen was lowered to values varying between 3.0 and 4.3 , which are precisely the values with which air becomes irrespirable at normal pressure. The table shows that, even at very low pressures, we find figures (numbers 28,30, and 33) which indicate the most complete exhaustion and the weakest tension, when we have taken sufficient precautions, to which we shall refer in a moment.

The differences between the results of the analyses at different pressures are exactly of the same order as those which separate the results obtained at the same pressure. This stands out in the most striking manner in the graph in Figure 18, which expresses the results in Column 10 . Thus at the same pressure of $24 \mathrm{~cm}$., 
there are deviations as great as those of the whole tracing, as the little crosses show. These are differences which experiments made in apparently identical conditions always display.

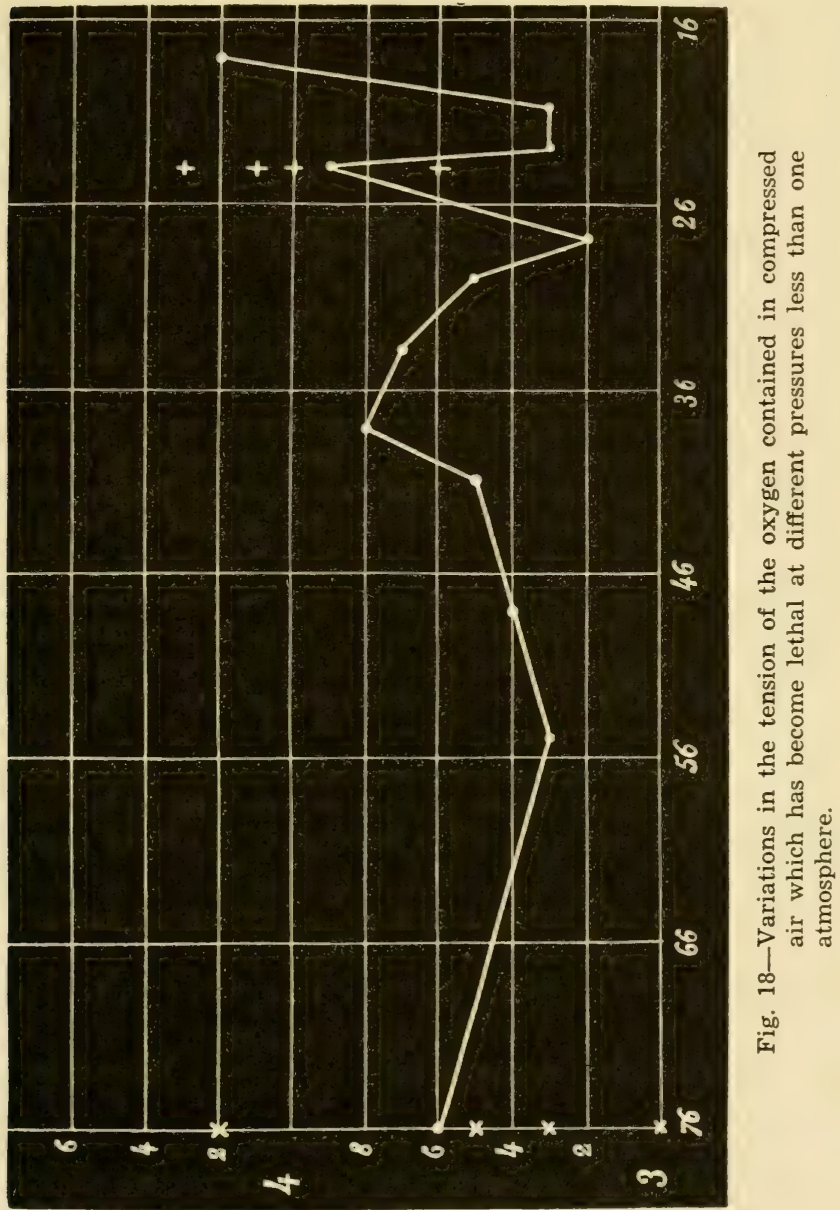

Summing up, we arrive at this very simple statement: In confined air, at pressures less than one atmosphere, the death of spar- 
rows occurs when the tension of the oxygen, measured by the method that has just been specified, is represented by a number varying between 3 and 4 , which we can call $k$.

If we refer now to line $O$ of Figure 17, we see that each of its points corresponds to the equation $\frac{x y}{76}=k$, therefore $x y=76 \mathrm{k}$.

Now $k$ having a value which varies from 3 to 4.3 , taking 3.6 as an average, for the point which corresponds to $41 \mathrm{~cm}$. of pressure, for example, the equation will be $\frac{41 \times 6.5}{76}=3.6$. In other words, it is the equation of a hyperbola having for asymptotes the axis of the $\mathrm{x}$ 's and a parallel to the axis of the y's at the zero of pressures, or, to use an exact expression, of an equilateral hyperbola.

These facts show us under a new aspect the action of the diminution of pressure upon the organism. They tend to show that it consists principally of diminishing the exterior tension of the oxygen, and, consequently, of placing the animal in conditions similar to those which would be given it by respiration at normal pressure in a medium containing less oxygen than the air. We could even state already that no other important element is involved, since at pressures from $20 \mathrm{~cm}$. to $25 \mathrm{~cm}$. we find again in the table the figures 3.1 or 3.3 , which indicate an exhaustion as great as at normal pressure.

Continuing this reasoning, we can determine the lower limit of pressure which it will not be possible to pass without killing the animals (we are still speaking of sparrows). It will be given by the formula $20.9 \times \frac{x}{76}=3$ and $20.9 \times \frac{x}{76}=4.3$, since 3 and 4.3 are the extreme numbers given us by the experiments reported above.

We reach thus the equation $\mathrm{x}=\frac{4.3 \mathrm{~cm} . \mathrm{x} 76}{20.9}=15.6 \mathrm{~cm}$. for the highest figure, and for the lowest, $\mathrm{x}=10.9 \mathrm{~cm}$.

But it is clear that, to reach such low pressures, we must take the greatest precautions, and slowly accustom the animal to this asphyxia of a new kind. A sudden change surprising it with too great an oxygen consumption would kill it, and that very thing 
happened (numbers 21, 31, and 32 of the table) at pressures of 20 and even 26 centimeters. We must not forget that the birds which die in containers of confined air die very slowly, grow cold, and therefore can live a long time with a very slight consumption of oxygen. Claude Bernard ${ }^{2}$ showed with admirable sagacity the difference existing between a vigorous and a weakened animal from this point of view.

It was with the purpose of reaching the lowest possible point, by going slowly, that the following experiments were made. liters.

Experiment XXXVIII. March 30. House sparrow. Bell-jar of 50

Entered at 2 o'clock. Current of air maintained by the steam pump. At 2:04, $51 \mathrm{~cm}$. of pressure; at 2:05, $39 \mathrm{~cm}$.; at 2:06, $33 \mathrm{~cm}$.; uneasy, panting a little. At 2:07, $25 \mathrm{~cm}$.; falls with its beak forward, panting, does not get up again. Pressure rises to $28 \mathrm{~cm}$.; the bird does not stir; pressure falls suddenly to $24 \mathrm{~cm}$. (2:09 o'clock), and the bird hops about staggering and falls immediately. At $2: 11,22 \mathrm{~cm}$., same condition; at $2: 13,16 \mathrm{~cm}$; ; violent convulsion; pressure restored to 20 $\mathrm{cm}$.; at 2:25, still $20 \mathrm{~cm}$.; pressure lowered again; at $2: 27$, only $17 \mathrm{~cm}$.; and at $2: 30$, only $16.5 \mathrm{~cm}$. At $2: 32$, the mercury suddenly goes to 8 $\mathrm{cm}$.; convulsions and death. Rectal temperature is $32^{\circ}$.

Experiment XXXIX. Same day, same apparatus.

Entered at 2:40. In one minute brought to $22 \mathrm{~cm}$.; falls on its side and does not get up. At 2:43, $20 \mathrm{~cm}$; at $2: 45,17 \mathrm{~cm}$; at $2: 54,16 \mathrm{~cm}$; at $3: 15,15.5 \mathrm{~cm}$. In the intervals, the pressure was lowered two or three times suddenly to $10 \mathrm{~cm}$., and raised immediately. The bird remained motionless, bristling, breathing with difficulty. Taken out at $3: 15$, is very cold.

Recovers very well after a quarter of an hour and survives. At $4: 30$, has a normal temperature.

Experiment XL. January 2. House sparrow, vigorous. Barometric pressure $753 \mathrm{~mm}$; bell-jar of 4.5 liters.

Decompression begun, with air flowing through chamber, at 2:35.

At 2:55, the pressure under the bell-jar is only $58 \mathrm{~cm}$; the bird is calm.

At 3:05, pressure, $48 \mathrm{~cm}$; at $3: 15,40 \mathrm{~cm}$; at $3: 25,30 \mathrm{~cm}$.; at $3: 35$, $23 \mathrm{~cm}$.; the bird is crouched on its tarsi.

At $3: 45$, pressure, $17 \mathrm{~cm}$.; the bird is lying on its side, but does not appear very sick.

From 3:50 to $3: 55$ the pressure is lowered to $15 \mathrm{~cm}$; from $3: 55$ to 4 o'clock, to $14 \mathrm{~cm}$.; from 4 o'clock to $4: 05$ to $11 \mathrm{~cm}$.; from $4: 05$ to $4: 10$, to $10 \mathrm{~cm}$.; the bird is on its side but fairly quiet.

Air is admitted suddenly; the bird gets up on its feet immediately; its rectal temperature is $28^{\circ}$. It is warmed by the stove, and gets up on the perch in its cage. But it dies during the night.

Here are sparrows with which we proceeded slowly enough to bring on weakness and chill, and which underwent diminutions of 
pressure quite comparable to those which the preceding calculations indicated. It is a matter of care and patience.

If now we examine Column 11 of Table $\mathrm{I}$, we find numbers representing the result of the addition of the carbonic acid produced and the oxygen remaining at the moment of death. They are represented by the line $\mathrm{CO}_{2}+\mathrm{O}_{2}$ in Figure 17. We see that these different numbers vary between 17.8 and 20.5: the general average is 18.9. And so we find at all diminutions of pressure the fact observed by earlier authors, which caused them to make such strange hypotheses on the nature of asphyxia in closed vessels, that is, the diminution of the elasticity of the air, or, in other words, the disappearance of a certain quantity of oxygen which is not recovered in the carbonic acid given off. Furthermore,-and this is very evident on the graph--this amount keeps increasing when the pressure diminishes; above one half atmosphere, it is on the average 18.7, and below, it is 19.2. So, at very low pressures, there is given off a greater proportion of carbonic acid in comparison to that of the oxygen absorbed. In studying the gases of the blood under diminished pressure, we shall easily understand this phenomenon.

That is not all: a careful inspection of Column 11 shows us another interesting fact. If we group on one side all the cases in which the number indicated in Column 10 is between 3 and 3.5, and on the other all those in which this number is above 3.5 , we shall find that for the first series the average is 18.6, while for the second it rises to 19.5. That means that the greater the exhaustion of oxygen, the greater has been the quantity of this gas not recovered in the carbonic acid exhaled. Hence we can draw the conclusion that in asphyxia in closed vessels, whatever the pressure may be, towards the end of the animal's life, the oxygen, which it continues to absorb in very small quantities, remains in the tissues under some form or other, without giving rise to carbonic acid.

This conclusion is corroborated also by the examination of Column 12 of the table, containing for each experiment the ratio between the carbonic acid produced and the oxygen consumed. We see that these numbers are in a general way proportionately smaller as the pressures become lower. In the first eleven experiments (above a half-atmosphere) the average is 0.85 , and for the others only 0.80 . We conclude then that at very low pressures the proportion of oxygen that is absorbed without producing carbonic acid is greater than at more moderate pressures.

I tried to ascertain whether some relation existed between the 
numbers contained in Columns 5, 7, and 10, which express different important elements of our experiments. To grasp these relationships, I drew three graphs in which the experiments are arranged

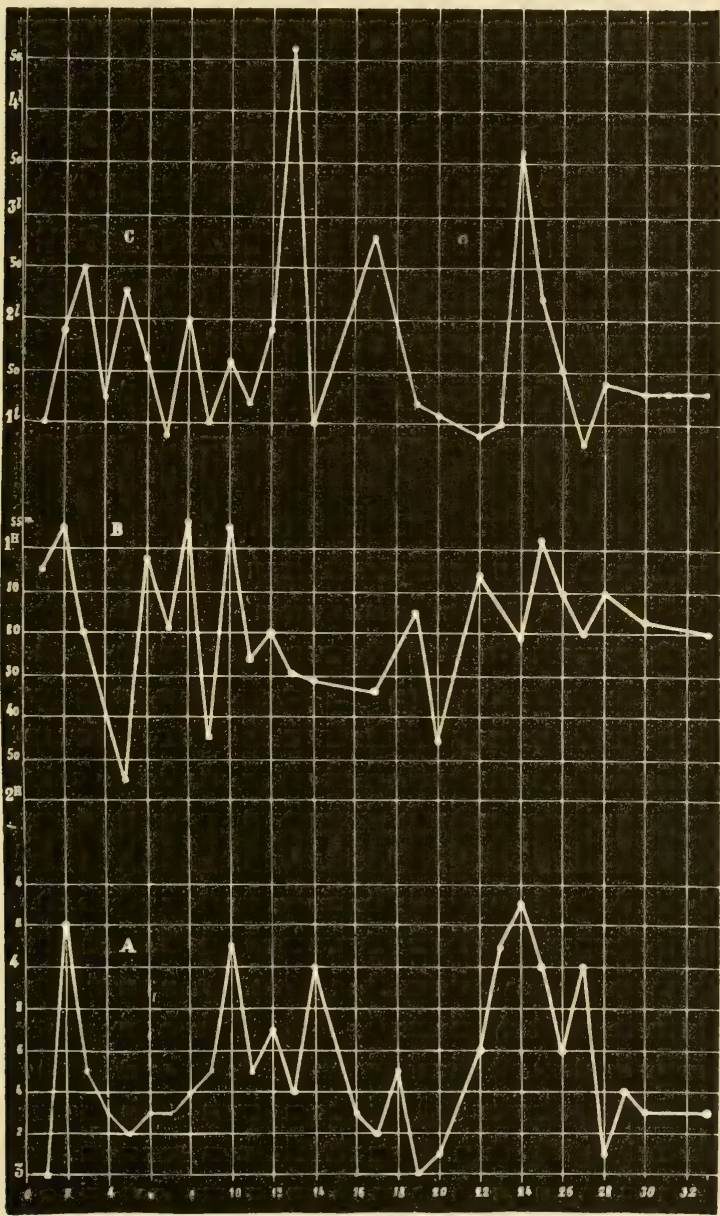

Fig. 19-Relations between oxygen tension (graph A), duration of life (B) and actual capacity of the vessels (C) in death in closed vessels under decreased pressure. 
according to their numbers in Column 1 of Table I on the axis of the abscissae, so that pressures decrease from left to right. To each of these experiments correspond three values plotted on the vertical ordinate; the first, $A$, expresses the final tension of the confined air (Column 10); the second, B, the duration of life (Column 7): this duration is calculated by reducing the volume of the rarefied air to $76 \mathrm{~cm}$. and seeing how long the birds lived for each liter of air: the third, C, represents the volume of rarefied air reduced to the pressure of $76 \mathrm{~cm}$. of mercury and permits us to compare the true quantities of air that the birds had at their disposal.

We do not see very clear relations between the line A which expresses the oxygen tension at the end of the experiment and line $\mathrm{B}$ which expresses the duration of the lives of the birds. We conclude from comparing the two graphs that the greater or less exhaustion of air (A) is by no means in constant relation to the length of life $(B)$, since a very short duration may coincide with considerable exhaustion (Experiment 8) or inversely (Experiment 15). However, if we take the average of the duration of life corresponding to very low oxygen tensions (below 3.5, Column 10), we have the figure of 1 hour and 11 minutes; whereas in making the same calculations for higher oxygen tensions we find 1 hour and 23 minutes (the general average being, Column 7, 1 hour 16 minutes). And so in a general way, the longer the animal lives, the more it exhausts the air, very naturally.

Inquiring next into the duration of life in its relation to the capacity of the bell-jars in which the animals died, and setting aside the wholly exceptional cases like those of Experiments 16 , $21,31,32$, and even 35 and 36 , we see that at first glance graph C, which expresses these varied volumes, has nothing in common with graph B. A very considerable capacity may coincide with a moderate duration of life (Experiments 13 and 24) or inversely (Experiment 9). But if, as in the preceding case, we consider capacities corresponding to longer than average durations of life ( 1 hour 16 minutes), we find that their average volume is 2 liters, while for the more rapid deaths the volume is only 1.5 liters. Generally speaking, then, life is longer when the capacity of the vessels is greater (the whole evidently related to the unit of volume and the unit of pressure).

Thus we confirm, unmodified by the influence of the diminution of pressure, a law which was earlier formulated by M. Claude Bernard, who, however, mentions numerous exceptions; the prin- 
cipal ones are due to the calmness or the agitation of the animal enclosed, which uses up more or less quickly the quantity of air left at its disposal.

We now have to compare graphs $\mathrm{A}$ and $\mathrm{C}$, that is, the capacity of the vessels with the exhaustion of oxygen. Here again the curves have little agreement. We even find strongly opposed results, as in that of Experiment 19, in which maximum exhaustion corresponds to a small vessel, and that of Experiment 24, where in a very large vessel there was little exhaustion compared to Experiments 14 and 16, which give opposite results. But if we take an average, we see that numbers less than 3.5 (graph A) correspond to an average of 1.8 liters, while those that are greater correspond to 1.6 liters. There is then some advantage in vessels of large capacity, another conclusion agreeing with those of Claude Bernard. But the differences are very slight, and when we examine these numerous results, we can understand the apparent contradictions of investigators.

Therefore, whatever point of view we take, we find that the results of the experiments under diminished pressure agree with all that we know about asphyxia in closed vessels. We are then more and more led to see in the rarefaction of the air only a physical process which leads to the same end as the impoverishment of oxygen, a chemical process. The following data also corroborate this view.

We know that at very low temperatures and under normal pressure animals exhaust much less the oxygen of the air in which they are confined than they do at an average temperature. Is the same thing true for death in closed vessels at low pressure? The following experiments give the answer to this question.

Experiments XLI to XLIII, simultaneous. December 12. Pressure $77 \mathrm{~cm}$. The temperature of the laboratory is $+6^{\circ}$. After the sparrows had been placed under the bell-jars, the latter were packed in snow, and the temperature dropped to about $+2^{\circ}$.

XLI. Bell-jar of 2.25 liters.

Entered at 2:40. Pressure brought to $54 \mathrm{~cm}$, and the cold lowers it to $52 \mathrm{~cm}$. The bird is found dead at 4 o'clock.

Lethal air: $\mathrm{O}=8.3 ; \mathrm{CO}=11.4$.

$$
\mathrm{CO}_{2}+\mathrm{O}_{2}=19.7 ; \frac{\mathrm{CO}_{2}}{\mathrm{O}_{2}}=0.90 \text {. }
$$

XLII. Bell-jar of 3.2 liters.

Entered at 2:50. Pressure brought to $44 \mathrm{~cm}$. by vacuum and cold. At 4 o'clock is breathing with great difficulty; at $4: 15$, dead. Lived 1 
hour 20 minutes in a quantity of air corresponding to 2 liters, at normal pressure, that is, 40 minutes per liter. At $4: 35$, rectal temperature $18^{\circ}$.

Lethal air: $\mathrm{O}_{2} 7.6 ; \mathrm{CO}_{2} 12.0$.

$$
\mathrm{CO}_{2}+\mathrm{O}_{2}=19.6 ; \frac{\mathrm{CO}_{2}}{\mathrm{O}_{2}}=0.90 \text {. }
$$

XLIII. Bell-jar of 5 liters.

Entered at 3 o'clock. Pressure brought to $27.5 \mathrm{~cm}$. Living at $₫: 35$. Found dead at 5:05.

Lethal air: $\mathrm{O}=10.4 ; \mathrm{CO}=8.8$.

$$
\mathrm{CO}+\mathrm{O}_{2}=19.2 ; \frac{\mathrm{CO}_{2}}{\mathrm{O}_{2}}=0.83 \text {. }
$$

Experiment XLIV. December 13. Outside temperature $+6^{\circ}$. Pressure $77 \mathrm{~cm}$.

Sparrow placed under bell-jar of 3.2 liters, at 2:45. Pressure brought to $30.5 \mathrm{~cm}$. including the following action of the cold. The belljar is surrounded by a mixture of ice and salt.

At 3:35, still living; at 3:45, dead. Lived about 55 minutes in an equivalent of 1.28 liters of air, that is, 43 minutes per liter.

The temperature of the bell-jar is then $-5^{\circ}$. Rectal temperature of the bird $+16^{\circ}$.

Lethal air: $\mathrm{O}=11 ; \mathrm{CO}=8.8$.

$$
\mathrm{CO}+\mathrm{O}=19.8 ; \frac{\mathrm{CO}}{\mathrm{O}}=0.89 \text {. }
$$

Experiments $X L V$ to $X L V I$, simultaneous. December 14. Temperature $+6^{\circ}$. Pressure $76.5 \mathrm{~cm}$. House sparrows.

$X L V$. Bell-jar of 3.2 liters.

Placed under bell-jar at 12:50, total reduction of pressure $29.5 \mathrm{~cm}$.

The bell-jar is surrounded with ice and salt. The interior thermometer registers $+1^{\circ}$ at $1 \mathrm{o}^{\prime}$ clock; at $1: 20$, it is $-2^{\circ}$; at $1: 35,-4^{\circ}$; at $2: 05,-4^{\circ}$.

At 2:05, the bird is still alive; dead at 2:10. Lived 1 hour $20 \mathrm{~min}$ utes in the equivalent of 1.24 liters of air, that is, 1 hour 4 minutes per liter. At 2:17, rectal temperature $15^{\circ}$.

Lethal air: $\mathrm{O}_{2} 10.3 ; \mathrm{CO}_{2} 7.4$.

$$
\mathrm{CO}_{2}+\mathrm{O}_{2}=17.7 ; \frac{\mathrm{CO}_{2}}{\mathrm{O}_{2}}=0.70 \text {. }
$$

XLVI. Bell-jar of 3.2 liters.

Entered at 2: 42 . Pressure brought to $29.5 \mathrm{~cm}$. No cooling mixture. The interior temperature of the bell-jar at $3: 05$ is $+8.5^{\circ}$, and at the time of death, $+6.5^{\circ}$. At $4: 15$, very sick; at $4: 25$, dead. Lived 1 hour 
40 minutes in the equivalent of 1.24 liters of air; that is, 1 hour 20 minutes per liter. At $4: 30$, rectal temperature is $19^{\circ}$.

Lethal air: $\mathrm{O}=9.2 ; \mathrm{CO}_{2} 9.2$.

$$
\mathrm{CO} z+\mathrm{O}_{2}=18.4 ; \frac{\mathrm{CO}_{2}}{\mathrm{O}_{2}}=0.79 \text {. }
$$

Table II

\begin{tabular}{|c|c|c|c|c|c|c|c|c|c|}
\hline 1 & 2 & 3 & 4 & 5 & 6 & 7 & 8 & 9 & \\
\hline 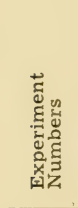 & 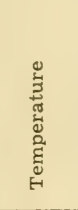 & 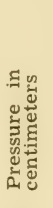 & 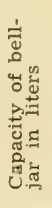 & 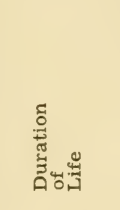 & 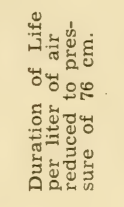 & $\begin{array}{r}\text { Compo } \\
\text { leth }\end{array}$ & $\begin{array}{l}\text { tion of } \\
1 \text { air }\end{array}$ & & 9 \\
\hline $\begin{array}{l}\text { XLI } \\
\text { XLII } \\
\text { XLIV } \\
\text { XLV } \\
\text { XLVI } \\
\text { XLIII }\end{array}$ & $\begin{array}{l}+2^{\circ} \\
+2^{\circ} \\
-5^{\circ} \\
+4^{\circ} \\
+6.5^{\circ} \\
+2^{\circ}\end{array}$ & $\begin{array}{l}52 \\
44 \\
30.5 \\
29.5 \\
29.5 \\
27.5\end{array}$ & $\begin{array}{l}2.25 \\
3.2 \\
3.2 \\
3.2 \\
3.2 \\
5.0\end{array}$ & $\begin{array}{l}1 \overline{\mathrm{h} .} 20 \mathrm{~m} . \\
\\
1 \text { h. } 20 \mathrm{~m} . \\
1 \text { h. } 40 \mathrm{~m} . \\
\end{array}$ & $\begin{array}{ll} & \\
& 40 \mathrm{~m} . \\
& 43 \mathrm{~m} . \\
1 \text { h. } 20 \mathrm{~m} . & \\
1 \text { h. } 20 \mathrm{~m} .\end{array}$ & $\begin{array}{r}8.3 \\
7.6 \\
11.0 \\
10.3 \\
9.2 \\
10.4\end{array}$ & $\begin{array}{r}11.4 \\
12.0 \\
8.8 \\
7.4 \\
9.2 \\
8.8\end{array}$ & \begin{tabular}{l|}
5.9 \\
4.4 \\
4.4 \\
3.8 \\
3.5 \\
3.7 \\
\end{tabular} & \\
\hline & & & & & $\begin{array}{c}\text { average } \\
57 \mathrm{~m} .\end{array}$ & & & $\begin{array}{l}\text { avg } \\
4.3\end{array}$ & \\
\hline
\end{tabular}

Table II, which summarizes these results, shows clearly that at low temperatures the exhaustion of air really is less complete. One needs only to compare the figures with the corresponding ones for the same pressures in Table I. The averages themselves are enlightening enough; the oxygen tension rose from 3.5 to 4.3 . Moreover, the average duration of life dropped from 1 hour 16 minutes to 57 minutes.

In this double comparison we see that the parallel I made still continues exactly. We can find many other agreements when we examine the general phenomena displayed by the animals: changes in respiration, circulation and temperature; presence or absence of convulsions, etc. I prefer to devote a special chapter to this subject.

For the moment we must take another step and pass from the realm of inductions to that of decisive experiments. The problem appears in the following terms.

We have seen that, in a confined atmospheric medium, at any pressure (below one atmosphere), the sparrows die when the tension of the oxygen in the surrounding air is lowered to an average of 3.6. When the pressure is sufficiently high, the tension figure goes thus low only after a certain time, after an exhaustion due to 
the animal's breathing; but the chemical alteration of the air which is the consequence becomes less and less important, as we have seen, in proportion as the pressure diminishes; and so, at about 15 centimeters of pressure, death occurs in pure air: it even occurs as I have often observed, in an air current, and the confinement, the chemical change, are evidently not factors.

If the various disturbances, whose details will be given later, which begin to appear when the pressure is lowered to 30 centimeters; if the serious symptoms, which occur at about 25 centimeters; if death, which ensues at about 18 centimeters, are all really due to the weak oxygen tension at these various periods, we should be able to avert them by increasing this tension suitably, without, however, changing the barometric pressure.

Super-oxygenated air: very low pressures. This is easily secured by using artificial air sufficiently rich in oxygen. If, in the expression $\frac{\mathrm{O}_{2} \times \mathrm{P}}{76}$ which represents the oxygen tension, the percentage of $\mathrm{O}_{2}$ increases in the same proportion as pressure $\mathrm{P}$ decreases, the amount of the tension will remain constant; if this amount is sufficient, it should produce no disturbance in the experimental animal. For example, if we pass to a half-atmosphere, to keep the oxygen tension in ordinary air at normal pressure, we must double the amount 20.9 and use an artificial air containing 41.8 per cent oxygen.

I shall give details of this important point in another part of this work. But here, where we are considering nothing but death in closed vessels, under different low pressures, the result should be expressed in another way. If our hypothesis is true, we shall arrive at the following formula: Whatever the pressure employed, whatever the composition of the artificial air, the death of the sparrows will always occur when the final tension of the oxygen falls to about the average amount previously established, that is, 3.6 .

The experimental procedure was as follows: After the bird had been placed under one of the bell-jars of the apparatus represented in Figure 15, I lowered the pressure in the bell-jar 30 to 40 $\mathrm{cm}$., which seems to have no immediate harmful effect on the birds, as we saw above. Moreover, I immediately connected cock M with a gasometer filled with oxygen, and allowed this gas to enter so as to restore normal pressure. Then I began again to lower the pressure of this mixture already more oxygenated than ordinary 
air, and again filled up with oxygen. After three or four such manipulations, the bell-jar was full of a mixture sufficiently oxygenated for the purposes of the experiment, that is, causing the bird to die under the diminution of pressure deemed desirable. I then took a certain quantity of the mixture for analysis.

I shall now give the details of the experiments; I shall discuss here only those made at very low pressures. We shall see, in the chapter dealing with death from carbonic acid, that this element complicates the question for normal pressure and for moderate decompressions when super-oxygenated air is used. I shall eliminate it here; besides, the proof we seek will be all the clearer, the lower the pressures fall.

Experiment XLVII. January 29. Bell-jar of 1.9 liters.

Mountain sparrow. Pressure lowered $50 \mathrm{~cm}$., sick, oxygen admitted; lowered $60 \mathrm{~cm}$, hardly affected, oxygen admitted; lowered 66.5 $\mathrm{cm}$., quite sick, oxygen admitted to $40 \mathrm{~cm}$., pressure lowered $52 \mathrm{~cm}$.

Cocks closed at 3:15; after sample of air is taken, the decompression is $54 \mathrm{~cm}$, at $3: 45$, in good condition; at 5 o'clock, panting; the actual pressure is $19 \mathrm{~cm}$. Dies at $6: 30$, without a motion.

Actual pressure, $18 \mathrm{~cm}$. Original mixture, O: 85.9 .

Lethal air: $\mathrm{CO}_{2} 68.1 ; \mathrm{O}=15.4$.

$\mathrm{CO}$ tension $=68.1 \times \frac{18}{76}=15.2$.

Oxygen tension $=15.4 \times \frac{18}{76}=3.6$.

Experiment XLVIII. April 23. Bell-jar of 1.5 liters.

Pressure lowered successively $54 \mathrm{~cm}$., $57 \mathrm{~cm}$., $62 \mathrm{~cm}$, $67 \mathrm{~cm}$; each time oxygen admitted, then air admitted until the decompression equalled $61.5 \mathrm{~cm}$. Cocks closed at 4:12. Found dead at 6:15. Thin layer of bloody suffusion in the cranial diploe. Pressure is $14 \mathrm{~cm}$.

Lethal air: $\mathrm{CO}_{2} 48.0 ; \mathrm{O}_{2} 23.8$.

$\mathrm{CO}_{2}$ tension $=8.8$. Oxygen tension $=4.3$.

Experiment XLIX. February 6. Bell-jar of 1.9 liters.

Pressure lowered $30 \mathrm{~cm}$., $50 \mathrm{~cm}$., $50 \mathrm{~cm}$, with successive admissions of oxygen; then to $14 \mathrm{~cm}$. Entered at 2:20; very restless; dead at $4: 45$. Bloody suffusion.

Actual pressure $12.5 \mathrm{~cm}$. Original mixture $\mathrm{O}_{2} 88.4$.

Lethal air: $\mathrm{CO}_{2} 66.0 ; \mathrm{O}_{2} 22.2$.

$\mathrm{CO}_{2}$ tension $=10.8$. Oxygen tension $=3.6$.

Experiment L. January 29. Bell-jar of 2.30 liters.

Pressure lowered $48 \mathrm{~cm}$., $52 \mathrm{~cm} ., 64.5 \mathrm{~cm}$., following successive admissions of oxygen; cocks closed at $2: 40$.

At 2:50, sample of air taken, which lowered the actual pressure to $10 \mathrm{~cm}$. At $3: 30$, still moving; at $4: 45$, dead. 
Actual pressure $8 \mathrm{~cm}$. Original mixture: $\mathrm{O}=82.3$.

Lethal air: $\mathrm{CO}_{2} 37.2 ; \mathrm{O}_{2} 41.8$.

$\mathrm{CO}$ ? tension $=3.9$. Oxygen tension $=4.4$.

Experiment LI. February 1. Bell-jar of 1.55 liters.

Pressure lowered $44 \mathrm{~cm}$, uneasy, oxygen admitted; lowered 52 $\mathrm{cm}$., same effect; lowered $65 \mathrm{~cm}$., struggled and vomited; same procedure again. Lowered $65 \mathrm{~cm}$., then sample of air taken, which lowers the pressure $68.7 \mathrm{~cm}$., and the actual pressure to $6.6 \mathrm{~cm}$. The bird moves at every stroke of the pump; very sick at once, and dies in an hour at the most. Cranial suffusion.

Original mixture: $\mathrm{O}_{2} 87.0$.

Lethal air: $\mathrm{CO}_{2} 17.3 ; \mathrm{O}_{2} 66.7$.

$\mathrm{CO}$ : tension $=1.5$. Oxygen tension $=5.8$.

The results of these different experiments are summarized in the following table.

Table III

\begin{tabular}{|c|c|c|c|c|c|c|c|}
\hline & 2 & 3 & 4 & 5 & 6 & 7 & \\
\hline 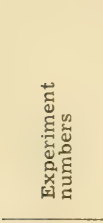 & 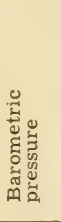 & 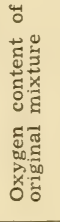 & 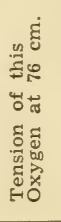 & $\begin{array}{l}\text { Compo } \\
\text { lethal }\end{array}$ & on of & 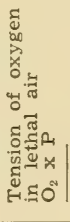 & $\mid$ \\
\hline $\begin{array}{l}\text { XLVII } \\
\text { XLVIII } \\
\text { XLIX } \\
\text { L } \\
\text { LI }\end{array}$ & $\begin{array}{r}18.0 \\
14.0 \\
12.5 \\
8.0 \\
6.6\end{array}$ & $\begin{array}{l}85.9 \\
88.4 \\
82.3 \\
87.0\end{array}$ & $\begin{array}{r}20.3 \\
14.5 \\
8.6 \\
7.5\end{array}$ & $\begin{array}{l}15.4 \\
23.8 \\
22.2 \\
41.8 \\
66.7\end{array}$ & $\begin{array}{l}68.1 \\
48.0 \\
66.0 \\
37.2 \\
17.3\end{array}$ & $\begin{array}{l}3.6 \\
4.3 \\
3.6 \\
4.4 \\
5.8\end{array}$ & \\
\hline
\end{tabular}

A glance at Column 7 shows that my expectations were realized; the numbers given are not far from the average previously found. The last, however, is noticeably higher. But an easy explanation of this difference is found in the number given in Column 4. In the very beginning, the bird was placed in an air which was certainly very rich in oxygen, but in which the actual tension of this gas was nevertheless extremely low. It was really "exhausted" air, and the bird was in asphyxiating conditions at the beginning of the experiment; and so it was in great distress immediately.

The verification of the hypothesis which had guided us comes likewise, and perhaps with still more evidence, from the consideration of the pressures to which it was possible to bring the birds without killing them immediately. While with ordinary air I could hardly go below $16 \mathrm{~cm}$., we find here, in Column 2, pressures of $14,12,8$, and even 6.6 centimeters. And what makes this fact 
still more remarkable is that I could not use the precautions the importance of which I stressed above, and that the decompression was therefore always very sudden.

Applying to oxygen the reasoning used on page 528 and fixing as limits of minimum tension of oxygen compatible with life the numbers 3 and 4.2, we find for the lowest barometric pressures to which it would be possible theoretically, in pure oxygen, with all necessary slowness and precautions, to bring sparrows without killing them the numbers taken from the equations $100 \times \frac{x}{76}=3$ and $100 \times \frac{x}{76}=4.2$. Whence $x=2.3 \mathrm{~cm}$. and $\mathrm{x}=3.2 \mathrm{~cm}$. It is evident that in practice one cannot go so low.

The ultimate phenomenon, that is, death, is not the only one whose barometric limit varies with the oxygen percentage of the medium. The other disturbances, uneasiness, cessation of movements, vomiting, general weakness, are in the same category. It has always been easy to prove that the bird which seemed sick at first diminution of pressure, when it reached $40 \mathrm{~cm}$. for example, gave no sign of uneasiness when, after admitting oxygen, I decreased the pressure again and reached the same level. I had to go farther, to $50 \mathrm{~cm}$. for example, to get the same morbid phenomena.

The experiments with super-oxygenated air have therefore completely proved what the experiments with ordinary air showed to be certain. It would have been possible to get a counter-verification from experiments in which we would have used air poor in oxygen. I could give with details some data of this sort; but the proof must already be thoroughly convincing in the reader's mind, and I shall merely say that with air containing only 10.2 per cent of oxygen, I could not reach a pressure lower than $28 \mathrm{~cm}$., the oxygen tension then being 3.7 .

It is then established that either in a closed vessel by respiratory depletion, or in a current of air, death occurs in rarefied air in consequence of a lessening of the tension of the ambient oxygen. Diminution of barometric pressure is only one method of obtaining this insufficient tension. But there is a second method which consists of lowering the percentage of oxygen; we need only consider

the equation mentioned s ) often already $\frac{\mathrm{O}_{2} \times \mathrm{P}}{76}=3.6$. 
The general conclusion from all this is that all disturbances, symptoms, and death, which occur in consequence of diminution of pressure, are due entirely to asphyxia; an animal subjected to an increasing diminution of pressure is like an animal which smothers in closed vessels in ordinary air, with the unimportant reservation, as we shall see later, of the action of the carbonic acid produced. When an animal in a closed vessel is subjected rapidly to a certain decompression, and allowed to die, as in the preceding experiments, the gradual depletion of the oxygen of the air in which it is confined acts exactly as if one continued in a pure air to diminish the barometric pressure around it.

Oxygen tension is everything; barometric pressure in itself does nothing or almost nothing.

I shall stress these facts and the conclusions to be drawn from them in another chapter, and I shall also indicate elsewhere the practical results which may be deduced from them.

I shall not now dwell upon the exterior phenomena displayed by the sparrows subjected to the lowering of pressure. This study, generalized and supported by precise observations made on animals of different species, will be taken up in a special chapter. I shall merely mention today three principal facts: 1 , the increase in number of respirations; 2 , the drop in temperature; 3 , the convulsions which precede death, and which will give us an opportunity to judge the theory which attributes the convulsions to the action of excess carbonic acid in the blood.

I shall now give the results of experiments made on birds other than sparrows.

Experiments $L I I$ to $L V$, simultaneous. July 2. Temperature $20^{\circ}$; pressure $76 \mathrm{~cm}$. Owls (Strix psilodactyla, Lin.)

LII. Young, weighing 125 grams. Bell-jar of 2.25 liters.

Entered at 3:07; left at normal pressure.

Seemed affected at about $3: 50$, dies at 5 o'clock, with $3.8 \mathrm{~cm}$. diminution of pressure due to absorption. Dead after 1 hour 20 minutes of distress. After 15 minutes, the rectal temperature is $31.3^{\circ}$; no rigidity.

Lethal air: $\mathrm{O}=3.3 ; \mathrm{CO}=13.4$.

$$
\mathrm{CO}_{2}+\mathrm{O}_{2}=16.7 ; \frac{\mathrm{CO}_{2}}{\mathrm{O}_{2}}=0.76 \text {. }
$$

LIII. Like the foregoing. Bell-jar of 7 liters.

Began at 3:15. At 3:20, pressure has been lowered $22 \mathrm{~cm}$., somewhat uneasy. At $3: 22$, pressure has been lowered $41 \mathrm{~cm}$., the bird is calm; at 3:25, staggers; cocks closed. Actual pressure $27.7 \mathrm{~cm}$. 
Soon closes its eyes and seems to sleep. Dies at 4:30, after 1 hour of uneasiness. Ten minutes after death, rectal temperature is $35.0^{\circ}$; after 25 minutes, it is $33.8^{\circ}$ : no rigidity.

Lethal air: $\mathrm{O}_{2}$ 13.4; $\mathrm{CO}=6.4$.

$$
\mathrm{CO}_{2}+\mathrm{O}_{2}=19.8 ; \frac{\mathrm{CO}}{\mathrm{O}_{2}}=0.87 \text {. }
$$

Oxygen tension $=4.8$.

LIV. Similar. Bell-jar of 7.5 liters.

Began at $3: 18$; at $3: 20$, decompression of $33 \mathrm{~cm}$., no uneasiness; at $3: 27,51 \mathrm{~cm}$. of decompression, vomits; at $3: 28$, actual pressure $22 \mathrm{~cm}$. Cock closed.

At 3:32, falls and seems about to die; a little air admitted and the pressure rises to $32 \mathrm{~cm}$; the bird gets up. Same procedure repeated twice. At $3: 58$, pressure is $23.5 \mathrm{~cm}$., the bird has half risen; cocks closed.

At $4: 10$, pressure lowered to $22.5 \mathrm{~cm}$. Dead at $4: 35$, without convulsions, after about 1 hour 10 minutes of respiratory embarrassment. After 20 minutes, the rectal temperature is $30.2^{\circ}$; after 30 minutes, $29.7^{\circ}$ : no rigidity.

Lethal air: $\mathrm{O}=17.1 ; \mathrm{CO}=3.3$.

$$
\mathrm{CO}_{2}+\mathrm{O}_{2}=20.4 ; \frac{\mathrm{CO}}{\mathrm{O}}=0.87 \text {. Oxygen tension }=5.0 \text {. }
$$

$L V$. Owl five years old, weighing 170 grams. Bell-jar of 11.5 liters.

Began at 3:08; considerable agitation, which lasts until 3:13, when the pressure has been lowered $36 \mathrm{~cm}$., the bird then grows calm. At $3: 16$, pressure has been lowered $44 \mathrm{~cm}$, vomits twice. At $3: 21,48$ $\mathrm{cm}$., at $3: 26,57 \mathrm{~cm}$., that is, approximately $19 \mathrm{~cm}$. of actual pressure. Falls and is about to die; pressure raised to $28 \mathrm{~cm}$., the bird gets up after a few minutes. Same procedure repeated twice, but each time the bird is evidently less affected. At 4:03, pressure is $20.2 \mathrm{~cm}$.: bird falls; cocks closed.

At $4: 10$, lowered to $19 \mathrm{~cm}$., bird is still prostrate, beak forward. Dead at 4:45, without convulsions, after about 1 hour 20 minutes of respiratory embarrassment. Twenty-two minutes after death, rectal temperature $30.2^{\circ}$; after 30 minutes, $29.6^{\circ}$ : no rigidity.

Lethal air: $\mathrm{O}=17.6 ; \mathrm{CO}_{2} 2.6$.

$$
\mathrm{CO}_{2}+\mathrm{O}_{2}=20.2: \frac{\mathrm{CO}_{2}}{\mathrm{O}_{2}}=0.79 . \quad \text { Oxygen tension }=4.4 \text {. }
$$

We see that our rule is verified, in spite of an irregularity greater than usual, presented by the experiments made at normal pressure. The value of the oxygen tension in the lethal air was, in fact: at $76 \mathrm{~cm} ., 3.3$; at $27.7 \mathrm{~cm} ., 4.8$; at $22.5 \mathrm{~cm} ., 5$; at $19 \mathrm{~cm} ., 4.4$. 
These last barometric pressures are very low, and quite evidently the transitions had not been careful enough.

Experiment LVI. August 3, hawk (Falco tinnunculus, Lin.). Pressure $75.5 \mathrm{~cm}$. Bell-jar of 13.5 liters.

Began at $3: 25$; current of air. The decompression at $3: 30$ is 8 $\mathrm{cm}$; at $3: 35,16 \mathrm{~cm}$; at $3: 45,30 \mathrm{~cm}$; at $3: 50,40 \mathrm{~cm}$; at $3: 53,50 \mathrm{~cm}$; that is, actual pressure about $25.5 \mathrm{~cm}$. Bird vomits and falls; pressure raised to $31.5 \mathrm{~cm}$., then slowly lowered to $25.5 \mathrm{~cm}$; the bird, which had recovered a little, falls again, seems about to die, and the pressure has to be raised to $27.5 \mathrm{~cm}$.

At $4: 05$, pressure is $25 \mathrm{~cm}$; at $4: 10,24.5 \mathrm{~cm}$; at $4: 15,21.5 \mathrm{~cm}$; the bird vomits, staggers, and reels, but seems to recover a little, while remaining weak. At $4: 17$, the pressure is only $20 \mathrm{~cm}$; at $4: 20,19.5 \mathrm{~cm}$. Cocks are closed, and the bird dies at 4:32. Lived about 40 minutes with respiratory embarrassment. Eight minutes after death, rectal temperature was $37.4^{\circ}$.

The air, as one might expect, is hardly altered; $\mathrm{O}=20.0 ; \mathrm{CO}=0.8$. Oxygen tension $=5.1$.

The interesting point of this last experiment is that a bird of prey, zoological neighbor of the vultures and the condors which mount to prodigious heights, was at least as sensitive to the lowering of pressure as a simple sparrow.

\section{B. Experiments on Mammals.}

These have been rather few, since the principal point of the question had been settled by the experiments on sparrows. They have shown me, as a general fact, that mammals can be brought to pressures considerably lower than birds. One might have conjectured as much anyway, since mammals deplete the oxygen of the confined air more than birds do. (See my Lessons on the Physiology of Respiration, page 510.)

They are, besides, more pliable, so to speak, that is, easier to reduce to the state of cold-blooded animals, enduring then as the latter do, extremely low pressures (See later); this is especially true of rodents. A remarkable example of this fact (Exp. LVII) was shown by a guinea pig, which, having been placed for four hours in a current of air (temperature $15^{\circ}$ ), continued to live under a pressure constantly lower than $20 \mathrm{~cm}$., which was repeatedly lowered to $11 \mathrm{~cm}$. for four or five minutes. It is true that after this time the unfortunate animal remained motionless, almost unconscious, with a rectal temperature of $20^{\circ}$, and that it died several hours after the experiment.

In another case (Exp. LVIII), a guinea pig was brought to and maintained at a pressure of $12 \mathrm{~cm}$. for about a quarter of an hour, 
by a gradual lowering of the pressure lasting an hour and a half The animal was then very weak, and its rectal temperature was only $25^{\circ}$; but three minutes after the animal was restored to normal pressure, the temperature rose to $31^{\circ}$, and the guinea pig could already get up on its feet. This animal survived.

CATS. Experiments LIX to LXIII, simultaneous. July 11; pressure $75 \mathrm{~cm}$. Cats from a month to a month and a half old.

LIX. Cat weighing 280 grams. Bell-jar of 3.2 liters. Entered at $3: 15$; normal pressure; died at $4: 35$, without convulsions.

280 grams lived 1 hour 20 minutes in 2.920 liters of air, which gives per liter and per kilogram

$$
\frac{80 \mathrm{~m} .}{2.92} \times \frac{280}{1000}=7.7 \mathrm{~m} \text {. }
$$

Lethal air: $\mathrm{O}=4.4 ; \mathrm{CO}=13.4$.

$$
\mathrm{CO} z+\mathrm{O}_{2}=17.8 ; \frac{\mathrm{CO}_{2}}{\mathrm{O}_{2}}=0.81 \text {. Oxygen tension }=4.4 \text {. }
$$

LX. Weight 380 grams. Bell-jar of 7 liters.

Began at $3: 20$; at $3: 25$, the pressure is $51.2 \mathrm{~cm}$; cocks closed; died at $4: 45$.

380 grams lived 1 hour 20 minutes in 6.62 liters of air at a pressure of $51.2 \mathrm{~cm}$; reducing to $76 \mathrm{~cm}$. of pressure and to 1000 grams, we get the value.

$\frac{80 \mathrm{~m} .}{6.62 \times 51.2} \times \frac{380}{1000}=\frac{80 \mathrm{~m} \times 380 \times 76}{6.62 \times 51.2 \times 1000}=7.1 \mathrm{~m}$.

76

Lethal air: $\mathrm{O}=7.2 ; \mathrm{CO}=11.4$.

$\mathrm{CO}_{2}+\mathrm{O}_{2}=18.6 ; \frac{\mathrm{CO}_{2}}{\mathrm{C}_{0}}=0.81$. Oxygen tension $=4.9$.

LXI. Weight 460 grams. Bell-jar of 13.5 liters.

Began at $3: 25$; at $3: 44$, pressure is $21.8 \mathrm{~cm}$. The animal is very sick, 250 respirations per minute. At 4 o'clock, violent convulsive movements, falls back, and dies at 4:13.

460 grams lived 29 minutes in 13.04 liters of air at $21.8 \mathrm{~cm}$., which gives 3 minutes per liter at $76 \mathrm{~cm}$. and per 1000 grams.

Lethal air: $\mathrm{O}=15.5 ; \mathrm{CO}_{2}$ 5.1.

$$
\mathrm{CO}_{2}+\mathrm{O}_{2}=20.6 ; \frac{\mathrm{CO}_{2}}{\mathrm{O}_{2}}=0.94 \text {. Oxygen tension }=4.4 \text {. }
$$


LXII. Weight 665 grams. Bell-jar of 15.5 liters.

Began at $3: 22$; at $3: 40$, the pressure is $27 \mathrm{~cm}$; vomits, defecates.

At $3: 48$, pressure is only $16 \mathrm{~cm}$; very uneasy. Cocks closed. Dies at $3: 53$, without convulsions.

Duration of life, per kilogram and per liter, 1 minute.

Lethal air: $\mathrm{O}_{2}$ 19.0; $\mathrm{CO}_{2}$ 1.0. $\mathrm{O}_{2} \times \mathrm{P}=4$.

LXIII. Weight 485 grams. Bell-jar of 15.5 liters.

Pressure reduced in 15 minutes to $16 \mathrm{~cm}$. Lying down, panting; dies in 20 minutes.

Duration of life, per kilogram and per liter, 3 minutes.

Experiment LXIV. August 4. Cat weighing 2.57 kilos; bell-jar of 21.5 liters.

Began at $4: 10$. At $4: 22$, the actual pressure is $29.5 \mathrm{~cm}$. Cocks closed; the animal does not seem in much pain.

At $4: 37$, violent struggles and cries. At $4: 45$, convulsions, with quivering of the cutaneous muscles. Dead at $4: 47$.

Duration of life, per kilo and per liter, 8.7 minutes.

Lethal air: $\mathrm{O}=10.3 ; \mathrm{CO}_{2} 9.6$.

$$
\mathrm{CO} z+\mathrm{O} z=19.9 ; \frac{\mathrm{CO}_{2}}{\mathrm{O}_{2}}=0.90 \text {. Oxygen tension }=4 \text {. }
$$

The value of the oxygen tension in these experiments was: at $76 \mathrm{~cm}$., 4.4; at $51.2 \mathrm{~cm}$., 4.9 ; at $29.5 \mathrm{~cm} ., 4$; at $21.8 \mathrm{~cm}$., 4.4 ; at $16 \mathrm{~cm} ., 4$.

If now we find the duration of life taking as base a liter of air and reducing the calculation to one kilogram of body weight, the result is: at $76 \mathrm{~cm}$., the duration of life was 7.7 minutes; at $5.12 \mathrm{~cm}$., 7.1 minutes; at $29.5 \mathrm{~cm}$., 8.7 minutes; at $27 \mathrm{~cm}$., 3 minutes; at $16 \mathrm{~cm}$., 3 minutes. We must not forget that the cat at $29.5 \mathrm{~cm}$. was very different from the others, and being much bigger, should consume less oxygen in a given time, and consequently live longer in a given space.

I thought it would be interesting to experiment on new-born animals, which resist asphyxia much longer than adults, as is known. However, I could not go noticeably farther with them in decompression than with adults. Kittens born two days before, brought rapidly to 8 to 12 centimeters of pressure, died in seven or eight minutes.

Here are the results of experiments in which the air was analyzed.

Experiments $L X V$ to LXVIII, simultaneous. July 4 ; pressure $76 \mathrm{~cm}$. Kittens born July 1, weighing an average of 125 grams.

LXV. Bell-jar of $675 \mathrm{cc}$., subtracting displacement of animal, $550 \mathrm{cc}$.

Entered at 2: 42 ; brought rapidly to a pressure of $58 \mathrm{~cm}$. At $3: 40$ seems dead, but does not really die until $4: 35$.

Lethal air: $\mathrm{O}_{2} 3.0 ; \mathrm{CO}_{2} 17.1$. 


$$
\mathrm{CO}_{2}+\mathrm{O}_{2}=20.1 ; \frac{\mathrm{CO}_{2}}{\mathrm{O}_{2}}=0.95 . \text { Oxygen tension }=2.2 .
$$

LXVI. Bell-jar of 2.5 liters.

Entered at 3 o'clock; at 3:06, pressure is $25.5 \mathrm{~cm}$; cocks closed; dies at 5:40.

Lethal air: $\mathrm{O}_{2} 7.1 ; \mathrm{CO}_{2} 13.5$.

$$
\mathrm{CO}_{2}+\mathrm{O}_{2}=20.6 ; \frac{\mathrm{CO}_{2}}{\mathrm{O}_{2}}=0.98 \text {. Oxygen tension }=2.4 \text {. }
$$

LXVII. Bell-jar of 3.2 liters.

Entered at 2:54. At 3 o'clock, pressure $20.5 \mathrm{~cm}$; mews. Cocks closed. Dies at $7: 15$.

Lethal air: $\mathrm{O}_{2} 8.5 ; \mathrm{CO}_{2} 12.0$.

$$
\mathrm{CO}_{2}+\mathrm{O}_{2}=20.5 ; \frac{\mathrm{CO}_{2}}{\mathrm{O}_{2}}=0.97 \text {. Oxygen tension }=2.2 \text {. }
$$

LXVIII. Bell-jar of 5 liters.

Entered at 2:38; at 2:48, pressure is $22 \mathrm{~cm}$; cat still walks and mews; at 2:53, pressure is $16.2 \mathrm{~cm}$; animal is lying flat. Cocks closed. At 3:08, pressure lowered to $13.4 \mathrm{~cm}$.

Dead at $7: 35$.

Lethal air: $\mathrm{O}=13 ; \mathrm{CO}=7$.

$$
\mathrm{CO}_{z}+\mathrm{O} z=20.0 ; \frac{\mathrm{CO}_{z}}{\mathrm{O}_{z}}=0.98 \text {. Oxygen tension }=2.2 \text {. }
$$

The ratio $\frac{\mathrm{O}_{2} \times \mathrm{P}}{76}$ is maintained here with remarkable regularity at 2.2, a number about half that given by adult cats.

Already, in my Lessons (page 510), I had found that, while adult cats leave on the average 5.3 per cent of oxygen in confined air, when they die at normal pressure, new-born kittens left only 3.0 per cent. For adult rats, the average was 2.0 per cent, and for a new-born rat, 0.75 per cent.

If now we make the calculations necessary to find the duration of life of these new-born kittens, reduced to a liter of air at $76 \mathrm{~cm}$. and to a kilogram of body weight, as we did for the adults, we find that this duration is: at $58 \mathrm{~cm}$., 33 minutes; at $25.5 \mathrm{~cm} ., 24$ minutes; at $20.5 \mathrm{~cm}$., 37 minutes; at $13.4 \mathrm{~cm}$., 32 minutes.

We see that the duration of life was obviously the same at very low pressures as at average pressures. Moreover, comparing these figures with those obtained from the study of adult cats, we see 
that the duration of life of the new-born kittens was about four times greater. These two facts agree with what is known about the vital resistance of new-born animals.

Finally, it is interesting to note that the ratio between the oxygen consumed and the carbonic acid produced was considerably higher in the new-born than in the adults: its average, in fact, is 0.97 , while for adults it is only 0.86 .

DOGS. Experiment LXIX. March 11. Dog weighing 4.3 kilos. Bell-jar of 31 liters.

Entered at 1:40 at a pressure of $43 \mathrm{~cm}$. Uneasy; lies down at 2 o'clock; found dead at 2:20.

Air at 2 o'clock: $\mathrm{O}_{2} 5.5 ; \mathrm{CO}_{2} 16.1$.

Air after death, $\mathrm{O}_{2} 5.4 ; \mathrm{CO}_{2}$ 16.7. Oxygen tension $=3.0$.

RABBITS. Experiment LXX. March 15. Rabbit. Bell-jar of 11.5 liters.

Entered at 2:28. Left at normal pressure.

At $3: 50$, standing, panting; at $3: 55$, struggles; at 4 o'clock, falls; at $4: 30$, last breath, without convulsions. Fifteen minutes after, its rectal temperature is $34^{\circ}$.

Lethal air: $\mathrm{O}=3.7 ; \mathrm{CO}_{2} 15.2$.

$$
\mathrm{CO}_{2}+\mathrm{O}_{2}=18.9 ; \frac{\mathrm{CO}_{2}}{\mathrm{O}_{2}}=0.96 . \quad \text { Oxygen tension }=3.7 \text {. }
$$

Experiment LXXI. March 16. Rabbit weighing 1.900 kilos. Belljar of 20.75 liters.

Began at 2:05; at 2:25, the pressure is only $41 \mathrm{~cm}$. Cocks closed. At 2:55, uneasiness; at $3: 20$, great uneasiness; at $3: 35$, falls; at $3: 50$, dead without convulsions; 5 minutes after, the rectal temperature is $35.3^{\circ}$.

Lived 1 hour 25 minutes in 18.85 liters of air at $41 \mathrm{~cm}$., which gives, per liter and per kilogram, a duration of 16 minutes.

Lethal air: $\mathrm{O}_{2}$ 5.9; $\mathrm{CO}=13.3$.

$$
\mathrm{CO} z+\mathrm{O} z=19.2 ; \frac{\mathrm{CO}_{2}}{\mathrm{O} z}=0.81 \text {. Oxygen tension }=3.2 \text {. }
$$

Experiment LXXII. March 14. Pressure $76.6 \mathrm{~cm}$; temperature $13^{\circ}$. Rabbit weighing 1.340 kilos. Bell-jar of 31 liters.

At 2:27, began the current of air; the manometer rises slowly; at 2:58 pressure lowered $41 \mathrm{~cm}$; up to that point the animal remained perfectly quiet. At 3:02, pressure lowered $50 \mathrm{~cm}$; rabbit becomes uneasy; the inlet cock is closed, and pumping continued. At 3:07, the pressure is only $15.6 \mathrm{~cm}$; the animal lies down. At $3: 12$, it is $16 \mathrm{~cm}$. Dead at $3: 20$.

Lethal air: $\mathrm{O} \approx 19 ; \mathrm{CO}=1.6$.

$$
\mathrm{CO}_{2}+\mathrm{O}_{2}=20.6 ; \frac{\mathrm{CO}_{2}}{\mathrm{O}_{2}}=0.84 \text {. Oxygen tension }=4.0 \text {. }
$$


Experiment LXXIII. March 15. Rabbit weighing 1.650 kilos. Bell-jar of 20.75 liters.

Began at $3: 48$. At $4: 05$, the pressure is $29 \mathrm{~cm}$. Cocks closed. The animal dies at $6: 42$; ten minutes after, its temperature is $32^{\circ}$. Nothing can be said about its duration of life, because a little air entered during the experiment.

Lethal air: $\mathrm{O}_{2} 11.0 ; \mathrm{CO}_{2} 9.0$.

$$
\mathrm{CO} z+\mathrm{O} z=20 ; \frac{\mathrm{CO}_{2}}{\mathrm{O}_{z}}=0.90 \text {. Oxygen tension }=4.2 \text {. }
$$

The value of the ratio $\mathrm{O} \times \mathrm{P}$ in these four experiments is: at 76

normal pressure, 3.7 ; at $41 \mathrm{~cm} ., 3.2$; at $29 \mathrm{~cm} ., 4.2$; at $16 \mathrm{~cm} ., 4.0$.

GUINEA PIGS. Experiments LXXIV-LXXV, simultaneous. August 5 .

LXXIV. Weight 420 grams. Bell-jar of 3.2 liters. Entered at $3: 45$, at normal pressure. Dead at 5:05, after uneasiness, sudden leaps, etc. . . Never remained quiet. A quarter of an hour later, its rectal temperature is $37^{\circ}$.

420 grams lived 1 hour 20 minutes in 2.78 liters of air, that is, 12 minutes per liter and per 1000 grams.

Lethal air: $\mathrm{O}=2.3 ; \mathrm{CO}_{2} 16.4$.

$$
\mathrm{CO} z+\mathrm{O} z=18.7 ; \frac{\mathrm{CO} z}{\mathrm{O} z}=0.88 \text {. Oxygen tension }=2.3 \text {. }
$$

LXXV. Weight 470 grams. Bell-jar of 5 liters.

Began at $3: 55$, and brought in 2 minutes to $46.5 \mathrm{~cm}$. of actual pressure.

Remains perfectly quiet. At 5:17, convulsive trembling. Dies at $5: 20 ; 17$ minutes after, the rectal temperature is $34^{\circ}$.

470 grams lived 1 hour 24 minutes in 4.53 liters at $46.5 \mathrm{~cm}$., representing at $76 \mathrm{~cm}$., 2.10 liters. Therefore 1000 grams lived 14 minutes per liter.

Lethal air: $\mathrm{O}_{2} 3.5 ; \mathrm{CO}_{2} 16.0$.

$\mathrm{CO} z+\mathrm{O} z=19.5 ; \frac{\mathrm{CO}_{2}}{\mathrm{O}_{2}}=0.92$. Oxygen tension $=2.1$.

Experiments LXXVI-LXXVII, simultaneous. June 23.

LXXVI. Weight 580 grams. Bell of 13 liters.

Began at 1:45. Reduced to a pressure of $16 \mathrm{~cm}$. with current of air at $2: 45$. Dead at $3: 10 ; 27$ minutes after, its rectal temperature is $31.5^{\circ}$.

Lived 1 hour 12 minutes in a volume of air corresponding to 2.6 liters at $76 \mathrm{~cm}$., that is, 16 minutes per 1000 grams per liter, 
Lethal air: $\mathrm{O}=14.5 ; \mathrm{CO}=9.8$.

$\mathrm{CO} z+\mathrm{O} z=24.3 ; \frac{\mathrm{CO} z}{\mathrm{O}_{2}}=1.51$. Oxygen tension $=3.0$.

LXXVII. Weight 490 grams. Bell-jar of 10 liters.

Began at 1:45. Brought to a pressure of $12 \mathrm{~cm}$. at 2:45.

Dies at 3 o'clock; 17 minutes after, temperature is $33.3^{\circ}$. Lived 15 minutes in 1.5 liters of air at $76 \mathrm{~cm}$; that is, 4.9 minutes per liter and per 1000 grams.

Lethal air: $\mathrm{O}=14.5 ; \mathrm{CO}_{2} 16.0$.

$$
\mathrm{CO}=+\mathrm{O}:=24.3 ; \frac{\mathrm{CO}_{2}}{\mathrm{O}_{2}}=1.51 \text {. Oxygen tension }=2.1 \text {. }
$$

Experiment LXXVIII. Weight 485 grams. Bell-jar of 13.5 liters, pressure $76 \mathrm{~cm}$.

Began at $3: 24$; no uneasiness. At $3: 30$, pressure lowered $50 \mathrm{~cm}$.: staggers, then recovers; respiratory rate 100 , walks a little. At 3:34, pressure lowered $56 \mathrm{~cm}$.; respiratory rate 135 ; at $3: 35$, pressure lowered 58.5, lies down on its belly. At $3: 40$, actual pressure $13.6 \mathrm{~cm}$.; respiratory rate 80 , violent, painful. Cocks closed.

$3: 45$, still lying down, pupils dilated; $3: 46$, little convulsive shudders; $3: 47$, fallen on its side; convulsive movements; rigidity; belly enormously swollen. $3: 49$, dies, having lived 9 minutes.

After 13 minutes, rectal temperature is $34.6^{\circ}$ : after 36 minutes, $31.8^{\circ}$; after 1 hour 16 minutes, $28.4^{\circ}$, and rigidity begins; after 2 hours 11 minutes, $25.4^{\circ}$; slight rigidity.

Lethal air: $\mathrm{O}=19.1 ; \mathrm{CO}_{2} 2.3$.

$$
\mathrm{CO}_{2}+\mathrm{O}_{2}=21.4 ; \frac{\mathrm{CO}_{2}}{\mathrm{O}_{2}}=1.27 \text {. Oxygen tension }=3.4 \text {. }
$$

Experiments $L X X I X-L X X X I$, simultaneous. May 28. Pressure 76.3 $\mathrm{cm}$.

LXXIX. Weight 620 grams. Bell-jar of 16 liters.

Began at 2:32; at 2:35, pressure lowered $41.3 \mathrm{~cm}$., that is, $35 \mathrm{~cm}$. of actual pressure; cocks closed.

At 4:50, falls on its side; at 5:30, dies; 30 minutes after, its rectal temperature is $28^{\circ}$.

620 grams lived 2 hours 55 minutes in 4.44 liters of air at $76 \mathrm{~cm}$. Which gives 24 minutes per, 1000 grams and per liter of air at $76 \mathrm{~cm}$.

Lethal air: $\mathrm{O}_{2} 4.9 ; \mathrm{CO}=17.2$.

$$
\mathrm{CO}_{2}+\mathrm{O}_{2}=22.1 ; \frac{\mathrm{CO}_{2}}{\mathrm{O}_{2}}=1.07 \text {. Oxygen tension }=2.2 \text {. }
$$

LXXX. Weight 520 grams. Bell-jar of 13.5 liters.

Began at 2:37. At 2:44, pressure $27.8 \mathrm{~cm}$.; cocks closed.

At $4: 10$, fallen on its belly; at $4: 55$, on its side; dead at $5: 05 ; 15$ minutes after, its rectal temperature is $28^{\circ}$. 
520 grams lived 2 hours 20 minutes in 4.76 liters of air at $76 \mathrm{~cm}$.; which makes 17 minutes, per 1000 grams and per liter of air at $76 \mathrm{~cm}$.

Lethal air: $\mathrm{O}=5.4 ; \mathrm{CO}=15.7$.

$$
\mathrm{CO}_{2}+\mathrm{O}_{2}=21.1 ; \frac{\mathrm{CO}_{2}}{\mathrm{O}_{2}}=1.01 \text {. Oxygen tension }=2.2 \text {. }
$$

LXXXI. Weight 620 grams. Bell-jar of 19 liters.

Began at 2:40; at 2:49 the pressure is $19.5 \mathrm{~cm}$; the animal staggers. Cocks closed.

At 2:55, falls; at $3: 20$, a little better; at $4: 15$, still making efforts to rise; at 5:10, convulsive jerks; dies at $5: 30 ; 20$ minutes after, the rectal temperature is $23^{\circ}$.

Lived 2 hours 40 minutes in 4.71 liters of air; which gives 21 minutes, per 1000 grams and per liter at normal pressure.

Lethal air: $\mathrm{O}_{2} 8.1 ; \mathrm{CO}_{2}$ 15.6.

$$
\mathrm{CO} 2+\mathrm{O}_{2}=23.7 ; \frac{\mathrm{CO}_{2}}{\mathrm{O}_{2}}=1.21 \text {. Oxygen tension }=2.0 \text {. }
$$

The value of the oxygen tension in these different experiments was:

At normal pressure, 2.3 ; at $46.5 \mathrm{~cm} ., 2.1$; at $41.3 \mathrm{~cm} ., 2.2$; at $27.8 \mathrm{~cm} ., 2.0$; at $19.5 \mathrm{~cm} ., 2.0$; at $16 \mathrm{~cm} ., 3.0$; at $13.6 \mathrm{~cm} ., 3.4$; at $12 \mathrm{~cm} ., 3.0$.

It will be noted that at very low pressures the sum $\mathrm{CO}_{2}+\mathrm{O}_{2}$ was: $21.1 ; 21.4 ; 22.1 ; 22.1 ; 23.7$; and 24.3 , that is, higher than the original proportion of oxygen. The excess is due, no doubt, to the carbonic acid contained in the intestines of these rodents, whose bellies balloon out at the beginning of very low pressures, and which probably then let escape a part of their expanded gases.

As to the duration of life, reducing it to 1000 grams of body weight, it was, per liter, : at normal pressure, 12 minutes; at $46.5 \mathrm{~cm}$., 14 minutes; at $41.3 \mathrm{~cm} ., 24$ minutes; at $27.8 \mathrm{~cm} ., 17$ minutes; at $19.5 \mathrm{~cm} ., 21$ minutes; at $16 \mathrm{~cm} ., 16$ minutes; at $13.6 \mathrm{~cm}$. and at $12 \mathrm{~cm}$., death came much more rapidly. We find here a regularity not displayed by the birds, which were extremely variable in their behavior under the bell-jars. The two extremes 12 and 24 are explained by the incessant movement or the complete calm of the experimental animals.

If we compare these numbers with those furnished us by the other mammals, we see that they are about double those given by adult cats, about equal those of rabbits, and much lower than those of new-born kittens. Let us say in conclusion that for sparrows, whose ordinary weight is about 30 grams, making the same calcula- 
Table IV

\begin{tabular}{|c|c|c|c|c|c|c|c|c|c|}
\hline 1 & 2 & 3 & 4 & & 6 & & & & \\
\hline 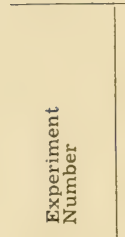 & 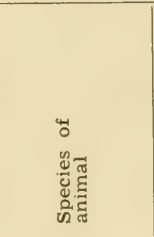 & $\begin{array}{l}\vec{c} \\
\vec{w} \\
\overrightarrow{0} \\
3\end{array}$ & 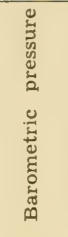 & 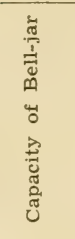 & 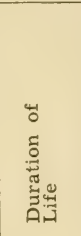 & 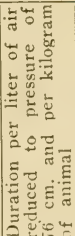 & \multicolumn{2}{|c|}{$\begin{array}{l}\text { Composition } \\
\text { of lethal air }\end{array}$} & 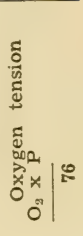 \\
\hline LII & $\begin{array}{l}\text { Strix psilo- } \\
\text { dactyla. } \\
\text { Id. - } \\
\text { Id. ---- } \\
\text { Id. -- } \\
\text { Falco Tin- } \\
\text { nunculus }\end{array}$ & $\begin{array}{l}\text { gm. } \\
125 \\
125 \\
125 \\
170\end{array}$ & \begin{tabular}{l|}
\multicolumn{1}{c}{ c. } \\
76 \\
27.5 \\
22.5 \\
19 \\
\\
19.5
\end{tabular} & $\begin{array}{l}\text { lit. } \\
2.25 \\
7 \\
7.5 \\
11.5 \\
\\
13.5\end{array}$ & $\begin{array}{rl}\text { h. } m . \\
1 & 53 \\
1 & 10 \\
37 \\
35 \\
\\
\\
\\
\\
12\end{array}$ & $\begin{array}{l}\mathrm{m} . \\
6.2 \\
3.4 \\
2.1 \\
2.1\end{array}$ & \begin{tabular}{r|}
$\mathrm{O}_{2}$ \\
3.3 \\
13.4 \\
17.1 \\
17.6 \\
\\
20
\end{tabular} & $\begin{array}{r}\mathrm{CO}_{2} \\
13.4 \\
6.4 \\
3.3 \\
2.6 \\
\\
0.8\end{array}$ & $\begin{array}{l}3.3 \\
4.8 \\
5.0 \\
4.4 \\
5.1 \\
\text { av. } 4.5\end{array}$ \\
\hline & & & MAI & LS & & & & & \\
\hline $\begin{array}{l}\text { IX } \\
\mathrm{X} \\
\mathrm{XIV} \\
\mathrm{XII}\end{array}$ & \begin{tabular}{cc|} 
Cat $1 \mathrm{mo}$. \\
old & --- \\
Id. & - \\
Adult & cat \\
Cat 1 & mo.
\end{tabular} & $\begin{array}{r}280 \\
380 \\
2570 \\
\end{array}$ & $\begin{array}{l}76 \\
51 \\
29.5 \\
\end{array}$ & $\begin{array}{c}3.2 \\
7 \\
21.5\end{array}$ & $\begin{array}{ll}1 & 20 \\
1 & 20 \\
& 25\end{array}$ & $\begin{array}{l}7.7 \\
7.1 \\
8.7\end{array}$ & $\begin{array}{r}4.4 \\
7.2 \\
10.3 \\
\end{array}$ & $\begin{array}{r}13.4 \\
11.4 \\
9.6 \\
\end{array}$ & $\begin{array}{l}4.4 \\
4.9 \\
4 \\
4.4\end{array}$ \\
\hline XI & $\begin{array}{l}\text { old } \\
\text { Id } \\
\text { Id }\end{array}$ & $\begin{array}{l}460 \\
665 \\
485\end{array}$ & $\begin{array}{l}21.8 \\
16 \\
16\end{array}$ & $\begin{array}{l}13.5 \\
15.5 \\
15.5\end{array}$ & $\begin{array}{l}29 \\
05 \\
20 \\
\quad \mathrm{a}\end{array}$ & $\frac{3}{3}$ & $\begin{array}{l}15.5 \\
19\end{array}$ & $\begin{array}{l}5.1 \\
1\end{array}$ & $\begin{array}{l}\frac{4.4}{4} \\
\text { av. } 4.4\end{array}$ \\
\hline LXVIII & \begin{tabular}{|c|} 
Cats 3 \\
days old \\
Id \\
Id. \\
Id.
\end{tabular} & $\begin{array}{l}125 \\
125 \\
125 \\
125\end{array}$ & $\begin{array}{l}58 \\
25.5 \\
20.5 \\
13.5\end{array}$ & $\begin{array}{r}10.5 \\
2.5 \\
3.2 \\
5\end{array}$ & $\begin{array}{ll}1 & 55 \\
2 & 35 \\
4 & 15 \\
4 & 30\end{array}$ & $\left|\begin{array}{c}33 \\
24 \\
37 \\
32 \\
\mid \text { av.31 }\end{array}\right|$ & $\begin{array}{r}0.3 \\
7.1 \\
8.5 \\
13\end{array}$ & $\begin{array}{l}17.1 \\
13.5 \\
12 \\
7\end{array}$ & $\begin{array}{l}2.2 \\
2.4 \\
2.2 \\
2.2 \\
\text { av.2.2 }\end{array}$ \\
\hline $\begin{array}{l}\text { XIX } \\
\text { XX } \\
\text { XXI } \\
\text { XXIII } \\
\text { XXII }\end{array}$ & \begin{tabular}{|l|} 
Dog \\
Rabbit \\
Id. \\
Id. \\
Id. \\
Id. ---- \\
\end{tabular} & $\begin{array}{l}4.3 \mathrm{~K} . \\
1.9 \mathrm{~K} . \\
1.6 \\
1.3\end{array}$ & 16 & 31 & $\begin{array}{l}\overline{2} \\
\frac{125}{13}\end{array}$ & $\overline{\overline{16}}$ & $\begin{array}{r}5.4 \\
3.7 \\
5.9 \\
11 \\
19\end{array}$ & \begin{tabular}{|c|}
15.2 \\
13.3 \\
9 \\
1.6
\end{tabular} & $\begin{array}{c}3.0 \\
3.7 \\
3.2 \\
4.2 \\
4.0 \\
\text { av. } 3.8\end{array}$ \\
\hline $\begin{array}{l}\text { XXIV } \\
\text { XXX } \\
\text { XXIX } \\
\text { XXX }\end{array}$ & $\begin{array}{l}\text { Guinea pig } \\
\text { Id. ---- } \\
\text { Id. ---- } \\
\text { Id. } \\
\text { Id. ---- } \\
\text { Id. ----- } \\
\text { Id. ---- } \\
\text { Id. } \\
\text { Id. ---- }\end{array}$ & $\begin{array}{l}470 \\
620 \\
520 \\
620 \\
580 \\
485 \\
490\end{array}$ & $\begin{array}{l}46.5 \\
35 \\
28 \\
19.5 \\
16 \\
13.5 \\
12\end{array}$ & $\begin{array}{l}3.2 \\
5 \\
16 \\
13.5 \\
19 \\
13 \\
13.5 \\
10\end{array}$ & $\begin{array}{ll}1 & 20 \\
1 & 20 \\
2 & 55 \\
2 & 20 \\
2 & 40 \\
1 & 12 \\
& 9 \\
& 15 \\
& \text { Av. }\end{array}$ & $\begin{array}{l}12 \\
14 \\
24 \\
17 \\
21 \\
16 \\
\frac{17}{17.3}\end{array}$ & $\begin{array}{r}2.3 \\
3.5 \\
4.9 \\
5.4 \\
8.1 \\
14.5 \\
19.1 \\
19\end{array}$ & $\begin{array}{r}15.6 \\
9.8 \\
2.3 \\
3.1\end{array}$ & $\begin{array}{l}2.1 \\
2.2 \\
2.0 \\
2.0 \\
3.0 \\
3.4 \\
3.0 \\
\text { av. } 2.5\end{array}$ \\
\hline
\end{tabular}


tions, we should find an average of about two minutes per kilogram and per liter. Now, if we refer to the celebrated and classic work of Regnault and Reiset on respiration, we shall find analogous results, that is, the greater consumption of oxygen in a given time by carnivores than by herbivores, by birds than by mammals, by small animals than by large ones, etc.

All the data which have just been given are summarized in Table IV.

I add, in conclusion, the account of an experiment (Exper. LXXXII) made on a hedgehog July 6, with the purpose of trying to put this animal into a state of hibernation by keeping it for a certain time at very low pressure. But we could not, without imminent danger, pass below a pressure of $18 \mathrm{~cm}$; at $26 \mathrm{~cm}$., the animal uncurled and vomited. After two hours, during which the pressure varied between $28 \mathrm{~cm}$. and $18 \mathrm{~cm}$., we removed the animal, which recovered rapidly and survived. This hedgehog therefore behaved like a cat or any other animal not endowed with the remarkable power of hibernation.

\section{Experiments on cold-blooded animals.}

I made only a few experiments on cold-blooded animals. Frogs, so useful for other researches, often manifest a strange unevenness in duration of life, composition of lethal air, etc., when they are allowed to die in closed vessels, even at normal pressure. However, here is a series of simultaneous experiments, in which, by taking great precautions and choosing my subjects with great care, I succeeded in getting an interesting result:

Experiments LXXXIII-LXXXVII, simultaneous. June 15, at 3 o'clock; temperature $22^{\circ}$.

LXXXIII. Normal pressure, vessel of 275 cc.; dies at 5 o'clock in the evening, June 17.

Lethal air: $\mathrm{O}=2.7$.

$L X X X I V$. Pressure of $20 \mathrm{~cm}$; vessel of 1.350 liters, representing 355 cc. at normal pressure; it dies June 16 at 2 o'clock.

Lethal air: $\mathrm{O}=$ 8.4. Oxygen tension $=2.2$.

LXXXV. Pressure of $14 \mathrm{~cm}$; vessel of 1.9 liters, representing 350 cc. at normal pressure, dies June 16 at 2:50.

Lethal air: $\mathrm{O}_{2}$ 15.3. Oxygen tension $=2.8$.

LXXXVI. Pressure of $10 \mathrm{~cm}$; vessel of 2.2 liters, representing 290 cc. at normal pressure; lived 4 hours.

Lethal air: $\mathrm{O}=18.5$. Oxygen tension $=2.4$.

LXXXVII. Pressure of $5.5 \mathrm{~cm}$; vessel of 2.8 liters, representing 200 cc.; lived 2 hours.

Lethal air: $\mathrm{O}_{2}$ 18.6. Oxygen tension $=1.3$. 
Finally I report the results of an experiment made on an insect, the poplar beetle (Chrysomelida) :

Experiment LXXXVIII. August 3, 4 o'clock in the evening; temperature $24^{\circ}$. 10 grams of beetles entered:
A. In a bell-jar of $60 \mathrm{cc}$. at normal pressure.
B. In a bell-jar of $800 \mathrm{cc}$. at a pressure of $9 \mathrm{~cm}$.
C. In a bell-jar of 1.5 liters at a pressure of $4 \mathrm{~cm}$.

On August 4, at noon, the insects are motionless and seem dead; the air of the bell-jars no longer has a trace of oxygen; there is 18 to 20 per cent of $\mathrm{CO}$. The insects return to life about an hour afterwards.

\section{Conclusions.}

The results which the data given in the present subchapter have brought us can be summarized in the following conclusion:

In a closed vessel, at pressures below one atmosphere, death occurs when the tension $\mathrm{O}_{2} x P$ of the oxygen of the air is reduced to a certain value which is constant for each species, or at least varies within narrow limits around an average (4.4 for adult cats; 3.6 for sparrows; 2.5 for guinea pigs; 2.2 for newborn kittens).

This average remains the same, whatever the initial composition of the air used; but for super-oxygenated air the carbonic acid must be absorbed as it is produced.

\section{Subchapter II}

\section{PRESSURES ABOVE ONE ATMOSPHERE}

\section{Experimental Set-up.}

After studying the composition of confined air which had become irrespirable under pressures less than one atmosphere, it was quite natural to find out what would happen if one used higher pressures. We have seen that, the weaker the pressure, the greater is the proportion of oxygen remaining in the lethal air, or, in other words, the less the air is exhausted. Would this law hold good at higher pressures? Would there come a moment when a sparrow would exhaust the oxygen of the air under pressure, as the beetles of which I gave an account above did at weaker pressures? Applying the law and taking as an average of the exhaustion in oxygen at normal pressure the figure 3.6, at 3.6 atmospheres we should find only 1 per cent of oxygen in the air which had become lethal by 
confinement, at 7.2 atmospheres only 0.5 per cent, and so on. We shall see how far this hypothesis is from the truth.

In the experiments which I shall report, I used sparrows almost exclusively. Their small size allowed me to use glass apparatuses whose advantages are evident, but whose dangers, when highly compressed air is used, are no less evident. In fact, glass has this serious disadvantage, that one is never sure that an apparatus which withstood a certain pressure at a certain moment, will be able to withstand it again. Furthermore, under the influence of atmospheric changes, the metallic pieces in which it must be held expand or contract in lengthy experiments, following a law different from that of the glass, which is thus subjected to pulls in opposite directions which threaten its solidity and may even crack it without the application of any pressure, since these glasses are very thick. At any rate, thanks to the precautions we used, the accidents which occurred never had serious consequences.

One of the apparatuses which I used most frequently and which allows me to compress air up to 25 atmospheres, consists of a glass cylinder, of a capacity of $650 \mathrm{cc}$. and a thickness of 18 millimeters, protected by a large-mesh jacket. This reservoir is topped with a bronze part, which exactly fits its orifice, or rather fits another fixed bronze plate which is fastened to the stand on which the reservoir rests by four steel columns which pass through both the fixed part and the movable part. These two parts are solidly held by four movable nuts which screw on the steel columns. All of this is plainly visible in Figure 20.

A Bourdon manometer, which indicates the pressure of the air in the reservoir, is fixed on the immovable plate. A screw cock with a very small opening at the right of the cylinder permits one to take a sample of this air whenever he wishes. To do so, one fits to this cock a rubber tube which dips into a mercury basin below a graduated tube; if then this cock is opened carefully, the compressed air escapes from the apparatus and enters the graduated tube; I always took care, of course, to let out a certain quantity before taking what I intended to analyze.

The air is compressed in the reservoir by means of a small forcepump; I had this pump enclosed in a metal jacket through which a constant stream of water passes; the operation of it is then less painful and-which is more important-no hot air is pumped to the animal. I can thus reach a pressure of 25 atmospheres in about 20 minutes. Finally, a large cock fastened to the movable part topping the cylinder opens or closes the apparatus hermetically. 
It establishes or cuts off communication with the pump, and, when the tube surmounting it is taken away, permits sudden decompression of the air in the reservoir, when necessary.

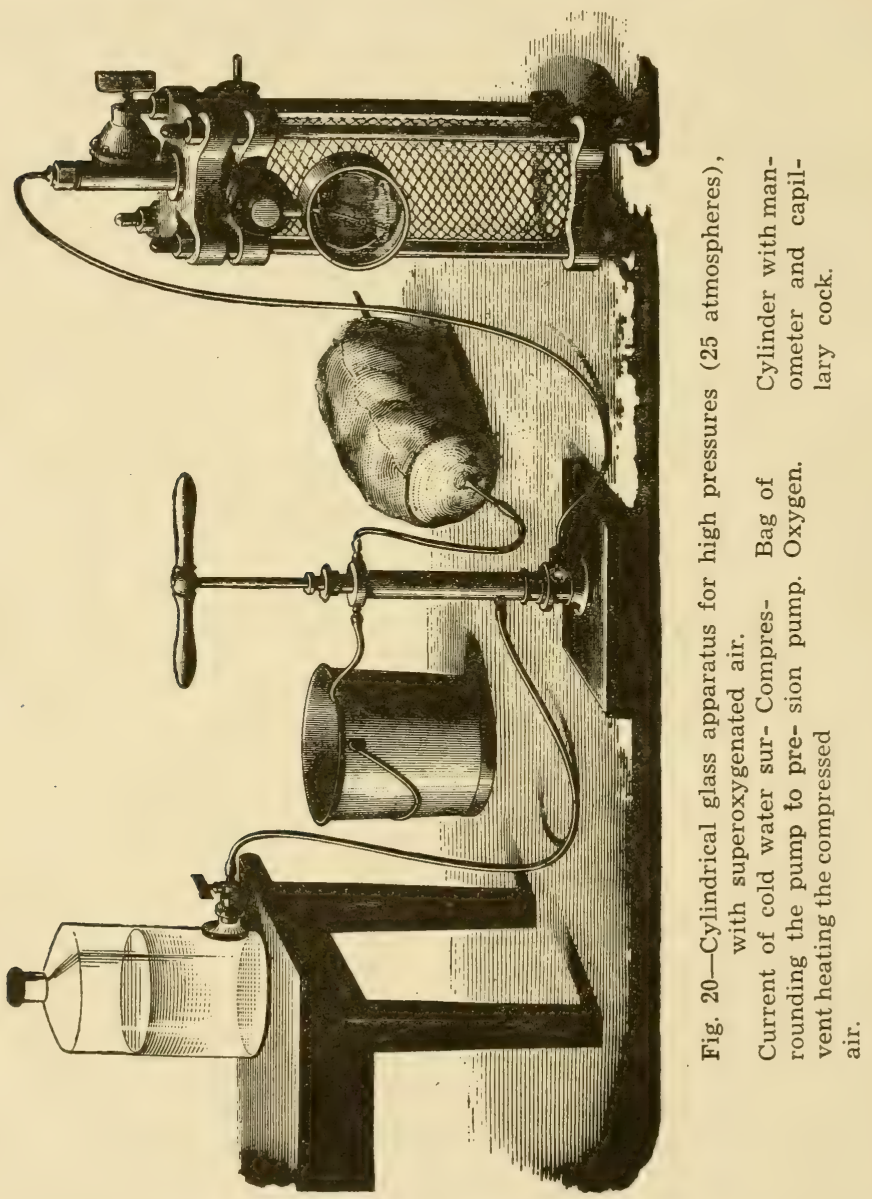

In the experiments in which I simply compressed the air, the bag pictured in the figure was not present, of course, and the suction of the pump was directly outside. 
I used even more often an apparatus made in a similar manner, whose reservoir was a simple receiver of a Seltzer water generator. I could take this only to 10 atmospheres; but the rounded form of the apparatus gave the animals more liberty.

Finally, I used a mercury bottle, mounted like the glass cylinder, The extreme solidity of this instrument would have allowed me to carry the pressure to 40 atmospheres without difficulty. Its capacity of 3 liters also has great advantages; the only inconvenience is that of not being able to see what is going on inside.

\section{Experiments.}

A. Compression with Ordinary Air.

I now come to the experiments. I shall list them, as I have done hitherto, in the order in which they were performed. What I said at the beginning of this sub-chapter indicates sufficiently why I began with a pressure of 3.75 atmospheres. The apparatus which I used in this first series is a Seltzer water receiver, of a total capacity of $1060 \mathrm{cc}$.

Experiment $L X X X I X$. July 18; temperature $26^{\circ}$. House sparrow, young. In 10 minutes the sparrow is taken to 3.75 atmospheres; it does not seem affected; but, an accident making the pressure fall suddenly, it bristles up and hides its head under its wing. The increase of the pressure to its original level restores its healthy appearance.

Cocks closed at 2 o'clock. At $2: 20$, sick; at $3: 10$, very sick; at $5: 20$, seems to be dying; at $6: 30$, the same. At 10 o'clock in the evening, thinking it dead, I withdrew air so that the pressure fell to 2 atmospheres; it was breathing then, and I left it until 10:30. Taken out then, it was still living, with a rectal temperature of $28^{\circ}$ (the same temperature as that of the receiver); it died during the night.

The air which I took at 10 o'clock, and which probably would have changed but little afterwards, contained: $\mathrm{CO}_{2} 7.2 ; \mathrm{O}_{2} 11.1$.

Experiment XC. July 19 ; temperature $25^{\circ}$. House sparrow, young. In 10 minutes, taken to 7 atmospheres; closed the cock at 2:10. At 4: 45 very sick, eyes closed. At 10 o'clock in the evening, found dead.

I made the decompression rapidly and on examining the jugülar vein, I found the blood red and frothy like foam.

The lethal air contained $\mathrm{CO}_{2} 3.7 ; \mathrm{O}_{2}$ 16.2.

Experiment XCI. July 20; temperature 21.5. House sparrow, young. Taken rapidly to $2 \frac{1 / 2}{2}$ atmospheres. Closed cocks at 5:30. Sick at 5:55; seemed dead at 9:45. I took out an air sample and opened the apparatus.

Taking the bird in my hand, I perceived that it was still breathing a little, and was still a little sensitive. The rectal temperature was $23.5^{\circ}$, probably equal to that of the receiver. I cut its head off; it had very energetic reflex movements. The bird therefore lived 
about $4 \frac{1}{2}$ hours, in a quantity of air corresponding to 2.650 liters at normal pressure.

The blood was very red in the left heart; less dark than in the ordinary condition in the right jugular; no free gases in the blood.

Lethal air: $\mathrm{CO}_{2} 11.2 ; \mathrm{O}_{2} 8.5$.

Experiment XCII. July 21; house sparrow, young. Put in a pressure of 5 atmospheres at 10 o'clock in the morning; found dead at 1 o'clock.

Lethal air: $\mathrm{CO}_{2} 6.0 ; \mathrm{O}_{2} 14.2$.

Experiment XCIII. July 24; temperature $21^{\circ}$. House sparrow. Placed in a pressure of $1 \frac{112}{2}$ atmospheres at 5:10. Died at 8:45. Rectal temperature $25.5^{\circ}$; venous blood fairly red; no free gases. Lived 3 hours 35 minutes in 1.580 liters of air, at normal pressure.

Lethal air: $\mathrm{CO}_{2} 15.2 ; \mathrm{O}_{2} 2.6$.

Experiment XCIV. July 25; temperature $23^{\circ}$. House sparrow, rather old. At 4:35 taken to 2 atmospheres. Found dead at 7:45.

Lethal air: $\mathrm{CO}_{2}$ 13.7; $\mathrm{O}_{2} 5.0$.

Experiment $X C V$. July 26; temperature $23^{\circ}$. House sparrow. At $1: 25$, taken to 5 atmospheres.

Died at 4:15. Rectal temperature $23^{\circ}$; blood and tissues red; the heart was still beating after removal. Lived 2 hours 50 minutes in the equivalent of 5.300 liters of air.

Lethal air: $\mathrm{CO}_{2} 5.1 ; \mathrm{O}_{2} 13.4$.

Experiment XCVI. August 4. House sparrow. At 4:35 taken to 6 atmospheres. At 5:30, very sick; found dead at $9: 30$. Venous blood red; gas in the right heart and the jugulars, but not in the left heart.

Lethal air: $\mathrm{CO}_{2} 4.2 ; \mathrm{O}_{2} 16.0$.

Experiment XCVII. August 11. House sparrow. At 2:55, placed at $1 \frac{1 / 2}{2}$ atmospheres. Very sick at 5:30. Found dead at 9 o'clock; venous blood, dark.

Lethal air: $\mathrm{CO}_{2} 15.4 ; \mathrm{O}_{2} 2.5$.

Experiment XCVIII. August 17. Yellow-hammer (Emberiza citrinella, Lin.). At $4: 45$, at 1 and $3 / 4$ atmospheres. Sick at 6 o'clock; found dead at 8 o'clock; venous blood dark; no gases.

Lethal air: $\mathrm{CO}_{2}$ 12.9; $\mathrm{O}_{2} 4.9$.

Experiment XCIX. August $19 ; 22^{\circ}$. Linnet (Fringilla cannabina, Lin.).

Taken to 8.8 atmospheres. Closed the cock at 2:50; at $3: 45$, distressed, made efforts to vomit. At $4: 45$, fell on its side, respirations grew slower and weaker; no convulsions. At 6 o'clock a quivering in one foot, then extension: it was the last movement.

Rectal temperature $25.5^{\circ}$. The venous blood was very red, without gas; the heart was still beating, auricles and ventricles. Lived 3 hours and 10 minutes in 9.330 liters of air at normal pressure.

Lethal air: $\mathrm{CO}_{2} 2.8 ; \mathrm{O}_{2} 17.4$. 
Experiment C. August 19; temperature $22^{\circ}$. Linnet.

At $6: 20$, taken to 95 centimeters pressure; at $9: 55$, found dead. Venous blood dark, without gas.

Lethal air: $\mathrm{CO}_{2} 13.3 ; \mathrm{O}_{2} 3.7$.

Experiment CI. August 20; mountain sparrow. Placed at 11/4 atmospheres.

Lethal air: $\mathrm{CO}=14.3 ; \mathrm{O}=3.4$.

The results of these experiments are grouped in the increasing order of pressures in the following table.

Table V

\begin{tabular}{|c|c|c|c|c|c|c|c|c|c|c|c|}
\hline 1 & 2 & 3 & 4 & & 5 & 6 & $i$ & 8 & 9 & 10 & 11 \\
\hline 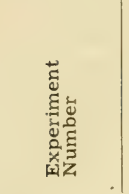 & 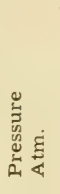 & 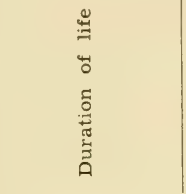 & 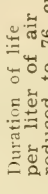 & & 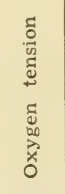 & $\begin{array}{l}\text { Com } \\
\text { sition } \\
\text { tethal }\end{array}$ & $\begin{array}{l}\text { of } \\
\text { air }\end{array}$ & $\begin{array}{l}D \\
x \\
0^{\prime}\end{array}$ & $\begin{array}{l}D_{1} \\
x \\
0^{\prime}\end{array}$ & $\begin{array}{l}0 \\
+ \\
0 \\
0\end{array}$ & $\begin{array}{l}0 \\
\end{array}$ \\
\hline \begin{tabular}{l|}
$\mathrm{C}$ \\
$\mathrm{CI}$ \\
XCIII \\
XCVII \\
XCVIII \\
XCIV \\
XCI \\
LXXXIX \\
XCII \\
XCV \\
XCVI \\
XC \\
XCIX
\end{tabular} & $\begin{array}{l}11 / 4 \\
11 / 4 \\
1.5 \\
1.5 \\
1.75 \\
2 \\
2.5 \\
3.75 \\
5.0 \\
5.0 \\
6 \\
7 \\
8.8\end{array}$ & $\begin{array}{c}3 \mathrm{~h} 35 \mathrm{~m} \\
\text { from } 2 \text { to } 3 \mathrm{~h} . \\
\text { less than } 3 \mathrm{hr} . \\
4 \mathrm{~h} 30 \mathrm{~m} \\
\text { more than } 8 \mathrm{~h} . \\
2 \mathrm{~h} 55 \mathrm{~m}\end{array}$ & $1 \mathrm{~h}$ & $\begin{array}{l}42 \mathrm{~m} \\
33 \mathrm{~m}\end{array}$ & \begin{tabular}{|r|}
26.1 \\
26.1 \\
31.3 \\
31.3 \\
36.5 \\
41.8 \\
52.2 \\
78.3 \\
104.5 \\
\\
125.4 \\
146.3 \\
183.9
\end{tabular} & \begin{tabular}{|l|}
$\mid 13.3$ \\
14.3 \\
15.2 \\
15.4 \\
12.9 \\
13.7 \\
$\mid 11.2$ \\
7.2 \\
5.5 \\
\\
4.2 \\
3.7 \\
2.8
\end{tabular} \mid & \begin{tabular}{r|}
3.6 \\
3.4 \\
2.6 \\
2.5 \\
4.9 \\
5.0 \\
8.5 \\
11.1 \\
13.8 \\
16.0 \\
16.2 \\
17.4
\end{tabular} & \begin{tabular}{|l|}
$\mid 15.6$ \\
17.9 \\
22.8 \\
23.1 \\
22.5 \\
27.4 \\
28.0 \\
27.0 \\
27.5 \\
\\
25.2 \\
25.9 \\
24.6
\end{tabular} & \begin{tabular}{|c|}
4.2 \\
4.2 \\
3.9 \\
3.7 \\
8.6 \\
10 \\
21.2 \\
41.3 \\
69 \\
\\
96.0 \\
113.4 \\
153.1
\end{tabular} & \begin{tabular}{|l|}
16.9 \\
17.7 \\
17.8 \\
17.9 \\
17.8 \\
18.7 \\
19.7 \\
18.3 \\
\\
\\
20.2 \\
19.9 \\
20.2
\end{tabular} & $\begin{array}{l}77 \\
81 \\
83 \\
83 \\
80 \\
86 \\
90 \\
173 \\
77 \\
\\
85 \\
78 \\
80\end{array}$ \\
\hline
\end{tabular}

If now we consider these results, occupying ourselves first with the composition of the air which had become irrespirable-and the preceding table makes this bird's-eye view easy-we see at once that the hypothesis suggested as a heading for this sub-chapter, far from being verified, is exactly opposite to the truth. The greater the pressure, the less the oxygen of the air was exhausted, as Column 7 of Table V shows. At 8.8 atmospheres, the highest pressure I used in this first series of experiments, there remained after death 17.4 per cent of oxygen.

This observation, already strange, becomes absolutely astonishing when we take account not only of the figure expressing the percentage, but also the number, hitherto constant in our experiments, which indicates the oxygen tension in the lethal air. We saw in the first chapter that this number oscillates between 3 and 4 . 
In the present experiments, Column 9 furnishes us analogous figures only for the pressures between 1 and 2 atmospheres. And even here there appear already the numbers 8 and 10, which soon become 20 and 40, and finally 113 and 153 at the pressures of 7 and 8.8 atmospheres.

So then, above 2 atmospheres, death in confined air cannot be attributed to lack of oxygen; we must seek some other cause.

My first thought naturally turned to carbonic acid.

Now considering Column 8 , in which are listed numbers obtained by multiplying the percentage of carbonic acid by the number of atmospheres, and which consequently represent the carbonic acid tension in the lethal air, we see that, from 2 atmospheres on, these numbers oscillate between 25 and 30 .

If now we refer to what M. Claude Bernard" said formerly about the conditions of death of birds confined at normal pressure in superoxygenated air, we see that they die when they have formed a proportion of carbonic acid which corresponds precisely to that which we have just indicated. The numerous experiments which I myself ${ }^{4}$ have carried on in this field have led me to similar results, and I have confirmed the accuracy of the explanation given by $\mathrm{Cl}$. Bernard of this strange asphyxia in a medium much richer in oxygen than ordinary air. It is a real poisoning due to the carbonic acid of the blood, which cannot be eliminated because of the pressure exerted upon it by the carbonic acid contained in the ambient atmosphere.

The cause of death, then, is the pressure exerted by this carbonic acid, a pressure measured exactly at one atmosphere by the percentage of carbonic acid present. At pressures above one atmosphere, the real pressure, the tension of the carbonic acid, is obtained by multiplying the percentage by the number of atmospheres, and in this way we obtained the figures in Column 8.

We can now give, for death in closed vessels, at pressures greater than one atmosphere, a formula quite analogous to the one w: gave earlier (see page 552) for pressures lower than one atmosphere, and say: The death of sparrows occurs when the tension of the carbonic acid, measured as I have just specified, is represented by a figure which oscillates between approximately 24 and 30 ; hereafter we shall take 26 as an average number.

The result of this fact is that, if we represent our results by a curve resembling that of Figure 17, in which the abscissae would represent the pressures, and the ordinates the proportions of carbonic acid, this curve would correspond to the formula $x y=25$ to 
30 , and consequently would also be a branch of an equilateral hyperbola.

But we must note immediately that this formula begins to be true only from $1 \frac{1}{2}$ and especially from 2 atmospheres. Below that, the figures of Column 8 are much lower. In this case the quantity of oxygen at the bird's disposal was not sufficient to permit the production of a quantity of carbonic acid fatal in itself. Of course the carbonic acid tension was not negligible, especially when it reached the value of 22 or 23 ; but in this case we must take into account the exhaustion of the oxygen, whose very advanced state is shown us by Column 9. In fact, we find here again the figures varying from 3 to 4 , which we recognize as expressing the oxygen tension which is too low to support life.

Influence of the temperature. The preceding results were obtained at temperatures above $20^{\circ}$. I wished to find out whether considerable cold would have much effect on the figures obtained. Here is what occurred.

Experiment CII. December 12; temperature of the laboratory $+6^{\circ}$. House sparrow. Placed at a pressure of 6 atmospheres; closed cocks at 2 o'clock. Surrounded the apparatus completely with a mass of snow at $0^{\circ}$. $+4^{\circ}$.

At $4: 20$, sparrow found dead. At $4: 25$, his rectal temperature was

Lethal air: $\mathrm{CO}: 2.9 ; \mathrm{O}: 17.4$.

$\mathrm{CO}: \mathrm{P}=17.4$.

Experiment CIII. December 13; temperature $+6^{\circ}$. House sparrow. At 2 o'clock, placed at 5 atmospheres. Surrounded the apparatus with a mixture of ice and salt whose temperature dropped to $2^{\circ}$. The inside thermometer could not be read. At 3:35, found dead. Rectal temperature, $+8^{\circ}$; venous blood red, without gas bubbles.

Lethal air: $\mathrm{CO}=3.4 ; \mathrm{O}=15.2$.

$\mathrm{CO} * \mathrm{P}=17.0$.

Experiment $\mathrm{ClV}$. December 14 ; outside temperature $+5^{\circ}$. House sparrow. At 2:50, taken to 4 atmospheres. Surrounded by a mixture of ice and salt.

At $4: 20$, very sick; at $4: 30$, dead. Inside temperature of apparatus $+1^{\circ}$; rectal temperature, $+17.5^{\circ}$.

Lethal air: $\mathrm{CO}=5.0 ; \mathrm{O}=13.3$.

$\mathrm{CO}_{3} \times \mathrm{P}=20$.

We see that the effect of the cold was very important, and that the birds could not in these conditions form as much carbonic acid as at high temperatures. That is easily understood, because of the chilling of the animal, which was not compatible with the 
exercise of the bodily functions and no longer permitted respiratory movements.

I even think that it is to the temperature that we must attribute results somewhat different from those I reported above, obtained with the same apparatus, but during a cooler season.

Experiment $C V$. January 31 . House sparrow. At 3:50, taken to 4 atmospheres. Died at 5:50. No cranial suffusions.

Lethal air: $\mathrm{CO}_{2} 5.8 ; \mathrm{O}_{2} 13.2$.

$\mathrm{CO}_{2} \times \mathrm{P}=23.2$.

Experiment CVI. March 18. House sparrow. At 2:10 taken to 6 atmospheres. Very sick at $3: 30$; found dead at 4:50. Red dots on cranium.

Lethal air: $\mathrm{CO}: 3.9 ; \mathrm{O}: 14.9$.

$\mathrm{CO}_{2} \times \mathrm{P}=23.4$.

B. Superoxygenated air: pressures below one atmosphere.

It is here that I think I should place the account of the experiments made by the method discussed on page 536 (Sub-chap. 1), in which the sparrows were kept in closed vessels, at pressures less than one atmosphere, but in superoxygenated air. Here, down to the low limits indicated, death took place not through too low oxygen tension but through too high carbonic acid tension, that is, through a mechanism identical with the one we are discussing now.

Here are the details of these experiments, all made with sparrows; the first two are a repetition of the classic experiments of Claude Bernard.

Experiment CVII. January 16. Bell-jar of one liter.

The bird was brought successively three times to a $40 \mathrm{~cm}$. drop in pressure, the pressure each time being restored to normal by the admission of oxygen. The mixture then contained 91 per cent of oxygen. I left the bird at normal pressure, and closed the cocks at 3 o'clock.

Died at 6:15; lived 3 hours 15 minutes.

Lethal air: $\mathrm{CO}=24.8 ; \mathrm{O}=64.5$.

$\mathrm{CO}_{2}+\mathrm{O}_{2}=89.3$. The ratio of the carbonic acid formed to the oxygen consumed was:

$$
\frac{\mathrm{CO}_{2}}{\mathrm{O}_{2}}=\frac{24.8}{26.5}=0.93
$$

Experiment CVIII. January 16. Bell-jar of 1 liter.

Brought three times in succession to a $40 \mathrm{~cm}$. drop in pressure; actual pressure, $36 \mathrm{~cm}$.

Closed cocks at 2;30; death at $6: 15$. Pressure $34 \mathrm{~cm}$. Original mixture: $\mathrm{O}: 82$, 
Lethal air: $\mathrm{CO}: 63.3 ; \mathrm{O}=17.5$.

$$
\mathrm{CO}_{2}+\mathrm{O}_{2}=80.8 ; \quad \frac{\mathrm{CO}_{2}}{\mathrm{O}_{2}}=0.98 . \quad \mathrm{CO}_{2} \times \mathrm{P}=28.3 \text {. }
$$

Experiment CIX. January 29. Bell-jar of 675 cc.; mountain sparrow.

Pressure lowered $50 \mathrm{~cm}$., the bird became sick; oxygen admitted; second decompression carried to $60 \mathrm{~cm}$., sick; oxygen admitted. Closed cocks at $3: 35$.

Left at normal pressure. At 5 o'clock, panting; at 6 o'clock, died without convulsions; a slight bloody suffusion on the cranium.

Lethal air: $\mathrm{CO}_{2} 24.8 ; \mathrm{O}_{2} 63.3$.

Experiment CX. January 30. Bell-jar of 1.3 liters.

Pressure lowered $44 \mathrm{~cm}$., $58 \mathrm{~cm}$., $36 \mathrm{~cm}$., then $48 \mathrm{~cm}$. Closed cocks at $3: 50$; dead at 6 o'clock.

The inner pressure was $25 \mathrm{~cm}$.

Original mixture: $\mathrm{O}_{2} 89.2$.

Lethal air: $\mathrm{CO}_{2} 72.1 ; \mathrm{O}_{2}$ 15.3.

$\mathrm{CO}_{2}+\mathrm{O}_{2}=87.4 ; \frac{\mathrm{CO}_{2}}{\mathrm{O}_{2}}=0.97$.

$\mathrm{CO}$ : tension: 23.7 .

Oxygen tension: $15.3 \times \frac{26}{76}=5.0$.

Experiment CXI. January 31. Bell-jar of 675 cc.

Pressure lowered $40 \mathrm{~cm}$., $50 \mathrm{~cm}$., $50 \mathrm{~cm}$., and compensated by oxygen. The last time, the pressure was lowered $55 \mathrm{~cm}$. Closed cocks at $3: 20$. Died at $5: 15 ;$ no bloody suffusions on the skull.

Original mixture: $\mathrm{O}_{2} 79.6$.

Lethal air: $\mathrm{CO}_{2} 35.3 ; \mathrm{O}_{2} 42.3$.

$$
\mathrm{CO} z+\mathrm{O} *=77.6 ; \frac{\mathrm{CO}}{\mathrm{O}_{2}}=0.94 . \quad \mathrm{CO} * \times \mathrm{P}=25.5 \text {. }
$$

Experiment CXII. January 31. Bell-jar of 1.3 liters.

Pressure lowered $40 \mathrm{~cm}$., $50 \mathrm{~cm}$., $50 \mathrm{~cm}$., the last time, $43 \mathrm{~cm}$.

At death, the pressure is only $36 \mathrm{~cm}$.

Original mixture: $\mathrm{O} z 89.8$.

Lethal air: $\mathrm{CO}_{2} 57.6 ; \mathrm{O}_{2} 30.1$.

$$
\mathrm{CO}_{2}+\mathrm{O}_{2}=87.7 ; \frac{\mathrm{CO}_{2}}{\mathrm{O}_{2}}=0.96 . \mathrm{CO}_{2} \times \mathrm{P}=27.2 \text {. }
$$

Experiment CXIII. February 2. Bell-jar of 1.350 liters.

Pressure lowered $30 \mathrm{~cm}$., $50 \mathrm{~cm}$., then $50 \mathrm{~cm}$., and compensated by oxygen; the last time pressure lowered $58 \mathrm{~cm}$. $51 \mathrm{~cm}$.

Closed cocks at $3: 45$; died at $6: 45$; the pressure was lowered only 
Original mixture: $\mathrm{O}=91.5$.

Lethal air: $\mathrm{CO}=36.0 ; \mathrm{O}=54.9$.

$\mathrm{CO} z+\mathrm{O}:=99.6 ; \frac{\mathrm{CO} z}{\mathrm{O}_{2}}=0.98 . \quad \mathrm{CO} z \times \mathrm{P}=24.2$.

Experiment CXIV. February 5. Bell-jar of 1.3 liters.

Pressure lowered $30 \mathrm{~cm}$., $50 \mathrm{~cm}$., $50 \mathrm{~cm}$., the fourth time left at $45 \mathrm{~cm}$.

Entered at 4 o'clock. Dead at 8:15; the pressure was $38 \mathrm{~cm}$.

Lethal air: $\mathrm{CO}=49.3 ; \mathrm{O}=36.6$.

$\mathrm{CO}=\times \mathrm{P}=24.6$.

Experiment CXV. February 6. Bell-jar of 675 cc.

Pressure lowered successively $30 \mathrm{~cm}$., $50 \mathrm{~cm}$., and $50 \mathrm{~cm}$., and compensation made each time with oxygen. Closed cocks at 2:35; the pressure was $57 \mathrm{~cm}$. Dead at 5:45. Cranial suffusions in places. Actual pressure $55 \mathrm{~cm}$.

Mixture before the experiment: $\mathrm{O}: 87.8$.

Lethal air: $\mathrm{CO}=36.3 ; \mathrm{O}=50.1$.

$$
\mathrm{CO} z+\mathrm{O} z=86.4 ; \frac{\mathrm{CO} z}{\mathrm{O} z}=0.97 ; \mathrm{CO} z \times \mathrm{P}=26.2 \text {. }
$$

Experiment CXVI. February 19. Bell-jar of 675 cc.

Pressure lowered once $30 \mathrm{~cm}$., and twice lowered $50 \mathrm{~cm}$; ; each time, oxygen admitted. Actual pressure finally $64 \mathrm{~cm}$. Closed the cocks at $1: 50$.

Dead at $3: 35$; little bloody mottlings on the cranium. Jugular blood red.

Lethal air: $\mathrm{CO}=27.7 ; \mathrm{O}=54.7$.

The $\mathrm{CO}$ : tension is $\mathrm{CO}_{2} \times \mathrm{P}=27.7 \times \frac{64}{76}=23.3$.

Experiment CXVII. February 19. Bell-jar of 1.35 liters.

Pressure lowered $30 \mathrm{~cm}$., $50 \mathrm{~cm}$., $50 \mathrm{~cm}$; the last time left at 46 $\mathrm{cm}$.

Cocks closed at 2 o'clock; at $4: 15$, very sick. At death, the pressure is $43 \mathrm{~cm}$. Slight cranial suffusions.

Lethal air: $\mathrm{CO}=42.4 ; \mathrm{O}=29.8$.

$\mathrm{CO} \approx \times \mathrm{P}=24.5$.

Experiment CXVIII. February 19. Bell-jar of 2.2 liters.

Pressure lowered $30 \mathrm{~cm}$., $50 \mathrm{~cm}$., $50 \mathrm{~cm}$., then to $34 \mathrm{~cm}$. of actual pressure.

Closed at 2:15; died at 6:45; enormous cranial suffusions.

Actual pressure, $29 \mathrm{~cm}$.

Lethal air: $\mathrm{CO}_{2} 66 ; \mathrm{O}=13.1$.

$\mathrm{CO} 2 \times \mathrm{P}=25.2$.

The pressure of the oxygen remaining is only $13.1 \times \frac{7}{76}=5$. 
Experiment CXIX. February 22. Bell-jar of 2.5 liters.

Pressure lowered $30 \mathrm{~cm}$., $50 \mathrm{~cm}$., $50 \mathrm{~cm}$, then to $38 \mathrm{~cm}$. Closed at 1:05. Dead at 7 o'clock. Slight suffusion on the cranium; venous blood red.

Actual pressure, $34 \mathrm{~cm}$.

Lethal air: $\mathrm{CO}_{2} 60 ; \mathrm{O}_{2} 27.4$.

$\mathrm{CO} 2 \times \mathrm{P}=26.8$.

All these results are summarized and grouped, following the descending order of barometric pressures, in the following table; I have added to it the experiments reported on page 537.

Table VI

\begin{tabular}{|c|c|c|c|c|c|c|c|c|}
\hline 1 & 2 & 3 & 4 & 5 & 6 & 7 & 8 & 9 \\
\hline 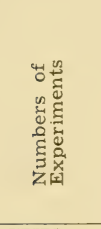 & 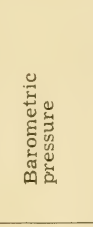 & 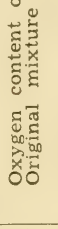 & 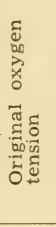 & $\begin{array}{l}\text { Compos } \\
\text { leth }\end{array}$ & $\begin{array}{l}\text { tion of } \\
1 \text { air }\end{array}$ & \begin{tabular}{l|l}
0 & 0 \\
& 0
\end{tabular} & 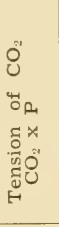 & 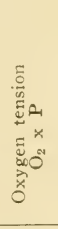 \\
\hline CVII & $76 \mathrm{~cm}$. & 91 & 91 & 24.8 & 64.5 & 0.93 & 24.8 & 64.5 \\
\hline CIX & 76 & 91 & 91 & 24.8 & 63.3 & 0.93 & 24.8 & 63.3 \\
\hline CXVI & 64 & 91 & 91 & 27.7 & 54.7 & 0.93 & 23.3 & 46.0 \\
\hline $\mathrm{CXV}$ & 55 & 87.8 & 63.5 & 36.3 & 50.1 & 0.97 & 26.2 & 36.2 \\
\hline CXI & 55 & 79.6 & 57.6 & 35.3 & 42.3 & 0.94 & 25.5 & 30.6 \\
\hline CXIII & 51 & 91.5 & 61.4 & 35.7 & 54.9 & 0.98 & 24.2 & 36.8 \\
\hline CXVII & 43 & 91.5 & 61.4 & 42.4 & 29.8 & 0.98 & 24.5 & 16.8 \\
\hline CXIV & 38 & 91.5 & 61.4 & 49.3 & 36.6 & 0.98 & 24.6 & 18.3 \\
\hline CXII & 36 & 89.8 & 45.9 & 57.6 & 30.1 & 0.96 & 27.2 & 14.2 \\
\hline CVIII & 34 & 82 & 36.7 & 63.3 & 17.5 & 0.98 & 28.3 & 7.8 \\
\hline CXIX & 34 & 82 & 36.7 & 60 & 27.4 & 0.98 & 26.8 & 12.2 \\
\hline CXVIII & 29 & 82 & 36.7 & 66 & 13.1 & 0.98 & 25.2 & 5.0 \\
\hline $\mathrm{CX}$ & 25 & 89.2 & 29.3 & 72.1 & 15.3 & 0.97 & 23.7 & 5.0 \\
\hline XLVII & 18 & 85.9 & 20.3 & 68.1 & 15.4 & 0.96 & 15.2 & 3.6 \\
\hline XLVIII & 14 & 85.9 & 20.3 & 48 & 23.8 & 0.96 & 8.8 & 4.3 \\
\hline XLIX & 12.5 & 88.4 & 14.5 & 66 & 22.2 & 0.99 & 10.8 & 3.6 \\
\hline $\mathrm{L}$ & 8 & 82.3 & 8.6 & 37.2 & 41.8 & 0.92 & 3.9 & 4.4 \\
\hline LI & 6.6 & 87 & 7.5 & 17.3 & 66.7 & 0.85 & 1.5 & \\
\hline
\end{tabular}

In this table a glance at Columns 5 and 8 are enough to prove that our expectations are realized and that, at these pressures less than one atmosphere, poisoning by carbonic acid comes when the tension of this gas can be expressed by numbers varying from 24 to 27 . That is the result obtained earlier for pressures greater than $1 \frac{1}{2}$ atmospheres.

This is deduced, as Column 5 shows, from the proportions of carbonic acid which may rise to 72 per cent. At very low pressures, below 20 centimeters, for example, the law below no longer holds; but that is easily understood. Let us take, for example, the pressure 
of 14 centimeters, noted in Experiment XLVIII. To reach the average figure of 26 , the percentage of carbonic acid in the lethal air must rise to $26 \times \frac{76}{14}=141$, which is evidently impossible. In other words, before the bird can reach the lethal tension of carbonic acid, it exhausts the oxygen of the surrounding medium, so that it succumbs to the kind of death customary in diminished pressures, when ordinary air is used. That is why we shifted to Sub-chapter I the experiments made under these conditions.

The analogy between these two kinds of experiments, apparently so different, is seen again in a rather interesting experimental detail, which, at first glance, seemed to me somewhat paradoxical. When I supplied pure air to a bird which was beginning to suffer from the effect of increased pressure, I did not relieve it at all; on the contrary, an evident improvement appeared when I allowed a part of its air to escape. 'This is easily explained; let us suppose that the bird is under a pressure of 3 atmospheres and that it has already formed 6 per cent of $\mathrm{CO}_{2}$; the pressure of this gas, $6 \times 3=18$, is enough to make the bird ill. If I admit 3 atmospheres of pure air, the $\mathrm{CO}_{2}$ tension becomes $3 \times 6=18$, that is, it does not change at all, since although the pressure increases one-half, the percentage diminishes one-half; the bird is therefore not relieved. If, on the contrary, I let out one-half of the air, the tension becomes $6 \times 1.5$ $=9$, so that an immediate betterment results. So this apparent paradox confirms again, in an indirect way, what I have already demonstrated.

The same thing holds good for experiments at low pressures with a superoxygenated atmosphere. Here, if the bird has been made ill by the carbonic acid it has formed, it is not relieved if air or oxygen is admitted; on the contrary, if the barometric pressure is lowered, it is relieved. Let us take the case of a bird at $38 \mathrm{~cm}$., that is, at a half-atmosphere. Let us assume that it has already formed 30 per cent of $\mathrm{CO}_{2}$; the $\mathrm{CO}_{2}$ tension is $30 \times 1 / 2=15$ and the bird begins to suffer from it. Let us admit air until the pressure is $57 \mathrm{~cm}$., that is, three-quarters of an atmosphere. The percentage will be only $30 \times 2 / 3=20$, but the tension will be $20 \times 3 / 4=15$, and the bird will be in the same state as before. If, on the contrary, we remove air and drop the pressure, for example, to $19,1 / 4$ of an atmosphere, the percentage of carbonic acid will not have changed, and its tension will be only $30 \times 1 / 4=7.5$, a tension almost harmless to the bird, which will be relieved immediately. 
C. Compressed air at very high pressure: fatal action of oxygen. The study of the alterations of compressed air which has become lethal through confinement was to give me a result that was interesting in a very different way.

When we examine carefully Column 8 of Table V, we see that, from 6 atmospheres on, the number of the carbonic acid tension is a little lower than one finds at a pressure from 2 to 5 atmospheres, and seems to continue diminishing as the pressure increases. This slight difference did not impress me at first; but when I made experiments at pressures higher than those of Table III in the cylindrical glass reservoir capable of supporting a pressure of 25 atmospheres, I obtained numbers which showed me the appearance of a new element in the question.

Here is the report of these experiments.

Experiment CXX. April 16.

Linnet; taken to 20 atmospheres, from $4: 55$ to $5: 10$.

Slight convulsions appear at $5: 15$; the feet, the head, the body quiver in spasms. Dies at 5:35. Lived 25 minutes.

Lethal air: $\mathrm{CO}_{2} 0.4$.

$\mathrm{CO}_{2} \times \mathrm{P}=8$.

Experiment CXXI. April 23.

Sparrow; at 9:45 taken to 6 atmospheres. Dies at 11:10; lived about 1 hour 20 minutes.

Lethal air: $\mathrm{CO}_{2} 3.5 ; \mathrm{O}_{2} 16$.

$\mathrm{CO}_{3} \times \mathrm{P}=21.0$.

Experiment CXXII. April 23.

Sparrow; taken at $3: 10$ to 3 atmospheres. At 4:05, very sick; at 4:50, dying. Dead at 5 o'clock; lived about 1 hour 50 minutes. Spot on the scalp; dark blood in the jugular; no gas.

Lethal air: $\mathrm{CO}=7.8 ; \mathrm{O}=10.7$.

$\mathrm{CO}_{2} \times \mathrm{P}=23.4$.

Experiment CXXIII. April 24.

Mountain sparrow; taken at $1: 40$ to 5 and $3 / 4$ atmospheres. At 3 o'clock still alive; found dead at 3:50; lived about 1 hour 30 minutes. Large scalp suffusions.

Lethal air: $\mathrm{CO}_{2} 3.8 ; \mathrm{O}_{2} \mathbf{1 5 . 5}$.

$\mathrm{CO}_{2} \times \mathrm{P}=21.8$.

Experiment CXXIV. April 26.

House sparrow; at normal pressure has respiratory rate of 144 . Taken to 3 atmospheres at 1 o'clock; respiratory rate 132 . At $1: 03$, to 6 atmospheres, respiratory rate, 130 ; at 1:06, to 9 atmospheres, respiratory rate 120 . Closed the cocks; at $1: 11$, respiratory rate 106; at 1:20, 80 ; at 1:50, 50, very sick; found dead at 2:25. Lived about 1 hour 10 minutes. 
Red blood in the jugular; bloody suffusions on the scalp.

Lethal air: $\mathrm{CO}_{2} 2 ; \mathrm{O}_{2}$ 17.5.

$\mathrm{CO}_{2} \times \mathrm{P}=18$.

Experiment CXXV. April 26.

- House sparrow; at 4:23, normal pressure, respiratory rate 135 . Began the compression. At 4:27, 6 atmospheres, respiratory rate 96 . At $4: 29,9$ atmospheres, respiratory rate 90 ; at $4: 31,12$ atmospheres, respiratory rate 90 . At $4: 53$, very sick. Each inspiration, which is very deep, is accompanied by a quivering of the wings. At 5:10, still a few respirations; at $5: 15$, dies.

Lived 45 minutes. Scalp suffusions in spots; red blood in the jugular.

Lethal air: $\mathrm{CO}=1.2 ; \mathrm{O}=18.4$.

$\mathrm{CO}_{2} \times \mathrm{P}=14.4$.

Experiment CXXVI. May 7.

Sparrow taken to 15 atmospheres; closed cocks at 2:15. At 3:20, found dead.

Lethal air: $\mathrm{CO}=0.8 ; \mathrm{O}=19.5$.

$\mathrm{CO} 2 \times \mathrm{P}=11.2$.

Experiment CXXVII. May 17.

Sparrow at 4 atmospheres; closed cocks at 4:45.

Sinks down at 5:34; dies at 6:20. Lived 1 hour 35 minutes. Red foam on the beak; scalp suffusions in blackish patches; venous blood of normal color; no gas.

Lethal air: $\mathrm{CO}_{2} 5.6 ; \mathrm{O}_{2} 13.2$.

$\mathrm{CO}_{2} \times \mathrm{P}=22.4$.

Experiment CXXVIII. May 18.

Sparrow at 8 atmospheres; $3: 17$.

Dead at 4:55; lived 1 hour 38 minutes. Red foam on the beak; bloody suffusions in reddish patches; venous blood red and containing some gas.

Lethal air: $\mathrm{CO}_{2} 2.4 ; \mathrm{O}=16.8$.

$\mathrm{CO}_{2} \times \mathrm{P}=19.2$.

Experiment CXXIX. May 21.

Sparrow at 14 atmospheres; closed the cock at 4:55. Found dead at 6 o'clock; lived less than one hour.

Venous blood very red, with gas. Scalp suffusions very extensive.

Lethal air: $\mathrm{CO}_{2} 0.9 ; \mathrm{O}_{2} 18.5$.

$\mathrm{CO}_{2} \times \mathrm{P}=12.6$.

Experiment CXXX. May 22.

Sparrow; at 12 atmospheres, at 2:45. Found dead at $3: 40$; lived less than 55 minutes.

Red blood in the jugular, with gas. Scalp suffusions.

Lethal air: $\mathrm{CO}_{2} 1.3 ; \mathrm{O}=19.1$.

$\mathrm{CO}=\mathrm{x}=15.6$. 
Experiment CXXXI. June 18.

Sparrow; taken to 14 atmospheres at $3: 33$. Dead at 4:12. Lived 39 minutes. Struggling, but no convulsions.

Venous blood very red, with gas. Scalp suffusions very extensive, of a bright red.

Lethal air: $\mathrm{CO}: 0.93$.

$\mathrm{CO}: \times \mathrm{P}=13.2$.

Experiment CXXXII. June 19.

Sparrow; taken at $3: 04$ to 2 atmospheres. Dead at 6:53 without convulsions, without foam on the beak; lived 3 hours 49 minutes. The cranial diploe contains bloody suffusions in small blackish patches. The color of the venous blood is normal; no gas.

Lethal air: $\mathrm{CO}=12.6 ; \mathrm{O}=3.2$.

$\mathrm{CO}_{2} \times \mathrm{P}=25.2$.

Experiment CXXXIII. June 19.

Sparrow; taken to 17 atmospheres from 2:04 to 2:15. Dead at 2:54. Lived 39 minutes; respiration very slow, no convulsions, red froth on beak.

Very extensive bloody suffusions; venous blood very red, containing much gas.

Lethal air: $\mathrm{CO}=0.6 ; \mathrm{O}=18.6$.

$\mathrm{CO}: \times \mathrm{P}=10.2$.

Table VII

\begin{tabular}{|c|c|c|c|c|c|c|c|c|c|}
\hline 1 & 2 & 3 & 4 & 5 & 6 & 7 & 8 & 9 & 10 \\
\hline 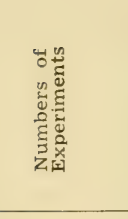 & 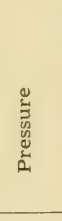 & 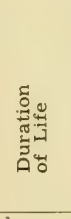 & 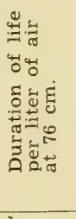 & 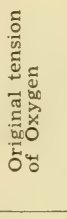 & $\begin{array}{r}\text { Compos } \\
\text { letha }\end{array}$ & ion of & $\begin{array}{l}a \\
x \\
\delta^{\prime \prime}\end{array}$ & $\begin{array}{l}A_{1} \\
x \\
0^{\prime}\end{array}$ & $810^{\prime \prime}$ \\
\hline $\begin{array}{l}\text { CXXXII } \\
\text { CXXII }\end{array}$ & 2 & $\begin{array}{rl}\text { h. m. } \\
3 & 49\end{array}$ & $\begin{array}{l}\text { h. m. } \\
34\end{array}$ & 41.8 & 12.6 & 3.2 & 25.2 & 6.4 & 0.72 \\
\hline $\begin{array}{l}\text { CXXII } \\
\text { CXXVII }\end{array}$ & 3 & 150 & & 62.7 & 7.8 & 10.7 & 23.4 & 32.1 & 0.75 \\
\hline $\begin{array}{l}\text { CXXVII } \\
\text { CXXIII }\end{array}$ & & 135 & 39 & 83.6 & 5.6 & 13.2 & 22.4 & 52.8 & 0.72 \\
\hline $\begin{array}{l}\text { CXXIII } \\
\text { CXXI }\end{array}$ & $5^{3} 3 / 4$ & 130 & 27 & 120.1 & 3.8 & 15.5 & 21.8 & 89.1 & 0.70 \\
\hline $\begin{array}{l}\text { CXXI } \\
\text { CXXVIII }\end{array}$ & & 120 & 22 & 125.4 & 3.5 & 16 & 21.0 & $\begin{array}{c}96 \\
1344\end{array}$ & $\begin{array}{l}0.71 \\
0.60\end{array}$ \\
\hline CXXIV & $\begin{array}{l}\circ \\
9\end{array}$ & $\begin{array}{ll}1 & 38 \\
1 & 10\end{array}$ & $\begin{array}{l}20 \\
14\end{array}$ & $\begin{array}{l}168 \\
188\end{array}$ & $\begin{array}{l}2.4 \\
2\end{array}$ & $\begin{array}{l}16.8 \\
17.5\end{array}$ & 18.0 & 157.5 & 0.59 \\
\hline $\mathrm{CX}$ & 12 & 45 & 6 & 250.8 & 1.2 & 18.5 & 14.4 & 222.8 & 0.50 \\
\hline CXXX & 12 & 45 & 1 & 250.8 & 1.3 & 18.7 & 15.6 & 224.4 & 0.59 \\
\hline CXXIX & 14 & 45 & 1 & 292 & 0.9 & 18.5 & 12 & 263.2 & 0.43 \\
\hline $\mathrm{CX}$ & 14 & 39 & 4 & 292 & 0.9 & 18.5 & 13.2 & 263.2 & 0.43 \\
\hline CXXVI & 15 & 39 & 1 & 313.5 & 0.8 & 19.4 & 11.2 & 291 & 0.53 \\
\hline CXXXIII & 17 & 39 & 3 & & 0.6 & 18.8 & 10.2 & 319.6 & 0.30 \\
\hline $\mathrm{CXX}$ & 20 & 25 & 2 & 418.0 & 0.4 & 18.8 & 8 & 319.6 & 0.30 \\
\hline
\end{tabular}

Before passing to the study of the results of these experiments, grouped in Table VII in increasing order of pressure, I think I should call attention to the fact that the preceding analyses of the 
gases were made meticulously from a very special necessity which is easily seen. In fact, the least error in the calculation of the proportion of carbonic acid would cause an enormous error in the product $\mathrm{CO}_{2} \times \mathrm{P}$ in the high pressures. The agreement in the results announced, on which I shall dwell now, is only the more remarkable.

A glance at Column 8 of the table, which contains the numbers expressing the carbonic acid tension in the air which had become

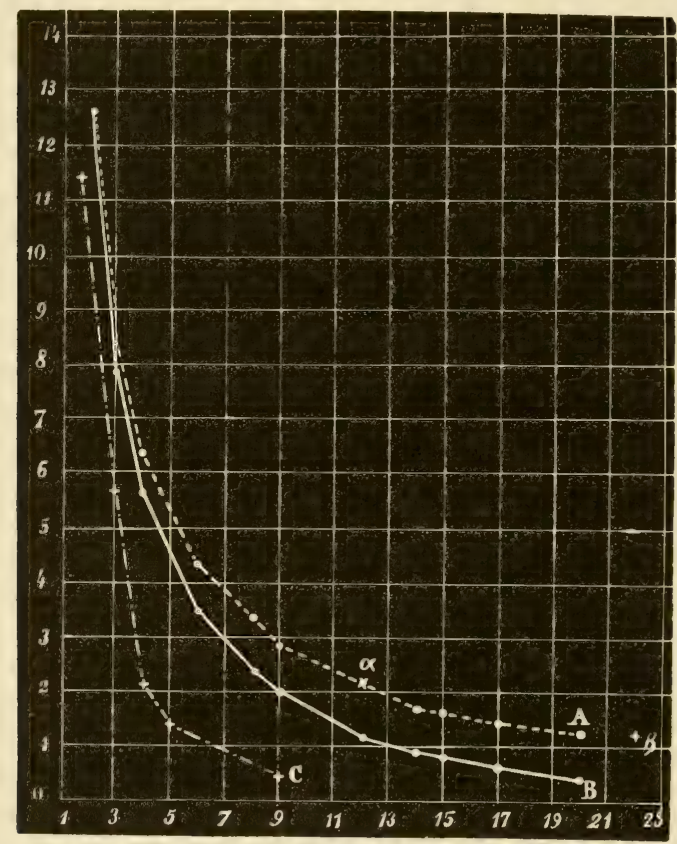

Fig. 21-Confined air which has become lethal under pressure; carbonic acid content: A, calculated proportions; B, proportions found experimentally; C, superoxygenated air.

irrespirable, completely confirms the suspicions which we had conceived on examining Table $\mathrm{V}$ in points relating to high pressures.

In fact, the number $\mathrm{CO}_{2} \times \mathrm{P}$, when closely inspected, is never constant. It diminishes from 3 atmospheres on, and this diminution is extremely rapid beginning with 8 atmospheres. 
The smaller and smaller quantity of carbonic acid, following the law expressed above, is shown very clearly in the graphs in Figure 21, in which the quantity of carbonic acid is measured on the vertical axis, while the atmospheres are reckoned on that of the x's. The solid line B expresses the figures of Column 6 , and the dotted line A connects the points which are calculated from the equation $\mathrm{CO}_{2} \times \mathrm{P}=26$, an average number taken from Table VI,

whence $\mathrm{CO}_{2}=\frac{26}{\mathrm{P}}$. This line, like that of the lethal proportions of oxygen in low pressures, is a branch of equilateral hyperbola, having the coordinates as asymptotes.

This constant drop of the graph below the curve which the theory indicates led me to think of the intervention of another agent than carbonic acid. Tentative experiments had already shown me that oxygen under a certain pressure is a cause of symptoms and death. Its fatal effect seemed manifest to me here.

Before trying to render this prime factor evident, I wish to call attention to a secondary point, which is, however, quite interesting.

Columns 3 of Tables V and VII show that, disregarding a few exceptions which are hard to explain, the duration of life from 1 to 9 atmospheres did not increase with the pressure, or, in other words, with the quantity of air which the birds had at their disposal. And that is easily understood, since they did not die from having exhausted this air, but simply when they had formed a certain quantity of carbonic acid always the same, or approximately so. The annoying interference of the oxygen which I have just mentioned even lessens the duration of life, as is clearly seen from 10 atmospheres on; death comes very quickly at very high pressures.

This is manifest in quite another way when we compare the duration of life not to the volume, but to the actual quantity of air contained in the receiver, or, which amounts to the same thing, to a liter of air at normal pressure; the duration of life is then expressed by numbers which decrease with a truly extraordinary rapidity. This is shown by Columns 4 of Tables V and VII; we see that, even at 4 atmospheres, the duration of life is reduced by about one-half, and that at 20 atmospheres, it is only 2 minutes per liter instead of 76 minutes, as we found it at normal pressure (See Table I, Column 7). This enormous difference cannot be attributed to the carbonic acid, whose tension diminishes equally; another factor 
evidently interferes here, and this dangerous factor is nothing but oxygen.

D. Compression with air of low oxygen content.

Let us now examine this hypothesis of a fatal action of the compressed oxygen with the effect of killing the bird before it has formed the percentage of carbonic acid required by the formula $\mathrm{CO}_{2} \times \mathrm{P}=26$. Let us refer to Table VII. If the explanation I have just given of the lowness of the numbers of Column $8\left(\mathrm{CO}_{2} \times \mathrm{P}\right)$ measuring the tension of the carbonic acid is correct, that is, if this lowness is due to the high value of the numbers of Column 5 $\left(\mathrm{O}_{2} \times \mathrm{P}\right)$, measuring the oxygen tension, the first will increase if I lower the second by lessening the factor $\mathrm{O}_{2}$ without changing factor P.

It was enough then to repeat the experiments, injecting into the compression apparatus not ordinary air, but air of low oxygen content. This was done in the following experiments.

Experiment CXXXIV. April 20.

Greenfinch (Loxia chloris, Lin.) Put into the apparatus for 5 minutes, then raised to 6 atmospheres of air; cock closed at 2:50. At 3 o'clock, we began to inject air very low in oxygen, and at 3:11, reached 22 atmospheres.

The moment of death cannot be clearly determined, but the bird had no convulsive movements at any time.

Considerable cranial suffusions.

Lethal air: $\mathrm{CO}_{2} 1.1 ; \mathrm{O}_{2} 9$.

Initial oxygen tension: 226.

- Final CO: tension: 24.2.

Experiment CXXXV. June 27.

A sparrow is placed in the apparatus, and air in which phosphorus has burned and which has become very low in oxygen is pumped in; the pressure is taken to 5 atmospheres.

The cock is closed at $3: 55$; the bird dies at 5:50. It lived therefore 1 hour 55 minutes; bloody suffusions, not very extensive; some gas bubbles in the right heart.

Composition of lethal air: $\mathrm{CO}_{2} 4.5 ; \mathrm{O}=5$.

Initial oxygen tension: 50 .

Final $\mathrm{CO}=$ tension: 22.5 .

Experiment CXXXVI. June 29.

Sparrow at 12 atmospheres, 1 of air and 11 of air in which phosphorus has burned.

Entered at 2:45; dead at $3: 15$; lived 30 minutes; cranial suffusions; gas in the right heart.

Lethal air: $\mathrm{CO}=2.1 ; \mathrm{O}=4.8$.

Initial oxygen tension: 84 .

Final $\mathrm{CO}_{2}$ tension: 25.2 . 
These results entirely justify our explanation, and show that the decrease of the product $\mathrm{CO}_{2} \times \mathrm{P}$, when the pressure increases, must be attributed to the intervention of the oxygen playing a fatal part.

We see furthermore that the points $a$ and $b$, which represent on Figure 21 the numbers furnished by Experiments CXXXIV and CXXXVI, are placed very exactly on line A, which was plotted according to the theory.

\section{E. Compression with superoxygenated air.}

This fatal effect of oxygen under a sufficiently high pressure was so remarkable a phenomenon that I felt I must try to exhaust all means of proving it indisputably.

Now a new method occurred to me, the opposite of the one which has just been used. I had only to make the compression with superoxygenated air, still in closed vessels. The influence of oxygen, if it is as serious as I thought, should bring death to animals at a moment when they were far from having furnished the same percentage of carbonic acid as at corresponding pressures in the case of ordinary air. This, indeed, happen in the following experiments.

Experiment CXXXVII. January 16.

Sparrow at 5 atmospheres, 4 of which are oxygen.

Entered at $3: 25$; at $3: 40$, falls with violent convulsions; at $3: 48$, on its back; the cranium, previously bared of feathers, shows abundant bloody suffusions. At $4: 35$, still breathes slowly; the convulsions lasted about 15 minutes.

At $4: 50$, dead. Rectal temperature is $18^{\circ}$, that of the laboratory air being $9^{\circ}$. Venous blood red; no gas; the heart is beating when in the outer air.

The original mixture contained $\mathrm{O}_{2}: 83$.

The tension of this oxygen $=83 \times 5=415$, corresponding to that of $415=19.7$ atmospheres.

\section{9}

Lethal air: $\mathrm{CO}_{2} 1.4 ; \mathrm{O}_{2} 80.5$.

$\mathrm{CO}_{2}$ tension $=1.4 \times 5=7.0$.

Experiment CXXXVIII. January 17.

At 3:30 taken to 3 atmospheres, 2 of which are oxygen.

At 3:50 breathes with great difficulty; uneasy. At 4:45, dead.

Lethal air: $\mathrm{CO}_{2} 5.6 ; \mathrm{O}_{2} 78.9$.

$\mathrm{CO}_{2}$ tension $=5.6 \times 3=16.8$.

The tension of the original oxygen was about $86 \times 3=258$, corresponding to 12.1 atmospheres. 
Experiment CXXXIX. January 19.

The sparrow being in the apparatus, a little air was removed by the pump, and replaced by oxygen which was raised to 2 atmospheres. When air was taken for analysis, the pressure fell to 1 and $3 / 4$ atmospheres.

Closed cocks at 2:40; dying at 4:45; found dead at 5:30.

Original mixture contains 83.6 per cent of oxygen.

Tension of this oxygen $=83.6 \times 1.75=146.3$, which corresponds to 7.3 atmospheres.

Lethal air: $\mathrm{CO}_{2} 11.9 ; \mathrm{O}_{2} 67.8$.

$\mathrm{CO}_{2}$ tension $=11.9 \times 1.75=20.8$.

Experiment CXL. January 22.

Put at 2 atmospheres, one of which is oxygen.

Entered at 3:05; at 5:30, still breathing; found dead at 6:30.

The original mixture contains $\mathrm{O}_{2} 58.8$.

The oxygen tension was 117.6, corresponding to 5.6 atmospheres. Lethal air: $\mathrm{CO}_{2} 13.4 ; \mathrm{O}_{2} 44.4$.

$\mathrm{CO}_{2}$ tension $=13.4 \times 2=26.8$.

Experiment CXLI. February 1.

Raised to 4 atmospheres, 3 of which are oxygen. After about a half hour, slight convulsions; dies in about an hour.

Cranial suffusions and venous blood very red; no gas in the blood.

Original mixture: $\mathrm{O}_{2} 75.6$.

Tension of this $\mathrm{O}_{2}=75.6 \times 4=302.4$ corresponding to 14.4 atmospheres.

Lethal air: $\mathrm{CO}_{2} 2.1 ; \mathrm{O}_{2} 71.1$.

$\mathrm{CO}_{2}$ tension $=2.1 \times 4=8.4$.

Experiment CXLII. February 17.

Raised to 5 atmospheres of air, to which are added $3 \frac{1}{2}$ atmospheres of oxygen. After 5 minutes, convulsions ensue; the bird dies in 20 minutes.

Blood red everywhere, even in the liver; no gas (cranium not examined).

Lethal air: $\mathrm{CO}_{2} 0.8 ; \mathrm{O}_{2} 47.8$.

$\mathrm{CO}$ tension $=0.8 \times 8.5=6.8$.

The oxygen tension in the original mixture must have been about $51 \times 8.5=433.5$, corresponding to 20.7 atmospheres.

Experiment CXLIII. February 19. Seltzer water apparatus.

Put into the air to which $1 / 4$ atmosphere of oxygen was added; closed at 4:25; dead about 6 o'clock.

No bloody suffusions on the cranium; venous blood black.

Lethal air: $\mathrm{CO}_{2} 22.1 ; \mathrm{O}_{2} 3.5$.

$\mathrm{CO}_{2}$ tension $=22.1 \times 1.25=27.6$.

The original oxygen tension must have been about $26 \times 1.25=32.5$, which corresponds to 1.5 atmospheres.

Experiment CXLIV. February 20.

I atmosphere of air; plus $1 / 2$ of oxygen.

When the bird, thought dead, is withdrawn, it still exhibits some 
slight respiratory movements. Red blood in the jugular. Red spots in the cranial diploe.

Lethal air: $\mathrm{CO}_{2}$ 16.7; $\mathrm{O}_{2} 28.6$.

$\mathrm{CO}_{2}$ tension $=16.7 \times 1.5=25.1$.

The original oxygen tension must have been about $46 \times 1.5=69$, corresponding to 3.3 atmospheres.

Experiment CXLV. February 20.

At $5 \frac{1}{2}$ atmospheres, 4 of which are oxygen.

After 5 minutes, trembles, the head oscillates. After 10 minutes great convulsions, the feet are doubled against the belly; the convulsions last 5 to 10 minutes, then the feet stretch out repeatedly. The bird remains prostrated; after 20 minutes, dead.

Enormous cranial suffusion. Rectal temperature $26.5^{\circ}$.

Lethal air: $\mathrm{CO}_{2} 1 ; \mathrm{O}_{2} 82.5$.

$\mathrm{CO}_{2}$ tension: 5.5 .

The oxygen tension in the original mixture was about $85 \times 5.5=$ 467.5, corresponding to 22.3 atmospheres.

Experiment CXLVI. February 22.

Raised to $2 \frac{1 / 2}{2}$ atmospheres, of which $1 / 2$ is oxygen.

Closed at 12:55; dead at $3: 55$. Bloody suffusions in the thickness of the cranial diploe; red blood in the jugular vein, rapidly becomes black.

Lethal air: $\mathrm{CO}_{2} 11.1 ; \mathrm{O}_{2} 33.3$.

$\mathrm{CO}_{2}$ tension $=11.1 \times 2.5=27.7$.

The original oxygen tension was about $46 \times 2.5=115.5$, which corresponds to 5.5 atmospheres.

The results of these experiments are grouped in Table VIII, following the increasing order of the oxygen tensions.

Table VIII

\begin{tabular}{|c|c|c|c|c|c|c|c|c|c|}
\hline 1 & 2 & 3 & 4 & 5 & 6 & $\tau$ & 8 & 9 & 10 \\
\hline 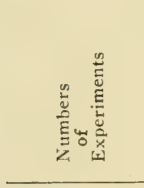 & 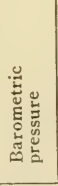 & 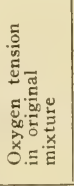 & 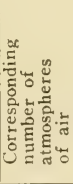 & 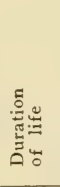 & 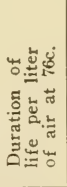 & \multicolumn{2}{|c|}{$\begin{array}{c}\text { Composition } \\
\text { of lethal air }\end{array}$} & $\begin{array}{l}a \\
\times \\
\delta^{\prime}\end{array}$ & 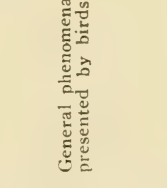 \\
\hline CXLIII & $\begin{array}{l}\text { atm. } \\
1.25\end{array}$ & 32.5 & atm. & $\begin{array}{l}\text { h.m. } \\
130\end{array}$ & $\begin{array}{l}\text { h.m. } \\
136\end{array}$ & $\begin{array}{l}\mathrm{CO}_{2} \\
22.1\end{array}$ & $\begin{array}{l}\mathrm{O}_{2} \\
3.5\end{array}$ & 27.6 & $\begin{array}{l}\text { No cranial } \\
\text { suffusions }\end{array}$ \\
\hline CXLIV & 1.5 & 69.0 & 3.3 & - & - & 16.7 & 28.6 & 25.1 & $\begin{array}{l}\text { Red dots on } \\
\text { cranium. }\end{array}$ \\
\hline CXLVI & 2.5 & 115.5 & 5.5 & 3 & 53 & 11.1 & 33.3 & 27.7 & $\begin{array}{l}\text { Cranial } \\
\text { suffusion. }\end{array}$ \\
\hline $\begin{array}{l}\text { CXL } \\
\text { CXXXIX }\end{array}$ & $\begin{array}{l}2.0 \\
1.75\end{array}$ & $\begin{array}{l}117.6 \\
146.3\end{array}$ & $\begin{array}{l}5.6 \\
7.3\end{array}$ & $\begin{array}{l}3 \\
220\end{array}$ & $\begin{array}{l}52 \\
31\end{array}$ & $\begin{array}{l}13.4 \\
11.9\end{array}$ & $\begin{array}{l}44.4 \\
67.8\end{array}$ & $\begin{array}{l}26.8 \\
20.8\end{array}$ & " \\
\hline CXXXVIII & 3.0 & 258.0 & 12.1 & 115 & 10 & 5.6 & 78.9 & 16.8 & $\begin{array}{l}\text { Convulsions, } \\
\text { suffusions. }\end{array}$ \\
\hline CXLI & 4.0 & 301.6 & 14.4 & 1 & 7 & 2.1 & 71.1 & 8.4 & \\
\hline CXXXVII & 5.0 & 415.0 & 19.7 & 120 & 6 & 1.4 & 80.5 & 7.0 & " \\
\hline $\begin{array}{l}\text { CXLII } \\
\text { CXLV }\end{array}$ & $\begin{array}{l}8.5 \\
5.5\end{array}$ & $\begin{array}{l}433.5 \\
467.5\end{array}$ & 20.7 & 20 & 2 & 0.8 & 47.8 & 6.8 & “" \\
\hline & & & 22.3 & 20 & 1 & 1.0 & 82.5 & & \\
\hline
\end{tabular}


If we examine Column 9, we see that the carbonic acid obeys the law given, up to a pressure corresponding to 5 or 6 atmospheres of air; but from there on, the product $\mathrm{CO}_{2} \times \mathrm{P}$ decreases rapidly. On comparing Columns 7 and 9 with Columns 6 and 8 of Table VII, we find numbers that are quite analogous, and that indicate a similar intervention of the fatal action of oxygen. It becomes very evident, when the tension of this gas can be represented by 150 , that is, when it corresponds to an atmosphere and a half of pure oxygen, or 7 atmospheres of air.

In Figure 7, the lower line $\mathrm{C}$ expresses the numbers of Column 9 ; we see that for the same barometric pressures it remains far below line $B$, which represents the results of the experiments in which ordinary air was used.

Finally, Column 6 shows, as did Column 4 of Table VII, that the duration of life, referred to a liter of ordinary air under normal pressure, continues to decrease with astonishing rapidity, when the pressure, or rather the oxygen tension, increases.

It is therefore overwhelmingly proved that oxygen, under a certain tension, is a dangerous agent which, in compressed air in closed vessels, first joins its action to that of the carbonic acid produced, and which for high tensions is the principal, soon the only, cause of death; this tension, measured by the expression $\mathrm{O}_{2} \times \mathrm{P}$, can be reached, according to the statement already made so often, by increasing either the barometric pressure $\mathrm{P}$, or the percentage of $\mathrm{O}_{22}$.

But it is established at the same time that the formula previously given, The death of sparrows occurs when the tension of the carbonic acid, measured as I have specified, is represented by a figure which oscillates between approximately 24 and 30 , expresses the truth. To prove it experimentally one need only guard against the excess of oxygen.

F. Compression with ordinary air: elimination of carbonic acid.

The presence of carbonic acid had prevented me, as we have just seen, from finding the real law which determines the exhaustion of the oxygen of compressed air for animals allowed to die in closed vessels.

But the fatal action of compressed oxygen which the studies just discussed had revealed to me no longer permitted me to think that the simple law, established for pressures lower than one atmosphere, could continue to be applicable to higher pressures.

It was, however, necessary to determine the facts. Apparently 
nothing could be simpler; I needed only to plan the experiments so that the carbonic acid would be eliminated as it was formed, so that it could not interfere with the result. But the very low capacity of the receivers which I had at my disposal made the task quite difficult, because the bird, as it stirred about, almost always finally came in contact with the potash, with resultant burns, considerable uneasiness, and often premature death.

I did not get a series of satisfactory results until I used an apparatus whose receiver is a mercury bottle; it then was easy for me to perform a large number of experiments, thanks to the capacity and the wide opening of my receiver. Besides, its great strength permitted me to carry the compression much higher than in glass apparatuses. The only inconvenience was the opacity, which prevented me from following the phases of the experiment and determining the precise moment of the death of the birds.

I filled a part of the cylinder with water containing potash in solution. The sparrow, enclosed in a little wire mesh ball, was suspended above the liquid. Under these conditions, there was no trace of carbonic acid in the air in which it stayed and died.

I report here a series of experiments that are quite characteristic.

Experiment CXLVII. September 18. Sparrow at $3 \frac{1}{4}$ atmospheres. Left in the air in which it died 1 per cent of oxygen.

Oxygen tension: $\mathrm{O} \approx \mathrm{x} \mathrm{P}=1 \times 3.25=3.25$.

Experiment CXLVIII. September 22. Sparrow at 61/4 atmospheres. Left 0.8 per cent of oxygen.

$\mathrm{O} \approx \mathrm{x} \mathrm{P}=5$.

Experiment CXLIX. October 3. Sparrow at 9 atmospheres.

Left 2.2 percent of oxygen.

$\mathrm{O}_{2} \times \mathrm{P}=20.8$.

Experiment CL. October 7. Sparrow at 12 atmospheres.

Left 5.6 per cent of oxygen.

$\mathrm{O}: \mathrm{x} \mathrm{P}=67.2$.

Experiment CLI. January 6. Sparrow at 15 atmospheres.

Left 14.5 per cent of oxygen.

$\mathrm{O}_{2} \times \mathrm{P}=217.5$.

Experiment CLII. September 30. Sparrow at 20 atmospheres.

Left 18.3 per cent of oxygen.

$\mathrm{O}_{2} \times \mathrm{P}=366.0$.

Experiment CLIII. October 1. Sparrow at 24 atmospheres.

Left 20.3 per cent of oxygen.

$\mathrm{O}$ × $\times \mathrm{P}=487.2$. 
Table IX

\begin{tabular}{|c|c|c|c|c|}
\hline $\begin{array}{c}1 \\
\text { Experiment Numbers }\end{array}$ & 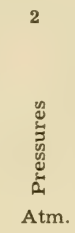 & 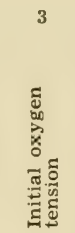 & 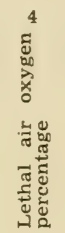 & 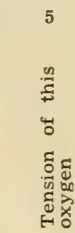 \\
\hline $\begin{array}{l}\text { CXLVII } \\
\text { CXLVIII - } \\
\text { CXLXIX - } \\
\text { CL } \\
\text { CLI } \\
\text { CLII } \\
\text { CLIII }\end{array}$ & $\begin{array}{l}31 / 4 \\
61 / 4 \\
9 \\
12 \\
15 \\
20 \\
24 \\
\end{array}$ & $\begin{array}{r}67.9 \\
130.6 \\
188.1 \\
250.8 \\
313.5 \\
418.0 \\
501.6 \\
\end{array}$ & $\begin{array}{r}1 \\
1 \\
0.8 \\
2.2 \\
5.6 \\
14.5 \\
18.3 \\
20.3 \\
\end{array}$ & $\begin{array}{r}3.2 \\
5.0 \\
20.8 \\
67.2 \\
217.5 \\
366.0 \\
487.2 \\
\end{array}$ \\
\hline
\end{tabular}

Line A of the following graph expresses the results of these last experiments; the oxygen content of the air in which the birds died is marked on the axis of the y's; the manometric pressures are

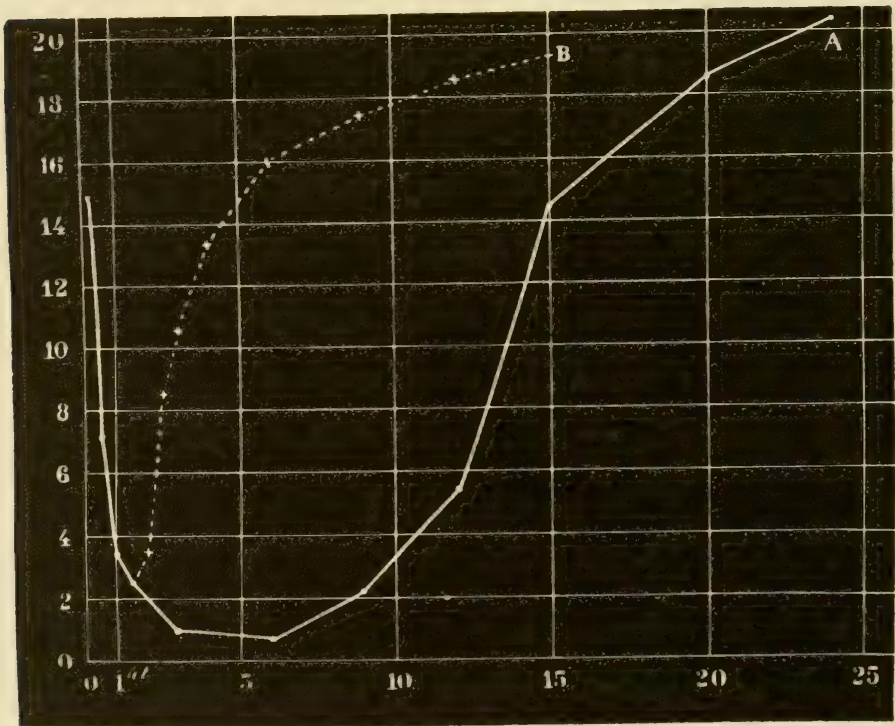

Fig. 22-Confined air which has become lethal under pressures of 20 cent. to 24 atmospheres; oxygen content: A, without carbonic acid; B, with carbonic acid. 
marked on that of the x's. I added the results already obtained for pressures lower than one atmosphere.

We see that the exhaustion of the air reaches its maximum at about 6 atmospheres. At higher pressures, it diminishes rapidly, so that at 24 atmospheres, the bird dies in an air that is almost pure.

The dangerous action of oxygen is shown very clearly, especially towards 15 atmospheres.

Line B expresses the results of Columns 7 of Tables V and VII, that is, the proportion of oxygen remaining in compressed air when carbonic acid is allowed to act on the experimental bird. We see that the two curves coincide only at $1 \frac{11}{2}$ atmospheres; above that, the acid acts strongly and brings on death in air that is hardly impoverished.

\section{Conclusions.}

The conclusions to be drawn from the data reported in the present subchapter are more complex than those of the preceding subchapter; the intervention of the carbonic acid and of the oxygen. for very high pressures, complicate them. We shall therefore make a distinction:

1. In confined air, at pressures higher than one atmosphere, if care is taken to eliminate the carbonic acid as it is produced, death occurs in the same conditions as for pressures lower than one atmosphere, that is, when the oxygen tension drops to a determined value (3.6 on the average for sparrows).

This is true only up to about 6 atmospheres; beyond that, the compressed oxygen acts to prevent the exhaustion according to the formula.

2. When the carbonic acid is not absorbed, it becomes a cause of death at the moment when its tension rises to a certain value (from 25 to 28 for sparrows).

This is absolutely exact only on condition of using, for rather high tensions, air with low oxygen content, so that the oxygen tension may not rise to the point where it is dangerous to the very life of the birds. 


\section{Subchapter III}

\section{SUMMARY AND CONCLUSIONS}

Summarizing, if we clear the principal results from the incidental questions which we have brought up and settled in the course of our research, the study of death in confined air under different pressures brings us to the following formulae.

In ordinary air:

A.-At pressures lower than one atmosphere, the death of animals occurs when the oxygen tension of the air is reduced to a certain constant value (which for sparrows equals on the average $\mathrm{O}_{2} \times \mathrm{P}=3.6$ ).

B.-For pressures included between 2 and 9 atmospheres, death occurs when the carbonic acid tension rises to a certain constant value (which for sparrows equals on the average $\mathrm{CO}_{2} \times \mathrm{P}=26$ ).

C.-For very high pressures, death is due exclusively to the too great tension of the ambient oxygen. It comes quickly when the tension of this gas reaches 300 or 400 .

D.-For pressures of 1 to 2 atmospheres, death seems to be due especially to the lowering of the oxygen tension, but in part also to the rise of the $\mathrm{CO}_{2}$ tension.

E.-Starting with 3 or 4 atmospheres, the fatal effect of the oxygen begins to be felt, and becomes very evident at about 9 or 10 atmospheres.

Experiments made either with gaseous mixtures more or less rich in oxygen, or in the presence of alkalis capable of absorbing the carbonic acid as it is formed, cause us to give to these laws an even greater character of generality, and we can formulate them in the following manner (applying them, for greater clearness, to sparrows):

The tension of a gas being represented by the product of its percentage multiplied by the barometric pressures, we see that death occurs:

A.-When the oxygen tension drops below 3.6, whether the barometric pressure is above or below the normal pressure; of course, in the first case, the carbonic acid must be removed by an alkali.

B.-When the carbonic acid tension rises above 26, whether the pressure is above or below the normal pressure; of course, in the latter case superoxygenated mixtures must be used. 
What we say of carbonic acid is general for all poisonous gases ( $\mathrm{CO}, \mathrm{HS}$, etc.) ; only the numerical value of the lethal tension will change. We shall return to this point when we speak of the hygiene of workmen in compression tubes.

C.-When the oxygen tension reaches about 300, whatever the percentage and the pressure are (the latter evidently cannot be lower than 3 atmospheres, with pure oxygen).

D.-These kinds of death can be combined by twos, A with B and $\mathrm{B}$ with $\mathrm{C}$, according to the pressures and gaseous compositions used.

Death A is a real asphyxia for lack of oxygen; death B is a poisoning by carbonic acid; death $\mathrm{C}$ can be called, for convenience and in spite of the strangeness of the expression, a poisoning by oxygen.

We see-and this is the most general result reached-that in all cases the barometric pressure in its variations is never directly, of itself, the cause of the phenomena. It is only one of the conditions which alter the tension of the gases, and the other factor, the percentage, can completely offset its effects, if its progress is in the other direction, just as it will increase them rapidly, if its progress is in the same direction.

If now we leave out the carbonic acid produced, to place ourselves in conditions nearer those in which our present problem appears in nature or industry, setting aside certain phenomena which are quite secondary and to which we shall return at the appropriate time, we reach these conclusions:

1. That three animals, the first of which exhausts by its respiration a closed space full of air, the second of which is compelled to breathe in a current of air of diminishing oxygen content, the third of which is subjected to a gradual decrease of pressure, are all three, by these different procedures, threatened by the same symptoms and the same death, a death from lack of oxygen, a real asphyxia;

2. That two animals, one of which breathes in a current of air of increasing oxygen content while the other is subjected to a barometric pressure increasing from 1 to 5 atmospheres, are in identical conditions. That, besides, the animal which breathes pure oxygen at 2, 3, 4 atmospheres, etc., is in the same conditions as the one which breathes pure air at 10, 15, 20 atmospheres; both are, by these different procedures, threatened by the same symptoms and the same death, a death from excess of oxygen, a poisoning of a sort hitherto unknown.

All the influence which barometric modifications exercise on 
animals is summed up in these terms: too low an oxygen tension or too high an oxygen tension.

Such is the very simple explanation given us by experiments in which we considered the ambient medium much more than the animal. But this too low or too high tension of the oxygen must be studied now, not only in its measure, but in its immediate consequences; the animal itself must also be examined with more care.

The first question which I shall now consider is that of the composition of the gases contained in the blood of animals subjected to different pressures.

1 See my Lecons sur la physiologie comparée de la respiration. Lessons XXVII and XXVIII, p. 498-526. Paris, 1870.

${ }^{2}$ Lecons sur les effets des substances toxiques et médicamentcuses. Paris, 185., p. 125.

3 Lecons sur les substances toxiques, p. 140.

- Lecons sur la physiologie de la respiration, p. 517. 


\title{
Chapter II
}

\section{GASES CONTAINED IN THE BLOOD AT DIF- FERENT BAROMETRIC PRESSURES}

\author{
Subchapter I \\ OPERATIVE METHODS AND EXPERIMENTAL \\ DISCUSSION
}

I think I should, at the beginning of this chapter, describe the apparatuses used for the extraction of the gas of the blood, and indicate with a few details the manner in which I use them. I shall also place here the account of the control experiments which I made to study the degree of precision which can be attained by such researches.

The first of the indispensable instruments is the syringe by means of which one takes from the blood-vessel a measured quantity of blood to be conveyed to the extraction apparatus.

The model upon which I fixed after many attempts is represented in Figure 23.

Its body is of thick glass, with ground bore and fittings, for without this precaution the glass bursts spontaneously at the least change of temperature. This body is held by and solidly cemented into two steel end-pieces, fitted with leather gaskets and fastened to each other by 4 strong rods of steel.

The piston, so arranged as not to turn of itself, is mounted on a rod equipped with a special screw thread, which in its whole course makes only one turn and a half. The upper part, closed by a screw, can be removed and the syringe opened so that the piston can be completely withdrawn for cleaning. This upper part is pierced by a small orifice, through which is introduced a little water which 
will form a hydraulic seal above the piston. Finally, on one of the sides, a graduated rule shows the quantity of blood that has been

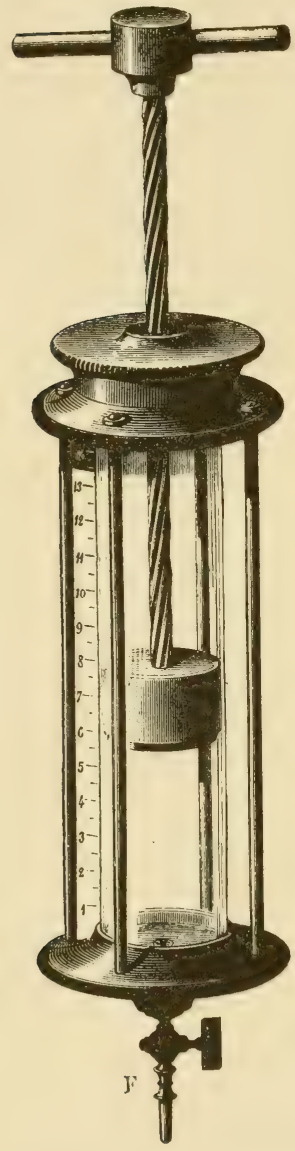

Fig. 23-Graduated syringe for extracting blood.

extracted. At the bottom of the syringe is screwed in a connecting piece with a cock, on which can be mounted tubes of different forms. The total capacity is from 80 to 100 cubic centimeters.

Such a syringe, which I have described in detail because it is the model on which I fixed after many attempts, as being the simplest, the most convenient, the strongest, and the least expensive, holds a vacuum perfectly. However, through excess of precaution, I never used it without introducing water above the piston, and submerging the whole lower part in water to a point above the end-piece; not a bubble of air can then enter.

A cannula being placed in the animal's artery, part $\mathrm{F}$ is connected to it, and when the serre-fine which closes the artery is opened, the blood rushes into the syringe with a pressure sufficient to raise the piston; I usually take 33 cubic centimeters for each analysis.

The blood extracted and held in the syringe is immediately taken to the apparatus for the extraction of gases. The most important part of this consists of the mercury pump whose description has been given above.

To the lateral tube, which I advise should be placed obliquely, as Figure 24 shows, is fastened, by means of a rubber tube with thick walls, a large glass tube about 75 centimeters long, whose lower extremity fits very tightly in the neck of a tubular balloon D, whose capacity is about 1 liter. From the tubulation of this balloon extends a glass tube of very small caliber, twice bent, whose end is closed by a cock $r$. 
To obtain a perfect seal in the whole of this apparatus, all the connections of the different parts are submerged in water, strong ligatures with rubber bands cut off the air completely, and besides, a zinc cuff full of water forms a hydraulic seal at the union of the

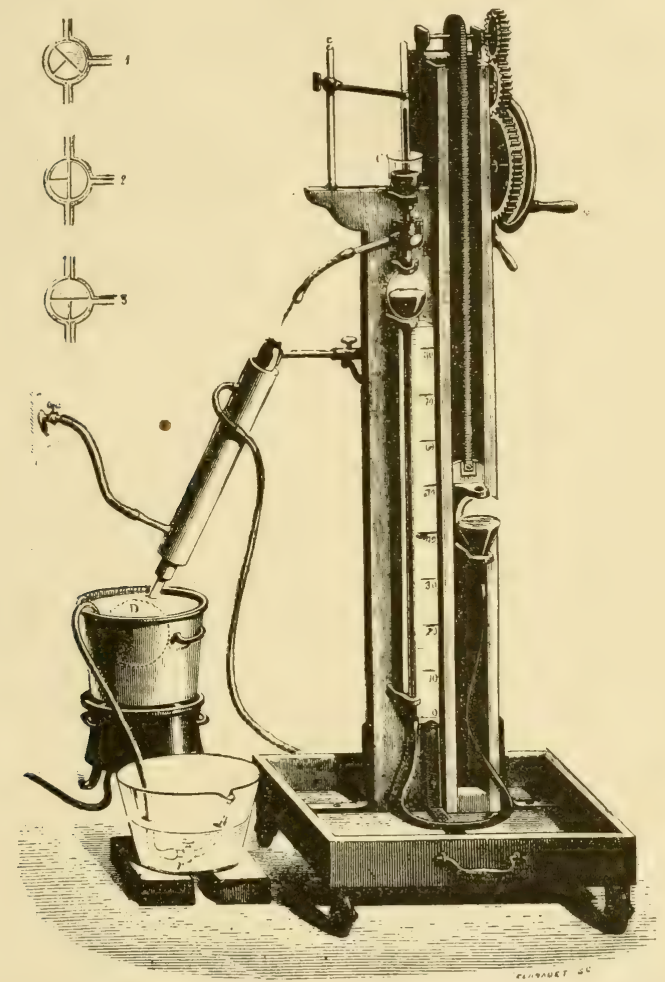

Fig. 24-Mercury pump set up for the extraction of blood gases. A. Barometric chamber. B. Movable bulb, communicating with A by rubber and glass tube. C. Mercury reservoir for collecting the gases. D. Balloon immersed in warm water, into which the blood is conducted through cock $r$, after a vacuum has been made. The large glass tube leading from $\mathrm{D}$ is surrounded by a current of water which cools the gases and forms a hydraulic seal. $R$. Threeway cock which can completely close the barometric chamber (position 1), or connect A with C (position 2) or A with D (position 3). 
tube and the balloon. The cock $r$ and the rubber tube on its end are also submerged.

Through the zinc cuft passes a current of water going upwards from below, intended to cool the glass tube. This arrangement, the idea of M. Gréhant, has this considerable advantage of stopping or at least of lessening considerably the coagulable froth which rises from the blood under the influence of the vacuum, a froth which may reach the chamber of the pump, mingle with the extracted gas or at least dirty the whole apparatus.

To make a vacuum in the system described above, I first fit to the rubber fastened on cock $r$ another tube which connects with an ordinary pneumatic machine. In this way I shorten the proceeding considerably; the vacuum is next secured perfectly by means of the mercury pump, according to the method described previously.

However, one would not secure a perfect vacuum, leaving the system at the ordinary temperature of the laboratory; I assured myself of that by very simple experiments, on the details of which I need not dwell here. Now the presence of a small quantity of air at the beginning of the experiment may cause difficulties. To remove it completely, I allow a few cubic centimeters of water to enter balloon $\mathrm{D}$, by opening cock $r$; then I warm the balloon until the bath begins to bubble; at the same time I cut off the current of cold water which was circulating in the zinc cuff. In this way, the very hot steam which escapes from the balloon drives out all the remaining gas, when the pump is operated, and after the fire is lowered and the current of cold water is allowed to flow, we have reached a vacuum as perfect as is necessary.

Then after the syringe full of blood is fitted to the rubber tube of cock $r$, submerging its lower part in the water and opening the cock, the suction due to the vacuum forces the blood into balloon $\mathrm{D}$; then I close the cock and take out the syringe. As a certain quantity of blood remains in the siphon and as it would be difficult to exhaust its gases, I plunge the flexible tube into a little dish full of mercury, and allow the mercury to rise to the point where the tube curves to enter the balloon.

The blood which has reached the balloon $\mathrm{D}$ is subjected there to the temperature of the bath, which I raised successively from $75^{\circ}$ to $100^{\circ}$. Now I always boil this bath; I am very well satisfied with the use of this high temperature, and the extraction of the gases has always been much more rapid and complete than when I limited myself, as my predecessors did, to keeping the blood at the 
temperature of the living body, or about that. The only inconvenience is that the froth is increased by this method; but, thanks to the length of the communicating tube and the current of cold water, this froth very rarely enters the pump; furthermore, one can easily check this froth by the skillful use of the three-way cock; but these are skillful tricks that cannot be described easily.

Introducing in this way, as I ordinarily did, $33 \mathrm{cc}$. of blood, the gases are extracted by three strokes of the pump on the average; I have seen them all come at the first stroke, and in other cases, after the third stroke which hardly brings two or three centimeters, I succeeded in getting one or two more by continuing the operation; but that is the exception.

I fairly often introduced in advance into balloon D, not merely a few drops of water, as I said above, but 30 or 40 cubic centimeters of water, which, of course, I boiled, and from which I extracted all the gases before introducing the blood. This procedure has the advantage, by diluting the blood, of lessening its coagulability and checking the froth which issues from it from persisting and stopping up tube DR, as sometimes happens; but this froth is then easier to remove by a stroke of the pump, and rises to the top of the tube; that is why I advised giving the tube a very decided slant from the cock on, so that the froth may fall back easily instead of remaining in the angle of the tubes.

I had made a certain number of experiments by this procedure, and I had assured myself by the comparative method, that it has no disadvantage from the standpoint of quality and quantity of gases extracted, when I read with surprise in the Proceedings of the Academy of Sciences ${ }^{1}$ a memorandum from MM. Estor and SaintPierre in which the presence of water is charged with causing enormously important differences in the extractions.

According to the experimenters of Montpellier, the mixture of water with the blood would facilitate the extraction of the oxygen so much that the average quantity of this gas would be increased from $4 \mathrm{cc}$. to $6 \mathrm{cc}$. per $100 \mathrm{cc}$. of blood. If it were so, one should, in the first place, always use this mixture, and secondly, never compare with each other results obtained with or without water.

Unfortunately, MM. Estor and Saint-Pierre, instead of making themselves comparative analyses made simultaneously with the same blood, preferred, following a method which seems to be familiar to them, to compare to each other analyses made on the blood of different animals and in entirely different conditions. Just one of the experiments reported in their memoir (Experiment 
XVI) was made on the same blood, divided into two parts: one, treated with carbon monoxide, gave 6.66 volumes of oxygen per 100 volumes of blood; the other, added to water and brought to a boil, released 27.72 volumes. The announcement of these results is almost enough to prove that both analyses are equally bad.

I might have limited myself to referring the reader to the experiments which I am about to report and in which water has often been added to the blood without making any change in the result. But, through excess of scruple, I shall report two experiments which were carried out with great care with the special purpose of checking the strange statement of the physiologists of Montpellier.

Experiment CLIV. January 15. Dog of medium size, exhausted by suppurations resulting from numerous operations.

Drew from the carotid $33 \mathrm{cc}$. of blood which were immediately introduced into the pump .... A

Immediately afterward, again drew $33 \mathrm{cc}$. of blood; but previously $50 \mathrm{cc}$. of water, from which the gases had been exhausted by vacuum and by boiling, had been introduced into ${ }^{2}$ the pump .... B

Blood A contained, per 100 volumes, 7.1 of oxygen.

Blood B contained, per 100 volumes, 6.2 of oxygen.

Experiment CLV. January 18. Large dog, intact.

Two pumps for extraction of gases were prepared; into one of them $33 \mathrm{cc}$. of water were introduced, then exhausted.

About $70 \mathrm{cc}$. of blood were drawn from the femoral artery; $33 \mathrm{cc}$. were introduced into pump A, $33 \mathrm{cc}$. into the second $\mathrm{B}$, in which is the water.

Blood A contains, per 100 volumes, 19.7 of oxygen and 45.0 of $\mathrm{CO}_{2}$. Blood B contains, per 100 volumes, 19.8 of oxygen and 44.2 of $\mathrm{CO}$.

We see that, whether we are handling a blood extremely low in oxygen, or a normal blood, the addition of water did not alter at all the quantity of oxygen extracted from the blood.

Furthermore, the so-called verification of this difference had as its first purpose an explanation of the strange persistence of MM. Estor and Saint-Pierre in maintaining that there is, from the standpoint of oxygen content, a considerable difference between the blood of the carotid and that of the femoral; an enormous difference, according to them, since when the blood of the carotid contains 21.06 volumes of oxygen, that of the femoral would contain only 7.62. They use this difference to support a theory of their own about the almost instantaneous combustion of the materials of the blood as it leaves the lung. I should certainly not have returned to this subject, which I thought I had previously exhausted, without new communications from MM. Estor and Saint- 
Pierre. But I must speak of it, since I have happened, in some of the experiments which are reported below, to compare analyses of the blood of the carotid with analyses of the blood of the femoral.

I shall therefore repeat here what I have already said elsewhere: ${ }^{4}$ MM. Estor and Saint-Pierre have made no direct comparative experiment; if they had made even one, they would have seen how mistaken their statement is. They have preferred to search in books, and to compare results obtained by M. Claude Bernard at different epochs, on dogs placed in the most varied general conditions, using carbon monoxide as the means of extracting the oxygen, with others for which they are indebted to several German physiologists who used mercury pumps of different models, and operated sometimes on dogs, sometimes on sheep. I showed in detail, in the work quoted above, how truly faulty such a method is, if one can give the name of "method" to such a procedure. I might today present the result of my own experiments, made simultaneously on the same animal and with the same apparatus. But I prefer to invoke the aid of two experimenters who have studied these questions with what I consider an exaggerated precision, but which is a sure guarantee of painstaking in the experiments. Now MM. Mathieu and Urbain, ${ }^{5}$ investigating whether there are differences in the blood of the various arteries, reached the following results, in regard to the carotid and the femoral (page 192) :

Carotid _ 20.45- 20.99- 15.06- 13.25- 12.75- 18.25 - 15.00- 15.75- 14.93 Femoral _- 18.03-17.69-13.81- 13.25-13.50- 18.00 - 15.75- 15.75- 14.48

We see, as the authors say correctly, that if there is a slight difference in favor of the blood of the carotid, it is infinitely less great than MM. Estor and Saint-Pierre claimed. Let us add that, according to the experiments of MM. Mathieu and Urbain, the difference would increase greatly when, instead of taking arteries of about the same caliber, one examines comparatively the blood of the carotid and that of an artery of small dimensions, whether it is close to or far from the heart. But we cannot dwell on these data; for our present purpose, it is enough for us to conclude that, even if it is preferable to take the blood always from the same artery, there is no serious disadvantage about taking it successively from the carotid and the femoral, in the same animal, when one is forced to it.

Furthermore, before expressing ourselves on the importance of the different causes of errors which may come from physiological 
causes, it is best for us first to get an accurate idea of the exactness one may hope to secure by using the apparatus which we have described. Let us consider that the vacuum is made, and that we are bringing to the cock $r$ the syringe containing, for example, $50 \mathrm{cc}$. of blood. Let us say first that it is impossible, considering the caliber of the syringe, to determine this quantity very exactly; we shall be below the truth in taking as possible errors either $49.8 \mathrm{cc}$. or $50.2 \mathrm{cc}$. Furthermore, there will remain in the rubber tube and the cock $r$ at least $0.5 \mathrm{cc}$. of blood which will escape

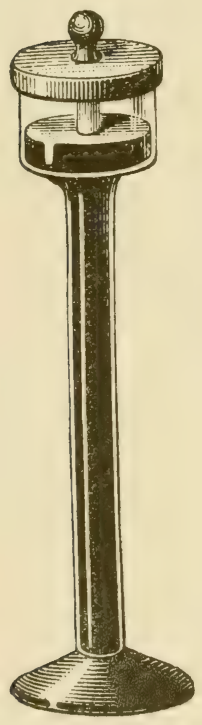

Fig. 25 - Small mercury reservoir. analysis: the truth is then that when we say we have tested $50 \mathrm{cc}$., we have really introduced into the apparatus $49.3 \mathrm{cc}$. or $49.7 \mathrm{cc}$. Let us now make the extraction, and let us suppose it perfectly complete: at least we have no means of measuring the very small residue which may remain in the apparatus. We shall obtain on the average $30 \mathrm{cc}$. of gases which will have to be collected in two different tubes, if we wish to use narrow tubes so that the readings may not bring too great a cause of error. At the same time as the gases, water vapor has penetrated into the pump and has condensed; each of our tubes always contains 1 or 2 cubic centimeters of water. How much carbonic acid in solution has this water absorbed? We do not know. That is not all; since the gas is at a high temperature, before measuring it, we must immerse the tubes completely in little glass mercury basins, narrow and deep, constructed for this purpose (Fig. 25); during this time, and under pressure, a new quantity of carbonic acid must enter into solution. Perhaps we can, for each tube, estimate at $0.2 \mathrm{cc}$. or $0.3 \mathrm{cc}$. the total quantity of this gas of which no account can be taken.

Now we have two tubes, one of which contains, I suppose, $20 \mathrm{cc}$., the other $10 \mathrm{cc}$; if we refer to what has been said on the possible errors of analysis by potash and pyrogallic acid, we shall see that we can vouch for the exactness of the composition only between limits analogous to the following: 


$\begin{array}{ccc} & \begin{array}{c}\text { First tube } \\ \text { cc. }\end{array} & \begin{array}{c}\text { Second tube } \\ \text { cc. }\end{array} \\ \text { Carbonic acid } & 12 & 1 \\ \text { Oxygen } & 11.9 & 6.9 \\ & 6.9 & 2.5 \\ & 7 & 2.6\end{array}$

Which, following the combinations, may give us the following extreme total results:

Carbonic acid 19 or 18.8

Oxygen

9.6 or 9.4

Let us add to this the quantity of carbonic acid contained in the condensed water, and the direct measure may give us a result for this gas which is below the truth, from $0.4 \mathrm{cc}$. to $0.6 \mathrm{cc}$.

We must now double all these figures, to get the total quantity of gas contained in $100 \mathrm{cc}$. of blood, the amount which is commonly used; so that, in spite of the greatest precautions, and supposing that the extraction of the gases has been perfect, it is impossible to say that the number obtained is not too high or too low for the oxygen and the nitrogen by 2 or 3 tenths, and for the carbonic acid by nearly a unit.

After that we can judge the value of these second and third decimals, which the tables of analyses almost always display following their whole numbers. I am strongly inclined towards this truth that, if the decimals are exact from the arithmetical point of view, the number of units itself is false from the chemical point of view, for to the different causes of error mentioned above, we should add the imperfection of the apparatuses which most of the operators use.

And what is to be said now from the physiological point of view? The analysis of which we have just spoken gives us, for a determined case, an absolute result, error excepted. But how many things cause complications, if we wish to compare it to another analysis made by the same experimenter, with the same instrument, on another animal belonging however to the same species! I have specified before ${ }^{6}$ the differences which, from the point of view of the oxygen content, may be presented by the blood of an animal placed in different conditions, as in digestion and fasting, etc. Since then, MM. Mathieu and Urbain, repeating with the gas pump the experiments which I had performed simply with carbon monoxide, and which, consequently, applied only to oxygen, have multiplied and varied the conditions in which the animals can be placed. 
Their work, which develops, confirms, or rectifies my former attempts, has shown that the absolute and relative proportion of the gases of the blood is subject to numerous variations.

But I limit myself for the moment to the study of those variations that may be important in the subject with which I am concerned at present.

Now we are considering here experiments made in the lapse of two or three hours at most. The only influences which can act in this case are: (1) the former bleedings; (2) the animal's respiratory rate; (3) its state of repose or agitation.

MM. Mathieu and Urbain (loc. cit., page 14 et seq.) attach much importance to the former bleedings. According to them, if $20 \mathrm{cc}$. of arterial blood are extracted from a dog, in a second bleeding of $20 \mathrm{cc}$. there will be considerably less oxygen and carbonic acid; successive bleedings would increase these differences. On the average, for bleedings of $20 \mathrm{cc}$. made at intervals of an hour and a half, we should have total diminutions of $1.25 \mathrm{cc}$.; $2.25 \mathrm{cc}$.; $3.00 \mathrm{cc}$; $3.50 \mathrm{cc}$; $3.75 \mathrm{cc}$. After a bleeding of $60 \mathrm{cc}$., the difference would be on the average $2.50 \mathrm{cc}$., and after a bleeding of $150 \mathrm{cc}$., $3.91 \mathrm{cc}$.

According to them, these modifications would be due principally to the diminution in vascular tension; in fact, they would not be noted if after the first bleeding a quantity of water equal to the quantity of blood removed were injected into the vessels.

The carbonic acid would vary under the influence of successive bleedings in the same direction and following a higher proportion than the oxygen.

As for me, I have never noticed such considerable differences in the gaseous content of blood drawn repeatedly from the vessels. Often the numbers obtained remained absolutely identical, when the animal was at rest. This happened, for example, in the following experiment.

Experiment CLVI. July 18. Large shepherd dog.

At 2 o'clock, drew $44 \mathrm{cc}$. of blood from the femoral; animal perfectly quiet.... A

Drew next $43 \mathrm{cc}$. of blood from the same artery ... . B

At $3: 30$, drew $42.5 \mathrm{cc}$. from the same artery .... C

Blood A contains per 100 volumes: $\mathrm{O}=21.4 ; \mathrm{CO}=39.5$.

Blood B contains per 100 volumes: $\mathrm{O}=21.2 ; \mathrm{CO}_{2} 40.1$.

Blood C contains per 100 volumes: $\mathrm{O}_{2} 21.5 ; \mathrm{CO}_{2} 38.6$.

The numerous experiments which will be reported in the present chapter show frequently that successive bleedings do not give such unlike results as one might think from the conclusions of MM. Urbain and Mathieu. 
To study the influence of the number of respirations by isolating it from that of the general movements of the body, which is always involved, I poisoned the animals by curare, and when they were completely paralyzed, I made use of artificial respiration by means of a bellows introduced into the trachea.

This bellows (Fig. 26) has an intake valve A, furnished with a tube permitting any gas to be pumped into the lungs, and with a graduated guide bar provided with a slide to control the movements of the bellows. The variable position of the slide determines the quantity of air injected. With this instrument, nothing is easier than to measure exactly the amplitude and the number of

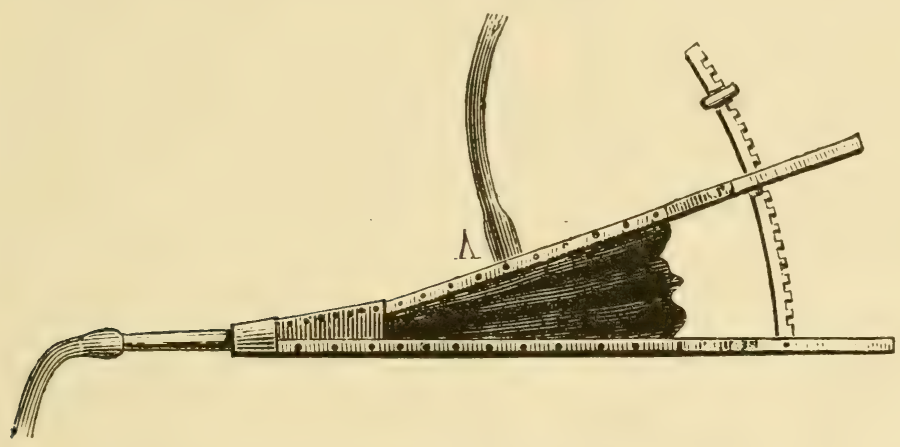

Fig. 26-Bellows for artificial respiration (A, pipe with valve which permits the use of any gas).

the artificial respirations. When the cannula has been introduced into the trachea, which it does not quite fill, the little space left between it and the walls is sufficient for the expiration to be made easily; besides, in this respect conditions are always identical.

I also used the apparatus construed according to the specifications of M. Gréhant, which in my laboratory is operated by a small water motor.

Here is the result of an experiment, taken as an example.

Experiment CLVII. February 19. Dog weighing 18 kilograms.

At 4:05, lethal dose of curare subcutaneously; falls at $4: 25$; trachea opened and artificial respiration carried on, the bellows delivering 350 cc.

At 4:40, the artificial respiration is fixed at 16 per minute; the pulse is 90 . At $4: 50,72$ cc. of blood taken from the femoral artery .... A 
Immediately after, respiration increased to 70 per minute; the pulse rises to 140 ; the rectal temperature is $38.5^{\circ}$. At the end of 10 minutes, 72 cc. of blood taken from the same artery . . . B

The pipe of the bellows is fitted to a bag of carbonic acid; after 15 minutes of artificial respiration, the heart stops. 55 cc. of blood immediately taken from the left heart by a cannula inserted through the left carotid .... C

The rectal temperature is then $36^{\circ}$.

Blood A contains per 100 volumes: $\mathrm{O}=19.7 ; \mathrm{CO}_{2} 36.7$.

Blood B contains per 100 volumes: $\mathrm{O}=20.7 ; \mathrm{CO}_{2} 30.1$.

Blood C contains per 100 volumes: $\mathrm{O}_{2} 5.2 ; \mathrm{CO}_{2} 90.2$.

We see that the rapidity of the respiratory movements, or more generally, that the passage through the lungs of a greater quantity of air in a given time has a double result: an increase in the proportion of the oxygen of the blood, and a decrease in the proportion of carbonic acid, the increase of the oxygen being much less than the decrease of the carbonic acid.

In order to study the influence of the state of repose or of the muscular contractions of the animal, and to isolate it from all circumstances of another sort, I killed a dog by section of the medulla, and then carried on artificial respiration in a regular manner. At the end of some time, the animal being naturally in complete immobility, I drew blood; then, by means of a strong induced current passing through the body from the mouth to the anus, I obtained general energetic movements that were more or less numerous, after which I drew blood again.

Here are the results of an experiment carried on in this way.

Experiment CLVIII. November 12. Strong dog weighing 15 kilograms. Medulla cut; artificial respiration fixed at 15 per minute for 5 minutes. Then drew $25 \mathrm{cc}$. of blood from the carotid ... A

Spinal cord then excited from medulla to anus by strong induced currents which cause general convulsions, especially in the posterior members. Artificial respiration is continued in the same rhythm. After 5 minutes of excitation, $25 \mathrm{cc}$. of carotid blood drawn . . . B

Blood A contains per 100 volumes: $\mathrm{O}_{2} 26.6$; $\mathrm{CO}_{2} 31.2$.

Blood $\mathrm{B}$ contains per 100 volumes: $\mathrm{O}_{2} 18.2 ; \mathrm{CO}_{2} 28.8$.

But we must realize that in the ordinary and natural state of things the two phenomena which we have artificially separated are combined, mingle, and superadd their effects, which then counterbalance each other. In the vast majority of cases, indeed, an animal which struggles breathes more frequently and deeply, and, conversely, repose accompanies a calmer and slower respiration. 
Experiment CLIX. January 24. Large hunting dog. Left femoral. 75 cc. of blood taken; the analysis was lost by accident.

74 cc. then taken; the animal, which had been tied down for a long time, had been perfectly quiet (A); at the end of an hour, the animal excited struggled violently, howling loudly, for some minutes, after which $76 \mathrm{cc}$. of blood were taken (B).

Blood A contains per 100 volumes: $\mathrm{O}_{2} 18.6 ; \mathrm{CO}_{2} 37.0$.

Blood B contains per 100 volumes: $\mathrm{O}_{2}$ 19.4; $\mathrm{CO}_{2} 35.2$.

Experiment CLX. March 5. Small dog, whose laryngeal recurrents were cut March 1, but in good shape. Femoral artery.

The animal being very calm, $40 \mathrm{cc}$. of blood were drawn (A); then the dog is made uneasy by placing a little ammonia under its nose, and the same quantity of blood was drawn (B).

Blood A contains per 100 volumes: $\mathrm{O}=11.7 ; \mathrm{CO}_{2} 33.6$.

Blood B contains per 100 volumes: $\mathrm{O}_{2}$ 12.4; $\mathrm{CO}_{2} 32.7$.

The dog was then poisoned by curare; the excitation of a sciatic nerve made the blood pressure rise $2 \mathrm{~cm}$., to $4 \mathrm{~cm}$., even after the section of the two pneumogastrics. The peripheral end of these no longer acting on the heart, the central end, when excited, increased the blood pressure. After having cut transversely the right half of the lumbar cord, an increase of pressure was obtained by excitation of the right sciatic; the left gave a doubtful result.

Here are two experiments that indicate that in most cases one does not need to give much consideration to any modifications in the behavior of the animal at different moments of the experiment. The comparative analyses show that for oxygen the causes of error hardly reach unity, and that for the carbonic acid they hardly exceed two units.

But in certain exceptional circumstances, the differences may reach values that are much higher. That happens sometimes, for example, when the trachea of an animal is opened and a cannula is inserted. All physiologists have noticed that in these conditions the animals are often seized by an extraordinary panting, which usually ceases at the end of a few minutes. Now if blood is drawn during this period, we find that its gaseous composition is very different from what it was before.

I shall offer as examples the two following cases, the most remarkable I have found.

Experiment CLXI. December 20. Vigorous dog, weighing 16.5 kilos.

At $3: 55$, I drew from the carotid $33 \mathrm{cc}$. of blood, which is quite dark .... A.

At 4 o'clock, I placed a tube in the trachea; the respirations became extremely rapid for 5 minutes; then calm returned and shortly after, a new acceleration, which ended at $4: 10$, the very moment when 
33 cc. more of blood was being drawn, which was evidently not so dark ..... B

Blood A contains per 100 volumes: $\mathrm{O}: 15.1 ; \mathrm{CO}_{2} 40.8$.

Blood B contains per 100 volumes: $\mathrm{O}_{2} 20.3 ; \mathrm{CO}_{2} 24.0$.

Experiment CLXII. January 24. Bulldog.

At 2:30, I extracted $32 \mathrm{cc}$. of blood from the carotid, the animal breathing through the natural channels ... A

I opened the trachea to place a tube in it; the respirations became extraordinarily hasty; at the end of 5 to 6 minutes of this rhythm, I took $33 \mathrm{cc}$. of blood, considerably redder .... B

Blood A contains per 100 volumes: $\mathrm{O}_{2} 16.0 ; \mathrm{CO}_{2} 41.5$.

Blood $\mathrm{B}$ contains per 100 volumes: $\mathrm{O}_{2} 23.4$; $\mathrm{CO}_{2}$ 15.2.

But, I repeat, this is an extreme; nothing quite comparable appeared in animals breathing through natural channels. A great number of experiments permit me to state that the circumstances depending upon the animal's behavior, although not negligible, are not such as to forbid the drawing of conclusions. Of course, I could not always prevent interference from them, but when it was very manifest, I abandoned the experiment.

Finally, without dwelling on the differences which may appear in the blood of a dog, depending on whether the animal is fasting or digesting such and such.kinds of food, I shall say that all of my dogs had eaten food with very little meat about eight o'clock in the morning; the experiments were generally performed from two to six o'clock.

We see that definitely the sources of error contained in our analyses, which have both chemical and physiological causes, are about one unit for oxygen and three or four units for carbonic acid. I maintain that in practice one cannot attempt to obtain greater accuracy than this without mistaking a systematic error for the truth.

Subchapter II

\section{GASES OF THE BLOOD UNDER PRESSURES OF LESS THAN ONE ATMOSPHERE}

1. Experimental Set-up.

Extraction of blood from the vessels of an animal subjected to the influence of diminished pressure was not an easy problem.

The apparatus at my disposal, which I used in my researches in diminished pressure, is composed of two vast cylindrical chambers (Fig. 27) which can be isolated from each other by a communicating door. These chambers are 2 meters high and 1 meter in 
diameter, which gives them a capacity of about 1.550 cubic meters: I say "about" because of the convex dome which tops them. They are suitably lighted by glass portholes as seen in the figure. The doors opening outward and resting on rubber gaskets close quite tightly, atmospheric pressure tending to fit them more closely to the gaskets as the pressure within diminishes. An exterior manometer, a sort of barometric tube whose chamber communicates

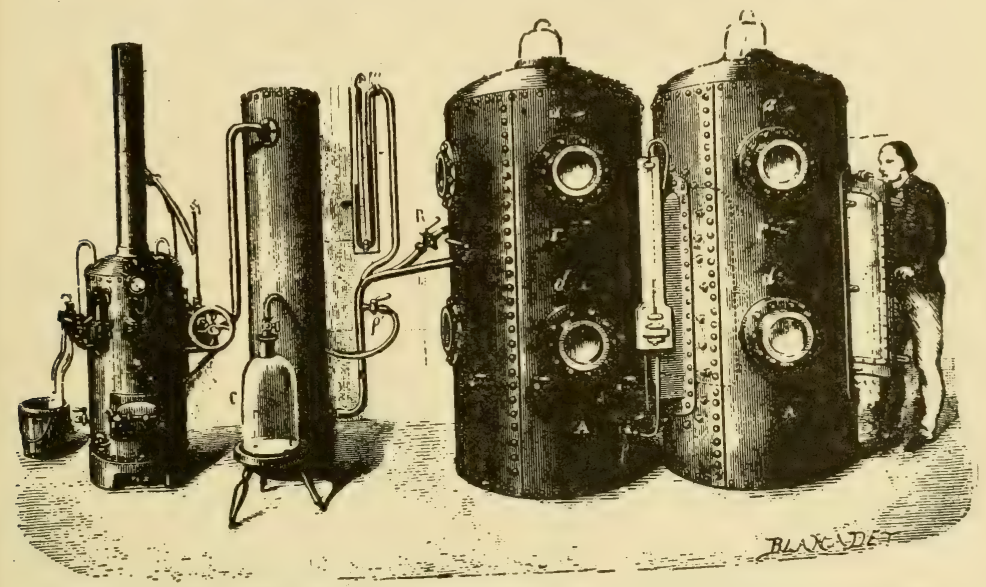

Fig. 27-Large apparatus for the study of low pressures. A. A'. Cylinders of riveted sheetiron, with glass portholes. B. Cylinder in which the pressure can previously be lowered to 5 centimeters, so as to obtain a rapid decompression in the large cylinders. C. Large glass bell-jar in which an instantaneous decompression can be made by using cylinder B. R. R'. Cocks which communicate each with one of the cylinders $A$ and A', which are separated by an inner door, shown by the dotted line. p. Communication cock for C; r, r', d, d'; s, s', s", openings and cocks for taking air samples, extracting blood, etc. a, a'. Thermometers. $m, m^{\prime}$. Manometers.

with one of the two large reservoirs, indicates immediately the amount of the inner decompression; thermometers pass through the wall.

The pressure is diminished by a pump moved, in the beginning, by a little steam engine, as the figure shows. I replaced it by a gas motor of the Lenoir system, a machine much easier to handle in a laboratory, and better adapted to tasks which one must undertake and leave according to circumstances over which one has no control. 
I can thus diminish the pressure 20 centimeters in 5 minutes, 40 centimeters in 10 minutes. I can get a pressure of 25 centimeters easily enough in 20 minutes; but I have had the greatest difficulty in going below this figure, and could not get below 17 centimeters.

We see in the figure an independent cylinder B. I used it as a vacuum reservoir, if I may use this term, in certain experiments. Finally, the tube, which in the figure communicates with a glass bell-jar $\mathrm{C}$, is the one which I later fitted to the table with pneumatic plates represented in Figure 15.

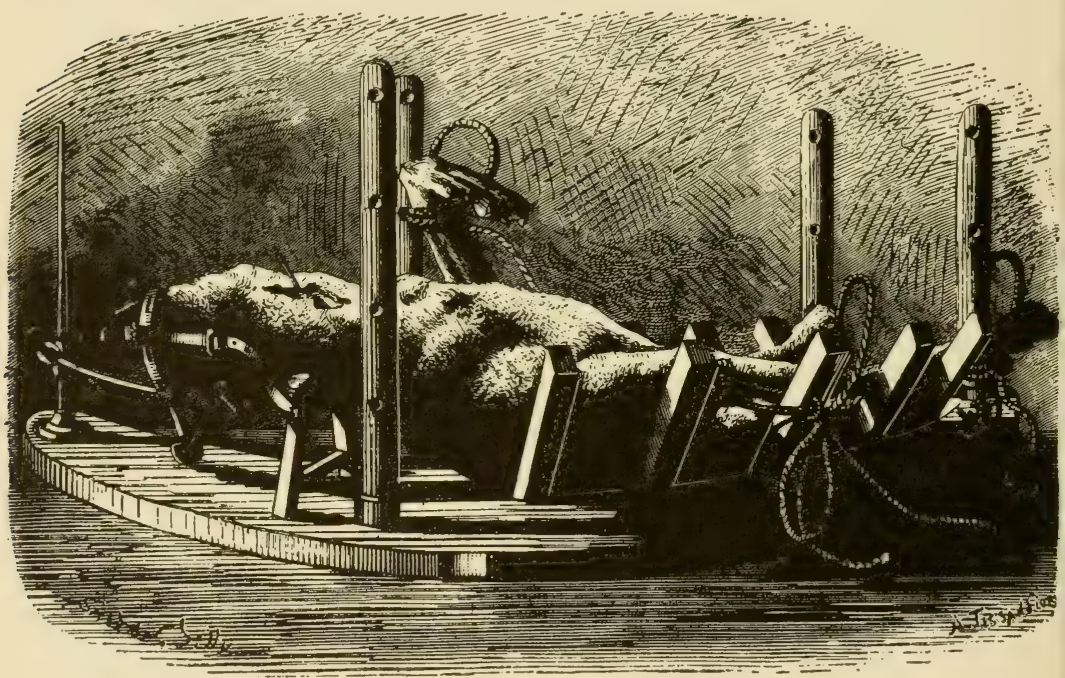

Fig. 28-Dog prepared to be placed in the cylinders of Figure 27 and to serve for the extraction of blood under diminished pressure.

The extraction of the blood of a dog placed in such an apparatus is a rather difficult enterprise.

The animal is first securely attached on its back, as shown in Figure 28, to the uprights of a sort of cage of solid wood, curved so as to conform exactly on its convex edge to the concavity of the cylinder, and capable of being fastened to it by holes which fit over the hooks of strong staples screwed to the sides of this cylinder. The head of the animal is held in a sort of movable muzzle, which allows the neck to be extended according to the require- 
ments of the experiment and to be held completely motionless. The front feet are fastened to the bars of this cage, and for the hind feet, two bars mounted in grooves in an arc can be separated more or less according to the size of the animal.

In this position one can draw blood either from one of the carotid arteries or from one of the femorals. The carotids are more convenient on account of both their size and their nearness to the wall of the cylinder, and I almost always used them.

This wall, opposite the place where the artery has been exposed, is pierced by several holes, like the head of a watering-pot; through one of these holes is passed the cannula used to extract blood; the other holes are closed by a handful of modeling wax firmly pressed over them.

And now how to extract the blood? In the artery it is subjected to a pressure equivalent to about 15 to 18 centimeters of mercury, which makes extraction very easy when the operation takes place in normal pressure. But the animal is placed in an apparatus in which the pressure is to be diminished and we are to expose the artery to the outside air. It is quite evident that when the pressure is lowered 15 to 18 centimeters, the blood will no longer have any tendency to flow from the vessel, and that when the pressure is carried still lower, the outside air will tend to rush into the animal's artery and from there to spread through the whole circulatory system.

There is the danger and there lies the difficulty. To avert the one and solve the other, I used (Fig. 29) first a cannula A forked at its free extremity, into which slipped a stylet ending in an olive. The latter was arranged so that it could exactly cover the orifice of the cannula when it was placed in the animal's artery. When I wished to extract blood, I pulled the stylet until the olive reached the fork. All this time the cavity of the cannula was completely closed, the stylet sliding tightly in a pierced rubber stopper which a head $a$ fastened closely. Then, by fitting the syringe in Figure 23 to the orifice $a$ ' by means of a rubber tube with thick walls, and by opening the cock, blood could be extracted without danger.

But in spite of all the precautions taken, I have had difficulties resulting from the entrance of a certain quantity of air. Indeed, a microscopic orifice is enough to let bubbles enter, and these, reaching the left heart and being pumped thence into the arteries, can, as you will see, cause very serious troubles. Sometimes the quantity of air admitted thus was even enough to bring on immediate death. 
I then had another cannula made, all of metal, formed of two pieces joined at $b$, of which Figure B gives a sufficient idea. I still had difficulties, and finally developed an arrangement pictured in

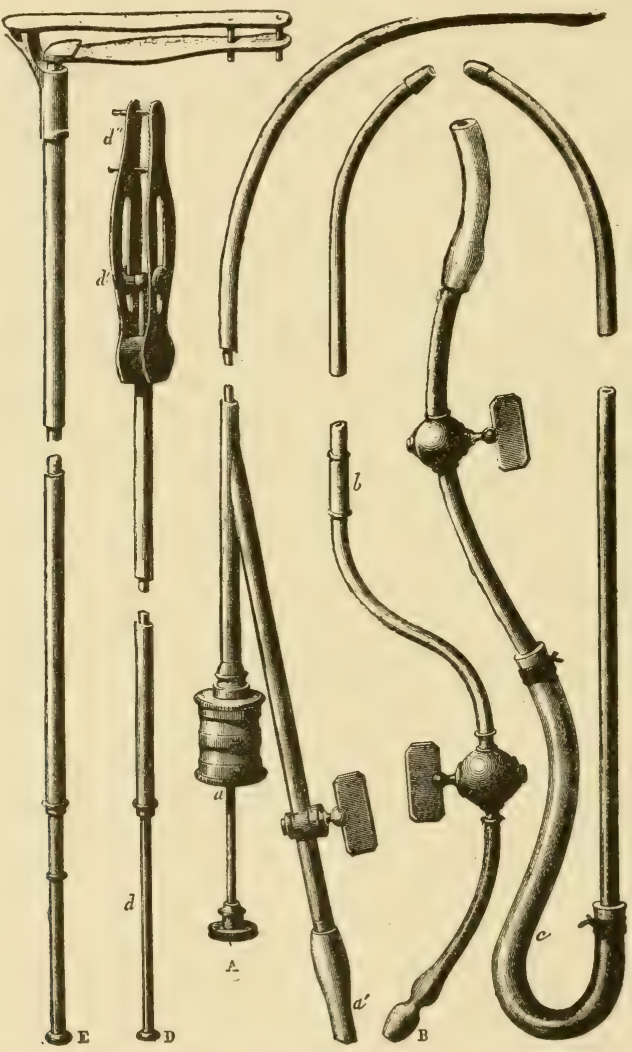

Fig. 29-Different forms of cannulae A, B, C, and of serres-fines D, E, for extracting blood under decreased pressure.

C which gave me excellent results, and which, as often happens, is the simplest of all.

The experiment is performed in the following manner: After the animal's carotid has been exposed and litigated at its upper extremity, I hook upon the walls of one of the compartments of the 
apparatus the framework which holds the dog. The operator enters the cylinder at the same time, and passes through one of the holes, with which the wall is riddled at that point like the head of a watering-pot, the serre-fine $D$, whose long handle $d$ remains out-

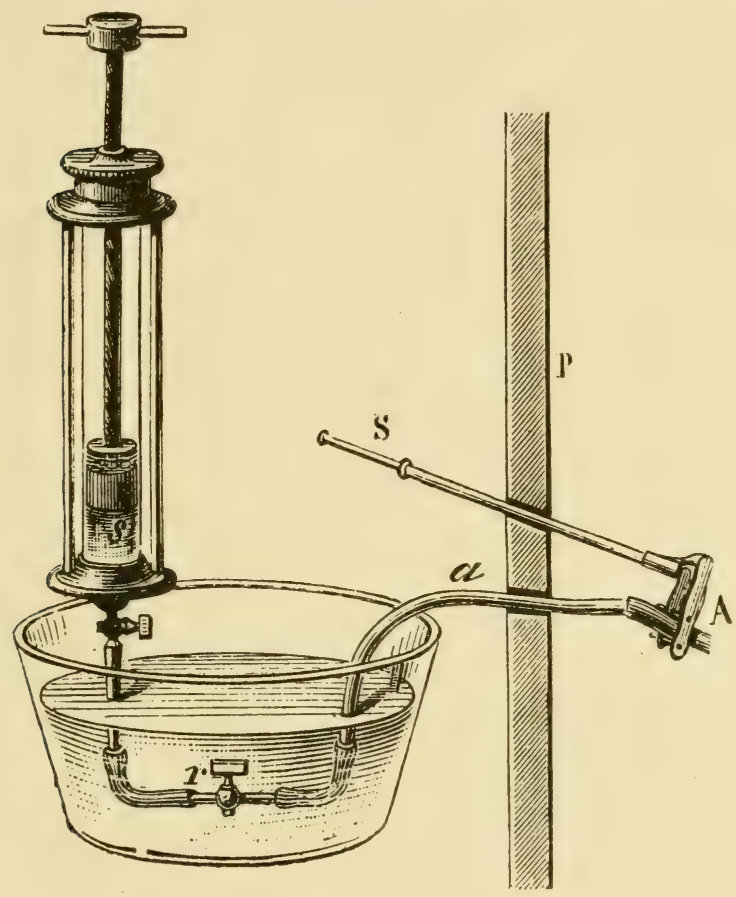

Fig. 30-Extraction of blood from an animal under decreased pressure: A artery; $\mathrm{P}$ wall of the apparatus; $\mathrm{S}$ serre-fine; $a$ cannula placed in the artery; $s$ syringe extracting the blood (its lower armature must be entirely immersed in water).

side. Then spreading apart the two jaws of the serre-fine, so as to make the little guide-rods leave their holes, he brings the carotid in to the space $d$," from which it cannot slip, thanks to the bolts; the movable lever $d$, controlled from the outside by the handle $d$, permits him to compress the artery as low as possible. He then opens the artery, and inserts in it the metal cannula, the end of 
which he passes through one of the holes in the wall. Next the rubber tubing and the cock are fastened on.

The cylinders having been closed and the decompression reached, when one wishes to draw blood, he arranges things as shown in Figure 30. The serre-fine is opened, the syringe whose piston is covered by a layer of water is applied, and suction is made. Since all the connections are immersed in water, no accidents can happen.

But after the extraction, there remains in the cannula a long clot which generally prevents a new extraction. It was to avoid this difficulty that I devised the stylet of the cannula A, which drove blood back into the animal; only, as I said, I could not be sure of complete closing. I must add that when the extractions were not too far apart, I could sometimes suck out by the syringe the clot which was still diffluent. At other times, immediately after drawing blood, I injected into the cannula a little sodium carbonate solution, to prevent coagulation.

I drew out thus, as I said, each time, from 30 to $40 \mathrm{cc}$. of blood. I waited until the decompression had been maintained for several minutes before making the extraction. The blood at normal pressure was sometimes taken in advance; but the tendency towards coagulation, which resulted from this practice, caused me usually to take it afterwards. I then took care to wait rather a long time. The account of experiments carried on thus will indicate these details.

\section{Experiments.}

Experiment CLXIII. June 22. Pressure $76.4 \mathrm{~cm}$; temperature 23' . Large dog, which had been operated on several times the day before: does not seem sick.

Drew from the femoral artery $46 \mathrm{cc}$. of blood, at normal pressure; blood quite red ..... A

Placed in the large apparatus; brought down $45 \mathrm{~cm}$., in a half hour; real pressure $31.4 \mathrm{~cm}$; after 10 minutes, drew from the carotid $46.5 \mathrm{cc}$. of blood; blood considerably less red .... B

Blood A (76.4 cm.) contains per 100 volumes: O $18.8 ; \mathrm{CO}=39.7$.

Blood B (31.4 cm.) contains per 100 volumes: $\mathrm{O}=12.0 ; \mathrm{CO}=31.0$.

Therefore at a pressure of $31.4 \mathrm{~cm}$, there has disappeared 36.2 per cent of the oxygen existing at normal pressure, and 21.9 per cent of the carbonic acid.

Experiment CLXIV. June 24. Pressure $76 \mathrm{~cm}$., temperature $21^{\circ}$. Large dog.

Normal pressure: drew from the femoral artery $46 \mathrm{cc}$. of blood, very red ..... A

Pressure lowered $54 \mathrm{~cm}$, in about three quarters of an hour (real 
pressure $22 \mathrm{~cm}$.). Drew from the same artery $40 \mathrm{cc}$. of blood, very dark .... B

Blood A (76 cm.) contains per 100 volumes: $\mathrm{O}_{2} 21.5 ; \mathrm{CO}_{2} 41.9$.

Blood B (22 cm.) contains per 100 volumes: $\mathrm{O}_{2} 10.7 ; \mathrm{CO}_{2} 22.0$.

50 per cent of the oxygen has disappeared and 47.5 per cent of the original carbonic acid.

Experiment CLXV. June 28. Pressure $76 \mathrm{~cm}$; temperature $21.8^{\circ}$. Dog of the preceding experiment, quite recovered, vigorous.

While ligating the left carotid in preparation, the femoral ligated three days before opens, and blood issues; the animal thus loses about 50 cc. of blood.

Then put into the apparatus, pressure is lowered $19 \mathrm{~cm}$. in 5 minutes (real pressure $57 \mathrm{~cm}$.) ; left there for a half hour. Then 42.3 cc. of blood drawn from the left carotid, not very red .... A

The animal, brought back to normal pressure, breathes quietly for an hour. Then $42.3 \mathrm{cc}$. of blood drawn from the same carotid; evidently redder.... B

Blood A (57 cm.) contains per 100 volumes: $\mathrm{O}=18.6$; $\mathrm{CO}=35.4$.

Blood B $(76 \mathrm{~cm}$.) contains per 100 volumes: $\mathrm{O}=21.6$; $\mathrm{CO}=36.3$.

Experiment CLXVI. July 4. Pressure $76 \mathrm{~cm}$; temperature $22^{\circ}$. Female dog of moderate size.

At 3 o'clock, 45.3 cc. of blood, not very red, drawn from a femoral .... A

Animal put into apparatus; howls and is very uneasy; pressure lowered $52 \mathrm{~cm}$; then $47 \mathrm{~cm}$; then $50 \mathrm{~cm}$; all in about a quarter of an hour. The real pressure is $26 \mathrm{~cm}$. $43.1 \mathrm{cc}$. of very dark blood then drawn from the same artery .... B

Blood A (76 cm.) contains per 100 volumes: $\mathrm{O}=18.3 ; \mathrm{CO}=32.8$.

Blood B (26 cm.) contains per 100 volumes: O= 9.8; $\mathrm{CO}=24.5$.

Experiment CLXVII. July 6. Pressure $76 \mathrm{~cm}$; temperature $24.5^{\circ}$. Dog of the preceding experiment, in good condition.

Put into the large apparatus; in a quarter of an hour brought to $44 \mathrm{~cm}$. of actual pressure; very uneasy; kept at this pressure for 20 minutes, and then $32.6 \mathrm{cc}$. of rather dark blood drawn from the left carotid .... A

The animal having been brought back to normal pressure, which took about 5 minutes, $42.3 \mathrm{cc}$. of blood, evidently redder, were drawn from the left carotid immediately .... B

Blood A (44 cm.) contains per 100 volumes: $\mathrm{O}_{2} 16.3 ; \mathrm{CO}_{2} 23.3$.

Blood B (76 cm.) contains per 100 volumes: $\mathrm{O}_{2} 19.8 ; \mathrm{CO}_{2} 29.1$.

Experiment CLXVIII. July 8. Pressure $75.9 \mathrm{~cm}$; temperature $25^{\circ}$. Very large dog.

Put into the apparatus; has a new cannula of Model A (Fig. 29) in the left carotid. Pressure lowered $20 \mathrm{~cm}$. in a quarter of an hour, and left there a quarter of an hour. $39 \mathrm{cc}$. of blood then drawn with difficulty .... A

Pressure lowered $30 \mathrm{~cm}$., and an attempt is made to extract blood; but it is impossible, the cannula is twisted. 
Brought back to normal pressure, the dog continues to howl and breathe very quickly and very noisily, as it has done since blood A was extracted. $48 \mathrm{cc}$. of very red blood then extracted .... B B

The animal when untied, cannot walk; it is not paralyzed in any limb, and yet cannot stand up on all-fours.

Next day, same condition, except that the respiration is easy.

It dies at the end of several days, having remained drowsy and unable to walk. In the autopsy a gray cerebral softening is found. Evidently bubbles had entered the circulatory system, some of which penetrated the nervous centers and cut off the circulation.

Blood A $\left(56 \mathrm{~cm}\right.$.) contains per 100 volumes: $\mathrm{O}_{2} 20.9$; $\mathrm{CO}=35.3$

Blood B $\left(76 \mathrm{~cm}\right.$.) contains per 100 volumes: $\mathrm{O}_{2} 26.4 ; \mathrm{CO}_{2} 22.7$

I shall not include in the general discussion of the experiments the preceding curious result; but I thought I should not omit it. I call the reader's attention to the localized cerebral softening due to the penetration of the air.

Experiment CLXIX. April 30. Pressure $77 \mathrm{~cm}$.; temperature $16^{\circ}$. Dog weighing $11.5 \mathrm{k}$.

At $4: 25$, put into the apparatus, and brought in 10 minutes to 36 $\mathrm{cm}$. of actual pressure. At $4: 45,46 \mathrm{cc}$. of very dark blood drawn from the right carotid .... A

5 o'clock. Returned to normal pressure; at 5:05, $46 \mathrm{cc}$. of very red blood drawn .... B

Blood A $\left(36 \mathrm{~cm}\right.$.) contains per 100 volumes: $\mathrm{O}=11.9 ; \mathrm{CO}_{2} 25.2$

Blood B $\left(77 \mathrm{~cm}\right.$.) contains per 100 volumes: $\mathrm{O}_{2} 20.6 ; \mathrm{CO}_{2} 39.0$.

Experiment CLXX. May 1. Pressure $76 \mathrm{~cm}$; temperature $16^{\circ}$. Dog of preceding experiment, quite recovered.

$4: 15$. 41 cc. drawn from left carotid; respiratory rate $60 \ldots$ A

$4: 30$. Put into the large receiver; at $4: 45$, pressure lowered $33 \mathrm{~cm}$., air admitted to $30 \mathrm{~cm}$. (pressure $46 \mathrm{~cm}$.). At 4:45, $38 \mathrm{cc}$. of blood drawn ..... B

Brought to $56 \mathrm{~cm}$. of actual pressure; at 5:15, respiratory rate 100 ; 41 cc. of blood drawn .... C

Brought slowly to normal pressure; at $6: 20$, respiratory rate 60 ; 41 cc. of blood drawn .... D

Blood A $(76 \mathrm{~cm}$.) contains per 100 volumes: $\mathrm{O}=21.9 ; \mathrm{CO}=34.7$.

Blood B $(46 \mathrm{~cm}$.) contains per 100 volumes: $\mathrm{O}=20.3$; $\mathrm{CO}=30.5$.

Blood C $(56 \mathrm{~cm}$.) contains per 100 volumes: $\mathrm{O}=21.1 ; \mathrm{CO}=34.7$.

Blood D $\left(76 \mathrm{~cm}\right.$.) contains per 100 volumes: $\mathrm{O}_{2} 21.1$; $\mathrm{CO}_{2} 35.2$.

The average between $\mathrm{A}$ and $\mathrm{D}$ is: $\mathrm{O}=21.5 ; \mathrm{CO}_{2} 34.9$.

Experiment CLXXI. May 3. Pressure $76 \mathrm{~cm}$. Young dog, very lively, weighing $4 \mathrm{k}$. Right carotid.

4:32. Put into the receiver; at $4: 45$, lowered $45 \mathrm{~cm}$., respiratory rate 24 , divided into periods of 3 or 4 medium and 1 very deep; then rest.

4:58. The decompression has varied between $44 \mathrm{~cm}$. and $47 \mathrm{~cm}$.; at present it is $45 \mathrm{~cm} . ; 31 \mathrm{~cm}$. of actual pressure. $41 \mathrm{cc}$. of blood drawn, darker than ordinary venous blood ..... A 
Brought slowly to normal pressure.

At $5: 07$, at $25 \mathrm{~cm} ; 16$ respirations of the same type. At 5:13, normal pressure; $41 \mathrm{cc}$. of blood drawn, lost; at $6: 20,16$ respirations, same type; $41 \mathrm{cc}$. of blood of ordinary color drawn . . . . B

Blood A (31 cm.) contains per 100 volumes: $\mathrm{O}_{2} 13.6 ; \mathrm{CO}_{2} 36.5$

Blood B $\left(76 \mathrm{~cm}\right.$.) contains per 100 volumes: $\mathrm{O}_{2} 19.4 ; \mathrm{CO}_{2} 48.4$

Experiment CLXXII. May 7; pressure $75 \mathrm{~cm}$; temperature $18^{\circ}$. Female dog weighing $11 \mathrm{k}$.

$3: 12$. Put into receiver; at $3: 25$ lowered $40 \mathrm{~cm}$.

$3: 45$, a decrease of $39 \mathrm{~cm}$. (36 cm. of actual pressure); 21 to 24 respirations; $41 \mathrm{cc}$. of very dark blood drawn .... A

$3: 50$. Brought to $46 \mathrm{~cm}$. pressure and maintained there. At 4:05, 41 cc. of blood, not so dark, drawn; 18 to 21 respirations . . . . B

Brought to normal pressure, at $4: 15$; at $4: 35,30$ respirations; at 5 o'clock, $41 \mathrm{cc}$. of not very red blood drawn ..... C

This dog, before blood was drawn, and after she was untied, developed strange tonic and clonic convulsions, with corneal lack of sensitivity and howls; the second attack was very severe, lasted 15 minutes at least, and was followed by a state of stupor, with little plaintive cries; hysteria? epilepsy?

Blood A (36 cm.) contains per 100 volumes: $\mathrm{O}=8.9 ; \mathrm{CO}=34.3$.

Blood $\mathrm{B}(46 \mathrm{~cm}$.) contains per 100 volumes: $\mathrm{O}=13.2 ; \mathrm{CO}=40.7$

Blood C (76 cm.) contains per 100 volumes: $\mathrm{O}_{2} 20.1 ; \mathrm{CO}_{2} 41.1$

Experiment CLXXIII. May 8. Pressure $75.5 \mathrm{~cm}$; temperature $17^{\circ}$. Little dog, weighing $5 \mathrm{k}$.

At 4 o'clock, $33 \mathrm{cc}$. of very red blood drawn from the right carotid $\ldots$ A

At $4: 28$, put into the receiver. At $4: 35$, pressure dropped $34 \mathrm{~cm}$; 13 respirations, deep; at 4:50, pressure dropped $50 \mathrm{~cm}$.; 20 respirations, shallower. At 5:05, pressure still at a diminution of $50 \mathrm{~cm}$; 18 respirations; $35 \mathrm{cc}$. of very dark blood drawn . . . . B

Blood A $(75.5 \mathrm{~cm}$.) contains per 100 volumes: $\mathrm{O}=22.6$; $\mathrm{CO}=39.7$.

Blood B (25.5 cm.) contains per 100 volumes: $\mathrm{O}=9.8 ; \mathrm{CO}=23.1$

Experiment CLXXIV. May 9. Pressure $75.5 \mathrm{~cm}$.; temperature 16.5 $5^{\circ}$ Dog of Experiment CLXXI, still somewhat sick. Left carotid. At $3: 30$, drew $27.5 \mathrm{cc}$. of blood .... A

At 3:50, put into receiver; at 4:03, the pressure is at $36 \mathrm{~cm}$; at $4: 18$, the same; 33 respirations, medium. Drew $41 \mathrm{cc}$. of very dark blood .... B

Blood A (75.5 cm.) contains per 100 volumes: $\mathrm{O}_{2}$ 13.3; $\mathrm{CO}_{2} 34.9$.

Blood $\mathrm{B}\left(36 \mathrm{~cm}\right.$.) contains per 100 volumes: $\mathrm{O}=8.5 ; \mathrm{CO}_{2} 21.4$.

Experiment CLXXV. May 15. Pressure $76 \mathrm{~cm}$; temperature $17^{\circ}$. Fat and strong female dog, which had eaten at noon.

At $3: 10$, drew $34.5 \mathrm{cc}$. of blood from the right carotid; animal quiet .... A

At $3: 20$, put into the apparatus, howls, is uneasy; at $3: 25$, pressure is $56 \mathrm{~cm}$. At $3: 35$, pressure maintained; drew $34.5 \mathrm{cc}$. of blood, animal quiet, 30 respirations; but has been very uneasy .... B 
At $3: 40$, pressure lowered $30 \mathrm{~cm}$; at $3: 55$, the same; drew 34.5 cc. of blood; animal quiet, but had been uneasy . . . . C

At 4 o'clock, pressure lowered $40 \mathrm{~cm}$; animal in the same condition; drew $34.5 \mathrm{cc}$. of dark blood .... D

Blood A $\left(76 \mathrm{~cm}\right.$.) contains per 100 volumes: $\mathrm{O}: 17.4 ; \mathrm{CO}_{2} 33.8$

Blood B (56 cm.) contains per 100 volumes: $\mathrm{O}_{2} 15.5 ; \mathrm{CO}_{2} 28.0$

Blood C (46 cm.) contains per 100 volumes: $O=12.5 ; C O=26.4$

Blood D (36 cm.) contains per 100 volumes: $\mathrm{O}_{2} 10.8 ; \mathrm{CO}_{2} 22.8$

Experiment CLXXVI. May 22. Pressure $76 \mathrm{~cm}$. Medium-sized dog, which had eaten at noon. Right carotid.

At normal pressure, 13 respirations.

3:35. Put into apparatus.

4:05, pressure lowered $40 \mathrm{~cm}$., maintained.

$4: 07,15$ respirations, somewhat irregular.

$4: 25$, the same; drew $33.3 \mathrm{cc}$. of blood, very dark . . . A

4:33, air admitted; pressure lowered $20 \mathrm{~cm}$.

$4: 50$, drew $33.3 \mathrm{cc}$. of blood, redder than A . . . B

4:55, normal pressure.

$5: 25$, drew 33.3 cc. of blood, quite red . . . . C

Blood A $(36 \mathrm{~cm}$.) contains per 100 volumes: $\mathrm{O}=9.6 ; \mathrm{CO}=33.9$

Blood B (56 cm.) contains per 100 volumes: $\mathrm{O}=12.4$; $\mathrm{CO}=35.0$

Blood C (76 cm.) contains per 100 volumes: $\mathrm{O}_{2} 16.9 ; \mathrm{CO}_{2} 45.7$

Experiment CLXXVII. June 21. Female dog of average size, never having been used before. Cannula in the right carotid artery.

4:15, decompression begun.

4: 45 , decompression of $54 \mathrm{~cm}$; great uneasiness from the beginning.

$5: 15 ; 56.5 \mathrm{~cm}$; 120 respirations.

$5: 30 ; 57.5 \mathrm{~cm}$; I draw $50 \mathrm{cc}$. of blood, very dark . . . . A

Air admitted until the decompression is only $36 \mathrm{~cm}$., then the decompression is resumed.

6: 08, pressure down $50 \mathrm{~cm}$.; I draw $35 \mathrm{cc}$. of blood, very dark. . B

$6: 20,56 \mathrm{~cm}$; $40 \mathrm{cc}$. of blood, also very dark . . . C

$6: 20$, air admitted; normal pressure restored at $6: 55$.

7:10, drew 57 cc. of blood, quite red .... D

Blood A $(19 \mathrm{~cm}$.) contains per 100 volumes: $\mathrm{O}: 4.9$

Blood B $(26 \mathrm{~cm}$.) contains per 100 volumes: $\mathrm{O}=6.5$

Blood C $\left(21 \mathrm{~cm}\right.$.) contains per 100 volumes: $\mathrm{O}_{2} 4.5$

Blood D (76 cm.) contains per 100 volumes: $\mathrm{O}=14.8$; $\mathrm{CO}=22.1$

Experiment CLXXVIII. July 3. Dog which has never been used, weighing $11 \mathrm{k}$.

$2: 30$, I draw from the right carotid $35 \mathrm{cc}$. of blood moderately red; the animal howls and struggles .... A

2: 40 , decompression begins.

3 o'clock, decompression of $55 \mathrm{~cm}$.

$3: 11$, decompression of $57 \mathrm{~cm}$; drew $35 \mathrm{cc}$. of blood, very dark . . B Admitted air.

Blood A (76.5 cm.) contains per 100 volumes: 19.2 of oxygen.

Blood B (19.5 cm.) contains per 100 volumes: 4.2 of oxygen. 
Experiment CLXXIX. July 5. $76.5 \mathrm{~cm}$. Dog weighing $10 \mathrm{k}$.

Drew from the right carotid $35 \mathrm{cc}$. of very red blood; 38 respirations, with little howls .... A

$3: 25$, put into the apparatus.

$3: 45$, pressure $30.5 \mathrm{~cm}$., struggles, howls. At 3:55, pressure 24.5; the gas machine stops.

4:05, pressure $38 \mathrm{~cm}$; machine started again; 26 respirations, quiet.

$4: 12,26.5 \mathrm{~cm}$; 60 respirations, interrupted by hiccoughs; at $4: 26$,

$19.5 \mathrm{~cm}$; 74 respirations, also with hiccoughs.

4:30, pressure $18 \mathrm{~cm}$; drew $35 \mathrm{cc}$. of very dark blood ... B

4: 42 , pressure $17 \mathrm{~cm}$.; 80 respirations; drew $35 \mathrm{cc}$. of very dark blood .... C

Opened the cock; at $4: 55$, the pressure had risen to $26 \mathrm{~cm}$; it was maintained there, and at $5: 10,35 \mathrm{cc}$. of dark blood drawn ... D

$5: 13$, returned to normal pressure.

$6: 00$, took $35 \mathrm{cc}$. of blood, very red... E

Blood A (76 cm.) contains per 100 volumes: $\mathrm{O}_{2} 20.8 ; \mathrm{CO}_{2} 46.1$

Blood B $\left(18 \mathrm{~cm}\right.$.) contains per 100 volumes: $\mathrm{O}=7.6 ; \mathrm{CO}_{2} 12.9$

Blood C (17 cm.) contains per 100 volumes: $\mathrm{O}=7.1 ; \mathrm{CO}_{2} 11.9$

Blood D $(26 \mathrm{~cm}$.) contains per 100 volumes: $\mathrm{O}=9.2 ; \mathrm{CO}=13.7$

Blood E (76 cm.) contains per 100 volumes: $\mathrm{O}_{2} 20.8$; $\mathrm{CO}_{2} 40.5$

When, after having followed the preceding experiments, we examine Table $\mathrm{X}$, which summarizes them and in which they are arranged in the order of decompression, one of the first facts to attract our attention is the remarkable variation presented by the figures in Columns 3 and 4, which express the quantities of oxygen and carbonic acid gas contained at normal pressure in $100 \mathrm{cc}$. of blood. The variations for oxygen (setting aside Experiment CLXXIV for reasons which I shall specify shortly) were from 16.9 to 22.6; those of carbonic acid, from 29.1 to 48.4. I should note that there is no proportion, either direct or inverse, between the increases or diminutions of these two gases, so that the variations of the total (Col. 5), which were from 48.2 to 67.8 , are not the expression of any distinct law.

The explanation of these variations cannot be found in the details of the experiments. All my dogs were in good health, fed on the same diet and at the same length of time before the experiment; I took care, as I said, to draw blood from them during a quiet period: they were, in short, as similar as possible. I am therefore led to believe that these results agree with the true state of things and that there are important differences between individuals in the oxygen content of the arterial blood, although all circumstances are similar. Furthermore, these variations are quite as apparent in the tables of analyses published by other authors; it would be a real delusion to get rid of them by getting some sort of an average. 


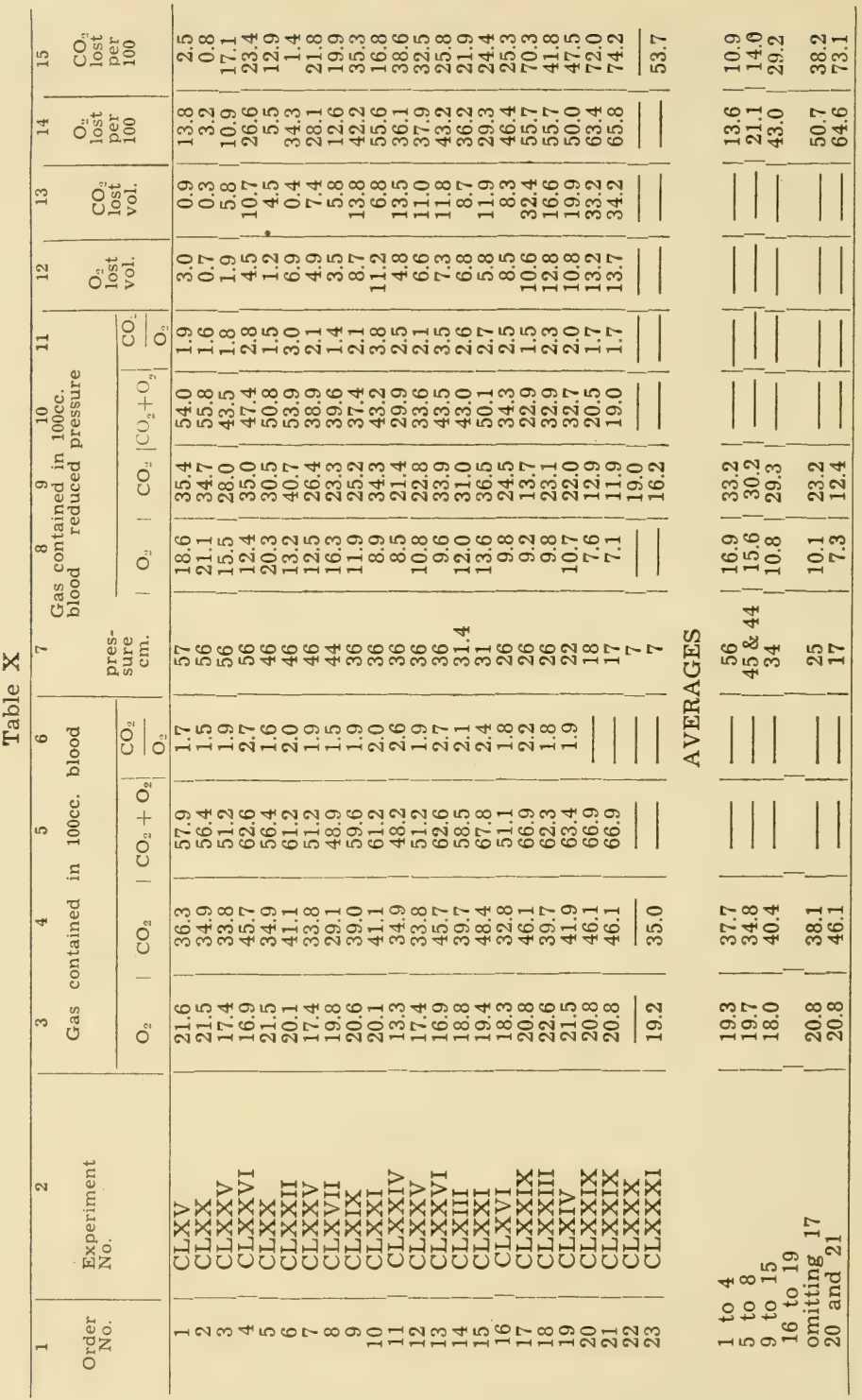


In my experiments, just one of the differences observed is explained by the state of the animal, in Experiment CLXXIV. Here we were handling a small dog $(4 \mathrm{k}$.), from which five days before I had drawn 110 cc. of arterial blood, that is, about half of the amount the loss of which would have killed it immediately, and which had remained sick and without appetite ever since. In the first experiment, its blood had given 19.4 per cent of oxygen and 48.4 of carbonic acid; in the second, there was only 13.3 of oxygen and 34.9 of carbonic acid: the two gases had therefore diminished considerably.

The variations of the carbonic acid are, as I said a while ago, considerably more extensive than those of the oxygen, but are no easier to explain: there is involved a collection of problems analogous to those which we (MM. Mathieu and Urbain and I) have already studied, and which would require very numerous experiments.

And now having come to the point which should interest us especially, a glance at the figures in Columns 8 and 9 of Table X, compared to the corresponding figures of Columns 3 and 4, show us that in all cases, under diminished pressure, the oxygen and the carbonic acid have diminished in the arterial blood. There was no exception to this general rule.

This is expressed very clearly in Figure 31 by the graphs composed of dashes connecting the little circles $\mathrm{O}-\mathrm{O}-\mathrm{O}-$. In this graph, the quantities of gas are measured on the axis of the y's and the pressures on that of the x's; the points on it have been determined by the following procedure.

I took the figures which express the averages and which are placed at the bottom of Table X. I assumed that the initial value, at normal pressure, of the oxygen (Col. 3) was always 20 , and that that of the carbonic acid (Col. 4) was always 40. Then the values at different pressures (Cols. 8 and 9) were modified by operations like the following:

Average of the experiments from 1 to 4

$\mathrm{O}_{2} 19.3$ (col. 3 ) : $20=16.9(\operatorname{col} .8): \mathrm{x}=17.5$

$\mathrm{CO}_{2} 37.7$ (col. 4 ) : $40=33.2$ (col. 9$): \mathrm{x}=35.2$

Similarly, at each pressure, I made the same calculation, not for the averages, but for the extreme values of the modifications, and obtained thus the points marked by the little isolated circles which accompany the two curves representing the averages.

The same data are expressed under a different form, perhaps more simple, by Columns 12,13,14 and 15. Columns 12 and 13 
indicate the absolute quantity of the gases which have disappeared. Columns 14 and 15, more instructive, express the proportion which has disappeared and not the absolute quantity. They were obtained by operations like the following:

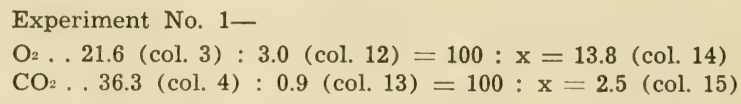

Examining first Column 8, we see that the quantity of oxygen

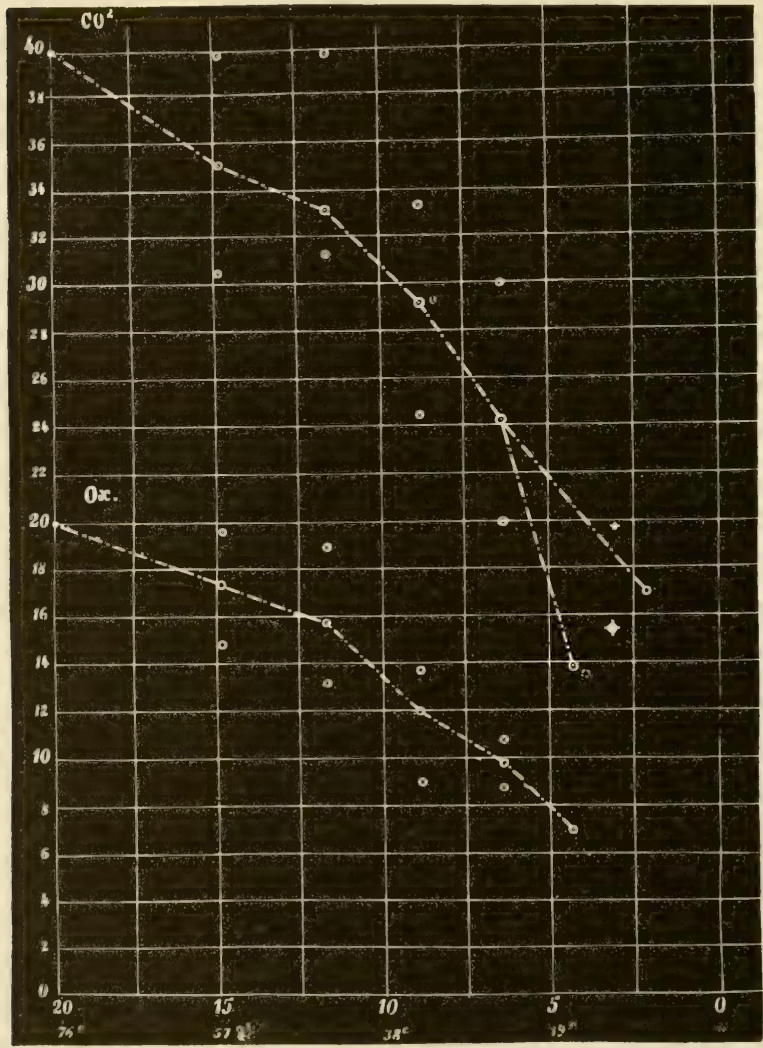

Fig. 31 - Decrease in amount of $\mathrm{O}$ and $\mathrm{CO}^{2}$ in the arterial blood, when the barometric pressure is diminished. 
contained in the arterial blood could, at pressures of 30 or $40 \mathrm{~cm}$., drop to $9 \mathrm{cc}$. per $100 \mathrm{cc}$. of blood; that is, at these pressures the arterial blood contained considerably less oxygen than ordinary venous blood.

The diminution of the carbonic acid was likewise (Col. 9) very considerable; the figures expressing the proportion of this gas have, in fact, dropped almost to $20 \mathrm{cc}$. per $100 \mathrm{cc}$. of blood. We shall refer later to the conclusions derived from these data.

In comparing the experiments made at the same degree of decompression, we find that the decreases in oxygen and in carbonic acid have varied peculiarly. The lowest figures of Columns 8 and 9 are not at the end, but towards the middle of the table. The results of this fact are still more evident in Columns 14 and 15; there, for example, at a pressure of $36 \mathrm{~cm}$., that is, about a half atmosphere, the arterial blood has lost, in the different experiments, from 36.1 to 55.6 per cent of its oxygen, and from 16.8 to 38.6 of its carbonic acid.

It is difficult to explain these differences by the different behavior of the animals observed while the pressure was being lowered. This element may be important; but it cannot be the only one, and very probably animals with the same behavior may differ in the result for the same decompression, some losing more and others less oxygen or carbonic acid. This has interesting practical results which I shall stress in their place.

Laying aside these individual differences, still more difficult to study here than in the case of normal pressure, and blending them in averages, we see (Col. 14) that on the average, the arterial blood at a pressure of $56 \mathrm{~cm}$. contains 13.6 per cent less oxygen than at normal pressure; that at $46 \mathrm{~cm}$., it contains 21.1 per cent less; at $36 \mathrm{~cm}$., 43 per cent, and at $26 \mathrm{~cm}$., 50.7 per cent. So at $26 \mathrm{~cm}$., on the average, half of the oxygen of the blood has disappeared. These figures show that the diminution of this gas is far from following Dalton's Law, which would give, for the same decompressions, losses of $26.3 ; 39.4 ; 52.6 ; 65.8$ per cent.

-The losses of carbonic acid (Col. 15) for the same decompressions, on the average, are $10.9 ; 14.0 ; 29.2 ; 38.2$ per cent of the gas existing at normal pressure; that is evidently still farther from Dalton's Law.

These figures even show that the average loss of carbonic acid is less than that of oxygen. The greatest proportion of loss, for the former gas (Col. 15) was 41.8 per cent; for the second, we twice had (Col. 14) 55.6. In one case, (Exp. CLXXII), at a pressure of 
$46 \mathrm{~cm}$., the quantity of carbonic acid had remained almost the same as at normal pressure. These results are expressed in another form in Columns 6 and 11, indicating the proportion of carbonic acid and oxygen under different pressures. We see that at normal pressure this proportion varied from 1.5 to 2.7 , with an average of 1.9 , whereas at low pressures it varied from 1.5 to 3.8 , with an average of 2.3. In almost all cases, the figure of Column 11 is higher than the corresponding figure in Column 6, whether the latter is high or low: the exceptions (Exp. CLXXV, CLXX, CLXVII, CLXXIV) are cases in which the blood at normal pressure contained small quantities of carbonic acid, varying from 29.1 to $35 \mathrm{cc}$.

These data can be expressed in a more precise manner by the following formula:

The combination of oxygen with the hemoglobin is likely to be partially destroyed, to be dissociated, at low pressures; this dissociation becomes evident at a decrease of $20 \mathrm{~cm}$. (pressure of $56 \mathrm{~cm}$.). It increases as the decompression goes lower. At intervals of $10 \mathrm{~cm}$., we find the averages: from 56 to $46 \mathrm{~cm}$., a loss of 7.5 per cent; from 46 to $36 \mathrm{~cm}$., a loss of 21.9 per cent; from 36 to $26 \mathrm{~cm}$., a loss of 7.7 per cent. The greatest loss then comes at about a half atmosphere.

The graph Ox of Figure 32 shows at the first glance the course of this gradual loss of oxygen; on the horizontal axis are counted the pressures, and on the vertical axis the percentages of the gases which have disappeared (Cols. 14 and 15 of Table X).

As to the carbonic acid, it behaves in about the same way; only its diminution is always less than that of the oxygen; this is easily seen on the graph $\mathrm{CO}_{2}$.

The graph shows again that the decrease in gases does not follow Dalton's Law (which would be represented by a line bisecting the angle of the coordinates). The carbonic acid is farthest from it. Yet I must say that the deviation is not very great for either gas.

That is very remarkable if we refer to current opinions about the state of gases in the blood, according to the researches of M. Fernet, classic today. First, the oxygen, chemically united to the hemoglobin, could not be changed as to its proportion by decreased pressure (or increased); now what happens is quite different, since the decrease in oxygen is very evident and is quite near the requirement of the law governing simple solutions.

The difficulty appears under an inverse aspect when we con- 
sider the carbonic acid. The experiments of M. Fernet have inspired the belief that most of the carbonic acid of the blood (0.964) is in the state of simple solution in the liquid, and that a relatively small proportion (0.597) is alone in the state of combination. Now what we have just said makes this interpretation of $M$. Fernet's experiments rather improbable. If the larger part of the

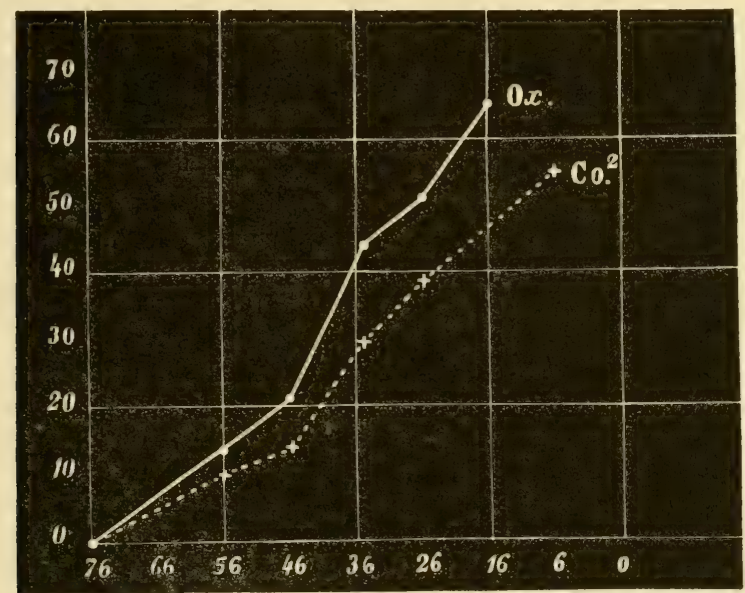

Fig. 32-Percentage decrease of $\mathrm{O}$ and of $\mathrm{CO}^{2}$ in the arterial blood when the barometric pressure is diminished.

carbonic acid was dissolved, the escape of the carbonic acid would take place more easily and more regularly under the influence of the decompression, and the graph $\mathrm{CO}_{2}$ would be closer to the bisecting line. Besides, we shall find in another part of this work other reasons for thinking that the carbonic acid of the arterial blood is, in the greater proportion, combined with carbonates and phosphates, and that only a very small part exists in a state of solution. However, these combinations are easily dissociated under the influence of a decrease in pressure.

These contradictions to the conclusions of M. Fernet do not imply any criticism of his important work. For we must note that the experiments of this physicist were made in vitro, and at a low temperature, whereas mine had as instrumental apparatus the living animal itself. The presence of tissues, the continual consumption of oxygen, the multiplicity of surfaces of contact with 
the blood and the air, the circulatory movements, the probable formation during the absorption of oxygen of substances capable of acting on the elimination of the carbonic acid, the increased temperature of the living body, are conditions which existed in one case and not in the other. Without mentioning the still entirely unknown elements of the complex problem of respiration, we have enough to give us an understanding rather than an explanation of the differences in our results.

Furthermore, I wished myself to make experiments in vitro, in which I should make changes in pressure much greater than those obtained by M. Fernet. The report of these experiments will form subchapter $\mathrm{V}$ of the present chapter.

The reader may have noticed that I studied the composition of the blood gases beginning with $56 \mathrm{~cm}$. Between $56 \mathrm{~cm}$. and $76 \mathrm{~cm}$., I thought I should not take account of any of my experiments. Here the value of the modifications found is precisely of the order of the errors of analysis. To draw any conclusions, one would have to make a considerable number of experiments and draw an average which would express the direction if not the real value of the modification. Now this direction seems to me sufficiently determined by what we know already. The decrease of the oxygen and the carbonic acid of the blood, evident and constant at $56 \mathrm{~cm}$., although very variable as to its value, surely begins considerably sooner, but at barometric levels and with an intensity which must vary from one animal to another, or in the same animal under different circumstances.

On the other hand, all the experiments show that the oxygen is always given off in greater proportion than the carbonic acid. That should be enough to make us think that this rule extends to the period included in the first 20 centimeters of lowered pressure, a period which has this special importance of being the one to whose influence the majority of dwellers in high places are subjected.

If our table of experiments shows that we did not begin at the outset of the decompression, it also shows that we did not go to the end, that is, until the diminution of pressure becomes incompatible with animal life. That was because my apparatuses did not permit me to do so, since leaks which could not be avoided in such huge receivers stopped the decrease of pressure at $17 \mathrm{~cm}$., as I have said.

I tried to fill this gap by an indirect means. I put a dog under the large glass bell-jar, and let it die there from decreased pressure. 
Then, taking it out as quickly as possible, I drew blood from its left heart by means of a cannula.

Here are two experiments carried out in this way.

Experiment CLXXX. May 15. Dog weighing $5 \mathrm{k}$.; bell-jar of 31 liters. Left carotid exposed in advance.

5:40, put under the bell-jar, and the decrease of pressure begun, maintaining a current of air.

$5: 47$, pressure $45 \mathrm{~cm}$; w was struggling, but now remains quiet.

5: $50,45 \mathrm{~cm}$.; 17 respirations, deep; remains motionless; trembles.

5:53, $35 \mathrm{~cm}$.; 17 respirations; motionless, head lowered; at 5:55, 12 respirations.

5:58, pressure $25 \mathrm{~cm}$; ; at 6 o'clock, 22 respirations; motionless.

$6: 05,16$ respirations; pressure brought to $15 \mathrm{~cm}$., at $6: 07$, can no longer remain half crouching, as it has done till now; lies down, its nose resting on the floor to support its head; takes 28 enormous respirations per minute. Pressure maintained at $15 \mathrm{~cm}$.

$6: 10,39$ respirations less ample.

$6: 13,35 \mathrm{~cm}$.; at $6: 15,44$ respirations; evacuation of fecal matter without apparent effort; at $6: 19,40$ respirations.

$6: 20$, I close the intake valve; the pressure drops at once to $7 \mathrm{~cm}$. The dog rises on all fours, stiffens violently, but with slow regularity, ceases to breathe, and sinks down dead.

I admit air: the animal's sides collapse. When taken out, it takes two or three little inspirations while the cannula is being inserted into the left heart. The heart is still beating a little; with much difficulty $32 \mathrm{cc}$. of very dark blood is drawn.

The lungs are red in wide patches, sinking in water, but unfolding completely with insufflation. They are in a sort of fetal state. No blood in the trachea or in the bronchioles.

The extracted blood contains per 100 volumes: $\mathrm{CO}=19.0 ; \mathrm{O}=4.9$.

Experiment CLXXXI. May 23. Dog weighing 4 kilos.

Took from the left carotid $33.3 \mathrm{cc}$. of blood.

6 o'clock. Put under the 31 liter bell-jar; pressure decrease begun.

$6: 06$, pressure $40 \mathrm{~cm}$; at $6: 08,35 \mathrm{~cm}$; 14 respirations.

$6: 12$, brought up to $45 \mathrm{~cm}$.; 10 respirations.

$6: 15$, pressure $31 \mathrm{~cm}$; rises, sits down, turns around.

$6: 17$, pressure $26 \mathrm{~cm}$; seated with its head lowered, 15 respirations; raises its head when the bell-jar is struck.

6:20, pressure $15 \mathrm{~cm}$; falls down, urinates, barks faintly and plaintively.

6:21, pressure $13 \mathrm{~cm}$; gets up, barks, and falls back.

$6: 25$, pressure $13 \mathrm{~cm}$.; lying down, 9 respirations, medium.

Cock closed; the pressure falls slowly to $7 \mathrm{~cm}$; the animal seems dead, when suddenly $(6: 27)$ it stands upright, stiffens slowly and strongly, and falls back.

Pressure raised to $15 \mathrm{~cm}$; it seems better, moves a little; pressure dropped to $7 \mathrm{~cm}$.; dies without moving.

Withdrawn immediately. I extract without difficulty from the left heart 50 cc. of very dark blood .... B 
At the first stroke of the pump, nothing comes. At the second, about $3 \mathrm{cc}$; at the third, a considerable quantity of gas, and at the fourth, almost nothing. The blood has not frothed perceptibly. Besides, this is the same result as in the preceding experiment and is explained by the small quantity of gas.

Blood A contained per 100 volumes: $C O=35.0 ;$ O $=19.2$

Blood $\mathrm{B}$ contained per 100 volumes: $\mathrm{CO}=16.2 ; \mathrm{O}_{2} 8.1$

These experiments do not permit us to draw any conclusions as to the oxygen, because evidently at the return to normal pressure, the oxygen of the air contained in the pulmonary vesicles was partly dissolved in the blood of the lungs, which was then pumped into the left heart. Moreover, the arterial blood was very red, which had already perplexed F. Hoppe very much, as we saw in the historical part of this book. But the carbonic acid is another matter, and we can see that it was reduced to $19.0 \mathrm{cc}$. and $16.2 \mathrm{cc}$. The proportion which had disappeared was, in Experiment CLXXXI, 53.7 per cent.

Now, referring to Table $\mathrm{X}$, we find at the pressure of $17 \mathrm{~cm}$. (Exp. CLXXIX) a much greater loss of 74 per cent. But in the first. place, this loss is not an average, since it is the result of only two analyses made on the same animal, in the same experiment, one at $18 \mathrm{~cm}$., the other at $17 \mathrm{~cm}$., with a 12 minute interval. Furthermore, to reach this enormous decompression, which I have not been able to reach since, I had to keep an animal for one hour at a pressure below $30 \mathrm{~cm}$.

I will again call attention in this Experiment CLXXIX to the very small proportion of carbonic acid which the blood retained in passing from 17 to 26 centimeters pressure (analysis D), in spite of a quarter hour interval. I thought I should not include this figure, Number 17, Table X, in the average of Column 15 and in the graph of Figure 32, which expresses it.

Another interesting point, on the contrary, is the return of normal proportions of oxygen and almost normal proportions of $\mathrm{CO}_{2}$ when the animal was restored to the pressure of $76 \mathrm{~cm}$. (three quarters of an hour afterwards). I have had numerous examples of this return of the gases, examples still more rapid.

As for the figures of the analyses B, C, D (Numbers 20, 21, 17 of Table X), I think we must consider them as minima for carbonic acid, and $\mathrm{I}$ preferred to set down on the graph $\mathrm{CO}_{2}$ of Figure 31 the results furnished by the experiments at 7 centimeters, which seem to be nearer the average and to comply better with the law of the graph.

It would be easy for me now to draw practical conclusions from 
the consideration of the preceding data, and show what happens to the blood of travellers who, either in a balloon, or on a mountain side, are subjected to considerable diminutions of pressure. But I think that these reflections will be better placed in the third part of this work, when I shall deduce from the whole collection of experimental data the explanation of the symptoms produced by the modifications of pressure. I shall here merely summarize in this simple formula the results obtained above:

When the pressure is lowered, the quantity of gases contained in the blood is equally diminished, but in a proportion a little less than that which Dalton's Law would indicate; the blood thus loses relatively more oxygen than carbonic acid.

Subchapter III.

\section{GASES OF THE BLOOD AT PRESSURES GREATER THAN ONE ATMOSPHERE}

\section{Experimental Set-up.}

The apparatus which I use for extracting the blood of animals subjected to pressures above that of the atmosphere consists (Fig. 33) of a straight cylinder of sheet steel 4 millimeters thick. The middle part of the cylinder is circular while the extremities are elliptical. The joints are fastened by many very small bolts. The elliptical form permits the insertion of the doors which close the extremities of the cylinder and which turn on the short axis.

These doors consist of a cast-iron frame in the middle of which is fastened a glass porthole 18 millimeters thick, with a diameter of 10 centimeters. They are put in place by holding them obliquely and inserting them into the cylinder; then pulled back, they meet the edge and close hermetically by use of a rubber gasket. Two arms furnished with screws keep them in place; the inner pressure towards the outside does the rest.

The total length of the cylinder is 1.50 meters; its diameter, in the circular part, is 40 centimeters; the total capacity therefore is about 153 liters.

Compression is made by a compression pump $\mathrm{C}$ of the Rouquayrolle and Denayrouze system, operated by a gas engine whose coupling gear A works the gears B; the air laden with water vapor which is thrown off by this pump and whose temperature rises 
considerably, is conveyed through a coil immersed in cold water D, furnished with a reservoir $\mathrm{E}$ for the condensed water.

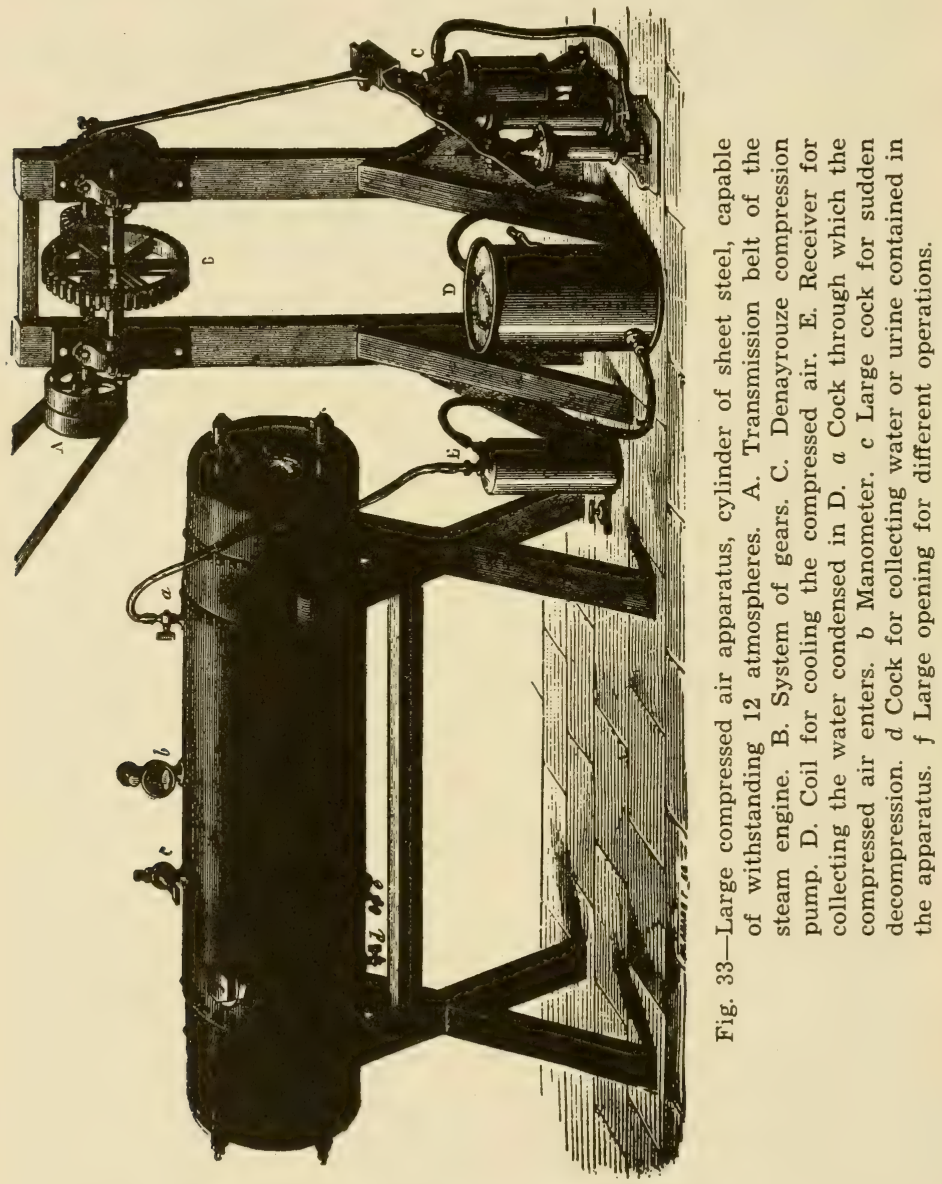

A cock $a$ makes or closes connection with the pump.

Another cock $c$, whose opening can be enlarged progressively, permits one to extract air from the receiver for analysis, to maintain a current of pure air under pressure, or to obtain a very sudden decompression. The manometer $b$ indicates the pressure. 
The cock $d$, placed on the slope of the inner lining of zinc, allows urine or the condensed water to be extracted. Finally, in $f$ is a large orifice, which can either be closed by a screw-head, as the figure shows, or allow the insertion of a thermometer, a serrefine with a handle, a cannula, etc. To prevent the air from escaping around these instruments, they are put through a rubber ball, (B, Fig. 34) held in a copper ring, whose screw thread closes it at will. This arrangement, while completely shutting out the air, gives the instruments a mobility which may be useful.

When one wishes to see what is going on in the apparatus, he puts a candle opposite one of the glass portholes, and looks through the other; a dangerous proceeding, for it was under these conditions that the explosion occurred of which I shall speak in another chapter.

The dog on which the operation is to be carried out is tightly fastened, the nose held in a muzzle, on a framework of iron and wood, whose form fits the inner wall of the apparatus, so that the animal, once placed within it, cannot change its position. Into one of its carotid arteries $\mathrm{A}$ is introduced a metal cannula $\mathrm{S}$, which can, when the animal is in position, be joined to a copper tube, which screws through the wall of the apparatus, and is provided on the outside with a cock $R$.

These arrangements having been made, cock $R$ is closed, and the serre-fine SF is placed in the carotid, thus preventing the blood from entering the cannula. Then the door of the cylinder is adjusted and the compression begun; it rises easily at the rate of about one atmosphere every four minutes, when all the cocks are tightly closed. It therefore takes about 40 minutes to reach 10 atmospheres, the maximum pressure which I have attained with this apparatus.

Nothing now is more simple than to extract the blood of the animal, when the desired pressure has been reached. One needs only to open cock $R$ and remove the serre-fine SF to see the carotid blood gush out with extraordinary force. In these conditions, indeed, the animal is like a sponge powerfully squeezed by a force corresponding to 1.03 kilos. multiplied by the number of atmospheres and by the exterior surface of its body. The whole procedure then consists of fitting the glass syringe of Fig. 23 to the thick rubber tubing which adheres to the cock. Opening the cocks with precaution, one sees the plunger of the syringe raised vigorously by the pressure of the blood. One must not fail to fit its own cock to the syringe, and to close it immediately when one has secured the 
desired quantity of blood, so as to prevent the gases, which are often given off, from escaping. When this discharge was considerable, I weighed the syringe to get the quantity of blood, volume readings then becoming very inexact.

2. Experiments.

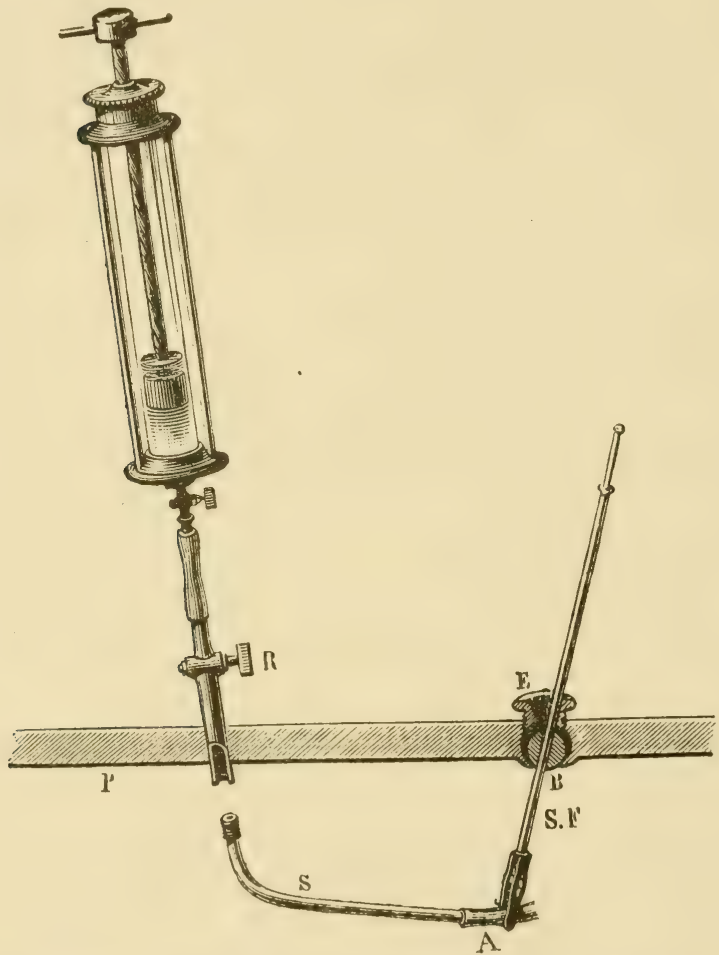

Fig. 34-Extraction of blood from an animal placed in compressed air.

Here now is the detailed account of the experiments made in the conditions specified above.

Experiment CLXXXII. July 23. Dog weighing 12 kilos.

Drew from left carotid $36 \mathrm{cc}$. of blood.... A

4:30. Put into compression apparatus, and air compressed with current passing through; at 5:08, pressure of 10 atmospheres reached. 
5:15, drew $36.7 \mathrm{gm}$. (cc.?) of very red blood; gases escape in the syringe, and the blood begins to coagulate very quickly . . . B B

Brought in 2 minutes to 6 atmospheres, and kept at this pressure under a current of air; at 5:45, drew $39.7 \mathrm{cc}$. of blood a little less red; no free gas ..... C

Brought suddenly to 3 atmospheres, and kept under a current of air.

$6: 33$, drew 38.2 cc. of blood; no free gases . . . D

Decompression made slowly. At 7 o'clock, the animal is well; it survives without ill effects.

Blood A (1 atm.) contains per 100 volumes: $\mathrm{O}=19.4 ; \mathrm{CO}=35.3 ; \mathrm{N} 2.2$ Blood B (10 atm.) contains per 100 volumes: $\mathrm{O}=24.6$; $\mathrm{CO}=36.4 ; \mathrm{N} 11.3$ Blood C (6 atm.) contains per 100 voolumes: $\mathrm{O}=23.7$; $\mathrm{CO}=35.6 ; \mathrm{N} 8.1$ Blood D (3 atm.) contains per 100 volumes: $\mathrm{O}=20.9$; $\mathrm{CO}=35.1$; N 4.7

Experiment CLXXXIII. July 27. Female dog weighing 9 kilos.

Drew $29.5 \mathrm{cc}$. of blood from the carotid . . . . A

Put into compression apparatus; before each blood extraction, I maintain the determined pressure, under a current of air, for several minutes.

$3: 21$, drew $29.5 \mathrm{cc}$. of blood at 2 atmospheres ... . B

$3: 48$, drew $34.3 \mathrm{cc}$. of blood at 5 atmospheres .... C

$4: 35$, drew $38.2 \mathrm{cc}$. of blood at $71 / 2$ atmospheres . . . D

Up to this time, no discharge of gas in the syringe.

5:15, drew $30.7 \mathrm{cc}$. of blood at 10 atmospheres; here, small bubbles of gas .....E

Decompressed in 30 minutes; died.

The rest of its story will be told in Chapter VII.

Blood A (1 atm.) contains per 100 volumes: $\mathrm{O}_{2}$ 18.3; $\mathrm{CO}=37.1$; N 2.2 Blood B (2 atm.) contains per 100 volumes: $\mathrm{O}=19.1 ; \mathrm{CO}=37.7 ; \mathrm{N} 3.0$ Blood C (5 atm.) contains per 100 volumes: $\mathrm{O}=20.6$; $\mathrm{CO}=40.5 ; \mathrm{N} 6.1$ Blood D (71/2 atm.) contains per 100 volumes: $\mathrm{O}=21.1 ; \mathrm{CO}=36.8 ; \mathrm{N}$ lost Blood E (10 atm.) contains per 100 volumes: $\mathrm{O}=21.4 ; \mathrm{CO}_{2} 36.8 ; \mathrm{N} 11.4$

Experiment CLXXXIV. August 5. Female dog weighing 11 kilos.

Drew 29.5 cc. of blood from the carotid . . . A

Put into the apparatus at 5:33. Same precaution as in the preceding experiment.

5:53, 3 atmospheres; drew $29.5 \mathrm{cc}$. of blood; the discharge of gas is evident .....B

$6: 28,6$ and $3 / 4$ atmospheres; drew $29.5 \mathrm{cc}$. of blood; further discharge of gas .... C

The animal cries and whimpers.

7:10, 91/4 atmospheres; drew $36 \mathrm{cc}$. of blood; gas in abundance.. D

The cock of the cannula is opened wide; there issues $250 \mathrm{gm}$. of very red blood, which coagulates immediately; much gas is discharged.

Decompressed rapidly, the animal dies immediately. The rest of its story in Chapter VII.

Blood A (1 atm.) contains per 100 volumes: $\mathrm{O}_{2} 18.4 ; \mathrm{CO}_{2} 47.7 ; \mathrm{N} 2.5$ Blood $\mathrm{B}$ (3 atm.) contains per 100 volumes: $\mathrm{O}_{2} 20.0 ; \mathrm{CO}=42.2 ; \mathrm{N} 4.4$ Blood C (63/4 atm.) contains per 100 volumes: $\mathrm{O}=21.0 ; \mathrm{CO}_{2} 41.3 ; \mathrm{N} 7.1$ Blood D (91/4 atm.) contains per 100 volumes: $\mathrm{O}_{2} 21.2 ; \mathrm{CO}_{2} 39.8 ; \mathrm{N} 9.3$ 
Experiment CLXXXV. August 7. Female dog weighing 8.5 kilos.

Drew at normal pressure $31.9 \mathrm{cc}$. of blood; the animal loses also, by accident, about $35 \mathrm{cc}$.... A

$5: 25,5$ atmospheres; drew 30.7 cc. of blood, from which bubbles of gas are discharged ..... B

6: 05, 8 atmospheres; drew 31.9 cc. of blood; numerous bubbles . . C

$6: 33,10$ atmospheres; drew $33.8 \mathrm{gm}$. of blood; gases were discharged in abundance, and coagulation threatened to take place rapidly .... D

Decompressed; the end of its story in Chapter VII.

Blood A (1 atm.) contains per 100 volumes: $\mathrm{O}_{2} 22.8 ; \mathrm{CO}_{2} 50.1 ; \mathrm{N} 2.3$ Blood B (5 atm.) contains per 100 volumes: $\mathrm{O}_{2} 23.9$; $\mathrm{CO}_{2} 35.2 ; \mathrm{N} 6.0$ Blood $\mathrm{C}$ (8 atm.) contains per 100 volumes: $\mathrm{O}_{2} 25.4 ; \mathrm{CO}=37.6 ; \mathrm{N} 9.5$ Blood D (10 atm.) contains per 100 volumes: $\mathrm{O}_{2} 25.2 ; \mathrm{CO}_{2} 39.0 ; \mathrm{N} 10.0$

Experiment CLXXXVI. August 8. Dog weighing 12.5 kilos.

Drew $33.8 \mathrm{cc}$. of blood at normal pressure, from right carotid . . A Put into apparatus at $4: 45$.

5:33, 51/2 atmospheres; drew 32.9 cc. of blood; discharge of gas . . B

$6: 41,10$ atmospheres; drew $36.1 \mathrm{gm}$. of blood; gas in abundance in the syringe .... C

Decompressed; the end of its story in Chapter VII.

Blood A (1 atm.) contains per 100 volumes: $\mathrm{O}_{2} 20.2 ; \mathrm{CO}_{2} 37.1$; $\mathrm{N} 1.8$ Blood $\mathrm{B}$ (51/2 atm.) contains per 100 volumes: $\mathrm{O}_{2} 23.7 ; \mathrm{CO}_{2} 35.5 ; \mathrm{N} 6.7$ Blood C (10 atm.) contains per 100 volumes: $\mathrm{O}_{2} 24.7 ; \mathrm{CO}_{2} 37.9 ; \mathrm{N} 9.8$

These different results are arranged in Table XI, by increasing order of pressures.

If now we examine the figures it contains, which is easily done by an inspection of Columns 12, 13, and 14, in which are indicated the modifications in percentages of the volume of the gases extracted from the blood under pressure, we see at first glance: 1) that the oxygen and nitrogen have always increased;2) that the carbonic acid has sometimes increased and sometimes diminished.

This can be shown in clearer form by making the following calculation on the different numbers.

We shall assume that, at normal pressure, the blood always contains 20 volumes of oxygen, 40 volumes of carbonic acid, and 2.2 volumes of nitrogen; the quantity contained at the other pressures will be easily deduced from a proportion.

And so, for the first experiment listed in the table, the proportions will be at 2 atmospheres:

$$
\begin{array}{r}
\mathrm{O}_{2}: 18.3: 20=19.1: \mathrm{x}=20.9 \\
\mathrm{CO}_{2}: 37.1: 40=37.7: \mathrm{x}=40.7 \\
\mathrm{~N}: 2.2: 2.2=3.0: \mathrm{x}=3.0
\end{array}
$$




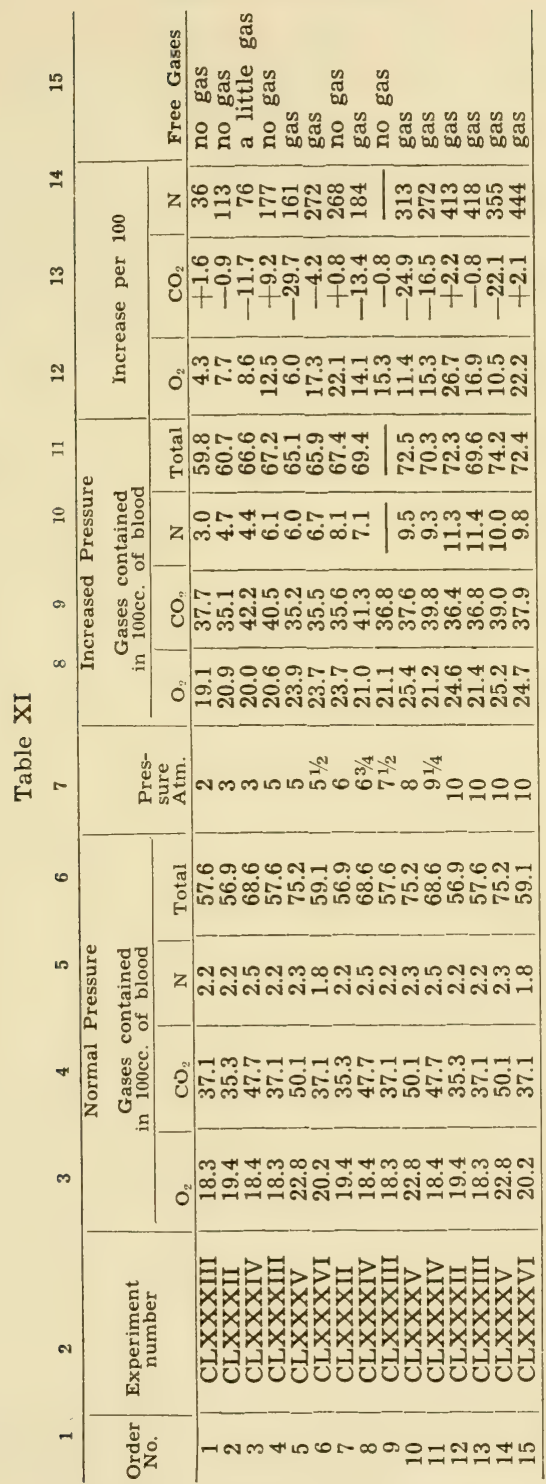


Making averages for identical pressures, we can draw up the following table:

Table XII

\begin{tabular}{c|c|c|c}
\hline \multicolumn{1}{c|}{1} & 2 & 3 & \multicolumn{1}{c}{4} \\
\hline Atmospheres & Oxygen & $\mathrm{CO}_{3}$ & $\mathrm{~N}$ \\
\hline 1 - & 20 & 40.0 & 2.2 \\
3 (Exp. 4, 5, 6) & 20.9 & 40.7 & 3 \\
5 (E) & 21.6 & 37.2 & 3.9 \\
7 (Exp. 7, 8, 9, 10) & 22.7 & 35.7 & 6 \\
10 - 23.1 & 35.5 & 7 \\
\end{tabular}

The results of this table are expressed in a very striking way by the following graphs (Fig. 35), in which the pressures are plotted on the horizontal axis, and the quantities of gas on the vertical scale.

Let us now examine the data for each of the three gases of the blood, using the figure and the two tables.

1. Oxygen. Its increase, we have said, is constant. But the comparison of Columns 3, 8, and 12 of Table XI shows us that this increase is, at the same time, very variable for the same pressure, and very small even under the enormous pressure of 10 atmospheres.

The variety of results should not surprise us, after what we have already seen in speaking of decreases in pressure, and after the inequalities indicated by the diverse figures in Column 3. It is impossible for us to connect this variety of results to any known condition; but it is very interesting to observe, because it can serve to give account of the intensity, very variable according to the subjects, with which the air compression acts.

As to the amount of this increase, it is really very curious to see how slight it is. Its maximum, under a pressure of 10 atmospheres, was 26.7 per cent, that is, in volume the quantity of oxygen contained in $100 \mathrm{cc}$. of arterial blood rose from $19.4 \mathrm{cc}$. to $24.6 \mathrm{cc}$. The figures relating to intermediary pressures have the same bearing. The graph Ox and Column 2 of Table XII show this slowness of increase with great definiteness.

We had already seen, moreover, by experiments made in expanded air, that the influence of barometric pressure, relative to the quantity of oxygen absorbable, is less for pressures near $76 \mathrm{~cm}$. than for those which are much lower. So the figures in Column 14 of Table X show that in passing from $76 \mathrm{~cm}$. to $56 \mathrm{~cm}$. the oxygen lessens only by 13.6 per cent, whereas in passing from $56 \mathrm{~cm}$. to $36 \mathrm{~cm}$. it lessens $43-13.6=29.4$ per cent. So the graph Ox (Fig. 31), 
which shows the changes in the oxygen content of the blood with changing pressure flattens out in the neighborhood of normal pressure.

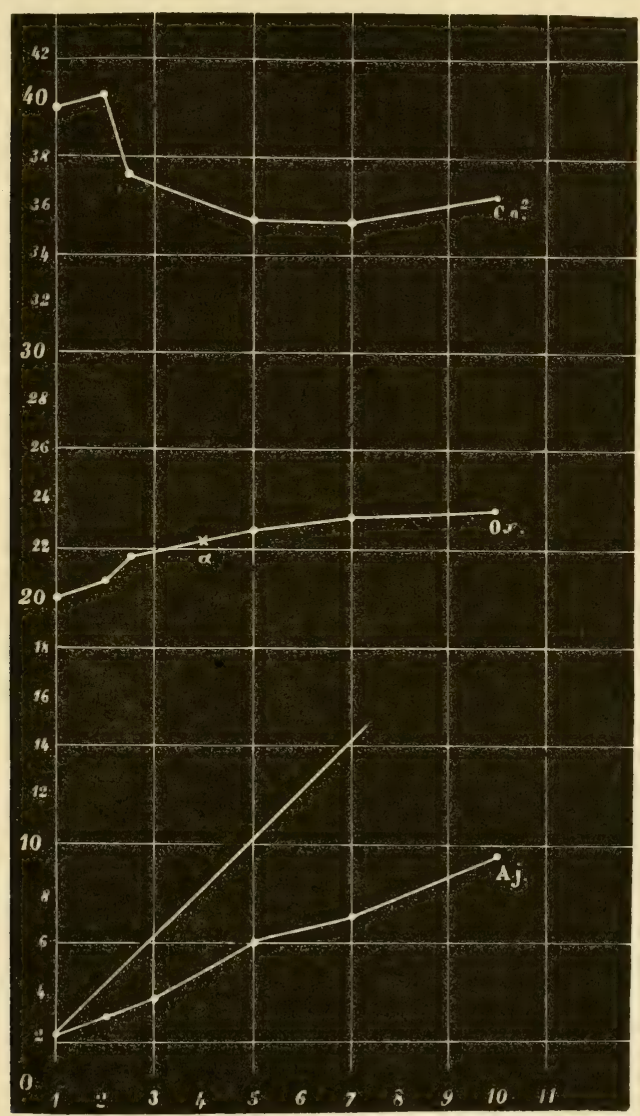

Fig. 35-Variations of blood gases at pressures higher than one atmosphere.

We can show this in a still clearer manner in another graph (Fig. 36). Let us take as the zero the barometric vacuum, let us plot the pressures in atmospheres on the axis of the x's, and let us put on the axis of the y's values proportional to the oxygen content 
at different pressures, and we thus obtain a curve Oab (graph and vertical lines dotted) which, after rising very rapidly in the region

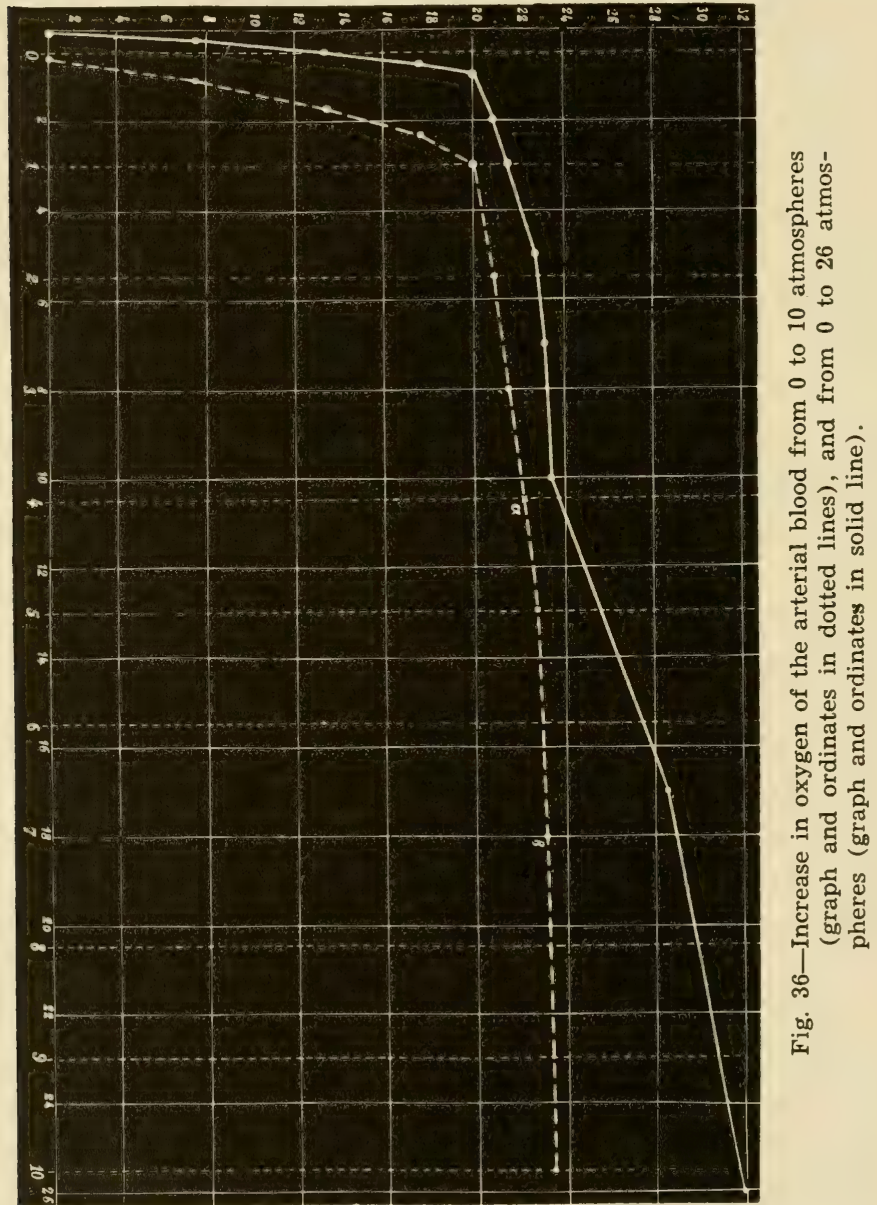

of zero to $1 / 2$ atmosphere, a little less in the region of $1 / 2$ to 1 atmosphere, levels off considerably, beyond that pressure.

The figures are no less clear; assuming that the zero of the oxygen corresponds to the lethal decompression of 7 to 8 centi- 
meters, equal to $1 / 10$ of an atmosphere, we see, by combining Tables $\mathrm{X}$ and $\mathrm{XI}$, that:

From $1 / 10$ to $1 / 4$ of an atmosphere, the proportion of oxygen has increased 7.5 From $1 / 4$ to $1 / 2$ of an atmosphere, the proportion of oxygen has increased 5.7 From $1 / 2$ to $3 / 4$ of an atmosphere, the proportion of oxygen has increased 4.3 From $3 / 4$ to 1 of an atmosphere, the proportion of oxygen has increased 2.5 From 0 to 1 atmosphere, the proportion of oxygen has increased 20.

From 1 to 2 atmospheres, the proportion of oxygen has increased 0.9 From 2 to 3 atmospheres, the proportion of oxygen has increased 0.7 From 3 to 4 ? From 4 to 5 dividing by 2 the difference from 3 to $5=1.1$ increased $\{0.5$ From 5 to 6 atmospheres, the proportion of oxygen has increaed 0.2 From 6 to 7 atmospheres, the proportion of oxygen has increased 0.2 From 7 to 8 atmospheres, the proportion of oxygen has increased 0.1 From 8 to 9 atmospheres, the proportion of oxygen has increased 0.1 From 9 to 10 atmospheres, the proportion of oxygen has increased 0.1

In other words, these data show that, in the living organism, the absorption of oxygen by the blood increases very rapidly for pressures less than one atmosphere, but very slowly, on the contrary, for pressures of several atmospheres. Everything seems to indicate that there exists, in the neighborhood of normal pressure, a point of chemical saturation of the oxy-hemoglobin, and that beyond this point there is added to the blood only the oxygen dissolved in the serum according to Dalton's Law. This will be verified when I speak of the experiments performed in vitro on blood taken from the vessels.

At the proper time we shall return to the reflections inspired by these interesting data. For the moment, let us be satisfied with observing that a laborer who works at a pressure of 2 to 5 atmospheres has not much more oxygen in his blood than at norma! pressure. Moreover,- and this is not to be overlooked in explaining the unevenness of the phenomena displayed by the different workmen-I have seen animals which normally had in their blood at normal pressure more oxygen than others at 10 atmospheres; and also in the experiments at diminished pressure certain of my dogs had at normal pressure (See Table X, Experiments 4 and 11) less oxygen than others at a pressure of 56 centimeters and even of 44 centimeters (Experiments 1, 2, 5, and 8).

2. Carbonic acid. As Table XI shows (Columns 4, 9, 13), some. times it increases, sometimes it diminishes. Its increase is always very slight (at the most, 9.2 per cent, that is, in actual quantity, $3.4 \mathrm{cc}$. per $100 \mathrm{cc}$. of blood) ; its decrease was very great (up to 29.7 
per cent, that is, $14.9 \mathrm{cc}$. per $100 \mathrm{cc}$. of blood [in original French, $110 \mathrm{cc}$.]). All that the figures permit us to say is that the carbonic acid always diminished when its original proportion exceeded $38 \mathrm{cc}$. per $100 \mathrm{cc}$. of blood.

The averages, represented, according to the agreement fixed above, by Column 3 of Table XII and by graph $\mathrm{CO}^{2}$ of Figure 35, indicate a decrease, irregular, it is true, but constant. However, one may say that it is established, as a general fact, that the increase of pressure above normal pressure does not change very considerably the carbonic acid content of the blood. The result was quite different, as we have seen, for pressures below one atmosphere; but we had already seen, in the neighborhood of $76 \mathrm{~cm}$., that the carbonic acid varies little, and in the figures of Column 14, for the pressure of $56 \mathrm{~cm}$., we find the very low ones of 2.5 per cent and 0.8 per cent. On the contrary, at the pressure of $36 \mathrm{~cm}$., for example, the blood contains an average of 29.2 per cent of carbonic acid less than at normal pressure, which corresponds to an average loss of $11.4 \mathrm{cc}$. per $100 \mathrm{cc}$. of blood.

The important practical conclusion derived from this fact is that the symptoms observed in men and animals subjected to high pressures cannot be attributed to the effect of carbonic acid. We shall return to this point.

If now we ask ourselves how it happens that the carbonic acid diminishes for very low pressures, without increasing above one atmosphere, the answer is hard to find. I have, however, settled upon the following explanation.

The respiratory exchanges are not made, as we say in common parlance, between the blood of the lungs and the air of the atmosphere. If it were so, this air, containing only very slight traces of carbonic acid, would play in respect to the blood with reference to the carbonic acid the role of a vacuum, and only a very small quantity would remain in the blood. But the exchanges are made between the venous blood and the air of the pulmonary vesicles. Now I found earlier ${ }^{7}$ that this air, even after an inspiration, still contains from 6 to 8 per cent of carbonic acid. M. Gréhant, ${ }^{8}$ who later did the same research by a method quite different from mine, reached a result as near mine as one could desire in such a subject. It is therefore the normal presence of this important proportion of carbonic acid in the air of the alveoli which maintains the usual quantity in the blood; this gas is thus its own obstacle, and one can easily see how an exaggerated pulmonary ventilation, lessening the 
proportion of $\mathrm{CO}_{2}$ in the alveolar air, lessens it at the same time in the blood.

This carbonic acid which remains thus in the lungs represents the regular excess of the carbonic acid formed in our tissues over that which is exhaled through the trachea. This quantity will not vary, if no change is made in the conditions of metabolism and of pulmonary ventilation. Now this seems to be the case during respiration in compressed air, at least for the phenomena that are gross and apparent. If then there is produced during the same time the same quantity of $\mathrm{CO}_{2}$, the quantity which will remain in the air of the lungs will be the same; but as this quantity is compressed, its volume decreases inversely as the pressure, and it is clear that then its percentage in the air of the lungs, whose total volume does not change, will diminish directly as the volume. So if the air in the lungs of an animal at normal pressure contained 6 per cent of $\mathrm{CO}_{2}$, at 2 atmospheres it will contain only 3 per cent, at 3 atmospheres 2 per cent, at 6 atmospheres 1 per cent, etc.

Now since the pressure exerted by this carbonic acid upon the carbonic acid of the blood evidently has as a measure the product of the percentage by the barometric pressure, it will be expressed in the different cases mentioned above: at normal pressure, by $6 \times 1=6$; at 2 atmospheres, by $3 \times 2=6$; at 3 atmospheres by $2 \times 3=6$; etc., that is, its value always remains the same. It is therefore not astonishing that the carbonic acid content of the blood does not vary either.

But why does it diminish in very low pressures? In this case, the same reasoning, the same conclusions, apparently. But here the question becomes complicated. First, if we assume that the animal is at a pressure of a half-atmosphere, the proportion of carbonic acid in the lungs will rise to 12 per cent; the oxygen content of the air in the pulmonary vesicles is thus diminished, and the animal is forced to maintain a more active ventilation which, lessening the tension $12 \times 1 / 2=6$, lets more acid escape from the blood.

But the principal reason lies elsewhere than in the decrease of barometric pressure; we shall see later, in fact, that the carbonic acid content of the blood diminishes merely from breathing an air with a smaller oxygen content. It is therefore in the troubled chemical conditions of the formation of $\mathrm{CO}_{2}$ that we must seek the most important cause of this diminution. No doubt the same thing is true of the diminution which coincides with pressures above one atmosphere.

3. Nitrogen. For this last gas, matters should take place with a 
great simplicity, and, in fact, they do so. As it enters into no combination, its proportion in the blood depends solely on pressure; so Columns 5, 10, 14 of Table XI show us that it increases considerably. We shall see what is the importance of this considerable quantity of nitrogen when we speak of the effects of sudden decompression.

And yet, strangely enough, the increase is far from following Dalton's Law. In fact, at 5 atmospheres, for example, we find in Column 5 the average number 6 , instead of 11 required by Dalton's Law; at 10 atmospheres, the average number is 10.4 instead of 22 . There is therefore about half as much nitrogen as the law would require. That is very striking in the graph $\mathrm{Az}$ in Figure 35, in which the straight line shows what the law would require.

This fact is very instructive, because it shows how incomplete the intrapulmonary agitation is, at least at high pressures. Now the results given by the oxygen tend in the same direction. Admitting that the hemoglobin is saturated chemically with oxygen in the neighborhood of normal pressure, the quantity of oxygen dissolved should be much greater at high pressures than experience indicates. At 10 atmospheres, for example, we should find, not 23.4 per cent, but about 29 . The insufficient mixing of the air in the lung should be considered here; furthermore, this insufficiency is evident at normal pressure, because blood extracted from the artery always gains considerably in oxygen content from agitation with the air. We shall see that the same thing is true in the case of high pressures.

All this can be summed up in the following sentence: in the living animal, when the barometric pressure increases, the oxygen increases in the arterial blood, but very slowly; the nitrogen increases more quickly, but in a quantity far from that required by Dalton's Law; as for the carbonic acid, it almost always diminishes.

\section{Subchapter IV}

\section{GASES IN THE BLOOD IN ASPHYXIA COMPARED TO DECREASED PRESSURE}

I think I demonstrated in the first chapter that the symptoms and death in expanded air are the result of weak pressure of outside oxygen, and that, in a word, it is a matter of simple asphyxia from lack of oxygen.

If this is so, one should, in the blood of a dog subjected to 
asphyxia, find the same low gas content as in the blood of dogs subjected to decompression.

To verify this hypothesis, two methods are possible: 1) to place an animal in a current of air, which becomes progressively poorer

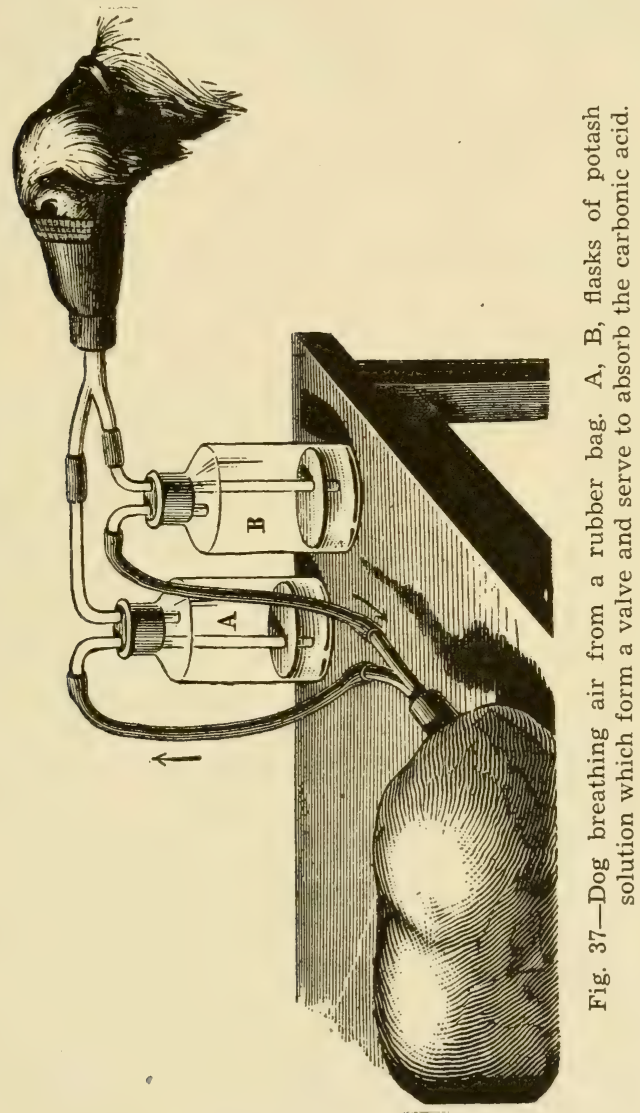

in oxygen; 2) to have the animal exhaust a certain quantity of air, getting rid of the carbonic acid, of course, as it is formed.

The first method seemed to me impractical. To use the second, I fitted to dogs a muzzle which communicated with a bag contain- 
ing from 130 to 150 liters of air; at the expiration as at the inspiration, the air bubbled through a potash solution intended to rid it of its carbonic acid, in which, let me say in passing, I was not. entirely successful: the air of the bag always contained from 1 to 2 per cent of this gas.

Figure 37 shows the set-up of the experiment. The inspired air and the expired air pass through the flasks $A$ and $B$, where a potash solution acts as a valve; in $\mathrm{A}$, the tube which communicates with the dog ends at the top of the flask; through it the inspiration is made; in $\mathrm{B}$, it descends and dips down a little into the liquid; through this the expiration is made.

The experiment having been set up in this way, from time to time I took samples of air from the bag and blood from the carotid for analysis.

Here are the results of some experiments.

Experiment CLXXXVII. April 1; mastiff dog, weighing 11 kilos. Bag containing 137 liters of air. Temperature $15^{\circ}$. Experiment begun at $2: 35$.

$2: 36 ; 16$ respirations; pulse 144 ; arterial pressure varying from $12.5 \mathrm{~cm}$. to $17 \mathrm{~cm}$; rectal temperature $39^{\circ}$. Took $25 \mathrm{cc}$. of blood from the carotid, light red; contains per 100 cc. 19 of oxygen and 48 of carbonic acid.

The animal is very calm and remains very calm all through the experiment.

$2: 55$; respirations, 16 ; pulse, 96 .

3 o'clock; took air from the bag; contained $\mathrm{O}_{2} 18.1 ; \mathrm{CO}_{2} 0.8$.

$3: 05$; respirations, 15 ; pulse, 78 ; temperature $39^{\circ}$. Took $25 \mathrm{cc}$. of blood, very red; contained $\mathrm{O}_{2} 17.0 ; \mathrm{CO}_{2} 49.0$.

3:30; respirations, 20, long; pulse, 64 ; pressure of $13 \mathrm{~cm}$. to $20 \mathrm{~cm}$.; temperature $38.8^{\circ}$.

$3: 35$; took air from the bag; contained $\mathrm{O}_{2} 15.9 ; \mathrm{CO}_{2}$ 1.0. Took 25 cc. of blood, red; contained $\mathrm{O}_{2} 15.0 ; \mathrm{CO}_{2} 46.5$.

4 o'clock; respirations, 12 ; pulse, 52 ; temperature $38.5^{\circ}$.

4:05; air contained $\mathrm{O}_{2} 14.1 ; \mathrm{CO}_{2} 1.3$. Took $25 \mathrm{cc}$. of blood, less red; contained $\mathrm{O}_{2} 13.6 ; \mathrm{CO}_{2} 46.3$.

4:20; cardiac pressure from 11 to $18 \mathrm{~cm}$.

4:30; respirations, 12 ; pulse, 40 ; temperature $38.2^{\circ}$. Air contained $\mathrm{O}_{2}$ 12.2; $\mathrm{CO}_{2}$ 1.7. Took 25 cc. of blood; analysis lost.

5 o'clock; respirations, 12 ; pulse, 40 ; temperature $38.0^{\circ}$.

5: 10; air contained $\mathrm{O}_{2} 9.6 ; \mathrm{CO}_{2} 2.0$. Blood 25 cc., still quite red; contains $\mathrm{O}_{2} 12.0 ; \mathrm{CO}_{2} 46.3$.

5: 20; pressure from 12 to $18 \mathrm{~cm}$.

5:36; respirations, 12 ; pulse, 64 , very irregular; temperature $37.5^{\circ}$. Air from the bag contained $\mathrm{O}_{2} 7.1 ; \mathrm{CO}_{2} 2.2$.

6 o'clock; respirations, 14 ; pulse, 104 ; temperature $37.5^{\circ}$. Took blood, 25 cc., quite dark; contained $\mathrm{O}_{2} 7.1 ; \mathrm{CO}_{2} 42.8$.

6:10; air of the bag contained $\mathrm{O}_{2} 5.9 ; \mathrm{CO}_{2} 2.1$. 
6:25; cardiac pressure, from $11 \mathrm{~cm}$. to $15 \mathrm{~cm}$.

$6: 30$; respirations, 20 ; pulse, 92 , very irregular; temperature $36.6^{\circ}$; the expirations become more abrupt; the animal's feet are still sensitive.

6:35; air of the bag contains $\mathrm{O}_{3} 4.6 ; \mathrm{CO}_{2}$ 2.2. Blood 25 cc., dark; contained $\mathrm{O}_{2} 5.0 ; \mathrm{CO}_{2} 36.7$.

7 o'clock; respirations, 24 , with very abrupt expirations; pulse, 84 ; temperature $35^{\circ}$. Feet still sensitive.

7:05; air of the bag contains $\mathrm{O}_{2} 2.7 ; \mathrm{CO}_{2} 1.9$.

$7: 15$; the phenomena are appearing rapidly; the dog has just lost sensitivity of the eye suddenly. Respirations, 4 ; pulse, 56 ; temperature $34.5^{\circ}$; cardiac pressure, about $4 \mathrm{~cm}$. Took $25 \mathrm{cc}$. of blood, very dark; contains $\mathrm{O}_{2} \quad 0$. $\mathrm{CO}_{2} 20.6$.

Last breath at $7: 17$.

We shall return to the different details of this protocol; but limiting ourselves for the moment to what concerns the gases of the blood, we can summarize the results of the analyses as follows:

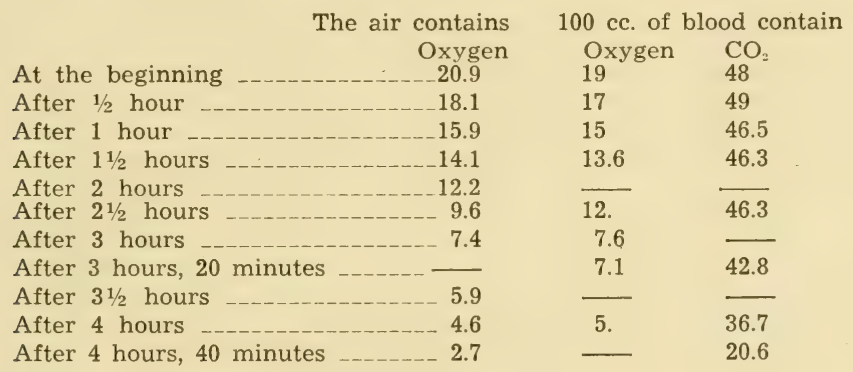

Experiment CLXXXVIII. April 4. Dog weighing 10.600 kilos. Bag containing 137 liters of air. Temperature $15^{\circ}$. Experiment begun at 2:05.

$2: 07$; respirations, 24 ; pulse, 92 ; temperature $38.5^{\circ}$; cardiac pressure from $12.5 \mathrm{~cm}$. to $18.5 \mathrm{~cm}$. Took $25 \mathrm{cc}$. of blood, very red; contained per 100 cc. $\mathrm{O}_{2}, 18.2 ; \mathrm{CO}_{2} 50.8$.

Slight agitation.

2:35; respirations, 20; pulse 100 , irregular; temperature $38.2^{\circ}$ Took air which contained: $\mathrm{O}=17.9 ; \mathrm{CO}=0.9$.

3:05; respirations, 18 ; pulse, 90 ; cardiac pressure has not changed; temperature $38^{\circ}$. Took air: $\mathrm{O}_{2}$ 16.3; $\mathrm{CO}_{2}$ 1.6; drew 25 cc. of blood, very red; contained: $\mathrm{O}_{2} 16.6 ; \mathrm{CO}_{2} 47.7$.

$3: 35$; respirations, 18 , expirations prolonged; pulse, 72 ; temperature $37^{\circ}$. The air contained $\mathrm{O}=14.8 ; \mathrm{CO}=1.7$.

4:05; respirations, 16 ; pulse, 90 ; pressure of $12.5 \mathrm{~cm}$. to $17.5 \mathrm{~cm}$. Air, $\mathrm{O}_{2}$ 13.4; $\mathrm{CO}_{2}$ 1.9. Red blood, 25 cc., contains $\mathrm{O}_{2} 15.9 ; \mathrm{CO}=45.1$.

$4: 35$; respirations, 16 ; pulse, 112 ; temperature $37^{\circ}$. Air, Oz 10.4; $\mathrm{CO}=1.7$. 
5: 05; respirations, 24 ; pulse, 94 ; temperature $36.2^{\circ}$. Air, $\mathrm{O}=8.3$; $\mathrm{CO}$ 2.5. Took blood, quite dark; $\mathrm{O}_{2} 9.8 ; \mathrm{CO}_{2} 40.2$.

5:35; air, $\mathrm{O}_{2} 6.2 ; \mathrm{CO}_{2} 1.7$.

5:50; respirations, 28 ; pulse, 148 ; temperature $34^{\circ}$. Very dark blood, 25 cc., contains $\mathrm{O}_{2} 6.7 ; \mathrm{CO}_{2} 37.9$.

5:58; Sudden violent struggling, after which the animal falls back, as if conquered, and thenceforth remains quiet.

6:05; air, $\mathrm{O}=4.0 ; \mathrm{CO}_{2} 1.6$.

$6: 20$; pulse, 68 ; pressure from $8 \mathrm{~cm}$. to $17 \mathrm{~cm}$; feet sensitive.

$6: 30$; respirations, 16 ; pulse, 68 ; temperature $34^{\circ}$.

6:35; air, $\mathrm{O}_{2} 3.0 ; \mathrm{CO}_{2} 0.8$.

$6: 40$; took 25 cc. of blood, very dark, which contained: $\mathrm{O}=0.7$; $\mathrm{CO}_{2} 25.0$,

The respirations slacken when I begin to draw blood; they cease at $6: 45$; I immediately draw blood which shows no trace of oxygen.

Summary:

\begin{tabular}{|c|c|c|c|}
\hline & \multicolumn{2}{|c|}{ The air contains } & blood con \\
\hline & Oxygen & Oxygen & $\mathrm{CO}_{2}$ \\
\hline At the beginning & 20.9 & 18.2 & 50.8 \\
\hline After $1 / 2$ hour & -17.9 & & \\
\hline After 1 hour & -16.3 & 16.6 & 47.7 \\
\hline After $1 \frac{1}{2}$ hours & -14.8 & & \\
\hline After 2 hours & -- 13.4 & 15.9 & 45.1 \\
\hline After $2 \frac{1}{2}$ hours & 10.4 & & \\
\hline After 3 hours & -- 8.3 & 9.8 & 40.2 \\
\hline After $3 \frac{1}{2}$ hours - & --6.2 & & \\
\hline After $33 / 4$ hours & $-\longrightarrow$ & 6.7 & 37.9 \\
\hline After 4 hours & --4 & - & \\
\hline After $41 / 2$ hours - & ---3 & 0.7 & 25 \\
\hline
\end{tabular}

The results of these two experiments are expressed on the following graph (Fig. 38), whose lines show the simultaneous variations of the oxygen of the air and the gases of the blood. The solid line relates to Experiment CLXXXVIII; the dotted line to Experiment CLXXXVII.

Here now is an experiment in which from the very outset a dog was made to breathe air low in oxygen:

Experiment CLXXXIX. May 20. At 3:30, the animal breathing ordinary air, 28 respirations, pulse 136; cardiac pressure, from 18 to $20 \mathrm{~cm}$.

Its blood contains: $\mathrm{O}=21.5 ; \mathrm{CO}_{2} 47.3$.

4:30; the dog is made to breathe through the potash valves, from a bag containing air with only 10 per cent of oxygen; it remains quiet.

5 o'clock; respirations, 16; pulse, 128; pressure, 16 to $19 \mathrm{~cm}$.

5:30; respirations, 16 ; pulse, 116 . Dark blood, contains: $\mathrm{O}=5.3$; $\mathrm{CO}=45.7$.

6 o'clock; respirations, 16 ; pulse, 80 ; pressure, from 8 to $13 \mathrm{~cm}$.

$6: 30$; respirations, 16 ; pulse, 56 .

$6: 45$; respirations, 8 ; pulse, 24. 
Dies at 6:53; I immediately draw with a cannula 25 cc. of blood from the left heart, which contains $\mathrm{O}_{2} \quad 0 ; \mathrm{CO}_{2} 29$.

The air of the bag contains 2.5 of oxygen.

Let us refer now, from the special point of view which interests us, to the two experiments CLXXXVII and CLXXXVIII. The preceding graph shows us that the oxygen of the blood diminished just as fast as the tension of the oxygen of the air; that is not surprising,

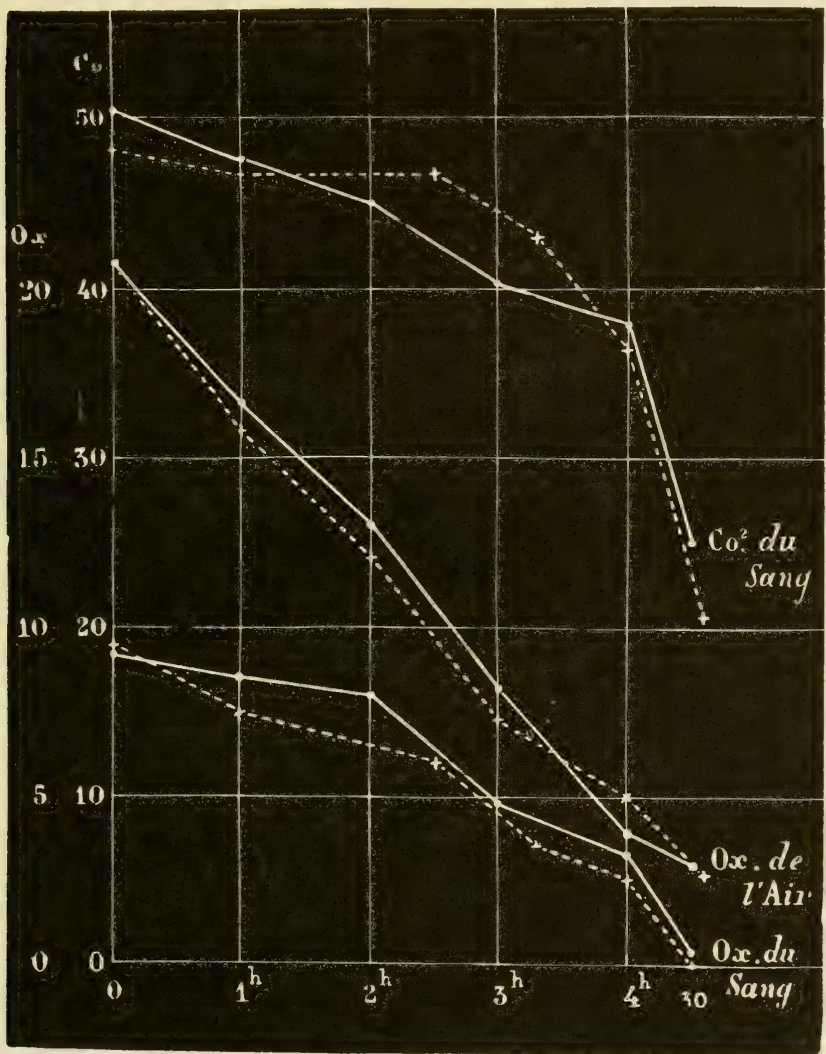

Fig. 38-Variations in the gases of the blood and the oxygen of the air in asphyxia in closed vessels, the carbonic acid being absorbed: to make the figure clearer, the ordinates corresponding to the oxygen content of the air are twice the height of the others. 
but it is stranger to see that the carbonic acid diminished equally, although a considerable quantity remained in the air of the bag, which should have increased the proportion of this gas.

If we wish to compare, not the trend, which quite evidently is the same, but the exact value of the variation of the blood gases in diminished pressure on the one hand, and in asphyxia on the other, we need only take the graph in Figure 31 and add to it the average results of the last experiments, making the same calculation of the numbers to bring the original value of the oxygen to 20 , and that of the carbonic acid to 40 .

This has been done in Figure 39 .

On the ordinates are plotted, as usual, the numbers relating to the percentages of the gases extracted from the blood.

The abscissae measure both the percentage of ambient oxygen and the barometric pressure. So 20.9 corresponds to 76 centimeters; 20.9

a half-atmosphere, 36 centimeters, corresponds to $\frac{20}{2}$, etc. . . ; that will permit us to see whether or not there is agreement between the results of the two kinds of experiments.

The points relating to diminutions of pressure are marked, as we have already said, by little circles connected by dashes and dots -._.o._.-. - o. The dotted lines ..... express the average of the two experiments of simple asphyxia which I have just reported.

Now in regard to the oxygen, we notice at once the remarkable agreement existing between the two curves; only for the rarefied air, as I have already indicated, I could not go below a pressure of 17 centimeters, corresponding to about 4.7 per cent of oxygen. Here is the first point gained.

For the carbonic acid, the agreement is less perfect. But we must note first that there remained in the air on the way to exhaustion a certain quantity of carbonic acid, without which the dotted graph would certainly have dropped more than it has. Furthermore, the irregularities between the averages connected by the line - $0 .-$.o are very great for the carbonic acid, as is shown by the little isolated circles, which correspond to each of the experiments. It is therefore probable that from a very great number of experiments we should obtain averages which would be closer together; but it seemed to me unimportant to continue this investigation.

The great interest lay in showing that, even at normal pressure, if the proportion of oxygen in the respirable air is low, we find in 
the proportions of oxygen and carbonic acid in the arterial blood the same modifications as in the case of respiration under diminished pressure. From this survey, as from that in the first chapter,

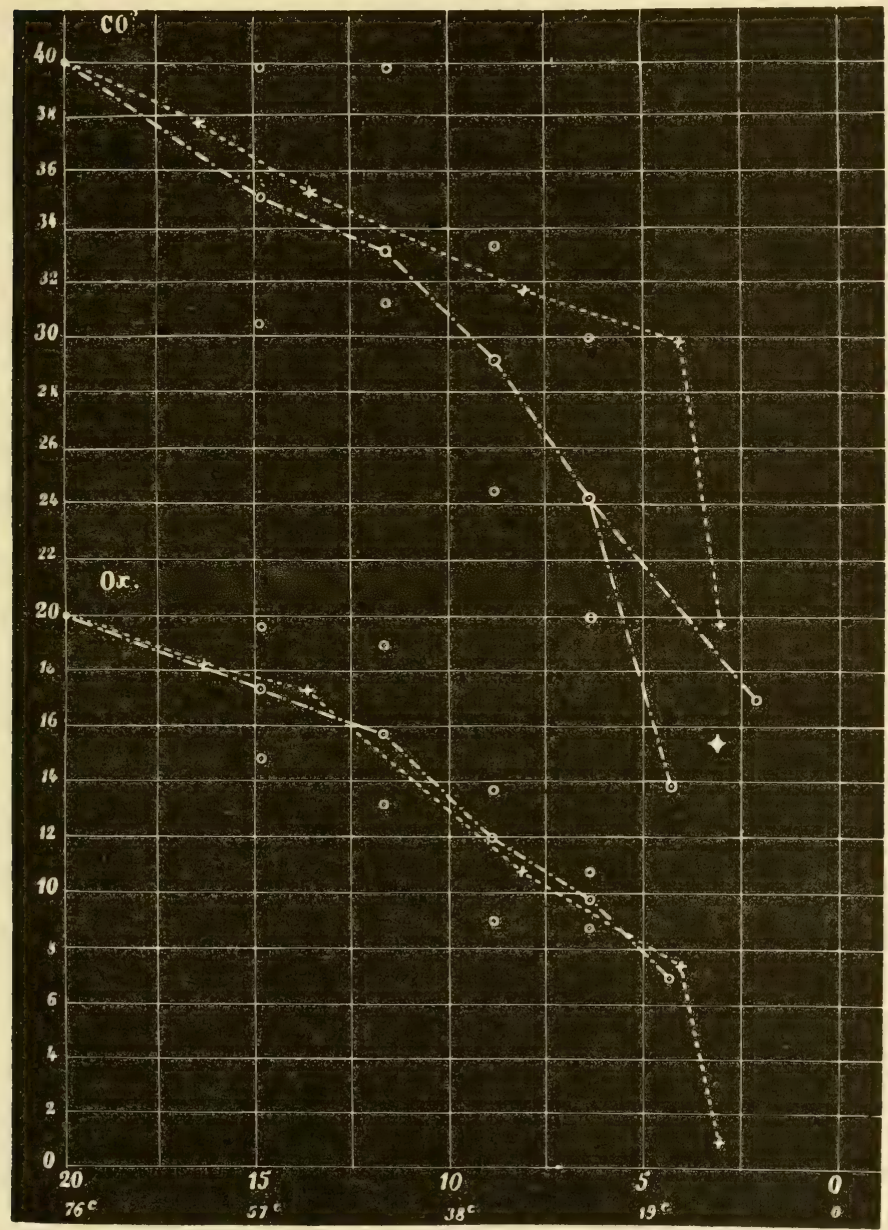

Fig. 39-Variations in the blood gases in asphyxia compared to decreased pressure. 
there appears once more the proof that decompression acts as a simple asphyxiating agent.

When this truth had been established, it became possible for me to find out how the gases of the venous blood vary during decompression. I had tried repeatedly to extract the venous blood of a dog placed in my large cylinders; difficulties which all experimenters will divine had prevented me from succeeding; clots formed in the cannulas, air bubbles, which the pressure of the blood no longer opposed, rushed into the right heart, etc.

But respiration in an air whose oxygen content was gradually lessened allowed me to avoid these difficulties. And so I did in the following experiments.

Experiment CXC. July 30. Dog weighing 12 kilos. Muzzle hermetically closed.

2:05; Forced to breathe with the potash valves from a bag containing 90 liters of air.

2:10; respirations, 26; pulse, 100 . Drew from the carotid 25 cc. of blood, not very red . . . . A

2:20, Drew from the left jugular, peripheral end, 25 cc. of blood, rather dark ..... A'

The animal, whose eyes are covered, remains perfectly quiet.

3:07; 22 respirations; pulse, 100.

$3: 10$; Drew $25 \mathrm{cc}$. of blood from the carotid, almost as red as A ....B B

$3: 15$; Took sample of air from the bag .... b

3:20; Drew 25 cc. of venous blood .... . B'

4: 10 ; Drew 25 cc. of arterial blood, dark ... . C

4:15; Took air from the bag ..... c

The animal suddenly makes a violent effort and pulls off the rubber bag for an instant (takes one inspiration of outer air); continued efforts and considerable panting.

$4: 22 ; 25$ cc. of very dark venous blood . . . . C'

$4: 30$; pulse, 60 ; 18 deep respirations.

4:38; dies; a few very weak heart beats. Drew arterial blood, very dark .... D

Took air from the bag.... d

Summary of the Experiment

\begin{tabular}{|c|c|c|c|c|c|c|c|}
\hline \multirow[t]{2}{*}{ Airs } & \multirow{2}{*}{\begin{tabular}{|c} 
Cor- \\
re- \\
spond- \\
ing \\
Pres- \\
sure
\end{tabular}} & \multirow[t]{2}{*}{ Bloods } & \multicolumn{2}{|c|}{$\underset{\text { Blood }}{\text { Arterial }}$} & \multicolumn{2}{|c|}{ Venous } & \multirow[t]{2}{*}{$\begin{array}{c}\text { Diff. in } \\
\mathrm{O}_{2}\end{array}$} \\
\hline & & & O. & $\mathrm{CO}$. & $\mathrm{O}_{2}$ & $\mathrm{CO}_{2}$ & \\
\hline $\begin{array}{l}\text { Normal } \\
\mathrm{b}\left(11.5 \text { of } \mathrm{O}_{2} ; 2.0 \text { of } \mathrm{CO}_{2}\right) \\
\mathrm{c}\left(4.7 \text { of } \mathrm{O}_{2} ; 2.1 \text { of } \mathrm{CO}_{2}\right) \\
\text { Lethal } \mathrm{d}\left(2.7 \text { of } \mathrm{O}_{2} ;\right.\end{array}$ & $\begin{array}{l}76 \\
41.8 \\
17.1\end{array}$ & $\begin{array}{l}\mathrm{AA}^{\prime} \\
\text { BB', } \\
\text { CC' }\end{array}$ & $\begin{array}{r}21.6 \\
19.6 \\
8.8\end{array}$ & $\begin{array}{l}45.0 \\
42.7 \\
34.4\end{array}$ & $\begin{array}{r}12.4 \\
10.2 \\
2.2\end{array}$ & $\begin{array}{l}46.8 \\
49.1 \\
36.5\end{array}$ & $\begin{array}{l}9.2 \\
9.4 \\
6.6\end{array}$ \\
\hline 1.9 of & 9.8 & D & 0.4 & 23.6 & - & - & - \\
\hline
\end{tabular}


Experiment CXCI. October 15. Female dog weighing 13 kilos. Breathing free air; respirations, 20; pulse, 148; rectal temperature, $39.8^{\circ}$.

2: 50; Drew 25 cc. of blood from peripheral end of jugular vein. A'

2:55; 25 cc. from carotid artery .... A

3 o'clock; Forced to breathe from a rubber bag containing 130 liters of air, through the double potash valves; the animal is very calm although it struggled considerably at the beginning of the experiment.

4 o'clock; 25 cc. of arterial blood . . . . B

4:12; 16 respirations; pulse, 86 ; temperature, $37.4^{\circ}$.

$4: 15 ; 25$ cc. of venous blood ... B B'

Air from the bag .... b

Animal very quiet.

$5: 15 ; 25$ cc. of venous blood . . . C'

Air from the bag ..... c

Respirations, 16; pulse, 92; temperature, $36^{\circ}$.

$6: 10 ; 25 \mathrm{cc}$. of venous blood . . . D'

Air from the bag .....d

Respirations, 16 ; pulse, 96 ; temperature, $35.5^{\circ}$.

$7: 10 ; 25$ cc. of arterial blood . . . E

25 cc. of venous blood ..... E'

Air from the bag . ....e

Respirations, 16; pulse, 100; temperature, $35.1^{\circ}$.

Death comes at 8:45; temperature $33^{\circ}$.

An accident prevents making an analysis of the blood.

The air of the bag contains per $100 \mathrm{O}_{2} 4.9 ; \mathrm{CO}=1.2$.

Summary of the Experiment

\begin{tabular}{|c|c|c|c|c|c|c|c|c|}
\hline \multirow[t]{2}{*}{ Airs } & \multirow{2}{*}{ 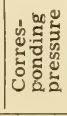 } & \multirow[t]{2}{*}{$\begin{array}{c}\text { Ben } \\
\text { Bloods }\end{array}$} & \multicolumn{2}{|c|}{$\begin{array}{l}\text { Arterial } \\
\text { Blood }\end{array}$} & \multicolumn{2}{|c|}{$\begin{array}{l}\text { Venous } \\
\text { Blood }\end{array}$} & \multirow{2}{*}{ 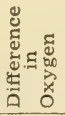 } & \multirow{2}{*}{ 爮苋 } \\
\hline & & & $\mathrm{O}_{2}$ & $\mathrm{CO}$. & O. & $1 \mathrm{CO}_{2}$ & & \\
\hline $\begin{array}{l}\text { Normal } \\
\mathrm{b}\left(16.3 \text { of } \mathrm{O}_{2} 1.7 \text { of } \mathrm{CO}_{2}\right) \\
\mathrm{c}(13.6 \text { of } \\
\mathrm{d}\left(10.6 \text { of } \mathrm{O}_{2} ; 2.4 \text { of } \mathrm{CO}_{2}\right) \\
\mathrm{e}\left(7.7 \text { of } \mathrm{O}_{2 ;} ; .1 \text { of } \mathrm{CO}_{2}\right) \\
\text { Lethal }\left(4.9 \text { of } \mathrm{CO}_{2} ; 1.2 \text { of } \mathrm{CO}_{2}\right)\end{array}$ & \begin{tabular}{|l}
76 \\
59 \\
49 \\
38 \\
28 \\
17
\end{tabular} & $\begin{array}{l}\mathrm{AA}^{\prime} \\
\mathrm{BB}^{\prime} \\
\mathrm{C}^{\prime} \\
\mathrm{D}^{\prime} \\
\mathrm{EE}^{\prime}\end{array}$ & $\begin{array}{l}22.2 \\
16.9\end{array}$ & $\begin{array}{l}29.4 \\
39.0\end{array}$ & $\begin{array}{r}17.2 \\
12.8 \\
11.3 \\
8.8 \\
6.0\end{array}$ & $\begin{array}{l}40.3 \\
39.2 \\
43.0 \\
45.8 \\
45.8\end{array}$ & $\begin{array}{l}5.0 \\
4.1 \\
4.2\end{array}$ & $\begin{array}{l}39.8^{\circ} \\
37.4^{\circ} \\
36.0^{\circ} \\
35.5^{\circ} \\
35.1^{\circ} \\
33.0^{\circ}\end{array}$ \\
\hline
\end{tabular}

Experiment CXCII. November 13. Dog weighing 16 kilos. Breathing free air; temperature $38.5^{\circ}$.

2: 45 ; Took 30 cc. of carotid blood .... A

2:54; Took $30 \mathrm{cc}$. of blood from the peripheral end of the jugular vein ..... A'

2:56; We begin to force the dog to breathe from the bag containing 130 liters of air through the potash valves.

3: 40 ; Rectal temperature $38^{\circ}$.

3:53; The animal is much hampered in its breathing, and has been struggling for a few minutes. Took $30 \mathrm{cc}$. of venous blood .... B'

4:05; Took $30 \mathrm{cc}$. of arterial blood .... B

Air from the bag .... b

4:15; Rectal temperature $36^{\circ}$. 
5 o'clock; Took 30 cc. of venous blood .... C'

5:07; Took $30 \mathrm{cc}$. of arterial blood .... C

Air from the bag .... c

5: 15 ; Rectal temperature $34^{\circ}$.

5:20; Arterial blood, $30 \mathrm{cc}$; animal dying . . . . D

5:30; Venous blood, animal dead.... D'

Summary of Experiment

\begin{tabular}{|c|c|c|c|c|c|c|c|c|}
\hline \multirow[t]{2}{*}{ Airs } & \multirow{2}{*}{ 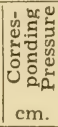 } & \multirow[t]{2}{*}{ Bloods } & \multicolumn{2}{|c|}{$\begin{array}{l}\text { Arterial } \\
\text { Blood }\end{array}$} & \multicolumn{2}{|c|}{ Venous } & \multirow{2}{*}{ 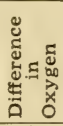 } & \multirow{2}{*}{ 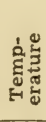 } \\
\hline & & & $\mathrm{O}_{2}$ & $\mathrm{CO}_{2}$ & $\mathrm{O}_{3}$ & $\mathrm{CO}_{2}$ & & \\
\hline $\begin{array}{l}\text { INormat } \\
\mathrm{b}\left(10.3 \text { of } \mathrm{O}_{2} ; 0.3 \text { of } \mathrm{CO}_{2}\right) \\
\mathrm{c}\left(4.7 \text { of } \mathrm{O}_{2} ; 0.3 \text { of } \mathrm{CO}_{2}\right) \\
\text { At death }\end{array}$ & $\begin{array}{l}76 \\
38 \\
17\end{array}$ & $\begin{array}{l}\text { AA' } \\
\text { BB', } \\
\text { CC', } \\
\text { DD' }\end{array}$ & $\begin{array}{r}18.0 \\
6.0 \\
3.7 \\
0.33\end{array}$ & $\begin{array}{l}49.0 \\
42.3 \\
29.7 \\
24.0\end{array}$ & $\begin{array}{r}14.7 \\
4.7 \\
2.8 \\
0.15\end{array}$ & $\begin{array}{l}54.0 \\
49.0 \\
37.0 \\
28.7\end{array}$ & $\begin{array}{l}3.3 \\
1.3 \\
0.9 \\
0.18\end{array}$ & $\begin{array}{l}38^{\circ} \\
36^{\circ} \\
34^{\circ}\end{array}$ \\
\hline
\end{tabular}

Figure 40 makes it still easier to comprehend the results of these three experiments in regard to the variation of the gases of the blood; as usual, the quantities of gas are plotted on the vertical axis, the oxygen content and the barometric pressure which corresponds to it are plotted on the axis of the x's. The results of Experiment CXC are marked by dotted lines .......; those of Experiment CXCI by dashes _ _ _ - ; those of Experiment CXCII by dashes and dots -.......

We see at first glance that in both the venous and the arterial blood the oxygen and the carbonic acid diminish when the tension of the oxygen breathed diminishes.

We see also that the difference in gaseous content between the arterial and the venous blood remains almost constant until the oxygen in the air is about half exhausted, that is, in the neighborhood of a half-atmosphere. Beyond that, the graphs draw closer together.

So, up to a certain degree, the venous blood loses oxygen in the same quantity as the arterial blood; that deserves some attention.

Let us take, for example, Experiment CXC. At the beginning, the arterial blood contains 21.6 of $\mathrm{O}_{2}$; the venous blood, 12.4; difference, 9.2; which means that the tissues needed for their regular maintenance and consumed as it passed 9.2 volumes of oxygen for each 100 volumes of blood.

We drop to a pressure of $41.8 \mathrm{~cm}$., and on account of the decreased capacity of the blood for oxygen at this pressure (See below in Subchapter V) there is now only 19.6 of this gas in the arterial blood; we find only 10.2 in the venous blood: difference, 9.4. The consumption of oxygen by the tissues has then remained the same, 
in spite of the decrease in the proportion of $\mathrm{O}_{2}$ in the blood, and we understand that the animal finds no serious trouble in its different functions: respiration, circulation, etc., as the detailed report of the experiment shows.

But we continue the decompression; the pressure now is only $17 \mathrm{~cm}$., and in the arterial blood there are only 8.8 volumes of oxy-

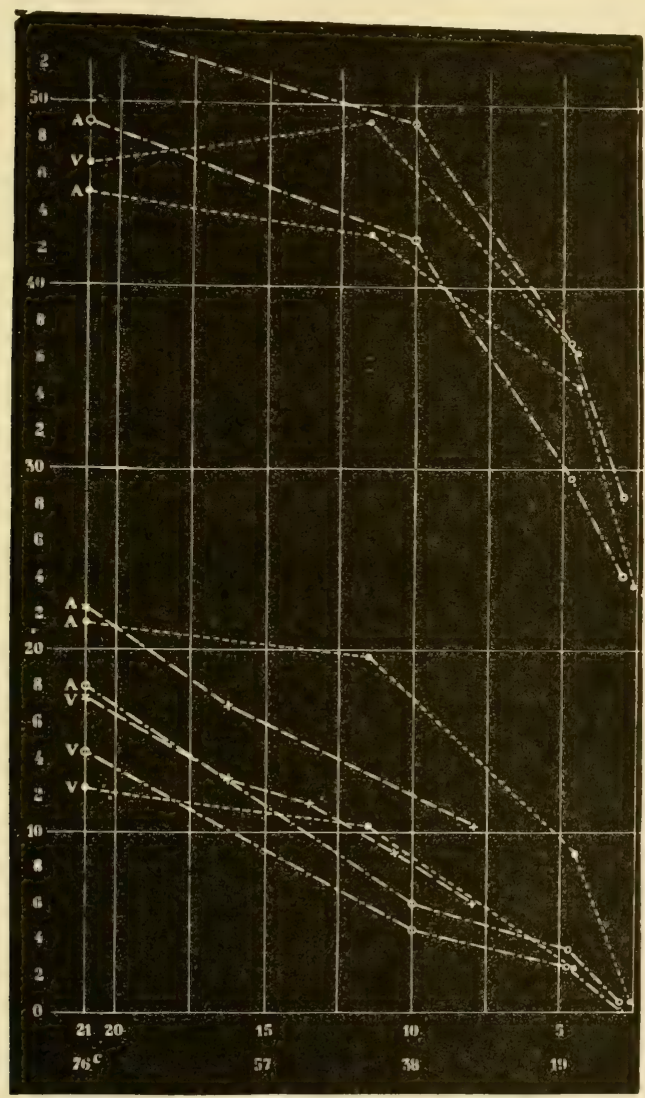

Fig. 40-Decrease of the gases of the arterial blood and the venous blood when the tension of the oxygen breathed decreases; the lower group corresponds to the oxygen of the blood, the upper to the carbonic acid. 
gen. Quite evidently, the oxygen consumption by the tissues could not have remained at the same value, which we have seen to be above 9 ; now the analysis of the venous blood shows that it dropped to 6.6 , that is, that there still remains in the venous blood 2.2 volumes of oxygen, which the tissues cannot easily extract. From this, there result for the animal evident metabolic disturbances, a lowering of temperature, a general depression of the muscles, particularly the heart, which adds still more to the distressing effect, lessening the oxygen consumption by lessening the circulatory activity.

The increasing difficulty of the dissociation of the oxy-hemoglobin of the venous blood when its proportion of oxygen is lessened considerably seems to be the cause of the distress of the animal, which can no longer extract from its blood the quantity of oxygen necessary for its metabolic equilibrium in a given temperature. Now, the proportional quantity of oxygen consumed by animals varies greatly from one individual to another, as, for example, is shown by Experiment CXC, in which it is 9.2 , compared to Experiment CXCII, in which it is 3.3. Furthermore, the absolute quantity of oxygen contained in a given volume of blood varies decidedly also, as we have learned from the numerous analyses already reported. Finally, the quantity of the blood itself likewise appears very variable. It is not at all surprising then that the behavior of different individuals of the same species and even more of representatives of different species should be very variable under the effect of the same decompression, one being much affected while the other experiences almost no effect. One can easily grasp this idea by assuming two animals in which two of these three conditions are identical and the third very different; it is useless to continue with this reasoning because we perceive a series of combinations whose effect makes the problem very complex and makes it impossible to predict the outcome with certainty.

We shall refer again to these facts in the third part of this book when we come to the explanation of the symptoms known by the names of balloon sickness and mountain sickness. 


\section{Subchapter V}

\section{THE QUANTITY OF OXYGEN WHICH CAN BE ABSORBED AT DIFFERENT BAROMETRIC PRESSURES BY THE BLOOD DRAWN FROM THE VESSELS}

The analyses of the gases contained in the blood of living animals subjected to pressures lower than one atmosphere gave me for oxygen, as I remarked before, results far different from the conclusions which could have been drawn from classic researches, particularly those of M. Fernet.

Magnus had already shown that when blood is placed under the belljar of the pneumatic machine and the pressure is gradually diminished, gases begin to escape only at very low pressures, and the blood turns dark (that is, loses a considerable part of its oxygen) only in the neighborhood of $10 \mathrm{~cm}$. of mercury.

M. Fernet had intended, as we saw in the historical part of this book, to find out whether the gases of the blood were in a state of simple solution or bound in a chemical combination. In the first case, he said with reason, the capacity of the blood for these gases should be proportional to the barometric pressure, following the well-known Law of Dalton. In the second, there will be no relation between this law and the proportion absorbed at different pres. sures. And if a gas is partly dissolved and partly combined in this liquid, it will be possible, by a simple calculation, to determine the proportional value of these two parts.

Now,-speaking only of oxygen-by agitating blood in contact with this gas under pressures varying from normal pressure to 647 $\mathrm{mm}$., M. Fernet reached this double conclusion: 1) that there is dissolved in the blood plasma a quantity of oxygen (coefficient of solubility at $16^{\circ}$, that is, volume of gas dissolved per unit of volume of liquid under normal pressure: 0.0288) nearly equal to that which is dissolved in pure water (coefficient of solubility at $16^{\circ}$, according to Bunsen: 0.0295$)$; 2) that the blood corpuscles combine chemically with a quantity of oxygen, independent of the pressure, much greater than the preceding, because it is on the average 0.0958 per unit of volume of blood. We see then that, according to these experiments, the barometric pressure, in these various modifications, can hardly modify the proportion of oxygen contained in the blood. In fact, it could act only on the simply dissolved gas, which is to the combined gas in the proportion of 0.0288 to 0.0958 , that is, of 1 to 3.3 , when the absorption experiments are performed with pure oxygen. 
Now, as M. Fernet remarks, since the respirable air contains only one-fifth of oxygen, the proportion dissolved in the serum must be diminished in the same proportion; whence it results that in the blood the proportion chemically combined independent of the pressure will be $3.3 \times 5=16.5$ times greater than that which follows the changes of the barometric column. And therefore, he concludes, "the absorption of oxygen is very nearly the same, whatever the atmospheric pressure, on mountain tops and in the plains."

To this conclusion, which considered only the quantity of oxygen absorbed by an animal in a given time under different pressures, and which agreed with facts previously noted by Regnault and Reiset, Vierordt and Lehmann, the physiologists have added a second,-which seems wholly justified, a priori, by the very researches of M. Fernet,--namely, that in the blood of the living animal, the quantities of oxygen are almost independent of the barometric pressure. "Otherwise," says Longet," for example, "we would reach this conclusion, that the blood of inhabitants of regions where the atmospheric pressure is half the normal would contain only half as much oxygen as the blood of those dwelling at sea level, where the pressure is 0.760 meters. How can we believe that observers would not have been struck by the profound modifications which such variations would not fail to produce in the manner of existence of these populations?"

This conclusion and the reasoning on which it is based were accepted by all the physiologists. It is very interesting to note that when M. Jourdanet stated, basing his assertions on a long medical practice, that in the lofty regions of the Mexican Republic, "the mode of existence of the population is profoundly modified," the very argument of Longet was turned against him, and the exactness of his observations was denied as contrary to the data of physiological chemistry.

The explanation given by M. Jourdanet of the special pathological state which he had noted on the plateaux of Anahuac was entirely based upon the lessened absolute quantity of oxygen contained by the blood of men and animals under so low a pressure. Now we have just seen in the first subchapter that he was absolutely right, and that, in spite of the natural astonishment of Longet. it is correct to say that if one lowers the barometric pressure one half, the oxygen content of the blood will be reduced almost one half.

There was then, between the result of M. Jourdanet's observations and our experiments on the one hand, and the logical conclu- 
sions from the analyses of M. Fernet on the other, a contradiction which could be only apparent, and which demanded explanation.

But in the first place, M. Fernet could change the pressure only in very narrow limits; for whole blood, the pressures had varied from 741 to 580 millimeters. I should inquire what would happen in experiments in which the pressure was diminished to the neighborhood of a vacuum on the one hand, and increased several atmospheres on the other.

The problem was infinitely easier to solve than in the time of M. Fernet; in fact, I had at my disposal means of extracting all the gases of the blood, which the physicist had not been able to obtain, in spite of all his efforts. He therefore had had to use direct measurement of the gases absorbed, that is, measuring the decrease in volume of gases agitated with blood which had previously been deprived of those which it contained at first; a series of very delicate operations, which required a very complicated set of tools, and the use of glass apparatus which would not permit high pressures. On the contrary, thanks to the mercury pump, after agitating the blood in a large quantity of air, under determined pressures, I could extract the dissolved gases easily and completely. I could thus make a large number of analyses, which, without claiming the exactness of second decimals, are quite accurate enough to reach the goal I had set for myself.

I shall report some of them; but I must first thank M. Gréhant, who was then taking my place on the Faculté des Sciences of Paris, and who, at my request, consented to carry out a great number of them.

\section{Pressures Lower Than One Atmosphere.}

My first experiments were simply made by placing in a flask with a wide mouth (Fig. 41) a certain quantity of defibrinated blood which I then agitated vigorously, without completely closing the flask. When the blood was thus saturated with oxygen, I fastened the flask to the end of a long cord and whirled it like a sling, which procedure brought out very rapidly the air bubbles which had remained suspended in the viscous liquid. I then took with a graduated syringe a certain quantity of blood, from which I extracted the gases by the mercury pump.

The mouth of the flask was then carefully closed by a rubber stopper through which passed a thermometer and two glass elbow tubes. One of these tubes dipped into the blood, so that one could obtain samples of the blood through it by means of cock R. Cock R' 
of the second tube led to a forked piece through which at the same time communication was made in $a$ with the pneumatic machine and in $b$ with a tube dipping into a reservoir full of mercury, which tube formed a barometer.

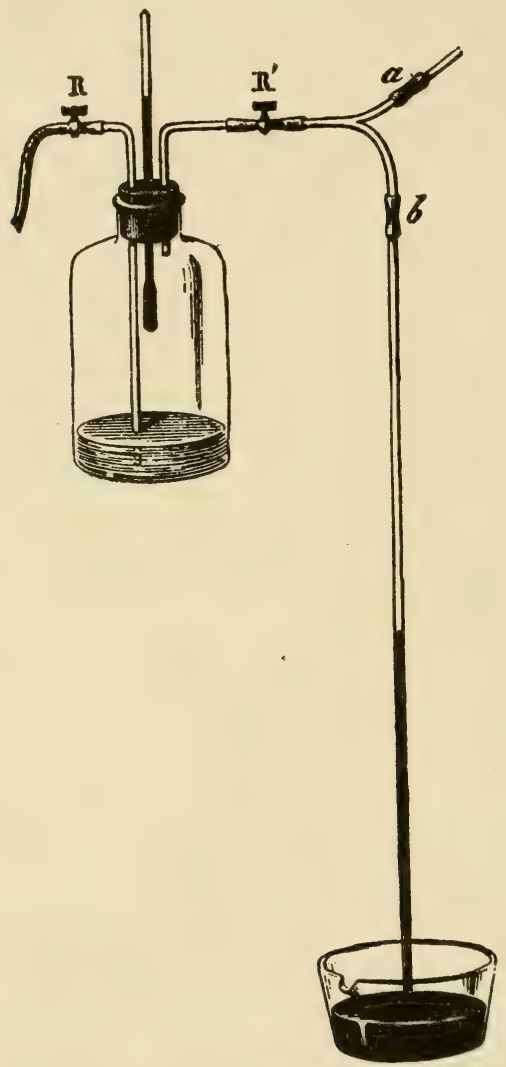

Fig. 41-Flask arranged for the saturation of blood by oxygen at different decompressions.

With my set-up thus arranged, I lowered the pressure to the desired point, closed cock R', took off the forked tube, and shook the flask vigorously for a quarter of an hour. Under these con- 
ditions, the oxygen which would have been present in excess because of the reduced pressure could escape from the blood, which was supersaturated at this new pressure. The flask was large enough in proportion to the quantity of blood, so that the oxygen thus set free was absolutely negligible. Furthermore, I made sure by a simple procedure that the pressure had not varied perceptibly during the agitation.

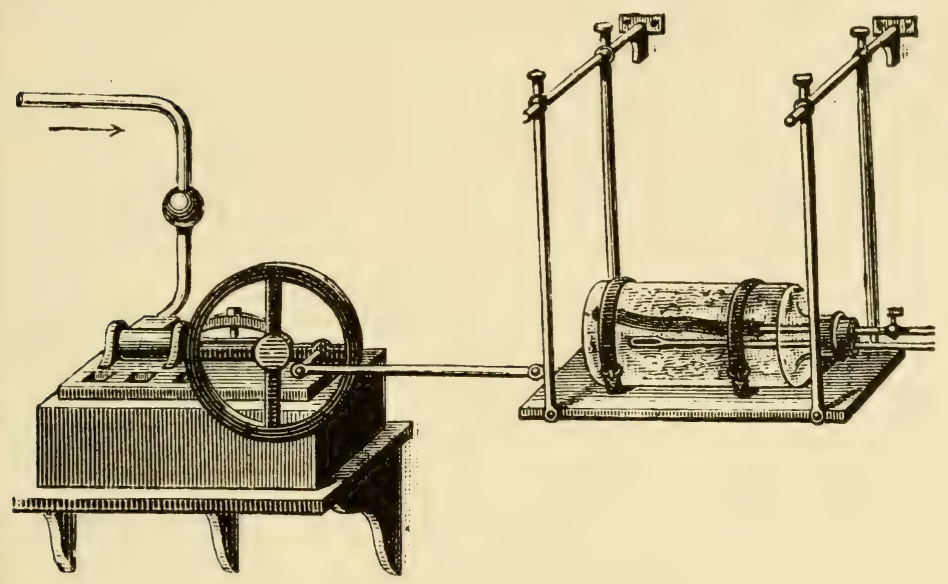

Fig. 42-Water motor shaking the flask containing the blood to be saturated with oxygen.

When this was done, I took a new sample of the blood for analysis of the gases.

Since I placed in the flask about $200 \mathrm{cc}$. of blood, it was possible for me to make several analyses with the same blood at different pressures.

Later, a useful improvement was added to this method, whose principal cause of error lies in the difficulty of shaking hard enough with the hand. The flask was firmly fixed on a plank which was vigorously moved by a little water motor (Fig. 42). Under these conditions, the saturation of the blood was accomplished with great rapidity, and a few whirls of the sling were enough to dispel the froth and the bubbles of gas in suspension. 
And now we come to the experiments.

Experiment CXCIII. December 1. Flask of 3 liters; 180 cc. of defibrinated dog blood.

After agitation at normal pressure, the blood contains per 100 cc. of liquid: oxygen, 19.0; carbonic acid, 35.2.

After agitation at a pressure of $56 \mathrm{~cm} .: \mathrm{O}_{2} \quad 17.2 ; \mathrm{CO}_{2} 28.4 ; \mathrm{N} 2.4$.

At $36 \mathrm{~cm}$ : $\mathrm{O} z 16 ; \mathrm{CO}_{2} 27.6 ; \mathrm{N} 1.6$.

At $6 \mathrm{~cm} .: \mathrm{O}_{2} 12.4 ; \mathrm{CO}=23.2 ; \mathrm{N} 1.0$.

Experiment $C X C I V$. January 7. Dog blood, agitated at $76 \mathrm{~cm}$., containing per $100 \mathrm{cc}$. of liquid: oxygen, 25.3; carbonic acid, 35.7; nitrogen, 2.3.

Agitated at a pressure of $38 \mathrm{~cm}$., still contained $\mathrm{O}_{2} 23.4 ; \mathrm{CO}_{2} 27.5$; N 1.4.

Experiment CXCV. January 9. Blood of sick, weak dog.

Shaken at $75 \mathrm{~cm}$., contains: $\mathrm{O}_{2} 12.3 ; \mathrm{CO}_{2} 41.6 ; \mathrm{N} 2.4 . \frac{\mathrm{CO}_{2}}{\mathrm{O}_{2}}=3.4$.

Shaken at $34 \mathrm{~cm}$., contains: $\mathrm{O}_{2} \quad 11.3 ; \mathrm{CO}_{2} 41 ; \mathrm{N} \quad 1.4 . \frac{\mathrm{CO}_{2}}{\mathrm{O}_{2}}=3.6$.

Shaken at $18 \mathrm{~cm} .: \mathrm{O}_{2} 10.4 ; \mathrm{CO}_{2} 35.6 ; \mathrm{N} \quad 0.9 \cdot \frac{\mathrm{CO} z}{\mathrm{O}_{2}}=3.4$

Shaken at $12 \mathrm{~cm} .: \quad \mathrm{O}_{2} \quad 10 ; \mathrm{CO}_{2} 28.7 ; \mathrm{N} \quad 0.6 . \frac{\mathrm{CO}_{2}}{\mathrm{O}_{2}}=2.8$

Experiment CXCVI. January 15. Dog blood.

Shaken at $77 \mathrm{~cm}$., contains $\mathrm{O} * 20.2 ; \mathrm{CO}=28.4 ; \mathrm{N} 2.4 \frac{\mathrm{CO}}{\mathrm{O}_{2}}=1.40$.

Shaken at $34 \mathrm{~cm}$., contains $\mathrm{O}_{2} 18.9 ; \mathrm{CO}_{2} 24.9 ; \mathrm{N} 1.3 . \frac{\mathrm{CO} z}{\mathrm{O}_{2}}=1.31$.

Shaken at $6 \mathrm{~cm}$., contains $\mathrm{O}_{2} 17.7 ; \mathrm{CO}_{2} 19.8 ; \mathrm{N} \quad 0.4, \frac{\mathrm{CO}_{2}}{\mathrm{O}}=1.12$.

Experiment CXCVII. January 21. Ox blood.

Shaken at $770 \mathrm{~mm}$., contains: $\mathrm{O}_{2} 19.3$.

Shaken at $83 \mathrm{~mm}$., contains: $\mathrm{O}_{2} 18.5$.

Shaken at $22 \mathrm{~mm}$., contains: $\mathrm{O}_{2} 13.3$.

Experiment CXCVIII. February 2. Blood of a dog subjected for several days to repeated hemorrhages and having on its thigh a large festering sore.

The blood was agitated twice; in one case, the temperature was that of the laboratory, $11.4^{\circ}$; in the other, the flask and the plank 
were submerged in water at $37^{\circ}$ long enough for a temperature equilibrium to be established.

1.) Temperature, $11.4^{\circ}$.

At $760 \mathrm{~mm}$., the blood contains $\mathrm{O}_{2} 8.1 ; \mathrm{CO}_{2} 27.6 ; \mathrm{N} 2.0$.

At $9 \mathrm{~mm}$., the blood contains $\mathrm{O}=5.1 ; \mathrm{CO}_{2} 17.5 ; \mathrm{N} 0.1$.

2.) Temperature, $37^{\circ}$.

At $760 \mathrm{~mm} ., \mathrm{O}_{2} 7.9 ; \mathrm{CO}_{2} 23.9 ; \mathrm{N} 1.2$.

At $407 \mathrm{~mm} ., \mathrm{O}_{2} 7.1 ; \mathrm{CO}=22.4 ; \mathrm{N} 0.8$.

Experiment CXCIX. March 6. Large hunting dog, in good health; $500 \mathrm{gm}$. of blood drawn from the carotid, shaken in the air, and filtered through linen. Flask of 2 liters.

Shaken for a half hour at the pressure of $775 \mathrm{~mm}$. (762 $\mathrm{mm}$. after a deduction of the tension of the water vapor) and at the temperature of $15.5^{\circ}$, the blood contained: $\mathrm{O}_{2} 23.2 ; \mathrm{CO}_{2} 30.2 ; \mathrm{N} 2.4$. $\mathrm{CO}$ ? $\frac{\mathrm{CO}}{\mathrm{O}_{2}}=1.30$

At $349 \mathrm{~mm} .: \mathrm{O}_{2} 22.6 ; \mathrm{CO}_{2} 27.4 ; \mathrm{N} \quad 1.0 . \frac{\mathrm{CO} z}{\mathrm{O}_{2}}=1.21$.

At $167 \mathrm{~mm} .: \mathrm{O}_{2} 21.5 ; \mathrm{CO}_{2} 25.1 ; \mathrm{N} \quad 0.6 . \frac{\mathrm{CO} z}{\mathrm{O}_{z}}=1.12$.

At $88 \mathrm{~mm} .: \quad \mathrm{O}_{2} 20.0 ; \quad \mathrm{CO}_{2} 21.0 ; \quad \mathrm{N} \quad 0.4 . \frac{\mathrm{CO}_{2}}{\mathrm{O}_{2}}=1.05$.

Experiment CC. March 12. Dog blood; temperature $12^{\circ}$. Flask of 4.330 liters.

Shaken at $749 \mathrm{~mm}$. (deduction made of the water vapor tension at $\left.12^{\circ}\right)$ contains: Oxygen $23.1 ; \mathrm{CO}_{2} 27.5 ; \mathrm{N} 2.6 . \frac{\mathrm{CO}_{2}}{\mathrm{O} 2}=1.18$.

At $361 \mathrm{~mm} .: \quad \mathrm{O}_{2} 23.0 ; \mathrm{CO}_{2} 22.0 ; \mathrm{N} \quad 2.0 . \frac{\mathrm{CO}_{2}}{\mathrm{O} z}=0.95$.

At $99 \mathrm{~mm}: \mathrm{O}_{2} 22.3 ; \mathrm{CO}_{2} \quad 18.9 ; \mathrm{N} \quad 0.3 \cdot \frac{\mathrm{CO}_{2}}{\mathrm{O}_{2}}=0.84$.

At $53 \mathrm{~mm} .: \mathrm{O}_{2} 20.8 ; \mathrm{CO}_{2} \quad 15.4 ; \mathrm{N} \quad 0.2 \cdot \frac{\mathrm{CO}_{2}}{\mathrm{O}_{2}}=0.74$.

Experiment CCI. May 29. Dog blood; temperature $24^{\circ}$; flask of 4.330 liters. 
At $738 \mathrm{~mm}$. (deduction of the water vapor tension), the blood contains: Oxygen 25.6; $\mathrm{CO}_{2} 23.0 ; \mathrm{N} 2.6 . \frac{\mathrm{CO}_{2}}{\mathrm{O}_{2}}=0.89$.

At $318 \mathrm{~mm} .: \mathrm{O}_{2} 23.7 ; \mathrm{CO}_{2} 18.9 ; \mathrm{N} \quad 1.8 . \frac{\mathrm{CO}_{2}}{\mathrm{O}_{2}}=0.79$.

At $128 \mathrm{~mm} .: \quad \mathrm{O}_{2} 23.0 ; \mathrm{CO}_{2} \quad 16.2 ; \mathrm{N} \quad 0.5 . \frac{\mathrm{CO}_{2}}{\mathrm{O}_{2}}=0.70$.

At $78 \mathrm{~mm} .: \quad \mathrm{O}_{2} 23.0 ; \mathrm{CO}_{2} 13.7 ; \mathrm{N} \quad 0.5 . \frac{\mathrm{CO}}{\mathrm{O}_{2}}=0.59$.

At $38 \mathrm{~mm} .: \mathrm{O}_{2} 19.3 ; \mathrm{CO}_{2} 10.8 ; \mathrm{N} \quad 0.3 . \frac{\mathrm{CO}_{2}}{\mathrm{O}_{2}}=0.55$

The accompanying graph (Fig. 43, A) summarizes and expresses the average of the results of the preceding experiments, in

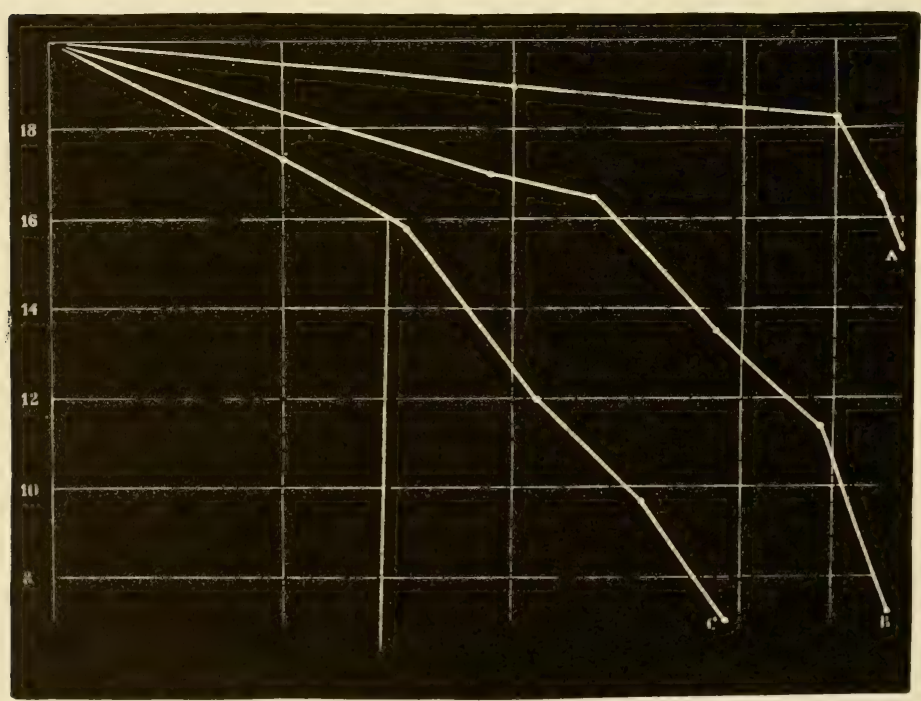

Fig. 43-Capacity of the blood for absorbing oxygen at pressures below one atmosphere. A. Laboratory temperature. B. Body temperature. C. Living animals. 
everything relating to oxygen. It was obtained by assuming that the initial proportion of oxygen at normal pressure was always 20 volumes per 100 volumes of blood, and by determining the value of the other numbers by proportions like the following, which applies to Experiment CXCIII: 19 (normal pressure) : $20=17.2$ (pressure of $56 \mathrm{~cm}$.) : $\mathrm{x}=18.1$.

A simple glance will show that, from normal pressure to that of 10 to 15 centimeters of mercury, the blood absorbs quantities of oxygen that are almost the same; one or two volumes less, and that is all. It is even very possible that this difference affects only the oxygen dissolved in the plasma, which rises, according to M. Fernet, to 2.88 per 100 volumes of liquid. So our analyses, which go to pressures considerably lower than those used by M. Fernet, give results which tend in the direction of the conclusions of this physicist.

But from 15 centimeters of mercury on, the oxygen escapes from the blood in a far greater proportion than the Law of Dalton would require. There occurs a dissociation of the combination of the oxygen with the hemoglobin, a dissociation whose intensity increases rapidly.

I have made a sort of control experiment using a method nearer that of M. Fernet, since instead of extracting the oxygen progressively by agitation at lower and lower pressures, I measured the quantity absorbed by blood that had previously been entirely deprived of gas.

Here are the results of three experiments carried out in this way. It will be seen that they agree, in their general trend, with those obtained by the first method.

Experiment CCII. December 30; pressure $762 \mathrm{~mm}$.

We prepare two mercury pumps and two apparatuses for extracting the gases of the blood, in which absolute vacuum is made.

From the jugular vein of a dog by means of a syringe $138 \mathrm{cc}$. of blood is drawn, and this blood is injected into a flask full of air; the blood is defibrinated and oxygenated by long shaking in the flask. $89.5 \mathrm{cc}$. of blood measured in a graduated test tube is passed into one of the pumps; this blood has been filtered through linen and freed of fibrin and air bubbles; the gases are extracted from the blood heated to a temperature of $35^{\circ}$ to $39^{\circ}$, until a dull click is heard; the blood is completely reduced. When the extraction has been made, the blood is cooled in cold water to about $10^{\circ}$.

The analysis of the gases extracted shows that $100 \mathrm{cc}$. of blood shaken in the air at a pressure of one atmosphere has absorbed 19.8 cc. of oxygen.

Air at a pressure of a half atmosphere is admitted to the empty apparatus; to do this, a long vertical tube, $T$ (Fig. 44) is used, into 
which mercury is poured; it is closed by a stopper with two holes, through which two glass tubes pass. One, $a$, is dipped into the mercury to a depth of $381 \mathrm{~mm}$., half of $762 \mathrm{~mm}$; it opens into the air and has a cock $r$. The second tube, $b$, which reaches merely to the upper part of the tube full of mercury, curves outside into a siphon which is joined by a rubber tube, $c$, to the central tube which projects from the middle of the little mercury basin $\mathrm{C}$ which tops the cock $\mathrm{R}$ of the gas

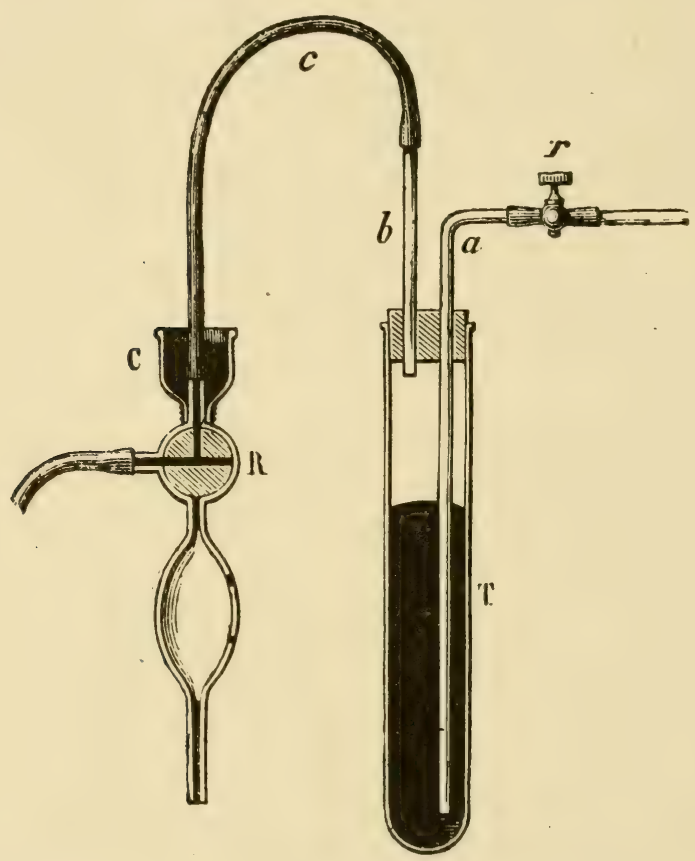

Fig. 44-Apparatus to bring blood into contact with the air at a specified decrease in pressure.

pump; when this cock is turned as the figure shows, and cock $r$ is opened carefully, the outer air is admitted bubble by bubble through the mercury, and when the air which has come in contact with the blood has a pressure equal to a half atmosphere, the outer air ceases to enter through tube $a$.

The blood then is agitated by raising and lowering the balloon of the extraction apparatus, and the agitation is made 25 times with air and with mercury; the blood becomes a very bright red. 
By working the pump and holding the balloon containing the blood above the horizon, the blood is made to pass into the barometric chamber and then into a syringe. In this way $69 \mathrm{cc}$. are obtained which are introduced into the second mercury pump. The extraction of the gases gives 14.5 cc. of oxygen; that is, per 100 volumes and after corrections, 19.8, exactly like the preceding.

So the blood absorbs exactly the same quantity of oxygen in both cases.

Experiment CCIII. December 31.

$100 \mathrm{cc}$. of dog blood absorbed at the ordinary pressure of $760 \mathrm{~mm}$. $32.4 \mathrm{cc}$. of oxygen. $100 \mathrm{cc}$. of the same blood, first deprived entirely of gas, absorbed under the pressure of $24 \mathrm{~mm}$., that is, at a pressure 32 times less, $26.1 \mathrm{cc}$. of oxygen.

Experiment CCIV. March 20 and 21. From a branch of the femoral artery of a terrier in good health $500 \mathrm{gm}$. of blood were taken and defibrinated by agitation in a flask.

In a large flask whose interior volume is equal to 4.335 liters, a vacuum is made by means of the pneumatic machine; next, the air is extracted by a mercury pump so as to bring the pressure of the remaining air to about 2 centimeters; $68 \mathrm{cc}$. of blood completely freed of gas by means of a mercury pump at $40^{\circ}$ are injected into the flask by means of a syringe, and the blood is shaken with the rarefied air for a half hour by the hydraulic motor. After the agitation, the pressure of the rarefied atmosphere is measured and the ascertained pressure of the water vapor tension at the temperature of the laboratory air is deducted, so as to obtain the pressure of the air assumed to be dry; it is only $152 \mathrm{~mm}$. The gases are extracted from the blood agitated with the air under this low pressure by passing the blood directly from the flask into an evacuated gas pump (the flask being weighed before and after).

2.) By means of a syringe, $68 \mathrm{cc}$. of blood freed of gas and $68 \mathrm{cc}$. of air are injected into the flask; agitation for a half hour, etc. . . . . In the following experiments, each time in the same way, $68 \mathrm{cc}$. of blood and $68 \mathrm{cc}$. of air are injected. Here are the results obtained after the necessary corrections:

$100 \mathrm{gm}$. of blood first freed of gases

At the pressure of $15 \mathrm{~cm}$. absorbed $7.3 \mathrm{cc}$. of oxygen.

At the pressure of $29 \mathrm{~cm}$. absorbed $9.9 \mathrm{cc}$. of oxygen.

At the pressure of $40 \mathrm{~cm}$. absorbed $12.3 \mathrm{cc}$. of oxygen

At the pressure of $51 \mathrm{~cm}$. absorbed $13.2 \mathrm{cc}$. of oxygen.

At the pressure of $75.6 \mathrm{~cm}$. absorbed $18.5 \mathrm{cc}$. of oxygen.

We conclude then from these data that down to low pressures the contradiction noted between experiments made in vitro on the capacity of blood for oxygen and the analyses of the blood of living animals exists entirely as it appeared to us at first. At all pressures, the blood, agitated in a flask, contains an almost equal quantity of oxygen (graph A of Fig. 43), whereas in the living animal the pro- 
portion of oxygen diminishes rapidly, as is shown by graph C, which reproduces graph $\mathrm{Ox}$ of Figure 31, and the analyses summarized in Table $\mathrm{X}$.

Considering this difficulty, I asked myself whether the high temperature of the animal's body could not cause some changes in the results I obtained at low temperatures. We knew already that to extract the oxygen of the blood completely we must add to the action of the vacuum that of a rather high temperature. I will report here an experiment which demonstrates this truth.

Experiment CCV. June 24. 65 cc. of defibrinated dog blood are placed at 4 o'clock in the receiver of a pump for the extraction of gases, in which an absolute vacuum had previously been made. The temperature is only $19^{\circ}$.

The blood is shaken repeatedly in the balloon and all the gas which will come out is extracted, but without warming it. We obtain thus, per $100 \mathrm{cc}$. of liquid, $11.2 \mathrm{cc}$. of oxygen, $20.0 \mathrm{cc}$. of carbonic acid, and $2.0 \mathrm{cc}$. of nitrogen.

This procedure is repeated until 6 o'clock; no more gas has come after several pump strokes, and the blood has remained bright red. The double-boiler is heated to the boiling point, and then, with a single pump stroke, the rest of the gas is extracted; the blood turns dark immediately. The quantity just extracted represents, per $100 \mathrm{cc}$. of blood: Oxygen 13.2; CO= 13.0; N 0.6.

So the blood contained in all: $\mathrm{O}=24.4 \mathrm{cc}$.; $\mathrm{CO}_{2} 33.0 ; \mathrm{N} 2.6$.

If this blood had been subjected to the experiments performed by the method previously described, and if a complete vacuum had been made in the agitation flask, at $19^{\circ}, 13.2 \mathrm{cc}$. of oxygen could have still been extracted by the heat. Temperature has, therefore. a great importance.

And so I set up the experiment in a slightly different manner. The agitation flask, instead of being fastened on the plank of Figure 42 , was solidly fastened underneath at a certain distance, so as to dip into a bath of lukewarm water whose temperature was kept at a fairly constant degree all through the agitation.

Here are the results of experiments made under these conditions.

Experiment CCVI. June 3. Dog blood; shaken for $1 / 2$ hour, the flask of 4.330 liters being submerged in water at $40^{\circ}$.

At $725 \mathrm{~mm}$. (deduction of water vapor tension) it contains: $\mathrm{O}_{2} \mathbf{1 5 . 4}$

At $280 \mathrm{~mm}$.: $\mathrm{O}_{2}$ 13.8.

At $100 \mathrm{~mm} . \mathrm{O}_{2} 8.5$.

Experiment CCVII. July 10. Dog blood; shaken for 20 minutes, the flask of 4.330 liters being submerged in water at $40^{\circ}$.

At $738 \mathrm{~mm}$. (with the usual deduction), the blood contains:

$\mathrm{O}_{2} 20.1 ; \mathrm{CO}_{2} 18.8 ; \mathrm{N} 1.5$. 
At $290 \mathrm{~mm} .: \mathrm{O}_{2} 16.4 ; \mathrm{CO}_{2} 13.0 ; \mathrm{N} 0.6$.

At $87 \mathrm{~mm} .: \mathrm{O}_{2} 11.3 ; \mathrm{CO}=8.6 ; \mathrm{N} 0.4$.

At $26 \mathrm{~mm} .: \mathrm{O}_{2} 7.2 ; \mathrm{CO}_{2} 7.0 ; \mathrm{N} 0.2$.

Experiment CCVIII. February 18. Defibrinated dog blood, interior temperature of the flask $38^{\circ}$. Agitation at normal pressure; blood contains $\mathrm{O}=20.2$.

At $38 \mathrm{~cm} .: \mathrm{O}_{2}$ 17.7.

At $19 \mathrm{~cm}$ : $\mathrm{O}_{2} \mathbf{1 6 . 4}$.

Experiment CCIX. February 26. Defibrinated dog blood. Agitation at normal pressure; interior temperature of the flask $38^{\circ}$; the blood contains $\mathrm{O}_{2} 18.2 ; \mathrm{CO}_{2} 10.1$.

At $38 \mathrm{~cm} .: \mathrm{O}_{2} 14.8 ; \mathrm{CO}_{2} 6.8$.

At $19 \mathrm{~cm} .: \mathrm{O}_{2} 10.6 ; \mathrm{CO}_{2} 7.0$.

These four experiments, when we get the averages, setting the origins of the graphs at 20 , give us graph B of Figure 43.

We see that the curve $B$ dips much more rapidly than the preceding $\mathrm{A}$, and more nearly approaches the one which, taken from Column 8 of Table $\mathrm{X}$, expresses the oxygen changes in the living animal, and is represented here in C. In other words, the contradiction noted loses much importance when we supply the temperature conditions given by the bodies of warm-blooded animals.

However, our analyses show that the arterial blood of a living animal subjected, for example, to a half atmosphere, could absorb a quantity of oxygen much greater than that which it really contains.

That is because the intra-pulmonary agitation of the blood with the air is no longer carried on in satisfactory conditions. Even at normal pressure, as we have seen, the arterial blood is not saturated with the oxygen which it can hold; it reaches that point of saturation-or nearly so-only after exaggerated respiratory efforts, which bring on an exaggeration of circulatory rapidity. At a half atmosphere, to obtain the same result as at ground level, the activity of intra-pulmonary mixing would have to be doubled; the respiratory movements must be doubled in amplitude and rapidity; the heart movements must be doubled in strength and number. That is evidently impossible.

Summarizing, the conclusions of M. Fernet's work are legitimate only under the conditions of pressure and temperature $\left(16^{\circ}\right)$ at which he worked. At lower pressures, at body temperature, the part of the oxygen which he considers as chemically combined in the blood because it is independent of the pressure, really follows the pressure changes, although considerably less quickly than a 
gas in simple solution would do. But in the living organism, this is complicated by an insufficient agitation of the blood in contact with the air, and so there results a much more rapid decrease of

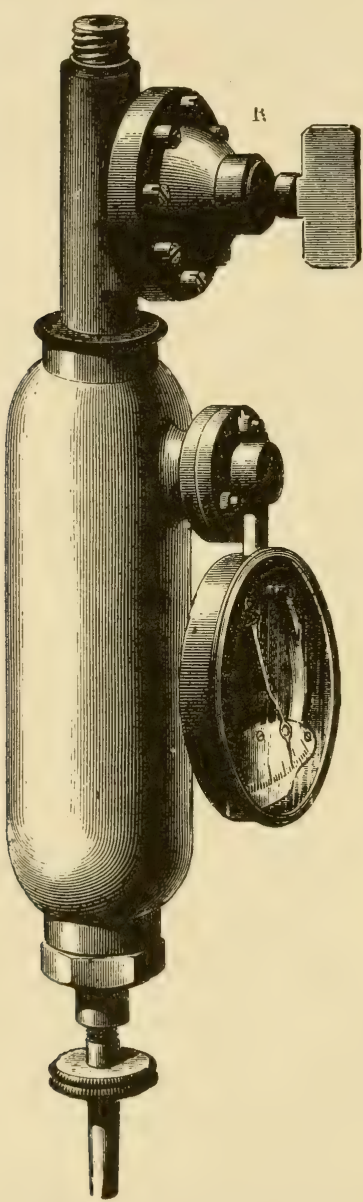

Fig. 45 - Apparatus to saturate blood with air at high pressures. R. Large cock by which compression is made. $r$. Capillary cock by which blood samples are taken. the oxygen of the blood than experiments in vitro would lead one to think.

\section{Increased Pressure.}

To study the absorption of oxygen by the blood at pressures greater than one atmosphere, I had made a bronze receiver, of a capacity of 175 cc., capable of resisting 25 atmospheres easily. (Fig. 45.) The procedure was very simple. In the apparatus, whose lower part could be unscrewed, was placed the defibrinated blood to be analyzed; I used about 100 cc. of it. Then, after the cylinder had been closed, I compressed the air by screwing on the compression pump, and closed cock $R$ when the manometer indicated that the desired pressure had been reached. I next agitated the apparatus by fastening it on the plank of Figure 42. Finally, to extract the blood into the graduated syringe, I had only to fit its extremity to the capillary cock $r$, which I halfopened; the air pressure immediately drove the blood out; a few strokes of the pump kept a constant pressure in the apparatus while the blood was being taken out. When I was dealing with very high pressures, when nitrogen dissolved in quantity was given off in the syringe, I substituted weight for volumetric measure, since the froth did not permit me to determine volume exactly.

When I wished to make an analysis at a certain compression, I began by supersaturating the blood by 
shaking it at a higher pressure, so as to be sure, when I had brought it to the desired pressure, that it really contained all the oxygen it could absorb. If several analyses at different pressures were to be made of the same blood, I followed the same procedure, beginning with the highest; this was quite legitimate, because the quantity of oxygen introduced into the apparatus under compression was always much greater than the blood could absorb. The pressure recorded in the experiment was the one read after the agitation and the absorption had been finished.

An important point was first determined: namely, that the increase of the oxygen contained in the blood was quite temporary and disappeared rapidly when the compression was over. The following experiment proved this.

Experiment CCX. June 20. Defibrinated dog blood.

At normal pressure, after long agitation, contains $\mathrm{O}=20.0$.

$100 \mathrm{cc}$. were put into the apparatus, and the compression was carried to 12 atmospheres, with superoxygenated gas, so that the oxygen tension corresponded to 44 atmospheres of air. After an agitation which was insufficient for complete saturation, the blood contained, per 100 cc.: $\mathrm{O}_{2} 37.7$.

I then placed in a flask the rest of the compressed blood, which was very red and contained much gas in suspension; the flask was whirled like a sling once, and 10 minutes after being taken from the apparatus, the blood contained only $20 \mathrm{vol}$. of oxygen, as at the beginning of the experiment.

We now come to the experiments carried on with care that the saturation should be complete; the pressure was made with ordinary air.

Experiment CCXI. June 20. Defibrinated dog blood.

At normal pressure contained $\mathrm{O}=20.0$.

At 12 atmospheres contained $\mathrm{O}=30.0$.

At 8 atmospheres contained $\mathrm{O}_{2} 25.7$.

At 4 atmospheres contained $\mathrm{O}=22.8$.

Experiment CCXII. January 22. Defibrinated dog blood.

At normal pressure contained $\mathrm{O}=20.2$.

At 18 atmospheres contained $\mathrm{O}=28.2$.

At 9 atmospheres contained $\mathrm{O}=25.9$.

I particularly call attention to the following experiment, which was carried out with the greatest precautions.

Experiment CCXIII. January 12. 500 cc. of blood taken from the femoral artery of a very large dog. This blood is defibrinated, filtered through linen, then shaken for a half hour with air at normal pressure; it contains 14.9 volumes of oxygen.

It is then placed in the apparatus; for each experiment, the agitation lasts a half hour. The findings were:

At 6 atmospheres, $\mathrm{O}=19.2$.

At 12 atmospheres, $\mathrm{O}_{2} 26.0$.

At 18 atmospheres, $\mathrm{O}=31.1$. 
Let us discuss the results of this last experiment.

Let us call $x$ the volume of supposed oxygen combined with the hemoglobin contained in $100 \mathrm{cc}$. of blood, a volume which, by hypothesis, would be independent of the pressure; let us call $y$ the volume of oxygen which $100 \mathrm{cc}$. of blood would absorb in a state of simple solution as a result of agitation in the air at normal pressure; we shall have:

$$
\begin{aligned}
& \text { At } 1 \text { atmosphere } \mathrm{x}+\mathrm{y}=14.9 \text { (1) } \\
& \text { At } 6 \text { atmospheres } \mathrm{x}+6 \mathrm{y}=19.2(2) \\
& \text { At } 12 \text { atmospheres } \mathrm{x}+12 \mathrm{y}=26.0 \text { (3) } \\
& \text { At } 18 \text { atmospheres } \mathrm{x}+18 \mathrm{y}=31.1 \text { (4) }
\end{aligned}
$$

Let us subtract (1) from (4), and we get $17 \mathrm{y}=16.2$; whence $\mathrm{y}=0.95$; from the equation (1) we then get $\mathrm{x}=14.9-0.95=13.95$.

Substituting these values in equations (2) and (3), we find the figures 19.6 and 25.4, instead of 19.2 and 26, differences which are quite in the order of experimental errors.

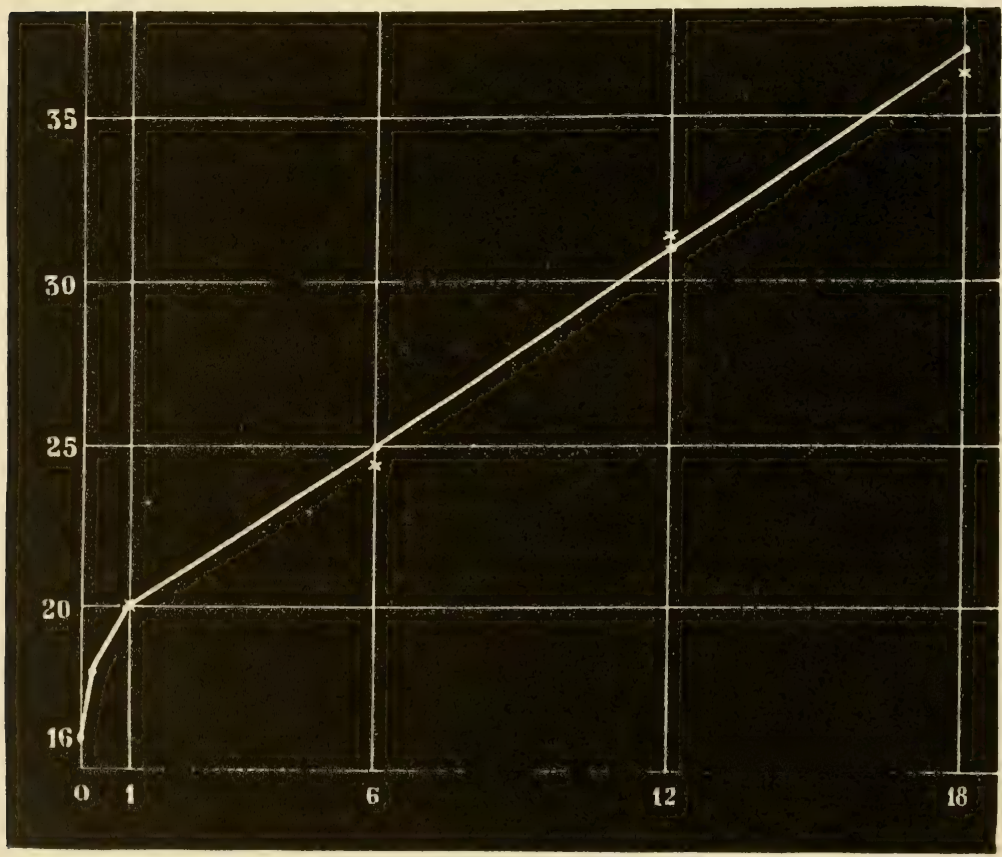

Fig, 46-Capacity of the blood for oxygen, from a vacuum up to 18 atmospheres of air. 
So the hypothesis is verified, and above 1 atmosphere, the pressure adds to the blood only the oxygen dissolved, whose increasing proportion follows Dalton's Law.

If then we take 20 as average proportion of oxygen contained in the blood at normal pressure, and if we assume, to make the calculation easy, that there is one volume dissolved, we shall find that at 6 atmospheres there will be 25 volumes; at 12 atmospheres, 31 volumes; at 18 atmospheres, 37 volumes.

These last results are marked on the graph of Figure 46 by points whose series naturally forms an absolutely straight line. Now if we had drawn on the same scale the graph of Experiment CCXIII and had then traced back the whole to its point of origin (14.9) on the line marked 20, the four points of this graph would be represented by the little crosses on the graph. We see how close they are to the theoretical points.

There has been added between 1 atmosphere and vacuum a reduction of graph A of Figure 43, which completes the survey of the capacity of blood for oxygen, from the lowest to the highest pressures.

The question arose whether for high pressures the temperature would cause any important difference in the capacity of the blood for oxygen. Since the experiments which I have just reported were carried on at the temperature of the laboratory, I performed another, shaking the blood in a bath kept at $40^{\circ}$. As the results agreed with the preceding, I thought it unnecessary to gather more data.

Here is the experiment.

Experiment CCXIV. January 15. 300 grams of arterial blood were drawn from a large dog, and were defibrinated and filtered through linen.

I placed 130 grams in the apparatus of Figure 31; I compressed the air to 22 atmospheres, and agitated the blood and the air for a half hour, the apparatus being submerged in water at $40^{\circ}$.

I lowered the pressure to 18 atmospheres, and 5 minutes after, I removed 28 grams of blood .... A

The pressure being lowered immediately to 12 atmospheres, I agitated the blood again and removed 33 grams .... B

A similar procedure gave me at 6 atmospheres 41 grams of blood. $\ldots \mathrm{C}$

Finally, at normal pressure, I had left 20 grams of blood .... D The analysis by the pump showed that:

A (18 atmospheres) contains, per 100 volumes: $\mathrm{O}=35.7 ; \mathrm{N} 19.2$.

B (12 atmospheres) contains, per 100 volumes: $\mathrm{O}: 30.9$; N 15.1 .

C (6 atmospheres) contains, per 100 volumes: $\mathrm{O}=27.1 ; \mathrm{N} 7.8$.

D (1 atmosphere) contains, per 100 volumes: $\mathrm{O}: 23.0 ; \mathrm{N} 1.3$. 
Using on these figures the calculations which have just been applied to Experiment CCXIII, we find for the coefficient of the oxygen dissolved 0.75 and for the values of B and C 31.2 and 26.7. The difference between the calculation and the experiment is, therefore, in the first decimals, and should not disturb us.

And so at body temperature, as at laboratory temperature, when the pressure is increased, the increase in the oxygen proportion follows Dalton's Law.

On the other hand, if we refer to what was observed directly in the living animal (Fig. 36, solid line), we see that the quantity of oxygen contained in the blood is considerably less than its maximum capacity in vitro.

This is in part due to the fact that the oxygen in simple solutior in the serum tends to penetrate also by simple solution into all the organic liquids and the tissues bathed by the blood, until an equilibrium of solution is established between them and this serum.

The slowing up of the respiratory movements and the circulation of the blood, so easy to observe in cold-blooded animals at high pressures, certainly is an added factor in the diminution of the quantity of oxygen introduced into the blood, by modifying the conditions of the air-blood agitation taking place in the lungs. There would be, on the part of the organism, a struggle for equilibrium, working inversely to that which we stressed above.

If we now refer to this observation already made several times that the blood in the conditions of normal respiration is never saturated with the oxygen that it can absorb, we shall perceive that when the increase of pressure introduces a little more oxygen into the blood, this oxygen will first be rapidly condensed by the blood corpuscles, so that the hemoglobin of the blood is completely saturated before a larger proportion remains in the serum.

But from the purely chemical point of view, the data which I have just reported present a new interest when they are compared with those recently obtained by MM. Risler and Schutzenberger. ${ }^{10}$ According to these chemists, the blood, or rather the hemoglobin, from which all possible oxygen has been removed by the action of the vacuum or of carbon monoxide, would still contain a quantity almost equal to what it has just lost.

There would therefore be here a sort of protoxy-hemoglobin, which the vacuum, even when aided by heat, and which the carbon monoxide could not reduce, and a deutoxy-hemoglobin, from which the vacuum and the carbon monoxide could take its second equivalent of oxygen. Beyond that, the hemoglobin, completely saturated. could take up no more oxygen, whose proportion would increase 
only by simple solution in the ambient serum. That strongly recalls the mode of union of the carbonic acid with the alkaline bases, whose protocarbonates are indecomposable by a vacuum, whereas the deuto-carbonates at very low barometric pressures lose their second equivalent of acid, as we have known since the research of $\mathrm{H}$. Rose. The whole blood then would behave towards oxygen as a solution of bicarbonate of soda does towards carbonic acid. In both cases, it is 1.) in solution in water and its proportion there can be indefinitely increased according to Dalton's Law; 2.) in union easily dissociated by a vacuum aided by heat; 3 .) in union unaffected by a vacuum and heat.

This resemblance is very striking if we note the manner in which this gas leaves the blood when the blood is agitated with air at different barometric pressures.

The agitation of blood with pure air, at normal pressure, very slowly takes from it a part of its carbonic acid, without being able to take it away altogether. If the air is expanded, the gas escapes a little more quickly. However, the experiments which have just been reported above show that, even at quite low pressures, the blood does not lose its carbonic acid quickly. However, this gas leaves the blood in slightly larger proportions than the oxygen;

$\mathrm{CO}_{2}$

so we see the proportion - lose value directly as the decompres$\mathrm{O}_{2}$

sion is increased (Exp. CXCIX, CC, and CCI).

On the other hand, when I brought about a progressive vacuum on blood placed in the mercury pump, I found that the acid left the blood in considerable proportions only at very low pressures, almost at the same time as the oxygen. In other words, the bicarbonates and the alkaline phospho-carbonates behave in the vicinity of a vacuum like the deutoxy-hemoglobin of which I was speaking a little while ago.

${ }^{1}$ Note sur les analyses du gaz du sang; infucnce de l'eau.-Proceedings, vol. LXXIV, p. $330 ; 1872$. The memoir is published in full in the Journal de l'Anatomie et de la Physiologie, vol. VIII, p. $187-200 ; 1872$.

2 The numbers expressing the volumes of the blood gases have always been reduced to the temperature of $0^{\circ}$ and the pressure of $76 \mathrm{~cm}$

${ }^{3} \mathrm{Du}$ siege des combustions respiratoires. Journal de l'Anatomie et de la Physiologie, vol. II, p. $302-322 ; 1865$.

Lecons, etc., p. 119.

${ }^{5}$ Des gaz du sang. Archives de Physiologie, vol. IV, p. 5-26, 190-203, 304-318, 447-469, 573-58i, $710-731 ; 1871$

Lecons, etc., p. 130 et seq.

Lecons sur la physiologie de la respiration, p. 161.

'Comptes rendus de la Société de Biologie for 1871 , p. 61.

- Traité de physiologie. Third edition, vol. V, p. 592; 1868.

10 Comptes rendus de l'Académie des sciences, vol. LXXVI, p. 440; February, 1873. 


\section{Chapter III}

\section{PHENOMENA PRESENTED BY ANIMALS SUBJECTED TO PRESSURES LESS THAN THAT OF THE ATMOSPHERE}

The phenomena presented by animals subjected to a decrease of pressure are exactly those which were noted in mountain travellers and aeronauts; however, I have some interesting details to add to what is already known. But I do not hesitate to confess that since these phenomena are of a purely descriptive nature, it seems to me that an exact analysis of them should be made only after a sufficiently detailed study of their cause; interest in them was obviously a minor matter.

I think, however, that I should report here the details of some experiments. It will then be easier to analyze the observations made and to group them around the principal physiological functions. But the conclusions which we draw from them will be supported equally by the numerous experiments reported in the first subchapter of Chapter I, and the second subchapter of Chapter II, experiments which I thought it unnecessary to describe again here.

After detailing these symptoms, I shall compare them with those presented by animals asphyxiated in closed vessels at normal pressure; I shall then deduce from all these facts the method which must be used in warding off the dangers of decompression, and I shall report the experiments carried out according to this method upon animals and even upon man. 


\section{Subchapter I SYMPTOMS OF DECOMPRESSION}

Experiment CCXV. March 2. Little dog, put into the big cylinder. 2:05; Normal pressure; respiratory rate 16 .

2:15; Pressure $40 \mathrm{~cm}$. respiratory rate 16 .

2:20; Pressure $26 \mathrm{~cm}$. respiratory rate 24 .

2:26; pressure $22 \mathrm{~cm}$. respiratory rate 40 . Lies down; respiration dicrotic; it breathes first by the thorax, and then the abdomen rises.

2:36; Pressure $20 \mathrm{~cm}$; respiratory rate 44.

2: 42; Pressure $19 \mathrm{~cm}$; respiratory rate 36 .

2:47; Pressure $18 \mathrm{~cm}$; respiratory rate 40.

2: 55; Inlet cock opened a little; pressure rises to $21 \mathrm{~cm}$. Respiratory rate falls to 30 . Cock closed. At 3:00, the pressure is only $19 \mathrm{~cm}$.; respiratory rate remains 30 .

3: 05; Pressure $18 \mathrm{~cm}$; Respiratory rate 28.

3: 10; Pressure $22 \mathrm{~cm}$; Respiratory rate 18 .

3: 14; Pressure $23 \mathrm{~cm}$.; Respiratory rate 16 .

3: 16; Pressure $25 \mathrm{~cm}$; Respiratory rate 14 .

$3: 18$; Return to normal pressure.

$3: 24$; Respiratory rate 14 .

The animal is in good condition.

Experiment CCXVI. March 21. Large spaniel at 3 o'clock in the large decompression cylinder. Its rectal temperature is $38.5^{\circ}$. At 4:58, pressure is only $25 \mathrm{~cm}$. Normal pressure rapidly restored; temperature of the animal dropped to $36.5^{\circ}$.

Experiment CCXVII. April 2. Female bulldog, having already had some operations; fastened in the same apparatus.

4:40 at normal pressure respiratory rate 24 , pulse 125 , rectal temperature $39^{\circ}$.

4: 45 ; pressure $46 \mathrm{~cm}$; respiratory rate 24 , pulse 110 .

4:55; pressure $36 \mathrm{~cm}$, respiratory rate 22 , pulse 100 .

5:05; the pump is stopped and the air returns to normal pressure; respiratory rate 20 , pulse 120 .

The femoral artery has been bared and around it has been placed a copper wire which records its movements and allows the pulse to be counted.

$5: 35$; the pump is set in operation and has brought the pressure to $46 \mathrm{~cm}$; respiratory rate 18 , pulse 104 .

5: 45; pressure $36 \mathrm{~cm}$., respiratory rate 24 , pulse 100 .

$6: 15$; pressure $41 \mathrm{~cm}$., respiratory rate 18 , pulse 100 .

6:20; normal pressure; rectal temperature $38.8^{\circ}$.

Experiment CCXVIII. April 23. Dog, which has been given a hypodermic injection of 5 centigrams of morphine hydrochloride.

At $4: 30$, put into the large cylinder with a manometer in the left femoral artery. Respiratory rate 20, pulse 126 .

At $4: 32$, pressure is $60 \mathrm{~cm}$., respiratory rate 24 and pulse 120 .

At 4:35, pressure is $45 \mathrm{~cm}$., respiratory rate 33 and pulse 184 . 
At 4:40, pressure normal; respiratory rate has fallen to 24 and pulse to 160 . The arterial pressure cannot be ascertained exactly because of clots.

Experiment CCXIX. May 27. Dog, fastened in the big apparatus, femoral artery exposed and cardiometer inserted.

5:40. Normal pressure; respiratory rate 30 ; pulse 134; arterial pressure 16 to $18 \mathrm{~cm}$.

5:55. Pressure $36 \mathrm{~cm}$; respiratory rate 60 ; the animal has been struggling occasionally.

6:05. Pressure $26 \mathrm{~cm}$; respiratory rate 70 , uneven. Connection made between artery and manometer; mercury rises and oscillates between 16 and $18 \mathrm{~cm}$. Pulse rate 160 to 180 per minute.

Return to normal pressure in five minutes; respiratory rate 20. The animal returns to normal state rapidly.

Experiment CCXX. April 22. Cat brought rapidly to $26 \mathrm{~cm}$. of pressure under a current of air at 2:30. Cannot stand up, lies down mewing.

$3: 20$. Respiratory rate 33 .

$3: 30$. Brought back to $36 \mathrm{~cm}$. because it seemed too sick.

5:30. Still lying curled up.

Taken out at 6 o'clock; did not urinate.

Kept under bell, but at normal pressure, under continued current of air.

April 23. 10 o'clock in the morning, taken out. Has urinated; its urine contains no sugar.

Recovers entirely.

Experiment CCXXI. May 14. Cat weighing $3.500 \mathrm{k}$. Hypodermic of 10 centigrams of morphine hydrochloride. It is placed under a large glass bell with a volume of 31 liters; its femoral artery is exposed, and a copper wire passed around it records the pulse. The animal remains quiet all through the experiment.

At 4:30, at normal pressure, respiratory rate 25; pulse 105 .

Lowering of the pressure is then begun, leaving a current of air, weak but sufficient to maintain the chemical purity of the air of the bell.

At 4:50, pressure $56 \mathrm{~cm}$; respiratory rate 40 , pulse 120 .

At $5: 10$, pressure $46 \mathrm{~cm}$; respiratory rate 40 , pulse 120 .

At 5:20, pressure $36 \mathrm{~cm}$; respiratory rate 48, pulse 132 .

At 5:30, pressure $26 \mathrm{~cm}$.; the animal is much affected, weak, with frequent convulsive starts; drools; respiratory rate 56, pulse 140 .

Pressure is lowered slowly to $20 \mathrm{~cm}$; the animal pants, shows general convulsive movements, and dies at 5:45.

The lungs are collapsed, without crepitation; superficial emphysema; no pulmonary apoplexy.

Dark blood in the left heart.

Experiment CCXXII. February 28. Temperature $13^{\circ}$.

Three rabbits of the same litter are placed at 2 o'clock under large bells, on the apparatus in Figure 1. A current of air is maintained under different pressures. 
A: the rabbit weighs $770 \mathrm{gm}$.; pressure is maintained between 70 and $76 \mathrm{~cm}$.

B weighs $770 \mathrm{gm}$.; pressure oscillates between 45 and $50 \mathrm{~cm}$.

C weighs $840 \mathrm{gm}$.; pressure oscillates between 38 and $40 \mathrm{~cm}$.

At 2:30: for rabbit A, respiratory rate 70; for B, 80; for C, 120.

They are removed at 6 o'clock without having shown any remarkable phenomena.

Temperature of $\mathrm{A}, 39.5^{\circ}$; of $\mathrm{B}$ and $\mathrm{C}$, only $38^{\circ}$.

March 3, experiment repeated with the same results. Rabbit B, which was brought to $36 \mathrm{~cm}$., then shows convulsive movements, which do not last. It urinates under the bell; this urine contains no sugar.

Experiment CCXXIII. March 18. Rabbit under a large bell of 31 liters.

$3: 15$, for a quarter of an hour has been under a current of air at diminished pressure; it has remained perfectly quiet, with a respiratory rate of 94 , the pressure being $56 \mathrm{~cm}$.

$3: 20$, pressure $46 \mathrm{~cm}$., respiratory rate 86 .

$3: 25$, pressure $42 \mathrm{~cm}$., respiratory rate 66 .

$3: 30$, pressure $42 \mathrm{~cm}$., respiratory rate 64 .

$3: 38$, pressure $35 \mathrm{~cm}$., respiratory rate 70 .

3: 50 , pressure $15 \mathrm{~cm}$., respiratory rate 90 .

$3: 53$, pressure $16 \mathrm{~cm}$., respiratory rate 45 , shallow.

Dies at 4 o'clock. Air admitted; the animal, which was swollen, collapses. Dark blood in the left heart; a few pulmonary ecchymoses.

Experiment CCXXIV. March 20. Rabbit of 2.7 kilos under the large bell; temperature $20^{\circ}$.

Placed at 2:26 under a current of air with diminishing pressure.

$2: 30$, pressure $56 \mathrm{~cm}$., respiratory rate 105 .

2:36, pressure $41 \mathrm{~cm}$., respiratory rate 99 .

There is a leak, air enters, and the pressure falls to O; respiratory rate 81 .

2: 46 , pressure back at $50 \mathrm{~cm}$., respiratory rate 138 .

2: 50 , pressure $44 \mathrm{~cm}$., respiratory rate 105 .

2: 54 , pressure $36 \mathrm{~cm}$., respiratory rate 120 .

$3: 10$, pressure $27 \mathrm{~cm}$., respiratory rate 102 .

Remains between 27 and $24 \mathrm{~cm}$. until $4: 18$; respiratory rate 84 .

The animal kept at the same pressure struggles violently at $6: 20$, falls on its back, makes 3 or 4 deep respiratory movements, then remains motionless, dies.

Interior temperature of the bell is $20^{\circ}$; that of the rabbit $32^{\circ}$.

Experiment CCXXV. May 22. Free rabbit in the large bell of 31 liters. At the beginning, respiratory rate 56 .

Pressure is rapidly lowered to $56 \mathrm{~cm}$., and the animal is kept there 20 minutes; its respiratory rate increases to 60 .

Pressure lowered to $36 \mathrm{~cm}$; respiratory rate rises to 100 . But the animal remains quiet, without apparent inconvenience.

Pressure lowered to $26 \mathrm{~cm}$., to $22 \mathrm{~cm}$., without the rabbit seeming much affected. At $16 \mathrm{~cm}$., symptoms appear. At $12 \mathrm{~cm}$., it struggles violently, is seized with general convulsions, and dies in a minute. 
The lungs are the seat of great congestion, with hemorrhagic spots and scattered emphysema. Their density is greatly increased, but they still float.

Experiment CCXXVI. May 23. Rabbit. Same bell, same decompressions, same general results.

Experiment CCXXVII. March 10. Temperature $15^{\circ}$. Guinea pig weighing $320 \mathrm{gm}$. placed in the bell of 27 liters. At 2:50, I open the communicating cock between this bell and a large cylinder in which the pressure has been greatly lowered; the pressure in the bell instantly falls to $16 \mathrm{~cm}$. The animal does not appear to suffer. Respiratory rate 129 .

Since the bell is not entirely air-tight, the pressure rises slowly.

At $3: 13$, it is $21 \mathrm{~cm}$; respiratory rate 104 . I then open the cock; the pressure drops to $17 \mathrm{~cm}$; the animal falls on its side, and rises almost instantly; respiratory rate 112 .

At 3:32, pressure $19 \mathrm{~cm}$., respiratory rate 120 ; animal quiet.

At $3: 35$, third opening of the cock; pressure drops to $16.5 \mathrm{~cm}$.; staggers slightly.

At $3: 42$, the pressure has risen to $18 \mathrm{~cm}$. Fourth opening of the cock; pressure falls to $13.5 \mathrm{~cm}$.; the guinea pig falls on its side; respiratory rate 108 .

At 3:45, pressure $14 \mathrm{~cm}$; respiratory rate 78 ; on its side.

At 3:51, pressure risen to $17 \mathrm{~cm}$. Fifth opening of the cock; pressure falls to $11.5 \mathrm{~cm}$; the animal, which had risen slightly, lies down slowly; respiratory rate 36 .

At 3:55, pressure $13 \mathrm{~cm}$.; respiratory rate 69 ; on its side.

4:01, pressure $14.5 \mathrm{~cm}$.; respiratory rate 92 ; recovered considerably.

$4: 08$, pressure $14.7 \mathrm{~cm}$., respiratory rate 90 . Violent jerking of the feet, the subcutaneous muscles, and the head; from this point to the end, the jerking keeps increasing.

$4: 13,16 \mathrm{~cm}$.; respiratory rate 93 .

$4: 15$, sixth opening of the cock; pressure falls to $13.5 \mathrm{~cm}$; a little more jerking, but the animal remains on its feet; respiratory rate rises to 108.

4:21, pressure $15 \mathrm{~cm}$; respiratory rate 85 .

$4: 30$, pressure $16 \mathrm{~cm}$., respiratory rate 90 ; seventh opening of the cock; pressure $11.5 \mathrm{~cm}$; the animal, which has been crouching, raises its head twice, then lies down slowly. The violent jerking stops for a few minutes.

$4: 33$, pressure $13 \mathrm{~cm}$; respiratory rate 52 .

4:39, pressure $15 \mathrm{~cm}$; the animal has remained lying down. Pressure lowered to $12 \mathrm{~cm}$; does not seem to notice it.

$4: 46$, pressure $14.5 \mathrm{~cm}$; respiratory rate 66 .

$4: 53$, ninth opening of the cock; pressure falls to $11.5 \mathrm{~cm}$; the animal raises its head, but remains lying down.

4:55, pressure $12 \mathrm{~cm}$.; respiratory rate 84 .

$4: 58$, pressure $13 \mathrm{~cm}$., respiratory rate 60 .

4:59, tenth opening, which lowers the pressure to $10.7 \mathrm{~cm}$.; the animal struggles considerably, and gets on its side.

5:00, pressure $11 \mathrm{~cm}$.; respiratory rate 55 . 
5:03, pressure $12 \mathrm{~cm}$.; respiratory rate 60 .

5:12, pressure $13 \mathrm{~cm}$.; I lower it to $11.7 \mathrm{~cm}$.; no apparent effèct.

$5: 20$, pressure $14 \mathrm{~cm}$.; respiratory rate 65 .

$5: 22$, twelfth opening; pressure falls to $10.8 \mathrm{~cm}$.

The animal twists and rolls on its side, with tonic and clonic convulsions.

5:24, pressure 11.7. The convulsions have ceased; only slight quivering of the feet; it remains lying down, and never gets up again.

$5: 37$, pressure $14.7 \mathrm{~cm}$.; respiratory rate 80 .

5: 40, pressure $15 \mathrm{~cm}$; lowered to $11.7 \mathrm{~cm}$.; the animal does not move but is evidently swelling.

5:53, pressure $15.5 \mathrm{~cm}$; same state. Fourteenth opening of the cock; lowered to $12.5 \mathrm{~cm}$.

6:45, pressure $19 \mathrm{~cm}$; animal in same condition. Communication with outside air opened wide. Swelling diminishes, but the animal breathes no better; it is almost insensible; its rectal temperature has fallen to $20^{\circ}$.

It remains lying on its side and dies in the night.

No ecchymoses in the lungs.

Experiment CCXXVIII. June 11; temperature $21^{\circ}$. Guinea pig, weighing 485 grams; put under a bell of 13.5 liters.

From 3:24 to $3: 30$, the pressure is lowered to $26 \mathrm{~cm}$.; the animal has not been struggling; but then he staggers, then recovers fairly well, scratches his nose, etc.

At $3: 32$, same state; respiratory rate 100 ; walks a little.

At $3: 34$, lowered to $20 \mathrm{~cm}$; respiratory rate rises to 135 ; the animal remains motionless.

At $3: 35$, pressure $17.5 \mathrm{~cm}$.; lies down on its belly.

At $3: 40$, pressure $13.7 \mathrm{~cm}$; respiratory rate 80 , deep, painful; pupils soon dilate; slight convulsive jerking comes on.

At 3:45, same pressure maintained; the animal falls on its side; convulsive movements, with rigidity. Belly enormously swollen.

Dies at $3: 49$.

At $4: 02$, rectal temperature is $34.6^{\circ}$.

Experiment CCXXIX. June 17; temperature $22^{\circ}$. Guinea pig in the large bell; current of air.

From 2:50 to $3: 45$, pressure is lowered to $36 \mathrm{~cm}$.

Then, progressively, from $3: 45$ to $4: 20$, to $13 \mathrm{~cm}$.; respiratory rate is then 20 , and the animal remains lying on its side.

At $4: 25$, pressure lowered for an instant to $10 \mathrm{~cm}$.

The animal makes convulsive movements of the feet and head; the breathing is difficult and jerky.

Pressure maintained at $12 \mathrm{~cm}$. until 4:40, then returned to normal.

Its rectal temperature is then $25^{\circ}$. Very soon it rises on its feet; regains strength, gets warm; at $4: 50$, its rectal temperature has risen to $31^{\circ}$.

It dies.

Let us now examine the results of these experiments successively from the point of view of the different physiological functions. 


\section{Respiration.}

In general, the respiration quickens when the pressure is lowered. But nothing is more irregular than these modifications in the respiratory rate. Here the effect of the suddenness of the phenomena is of greatest importance. The animal is startled, stirs about, struggles; it is irritated by the expansion of gases of which I shall speak under the heading of digestion, and all these effects accelerate its breathing. But it often happens that the respiration grows slower and becomes deeper; that is almost the rule at very low pressures. This is noticed particularly when the animal remains quiet; agitation has always seemed to me to speed up the breathing.

In a word, here as in all the other circumstances, lessening of pressure acts the same as asphyxia. We know that in asphyxia in a closed vessel there is also a phase of respiratory acceleration, followed by a phase of retardation in which the thoracic movements are made slowly and painfully. The experiments reported in Chapter I also show frequent examples of this respiratory acceleration in animals kept at various low pressures.

But to show how difficult it would be to include all these facts in a general formula, it is sufficient to study the experiments closely, being careful especially to show by graphs the results in which comparison is difficult.

In Figures 47 and 48, in which the graphs show only respiratory movements, and in Figures 49, 50, and 51, in which the pulse rate is also plotted, the direction of the arrows indicates the series of successive alterations in pressure to which the animals were subjected. When the arrow points to the right, the pressure decreases; towards the left, it increases. Pressures are reckoned on the axis of the abscissae; on the vertical axis are written the numbers corresponding to the respiratory movements $\mathrm{R}$ and to the pulse $\mathrm{P}$.

Line B (Fig. 47) gives the details of Experiment CCXV, made on a dog. We see that here effects were produced in a simple and regular manner, the number of respirations increasing or decreasing inversely as the pressure.

Line A, on the contrary (Exp. CCXVII, another dog), shows a singular complication; in a general way, the number of respiratory movements decreases as the pressure decreases.

We note similar differences with rabbits. While Experiment CCXXV shows a simple relation between the pressure and the number of respiratory movements, Experiment CCXXIV, repre- 
sented by line C, and Experiment CCXXIII, represented in D, seem to defy any generalization.

But the maximum of complication imaginable is furnished by

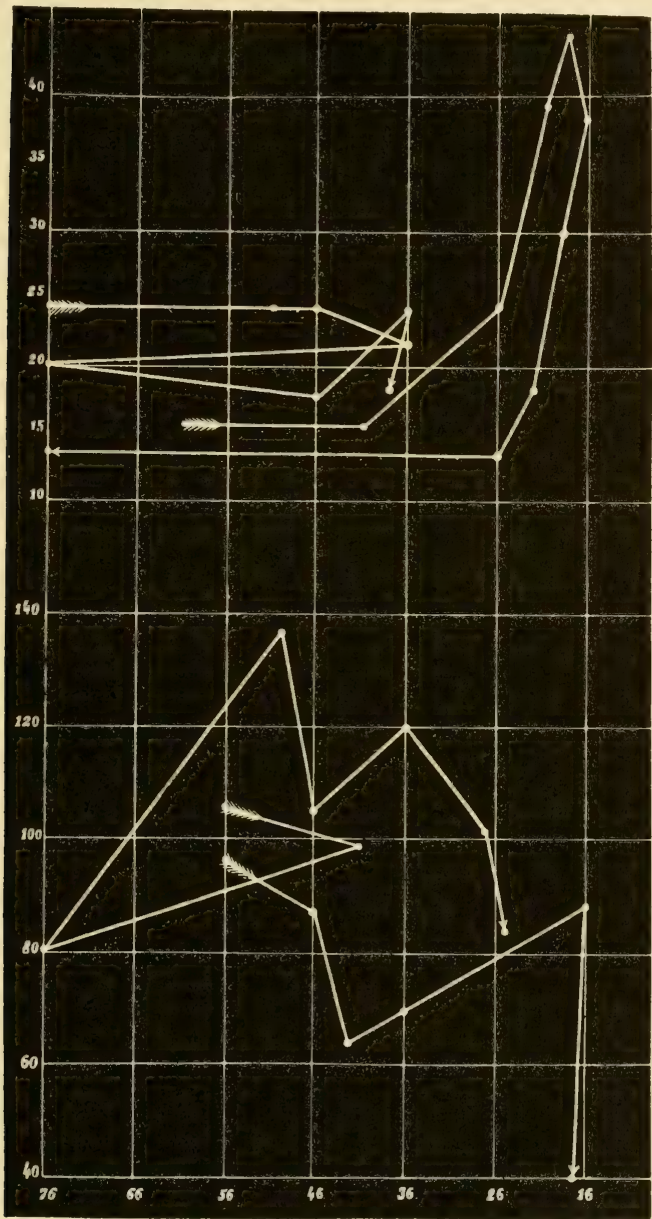

Fig. 47-Modification of the number of respiratory movements under the influence of decompression: A, B, dogs; C, D, rabbits, 
the graph of Figure 48, representing Experiment CCXXVII, made on a guinea pig.

Indeed, we find all possible combinations and the most astonishing differences in both the direction and the amount of the modifications in respiratory rate. Let us remember that this experiment had an exceptional duration, and that the animal had been

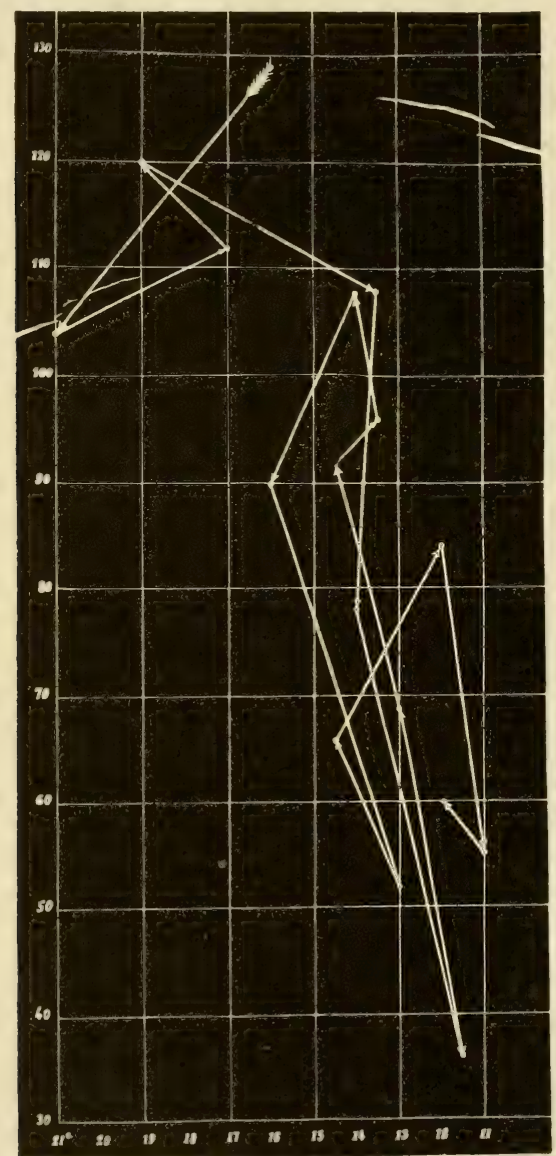

Fig. 48-Modification of the number of respiratory movements under the influence of decompression: Guinea pig, Experiment CCXXVII. 
chilled to the point of death before being returned to normal pressure.

These facts, which I might have multiplied, serve to show that outside the general rule are found numerous exceptions, which explain the lack of agreement on this subject among observers on mountains and aeronauts. We shall return to this point later.

Finally, let us note that besides the rate, respiration is affected in its rhythm; it becomes irregular, often dicrotic, sometimes deeper, and I have seen it in dogs at very low pressures separated into two parts: thoracic inspiration and then diaphragmatic inspiration. Moreover, every general movement is accompanied by a sort of anhelation. All that agrees with what has been observed in man.

The lessening of the maximum of respiratory capacity was shown by an experiment made upon myself, the details of which will be given in Subchapter III. At normal pressure it was represented by the number 17.3, arbitrary value; at $430 \mathrm{~mm}$. of pressure. it had fallen to 11.8, and after a half-hour stay under pressures of about $420 \mathrm{~mm}$., it was only 9.9 .

\section{Circulation.}

Besides the experiments reported above, I think I should give the details of one which I made upon myself.

Experiment CCXXX. July 29, the temperature being $23.5^{\circ}$, the pressure $75.5 \mathrm{~cm}$., I enter the large cylinder, and sit down there, remaining very quiet.

At 2:35, my pulse rate was 64 , at normal pressure.

At 2:45, pressure $72 \mathrm{~cm}$.; pulse rate only 60 ; perhaps resting alone was enough to cause this drop.

At 2: 55 , pressure $63 \mathrm{~cm}$; pulse 63 .

At 3 o'clock, pressure $60 \mathrm{~cm}$; pulse 67 . I am now forced, by the expansion of the intestinal gases, to open my garments wide.

At 3:08, pressure $55 \mathrm{~cm}$.; pulse 67 . I now rise and take two or three steps in the cylinder; my pulse immediately rises to 80 .

I let the pressure slowly rise.

At 3:15, pressure $62 \mathrm{~cm}$; pulse 63 .

At 3:24, pressure $72 \mathrm{~cm}$; pulse 60 .

At $3: 28$, return to normal pressure; pulse only 59 .

I leave the cylinder and walk rather rapidly in the laboratory; my pulse rises only to 67 .

I have experienced no disagreeable sensations, except the tension of intestinal gases, and a need of swallowing my saliva frequently to clear the Eustachian tube.

The experiments upon myself, whose details Subchapter III of the present chapter will recount, give the same results. 
We see that in the decompression chamber the circulatory acceleration appears quickly, as aeronauts had already observed. It increases considerably at the slightest movements.

Experiments on animals give evidence of the same sort. They usually show remarkable agreement between the variation of the number of respiratory movements and that of the cardiac beats.

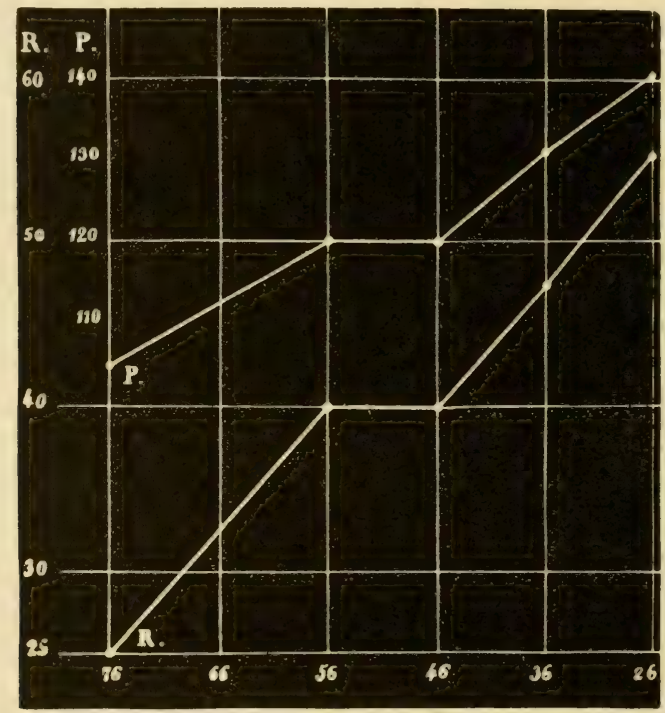

Fig. 49-Simultaneous modifications of the number of respiratory movements $\mathrm{R}$ and the pulse $\mathrm{P}$ under the influence of decompression. Cat, Experiment CCXXI.

Figure 49 gives a remarkable example of this, taken from Experiment CCXXI, made on a cat. The line of the pulse is marked $\mathrm{P}$; it corresponds to Column $\mathrm{P}$ of the ordinates. The line of the respiration is indicated by the letter $R$, as is the value of its ordinates. The pressures are reckoned on the axis of the abscissae.

The same agreement, though less constant, is observed in Figure 50, which shows the observations made during Experiment CCXVIII.

Finally, in Figure 51, which gives the strange results of Experiment CCXVII, we see that if the number of respiratory movements diminishes with the pressure, the same is approximately true of 
the heart beats. The latter even follow this general rule much more exactly than the former.

Because of the clots which formed in the arteries and the apparatuses, it has been almost impossible for me to measure in a consistent manner the modifications of the cardiac pressure. The
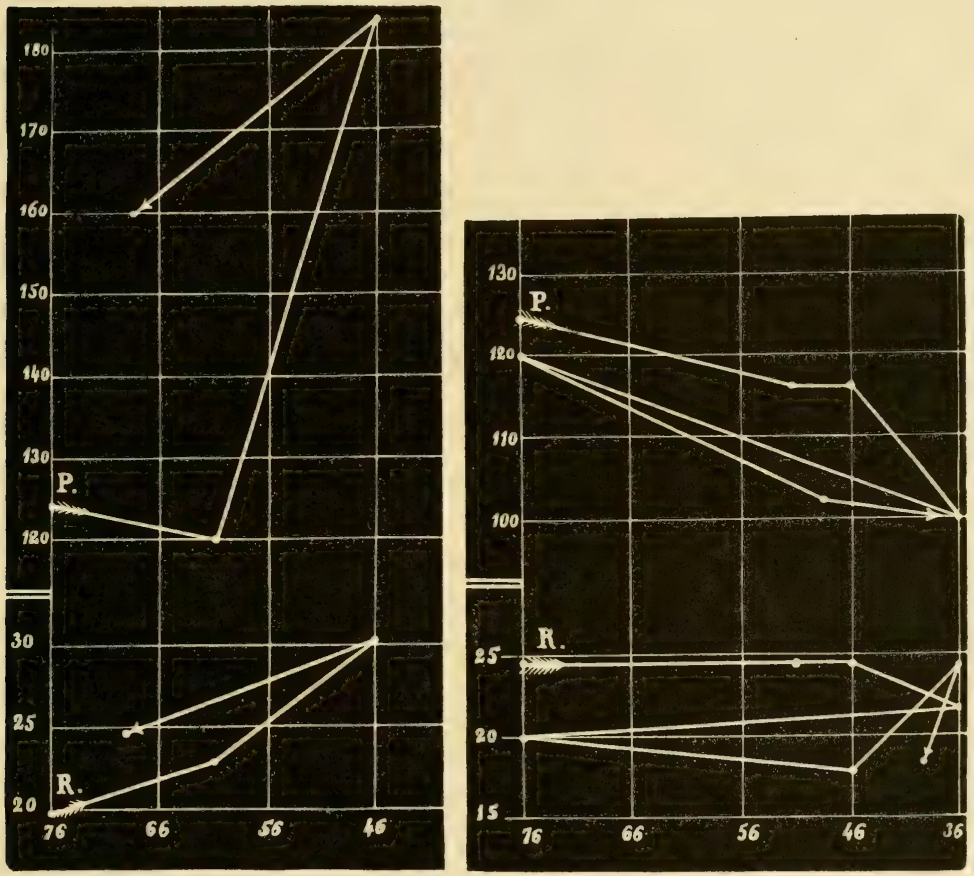

Fig. 50-Dog, Experiment CCXVIII. Fig. 51-Dog, Experiment CCXVII. Simultaneous modifications of the number of respiratory movements $\mathrm{R}$ and the pulse $\mathrm{P}$ under the influence of decompressio-.

rare observations which I could make showed only slight diminutions; it seemed to me that it would be necessary to go very far to obtain noteworthy differences in animals which must be kept motionless. At a pressure of $26 \mathrm{~cm}$., the heart had retained the same strength as at normal pressure (Exp. CCXIX). The results would no doubt be different, if the animals were performing labor comparable to that of travellers climbing a mountain. 
I add that under the influence of pressures which are very weak and very quickly reached, I have sometimes seen nasal and pulmonary hemorrhages. But this is a very rare symptom in animals; in fact, it is not as common in man as is ordinarily stated.

\section{Digestion.}

As a certain degree of decompression is approached, travellers have experienced nausea; I have likewise seen my animals stagger, wag their heads with evident distress, and vomit. Almost all birds showed this symptom.

Animals subjected to extreme decompressions, and especially herbivores, were swollen in a very remarkable way by the expansion of their intestinal gases. It seemed to me, in some cases, that this swelling was great enough to act even on the respiration and hamper its movements.

I have verified upon myself this disagreeable swelling, in Experiment CCXXX and in several others of the same sort reported in Subchapter III; but it never brought serious inconvenience, when the garments which confined the waist were unfastened and opened; besides, the gases easily found vent through the two intestinal orifices.

I even tried direct experiments, to obtain ocular evidence of this evacuation of gas.

Experiment CCXXXI. December 10. A dog, which had just been killed by direct application of electrical stimulation to the heart, was fastened on a trough and placed in the decompression cylinders. Into its rectum was inserted a glass elbow tube, which by means of rubber packing completely closed the anus. The other end of the tube was immersed several centimeters deep in a glass full of water.

The decompression was then begun, and as fast as the barometer fell, bubbles of gas burst on the surface of the water, and the greater the speed of the decompression pump, the more rapidly the bubbles followed each other.

However, the belly was visibly swelling.

On return to normal pressure it suddenly collapsed, and water entered the rectum.

Experiment CCXXXII. February 27. Dog killed by hemorrhage, and prepared like the dog in the preceding experiment. It had also in its esophagus a tube immersed a little way in the water.

At the very first strokes of the pump, the air left the anus constantly; several times the machine was stopped, and the gaseous evacuation ceased immediately. But no gas left by the esophagus.

The pressure was lowered to $30 \mathrm{~cm}$. in 2 hours and 20 minutes.

On return to normal pressure, the belly collapsed. 
So the expanded gases leave very easily by the anus; but the last experiment shows, strangely enough, that they cannot, in a cadaver, escape by the cardia, nor probably by the pylorus, so that the stomach is distended. But in the living being this is not the case, and eructation is produced, thanks to muscular action.

This influence of decompression upon the intestinal gases is not very important, but is interesting as being the only effect (or nearly so) that it causes as a purely physical agent.

On several occasions in my cylinders I have also felt nausea and sickness caused by decompression.

\section{Nervous and Muscular Effects.}

When the pressure is lowered considerably, we have seen the muscular strength of animals diminish rapidly. Birds refuse to attempt to fly. They all quickly become and remain motionless, no matter how much one excites and threatens them, or how fierce or frightened they seemed at first; at lower pressures, they are no longer able to remain upright but crouch; at still lower pressures, they fall on their sides.

In Subchapter III, I shall give the details of experiments in which I underwent quite low pressures. I mention here this interesting note that, when I wanted to raise my leg which had been bent for some time, it was seized by convulsive jerks which I could not control, but which ceased as soon as I rested it once more on the floor. Similar quiverings have been reported by aeronauts, who generally attributed them to the cold. M. Sivel, who has experienced them, compares them to the period of chill in attacks of intermittent fever.

Animals subjected to rather low pressures become, as it were, insensible and indifferent to everything; it seems evident to me that sensibility as well as strength of reaction fail them at the same time. Furthermore, in man, sensorial impressions are strangely lessened in keenness; we shall see the proof of that in the story of the ascent of Crocé-Spinelli and Sivel. The same thing is true of moral energy, of intellectual activity; in one of my experiments, I was surprised at not being able to multiply 28 , the number of my heart-beats in a third of a minute, by 3 . I had to be satisfied with writing down these numbers in my notebook; this weakness, moreover, left me quite indifferent.

When decompression approaches the fatal limit, when it has lasted a long time, or when it has been brought on very suddenly, we often see occurring in the animals convulsive jerkings which 
recall, in an exaggerated way, the trembling I myself felt. At the extreme limits, when death comes, real convulsions appear, whose violence is in proportion to the strength which the animal then retains.

When the decompression has been brought on slowly, when it has lasted a long time, when the animal is much weakened and chilled, no convulsions are observed, or they are very slight. I have shown elsewhere that the same thing is true in ordinary asphyxia, in closed vessels. For example, here is an experiment.

Experiment CCXXXIII. September 17. Two starlings.

A. One is placed under a bell of $900 \mathrm{cc}$, inverted over a basin of water. At the end of three quarters of an hour violent convulsions occur, and the bird dies.

B. The second is put under a bell of 14 liters, also inverted over water. At the end of about 6 hours, respiration seems much affected. Death occurs after 9 hours and 25 minutes, with gradual phenomena, without convulsions.

The convulsions produced by decompression, by asphyxia, and, I add, by hemorrhage, are merely a violent response of the spinal cord, over-stimulated by a sudden change in the conditions of its nutrition. If the transitions are carefully managed, if there are only slow and progressive changes, we see no more violent symptoms, no more convulsions.

The experiments reported in Chapter II, Subchapters I and IV, show that in decompression carbonic acid diminishes considerably in the blood. When death is reached, when convulsions occur, the animal has lost more than two-thirds of it. Very evidently the convulsive phenomena must not be attributed to this gas, as is stated in the theory propounded in 1850 by M. Brown-Séquard, and accepted today by a great number of physiologists. ${ }^{1}$ We shall see directly, in another chapter, that carbonic acid is a narcotic of the nerves and the muscles, far from tending to over-stimulate them.

Here, I simply wish to call attention to the fact that in all the experiments which this learned physiologist has brought to support his statement, the oxygen diminished rapidly to the point of disappearing, while the carbonic acid itself hardly increased in the blood and the tissues. What we have just said is enough, without further insistence, to prove that it is to this sudden decrease of oxygen that we should attribute the medullary excitations and the muscular contractions.

I think I should add here that in animals killed by decompression, as in animals rapidly asphyxiated or bled to death, one can 
see, in the moments which precede death, the intestines twisting in the belly in violent peristaltic movements.

\section{Nutrition.}

All the phenomena which we have just reviewed are only the consequences of disturbances of the nutrition of the tissues, disturbances due to the lessened quantity of oxygen in the blood. Our experiments on superoxygenated atmospheres have shown, in fact, that decompression as a physical agent plays a role that is almost negligible, and that the question is exclusively of a chemical nature.

We ought therefore to study carefully these nutritive disturbances, which manifest themselves so clearly to us by the lowering of temperature. We shall therefore inquire into the modifications undergone by the chemical phenomena of respiration: 1.) oxygen absorption, which is the primary factor; 2.) carbon dioxide excretion, which measures the energy of the intra-organic combustions; and 3.) the renal excretion, which can also serve as a measure of the chemical activity of the living body.

1. Chemical phenomena of respiration. The numerous experiments reported in Chapter I on the death in closed vessels of animals subjected to more or less weak pressures make it possible for us to calculate easily the quantity of oxygen consumed and the quantity of carbonic acid exhaled, per unit of time, for each animal species, or for each kilogram of animal. I shall do so in a moment, taking into account only the experiments in which the behavior of the animal has been noted, for it is quite evident that results can be modified, even reversed in their general direction, by the single fact of a considerable uneasiness compared to an absolute repose.

But it seemed to me desirable, for this delicate verification, to carry out special experiments, in which special precautions should be taken. Besides, the experiments of Chapter I end in death, and although comparable in this respect, they cannot be as convincing as those in which the animals survive.

Here are some of these new data.

Experiment CCXXXIV. June 30. Rats of the same litter, each weighing 50 grams.

A. Confined from $4: 16$ to $4: 58$ (42 minutes) under an airtight bell, containing 3.2 liters; normal pressure.

B. Confined from $4: 34$ to $5: 18$ (42 minutes) under a bell of 7.1 liters, in which the pressure is rapidly brought to $34 \mathrm{~cm}$. The volume of the bell corresponds to 3.17 liters at normal pressure. 
C. Confined from 4:30 to 5:12 (42 minutes) under a bell of 11.5 liters, in which the pressure is rapidly brought to $20 \mathrm{~cm}$. The volume of the bell corresponds to 3.03 liters at normal pressure.

The three animals remain quiet, except $B$, which moves a little. C lies on his belly, but gets up when we excite him a little; he is better towards the end of the experiment; none of them appears then to suffer from the confinement.

When the experiment is over, the rectal temperature of $\mathrm{A}$ is $38.1^{\circ}$; of $\mathrm{B}, 33.1^{\circ}$; of $\mathrm{C}, 32.0^{\circ}$.

The composition of the air is as follows:
A. $\mathrm{O}=14.8 ; \mathrm{CO}_{2}=2.2$.
B. $\mathrm{O}=16.0 ; \mathrm{CO}_{2} 3.9$.
C. $\mathrm{O}=17.2 ; \mathrm{CO}_{2} 3.2$.

So the oxygen consumed, in vessels containing about the same quantity of air, was for A, 6.1 per cent; for B, 4.9 per cent; for C, 3.7 per cent.

Establishing now the absolute value of oxygen consumption and carbonic acid production during the $\mathbf{4 2}$ minutes of the experiment, we find that:

Oxygen

$\mathrm{CO}_{2}$

A, who had at his disposal $672 \mathrm{cc}$., has consumed 195 and produced $166 \mathrm{cc}$.

$\mathrm{B}$, who had at his disposal $666 \mathrm{cc}$, has consumed 155 and produced $123 \mathrm{cc}$.

C, who had at his disposal 636 cc., has consumed 112 and produced $97 \mathrm{cc}$.

Experiment CCXXXV, June 3. Rats of the same litter. Outside temperature $25^{\circ}$.

a. Placed from 2:20 to 4:50 (2 hours, 30 minutes) at normal pressure, under a bell of 7.6 liters.

b. Placed from 2:40 to $5: 15$ (2 hours, 35 minutes) at a pressure of $50 \mathrm{~cm}$., under a bell of 11.5 liters, whose capacity at this pressure corresponds at normal pressure to 7.57 liters.

c. Placed from 2:55 to $5: 30$ (2 hours, 35 minutes) at a pressure of $37 \mathrm{~cm}$., under a bell of 15.5 liters, whose capacity at this pressure corresponds at normal pressure to 7.53 liters.

The animals remain very calm, and do not seem inconvenienced. At the end of the experiment, the temperature of $a$ is $35^{\circ}$; that of $b$, $34^{\circ}$; that of $c, 32.5^{\circ}$. (The thermometer was not exact, and these values should be considered not as absolute, but as comparative.)

Chemical analysis gave:

For $a,: \mathrm{O}=11.3 ; \mathrm{CO}_{2} 8.1$.

For $b,: \mathrm{O}=12.5 ; \mathrm{CO}=7.8$.

For c, : $\mathrm{O}=13.1 ; \mathrm{CO}=5.9$.

Making the same calculations as for the preceding experiment, we find that in 2 hours and 35 minutes

$a$, who had at his disposal $1596 \mathrm{cc}$., consumed 729 and produced $615 \mathrm{cc}$.

$\mathrm{b}$, who had at his disposal $1589 \mathrm{cc}$., consumed 636 and produced $590 \mathrm{cc}$.

c, who had at his disposal $1581 \mathrm{cc}$., consumed 587 and produced $452 \mathrm{cc}$. 
If we calculate the oxygen consumption for one hour, to compare the results of these two experiments more easily, we find that

\section{Oxygen \\ $\mathrm{CO}=$}

A, at normal pressure, consumed 278 cc., and formed 237

$a$, at normal pressure, consumed 282 cc., and formed 246

$b$, at $50 \mathrm{~cm}$. pressure, consumed $246 \mathrm{cc}$., and formed 237

c, at $37 \mathrm{~cm}$. pressure, consumed $227 \mathrm{cc}$., and formed 180

$\mathrm{B}$, at $34 \mathrm{~cm}$. pressure, consumed $221 \mathrm{cc}$., and formed 175

$\mathrm{C}$, at $20 \mathrm{~cm}$. pressure, consumed $160 \mathrm{cc}$., and 'formed 138

The remarkable agreement between experiments $\mathrm{A}$ and $a$ on the one hand, $c$ and $B$ on the other, shows that, in spite of the causes of error inherent in our experimental procedure,-causes of error which compel us to disregard the third figure in the numbers reported above,-we can state definitely that the oxygen con-

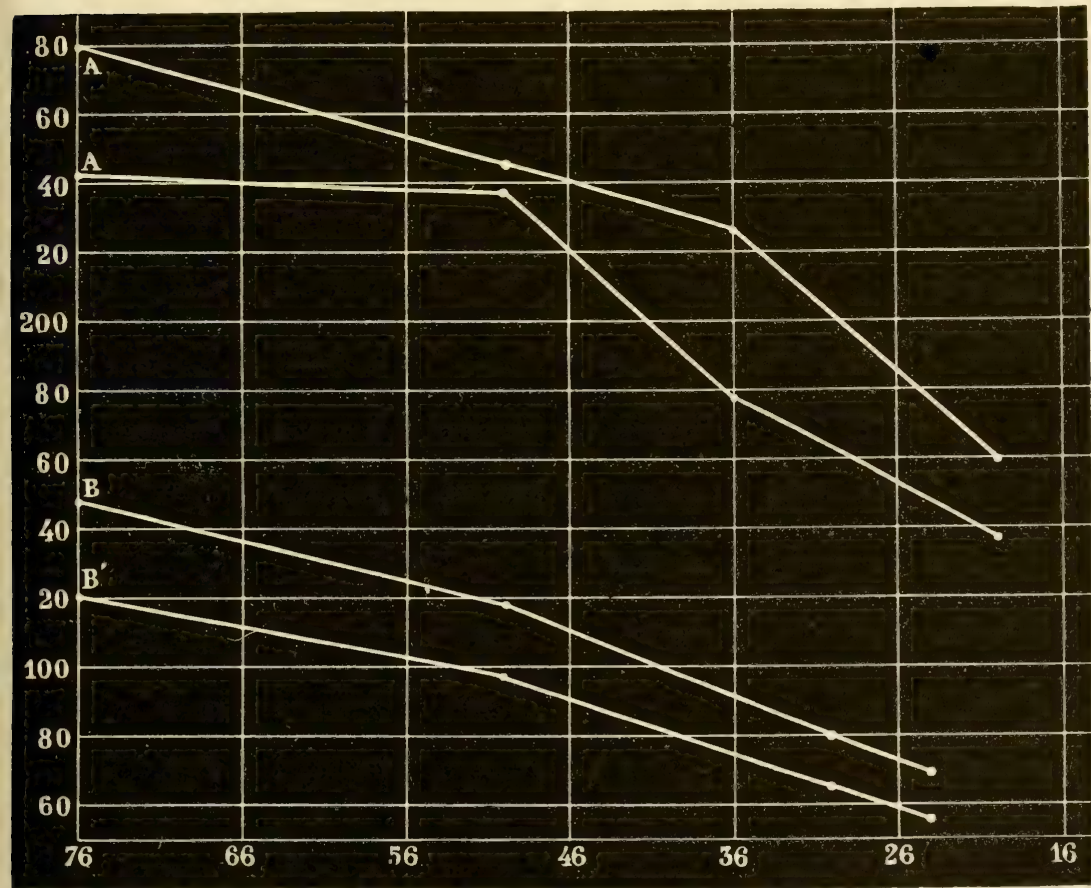

Fig. 52-Consumption of oxygen and production of carbonic acid at different pressures. 
sumption in a given time diminishes when the pressure itself diminishes; this fact is shown very clearly in graph $\mathrm{A}$ of Figure 52, which indicates the average of the results of the two preceding experiments.

The production of carbonic acid gives rise to similar conclusions. Graph A' expresses its different stages.

Let us refer now to the experiments of Chapter I, Subchapter I, and particularly to Table I, which summarizes them. We find here all the elements necessary for our calculation. Now if, without following all the details of the experiments, we take averages at different decompressions, we see that, in one hour, a sparrow:

\section{Oxygen $\mathrm{CO}$}

At normal pressure (Exp. 1, 2, 3, 4) consumed $147 \mathrm{cc}$. and produced $122 \mathrm{cc}$. At about $50 \mathrm{~cm}$. (Exp. 5, 6, 7, 8) consumed $118 \mathrm{cc}$. and produced $97 \mathrm{cc}$. At about $30 \mathrm{~cm}$. (Exp. 13, 14, 17) consumed $80 \mathrm{cc}$. and produced $65 \mathrm{cc}$. At about $24 \mathrm{~cm}$. (Exp. 24,25,26,27) consumed $72{ }^{\circ} \mathrm{cc}$. and produced $57 \mathrm{cc}$. At about $20 \mathrm{~cm}$. (Exp. 33) . . . consumed $60 \mathrm{cc}$ and produced -

These results are indicated by Graphs B and B' in Figure 52. We see that, in spite of the important difference of methods (since here the sparrows remained until death, and consequently towards the end of life were all subjected to the same oxygen tension, the tension which produces death), the results have remarkable agreement with the preceding ones, not only as to the general direction of their variation, but even as to the proportion of this variation.

I am therefore quite justified in drawing from this collection of data the conclusion that, at low barometric pressures, an animal consumes, in a given time, a considerably smaller quantity of oxygen, and produces a considerably smaller quantity of carbonic acid than at normal pressure. This diminution, which increases proportionately as the pressure is lowered, is clearly apparent at a diminution of a third of an atmosphere, which corresponds to a height of more than 3000 meters above sea level.

We shall refer frequently to the consequences of this important principle, which is sufficient explanation, evidently, of all the symptoms caused by lowered pressure.

2. Urinary excretion. After having ascertained that oxygen consumption and the intra-organic combustions which result in a production of carbonic acid are considerably diminished by a stay in decompressed air, I had to investigate whether these modifications of nutrition do not also appear in the urinary excretion.

I have given particular attention to urea. The analyses were made sometimes by the method of M. Gréhant (use of the Milon 
reagent and a vacuum), sometimes by that of M. Yvon (by hypobromide of soda).

Dogs were used as subjects of my experiments. The animal, enclosed in advance in the cylinders in which the decompression was to be carried on, was fed on a definite diet for two or three days; then we calculated the quantity of urea excreted in 24 hours, drawing the urine two mornings in succession, because dogs which are confined urinate at very irregular intervals. Of course, the urine voided spontaneously by the animal was carefully collected. The decompression having been maintained for several hours, we made a new analysis including the urine of the day from the morning of the experiment to the next morning. Sometimes, we also collected in the same way the urine of the 24 hours following.

Here are some of the results obtained.

Experiment CCXXXVI. July 3. Dog weighing 12 kilos; eats every day, between 7 and 8 in the morning, $250 \mathrm{gm}$. of bread and $250 \mathrm{gm}$. of meat boiled together with $500 \mathrm{gm}$. of water.

July 4 , at 10 in the morning, dog's bladder emptied.

July 5, bladder emptied again at the same hour; he has not urinated spontaneously; we obtain thus $260 \mathrm{cc}$. of urine, which treated by the Yvon method give $7248 \mathrm{cc}$. of nitrogen.

We conclude then that he voided $19.4 \mathrm{gm}$. of urea.

On that day, from 11 to 6 , the animal was subjected to a pressure of $38 \mathrm{~cm}$.

After he had left the apparatus, catheterization brought $100 \mathrm{cc}$. of urine, containing $7.4 \mathrm{gm}$. of urea. The next day at 11 in the morning, another catheterization, giving $80 \mathrm{cc}$. of urine, with $4.4 \mathrm{gm}$. of urea.

Produced then in these 24 hours only $11.8 \mathrm{gm}$. of urea.

The next day (July 7), catheterized at $1: 15$; the urine, added to what he voided during the night, amounts to $240 \mathrm{cc}$., containing 15.4 gm. of urea.

Experiment CCXXXVII. Same dog, kept on the same diet.

Catheterized July 7 at $1: 15$, as has just been said, then July 8 at 10:30 (21 hours), gives $246 \mathrm{cc}$. of urine containing $19.6 \mathrm{gm}$. of urea.

July 8 , from 10:55 to $4: 45$, is kept at $38 \mathrm{~cm}$. pressure.

July 9 , at $1: 15$, has given (in 27 hours) 385 cc. of urine containing $24.7 \mathrm{gm}$. of urea.

If we reduce these secretions to their proportionate value for 24 hours, we find:

At normal pressure: $22.4 \mathrm{gm}$.

At a half-atmosphere, $21.9 \mathrm{gm}$.

Experiment CCXXXVIII. July 13. Same dog, subjected to same procedure. But he is tired of being confined.

From July 13, at 7:45 in the morning (fasting) to July 14 at 8 in the morning (fasting) voided $200 \mathrm{cc}$. of urine, giving $13 \mathrm{gm}$. of urea.

July 14, from $8: 30$ in the morning to $5: 45$ in the evening, kept at a pressure varying from $30 \mathrm{~cm}$. to $35 \mathrm{~cm}$. Does not seem weakened. 
July 15 , at 8 in the morning (fasting), all the urine collected, amounting to $211 \mathrm{cc}$. with only $7 \mathrm{gm}$. of urea.

In the following 24 hours, he voids $130 \mathrm{cc}$., with $8.2 \mathrm{gm}$. of urea.

Experiment CCXXXIX. June 9. Dog weighing 19.3 kilos. Kept for 4 days on a ration of $375 \mathrm{gm}$. of bread, $375 \mathrm{gm}$. of meat, and $500 \mathrm{gm}$. of water.

From June 9, at 10 o'clock in the morning to June 10, at 10:45, voided 276 cc. of urine, which analyzed by the Gréhant method contains $27.9 \mathrm{gm}$. of urea.

June 10, from $11: 30$ in the morning to $6: 30$ in the evening, kept between 25 and $30 \mathrm{~cm}$. of pressure. On leaving the apparatus, he is very much weakened, almost refusing to stand up. Catheterization extracts only a few drops of urine.

June 11 , at $10: 30$ in the morning, the catheter brings $390 \mathrm{cc}$. of clear urine, containing neither sugar nor albumen. It gives $20.7 \mathrm{gm}$. of urea.

Experiment CCXL. June 17. Same dog, kept on the same diet, but not confined. June 17 , at 10 in the morning, placed in the apparatus; June 18, at the same hour, gave $370 \mathrm{cc}$. of urine, containing $27.5 \mathrm{gm}$. of urea (Yvon method).

June 18, from 11 to $5: 30$ kept between 36 and $38 \mathrm{~cm}$. pressure. Respiratory rate rises from 16 to 24 and even 30 . Leaves the apparatus a little weakened; rectal temperature has fallen from $39.2^{\circ}$ to $39.0^{\circ}$.

Catheterization yields $100 \mathrm{cc}$. of urine, without sugar, containing $7.5 \mathrm{gm}$. of urea; the next day at noon produces $130 \mathrm{cc}$. of urine containing $6 \mathrm{gm}$. of urea; about $13.5 \mathrm{gm}$. in the 24 hours.

Experiment CCXLI. June 23. Same dog; regular diet, but a somewhat smaller quantity.

At normal pressure, in 24 hours, yields 250 cc. of urine containing $20 \mathrm{gm}$. of urea (Yvon method).

From 1 o'clock to $6: 30$ subjected to a pressure of $38 \mathrm{~cm}$. Voids in the 24 hours $220 \mathrm{cc}$. of urine containing $14.4 \mathrm{gm}$. of urea.

The next day, at normal pressure, yields in 24 hours $36.8 \mathrm{gm}$. of urea in $600 \mathrm{cc}$. of urine.

Experiment CCXLII. October 26. Dog weighing 20.5 kilos; kept for preceding 10 days on the following daily ration: $250 \mathrm{gm}$. meat, 250 gm. bread, $500 \mathrm{gm}$. water.

From October 26, at 9 in the morning, to October 27, at 9:30, voids $336 \mathrm{cc}$. of urine containing $23.4 \mathrm{gm}$. of urea (Yvon method).

October 27, from 9:45 to 5, subjected to a pressure varying from 30 to $40 \mathrm{~cm}$. The next day, at $9: 45$, yields $570 \mathrm{cc}$. of urine, with 23.5 gm. of urea.

In the following 24 hours, yields $330 \mathrm{cc}$. of urine with $17.3 \mathrm{gm}$. of urea.

The day after, $390 \mathrm{cc}$. of urine, with $21.8 \mathrm{gm}$. of urea.

These experiments show conclusively that a stay of several hours in an atmosphere whose pressure has been lowered by more 
than half diminishes considerably the quantity of urea excreted in 24 hours. Whatever may be the various causes of error inherent in the experimental procedures, the exact agreement in direction, if not in absolute value, of the variations in all the experiments established satisfactorily a degree of certainty.

This decrease has not been proportional to the decrease in pressure; it has varied with circumstances generally unknown; its maximum was 50.8 per cent in Experiment CCXL.

In examining the record of these experiments, we notice that in number CCXLII, the decrease in urea was not seen on the day of the decompression, (23.4 gm. to $23.5 \mathrm{gm}$.) but the next day (17.3 gm.); the day after, normalcy was almost established (21.8 gm.). In another case, Exp. CCXLI, on the day after the stay in decompressed air, the quantity of urea yielded was much increased, and rose considerably above the original figure, under normal pressure. These are questions of detail for the study of which we should be forced to increase the number of experiments, taking as subject man, in whom uniformity of diet, uniformity of movement, etc., can be more exactly obtained.

Disregarding these secondary points, it is established that at low pressures the decrease in activity of chemical phenomena affects not only those which produce carbonic acid, but also those which cause the excretion of urea. The whole combination of intra-organic acts of oxidation is therefore considerably decreased when the air is sufficiently expanded.

We must note that uric acid did not seem to be increased in the urine of the dogs, when the urea diminished; at least we did not note any precipitate, either spontaneous or following the acidification of the urine. This fact supports many others in showing that urea is not a product of the oxidation of uric acid, but that these two substances proceed from different chemical transformations.

3. Sugar of the liver and of the blood, glycosuria. I have repeatedly established the presence of sugar in the urine of animals kept for several hours at low pressures. But the phenomenon always appeared in an irregular manner, so that I have not been able to reproduce it at will in comparable experiments.

On the other hand, when the decompression is great and acts for a long time, sugar is more or less decreased in the liver; it may even wholly disappear. Example:

Experiment CCXLIII. August 1. Rat, kept in a large bell, with air renewed from time to time, at a pressure oscillating between 30 and $40 \mathrm{~cm}$., from $1: 10$ to $6: 45$. 
Pressure is then lowered to $8 \mathrm{~cm}$; the animal dies at the end of 5 minutes.

The liver is removed immediately, thrown into boiling water, then crushed with charcoal; no trace of sugar.

Here then the chemical process which transforms the glycogen of the liver into sugar is also hampered by the decreased pressure. Here again, we find the absolute similarity between death by decompression and slow asphyxia in closed vessels. We know that in asphyxia also glycosuria is a phenomenon which is sometimes but not always observed. We understand that multiple conditions control its appearance. In fact, it is necessary that at a certain moment the liver should still be furnishing a great quantity of sugar to the blood, and that oxidation within the blood should at the same time be greatly hindered. These are conditions which are very complex and hard to produce at will.

The amount of sugar in the arterial blood should also be carefully ascertained. Here are some experiments performed for this purpose; the analyses were made by M. Dastre, who has had great experience in this kind of research.

Experiment CCXLIV. February 26. Small Havanese dog.

Its arterial blood contains per kilogram $0.95 \mathrm{gm}$. of glucose.

It is placed under a large bell, at a pressure of about 20 or $25 \mathrm{~cm}$; at the end of a quarter of an hour it dies, the pressure having perhaps gone too low through carelessness.

The blood of the right heart contains $3.48 \mathrm{gm}$. of glucose per kilogram.

Much glycogenic material in the liver.

Experiment CCXLV. February 27. Small dog, puny, sickly.

Its arterial blood contains $1.80 \mathrm{gm}$. of glucose.

Placed for three hours, under a current of air, at a pressure varying between 15 and $25 \mathrm{~cm}$. Then killed by sudden decompression falling to $5 \mathrm{~cm}$.

Blood of the right heart contains $1.84 \mathrm{gm}$.

Much sugar and glycogenic material in the liver.

No urine in the bladder; the kidneys and bladder, crushed in water, do not reduce to copper reagent.

The temperature was not measured; but the animal did not seem to have grown perceptibly colder.

Experiment CCXLVI. March 3. Small dog.

Arterial blood contains $1.5 \mathrm{gm}$. of glucose.

Brought in 20 minutes to a pressure of $17 \mathrm{~cm}$, where it remained for 10 minutes. Then killed quickly by decompression $(9 \mathrm{~cm}$.).

Arterial blood, taken from the heart during the last beats, contains $3.3 \mathrm{gm}$. of glucose.

Rectal temperature $38^{\circ}$. 
Much sugar and glycogenic material in the liver . sugar.

No urine; the bladder and kidneys, crushed with water, give no

And so, when the decompression has not lasted long but has been great, sugar increases in the blood; it returns to its normal value when the decompression has been sufficiently prolonged. This difference I think can be explained in the following manner: the liver, irritated by the action of blood that has suddenly lost its oxygen, pours into the circulation a large quantity of sugar which is shown by analysis, if the animal is killed in a short time; if, on the contrary, there is some delay, this sugar disappears, and since the liver is producing less and less of it, it returns to its usual value, then lessens and finally disappears, even from the liver, as is shown by Experiment CCXLIII on the rat.

4. Temperature. It is not surprising to see the temperature of the body fall, in consequence of this lessening of the chemical phenomena of the organism.

This phenomenon had already been observed in mountain ascents. Some attributed it to the surrounding cold, others to the labor performed, and in this connection I spoke, in the historical part, of the theory of M. Lortet.

But the experiments reported above, show, by many examples, that the temperature of animals subjected to decompression falls without their doing the least work, without the air being chilled, and without the possibility of attributing the phenomenon to the current of air which must be kept around them to avoid the accumulation of carbonic acid. The loss is generally 2 or 3 degrees for a drop of a half or two-thirds of an atmosphere in a half-hour, for example. But that depends on the degree of the decompression, its duration, and the animal species.

Thus, in a large dog (Exp. CCXVI), brought in two hours to $25 \mathrm{c} n$. pressure, the temperature had dropped 2 degrees.

All the experiments give similar results. I shall mention particularly, because it eliminates the effect of the current of air (Exp. CCXXII), that in which three rabbits were subjected, one to a current of air at normal pressure, the second to a current under a pressure of 50 to $55 \mathrm{~cm}$., the third to a current under a pressure of $40 \mathrm{~cm}$., all of them for four hours. At the end of this time, the temperature was, for the first, $39.5^{\circ}$; for the other two, $38^{\circ}$. The birds mentioned in Chapter I, Subchapter I, present phenomena of the same sort, whose details it would be useless to stress.

But it is with guinea pigs that I have succeeded in getting the 
greatest drops in temperature. One of them (Exp. CCXXIX), kept for an hour at a pressure of $35 \mathrm{~cm}$., and for an hour more at 25 and even $22 \mathrm{~cm}$., had a rectal temperature of only $25^{\circ}$, on leaving the bell. But after a few minutes the temperature rose to $31^{\circ}$ and the animal survived. The.guinea pig of Experiment CCXXVII, whose respirations furnished the graph in Figure 48, which remained nearly four hours oscillating between 21 and $11 \mathrm{~cm}$., had a temperature of only $20^{\circ}$; it is true that he died during the night after the experiment.

Decompression then is in itself a cause of a drop in body temperature. In balloon ascensions, this cause is added to the direct action of an extremely low environmental temperature. In mountain journeys, these two causes take on a more serious importance because of the expenditure of energy required by the ascent. It is within these limits that the idea of Lortet can a priori be exact; but the decompression certainly must hinder the internal oxidation from acting as it would at normal pressure; no one will ever have mountain sickness from climbing a hill 1000 meters high, even if he were loaded with the heaviest burdens.

5. Development. I think I should report here an experiment which shows that the development of chrysalises is considerably impeded by lowering the pressure.

Experiment CCXLVII. June 23. Silkworm cocoons, within a day of the same age, sent from Alais by M. Raulin, are placed:

A. 12 in a bell open above, and consequently at normal pressure;

B. 18 in a bell of 3.2 liters, at a pressure of $50 \mathrm{~cm}$.;

C. 18 in a bell of 7 liters; pressure of $38 \mathrm{~cm}$;

D. 18 in a bell of 13 liters; pressure of $25 \mathrm{~cm}$;

E. 5 in a bell of 6 liters; pressure of $5 \mathrm{~cm}$.

Bell D is broken June 25; the water of the hydraulic seal enters with the air; it is left unchanged. Every other day the air is changed in bells $\mathrm{B}$ and $\mathrm{C}$; every day that in bell $\mathrm{E}$ is changed.

July 8 , the experiment is stopped, everything is thrown open to the air, and the cocoons are opened.

The cocoons of $\mathrm{A}$ and $\mathrm{D}$ have been open since morning; the moths have issued.

Of the chrysalises in B, 3 are metamorphosed, but the moths have remained in the cocoon.

The others show considerable signs of life but are not metamorphosed.

Those of C show some signs of life, but are not metamorphosed.

The cocoons of $\mathrm{E}$ are not opened.

July 15, 3 more chrysalises in B are metamorphosed; but all are dead. 
C: all are dead too; but under the case of the chrysalis, metamorphosis is already far advanced.

D: all dead, with a considerably lower degree of development.

It would be interesting to make experiments with the eggs of frogs, the larvae of insects, etc.

\section{Lower limit of pressure.}

The degree of decompression at which the different symptoms I have just enumerated occur, that of the lower limit incompatible with life, varies according to the species. The variation depends also upon whether the animals remained calm or were restless during the experiment.

In sparrows, uneasiness generally begins to appear at about a half-atmosphere. The bird becomes restless; it stops hopping about, and its breathing becomes more rapid; about $25 \mathrm{~cm}$. it begins to vomit and waver on its feet; soon it falls, and if the decompression approaches the fatal limit, it whirls about and jerks convulsively. We saw above that this limit was ordinarily from 17 to $18 \mathrm{~cm}$.

It may vary, between rather narrow limits, for the same species, in different animals, even when all the conditions of life appear quite identical. Here is an experiment in proof.

Experiment CCXLVIII. June 18. 4 sparrows: A, old, vigorous male; B, C, D, females, in good health; all together in the same cage for several days. Placed together in a large bell of 30 liters, under a current of air. A cloth covering the bell keeps them from being frightened and stirring about unequally; they remain very calm during all the first part of the experiment, that is, until they are affected by the rarefied air.

Decompression begins at $4: 45$.

At $4: 49$, pressure is only $38.8 \mathrm{~cm}$.; B and D vomit repeatedly.

At 4:52, pressure $29.8 \mathrm{~cm}$; A also vomits.

At $4: 53$, pressure $27.8 \mathrm{~cm}$.; C vomits; D is very sick.

At 4:54, pressure $26.8 \mathrm{~cm}$; all panting and crouched down, except C, which is standing on its feet.

At 4:55, pressure $24.8 \mathrm{~cm}$; ; all are walking, dragging themselves this way and that, except that A remains motionless, its beak on the floor.

At 4:56, pressure $23.8 \mathrm{~cm}$; A is evidently the sickest; then come $\mathrm{D}$, then $\mathrm{B}$, and finally $\mathrm{C}$, considerably better than the others.

At $4: 58$, pressure $21.3 \mathrm{~cm}$.; $\mathrm{A}$ and $\mathrm{D}$ seem dying; they have fallen over, panting and in convulsions.

At 4:59, pressure $20.3 \mathrm{~cm}$., then the cocks are opened wide; $A$ and $\mathrm{D}$ remain for some time on their backs, and do not recover until after the others.

At 5:30, all are well.

They survive. 
I have shown that it is possible, with suitable precautions, to reach $10 \mathrm{~cm}$. (Exp. XXXIX), a limit which agrees with that indicated by the calculation for the minimal pressure of oxygen. This limit must be reached very slowly. On the other hand, if the drop is sudden, the symptoms appear much sooner, and for example, death occurs suddenly between 25 and $30 \mathrm{~cm}$. The same thing is true when the animal struggles.

Inversely, it often happens that an animal which appears very uneasy, near death, under a very low pressure, recovers, gets up, and becomes fairly well accustomed to it.

All these data, which complicate the numerical solution of the problem, agree perfectly with the observations of mountain travellers and with what we know of the conditions of asphyxia.

The more carefully the transitions are managed, the more easily the experimental animals become accustomed to them; the greater the consumption of oxygen, the more quickly the effect of its lack will be noted. Travellers, like birds under decompression, like asphyxiated animals, in a general way, suffer more in proportion to their activity; we have had many examples of travellers being forced at certain heights to stop in order to become accustomed to conditions, and to lie down in order to lessen the consumption of oxygen. The data I have given agree with this perfectly.

Add that, after a certain number of experiments, summarized in Table II, the resistance is considerably less when the temperature is very low. This is an important consideration, for travellers, like aeronauts, are generally exposed to this depressing condition. Now nothing is more natural than that the consumption of oxygen should be increased by the cold, if the temperature of the body is not to be considerably lowered.

Different species. If we consider the average resistance presented by the different species, we find that in birds, birds of prey appear almost as sensitive to decompression as sparrows. This is a strange fact, when we consider the considerable atmospheric heights reached by the large birds of prey.

The following experiment, if we compare it with the preceding one, made the same day, gives a clearer proof than those taken from Table IV.

Experiment CCXLIX. June 18. Gull (Larus ridibundus Lin.) and hawk (Falco tinnunculus Lin.).

Decompression was made in the same conditions of speed as for the sparrows in Experiment CCXLVIII. I summarize in the following table the phenomena presented by the three species under the same pressure. 


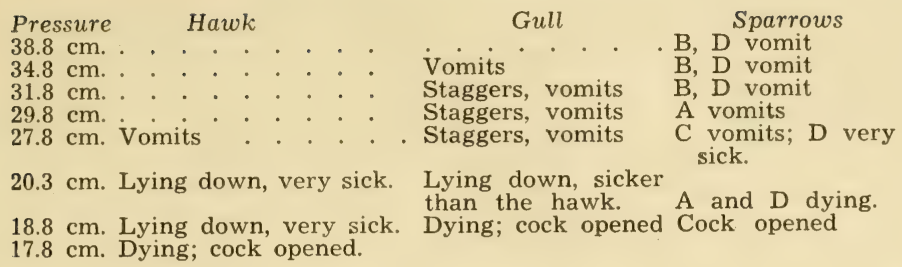

And so the hawk is hardly more than a centimeter ahead of the gull, and two or three ahead of the sparrows. It would be very interesting to run an experiment not merely on a zoological representative of the high-flying birds of prey, but on one of these birds itself, a condor, for example; unfortunately, physiologists are not likely to have such luck.

Among the mammals, cats seem almost as susceptible as sparrows. They are certainly more so than dogs, for whose death the pressure must be lowered to 10 or 8 centimeters. Furthermore we have seen in the historical part that cats are hard to raise at high altitudes and even die soon there.

Guinea pigs and rabbits are very easy to bring to low pressures, and since their temperature drops very quickly, they reach the state of cold-blooded animals, so to speak.

New-born kittens are nearly in this state; and so they die a little later than adults.

I had hoped, by subjecting to decompression an animal which hibernated, to bring it to very low pressures also, thinking that it would hibernate, so to speak; but the only experiment which I tried, on a hedgehog, disappointed me. I could not go below 18 centimeters without the life of the animal seeming immediately in danger.

Finally I add that, as might have been expected, cold-blooded animals resist extremely low pressures.

\section{Death.}

I have shown above that sometimes the animal dies without any movement, sometimes rises and stiffens violently before dying, and sometimes has real convulsions. All that, we have seen, depends on the state of exhaustion of the animal, the time which the experiment has lasted, etc.

Autopsy shows hardly any interesting results. The blood is dark everywhere, except in the pulmonary veins, where it absorbs oxygen during the return to normal pressure. It never contains free gases. 
In mammals, the lungs are sometimes a little emphysematous; almost always they are ecchymosed in places, sometimes, but rarely, with real hemorrhage; in other cases, following sudden decompressions, I have seen them practically carnified, returned to the fetal state, and sinking in large fragments to the bottom of the water. When I discuss sudden decompressions, I shall try to explain this strange phenomenon.

One curious fact is the suddenness with which rigor mortis appears. I have observed this result carefully in sparrows. If one cuts off the head of one of these birds, rigor mortis does not appear for about three-quarters of an hour, whereas it comes between 10 and 20 minutes after death in rarefied air.

I shall take as examples a certain number of experiments reported in Chapter I. They give the data for the following table.

Table XIII

\begin{tabular}{|c|c|c|c|c|c|}
\hline Experiment & 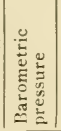 & 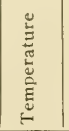 & $\begin{array}{l}\text { Rigor mortis } \\
\text { appeared after }\end{array}$ & $\begin{array}{l}\text { Temp. of animal } \\
\text { at time of rigor }\end{array}$ & Observations \\
\hline $\begin{array}{l}\text { XIX } \\
\text { XVI } \\
\text { XVII } \\
\text { XVIII } \\
\text { XX } \\
\text { XXI } \\
\text { XXII }\end{array}$ & $\left|\begin{array}{l}76 \\
19.7 \\
20.8 \\
27.8 \\
30.8 \\
30.3 \\
26.1\end{array}\right|$ & $\begin{array}{l}19^{\circ} \\
19^{\circ} \\
19^{\circ} \\
19^{\circ} \\
20^{\circ} \\
20^{\circ} \\
20^{\circ}\end{array}$ & $\begin{array}{l}\text { More than } 38 \mathrm{~min} \text {. } \\
\text { Less than } 25 \mathrm{~min} \text {. } \\
\text { Less than } 20 \mathrm{~min} \text {. } \\
17 \text { minutes } \\
15 \text { minutes } \\
\text { Less than } 20 \mathrm{~min} \text {. } \\
\text { Less than } 17 \mathrm{~min} \text {. }\end{array}$ & $\begin{array}{l}24^{\circ} \text { (about) } \\
31.6^{\circ} \\
26.7^{\circ} \\
20.5^{\circ} \\
24^{\circ} \text { (about) } \\
34.7^{\circ}\end{array}$ & $\begin{array}{l}\text { Head cut off. } \\
\text { Lived } 1 \mathrm{~h} .45 \mathrm{~m} \text {; calm. } \\
\text { Died in } 2 \mathrm{~m} \text {. Convuls. } \\
\text { Lived } 2 \mathrm{~h} \text {. No convuls. } \\
\text { " } 6 \mathrm{~h} .53 \mathrm{~m} \text {. Calm. } \\
\text { " } 4 \mathrm{~h} \text {. } 25 \mathrm{~m} \text {. Calm. } \\
\text { Died in } 6 \mathrm{~m} \text {. No great }\end{array}$ \\
\hline XXIV & 30.3 & $20^{\circ}$ & Less than $20 \mathrm{~min}$. & $27^{\circ}$ & $\begin{array}{l}\text { convulsions. } \\
\text { Lived } 1 \mathrm{~h} .31 \mathrm{~m} \text {. } \\
\text { Agitation. }\end{array}$ \\
\hline XXVI & 24.2 & $20.5^{\circ} \mid$ & About $15 \mathrm{~min}$. & $28^{\circ}$ (about) & $\begin{array}{l}\text { Lived } 2 \mathrm{~h} \text {. } 10 \mathrm{~m} \text {. Great } \\
\text { agitation and violent } \\
\text { convulsions. }\end{array}$ \\
\hline XXVII & 24.2 & $20.5^{\circ}$ & 11 minutes & $27.2^{\circ}$ & Lived 1 h. $50 \mathrm{~m}$. Very \\
\hline XXVIII & 24.2 & $20.5^{\circ}$ & Less than $20 \mathrm{~min}$. & $\mid 28^{\circ}$ (about) & $\begin{array}{l}\text { Lived } 1 \text { h. } 4 \mathrm{~m} \text {. } \\
\text { Agitation. }\end{array}$ \\
\hline
\end{tabular}

We see that this is a phenomenon that is absolutely constant and independent of the speed of death, the quiet or agitation of the bird, and the degree to which its temperature has fallen.

It does not exist in asphyxia in closed vessels, at normal pressure (except in the conditions of Experiment CCL) and I think it can be attributed only to the exhaustion of the carbonic acid of the blood and the tissues, by breathing in rarefied air. We shall see in Chapter VIII that this exhaustion is real. 


\section{COMPARISON OF THE PHENOMENA OF DECOMPRES- SION WITH THOSE OF ASPHYXIA IN CLOSED VESSELS}

I have repeatedly stressed the parallel between the phenomena of decompression and those of asphyxia in closed vessels, a parallel continued even in the smallest details. I did so in the first chapter, comparing the duration of life of animals in both situations, under the influence of different conditions. I did so again in regard to the gases contained in the arterial blood in animals under low pressures and in those asphyxiated in closed vessels, when the carbonic acid is removed as it is produced (Chap. II, Subchap. IV).

The descriptions given by countless authors who have killed animals by asphyxia agree in every point with the phenomena which we have just enumerated. The respiratory rate is shown becoming generally faster at first, then slowing up and appearing very painful when the animal suffers considerably. The pulse rate, in its number and strength, has been much less studied. But the nausea, the frightened movements, the final convulsions in the circumstances which we have specified elsewhere have all been noted. If the phenomena of nutrition have not had sufficient attention, we have not forgotten the drop in body temperature, and M. Claude Bernard mentioned the disappearance of the sugar of the liver in slow asphyxia.

We must note, however, that in the conditions of asphyxia in which these experimenters placed their animals, the carbonic acid was stored up in the surrounding air, without their having determined the influence exerted by this gas, some denying it completely, others exaggerating it grossly.

The phenomena relating to the decrease in oxygen absorbed, and in the carbonic acid and urea excreted by animals breathing an atmosphere low in oxygen content, have not been studied carefully enough up to the present. I do not even know any study relating to urinary excretion, and that lack is easily understood; it would be exceedingly difficult to keep animals on which such an experiment could be made for a considerable length of time in rarefied air that was suitably renewed.

As to the absorption of oxygen, while making several successive analyses of the air of a bell in which an animal was slowly asphyxiated, I have very often observed that the animal consumed 
less and less oxygen for equal units of time in proportion to the progress of the experiment towards its fatal conclusion.

Experiment CLXXXVII furnishes an example of this: here, carbonic acid was absorbed by potash as it was formed, so that comparison with pure expanded air is quite legitimate; in the first two hours the dog had consumed 41 per cent of the oxygen of the closed sack in which he was breathing, while in the following two hours he consumed only 36 per cent, the total volume of the sack being moreover much reduced in consequence of the absorption of the carbonic acid.

The experiments which will be reported in Chapter VIII (Subchap. II) will give the same sort of evidence. So the lack of oxygen in the air gives the same result as its expansion.

As to the lowering of temperature, the experiments of Chapter II, Subchapter IV, give us interesting figures. In Experiment CLXXXVII, in which asphyxia lasted 4 hours and 45 minutes, the temperature had fallen from $39^{\circ}$ to $34.5^{\circ}$. In Experiment CLXXXVIII: duration 4 hours 30 minutes; temperature, from $38.5^{\circ}$ to $34^{\circ}$. There also the two terms which we are seeking to compare at present are identical.

If we consider respiratory and circulatory phenomena from the simple point of view of number of movements, we find the same general tendency and the same irregularities, in asphyxia as in decompression.

Figure 53 gives an idea of their trend: the unbroken line gives the results of Experiment CLXXXVII, the dotted line those of Experiment CLXXXVIII. The oxygen content of the air is inscribed on the axis of the abscissae. The number of respirations $(R)$ and of the pulse (P) on the axis of the ordinates, on different scales.

We see that in these graphs is shown, after a phase of uncertainty and irregularity, a period of acceleration in the two types of movement, followed by a period of sudden slowing up.

In some cases, at the end of life, the heart again begins to beat rapidly, but its beats are very weak. This occurred in one of the experiments reported in Subchapter II of Chapter VIII, in which the beats, after having fallen from 120 to 14 at the moment when insensitivity of the eye appeared, rose suddenly to 60 for some minutes, when respiration ceased.

As to blood pressure, it drops slowly at first, then rapidly. Figure 54, whose graphs relate to Experiment CLXXXVII, shows the course of the maxima and minima, in proportion to the oxygen content of the air. 
All these phenomena prove once more that the effects of decompression are identical with those of slow asphyxia, or, in better terms, of breathing an air with low oxygen content.

This identity is indicated again by an interesting coincidence. The details of the experiments reported in the present book show that not only death but also the different symptoms appear in

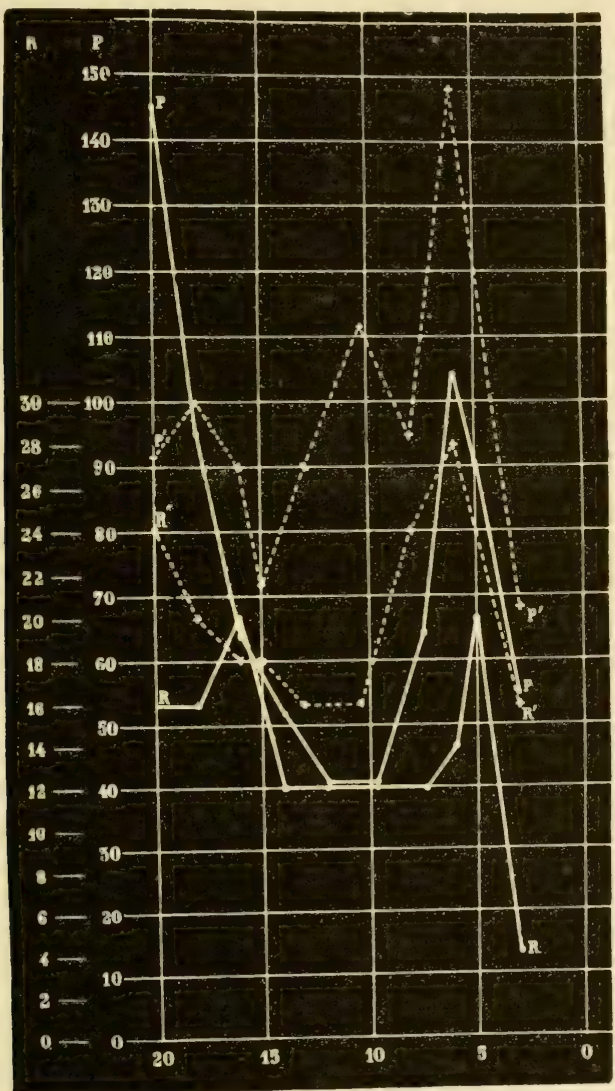

Fig. 53-Asphyxia without carbonic acid. Number of heart beats P, P', and of respiration $\mathbf{R}, \mathbf{R}$, in relation to the gradual impoverishment of the air. 
asphyxia at a degree of oxygen lack and in expanded air at a degree of decompression in which the oxygen tension is identical.

So, in dogs, respiratory disturbances appear in confined air at about the time when there is only 12 per cent of oxygen; in pure air, they appear at about the pressure of $43 \mathrm{~cm}$., a pressure which is met at about 5000 meters altitude; in both cases the oxygen tension is the same, for $12 \times 76=20.9 \times 43.6$. As to serious symptoms, nausea, etc., the proportion of oxygen in the confined air must drop to about 8 per cent, or the barometric pressure of the pure air must be reduced to about $30 \mathrm{~cm}$., which corresponds to a height of 7300 meters; the oxygen tension is the same in both cases.

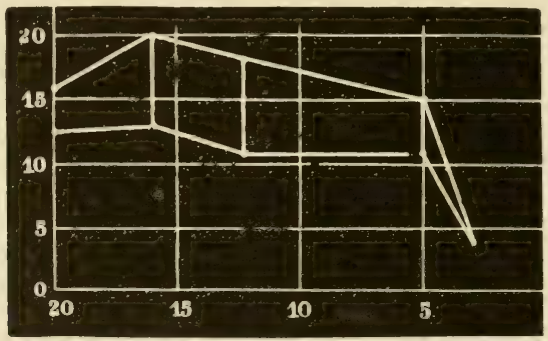

Fig. 54-Maxima and minima of cardiac pressure in asphyxia without carbonic acid.

Now-new confirmation-, it is at these altitudes approximately that the symptoms and disturbances which constitute "balloon sickness" occur in aeronauts, motionless in their basket.

The agreement becomes still more interesting when it concerns observations on man himself.

The most important are contributed by M. Felix Leblanc,? who had the opportunity to analyze the air of the mines of Poullaouen and Huelgoat, in Brittany, whose treatise contains valuable information about the sensations of the miners.

The pyrites which are present in abundance in the veins being worked combine with a part of the oxygen in the air, which is thus lessened without being tainted at the same time by carbonic acid or other gases, as happens in confined places.

From the data reported by $M$. Leblanc we extract the following:

A: In a place where there is only 16.7 per cent of oxygen, respiration is only slightly affected, but the air is considered "weak" by the miners; 
B: With 15.3 per cent of oxygen, breathing is continuous and not very difficult.

C: With 9.8 per cent of oxygen, the air is asphyxiating, and at the end of one or two minutes, fainting fits occur. M. Leblanc, who went in suddenly, almost fainted, and the master miner who accompanied him was seized by vertigo and nausea.

Now, in observation $\mathrm{A}$, the oxygen tension equals that existing in pure air at $60.4 \mathrm{~cm}$. of pressure; which corresponds to a height of 1800 meters. For observation B, the equivalent pressure is 55.3 $\mathrm{cm}$., and the altitude 2500 meters. For C, the pressure is $35.4 \mathrm{~cm}$., and the altitude 6000 meters.

It is absolutely certain that a dweller in the plains, suddenly transferred to heights of 1800 and particularly 2500 meters, and driven immediately to the hard work of miners, would, like them, find the air weak and breathing rather difficult. It is absolutely certain that an aeronaut who was transferred to a height of 6000 meters as suddenly as in the observation of M. Leblanc and who, like this chemist, tried to make the effort necessary to climb a slope and empty a flask full of mercury, would also experience decidedly serious symptoms.

Finally - the last resemblance to which we shall call attention - the strange rapidity with which rigor mortis appears in animals dying in rarefied air is found also in death by asphyxia, when the carbonic acid formed is eliminated by absorbing it with potash. Example:

Experiment CCL. March 20. At 3 o'clock, a finch is placed under a bell of 3 liters on a tripod which isolates it from a crystallizing pan full of a potash solution. An elbow tube connects this bell with another which rests on the water basin, and in which the water will rise proportionately with the absorption of $\mathrm{CO}_{2}$, so that the pressure will always remain the same.

At 4 o'clock, the bird, which was a little uneasy at the beginning, lies down and remains quiet; pants.

It dies at $6: 23$; rectal temperature $31^{\circ}$.

Rigidity begins in the wings at $6: 34$; it is complete at $6: 45$.

Our parallel between the symptoms of decompression and those of asphyxia is therefore complete, and continues even to the least details with remarkable precision.

In both cases, the whole thing is summarized in this formula: nutritional disturbances due to the introduction into the organism of an insufficient quantity of oxygen in a given time. 
Subchapter III.

\section{MEANS OF AVERTING THE SYMPTOMS OF DECOMPRESSION}

The numerous data now enumerated have shown very clearly that the symptoms of decompression are due, not to the lessening of atmospheric pressure, but to the diminution of the tension of the oxygen, which no longer enters the blood, or consequently the tissues, in sufficient quantity to maintain the vital combustions at their normal rate. The preventive measures for these symptoms are naturally derived from this very idea.

The tension of a gas, we have often said already, is expressed by the product $\mathrm{P} \times \mathrm{Q}$, in which the barometric pressure $\mathrm{P}$ is multiplied by the percentage of $Q$ of the gas in the surrounding mixture. If then we increase the factor $Q$ at the same time that we diminish factor $\mathrm{P}$ by the use of the pneumatic pump, there will be no change in the tension, and the symptoms should be averted. At the same time, if the result justifies our expectations, the theory which serves as the base will once more be verified.

But the experiment, under the form I have just indicated, is very hard to carry out. We reach the same conclusions by executing it in the conditions of the experiment whose details I shall now give.

Experiment CCLI. April 23. Sparrow, under a bell of 1.5 liters, on the plate of the pneumatic machine. Outside pressure is $75 \mathrm{~cm}$.

$3: 20$, brought in a few minutes to $25 \mathrm{~cm}$. pressure; respiratory rate 212 .

At $21 \mathrm{~cm}$., whirls, falls head over heels, about to die. I restore normal pressure by admitting air very rich in oxygen (by accident, outer air enters at the same time); the bird recovers immediately and seems lively and well.

$3: 30$, the air then contains 35 per cent of oxygen. I bring the bird to $18 \mathrm{~cm}$. pressure; he is then very sick, with a respiratory rate of 176; I admit oxygen again, he recovers immediately.

$3: 40$, the air contains 77.2 per cent of oxygen. The bird under $13 \mathrm{~cm}$. pressure has a respiratory rate of 168 , but he falls only at $10 \mathrm{~cm}$. Likewise recovers immediately after the admission of superoxygenated air.

$3: 50$, the air contains 87.2 per cent of oxygen. The sparrow, at $10 \mathrm{~cm}$., has a respiratory rate of 176 , and seems in no danger; but at $8 \mathrm{~cm}$., he falls on his back and is about to die. New admission of oxygen, recovers again.

$4: 05$, the air contains 91.8 per cent of oxygen. We continue to the 
pressure of $7.5 \mathrm{~cm}$; the bird is very sick, and we have barely time to open the cocks.

The minimal tensions of oxygen have been successively $5.8 ; 6.3$; $10 ; 9.2 ; 9.1$.

The bird survives.

And so dangerous decompressions have become successively harmless, because the percentage of oxygen in the air has been sufficiently and progressively increased. We reached $12.5 \mathrm{~cm}$. before the symptoms which announce imminent death reappeared, and we saw a bird survive after having undergone the prodigiously low pressure of $7.5 \mathrm{~cm}$. I do not doubt that we could go even farther if we proceeded slowly enough.

I have often repeated in public this very simple experiment, which can be carried out in all physics laboratories, and which is at the same time very conclusive and very impressive. Figure 55 shows the experimental set-up.

By itself, it would be enough to bring conviction; but to increase the convincing effect, one can complete it by the following crucial experiment.

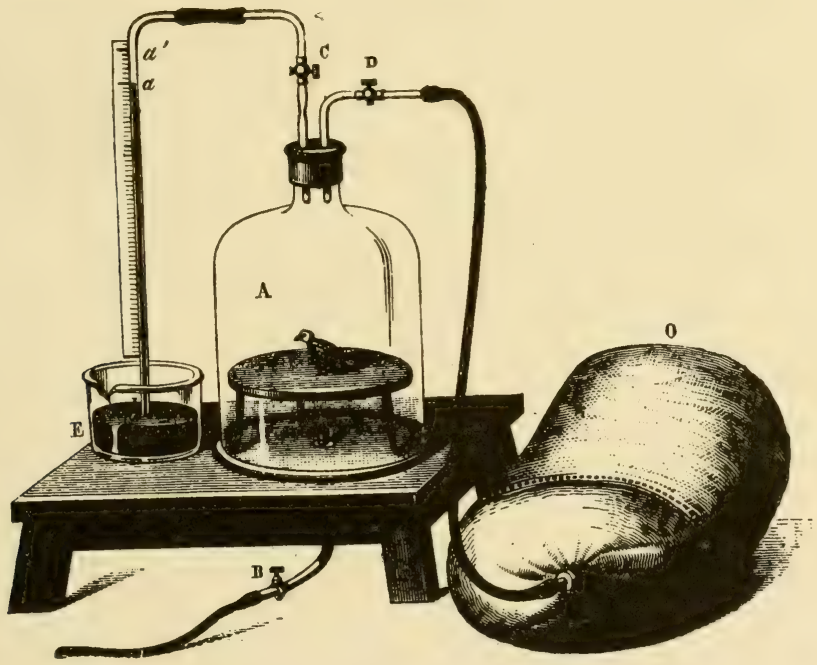

Fig. 55-Bird in air increasingly expanded and increasingly oxygenated. A. Bell-jar communicating at B with the pump, at $\mathrm{C}$ with a barometric tube, at $\mathrm{D}$ with a bag full of oxygen $\mathrm{O}$. 
Experiment CCLII. April 24. Under a bell of 2.5 liters, placed on the plate of the pneumatic machine, and previously filled with air very rich in oxygen, a sparrow is placed. Outside pressure $75 \mathrm{~cm}$.

The air then contains 82.2 per cent of oxygen; the pressure is lowered. At 5:30, the pressure is only $13.5 \mathrm{~cm}$; the bird is uneasy and flutters in the bell. At $9.5 \mathrm{~cm}$., it is very sick and about to die. Air somewhat superoxygenated is admitted. The bird recovers immediately.

$5: 38$, the air contains 55.7 per cent of oxygen; we begin to lower the pressure again, without being able to go lower than $11 \mathrm{~cm}$. Air somewhat superoxygenated is admitted; bird quite recovered.

$5: 45$, the analysis of the air has been lost. In the decompression we reached only $13 \mathrm{~cm}$. This time too, the bird is so sick that it remains some seconds motionless on its back after normal pressure is restored with ordinary air.

5:55, the air contains only 22 per cent of oxygen; so that we cannot pass below $18 \mathrm{~cm}$.

6: 05 , this time we use ordinary air; at $20.5 \mathrm{~cm}$., the bird is very sick; but he recovers perfectly under normal pressure. He has a large bloody spot on his head.

The oxygen tension at the moment when pressure had to be restored was successively $10.7 ; 8.0 ; 5.0 ; 5.6$.

This last experiment can be made still more simple.

Experiment CCLIII. June 5. Green grosbeak (Fringilla chloris Lin.). Put under the bell of the pneumatic machine.

Pressure slowly decreased; sick at $30 \mathrm{~cm}$. of actual pressure, and as it stirred about somewhat, was quite sick at $22 \mathrm{~cm}$.

I then let pure nitrogen enter the bell to restore normal pressure. The bird, far from recovering, dies almost immediately.

It has in the cranial diploe a huge dark effusion.

Whatever the operative procedure used, these different experiments show clearly both the cause of the symptoms resulting from decompression and the means of averting them.

Evidently I could not limit myself to experiments made on animals, however convincing, when I was issuing practical precepts intended for mountain travellers and aeronauts.

I resolved to begin by experimenting on myself. I had already undergone, in my large sheet-iron cylinders, rather considerable decompressions, to the point of experiencing certain discomforts. I then thought of trying the test again, so as to remove the symptoms by breathing a superoxygenated air.

I placed beside me in the apparatus a large rubber bag, containing air whose oxygen content was in proportion to the degree of decompression. Figure 56 shows the set-up of the experiments.

I give here the details of three of them, and of a fourth which 
was carried on by my regretted colleagues and friends, MM. Crocé-Spinelli and Sivel.

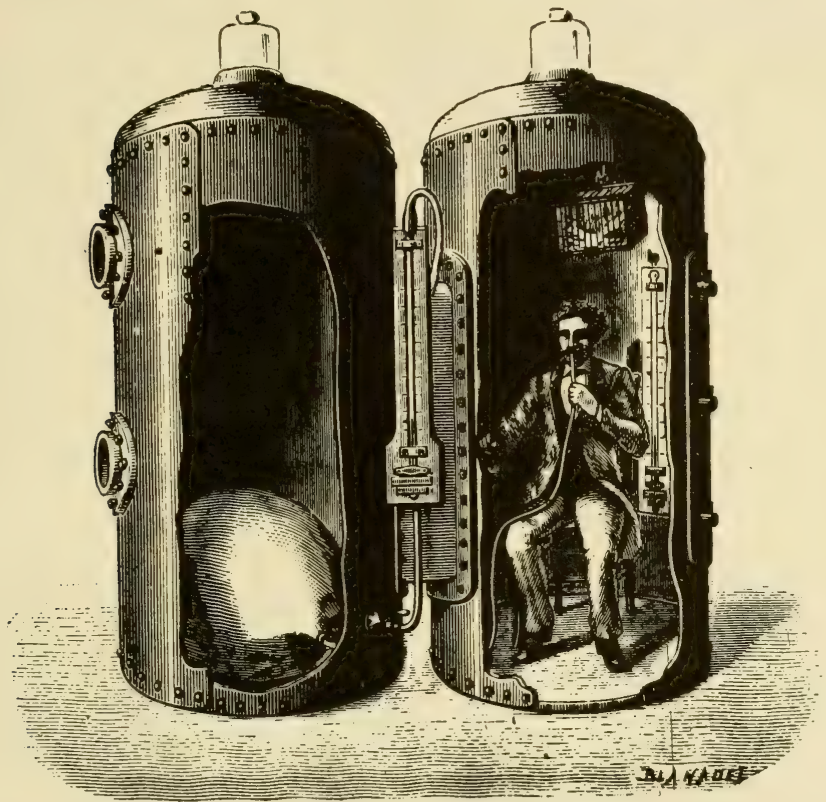

Fig. 56-Respiration of superoxygenated air, expanded by decrease of pressure.

Experiment CCLIV. February 20, 1874. Outside pressure $758 \mathrm{~mm}$. $2: 30$, I enter and seat myself comfortably in the cylinders, having with me a bag filled with air extremely rich in oxygen; beside me, a sparrow in a cage.

My pulse rate is 64; my temperature taken under the tongue with great care is $36.5^{\circ}$; an expiration in a Hutchinson spirometer gives me a value fixed on the arbitrary scale as 17.3.

$2: 37$, the door is closed, the decompression begins.

2:45, pressure $710 \mathrm{~mm}$.; pulse 68 .

2:58, pressure $590 \mathrm{~mm}$; pulse, 70 ; I am at a decompression corresponding approximately to the elevation of Mexico, 2150 meters.

3:02; $535 \mathrm{~mm}$.; pulse, 73 .

$3: 06 ; 500 \mathrm{~mm}$.; intestinal gases escape.

$3: 08 ; 465 \mathrm{~mm}$.; pulse, 78 .

$3: 12$; $450 \mathrm{~mm}$.; pulse, 84 ; it is the barometric pressure of Calamarca, at 4150 meters; I have slight nausea. 
$3: 14$; 450 meters.; pulse drops to 80 ; nausea disappears; the abdomen is slightly distended; my face feels congested and I have slight dizziness .

$3: 17 ; 430 \mathrm{~mm}$; pulse, 84 . I breathe oxygen three times; my pulse falls to 78 ; dizziness.

$3: 21$; pressure is only $418 \mathrm{~mm}$; which corresponds to the elevation of Mont Blanc, 4800 meters; my pulse rate continues to drop after some breaths of oxygen; it is only 70 ; at each respiration, dizziness.

3:23; $420 \mathrm{~mm}$; I rise breathing air; my pulse rate rises immediately to 96 , then to 100 ; I have outright vertigo; I sit down again.

$3: 25 ; 445 \mathrm{~mm}$; pulse rate drops to 90 , then after a breath of oxygen, to 70 , at $3: 26$, at a pressure of $460 \mathrm{~mm}$.

$3: 28 ; 450 \mathrm{~mm}$; the bird falls in its cage.

$3: 30 ; 440 \mathrm{~mm}$; pulse, 76 ; belching of gas.

$3: 32 ; 435 \mathrm{~mm}$. Wishing to raise my right leg without leaving my chair, it was seized with convulsive trembling in the muscles of the calf and thigh, a trembling which I could not control with my hand; it ceased when I placed my foot firmly on the floor; temperature under the tongue is $36.8^{\circ}$.

$3: 34 ; 443 \mathrm{~mm}$.; pulse, 80 ; a breath of oxygen.

$3: 35 ; 445 \mathrm{~mm}$.; pulse rate falls immediately to 70 ; trying to whistle at this moment, I note that it is impossible.

$3: 37 ; 436 \mathrm{~mm}$.; pulse, 80 .

$3: 39 ; 430 \mathrm{~mm}$.; I breathe into the spirometer; dizziness; I am now only 11.8 (on the arbitrary scale mentioned above).

$3: 43 ; 435 \mathrm{~mm}$.; pulse, 80 .

$3: 45 ; 423 \mathrm{~mm}$; pulse 90 . I take several breaths of oxygen; dizziness.

$3: 47 ; 423 \mathrm{~mm}$.; pulse rate has fallen to 69 .

$3: 48 ; 423 \mathrm{~mm}$.; I move about on my chair; slight dizziness.

$3: 49 ; 425 \mathrm{~mm}$.; pulse 78 .

3:50; $420 \mathrm{~mm}$; ; pulse 86 .

$3: 51 ; 418 \mathrm{~mm}$.; pulse 87 ; I take a breath of oxygen.

$3: 53 ; 426 \mathrm{~mm}$.; pulse 78 .

$3: 55 ; 430 \mathrm{~mm}$; pulse 80 ; some breaths of oxygen; dizziness.

$3: 57 ; 430 \mathrm{~mm}$; pulse 72 .

$3: 59 ; 420 \mathrm{~mm}$.; pulse 84 . I am quite uncomfortable; having found that the number of my heart beats for 20 seconds was 28 , I have very great difficulty in multiplying this number by 3 , and I write in my notebook "hard to calculate."

4:01; $413 \mathrm{~mm}$; ; pulse 88 .

$4: 03 ; 408 \mathrm{~mm}$; pulse 92 ; painful nausea; dizziness; congestion in

the head; convulsive trembling when I raise my leg.

$4: 04 ; 415 \mathrm{~mm}$.; pulse 90 ; I breathe oxygen; dizziness.

$4: 05 ; 416 \mathrm{~mm}$;; pulse only 75 .

4:07; $420 \mathrm{~mm}$.; I breathe into the spirometer, and go only to 9.9; dizziness and vertigo after having breathed.

$4: 09 ; 430 \mathrm{~mm}$.; temperature under the tongue, $36.7^{\circ}$. 
disappeared and well-being was restored immediately. The pulse rate-and this is a very exact indication-dropped immediately, to return soon to its former figure.

The graphs of Figure 57 show very clearly these curious changes. The hours are marked on the horizontal axis. The upper graph represents the downward course of the barometric pressure, with the elevation corresponding to certain decompressions; the lower graph indicates the variations in heart rate. At every breath of oxygen, marked $\mathrm{O}$, we see an instant fall of this latter line; the demonstration is very clear.

Such sudden modifications in the circulatory rhythm must necessarily have ill consequences; it is to them that I attribute the dizziness which accompanied each breath of oxygen. I add that on the evening of this experiment for several hours I felt symptoms of cerebral congestion which continued to annoy me somewhat.

I wish the reader also to note the muscular trembling and the strange state of mental weakness from which I suffered on reaching the pressure of $420 \mathrm{~mm}$., that is, about that of the elevation of Mont Blanc; with a pencil in my hand, I was almost incapable of multiplying 28 by 3 .

On the ninth of March, the next month, MM. Crocé-Spinelli and Sivel, who were planning ascents to a great height, came to my laboratory with the purpose of studying upon themselves the disagreeable effects of decompression and the favorable influence of superoxygenated air.

I can do no better than to reproduce the account which $M$. Crocé-Spinelli drew up for me immediately, from the notes which he and M. Sivel took constantly in the apparatus, of phenomena which they both experienced.

Experiment CCLV. The diminution of pressure went on regularly; in 35 minutes they were brought to $304 \mathrm{~mm}$; the return to normal pressure was made in 22 minutes. They therefore remained for 25 minutes below a pressure of $450 \mathrm{~mm}$.

Sir:

Paris, March 10, 1874.

I am transmitting to you the data which M. Sivel and I collected and the impressions we felt in your decompression bells, March 9, 1874.

Emotion did not appreciably affect these observations, for I think that none existed in M. Sivel, and it was extremely weak in me during the whole experiment. The constant preoccupation of observing data explains that well enough.

The experiment began at $10: 31$. 
The first moments of the decompression gave rise to no disagreeable impression. At 10:34 at a pressure of $70.5 \mathrm{~cm}$. of mercury I found a pulse rate of 80 in M. Sivel; and very shortly after, at 68 $\mathrm{cm}$., 92 in myself. At 1:40, pressure $56 \mathrm{~cm}$., the pulse rate of M. Sivel was 100 ; mine was also. At $1: 44$, pressure $51 \mathrm{~cm}$., my pulse was 116, M. Sivel's 108.

Beginning with a pressure of about $48 \mathrm{~cm}$., oppression begins to be quite perceptible. I become lazier and am satisfied with considering what effects I feel. My face feels hot, and so does M. Sivel's at a pressure of about $44 \mathrm{~cm}$. Besides, I have prickly sensations in my head, an itching which feels like a scalp affection. Mental energy is not at all weakened, for we are gay and talkative.

At 1:40, about $41 \mathrm{~cm}$., M. Sivel breathes oxygen from the bag, not from necessity, but to lessen the considerable tension of the container, which is ready to burst. At a pressure of $40 \mathrm{~cm}$., I feel uncomfortable, my head seems to be in a vise, and I feel as if I were pressing my forehead hard against a bar of small diameter. My pulse rate is 135 .

At 1:57, at a pressure of $39 \mathrm{~cm}$., I breathe some gulps of oxygen from the bag which M. Sivel holds out to me. I feel better and my pulse rate falls to 128 , although the decompression is continued.

We pass each other the oxygen bag. My companion uses it until the maximum decompression, 5 or 6 times, often very freely, and I do 3 or 4 times, in a way that is generally more moderate and even awkward, for, feeling at first a certain distaste for breathing this gas which smells of rubber, I lose a fairly large quantity of it. However, as the pressure lowers, I overcome this repugnance more easily, and feel instinctively the necessity of absorbing this gas. At 38 and $37 \mathrm{~cm}$., my pulse rate is 128 after breathing oxygen; at 35 $\mathrm{cm}$., it is 132 . It is certain that if oxygen were not inhaled, it would be higher.

In M. Sivel, the absorption of the oxygen produced the following effects: the bell seemed to him to be moving as if he were drunk, and this effect lasted for several seconds; he had a slight sensation of seasickness. Then this discomfort vanished and his mind became keener than before the oxygen was inhaled.

In me, the same impressions were present, but in a greater degree. Moreover, below $35 \mathrm{~cm}$., my vision, which was growing dull, became very noticeably keener after the absorption of oxygen. I saw clearly after having seen dimly; the interior of the bell seemed suddenly to become lighter.

At these low pressures, the mind had become very dull in both of us, but particularly in me. During the four minutes preceding the time when we reached $30.4 \mathrm{~cm}$., I could only note down the pressures which M. Sivel dictated to me very loudly, and the simplest calculations seemed very difficult to me. I was very deaf and had to have the pressure figures repeated several times. The air no longer seemed to conduct sound.

At 11:08, at a pressure of $30.4 \mathrm{~cm}$, neither M. Sivel nor I was saying a word. However, we had been very gay, very talkative and active to about $37 \mathrm{~cm}$. It is true, we no longer had any oxygen, and 
this fact caused a sort of instinctive regret in me. M. Sivel's mind then wavered a bit, and I was in a state of decided prostration. The weakness, however, had not yet reached such a point that we could not have endured (with some difficulty, it is true) two or three centimeters more of decompression, especially M. Sivel, who throughout showed himself less affected than I.

During the whole experiment, neither of us noted anv abdominal distention or pulmonary oppression, which astonished me in myself, since I have very sensitive lungs. Our faces had finally purpled. M. Sivel had become deep violet, and I, who am ordinarily pale, light violet. My right ear was very red.

M. Sivel, having noted my state of great discomfort, asked me whether I thought that the decompression should be stopped. I answered yes, because there was no more oxygen. The memory of this fact did not return to me immediately after the experiment, and it is only at this moment when I am writing that it becomes very clear to me.

They stopped the machine then and opened the intake cocks. Here is the pulse rate noted during the period of recompression: in me, at $52 \mathrm{~cm} ., 104$; at $59 \mathrm{~cm} ., 100$; at $66 \mathrm{~cm}$., 96 . In M. Sivel, at $62 \mathrm{~cm}$., 98.

In 7 minutes, we returned to $45 \mathrm{~cm}$, and in spite of the speed of the rise in pressure, we not only felt no discomfort, but on the contrary, experienced a very agreeable sensation, I in particular. It was not until afterwards that buzzing in the ears began in both of us. M. Sivel drank some water and ate a little, and twice felt relief when his ear suddenly became unstopped. I was more sensitive to the buzzing than he; my ear was unstopped only once, and I had severe pain. This pain increased at about $70 \mathrm{~cm}$., when the operators, seeing on the outer manometer only a few centimeters of decompression left, opened the intake cock wide. That probably caused the earache which persisted in me after the experiment.

On leaving the bell at 11:30, after a 59 minute experiment, I felt as if there were cotton in my ears, tightly wedged in, but I was not in pain. My head was free, but my mind a little feverish. All day I felt my ears, especially the right one, very dull. In the evening the right ear ached. I went to bed at 11 , but could not get to sleep till 4 in the morning. I had not only twinges and a neuralgia in my temples, but the inner ear seemed swollen, and a pressure of the hand caused pain. I soothed the pain by wrapping my head up. As for M. Sivel, this experience left him no ill effects.

I should say that my "bell companion" is of a sanguine temperament, that he enjoys excellent health, and that he has a very vigorous appearance. He is used to long journeys, on land and sea, and he has made two balloon ascensions. Although of a good constitution, I am evidently less strong than he. I have a "lymphaticonervous" temperament.

It seems a good idea to compare the sensations felt in the bell with those I experienced in the ascent to 4600 meters, under a barometric pressure of $429 \mathrm{~mm}$., in the company of MM. Jobert, Pénaud, Dr. Pétard, and Sivel. In this ascent, I felt no disagreeable sensation 
caused by the decompression, nor did my companions. Now in the bell, about $50 \mathrm{~cm}$., my face prickled, and M. Sivel had the same sensation at $44 \mathrm{~cm}$. Before $429 \mathrm{~mm}$, the discomfort was already very considerable, and I had the feeling of a bar across my forehead, whereas there was nothing of the sort during the ascension. In the bell, my pulse rate was 116 at $51 \mathrm{~cm} ., 135$ at $40 \mathrm{~cm}$, and in the basket of the balloon, it was 116 between 43 and $44 \mathrm{~cm}$. The pulse rate of $\mathrm{M}$. Sivel was 108 at $46.5 \mathrm{~cm}$. in the bell, and 110 at $43 \mathrm{~cm}$. in the basket.

I noted the ear buzzing in the ascension exactly as in the bell. As the balloon descended, it seemed as if there were cotton in my ears. This impression lasted till the next day, but the pain was never more than very slight. As in the bell, the pain increased during the last centimeters of recompression, because of the rapidity of the descent.

In this experiment, the two aeronauts went to a pressure of $304 \mathrm{~mm}$. of mercury, corresponding to an elevation of 7300 meters. They were, consequently, much more greatly affected than I had been, not having passed $418 \mathrm{~mm}$., an elevation of 5100 meters; nervous phenomena dominated the scene in them; dimness of vision, intellectual indolence were very noticeable in M. CrocéSpinelli. M. Sivel, who entered the apparatus fasting, began to eat during the decompression; he soon stopped, and as I signed to him through the glass portholes to continue, he replied by a gesture of disgust.

The favorable action of oxygen was also very evident; after several inhalations the distressing symptoms disappeared. At one time, at very low pressures, the lips and the right ear (the only one I saw) of M. Crocé-Spinelli had become so purple that I was preparing to open the cocks, when he put the oxygen tube to his mouth; the effect, that is, the return to normal color, was instantaneous. M. Crocé-Spinelli told me when he had left the apparatus, that he resorted to oxygen at that time because he could hardly see his paper, which suddenly at the first inhalation appeared to him very white, as if he were dazzled.

In these two experiments, oxygen had been used only intermittently, to lessen for some instants the severity of the symptoms of decompression. I wanted to operate a little differently, letting the discomforts come on to a certain degree, then breathing superoxygenated air continuously, still decreasing the barometric pressure, and seeing what would happen.

Here is the account of two experiments carried on according to this procedure.

Experiment CCLVI. March 28. I enter the apparatus at 10:55; the door is closed at 11:04; my pulse rate is 58. Barometric pressure, $761 \mathrm{~mm}$. 
$11: 10$; pressure $715 \mathrm{~mm}$; pulse 62 .

$11: 20 ; 580 \mathrm{~mm}$; pulse 63 .

$11: 23 ; 535 \mathrm{~mm}$; pulse, 63 ; slight nausea.

$11: 25 ; 510 \mathrm{~mm}$.; gas escaping above and below.

$11: 27 ; 495 \mathrm{~mm}$; pulse, 66 .

$11: 31 ; 455 \mathrm{~mm}$; pulse, 64 ; nausea; gas escapes, and yet the abdomen remains somewhat distended.

$11: 33 ; 435 \mathrm{~mm}$; pulse, 70; act of whistling, which I manage very well at normal pressure and which had become difficult at $520 \mathrm{~mm}$., is completely impossible.

11: 35 ; $425 \mathrm{~mm}$; pulse, 72 ; a little trouble with vision, which is less clear.

$11: 37 ; 412 \mathrm{~mm}$.; pulse, 76 ; I am quite uncomfortable, with my eyes somewhat affected.

I begin then to inhale continuously from the bag full of superoxygenated air which I have beside me; the exhaled air goes outside. Occasionally I am dizzy, then every symptom disappears, and until the end of the experiment, I am in a state of perfect comfort.

The pulse rate, which had fallen instantly to 63 , is still falling, although the decompression progresses.

11: 41 ; pressure, $408 \mathrm{~mm}$; pulse, 60 .

11: $46 ; 382 \mathrm{~mm}$.; pulse, 63 .

$11: 47$; $380 \mathrm{~mm}$.; gas escapes by the mouth and anus; perfect confort.

11:48; $369 \mathrm{~mm}$; pulse, 58; more gas.

11:51; $355 \mathrm{~mm}$; pulse, 59 .

$11: 52 ; 350 \mathrm{~mm}$; more gas.

$11: 55 ; 338 \mathrm{~mm}$; I make efforts to open and close a flask; the pulse rises to 63 ; pressure begins to rise again.

$11: 59 ; 400 \mathrm{~mm}$; pulse, 60 .

12 (noon); $440 \mathrm{~mm}$; impossible to whistle.

12: $02 ; 490 \mathrm{~mm}$., pulse, 60 ; impossible to whistle; I stop breathing superoxygenated air.

$12: 03 ; 520 \mathrm{~mm}$; impossible to whistle; pulse, 56 .

$12: 05 ; 540 \mathrm{~mm}$; I begin to be able to whistle.

12:07; $570 \mathrm{~mm}$.; I whistle very well; pulse, 59 .

$12: 10$; return to normal pressure; pulse, 52 .

This experiment shows very clearly that continuous inhalations of oxygen, after having checked painful symptoms, prevent them from reappearing, although the barometric pressure continues to fall. Nothing is more conclusive. The decompression reached was $338 \mathrm{~mm}$., corresponding to the elevation of about 6500 meters, that is, a little more than that of Chimborazo.

Figure 58 shows the different phases through which the heart beats passed before and during inhalations of oxygen, whose beginning is marked by 0 .

Among other phenomena which continued in spite of the inhaling of oxygen, because they depend entirely upon the decrease 
of the density of the air, I shall mention the evacuations of gas and the inability to whistle, which had already been noted in the pre-

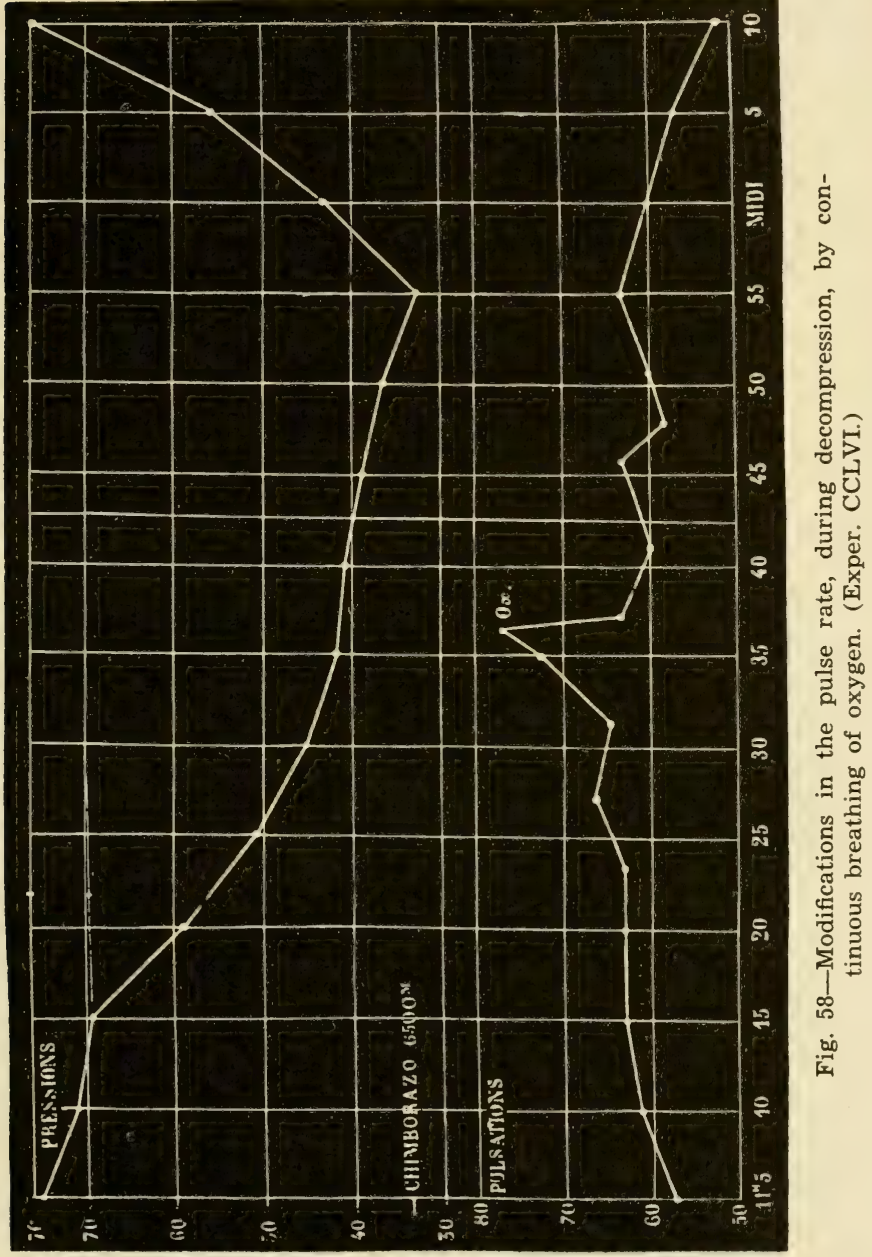

ceding experiment, but of which neither aeronauts nor mountain climbers speak; it was observed below $500 \mathrm{~mm}$. 
The following experiment, conducted in the same manner, is even more striking because of the enormous decompression to which I subjected myself without harm.

Experiment CCLVII. March 30. I enter the apparatus at 10:15; pressure $759 \mathrm{~mm}$. I have with me a sparrow, whose rectal temperature is $41.9^{\circ}$, a rat, and a candle.

10:22; they close the door; pulse rate, 60 .

10: 29; pressure $710 \mathrm{~mm}$; ; pulse, 63 .

$10: 34 ; 665 \mathrm{~mm}$.; pulse, 64 .

$10: 40 ; 640 \mathrm{~mm}$.; pulse, 65 ; I see bubbles of gas appearing in the water I have beside me in a glass.

$10: 43 ; 605 \mathrm{~mm}$.

10:46; $580 \mathrm{~mm}$.; pulse, 66 .

At $555 \mathrm{~mm}$., I whistle easily enough; the flame of the candle grows rather blue, the wick lengthens; it is almost half the length of the flame.

At $510 \mathrm{~mm}$., impossible to whistle high notes.

10:53; $480 \mathrm{~mm}$; pulse, 70; a little discomfort.

10:55; $455 \mathrm{~mm}$.; pulse, 78; a feeling of congestion in the head; gas escaping above and below.

$10: 58 ; 430 \mathrm{~mm}$.; pulse, 80 ; the bird vomits, appears quite sick, but remains perched; the rat seems quite calm.

$11: 00 ; 410 \mathrm{~mm}$; ; pulse, 86 ; I place before my mouth the tube of the oxygen bag, which the decompression has distended, and breathe a very highly superoxygenated mixture; dizziness.

11:02; $400 \mathrm{~mm}$.; pulse has dropped to 64 ; the bird vomits again; the rat seems very uneasy.

11:05; $378 \mathrm{~mm}$.; pulse, 66 ; impossible to whistle.

$11: 09 ; 360 \mathrm{~mm}$; pulse, 72 ; a little discomfort, although I have breathed oxygen continuously, but at a distance, it is true. I then take the discharge tube in my mouth, without closing the nostrils, and keep it there until the end of the experiment. The discomfort disappears immediately.

$11: 11$; $348 \mathrm{~mm}$; pulse, 66 ; the sparrow's respiratory rate is 126 .

11:14; $323 \mathrm{~mm}$; pulse, 64 ; the sparrow, which is vomiting hard, nevertheless remains on its perch.

$11: 17 ; 310 \mathrm{~mm}$.; I have a little discomfort, with a pulse of 75 .

$11: 19 ; 300 \mathrm{~mm}$.; the sparrow is very sick.

11:22; $295 \mathrm{~mm}$.; pulse, 64; my discomfort has entirely disappeared. $11: 24 ; 288 \mathrm{~mm}$.

$11: 27 ; 280 \mathrm{~mm}$.; pulse, 66 ; the flame of the candle is very blue; the wick is about $3 / 5$ the length of the flame.

$11: 33 ; 258 \mathrm{~mm}$; pulse, 70 ; the bird vomits and seems extremely sick, but it still remains on its perch.

$11: 34 ; 255 \mathrm{~mm}$.

$11: 36 ; 248 \mathrm{~mm}$.; pulse, 64 ; I let the pressure increase.

$11: 38 ; 290 \mathrm{~mm}$.; pulse, 63 .

$11: 40 ; 340 \mathrm{~mm}$.; the rectal temperature of the sparrow is only $36.4^{\circ}$

11:43; $390 \mathrm{~mm}$.; pulse, 54 ; I stop breathing oxygen. 
11:44; $420 \mathrm{~mm}$; impossible to whistle; the bird is still very sick, crouching on its perch.

11:46; $480 \mathrm{~mm}$.; impossible to whistle.

11:47; $550 \mathrm{~mm}$.; still impossible to whistle; pulse, 66 .

11:48; $580 \mathrm{~mm}$.; I can whistle the low notes, but not the high ones. $11: 49 ; 630 \mathrm{~mm}$.; I can whistle very well.

11:51; returned to normal pressure; pulse, only 52 . The rectal temperature of the sparrow is $36.1^{\circ}$; that of the rat, $34^{\circ}$; my temperature under the tongue is $36.5^{\circ}$.

At $3: 30$, the sparrow's rectal temperature is still only $38.7^{\circ}$.

Here is an experiment in which in an hour and a quarter I reached a minimum pressure of 248 millimeters, that is, less than a third of normal pressure, during which experiment I remained 45 minutes below 400 millimeters, without having experienced discomfort from the moment when I began to breathe the superoxygenated air regularly. My pulse, as the lower graph in Figure 59 shows, remained from then on at its normal figure; it even dropped towards the end, either because of the long rest in a seated posture, or under the influence of breathing superoxygenated air. Beside me, a sparrow and a rat were very sick, and

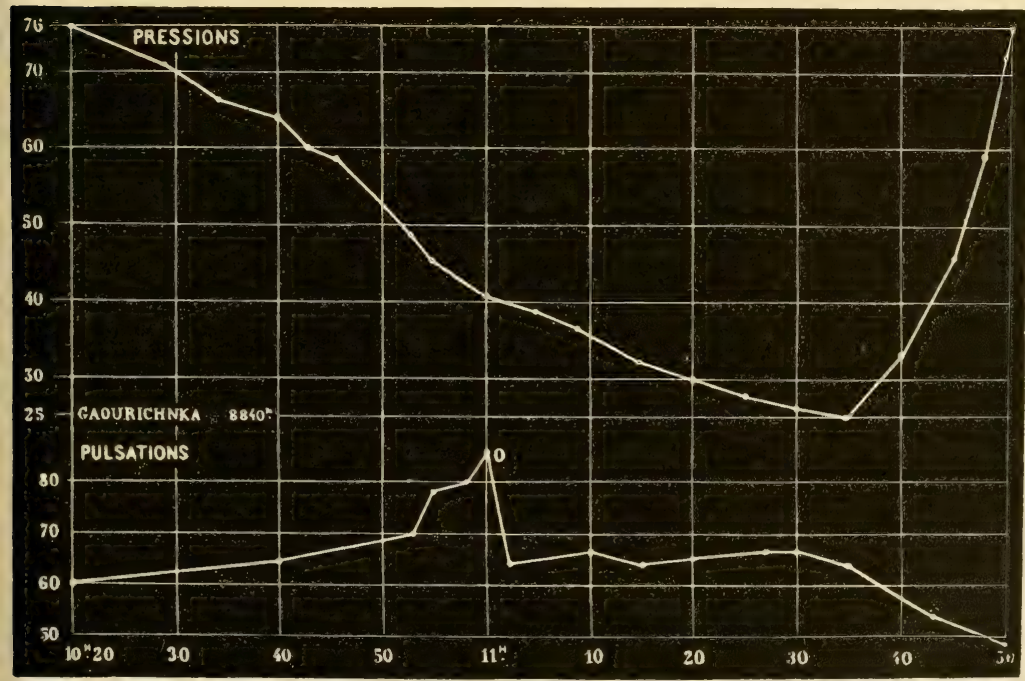

Fig. 59-Modifications in the pulse rate, during decompression, by continuous breathing of oxygen. (Exper. CCLVII.) 
their temperature dropped several degrees. As for me, far from running any risk, I felt none of the slight discomforts of decompression, nausea, headache, or congestion of the head, nor did I feel any after leaving the apparatus. It even seemed to me as if I could have gone lower yet, with no inconvenience, and I was quite ready to do so, had not my steam pumps, weary with work, refused to continue exhausting the air of the cylinders. Perhaps I must blame the complicity of the people witnessing the experiment, who frequently came and looked at me through the portholes and, in spite of the quite natural appearance of my face, seemed greatly terrified at seeing me exposed to this enormous diminution of pressure. In fact, it corresponded to more than 8800 meters, that is, an elevation greater than that which mountain travellers and aeronauts, except MM. Coxwell and Glaisher, have ever been able to reach. I felt no discomfort at this pressure which was nearly fatal to the two brave Englishmen, and at which a few months later MM. Crocé-Spinelli and Sivel were to perish.

1 See his experimental researches on the physiological properties and the uses of red blood and dark blood. Journal de la physiologie de l'homme et des animaux; 1858, p. 99, $101,105$.

Recherches sur la composition de l'air de quelques mines (Annales de chimie et de physique, Third series, vol. XV). 


\title{
Chapter IV \\ ACTION OF COMPRESSED AIR ON ANIMALS
}

\author{
Subchapter I
}

\section{TOXIC ACTION OF OXYGEN AT HIGH TENSION}

The experiments reported in Chapter I, Subchapter II, have brought us to this remarkable conclusion, that compressed air, or, to speak more exactly, the oxygen which has reached a certain tension constitutes a dangerous element, often even fatal, for animal life.

This unexpected revelation, which is deduced from all our series of experiments in such a way as to be convincing to the most suspicious mind, deserved deep study. The symptoms of this unknown sort of poisoning in its different degrees had to be analyzed; the concentrations at which oxygen becomes dangerous had to be determined, both as to its tension in the exterior respiratory medium and as to its proportion in the interior respiratory medium, the blood; an explanation had to be found for its inner mode of action upon the different anatomical elements.

This new problem left far behind it in scientific interest the analysis of some modifications in the respiratory and circulatory rhythms hitherto studied by the authors who gave their attention to compressed air. I devoted myself to it at the very beginning with all the concentration of which I was capable. Having demonstrated successively that compressed air acts only by the tension of the oxygen which it contains, and that this oxygen can kill animals rapidly with convulsive symptoms, following the usual 
method of physiologists, I had to set aside for the moment the effects of low concentrations of oxygen, which are hard to estimate, and study first the violent symptoms caused by high concentrations. In the first place, I investigated the action of oxygen under high tension, generally adding to the manometric pressure a percentage of oxygen sufficient to produce a value much greater than that in the air which we breathe.

I think it advisable to report here a certain number of experiments which will permit me to give first a description of the symptoms resulting from what I shall call, if only for convenience in nomenclature, poisoning by oxygen.

Already we have noted the convulsions which had attacked sparrows subjected to this dangerous agent. The following experiments, almost all performed in the Seltzer water apparatus, will furnish us new examples.

Experiment CCLVIII: January 29. House sparrow subjected to 6 atmospheres, 5 of which were oxygen, from $3: 50$ to $3: 58$. The mixture contained 81 per cent of oxygen, and the tension of this gas was therefore equivalent to $81 \times 6=486$, which corresponds to $\frac{486}{20.9}=23.2$
atmospheres of air.

At 4:03, violent convulsions, the head hanging down; whirling.

I lower the pressure and bring it to 3.5 atmospheres. During the decompression, new convulsions.

Immediately after, third attack; then new attacks, weaker and weaker, at 4:06, 4:11, 4:14.

During the attacks, and in the intervals, the respirations are very deep and very hasty; the beak is wide open.

The attacks come oftener at intervals of 1 to 2 minutes, becoming weaker and weaker. They subside about $4: 40$; the bird remains lying on its back, its respirations become rarer and rarer, and cease at 5 o'clock, without any other movement.

At $5: 10$, the rectal temperature is $24^{\circ}$.

Experiment CCLIX. February 2. House sparrow, subjected to 6 atmospheres, 5 of which are oxygen. The oxygen tension is about 450 .

After 5 minutes, strange tremors, a quivering through the whole body; then it remains motionless, its beak down.

After 10 minutes, an attack of strong convulsions; another at 12 minutes; a third, weaker, at 17 minutes. The bird is very sick, breathes from 50 to 70 times a minute, its beak wide open.

Brought back carefully to normal pressure; recovers a very little; rectal temperature, $34^{\circ}$ to $35^{\circ}$. In its cage it has new convulsive attacks; at the end of a quarter of an hour, gets up on its feet; but when it is threatened with the finger, it draws back walking on the whole tarsus, and falls backwards. 

night.

After 2 or 3 hours, seems fairly well recovered, but dies in the

Experiment CCLX. February 5. Sparrow subjected to 5 atmospheres, 4 of which are oxygen. The oxygen tension is about 400 . After about 15 minutes, strong convulsions occur; I allow 2 or 3 attacks, then restore normal pressure.

The rectal temperature is $32^{\circ}$.

The bird has evidently retained all its intelligence; it pecks viciously when a finger is presented to it, and uses its wings and feet strongly.

One hour afterwards, its temperature is $34^{\circ}$. It has had more of the slight convulsive attacks, and cannot keep on its feet.

3 hours afterwards, its rectal temperature has risen to $39.5^{\circ}$. Survives.

Experiment CCLXI. February 26. Sparrow; rectal temperature $40.5^{\circ}$.

Subjected to 5 atmospheres, 4 of which are oxygen (tension of about 400 ).

At the end of 5 minutes, beginning of uneasiness. I restore normal pressure rapidly by the capillary cock.

The temperature is $40.3^{\circ}$, but it rises rapidly to $40.5^{\circ}$ after respiration in the air. The bird is very vigorous and very vicious. Red cranial suffusions, in abundant spots.

The bird walks, runs, climbs about the cage, but does not fly. If it is tossed into the air, it has great difficulty in flying and soon falls; it then refuses to fly up from the ground.

Survives; the next day, it flies very well; the suffusions persist for several days.

Experiment CCLXII. March 2. Sparrow at 5 atmospheres, 4 of which are oxygen.

After 5 or 7 minutes, convulsions begin; at the first appearance, I open the little cock. The rectal temperature rises to $41^{\circ}$, but very slowly after $38^{\circ}$.

Small bloody suffusions.

Experiment CCLXIII. May 23. At 4 o'clock, sparrow taken to 5 atmospheres, 4 of which are oxygen. Tension about 400 .

After 15 minutes, slight convulsions; at 20 minutes, severe convulsions, two or three attacks. At 30 minutes, taken out.

Rectal temperature, $33^{\circ}$.

At 5: 45 , rectal temperature, $35^{\circ}$; still trembling, quite sick.

At 7 o'clock, dead; muscular contractions singularly slow.

Experiment CCLXIV. February 12. Sparrow; cylindrical apparatus.

At normal pressure, respiratory rate, 135. Raised to 3 atmospheres of air, respiratory rate, 115 .

At $4: 20$, I pass a current of oxygen into the apparatus, and raise the pressure to 2 superoxygenated atmospheres. 
At 4:30, new ventilation, and pressure raised to 3 atmospheres.

At $4: 40$, the same; pressure at 4 atmospheres.

At $4: 55$, the same, $5 \frac{1}{4}$ atmospheres; little convulsions begin to appear.

At 5:06, new ventilation carried to 6 atmospheres. Convulsions return, in spasms.

Dead about 6:50.

The air then contained 73 per cent of oxygen and 0.5 per cent of carbonic acid.

The oxygen tension $\mathrm{P} \times \mathrm{O}_{2}=438$ corresponds to 21 atmospheres of air.

Blood very red in the jugular. Bloody suffusions extending over the whole cranium.

Experiment CCLXV. March 29. Sparrow placed in the small Seltzer water apparatus.

At 2:50 we begin to compress oxygen up to 8 atmospheres; the capillary cock being open, the compression maintained is carried on in a current of air delivering more than a liter per minute.

At 3:15 great convulsions occur; I allow two attacks to succeed each other, at three minutes interval. Then, rapid decompression. The bird pecks the finger which I offer it, and appears intelligent.

Its rectal temperature is $32^{\circ}$. When out of the apparatus, it has a third attack, and dies at 3:22. The blood of the jugular vein is dark and contains no free gases.

Experiment CCLXVI. July 9. Sparrow taken to 7 atmospheres of superoxygenated air.

After 10 minutes, seized by tonic convulsions. Taken out after 15 minutes; the convulsions continue, or rather the bird is in constant opisthotonos. From time to time, the stiffness increases; the bird cries out, spreads its wings, and wraps itself in them; the tail feathers are spread out. Remains sensitive and appears intelligent. The attacks of rigor are some of them spontaneous, others clearly provokable by stimuli.

It dies 20 minutes afterwards.

Experiment CCLXVII. July 18. Sparrow taken to 5 atmospheres of superoxygenated air.

After 5 minutes, vomits, and appears in very bad shape. But the convulsions do not come until about 20 minutes after, and they are violent.

Taken out 5 minutes afterwards, it continues to have convulsions and stiffness with opisthotonos. Pecks the finger presented to it. Its rectal temperature is $37^{\circ}$.

Two hours after, is perfectly recovered; its temperature has risen to $41^{\circ}$.

Experiment CCLXVIII. May 24, 1874. Experiment made before a Committee of the Academy of Sciences.

Sparrow taken to 6 atmospheres, superoxygenated. It is 4 o'clock.

After about 15 minutes, slight convulsions occur, soon followed by severe attacks. 
The bird is removed; it has large ecchymoses on the cranium. Its rectal temperature is only $30^{\circ}$.

Remains very sick and dies in the night.

The data which have just been given permit us from now on to describe the violent symptoms due to compressed air, to too high oxygen tension, and to prepare the physiological analysis of this poisoning.

The first question which we should ask ourselves is as follows: at what oxygen tension do the convulsive symptoms appear? Let us collect in a table (Table XIV) the experiments of Chapter I and those which precede.

\section{Table XIV}

\begin{tabular}{|c|c|c|c|c|c|}
\hline 1 & 2 & 3 & 4 & 5 & 6 \\
\hline $\begin{array}{l}\text { Experiment } \\
\text { Numbers }\end{array}$ & 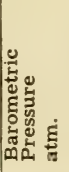 & 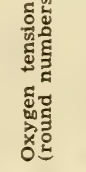 & 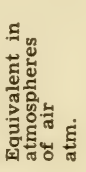 & 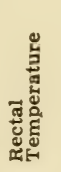 & Symptoms and observations \\
\hline $\begin{array}{l}\text { CXXXIX } \\
\text { CXXXVIII } \\
\text { CXLI } \\
\text { CXX } \\
\text { CCLX } \\
\text { CCLXI } \\
\text { CCLXII } \\
\text { CCLXVII } \\
\text { CCLXII } \\
\text { CXXXVII } \\
\text { CXLII } \\
\text { CCLXIV } \\
\text { CXLV } \\
\text { CCLXVIII } \\
\text { CCLVII } \\
\text { CCLIX } \\
\text { CCLXV }\end{array}$ & $\begin{array}{l}1.75 \\
3 \\
4 \\
20 \\
5 \\
5 \\
5 \\
5 \\
5 \\
5 \\
8.5 \\
6 \\
5.5 \\
6 \\
6 \\
6 \\
8\end{array}$ & $\begin{array}{l}150 \\
260 \\
300 \\
\text { abt. } 420 \\
\text { id. } \\
\text { id. } \\
\text { id. } \\
\text { id. } \\
\text { id. } \\
\text { id. } \\
430 \\
440 \\
460 \\
480 \\
\text { id. (?) } \\
\end{array}$ & $\begin{array}{l}7 \\
13 \\
15 \\
20 \\
\text { abt. } 21 \\
\text { id. } \\
\text { id. } \\
\text { id. } \\
\text { id. } \\
\text { id. } \\
21.5 \\
22 \\
23 \\
24 \\
\text { id. (?) } \\
\end{array}$ & $\begin{array}{l}\bar{Z} \\
\bar{Z} \\
32^{\circ} \\
40.2^{\circ} \\
38^{\circ} \\
37^{\circ} \\
33^{\circ} \\
18^{\circ} \\
\overline{27^{\circ}} \\
30^{\circ} \\
35^{\circ} \\
32^{\circ}\end{array}$ & 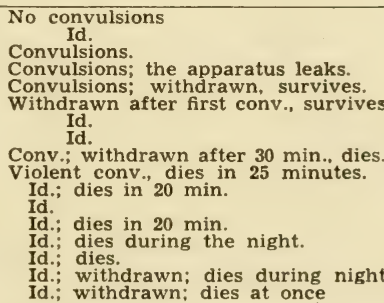 \\
\hline
\end{tabular}

We see from an examination of this table that the convulsions begin to appear with an oxygen tension expressed by the figure 300 , which, if we used pure air, would correspond to about 15 atmospheres.

The harmful effects were observed much sooner, as graph A of Figure 22 shows, which expresses the proportion of oxygen remaining in the compressed air in which the birds died, when we took care to eliminate the carbonic acid formed. The harmful effects are very clear beginning with 6 and especially with 12 atmospheres.

But the convulsions appear surely only between 15 and 20 atmospheres. Experiment CXX, in which a linnet was taken to 20 atmospheres of air, shows their appearance; only they were 
considerably weaker than those obtained with superoxygenated air. Furthermore, in Experiment CXXXIII, in which the pressure was 17 atmospheres, there were no convulsions. This apparent contradiction is explained by the simultaneous influence of the carbonic acid produced, which, being stored in the organism, plays a very pronounced anesthetic part there, as we shall see in a special chapter. Now we shall show in a moment that anesthetics stop or hinder the convulsions due to oxygen.

Let us give now a brief description of these convulsions; we shall have to return to them when we have studied them in dogs.

These convulsions occur at the end of a variable time, generally from 5 to 10 minutes; the bird shakes its head and feet as if it were walking on hot coals. There are strange tremblings, quiverings through the whole body. Soon, in more serious cases, it halfopens its wings, moves them quickly, and falling on its back, it whirls rapidly in the receiver, beating the air with its wings violently, its feet curled up against its belly; these phenomena last for a few minutes, then grow calm, then reappear in attacks which are more and more frequent and less and less strong until death. During the attacks, and in the intervals, the respirations are very deep and very hasty; the beak is very wide open. At very high pressures, death comes at the first attack.

These remarkable symptoms continue to appear after the bird, removed from the influence of oxygen, has been restored to the open air under normal pressure; they may even then end in death.

These attacks are often very clearly provokable, like those of strychnine (See Experiment CCLXVI); their general appearance recalls at the same time the irregular quiverings of poisoning by phenol, ${ }^{1}$ and the tonic and clonic convulsions of convulsive strychnine attacks.

Neither sensitivity nor intelligence seems affected; the bird, taken from the receiver, looks at and tries to peck the finger which threatens it; it closes its eyelids when some object approaches its eye.

General locomotion is evidently much affected, besides the convulsive attacks, of course; the bird has ataxic movements; in certain cases, it can hardly stand on its feet; in others, it can walk, but not fly.

Finally-and this is the most important point of this research, after the observations of these symptoms-the inner temperature drops in all cases rapidly and considerably. It falls 10 and 15 degrees; I call particular attention to Experiment CCLV, in which, 
although the temperature had fallen to $32^{\circ}$ in less than a halfhour, it rose rather quickly to nearly $40^{\circ}$ and the bird survived.

I shall later dwell upon this remarkable fact, to which at present I merely call attention; it shows very clearly that the symptoms of oxygen poisoning are not due to an exaggerated activity im. parted to the intra-organic combustions.

The first idea which would come to mind, and I admit freely that it came to mine immediately, is that under the influence of this super-saturation of oxygen the animal tissues would be consumed excessively, that an increase in the temperature would result, and that the convulsions which appeared could be compared to those which precede the death of animals over-heated in a drying-oven. Now we can state immediately that this is not true, although later I shall analyze this important phenomenon thoroughly.

Finally I shall say a few words of a symptom always present in birds in cases of oxygen poisoning, a symptom which I have designated by the expression "bloody suffusions of the cranium." They are hemorrhages which fill the cranial diploe; in the mildest cases they consist only of very small dots; these dots are replaced by wide spots which become confluent in severe cases, and the spongy tissue of the bone fills with blood. They always begin in the occipital, but may affect the whole cranium. They appear before the convulsions, and when the bird does not die, they are not absorbed for several weeks. Although they always exist when the symptoms due to oxygen become serious, they are not especially characteristic of this poisoning. Since my attention was called to their existence, I have found them quite often in asphyxia and death by decompression. In fact, they were noted in some of the experiments reported in Chapter I; when they are not mentioned, it simply means that no one looked for them. I should add that I never saw them so extensive or so deep as in oxygen poisoning. I have no understanding of their mechanism; they appear without any convulsive phenomenon, and autopsies have not shown any apoplexies in any other part of the body.

Let us now analyze a little more deeply the phenomena just described. Upon what anatomical element does excessive oxygen act? What is the cause of the convulsions? Is the heart directly attacked, as it is by such a great number of poisons? The data which have just been reported would be insufficient to permit us to reply completely to these different questions. 
We have had to use the best physiological reagent, the frog.

Experiment CCLXIX. February 27. Frog subjected at 2 o'clock to 7 atmospheres, 6 of which were oxygen. The oxygen tension corresponds to 505 . In the evening, at 7 o'clock, nothing particular; seems a little uneasy.

February 28, at 9 o'clock in the morning, dead. No reflex actions of any sort; the motor nerves and the muscles are excitable. The heart, of a fine carmine red, beats slowly when exposed. Free gases in the blood.

The lethal air contains no trace of carbonic acid.

Experiment CCLXX. March 4. Frog subjected at 4 o'clock to 5 atmospheres, 4 of which were oxygen; the tension of this gas is about 300.

At 10 o'clock in the evening, swollen.

On March 5, at 2 o'clock, seems dead. The heart no longer beats spontaneously, but is excitable; the motor nerves and the muscles are excitable. By cutting through the spinal cord in the back, movements in the lower limbs are caused.

Experiment CCLXXI. February 29. Frog subjected at 6 o'clock to 4 atmospheres, 3 of which were oxygen.

The tension of this gas is 254 .

The next day, March 1, at 3 o'clock, it is rigid and swollen, seems to have convulsive movements when one raps on the table. At 7 o'clock in the evening, is much weaker.

March 2, at 1 o'clock, dead, stiff. The heart beats, the nerves and the members are excitable; no movement is produced when the spinal cord is cut.

The lethal air contains no trace of carbonic acid.

Experiment CCLXXII. April 18. Frog subjected at 6 o'clock in the evening to $4 \frac{1}{2}$ atmospheres of superoxygenated air. The oxygen tension is represented by 335 . Temperature $15^{\circ}$.

The next day, nothing especial in the appearance of the frog.

April 20, found dead at 1 o'clock. The heart, very pink, is still beating a little. The muscles are perfectly contractile.

Experiment CCLXXIII. June 17. Frog subjected at 4:30 to a pressure of 5 superoxygenated atmospheres. The heart is laid bare, temperature $20^{\circ}$.

June 18 , at 11 o'clock in the morning, very weak, prostrated. No respiratory movements. Pulsations of the ventricles, rare, irregular; but the auricles alone beat 40 times per minute.

At 3 o'clock, decompression. A few weak heart beats yet. There are no reflex acts, but the motor nerves and the muscles are quite excitable.

Sugar in the liver, in a rather large quantity.

We conclude from all these experiments that oxygen does not kill by acting on the heart, the motor nerves, or the muscles. But 
the reflex acts of the spinal cord; after being considerably excited, are checked.

The fact that the convulsions come from the spinal cord, communicating its excitation to the muscles by means of the motor nerves, is abundantly proved by experiments in which the motor nerve has been cut: Example:

Experiment CCLXXIV. June 20. Frog; left sciatic nerve cut.

3 o'clock in the afternoon; subjected to 3 superoxygenated atmospheres, containing 60.5 per cent of oxygen, $3 \times 60.5=181.5=9$ atmospheres of air.

Respiration ceases for a moment.

June 21. Respirations very rare; eyes protruding with widely rounded pupils; frog is swollen, rather weak; no convulsions.

June 22. 11 o'clock in the morning. No respiration; weak; eyes closed by the transparent lid. Clonic convulsions beginning in the right front leg, then becoming generalized, except in the left hind foot; then general stiffness; then weakness.

These attacks are excitable at will, by shock; but the frog soon seems insensible, as if dead.

Sudden decompression; no effect. In the outer air, does not breathe; the heart, exposed, beats 50 times per minute; the blood, which was red at first, grows progressively darker.

After about a quarter hour, excitation brings on new convulsive attacks, like the preceding. On exciting the right hind foot, movements of the right front leg are produced, but not of the left.

Frequently fibrillary contractions, in the muscles of the chest especially and also in the limbs, except the left hind foot.

During the convulsions, the heart does not seem altered.

Dies about 2 o'clock.

So section of a motor nerve prevented all convulsive movement, fibrillary or generalized, from appearing in the corresponding muscles.

Since oxygen injures the spinal cord, like strychnine, phenol, etc., convulsions should be prevented by chloroform, which, as I have shown before, ${ }^{2}$ acts particularly on the spinal cord. In fact, this very thing happened in the following experiment.

Experiment CCLXXV. February 26. Etherized sparrow, put into the receiver; rouses during the compression. I put some drops of ether into the vessel in which the oxygen sucked in by the pump is bubbling in the potash, and raise the pressure to 5 atmospheres, 4 of which are oxygen.

The bird becomes unconscious again, after some quiverings of the feet; he dies slowly, in 25 minutes, without any convulsion.

Huge cranial suffusions.

The lethal air contains $\mathrm{CO}_{2} 2 ; \mathrm{O}=76$. The original pressure of the oxygen was therefore about $78 \times 5=390$, corresponding to 19 atmospheres of air. 
This experiment shows not only that anesthesia prevents convulsions from oxygen, like those of other poisons of the spinal cord, but also that it does not prevent death from coming, although it comes calmly. The following experiment, in which the animal was removed after the action of the oxygen, its convulsions appearing gradually as consciousness returned, is still more convincing.

Experiment CCLXXVI. February 24. Chloroformed rat, nearly died during anesthesia.

Begins to be sensitive after about a half-hour. Rectal temperature $35^{\circ}$.

Subjected to 5 atmospheres, and after 10 minutes to $6 \frac{1 / 2}{2}$ atmospheres of oxygen.

At the end of 20 minutes of compression seems very sick; a few slight quiverings; the convulsions not appearing, it is withdrawn.

Rectal temperature $34^{\circ}$.

Put back into the cage, remains stretched out; it is soon seized by convulsions; stiffening of the tail, etc. They appear spontaneously or as soon as the animal is touched.

One hour after, same condition; temperature $32^{\circ}$.

$2 \frac{1}{2}$ hours after, very slight convulsions; temperature $28^{\circ}$. Evidently dying.

February 25. Found dead and cold.

I do not dwell upon this point, because the experiments made on dogs will give us analogous data.

Before coming to the experiments on dogs, I think I should report one more which was performed on sparrows, and in which we see demonstrated the important part played by the blood in oxygen poisoning.

Experiment CCLXXVII. July 17. Two sparrows are subjected, from 5:02 to 5:07, to 8 atmospheres of superoxygenated air, in which the oxygen tension is equivalent to 424 , that is, 20 atmospheres of air.

One, A, is in good shape; the other, B, which weighs $20 \mathrm{gm}$., was bled at 4 o'clock of $0.7 \mathrm{cc}$. of blood from the jugular; it is still very weak; its rectal temperature is only $32^{\circ}$, while $A^{\prime}$ s is $42^{\circ}$.

At 5:10 or 5:12, A shows slight convulsive shivers, and about 5:20 real convulsions, which last until $5: 33$, when he dies. B is not affected until 5:25 and then slightly; no general quiverings, but great efforts in breathing, stiffness, etc., which become true convulsions, of the feet, if not of the wings, about $5: 35$; he has a few of them, then remains on his back as if dead.

Decompression at $5: 45$.

A, rectal temperature $31^{\circ}$.

$B$, rectal temperature $28^{\circ}$.

Enormous cranial suffusions on the two birds.

$\mathrm{B}$ is still breathing; his rectal temperature drops and is $25^{\circ}$ at 6 
o'clock; he dies then. When the muscles were pinched, they contracted slowly and strongly as if with cramps.

So in the animal which had been bled the symptoms appeared much more slowly than in the healthy animal. That is the effect both of the general weakening he had undergone and of the diminished quantity of blood, which, since it contained a smaller quantity of oxygen, could carry this dangerous agent to the spinal cord only in smaller proportion.

It would be premature to dwell at this moment on the part played by the blood in oxygen poisoning. This question will recur in a much more significant manner when we have studied the experiments made on dogs, which I shall now report in detail.

When I used dogs as experimental animals, my special purpose was to investigate the proportion of oxygen contained in the blood when the convulsive symptoms occurred. I intended also to continue at the same time, thanks to the use of superoxygenated compressed atmospheres, the research of the proportions established in the living animal between the tension of the oxygen in the respiratory medium and the oxygen content of the arterial blood, proportions studied in Subchapter III of Chapter I up to 10 atmospheres of air only.

The experimental animal was fastened on his board as is explained in the subchapter just mentioned. To succeed in making him breathe compressed oxygen, I had recourse to a special device, not having at my disposal the quantity of oxygen necessary to compress this gas to several atmospheres in a receiver of 150 liters capacity.

I fixed in the dog's trachea a metallic tube as wide as possible, and connected it with a rubber bag having a capacity of about 30 liters. This bag was placed beside the animal, and the air injected into the chamber by the pump compressed both the oxygen and the animal at the same time. The experiment never lasted long enough for the dog to exhaust the oxygen entirely. But as the expirations were made into the bag, carbonic acid was stored up there, which consequently accumulated also in the blood. And so we should not take account of the proportion of this gas shown by the analyses; I thought, however, that I should indicate it as a matter of information in the account of the experiments. In a certain number of cases, to avoid this accumulation, I attached to the tube which went from the trachea to the bag, a flask in which the superoxygenated air bubbled in a solution of potash; in other cases, the solution was in the bag itself. These experiments, 
compared to those in which no such precaution had been taken, allow me to state that in the latter the influence of the carbonic acid was quite negligible; that will be explained naturally, when we discuss poisoning by carbonic acid in Chapter VIII.

Here now is the report of a certain number of experiments.

Experiment CCLXXVIII. November 16. Black dog, short-haired, new subject, weighing about 12 kilograms.

It is fastened on its back, and in its trachea is inserted a metal tube, at the end of which is a rubber tube considerably narrower. Respiration is carried on in series of extreme frequency, separated by a few intervals of calm.

At the end of about a half-hour, the rectal temperature is $36^{\circ}$ (in a healthy dog the same thermometer gives $38.5^{\circ}$ ).

Then from the left carotid $35 \mathrm{cc}$. of blood is drawn, which is immediately taken to the pump for extracting gases .... A

The dog is next placed in the compression apparatus; to the tube in its trachea is then fitted a rubber bag containing oxygen; then the animal is fastened as explained above.

Pressure is begun at $3: 56$.

At $4: 21$, the pressure is 5 atmospheres; I draw $38 \mathrm{cc}$. of very red blood, not letting gas escape .... B

At $4: 40$, at 7 atmospheres, drew $31 \mathrm{cc}$. of very red blood, in which escape of gas is at least doubtful .... C

Pressure is raised to 8 atmospheres, and at 4:45 decompression is made suddenly in $3 \frac{1}{2}$ minutes.

The animal is immediately withdrawn from the apparatus; there are no free gases in either the arterial or the venous blood; the heart sounds are normal, without any gurgling indicating the presence of gas. The rectal temperature is $30^{\circ}$. There has been an evacuation of fecal matter, and the mouth is full of froth.

The paws are much stiffened; when the animal is unfastened, he is in very pronounced opisthotonos; the whole body is in tonic convulsion. Fecal matter continues to be discharged. The eye closes when the cornea, but not when the conjunctiva, is touched; the pupils, much dilated, do not contract in light.

The arterial pressure in the carotid varies between 9 and 12 centimeters.

The symptoms continue to increase in intensity. About 5 o'clock, the convulsions are extremely violent; in the midst of continuous stiffenings, there appear clonic convulsions of the limbs, the neck, and the jaws. The eyes are convulsed. The penis is so retracted that to catheterize the animal the prepuce has to be slit its whole length; no urine in the bladder. The animal froths terribly.

About 5:30, the temperature is 29 degrees. Vomiting begins. The convulsions appear like fits, with no real rest in the interval; it appears much like successive strychnine attacks, except for the almost complete permanency of the stiffenings and the opisthotonos. Clonic convulsions are caused by touching the animal, by hitting the table, 
by inserting the thermometer into the depths of the rectum. During the attacks, the respiration stops, but the heart continues to beat.

Gradually intervals of comparative repose appear. The animal begins to grind its teeth with such extraordinary force that one would expect them to break. The temperature rises again; at 6 o'clock it is $31^{\circ}$.

$6: 15$; now and then, the stiffness disappears; the respiration is better; the tail moves.

$6: 45$; the animal is still lying on its side; the clonic convulsions are like those of phenol, in that they almost imitate the motions of walking; they follow each other in attacks separated by an interval of relative repose. At each attack, violent opisthotonos, with quivering of the jaws, then a snapping of the teeth; from time to time, general stiffening with motionlessness, the stiffening less than at the beginning. The pupils are still insensitive to light. The temperature is 32 degrees. The heart beats hard and fast.

The next day, at 11 o'clock in the morning, the animal, in whose trachea the cannula has been left, is lying as on the day before; it is in opisthotonos with permanent contractions of the limbs; the anal sphincter is closed; weak, but almost continuous quiverings. Viscous salivation, as well as watering of the eyes, has continued; the pupils are dilated; the cornea is sensitive, but not the conjunctiva. Respiration quite calm; pulse 80 , weak; temperature $27^{\circ}$.

I administered chloroform until the cornea lost sensitivity; the stiffening and quivering disappear to reappear soon.

The animal dies during the day.

Now here is the result of the analyses:

A: Ordinary air, normal pressure; 100 cc. of blood contain O. 15.5 cc.; $\mathrm{CO}=22.9$. $^{3}$

B: 5 atmospheres of superoxygenated air: 100 cc. of blood contain $\mathrm{O}_{2} 24.0 ; \mathrm{CO}_{2} 63$.

C: 7 atmospheres of superoxygenated air: 100 cc. of blood contain $\mathrm{O}_{2} 31.5 ; \mathrm{CO}_{2} 54.6$.

The air of the bag, after the experiment, contained per $100, \mathrm{O}_{2} 66$; $\mathrm{CO}_{3}$ 5.4. The original composition was therefore about 75 per cent of oxygen.

The oxygen tension in $\mathrm{B}$ was about $70 \times 5=350$.

In $\mathrm{C}$, it was about $68 \times 7=476$.

It was raised to $66 \times 8=528$, which corresponds to about 26 atmospheres of air.

This experiment is particularly remarkable; here is an animal which, after being exposed for three-quarters of an hour to an oxygen tension corresponding to nearly 26 atmospheres of air, died after about 24 hours of violent convulsions.

Experiment CCLXXIX. November 20. Rather young dog, weighing about 8 kilograms.

Tube placed in the trachea.

After a quarter of an hour, the rectal temperature is $39.4^{\circ}$; pulse 
144 , respiratory rate 24 ; blood pressure in the carotid varies between 15 and $17 \mathrm{~cm}$. of mercury.

At $3: 38$, drew 38 cc. of blood .... A

Placed in the apparatus at $4: 10$, with a bag full of a mixture with 89.5 per cent of oxygen.

At $4: 30$, pressure is 5 atmospheres, maintained there.

At $4: 38$, drew $43 \mathrm{cc}$. of very red blood; no gas escapes ... . B

At 4:40, decompression in $1 \frac{1 / 2}{2}$ minutes.

The animal is immediately withdrawn, the bag is removed, and it is noted that it has already vomited in the apparatus. It vomits again. It shows attacks of stiffening without clonic jerks. The temperature is $36.5^{\circ}$ : the arterial pressure from 11 to $12 \mathrm{~cm}$; pulse is 140 , respiratory rate 24 .

These attacks of convulsive stiffening last about 20 minutes.

At 6 o'clock, the temperature is $35^{\circ}$, the arterial pressure $12 \mathrm{~cm}$., the pulse 140. The dog begins to be able to stand on its feet.

At $6: 30$, the animal, whose cannula has been removed, remains lying down with a sort of muscular trembling, resembling that of phenol poisoning. Its eyes are sensitive, and the pupils contract and dilate as if by tremors which are related to the quivering of the limbs. There are occasional stiffenings of the front feet, but they can easily be bent.

The next day, in good health.

The analyses gave the following results:

A: Air, normal pressure; $100 \mathrm{cc}$. of blood contain: $\mathrm{O}_{2} 17.0 ; \mathrm{CO}_{2}$ 39.0 .

B: 5 atmospheres of superoxygenated air: $100 \mathrm{cc}$, of blood contain: $\mathrm{O}_{2} 24.8 ; \mathrm{CO}_{2} 75.0$.

The gas in the bag after the experiment contains 76.2 of oxygen and 8.1 of carbonic acid. The oxygen tension in B was then about $77 \times 5=385$.

Experiment CCLXXX. November 25. Dog of average size.

Tube in the trachea; left carotid exposed.

Rectal temperature $38.1^{\circ}$. $^{4}$

$3: 12$; drew 33 cc. of blood; the animal breathes quietly . . . . A

Placed in the apparatus at 3:55, with oxygen bag; between the bag and the tube in the trachea a flask is placed, at the bottom of which are bits of potash; by this means I intend to diminish the proportion of carbonic acid stored in the bag.

$4: 25$; pressure 7 atmospheres; at $4: 28$, with great difficulty drew 23 cc. of blood .... B

4:38, pressure $7 \frac{1}{4}$ atmospheres; sudden decompression.

Withdrawn at $4: 45$, the animal's eyes are sensitive; its temperature is $36^{\circ}$; there are stiffenings of the hind legs and the neck; the respiration seems suspended, the heart beats very feebly.

After 10 mmutes the stiffenings increase, but the respiration returns, and the heart beats more quickly and strongly. Soon after, the animal again becomes limp, as it was when it was taken from the apparatus; its respiration is weak; it dies at 5:50, without moving.

At $5: 20$, its temperature was $34.5^{\circ}$; at $5: 50$, it had fallen to $33.5^{\circ}$. 
At 5:05, I drew $33 \mathrm{cc}$ of blood from the carotid .... C

At $5: 30$, drew $33 \mathrm{cc}$. of blood also from the carotid .... D

The autopsy shows the heart full of dark blood on the right, a little red on the left. There are in the bladder some drops of urine with an exceedingly high sugar content. The liver contains much sugar.

Blood A (air, normal pressure) contained . . $\mathrm{O}_{2} 14.4 ; \mathrm{CO}_{2} 41.0$

Blood $\mathrm{B}$ (oxygen, 7 atmospheres) contained . $\mathrm{O}_{2} 24.1 ; \mathrm{CO}_{2} 68.5$

Blood C (air, normal pressure, $40 \mathrm{~min}$. after decompression) contained . . $\mathrm{O}_{2} 15.8 ; \mathrm{CO}_{2} 16.5$

Blood D (air, $70 \mathrm{~min}$. after decompression) contained $\mathrm{O}_{2} \quad 15.8$; $\mathrm{CO}_{2} 28.3$

The gas in the bag contained before the experiment 79 per cent of oxygen; the oxygen tension in B was probably $74 \times 7=518$; it rose to a maximum of 550 at $4: 38$.

16 kilos.

Experiment CCLXXXI. November 27. Shepherd dog, weighing

Tube in the trachea; rectal temperature $38.5^{\circ}$.

At $4: 50$, drew $33 \mathrm{cc}$. of blood from the left carotid . . . . . A

Placed at 5:08 in the compression apparatus with the oxygen bag, without the potash flask.

At 5:12, pressure is $13 / 4$ atmospheres; drew 33 cc. of blood, very red. . . . . B

At 5:48, 7 atmospheres; this pressure maintained, and at 5:50, drew 39 cc. of very red blood, without free gases. . . . . C

At 5:53, decompressed in 2 minutes.

Withdrawn; temperature $38.5^{\circ}$. Is stiffened, and every three or four minutes, enormous tonic convulsion, with very violent opisthotonos, suspension of respiration, the heart continuing to beat, although more slowly. The eye lacks sensitivity. The excitability is much less evident than in strychnine poisoning. There are 4 or 5 of these frightful convulsions during which it seems as if the animal is going to fall from the table.

At $6: 10$, I administer to the dog a mixture of chloroform and ether; at the beginning, it seems as if the convulsions grow worse. But at the end of 2 or 3 minutes they disappear, and there are only. quiverings of the front legs, like those caused by phenol, which disappear in their turn, as does the stiffening; the animal becomes relaxed and calm.

$6: 15$, the anesthetic withdrawn. Sensitivity returns, then some fits of stiffening; but there are no more great convulsions. Temperature $39^{\circ}$.

$6: 22$; drew 33 cc. of blood, medium red. . . . . D

$6: 45$; the temperature is $38.5^{\circ}$.

7 o'clock; drew 33 cc. of blood, very dark. . . . . E

The next day, the animal is quite recovered.

Blood A (air) . . contains, in 100 cc. . . $\mathrm{O}_{2} 16.9 ; \mathrm{CO}_{2} 33.1$

Blood B (oxygen, $13 / 4$ atm.) contains, in 100 cc. $\mathrm{O}_{2} 21.4 ; \mathrm{CO}_{2} 36.6$

Blood C (oxygen, 7 atm.) . contains, in 100 cc. $\mathrm{O}_{2} 32.5 ; \mathrm{CO}_{2}$ $73.8 ; \mathrm{N} 4.1$ 
Blood D (air, $27 \mathrm{~min}$. after decompression) . contains, in $100 \mathrm{cc}$ $\mathrm{O}_{2} 16.9 ; \mathrm{CO}_{2} 21.0$

Blood E (air, $67 \mathrm{~min}$. after decompression) . contains, in $100 \mathrm{cc}$ $\mathrm{O}_{3} 17.0 ; \mathrm{CO}_{2} 31.5$

The bag contained after the experiment a mixture of $\mathrm{CO}_{2} 10.7$ and $\mathrm{O}_{2} 70$ per cent.

Therefore the oxygen pressure when blood B was drawn was about $1.75 \times 79=138$, and when blood $\mathrm{C}$ was drawn, about $7 \times 71$ $=497$.

Experiment CCLXXXII. December 3. Dog.

Tube in the trachea; rectal temperature $38^{\circ}$; respirations extraordinarily rapid.

$3: 20$; blood drawn from the left carotid, 33 cc. . . . . A

The oxygen bag is attached to the cannula in the trachea; a flask at the bottom of which there are a few bits of potash is placed where the air will pass over it.

$3: 30$; drew $33 \mathrm{cc}$. of blood considerably redder; respiration has become much slower. ..... B

$3: 45$; placed in the large compression apparatus.

4 o'clock; pressure is $3 \frac{1}{1} 2$ atmospheres; drew 33 cc. of very red blood; no gas. ...... C

A series of petty accidents occur; at $4: 40$, I wish to decompress suddenly; but the rubber bag gets in front of the opening, and the decompression is not finished until $5: 45$.

The animal has neither convulsions nor quiverings; its temperature is $36^{\circ}$.

Blood A (air, normal pressure) . . contains . . . $\mathrm{O}_{2} 18.1 ; \mathrm{CO}_{2} 24.9$

Blood B (oxygen, normal pressure) contains ... $\mathrm{O}_{2} 20.9 ; \mathrm{CO}_{2} 33.7$

Blood C (oxygen, $3 \frac{112}{2}$ atmospheres) contains ... $\mathrm{O}_{2} 27.5 ; \mathrm{CO}_{2} 56.5$

The air of the bag contained before the experiment 85 per cent of oxygen; when blood $\mathrm{C}$ was drawn, the tension was about $80 \times 3.5$ $=280$.

Experiment CCLXXXIII. December 10. Vigorous dog, weighing 12.5 kilos.

At $3: 45$, tube placed in the trachea; the respiration becomes panting.

$3: 55$; drew $33 \mathrm{cc}$. of blood; the temperature is $38.5^{\circ} \ldots \ldots$ A

$4: 10$; forced to breathe from the rubber bag containing oxygen.

$4: 18$; drew 33 cc. of blood, redder. . . . . B

$4: 35$; placed in the large apparatus with the rubber bag, in which a potash wash has been placed.

$5: 05$; the pressure is 6 atmospheres; drew 38 cc. of blood. . . C

5:35; the pressure is 9 atmospheres; drew 35 cc. of blood. . . D

Some very small bubbles of gas appear.

$5: 38$; decompression in 3 or 4 minutes.

When the animal is taken out, it is dead. The right auricle is still beating. The venous blood is quite red, and when it is caught in a glass, small bubbles of gas escape which come to the surface or remain clinging to the walls of the glass. Same phenomenon for the 
arterial blood, only the bubbles are much smaller. The muscles and the motor nerves respond to electricity.

When I drew blood D, the blood came with great difficulty into the syringe in slow spurts. Probably the animal was dying at that very moment; he had been observed to breathe up to that time; afterwards, not.

At 7 o'clock, no rigor mortis.

Blood A (air, normal pressure) . . . . $\mathrm{O}_{2} 19.8 ; \mathrm{CO}_{2} 20.9 ; \mathrm{N} 2.1$

Blood $\mathrm{B}$ (oxygen at $88 \%$, normal pressure). $\mathrm{O}_{2} 20.9 ; \mathrm{CO}_{2} 34.5 ; \mathrm{N} 1.5$

Blood C (oxygen, 6 atmospheres) . . . . $\mathrm{O}_{2} 26.3 ; \mathrm{CO}_{2} 63.5 ; \mathrm{N} 3.9$

Blood D (oxygen, 9 atmospheres) ..... O $\mathrm{O}_{2} 30.7 ; \mathrm{CO}_{2} 61.5 ; \mathrm{N} 5.5$

The air of the bag, before the experiment, contained 88 per cent of oxygen. So, taking account of the respiratory alteration, the oxygen tension, when blood $C$ was drawn, could be expressed by $80 \times 6$ $=480$, and when blood D was drawn, by $78 \times 9=702$.

Experiment CCLXXXIV. December 17. Young dog, weighing.

\section{5 kilos.}

$3: 30$; rectal temperature $39^{\circ}$.

Tube placed in the trachea; respirations very rapid.

3: 40 ; drew 33 cc. of blood from the carotid, not very red. . . . A

$3: 42$; forced to breathe from the oxygen bag, with a potash wash in the bag.

$3: 50$; rectal temperature, $38.8^{\circ}$; drew 33 cc. of very red blood. B

Placed in the compression apparatus at 4:05.

$4: 50 ; 7$ atmospheres; we try in vain to extract blood.

Taken to 7 and $3 / 4$ atmospheres, and decompressed suddenly.

Withdrawn; temperature $37^{\circ}$. A few stiffenings and clonic convulsions. The heart beats slowly, the blood is very dark.

Dies at 5:10, without a last sigh, with complete resolution.

No urine in the bladder. But the kidneys, crushed with sulfate of soda and animal charcoal, give a yellow precipitate with very good Bareswill's reagent. The blood, treated in the same way, gives a similar enormous precipitate; the potash browns the boiling liquid. Blood A (air, normal pressure) ..... contains $\mathrm{O}_{2} 12.1 ; \mathrm{CO}_{2} 29.6$

Blood B (oxygen at $91 \%$, normal pressure) contains $\mathrm{O}_{2} 14.1 ; \mathrm{CO}_{2} 24.5$

The oxygen tension was about $7.75 \times 80=620$.

Experiment CCLXXXV. December 20. Very vigorous dog, weighing 16.5 kilos. Rectal temperature $38.5^{\circ}$.

$3: 55$; drew $33 \mathrm{cc}$. of rather dark blood. Respirations a little slow. ..... A

4 o'clock; tube in the trachea; very much exaggerated respirations for 4 to 5 minutes; then, period of calm, followed by other exaggerated respirations. At $4: 10$, while I am preparing to draw blood, the respirations grow calm and return to normal type. At 4:12, drew 33 cc. of blood, less dark. . . . . B

$4: 30$; placed in the compression apparatus, with rubber bag.

5:05; pressure is 6 and $3 / 4$ atmospheres; drew $40 \mathrm{cc}$. of very red blood, from which very small bubbles of gas escape. . . . . C

5:12; decompressed suddenly. 
When placed upon the table, has abundant froth in the mouth; is in very violent opisthotonos, replaced from time to time by a pleurosthotonos on the right side; at times strong clonic convulsions, with a few intervals of complete repose. During the attacks, respiration stops, and it is very difficult to detect the heart beats. The eye remains sensitive.

At $5: 15$, the temperature is $36.7^{\circ}$, and the pulse only 20 .

At 5:30; respiratory rate 48 , pulse 112 .

At $5: 38$, a little while after a strong convulsion, I draw $33 \mathrm{cc}$. of very red blood. ..... D

At 5: 45 , temperature $35^{\circ}$.

I had the dog inhale chloroform through the trachea; respiration is very active; the feet are then stiffened. Soon the respiration stops in its turn; the eyes are very much swollen.

I use artificial respiration; the heart resumes strongly enough, and respiration returns; then everything stops in spite of artificial respiration, and the animal dies about 6 o'clock.

The serum of the blood, treated by sulfate of soda and animal charcoal, gives with copper reagent a very abundant yellowish-red precipitate.

Blood A (air, normal pressure, normal respiration) $\mathrm{O}_{2} 15.1 ; \mathrm{CO}_{2} 40.8$ Blood B (air, normal pressure, tracheal respiration) $\mathrm{O}_{2} 20.3 ; \mathrm{CO}_{2} 24.0$ Blood C (oxygen, 63/4 atmospheres) . . . . O $\mathrm{O}_{2} 34.6 ; \mathrm{CO}_{2} 92.5 ; \mathrm{N} 3.6$ Blood D (during convulsions) . . . . . . . . $\mathrm{O}_{2} 19.0 ; \mathrm{CO}_{2} 14.8$

The composition of the air of the bag, before the experiment, being $80 \%$ of oxygen, the tension at the time of drawing blood was about $6.75 \times 84=567$. dog.

Experiment CCLXXXVI. January 22. Temperature $16^{\circ}$. Large

At 3:10, tube placed in the trachea; rectal temperature $39.5^{\circ}$.

At $3: 30$, the animal breathing slowly and deeply, $33 \mathrm{cc}$. of carotid blood drawn. ..... A

At $3: 40$, dog is placed in the compression cylinder, with the rubber bag containing air with $88.6 \%$ oxygen.

At 4 o'clock, pressure is 4 atmospheres; then $33 \mathrm{cc}$. of very red blood drawn. ..... B

At $4: 15$, pressure is $6 \frac{1 / 2}{2}$ atmospheres. Drew $38 \mathrm{cc}$. of very red blood, which coagulates very rapidly. . . . . C

At 4:17, decompressed in 2 minutes.

Taken out in strong convulsions. They consist of attacks of stiffness of the paws and of the body in opisthotonos, so strong that the dog can be carried by one paw, like a piece of wood. (See Fig. 61.) They can be brought on at will.

Rectal temperature $37^{\circ}$.

At $4: 40$, drew $33 \mathrm{cc}$. of moderately red blood; the temperature has dropped to $36^{\circ} \ldots \ldots$ D

The convulsions continue to decrease; the cannula is removed. At 5:35, the convulsions have stopped. I draw a little carotid blood, which, boiled with charcoal and sulfate of soda, gives a very strong 
reduction of the copper reagent. Nothing by sulfate of lime or nitric acid.

The animal is placed in a cage fitted to collect the urine.

This urine, the next day, reduces copper reagent, giving an abundant yellow precipitate.

Blood A (air, normal pressure) . . . . $\mathrm{O}_{2} 15.8 ; \mathrm{CO}_{2} 43.0$

Blood B (oxygen; 4 atmospheres) . . . . . $\mathrm{O}_{2} 23.9 ; \mathrm{CO}_{2} 59.0$

Blood C (oxygen; 61/2 atmospheres) . . . . . $\mathrm{O}_{2} 28.7 ; \mathrm{CO}_{2} 69.4$

Blood D (air; returned to normal pressure, convulsions) $\mathrm{O}_{2} 12.4 ; \mathrm{CO}_{2} 9.9$

The bag contained at the beginning air with $88.6 \%$ of oxygen.

At the moment when blood B was drawn, the oxygen tension was about equivalent to 320 , representing 16 atmospheres. For blood C, the figures would be 480 and 24 atmospheres.

Experiment CCLXXXVII. January 23. Temperature $16^{\circ}$. Large dog.

Rectal temperature $39^{\circ}$. Tube placed in the trachea at $3: 15$. Its respiratory rhythm does not change noticeably; it was very rapid.

At $3: 53$, its temperature dropped to $38.5^{\circ}$. $33 \mathrm{cc}$. of moderately red blood drawn from the carotid. . . . . A

At 4:02, placed in the apparatus with the bag containing superoxygenated air.

At $4: 15$, pressure is 2 and $3 / 4$ atmospheres.

I drew $45 \mathrm{cc}$. of very red blood, containing no free gases, with a manifest tendency to coagulation. An accident prevents me from analyzing it for its gaseous content.

At $4: 38$, pressure is $7 \frac{1}{4}$ atmospheres.

I again draw $45 \mathrm{cc}$. of very red blood, coagulating rapidly, in which no free gases appeared. ..... B

At 4:40, decompression in 2 minutes.

Taken out in strong convulsions. Rectal temperature $37^{\circ}$.

The convulsions, at first rather moderate, with intervals of flaccidity, continue to increase in strength. In the intervals of tonic convulsions, the animal moves its feet as if it were walking. The tonic convulsions are so strong that the animal can be lifted like a piece of wood, by one foot. Its feet are stiff, its body in right pleurosthotonos, with opisthotonos of the neck, its eyes open, protruding; the pupils dilated; it is vomiting.

At 5 o'clock it dies. The heart continues to beat for some minutes.

At $5: 10$, drew 33 cc. of very dark blood with a catheter from the left heart, which is no longer beating. . . . . C gestion.

There is no urine in the bladder; very severe pulmonary con-

Blood A (air, normal pressure) . . . . . O $\mathrm{O}_{2}$ 17.2; $\mathrm{CO}_{2} 22.3$

Blood B (oxygen, 71/4 atmospheres) . . . . O $\mathrm{O}_{2} 30.1 ; \mathrm{CO}_{2} 72.3$

Blood C (after death) ..... $\mathrm{O}_{2} 1.4 ; \mathrm{CO}_{2} 29.0$

The air of the rubber bag, analyzed after the animal had been taken from the apparatus, contained $\mathrm{O}_{2} 74 \% ; \mathrm{CO}_{2} \quad 10 \%$.

At the moment when blood $B$ was drawn, the oxygen tension was about 540 , equivalent to 27 atmospheres. 
Experiment CCLXXXVIII. January 24, temperature $17^{\circ}$. Vigorous bulldog.

Rectal temperature $38.5^{\circ}$.

At 2:30, $33 \mathrm{cc}$. of carotid blood drawn; the animal breathes quietly, by natural channels. ..... A

Tube placed in the trachea; respiration becomes much more rapid.

At 2: 45,33 cc. of blood drawn. . . . . B

At $3: 25$, the animal is placed in the apparatus, with the bag containing superoxygenated air.

At $3: 45$, pressure 4 atmospheres, $41 \mathrm{cc}$. of blood drawn. ..... C

At $4: 03$, pressure has risen to 6 and $3 / 4$ atmospheres; 57 cc. of blood drawn. ..... D

At 4:07, decompression in 3 minutes. Rectal temperature $37^{\circ}$; the animal is in strong convulsions.

At $4: 33$, the rectal temperature has fallen to $36^{\circ}$.

At $4: 35$, I administer chloroform; the first application causes convulsions, which soon cease, and the animal becomes insensible and in resolution. I stop administering chloroform at 4:45. Up to 5:55, there are no more convulsions. Then they reappear.

The animal survives.

Blood A (air, normal pressure, respiration by natural channels)

$\mathrm{O}_{2} 16.0 ; \mathrm{CO}_{2} 41.5$

Blood B (air, normal pressure, tracheal respiration) $\mathrm{O}_{2} 23.4 ; \mathrm{CO}_{2} 15.2$

Blood $\mathrm{C}$ (oxygen, pressure 4 atmospheres) . . . $\mathrm{O}_{2} 28.5 ; \mathrm{CO}_{2} 68.3$

Blood D (oxygen, pressure 63/4 atmospheres) $\ldots \mathrm{O}_{2} 30.7 ; \mathrm{CO}_{2} 82.0$

Since the bag from which the animal had breathed contained after the experiment $74.5 \%$ of oxygen and $8.6 \%$ of carbonic acid, we can reckon at 300 the oxygen tension at the moment when blood $\mathrm{C}$ was drawn, that is, 15 atmospheres of air, and at 510 at the moment when blood D was drawn, that is, 25 to 26 atmospheres.

Experiment CCLXXXIX. January 28. Large dog, fasting since the morning of January 27.

At 2:35, I draw 33 cc. of carotid blood, moderately red. . . A

I mix a few cubic centimeters of it with distilled water, to examine it for sugar $(a)$. The rectal temperature is $38^{\circ}$.

The trachea is not opened, but the muzzle, pictured in Figure 37, is fitted to the animal, and at $3: 15$ the dog is placed in the apparatus with the oxygen bag.

At $3: 50$, the pressure is $63 / 4$ atmospheres. Decompression is made in 5 minutes.

The animal is in strong convulsions; tonic stiffenings, clonic convulsions. Attacks provoked at will.

At 4 o'clock, I draw during the convulsions 23 cc. of dark carotid blood..... B

Rectal temperature is only $36.5^{\circ}$.

At 4:25, drew $33 \mathrm{cc}$. of moderately red blood; the animal has just had an attack. . . . . C

At $4: 50$, the temperature is only $36^{\circ}$. 
At 5:10, another $33 \mathrm{cc}$ of blood, which is redder; the convulsions had ceased a few minutes before. ..... D

At 6 o'clock, the animal is no longer in convulsions; when completely unfastened and placed on the floor, it walks like a hyena, hind quarters very low. It is set aside for the collection of the urine.

It does not urinate until the next day at 3 o'clock; no sugar. At that time, its temperature has risen to $39.5^{\circ}$.

Blood $a$, boiled with charcoal, does not reduce Fehling's solution.

On the contrary, a mixture of bloods B, C, D, boiled in a similar way, gives a very considerable reduction. A part of the colorless liquid obtained by boiling this blood with the addition of water and much charcoal, being placed on the drying-stove, with brewer's yeast, in a tube inverted over mercury, ferments and gives off a gas which is absorbed by potash. Another part, cooled with copper reagent, discolors it and precipitates.

Blood A (air, normal pressure) . . . . contained $\mathrm{O}_{2} 16.0 ; \mathrm{CO}_{2} 44.5$ Blood B (in open air, convulsions) . . . contained $\mathrm{O}_{2} 9.7 ; \mathrm{CO}_{2} 48.2$ Blood C (after $25 \mathrm{~min}$. in the open air) contained $\mathrm{O}_{2} 13.9 ; \mathrm{CO}_{2} 10.5$ Blood D (after $1 \mathrm{~h} .10 \mathrm{~min}$. in the open air) contained $\mathrm{O}_{2} 18.5 ; \mathrm{CO}_{2} 19.0$

The air of the bag after the experiment contained $61.5 \%$ of oxygen and $12.9 \%$ of carbonic acid. The oxygen tension had risen to nearly 420 , that is, 21 atmospheres of air.

Experiment CCXC. February 4. Large dog, which had not eaten since the day before in the morning. Rectal temperature $37.5^{\circ}$.

At $3: 15,33$ cc. of rather red blood drawn from the carotid. . . A

A small quantity of this blood is boiled with water, sulfate of soda, and charcoal.

The animal, furnished with the muzzle and the oxygen bag, is placed in the apparatus at 4 o'clock.

At 4:40, I make the decompression in a few minutes; the pressure had reached $71 \frac{1}{2}$ atmospheres.

The animal is in excitable convulsions; its temperature is only $36^{\circ}$.

At $5: 20$, drew $33 \mathrm{cc}$. of very red blood. . . . B B

The animal had just had convulsions, and in the interval breathed very rapidly.

At 5:40, drew another $33 \mathrm{cc}$. of blood. ..... C

The convulsions are over at the time; the animal, when unfastened, cannot walk.

It survives; the urine which it voids during the night contains no sugar; the very abundant saliva found in the muzzle did not contain any either. On the other hand, blood B was certainly richer in sugar than blood $\mathrm{A}$.

Blood A (before the experiment) . . . . contained $\mathrm{O}_{2} 18.7 ; \mathrm{CO}_{2} 44.0$ Blood $\mathrm{B}$ (afterwards, during the convuls.) contained $\mathrm{O}_{2} 23.2 ; \mathrm{CO}_{2} 19.4$ Blood C (convulsions over) $\ldots \ldots \ldots$. contained $\mathrm{O}_{2} 20.3 ; \mathrm{CO}_{2} 22.0$

The air of the bag, after the experiment, contained $57.6 \%$ of oxygen and $7.4 \%$ of carbonic acid.

The oxygen tension had therefore risen to about 440 , that is, 22 atmospheres. 
Experiment CCXCI. February 5. Terrier, medium size, fasting since the preceding evening.

Rectal temperature $39.5^{\circ}$.

At 5 o'clock, put into the apparatus with the muzzle and the oxygen bag.

At $5: 40$, pressure is 7 and $1 / 3$ atmospheres.

From 5:40 to 5:45, decompression.

Is in strong convulsions, with violent snapping of the teeth. Temperature $38^{\circ}$.

Dies at 6 o'clock.

The air of the bag, after the experiment, contained $77.2 \%$ of oxygen and $8 \%$ of carbonic acid.

The oxygen tension had been about 560 , corresponding to 28 atmospheres of air.

Experiment CCXCII. February 7. Vigorous poodle.

Temperature $39.8^{\circ}$.

Took blood from the carotid to analyze for sugar. . . . . a

At 4 o'clock, muzzle and oxygen bag; the compression begins.

At $4: 43$, the pressure is $71 / 4$ atmospheres; rapid decompression. Taken out of the apparatus, the dog has 2 or 3 convulsions; its temperature is $38^{\circ}$; it dies while we are drawing a little very dark arterial blood, which is treated with sulfate of soda...... b

$a$ and $b$ are treated in the same way, with the same addition of water and according to the method of $\mathrm{Cl}$. Bernard. Now $5 \mathrm{cc}$. of the filtered liquid furnished by a reduce only 10 drops of copper reagent, while the same volume of the liquid in $b$ reduces 15 .

The air of the bag before the experiment contained $90 \%$ of oxygen. After the experiment, there was only $76.5 \%$ with $10.7 \%$ of carbonic acid.

The oxygen tension had therefore risen to about 600 , which corresponds to 30 atmospheres of air.

Experiment CCXCIII. February 18. Dog weighing 10 kilos, fasting since the morning of February 17 . Rectal temperature $40^{\circ}$.

At $1: 30$, I put a tube in its trachea.

At 2 o'clock, its rectal temperature is only $39.8^{\circ}$.

From 2:05 to 2:20 (15 minutes), I force it to inspire and expire in a rubber bag containing 41 liters of air; towards the end, the animal experiences a certain respiratory difficulty, takes great inspirations, and struggles a little. I call the air of this bag $a$.

At 2: 45 , I take $25 \mathrm{gm}$. of blood from the carotid and $\mathrm{mix}$ it with $25 \mathrm{gm}$. of sulfate of soda and $10 \mathrm{gm}$. of distilled water . . . x

At 2:55, put into the compression apparatus, with the oxygen bag, in which is a little alkalinized water.

At $3: 16$, pressure is $5 \frac{1}{2}$ atmospheres; decompression in $2 \frac{1}{2} \mathrm{~min}$ utes. The dog displays only slight convulsions, lasting hardly quarter of an hour. He has salivated very abundantly; his temperature is $38^{\circ}$.

At $3: 25$, drew $25 \mathrm{gm}$. of carotid blood which is treated like blood $x \ldots . . . y$

At $3: 40$, drew $33 \mathrm{cc}$. of blood; the animal has been breathing quietly for some time. ...... A 
From 3:43 to $3: 58$ (15 minutes), I make the dog breathe in a bag containing the same quantity of air as bag $a$; I call this air $b$. The animal suffers also at the end of this respiratory period.

At $4: 20$, the animal being very quiet, I draw $33 \mathrm{cc}$. of carotid blood. ..... B

At $4: 45$, rectal temperature $36.5^{\circ}$.

At 6 o'clock, drew 33 cc. of blood. . . . . C

Immediately after, his temperature is $37^{\circ}$.

At $6: 15$, I draw more blood which I treat like $x$ and $y \ldots \ldots z$ Rectal temperature $37^{\circ}$.

I remove the tracheal cannula; the dog can walk a little. At $7: 10$, his temperature has risen to $39^{\circ}$. He survives.

Since the air of the bag contained before the experiment $90.8 \%$ of oxygen, and after the experiment, $77.3 \%$ of oxygen and $8.4 \%$ of carbonic acid, the tension rose to 440 , that is, 22 atmospheres of air. Blood A (22 min. after the decompression) contained $\mathrm{O}_{2} 17.5 ; \mathrm{CO}_{2} 20.0$ Blood B (1 hour after the decompression) contained $\mathrm{O}_{2} 17.2 ; \mathrm{CO}_{2} 17.0$ Blood C (2 hours 40 minutes after the decompression) contained $\mathrm{O}_{2} 16.3 ; \mathrm{CO}_{2} 26.5$

The liquids produced by boiling bloods $x, y$ and $z$ give the following results:

$5 \mathrm{cc}$. of the liquid furnished by $x$ (before the compression) discolor 15 drops of copper reagent.

$5 \mathrm{cc}$. of the liquid furnished by $y$ (10 minutes after the decompression) discolor 35 drops of copper reagent.

$5 \mathrm{cc}$. of liquid furnished by $z$ ( 3 hours after the decompression) discolor 15 drops of copper reagent.

The analyses of airs $a$ and $b$ show that:

1. In $a$, before oxygenated compression, the dog consumed in 15 minutes 4.89 liters of oxygen, and produced 2.99 liters of $\mathrm{CO}_{2}$; that is, in one hour 15.56 liters of oxygen and 9.98 liters of $\mathrm{CO}_{2}$.

2. In $b$, after the compression, the dog consumed in 25 minutes only 3.37 liters of oxygen, and produced only 1.88 liters of $\mathrm{CO}_{2}$; that is, in one hour 8.88 liters of oxygen and 4.51 liters of $\mathrm{CO}_{2}$.

Experiment CCXCIV. February 23. Strong female spaniel.

Rectal temperature $39^{\circ}$.

At $2: 15$, I put a tube into the trachea; the respirations become very rapid, 110; pulse 120 .

At 2: 40 , took from the carotid $25 \mathrm{gm}$. of blood, which is treated as usual in the test for sugar. . . . . x

At 2:40, the rectal temperature is $38^{\circ}$. The respiration grows calm, and falls to 40 per minute.

From 2:45 to 3 o'clock ( 15 minutes), the animal breathes in a closed bag, containing 47.14 liters of air. The breathing, calm at first, becomes difficult at the end of 7 or 8 minutes. I call the air of this bag. . . . . . a

At 2:45, the rectal temperature is still $38^{\circ}$.

At $3: 15$, put into the apparatus with the oxygen bag.

At $3: 40$, pressure is 6 and $3 / 4$ atmospheres; decompressed sud- 
denly. Is in quite strong convulsions. White foam very abundant in the mouth.

Rectal temperature $37^{\circ}$.

At 3:45, drew a little blood for sugar analysis; the animal is in convulsions. ..... y

At 4 o'clock, the animal is calm; respiratory rate 14 , pulse 60 .

From $4: 12$ to $4: 27$ (15 minutes), made to breathe in the same quantity of pure air as above. . . . b b

The respirations remain calm the whole time.

At 5 o'clock, rectal temperature still $37^{\circ}$. The animal, when put on the floor, walks quite well. It survives.

The air of the oxygen bag contained at the beginning of the experiment $86.4 \%$ of oxygen; at the end, it contained only $68.1 \%$ with $10.4 \%$ of carbonic acid. The oxygen tension then must have risen to about 460 , or 23 atmospheres.

The liquid furnished by blood $x$ discolors per 5 cc. between 10 and 15 drops of copper reagent; that of blood $y$ discolors between 15 and 20.

As to the consumption of oxygen, it was in experiment $a \mathbf{3 . 9 5}$ liters, and in experiment $b$ it fell to 2.15 liters. The production of carbonic acid also dropped from 2.41 liters to 1.99 liters.

Experiment CCXCV. February 24. Female dog weighing 17 kilos.

2:55; respiration by natural channels, calm; vaginal temperature $40^{\circ}$. I draw 33 cc. of carotid blood. . . . . A

$3: 12$; I place a tube in the trachea; rapid respirations; then I take $500 \mathrm{gm}$. of arterial blood.

$3: 47$; took 25 cc. of blood (temperature $39^{\circ}$ ). . . . B B

From 4:10 to 4:40, placed in the apparatus with a bag containing air with $93 \%$ oxygen. Pressure rises to 6 and $3 / 4$ atmospheres.

Decompressed suddenly, found dead, limp, temperature $37^{\circ}$.

The oxygen tension had risen to about 580, that is, 29 atmospheres of air.

Blood A (natural respiration) $\ldots \ldots \ldots \ldots \mathrm{O}_{2} 17.0 ; \mathrm{CO}_{2} 38.5$

Blood $\mathrm{B}$ (tracheal respiration, copious bleeding) $\mathrm{O}_{2} 16.5 ; \mathrm{CO}_{2} 14.4$

Experiment CCXCVI. February 25. Dog weighing 15 kilos.

While he is breathing by the natural channels, I draw $33 \mathrm{cc}$. of carotid blood. . . . . A

Rectal temperature is $40^{\circ}$.

I then place a tube in the trachea, and extract in one hour $400 \mathrm{cc}$. of arterial blood. He does not make any extraordinary or rapid respirations, but his temperature drops to $37.5^{\circ}$; I take the last $33 \mathrm{cc}$. of blood for analysis. . . . . B

From $3: 45$ to $4: 40$, raised to the pressure of $6 \frac{1 / 2}{2}$ atmospheres, with a bag containing air with $90 \%$ of oxygen.

Taken out in strong convulsions, excitable by the introduction of the thermometer into the rectum. Temperature $36^{\circ}$.

The convulsions continue, and the animal dies during the night.

The maximum oxygen tension was about 520, corresponding to 26 atmospheres of air. 
Blood A (natural respiration) $\ldots \ldots \ldots \ldots \ldots \mathrm{O}_{2} 19.0 ; \mathrm{CO}_{2} 42.0$ Blood $\mathrm{B}$ (tracheal respiration, copious bleeding) . . $\mathrm{O}_{2}$ 13.1; $\mathrm{CO}_{2} 13.2$

Experiment CCXCVII. May 24, 1874. Experiment made before the committee of the Academy of Sciences.

Female dog of moderate size. Tube in the trachea. Oxygen bag.

Compression taken to 7 atmospheres. At that time $(5: 30)$, I draw 35 cc. of carotid blood, from which some free gases escape. This blood contains $33.2 \mathrm{cc}$. of oxygen per $100 \mathrm{cc}$. of blood, 76 of carbonic acid, and 6.6 of nitrogen.

Sudden decompression at $5: 35$; the animal has no convulsions. A quarter of an hour afterwards, they occur in fits, and can be produced; at certain moments, the dog becomes as stiff as wood.

She is chloroformed; the convulsions cease, but reappear when consciousness returns. At 6:30, lying on her side, constantly makes the movements of walking with her two front feet.

At $7: 30$, rigidity again.

The next day, at noon, this rigidity persists. The animal has remained all night lying on the ground, without having moved from the spot. The eye lacks sensitivity, the pupil does not react to light; the rectal temperature is $23^{\circ}$, that of the room being $19^{\circ}$.

The dog dies during the day.

I hope that the reader will not object to this long series of descriptions. The symptoms which I am studying at present seemed to me so important that it was necessary to give many examples in detail. The questions which present themselves are numerous. We are now well enough informed to settle almost all of them.

But first, according to our custom, we should draw up a table (Table XV) which summarizes the principal results of the data which we have just reported. I listed the experiments according to the increasing oxygen tension, expressed in Column 4 by its real value, and in Column 5 by the equivalent in atmospheres.

We are now ready to make a complete description of the fatal effects of oxygen, to describe its symptoms, and even to analyze the mechanism of the poisoning.

Let us first discuss the concentrations.

The convulsive symptoms, as Columns 5 and 10 of the table show us, did not appear clearly until about 19 atmospheres. Dogs, then, seem a little less sensitive than birds, upon comparing this result with that in Table XIV. That would not be surprising, but I do not hesitate to say that on this point my experiments do not furnish sufficiently definite information.

I can only say that the duration of the compression has much to do with the intensity of the symptoms of oxygen poisoning. 


\begin{tabular}{|c|c|c|c|c|c|c|}
\hline 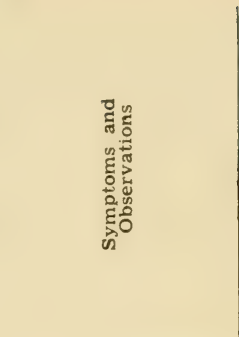 & 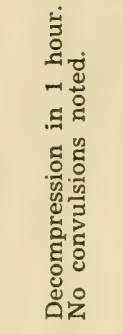 & 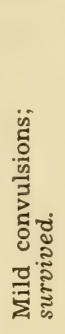 & 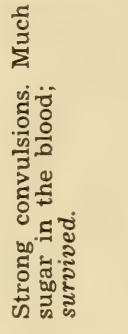 & 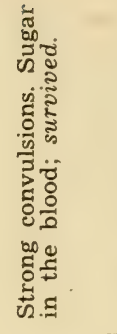 & 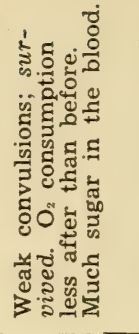 & 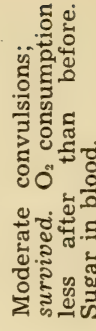 \\
\hline 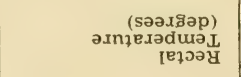 & 家 & 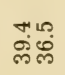 & \begin{tabular}{l|ll}
$\circ$ & 0 \\
$\infty$ & 0 & 0 \\
$\infty$ & 0 & 0
\end{tabular} & 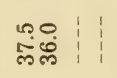 & 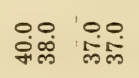 & 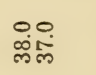 \\
\hline 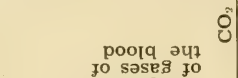 & 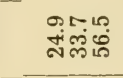 & 官: & 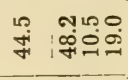 & + & $\begin{array}{l}0010 \\
1 \quad 0000 \\
1000\end{array}$ & \\
\hline uot?!nsoduos & 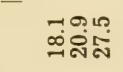 & 욤 & ○ & ๓ & 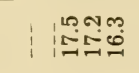 & 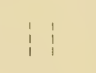 \\
\hline 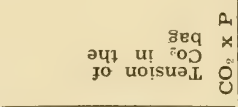 & 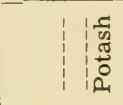 & ln & i⿻日乚 & 绾 & 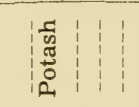 & คุ \\
\hline 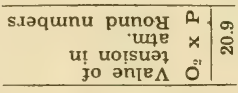 & F゙ & 0 & ลี & สี & สิ & $\dddot{N}$ \\
\hline 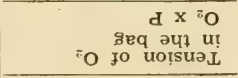 & \& & ఖ్లి & ๙ั่ & o & ศ్ & $\stackrel{8}{\circ}$ \\
\hline 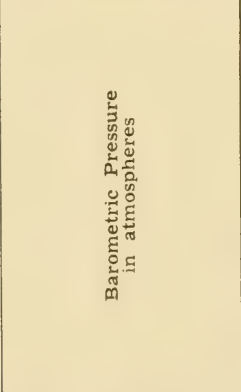 & 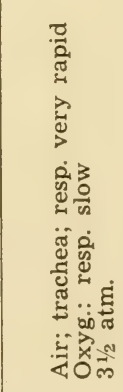 & 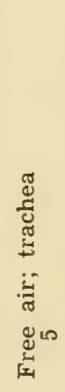 & 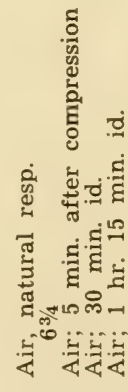 & 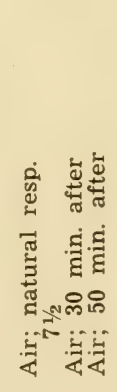 & 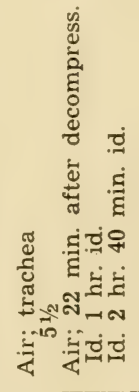 & 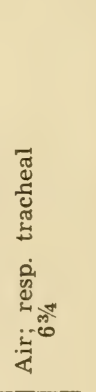 \\
\hline 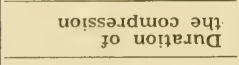 & ह 1 & లి & ణొ & 우 & 1 & นุ \\
\hline 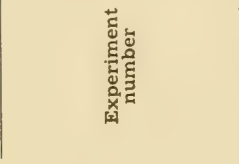 & 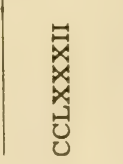 & 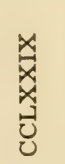 & 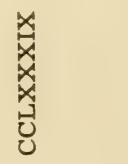 & $\begin{array}{l}u \\
x \\
u \\
u\end{array}$ & 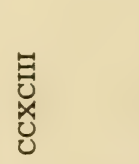 & 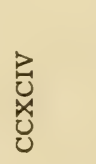 \\
\hline
\end{tabular}


Compressed Air; $\mathrm{O}_{2}$ Poisoning

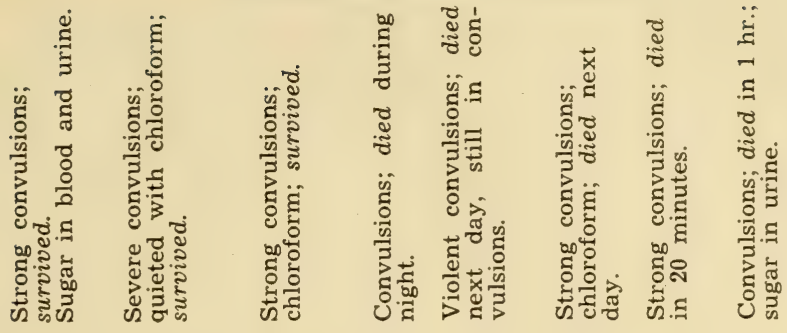

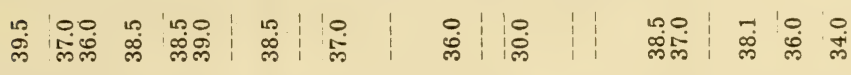

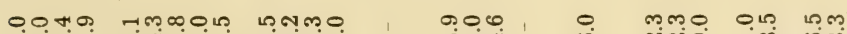

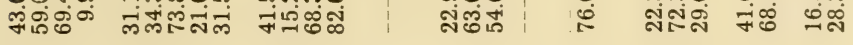

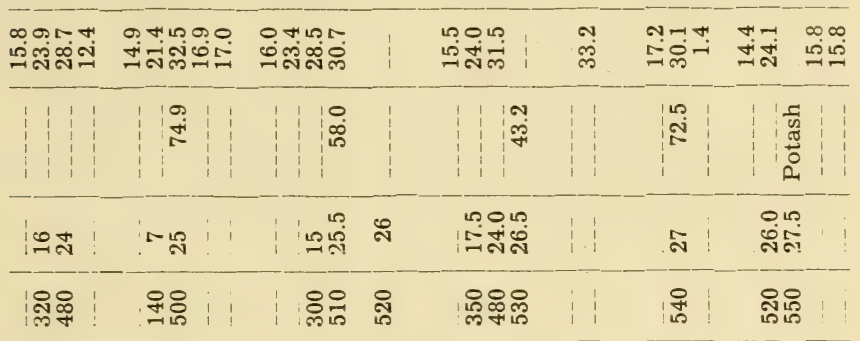

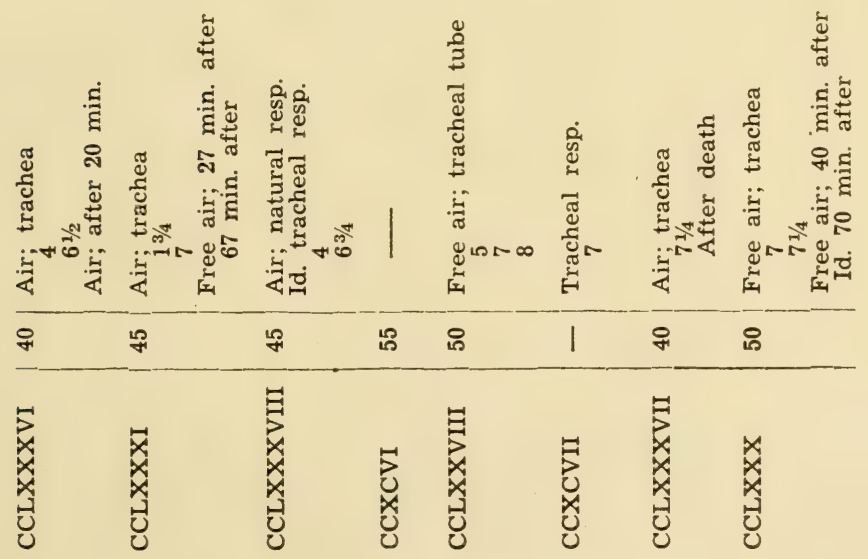




\begin{tabular}{|c|c|c|c|c|c|c|}
\hline 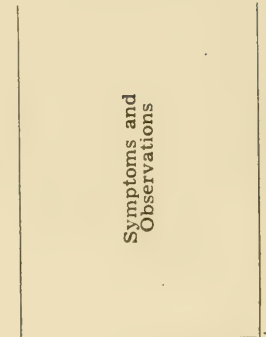 & 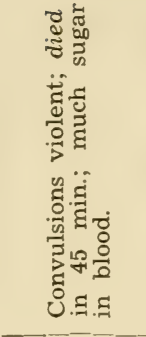 & 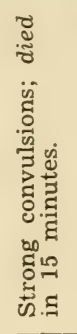 & 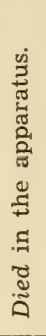 & 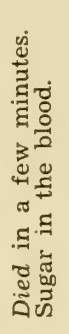 & 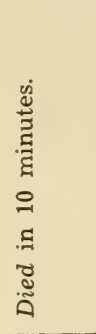 & 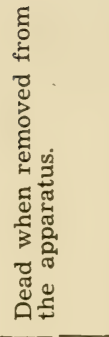 \\
\hline 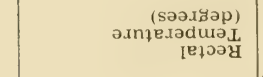 & $\begin{array}{l}n \text { r } \\
\infty \\
\infty\end{array}$ & $\begin{array}{l}\text { மீ: } \\
\text { మై }\end{array}$ & & $\begin{array}{l}\infty 0 \\
0 \dot{\infty} \\
\dot{m}\end{array}$ & 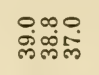 & \begin{tabular}{l|l|l}
$\infty$ & & \\
$\infty$ & &
\end{tabular} \\
\hline poolq әит & 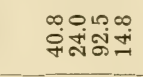 & i & & & พัฒ & 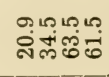 \\
\hline uo!n!soduos & 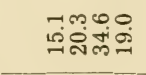 & & & & $\vec{\Xi} \overrightarrow{ \pm}$ & 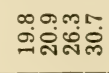 \\
\hline 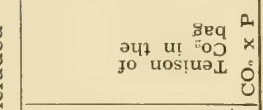 & & 离 & & $\stackrel{\infty}{\stackrel{\infty}{1}}$ & \begin{tabular}{c|c}
$\frac{\pi}{0}$ \\
0 \\
$\pi$ \\
0 \\
0 \\
0
\end{tabular} & $\mid \begin{array}{l}1 \\
1 \\
1 \\
\text { क } \\
0 \\
0 \\
0\end{array}$ \\
\hline 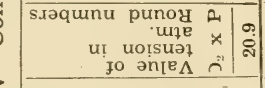 & : & iః & ลิ & ి̊ & मु- & 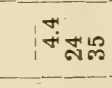 \\
\hline 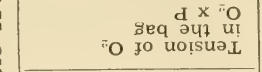 & : & i̊ & 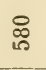 & ) & , ஓః్ & 我通 \\
\hline 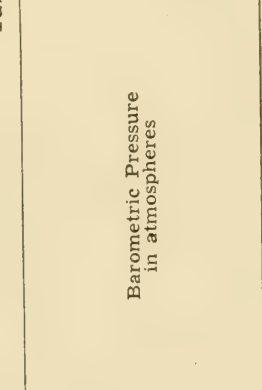 & 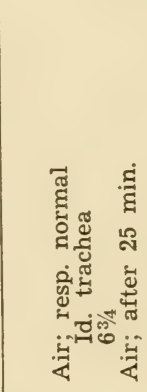 & 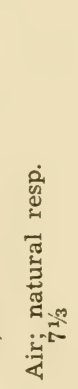 & & 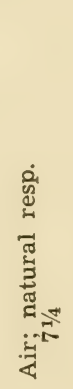 & 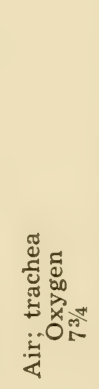 & 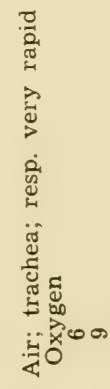 \\
\hline $\begin{array}{l}\text { uoțssarduroo aut } \\
\text { Jo uongexna }\end{array}$ & สี่ พ & \& & 周 & $q$ & เి & பㅇ \\
\hline 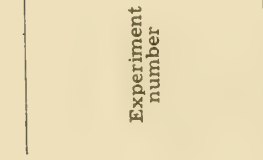 & \begin{tabular}{l}
$x$ \\
$x$ \\
$x$ \\
\hdashline \\
0 \\
0
\end{tabular} & 式 & 己 & 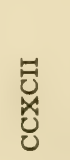 & 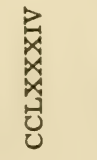 & 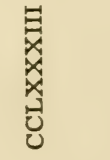 \\
\hline
\end{tabular}


I have sometimes seen them occur at pressures hardly over 10 atmospheres of air, and even result in death. Here, for example, are three experiments.

Experiment CCXCVIII. April 26. A rabbit and two sparrows are placed in the large compressed air receiver.

From 1:45 to $2: 45$, the pressure is raised to 10 atmospheres.

About 5 o'clock, on looking through the windows of the apparatus, we see the animals are dead.

Experiment CCXCIX. April 30. Dog weighing 4.300 kilos. At $9: 45$, placed, free, in the large receiver.

The pressure is raised to 10 atmospheres at 10:30; then the little exhaust cock is opened, so that a current of air under 10 atmospheres is maintained; the pressure even rises to 11 atmospheres at 10:45; at that time we look in through the portholes and see the dog lying on its back, in a kind of convulsion. The pressure is lowered to 10, and almost immediately the animal recovers, stands up on his feet, and barks wildly.

At noon, the pressure is still 10 atmospheres; the dog has remained standing and begins to bark furiously when anyone approaches the apparatus.

The current of air under pressure is maintained.

At $2: 15$, the animal is lying down, struggling half convulsively.

It dies at 5 o'clock; as the cock has been closed for some time, a sample of air is taken which appears practically pure $\left(\mathrm{O}_{2}, 19.8 ; \mathrm{CO}_{2}\right.$ $0.4)$.

Experiment CCC. February 15. Two mountain sparrows are kept, from $11: 30$ to $5: 30$, under a pressure of air varying from $8 \frac{1}{2}$ to $9 \frac{1 / 2}{2}$ atmospheres; constant current of air.

One of them (A), at the end of a stay of several hours, gives increasing signs of discomfort.

Very slow decompression. A is much weakened, has convulsive movements of the wings, feet, and tail; its temperature, which was $41^{\circ}$ at the beginning, is only $33.8^{\circ}$. At 7 o'clock in the evening, it still has convulsive movements, leans backward on its tail.

The other sparrow seems quite well. Its temperature is $39^{\circ}$.

Both die during the night.

I do not dwell on these last experiments. To return to those summarized in Table $\mathrm{XV}$, we see that though for compressions of short duration convulsions begin to appear with an oxygen tension a little lower than the value of 19 atmospheres of air, they are strong and constant above 20 atmospheres, and always entail a very rapid death when above 27 atmospheres. In the only experiment (Experiment CCLXXXIII) in which the oxygen tension rose to the value of 35 atmospheres, the animal was already dead when taken from the apparatus.

Let us consider now the oxygen content of the arterial blood, 
as shown in Column 7 of the table. We find rather large differences there. Whereas, for example, in Experiment CCLXXXI, in which the oxygen proportion rose from 14.9 to 32.5 , although seized by violent convulsions, the animal survived, the dog in Experiment CCLXXXVII died in 20 minutes, without having in its blood more than $30.1 \%$ of oxygen, the initial proportion being 17.2. All the results show that it would be impossible to fix exactly either the absolute quantity of oxygen with which convulsions and death occur or its proportional increase. Yet whenever the animal died, the quantity of oxygen always exceeded 30 volumes per 100 volumes of blood.

The average incrcase is, we see, very slight, since it oscillates between a third or a half above what exists normally.

If, in order to examine their general course with more profit, we express by graphs, in our usual manner, the results contained in Column 7, we get Figure 60. The many variations which we noted are shown here very clearly.

But if we slide all these lines up vertically, making the origin of each the number 20 , and if we take the average of the different points corresponding to about the same pressure, we get definitely a line - - of remarkable regularity, that is, a straight line.

So, in the living animal, we find confirmed the experiments in vitro included in Subchapter V of Chapter II: from one atmosphere on, there is added to the biood only dissolved oxygen.

It is a fact worth noting that convulsions may appear when the blood has an oxygen content appearing sometimes in healthy animals, which they may almost reach after rapid respiration. We see first then that it is not the proportion of oxygen contained in the blood which is of itself dangerous; we see next that the increase of this proportion, even to a high degree, does not constitute the danger. This increase must be permanent, must be the result, not of a better saturation of the corpuscles as an effect of more complete aeration, a saturation which the reducing action of the tissues soon restores to the normal degree, but of a saturation due to the fact that the tissues themselves are saturated with oxygen and in equilibrium with the blood.

That is why the convulsions occur only after the compression has lasted some time. The tissues must be impregnated with oxygen in addition to what the blood, loaded with it in the lungs, brings them and incessantly gives over to them.

At the beginning of these experiments I asked myself whether the blood was not directly altered by the excess of oxygen, and did 
not thus become the cause of the convulsive symptoms. Inspection of the corpuscles through the microscope, it is true, showed me no alteration of forms and dimensions; but that did not satisfy me. I

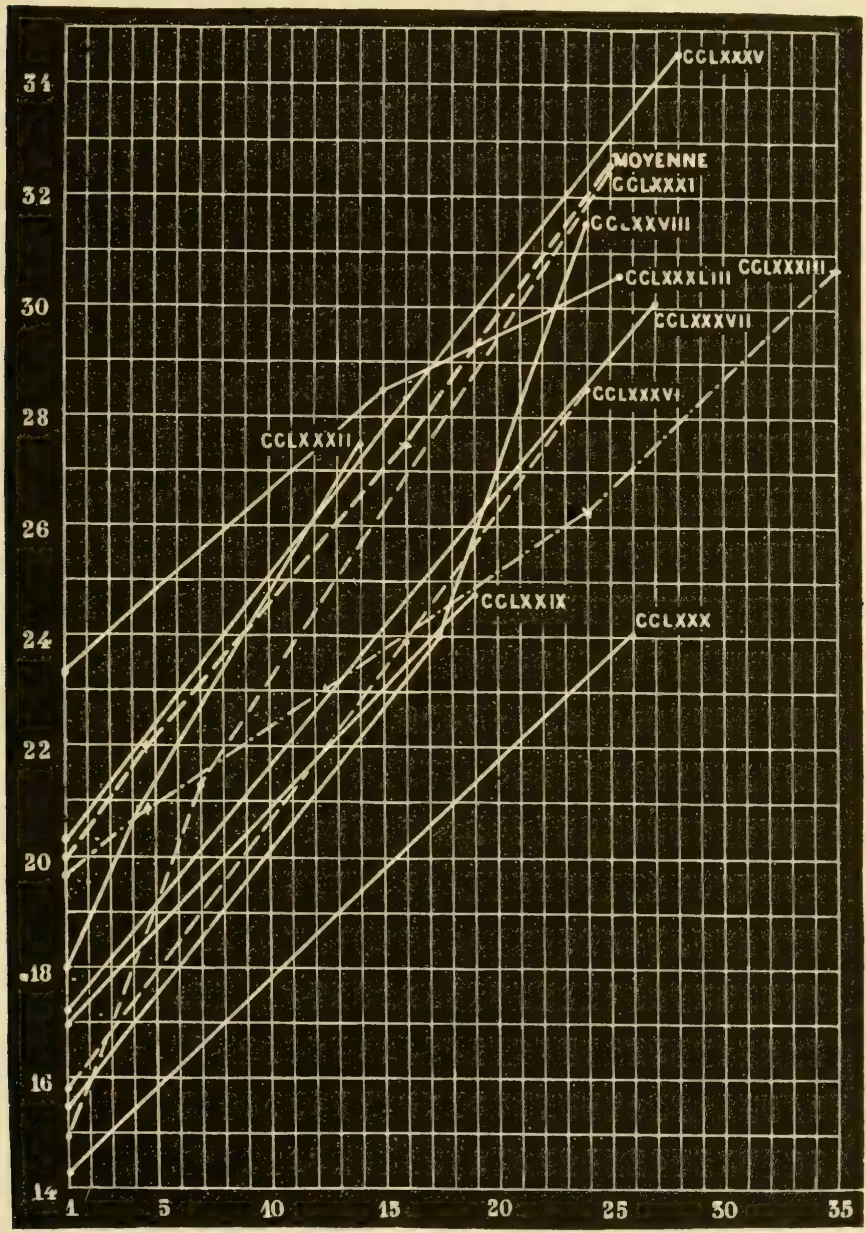

Fig. 60-Dogs poisoned by oxygen: increasing oxygen content of their arterial blood. 
resolved then to inject into a healthy dog blood which had been greatly superoxygenated. I did so in the following experiments.

Experiment CCCI. June 30. Defibrinated dog blood, shaken in the apparatus pictured in Figure 45, under a pressure of 10 atmospheres of air with $65 \%$ of oxygen. Next the excess of gas was expelled by whirling the flask containing the blood at the end of a cord, like a sling. It then contained 24 volumes of oxygen per 100 volumes of blood. I injected $200 \mathrm{cc}$. of it into the femoral vein of a female dog weighing 6 kilos.

No symptom, not even apparent discomfort.

Experiment CCCII. July 23. Defibrinated dog blood; treated like the preceding at 10 superoxygenated atmospheres; it contained 34 volumes of oxygen.

I bled a little dog weighing $1640 \mathrm{gm}$. from the carotid; I took from him $20 \mathrm{cc}$. of very red blood (this blood clotted with extraordinary rapidity), containing only $7.3 \%$ of oxygen, with $33 \%$ of carbonic acid; the arterial pressure was $13 \mathrm{~cm}$.

I injected into his jugular vein $35 \mathrm{cc}$. of the blood supersaturated with oxygen, which had been whirled like a sling.

No effect.

Experiment CCCIII. August 10. Defibrinated dog blood, treated as above, at 10 superoxygenated atmospheres; contained 33 volumes of oxygen.

Little dog weighing 2085 gm.; rectal temperature $36^{\circ}$; pulse 160 ; respiratory rate 50 . I took $100 \mathrm{cc}$. of blood from him; he became very weak; his temperature fell to $34.5^{\circ}$; pulse 128 ; respiratory rate 30 .

I then injected into his jugular $110 \mathrm{cc}$. of superoxygenated blood; immediately the animal revives, and when put down on the floor, seems only a little weak.

No after-effect.

And so in conditions of compression, that is, oxygen saturation, similar to and even greater than those which caused death, the blood acquired no dangerous quality, and can be substituted safely, in a very great proportion (1/19 of the weight of the body) for the blood of another animal. I must add that the agitation in compressed oxygen had lasted only a very short time, less than one hour. We shall see in Subchapter III of Chapter VI other experiments made from another point of view with blood shaken for several hours with compressed oxygen.

But let us come to the description of the convulsive attack itself. It is truly curious and terrifying.

Let us take a case of average intensity. When the animal is taken from the apparatus, it is generally in severe tonic convulsions; the four feet are stiff, the trunk is bent back or a little to 
one side, the eyes protrude, the pupils are dilated, the jaws are clenched. Ophthalmoscopic examination shows copious hemorrhage at the back of the eye. Soon there occurs a sort of relaxing to which succeeds a new fit of stiffness with clonic convulsions resembling both a strychnine crisis and an attack of tetanus. These fits during the intervals of which the dog does not relax completely, but remains in opisthotonos, breathing with great difficulty, check the respiration, the heart still continuing to beat, although often with surprising slowness; the arterial pressure drops considerably. Sensitivity remains and one can excite new convulsions by it. After some time, these convulsive periods, which at first appear every five or six minutes, become rarer, then less violent; the stiffness

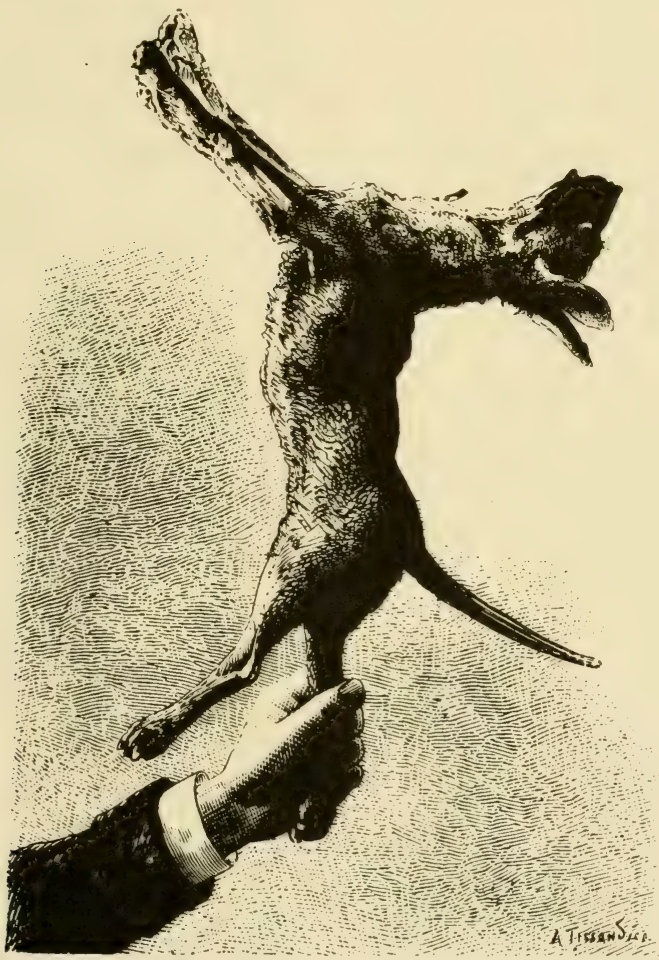

Fig. 61-Dog during the tonic convulsions of oxygen poisoning. 
lessens in the intervals, and finally all symptoms disappear at the end of a few minutes or, at the most, a few hours.

In lighter cases, instead of attacks so violent that one can lift the animal by a single foot, stiff as a piece of wood, as Figure 61 shows, we observe irregular movements, local convulsions, symptoms, in a word, which are much like those of poisoning by phenol. We sometimes see acts which seem to indicate a certain mental disturbance.

In very serious cases, on the contrary, the stiffness is continual, with a few clonic increases from time to time; the teeth grind and clench so as to appear nearly ready to break, and death may occur after one or two attacks, separated by a few minutes. We then find the blood red, even in the portal system; then it turns dark. When the animal no longer makes any movement, the heart still continues to beat for a few minutes. At other times, as in Experiments CCLXXVIII and CCXCVII, the convulsions last nearly 24 hours before ending in death.

We find no congestions or ecchymoses in the lungs and the nervous centers. Only consistently in sparrows, we see the cranial diploe filled with a hemorrhage in dots, in smaller or larger spots, or even in a sheet covering the occipital region, and, in the most violent cases, the whole extent of the cranium. These bloody suffusions, the cause of which does not seem to me easy to explain, are invariably present in oxygen poisoning. They appear some time before the moment of death. But they are not peculiar to this kind of death, and in the preceding experiments we find them noted, even in simple asphyxia, under diminution of pressure (See Experiments CCLII and CCLIII).

The appearance of the symptoms which we have just described seems to indicate that the toxic action produces its effect on the nervous centers, as do strychnine, phenol, and other poisons which cause convulsions. This conjecture is corroborated by the fact that inhalations of chloroform stop the convulsions momentarily, although they reappear when the anesthesia has worn off. Let us remember that, according to our experiments on frogs, if the sciatic nerve has been cut in the hind leg, there are no convulsions in the muscles animated by this nerve.

To summarize all these facts, I shall quote here the conclusions of the report which I had the honor to make on this subject to the Academy of Sciences, February 17, 1873. 
1. Oxygen acts like a poison which is rapidly fatal, when its quantity in the arterial blood rises to about 35 cubic centimeters per 100 cubic centimeters of liquid;

2. The poisoning is characterized by convulsions which, according to the intensity of the symptoms, represent the different types of tetanus, strychnine, phenol, epilepsy, etc.;

3. These symptoms, which are quieted by chloroform, are due to an exaggeration of the excito-motor power of the spinal cord;

4. They are accompanied by a considerable and constant drop of the body temperature.

It is this last point, purposely set aside until now, that I shall discuss next.

\section{The Diminution of Oxidations by Oxygen Poisoning.}

When for the first time I saw a sparrow struggling in violent convulsions under the influence of compressed oxygen, I imagined at first that the intra-organic oxidations had been so overstimulated in this bird that it was dying from burning itself out too quickly, producing thus a quantity of exaggerated heat, which perhaps became the direct cause of death. I thought therefore that the thermometer would show me a rise in the bird's temperature. Great was my surprise when I noted an absolutely opposite result.

In fact, in all the experiments, as the numbers listed in Column 5 of Table XIV and Column 9 of Table XV show, the temperature of the experimental animals dropped considerably, before and during the convulsions due to the oxygen.

At the beginning of the poisoning, when the convulsive symptoms were just commencing to appear, the temperature fell (Experiments CCLXI, CCLXII, CCLXVII). During the convulsions, it falls more, and when the convulsions are to end in death, it reaches very low figures (Experiments CCXCIII, CCLXXXI, CCLXXVIII, CCXCVII), especially in birds, in which it goes below 30 , and sometimes even below 20 degrees (Experiment CXXXVII).

If, on the contrary, the animal is to survive, its temperature rises and returns in a few hours to its normal value (Experiments CCLX, CCLXII, CCLXVII, CCLXXXIX, CCXCIII).

It is, therefore, a firmly established fact that the excess of oxygenation of the organism results in a diminution of intensity in the chemical acts which produce the animal heat.

If the falling of the temperature of the body has given us a certain though indirect demonstration of this strange fact, we should find the direct proof when we examine either the absorp- 
tion of the oxygen or the two important excretions of urea and carbonic acid.

Pulmonary exchange. Let us speak first of the consumption of oxygen and the production of carbonic acid, which are measured by the same experiment.

The experiments reported in Chapter I on birds which died in confined and compressed air show that these two phenomena lessened in intensity during the compression. But it is not possible to draw any conclusion, because the carbonic acid which is stored up in the tissues of the animal adds its action to that of the oxygen, and we shall see in Chapter VIII that carbonic acid also diminishes the oxidations.

As to the experiments reported in the present chapter, they cannot furnish any information as to what takes place during the compression.

I therefore had to plan special experiments; unfortunately, the problem presented more serious difficulties than one might have supposed at first glance.

In dealing with animals kept in closed vessels, as the idea was to turn out, for the reason which has just been stated it was necessary to eliminate the carbonic acid and keep to the measurement of the oxygen consumed. Now under the influence of pressure, there must be dissolved, in the very body of the animal, a certain quantity of oxygen which it is impossible to estimate and subtract from the total quantity of oxygen that has disappeared.

That is not all. In the numerous experiments which I have tried by this method, I took care always to act comparatively, to put simultaneously two identical animals, one under a bell of known capacity at normal pressure, the other in a compression receiver at a determined pressure, with a potash solution which absorbed the carbonic acid as it was formed. After a certain time had elapsed, I analyzed the two airs, and I could easily determine the quantity of oxygen absorbed by each of the two animals during a certain unit of time. Unfortunately, the percentage analyses made necessarily upon a small volume taken from the total mass of air in the experiment have to be multiplied by this mass, to get the total consumption, and the causes of error of either chemical or physiological nature then assume a value so great that they exceeded the differences noted between the two analyses.

I therefore had to give up this type of experiment completely. I used two others, which are not subject to the same criticism.

The first is a little indirect. It consists of comparing the quantity 
of carbonic acid given off by the same animal placed successively in a closed vessel, in ordinary air or in a superoxygenated air at the same degree of compression. The special action of the carbonic acid is thus eliminated, because it is obviously the same in both cases. Here are the details of an experiment conducted in this way.

Experiment CCCIV. Albino rat. Rectal temperature $38^{\circ}$. May 10. Placed from 4:05 to 6:35 (2 hours 30 minutes) in the large receiver made of a mercury bottle (containing 3 liters), under a pressure of $31 / 4$ atmospheres of air. When he is taken out, his temperature has fallen to $30^{\circ}$; he is quite sick, breathes slowly and deeply, but recovers quite quickly.

The air of the flask contains $12.5 \%$ of oxygen, and $6.6 \%$ of carbonic acid.

May 12. The animal has recovered perfectly; we begin again the same experiment, as to pressure and length; but this time we use air containing about $60 \%$ of oxygen. The tension of this gas corresponds then to that of compressed air from 9 to 10 atmospheres.

At decompression, the animal is found very low, not sensitive to pinching, but sensitive in the cornea. His rectal temperature is only $23.8^{\circ}$. He does not move, and dies at the end of a half-hour; no gas in the blood vessels.

The air in the receiver contained only $5.3 \%$ of carbonic acid.

Experiment CCCV. July 1. A. Two sparrows weighing together $38 \mathrm{gm}$. are subjected to a pressure of 5 atmospheres of air for 32 minutes, in the Seltzer water receiver.

Taken out after sudden decompression, seem very well, with slight bloody suffusions on the cranium.

During this time they consumed $3.9 \%$ of oxygen, and produced $2.8 \%$ of carbonic acid.

B. Two other sparrows, weighing together $39 \mathrm{gm}$., are placed next in the same apparatus, at the same pressure, but in air containing $72.6 \%$ of oxygen; the tension, $5 \times 72.6=363.0$, corresponds to about that of 18 atmospheres of air. They remain in the apparatus for 27 minutes.

At the end of 5 minutes there occurred in the two birds convulsions which lasted with intensity for 15 minutes. Then the sparrows remain lying on their backs, panting heavily.

One of them dies at the end of an hour; the other, after seeming to recover, but keeping up incessant muscular quiverings, is seized with convulsions after an hour and a half, and dies in a half hour. sions.

Both immediately take on rigor mortis; moderate bloody suffu-

In 27 minutes they consumed $2.05 \%$ of oxygen, 1.07 in the 'first 17 minutes and only 0.35 in the last 10 ; they produced in the first 17 minutes $1.07 \%$ of carbonic acid, and 0.28 in the rest of the time, in all 1.35 .

We see from these figures that in 10 minutes at 3 atmospheres of air $1.2 \%$ of oxygen was consumed and $0.8 \%$ of carbonic acid was 
formed, while at a tension corresponding to 18 atmospheres of air the consumption was only 0.7 and the production 0.5 .

These experiments show very clearly that the absorption of oxygen and the production of carbonic acid decrease when the oxygen tension increases; the difference increases in proportion to the length of the experiment. Experiment CCCVI shows that at 9 or 10 atmospheres of air this effect is produced clearly, and that at this low pressure death may occur after an exposure that has been prolonged enough.

The second experimental method I used consisted of collecting and measuring all the carbonic acid produced by an animal during a certain time under different pressures but in a current of air that is always pure.

Experiment CCCVI. Rat weighing $160 \mathrm{gm}$.

July 28. Placed for a half hour in the Seltzer water apparatus, at normal pressure, under a current of air providing 2 liters per minute. The apparatus is immersed in water at $20^{\circ}$. The air which escapes is collected in a bag, and then connected with the potash bubbler of Figure 65, which absorbs all the carbonic acid from it; the carbonic acid is then extracted by one stroke in the mercury pump.

The temperature of the animal dropped from $38^{\circ}$ to $37.5^{\circ}$.

It produced $247 \mathrm{cc}$. of carbonic acid.

August 2. Same animal, same general arrangements.

Kept under a current of air but this time at a pressure of 9 atmospheres, during the same length of time.

On being taken from the apparatus, its temperature has dropped from $38.1^{\circ}$ to $34.6^{\circ}$.

Produced $176 \mathrm{cc}$. of carbonic acid.

In two of the experiments (CCXCIII and CCXCIV) made on dogs, which were reported in the preceding subchapter, I measured the oxygen consumption, and at the same time the production of carbonic acid, not during the compression, but during the moments following the decompression, and even in the midst of an attack of convulsions.

This measurement was interesting only from the comparative point of view. The method which I used, which makes no claim to absolute accuracy, allows me to compare what a dog was capable of absorbing and producing before being subjected to compressed air with what he consumes and produces when he has been taken from the cylinder.

The experimental animals had a tube in the trachea. I connected this tube with a bag filled with a known volume of air and let the animal breathe into the bag for a certain time. Since the 
operation was repeated several minutes after the decompression, two chemical analyses allowed me to determine the quantity of the gases absorbed and given off in both cases.

Experiment CCXCIII shows that although before the compression the dog had consumed in a quarter of an hour 4.89 liters of oxygen and produced 2.99 liters of $\mathrm{CO}_{2}$, after he had been taken from the apparatus in the same time he consumed only 2.02 liters and formed only 1.12 liters. Similarly, in Experiment CCXCIV, the consumption of oxygen fell from 3.95 liters to 2.15 liters, and the production of carbonic acid from 2.41 liters to 1.99 liters.

The decrease in the production of carbonic acid through the superoxygenation of the organism is indicated again by the study of the numbers listed in Column 8 of Table XV. If we examine Experiments CCLXXX, CCLXXXI, CCLXXXV, CCLXXXVI, CCLXXXVII, CCLXXXIX, CCXC, CCXCIII, we see that some minutes after the decompression we find in the blood only minimal proportions of carbonic acid. And this fact is all the more remarkable because, in the conditions in which the experiments were made, carbonic acid had been stored up in the blood in considerable quantity during the compression. Now when the animal was restored to the open air, this acid lessened to far below the normal proportion; in Experiment CCLXXXIX, it fell to 10.5 volumes per 100 volumes of blood, although its regular proportion, before the compression, was 44.5; in Experiment CCLXXXVI, the proportion before the compression being 43.0, it became 69.4 during the compression, and dropped to 9.9, 20 minutes after; in Experiment CCLXXXV, the same figures were 40.8 , then 92.5 , and finally 14.8 .

It is quite clear then that, in consequence of the exaggerated superoxygenation of the organism, carbonic acid ceased to be produced in the tissues, and to pass into the blood, or at least that these phenomena were considerably slackened. This would have been manifest even during the compression, if I had been able to keep the animals in a current of compressed oxygen, to avoid the storing up of the carbonic acid due to the confinement. Furthermore, the experiments reported in Chapter II, in which we were dealing with pressures which were rather low but were made with almost pure air, showed, as we have noted, a diminution of the carbonic acid of the blood (See Table XII).

It appears from these data that the pulmonary ventilation would be capable of removing from the blood much more considerable proportions of carbonic acid than one would have thought, of almost exhausting, in a word, the bicarbonates and the phospho-car- 
bonates, if the organism did not unceasingly furnish the venous blood with a constant source of this gas. We shall return to these data in another chapter, but it would be interesting to see, by a simple experiment, in which the same blood would be forced by a pump to pass constantly through the lungs, in which artificial respiration would be maintained, how much carbonic acid this blood could lose.

Before leaving this subject, let us say that the carbonic acid reappears but slowly in normal proportion in the arterial blood, when the superoxygenated animal recovers and lives. In Experiment CCLXXXIX, at the end of 1 hour and 15 minutes the proportion of carbonic acid was only 19.0; in Experiment CCXCIII, after 2 hours and 40 minutes, it had risen only to 26.5; but in Experiment CCLXXXI, at the end of 67 minutes it had returned to its original figure, 31.5. Let us note that this tendency to return to the normal proportion does not always indicate that the animal will survive, as Experiment CCLXXX shows.

Excretion of Urea. I now come to the urea. The experiments were conducted like those in the case of diminished pressure. The animal, subjected to a fixed diet for several days, was kept for several hours in compressed air, with a suitable current of air. The urine voided spontaneously or collected with a catheter in the preceding 24 hours was compared with that given in the 24 hours in which the compression took place. The account of the experiments will give the necessary details.

Experiment CCCVII. Dog weighing 12 kilos, eats every day at 7 o'clock in the morning a soup composed of $250 \mathrm{gm}$. of bread, $250 \mathrm{gm}$. of meat, and $500 \mathrm{gm}$. of water.

July 25 , at 8 o'clock in the morning, catheterized the animal, which was then placed in a cage where the urine can be collected; he does not urinate, and July 26 , at 8 o'clock, another catheterization gives $280 \mathrm{cc}$. of urine. This urine, analyzed by the Yvon process, gives $4500 \mathrm{cc}$. of nitrogen, that is, $12.1 \mathrm{gm}$. of urea.

July 26, from 9 o'clock to 3 o'clock, is subjected to a pressure of 8 atmospheres, under a current of air. Decompressed from 3 o'clock to $\mathbf{5}$ o'clock, is taken out in good condition. His rectal temperature is $35.5^{\circ}$.

July 27 , at 8 o'clock in the morning (rectal temperature $35.7^{\circ}$ ) he is catheterized and the urine thus obtained is added to what he voided spontaneously. The total is $350 \mathrm{cc}$. of urine, which gives only $1398 \mathrm{cc}$. of nitrogen corresponding to $3.7 \mathrm{gm}$. of urea. I must add that the animal would eat only half his meal.

July 28, at 8 o'clock in the morning, catheterized again; there are $520 \mathrm{cc}$. of urine giving $3838 \mathrm{cc}$. of nitrogen, that is, $10.3 \mathrm{gm}$. of urea. During this day, the animal had absolutely refused to eat. 
Experiment CCCVIII. Dog weighing 16 kilos; since July 31, eats every day $250 \mathrm{gm}$. of bread, $250 \mathrm{gm}$. of meat.

August 3, at $8: 30$, catheterized.

August 4 , at $8: 30$, catheterized, and this urine added (100 cc.) to what was voided in the 24 hours $(475 \mathrm{cc}$.) It gives, by the Yvon procedure, $8062 \mathrm{cc}$. of nitrogen, that is, $21.6 \mathrm{gm}$. of urea. Rectal temperature $35.8^{\circ}$. At 9 o'clock in the morning, placed in the apparatus, where the pressure rises to 8 atmospheres; decompression begun at $4: 50$, still under a current of air; the animal is removed from the apparatus at 6:20; he is in good condition; his temperature is $35.5^{\circ}$.

August 5, at $8: 30$ in the morning, the catheter drew 245 cc. of urine; there was none in the apparatus. It gave only $6329 \mathrm{cc}$. of nitrogen, corresponding to $16.9 \mathrm{gm}$. of urea.

These examples are enough to show that the chemical phenomena on which depend the formation of urea and analogous products are impeded in the same manner as those which determine the production of carbonic acid.

Sugar of the Blood; Glycosuria. A search for sugar in the blood and the urine shows us another chemical transformation, the destruction of this sugar, impeded by the action of oxygen under tension. In Experiment CCLXXXVI, the dog, which survived after convulsions of extreme violence, voided after the decompression urine with great sugar content; in Experiment CCLXXXI, which ended in rapid death, the few drops of urine which the bladder contained had high sugar content. This glycosuria, however, is not constant (Experiment CCXC).

Experiments CCLXXXV, CCLXXXVI, CCLXXXIX, CCXC, CCXCII, CCXCIII, and CCXCIV, that is, all in which the blood was tested for sugar, showed first that there is always much glucose in the arterial blood of a dog which has been subjected to compression. But as we always find glucose in arterial blood when it is treated according to the method of $\mathrm{M}$. Cl. Bernard by boiling with sulfate of soda, comparative experiments CCLXXXIX, CCXC, CCXCII, CCXCIII, CCXCIV had to be made on the blood before and after compression, which showed very clearly that the latter contains more sugar than the former. Experiment CCXCIII proves besides that this excess of sugar disappears at the end of some time.

So the sugar which comes from the liver is much less rapidly broken down in the organism under the influence of compressed oxygen than at normal pressure, so that it is stored up in the blood to the point of producing glycosuria.

As to the production of the hepatic glucose itself, it is hampered by the sufficiently prolonged action of oxygen at high tension, as the following experiments prove. 
Experiment CCCIX. March 7. Albino rat.

Rectal temperature $39.6^{\circ}$.

Kept for three hours in compressed air at 12 atmospheres, above a potash solution which absorbs the carbonic acid as it is formed.

Withdrawn suddenly, its rectal temperature is only $35.5^{\circ}$; it dies quickly with air in its heart.

Its liver does not contain sugar; much glycogenic material. $39.9^{\circ}$.

Experiment CCCX. March 15. Albino rat; rectal temperature

At 12 atmospheres of air for 3 hours, with potash.

Withdrawn; temperature $37.2^{\circ}$; dies like the rat in the preceding experiment.

No sugar in the liver.

In summary, consumption of oxygen, production of carbonic acid and urea, breaking down of glucose in the blood, all chemical phenomena which can be measured easily, appear to be considerably slowed down by the action of oxygen under high tension. And as these are the phenomena which determine the production of heat, it is not surprising to see that the temperature of the animals drops considerably. Nor is it astonishing to see that death is the consequence of such a depression in the intensity of the physicochemical acts of nutrition.

But the violent excitation, the constant convulsions which accompany this death are still unexplainable by the depression alone; still less explainable is the persistence of the symptoms after normal pressure has been restored. In fact, in studying diminished pressure, we have noted a diminution of the chemical acts, analogous to what increased pressure revealed, and yet the convulsive struggling which precedes death by rapid decompression is in no way comparable to the violent convulsions due to oxygen and, furthermore, the return to free air marks irrevocably the end of all these symptoms.

This shows then that during compression the regular chemical acts of nutrition have been not only slowed up, but also modified; it is supposable that the result of this deviation has been the formation of some substance capable of playing a toxic part, a substance which, persisting after decompression, would continue to cause the symptoms and might bring on death, a substance the elimination or destruction of which would be necessary for a return to the state of health.

The chapter especially devoted to the study of fermentations will confirm us in this idea, and will even permit us to express it with more precision and clarity. 


\section{Aquatic or Invertebrate Animals.}

The experiments reported up to this point were made only with vertebrate air-breathing animals: mammals, birds, frogs. It was interesting to study the action of oxygen at very high tension on invertebrate air-breathing animals and on aquatic animals.

Experiment CCCXI. April 25. Beetles, flies, caterpillars; centipedes; woodlice; arranged in two similar groups.

A. Placed in a corked flask; ordinary air, normal pressure.

B. In the compression apparatus, and taken to 6 superoxygenated atmospheres; the pressure falls to 2 atmospheres.

April 26. All alive except the flies in B.

Experiment CCCXII. May 12.

Lizard; golden beetles; carpenter bee, loaded with mites; drone, red fleas; flies; spiders; woodlice; centipedes.

At 5 o'clock in the evening, taken to 6 superoxygenated atmospheres.

May 13; 10 o'clock in the morning, decompressed.

The drone, the flies, the woodlice are dead, as are several red fleas; the others still move their feet a little, as does the carpenter bee.

The lizard has spontaneous and excitable convulsions; he dies some hours afterwards.

The beetles, the spiders, the mites, the centipedes are in good condition and survive.

Experiment CCCXIII. May 14.

Golden beetle, bees, ants, red fleas, wood fleas; flies; woodlice; spiders; snails; earthworms.

At 5 o'clock in the evening, placed in the cylindrical glass apparatus, with branches, earth, etc., to allow them to separate from each other. Taken to 5 superoxygenated atmospheres.

May 15, 2 o'clock. All dead except the spiders, the earthworms, which are twisted and intertwined, and the snails.

,All die in the open air.

Experiment CCCXIV. May 16.

A capricorn beetle, 1 dragon fly, 1 blue butterfly, several bees, drones, ants, red fleas, flies, syrphus flies; centipedes, geophiles; woodlice; spiders.

At 11 o'clock in the morning, taken to 5 superoxygenated atmospheres; at 1 o'clock raised to 6 ; at 2 o'clock to 11 atmospheres.

Almost immediately all fall to the bottom, motionless, except the ants and the centipedes, which run up and down.

The flies die in a half hour at most.

4 o'clock; none of the insects are moving. Decompression made. The bees, the flies, the syrphus flies, and the butterfly are dead.

The capricorn beetle, the dragon fly, the drones, the fleas, the ants, the woodlice are still moving a little.

The myriapods and the spiders are in good condition. 
The next day, all are dead except the myriapods.

Experiment CCCXV. June 23.

Silkworm cocoons, sent by M. Raulin, from Alais, all of the same day.

A. 12 are placed in an open bell-jar.

B. 6 in the cylindrical glass apparatus, at 5 superoxygenated atmospheres.

C. (By some mistake, probably of the proof-reader, the conditions in $\mathrm{C}$ were not given; the pressure was probably much higher than in B. Translator.)

The air was changed every other day.

July 8. A. All have emerged.

B. No motion.

C. All dead; the skin of the chrysalises is not separable; they evidently were killed very soon.

So the formidable influence of compressed oxygen is felt by invertebrate animals as well as those belonging to the higher types.

The animals which in the simultaneous experiments first felt the fatal effects of oxygen were the flies; after them the bees and the butterflies; then the dragon flies and the fleas; considerably later, the ants and the coleoptera (longicorn and carabic). The woodlice, and especially the arachnids (spiders, acaridae) and the myriapods (centipedes, geophiles) are much more resistant. Then come the earthworms and the snails, at least for length of life, if not for lethal concentration.

The great importance of this kind of research is to show that death from excess of oxygen does not depend upon a mechanism peculiar to animals with red corpuscles, but is a general fact. There is present a profound modification in the metabolism of the tissues. We should note that these animals never seemed excited; on the contrary, they quickly become motionless and fixed in some corner of the apparatus, and die without showing any convulsion.

As a type of aquatic animal to be studied, I generally used young eels, called "de la montée", the hearts of which one can easily see beating.

Experiment CCCXVI. April 1. Small eels "de la montée", transparent, temperature $15^{\circ}$.

A. 5 are placed in a well-corked test tube;

B. At three o'clock, 5 are placed in the cylindrical apparatus and raised to 11 atmospheres of an air with $50 \%$ of oxygen. Oxygen tension 550, corresponding to about 26 atmospheres of air.

In the evening at 7:30, nothing particular apparent.

April 2, 1 o'clock. A: in good condition.

B: dead, stiff, not trànsparent, and not contractile when stimulated electrically. 
Experiment CCCXVII. April 2. Similar eels.

A: these are the same ones as A of the preceding experiment.

B: at 3 o'clock, 5 are placed in the apparatus at $5 \frac{1}{2}$ atmospheres of air with $57.5 \%$ of oxygen. The tension is therefore 316 , corresponding to 15 atmospheres of air.

April 3, 10 o'clock in the morning; A, very lively; when quiet, respiratory rate 78 and pulse 40 .

B: move when the apparatus is shaken, but not spontaneously. Pulse 20 at the most; respirations, when eels are quiet, are not visible; after they were shaken, I counted 22. From time to time, violent struggling.

6 o'clock in the evening; in convulsions and are twisted in the shape of an 8 .

April 4, 1. o'clock. B: all dead, opaque.

Experiment CCCXVIII. April 4. Similar eels.

A: These are the eels of the two preceding experiments. of air.

B: at 4 o'clock, 5 are placed under pressure of 10 atmospheres

April 5, 9 o'clock in the morning: A: very lively, 66 very ample respirations; pulse 26 .

B: at the bottom of the apparatus, hardly moving; respirations invisible; pulse 20.

April 7. Same, all living; rapid decompression.

Experiment CCCXIX. July 8. Eels, not transparent.

At 5 o'clock in the evening, under compression of 10 atmospheres of air containing $50 \%$ of oxygen; the apparatus is shaken to saturate the water containing the eels.

July 9, 1 o'clock; all dead, opaque.

I tip the apparatus so that not the air but the water will escape; this water, when collected in the syringe, froths, and is taken to the mercury pump.

It contains 14 volumes of oxygen per 100 volumes of liquid, and the same quantity of nitrogen.

Much weaker pressures are enough to kill aquatic animals when their action is continued long enough.

Experiment CCCXX. May 20. Frog tadpoles, several days out of the egg and in very good condition in the laboratory.

A: 5 in a little corked flask, with water, at normal pressure.

B: 5 in a flask with water, all in the glass compression apparatus, at 7 atmospheres of air.

May 22: all living. before.

May 24: all living in A, all dead in B, probably since the day

Experiment CCCXXI. May 24. Same experiment, with similar animals; 7 atmospheres of air.

May 27; all the tadpoles in the compressed air are dead.

So aquatic animals are killed like air-breathing animals, when 
oxygen is dissolved in the water in sufficient quantity. A pressure of 15 atmospheres kills them quickly and they cannot live in 7 atmospheres. The transparency of the eels allowed us to note a considerable slowing down of the heart beats, while the respirations weakened so as to be almost invisible.

In another part of the book we shall draw conclusions from these last experiments from the point of view of the physics of the earth. It is enough here to note the generality of the fatal action of compressed oxygen, which acts upon warm-blooded animals as well as upon cold-blooded animals, upon vertebrates and invertebrates, upon animals which live in the water and those which breathe air, upon adult animals and those in the process of development. Chapters V and VI will permit us to extend this formula to plants, to ferments, in a word, to every living thing.

Subchapter II

\section{ACTION OF COMPRESSED AIR AT LOW PRESSURES (FROM 1 TO 5 ATMOSPHERES)}

The great interest attached to the toxic action of oxygen at high tension has caused me, as I said when I began this chapter, to begin this exposition as well as my research by a detailed analysis of the effects of this poison of a new type. I confess that I have long neglected, almost scorned, this study of the effects of slightly compressed air which French and German doctors have so long been testing, as we saw in the first part of this book. I could not, however, help being somewhat interested in it. My researches even gave it a new interest, unknown to former experimenters.

In fact, the experiments which have just been reported have shown that poisoning by oxygen at high tension first checks the intra-organic combustions, lessens the quantity of oxygen absorbed, of urea excreted, and consequently lowers the temperature of the body in warm-blooded animals. Now it is evident from the experiments contained in Chapter III, that the same physiological effects also result from diminished pressure, or, to speak more exactly, from too low tension of the oxygen breathed.

Quite naturally then it was desirable to know where between these two extremes, which are equally dangerous, is the point where the organic combustions are at their maximum intensity.

Besides, it was proved by the same experiments that prolonged 
exposure to a much rarefied air on the one hand, or to a very much compressed air on the other is fatal to animals, even if the modifications of pressure are not such that they bring on the rapid symptoms of asphyxia or of poisoning by oxygen. It is very important to determine what barometric pressure is most favorable to life. And it is by no means proved that this favorable point coincides with the maximum of combustion which we shall try to determine at the same time; this even seems improbable a priori.

It was with the purpose of settling these two questions that the experiments reported in the present subchapter were undertaken. However, I must remind the reader again that I am acting as an experimental physiologist and not as a hygienist or a doctor. To study the continued effect of compressed air, I used the lower animals exclusively, because they are much better adapted to experiments in which a prolonged stay in almost confined air is indispensable, and because they do not present the physiological inequalities which so seriously complicate researches on the metabolism of higher animals.

Everything seemed to indicate to me that the maxima which I was seeking were included between normal pressure and 5 atmospheres. This is suggested by graph A of Figure 22, which expresses the oxygen content of the compressed and confined air in which animals died without the interference of carbonic acid. It was between these limits then that I made my investigations.

In fixing these limits I had a reason of another sort, which is also important. It was absolutely proved by the experiments on diminution as well as on increase of pressure that the latter acts only as modifier of the oxygen tension, so that an air rich in oxygen and below one atmosphere in pressure produces the same effects as an air poor in oxygen but sufficiently compressed. In the preceding subchapter I repeatedly obtained the oxygen tension $\left(\mathrm{O}_{2} \times \mathrm{P}\right)$ by multiplying the factor pressure $(\mathrm{P})$ by the factor of oxygen percentage $\left(\mathrm{O}_{2}\right)$. So ordinary air at normal pressure has as its value, from the point of view which interests us, 20.9; at two atmospheres, this value becomes $2 \times 20.9=41.8$; at five atmospheres, $5 \times 20.9=$ 104.5. That is, one can use either ordinary air at two atmospheres of pressure or air with $41.8 \%$ of oxygen under normal pressure (if care is taken to remove the carbonic acid, the toxic acid of which might complicate the symptoms); and ordinary air at 5 atmospheres, or, obviously, pure oxygen.

This observation presents very great practical interest, because it permits experimentation at normal pressure, that is, in material 
conditions easy to realize which do not require, as do high pressures, the use of expensive and fragile glass apparatuses.

Finally, it seemed to me that I simply could not neglect these modifications in the circulation and the respiration, which before my time interested so many observers, whose statements, as we saw in the historical part, are far from being always in harmony. I was particularly anxious to measure the mechanical action of compressed air, acting upon the gaseous reservoirs of the organism, that is, the intestine and the lung.

In consequence, the experiments reported in this subchapter will naturally be divided into two categories: in some, the superoxygenated air will act for only a short time, several hours, a day at the most; in others, its action will be continued until it is ascertained whether or not it has any effect.

1. Short Stay in Compressed Air.

A. Experiments Made Upon Myself.

I shall first report the experiments made upon myself with the purpose of investigating on the one hand the respiratory and circulatory phenomena, and on the other hand the action of compressed air upon the excretion of urea, that is, upon one of the evidences of intra-organic combustions.

For this part of my researches, Dr. Jourdanet lent me a chamber which he has had made for therapeutic applications, and in which an ingenious arrangement allows one to secure at will an increase or a diminution in pressure.

This chamber, the general aspect of which is given in Figure 62, measures 2.58 meters in height and 1.46 meters in diameter, and consequently contains about $31 / 2$ cubic meters of air; it is closed by two doors, one inside and the other outside, on rollers guided by grooves; these doors are fastened together, when they are closed, by three long screws, which pass through holes cut through their walls. As they are fitted tightly on the walls of the cylinder by rubber gaskets, there is always one of them closed hermetically, for compressed as well as for expanded air. A rubber tube communicates with one or the other of the decompression or compression pumps; communication with the outer air is secured by openings which are not seen in the figure and which are controlled by inner cocks, which the experimenter manages; another cock permits his assistants to make the decompression if any accident happens to him. On both the inside and the outside are precision thermometers and manometers.

In this apparatus, operating at full speed, in one hour I can 
reach one atmosphere of pressure above normal, at the same time being under a current of pure air which is sufficiently strong to keep the temperature in the chamber from rising more than 2 or. $j$ degrees.

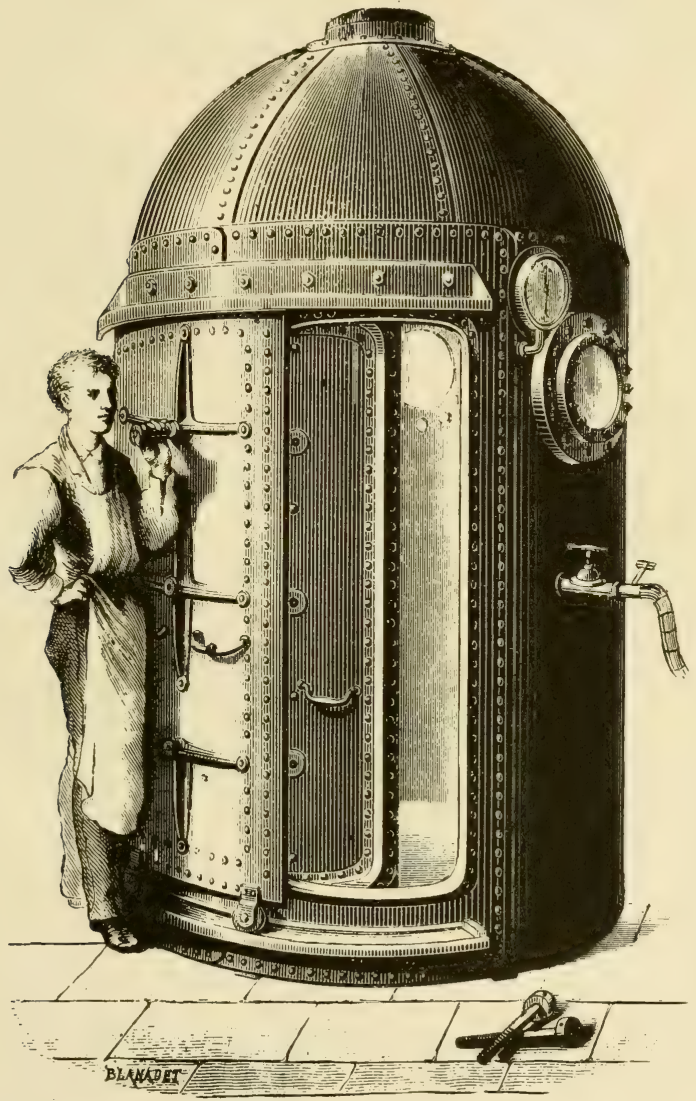

Fig. 62-Apparatus of M. Jourdanet for the therapeutic use of compressed or expanded air.

The number of heart beats was counted for five minutes, to avoid causes of error against which often no precautions are taken. The number of respirations was counted for 5 and often 10 minutes. 
To measure the quantity of air expired, I found nothing more convenient or more accurate than a gasometer. The one I had made especially for this purpose and which is pictured in Figure 63, has several dials, by means of which one can estimate the volume of air which has passed through the apparatus to within $50 \mathrm{cc}$.

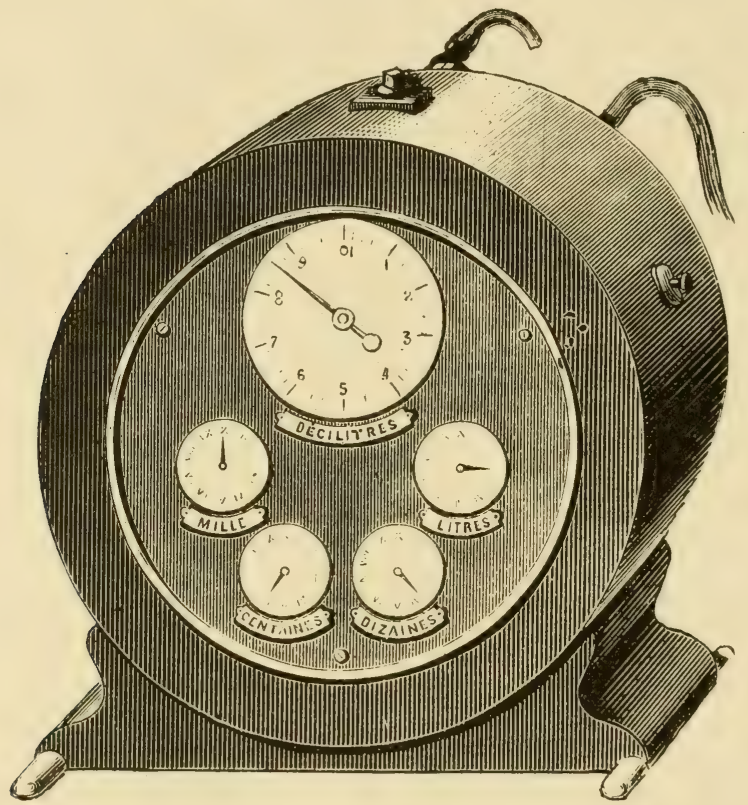

Fig. 63-Gas meter for measuring respiratory movements.

When it was necessary to measure the maximum expirations, I stood up, with my garments loosened, and after the inspiration, I took in my mouth, without any supplementary tube, the pipe leading to the gasometer and exhaled rather slowly until the lungs were empty, my nose, of course, being closed tightly by my left hand; I thus made at least 10 expirations, of which I took the average.

The same arrangement was used when I wished to exhale into a rubber bag to check the quantity of carbonic acid produced in a given time. I generally breathed for 10 minutes into the bags; then the air from them was passed for a whole night through the potash bubblers which I shall describe later; there it was completely freed 
of its carbonic acid; the potash solution was then analyzed in the mercury pump.

But to measure the regular respirations, the arrangement was more complicated; I had to have an apparatus which operated without the least attention, for we know how easily the respiratory movements are modified, when one wishes to examine them. The

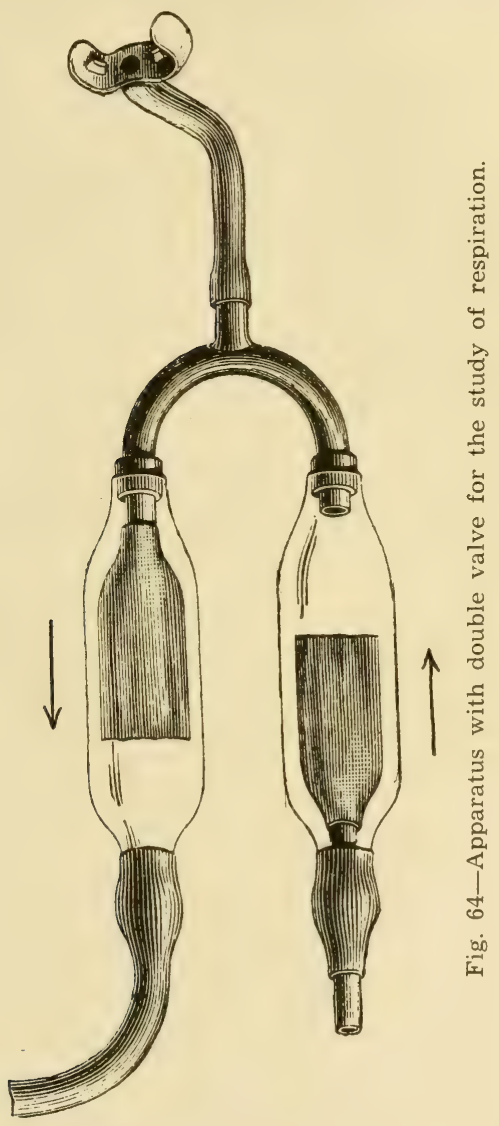

arrangement in Figure 64 gives excellent results, as many test experiments have shown me.

A rubber mouthpiece, which is applied to the dental arches and 
which the lips support without inconvenience or effort, is connected by a large rubber tube and a Y-shaped piece of copper to two glass tubes, each of which contains a membraneous valve, like those used by MM. Denayrouze in their well-known apparatuses; these valves are excellent, very delicate, and hold very well, if they are kept wet. As they are placed in opposite directions, one permits only the intake of inspired air, the other the escape of expired air, which a rubber tube suitably placed conducts to the gasometer. Of course the nose is closed the whole time by a sort of pincer to which one easily becomes accustomed.

I breathed thus for 10 and sometimes 20 minutes, remaining in perfect calmness, reading, and merely looking at the time or counting my respirations; sometimes the assistant did this for me, looking in through one of the glass portholes.

Besides, I regulated all the other conditions of my life very carefully; every day I went to the laboratory and sat there from 2 to 6 hours in or out of the apparatus; I took no other exercise.

It was with all these precautions that the following experiments were carried on.

Experiment CCCXXII. November 6. I begin by putting myself regularly on the following diet, which previous tests showed me was suitable. My weight is 73 kilos; height, 1.73 meters.

At lunch (12:15); two medium sized eggs, $70 \mathrm{gm}$. of lean mutton, $140 \mathrm{gm}$. of bread, $800 \mathrm{cc}$. of a mixture half wine and half water.

At dinner (7 o'clock): $120 \mathrm{gm}$. of lean beef, $200 \mathrm{gm}$. of mashed potatoes, 6 brandied cherries, bread and wine as at lunch.

November 7. After having emptied my bladder at noon, I keep my urine until Nov. 8, at noon .... A

I do the same the following days.

This day I remain at normal pressure.

November 8. I place myself in the cylinder from 3 o'clock to 6 o'clock; but I keep a current of air at normal pressure.

Urine from Nov. 8 to Nov. 9 . . . . B

November 9. Seated at 2:45 in the open apparatus; pulse 78; respiratory rate 8 ; maximum expiration 3.7 liters.

At $3: 18$, compression begun.

At $3: 45$, pressure $+30 \mathrm{~cm}$. liters.

At 4 o'clock, pressure $+45 \mathrm{~cm}$; p pulse 80 ; maximum expiration 4

At $4: 12$, pressure $+53 \mathrm{~cm}$.

At 4:42, same pressure; pulse 72 . 4 liters.

At $5: 10$, same pressure; respiratory rate 8.2 ; maximum expiration

At 5:32, the pressure was maintained at the same level; I begin the decompression; I leave the apparatus at 6:53.

At normal pressure, maximum expiration 3.7 liters. 
Urine from Nov. 9 to Nov. 10 .... C.

November 10. Seated in the apparatus at $2: 35$.

Maximum expiration 3.8 liters; calm respiration is 7.6 per minute, equivalent to 6.3 liters, or 0.83 liters for each expiration; pulse 68 .

Closed the doors at 2:55.

At $3: 20$, compression of $+37 \mathrm{~cm}$; maximum expiration 3.8 liters.

At $3: 38$, $+56 \mathrm{~cm}$; maximum expiration 4 liters.

At $3: 50$, same pressure; 8.1 respirations per minute, equivalent to 6.7 liters, or 0.82 liters per expiration.

At 4:25, same pressure; calm expirations give 6.2 liters per minute, without counting the number.

At 4:50, same; 6.5 liters per minute.

At 5 o'clock, the same; pulse 69 .

At 5:10, the same; maximum expiration 4 liters.

At 5:37, the same; began the decompression.

At 5: 45 , pulse 63 .

At $6: 15$, pressure $+15 \mathrm{~cm}$; pulse 60 .

At $6: 20$, pressure $+10 \mathrm{~cm}$; calm expirations give 6.2 liters per minute.

Normal pressure at $6: 30$.

Urine from Nov. 10 to Nov. 11 .... D

November 11. End of the experiment at noon.

The urine was analyzed by the Gréhant method, but the analysis was lost.

Experiment CCCXXIII. November 15. I enter the apparatus with a rather severe cold in the head, a cough, and tracheal pains showing the beginning of a cold in the chest. liters.

At 2:40, at normal pressure, my maximum expiration gives 3.75

At 2:50, pulse 77.7 .

From 2:55 to $3: 05$,breathed quietly into a bag .... A

Ordinary expirations as reckoned on the gasometer give 6.5 liters per minute.

Respiratory rate 9 .

At 3:10, compression begun.

At 3:55, compression of $+52 \mathrm{~cm}$; pulse 65 . liters.

At 4 o'clock, compression $+60 \mathrm{~cm}$; maximum expiration 4.08

At $4: 20$, compression $+56 \mathrm{~cm}$; respiratory rate 7.5 .

At $4: 30$, same; pulse 62.5 .

Calm expirations give 5.86 liters per minute.

From 4:45 to $4: 50$, breathed quietly into a bag . . . B

At 4:52, began the decompression.

At 5 o'clock, pressure $+40 \mathrm{~cm}$; calm expirations give 5.93 liters per minute.

At 5:15, pressure $+32 \mathrm{~cm}$; the snuffles which had left me begin again as does the heaviness in the head; some minutes after, (pressure $+20 \mathrm{~cm}$.) the cough reappears.

At 5:55, normal pressure. Pulse 65; the pulmonary ventilation gives 6.28 liters per minute; maximum expiration is 3.8 liters. 
The cold in the head stops in the night and the cold in the chest disappears.

Gas A gives for $10 \mathrm{~min} .2 .643$ liters of $\mathrm{CO}_{2}$, that is, for 1 hour 15.858 liters Gas $\mathrm{B}$ gives for $10 \mathrm{~min}$. 2.710 liters of $\mathrm{CO}_{2}$, that is, for 1 hour 16.260 liters.

Experiment CCCXXIV. December 17. Barometric pressure $74 \mathrm{~cm}$.: I begin again the diet of Experiment CCCXXII.

The urine was collected from noon December 17.

December 17. Remained at normal pressure.

Urine from Dec. 17 to Dec. 18 noon ... . A

December 18. At normal pressure, from 2:30 to 3 o'clock, the maximum expiration is 3.76 liters; quiet pulmonary ventilation is 6.54 liters per minute; pulse 81 .

At 3 o'clock, began the compression.

At $3: 44$, compression $+48 \mathrm{~cm}$; the maximum expiration gives 3.96 liters.

At 4:30, same pressure; pulse 79; pulmonary ventilation 6.74 liters per minute; 8.3 average respirations per minute.

At 5: 12 , compression $+52 \mathrm{~cm}$; decompression begun.

At $6: 15$, normal pressure; pulse 59 ; 8 average respirations; maximum expiration 3.81 liters.

At $7: 30$, pulse 60 .

At $8: 15$, pulse 83 .

Urine from Dec. 18 to Dec. 19 at noon . . . B B

December 19. Barometric pressure $74 \mathrm{~cm}$.

At $9: 30$ in the morning, pulse 64 , and respiratory rate 8 ; at noon, same.

At 2 o'clock, still normal pressure, pulse 68 .

At 2:20, compression begun.

At $3: 10$, compression $+45 \mathrm{~cm}$.

At $3: 35$, compression $+54 \mathrm{~cm}$.

At $3: 50$, compression $+56 \mathrm{~cm}$; pulse 82 ; maximum expiration 3.92 liters.

At 4 o'clock, same; began the decompression.

At $4: 45$, compression $+37 \mathrm{~cm}$. liters.

At 5:50, normal pressure; pulse 68 ; maximum expiration 3.80

Urine from Dec. 19 to Dec. 20, at noon . . . C

December 20, pressure $74 \mathrm{~cm}$.

At 4 o'clock, normal pressure; pulse 85 ; respiratory rate 6.5 .

At $4: 10$, began the compression.

At $5: 10$, compression $+50 \mathrm{~cm}$; 6.6 calm expirations; I begin the decompression.

At $5: 30$, compression $+41 \mathrm{~cm}$; pulse $66 ; 6$ respirations.

At $6: 15$, normal pressure; pulse $58 ; 5.6$ calm expirations per minute.

Urine from Dec. 20 to Dec. 21, at noon .... D

December 21, normal pressure; same diet.

Urine from Dec. 21 to Dec. 22 at noon . . . . E

December 22, normal pressure; same diet.

Urine from Dec. 22 to Dec. 23, at noon . . . . F 
The analysis of the urines by hypobromite of soda gives:

A (normal pressure) $1650 \mathrm{cc}$. containing $20.15 \mathrm{gm}$. of urea.

B (compressed air) $2010 \mathrm{cc}$. containing $24.72 \mathrm{gm}$. of urea.

C (compressed air) $1990 \mathrm{cc}$. containing $26.04 \mathrm{gm}$. of urea.

D (low compression) $2255 \mathrm{cc}$. containing $21.18 \mathrm{gm}$. of urea.

E (normal pressure) $2080 \mathrm{cc}$. containing $20.80 \mathrm{gm}$. of urea.

F (normal pressure) $2125 \mathrm{cc}$. containing $22.50 \mathrm{gm}$. of urea.

Experiment CCCXXV. February 9. M. Regnard, one of my assistants, 27 years, weighing 75.5 kilos, height 1.83 meters.

At 1:45, normal pressure; pulse 70 ; respiratory rate 15.6 ; pulmonary ventilation of 12.28 liters per minute. Maximum expiratory capacity 4.15 liters.

At 2 o'clock, began the compression.

At 2:45, compression of $+52 \mathrm{~cm}$., left until 4 o'clock. At that time, pulse 57 , respiratory rate 14.6 ; pulmonary ventilation 13.22 liters; maximum expiration 4.64 liters.

At 4:20, began the decompression.

At 5:30, normal pressure; pulse 56 ; respiration 16; pulmonary ventilation 13.02 liters; maximum expiration 4.60 liters.

Let us see now in summary what these experiments have given us in regard to each important physiological function. The following table will aid our survey.

Table XVI

\begin{tabular}{|c|c|c|c|c|c|c|c|c|c|c|c|c|}
\hline & $\begin{array}{c}2 \\
\text { Before }\end{array}$ & the $\mathrm{c}$ & $\begin{array}{c}4 \\
\text { ompres }\end{array}$ & $\begin{array}{c}5 \\
\text { sion }\end{array}$ & $\begin{array}{c}6 \\
\text { Duri }\end{array}$ & ${ }^{7}$ & $\stackrel{8}{8}$ & $\begin{array}{r}9 \\
\text { sion }\end{array}$ & $\begin{array}{c}10 \\
\text { After }\end{array}$ & $\begin{array}{c}11 \\
\text { the }\end{array}$ & 12 & 13 \\
\hline $\begin{array}{l}\text { Experimer } \\
\text { numbers }\end{array}$ & 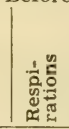 & 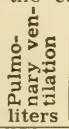 & 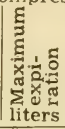 & $\frac{0}{3}$ & 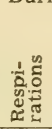 & 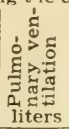 & 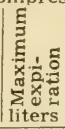 & $\frac{\mathscr{D}}{3}$ & 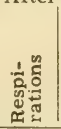 & 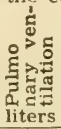 & 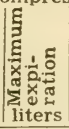 & 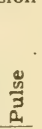 \\
\hline CCCXXII & 8 & & 3.7 & 78 & 8.2 & & 4.0 & 72 & & & 3.7 & \\
\hline $\mathrm{CCC} 2$ & 7.6 & 6.3 & 3.8 & 68 & 8.1 & 6.5 & 4.0 & 69 & & 6.2 & & 60 \\
\hline CCCXXIII & 9 & 6.5 & 3.75 & 78 & 7.5 & 5.86 & 4.08 & 62 & & 6.28 & 3.8 & 65 \\
\hline CCCXXIV & - & 6.54 & 3.76 & 81 & 8.3 & 6.74 & 3.96 & 79 & 8 & - & 3.81 & 59 \\
\hline $\mathrm{Cr}$ & & & & 68 & & & 3.92 & 82 & & & 3.80 & 68 \\
\hline CCCXXIV & 6.5 & - & & 85 & 6.6 & & & - & 5.6 & & & 58 \\
\hline Ave & 7.7 & 6.4 & 3.75 & 76 & 7.7 & 6. & 3.99 & 73 & 6.8 & 6.2 & 3.78 & 62 \\
\hline $\mathrm{CCCX}$ & 15.6 & 12.28 & 4.15 & 70 & 14.6 & 13.22 & 4.64 & 57 & 16. & 13.2 & 4.60 & 56 \\
\hline
\end{tabular}

Respiration. The number of respirations (Columns 2 and 6), which is, as we know, always very difficult to measure exactly on one's self, has sometimes slightly increased, sometimes diminished; the average is the same for compressed air and for normal pressure at the beginning; I do not count Column 10 in which only two figures are listed.

The amount of pulmonary ventilation (Columns 3 and 7), that is, the quantity of air which passes through the lungs during a minute when the respirations are calm, also remained the same. 
We may conclude that variations are in a general way very slight. This point, which had not been clearly determined by the authors who preceded me, is of great importance, as we shall show later.

Finally, my experiments show, as all observers had already noted, a considerable increase of the maximum pulmonary capacity (Columns $4,8,12$ ). On the average, the strongest expiration which I can make rose from 3.75 liters to 3.99 liters; this is an increase of $240 \mathrm{cc}$. that is, $6.9 \%$. In M. Regnard it was $450 \mathrm{cc}$., or $11 \%$. After the decompression I rapidly returned to the normal state.

Circulation. The average pulse rate decreased considerably during the stay in compressed air; from 76 at the beginning, it became 73 at the maximum of the compression and 62 when I left the cylinder.

But I must say that the apparent clearness of this result is decidedly lessened by the fact that at normal pressure my pulse, when taken at the same hours, that is, at the same time after lunch and after a seated rest of several hours, gave variations which were absolutely of the same order.

Metabolism. My experiments are very few; but they have been conducted with the greatest physiological precautions. The analysis of the air expired quietly for 10 minutes gives me (Experiment CCCXXII) for one hour at normal pressure 15.858 liters of carbonic acid; at the maximum of the compression $(56 \mathrm{~cm}$.), it gave 16.260 liters, an increase of 0.418 liters, or $26 \%$.

The production of urea (Experiment CCCXXIII) gave a more interesting result; under the influence of compressed air, it increased considerably (from $20.15 \mathrm{gm}$. it rose to $24.72 \mathrm{gm}$., then to $26.04 \mathrm{gm}$.) to fall again under normal pressure to amounts near its original rate (21.18 gm.; 20.80 gm.; $22.50 \mathrm{gm}$.). So that, on the average, at normal pressure it was $21.9 \mathrm{gm}$. and rose to $25.3 \mathrm{gm}$. in air compressed to $+53 \mathrm{~cm}$.

I shall take the opportunity, in the third part of this book, to compare these figures with those obtained by M. G. Liebig and M. Pravaz in recent investigations.

\section{B. Production of Urea: Experiments on Dogs.}

I tried again to measure the modifications caused in the production of urea by experimenting on dogs. I kept them, of course, on a strict diet; the urine was collected by catheterization once every 24 hours and added to what the animal voided spontaneously.

Here are the results of one of these experiments, which no accident hindered. 
Experiment CCCXXVI. February 9. Dog weighing 10.8 kilos, kept on a diet and used to staying in cages and in the compressed air apparatus in Figure 33.

February 12 at 6 o'clock in the evening, catheterized.

February 13. Remained at normal pressure; catheterized at 6 o'clock in the evening; in 24 hours gave $650 \mathrm{cc}$. of urine . . . . A

February 14. From 9 o'clock in the morning to 5:45, kept under current of air at the total pressure of three atmospheres. Catheterized at 6 o'clock; gave in all $610 \mathrm{cc}$. of urine. . . . . B

February 15. Same pressure; urine of 24 hours, 1080 cc. . . . . C

February 16. Normal pressure; urine of 24 hours, 1350 cc. . . . D

February 17. Normal pressure; urine of 24 hours, 1370 cc. . . . . E Analysis of urine by the Yvon method.

A (normal pressure) contained $7.9 \mathrm{gm}$. of urea.

B (3 atmospheres) contained $10.4 \mathrm{gm}$. of urea.

C (3 atmospheres) contained $9.0 \mathrm{gm}$. of urea.

D (normal pressure) contained $9.1 \mathrm{gm}$. of urea.

E (normal pressure) contained $8.4 \mathrm{gm}$. of urea.

It is quite evident that since the catheterization was made immediately after the decompression, urine $\mathrm{D}$ contained a part of the products of katabolism formed during the stay in compressed air; it ought therefore to be included in the urine of the compression. Taking this into consideration, we see that the urea increased as a result of the daily stay of 9 hours in air at 3 atmospheres; indeed, it rose then on the average to $9.5 \mathrm{gm}$., while at normal pressure it was on the average only $8.1 \mathrm{gm}$.

\section{Chemical Phenomena of Respiration.}

I made a certain number of attempts to estimate the quantity of carbonic acid formed by an animal placed sometimes at normal pressure, sometimes at increased pressure without exceeding 5 atmospheres. But I encountered experimental difficulties which prevented me from reaching a conclusion.

To obviate these difficulties, instead of compressed air I used superoxygenated air, and adapted slightly the apparatus set up in my laboratory by my two assistants, MM. Jolyet and Regnard, an apparatus which is both a simplification and an improvement of the Regnault and Reiset apparatus.

Here is a short description of it, which Figure 65 will allow the reader to follow easily.

The experimental animal is placed under the bell $\mathrm{C}$, which is provided with a thermometer $t$, a manometer $m$, and a little rubber bag $v$, intended to offset the influence of outside modifications of the barometric pressure, which must be taken into account in experiments which may last several days. 
The air of this bell is constantly purified of the carbonic acid produced in it by the respiration of the animal, by action of pipettes $\mathrm{P}$ and $\mathrm{P}^{\prime}$ and the washbottle $\mathrm{A}$. Bottles and pipettes contain a very much concentrated solution of potash, the $\mathrm{CO}_{2}$ content of which was previously determined by the mercury pump and an acid; they

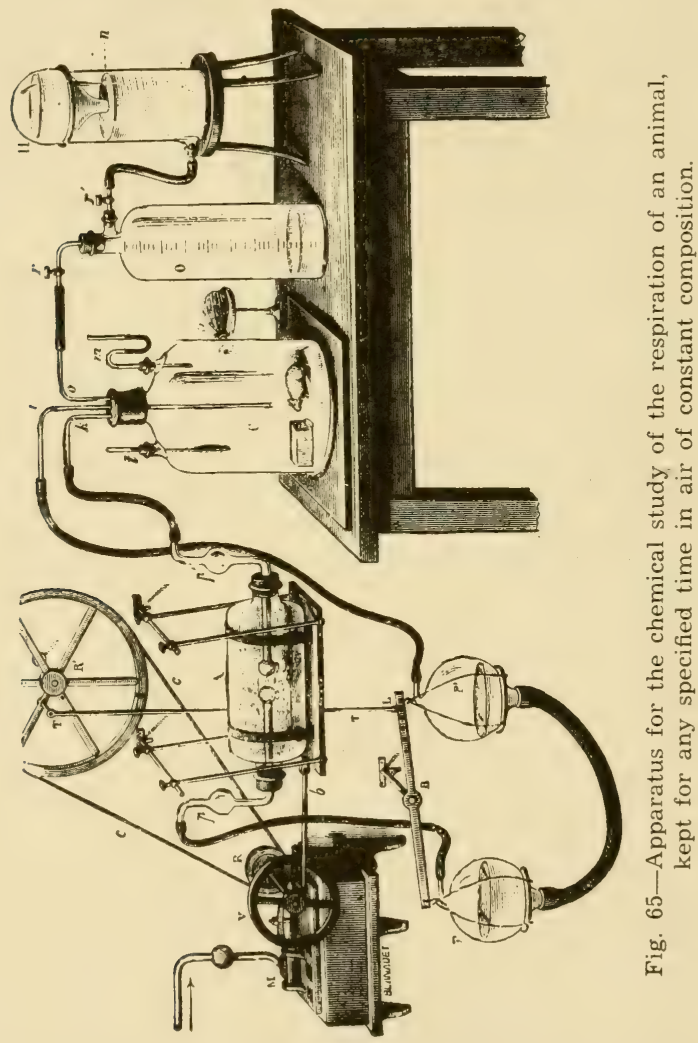

are operated by a liftle water motor $\mathrm{M}$, and a set of pulleys and eccentrics which can be understood by a mere inspection of the figure; the agitation of flask $\mathrm{A}$ is so energetic that it seems filled with foam. The air which passed through the alkaline solutions following the course iP'PpAp' $K$, returns to the bell absolutely freed of its $\mathrm{CO}_{2}$. 
But the animal consumes oxygen, and consequently there is a tendency towards a diminution of pressure in the apparatus. Now pure oxygen, obtained by decomposition of water by a battery, is contained in the graduated flask $\mathrm{O}$, and by means of an apparatus with constant level $\mathrm{H}$, filled with a concentrated solution of calcium chloride, the oxygen comes bubble by bubble to replace what was removed by respiration.

When the experiment is over, a simple reading on the graduated bell gives the quantity of oxygen consumed; for the carbonic acid produced, the potash solution is collected, and analyzed in the presence of an acid in the vacuum of the mercury pump.

Experiment CCCXXVII. Rat weighing $360 \mathrm{gm}$., accustomed for about ten days to living in the bell under a current of air, with its food and its box. air.

1.) December 23 , at 3 o'clock, the experiment begins in ordinary

At the end of 24 hours, the experiment is stopped; we find that the animal has consumed 12.360 liters of oxygen, and formed 7.310 liters of carbonic acid.

The temperature of the rat before the experiment was $38.5^{\circ}$; afterwards it was $38^{\circ}$.

2.) December 25 , at 4 o'clock, a current of oxygen is passed through the bell in which the rat is kept and through the apparatus. Then, since the system is closed, the pipettes are operated for a quarter of an hour to mix the air of the different receivers. Then a sample is taken which gives $87.5 \%$ of oxygen.

After 24 hours, experiment stopped; the oxygen consumption was 11,352 liters; the carbonic acid production was 6.964 liters.

Temperature of the rat: before, $38^{\circ}$; after, $37.5^{\circ}$.

3.) January 3 , at 3 o'clock, performed the experiment again in ordinary air.

In 24 hours, the oxygen consumption was 12.840 liters; the production of carbonic acid 6.820 liters. oxygen.

4.) January 5 , at 3 o'clock, experiment in air with $48.7 \%$ of

In 24 hours, the oxygen consumption was 13.724 liters; the carbonic acid production 10.320 liters.

Summarizing, if we change oxygen percentages to their equivalents in barometric pressure, we shall say that there were

At 1 atmosphere, 12.60 liters of oxygen consumed, 7.06 liters of $\mathrm{CO}_{2}$ formed.

At 2.3 atmospheres, 13.72 liters of oxygen consumed, 10.32 liters of $\mathrm{CO}_{2}$ formed.

At 4.2 atmospheres, 11.35 liters of oxygen consumed, 6.96 liters of $\mathrm{CO}_{2}$ formed. 
The activity of organic combustions then increased at first, and then diminished, after passing a certain maximum which is probably above 2 atmospheres.

Cold-blooded animals gave me a similar result. But for them it was not necessary to use such a complicated apparatus, considering the low level of their respiration. The arrangement of the equipment was the same as in the experiments made on tissues (Chapter VI), represented in Figure 74; the animal was placed in the flask, raised on a little tripod which prevented it from touching the potash solution.

Experiment CCCXXVIII. January 11. Three frogs (A, B, C), nimble and healthy, are placed each in one of these apparatuses. The temperature is $15^{\circ}$.

A weighs $28 \mathrm{gm}$. and is placed in ordinary air;

B weighs 20 gm., air with $56.3 \%$ of oxygen;

C weighs 20 gm.; air with $92.5 \%$ of oxygen.

The animals are left in these conditions until January 15.

We then made the analysis of the potash solutions and read the graduated bells. The result was

A consumed $205 \mathrm{cc}$. of oxygen and produced --_- of $\mathrm{CO}_{2}$.

$\mathrm{B}$ consumed $157 \mathrm{cc}$. of oxygen and produced $71.8 \mathrm{cc}$. of $\mathrm{CO}_{2}$.

$\mathrm{C}$ consumed $114 \mathrm{cc}$. of oxygen and produced $62.8 \mathrm{cc}$. of $\mathrm{CO}_{2}$.

If we take account of the different weights of these different animals and if we reduce them all to $20 \mathrm{gm}$., we see, when we reduce the oxygen content of the air to corresponding values in barometric pressure, that there was:

At 1 atmosphere, $146 \mathrm{cc}$. of oxygen consumed and _... of $\mathrm{CO}_{2}$ produced.

At 2.7 atmospheres, $157 \mathrm{cc}$. of oxygen consumed and $71.8 \mathrm{cc}$. of $\mathrm{CO}_{2}$ produced.

At 4.4 atmospheres, $114 \mathrm{cc}$. of oxygen consumed and $62.8 \mathrm{cc}$. of $\mathrm{CO}_{2}$ produced.

This experiment brings us to the same conclusions as the preceding in regard to the intra-organic combustions.

\section{Pulmonary Capacity.}

The experiments which I reported some pages back corroborated the statement of the earlier authors that the maximum inspiration is greater in compressed air than at normal pressure.

Since this modification is rather considerable and since it is the instantaneous result of the increase of the ambient pressure, I was led to believe that it is due to a mechanical action, acting, of course, upon the only compressible part of our body, that is, the intestinal gases. The mere diminution in volume of these gases should, in my opinion, have as its result an increase of the thoracic cavity, since 
the diaphragm drops at the same time as the abdominal wall, following the retreat of the intestines.

For the purpose of confirming this and of measuring the increase thus gained, I made the following experiment:

A dog was killed by section of the medulla; immediately after, his thoracic capacity was measured by the accurate procedure devised by $M$. Gréhant; ${ }^{5}$ then there was introduced into his trachea a tube in the shape of a $\mathrm{Y}$, one of the branches of which opens into the air, while the other communicates with a rubber bag carefully emptied of air; two valves arranged in opposite directions permit the outer air to enter by the first branch, whereas it cannot, once it has entered the lungs, escape except through the second branch into the bag. When these arrangements had been made, the body of the animal was placed in a compression apparatus. Its lungs, in communication with the air, could undergo the changes in capacity the existence of which we were seeking to verify. Then a sudden decompression was made; the air in the lungs, which was then in excess, escaped and lodged in the bag, where we could measure its volume, which would indicate whether there was an increase in the thoracic capacity.

Here is the simple formula which serves to find and calculate this increase.

Let us call the pulmonary capacity at normal pressure $\mathrm{C}$, the compression (total number of atmospheres) to which the animal was subjected $P$, and the volume of air found in the bag after the decompression V. It is evident that the formula $\frac{\mathrm{C}+\mathrm{V}}{\mathrm{P}}$ will represent the pulmonary capacity during the compression, and the comparison of the number thus obtained with $\mathrm{C}$ will show the value of the increase.

When this had been established, I ligated the intestinal tube at its two ends, anus and esophagus, and collected the gases from it under water; it was interesting to see the relation between their volume and that of the thoracic variations.

Experiment CCCXXIX. June 27. Dog of 4.250 kilos, which had just been poisoned by curare.

It was placed, prepared as was just explained, in the cylindrical apparatus, and the pressure was raised to 3 atmospheres; after the decompression there were $260 \mathrm{cc}$. of air in the bag.

The lungs and trachea of the animal, carefully extracted, and macerated under water, after being cut into pieces so small that the fragments sank to the bottom of the water, gave up only $115 \mathrm{cc}$. of air. 
There was, therefore, a $15 \mathrm{cc}$. increase in volume.

The digestive tube contained $60 \mathrm{cc}$. of gas, $45 \mathrm{cc}$. of which was in the small intestine. At 3 atmospheres, the volume would be only $20 \mathrm{cc}$. So the $40 \mathrm{cc}$. decrease was filled about one third by the diaphragm and two thirds by the abdominal wall.

Experiment CCCXXX. June 28. Dog weighing 8.7 kilos, killed by section of the medulla.

The pulmonary capacity was $300 \mathrm{cc}$.

After the pressure had been raised to 3 atmospheres, there were $750 \mathrm{cc}$. in the bag.

According to the formula given above, the increase in the thoracic capacity was $50 \mathrm{cc}$.

The compression was begun again and raised to 6 atmospheres. At the decompression there were in the bag 2000 cc.; the increase in this case was 83 cc.

There were in the alimentary canal $160 \mathrm{cc}$., which at 3 atmospheres was reduced to $53 \mathrm{cc}$. (decrease of volume: $107 \mathrm{cc}$.), and at 6 atmospheres amounted to only $27 \mathrm{cc}$. (decrease: $133 \mathrm{cc}$.).

Experiment CCCXXXI. July 3. Dog weighing 8.4 kilos, killed the day before.

The pulmonary capacity was 369 cc.

Compression made to $100 \mathrm{~cm}$. of mercury (total pressure). The bag then contained $157 \mathrm{cc}$.

The real volume is derived from the proportion $100: 76=$ $(369 \mathrm{~cm} .+157=526 \mathrm{cc}):. \mathrm{x}=399 \mathrm{cc}$; that is, an increase of $30 \mathrm{cc}$.

Experiment CCCXXXII. July 13. Dog weighing 6.63 kilos.

The pulmonary capacity is $196 \mathrm{cc}$.

Compression made to 3 atmospheres, then there was in the bag 512 cc. of air.

The pulmonary capacity then was $236 \mathrm{cc}$; an increase of $40 \mathrm{cc}$.

Experiment CCCXXXIII. July 26. Dog weighing 5.5 kilos, killed by curare.

Pulmonary capacity 232 cc.

Taken to 3 atmospheres; the bag contained 627 cc.; the capacity then was $286 \mathrm{cc}$, an increase of $54 \mathrm{cc}$.

Taken to 6 atmospheres; the bag contained $1535 \mathrm{cc}$; therefore the capacity was $294 \mathrm{cc}$, or an increase of $62 \mathrm{cc}$.

So our anticipation was realized; the pulmonary capacity increased in compressed air, by a simple physical effect, without any active intervention of the respiratory muscles. But this increase represented only a fraction of the decrease in volume of the intestinal gases. Furthermore, my experiments show that it is far from increasing proportionally to the pressure; so in Experiment CCCXXX, at 3 atmospheres it was $16 \%$ of the initial capacity, and at 6 atmospheres only 26\%; in Experiment CCCXXXIII, at 3 atmospheres, it was $23 \%$, and at 6 atmospheres only $26 \%$; even 
more, in Experiment CCCXXXI, with only a third of an atmosphere, it was $8 \%$. That is easily understood, because in its descent upon the abdomen the diaphragm must meet more obstacles than the walls of the belly.

E. Intra-Pulmonary Pressure.

We have known for a long while that at the beginning of the inspiration, the air contained in the chest is a little rarefied, and that it is a little compressed at the beginning of the expiration, that, in other words, as I have said elsewhere, "the glottis does not suf-

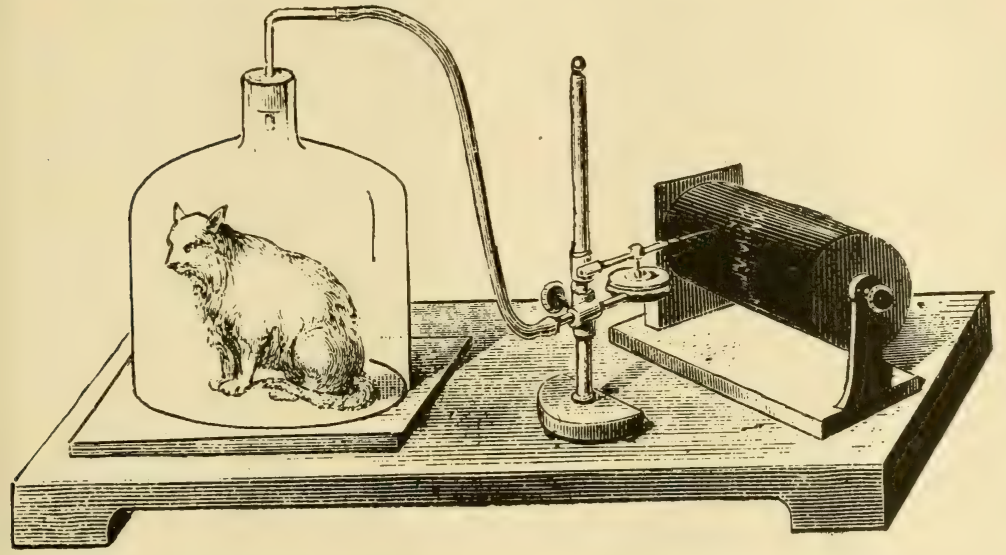

Fig. 66-Apparatus for the observation of variations of the intrapulmonary air tension.

fice for the output of the respiratory pump." Are these variations in the intra-pulmonary pressure, which have such an important influence on the course of the blood the same in compressed air as in normal air? We have seen that Pravaz did not hesitate to consider them increased; but he did not furnish, any more than Vivenot and the other doctors who adopted his opinion, any experimental proof to support his word. To study this difficult question, I used an experimental method which I published long ago. ${ }^{6}$ An animal is placed under a tubular bell which is well ground to fit its base (Figure 66), through the stopper of which passes an elbow tube, which is attached to a Marey polygraph by a rubber 
tube. The oscillations of the needle, which correspond to the respiratory movements, are, as I have shown, caused by the changes of the intra-thoracic pressure, and their size gives a relative measure of it.
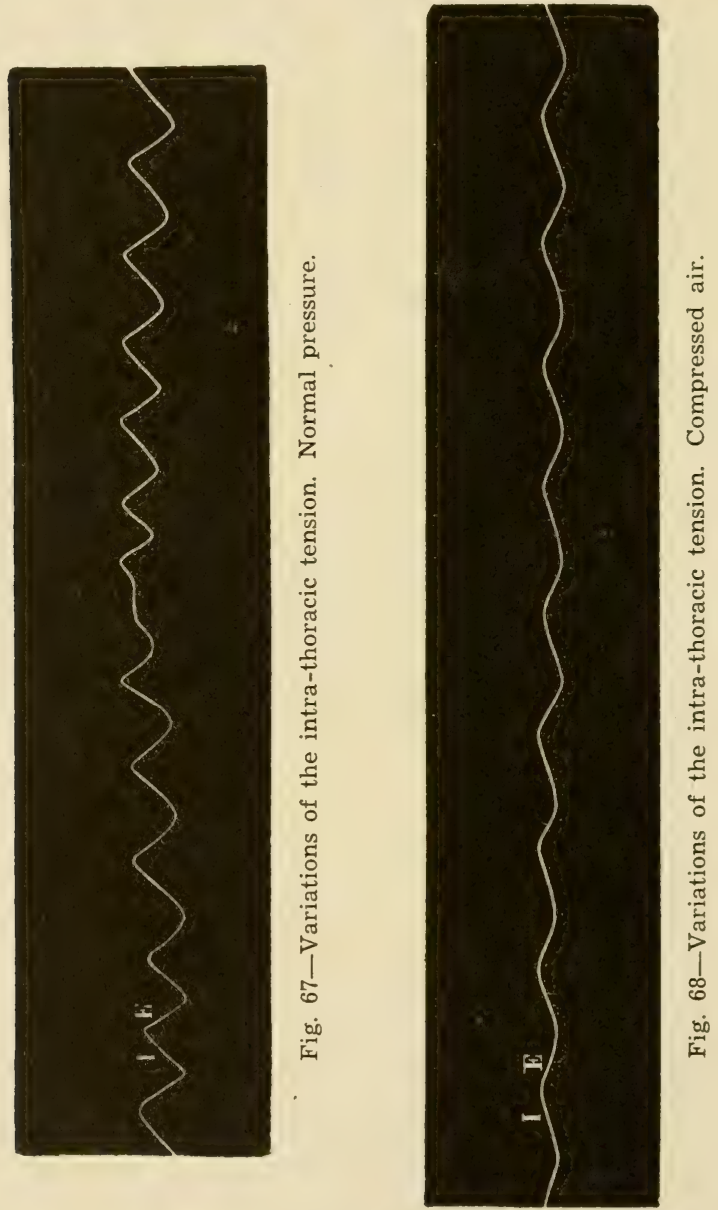

It is very simple then to examine the tracings one obtains, either at normal pressure or in compressed air. The only precautions to 
be taken are to ventilate the bell properly before inserting the stopper, to make a record only when the animal is very calm, and for compressed air, to avoid variations of pressure during the recording. bell.

Experiment CCCXXXIV. February 12. A cat is placed under the

At normal pressure it gives the tracing in Figure 67.

We take it into the compression cylinder and in about an hour, reach a compression of $+53 \mathrm{~cm}$. (total pressure $128 \mathrm{~cm}$.) We then obtain the tracing in Figure 68.

Examination of these two tracings shows: 1) that the number of respirations has diminished (in the proportion of 10 to 7) ; 2) that the amplitude of the oscillations has likewise diminished, that is, that the variations of the intra-thoracic air pressure were less in compressed air than at normal pressure.

F. Arterial Pressure.

The increase of the arterial pressure under the influence of compressed air has been admitted on the strength of the sphymographic tracings of Vivenot; but no direct experiment had been made, or rather had succeeded, in the aim of ascertaining by the manometer the direction and the amount of the modification.

I have tried to fill this gap by the following experiments.

Experiment CCCXXXV. February 17. Dog of average size, new subject, fastened upon the dog board.

Ludwig's recording manometer, attached to a cannulated femoral artery, gives the tracing of Figure 69, in which the low points are $5.5 \mathrm{~cm}$. above the zero line, which indicates a pressure of $11 \mathrm{~cm}$., and

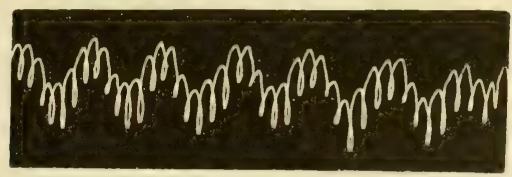

Fig. 69-Tension of the blood in the femoral artery. Normal pressure.

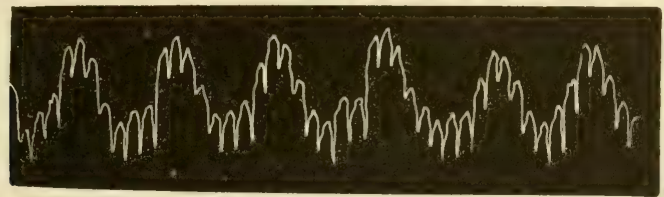

Fig. 70-Tension of the blood in the femoral artery. Compressed air. 
the highest points at $6.7 \mathrm{~cm}$, or a pressure of $13.4 \mathrm{~cm}$., so that the amount of the respiratory oscillation is $2.4 \mathrm{~cm}$., and the average pressure $12.2 \mathrm{~cm}$.

The animal is then placed in the compression apparatus, and a pressure of $+53 \mathrm{~cm}$. is reached in 45 minutes. Then we obtained with the same artery the tracing in Figure 70; low pressure $12 \mathrm{~cm}$; high pressure $15.6 \mathrm{~cm}$; average $13.8 \mathrm{~cm}$; amount of oscillation $3.6 \mathrm{~cm}$.

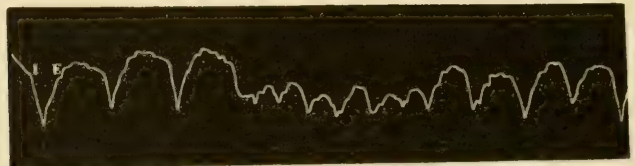

Fig. 71-Tension of the blood in the carotid artery. Normal pressure.

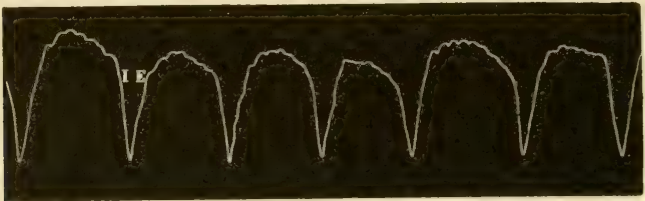

Fig. 72-Tension of the blood in the carotid artery. Compressed air.

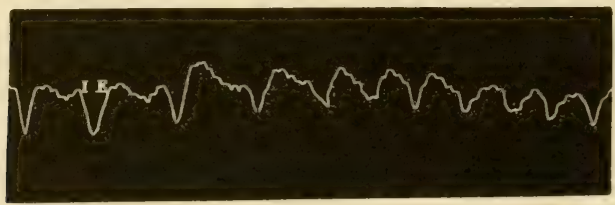

Fig. 73-Tension of the blood in the carotid artery. Normal pressure.

The pulse rate dropped from about 216 to 200 , and the respiratory rate from 41 to 29 per minute.

Experiment CCCXXXVI. February 23. Large dog, new subject, strong, in which a subcutaneous injection of $10 \mathrm{cg}$. of chlorhydrate of morphine had been made to quiet its constant struggling. It slept during the entire experiment.

At normal pressure we obtained the tracing of Figure 71 from a carotid artery.

After the doors had been closed and the pressure raised in three quarters of an hour to $53 \mathrm{~cm}$., we got the tracing in Figure 72.

Finally, after return to normal pressure in 5 minutes, we traced Figure 73. 
The experiment is summarized as follows.

\begin{tabular}{|c|c|c|c|c|c|}
\hline & $\begin{array}{r}\text { Minimum } \\
\text { Pressure }\end{array}$ & $\begin{array}{l}\text { Maximum } \\
\text { Pressure }\end{array}$ & $\begin{array}{l}\text { Average } \\
\text { Pressure }\end{array}$ & $\begin{array}{l}\text { Respiratory } \\
\text { Oscillations }\end{array}$ & $\begin{array}{l}\text { Number of } \\
\text { Respirations }\end{array}$ \\
\hline Tracing A & $5.2 \mathrm{~cm}$. & $7.2 \mathrm{~cm}$. & $5.8 \mathrm{~cm}$. & 3 to $10 \mathrm{~mm}$ & 48 \\
\hline Tracing B & $8.8 \mathrm{~cm}$. & $13.4 \mathrm{~cm}$. & $10.4 \mathrm{~cm}$. & 16 to $23 \mathrm{~mm}$ & 28 \\
\hline Tracing C & $8.0 \mathrm{~cm}$. & $11.0 \mathrm{~cm}$. & $9.8 \mathrm{~cm}$. & 3 to $14 \mathrm{~mm}$ & 40 \\
\hline
\end{tabular}

Now comes the question: What is the reason for these variations in the circulatory phenomena? Should they be attributed to the action of the superoxygenated blood on the heart and the nervous system which controls this organ and the movements of respiration? Or, on the contrary, are they the consequence of the decrease in volume of the intestines, reacting on the play of the intrathoracic organs?

We might discuss this point at length. The surest method is to experiment. If we take the arterial pressure tracings of a dog which breathes first ordinary air and then air with an oxygen content of about $35 \%$, which corresponds nearly to the tension obtained in our compression apparatuses, we find that in spite of a certain slowing down of the respiratory movements, when the animal is breathing the superoxygenated air, the arterial pressure is not modified, and that the play of the thorax influences it equally in both cases.

It becomes evident by comparison of these results that:

1). The pressure of the blood (maximum, minimum, average) has increased in compressed air;

$2)$. The variation due to the respiratory influence has increased considerably in compressed air, which is contrary to the conclusions of Vivenot, which were based, moreover, on observations made on emphysematous patients;

3). These variations were accompanied by a slowing down of the respiration;

4). They are due not to the action of the oxygen absorbed in greater quantity by the blood, but to the pressure, as an agent of the mechanical type.

\section{Prolonged Stay in Compressed Air.}

In this second section I shall enumerate the experiments which were designed to determine whether a slight increase in the oxygen tension can act favorably or unfavorably on the life of animals, on their development, in a word, on the phenomena of their existence as a whole, outside all physiological analysis. To study this important question, I experimented upon eggs, cocoons, small air- 
breathing or aquatic animals; I used sometimes compressed air, but more often, for ease in arranging the experiments, air in which the oxygen content had been increased.

Let us now discuss the experiments.

Experiment CCCXXXVII. July 31. Placed in two large balloon flasks, a certain number of fly pupae of the same age.

A, the balloon flask is full of air.

$B$, the balloon flask is full of oxygen.

August 9. 6 emergences of flies in A, none in B.

August 10. All emerged in A, almost all in B.

Experiment CCCXXXVIII. June 23. Silkworm cocoons, of the same day (this experiment was made at the same time as Experiment CCCXV).

A, 12 were placed under an open bell.

B, 12 in a flask of 3 liters, at a pressure of 2 atmospheres.

C, 6 in a Seltzer water receiver with a capacity of 1 liter, at 5 atmospheres of air.

The air in B and C was changed every other day.

July 8. A, all emerged.

$\mathrm{B}$, all the chrysalises were very active; 2 were transformed but remained in their cocoons.

C, the chrysalises were motionless; but when the skin was removed from some of them, the butterfly was almost complete, with some reflex movements.

$\mathrm{B}$ and $\mathrm{C}$ were placed in the open air.

July 15. B, one butterfly out of the cocoon and alive; a few others transformed, but remaining in the cocoon and dead; under the skin of the remaining chrysalises, the butterfly was found ready to emerge, but dead.

$\mathrm{C}$, all the chrysalises were dead, without having made any movements in the open air; under the skin of the chrysalis, the butterflies were downy, but not far advanced.

Experiment CCCXXXIX. April 15. Frog eggs already somewhat bilobed, placed in equal numbers in a similar quantity of water; in addition, 5 tadpoles which had emerged 4 days before.

$A$ and $A^{\prime}$, under closed bells, ordinary air.

B and B', under bells with $95 \%$ of oxygen, recently prepared by chlorate of potash, well washed over potash and having remained 2 hours over pure water.

These 4 bells were inverted over plates full of water and I placed in the water outside, several tadpoles which were to serve as controls.

April 25. A and A', all emerged and very lively.

B and B', all dead, after the eggs had developed almost to the point of emerging.

The controls are all in good shape. 
Experiment CCCXL. April 28. Frog tadpoles that had emerged 8 or 10 days before, in equal numbers.

A, A', bells inverted over water, full of ordinary air.

B, B', bells arranged in the same way, filled with $95 \%$ oxygen, well washed.

Controls outside the bells as in the preceding experiment.

May 1. All living.

May 3. The controls and the tadpoles in $\mathrm{A}$ and $\mathrm{A}^{\prime}$ are living; those in $\mathrm{B}$ and $\mathrm{B}^{\prime}$ are all dead.

Experiment CCCXLI. May 8. Tadpoles; experiment prepared like the two preceding, with the same oxygen kept over very clean water.

May 10, two tadpoles dead in the oxygen.

May 11, all dead in the oxygen, all alive in the air.

Experiment CCCXLII. April 26. Frog eggs, not yet bilobed. In equal numbers, in the same quantity of water, under closed bells.

A in ordinary air.

B in air containing $24 \%$ of oxygen.

$\mathrm{C}$ in air containing $28 \%$ of oxygen.

$\mathrm{D}$ in air containing $51 \%$ of oxygen.

$\mathrm{E}$ was to contain at least $80 \%$ of oxygen; but the analysis could not be made on account of an accident.

May 4. A, large number of tadpoles emerged.

$\mathrm{B}$, almost as many as in $\mathrm{A}$.

C, far less.

$\mathrm{D}$, only 5 or 6 .

$\mathrm{E}$, only 2 .

Later (bell $\mathrm{E}$ having been turned over), the development became equal.

May 21, all the tadpoles in all the bells are well and similar.

Experiment CCCXLIII. May 28. Frog tadpoles; water.

$\mathrm{A}$, in flask in probably $90 \%$ of oxygen.

$\mathrm{B}$, in glass apparatus at 5 atmospheres of ordinary air.

The tadpoles in B die May 30 .

Those in A die May 31.

Experiment CCCXLIV. June 2. Little eels "de la montée"; placed 3 in each jar.

A, under bell full of air.

B, under bell with more than $90 \%$ of oxygen.

$\mathrm{C}$, in the glass apparatus, at 5 atmospheres of ordinary air.

June 4. A, all alive.

B, 1 dead, 2 very sick.

C, 2 dead, the third very sick.

Experiment CCCXLV. April 7. Frog eggs, in nearly equal quantities, in water.
A, under bell full of air.
$B$, under bell full of air with about $55 \%$ of oxygen.
C, under bell full of air with about $65 \%$ of oxygen.
$\mathrm{D}$, under bell full of pure oxygen $90 \%$ to $95 \%$. 
April 10. The young tadpoles are moving in A and B; some are free in A.

April 20. All dead in $\mathrm{C}$ and $\mathrm{D}$; the tadpoles are alive and free in $\mathrm{A}$ and $\mathrm{B}$.

May 1. Same.

May 4. As neither water nor air was changed, there was beginning to be a little putrefaction in the eggs of $\mathrm{A}$ and $\mathrm{B}$; however the tadpoles are still alive.

May 10. All dead; foul odor in A; a little less in B; no odor of putrefaction, but a sort of fishy smell in $\mathrm{C}$ and $\mathrm{D}$.

Experiment CCCXLVI. April 13. Tadpoles.

A, free air.

B, 5 atmospheres of air.

April 20. All alive.

May 1. A, living; B, dead.

Experiment CCCXLVII. June 26. Carp and larvae of midges in great number, in water with algae.

A, under bell full of air.

$\mathrm{B}$, under bell full of air with $85 \%$ of oxygen.

July 5. The animals in B are less lively than those in A; the algae look sick.

July 11. All, algae, carp, larvae, dead in B; on the contrary, all are quite alive in $\mathrm{A}$, the air of which still contains all its oxygen.

Experiment CCCXLVIII. October 4. Larvae of mosquitoes, in great numbers, in water.

A, under a bell full of ordinary air.

$\mathrm{B}$, under a bell full of air with $52 \%$ of oxygen.

C, under a bell full of air with $62 \%$ of oxygen.

$\mathrm{D}$, under a bell full of air with $89 \%$ of oxygen.

November 8. All the larvae are alive under the different bells; in $\mathrm{A}$, a great many are transformed, none in B, C, D.

The experiments which have just been reported were made on vertebrates (fish, tadpoles, and frog eggs) and on invertebrates (chrysalises, larvae of aquatic insects, little aquatic crustaceans); they gave similar results, and this fact permits one, I think, to deduce generalized conclusions.

To me, they seem first to prove that compression to 4 or 5 atmospheres, or, to speak more exactly, oxygen at a tension of 80 and above, has a fatal effect on animals, which is apparent in a few days on cold-blooded animals, and which, of course, would give fatal results much more rapidly in warm-blooded animals.

The second conclusion to be drawn from the experiments is that increase in the oxygen tension above its normal value in ordinary air seemed to bring no advantage, far from it. When any difference is noticeable, it is in favor of normal air; life persists 
longer there; the development of tadpoles or the larvae of insects takes place more quickly there.

It seems then to be demonstrated that, for healthy animals, the ordinary atmospheric pressure provides the best condition of life, and that an increase, if at all considerable, is more to be feared than to be desired.

1De laction torique de lacide pliénique, by MM. Paul Bert and Jolyet. Mémoires de la Société de biologie, 1870 , p. $63-88$

${ }^{2}$ Comptes rendus de l'Académie des Sciences, vol. LXIV, p. 622, 1867.

3 These numbers and those of the following experiments are reduced to $0^{\circ}$ and $76 \mathrm{c}$. pressure.

4 These temperatures, recorded by my thermometer in this experiment and in several others, are certainly too low. speaking absolutely. But that is of little importance, since only the comparison is of interest.

5 Physical researches on the respiration of man. Journal de l'anatomic et de la physiologic of Robin: First year. p. 524; 1864 .

- Lecons sur la physiologie de la respiration, p. 384. 


\section{Chapter V}

\section{INFLUENCE OF CHANGES IN BAROMET- RIC PRESSURE ON PLANT LIFE}

It was impossible not to wonder whether barometric pressure has some direct or indirect effect upon the phenomena of vegetation.

Everyone knows that as one ascends mountains, the vegetation is modified. Certain species disappear, others appear which do not grow in the plains. At great heights, vegetation becomes scanty, and finally disappears.

These changes in the flora have been carefully studied by botanists who realize that not only altitude, but also latitude influence this geographical distribution of a new type. The habitats of certain species or certain groups vary in altitude according to the nearness to or the distance from the equator of the mountain under consideration.

These observations added to the fact that as one ascends the temperature drops and the other fact that certain plants called alpine are found at sea level in cold regions have led botanists to think that the influence of altitude is only the influence of temperature; so that temperature alone is considered by the classic authors as the determining factor of the characteristics of the flora of high altitudes.

There is no proof, however, that diminished pressure in itself is not a factor in these differences; there is no proof that plants of the plain would live at a very low barometric pressure, even if the temperature there satisfied their needs. For plants, in fact, to the absorption of oxygen is added the daily intake of carbonic acid, and the effect of pressure upon these gases is not negligible.

On the other hand, when we investigate the depths of the ocean, we find that plant life ceases at depths which are not very great, 
and that different groups of algae correspond to different levels. Here, it is not to warmth but to light that changes in the bathymetric distribution are usually attributed. The problem is also complicated by the varying content of free oxygen and carbonic acid in the depths. But besides these conditions ordinarily considered, we must not forget the pressure, which may perhaps have some effect.

We realize that these questions cannot be solved by direct observation and that they demand the assistance of experimentation. But we also understand that it is extremely difficult to carry on such experiments. Plants do not betray by immediate signs, as animals do, the painful effects of new conditions. They must be kept under these conditions for a long time to give results. Besides, to live they must have light. Glass apparatuses capable of sustaining decreased pressures are difficult and costly to install. It is still more difficult when we wish to use increased pressure; the small dimensions, the thickness of the glass, the use of cast-iron pieces and protecting grillwork make it almost impossible to carry on experiments under satisfactory conditions.

There is, however, one plant phenomenon which lends itself to experimentation at different pressures, because it takes place in darkness and requires little room; that is germination. It is to such experiments that I have devoted myself almost exclusively.

For vegetation properly so-called, I have often used sensitive plants. This valuable plant was used thus as a reagent, as a kind of warm-blooded plant, as I once called it. ${ }^{1}$

In my bibliographical research, made earlier at the end of my experiments when I was beginning to write the present volume, I found that an early experimenter had already investigated this question, and I quote here his account of his attempt to settle it. ${ }^{2}$

To study the influence of different pressures of the air on vegetation, or rather on the size and form of plants, at the same time I sprouted barley in air rarefied by one half, in which the barometer stood at 14 inches, and in air compressed to double the ordinary pressure, that is, a pressure of $2 \times 28=56$ inches of mercury. In both experiments the seeds were sown in heather compost and equally moistened. Each of the two bells in which the germinating process took place contained about 320 cubic inches of air, and consequently the first contained $320=160$ cubic inches of atmospheric air, and the

second $320 \times 2=640$ cubic inches.

The germination of the barley took place at about the same time in both receivers, and the budding leaflets showed about the same 
shade of green; but at the end of two weeks, there were the following differences in the two bells.

In rarefied air the shoots had reached the height of 6 inches, and in the compressed air 9 to 10 inches. The former were unfolded and soft; the latter were rolled around the stem and were firm. Finally, the former were moistened on the surface, and especially towards the tip, with drops of water, two of which were always opposite each other, whereas the latter were almost dry, especially on the surface. This difference surprised me and my classes; I am inclined to believe that the decrease in the height of plants, as one ascends mountains, is the result rather of decreased pressure than of decreased temperature.

We see that really no conclusion can be drawn from this attempt, since the point of comparison, the control, that is, germination under normal pressure, had been forgotten; a derogation of the rules of the experimental method which is unfortunately too common in naturalists.

\section{Subchapter I}

\section{PRESSURES LOWER THAN ONE ATMOSPHERE}

\section{Germination.}

Let us begin with experiments made at pressures less than that of the atmosphere, and first, by experiments on germination.

Experiment CCCXLIX. May 21. Wheat. Sown on damp earth, in about equal numbers of seeds and covered by bell-jars.

A. Bell of 2.2 liters. Left at normal pressure.

B. Bell of 7.1 liters. Taken to $50 \mathrm{~cm}$. pressure.

C. Bell of 11 liters. Taken to $25 \mathrm{~cm}$. pressure.

May 11. A. The shoots are about $20 \mathrm{~cm}$. high; they are very fine, very green, very numerous.

B. The shoots are not more than $15 \mathrm{~cm}$. high; they are much less numerous, but quite green and erect, although rather sickly in appearance.

C. Not more than $10 \mathrm{~cm}$; shoots scanty, yellow, drooping.

May 27. A: all up and growing green and thick-set.

B : germination much less advanced.

C: Much less yet.

Several times during the experiment there was a leak and a vacuum had to be restored; the air therefore was sufficiently renewed.

The earth was well watered and the air saturated with moisture.

Experiment CCCL. June 17. Barley.

Sown in pots full of earth, in equal number of seeds, and placed immediately:

A. Under a bell of 2.2 liters. Left at normal pressure.

B. Under a bell of 7.1 liters. Taken to $50 \mathrm{~cm}$. pressure.

C. Under a bell of 11 liters. Taken to $25 \mathrm{~cm}$. pressure. 
June 20. They begin to sprout everywhere.

June 21. Already an evident difference.

June 22. A. The numerous, very green, and very stiff sprouts measure about $10 \mathrm{~cm}$.

B. Less numerous, less green; about $8 \mathrm{~cm}$.

C. Still less; about $6 \mathrm{~cm}$.

June 23. I cut all the shoots even with the barley seed; there are 76 in $\mathrm{A}, 36$ in $\mathrm{B}, 25$ in C. I put these shoots in the drying-oven and dry them at 100 degrees for 2 days.

After this time, each shoot in A weighs $8.8 \mathrm{mg}$; each shoot in $\mathrm{B}, 7.1 \mathrm{mg}$; each shoot in C, $6.2 \mathrm{mg}$. earth.

Experiment CCCLI. June 11. Barley and cress on moistened

A. Normal pressure. Bell of 1 liter.

B. Air at a pressure of $12 \mathrm{~cm}$. Bell of 6 liters.

C. Air at a pressure of $8 \mathrm{~cm}$. Bell of 8 liters.

The air is renewed every day.

June 16. The shoots in A are very fine and vigorous; nothing in $\mathrm{B}$ or $\mathrm{C}$.

June 20. B: a few radicles and white molds; C: only molds. $\mathrm{I}$ bring $\mathrm{B}$ and $\mathrm{C}$ to normal pressure; the seeds germinate, those in $\mathrm{C}$ being delayed during the first few days.

I think it unnecessary to report a larger number of experiments; each of the preceding experiments is really multiple because of the number of seeds sown together. The following experiments corroborate their results, which are certainly sufficiently clear.

They permit us to draw the indubitable conclusion that the lower the pressure, the less energetic and rapid is the germination. I call particular attention to the results of Experiment CCCL, to which the system of weighing gave especial precision. They show that at normal pressure each of the barley shoots weighed more than 8 milligrams, whereas at the pressure of $50 \mathrm{~cm}$., they weighed only 7 , and at $25 \mathrm{~cm}$., only 6 .

Furthermore, a much smaller number of seeds germinated at low pressure than at normal pressure. It is rather difficult to understand the reason for this inequality, which was very evident in each experiment; in the same experiment, CCCL, in which the shoots were counted, we found 76 at normal pressure, 36 at 50 $\mathrm{cm}$., and only 25 at $25 \mathrm{~cm}$.

It is even now, therefore, quite evident that germination must take place less rapidly and less surely, for seeds like barley, at high altitudes than on the plain, if we assume that all conditions of humidity, temperature, and the electrical state of the atmosphere are similar.

And now there appears the question which we had to settle 
when we were speaking of animals. Are the slowness and the checking of germination due to the low pressure as a physical condition, or should these phenomena be attributed to the lowered oxygen tension of the air? All that I have said hitherto justified me in maintaining the truth of the latter hypothesis. Nevertheless I wished to test it again by double experimental control, although, it is true, I limited myself to a small number of experiments.

There are two methods to be used, as we have already seen. We can study germinations at normal barometric pressure, but in atmospheres with low oxygen content. Evidently, if in this case we see that germination takes place more quickly in air than in a medium with less oxygen, the lack of oxygen must be the cause.

We can also compare with germinations in air, at normal pressure, other germinations at low pressures but in superoxygenated media, so that the real tension of the oxygen is about equal to that in air under ordinary barometric conditions.

Here first is an experiment made by the first of these methods.

Experiment CCCLII. July 12. Barley sown on wet filter paper; 20 seeds in each plate.

A. Bell of 13 liters; left in air at normal pressure.

B. Bell of 20 liters; I make a vacuum, and admit air in which the oxygen content has been made very low by burning phosphorus. The mixture contains $10 \%$ of oxygen.

It will be noted that the capacity of the bells varies inversely with the quantity of oxygen.

July 16. The sprouts in A are stronger than in B.

July 18. The sprouts in A (air) are $12 \mathrm{~cm}$. on the average; those in B (nitrogen) $10 \mathrm{~cm}$.

July 22. A on the average $21 \mathrm{~cm}$.; B on the average $19 \mathrm{~cm}$.

This experiment shows very clearly that in air with low oxygen content, even if the total quantity is quite sufficient, germination takes place less quickly than in ordinary air.

I did not think I should dwell on this sort of experiments, because the former researches of Senebier, Saussure, Lefébure, etc., although they lack precision from the point of view of chemical analysis of the atmospheric medium, give clear testimony for the same conclusion.

Here are some experiments made by the second method.

Experiment CCCLIII. October 9, 1872. Barley and cress, sown on wet paper.
A. Air at normal pressure.
B. Air at a pressure of $16 \mathrm{~cm}$. 
C. A vacuum is made, then oxygen is admitted until normal pressure has been restored; then the same operation was repeated; finally this superoxygenated atmosphere (the sample of which intended for analysis was unfortunately lost) is brought to a pressure of $16 \mathrm{~cm}$.

October 12, a few seeds begin to germinate in A.

October 14, germination begins in C.

October 16, the sprouts are a little finer in A than in C. of C.

October 19, a few sprouts appear in B; A is still a little ahead

October 23, in A, the barley is $8 \mathrm{~cm}$. high, the cress $3 \mathrm{~cm}$; in $\mathrm{C}$, the barley is $7 \mathrm{~cm}$. high, the cress $3 \mathrm{~cm}$., but its sprouts are not quite so fine as in A; B has only one barley sprout $6 \mathrm{~cm}$. high at most, and the cress is only $1.5 \mathrm{~cm}$. high.

Experiment CCCLIV. November 4. Sowing of barley and cress on wet paper (a score of seeds).

A. Air at normal pressure.

B. Air at a pressure of $15 \mathrm{~cm}$.

C. $71 \%$ of oxygen, brought to a pressure of $20 \mathrm{~cm}$., which corresponds to $18 \%$ at normal pressure.

November 7, a few sprouts appear in A.

November 8 , a few in C.

November 11, beginning of germination in $\mathrm{B}$.

November 25, conditions are as follows:

A. The seeds have all sprouted, the sprouts are very green; the cress is about $2 \mathrm{~cm}$. high, the barley $12 \mathrm{~cm}$.

B. Has risen to $25 \mathrm{~cm}$. pressure. Cress longer, but not so green as in A. Only 3 sprouts of barley, as long as, but thinner and less green than in $\mathrm{A}$.

C. Has risen to $40 \mathrm{~cm}$. pressure (consequently is less oxygenated). The sprouts, very numerous and very fine, are quite like those in $\mathrm{A}$.

These experiments bring us to the same conclusions as the preceding ones. We see, in fact, that seeds sown in superoxygenated atmospheres have sprouted as quickly as in air at normal pressure, in spite of the low barometric pressure to which they were subjected. The low pressure therefore has no effect when the percentage of oxygen is sufficient to maintain the real tension of this gas at a value approximating that in ordinary air at $76 \mathrm{~cm}$.

It is proved then that the delay in germination noted in all the preceding experiments when the barometric pressure is very low is due to low oxygen tension. The seeds do not absorb enough, even though they have at their disposal very great quantities of oxygen in weight. As in the case of blood corpuscles, absorption of oxygen by plant cells is in proportion to the outer tension of this gas.

It was interesting to find out the lower limit of pressure at which germination can take place. The preceding experiments 
show already that it still takes place, though very slowly, at the pressure of $15 \mathrm{~cm}$., a pressure much lower than that of the atmosphere at the summit of the highest mountain, Mount Everest in the Himalayas.

The following experiments answer this question.

Experiment CCCLV. December 14. Barley (about a dozen seeds) and cress on wet paper. Bells of 1.5 liters.

A. Air; normal pressure.

B. Air; pressure of $6 \mathrm{~cm}$; the oxygen tension corresponds to $76: 6=21: \mathrm{x}=1.6 \%$ at normal pressure.

December 17. A. A few seeds of cress have split their coverings.

December 20. A. All the seeds of cress have split their coverings; a few seeds of barley have sent out radicles.

B. Pressure of $7 \mathrm{~cm}$; nothing has appeared.

January 14. A. The cress seeds have germinated; the barley shoots are $12 \mathrm{~cm}$. high.

B. Two barley seeds have sprouted; they are $6 \mathrm{~cm}$. high. All the seeds of B, both cress and barley, sprout when brought to normal pressure.

Experiment CCCLVI. March 11. 40 seeds of barley and cress sown on wet filter paper.

A. At normal pressure.

B. In a bell of 7 liters, brought to a pressure of $4 \mathrm{~cm}$.

March 28. A. All sprouted; the barley has sprouts 4,5 , and $6 \mathrm{~cm}$. high; B, in which the air was changed March 15, 18, 23 and 26, shows no sign of germination. Pressure is raised to $8 \mathrm{~cm}$.

April 26. The air in B was changed March 31, and April 6, 8, and 11; nothing has appeared yet except molds.

Sown in the air on wet paper.

May 20. Fine shoots of cress, but the barley has not sprouted.

It is therefore at a pressure of about $7 \mathrm{~cm}$. that germination can no longer take place. It is interesting to note that this decompression is exactly that at which warm-blooded animals succumb rapidly, no matter what precautions are taken, and at which coldblooded vertebrates cannot live long.

If we look for the percentage of oxygen to which the oxygen tension at this pressure of $7 \mathrm{~cm}$. corresponds at normal pressure, we find it by means of the following proportion 20.9: $7=76: \mathrm{x}=2.5$. This is very close to the experiments of Lefébure, who showed that germination of the turnip still takes place, although slowly and incompletely, when the air contains only $1 / 32$ of oxygen, that is, $3.4 \%$. 


\section{Vegetation.}

I made also a few attempts to obtain effects on vegetation properly so-called.

Experiment CCCLVII. June 15. Barley.

Seeds of barley in the same quantity sown in three similar pots, full of earth; all left under similar conditions.

June 25. All three sowings have sprouted, but rather unevenly; in the first, the sprouts measure on the average $14 \mathrm{~cm}$.; in the second, $15 \mathrm{~cm}$.; in the third, 16 to 17 .

They are placed under three bells.

A. The least satisfactory sowing; left at normal pressure.

B. The intermediate sowing; taken to a pressure of $50 \mathrm{~cm}$.

C. The best; taken to $25 \mathrm{~cm}$.

June 27. The three sowings have kept their original differences. July 3. Same result.

Experiment CCCLVIII. July 24. Sensitive plants of the same sowing; one in each pot, about $10 \mathrm{~cm}$. high.

A. 4 pots under a bell of 3.5 liters at normal pressure.

B. 4 pots under a bell of 7.1 liters; brought to a pressure of $50 \mathrm{~cm}$. $25 \mathrm{~cm}$.

C. 4 pots under a bell of 11 liters; brought to a pressure of

All are set on plates full of well-moistened earth, and are placed in sufficient light.

The pressure is lowered carefully; the folioles closed when the pressure had been lowered about $20 \mathrm{~cm}$., then opened again later.

In the evening, $\mathrm{C}$ closes its folioles much later than the other two.

July 25. Air has leaked into C; the pressure is about $40 \mathrm{~cm}$. It is lowered to $25 \mathrm{~cm}$. Some folioles and even some leaves are already falling; one or two sensitive plants seem dead.

B. Rather sickly.

A. In good shape.

July 26. C. The pressure has risen to about $45 \mathrm{~cm}$; nevertheless the sensitive plants are all dead.

B. All sickly, some dead.

A. In very good shape; they are growing.

July 27. B. All dead.

A. In good shape.

Experiment CCCLIX. August 1. Sensitive plants like those of the preceding experiment. Two in each bell.

A. Taken to a pressure of $60 \mathrm{~cm}$.

B. Taken to a pressure of $50 \mathrm{~cm}$.

C. Taken to a pressure of $25 \mathrm{~cm}$.

August 3. A few folioles and leaves fall in C.

August 6. 3 o'clock. A. Folioles sensitive and open; B. Halfclosed or not very sensitive; C. Completely closed.

August 7. Brought back to normal pressure.

All are sensitive; C. Much less than the others; C does not close well in the evening.

August 9. A. In good shape; very sensitive; B. Not very sensitive; sickly; yellowish; C. Leaves are falling; dying. 
It is quite certain then that under the influence of low barometric pressures, sensitive plants quickly lose their sensitivity and die. Now we should learn the cause of this death. Should we attribute it, as we have been accustomed, so to speak, to do hitherto, to low oxygen tension? Should we merely blame the expansion of the gases within the plant, an expansion which is due to the decompression and which would be great enough to affect such a delicate plant fatally?

The following experiment answers this question.

Experiment CCCLX. July 25. Two pots, each containing 3 young sensitive plants.

A. Taken to a pressure of $25 \mathrm{~cm}$.

B. Pressure lowered $50 \mathrm{~cm}$., and oxygen admitted then pressure brought to $25 \mathrm{~cm}$. The oxygen tension in this bell corresponds about to that of the air at normal pressure.

July 26. A. Sick.

July 27. A. Dead; B. In good health.

Here again the too low oxygen tension killed the sensitive plants subjected to low pressure.

Finally here is an experiment which, although it was made on an almost microscopic plant, has a certain interest.

Experiment CCCLXI. April 8. Fragments of frog eggs, with a little of Priestley's "green matter."

A. Flask at normal pressure.

B. Flask at a pressure of $25 \mathrm{~cm}$.

April 25. Green matter abundant in A; nothing in B.

So a lowering of the pressure is harmful to vegetation as it is to germination; it kills plants at the same degree at which it kills cold-blooded animals, and completely checks the life of seeds, without, however, killing them entirely.

The unity of the phenomena of respiration in the two kingdoms is emphasized here very clearly.

\section{Subchapter II \\ PRESSURES ABOVE ONE ATMOSPHERE}

\section{Germination.}

Let us now take up experiments made under increased pressure; and first, germination. I have always made my sowings on wet paper, because previous experiments have shown me that the presence of earth complicates the results. 

paper.

Experiment CCCLXII. July 7. Sowings of barley on wet filter

A. Receiver of 1 liter, taken to 1 and $3 / 4$ atmospheres.

B. Similar receiver; normal pressure; well corked.

July 9. B. Begins to sprout; A. Nothing.

July 10. B. The sprouts are about $2 \mathrm{~cm}$. high; they begin to appear in A.

The air is renewed every day.

July 13. B. Sprouts about $12 \mathrm{~cm}$. high; A. Only 8 to $10 \mathrm{~cm}$. high. Experiment stopped.

Experiment CCCLXIII. July 13. Sowings of barley on wet filter paper. 20 seeds in each sowing.

A. Cylindrical receiver holding 650 cc., taken to 5 atmospheres. Air changed every day.

B. Test glass of about the same dimension; left at normal pressure; well corked.

July 16. Germination begins in B.

July 18. In B, the sprouts are about $7 \mathrm{~cm}$. high; germination is beginning in $\mathrm{A}$.

July 20. B. $13 \mathrm{~cm}$; A. 3 to $5 \mathrm{~cm}$.

July 26. B. $18 \mathrm{~cm}$; A. 3 to $5 \mathrm{~cm}$.

Decompression made, the different seeds removed carefully and placed on wet earth.

A. Grows rapidly and nearly overtakes B.

Experiment CCCLXIV. July 31. Sowings of barley on wet paper.

A. Cylindrical receiver taken to 10 atmospheres.

B. Test glass of same volume; normal pressure; well corked.

August 3. Germination begins in B.

I decompress $\mathrm{A}$; but on recharging it, I cannot get it above 7 atmospheres.

August 5. The sprouts in B are 5 to $6 \mathrm{~cm}$. high; in A, only a few radicles have sprouted.

August $7.13 \mathrm{~cm}$. in $\mathrm{B}$; in $\mathrm{A}$, only a few radicles.

I stop the experiment; the air in A, when analyzed, contains no carbonic acid.

A. Sown on wet paper; has not begun to germinate August 10.

Experiment CCCLXV. March 1. Sowings of 30 barley seeds.

A. In the cylindrical reservoir, ordinary air, pressure of $23 / 4$ atmospheres.

B. Closed test glass; normal pressure.

March 4. Air changed.

March 8. Shoots greener and longer in B than in A. Air changed.

March 10. A. 9 seeds not germinated; 11 with radicles only; 10 with pale shoots $2 \mathrm{~cm}$. long.

B. 11 seeds not germinated; 5 with radicles only; 11 with fine green shoots $4 \mathrm{~cm}$. long. 
Experiment CCCLXVI. March 30. Sowings of 20 barley. seeds on the same quantity of paper wet with $10 \mathrm{cc}$. of water.

A. Small Seltzer water receiver; 2 atmospheres of air changed every day, sometimes twice a day.

B. Similar receiver, corked at normal pressure.

April 3. Radicles appearing in both.

April 7. A. Is a little slow, in comparison with B.

Experiment CCCLXVII. April 16. Sowings of 20 barley seeds. Same quantity of paper and water.

A. Small Seltzer water receiver without a wire jacket; taken to $21 / 2$ atmospheres. As this receiver leaks a little, I recharge it at least twice a day, sometimes to 3 atmospheres; this gives sufficient ventilation.

B. Similar receiver, with a jacket, corked; normal pressure; air changed every day.

April 19. Radicles appear in A and B.

April 24. No very clear difference; the shoots are about $6 \mathrm{~cm}$. high, but they are a little paler in A than in B.

April 28. The two sowings are almost identical, measuring 10 to $12 \mathrm{~cm}$. The shoots in A are not as green as those in B, and yet they receive considerably more light.

Experiment CCCLXVIII. April 28. Sowings of 20 barley seeds and radish seeds.

A. In the cylindrical receiver, at 10 atmospheres of air; the air is changed every day, morning and evening.

B. In a vessel poorly corked; normal pressure.

May 7. A. No apparent development; B. The radish sprouts are $1.5 \mathrm{~cm}$. high; the barley sprouts $3 \mathrm{~cm}$. high.

May 12. A. A very few radicles of radish and barley.

B. The radish shoots are 3 to $5 \mathrm{~cm}$. high; the barley, 5 to $8 \mathrm{~cm}$. I make the decompression and sow A on wet paper; the radishes begin to sprout May 16; the barley molds.

Experiment CCCLXIX. June 11. Sowed 20 barley seeds and 20 cress seeds.

A. In the cylindrical receiver, at 5 atmospheres of air; air changed twice a day.

B. In a closed test glass; normal pressure.

June 13. A few radicles of barley and cress in A and B.

June 16. A. The cress has germinated; the barley has not sprouted.

B. Cress finer than in A; barley measuring 1 to $2 \mathrm{~cm}$.

June 18. A. The cress sprouts are $1.5 \mathrm{~cm}$. to $2.5 \mathrm{~cm}$. high; the leaves are not yet unfolded and do not smell of cress; the barley sprouts, to the number of 16 , are beginning to leave their cover, and are $1.5 \mathrm{~cm}$. to $4 \mathrm{~cm}$. high.

B. The cress sprouts, $3 \mathrm{~cm}$., very green, spread out in a rosette, smelling very strong of cress; 20 barley shoots from 8 to $9 \mathrm{~cm}$., some as high as $12 \mathrm{~cm}$. 
Experiment CCCLXX. June 19. Barley and cress on wet paper.

A. Under a bell; normal pressure.

B. 6 atmospheres of air.

Air changed every day.

June 22. A. Cress germinated; little stalks of barley started.

B. Cress hardly shows any sign; a few barley radicles to be seen.

June 29. A. Cress, $3 \mathrm{~cm}$., very green and smelling strong; barley from 12 to $20 \mathrm{~cm}$.

B. Cress, $2 \mathrm{~cm}$., very green and smelling strong; barley, stalks $1.5 \mathrm{~cm}$. high.

Experiment CCCLXXI. August 17. Sowings on wet paper of seeds of marvel-of-Peru, castor beans, and melon, which were decorticated after being kept for two days in water.

A. Cylindrical apparatus at 2 atmospheres of air.

B. Open vessel.

August 18. 9 o'clock in the morning; in A and in B, some marvels-of-Peru have germinated.

I raise $A$ to 6 atmospheres, and change the air every day.

August 23. A. Same condition.

B. The radicles of the melon and castor bean seeds are appearing.

August 26. A. Nothing has sprouted.

B. The marvels-of-Peru are 2 to $3 \mathrm{~cm}$. high; the melon and castor bean seeds have sent out all their roots.

B continues to sprout in the open air, whereas nothing sprouts in $\mathrm{A}$.

These experiments show very clearly that, beginning with a certain pressure, germination is delayed, and that at a higher pressure it does not take place. Furthermore, certain seeds die then and cannot develop when brought back to normal pressure.

But before studying these results in detail, we must once more settle the question which we have encountered several times, and find out whether this fatal effect is due to the pressure itself or to the increased chemical tension of the oxygen.

And here, once more we have the different methods which we are accustomed to using: 1). to make the compression with air with low oxygen content, so that the tension of this gas is equivalent to that of the oxygen in the air at normal pressure; 2 ). to make experiments at normal pressure with air which has a greater oxygen content than ordinary air; 3 ). to use both low pressure and air which is superoxygenated, so that we obtain high tension with low pressure. 


\section{A. High Pressures with Air of Low Oxygen Content.}

Experiment CCCLXXII. July 13. Sowings of barley on wet paper.

A. Receiver at normal pressure, well corked.

B. Similar; taken to 4 atmospheres, 3 of which are of air with very high nitrogen content.

July 14. Raised to only 2 atmospheres. Renewal has been made and is made every day with air of very high nitrogen content.

July 16. 3 atmospheres. Nothing in either A or B.

July 17. A little germination in both.

July 19. A. Sprouts a little stronger than those in B.

July 22. Same.

The air in B. contains $1.7 \%$ of carbonic acid and $11.9 \%$ of oxygen. The oxygen tension at the end was therefore $13.6 \times 3=40.8$.

Experiment CCCLXXIII. November 4. Barley and cress on wet paper.

A. Glass receiver at normal pressure.

B. Cylindrical apparatus, at 8 atmospheres of air with low oxygen content; the mixture contains $5.7 \%$ of oxygen, the tension of which $5.7 \times 8=45.6$ corresponds to about 2 atmospheres of air.

November 7. A, a few seeds have germinated.

November 8. A, a few more; B, nothing. The apparatus leaks, the pressure has fallen to 6 atmospheres; it is raised to 8 with the same air.

November 9. A few barley seeds are germinating in B; in A, the sprouts are already fine.

November 11. Same condition; decompression is made, and the seeds from B are sowed on wet earth. The gas in the apparatus contains $\mathrm{CO}_{2} 3.2 ; \mathrm{O}_{2}$ 1.6; the $\mathrm{CO}$ tension is therefore $3.2 \times 8=25.6$.

November 20. The cress is $3 \mathrm{~cm}$., the barley 5 or 6 .

Experiment CCCLXXIV. August 2. Sowings of barley and cress.

A. Cylindrical apparatus taken to 10 atmospheres of an air which contains $9.8 \%$ of oxygen; the tension of this gas is therefore 98 , corresponding to about 5 atmospheres of air.

B. Test glass, normal pressure.

August 3. I bring $\mathrm{A}$ down to 7 atmospheres; the oxygen tension is only $7 \times 9.8=68.6$, or a little more than 3 atmospheres of air.

August 4. The cress and barley have sprouted in both, but $\mathrm{A}$ is evidently more delayed than $\mathrm{B}$.

It is already plain from these experiments that the oxygen is to blame. In fact, in Experiment CCCLXXII, if we had used ordinary air, germination would have been considerably delayed, whereas it was hardly delayed at all; in the other two experiments, it would have been completely stopped by pressures of 8 and 10 atmospheres, whereas there was only a delay explainable by the oxygen tension, which was already equivalent to 2 atmospheres (Exp. CCCLXXIII) or 3 atmospheres (Exp. CCCLXXIV).

In Experiment CCCLXXIII a new element, the high tension of 
carbonic acid, was introduced and complicated the results. That is why I did not make more experiments by this method, in which it is quite difficult to renew sufficiently an air with low oxygen content.

B. Normal Pressure: Superoxygenated Air.

I now come to the more numerous and much more conclusive experiments conducted by the second method. seeds.

Experiment CCCLXXV. July 12. Barley sown on wet paper; 20

A. Bell of 7 liters; air containing $65 \%$ of oxygen, which corresponds to 3 atmospheres of air.

B. Bell of 13 liters; ordinary air.

July 18. A, the shoots are $8 \mathrm{~cm}$. high; those in B, $12 \mathrm{~cm}$.

July 22. A, an average of $15 \mathrm{~cm}$.; B, an average of $21 \mathrm{~cm}$.

Experiment CCCLXXVI. November 4. Sowings of barley and cress on wet paper. of air.

A. Air with $79 \%$ of oxygen, equivalent to about 4 atmospheres

B. Ordinary air.

November 7. A few seeds germinating in B.

November 9. A few seeds germinating in A.

November 25. A. Only two barley seeds have sprouted, and measure $4 \mathrm{~cm}$.; the cress is about $2 \mathrm{~cm}$; none of the shoots are very green.

B. All the seeds have germinated and are very green; the cress is about $2 \mathrm{~cm}$. high, the barley $12 \mathrm{~cm}$.

Experiment CCCLXXVII. December 7. Twenty seeds of barley and cress on wet paper. Bells of 2 to 3 liters.

$\mathrm{A}$, in air with $65 \%$ of oxygen.

$B$, in air with $40 \%$ of oxygen

C, in air with $31 \%$ of oxygen.

$\mathrm{D}$, in ordinary air.

December 17. The cress has sprouted in all quite equally. The barley is sending out radicles in all.

January 1. A. The barley shoots are $9 \mathrm{~cm}$. high, the stalks are half open, slender, not many; the cress is $2 \mathrm{~cm}$. high; not all of the seeds have germinated.

B. Barley $12 \mathrm{~cm}$., stalks green; cress $2 \mathrm{~cm}$.

C. Barley $13 \mathrm{~cm}$., stalks slender, but closed; cress $3 \mathrm{~cm}$.

D. Barley $10 \mathrm{~cm}$., stalks thick, unfolded, green; cress $2 \mathrm{~cm}$., thick, very green.

January 14. A. Barley $11 \mathrm{~cm}$., stalks faded, slender, scanty; cress $2 \mathrm{~cm}$.

B. Barley $14 \mathrm{~cm}$., stalks green, unfolded; cress $3 \mathrm{~cm}$.

C. Barley $16 \mathrm{~cm}$., stalks long, slender, folded; cress $4 \mathrm{~cm}$.

D. Barley $13 \mathrm{~cm}$., leaves open, very green; cress $3 \mathrm{~cm}$. 
January 20. A. Barley $11 \mathrm{~cm}$., all yellow, dying; B and C, barley $20 \mathrm{~cm}$., stalks yellowish; D, $14 \mathrm{~cm}$., very green.

So $\mathrm{B}$ and $\mathrm{C}$ sent out stalks longer than $\mathrm{D}$, but not as healthy; $A$ is in very bad condition.

Experiment CCCLXXVIII. March 11. 40 seeds of barley and of cress are sown on wet filter paper, and placed:

A. In a bell of 2.5 liters, full of air at normal pressure.

B. Bell of 2.25 liters; normal pressure; air containing $30.2 \%$ of oxygen, which corresponds to about $1 \frac{1 / 2}{2}$ atmospheres of air.

C. Bell of 2.6 liters; normal pressure; air containing $43 \%$ of oxygen, or a little more than 2 atmospheres of air.

D. Bell of 2.5 liters; normal pressure; air with $58.3 \%$ of oxygen, or $23 / 4$ atmospheres of air.

March 29. Experiment stopped; the barley and the cress have sprouted in all four bells; in A and B the sprouts are a little greener and from 1.5 to $2 \mathrm{~cm}$. longer than in $\mathrm{C}$ and $\mathrm{D}$. Besides, the air in $\mathrm{B}$ contains only $17.5 \%$ of oxygen, with $13.4 \%$ of carbonic acid; the air in $\mathrm{C}$ contains $28.2 \%$ of oxygen and $12.3 \%$ of $\mathrm{CO}_{2}$; that in $\mathrm{D}, 44.8 \%$ of oxygen and $11.2 \%$ of $\mathrm{CO}_{2}$; the air in $\mathrm{A}$ has been renewed.

Experiment CCCLXXIX. May 6. Sowings of barley.

A. Air with $94 \%$ of oxygen, that is, $4^{1 / 2}$ atmospheres of air.

B. Ordinary air.

May 13. The barley has sprouted in both; A seems a little better and is greener.

But on the following days, B has the advantage, and on May 20, the sprouts in A are only 2 to $3 \mathrm{~cm}$. high, whereas those in B are 8 to $9 \mathrm{~cm}$. high.

However, the analysis of the air in B discloses no more oxygen, and there is $25.4 \%$ of carbonic acid; in $\mathrm{A}$, there is $19.9 \%$ of $\mathrm{CO}_{2}$, and only $71.6 \%$ of oxygen.

The average oxygen tension then was about 4 atmospheres of air.

\section{Low Pressures : Superoxygenated Air.}

Experiment CCCLXXX. November 4. Sowings of barley and cress on wet paper.

A. At a pressure of 3 atmospheres of an air containing $86.9 \%$ of oxygen. The tension of this gas is then 260, corresponding to about $12 \frac{1}{2}$ atmospheres of air.

B. Normal pressure, ordinary air.

November 7. Nothing in A; a few sprouts in B.

November 11. Nothing in A; all have germinated in B. The air in A still contains $86.2 \%$ of oxygen, with $0.7 \%$ of carbonic acid.

The seeds in A are sown on wet earth. November 20, the cress begins to sprout, but the barley is dead.

Experiment CCCLXXXI. May 31. Sowings of barley seeds on wet paper.

A. $5 \mathrm{gm}$. in the cylindrical reservoir at 3 and $1 / 3$ atmospheres of an air containing $54 \%$ of oxygen; the tension corresponds to 180 , that is, about 9 atmospheres of air. 
B. $8 \mathrm{gm}$., normal pressure, ordinary air, bell of $1840 \mathrm{cc}$.

June 3. No germination. Air changed in B and oxygen changed in A. After this, the air in A contains $46.2 \%$ of oxygen, the pressure is dropped to 3 atmospheres; the tension then is 138 , that is, a little less than 7 atmospheres.

June 7. A. A very few radicles; the pressure has fallen to 2 atmospheres; the air contains $2 \%$ of $\mathrm{CO}_{2}$ and $41.2 \%$ of oxygen.

B. The shoots are 3 to $5 \mathrm{~cm}$. high and are very green. The air contains $8 \%$ of $\mathrm{CO}_{2}$ and $11.2 \%$ of oxygen.

Assuming for $\mathrm{A}$ an average pressure of $2 \frac{1}{2}$ atmospheres, we find that in 4 days, the seeds in A have consumed, per $10 \mathrm{gm}$., $136 \mathrm{cc}$. of oxygen, and those in B $225 \mathrm{cc}$.

The seeds in A are sown on wet earth and develop.

Table XVII summarizes the principal results of the experiments above. They are arranged by the increasing order of oxygen tensions expressed in atmospheres.

The different methods used agree in showing that even a slight increase in oxygen tension acts unfavorably on germination; beginning with two atmospheres or $40 \%$ of oxygen, it is manifestly delayed.

At 5 atmospheres, which corresponds to pure oxygen, the delay in germination is very great.

Above 7 atmospheres, the seeds merely send out a few radicles, no stalk appearing.

Finally, at about 10 atmospheres, the barley seeds, when brought back to normal pressure, are dead and do not germinate, whereas cress seeds are resistant and sprout, although somewhat slowly (Exp. CCCLXXX).

Now cress seeds have thin, dry cotyledons and contain no albumen. I wondered whether the death of the barley seeds did not result from some chemical change in their considerable albumen content.

My experiments on fermentation, which will be reported in this chapter, have convinced me of the truth of this hypothesis. Besides, we see by Experiment CCCLXXI that fleshy seeds like those of the castor bean and melon were much more affected by the pressure than those of the marvel-of-Peru, which are more like cress seeds.

In conclusion, I call attention to the fact that to obtain conclusive results, the seeds must be wet. Otherwise, the oxygen, in spite of the high tension, would not kill them. Example:

Experiment CCCLXXXII. July 19. Dry wheat placed in a flask; in another, wheat previously moistened, which however is not covered with water, 
The two flasks are subjected to 15 atmospheres of an air containing $70 \%$ of oxygen.

July 31. Decompression and sowing.

The dry wheat sprouts very well; the other rots in the ground without sprouting.

TABLE XVII

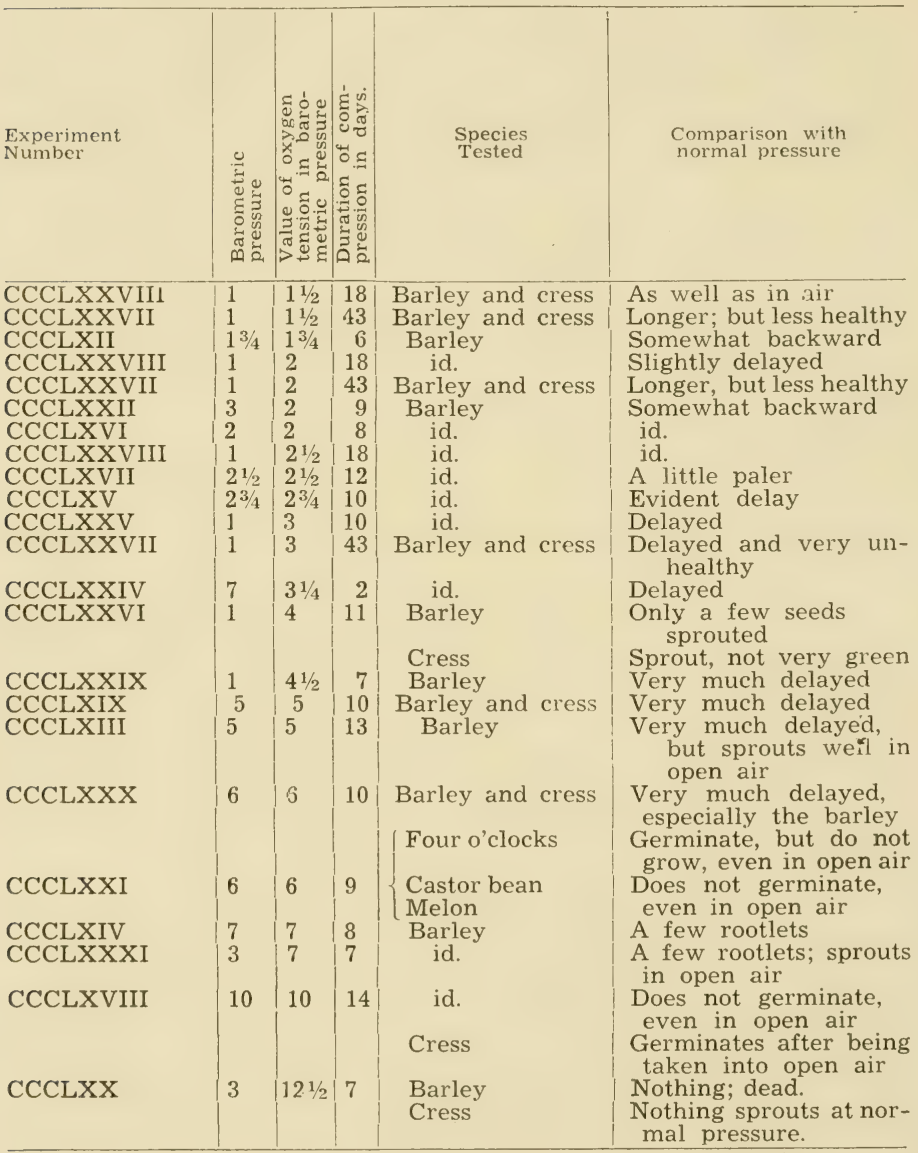




\section{Vegetation.}

Experiments on vegetation are very hard to perform, as is easily understood, because of the small size of the glass receivers and their lack of transparency. Yet here are a few which are sufficiently conclusive.

Experiment CCCLXXXIII. April 28. Barley sprouted 10 to $12 \mathrm{~cm}$. high in the large Seltzer water receivers (2 liters).

A, which is in the receiver with a wire jacket, is closed and left at normal pressure.

$\mathrm{B}$, in a receiver without a jacket, which lets more light through, is taken to 3 superoxygenated atmospheres, changed twice a day.

May 7. In A, the sprouts have more than doubled their length; B has not changed: left in open air, the stalks turn yellow and die.

Experiment CCCLXXXIV. July 25. Little sensitive plants 6 to 8 cm. high, healthy, in a pot.

A. Placed, in the pot, in a receiver of 1 liter, with wire mesh jacket; left at normal pressure, well corked.

B. Another pot in a similar receiver, without the wire mesh jacket, and consequently under better lighting conditions. Carried to 6 atmospheres of air.

By evening B has lost sensitivity.

July 26. The leaves in B are falling.

July 27. B completely dead; A healthy.

Experiment CCCLXXXV. August 1. Sensitive plants like those in the preceding experiment. Same receivers.
A. At 3 atmospheres.
B. Under normal pressure.

August 5. Both sensitive and healthy.

Experiment CCCLXXXVI. July 25. Small sensitive plants, quite sensitive.

A. Cylindrical apparatus at 4 atmospheres with $80 \%$ of oxygen; tension 320 , equivalent to nearly 16 atmospheres of air.

B. Normal pressure, air.

July 27. A, dead; B quite sensitive.

So sensitive plants die quickly at 6 atmospheres of air, and it is more than probable that the other green plants would die at the same pressure, although much less rapidly. Plants, therefore, seem to dread excessive oxygen tension still more than animals, even warm-blooded animals. 


\section{Subchapter III}

\section{SUMMARY}

The experiments included in the present chapter prove in summary that at pressures above or below one atmosphere, the germination and the vegetation of green plants are delayed, even arrested. Just as for animals, this fatal effect is due not to the pressure itself, but to the oxygen tension, either too weak, whence there results a kind of asphyxia, or too strong, killing the seeds or the plants.

In the third part of this book, we shall draw from these data the conclusions which they permit in regard to the geographical distribution of plants and the appearance of plant life on the surface of the earth.

\footnotetext{
$1 \mathrm{P}$. Bert. Sur les mouvements de la sensitive, Second memoir. Société des sciences physiques et naturelles de Bordeaux, Vol. VIII, p. 1-58, 1870.

2 Döhereiner, Experiences sur la germination dans l'air condensé ou raréfié. Biblioth. univ. de Genève, Vol. XXII, p. 121, 1823.
} 


\section{Chapter VI}

\section{EFFECT OF CHANGES IN BAROMETRIC PRESSURE ON FERMENTS, POISONS, VIRUSES AND ANTOMICAL ELEMENTS}

The admirable researches of M. Pasteur have shown that the phenomena known by the name of fermentations belong to two very distinct categories. Some are related to the development of microscopic living beings, vegetable or animal, such as alcoholic, acetic, and butyric fermentations and putrefaction. Others are caused by the action, still not understood, of substances produced by living beings, but soluble in water, and keeping their power after being isolated from the liquids in which they existed, and even after being dried; such is the transformation of starch into glucose under the influence of animal or vegetable diastase; or the formation of the essence of bitter almonds by synaptase acting on the amygdalin, etc.

It was quite natural to inquire whether changes in the barometric pressure (we can now say in the tension of the ambient oxygen) would have any appreciable effect on these phenomena. In the first place, for true fermentations, it was simply a question of whether an agent which according to its concentrations is both so necessary and so dangerous as oxygen, the lack of which ends life and the excess of which kills animals and plants which are visible to the naked eye and are of a rather complex anatomical organization, would have no effect upon microscopic beings, reduced to cellular structure. As for the false fermentations, the zymotic fermentations, since they surely play a very great part in the chemical phenomena of metabolism in all living beings, it was interesting to find out whether oxygen tension could act upon them.

Poisons and viruses, which resemble the ferments of these two classes from so many points of view, also deserved to be tested. 
And finally, after studying these varieties of free anatomical elements, I thought I should investigate the effect of changes in the oxygen tension upon the different anatomical elements, which in combination constitute a living being.

The strange effects of increased pressure were to engage my attention particularly. Nevertheless I made a few experiments with rarefied air; but I combined my report of them with that of the others, since generally they were made simultaneously.

Finally I should say that I employed in turn according to the best interest of the experiments either ordinary air compressed, or superoxygenated air compressed, or superoxygenated air at normal pressure. I consider that all my previous researches have sufficiently demonstrated this truth, that the effect of the compression is nothing but the effect of oxygen at high tension. Furthermore, for the questions discussed in this chapter, the experiments constitute a control which is proof in itself.

\section{Subchapter I}

\section{FERMENTATIONS BY ORGANISMS}

\section{Putrefaction.}

As a type and as a subject of study I selected the fermentations of putrefaction in particular. Certainly, from the standpoint of chemistry, the phenomena presented by putrefaction are extremely complex and hard to follow. But its consistency, the facility with which it is produced, and its characteristic outward signs which are easy to observe seemed to me very advantageous for my purpose. And so I shall begin by reporting the principal experiments which I performed on this important subject.

I shall first take up the putrefaction of meat.

\section{A. Meat.}

Experiment CCCLXXXVI. July 21. Temperature $22^{\circ}$. Muscles of a dog killed some hours before. $100 \mathrm{gm}$., cut in pieces, are placed:

A, in a flask of 2 liters, at normal pressure;

$\mathrm{B}$, in a flask of 4.250 liters, at a pressure of $38 \mathrm{~cm}$;

C, in the Seltzer water receiver, containing 1050 cc., in which I compress to $5 \frac{1 / 2}{1}$ atmospheres a superoxygenated air containing $75.7 \%$ of oxygen. pheres.

Oxygen tension: $75.7 \times 5.5=416$, equivalent to about 20.8 atmos-. 
July 25. A. The manometric tube attached indicates about $1 \mathrm{~cm}$. (mercury) excess pressure. The meat is evidently very rotten. The air of the flask is horribly foul; it contains $38 \%$ of carbonic acid, but no trace of oxygen. Therefore $410 \mathrm{cc}$. of oxygen were consumed and 760 cc. of carbonic acid produced.

B. The pressure has dropped $1 \mathrm{~cm}$. at the most; the meat looks rather rosy. The air of the flask is a little less foul than that in A; it contains $30.9 \%$ of $\mathrm{CO}_{2}$, but no trace of oxygen. Therefore $440 \mathrm{cc}$. of oxygen were consumed and $649 \mathrm{cc}$. of $\mathrm{CO}_{2}$ were produced.

C. Pressure maintained well. The meat is amber colored. The air of the receiver has no odor; it contains $7.2 \%$ of $\mathrm{CO}_{2}$ and $69 \%$ of oxygen. Therefore about $357 \mathrm{cc}$. of oxygen were consumed and $396 \mathrm{cc}$. of $\mathrm{CO}_{2}$ were produced.

Experiment CCCLXXXVII. July 27. 7 o'clock in the evening. Temperature $23^{\circ}$. A small dog having died the evening before, its hind feet, weighing $95 \mathrm{gm}$., were placed:

A, under a bell of 3.200 liters, full of air at normal pressure; the bell being tightly closed.

B, in the Seltzer water apparatus (1050 cc.), with 4 superoxygenated atmospheres.

July 28. At 5 o'clock, the air is changed in A and in B, which is kept at 7 atmospheres.

July 29. 2 o'clock. A. The air, which has no odor, contains: $\mathrm{O}_{2}$ 17.1; $\mathrm{CO}_{2}$ 1.8. The meat is reddish.

B. The air has no odor, and contains: $\mathrm{O}_{2} 65.5 ; \mathrm{CO}_{2} 0.8$. The oxygen tension therefore was at the beginning about $66 \times 7=462$, equivalent to 23 atmospheres of air. The meat is yellowish. I change the pressure to $6 \frac{1 / 4}{4}$ atmospheres.

July 31. 5 o'clock in the evening. Temperature $23^{\circ}$. A. The air smells very bad; it contains: $\mathrm{O}_{2} 3.8 ; \mathrm{CO}_{2} 17.2$; therefore, since July 29 , $534 \mathrm{cc}$. of oxygen has been consumed and $117 \mathrm{cc}$. of $\mathrm{CO}_{2}$ has been formed.

B. No odor. $32 \mathrm{cc}$. of oxygen has been consumed, and $50 \mathrm{cc}$. of $\mathrm{CO}_{2}$ formed.

A is taken out and the air changed, with the same bell; the meat has a terrible odor; the hairs and the epidermis are coming off.

$B$ is taken to 6 atmospheres.

August 3. 2 o'clock. Temperature $21^{\circ}$. A. Air has a disgusting stench; covered with mold. The air contains no trace of oxygen, but 23.9 of $\mathrm{CO}_{2}$; since July 31,651 cc. of oxygen has been consumed and 741 cc. of $\mathrm{CO}_{2}$ has been formed.

B. No odor, no mold. The air contains 59.2 of oxygen and 5.2 of $\mathrm{CO}_{2}$. Therefore $348 \mathrm{cc}$. of oxygen has been consumed, and $212 \mathrm{cc}$. of $\mathrm{CO}_{2}$ formed.

$\mathrm{B}$ is taken out and put on a plate in the laboratory. The next day it begins to smell bad; on August 7, mold appears on it.

Experiment CCCLXXXVIII. November 14. Temperature $14^{\circ}$.

A. I place in the cylindrical glass apparatus two mutton cutlets, and subject them to a pressure of 11 atmospheres, with air containing 
$79.9 \%$ of oxygen. The tension of this gas is therefore 879 , corresponding to about 44 atmospheres of air.

B. Another cutlet is hung up in a huge closed bell.

November 19. B is foul.

A looks good. The manometer has fallen to 7 atmospheres. The air, which has absolutely no odor, contains $78.4 \%$ of oxygen and not a trace of carbonic acid.

I raise the pressure again to 11 atmospheres with new oxygen.

November 21. Still no bad odor in A; appearance good.

I take a fresh cutlet $\mathrm{C}$, and hang it in a bell absolutely full of water. I then admit to this bell a certain quantity of compressed air coming from A; some water remains at the bottom of the bell. A then drops to 6.5 atmospheres.

November 24. No odor in A. A very slight leak is permitted so that on November 25 the pressure is normal; the cutlets have a yellowish color.

$\mathrm{B}$ is then in complete putrefaction. $\mathrm{C}$ is yellowish, and the water has risen in its bell.

December 13. I open the apparatus and end the experiment.

A. Meat, rose colored, a little acid; faint odor of pickle. I have the cutlets broiled; they have an insipid, but not repulsive taste.

$B$ had to be disposed of December 10, reduced to absolute decay.

C. Meat.flabby, pink, a little acid; disagreeable odor, not that of ordinary putrefaction.

Experiment CCCLXXXIX. November 22.

A. In the Seltzer water receiver $(1050 \mathrm{cc}$.) are placed two cutlets, which are taken to 8 superoxygenated atmospheres.

B. Another cutlet is placed in oxygen under a bell.

C. A third, under a bell, in air.

November 24. A has dropped to 2 atmospheres; I take it back to 8 atmospheres; the meat is a dull red.

$\mathrm{B}$ is bright red.

$\mathrm{C}$ is of ordinary color.

December 1. A has no bad odor; normal consistency; alkaline reaction; yellowish appearance.

B. Bad odor; alkaline reaction.

C. Absolutely foul odor; flesh diffluent; acid reaction; darkens paper with lead acetate.

Experiment CCCXC. December 11.

Under two bells inverted over water, one of which, A, contains air, the other, B, oxygen, fragments of muscle are hung.

January 8. The air is foul in both bells; A shows a great deal of mold; B, only a little.

Experiment CCCXCI. December 19. Three pieces of lean meat are cut as nearly alike in form as possible.

A. One, weighing $45 \mathrm{gm}$., is hung under a closed bell, of 11.5 liters, full of ordinary air.

B. The second, weighing $40 \mathrm{gm}$., is hung in a bell of 3.2 liters, which contains air with $90 \%$ oxygen. 
C. The third, weighing $35 \mathrm{gm}$., is placed in the cylindrical glass apparatus, and subjected to the pressure of 10 atmospheres of air containing $88 \%$ of oxygen; the oxygen tension therefore is 880 , corresponding to 44 atmospheres of air.

December 26. Samples of air are taken from the three bells without the air being renewed.

A. The meat looks bad; the lower part is evidently putrefied. The air has an insipid odor, slightly gamy. The air contains: $\mathrm{O}_{2}, 12.2$; $\mathrm{CO}_{2} 6.4$.

B. The meat has about the same appearance. Insipid odor. The air contains: $\mathrm{O}_{2} 70 ; \mathrm{CO}_{2} 12.9$.

C. The meat looks good but rather brown. No odor. The composition of the air has not changed.

January 8. Samples of air are taken again, and the experiment is stopped.

A. Meat very acid, with a horrible odor; softened. The air contains $7 \%$ of oxygen and $12.3 \%$ of $\mathrm{CO}_{2}$.

B. Meat very acid; odor very bad, but not as strong as A. The air contains $40 \%$ of oxygen and $38.2 \%$ of $\mathrm{CO}_{2}$.

C. Meat a little acid, grayish, firm, with a slight sourish odor, which is not disagreeable. Cooked, it is insipid, but without a bad taste.

The composition of the air has not changed. If we try to determine, in these two periods, the quantity of oxygen which has been consumed, and the quantity of $\mathrm{CO}_{2}$ which has been produced by the meat placed in these different conditions, we get the following results, in which all are reduced to an equal weight, $100 \mathrm{gm}$. of meat.

From December 19 to 26:

A (ordinary air, normal pressure) has consumed 2.2 liters of oxygen and produced 1.6 liters of $\mathrm{CO}_{2}$.

B (air with $90 \%$ of oxygen, normal pressure) has consumed 1.7 liters of oxygen and produced 1.2 liters of $\mathrm{CO}_{3}$.

C (air with $88 \%$ of oxygen, 10 atmospheres) has consumed 0 liters of oxygen and produced 0 liters of $\mathrm{CO}_{2}$.

From December 26 to January 8:

A (air with $12.2 \%$ of oxygen) consumed 1.3 liters of oxygen and produced 1.4 liters of $\mathrm{CO}_{2}$.

B (air with $70 \%$ of oxygen) has consumed 2.6 liters of oxygen and produced 2 liters of $\mathrm{CO}_{2}$.

C (air with $88 \%$ of oxygen, 10 atmospheres) has consumed 0 liters of oxygen and produced 0 liters of $\mathrm{CO}_{2}$.

I call particular attention to this experiment. It shows that in twenty days the meat in compressed oxygen consumed no oxygen and produced no carbonic acid; it showed no sign of putrefaction.

We see, furthermore, that the meat consumed less oxygen in air with $90 \%$ of oxygen than in air with $21 \%$, but more in air with $70 \%$ than in air with 12 . 
Experiment CCCXCII. January 17. Pieces of meat equal in weight and similar in form.

A. Placed in a bell of 15.5 liters, in which the pressure is lowered to a half-atmosphere.

B. Bell of 7.1 liters; ordinary air, at normal pressure.

C. Bell of 2.6 liters; air at normal pressure, containing $59 \%$ of oxygen.

D. Bell of 3.2 liters; air at normal pressure, containing $59.8 \%$ of oxygen.

All these bells are hermetically closed, with hydraulic seal.

January 23. The meat least altered in appearance is that in A; those most altered are in $\mathrm{C}$ and D. Air samples are taken:

B contains $13.5 \%$ of oxygen and $7.2 \%$ of carbonic acid.

A contains $16.4 \%$ of oxygen and $5.3 \%$ of carbonis acid.

C contains $25.2 \%$ of oxygen and $19.1 \%$ of carbonic acid.

D contains $36.0 \%$ of oxygen and $17.3 \%$ of carbonic acid.

We can calculate easily by means of these data that in 6 days:

A (ordinary air, at $1 / 2$ atmosphere) had consumed $343 \mathrm{cc}$. of oxygen and formed 418 of $\mathrm{CO}_{2}$.

B (ordinary air, at 1 atmosphere) had consumed 524 cc. of oxygen and formed 514 of $\mathrm{CO}_{2}$.

C (superoxygenated air, corresponding to $2 \frac{1}{2}$ atmospheres) had consumed $642 \mathrm{cc}$. of oxygen and formed 496 of $\mathrm{CO}_{2}$.

D (superoxygenated air, corresponding to 3 atmospheres) had consumed $761 \mathrm{cc}$. of oxygen and formed 556 of $\mathrm{CO}_{2}$.

The consumption of oxygen then consistently increased from $1 / 2$ atmosphere to 3 atmospheres.

Experiment CCCXCIII. January 14. Pieces of beef are placed in two small flasks (A and A'), through the stoppers of which a capillary tube passes; they are then placed in the cylindrical apparatus under a pressure of 10 superoxygenated atmospheres.

January 27. Decompression; the meat, slightly brownish, does not seem spoiled. The capillary tubes are rapidly sealed with boiling wax, and the two flasks are inverted in vessels full of water. Two pieces of meat are placed in the same way beside them (B and B').

February 10. B and B' are evidently rotten, and smell bad through the corks.

A has admitted a little water; since then, the meat has become red again; the water is slightly bloody and covered with mold. A', on the contrary, is very firm, very wholesome, amber in color.

March 25. Same appearance; the water has continued to rise in A. This flask is opened; it smells very bad.

May 22. End of the experiment. The controls B and B' are in foul decay; through the microscope we see in it many vibriones, but no more distinct muscular fibers; only a few of Bowman's disks.

For some days we have noticed that bubbles of gas are escaping through the pores of the cork in A'. The meat has become red, but it is firm and stiff. It smells bad and is negative to reagents. Through the microscope we see a few scattered vibriones; the muscular fibers have remained well striated. The air of this flask contained $75 \%$ of gas soluble in a potash solution. 
Experiment CCCXCIV. June 19. Temperature $18^{\circ}$.

Placed in two flasks with cork stoppers water in which fragments of meat have been macerated:

A. Kept as control.

B. Cork pierced by a hole, flask shaken until all its walls are wet, then placed in the large mercury receiver, in which compression is made to 20 atmospheres with $88 \%$ of oxygen. The pressure therefore corresponds to 88 atmospheres.

June 24. Temperature $19^{\circ}$. The pressure is still 13.5 atmospheres. $\mathrm{A}$ is red and smells bad. Decompression is made and B is immediately sealed; it is amber colored and seems to have no odor.

July 6 . A is very red, rather alkaline; its odor is foul; there is no mold on the surface of it; the very abundant precipitate contains great numbers of very active vibriones, whose extremity ends in a refracting enlargement, and also very active bacteria termo. (The microscopic observations are made with the aid of M. Gayon, assistant to M. Pasteur, at the Normal School.)

$\mathrm{B}$ had begun to redden a few days before; the cork was evidently imperfect. The liquid is covered with greenish mold, consisting of a penicillium with elliptical glossy spores (virens?); it is very slightly alkaline. It exhales a faint odor of mold, but not of putrefaction. There are no vibriones in it, but very small and very active bacteria, and besides, long filaments of unknown nature.

Experiment CCCXCV. June 26, 1874. Temperature $19^{\circ}$.

Two thin pieces of meat are placed each in a flask:

One, A, is corked and kept as control.

The second, B, is corked, the cork pierced by a hole, then taken to 15 superoxygenated amospheres. I added a little water, then shook it so as to wet the walls and the cork.

July 21. Decompression made. A has smelled very bad, for some time, through the cork, and is evidently entirely decayed. B is yellowish, seems wholesome, and exhales no odor. The cork has been almost entirely driven in. However I cover the whole orifice of the flask with boiling wax.

August 3. Same condition.

The flasks are kept the rest of the year, and the meat in B keeps the same appearance.

January 16, 1875, I show A and B to the Society of Biology. A is completely rotten. B has exactly the same appearance as on July 21.

June 28, 1875, I show these flasks to the Academy of Sciences; same appearance.

August 3, opened in the chemistry laboratory of $M$. Chevreul, before M. Cloez; sourish, agreeable odor; slightly acid reaction. The flask being broken, right in the laboratory I place the meat, without precautions, in a flask with a ground stopper. faction.

August 7, same odor and same appearance; no trace of putre-

Experiment CCCXCVI. June 25. Two pieces of meat, weighing 31 gm., are cut in similar form. 
One, A, is hung in a bell of 11.5 liters full of air, with hydraulic seal.

The other, B, is placed in the glass cylindrical apparatus (capacity 650 cc.) at the bottom of which are a few cubic centimeters of water. Compression is made to $10 \frac{1}{2}$ atmospheres, with air containing $81.1 \%$ of oxygen (tension $850=42.5$ atmospheres of air), and then the apparatus is shaken so as to wet all its walls.

June 30. A, horribly rotten, covered with mold; the air contains $16.3 \%$ of oxygen, and $2.8 \%$ of carbonic acid.

Therefore $522 \mathrm{cc}$. of oxygen were consumed, and $328 \mathrm{cc}$. of carbonic acid were formed.

B. Amber colored; no odor. The air has retained almost exactly its original composition, since it contains $80.4 \%$ of oxygen and no carbonic acid.

Therefore $49 \mathrm{cc}$. of oxygen were consumed. Pressure lowered to 2.75 atmospheres; oxygen tension: $220=11$ atmospheres.

July 12. B left in the same air; same appearance; still the same odor.

But the air contains only $69 \%$ of oxygen, with $12 \%$ of $\mathrm{CO}_{2}$.

Therefore $210 \mathrm{cc}$. of oxygen were consumed, and $21 \mathrm{cc}$. of carbonic acid freed.

The pressure is lowered to 2.5 atmospheres; the tension is only 172 $=8.6$ atmospheres.

July 21. Same pressure, same air. The appearance is the same; there is no odor.

The air contains only $57.2 \%$ of oxygen, with $23 \%$ of $\mathrm{CO}_{2}$.

Therefore 1583 cc. of oxygen were consumed.

July 27, same appearance; still no odor.

Without uncorking the apparatus, I empty it completely, ventilate it with oxygen, and raise the pressure again to $101 / 2$ atmospheres. The air then contains $77.6 \%$ of oxygen, and $1.2 \%$ of $\mathrm{CO}_{2}$, oxygen tension $814=40.7$ atmospheres of air.

At the same time, I suspend in a bell of 15.5 liters a piece of meat weighing $20 \mathrm{gm}$. C.

August 3. B. The pressure has been maintained; the meat has still the same appearance. The air, which has no odor, contains $74.9 \%$ of oxygen and $3.2 \%$ of $\mathrm{CO}_{2}$.

We see easily that, applying it to $100 \mathrm{gm}$. of meat, $390 \mathrm{cc}$. of oxygen have been consumed, and $397 \mathrm{cc}$. of $\mathrm{CO}_{2}$ formed.

C. The meat is alkaline, foul. The air contains $16.2 \%$ of oxygen and $3.6 \%$ of $\mathrm{CO}_{2}$.

Therefore, per $100 \mathrm{gm}$. of meat, $2295 \mathrm{cc}$. of oxygen have been consumed and $3605 \mathrm{cc}$. of $\mathrm{CO}_{2}$ freed.

August 5. Decompression made for the meat which was at 10 atmospheres. It is yellow, quite firm, and has no odor.

I put it in a test glass which had been kept in boiling water, and close it with a rubber stopper which also had been kept a long time in boiling water.

January 18, 1875. The meat has kept nearly its original appearance. When opened, it is hardly softened, but smells very bad. Negative to reagent papers. 
Experiment CCCXCVII. July 21, 1874. 6 o'clock in the evening. Pieces of meat placed:

A. In a corked matrass;

$\mathrm{B}$, in a similar matrass, the neck of which I draw out in a flame, leaving only a little orifice. I put it into the iron apparatus, and raise the pressure to 15 superoxygenated atmospheres.

July 22. The pressure has fallen; I take B out, and shake it so that all the walls are wet. Then I put it back and raise the pressure to $81 \frac{1}{2}$ superoxygenated atmospheres.

A begins to smell bad.

July 23. Taken to 12 superoxygenated atmospheres.

July 24. Taken to 15 superoxygenated atmospheres.

July 30 . The pressure is 14 atmospheres; I make the decompression, and close the tapering end of $\mathrm{B}$ with a flame; no odor, amber color.

A smells simply horrible.

January 17, 1875. Presented to the Society of Biology. A is a mass of decay horrible in appearance and odor.

B, which I do not open, has retained its original form and appearance. One merely sees some white spots which seem to be fat.

May 27, 1875. A is horrible; no fibers recognizable through the microscope.

B has burst in the night; the meat is amber colored; it has kept its consistency, its fibers with their striae; slightly alkaline; rather weak odor of decay.

Experiment CCCXCVIII. January 22. Strips of meat, each weighing $20 \mathrm{gm}$., suspended:

A. In the glass compression apparatus at 5 atmospheres of air, which represent $3250 \mathrm{cc}$. of air.

B. In a bell containing $2500 \mathrm{cc}$. of air, at normal pressure.

C. In a bell of 7100 cc., at a half-atmosphere.

January 26. The three pieces of meat have an alkaline reaction. A has a slight odor. B smells considerably worse than C.

The air of A contains $20.4 \%$ of oxygen; that of B $16.5 \%$; that of C $19.2 \%$.

From these figures we draw the conclusion that in apparatus A 100 grams of meat have consumed $81 \mathrm{cc}$. of oxygen; in bell B, 550 cc., and in bell C, only $300 \mathrm{cc}$.

Experiment CCCXCIX. January 28. Strips of meat, each weighing 39 grams, placed in the same apparatuses as in the preceding experiment:

A. At 3 atmospheres of air, potash solution in the bottom of the apparatus.

B. Normal pressure.

C. A third of an atmosphere.

February 2. A little odor in all; all the meat alkaline.

A contains $12.9 \%$ of oxygen. B $16.1 \%$. C $18.2 \%$. Therefore per 100 grams there was a consumption of oxygen: in A of $405 \mathrm{cc}$; ; in B of $313 \mathrm{cc}$; in C of $103 \mathrm{cc}$. 
We must note that the oxygen tension had diminished in $\mathrm{A}$, since at the end of the experiment it was only $12.9 \times 3=38.7$, that is, less than 2 atmospheres of air.

Experiment CCCC. February 3. Strips of meat weighing 39 grams. Same bells; but a solution of potash at the bottom of the bells, and papers saturated with potash on the walls:

A. Normal pressure.

B. A third of an atmosphere.

February 8. The air in A contains $10.9 \%$ of oxygen; that of B $15.6 \%$. No carbonic acid.

Whence, per 100 grams, consumption of $249 \mathrm{cc}$. in A; of only 141 cc. in $\mathrm{B}$.

Experiment CCCCI. February 10. Strips of 43 grams. Same apparatuses. Potash in both.

A. Normal pressure.

B. 3 atmospheres of air.

February 13. The air in A contains $20.1 \%$ of oxygen; that in B 18.9 .

Whence a consumption, per 100 grams: in A of $19 \mathrm{cc}$. of oxygen; in $\mathrm{B}$, of $38 \mathrm{cc}$.

Experiment CCCCII. February 16. Strips of meat weighing 50 grams each. Potash in the receivers.

A. Normal pressure. Bell containing 2.450 liters of air, that is, 512 cc. of oxygen.

B. Cylindrical glass apparatus, at 4 atmospheres of air, containing a quantity of oxygen corresponding to $504 \mathrm{cc}$., at normal pressure.

February 19. A. Bad odor; its air contains $16.8 \%$ of oxygen.

B. Odor not quite so bad; the air contains $16.4 \%$ of oxygen.

Whence, per 100 grams, consumption in A of $101 \mathrm{cc}$. of oxygen; in $\mathrm{B}$ of $109 \mathrm{cc}$.

Experiment CCCCIII. February 22. 30 grams of meat. Same apparatuses as in the preceding experiment. Potash in both:

A. Normal pressure.

B. 4 atmospheres of air.

February 24. No odor in either.

The air of A contains $21.0 \%$ of oxygen; that in B $20.8 \%$.

Experiment CCCCIV. March 17. Pieces of meat and water; in 2 small matrasses tapered in a flame.

A. At normal pressure.

B. B'. At 15 atmospheres of a compression made with air containing $80 \%$ of oxygen.

March 26. Decompression. A rotten, foul. B has no odor and is negative to reagent papers. I close B' with the flame.

May 15. B' has a good appearance; the liquid in which the meat is lying has the natural light red color.

June 10. The appearance of B' changed a few days before; it has lost its light red color. During the night of June $9-10$, the matrass burst; the pieces of meat have a foul odor, with a slightly alkaline 
reaction; but they have kept their form, and the muscular striae are easily seen through the microscope. A, on the contrary, is a mass of horrible decay, and the striae cannot be recognized.

Experiment CCCCV. May 28. Meat in pieces, in 2 matrasses drawn out in a flame and open at the extremity.

A. Left in open air.

B. Placed at 8 superoxygenated atmospheres.

Since the apparatus has a leak, compression is made several times, up to 23 superoxygenated atmospheres; for several days the pressure remains at 15 atmospheres.

June 26. A has been horribly decayed for a long time.

B. Has no odor; is amber colored.

June 28. I present the matrass B to the Academy of Sciences; I open it in the meeting; the meat is negative and has only a slight sourish odor, not disagreeable.

I recork the matrass without special care, with a hollowed out cork, and take it to the laboratory.

July 3. No odor.

July 11. Very slight odor.

July 19. The meat is covered with mold, but does not have an odor of decay.

Experiment CCCCVI. November 29. Barometric pressure $758 \mathrm{~mm}$; temperature $14^{\circ}$. From the top of three bells pieces of meat are hung, each weighing $25 \mathrm{gm}$. A solution of potash at the bottom of each bell will absorb the carbonic acid as it is produced.

The cork of the bell allows passage of an elbow tube, the extremity of which, being immersed in mercury, will serve as a manometer.

Bell A (4.6 liters) contains normal air.

Bell B (1.9 liters) contains air with $45.5 \%$ of oxygen.

Bell C (1.5 liters) contains air with $91.7 \%$ of oxygen.

December 4 . The bells are opened and the air analyzed; the barometric pressure is $735 \mathrm{~mm}$; temperature $14^{\circ}$. The meat in bell $\mathrm{C}$ does not smell as bad as the others.

The absorption of $\mathrm{CO}_{2}$ has caused a drop of $2.7 \mathrm{~cm}$. in ben A, one of $10 \mathrm{~cm}$. in $\mathrm{B}$, and $10 \mathrm{~cm}$. in $\mathrm{C}$. There is no carbonic acid in any of the bells.

The air in A now contains only $17.2 \%$ of oxygen; that in B only $35.3 \%$; that in $\mathrm{C}$ still contains $91.5 \%$.

Simple calculations, in which account is taken of the barometric pressure and the difference in tension in the bells, show that:

A, which had at its disposal $961 \mathrm{cc}$. of oxygen, consumed $258 \mathrm{cc}$. of it $\mathrm{B}$, which had at its disposal $867 \mathrm{cc}$. of oxygen, consumed $284 \mathrm{cc}$. of it C, which had at its disposal $1376 \mathrm{cc}$. of oxygen, consumed $183 \mathrm{cc}$. of it

If we consider first those of our experiments which dealt with decreased pressure, we see clearly that in rarefied air putrefaction was considerably delayed and oxidation diminished.

In Experiment CCCXCII, whereas a certain weight of muscles had, in a certain time, at normal pressure consumed 524 cc. of 
oxygen and formed $514 \mathrm{cc}$. of carbonic acid, the consumption of oxygen at a half-atmosphere had dropped to $343 \mathrm{cc}$. and the production of carbonic acid to $418 \mathrm{cc}$. The same result in Experiment CCCXCVIII, in which the consumption of oxygen had dropped from $550 \mathrm{cc}$. to $300 \mathrm{cc}$., for the same change in pressure; furthermore, meat kept in decompressed air did not smell nearly as bad as the other. Finally, in Experiment CCCXCIX, at a third of an atmosphere, the consumption of oxygen was exactly a third of that at normal pressure.

But these results are not very extraordinary; it has been known for a long time that putrefaction does not take place in a vacuum, and it was quite natural to think that it would become less active in proportion as the air was more rarefied.

The effects of increased oxygen tension were much more interesting to study.

The most salient fact shown me by the experiments is that in air which is sufficiently compressed putrefaction does not take place, that no disagreeable odor appears, and that the muscle keeps its normal appearance, except its color; its microscopic structure is not perceptibly altered (Exp. CCCXCIII and CCCCIV).

Almost all the experiments reported above present remarkable. examples of this fact.

But that is not all; when the excess pressure is reduced, and when sufficient precautions are taken to protect against germs brought from outside, putrefaction does not appear; so that for weeks, for months, meat in a fresh state can be kept at normal pressure. I call particular attention to this point of view in the experiments in which I cooked and ate meat kept thus for 20 days (Exp. CCCXCI), or a month (Exp. CCCLXXXVIII).

To secure conclusive and constant results, the greatest precautions in detail are necessary. I did not always take them at the outset; whence there result, in certain of the preceding experiments and in others on blood, milk, etc., apparent exceptions, which I included nevertheless, because they are instructive.

And so, in my first experiments, when I wished to preserve a substance, after subjecting it to compression, I closed with a good cork stopper the flask in which it was placed; this stopper was pierced by a hole, and when I had withdrawn the flask from the apparatus, I applied over this small orifice a drop of melted wax, with which, moreover, I sealed the whole stopper.

I soon found out that this precaution was insufficient. The stoppers, even when new, well washed, and heated, too often con- 
ceal germs which are still active. I then had recourse to matrasses, balloons, tubes, which I tapered in a flame, after having placed the experimental substances within; the almost capillary hole of the part tapered out permitted an equilibrium of pressure to be established.

I next perceived, at my cost, that the germs which remained in a dry state on the walls of the little receiver were sufficient, especially when we were dealing with putrefaction, with which my dissection laboratory was crammed, to affect the phenomena. I could guard against these with certainty only by adding a little water and shaking the receiver carefully, before subjecting it to compression, so as to kill at the same time both the germs contained in the substance and those on the walls which were wet.

It must not be thought, however, I make haste to say, that this method of preservation has a practical value; meat which has been compressed has an insipid taste which makes it disagreeable. This taste is probably due in part to the acid developed in it during the compression, an acid which is not volatile, nor odoriferous, and which is probably lactic acid.

This meat, which does not decay, absorbs infinitely less oxygen than that which remains under normal conditions. That was studied particularly in Experiments CCCLXXXVI and CCCLXXXVII.

But the most remarkable example is furnished by Experiment CCCXCI, in which in 20 days meat placed under a compression of oxygen equivalent to 44 atmospheres of air consumed no oxygen and produced no carbonic acid; whereas a similar weight of the same meat left at normal pressure had consumed 3.5 liters of oxygen and formed 3 liters of carbonic acid.

If pressure is lowered to normal, and sufficient precautions are taken to keep out the dust of the air, the meat, which will be preserved without decay indefinitely, as we have just said, will consume only very small quantities of oxygen. The following experiment shows this clearly.

Experiment CCCCVII. February 20. 15 pieces of meat, each weighing $1 \mathrm{gm}$., are placed in 15 tubes. Then these tubes are drawn out in a flame and subjected to 15 superoxygenated atmospheres in the iron apparatus.

March 3. Decompression is made carefully and the 15 tubes are closed by the flame. The analysis of 3 of them, made immediately, gives 70 to $80 \%$ of oxygen.

March 13. One of the tubes is broken under mercury; meat amber in color, no odor, acid reaction. There is $6.2 \%$ of carbonic acid and $77.8 \%$ of oxygen. 
The piece of meat is then placed without precautions in a tube closed with a cork $(a)$.

In the same way, in another tube, is placed $1 \mathrm{gm}$. of fresh muscle (b).

March 19. The piece (a) has produced very little $\mathrm{CO}_{2}$ and consumed little oxygen: The piece (b) has consumed all the oxygen of the tube, that is, $7 \mathrm{cc}$.

March 27. Another tube, opened in the same way under mercury, contains $11.0 \%$ of $\mathrm{CO}_{2}$ and $74.2 \%$ of oxygen.

The piece of meat is placed in a graduated tube full of air and well corked (c); another piece, fresh, of the same weight, is placed in the same way in a graduated tube of the same capacity $(d)$.

April 10. Tube c contains $1.6 \mathrm{cc}$. of $\mathrm{CO}_{3}$ and $2.8 \mathrm{cc}$. of oxygen, that is, $7.3 \%$ of $\mathrm{CO}_{2}$ and $12.7 \%$ of oxygen; tube $d$ contains 6.2 cc. of $\mathrm{CO}_{2}$ and $0.2 \mathrm{cc}$. of oxygen, that is, $28 \%$ of $\mathrm{CO}_{2}$ and only $0.6 \%$ of oxygen.

These results agree with those of the experiments of M. Pasteur, showing that the consumption of oxygen by organic substances is extremely low, when microscopic living beings are kept from developing there. To the proofs he has furnished I shall add the following experiment, in which the action of antiseptics has given the same result as that of oxygen at high tension.

Experiment CCCCVIII. June 26. A. 14 grams of muscles with a little water are placed in a corked flask, containing $590 \mathrm{cc}$. of air, and inverted over water.

B. 40 grams, in a flask of $750 \mathrm{cc}$. are moistened with a few drops of phenol and then shaken. The flask is corked and inverted beside A.

C. 40 grams; flask of 780 cc.; I add to it 2 grams of chloral, which, as it dissolves, whitens the meat; well shaken, corked, inverted near the others.

July 12. A. Is decayed; exhales a foul odor; the air (strong explosion when it is uncorked under mercury, so that a part of the gas cannot be collected under the test glass) contains $35 \%$ of $\mathrm{CO}_{2}$ but no trace of oxygen.

B. No odor of putrefaction; the air contains $18.6 \%$ of oxygen and $1.1 \%$ of $\mathrm{CO}_{2}$.

C. No odor; the air contains $18.1 \%$ of oxygen and $0.9 \%$ of $\mathrm{CO}_{2}$.

And so, proportioning the figures to 100 grams of muscles, we see that those which have putrefied have exhausted the $880 \mathrm{cc}$. of oxygen which they had at their disposal, and formed $1512 \mathrm{cc}$. of $\mathrm{CO}_{2}$ (without counting that which escaped when the flask was uncorked); on the contrary, 100 grams preserved by phenol have consumed only $35.1 \mathrm{cc}$. of oxygen and formed $21.9 \mathrm{cc}$. of $\mathrm{CO}_{2} ; 100$ grams preserved by chloral have consumed $35.3 \mathrm{cc}$. of oxygen and formed $15.0 \mathrm{cc}$. of $\mathrm{CO}_{2}$.

Let us return now to the action of the oxygen, and let us take 
as the measure of the intensity of the phenomena of putrefaction the consumption of this gas in a given time.

We shall state here that we are relying both on experiments made in compressed air, and on those in which high oxygen tension was obtained by increasing not the pressure, but the percentage under ordinary barometric pressure. We are sufficiently justified in this identification by all that we have hitherto observed.

Experiment CCCXCII shows us that the quantity of oxygen consumed increases with a tension corresponding to 2 and even to 3 atmospheres of air; Experiments CCCXCIX and CCCCI give the same result for 3 atmospheres; but Experiment CCCXCI shows, in its first part, that there is a decrease at the tension of $4 \frac{1}{2}$ at-

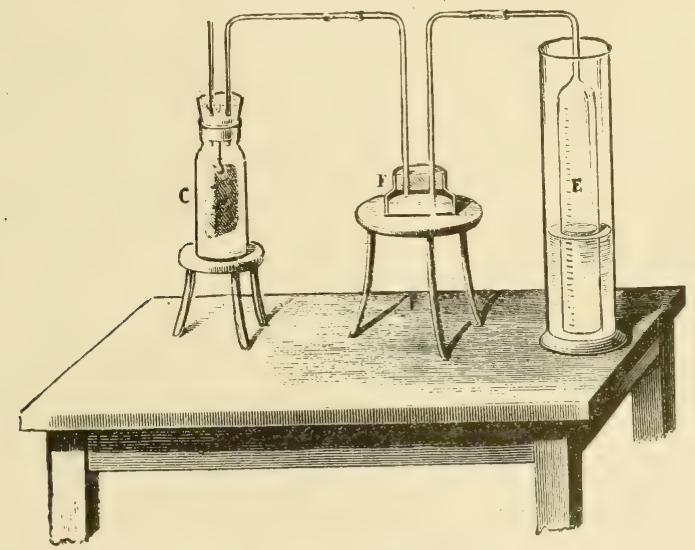

Fig. 74-Oxygen consumption and carbonic acid production by a piece of meat in an atmosphere of constant oxygen content.

mospheres; finally, Experiment CCCCII shows equality of consumption at 4 atmospheres.

It seems then, at first, that the maximum consumption of oxygen occurs between 3 and 4 atmospheres. But the question is more difficult to settle than one would think at first, and requires experiments carried on with special precautions. In fact, in Experiment CCCXCII, for example, the air of bell D, in which the oxygen tension corresponded at first to 3 atmospheres of air, and in which there was more active oxidation, corresponded to less than 2 atmospheres at the end of the experiment. One must use here an 
experimental device which allows one to keep the same oxygen tension for the whole duration of the experiment and to dispose of the carbonic acid as it is produced.

For this purpose, I set up the apparatus pictured in Figure 74.

It is a flask C (sometimes a bell) full of superoxygenated mixture, proportioned in advance; at the bottom is a solution of potash whose carbonic acid content has also been determined by means of the mercury pump. A piece of meat, of known weight, is suspended in it. The absorption of the oxygen and the fixation of the $\mathrm{CO}_{2}$ cause pure oxygen contained in a graduated test tube $\mathrm{E}$ to enter the flask, bubble by bubble; a flask-valve $\mathrm{P}$ prevents the air of the flask from flowing back in case its volume changes (temperature, decrease of pressure, etc.). Several apparatuses are placed thus which operate simultaneously and in identical conditions, except the oxygen content of the air of the flasks. When the experiment is over, analysis of the air of the flasks, the height of the column of water in the test tube, and the quantity of $\mathrm{CO}_{2}$ contained in the potash give all the elements of the problem.

But first I had to determine the degree of accuracy of this experimental method. It was easy to make the test by using ordinary air and making several simultaneous experiments under identical conditions. Here is the result.

Experiment CCCCIX. January 18. Pieces of meat weighing $25 \mathrm{gm}$., in 4 bells of equal size with ordinary air.

January 22. The analysis of the potash solutions shows that the production of carbonic acid was $195.8 \mathrm{cc}$; $197.8 \mathrm{cc}$; $204.8 \mathrm{cc}$. and $206.8 \mathrm{cc}$.

The margin for error, then, for carbonic acid is about $5 \%$. Let us see now the results of the experiments.

Experiment CCCCX. January 4. Pressure $745 \mathrm{~mm}$; temperature $16^{\circ}$. Piece of meat weighing $25 \mathrm{gm}$., at the top of 2 bells.

A contains normal air.

B contains air with $49.6 \%$ of oxygen.

January 7 . We find by analysis of the bells and the potash solutions that:

A has produced 232 cc. of $\mathrm{CO}_{2}$.

$\mathrm{B}$ has produced $245 \mathrm{cc}$. of $\mathrm{CO}_{2}$.

Experiment CCCCXI. January 24. Pressure $761 \mathrm{~mm}$; t temperature $12^{\circ}$. Same experimental set-up, 3 bells. They contain: A ordinary air, B air with $53 \%$ of oxygen, C air with $79.7 \%$ of oxygen.

January 29. Analyzed the potashes.

A produced $223 \mathrm{cc}$. of carbonic acid.

B produced $270 \mathrm{cc}$. of carbonic acid.

C produced $250 \mathrm{cc}$. of carbonic acid. 
Experiment CCCCXII. February 1. Instead of bells, of unequal volumes, we use flasks of small dimensions, as is represented in Figure 74.

In flask $\mathrm{A}$ is ordinary air; in B, air with $37.3 \%$ of oxygen; in $\mathrm{C}$, air with $61.2 \%$; in $\mathrm{D}$, air with $81 \%$.

February 7. Experiment ended; the analysis of the potash solutions shows that:

A has produced $317 \mathrm{cc}$. of carbonic acid.

$\mathrm{B}$ has produced $326 \mathrm{cc}$. of carbonic acid.

C has produced $393 \mathrm{cc}$. of carbonic acid.

$\mathrm{D}$ has produced $328 \mathrm{cc}$. of carbonic acid.

Experiment CCCCXIII. February 14. Temperature $16^{\circ}$. Same apparatuses.

In flask $\mathrm{A}$, ordinary air.

In flask B, air with $41.5 \%$ of oxygen.

February 17. Ended the experiment.

A produced 130 cc. of carbonic acid.

B produced 178 cc. of carbonic acid.

If we call the quantity of carbonic acid produced under normal pressure 100 in each of these experiments, we shall obtain by simple proportions the following figures, which show the course of the production of carbonic acid.

Ordinary air (1 atmosphere) there are 100 cc. of $\mathrm{CO}_{2}$ CCCCXII Air with $37.3 \%$ of $\mathrm{O}_{2}$ (1.8 atmospheres) there are $103 \mathrm{cc}$ of $\mathrm{CO}_{2}$ CCCCXIII Air with $41.5 \%$ of $\mathrm{O}_{2}$ (2 atmospheres) there are $129 \mathrm{cc}$. of $\mathrm{CO}_{2}$ CCCCX Air with $49.6 \%$ of $\mathrm{O}_{2}\left(2.3\right.$ atmospheres) there are $106 \mathrm{cc}$. of $\mathrm{CO}_{2}$ CCCCXI. Air with $53 \%$ of $\mathrm{O}_{2}(2.5$ atmospheres $)$ there are $121 \mathrm{cc}$. of $\mathrm{CO}_{2}$ CCCCXII Air with $61.2 \%$ of $\mathrm{O}_{2}$ (2.9 atmospheres) there are $124 \mathrm{cc}$. of $\mathrm{CO}_{2}$ CCCCXI Air with $79.7 \%$ of $\mathrm{O}_{2}$ (3.8 atmospheres) there are $112 \mathrm{cc}$. of $\mathrm{CO}_{3}$ CCCCXII. Air with $81 \%$ of $\mathrm{O}_{2}(3.9$ atmospheres $)$ there are 103 cc. of $\mathrm{CO}_{2}$

It appears from these figures that the maximum of combustion in tissues takes place above normal pressure, at about three atmospheres. This was the conclusion which we had already reached in Subchapter II of Chapter IV, for combustions investigated in living beings.

When pressures become very high, the decrease of oxidations in the tissues becomes extremely clear. At 23 atmospheres, the proportion of oxygen consumed has lessened in the ratio of 534 to 32 (Experiment CCCLXXXVII). In Experiment CCCXCVI, consumption at normal pressure in 5 days was 522 cc. of oxygen, whereas it was only $49 \mathrm{cc}$. in compressed air at a tension equivalent to 42.5 atmospheres of air, and in the 9 following summer days, although the tension had been lowered to 11 atmospheres, only 210 cc. of oxygen were consumed. 
We see then that the tension figure, at which the rapid oxidations due to the ferments of putrefaction begin to decrease, coincides exactly with that at which the fatal effect of oxygen begins to appear. Therefore the anatomical elements of a complex organization are susceptible to the same concentration as those which live isolated, under the form of microzoa and microphytes. We shall gain new confirmation of these facts when we take up the effects of compressed oxygen on plants and germination.

Similarly, Experiment CCCLXXXVI shows us that the pressure of 21 atmospheres completely kills the microscopic beings of putrefaction, as it kills higher animals.

Let us add finally that meat which was preserved thus intact during compression and after compression is none the less an excellent medium for the development of microscopic organisms, and that putrefaction occurs rapidly in it, when germs brought by the air come in contact with it in sufficient quantity. Experiment CCCXCIV, in which germs penetrated into the flask through an imperceptible crack in the cork, is quite characteristic. But for microscopic beings, as for those of great size, the crop is proportional to the sowing; it is not surprising therefore that under these conditions putrefaction in meat which has been subjected to high compression takes place rather slowly (Exp. CCCCVII), and that in certain cases (Exp. CCCCV), when the chances of the experiment have allowed the germs of molds, and not the vibriones of putrefaction, to enter the tubes, putrefaction was replaced by a microscopic vegetation.

I have sometimes seen meat kept in vessels closed by the flame after the phase of oxygenated compression, remain in a state of good preservation for weeks and months, then begin to putrefy; Experiments CCCXCVII and CCCCIV give examples of this. In this case, in my opinion, the oxygen did not kill all the vibriones of putrefaction; it left some, merely sick, numbed, as it were, which regained new activity in time. That happens, too, when meat has been heated to a temperature considerably below the boiling point; it happens in an apparatus in which a vacuum has been made by boiling, when air is admitted through carded cotton, if the filter is insufficient; it happens, in a word, whenever the ferments are either in very small numbers or altered by some strange circumstance.

Of course I had to study the putrefaction of some other substances. I record my experiments here. 


\section{B. Blood.}

Experiment CCCCXIV. June 9. Defibrinated dog's blood.

A. 30 cc. placed in a flask at normal pressure.

B. 30 cc. in another flask closed by a cork with a hole. Placed in the iron apparatus and taken to 12 superoxygenated atmospheres.

The pressure falls in the days following, and cannot be kept above 8 atmospheres.

June 13. B is decompressed and sealed.

June 18. A. Horrible odor; B. slight odor. nated.

Experiment CCCCXV. June 19; 1874. Dog blood, fresh, defibri-

A. In a corked flask, ordinary air.

B. Flask closed by a stopper of cork with a hole, subjected after agitation to 20 superoxygenated atmospheres, equivalent to 88 atmospheres of air.

June 24. A. Smells very bad.

B. Decompressed, no odor, is translucent, as if varnished; I seal the orifice of the flask with wax.

July 6. A. Wrinkled layer on the surface; repulsive odor. No globules visible; vibriones with a shiny terminal point, quite numerous, and also motionless bacilli; crystals of hemoglobin.

B. The blood has become slightly turbid; no white layer on the surface; strange odor, very slightly putrid. Blood corpuscles pink and extraordinarily pale; no crystals; some few vibriones with shiny point.

July 12. B. Still no putrid odor.

The stopper is merely put back on B, without being sealed again. In the following months, it is opened frequently and closed without precaution; the stopper even happens to fall on the floor and is put back without any care. Nevertheless the putrid odor does not appear clearly.

January 16, 1875. Presented to the Society of Biology.

A. Is horribly putrid.

B. Can be sniffed without disgust, but does have a slight odor.

Experiment CCCCXVI. July 21. Dog blood, defibrinated.

In equal quantities in:

A. Matrass closed with a cork stopper.

B. Similar matrass drawn out in the flame; it is subjected to 15 superoxygenated atmospheres.

July 22. A. Begins to smell bad.

B. Pressure has fallen; I take $\mathrm{B}$ out and shake it to moisten the walls of the matrass; then I take it to $81 / 2$ superoxygenated atmospheres.

July 23. Raised to 12 atmospheres.

July 24. Raised to 15 atmospheres.

July 30. A. Smells horribly bad.

B. Still 14 atmospheres; decompressed; no odor; closed the pointed end of the matrass with the flame.

A drop of this blood, examined through the microscope, shows no corpuscles; it looks as if it were varnished. 
And so, as a result of compression, when the experiment has been well conducted, the blood is preserved without putrefying, both in the compressed air, and on being removed from the compressed air. The only change consists of the varnished appearance which it takes on, due to the fact that the hemoglobin leaves the corpuscles and is dissolved in the serum. This always occurs, moreover, in dead blood, and even in blood which has putrefied in closed vessels, after the putrid fermentation is over.

Not only are the vibriones killed thus before beginning their work, but when blood in the process of putrefaction is compressed, the putrefaction ceases, and the characteristic odor decreases to the point of disappearing.

But experiments on blood present a difficulty about which I should like to say a few words now, because it caused failure in a number of my experiments at the beginning, and because it might, if I did not mention it, cause uncertainty in the minds of those who would like to run control experiments on my work.

I often saw blood which had kept well in the apparatus decay rapidly at normal pressure, even in vessels carefully closed by the flame. When I examined these data carefully, I found that this happened only in experiments made in tubes, never in those made in matrasses. This peculiarity results, as I suspected immediately, from the fact that the thickness of the layer of blood is different in the two operative methods.

I then perceived that oxygen, even at the highest tensions, penetrates the blood only a little way. Example:

Experiment CCCCXVII. December 2. 100 cc. of blood are placed in a test tube with a foot; they rise to a height of $10 \mathrm{~cm}$; compression in the mercury bottle to 20 superoxygenated atmospheres.

December 6. Instantaneous decompression; very little gas escapes from the liquid; no froth.

The floating serum rises to a height of $3 \mathrm{~cm}$; below is a layer of very red blood $3 \mathrm{~cm}$. thick; the rest of the blood is quite dark.

It is then quite evident that there can be an excess of oxygen only in the superficial layers of the liquid, and that consequently vibriones in the deep layers will not be affected by the oxygen, or at least only slightly. Thence arises the putrefaction which appears more or less quickly, and which in one case I saw appear during the compression; the variations result from many circumstances in the multiplicity of which the height of the column used stands out definitely. One should never use blood in a thickness of more than a half-centimeter, if one is to be absolutely certain of succeeding. 
C. Eggs.

Experiment CCCCXVIII. June 19. Eggs beaten and well shaken. Placed in equal quantities in:

A. Flask with stopper, ordinary air.

B. Flask closed with a cork stopper with a hole, subjected, after agitation, to 20 superoxygenated atmospheres, equivalent to 88 atmospheres of air.

June 24. A. Foul, with mold on the surface.

B. Decompressed, no odor. The flask has been uncorked by the expansion of gases; the stopper has to be cut and replaced. The flask therefore remains open to the outer air for about 5 minutes. I seal it carefully.

June 28. A. Is completely mottled.

B. Appears wholesome, the yolk clearly floats on top.

July 6. A. Horrible odor; the stopper pops out when the flask is opened; the egg is all mottled and greenish.

B. There are still two layers; yolk greenish; no odor; there is mold on the lower surface of the stopper. odor.

July 12. B, which was recorked without precaution, has no putrid

Experiment CCCCXIX. July 21, 1874. Beaten egg.

A. In a matrass closed with cork stopper.

B. In a similar matrass, drawn out in a flame. Subjected to 15 superoxygenated atmospheres, shaken.

July 30. A. Smells horribly bad and is mottled.

B. Decompressed; has no odor, and its two layers are very clearly separated. I close it with the flame.

At the end of several months, B begins to coagulate in a mass. alkaline.

January 18,1875 . A. Horrible odor; is only a greenish pulp, very

B. I open the matrass; the egg is entirely coagulated; yolk reddish; no disagreeable odor; reaction clearly acid.

Experiment CCCCXX. May 29. Beaten egg.

A. In an open matrass, covered with a paper cone; normal pressure.

B. In a matrass drawn out in a flame. Taken to 23 superoxygenated atmospheres.

June 5. A. Exhales a horrible odor.

The compression apparatus has leaked; I make a recompression several times; it finally drops to 5 atmospheres.

June 26. Decompression.

A. Is coagulated, foul, with a dark layer at the bottom of the glass.

B. Is divided into two very definite layers, not coagulated, without odor.

Experiment CCCCXXI. March 17. Beaten eggs, in 2 tubes.

A. Closed with a stopper, free air.

B. Drawn out in a flame; at 15 atmospheres of air containing $80 \%$ of oxygen. 
March 26. Decompression.

A. Foul odor; coagulation; I close it with a flame. flame.

B. No odor; liquid in two clearly distinct layers; closed with a

May 15. A. Explosion when the tube is opened; foul odor; vegetation on the surface.

B. Not coagulated; no explosion when the tube is opened; very slight acidity; agreeable sourish odor, like that of cider; no vegetation on the surface; closed with a flame.

June 10. Spontaneous explosion of tube B; however, little odor; matter acid, coagulated.

Eggs then do not decay either during or after decompression when they are protected from the germs of the air. But they finally have an acid reaction, which, without developing an odor, causes their albumen to coagulate. That would be an exceedingly interesting chemical phenomenon to study in detail.

These different experiments then show very clearly that when the experimental precautions which I have stressed are taken, meat, eggs, blood, that is, the most corruptible of substances, are preserved without putrefaction by oxygen at high tension. When withdrawn from the apparatus and kept in closed vessels, they remain indefinitely without putrefying, but at the same time undergoing certain changes which would make them unfit for customary uses.

\section{Coagulation of Milk.}

Milk, upon which I experimented from the double point of view of putrefaction and coagulation, caused me a good deal of trouble on the latter score.

Experiment CCCCXXII. August 8. Milk, placed in 3 small wellwashed bottles.

A. Left at normal pressure.

B. Placed in a compression receiver and taken to 4 atmospheres of air.

C. Taken to 7 atmospheres of air with $70 \%$ of oxygen, equivalent to 24 atmospheres of air.

August 15. A. B. C. Milk sour; all clotted.

Experiment CCCCXXIII. January 27. Milk placed in 2 small similar bottles.

A. Closed with a cork stopper.

B. The same, but the stopper has a glass capillary tube through it; the bottle is subjected, in the glass cylindrical receiver, to a pressure of 10 atmospheres, with air containing $84 \%$ of oxygen. The oxygen tension, 840 , is therefore equivalent to 42 atmospheres of air.

B. Appears to be curding a little more slowly than A. 
February 3. Decompressed B and closed the hole with burning wax. $A$ and $B$ have the same appearance.

May 22. A. The stopper blows out when I open the flask. Very strong butyric odor; very acid reaction. Numerous very active vibriones, some of which are oval and wide, are to be seen in it.

B. The stopper does not blow out; very slight butyric odor, very acid reaction. A few bacillus vibriones, very small and active.

Experiment CCCCXXIV. May 22. Temperature $18^{\circ}$. Boiled milk, placed in four flasks well-washed with hot alkaline water.

A, A', two flasks well corked and sealed.

B, B', two flasks, closed with a cork stopper pierced by a hole, taken to 10 atmospheres of air with $70 \%$ of oxygen, which is equivalent to 35 atmospheres of air.

May 24. Decompressed B and B' and closed the holes with melted wax.

The four flasks appear curded to the same degree.

Experiment CCCCXXV. May 26. Boiled milk, with the addition of water alkalinized by carbonate of soda.

A, A'. Two flasks are closed and sealed.

B, B'. Two others, whose stoppers are pierced by a hole, are placed in the cylindrical glass apparatus under a pressure of 10 atmospheres of air with $70 \%$ of oxygen, or about 35 atmospheres of air.

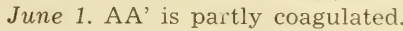

BB' is hardly coagulated at all.

June 3. Decompressed BB' and closed the holes with melted wax.

The liquid is less clearly coagulated in BB' than in AA'.

June 26. BB' are less clearly coagulated than AA'.

BB' are neutral or hardly acid.

AA' are extremely acid.

Experiment CCCCXXVI. August 7, 1874. Boiled milk, placed in two matrasses, in which the liquid occupies only a small part.

A, closed with a stopper of new and well heated cork.

$\mathrm{B}$, drawn out in a flame, except a little hole in the extremity; taken to and kept at a pressure of between 8 and 12 superoxygenated atmospheres.

August 17. A, yellowish clot with mold; foul.

B, decompressed, closed with a flame; white clot.

January 18, 1875. A, yellowish mass with deep yellow skin. Smells bad; alkaline reaction.

$\mathrm{B}$, very white and very clean clot; has no bad odor.

Experiment CCCCXXVII. August 7, 1874. Boiled milk, with the addition of alkalinized water; arranged as in the preceding experiment; one of the matrasses, $B$, placed beside the one of the experiment above.

August 17, at decompression, same difference in the general appearance.

January 18, 1875. A, foul; yellowish with a yellow skin; alkaline.

$\mathrm{B}$, fresh odor, sourish; white, clean clot; reaction quite acid. 
Experiment CCCCXXVIII. January 20. Boiled milk, in tubes, diluted with water.

A, normal pressure.

B, 21 superoxygenated atmospheres; tube drawn out in the flame.

The pressure falls repeatedly.

January 25. Decompression made.

May 17. A, foul odor; thick mold on the surface; liquid yellowish with clots.

B, very slight butyric odor, not disagreeable; acid; liquid very white with lumps; a few globules of milk recognizable through the microscope.

Experiment CCCCXXIX. January 20. Milk with the addition of a solution of soda.

Experiment made at the same time as the preceding one.

May 17. The milk which was not compressed has a foul odor; the other has no odor.

Experiment CCCCXXX. March 16. Boiled milk, in tubes.

A, normal pressure.

$\mathrm{B}$, at 10 superoxygenated atmospheres, in the cylindrical glass apparatus.

March 18. The milk is clotting perceptibly at the same time in $\mathrm{A}$ and in $\mathrm{B}$.

We see that for milk as for the other substances putrefaction has been checked by compressed air; on the condition of giving up corks and using exclusively tubes or matrasses closed with a flame.

But coagulation was not prevented, nor was rapid acidification; these changes did not even seem delayed appreciably. A previous strong alkalinization of the milk did not check them either; however, in this case, an evident delay resulted.

Could it be that oxygen under high tension really has no effect on the lactic vibriones discovered by M. Pasteur: Or could it be that coagulation of milk is not the work of these microscopic beings, but instead of some agent invulnerable to oxygen, as soluble ferments are, as we shall see?

Before giving an answer to these questions, I had to reflect on the experimental cause of error revealed to me by my experiments on blood. The thickness of the layers of the liquid which compressed oxygen must saturate to carry out its destructive work might play an important part here.

I had to eliminate this harmful influence; and so I did, for example, in the following experiments. 
Experiment CCCCXXXI. August 10. Boiled milk; placed in a layer

2 to 3 millimeters thick in two new, well-washed crystallizing pans:

$\mathrm{A}$, in the open air, under a glass which kept out dust;

$B$, at 25 atmospheres of superoxygenated air.

August 14. Decompressed.

A has been coagulated since August 11, and smells very bad.

$\mathrm{B}$ is liquid, has no odor, and seems quite normal.

Experiment CCCCXXXII. May 25. On the bottom of 6 tubes a few drops of boiled milk (depth $1 / 2$ centimeter) are carefully dropped.

A. 2 tubes are closed with a flame and kept as controls.

B. The other 4, drawn out in the flame but open, are subjected to 15 superoxygenated atmospheres in the glass cylinder.

June 1. Decompressed.

A has been coagulated since May 27.

$\mathrm{B}$ is not coagulated; closed with the flame.

June 6. B not yet coagulated.

These experiments prove very clearly that oxygen under high tension prevents the coagulation of milk, that is, kills the vibriones which cause lactic fermentation. As the action of these vibriones takes place very rapidly, to check it oxygen must be used in a very high concentration upon a thin layer of liquid, which must be saturated rapidly. For putrefaction, which works much more slowly, these excessive precautions are not necessary; since milk does not, like blood, consume the oxygen as it penetrates the liquid, the oxygen has time to go to the bottom of the tubes and kill there the agents of putrefaction. That explains why it is so easy by compressed air to prevent milk from putrefying, and so hard to prevent it from coagulating.

3. Alteration in urine.

Since the research of M. Van Tieghem, we know that the transformation of urea to carbonate of ammonia is a true fermentation, due to the development of a microphyte, of a torula.

Therefore I studied it somewhat in detail.

Experiment CCCCXXXIII. August 8. Temperature $27^{\circ}$. Urine of the day before, quite acid; in equal quantities in three small bottles covered by paper cones, and placed:

A, at normal pressure, under a bell;

B, in the small Seltzer water receiver, at 4 atmospheres of air;

$\mathrm{C}$, in the cylindrical glass receiver, at 7 atmospheres of an air containing $70 \%$ of oxygen, which corresponds to 24 atmospheres of air. August 11. A, quite turbid, foul, but still acid.

B, decompressed; a little turbid, a little bad odor. Taken to 5 atmospheres of air.

C, decompressed; no turbidness; fresh odor. Taken to 5 atmospheres with $71 \%$ of oxygen, that is, about 18 atmospheres of air. 
August 15. A, completely turbid, very alkaline, horribly foul.

B, turbid, fairly alkaline, not quite so foul.

C, slightly turbid, a little alkaline, begins to smell bad.

Experiment CCCCXXXIV. May 13. Fresh urine, very acid, in two similar flasks.

A, corked, at normal pressure;

$\mathrm{B}$, taken to 10 atmospheres of superoxygenated air.

May 18. A, turbid, neutral.

B, clear, acid.

Experiment CCCCXXXV. June 19. Mixture of fresh urine and urine already spoiled.

A, flask with a stopper.

$\mathrm{B}$, flask with a cork stopper with a hole, taken to 20 atmospheres of superoxygenated air, corresponding to 88 atmospheres of air.

June 24. A, turbid, smells bad; I close the hole in the stopper with wax.

B, decompressed; clear, no odor.

July 6. A, strong odor; turbid; a film on the surface, in which there are myriads of moving organisms and rounded crystals. Strongly alkaline; to acidify a certain quantity, it is necessary to add 4 drops of sulphuric acid.

B, no odor; turbid; film; moving protozoa, but no crystals. Not very alkaline; a single drop of sulphuric acid acidifies the same quantity as in A.

July 30. A is horribly foul and very alkaline; B, which had the stopper replaced without care, has no odor and is not very alkaline.

However the two urines give, by the Yvon method, the same quantity of nitrogen ( 3.5 to 3.7 per cubic centimeter).

Experiment CCCCXXXVI. July 21, 1874. Fresh urine, in equal quantities in two equal matrasses:

A, closed with a cork stopper;

$\mathrm{B}$, drawn out in a flame, with a tiny orifice. Placed at 15 superoxygenated atmospheres; matrass shaken.

July 30. A, turbid, very bad odor.

$B$, clear and has no odor. While I was trying to close the matrass with a flame, it broke; I decanted the urine into a similar matrass which also broke, then finally into a closed tube well washed with boiling water, and then closed with a flame.

In the following months, the turbidness in A keeps increasing; foul odor; color deeper and deeper.

On the contrary, B remains limpid and pale in color.

January 16, 1875. Presented to the Society of Biology. A, very dark-colored, turbid, foul; B, clear, with a slight flaky deposit.

January 18. A, dark-colored, turbid, foul, very alkaline. Analysis by the Yvon process gives $5.8 \mathrm{cc}$. of nitrogen for $1 \mathrm{cc}$. of urine; but by the Grihant process we get only $2 \mathrm{cc}$. of nitrogen, that is, 0.5 centigrams of urea; that is because the Yvon process includes the carbonate of ammonia. 
B, clear; odor quite fresh; normal acidity. The Yvon process gives $6.1 \mathrm{cc}$. of nitrogen for $1 \mathrm{cc}$. of urine; the Gréhant process gives $6.0 \mathrm{cc}$., that is, $1.6 \mathrm{cgm}$. of urea.

May 17. Urine B, which was closed with a flame, is neutral, with hardly any smell; there is a thick vegetation on its surface. Analysis by the Gréhant process gives $1.5 \mathrm{cc}$. of nitrogen for $1 \mathrm{cc}$. of urine, corresponding to $0.4 \mathrm{cgm}$. of urea.

Experiment CCCCXXXVII. May 20. Fresh urine, in three tubes; to each of them I add a small piece of Musculus paper, laden with urinous ferment, which M. Pasteur sent me; this paper, prepared more than six months before, is still very powerful:

$\mathrm{A}$, in open air;

B and B', at 21 atmospheres of air with $81 \%$ of oxygen.

May 24. Decompression.

A, strong odor; very alkaline.

B, B', slight odor; B neutral, B' very slightly alkaline.

Experiment CCCCXXXVIII. May 28. Fresh urine, in two matrasses closed with a cork stopper which is hollowed out;

$A$, in open air;

$\mathrm{B}$, at 23 superoxygenated atmospheres, which fall slowly to 5 .

June 26. Decompression.

A has been foul and turbid for some time.

B, clear with a slight deposit, no odor, closed with wax.

June 28. Presented to the Institute, closed without care, and taken back to the laboratory.

July 11. Is covered with a green mold, but has no odor of ammonia.

So urine is preserved with all its qualities, its color, its odor, its normal acidity, and urea is kept in it in its original proportion. Experiment CCCCXXXVI, which was performed with particular care, is quite conclusive in reference to all of these properties. The agreement of the figures given by the Gréhant process and the Yvon process for the quantity of nitrogen extracted from the compressed urine shows that there was no carbonate of ammonia formed in it, whereas there was much in the urine left at normal pressure.

But if, as in Experiments CCCCXXXV and CCCCXXXVII, a considerable quantity of ferment is added to the fresh urine, alteration will begin. That evidently, as we have already decided in regard to blood and milk, is the result of the fact that the oxygen does not have time to kill the ferments before they have begun to act upon the fermentable matter; however, even in these cases, their action is delayed.

I must say, however, that these experiments on urine should be resumed with special persistence; when the Musculus paper is used, 
there seems to be something complex, the simultaneous action of an organic ferment and a soluble ferment.

4. Brewers Yeast.

Brewers yeast is killed by compressed air, as is shown by the following experiment.

Experiment CCCCXXXIX. June 26. Pieces of very active brewers yeast are placed:

$A$, in a closed flask, normal pressure.

$\mathrm{B}$, in a flask taken to 15 superoxygenated atmospheres.

July 21. A, decayed, with a foul odor; no recognizable trace through the microscope.

B, decompressed; good, fresh odor; seems wholesome outwardly and through the microscope. However, when placed in water with glucose in it, it decays without fermenting, turning acid.

So the yeast lost all its power and life; yet it was preserved from putrefaction by the very agent that killed it.

It is not surprising then that at normal pressure, fermentation by yeast proceeds more energetically than in compressed oxygen. Examples:

Experiment CCCCXL. August 6. Brewers yeast is added to equal quantities of a solution of glucose, at the bottom of four similar tubes:

A, 2 left at normal pressure;

B, 2 taken to 10 superoxygenated atmospheres.

August 8. A, 5 cc. of liquid reduce between 20 and 30 drops of blue reagent.

B, 5 cc. reduce between 40 and 45 drops.

So compressed yeast consumed much less sugar than the other.

Experiment CCCCXLI. May 13. 50 cc. of glucose solution are placed in two flasks, with a piece of brewers yeast of the same weight.

A, closed, left at normal pressure.

$\mathrm{B}$, taken to 10 atmospheres of an air with $76 \%$ of oxygen; tension corresponding to 38 atmospheres of air.

May 18. A, $5 \mathrm{cc}$. of the liquid reduce $1.3 \mathrm{cc}$. of Fehling's solution.

$\mathrm{B}, 5$ cc. reduce $5 \mathrm{cc}$.

The liquid in which the yeast was subjected to compression therefore contained much more glucose than the other.

Experiment CCCCXLII. December 2. Into each of four tubes are poured $3 \mathrm{cc}$. of a weak glucose solution and a piece of brewers yeast as big as the head of a pin.

$A$ and $A^{\prime}$, drawn out in the flame, are kept at normal pressure.

$\mathrm{B}$ and B' are taken to 18 superoxygenated atmospheres.

December 8. Decompression; A and A' contain no trace of glucose.

B and B' contain $15.6 \mathrm{mg}$. of glucose. 


\section{Wine Ferments.}

The same thing is true for the two fermentations which appear so often in wine, and follow the development of mycoderma aceti and mycoderma vini. In the following experiments, the two mycoderms are generally used simultaneously.

Experiment CCCCXLIII. August 8. Temperature 27․ Wine decidedly acid, placed in equal quantities in 3 small bottles; I add to each a small quantity of acetic ferment in full activity: over it.

A, left at normal pressure, covered with a paper cone turned

B, taken to 4 atmospheres of ordinary air.

C, to 7 atmospheres of air with $70 \%$ of oxygen; tension equivalent to 24 atmospheres of air. membrane.

August 11. A. The wine is covered with a very definite white

$B$, very slight film over almost the entire surface.

C, a few very slight small spots.

$\mathrm{B}$ and $\mathrm{C}$ remain under compression.

August 15. A, very thick membrane.

$\mathrm{B}$, pellicle a little thicker than on August 11 .

C, spots as on August 11 .

Experiment CCCCXLIV. August 15. I add to wine placed in a thin layer at the bottom of two matrasses films of mycoderm of vinegar.

A is closed and inverted over water.

$\mathrm{B}$ is agitated for a long time by a current of almost pure oxygen; then I close the matrass, and invert it beside A.

August 17. A is covered with a white film of mycoderms.

$B$ has nothing on the surface.

August 19. A, thick pellicle.

$\mathrm{B}$, slight film.

August 21. A, quite thick membrane.

$\mathrm{B}$, the film slightly thickened.

Experiment CCCCXLV. January 27. Ordinary wine placed in two vials; on the surface is spread a little mycoderm from wine exposed in the laboratory, on which had been sown mycoderma aceti.

This wine contained $11.9 \%$ of alcohol and its equivalent of acidity was 0.08 .

A, with a cork stopper, and left at normal pressure;

$\mathrm{B}$, closed similarly with a stopper with a hole, and taken to 10 atmospheres of an air with $84 \%$ of oxygen; tension equivalent to 42 atmospheres of ordinary air.

February 3. A, slight film on the surface. wax.

$\mathrm{B}$, decompressed; nothing on the surface; stopper sealed with

February 17. A, thick membrane.

$\mathrm{B}$, nothing on the surface.

May 24. Shown to the Committee of the Academy of Sciences. 
A, turbid, with a thick layer of mold on the surface; microscopic examination shows that there are present only mycoderma vini and some ferments of bitters.

When filtered and tasted, it is a horrible parody of wine. It has only $9 \%$ of alcohol and its equivalent of acidity is only 0.045 .

B, very clear, but very much "faded", with a slight deposit of coloring matter, in which are present a little mycoderma vini and numerous filaments of ferment of bitters.

As for the taste, it is not acid, but rather a little bitter, and is like good Burgundy which is too old; it was a very mediocre wine. is 0.07 .

It still contains $11 \%$ of alcohol and its equivalent of acidity

When exposed to the air, the next day it is extremely acid and quite unfit for drinking.

(The chemical analyses were made in the laboratory of $\mathbf{M}$. Schutzenberger, and the microscopic examinations were made by $\mathbf{M}$. Gayon.)

Experiment CCCCXLVI. February 24. Fine Burgundy wine. side.

A, kept as control in a full flask, well corked and lying on its

B, flask almost full, at normal pressure; I sow on top of it mycoderm of vinegar, and close it.

C, large test glass with a strong stopper of new cork with a hole in it. I sow on top of it more mycoderms than on B. Taken to 10 superoxygenated atmospheres.

March 1. B is covered with mycoderms.

C, which I decompress in 24 hours has no sign of them; I seal the hole in the cork.

May 17. The three flasks are taken to the laboratory of $\mathbf{M} . \mathbf{H}$. Ste.-Cl. Deville, and uncorked before MM. Deville, Boussingault, Debray, etc.

A, fine red color; no deposit. Very firm in taste, no bitterness.

$\mathrm{B}$, horrible weak wine, turbid, pale.

C, color very fine, a little amber. Deposit abundant, very adherent. Agreeable odor. Taste not acid, but a little flat and definitely bitter, although not too disagreeable. Absolutely like our good Burgundy wines, when they begin to be slightly bitter.

Experiment CCCCXLVII. June 19. Ordinary wine; placed in two flasks and in it are sown mycoderms very active in the laboratory.

A, well closed; normal pressure.

$\mathrm{B}$, closed, with a hole in the cork; taken to 20 atmospheres of air with $88 \%$ of oxygen, corresponding to 88 atmospheres of air.

June 24. A, covered with mycoderms.

$\mathrm{B}$, decompressed, without mycoderms, but with a deposit of coloring matter; so it is "faded". Well sealed.

July 6. A, clear wine, rosy, with a film of mycoderma vini on the surface, and a gelatinous, flaky deposit, containing much mycoderma aceti. Strong odor of vinegar. To neutralize the acidity, I had to use a quantity of lime water 2.3 times greater than for B. 
B, clear, pale; on the surface, iridescent film, without organisms; deposit of coloring matter. Very weak acid odor.

Experiment CCCCXLVIII. June 26. Good Burgundy wine in a flask taken to 15 atmospheres of superoxygenated air.

July 21. Decompressed. Very pale color of Rancio wine. No longer has any bouquet. No acidity; very weak, with a slight taste of boiled wine.

Experiment CCCCXLIX. July 21, 1874. Ordinary wine, in two matrasses one quarter full.

A, sowed mycoderms of wine; closed, sealed, at normal pressure.

$\mathrm{B}$, sowed similarly; the matrass is drawn out in the flame, and taken to 15 superoxygenated atmospheres.

July 30. A, covered with mycoderms.

B, without mycoderms, but pale, with adherent deposit. Decompressed, closed with a flame.

January 18,1875 . A, very thick membrane on the surface; very pronounced acetic odor; taste of vinegar. The acidity, measured by soda and litmus, is 6 times stronger than in B. It turns the solution of potassium bichromate green in sulphuric acid; therefore it still contains alcohol.

$\mathrm{B}$, color very pale; very thin films on the surface and on the walls of the vessel; definite winy odor, taste not very acid, an extremely weak wine. Still contains alcohol.

Experiment CCCCL. May 20. Wine in tubes, on the surface of which mycoderms have been sown;

$A$, in open air, covered with an inverted cone.

B, at 21 atmospheres of an air with $81 \%$ of oxygen.

May 24. Decompressed.

A, thick layer of mycoderms, liquid turbid.

B, "faded", yellowish; precipitate of coloring matter; no mycoderms; clear liquid.

I boil wine in balloon flasks; during the boiling, I close each flask with a stopper furnished with a long tube curved and drawn out, through which the air enters slowly, cooling as it enters.

When the liquid is cool, I open the flasks for an instant and throw into one, $\mathrm{A}^{\prime}$, the contents of tube $\mathrm{A}$; into the other, $\mathrm{B}^{\prime}$, the contents of tube $\mathrm{B}$.

May 31. A', thick pellicles.

B', no mycoderms.

Experiment CCCCLI. May 28. Wine in a matrass; mycoderms sowed on the surface;

A, open air;

$B$, at 23 superoxygenated atmospheres, which in the last days of the compression, fall to 5 .

May 31. A is covered with a continuous film.

June 26. Decompression.

A, thick layer of mycoderms; liquid very turbid.

$\mathrm{B}$, liquid very clear, with deposit of coloring matter; nothing on the surface. 
So under the influence of oxygen at high tension, the mycoderm which consumes the alcohol entirely and the one which merely transforms it into acetic acid are absolutely killed. The wine thus retains its alcohol and its acid content (Exp. CCCCXLV).

The effect of the oxygen begins to appear before the tension which corresponds to 5 atmospheres of air (Exp. CCCCXLIV.)

However the wine undergoes certain alterations. The coloring matter is precipitated in the form of films adhering to the vessel, it "fades" more or less completely, and sometimes has a beautiful, slightly amber color (Exp. CCCCXLV), sometimes a tint like Rancio wine (Exp. CCCCXLVIII) or finally an almost entire loss of color (Exp. CCCCXLIX).

In taste, the wine appears to age rapidly (Exp. CCCCXLVI); it even becomes quite bitter (Exp. CCCCXLV) or very much weakened (Exp. CCCCXLVI). It loses its bouquet, and sometimes has a slightly cooked flavor (Exp. CCCCXLVIII).

In a word, the wine appears to undergo the alterations produced by excessive heating, brought on by contact with the air.

I will call attention to the fact that in all these experiments the pressure was extremely high, carried no doubt far beyond what would be needed to kill the germs. A weaker pressure perhaps would not change the wine, and yet would preserve it from harmful fermentations. Perhaps it would even be slightly improved, as happens in the case of harsh and raw wines when they are heated in accordance with the rules established by M. Pasteur.

Besides, the wines were tasted after a fairly long time. Possibly if they had been tasted immediately, a certain improvement would have been noted.

All these questions, moderately interesting from the scientific point of view, take on a considerable importance when considered from another point of view. However, I could not turn aside unduly from my general studies to investigate them, and after noting the preceding facts, I had to postpone until another time detailed researches and practical applications, if possibly there are any.

I merely report here an experiment which proves that the limit at which oxygen at high tension acts unfavorably on wine is quite low; hence we conclude that its favorable concentration, if there is one, as the preceding experiments seem to indicate, might be obtained industrially, since ordinary air could be used.

Experiment CCCCLII. July 15. Good red wine in two sealed bottles the corks of which are pierced by a hole,

$A$, in the air, upright. 
$\mathrm{B}$, at 10 atmospheres of air, upright.

July 29. Decompressed. The appearance of A has not changed.

B is violet colored, with a colored precipitate, abundant, adhering to the vessel.

October 4. Tasted. A, good taste, quite good bouquet.

$\mathrm{B}$, colorless, bouquet lost, smells flat.

\section{Molds.}

In a great number of experiments, generally made with another purpose, several of which have already been reported, I have observed that oxygen at high tension kills microscopic organisms, animal or vegetable, besides ferments. Liquids suited to the development of infusoria contain no trace of them after a certain time in compressed oxygen; they are completely purified of them, when they already contained them, both animal and vegetable, both simple monads and the highest infusoria in the series.

Evidently these facts have only a slight importance, considering all those which we have already enumerated, and so we shall not give a report of any special experiment. The universality of the fatal effect of oxygen at high tension has been sufficiently established by all the experiments reported hitherto. It would be a strange philosophy to imagine-and yet eminent intellects have made this serious mistake in the matter of so-called spontaneous generation-that microscopic dimensions can give special powers to beings of that size, and authorize in their favor infringements of the most general rules of nature.

Quite naturally molds have behaved like the so-called higher plants. And yet it seems worth while to report here a few exper:ments which deal principally with them. These data may be useful, in fact, in solving questions relating to the general theory of fermentations.

Experiment CCCCLIII. June 26, 1874. Two pieces of wet bread, measuring a few cubic centimeters, are placed:

A, in a large flask closed with a cork stopper.

$\mathrm{B}$, in a small flask closed similarly but with a cork pierced by a hole. Taken to 15 superoxygenated atmospheres.

July 21. A has for several days been in deliquescence and is covered with green mold.

$\mathrm{B}$, white, firm, very fresh in appearance; no vegetation.

January 18, 1875. A is only shapeless fragments, in which there is no sugar left; neutral to litmus.

B presents exactly the same appearance as on July 21. When opened, it has a slight acid odor, agreeable, which is not that of acetic acid, but is like that of lactic acid. It turns litmus a deep red, and owes this effect to an acid which resists prolonged boiling and com- 
plete dehydration. It precipitates copper reagent in abundance; it is turned completely blue by iodine.

Experiment CCCCLIV. July 21, 1874. Bread cut in small pieces, moistened, and placed:

$\mathrm{A}$, in a closed matrass;

$B$, in a matrass drawn out in a flame; it is subjected to 15 superoxygenated atmospheres.

July 30. A, covered with mold.

$\mathrm{B}$, has not changed in appearance.

January 18, 1875. A, in decay.

B, which I do not open, looks the same as on July 30 .

August 3. B is opened $\mathrm{m}$ the laboratory of $\mathrm{M}$. Cloez and in his presence; the appearance has not changed; the reaction is slightly but clearly acid; odor sourish, agreeable.

I call attention to this acid reaction presented by the bread in spite of its apparent preservation and the complete lack of mold. We had already noted a similar reaction in meat and egg, protected against putrefaction by compression.

I observed it when I used cooked starch instead of bread to simplify experimental conditions.

Experiment CCCCLV. July 21, 1874. I scatter over starch cooked with a good deal of water various dusts taken from a corner of the laboratory.

A, closed matrass, normal pressure;

$B$, matrass drawn out in a flame, 15 superoxygenated atmospheres.

July 30. Decompressed B; while it was being closed with a flame, the matrass broke. I immediately poured the contents into a tube washed in boiling water, which I closed at once with a flame.

January 18, 1875. A, covered with mold, contains neither sugar nor starch.

$\mathrm{B}$, clean, without mold, contains much glucose, and is colored very blue by the aqueous solution of iodine.

Experiment CCCCLVI. August 7, 1874. Starch cooked and much diluted with water:

A, in a matrass closed with a stopper.

$\mathrm{B}$, in a matrass, drawn out in a flame, maintained between 8 and 12 superoxygenated atmospheres, until August 17, when I decompress it and close it with a flame.

January 18, 1875. A, foul, neutral;

$\mathrm{B}$, no change in outer appearance; sourish and perfumed odor, recalling that of cider.

Very acid, it is colored blue by iodine and contains glucose.

M. Schutzenberger, who consented to examine this substance, found in it volatile acids, acetic and formic, and a fixed acid, giving, with zinc, crystals of the same form as the lactates. 
Experiment CCCCLVII. July 5, 1875. Cooked starch and water; glass tubes. pheres.

A, closed with a flame, ordinary air;

B, drawn out in a flame; taken to 15 superoxygenated atmos-

July 17. Decompressed; B closed with a flame.

November 16, 1876.

A, neutral, contains much glucose; no odor.

B, clearly acid; much glucose; no noticeable odor.

FRUITS. Experiment CCCCLVIII. June 26, 1874.

A, 3 entire cherries, very ripe, are placed in a small flask with a little water.

Taken to 15 superoxygenated atmospheres.

$B$, unfermented juice of cherries left at normal pressure, in a closed flask;

C, unfermented juice of cherries, placed beside A.

July 21. B, evidently spoiled, covered with mold.

$\mathrm{A}$ and $\mathrm{C}$, in very good condition, have a rather deep color.

January 18,1875 . B is a horrible magma.

A. The cherries are very fine and very firm, absolutely just as they were July 21.

November 30,1876 . The cherries in A still look the same.

May 1, 1877. Same.

Experiment CCCCLIX. May 28. Matrass containing: A and B, whole cherries; A' and B', pears.

$\mathrm{A}$ and $\mathrm{A}^{\prime}$ are left in the air, covered by an inverted paper cone.

B and B' are placed in 23 superoxygenated atmospheres; the pressure gradually falls to 5 atmospheres.

Beginning with May $31, \mathrm{~A}$ and $\mathrm{A}^{\prime}$ are covered with mold.

June 26. A and A' are molded, the pears in shapeless pulp.

$\mathrm{B}$ and $\mathrm{B}$ ' have no mold; the cherries are brown, the pears amber colored.

Experiment CCCCLX. January 20. Juice of pounded onion with powdered chalk added; tubes:

A, normal pressure;

$B$, at 21 superoxygenated atmospheres.

January 23. Decompressed; the tubes closed with a flame.

May 17. A, neutral; abundant vegetation on the surface.

$\mathrm{B}$, neutral; no mold.

Experiment CCCCLXI. July 5, 1875. Stoned cherries, to which a little glucose is added. Placed in columns about $10 \mathrm{~cm}$. high in three tubes, taken to 15 superoxygenated atmospheres.

July 17. Decompressed; the cherries taste like cooked cherries but too acid. Tubes closed with a flame.

November 16, 1876. The appearance of the cherries has not changed; no explosion when the tubes are opened; cherries taste like brandied cherries, but too acid.

By the method of oily drops, M. Dastre finds much alcohol in them; he estimates the proportion of it at $1 \%$. 
Experiment CCCCLXII. July 5. Apricots and cherries in flasks.

$A$, in open air;

$\mathrm{B}$, at 8 superoxygenated atmospheres.

July 9. A, covered with mold.

$\mathrm{B}$, without mold; the apricots have a strange pungent odor.

Experiment CCCCLXIII. July 15. Apples, pears, grapes, in separate bottles, closed by sealed stoppers which are pierced by holes.

$A$, in the open air.

$\mathrm{B}$, at 10 atmospheres of air.

July 29. Decompression.

A, the apples and pears are spoiling; liquid is issuing from them; the grapes are putrefying; all of the grapes have fallen from the stalk, which is left hanging; mold; closed with wax.

$\mathrm{B}$, apples and pears have become brown, and seem cooked; grapes well preserved; no mold; closed with wax.

October 4. A: fruits completely decayed;

$\mathrm{B}$, apples and pears softened, taste like cooked fruits; grapes with mold, but the fruit still clings to the stalk.

Experiment CCCCLXIV. September 23. Reine-claude plums, ripe, very wholesome:

A: normal pressure;

B: 15 superoxygenated atmospheres.

September 29. A: intact; normal taste;

B: also intact in appearance; taste of cooked plums.

Fruits then are perfectly preserved, as far as form is concerned, in oxygen at high tension; they are protected from mold. The cherries in Experiment CCCCLVIII, kept unchanged in appearance for 3 years, after return to normal pressure, give a striking example of that. But their color changes, their taste especially, which is more or less like cooked or brandied fruit. This research should be continued from the chemical point of view, especially considering the production of alcohol noted in Experiment CCCCLXI. The relation of these data to those noted by MM. Bellamy, Lechartier, and Pasteur should be investigated.

\section{Subchapter II}

\section{DIASTATIC FERMENTATIONS}

I now come to the study of the effect (if there is one) of oxygen at high tension upon the ferments which are soluble in water and precipitated by alcohol, which are called diastatic ferments, zymotic, or false ferments, etc. 


\section{Saliva and Diastase.}

The zymotic fermentation upon which I was to experiment most frequently is that by which diastase transforms starch into glucose. Besides the considerable interest presented by this phenomenon, which plays so great a part in the digestion of animals (saliva and pancreatic juice), in their nutrition (hepatic glycogenesis), that of plants and germination, I was influenced by the ease with which one can measure its effects exactly.

The first question to be settled was whether the diastatic ferment. is killed by oxygen at high tension, as the organic ferments so surely are. The following experiment will give the answer.

Experiment CCCCLXV. June 26. Diastase is dissolved in a little water and placed in two tubes:

A: normal pressure.

B: at 15 superoxygenated atmospheres.

July 21. Decompressed B, which has no odor and has retained the most energetic transforming power, whereas A smells bad and no longer has any effect on cooked starch.

Experiment CCCCLXVI. February 16. Diastase and water in a tube drawn out. Placed at 15 atmospheres of superoxygenated air.

May 5. Decompressed, has retained all its effect. I make a new solution of diastase in a tube which I close with a flame, as I also do with the first.

May 17. The diastase which was compressed still acts upon starch; it has no odor. The other has a butyric odor and no strength left.

So diastase, far from being spoiled by oxygen at high tension, is preserved perfectly in it. It even appears that it remains powerful almost indefinitely, in all probability because of the destruction by the compressed air of the organic ferments, which would have caused it to putrefy at normal pressure.

We get the same result when we experiment upon, not pure diastase dissolved in water, but the complex mixture which constitutes the buccal saliva. Example:

Experiment CCCCLXVII. July 21, 1874. Human saliva diluted with water and placed in a matrass drawn out in a flame, and subjected to 15 atmospheres of superoxygenated air.

July 30, I make the decompression and close the end of the tube which was drawn out.

January 18, 1875. This saliva, which has no odor and appears quite normal, neutral to reagents, has a powerful transforming effect upon starch cooked in glucose.

So saliva is preserved in compressed air; but I must confess that it keeps very well in open air also. Unfiltered human saliva, 
placed in a closed tube January 18, was still active February 12; although a very small orifice was left open in the tube then, the saliva still had considerable activity May 17.

The same thing is true of the pancreatic juice and in general of the soluble ferments, which even resist beginning putrefaction.

But now, even if it is preserved in compressed air, does the ferment retain its activity there? And does it act there with more or less energy than at normal pressure?

Experiments will give the answer. I call attention to the fact that I took raw starch in suspension in water, because cooked starch is transformed instantaneously on contact with saliva.

Experiment CCCCLXVIII. July 18. My saliva, filtered, is mixed with a certain quantity of water holding raw starch in suspension; it is mixed carefully and placed in 3 open tubes:

A. Left at normal pressure.

B. Taken to a half-atmosphere.

C. At 8 superoxygenated atmospheres.

The tubes and apparatuses are placed in identical conditions of temperature.

July 20. Withdrew the tubes, filtered the liquids rapidly, and tested them with Fehling's reagent.

A. 5 cc. reduce from 75 to 85 drops of copper reagent.

B. 5 cc. reduce from 65 to 75 drops of copper reagent.

C. $3 \mathrm{cc}$. reduce from 50 to 60 drops of copper reagent.

Experiment CCCCLXIX. May 26. Filtered saliva, mixed with raw starch in suspension in an equal volume of water. The liquid, well mixed, is placed in equal quantities in 2 tubes, one of which, $\mathrm{A}$, is left at normal pressure, the other, $\mathrm{B}$, is subjected to 15 superoxygenated atmospheres.

June 3. A evidently contains much more sugar than B.

However the deposit at the bottom of tube $\mathrm{A}$ is colored an intense blue by iodine, whereas that in B gives only a greenish discoloration.

Experiment CCCCLXX. January 20. Saliva, raw starch, and water. Well mixed and placed in tubes. We make sure that the mixture contains no glucose.

A. At normal pressure, covered with an inverted paper cone.

B. At 21 atmospheres of superoxygenated air.

Both are placed in the drying-oven, at 30 degrees.

January 25. Tested with copper reagent.

A. 7 cc. reduce 35 drops.

B. 7 cc. reduce only 14 drops.

Experiment CCCCLXXI. March 22. Saliva, raw starch, and water. Mixture placed in tubes.

A, A'. At normal pressure.

B, B'. At 9 superoxygenated atmospheres.

March 24. Tested with copper reagent. 
A and A' contain a little more glucose than B and B'; slight, but evident difference; examinations made with great care on white paper.

Experiment CCCCLXXII. May 25. Saliva, raw starch, and water. Equal quantities in six tubes.

A. Three are drawn out in the flame and left at normal pressure.

B. Three at 15 atmospheres of superoxygenated air.

May 27. Analyses of the tubes by M. Dastre. glucose.

A. Contain $2.2 \mathrm{mg}$; $2.9 \mathrm{mg}$; $1.7 \mathrm{mg}$; an average of $2.3 \mathrm{mg}$. of glucose.

B. Contain $1.6 \mathrm{mg}$; $1.9 \mathrm{mg}$; $1.7 \mathrm{mg}$; an average of $1.7 \mathrm{mg}$. of

In these experiments, the transformation of starch into sugar continued to operate in compressed oxygen, but its intensity has evidently diminished.

But to obtain this result, one must not wait too long, but must examine the liquids after a very few days. Otherwise, especially if diastase was used, the result would be just the opposite, and the compressed liquid would be richer in sugar than the other. This happened, for example, in the following experiments.

Experiment CCCCLXXIII. June 26. Raw starch in suspension in water, mixed with a certain quantity of diastase. Well shaken; placed in 2 tubes:

A. Normal pressure.

B. 15 superoxygenated atmospheres.

July 21. A, 5 cc. reduce 25 drops of copper reagent.

B left under compression till then; 5 cc. reduce 40 drops.

In both there is still some starch.

Experiment CCCCLXXIV. March 1. Saliva, raw starch, water, equal quantities in 12 tubes:

A. Six are drawn out in the flame and left at normal pressure.

B. Six are placed at 15 superoxygenated atmospheres.

March 28. Analysis of the tubes by M. Dastre.

A. 2 tubes contain quantities of glucose proportional to the numbers 45 and 39 ; hence, an average quantity of $1.7 \mathrm{mg}$.

B. 3 tubes analyzed contain quantities of glucose proportional to the numbers $111,119,115$; hence an average quantity of $4.6 \mathrm{mg}$. of glucose.

That is easily explained; the diastase which had been left in the air had altered a little, whereas that which was under compression had kept its properties and continued to act.

\section{Pepsin.}

Experiment CCCCLXXV. February 16. Boudaut pepsin; three tubes, in each of which are placed 2 grams of pepsin with $5 \mathrm{cc}$. of distilled water. 
A. In the air, covered with a paper cone.

B and B'. In 15 atmospheres of superoxygenated air.

March 5. Decompression.

A. Smells rather strong and is covered with mold which forms a stopper; very acid.

$B$ and B'. No odor; no mold; acid.

I put B and B' each in a glass with 10 grams of cooked white of egg which has been cut into pieces; the glasses, which are of the same size, are next filled with water acidulated with hydrochloric acid.

I take 2 grams of powdered pepsin, place them in 5 cc. of distilled water, and add 10 grams of the cooked white of egg, and the same quantity of acidulated water.

The three glasses are placed in the drying oven at 38 degrees.

March 8. There remain in each glass 2 grams of insipid white of egg.

So pepsin, after being subjected to the effect of oxygen at high tension, behaved absolutely as before.

\section{Inversive Ferment of Yeast.}

The ferment which I used, like the myrosine and emulsine to be discussed in the following sections, had been prepared by $\mathbf{M}$ Schützenberger, then head of the laboratory of chemical research of the Faculty of Sciences.

Experiment CCCCLXXV (2). February 16. Placed 5 cc. of liquid in three tubes drawn out in the flame.

A. In open air, covered by a paper cone.

B and B'. At 15 atmospheres of superoxygenated air.

March 5. Decompression; I close the three tubes with the fiame; but first I make sure that the ferment in tubes $A$ and $B$ transforms cane sugar rapidly into glucose.

March 15. Placed in the drying oven, in which the temperature varies from 25 to 40 degrees.

March 25. Withdrawn from the drying oven; A, B, and B' are still potent.

May 17. A is alkaline and foul; has no potency.

$B$ and $B$ ' are acid, have no odor, and have kept their power.

4. Myrosin.

Experiment CCCCLXXVI. February 16; in 3 tubes drawn out in the flame; liquid to a height of $5 \mathrm{~cm}$.

A. Free air, covered with a paper cone.

B and B'. At 15 atmospheres of superoxygenated air.

March 5. Decompressed; A and B act perfectly upon potash myronate to give essence of mustard.

March 15. Placed in the drying oven, from 25 to 40 degrees.

March 25. Taken from the drying oven; A and B are still potent.

May 17. A, B, and B' are still potent, but the last two have more energetic action. 


\section{Emulsin.}

Experiment CCCCLXXVI (2). February 16. This experiment was performed at the same time and under the same conditions as the three preceding ones.

March 15. There is much mold on the emulsin which was not compressed; no molds on the other, any more than on the other tubes.

The formation of the essence of bitter almond on contact with amygdalin takes place in both liquids, March 25, when taken from the drying oven.

May 17. The emulsin which was not compressed is covered with mold, alkaline, foul, and impotent.

The other seems fresh, has no odor, is slightly acid, and acts energetically and rapidly.

In summary, all the soluble false ferments upon which we experimented, salivary diastase, pepsin, inversive ferment, myrosin, emulsin, have given us the same result and have kept their characteristic power after the prolonged effect of oxygen at high tension. And even more, since the oxygen frees them of the germs of mold, vibriones, etc., which sooner or later destroy them in the open air, they remain themselves for an apparently indefinite time.

This remarkable power can perhaps be used in practice, and especially in therapy. It would be a good idea, I feel sure, to substitute for powders and extracts, so harmful to the digestive juices, the juices themselves, previously subjecting them to a sufficient pressure, to prevent putrefaction in them. But I can merely suggest this idea here.

\section{Subchapter III}

\section{EFFECT OF OXYGEN AT HIGH TENSION UPON THE ANATOMICAL ELEMENTS}

After noting, in Chapter IV, the rapidly fatal effect of oxygen at high tension upon the higher animals, we tried to analyze this effect, according to the methods introduced by M. Claude Bernard in toxicology. Sectioning of the nerves, examination of the heart, use of anesthetics, and the injection of the blood of animals killed by oxygen into the veins of other animals have showed us that the violent symptoms which precede and bring on death, are the result of an over-excitement of the nervous centers, so that I was led to compare the effect of oxygen with that of strychnine and phenol. After death, the muscles are still contractile, the nerves are 
excitable, the reflex acts are possible, and the heart is still beating. But does this mean that the nervous anatomical elements alone are attacked by oxygen? All that we have said hitherto is opposed to that hypothesis; the considerable decrease of the intra-organic oxidations, the death of lower animals, the death of plants and ferments, all these phenomena show a universality of effect which evidently must extend to the anatomical elements of the higher animals.

Yet I could not be satisfied in this case, any more than in any other, with conclusions drawn from analogy. I thought direct experiments necessary; but I confess that, seeing how well they agreed with what appeared so probable, I did not make their number very great.

Experiment CCCCLXXVII. February 20. The hind-quarters of a frog are cut in two, following the vertebral axis.

A. One of these parts is left at normal pressure, hung in a closed test glass, at the bottom of which water is placed to prevent desiccation.

B. The other is hung similarly in the cylindrical glass apparatus, in which the pressure is raised to 10 atmospheres of air with $80 \%$ of oxygen.

February 24. A. The sciatic nerve is no longer excitable; the muscles still contract under the influence of a rather weak current; they are neutral in reaction.

B. Neither the muscles nor the nerves are excitable by the strongest currents. There is evident rigidity, and the muscles are very acid.

Experiment CCCCLXXVIII. March 2, 2 o'clock. Halves of frogs arranged as in the preceding experiment; $\mathrm{A}$ at normal pressure, $\mathrm{B}$ at 15 superoxygenated atmospheres.

March 3. 4 o'clock. A: sciatic nerve quite excitable; muscular contraction very strong and very sudden, as in the normal state.

B: The sciatic nerve can no longer be excited by any current. The muscles still contract; but the contraction is slow, resembles a kind of a cramp, and lasts after the stimulus has ceased.

Experiment CCCCLXXIX. April 8. Experiment still arranged in the same way; A at normal pressure, B at 3 atmospheres of air containing $50 \%$ of oxygen, which corresponds in tension to 7.5 atmospheres of air.

April 10. A. Muscular contractions obtained with the inductorium, the movable coil being $16 \mathrm{~cm}$. from the exterior of the fixed coil.

B. To get contractions, it is necessary to bring the coil to 5 centimeters. The contraction is accompanied by contracture.

Experiment CCCCLXXX. June 12, 4 o'clock. The hearts of 4 frogs are removed. These hearts are placed 2 by 2 in a capsule in which they lie in the vitreous humor of a dog.

A. Left at normal pressure. 
B. Compressed in the cylindrical glass apparatus to 10 superoxygenated atmospheres.

6 o'clock. A. The hearts are still beating occasionally, especially the auricles; they can be stimulated. ulation.

B. They have completely stopped, and cannot be revived by stim-

These data show that muscular contractility, motor rerve excitability, and the rhythmic action of the nerve ganglia of the heart stop much sooner in oxygen under high tension than under normal pressure with ordinary air. In other words, the muscular, nerve, and ganglionic anatomical elements, like the free elements which constitute the ferments, are killed by compressed oxygen.

Other researches, in which I used the method of animal grafting, the only one which could inform us on this point, show that not only the vital properties of the higher order, the animal order, are destroyed in the muscular and nervous elements, but that all the anatomical elements are killed by oxygen at high tension. In fact, the grafts carried out with parts subjected in advance to its effect were absorbed without having become adherent.

Experiment CCCCLXXX1. March 15. Tails of rats, with skin removed, are hung in closed glass tubes, with a little water at the bottom.

One of them, A, is left at normal pressure.

The other, B, the stopper of which is pierced by a hole, is subjected to 10 atmospheres of superoxygenated air, from March 16 to March 20. Temperature 12 degrees.

March 20. A smells rather bad. B no odor.

Grafted under the skin of the back of two rats.

No complication.

July 16. Graft A has taken root perfectly.

$\mathrm{B}$ is almost entirely absorbed.

Experiment CCCCLXXXI (2). March 22. Tails of rats, with skin removed, hung in tubes, above a little water.

A. Normal pressure.

B. At 9 superoxygenated atmospheres.

March 24. Grafted on two rats.

No complications.

June 1. A, graft has taken root perfectly.

B. Almost entirely absorbed.

The transfusion of blood, which is only a particular case of the general method of animal grafting, also shows that the blood which has undergone the prolonged action of compressed oxygen is incapable of maintaining life; its anatomical elements, its corpuscles, are killed and their introduction into the organism even causes death. Example: 
Experiment CCCCLXXXII. April 20. 100 cc. of dog blood, defibrinated, are shaken continuously for 18 hours in the apparatus pictured in Figure 45, with oxygen compressed to 18 atmospheres.

April 21, from a little dog (weighing 5 kilograms) $100 \mathrm{cc}$. of blood are taken, a loss of blood which certainly would ${ }^{2}$ not have killed him, and into his femoral vein is slowly injected the $100 \mathrm{cc}$. of blood which had been shaken and deprived of free gases.

The injection is made at 11 o'clock. Immediately after, the animal begins to run; but he soon retires to a corner, falls into a sort of somnolence, and dies at $5: 30$; his rectal temperature at this time is $29.5^{\circ}$.

So the anatomical elements of the bones and the cellular tissue were killed by the oxygen at high tension; the blood acquired toxic properties; grafts were absorbed without having made vascular adherences. If they did not cause cellulitis, that is probably because the oxygen had killed all the atmospheric germs which might have lodged there; besides, I obtained similar results before.

We conclude from these data that the death of higher animals in compressed oxygen, although its immediate cause is the superexcitation of the central nervous system, as we have demonstrated, is really due to a general effect of the oxygen upon the whole organism. But the nervous elements, which are more susceptible, react first, disturb the vital mechanisms, so that death occurs before the other elements are noticeably affected.

Hence we draw again the conclusion that the death of the anatomical elements has nothing to do with putrefaction; it is not the first stage of putrefaction, as might have been thought with apparent reason; it is quite a different thing, because pressure, which hastens death, prevents putrefaction.

\section{Subchapter IV}

\section{ON THE USE OF OXYGEN AT HIGH TENSION AS AN EXPERIMENTAL METHOD}

The data which have just been reported in the two preceding subchapters seem to me to present considerable interest, not only in themselves, but from the point of view of the use of oxygen at high tension as an experimental method. We have seen, in fact, that the microscopic organisms which constitute the true ferments and that anatomical elements, isolated or grouped in tissues, are killed by oxygen; that on the contrary the unformed ferments, the 
soluble ferments, the diastases, resist it perfectly and are even preserved by it.

We possess then a valuable instrument of differentiation to distinguish what belongs to one or the other of the two classes of fermentations.

If we are dealing with a true fermentation, it will be checked completely by compressed oxygen, under a tension corresponding to about 30 atmospheres of air, and since the ferment is killed, it will not appear again, even when the pressure becomes normal once more. If the fermentation is due to the presence of a substance analogous to diastase, this substance, when subjected to compressed air, should keep its active properties there almost indefinitely, as a subsequent experiment will show.

I make haste to say, however, that although it is very easy to decide in this way whether a given phenomenon is a true fermentation, the method will not distinguish between a pseudo-fermentation and the result of a simple oxidation. An example taken from the dry rot of fruit will explain my idea.

\section{Dry Rot of Fruit.}

Certain fruits, for example medlars and service-apples, are commonly attacked by dry rot, so that, since they can be eaten only in this condition, it is generally confused with ripeness. Is dry rot the final stage in a vital evolution of the cells of the fruit? Is it the result of the reaction of a diastatic matter previously formed on the tannin, which disappears during the dry rot? Or, finally, the result of an oxidation of this tannin, the disappearance of which takes from the fruit its disagreeable taste? Let us see first what experiments say.

Experiment CCCCLXXXIII. September 29. Service-apples not affected by dry rot, in good condition, placed carefully in test glasses.

A, left in open air.

B, subjected to a pressure of 10 superoxygenated atmospheres.

October 4. Decompressed.

A, beginning to rot.

$\mathrm{B}$, evidently still more rotten.

Experiment CCCCLXXXIV. November 5. Medlars not affected by dry rot.

$\mathrm{A}$, at normal pressure.

$\mathrm{B}$, at 17 atmospheres in air containing $78 \%$ of oxygen.

November 11. Decompressed.

A, still very hard, do not suffer dry rot until a week after.

B, completely rotten, and consequently, from the sudden decompression and the escape of gases, cracked and burst. 
So not only was dry rot not checked by the effect of oxygen at high tension, but, on the contrary, it was accelerated. That alone is enough to show us that we are not dealing with an act of cellular life.

But is it a diastatic act? Are we dealing with a direct oxidation? Oxidations of this sort are not checked by oxygen at high tension; at least, that is the case with pyrogallate of potash.

Experiment CCCCLXXXV. February 10. At the bottom of a glass is a solution of pyrogallic acid; a little capsule containing potash floats on the surface. The whole is subjected to 10 superoxygenated atmospheres in the cylindrical glass apparatus.

February 13. The apparatus is shaken without being opened; as soon as the potash touches the acid, the liquid reddens instantaneously, certainly more rapidly than it would have done at normal pressure.

The acceleration of dry rot in compressed oxygen seems to indicate that it is the result of an oxidation. The following experiment, seems to demonstrate this fact.

Experiment CCCCLXXXVI. November 12. Very hard medlars are pounded in a mortar, and the paste thus obtained is poured into a glass.

Two hours after, dry rot has begun on the surface of the pasty mass.

In summary, we see, thanks to the use of oxygen at high tension, that dry rot is certainly not an act in the life of the cells of the fruit, but very probably the result of a direct oxidation.

\section{Ripening of Fruits.}

The same question can be asked about the regular ripening of fruits. If this is a phenomenon of diastatic type, it will continue in compressed oxygen; if it is an act of cellular life, it will be checked. The experiment is quite difficult to carry out, because we must use fruits which ripen easily and quickly off the tree, which are not too subject to harmful changes, and which are small enough to be penetrated by the oxygen rapidly.

Experiment CCCCLXXXVII. July 9. Gooseberries which are hardly pink, beginning to ripen.

$A$, at normal pressure.

$\mathrm{B}$, in the cylindrical glass apparatus.

July 17. Decompressed.

A, very red, sweet, tender, quite ripe.

$\mathrm{B}$, have not changed color; are firm and hard, acid, with the taste of rather tart cooked gooseberries. 
Experiment CCCCLXXXVIII. July 19. Plums beginning to ripen.

A, normal pressure.

B, 15 superoxygenated atmospheres.

July 26. Decompressed.

$A$, are eatable, softened, and quite yellow.

$\mathrm{B}$, have become a dark brown color; remained very hard, extremely acid, with the odor and taste of cooked plums.

The two examples are sufficient to show very clearly that the ripening of fruits is a vital act, due to a certain cellular evolution, and consequently essentially different from dry rot, with which it is often confused.

I call attention to this cooked taste which fruits acquire under the influence of compressed oxygen. It was noted in the experiments of Subchapter I, in reference to the development of mold. It is evidently due either to an exaggerated oxidation or to the effect of a diastatic pseudo-ferment.

\section{Venoms.}

The only venom upon which I could experiment is scorpion's venom, the dried vesicles of which I kept for several years; it came from the Buthus occitanus (Amor.) and had been sent me from the south of Algeria.

Experiment CCCCLXXXIX. December 2. Twelve dried scorpion: vesicles; they are crushed with a little water; then they are subjected to the pressure of 18 superoxygenated atmospheres. (The liquid is neutral, and has no effect upon starch.)

December 8. Decompression. The liquid part (A) is inoculated under the skin of a big rat, and a part of the solid fragments, crushed in water (B), is inoculated subcutaneously on the left thigh, at the level of the sciatic nerve, of a young rat.

A quarter of an hour later, I look at rat $\mathrm{A}$, and am much surprised to see it already on its side, its eyes are watering and lack sensitivity, its breathing is slow and difficult, its heart is beating irregularly. It has, especially in the hind legs, very strong tonic convulsions, which become remittent, and the animal dies in about a half-hour. The muscles for some moments have exhibited very strange fibrillary movements. The nerves no longer have any power over the muscles.

The lungs are quite healthy; the blood in the heart is dark, on the left as well as on the right; the heart is in diastole; the blood turns red in the air and coagulates very well; the corpuscles are intact; rigor mortis comes on very quickly.

Rat B is affected a half-hour after the inoculation.

At first, cries indicating local pain; then general palsy, slowness of motion; respiration very irregular, sometimes remains 5 or 6 seconds without breathing; the pulse follows the respiration. 
The left hind leg remains almost constantly stiff (local action?). Sensitivity continues to decrease, disappearing in the eye (the cornea last) before the limbs. Slight convulsions, which seem to be excited by pinching.

After three quarters of an hour, it remains lying on its side; the temperature drops rapidly; after an hour and a half, it is $29^{\circ}$.

It dies in about 2 hours. tion.

Hemorrhage in the brain and the cerebellum; no local inflamma-

So the effect of scorpion's poison persists with all its characteristics which I noted before, ${ }^{3}$ after the venom had been subjected to oxygen at high tension. Besides, I was not at all surprised, because venom resists (the venom of the scorpion, without even being dissolved by it) even the action of pure alcohol.

\section{Viruses.}

I was able to make a greater number of experiments on viruses.

\section{A. Vaccine.}

Experiment CCCCXC. November 10. Twelve newly born babies are vaccinated with vaccine taken from the same child; two leave the hospital before pustules develop; in a third, the vaccine does not take; in the other 9 , pustules develop to the number of 35 (from 1 to 6 ) per 54 punctures.

From the same vaccine-bearing child and from the same pustules, Bretonneau tubes are filled, which from November 11 to November 18 are subjected to a pressure of 23 superoxygenated atmospheres.

November 18 . With the compressed vaccine seven newly born children are vaccinated. Four of them leave the next day but one, before any development could be noted; on the other three the vaccine takes, and produces 13 pustules $(6,6,1)$ from 18 punctures.

(Operations performed by Dr. Budin, then an intern.)

So clear an experiment seems to me sufficient for drawing conclusions. And my conclusion is that the vaccine virus, which resists so completely the action of oxygen at high tension, does not owe its special power to living organisms (bacteria, vibriones) or to cells (leucocytes, special corpuscles), acting like true ferments.

And yet I am far from denying that the corpuscles, irregular in form and dimensions, which float in the vaccine, contain in them the virulent principle, as seems very probable since the research of M. Chauveau. But I am certain that living organisms are not there.

Perhaps the virulent material is thus precipitated in insoluble flakes; perhaps these corpuscles are endowed with the power of fixing the active principle, as the blood corpuscles fix the hemo- 
globin and the amylaceous corpuscles of the green cells fix the chlorophyll.

B. Glanders.

Experiment CCCCXCI. July 15. Pus of glanders sent from Alfort by Professor Trasbot.

Equal quantities are placed in two small bottles, to a depth of about 1 centimeter.

A, at normal pressure.

$\mathrm{B}$, taken to 20 superoxygenated atmospheres.

July 21. Decompressed.

$A$ is decayed.

$\mathrm{B}$ has no odor.

The same day, these two puses are inoculated in two horses.

A, has only local symptoms, evidently due to the putrid inoculation, loosening of the skin and abscess; gets well.

B, dies of the glanders, after showing, M. Trasbot writes me, "as complete an eruption as possible."

Our conclusions for the virus of glanders and the corpuscles which it contains, upon the virulent role of which M. Chauveau has dwelt, will be identical therefore to those which we drew from the experiments on the vaccine-virus. Here too it is not a matter of microscopic organisms acting like true ferments.

\section{Anthrax.}

The researches of $M$. Davaine have called attention to the part which may be played in the infection of the virus of anthrax by microscopic organisms, the "bacteridies," which he found exist and are constantly present in virulent liquids. Experiments made by dilutions, filtrations, and precipitations have led this learned physician to declare that these "bacteridies" were really the agents of the virulence, and that, when introduced into the blood of a healthy animal, they bring on death by their prodigiously rapid development. So that anthrax would definitely be a true parasitic disease.

But all these methods are open to one objection. These microscopic organisms, whose nature is not yet clearly understood, may be only the vehicle, not the original cause of the virulent agent with which they might be merely laden.

I therefore had to begin experiments following the new method, but taking the greatest precautions: 1). that the layer of blood be thin enough to be penetrated by the oxygen; 2 ). that there should not remain within the limits of the blood any isolated spots which would dry out and then resist perfectly the action of the oxygen. 
Experiment CCCCXCII. October 6. Blood from a sheep sick with the anthrax (sent by Professor Trasbot). This blood inoculated in guinea pigs was followed to the fourth virulent generation.

Subjected in a thin layer to 20 superoxygenated atmospheres.

October 9. Decompressed; inoculated in a guinea pig.

October 10. The animal dies at 1 o'clock p. m.

Experiment CCCCXCIII. November 20. Professor Trasbot sends me serum taken from a sheep which had been inoculated with the blood of a horse which had died of anthrax; many "bacteridies."

I inject $1 / 2$ cc. under the skin of a guinea pig.

November 21. The animal was found dead in the morning.

I take a little of its blood, which contains "bacteridies," mix it with the serum which flowed from the spot of inoculation, and subject it, in a thin layer (about $3 \mathrm{~mm}$.), to the action of 20 atmospheres of superoxygenated air.

November 30. Decompression; the blood is red to the bottom.

Injection into two guinea pigs.

December 1 . Both found dead in the morning.

I give a subcutaneous inoculation with their blood to a guinea pig and a dog.

December 2. The guinea pig and the dog are dead.

Here are experiments in which the "bacteridies" must have been killed by the compressed oxygen, and in which nevertheless the blood kept all its virulence; the second is particularly conclusive, for in Experiment CCCCXCII the duration of the compression perhaps had not been sufficient. They prove then that this dangerous property was not due, at least in the blood which I used, to the existence of these tiny organisms. I also saw them corroborated by experiments which cannot be reported here but in which I saw the virulent matter precipitated from the same blood by alcohol, filtered, then dried, without losing its dangerous power, which it could still transmit, as before, from generation to generation.

And yet I think it would be unwise to apply this conclusion to all the bloods called "charbonneux" (containing the germs of anthrax), and that it would be necessary first to make many more experiments, using bloods from various sources, for it might be that several diseases are confused under the common name charbon (anthrax). ${ }^{4}$ 


\section{Subchapter V SUMMARY}

As a result of these numerous experiments, we are now in a position to state the first cause of the death of animals and plants subjected to a fairly high oxygen tension. Let us set aside the violent convulsions displayed by the higher animals and go to the bottom of the phenomena.

Life is only the result of a complex and harmonious combination of chemical changes belonging to the group of fermentations; some are due to the direct intervention of the formed elements of the body; others are the consequence of the action of unstable and soluble substances, like diastase, previously formed by the action of the formed elements. In the interior of each of the anatomical elements the vital activity is maintained only by the action of these substances, which are created, act, are transformed, and are destroyed there.

But that life may be maintained, the multiple phenomena must go on with constant regularity, or rather harmony. When their intensity alone is modified, without their relations being altered, vital activity decreases, sometimes is even halted, possibly for a long time, and then reappears when more favorable conditions occur. This happens through cold, through desiccation, and, to return to our subject, through decreased pressure. Seeds, preserved intact in a vacuum, germinate when returned to the air; meat, which has remained fresh in a vacuum, decays when oxygen restores activity to its vibriones.

When, on the contrary, it is not merely the quantity, but also the quality of the chemical changes that is altered, symptoms appear, the details of which are far from being known and which have such consequences that even if normal conditions are restored, the vital activity is not resumed. This happens through heat, through excessive moisture, and through increased pressure. Seeds kept apparently intact in compressed air do not germinate when returned to normal pressure, and it is in vain that oxygen at its usual tension comes in contact with the definitely dead vibriones which swarmed upon the meat previously subjected to compressed oxygen.

We do not need to go as far as death to show these important differences. An animal subjected to decompression is seized, at a certain moment, by convulsions, which a return to normal pressure checks immediately: Sublata causa, tollitur effectus (If the cause 
is removed, so also is the effect). But the convulsions due to excessive pressure continue even when the apparent cause has been removed; that is because the real cause, the chemical change, still exists, still operates, and excites the nervous centers.

Under the influence of oxygen at high tension, within the interior of the anatomical elements, either isolated in individual cells or grouped in tissues, chemical alterations take place, which produce lasting substances, the presence of which disturbs the harmony necessary for the continuance of life, in the element first, then in the complex being.

These are, indeed, rather vague terms, but this vagueness results from the general condition of science and should not be made a reproach against me. What do we know about the molecular transformations which take place regularly in the tissues and in the interior and on the surface of the anatomical elements? The little knowledge we have I have subjected to experimentation; I have seen that the transformation of starch into glucose, that the reduction of glucose into its primary elements are delayed by oxygen under high tension. Now these are general acts which appear, we know, in the life of a mycoderm cell, as in the cell of a mammal or a bird. They are delayed, but yet the soluble ferment which produces them is not altered at all, and will resume all its activity later, at normal pressure. Why then, after this return to normal pressure, does not life reappear, as after the suspension due to a vacuum or to cold? Can it be that the ferment, whose regular action has diminished, has acquired a new one, which has produced this lasting substance the origin of which we are seeking? Has the fermentable matter, on the contrary, changed so that now it withstands the action of the preserved ferment?

It is very difficult to answer these questions today. All that I can say is that the substances subjected to compression: meat, eggs, milk, and bread, soon give an acid reaction, due probably in part to lactic acid. It is not impossible that the presence of this acid in the interior of the anatomical elements is the cause of death.

But without discussing any longer phenomena the inner significance of which we cannot explain, we are justified by the numerous experiments, the report of which has filled so many pages, in saying that, under the influence of oxygen at high tension, within each anatomical element chemical alterations take place which are incompatible with the life of this element. When this is granted, all the varied phenomena which we have enumerated are easily connected and explained. 
Are we dealing with a living being reduced in its elementary structure to a single cell or a small number of cells? Since its vital activity is generally manifested to us by phenomena known by the name of true fermentations (alcoholic, acetic, lactic, and putrefactive), its death will result in the permanent stoppage of these phenomena, unless new ferments are sowed.

Or, to go at once to the opposite extreme, are we dealing with an animal which is very complex in its structure? The anatomical elements which form its tissues are threatened with death. Those among them which in biochemistry played the part of formed ferments cease to act, or lose energy of action. The phenomena of zymotic fermentation which take place both without and within them lose intensity and degenerate. Their personal qualities, their contractility, their power of transmitting stimuli or of changing them into reaction become modified and tend to disappear.

Hence come the general lessening of the chemical phenomena of life; the decrease in oxygen consumption, in carbonic acid production, and in excretion of urea; the appearance in the urine of sugar which is no longer sufficiently broken down; and finally, an enormous lowering of the temperature.

And at the same time,--since whenever a great and rapid disturbance affects the equilibrium of the functions of a higher animal (hemorrhage, asphyxia, etc.), it is the central nervous system which, as it is the first to be stimulated, shows by its violent reactions the danger which threatens the whole organism,- - there appear these convulsions which give evidence by their persistence after a return to normal pressure that a profound chemical change has taken place in the tissues of the spinal cord or in the blood which supplies them and would thus bring them a kind of poison. Last come the muscular contractions modified in their behavior, like cramps, such as occur in every dying muscle.

Between these two extremes, the isolated cell and the warmblooded vertebrate, all the intermediaries: on the one hand, molds, algae, seeds, vascular plants; on the other, annelids, mollusks, insects, fish, reptiles. The whole aggregation of living beings, in a word, dies absolutely when the oxygen tension rises high enough. Not one, we can affirm, would withstand a tension corresponding to the pressure of 20 atmospheres of air. We shall return to the inferences suggested by this unexpected phenomenon.

${ }_{1}$ See my Mémoire sur la vitalité des tissus animaur (Annales des sciences naturelles. Zoologie, 1866).
2 Paul Bert. Note on a certain sign of approaching death in dogs subjected to rapid blood-
letting (Mémoire de la Société des sciences de Bordeaur, Vol. IV, p. 75,1866 ).
3 Contributions to the study of venoms: scorpion venom. Comptes rendus de la Société de
biologie pour 1865, p. 136 .
See the discussions of MM. Davaine, Jaillart, and Leplat: Comptes rendus de l'Académie
des sciences, Vol. LXI, 1865 . 


\section{Chapter VII}

\section{EFFECTS OF SUDDEN CHANGES IN BAROMETRIC PRESSURE}

Hitherto, I have spoken only of the phenomena following gradual changes in the amount of the barometric pressure, which are, as we have seen, phenomena of the physico-chemical type, resulting from the presence in the blood of larger or smaller quantities of oxygen. But it is only in these conditions of gradual change that I could be brought to deny the effect of the pressure as a direct agency, of the physico-mechanical type. Of course it may be different when we are dealing with sudden and considerable changes. The experiments reported in this chapter were intended to settle this question.

\section{Subchapter I}

\section{EFFECT OF SUDDEN INCREASES IN PRESSURE}

This part of the work will not be long. The sudden increase of pressure seems to have no appreciable effect on animals.

At first, when it was a matter of animals previously subjected to a very low pressure, like that discussed in Chapters I and III, the restoration of normal pressure had no apparent ill consequence. But on the contrary, when the decompression was very great, its favorable effect appeared immediately, and the animal returned at once to a normal state. We could see it then perceptibly "deflate," especially in the case of a herbivorous mammal, as a result of the return to their original volume of the intestinal gases, which the decompression had expanded.

The experiments on sudden increase of pressure were made on rats or birds placed in the Seltzer water receiver. This receiver 
by means of a copper tube was put in communication with the large metal receiver (Fig. 33) in which the pressure had been raised to 10 atmospheres, then the communication cock $c$ was opened, and the equilibrium of pressure suddenly established. The animal then seemed to cower, to crouch, as if frightened; but after a few minutes, regained all its liveliness.

There is no reason for surprise at these negative results, because we have seen that workmen in caissons and divers in suits are subjected to sudden pressures of several atmospheres without feeling other inconveniences than more or less keen pains in the ears, which pains animals do not seem to feel, since in animals, no doubt, the Eustachian tube opens more easily than ours.

The effect of sudden increases of barometric pressure, almost non-existent in air-breathing animals, is, on the contrary, very considerable in fish provided with a swimming bladder. Whether the bladder is closed or not, as soon as the pressure of the air above the water in which the fish is swimming is increased a little, the fish drops to the bottom of the vessel, from which the greatest muscular efforts can raise it only for an instant. But after several days during which the pressure has been maintained, it regains complete freedom of action. That is because during this interval a new secretion of oxygen has restored to its swimming bladder its original volume and to its body its original density. All these facts, which I have often witnessed, have been completely described and explained by Dr. Armand Moreau.

\section{Subchapter II}

\section{INFLUENCE OF SUDDEN DECREASE OF PRESSURE BEGINNING WITH ONE ATMOSPHERE}

The study of this influence presents great difficulties without being particularly interesting. As a matter of fact, for slight decompressions, no matter how suddenly they are produced, the result is almost negligible in air-breathing animals; for great decompressions, it is combined with that of anoxemia, beside which it is of only slight importance.

When a sudden drop to a half-atmosphere is made, the animals tremble, leap, sometimes whirl, but soon recover, or at least show only the symptoms of asphyxia due to the low oxygen content of their blood. 
These evidences of distress are no doubt due to the sudden expansion of all the gaseous reservoirs of the organism, and we can see that they are especially important in birds, in which these reservoirs extend through the whole body; but equilibrium is reestablished almost immediately in the latter, because of the communication of the air sacs with the trachea and consequently with the interior. Mammals, and especially the herbivores, are a little swollen by the expansion of the intestines and the stomach, but they quickly expel the gases which distress them. This is shown by the following experiment:

Experiment CCCCXCIV. June 9. Dog, just killed by electrical stimulation of the heart. There is introduced into the rectum, by the help of a little bladder which completely covers the anus, a glass elbow tube, the end of which is immersed several millimeters in a glass full of water. The animal is thus placed in one of the large cylinders of Figure 27. Then decompression to $34 \mathrm{~cm}$. is made as rapidly as possible; during this time bubbles of gas quickly follow each other escaping from the anal tube; however the abdominal wall is evidently swelling. Air is admitted; the wall collapses; there is still a considerable quantity of gas in the intestine.

The same effect is produced, as has been known for a long time, in fish provided with a swimming bladder opening into the esophagus, like the carp. If the decompression is not made too quickly, one can see bubbles of gas from the bladders escaping from their mouths; then, when normal pressure is restored, they drop to the bottom of the water, since their density has become too great. Under these conditions they return with difficulty to the surface to swallow air and thus fill their bladders again; to get definite information on this direct absorption, which might be doubted, I made the following experiment:

Experiment CCCCXCV. June 1. A carp weighing a half-pound is subjected, in the water, to a decompression of two-thirds of an atmosphere. It throws off a great quantity of air. The crystallizing dish in which it is swimming is then placed under a bell containing a mixture of air, oxygen, and hydrogen in proportions not fixed.

June 3. The fish dies; its swimming bladder contains 11.4 cc. of gas of the following composition per 100: hydrogen 33.3 ; oxygen 16.7 ; nitrogen 50.0 .

Let me say in passing that carp, in the natural state, when coming to the surface of the water to swallow air, do not admit it to the bladder, and probably use it only to aerate their gills more thoroughly. For example:

Experiment CCCCXCVI. June 5. Carp weighing $200 \mathrm{gm}$. The ves- 
sel in which it is swimming is placed under a bell containing a mixture of oxygen and hydrogen unproportioned.

bladder.

June 9. The fish is killed. There is no hydrogen in the swimming

Fish with closed bladders, becoming lighter than the water when decompression is made, come to the surface and die on account of the bursting of the overinflated bladder. This fact has long been well known to fishermen, who pierce the bladder with a pointed piece of iron or wood, so that the entrails may not burst and soil the fish.

The same phenomenon (I mention this so as not to return to this type of data again) may be observed in fish with closed bladders kept for several days under increased pressure:

Experiment CCCCXCVII. May 4. Sticklebacks in the glass cylindrical apparatus. Subjected to a pressure of 2 atmospheres, they sink to the bottom immediately.

May 10. Swim freely. Decompression made; come to the surface immediately. When removed, they die.

So these fish had formed in their bladders a sufficient quantity of gas to regain freedom of movement, with their original density. But the decompression was fatal to them.

The closed air bladder is therefore very unsuitably called "swim. ming" bladder, because it is harmful to the fish and compels it to remain at a certain depth of water, under pain of bursting at the surface or sinking indefinitely into the depths, if it passes the narrow limits between which it is permitted to move vertically.

I succeeded in getting a result similar to that of Experiment CCCCXCVII with frogs rapidly decompressed from 5 to 6 atmospheres to normal pressure. When the air of the lungs expanded enormously, the tracheal opening closed; the stomach issued through the mouth, the lungs burst, and the body was transformed into a sort of overinflated balloon. All that is simple and to be expected.

But let us return to air-breathing animals. When very rapid decompression is made, they too die almost at once. Can an important part in this death be attributed to the suddenness of the decompression? That almost reverts to the question which we have already asked. Is the purely mechanical or physical effect of the decompression perceptible? The experiments reported in the preceding chapters show that it is very slight at any rate, because an animal can, for example (Experiment CCLI), be brought 
very rapidly without inconvenience to a pressure of $7 \mathrm{~cm}$., if the air has a high oxygen content.

Let us now examine the results of a few experiments made especially with a view to sudden decompression:

Experiment CCCCXCVIII. March 2. Dog weighing 2.300 kilos, placed in a bell of 31 liters capacity. This bell (Fig. 27, C) is connected by a rubber tube with thick walls to a huge receiver of sheetiron (B) in which the pressure has been brought to a $10 \mathrm{~cm}$. A communication cock is opened, and the pressure falls immediately in the bell to $12 \mathrm{~cm}$. Immediately convulsive struggling, howls, foamy nasal hemorrhage; dead in 3 or 4 minutes. The lungs display ecchymoses which do not disappear entirely after insufflation. Bronchi and trachea full of bloody foam. Dark blood in the left cavities of the heart, very dark blood on the right, without free gases.

Experiment CCCCXCIX. March 7. Large cat. Same experimental procedure. Pressure is brought suddenly to $16 \mathrm{~cm}$.; the animal rears up almost immediately, struggles violently, yawns. At the end of 2 minutes, falls on its side, its tongue is dark; at 3 minutes, its pupils dilate, shivers occur in the cutaneous muscles. Dead after 6 minutes. Withdrawn immediately, the animal, which is much swollen, collapses when normal pressure is restored; no gas in the blood; dark blood in the left heart, still more in the right heart; pulmonary veins red; pulmonary ecchymoses.

Experiment D. March 15. Sparrow placed immediately by a similar arrangement at $12 \mathrm{~cm}$. pressure.

Struggling; very speedy death without true convulsions. No free gases in the blood.

Experiment DI. June 18. Cat brought very rapidly to a pressure of $12 \mathrm{~cm}$. Dies after a very rapid phase of convulsions. Lungs congested, expand and become blanched when insufflated; the most congested parts do not sink in water. No gas in the blood, examined with great care.

Experiment DII. December 16. Two rats, placed in a bell of 2 liters, are brought as rapidly as possible ( 2 or 3 minutes) to a pressure of $4.5 \mathrm{~cm}$. They whirl, leap, die without true convulsions. Withdrawn immediately, and opened, one, $\mathrm{A}$, in the air, the other, $\mathrm{B}$, under water: the hearts are still beating.

A. Blood examined by a magnifying-glass in the vessels, then with a microscope; no gas bubbles. Lungs very red in places, the red pieces sink in water; they expand with insufflation.

B. No bubbles of gas can be seen escaping under water.

Experiment DIII. December 16. Rat killed by the same process, at the same pressure; but kept for 10 minutes at $4.5 \mathrm{~cm}$. No gas in the blood, meticulous examination. Lungs adherent to the thorax, but regain normal position when it is opened; reddish with small dots, all parts float. The liver macerated with charcoal shows an enormous quantity of sugar. 
When we compare these few data with those which have already been reported and in which the decompression was made very suddenly, we see that the physical phenomena amount to very little, even when the rapidity of the experiment should have increased their importance. We have already spoken of the expansion of the intestinal gases; when the vacuum is made suddenly, they do not have time to escape, and must contribute a part, though small, to the distress of the animal.

The pulmonary ecchymoses mean nothing, because we find them in simple asphyxia, at normal pressure.

The pulmonary hemorrhages are not a constant fact; besides, we see them occur in certain cases when the pressure was diminished slowly; it is therefore difficult to ascribe them to the suddenness of the decompression. I should rather think that the suddenness caused the strange appearance of the lungs of the dog in Experiment CLXXX, "The lungs are red in large patches, sinking in water, but expanding completely after insufflation."

This sort of fetal state seems to me to be due to a sort of suction exercised in spots by the pressure of $7 \mathrm{~cm}$. under which the animal died.

We saw in the historical part of this work that former authors attached much importance to this phenomenon which some of them considered constant and extending to the whole lung. We have reported on this point the observations of Musschenbroeck, Guideus, and Veratti.

I myself have never seen the lungs of animals which were killed by sudden decompression completely collapsed and heavier than water in their entire mass. No doubt, as the ancients thought without expressing themselves very clearly, when the weight of the air is reduced to an amount below the strength of pulmonary elasticity, the lung should collapse and a relative vacuum be made in the pleura. But in the first place, this can happen only at pressures lower than those at which animals die, because the pulmonary elasticity of a dog, even in the condition of maximum inspiration, even added to the negative pressure, does not go beyond 5 or 6 centimeters of mercury; this value is still less for smaller animals. Finally, even supposing this empty space exists in the pleura, it is evident that, when normal pressure is reestablished, the lungs will be retracted to their original position, or the ribs would be broken under the atmospheric pressure, as I formerly showed experimentally; so that, even if this phenomenon occurred, there will be no trace of it in the autopsy. For the pulmonary retraction to 
persist, either at the time of the sudden reestablishment of normal pressure some vesicle must be broken, thus allowing the air to penetrate the pleura; or after a long stay in the vacuum, gas or liquids must be emitted, and it is probably for this reason that, according to Veratti, the lungs are found in this state only when the animals have remained some time under the pneumatic bell.

As to the escape of gas into the blood, to which former authors, since Robert Boyle, have attributed such an important part, and which F. Hoppe considered the principal cause of death, I must say that I have found no free gases in the blood vessels when the decompression was sudden any more than when it was more carefully controlled. And yet in vitro the liberation of the gases of the blood begins under low decompression. For instance:

Experiment DIV. June 23. Two glass tubes are filled, one with blood, defibrinated and settled, the other with water. Two hours after, no gas bubble having escaped, we begin to lower the pressure, stopping for 5 minutes every 10 centimeters.

At a pressure of $66 \mathrm{~cm}$., no bubbles of gas escape; at $56 \mathrm{~cm}$., nothing; at $46 \mathrm{~cm}$., bubbles appear on the walls of the tubes, both in the water and in the blood; at $36 \mathrm{~cm}$., the escape is abundant in both tubes.

An escape of gas must therefore take place in the blood vessels, and first in the venous system where the pressure is less. But we must note that the oxygen, granting that it leaves the blood, must be immediately absorbed by the tissues, which are eager for it; that the carbonic acid must pass through the pulmonary membranes with the greatest ease; and that the escape is limited to the nitrogen, the proportion of which (from 1 to 2 per 100 volumes of blood) is so slight. And, as the escape is very slow, it no doubt has time to diffuse by way of the lungs. So that whether blood is drawn from the living animal, as we succeeded in doing at a pressure of 17 centimeters (Experiment CLXXIX) or the blood of an animal killed by sudden or slow decompression is examined, no free gases are found in it. (See particularly Experiments DI, DII, and DIII, in which search for gases was made with the greatest care.) 


\section{EFFECT OF SUDDEN DECREASE OF PRESSURE BEGINNING WITH SEVERAL ATMOSPHERES}

The subject of our researches here becomes much more interesting. Indeed, it draws nearer the phenomena which we mentioned in the historical part, in speaking of laborers who work on the piers of bridges and of divers in suits.

I shall begin, as usual, by a detailed account of a certain number of experiments. I report first those in which the decompression was made without interruption and as rapidly as possible.

\section{Decompression without Interruption.}

A. Experiments Made on Sparrows.

Experiment DV. July 20. House sparrow. Seltzer water receiver. Brought in 20 minutes to 8 atmospheres; left for 5 minutes under pressure. Opened the large cock first, and made the decompression in a few seconds. Struggled at the moment of decompression, then did not appear sick, and survived.

Experiment DVI. August 3. House sparrow. Same apparatus. Taken to 8 atmospheres at 12:30.

At 2 o'clock, sick; at 2:45, very sick. Took a sample of air which contained $2.1 \%$ of $\mathrm{CO}_{2}$. Tension: $2.1 \times 8=16.8$.

Opened the large cock suddenly; the bird fell backward violently; rose immediately: its rectal temperature was $25^{\circ}$, that of the outer air being $20^{\circ}$, blood of the jugular veins very red; no gas seen. Remained on its back and died in 10 minutes. At death, the venous blood is dark; bubbles of gas seen in the jugulars.

Experiment DVII. May 1. House sparrow. Glass cylindrical receiver .

2:05, raised to 10 atmospheres; surrounded by papers wet in potash solution so that the $\mathrm{CO}_{z}$ is absorbed as it is produced.

At 3:40, the bird appears dead; the pressure is $91 / 2$ atmospheres; the air contains $14.1 \%$ of oxygen, and no doubt very little carbonic acid. Decompression made rapidly. Almost immediately, the bird, which raised its head at the moment when the cock was opened, became very lively; bloody suffusions on the cranium. Survived. tus.

Experiment DVIII. May 10. House sparrow. Cylindrical appara-

From $4: 15$ to $4: 20$, raised to 16 atmospheres. After 5 or 6 minutes shows quiverings with great distress, slight convulsions, etc. characteristic of poisoning by oxygen, the tension of which was $16 \times 20.9=334$. At $4: 30$, decompression made in 1 minute; did not 
seem to suffer from the decompression; no gas in the jugulars, in which the blood was very red. Enormous bloody suffusions on the cranium. Rectal temperature $35^{\circ}$. At 4:35, great convulsions, died. Rectal temperature $34^{\circ}$. The blood was very red in the left heart, without gas. In the right heart and the jugulars, it was dark with gas in very small bubbles; these bubbles were present in the portal system.

Experiment DIX. October 27. Sparrow (cylindrical receiver). Taken to 8 atmospheres. Decompression made in 5 seconds. Taken from the apparatus, did not seem at all inconvenienced.

Experiment DX. October 27. Sparrow (cylindrical receiver).

Taken to 10 atmospheres. Decompression made in 5 seconds. No symptom, survived.

Experiment DXI. October 27. Sparrow (cylindrical receiver.)

Taken to 12 atmospheres. During this time remained motionless at the bottom of the apparatus. When sudden decompression was made, darted to the top of the cylinder, then fell back. Was dead before being taken from the apparatus. Air in quantity in the jugulars and the right heart.

Experiment DXII. October 27. Sparrow (cylindrical receiver).

Taken to 14 atmospheres. Sudden decompression; died in a few minutes. Air in quantity in the jugulars and the right heart.

Experiment DXIII. October 27. Sparrow (cylindrical receiver.)

Taken to 14 atmospheres. Sudden decompression, without symptoms. Found dead the next day.

Experiment DXIV. October 27. Sparrow; cylindrical apparatus. Taken to 15 atmospheres, and suddenly decompressed immediately. Removed from the apparatus, could not walk, flapped its wings, had convulsions, and soon died. Air in quantity in the jugular veins and the right heart.

Experiment DXV. June 29. Two sparrows were taken in one hour to a pressure of 7 atmospheres under a current of air maintained by the large sheet-iron cylinder. At this moment, the rubber communication tube burst; the decompression was instantaneous. The two birds died in a quarter of an hour.

We must add to these experiments made on sparrows the results of a great number of others already reported with another purpose in the subchapter of Chapter I. We shall return to them later.

For the moment I set aside the discussion which these experiments deserve and report those made on mammals.

First, rats, for which we generally used the small glass apparatuses. 
B. Experiments Made on Rats.

Experiment DXVI. August 9, 1871. Rat. Seltzer water receiver.

$9: 25$, placed at 7 atmospheres. $10: 10$, pressure fell to $6 \frac{1 / 2}{2}$, the animal is rolled up in a ball, with hair bristling; respiratory rate 75 . I open the large cock suddenly; the animal arouses immediately, and does not seem to be in pain.

Experiment DXVII. August 10. Same animal, same apparatus.

$4: 10$, placed at 6 atmospheres. 5:25, respirations difficult, dicrotic; the animal is lying curled up on the bottom of the vessel. Took sample of air, which contained $5.2 \%$ of $\mathrm{CO}$. Tension: $5.2 \times 6=31.2$. The pressure then falls to $5 \frac{1}{2}$. I open the large cock suddenly. The animal almost immediately stands up on his feet, and seems quite well.

Experiment DXVIII. August 12. Same animal, same apparatus.

At $4: 15$, placed at $6 \frac{1 / 2}{1}$ atmospheres. The apparatus leaks; at 6 o'clock, the pressure is $41 / 2$ atmospheres; the animal is very sick. I take a sample of air, which contains $6.1 \%$ of $\mathrm{CO}_{2}$.

Tension: $6.1 \times 4.5=27.4$. I open the cock wide; the rat does not recover immediately, but he is well the next day.

All the experiments reported next were made in the large cylinder of sheet-iron pictured in Figure 33. The large cock which is opened suddenly is the one lettered $c$ :

Experiment DXIX. May 24. Two rats in the large cylindrical apparatus (experiment made before the Committee of the Institute).

They are taken to $8 \frac{1}{2}$ atmospheres; the decompression is made in 2 minutes. The rats run about when taken from the apparatus; a few minutes after, they become paralyzed and die. Gas is found in the whole venous system.

\section{Experiments Made on Rabbits.}

Experiment $D X X$. June 22. Rabbit.

Taken to 8 atmospheres. Decompressed in 3 minutes. Ears bright red; no symptom either immediate or later.

Experiment DXXI. November 7. Two rabbits.

Taken to 7 atmospheres. Decompressed in $2 \frac{1}{2}$ minutes. No symptoms.

Experiment DXXII. November 10. Same animals.

Taken to $81 / 8$ atmospheres; decompressed in $2 \frac{11}{4}$ minutes.

No symptom either immëdiate or delayed.

Experiment DXXIII. November 15. Rabbit. effect.

Taken to $6^{1 / 2}$ atmospheres. Decompressed in $4 \frac{1 / 2}{2}$ minutes. No

\section{Experiments Made on Cats.}

Experiment DXXIV. May 23. Male cat, extraordinarily vigorous and wild. Taken to 10 atmospheres. Sudden decompression. Leaps 
out of the apparatus, apparently well, and hides under a piece of furniture. Half an hour later, it is found there paraplegic. The hind legs are stiff, with the claws extruded; they are sensitive, as is the tail, but are no longer under voluntary control. Bloody urine containing spermatozoa is drawn from the animal. The anal sphincter is contracted.

May 24. Same condition; except that the tail and the hindquarters are entirely without sensitivity and are relaxed. By pinching a foot, very distinct reflex movements are obtained, which, however, do not pass from one member to the other. blood.

The bladder is enormously distended by urine containing much

The anal and vesical sphincters are strongly contracted.

The animal mews faintly; it is very weak, drags itself along with difficulty by its front feet; rectal temperature $33^{\circ}$.

Killed by section of the medulla.

Vesical mucous membrane shows hemorrhages in dots; no blood in the ureters or in the pelvis of the kidneys. Nothing unusual in the lungs, heart, or brain. No hemorrhage or congestion of the spinal cord; but on the level of the last two thoracic and the first two lumbar vertebrae there exists a softening of the spinal cord so advanced that at certain points (last thoracic), the spinal marrow runs like cream. The microscope shows the nervous elements intact, without a trace of bloody effusion.

\section{Experiment $D X X V$. June 17. Cat.}

From 12:20 to $1: 30$, taken to 10 atmospheres. At 1:39, decompressed suddenly in 3 minutes. When taken from the apparatus, runs in all directions as if panic-stricken. At 1:48, begins to be paralyzed in the hindquarters; at 1:50, lies on its side, unable to rise. Pupils contracted, the left more than the right; rectal temperature $39.5^{\circ}$; pulse 140 , regular; respiratory rate 36 , difficult, irregular. Motility and sensitivity completely gone in the hindquarters and the tail. 2 o'clock. No respirations; action of the heart still regular.

Immediate autopsy. Auricles still contract; on pricking the right auricle, frothy blood containing air issues; the left auricle, on the contrary, contains no air. On exposing the spinal marrow, we see in veins of the meninges a great quantity of small air bubbles; these bubbles also issue from the vessels of the spinal marrow when it is cross-sectioned. No sign of hemorrhage or congestion in the cord.

Experiment DXXVI. June 22. Cat of Experiment DLXVII (placed with the rabbit of DXX). 3:20, began the compression. At 4 o'clock, $5 \frac{1}{2}$ atmospheres; the motor stops. Began again at $4: 20$; at $4: 45,8$ atmospheres. Current of air maintained under pressure.

At 4:50, decompression in 3 minutes. The cat leaps out of the apparatus and flees. At 5 o'clock, it is seized by an attack of convulsions, with violent struggling which lasts about 5 minutes. During these disordered and indescribable movements, the hindquarters progressively stiffen and become motionless, while the forequarters and the head are prey to the strangest contortions. Repeatedly the animal, 
which is curled up, turns backwards and bites his hind legs and thighs with a kind of fury.

After 5 minutes, relatively calm; the left pupil dilated inordinately; almost complete paraplegia. Defecation by intestinal contraction, the anal sphincter not being paralyzed. Urination; no blood or sperm. $5: 30$. I show the animal to the Society of Biology; the paraplegia is complete as to movement and sensitivity. The pupils are in their normal state. 5:45. Apparent improvement; the left leg is sensitive, and the animal moves it a little, and when I support it, even leans on it a little; nothing in the right leg. 6:15. The right leg recovers a little in its turn; the tail begins to be sensitive.

June 23. The paraplegia has become complete again, and has even spread a little into the lower dorsal region. The following days, paralysis still more complete and extending a little higher. Dies June 26, the bladder distended; it could not be made to urinate; it ate.

Autopsy. All the spinal marrow is softened a little; it is diffuent below the cervical enlargement. At this precise point, it is a little yellowish, and contains a little altered blood and some granular bodies in the process of formation; the veins of the meninges contain a mixture of air and blood; air escapes from the vessels of the spinal cord. Sugar in the liver, a little in the urine, which also contains a little blood.

\section{E. Experiments Made on Dogs.}

Experiment DXXVII. May 17. Dog weighing 4 kilos. Pressure raised to 4 atmospheres. After about $1 / 4$ of an hour, opened the large cock suddenly; decompression in less than 2 minutes. The animal is in good shape.

Experiment DXXVIII. June 18. Small dog. Taken in one hour to 10 atmospheres; stays there about 1 hour; decompressed in 3 minutes. The animal cannot get out of the apparatus; there are no other movements than those of respiration; constant cries of pain.

Placed on the autopsy table, gas is observed in the jugular which has been exposed. Through the jugular a cannula is passed into the right heart, from which is extracted 33.9 cc. of gas containing $20.8 \%$ of $\mathrm{CO}_{2}$ and $79.2 \%$ of nitrogen, with some traces of oxygen. The right heart and the veins are full of gas and frothy blood; the same thing is true of the veins of the pia-mater and the choroid plexuses. Stomach much distended by gases.

Experiment DXXIX. July 9. Dog weighing 12 kilos.

1:45: taken to 5 atmospheres; left 30 minutes under a current of air. Decompressed in 2 minutes. No immediate or delayed symptom.

Experiment $D X X X$. July 13. Dog which has lost much blood. Taken to 6 atmospheres and decompressed in 2 minutes. The animal drags its hind legs and walks on its nails; after an hour, walks better, but lies down again as soon as we stop stimulating him. Better the next day. 
Experiment DXXXI. July 17. Dog of Experiment DXXIX and Experiment DLXXI (slow decompression).

From 1:36 to 2 o'clock, taken to 6 atmospheres; left $30 \mathrm{~min}$.

Decompressed in 2 minutes; comes out in good condition, shakes himself, and walks very well. No symptom.

Experiment DXXXII. July 22. Dog.

From 5:30 to $6: 10$ taken to $6 \frac{1 / 2}{2}$ atmospheres. I then draw blood from which no free gases escape in the syringe. However this blood contains $7.7 \%$ of nitrogen. At $6: 40$, reached $81 / 2$ atmospheres; decompressed in 3 minutes. At 6:50, I draw blood from the carotid; this blood contains $2 \%$ of nitrogen.

The animal has remained fastened on the operating table; while sewing up the wound in the neck, I see bubbles of air in the jugular; it begins then to take deep breaths, which end in death at $7: 15$. No gas is found in the blood of the right or left heart; but there are numerous bubbles in all the little veins of the general and the portal systems. The stomach is enormously distended; $550 \mathrm{cc}$. of gas is drawn from it; the intestine contains much gaseous froth and is swollen with it.

Experiment DXXXIII. July 24. Dog of Experiment DXXXI.

From $3: 30$ to $3: 55$, taken to 6 atmospheres; left 2 hours under a current of air. Decompressed in 2 minutes, no symptom.

Experiment DXXXIV. July 25. Dog of preceding experiment.

From 2 o'clock to $2: 45$, taken to 7 atmospheres.

Decompressed immediately in 2 minutes: jumps alone from the top of the apparatus. Five minutes after, falls on its side, its hindquarters paralyzed; sensitivity much dulled. The front feet are in forced extension and quiver at each breath.

July 27. Complete paraplegia of movement; muscles relaxed; tail and feet insensible, but with reflex movements of the tail. The anal sphincter is relaxed, but the introduction of a thermometer provokes violent reflex movements; temperature $39.5^{\circ}$. Bladder paralyzed; when the belly is pressed, the urine issues in jerky spurts; if overflows regularly; no sugar.

August 1. The animal has remained lying on its right side; the paralysis has made ascending progress; the ribs are motionless, and the respiration is purely diaphragmatic; we then see clearly the lifting of the lower ribs by the diaphragm.

On pinching the right hind foot, it draws away, as does the tail: no movement in the left hind foot. The left sciatic, when exposed and pinched vigorously, causes some slight movements in the flexor muscles of the leg, but the animal feels nothing. The right sciatic gives marked movements, and the animal shows pain when it is pinched. The muscles tested by electricity require for contraction a current a little stronger on the left than on the right, which is no doubt due to the different action of the nerves. The toes of the hind feet, when taken in the hands, are warmer than the toes of the front feet; the latter are sensitive and are drawn away when pinched. The anal sphincter contracts convulsively when touched; the rectal temper- 
ature is $38^{\circ}$. The urine issues when the right sciatic nerve is stimulated: no sugar. I kill the animal, which is very sick, by opening the thorax.

The left sciatic nerve is reddish, its vessels are bloodshot; in most of its fibers the myelin is a little turbid and is beginning to separate. The right sciatic nerve is intact.

The spinal cord is softened in the region of the lumbar enlargement. Transverse sections show the following changes. Below the enlargement, red dots in the gray matter; in the upper part of the enlargement, where section is possible, we find complete suffusion of the left posterior horn of the gray matter and suffusion in parts of the horn on the right side; the antero-lateral and posterior columns on the left are of a very marked yellowish-gray; all of it is very soft.

Below the dorsal region, uniformly red appearance of all the gray matter, which is less soft, with coloration spreading into the posterior white matter, especially on the left; yellowish gray softening of the left antero-lateral column and the posterior column.

The alteration lessens as it goes upward and ceases above the brachial enlargement; the cord there is firm, but a little suffused.

Experiment DXXXV. August 3. Dog.

At 8 atmospheres, the little apparatus, which supports the cannula for drawing blood (Fig. 34, E), is violently thrown forward: the pressure falls in 3 or 4 minutes.

The dog comes out, runs a few steps, then falls and dies rapidly. Gas in abundance in the right heart, but not in the left heart.

Experiment DXXXVI. August 5. Pregnant bitch taken to $91 / 4$ atmospheres, bled of $375 \mathrm{cc}$. of blood (See Exp. CLXXXIV) ${ }^{1}$; decompressed rapidly: takes a few breaths and dies.

Both sides of the heart are full of gases almost completely free: the stomach contains little gas.

The hearts of the foetuses and their veins contain both gas and a very dark blood. In the allantoid liquid abundant bubbles are floating; the placenta is all torn by the gases; no gas in the amnion.

Experiment DXXXVII. October 16. Dog which has already served for Experiments DLXXVII and DLXXVIII (10 atmospheres, slow decompression). From $1: 10$ to $1: 45$, taken to 7 atmospheres, decompressed at 1:55 in $2 \frac{1 / 2}{2}$ minutes.

Taken from the apparatus, is lively and seems to feel no painful symptom. $3 \frac{1 / 2}{2}$ minutes after the decompression, raises its right front foot and seems to be in pain. After 5 minutes, struggles, wavers in its hindquarters, has an almost sudden erection. After 7 minutes, enormous convulsive stiffening of the hindquarters, which one can hardly bend. The tail moves and the front legs are not affected.

The animal is recompressed to 7 atmospheres and decompressed very slowly. (See Exp. DLXXXVIII.) Dies the next day.

Experiment DXXXVIII. October 18. Dog.

From 2:25 to $3: 10$ compressed to 7 atmospheres, and left $7 \mathrm{~min}$ utes. Decompressed as rapidly as possible, in 2 minutes, from $3: 17$ to $3: 19$. Withdrawn from the apparatus, comes, goes, fawns; but at $3: 21$ 
is seized by paralysis of the hindquarters; he soon remains lying down, and his sufferings are shown by howls.

Taken to 7 atmospheres again, and then to an extremely slow decompression. (See Exp. DLXXXVII.) Dies in the evening.

Experiment DXXXIX. October 20. Dog.

Subjected to $3 \frac{1 / 2}{2}$ atmospheres. Arterial blood drawn under mercury in a test tube. Very small bubbles of gas are plainly escaping, and collecting at the upper part of the tube.

Decompressed in 1 minute, shows no symptom; the heart sounds are normal.

Experiment DXL. October 23. Same animal taken to $4 \frac{1}{2}$ atmospheres, and left 10 minutes. Decompressed in $1 \frac{1 / 4}{4}$ minutes, experiences no symptoms immediate or delayed.

Experiment DXLI. October 25. Same animal taken to 5 atmospheres; left 10 minutes and decompressed in $13 / 4$ minutes. Still no symptom.

Experiment DXLII. October 31. Dog.

Taken to $71 / 4$ atmospheres. Decompressed in $11 / 4$ minutes. Taken out at 2:07, without immediate symptoms.

At $2: 15$, is found weak, staggering, has vomited several times. At 2:35, enormous gurglings heard in the heart, and the animal dies suddenly.

Gas in the heart and the whole venous system, even the portal vein. Nothing in the left heart.

Experiment DXLIII. October 31. Dog.

Placed beside the former; has no immediate symptom. But at $2: 15$ is found lying on its side motionless; respiration is difficult, whistling, as if the animal were going to die soon. There are gurglings in the heart.

$\mathrm{He}$ is made to inhale oxygen (See conclusion, Exp. DLXXXIX). He dies during the night.

Experiment DXLIV. November 12. Dog.

Taken to $7 \frac{1}{4}$ atmospheres. Decompressed in 2 minutes. Dies in about 25 minutes. Free gas in all the little veins; right heart full of foam; bubbles less numerous in the left heart.

Experiment DXLV. November 12. Dog.

Placed beside the former. Seized by symptoms of paralysis and dies after about $1 \frac{1}{2}$ hours, after he has been given oxygen. (See Exp. DXC.)

Experiment DXLVI. November 15. Dog.

Taken to $6 \frac{1 / 2}{2}$ atmospheres; decompressed in $4 \frac{1}{2}$ minutes. No symptom; no gas in the blood of the jugular vein, which I examined with the microscope to make more certain.

Experiment DXLVII. November 25. Bitch.

From 2:25 to 3 o'clock taken to $7 \frac{1}{2}$ atmospheres.

At $3: 14$, decompressed in $2 \frac{1}{2}$ minutes. 
At $3: 23$, is paralyzed in the hindquarters, then falls; in a few minutes, respiration stops, and the heart beats only 20 times per minute; loud gurgles heard in the heart; eye lacks sensitivity, pupils dilated. DXCI.)

Oxygen administered, but the animal dies at 3:35. (See Exp.

Experiment DXLVIII. November 27. Very small poodle.

Raised to 7 atmospheres from 3 o'clock to $3: 53$.

Decompressed in $2 \frac{1}{4}$ minutes.

Taken from the apparatus, seems gay for a few minutes, then, at $4: 10$, begins to limp, is paralyzed in the hindquarters, and suddenly falls on its side. Very loud gurgles in the heart. DXCII.)

Oxygen administered, but the animal dies at 4:27. (See Exp.

Experiment DXLIX. December 6. Short-haired dog, very lively. pheres.

Put under pressure from 2:30 to $4: 20$ and taken to $7 \frac{1 / 2}{2}$ atmos-

At 4:20, decompression in 2 minutes.

Leaves the apparatus. At the end of 10 to 15 minutes, is paralyzed in the hindquarters, and seems quite ill with perhaps gurgling in the heart (?).

Then recovers a little, but yet cannot stand on its hind legs, which have retained sensitivity.

December 7. Is still paraplegic and can hardly stand on its front legs. Reflex movements, reflex sensitivity in the hind legs, which are warmer than the front legs.

December 11. Scab on the left shoulder, on which it is lying; odor of urine; hyperesthesia in the front feet; dying.

Experiment DL. December 6. Spaniel, placed beside the preceding animal.

Remained in the apparatus from which it was removed paraplegic, with very loud gurgles in the heart. It was given inhalations of oxygen. (See the continuation of its history, Experiment DXCIII.)

Experiment DLI. December 22. Dog.

Taken to $8 \frac{1}{2}$ atmospheres. Decompressed in $2 \frac{1}{2}$ minutes.

Taken from the apparatus, is already limp, and dies in 5 or 6 minutes. Air in great quantity in the right heart and the veins. Some bubbles in the left heart. Gas in abundance in all the vessels of the lower region of the spinal cord.

Experiment DLII. January 16. Bitch weighing 6.5 kilos, in bad state generally.

Taken to $7 \frac{1}{2}$ atmospheres, then decompressed suddenly. No symptom immediate or delayed.

Experiment DLIII. January 23. Same animal.

Taken again to $7 \frac{1}{2}$ atmospheres and decompressed suddenly. About 10 minutes afterwards, bites its hindquarters, as if it felt keen pains there; it then seems to have some trouble in locomotion, but this disappears quickly. 
Experiment DLIV. January 25. Same animal.

Taken to 8 atmospheres, and decompressed suddenly. No apparent effect.

Experiment DLV. January 29. Same animal.

Taken to $81 / 2$ atmospheres, and decompressed suddenly.

Experiences a little irregularity and difficulty in the hindquarters, but seems very gay, with no uneasiness; no gurgles in the heart; no gas observed in the jugular, which has been exposed.

Experiment DLVI. February 11. Same animal.

Compressed to 8 atmospheres and left under pressure 5 minutes, then decompressed in exactly 3 minutes.

At the fifth minute, after the beginning of the decompression, blood is drawn from the carotid; no gas found in it.

At the tenth minute, blood drawn from the right heart with a cannula: no gas there either.

No symptom.

Experiment DLVII. February 12. Sickly dog, very thin, weighing 8 kilos.

From $4: 30$ to $5: 32$, taken to 8 atmospheres; decompressed in 3 minutes.

Placed on the floor, does not seem at all uneasy, and walks.

At 5:42, the hindquarters become stiff and motionless.

At 5:55, the forequarters are similarly affected; great respiratory distress.

Dies at 6:05. Air in the veins.

Experiment DLVIII. February 27. Poodle weighing 7 kilos.

Placed in the apparatus at 8 o'clock in the morning, at 9:30 is at 10 atmospheres; the pump is stopped.

At 10 o'clock, the pressure is only $93 / 4$.

At 10:30, I look at the animal; it is well, and puts its nose against the porthole; the pressure is $9 \frac{11}{2}$ atmospheres.

I enter the laboratory again, and immediately a violent explosion is heard. The porthole glass has burst and its fragments had enough force to cut a lead water pipe one meter away; the apparatus was lifted, torn from its supports by the recoil, and overthrown.

I take the animal out with great difficulty, for it has become cylindrical, and is hard to pull through the door. General subcutaneous intra- and submuscular emphysema. I open the belly; the gas which distends it escapes whistling.

The right heart is full of gas, as are all the veins, the pulmonary artery, and the pulmonary veins. But there is none in the left auricle or the aorta. There is gas in the anterior chamber of the eye, and in the cerebro-spinal liquid. The nerve fibres of the spinal cord are dissociated by bubbles of gas, which are not in the vessels.

There is no hemorrhage in the brain or the cord; the lungs are a little congested: no blood in the trachea.

I extract $50 \mathrm{cc}$. of gas from the right heart (there is much more of it) taking all precautions to prevent entrance of air. This gas contains per 100 parts: $\mathrm{O}_{2} 1.9 ; \mathrm{CO}_{2} 15.1 ; \mathrm{N} 83.0$. 
Experiment DLIX. May 6. Dog weighing 11 kilos.

From 1 o'clock to $1: 58$, compressed to $7 \frac{1}{2}$ atmospheres.

I maintain a current of air under pressure until 7 o'clock, when I make the decompression in 3 minutes.

On leaving the apparatus, the animal staggers, then stops, falls, and dies.

There are abundant bubbles of air in the right heart and the veins, tiny bubbles in the left heart.

No gas in the subcutaneous cellular tissue, except in the hollows of the armpits; gas is also found in small bubbles in the tissue of the epiploon.

The intestines do not appear more swollen than under ordinary conditions.

Experiment DLX. June 3. Bitch of Experiments DLII to DLVI. Well fed, has become fat and very well.

From 3:05 to 4:05 was taken to 8 atmospheres and decompressed immediately in $13 / 4$ minutes.

Taken from the apparatus, it runs everywhere, apparently gay, and wagging its tail.

But after 3 or 4 minutes, utters pitiful howls and tries to bite its hindquarters, which begin to be paralyzed.

Auscultation of the heart shows considerable gurgling on the right, but not on the left.

Two or three minutes later, the howls cease, the paralysis, both of sensibility and movement, is complete.

It increases, affects the whole body, with rigors in the legs and neck. The respiration, which for a long time has been merely diaphragmatic, becomes very difficult; the heart slows down and the animal dies about $4: 30$.

I find gas in the general venous system and the portal vein, but not in the arteries.

There is emphysema in the subcutaneous tissue of the armpits; there are innumerable little bubbles in the fatty tissue under the muscles of the thorax, and in the sub-aponeurotic layer all along the back, in the epiploon, the mediastinum, the furrow of the heart, and the fatty tissue of the medullary canal.

Index of air in the vessels of the medullary and cerebral piamater: nothing in the velum interpositum, or the cerebro-spinal liquid.

No blood effusion in the brain; rather large dotting on the spinal cord. Lungs healthy, without congestion or emphysema; congestion of the spleen; little suffusions of the great epiploon.

Experiment DLXI. July 21. Dog weighing 6.5 kilos.

From 2:30 to 4 o'clock, taken to 8 atmospheres.

At $4: 10$, decompressed in $1 \frac{1 / 4}{4}$ minutes.

Dies at 4:22, with air in quantity in the whole venous system; small bubbles in the left heart.

Lungs blood-shot, edematous. 
Experiment DLXII. May 24. Large spaniel. Sciences.)

(Experiment made before the Committee of the Academy of

Compression raised to $8 \frac{1}{2}$ atmospheres, and decompression made in 2 minutes.

The dog appears gay and runs about wagging his tail. After a few minutes, he sits down and becomes sad. Some minutes later, he falters on his front legs and falls down.

Gurgles can be heard in the right heart.

The animal seems to be in great pain and bites violently at whatever is held out to him. He soon dies.

Gas in fine bubbles in the whole venous system; none in the arteries.

Experiment DLXIII. June 4. Young dog in good health, weighing 4.500 kilos.

The jugular vein is exposed without being opened; the animal, fastened on the operating board, is carried to the compression apparatus, and rapidly taken to 6 atmospheres, and this pressure is maintained under a current of air for $3 \frac{1}{2}$ hours. It howls a great deal.

Decompression in 20 seconds. The animal is taken from the cylinder and unfastened. Complete paralysis of movement and of sensibility in the four legs; rapid pulse, accelerated respiration; no howls.

Put back immediately on the operating table; 50 cc. of blood are drawn from the peripheral end of the jugular; no gas to be seen; blood is slowly ejected under water; no gas bubbles. A cannula is inserted into the right auricle; $50 \mathrm{cc}$. of blood is drawn and treated in the same way; no bubbles.

The dog is attacked by diarrhea and involuntary urination.

It dies during the night.

The autopsy shows the presence of large bubbles of gas in the venous system (vena cava, azygos vein, mesenteric veins). Much is found in certain lobes of the liver and in the kidneys, a little in the spinal cord, no trace of it in the brain, the meninges, or the muscles.

Experiment DLXIV. June 12. Young white dog of small size, in very good health. Placed in the large cylinder; brought rapidly to $5 \frac{1}{2}$ atmospheres of pressure. Maintained under this pressure with a current of air for 4 hours.

The animal seems very quiet during all this time.

Decompressed in 20 seconds.

When taken from the apparatus, it runs away, and we have great difficulty in catching it. When the right jugular and femoral veins are exposed, we see passing a long series of gas bubbles which keep growing larger.

After a few minutes, by means of a syringe, we draw from the peripheral end of the jugular a certain quantity of blood which is gently ejected under water: immediately numerous bubbles are seen escaping to the surface.

Dog, kept under observation for several days, shows no delayed symptom. 
I summarize in the following table the principal results furnished by the experiments just read. I have listed them here by increasing order of pressures.

I have included in this table the results of experiments in which I attempted to save the animals, either by recompressing them or by administering oxygen. (See Subchapter IV.)

Table XVIII

\begin{tabular}{|c|c|c|c|c|}
\hline $\begin{array}{l}\text { Experiment } \\
\text { number }\end{array}$ & $\begin{array}{l}\text { Duration } \\
\text { of } \\
\text { compression }\end{array}$ & 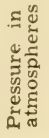 & $\begin{array}{c}\text { Duration } \\
\text { of } \\
\text { Decompression }\end{array}$ & Condition of animal \\
\hline
\end{tabular}

\begin{tabular}{|c|c|c|c|c|}
\hline \multicolumn{5}{|c|}{ Sparrows } \\
\hline DXV & slow compr. & 7 & instan- & Dead in a quarter of an hour. \\
\hline $\begin{array}{l}\text { DV } \\
\text { DIX } \\
\text { DVI }\end{array}$ & $\begin{array}{l}5 \min . \\
2 \text { min. } \\
2 \text { hours }\end{array}$ & $\begin{array}{l}8 \\
8 \\
8\end{array}$ & $\begin{array}{l}\text { taneous } \\
\text { a few sec. } \\
\text { id. } \\
\text { id. }\end{array}$ & $\begin{array}{l}\text { Two animals. } \\
\text { No symptoms. } \\
\text { id. } \\
\text { Died in } 10 \mathrm{~min} \text {. Gas in the } \\
\text { blood. }\end{array}$ \\
\hline $\begin{array}{l}\text { DVII } \\
\text { DX } \\
\text { DXI }\end{array}$ & $\begin{array}{l}1 \text { h. } 35 \text { min. } \\
\text { a few min. } \\
\text { id. }\end{array}$ & $\begin{array}{l}91 / 2 \\
10 \\
12\end{array}$ & $\begin{array}{l}\text { id. } \\
\text { id. } \\
\text { id. }\end{array}$ & $\begin{array}{l}\text { No symptoms. } \\
\text { id. } \\
\text { Died almost immed. Gas in }\end{array}$ \\
\hline DXII & id. & 14 & id. & $\begin{array}{l}\text { abundance. } \\
\text { Died in few minutes. Gas }\end{array}$ \\
\hline DXIII & id. & 14 & id. & $\begin{array}{l}\text { No immediate symptoms. } \\
\text { Dead next day. }\end{array}$ \\
\hline DXIV & id. & 15 & id. & $\begin{array}{l}\text { Died quickly. Gas in abun- } \\
\text { dance. }\end{array}$ \\
\hline DVIII & $5 \mathrm{~min}$. & 16 & id & $\begin{array}{l}\text { Died in a few minutes. Gas: } \\
\text { convulsions from oxygen had } \\
\text { begun. }\end{array}$ \\
\hline
\end{tabular}

Rats

\begin{tabular}{l|r|r|l|l}
\hline DXVII & $11 / 4 \mathrm{~h}$. & $51 / 2$ & a few sec. & No symptoms. \\
DXVIII & $13 / 4 \mathrm{~h}$. & $61 / 2$ & id. \\
DXVI & $3 / 4 \mathrm{~h}$. & $61 / 2$ & a few sec. & No symptoms. \\
DXIX & - & $8 \frac{1}{2}$ & 2 min. & Two animals. Dead in a few \\
& & & & minutes. Gas in the blood. \\
\hline
\end{tabular}

Rabbits

\begin{tabular}{l|c|c|c|c|c}
\hline DXXIII & $13 / 4 \mathrm{~h}$. & $61 / 2$ & $41 / 2$ min. & No symptoms. \\
DXXI & a few min. & 7 & 2 to 3 min. & Two animals. \\
DXX & 5 min. & 8 & id. & id. \\
DXXII & - & $81 / 8$ & id. & Two animals. \\
\hline
\end{tabular}


Table XVIII-Continued

\begin{tabular}{|c|c|c|c|c|}
\hline $\begin{array}{l}\text { Experiment } \\
\text { number }\end{array}$ & $\begin{array}{c}\text { Duration } \\
\text { of } \\
\text { compression }\end{array}$ & 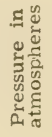 & $\begin{array}{c}\text { Duration } \\
\text { of } \\
\text { Decompression }\end{array}$ & Condition of animal \\
\hline
\end{tabular}

Cats

\begin{tabular}{l|l|l|l|l}
\hline DXXVI & 5 min. & 8 & 2 to 3 min. & $\begin{array}{l}\text { Paraplegia, dies in 4 days; } \\
\text { medullary softening. Exp. } \\
\text { made at the same time }\end{array}$ \\
$\begin{array}{l}\text { as Exp. DXX. } \\
\text { DXes in 15 min. Gas in the } \\
\text { Dlood. } \\
\text { Dilled next day. Medullary } \\
\text { softening. }\end{array}$ \\
\hline
\end{tabular}

Dogs

\begin{tabular}{|c|c|c|c|c|}
\hline $\mathrm{xxx}$ & & $3^{1 / 2}$ & 1 to $2 \mathrm{~min}$. & ex \\
\hline XVII & $15 \mathrm{~min}$ & $\begin{array}{l}4 \\
41 / 2\end{array}$ & $\begin{array}{l}2 \text { to } 3 \mathrm{~min} . \\
\text { id. }\end{array}$ & nal as in \\
\hline 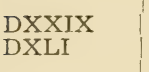 & $30 \mathrm{~min}$. & 5 & $\begin{array}{l}\text { id. } \\
\text { id. }\end{array}$ & al as in \\
\hline DLXIV & 4 hours & $51 / 2$ & $20 \mathrm{sec}$. & e veins; no \\
\hline XXXI & $30 \mathrm{~min}$. & 6 & id & $\begin{array}{l}\text { symptoms. } \\
\text { id. Same dog as in } \\
\text { Exp DXXIX }\end{array}$ \\
\hline DXXXIII & 2 hours & 6 & id. & id. Same dog as in \\
\hline $\mathrm{xxx}$ & a few $\min$ & 6 & & $\begin{array}{l}\text { Drags hind-quarters a little. } \\
\text { Recovers. }\end{array}$ \\
\hline DLXIII & $3 \mathrm{~h} .30 \mathrm{~min}$. & 6 & 20 sec. & $\begin{array}{l}\text { te paralysis; no gas. } \\
\text { s everywhere. }\end{array}$ \\
\hline DXLVI & a few $\min$ & $6^{1 / 2}$ & $41 \frac{1}{2} \mathrm{mi}$ & $\begin{array}{l}\text { No symptoms. No gas in } \\
\text { jugular blood. }\end{array}$ \\
\hline DXXXI & id. & 7 & $2 \mathrm{~m}$ & $\begin{array}{l}\text { Paraplegia, medullary sof- } \\
\text { tening. Dies in a week. Same } \\
\text { dog as in Exp. DXXXIII. }\end{array}$ \\
\hline DXXXVIII| & $7 \mathrm{~min}$. & 7 & $2 \mathrm{~min}$. & $\begin{array}{l}\text { Paraplegia; recompressed and } \\
\text { decompressed slowly. Dies in } \\
\text { the evening. }\end{array}$ \\
\hline $\mathrm{DXXXV}$ & $10 \mathrm{mi}$ & 7 & $2^{1 / 2}$ & $\begin{array}{l}\text { Paraplegia; recom } \\
\text { decompressed sl } \\
\text { next day. No gas } \\
\text { Small bloody spo } \\
\text { marrow. }\end{array}$ \\
\hline DXLVII & $15 \mathrm{mir}$ & $7^{1 / 2}$ & $2 \min$. & $\begin{array}{l}\text { Paralyzed, much gas in heart; } \\
\text { dying. Oxygen inhaled; res- } \\
\text { piration restored; accident; }\end{array}$ \\
\hline DX & few & 7 & 2 & $\begin{array}{l}\text { Paralyzed; oxygen inha } \\
\text { dies. }\end{array}$ \\
\hline
\end{tabular}


Table XVIII-Continued

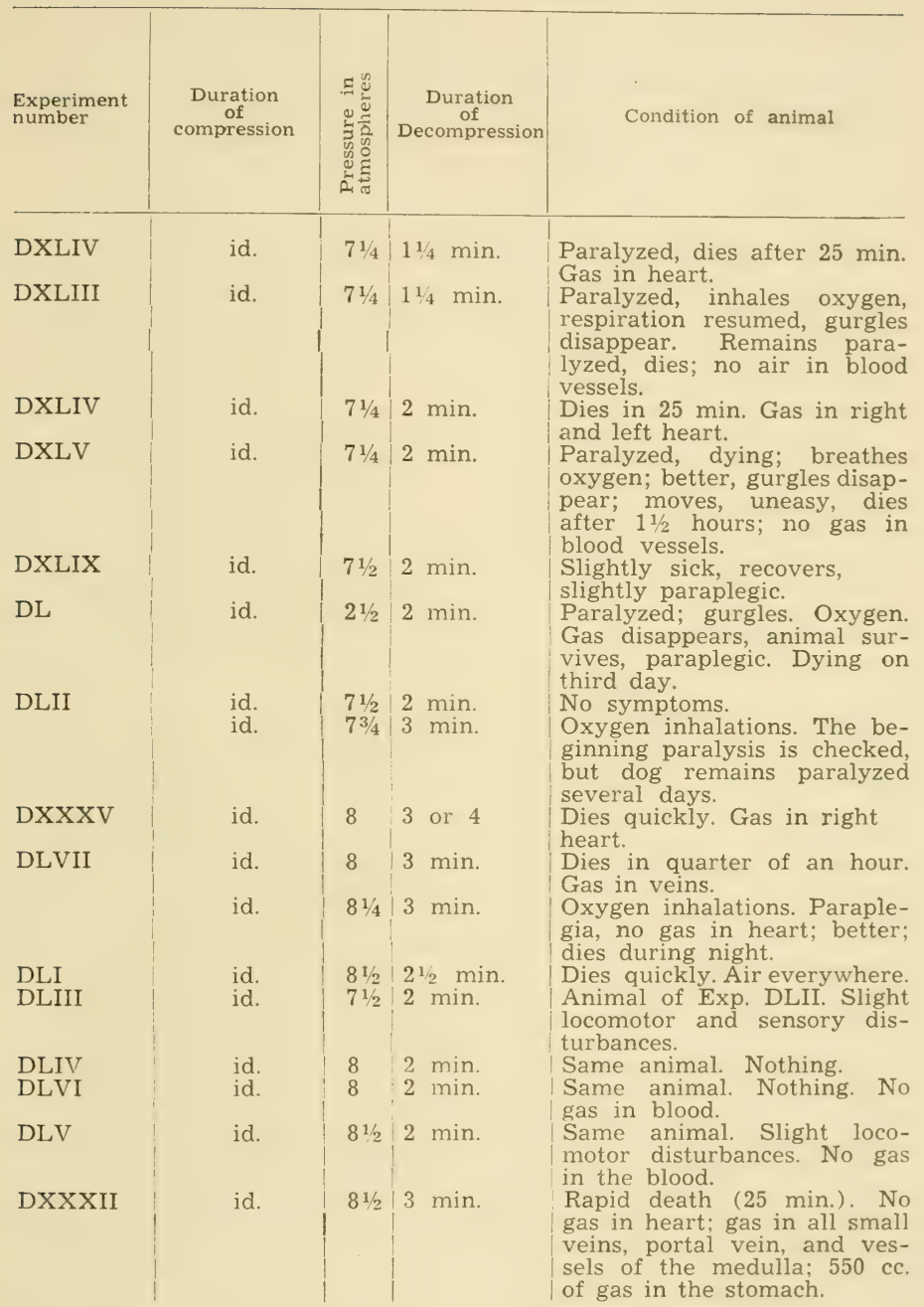


Table XVIII—Concluded

\begin{tabular}{|c|c|c|c|c|}
\hline $\begin{array}{l}\text { Experiment } \\
\text { number }\end{array}$ & $\begin{array}{c}\text { Duration } \\
\text { of } \\
\text { compression }\end{array}$ & 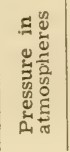 & $\begin{array}{c}\text { Duration } \\
\text { of } \\
\text { Decompression }\end{array}$ & Condition of animal \\
\hline DXXXVI & id. & $91 / 4$ & $3 \mathrm{~min}$. & $\begin{array}{l}\text { Blood drawn at } 3 \text { atm. re- } \\
\text { leased free gases. Died after } \\
\text { a few breaths. Gas every- } \\
\text { where. She is pregnant; gas } \\
\text { in blood of foetuses and al- } \\
\text { lantois; placenta torn. }\end{array}$ \\
\hline DXXVIII & id. & 10 & $3 \mathrm{~min}$. & $\begin{array}{l}34 \text { cc. of gas drawn from } \\
\text { right heart }\left(\mathrm{CO}_{2} 20.8 ; \mathrm{N} 79.2 \text {; }\right. \\
\mathrm{O}_{2} \text { traces). Gas in vessels of } \\
\text { pia mater. }\end{array}$ \\
\hline DLVIII & 1 hour & $91 / 2$ & Explosion & $\begin{array}{l}\text { Instantaneous death. Huge } \\
\text { subcutaneous and submuscu- } \\
\text { lar emphysema, gas in belly, } \\
\text { in epiploon, the anterior } \\
\text { chamber of the eye, the cere- } \\
\text { bro-spinal liquid, the spinal } \\
\text { cord. No hemorrhage in spinal } \\
\text { cord, brain or lungs. No gas } \\
\text { in left heart. Right heart full } \\
\text { of gas ( } \mathrm{CO}_{2} \text { 15.2; N. 82.8; O } \\
2.0) \text {. }\end{array}$ \\
\hline DLIX & 5 hours & $71 / 2$ & & $\begin{array}{l}\text { Rapid death; subcutaneous } \\
\text { emphysema. Gas all through } \\
\text { blood. }\end{array}$ \\
\hline DLX & a few min. & 8 & $1 \mathrm{~m} .45 \mathrm{sec}$. & $\begin{array}{l}\text { Animal of Exp. DLII to DLVI. } \\
\text { Dies. Gas in venous system; } \\
\text { subcutaneous emphysema. }\end{array}$ \\
\hline $\begin{array}{l}\text { DLXII } \\
\text { DLXI }\end{array}$ & $\begin{array}{l}\text { id. } \\
10 \text { min. }\end{array}$ & $\begin{array}{l}81 / 2 \\
8\end{array}$ & $\begin{array}{l}2 \mathrm{~min} \\
11 / 4 \mathrm{~min} .\end{array}$ & $\begin{array}{l}\text { subcutaneous empnysema. } \\
\text { Dies. Gas in veins. } \\
\text { Dies in } 12 \text { min. Gas in veins } \\
\text { and left heart. }\end{array}$ \\
\hline
\end{tabular}

2. Slow Decompression or Decompression in Stages.

The preceding data furnish ample material for a fairly complete account of the curious phenomena due to sudden decompression and for an explanation of them. However, there is such variety in the details that it seems best to report in addition a certain number of experiments of the same type, in which, however, the decompression was made more slowly, for the purpose of finding out the precautions that must be taken if the decompression is to be harmless.

Here are these experiments:

Experiment DLXV. June 20. Guinea pig. From 2:45 to $3: 50$ brought to 10 atmospheres; I establish a current of air under pressure. 
At 4:04, opened the cock wide; in 1 minute, the pressure falls to 5 atmospheres; I then keep the cock open a little; the pressure is down to normal at $4: 30$.

Opened the apparatus: the guinea pig seems in good condition; but at $4: 40$, he struggles, rolls up, is paralyzed in ascending progress, the respiration is disturbed, and stops at $4: 45$.

Gas in abundance in the right heart, in the veins of the legs and the arteries. No gas in the left heart, the pulmonary and coronary veins, and the portal system.

No gaseous distention of the stomach and the intestines.

Experiment DLXVI. June 20. Cat, placed beside the guinea pig of the preceding experiment.

Taken to 10 atmospheres. Dropped in 1 minute to 5 atmospheres, then in 25 minutes to normal pressure.

No immediate or delayed symptom.

Experiment DLXVII. June 29. Cat and rabbit brought in $1 \frac{1 / 2}{2}$ hours to 10 atmospheres. Pressure maintained under a current of air for 5 hours.

Decompression in 2 hours.

They are taken out all wet, trembling (the cat was trembling in the apparatus in the compressed air), they did not cry out; no paralysis; they recover rapidly and survive.

The temperature of the cat has fallen from $39.5^{\circ}$ to $34.3^{\circ}$; that of the rabbit from $39.6^{\circ}$ to $36.7^{\circ}$.

Experiment DLXVIII. July 2. Rabbit of Experiment DXX. From $2: 50$ to $3: 55$, raised to 10 atmospheres; current of air for 30 minutes.

The decompression is begun at $4: 27$; it is made with calculated slowness, watch in hand, at the rate of about 1 atmosphere per 2 minutes; it is finished at $4: 47$.

The rabbit seems well. However, it is seized by paraplegia about 6 o'clock, still preserving its sensibility; still living at 7:30; found dead the next day.

Experiment DLXIX. July 2. White cat placed beside the rabbit of the preceding experiment.

Taken to 10 atmospheres, decompressed regularly in 20 minutes.

The white cat cries out, breathes with difficulty; at the end of a few seconds, seems furious, bites itself, bites the gray cat of the following experiment, which is stretched out near it. Has convulsive quiverings; its pupils are very much dilated. Dies in 5 minutes. With the greatest precaution I draw gas from the right heart; the $23.8 \mathrm{cc}$. of gas which I obtain thus contain $15.9 \%$ of $\mathrm{CO}_{2}$, the rest is nitrogen, without a trace of oxygen.

Gas in all the circulatory system: veins, arteries, portal system, inner vessels of the spinal cord. The latter is very hard and shows no sign of tearing.

Experiment DLXX. July 2. Gray cat, placed beside the animals of the two preceding experiments.

Is dying when taken out, and dies immediately afterwards. 
I draw from its right heart $33.1 \mathrm{cc}$. of gas, which contains $17 \%$ of $\mathrm{CO}_{3}$.

Same results at autopsy as in the preceding experiment.

Experiment DLXXI. July 10. Dog of Experiment DXXIX.

From 2: 40 to $3: 40$, taken to 10 atmospheres. As it approaches 10 atmospheres, has a sort of convulsion.

Under pressure for 30 minutes.

Decompressed from 10 to 6 atmospheres in 1 minute; then from 6 to 1 in 1 hour. Same convulsions during the decompression.

As it leaves the apparatus, it cannot stand-up on its hind legs; howls and whimpers; lies down on its side; trembling and strong extension of its front feet at every inspiration. Hind legs flexed, motionless, but sensitive.

About 5:30 gets up, walks a little, slowly, then lies down again, still weak in the hindquarters.

July 11. Well.

Experiment DLXXII. July 23. Dog of Experiment CLXXXII.

At 5:08, dog taken to 10 atmospheres; at 5:15, dropped in $2 \mathrm{~min}$ utes to 6 atmospheres; at 5:45, dropped in 2 minutes to 3 atmospheres; at $6: 33$, decompressed in less than 30 minutes.

No immediate or delayed symptom.

Experiment DLXXIII. July 27. Dog of Experiment CLXXXIII. Taken to 10 atmospheres, 143 cc. of blood drawn.

Decompressed at the rate of 1 atmosphere per 3 minutes, very regularly.

The operation is over at $5: 45$.

Removed at 6 o'clock, is paraplegic: right leg almost insensible, left one slightly sensitive, tail sensitive.

At 7 o'clock, difficult breathing. Ascending paralysis which has invaded the whole body; the ribs no longer move; breathing purely diaphragmatic.

Found dead the next day.

Experiment DLXXIV. August 7. Bitch taken to 10 atmospheres, $128 \mathrm{cc}$. of blood drawn. (See Exp. CLXXXV.)

I make the decompression by means of the graduated cock; in 20 minutes, the pressure drops $2 \frac{1}{2}$ atmospheres; in the following $20 \mathrm{~min}$ utes, it drops $1 \frac{1 / 4}{4}$ atmospheres, and $13 / 4$ atmospheres in the following 16 minutes; it is then $4 \frac{1}{2}$ atmospheres, and I open the large cock, which restores normal pressure in 3 minutes.

It is all finished at $7: 31$.

Removed at $7: 40$, the animal is completely paralyzed; gurgling heard in the heart: 80 extremely irregular heartbeats; 80 to 100 respirations, still operated somewhat by the ribs; no apparent uneasiness; great quantity of froth in the mouth.

Dies at 8 o'clock.

Left heart: dark blood with a little gas. Right heart: dark blood frothy with fine bubbles of gas.

Gas in all the veins and arteries, except the veins of the portal system, while the mesenteric arteries are full of it. 
Abundant foam in the stomach and intestine, but not enormous or dangerous from its volume. Foam in the bronchi: lungs healthy, without congestions and effusions.

Experiment DLXXV. August 8. Dog taken to 10 atmospheres, and bled of $133 \mathrm{cc}$. (See Exp. CLXXXVI.)

Decompressed in 50 minutes, very regularly, that is, about $5 \mathrm{~min}$ utes per atmosphere.

Normal pressure established at $7: 30$.

At $7: 35$, very loud gurgling heard in the heart. The animal, when placed on the floor, is paralyzed in the hindquarters and the ribs. Rectal temperature $39^{\circ}$.

8:30, very loud gurgling on the right, much less on the left; progressive paralysis; the animal is conscious and raises its head when called; rectal temperature $36^{\circ}$.

$9: 30$, state still more serious; temperature $35^{\circ}$; the eyes are almost the only movable parts. Still loud gurgling on the right, less on the left.

Found dead the next day.

Experiment DLXXVI. August 9. Dog.

Taken from 8 o'clock to $9: 12$ to 10 atmospheres; seems to undergo a sort of convulsive struggling in the apparatus.

Decompressed very regularly in 1 hour and 30 minutes, that :s, 10 minutes per atmosphere.

Taken out at 10:42, gay and well.

At 10:47, the left front leg stretches out, then is paralyzed in movement but remains sensitive.

At 10:50, the animal falls, the right hind leg is stretched out, paralyzed in movement.

10:55, this leg is better, but the left hind leg is affected in its iurn.

11 o'clock, the whole left side is paralyzed, but sensitive.

Experiment DLXXVII. October 25. Vigorous dog placed free in the large apparatus.

From 2:30 to 4 o'clock, the pressure is taken to 10 atmospheres. About 3:50 the dog, which has howled all the time it has been in the apparatus, is seized by an attack of tonic and clonic convulsions which lasts some 20 seconds.

After this, it remains weak and staggering for some minutes.

At $4: 10$, the animal seems well; decompression is made by passing abruptly from 10 atmospheres to 8 , from 8 to 6 , from 6 to 4 , from 4 to 2 , from 2 to 1 . At each stage, a pause of 15 minutes is made. The whole decompression lasts 1 hour and 10 minutes.

No symptom has appeared during the decompression. The cylinder is opened, and the animal comes out freely. But after 2 or 3 minutes, it utters cries of pain.

At 5:45, it lies down; the hindquarters are stiff; when it is forced to stand up, it lifts the left front foot, which seems to give it pain.

At $6: 15$, is howling less, but is still in the same state.

Well the next day. 
Experiment DLXXVIII. October 28. Dog of the preceding experiment, quite recovered.

Taken to 10 atmospheres; after 5 minutes, has an attack of convulsions. At the end of 15 minutes, decompression is made at the rate of 8 minutes per atmosphere, very regularly, the whole requiring 1 hour 12 minutes.

Shows no symptom either immediate or delayed.

Experiment DLXXIX. November 14. Dog.

Taken to 9 atmospheres. Decompressed in about 1 hour.

When taken from the apparatus, its rectal temperature is $20^{\circ}$. It has loud gurgles in the heart and soon dies.

Experiment DLXXX. June 27. Dog weighing 19.3 kilos.

From 1 o'clock to 2 o'clock is raised to $71 \frac{1}{2}$ atmospheres, with a current of air. A leak develops; at 3 o'clock, the pressure is 6 atmospheres; at $6: 45$ it is only $4 \frac{11}{2}$ atmospheres, in spite of the constant pumping.

Decompressed from $6: 45$ to $7: 45$.

When taken out, the big dog is very wet, cold, dying; it dies after a few breaths. Pulmonary ecchymoses are found, and gas everywhere in the blood.

Experiment DLXXXI. June 27. Two puppies, very young, weighing about 1.5 kilos.

Placed beside the animal of the preceding experiment.

The puppies are also very wet; but they show no symptom, either immediate or delayed.

I summarize in Table XIX the data relating to the progressive and slow decompression.

3. Summary and Conclusions from the Preceding Experiments.

Let us now consider these experimental results in their entirety. The first striking fact when we examine Table XVIII is that sudden decompression is much less dangerous to birds than to mammals. A sparrow, in fact, (Exp. DX) survived the decompression from 10 atmospheres, another (Exp. DXIII) did not die for a long time after a decompression from 14 atmospheres.

On the contrary, in mammals, symptoms began to appear at 6 atmospheres (Exp. DXXX); death struck almost all the animals decompressed from 8 atmospheres, and all of those decompressed from 9. Dogs and cats seemed even more susceptible than rabbits; Experiments DXX and DXXVI made simultaneously on a cat which died and a rabbit which survived, are characteristic, except for individual differences.

In the same species, in fact, we notice differences which are very important. In dogs, for example, we have always had severe 
Table XIX

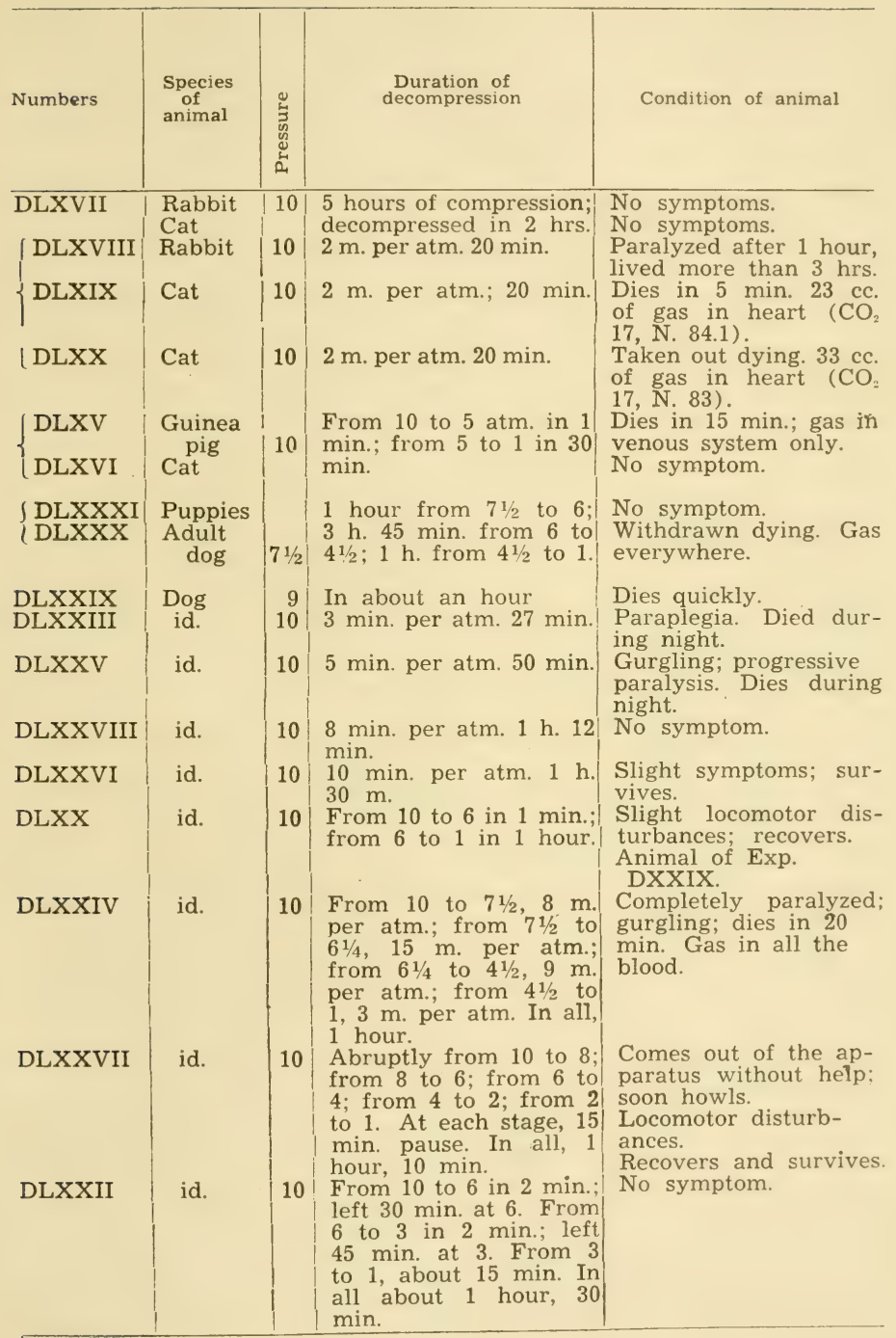


symptoms, often death, at 7 atmospheres, except the animals of Experiments DXLIX and DLII which resisted the decompression of $71 / 2$ atmospheres, and that of DLV which survived even $81 / 2$.

This last animal, from this point of view, is particularly interesting. In a series of sudden decompressions, beginning with $7 \frac{1}{2}$ atmospheres (Exp. DLII and DLIII), then with 8 atmospheres (Exp. DLIV and DLVI), and even $81 / 2$ atmospheres (Exp. DLV), it showed no sign of sickness. Then four months later, decompressed from 8 atmospheres, it died in less than a half-hour (Exp. DLX). During the first series of experiments, it was thin and in very bad shape; at the time of the last, on the contrary, good care had made it fat and healthy.

Must we attribute the difference in results to this difference in condition? The cause, purely physico-chemical, which we shall be compelled to attribute to the symptoms of decompression, does not lend itself to this interpretation. Furthermore, Experiment DLVII shows us a dog in just as bad a condition, at least, which at the first trial, died from a decompression beginning with 8 atmospheres.

No less inexplicable is the resistance of the puppies of Experiment DLXXXI when the adult dog placed beside them during more than 5 hours (Exp. DLXXX) died immediately after a slow decompression, beginning with $7 \frac{1}{2}$ atmospheres.

But setting aside these irregularities which may suggest important considerations in practice, let us now examine the symptoms in themselves.

In sudden decompression beginning with 8 atmospheres and above, we have seen almost always a practically instantaneous death. It appeared also, but more rarely, in decompressions beginning with 7 to 8 atmospheres. Generally then the symptoms consisted of a paralysis of the hind legs, a paralysis sometimes slight and transitory, sometimes persisting for several days, sometimes, finally, rapidly ascending and involving death by asphyxia after several hours.

The cases in which the paralysis receded were, as one might expect, the limited cases (Exp. DXXX, DLXXI, DLXXVI); the limbs alone had been affected; voluntary movement alone had been lessened. These symptoms disappeared of themselves in less than an hour; all that I saw last longer continued till death.

When death occurred, we usually found to explain it and to explain the more or less complex phenomena which had preceded it, a more or less extensive softening of the spinal cord, much advanced in the lumbar regions, and making progress in the rest of 
the organs, in which inflammatory lesions like those described in Experiments DXXVI and DXXXIV preceded it.

There now remain to be explained at the same time the initial cause of these cases of paralysis of greater or less length, and the reason for the almost immediate death which so often occurred.

Let us say next that the hypothesis of M. Bouchard is not at all verified. We have indeed sometimes found the stomach and intestines slightly distended by gases; but, besides the fact that this distention has never been very great, we have never seen in the lungs or nervous centers the congestions and hemorrhages to which sudden death is due, according to this author. Furthermore, in all cases, we have noted the persistence of the heart beats, and therefore we must set aside also the idea of syncope.

We can go still further. The evident proof that the symptom: which attack decompressed animals are not due to abrupt oscillations of the blood which has been driven back by sudden expansion of the intestinal gases is easily drawn from the experiments reported in Chapter IV. We see indeed that dogs could be brought in a few minutes from 7 or 8 atmospheres to normal pressure without showing symptoms similar to those which have just been described, with which it is impossible to confuse the phenomenon of oxygen poisoning, of which they presented the strange and terrible picture.

But the true cause of all these symptoms was shown very clearly, and the hypothesis of MM. Rameau and Bucquoy (see page 501) received the strongest confirmation from our experiments. The gases of the blood, as the professor of Strasburg had foreseen, are liberated under the influence of sudden decompression, and then cause symptoms comparable to those of an injection of air into the veins. But the phenomenon is more varied and complex than the learned physicist could have thought it.

In the first place, it is not the three gases of the blood, as he thought, that thus regain their gaseous form. We might have foreseen this result, because our previous researches (Chapter II, Subchapter III) had showed us that the proportion of the oxygen is hardly increased by pressure, and that of the carbonic acid is not increased at all. We were therefore in a position to state, and we might have thought that we had the right to do so, that the gas which would threaten life on being liberated would be exclusively the one the proportion of which was considerably increased in the blood, that is, nitrogen.

This conclusion could also be drawn from the experiments of 
Chapter IV to which I alluded a moment ago; here no symptom appeared, no gas bubble was freed in the vessels, because the air which the animals were breathing had a very low nitrogen content.

But there is better proof; I could, as Experiments DXXVIII, DLVIII, DLXIX, and DLXX show, extract the gases collected in quantity in the heart and analyze them. I did indeed find them composed chiefly of nitrogen; but I must confess that I was much surprised to find, besides the nitrogen, a quantity of carbonic acid which varied from $15 \%$ to $20 \%$ and even, in one case (Exp. DLVIII), a little oxygen.

The explanation of these facts should probably be drawn from the circumstances that the liberation of the nitrogen takes place in little bubbles, which the circulatory movements stir up before they can collect in the heart in vast collections of gas, so that the blood is, as it were, traversed by a current of nitrogen. Now we have known for a long time that such a current carries with it much carbonic acid.

As for Experiment DLVIII in which I found $2 \%$ of oxygen, that is the one in which the apparatus exploded, and in which the an:mal, which was killed instantly, had not consumed the slight excess of oxygen which had been liberated in its blood.

At any rate, most of the free gas is made up of nitrogen, and from this fact a very serious danger results; for carbonic acid and even oxygen might be redissolved rapidly, and Nysten " long ago demonstrated that their presence in the venous system is not dangerous, unless enormous quantities, especially of carbonic acid, are introduced. It is true that in our experiments there is gas in the arterial system itself.

It is probable that all the excess nitrogen thus passes to the gaseous state. Now we have seen that at 10 atmospheres there are about 8 cubic centimeters of nitrogen in excess in 100 cubic centimeters of blood. Supposing that a dog weighing 14 kilograms contains 1 kilogram of blood, we find that there may be liberated in the arterial and venous vessels 80 cubic centimeters of nitrogen, bringing with them about 20 cubic centimeters of carbonic acid; that is sufficient to bring on symptoms that are immediately fatal.

Now we can picture the effects of sudden decompression. Let us first represent things as bad as possible; let us suppose an animal brought in 2 or 3 minutes from 10 atmospheres to normal pressure. Immediately, in the whole vascular system, gases escape in abundance; there is frothy blood in the veins, in the arteries, in the portal system, even in the vessels of the placenta and the foetuses, 
when the animal was pregnant (Exp. DXXXVI). The heart, which continues to beat for a few minutes more, pumps into the arteries the gases which its left cavities contained, although they are rarely found there; the course of the venous blood, which continues a little while, brings to the right cavities tiny bubbles of gas which collect there in such quantity that a cat (Exp. DLXX) furnished me with 33 cubic centimeters of it, and a little blood freed of gaseous bubbles proceeds to the left heart by some of the pul. monary arteries. The others are obstructed by the foam sent out by the right heart. We find here the effects of this difficulty which gases have in passing through the capillaries, difficulties which so often cause the injections of anatomists to fail: we see bubbles of gas refusing to pass through the lungs, and in certain experiments we have seen the mesenteric arteries full of bubbles of gas without the blood of the portal vein containing any.

Let us suppose now the lightest case, either of an animal decompressed from only 6 atmospheres (Exp. DXXX), or, beginning with 10 atmospheres, of one decompressed very slowly (Exp. DLXXI, DLXXVI, and DLXXVII). In these cases, bubbles of gas will be liberated, though smaller and much less numerous; those of the venous system will stop in the lungs, and will cause some respiratory difficulties; then when they have been agitated and made extremely small (one sometimes needs the microscope to see them), they will reach the left heart and thence be pumped into the arteries, where they will join those which spontaneously developed there and which the circulation has not yet driven into the veins. It may be that they will finally be redissolved without causing any very definite symptoms; but if, unfortunately, some of them, drawn by the circulation into the capillaries of the nervous system, check locally the course of the blood there, immediately, instantaneously, as in the experiment of Sténon, a paralysis or a local excitation is the result; only in the case in point, the bubble is so small that it soon disappears and everything returns to the normal state.

We understand that between these two extremes there must lie many intermediary cases, and the experiments reported above present plenty of examples. Nothing is more startling than to see animals decompressed from 6 to 8 atmospheres leaping out of the apparatus, as if delighted with their liberty, then seized after a few minutes by a paralysis which always begins in the lower limbs, but which often invades next all the rest of the body.

Another surprising thing is this interval of 5 to 10 and even 15 
minutes which almost always elapses between the moment of decompression and that of paralysis, either because the gas does not escape immediately in the whole body, or because a certain time is needed for the bubbles of air to cut off the medullary circulation.

It is no less strange to see, in certain experiments, for instance DLXXV, life persisting for hours when the almost general paralysis of the animal left free only the movements of the diaphragm, and gurgling could be heard in the heart, revealing at the beginning the presence of a great quantity of gas in the right heart and the lungs.

In this case, the animal is slowly asphyxiated, as is proved by the increasing darkness of the blood flowing in its arteries. It is evident that the pulmonary output is insufficient to provide an adequate quantity of oxygenated blood in the arteries.

If now we ask why the nitrogen thus liberated is not finally redissolved in the blood, or why it does not escape through the lungs, the reply is easy.

As a matter of fact, the blood circulating through the vessels under normal conditions is almost saturated with nitrogen through the respiration of air; when arterial blood is shaken with air, it can be made to absorb only some tenths of a cubic centimeter of nitrogen more than it already contained. There is no reason then why the excess which has been liberated should be redissolved. Now the free nitrogen does not escape through the lungs because it is in an atmosphere which is four-fifths nitrogen, and nothing urges it out.

Continuing this reasoning, we begin to think that there might be an advantage in causing the animal to inhale pure oxygen or a mixture of oxygen and hydrogen, to stimulate at the same time the dissolving of the nitrogen in the blood and its diffusion through the pulmonary membranes. And this I did with some success in the experiments which I shall report later.

Finally, a third strange fact, the paralysis always began in the hindquarters (except in Experiment DLXII). Why is this place selected? Is it a sufficient explanation to say: the lumbar region of the spinal cord is the part which works hardest when the animal jumps and runs? I merely remind the reader that paraplegia is also the most frequent symptom in divers and workmen in caissons.

When death occurs shortly after the beginning of the paralysis, it is evidently under the influence of the same cause as the paralysis; the bubbles of gas, after cutting off the circulation in the lumbar 
enlargement, check it in higher points (where autopsy finds them) until finally respiration ceases; during this time, besides, the pulmonary arteries are filled with free gases; asphyxia comes everywhere at the same time.

But it has happened sometimes that the paralysis was localized in the lower limbs, or at least has made only rather slow ascending progress; so that death occurred only after several days (Exp. DXXIV, DXXVI, DXXXIV). If we consider the lack of care for the animals, we may think that some might survive, though paralyzed, as happens to some divers.

At death, there was found, as we have already noted, a more or less extensive softening, in the midst of which bubbles of gas (Exp. DXXVI) were sometimes seen even after 4 days, and which were surrounded by the inflammatory processes which had caused death. I call attention to the rapidity with which a softening occurred so great that the spinal marrow was liquid like cream; in Experiment DXXIV, it was less than 24 hours.

I shall only mention to the reader the remarkable physiological symptoms which accompany these interruptions of the medullary circulation and the following changes in metabolism. Those who have had the patience to read the preceding experiments must have noted the strange occurrences of an emission of bloody urine and sperm, of contraction of the limbs, of constriction with exaggerated reflex movements of the anal and bladder sphincters, of sensitivity retained after the loss of motility, etc. I shall only recall here the curious point of the afferent and efferent conductivity of the sciatic nerve, so much affected by the change in the corre. sponding region of the spinal cord (Exp. DXXXIV). I consider that these softenings produced experimentally might contribute greatly to the progress of the physiology of the spinal cord, and render useful services to the medical diagnostician: it is a mine to be worked which would be as prolific as the one which gave so many useful results in the skillful hands of Professor Charcot.

Some of the experiments reported above show that the presence of bubbles of gas in the blood is not a necessary cause of death or even of symptoms manifest to the eyes of the observer. Thus in Experiment DXXXIX, in which the pressure was $3 \frac{1}{2} 2$ atmospheres, from the blood received under mercury in a test tube very small bubbles of gas escaped, and yet the animal, decompressed in 1 minute, did not seem at all affected. Looking very closely and using a magnifying glass, I even saw in one case (Exp. CLXXXIV) 
the bubbles of free gases escaping under mercury from the blood of a dog placed at 3 atmospheres.

It is evident that in the dog of Experiment DXXXIX, which was some days afterwards decompressed from 5 atmospheres without symptoms, the blood in circulation contained fine bubbles. But they could pass through the capillaries without obstructing the circulation, and probably were dissolved more or less rapidly.

The presence of such bubbles would be enough, I think, even if there were no stoppage of the circulation, to explain, on the basis of irritation of the tissues, the slight symptoms of workmen in caissons, the "puces" (fleas) and the "moutons" (sheep), discussed in the historical part. We therefore understand the risks run by these workmen, whose paralysis or death at these limits depends upon the size of a bubble of gas. It is not surprising then that symptoms, slight in some and fatal in others, appeared after too sudden decompression from about 4 atmospheres.

But the presence of bubbles of nitrogen in the blood, irritating the tissues in contact with them, when they are small enough to traverse the capillaries, or causing more serious and more lasting symptoms, when they interrupt the circulation, does not constitute the only danger to which animals rapidly decompressed are exposed, nor is it perhaps the most dangerous.

Indeed, the very tissues of the organism, which are impregnated with liquid, and the liquids other than the blood are laden with a growing proportion of nitrogen, from contact with the blood which is supersaturated with it. And when the decompression occcurs, these gases must necessarily return to a free state, distending and even lacerating the tissues from which they escape. Experiments DXXXVI, DLVIII, DLIX, DLX, and DLXIII have shown us gases in the subcutaneous or intermuscular tissue, in the liquids of the eye, in the cerebro-spinal liquid, in the spinal cord, etc. Experiment DLVIII, in which the explosion took place, is quite remarkable in this reference; the subcutaneous emphysema was such that the dog had become absolutely cylindrical. Let us mention particularly also Experiment DXXXVI, in which in a pregnant bitch we found gas not only in the blood vessels and tissues of the animal, but also in those of the foetuses, and even in the allantoid liquid; the amnion, which is much less vascular, contained none.

These gases, imprisoned in the meshes of the tissues, must, when they do not cause death, be the cause of pains and local swellings, and it is evidently to them that we must ascribe the muscular 
swellings, the swelling of the breasts, etc., of which we have given several examples in the chapter devoted to history.

In summary, sudden decompression causes many more or less severe symptoms, all of which are easily explained by the liberation in the blood plasma as well as in the interior of the tissues, of the nitrogen which was dissolved in excess under the influence of the pressure.

I admit that, in this collection of data which, although infinite in variety, still has a single simple cause, one point still surprises me. I cannot understand why, in certain dogs subjected to high pressure, the blood extracted from the vessels did not contain free gases: for instance, in Experiments DXLVI and DLVI, in which the pressure was $61 / 2$ and 8 atmospheres. Experiment DLXIII is particularly interesting in this connection: the dog, decompressed after a long stay at 6 atmospheres, was paralyzed, and yet no free gas appeared in its blood; but the symptoms having grown more serious, gas was found after death not only in the blood but also in various organs, and particularly in the spinal cord: this was probably the cause of the immediate paralysis.

It was also somewhat difficult at first to understand why dogs suddenly decompressed from 5 or 6 atmospheres, rabbits from 6 , 7,8 , and sparrows from $8,9,10$, did not die, and did not even show any symptoms, though they certainly had free gases in the blood, since I sometimes observed the presence of gas in an experimental animal, as in Experiments DXXXIX and DLXIV. I think that this apparent anomaly should be explained by the fact that the escape of bubbles which were very small at the time permitted them to pass without hindrance through the system of capillaries and to gather in the venous system. Now if all the gas thus set free is collected in the veins, it cannot constitute a serious danger for the animal.

Let us consider again a calculation which we have already made. At 5 atmospheres, for example, Table XII shows that a dog has an average of 6 volumes of nitrogen per 100 volumes of blood, that is, about 4 volumes more than the blood can dissolve at normal pressure. Let us take a dog weighing $10 \mathrm{kilos}$, and let us suppose that it has in its blood and lymph vessels 1 liter of liquid; there will be $40 \mathrm{cc}$. of nitrogen, with about $10 \mathrm{cc}$. of $\mathrm{CO}_{2}$ which, as a maximum, will collect in the hollows of the right heart. This collection will be made progressively, for it is well known that in a liquid supersaturated with gases by pressure, the gases will not escape instantaneously at the time of the decompression. 
Now the $10 \mathrm{cc}$. of carbonic acid will be dissolved again or will be given off at once by the lungs; as for the $40 \mathrm{cc}$. of nitrogen, which corresponds to what would be present in $50 \mathrm{cc}$. of air, we know that although such a volume of air, injected suddenly into a vein of the heart, can check the contractions of this organ, especially when this air is cold, one can, on the contrary, introduce without harm into the circulatory channels much larger quantities of air, if moderate and successive injections are made.

Nysten long ago demonstrated this fact; but since misapprehensions on this point are still common, I think I should report a few very convincing experiments in this connection:

Experiment DLXXXII. February 24. Little dog, weighing 4 kilos, sick. Injected into the jugular vein in 4 minutes $14 \mathrm{cc}$. of air. The animal dies in 10 minutes.

Bloody foam in the right heart and the pulmonary artery; no gas in the left heart.

Experiment DLXXXIII. July 25. Dog weighing 5 kilos. Outer temperature $21^{\circ}$.

At 3 o'clock, single injection in the left femoral vein of $20 \mathrm{cc}$. of air.

Immediately the heart is heard to beat with the noise of a dry sponge being squeezed under water. The animal ceases to breathe; the heart seems to stop; the conjunctiva, but not the cornea, becomes insensible.

Then the respirations begin again, at first very rare and very deep, then hasty. The heart sounds reappear, normal.

3:15; new injection of 20 cc. Same phenomena, although less pronounced: sensitivity, respiration, heart beats do not completely disappear; stiffenings of the front legs; little cries.

$3: 25$; the animal seems quite recovered. Injection at one time of $40 \mathrm{cc}$. of air. Immediately stiffenings of the legs, heart sounds, respiratory difficulties; the whole condition becomes worse, and at 3:35 the heart can no longer be heard.

Autopsy at 3:50. Right auricle and ventricle full of blood frothed with air, with clots full of air; a little gas in the vena cava. No air in the pulmonary arteries or the left heart.

Experiment DLXXXIV. February 14. Bulldog weighing 12 kilos.

Progressive injection in 9 minutes of $130 \mathrm{cc}$. of air, into the left jugular vein.

Seems rather uneasy during the injection, but released immediately after, is in good condition.

Experiment DLXXXV. February 24. Vigorous hunting dog, weighing 15.5 kilos. Outside temperature $14^{\circ}$.

3:15. Every two minutes, an injection of $65 \mathrm{cc}$. of air in 30 seconds into the right jugular vein, with an excellent glass syringe.

At each injection the animal moans, and immediately, even at a distance, the sounds of heart gurgles are heard. 
After the 10th injection (650 cc.), the animal does not seem to be in danger. At the 24th minute, injections are resumed, but this time every minute.

After the 17 th injection (1100 cc.), the animal groans, urinates, stretches out its legs with force. The heart beats grow slow, the respirations are very rare, and the animal dies at 3:55. Its temper. ature dropped $1^{\circ}$.

I found the right heart full of foam, blood frothed with air, with a large quantity of free air; it was present also in the venae cavae and the pulmonary arteries.

Numerous bubbles of air in the left heart and the cardiac arteries and veins; there was none in the arteries of the limbs and the portal vein.

In Experiment DLXXXII, a dog, which was small, it is true, and sick, was killed by an injection of $14 \mathrm{cc}$. of air, while in Experiment DLXXXV, it was necessary to go as high as 1100 cc. to kill a large dog. These experiments, in short, show us as many differences for artificial injections of air into the veins as for the sort of physiological injection which takes place during sudden decompression.

One of the most important elements to be considered in regard to the appearance of morbid symptoms following decompression is the length of the stay in the compressed air. This plays the principal part, after the degree of compression and the speed of the decompression. So, whereas for dogs decompressed immediately after the desired degree had been reached there are no serious symptoms, as Table XVIII shows, before reaching 7 atmospheres, in Experiment DLXIII, we see a dog dying quite rapidly after leaving the apparatus in which the pressure of 6 atmospheres had been maintained for $3 \frac{1}{2}$ hours. Experiment DXV made on a sparrow is still more remarkable. However, Experiment DLXIV shows us a dog which had no symptoms after a stay of 4 hours under $5 \frac{1}{2} 2$ atmospheres; but he had in his blood abundant bubbles of gas, and was consequently under the threat of an imminent morbid attack.

In conclusion, it is possibly interesting to note that aquatic animals are killed by sudden decompression for the same cause as terrestrial animals and by the same mechanism. But it will no doubt seem enough to report one experiment to support this statement which presents true interest in regard to the conditions of life of these creatures:

Experiment DLXXXVI. April 6. Eels "de la montée" (young), transparent, subjected for two days to a pressure of 10 atmospheres of air.

2 o'clock, decompressed suddenly; emit from their mouths bubbles of gas. 
6 o'clock, all dead; the hearts, which are full of air, can be seen beating; because of the transparency, bubbles of gas can be seen in all the vessels.

\section{Subchapter IV}

\section{PROPHYLAXIS AND TREATMENT OF SYMPTOMS OF SUDDEN DECOMPRESSION}

Considering these dangerous symptoms, a double question is naturally suggested: how to prevent them, and how to cure them.

They will be prevented, as common sense suggests and experience proves, by making the decompression slow enough. On this point the experiments summarized in Table XIX give very clear indications. We see, for example, that from 10 atmospheres on, we avoided serious symptoms by giving more than 1 hour and 10 minutes to the decompression (Experiments DLXXI, DLXXII, DLXXVII, DLXXVIII). But this is the minimum time, since an hour, in Experiment DLXXIV, did not prevent death. I set aside Experiments DLXXX and DLXXXI, which show a peculiarity that I still cannot explain.

I did not perceive great differences between the cases in which the decompression was made continuously at the rate of 8 minutes per atmosphere (Exp. DLXXVIII), or 10 minutes (Exp. DLXXVI), and those in which it was made by sudden drops with intervals of rest (Exp. DLXXII, DLXXVII). Besides, the data are not numerous enough to permit conclusions in favor of either of these methods.

But it is certain that beginning with 10 atmospheres one cannot be sure that a dog will be out of danger unless the decompression is given a duration of at least 12 minutes per atmosphere. We shall return to these data in the third part of this work.

And now for the second question. The decompression was made too quickly. Gases escape into the blood, which obstruct certain vessels and threaten the experimental animal with death. Evidently I should have thought of causing them to be redissolved by subjecting the animal to a new compression with the purpose of decompressing him with controlled slowness. And that is what I did in the two following cases:

Experiment DLXXXVII. October 18. Dog of Experiment DXXXVIII.

It is paraplegic as a consequence of a sudden decompression from

7 atmospheres; the paraplegia began at $3: 21$. 
From $3: 25$ to $4: 05$ was taken again to 7 atmospheres, and kept there until 4:12. Then decompressed slowly; normal pressure was reestablished at 6 o'clock.

On leaving the apparatus, the animal is still paralyzed in the hindquarters, or rather, its hind legs, stiff and contracted, no longer are controlled by the will; sensitivity remains, and we obtain reflex movements by pinching, but very slowly.

Dies during the night.

Experiment DLXXXVIII. October 16. Dog of Experiment DXXXVII.

Paraplegic and stiff since 2 o'clock, as a consequence of a decompression from 7 atmospheres. Recompressed to 7 atmospheres from 2: 15 to $3: 02$, then decompressed in an hour.

The animal seems better and calmer; but it is still paraplegic though not stiff; the temperature of the hind legs has risen.

Dies the next day.

No gas is found in the vessels; but the spinal cord presents, from the lumbar enlargement to the middle of the dorsal region, little bloody spots scattered in the antero-lateral fasciculi. There is no softening.

I did not multiply these experiments; it is evident that the recompression was managed here too slowly for it to be possible to draw any conclusion from these results. However, I do not doubt the effectiveness of this method, on condition that one could obtain a very rapid recompression. We saw in the historical part that it was already used by workmen and recommended by the physicians who had attended them.

The considerations already presented (Page 884) had put me on the track of a quite different method, which aimed not at redissolving the bubbles of free gases in the blood, but at forcing them to escape through the respiration.

These bubbles are composed, I have said, of nitrogen; when they reached the pulmonary capillaries, there is not much likelihood that they will be diffused and mingle with the air of the lungs, because that air also is four-fifths composed of nitrogen. Considering this, I thought that if the animal were caused to breathe a gas containing no nitrogen, pure oxygen, for example, the diffusion would take place much more rapidly, and perhaps would even be rapid enough to cause all the gas to disappear from the blood, and thus save the animal. I give here the results of some experiments performed in this way:

Experiment DLXXXIX. October 31. Dog of Experiment DXLIII.

Decompressed from $7 \frac{1}{4}$ atmospheres, lying down, very sick since 2:15, with gurgling in the heart.

At 2:20, pure oxygen administered to him continuously.

At $2: 30$, the sound of gurgling has ceased, respiration is freer, 
the animal tries to rise using its front feet; its eyes are no longer wild.

At $4: 30$, use of oxygen discontinued. The animal is quite recovered in regard to respiration and heart.

But it is still paralyzed, or at least cannot stand up on its feet, although it moves its limbs and head spontaneously.

Found dead the next day. No gas in the heart or the vessels.

Experiment DXC. November 12. Dog of Experiment DXLV.

3:12. Decompressed from $71 / 4$ atmospheres, paralyzed, with loud gurgles in the heart, and great respiratory difficulties.

$3: 20$. We begin administering pure oxygen.

$3: 35$. The respirations are very deep and frequent; there are no sounds of heart gurgles. The animal makes general movements, and tries to take off the muzzle with its paws.

The respirations become regular for a certain time, then they decrease in intensity, and about $4: 30$, it is clear that the animal is becoming exhausted and is going to die. heart.

It is opened at 4:45, when about dead. No gas in the veins or

Experiment DXCI. November 25. Bitch of Experiment DXLVII.

Decompressed from $7 \frac{1}{2}$ atmospheres, paralyzed at $3: 23$, gurgles, lack of sensitivity, etc.

$3: 28$. Since the respiration has stopped, we are obliged to give artificial respiration with oxygen. After 6 to 7 artificial respirations, spontaneous movements return, the heart begins to beat distinctly, the gurgles diminish, insensibility disappears.

But at this moment the supply of oxygen fails and we cannot continue the experiment; the animal dies almost immediately afterwards.

We find the right heart much distended with blood, with only a little foam.

Experiment DXCII. November 27. Dog of Experiment DXLVIII.

Paralyzed, very loud gurgles, decompressed from 7 atmospheres. At the moment when oxygen inhalation has begun, the heart gurgles seem to increase a little, then the heart almost completely ceases to beat; gradually it becomes quite strong and frequent. But gas does not cease escaping from the upper end of the jugular vein, which has been exposed, and the animal dies after a half-hour.

Blood very red, and without gas in the left heart; blood fairly red with tiny bubbles in the right heart.

Experiment DXCIII. December 6. Dog of Experiment DL.

Decompressed from $7 \frac{1}{2}$ atmospheres at $3: 22$. Immediately paraplegic, front legs a little stiffened, but pulling back when pinched; hind legs stiff and insensible; very loud gurgles.

I give oxygen inhalations and expose its jugular vein, which is full of gas.

Immediately the respirations grow regular; little by little the gas bubbles become smaller in the jugular, sensitivity returns a little to the hind legs; the animal is evidently better. 
About 5 o'clock, the gases have completely disappeared from the jugular, the animal raises its head when called by a whistle. The oxygen inhalations are continued until 9 o'clock in the evening.

December 10. Is no longer completely paralyzed in the hindquarters; can stand up and drags its feet on the back of its toes when walking. Exaggerated sensitivity in the hind legs. Disposition becomes bad.

December 11. Lying down, paralyzed; slight reflex movements of the hindquarters. Very much exaggerated sensitivity in the front legs. Rectal temperature $37.9^{\circ}$.

December 12. Dies.

Nothing noteworthy in the thoracic and abdominal viscera.

No medullary softening. Cross sections of the spinal cord show in the white and the gray substances red dots which diminish progressively from the lumbar region to the cervical region.

Experiment DXCIV. December 11. Dog.

Compressed to 8 atmospheres. Decompressed very slowly to $73 / 4$. Then in 3 minutes to normal pressure; 5:15. tions.

The animal is withdrawn immediately and given oxygen inhala-

5:25. Pulse 120 ; the rectal temperature, which before the experiment was $38.5^{\circ}$, is $37.5^{\circ}$. Respiration regular; bubbles of gas are visible in the jugular, which has been exposed.

5:30. Placed on the floor a moment; is paraplegic.

5:50. Pulse 90; there have been no gurgles in the heart; no more gas is seen in the jugular; temperature $37.2^{\circ}$.

$6: 15$. Use of oxygen discontinued; placed on the floor; is no longer paralyzed, and drags the left hind foot on the toes only a little; the hind legs seem insensible.

It is affected by a peculiarity of movement which makes it turn to the right; its head is bent strongly towards the right, its eyes turn in the same way. It has strong nystagmus and quiverings of the neck muscles. When it wants to walk, it takes many precautions, then at the least obstacle it falls, turning on its right side.

6:30. Manifest improvement; the hind legs and the tail are sensitive; the animal walks much better and appears intelligent.

6:45. The improvement does not continue; the animal again drags its left foot.

December 12. More paralyzed than the day before, can hardly walk, and still turns towards the right.

Stimulus of the hind legs causes energetic reflex movements; but the dog does not seem to notice it. The hind legs, especially the left, are warmer than the others.

December 14. Still paraplegic, cannot stand up even an instant.

December 18. Same condition; urinates easily; energetic reflex movements.

Experiment DXCV. December 13. Dog.

Taken to $81 \frac{1}{4}$ atmospheres: decompressed in 3 minutes. Immediately, at 3 o'clock, oxygen administered. 
It is not paralyzed; but after some minutes, paraplegia begins and becomes complete, with reflex movements persisting. well.

No gurgles in the heart heard at all, and respiration goes on fairly

4:50. Oxygen discontinued. The animal cannot stand on its hind legs.

Respiration maintained well, heart beats are unaltered.

6:30. Same condition; sensitivity in the hind legs dulled.

December 14. Lying down, cannot stand on its hind legs, although it can move them spontaneously, and perceives pricks in them. Dies during the night of December 14-15.

The data which have just been reported, and the results of which had already been listed in Table XVIII, show that one of our anticipations was completely realized. Under the effect of inhalation of pure oxygen, the gases contained in the veins and the right heart diminished, then disappeared; the heart gurgles either did not appear or stopped when the respiration of oxygen began early. The danger of an immediate death, through stoppage of the pulmonary circulation, was therefore averted. ${ }^{4}$

But yet we could not save our animals; the paralysis persisted, and in spite of a real immediate improvement, ended in carrying off our experimental subjects.

That is because the inhalation of oxygen could not bring back into the blood stream and dispose of the bubbles of gas which had stopped here and there in the capillaries of the central nervous system. And it could not, for an even better reason, cause the absorption of the bubbles which, as we have seen, escape into the interior of the tissues.

Upon them, only recompression can have a beneficial effect. But, on the other hand, recompression cannot cause a considerable collection of gases in the right heart to be redissolved.

We are, therefore, led to recommend the successive use of the respiration of oxygen, to eliminate the nitrogen stored up in the right heart, and recompression to dissolve the bubbles which have stopped in the capillaries or are scattered through the tissues.

Even so, we cannot be sure of a cure, because the bubbles of gas, when they pass to a free state in the interior of delicate tissues, like those of the spinal cord, may have caused disturbances or lacerations there, the fatal effects of which cannot be averted by the disappearance of the bubbles.

It is, then, upon preventive measures, that is, slow decompression, that industry must depend, and that is a point to which we shall return in our third part. 


\section{Subchapter V}

\section{SUMMARY}

In summary, sudden decompression, beginning with several atmospheres, brings on symptoms of varying severity depending upon the degree of compression, the speed of the decompression, the animal species, the individuals, and the state of the experimental animal at the time.

These symptoms must be attributed to the escape of nitrogen which had been stored up in excess in the organism, following Dalton's law.

This gas changes to a free state in the blood vessels, the different organic liquids, and even the interior of the tissues; it may therefore, according to circumstances, check the pulmonary circulation, soften and cause anemia in certain regions of the nervous centers and especially the lumbar enlargement of the spinal cord, lacerate the tissues, and produce swellings or a more or less extensive emphysema. The severity of the symptoms depends upon both the seat and the extent of these multiple disorders.

A controlled decompression of 12 minutes per atmosphere is necessary to prevent these symptoms in dogs, when the compression has risen to about 10 atmospheres.

A recompression, either immediate or following the inhalation of oxygen in case heart gurgles are observed, is the only means of combatting successfully the symptoms of decompression.

1 At 3 atmospheres, gas escapes in the syringe from the blood drawn.

2 Recherches de physiologie et de chimie physiologique. Paris, 1811, p. 55 and 81 .

${ }^{3}$ Loc. cit., p. 15 et seq.

${ }^{4}$ Consequently the inhalation of oxygen would be an effective means of checking the effects of the introduction of air into the veins. With this in view, $I$ have made a number of experiments quite encouraging for surgeons. 


\section{Chapter VIII \\ VARIOUS QUESTIONS}

In this chapter I deal with a number of questions which have only a somewhat indirect connection with the subject of my researches, but which are not, however, foreign to it. Such are the questions of asphyxia and the toxic action of carbonic acid, which has been so often mentioned, especially in the first chapter of this work.

\section{Subchapter I}

\section{ACTION OF CARBONIC ACID UPON LIVING BEINGS}

The experiments reported in Chapter I, subchapter II, have shown me that the death of animals confined in closed vessels, in air compressed to several atmospheres, occurs when the tension of the carbonic acid which they have formed by respiration rises to a certain constant value.

This first observation attracted my attention particularly to the stuty of the effects of carbonic acid upon living beings, so that this study is connected indirectly to my project. It is the results of these researches that I shall report here.

1. The Lethal Tension of Carbonic Acid in the Ambient Air.

I first remind the reader that the tension of a gas $T$ is the product of the two factors, the percentage $\mathrm{C}$ and the barometric pressure P.

In sparrows, as we have seen, death occurs when the carbonic acid tension rises to a value of 24 to 28 , when, in other words, one has the equation

$\mathrm{C} \times \mathrm{P}=24$ to 28 . 
And so, the higher the pressure, the lower may be the percentage necessary to cause death, and vice versa. Likewise, at normal pressure and pressures below normal, to produce death, the animals must have been confined in superoxygenated air, for ordi. nary air could not furnish the 24 to 28 per cent lethal at one atmosphere, the 48 to 56 per cent lethal at a half-atmosphere, etc. This is, in fact, what the numerous experiments listed in Chapter I showed us.

1 have made a good many experiments upon animals of different species, from which it appears that the value of the lethal tension of carbonic acid varies according to the species.

Here, for example, are two experiments on rats:

\section{Experiment DXCVI. August 5.}

Rat placed at 3 o'clock in the small Seltzer water receiver, at 7 atmospheres.

Found dead at 6 o'clock; the muscles still contract.

Lungs inflated to the maximum, not retracting when the chest was opened; gases expanded in the stomach.

Gas in the blood of the right heart, but not in the left heart.

Lethal air, $\mathrm{CO}_{2} 4.4 ; \mathrm{O}, 14.8$.

$\mathrm{CO}_{2}$ tension $=30.8$.

Experiment DXCVII. August 19.

Rat weighing $180 \mathrm{gm}$., placed at $11: 45$ at $7 \frac{1}{2}$ atmospheres.

Same apparatus; dies at 2 o'clock.

Enormous expansion of the gases of the stomach.

No gas, even in the right heart.

Lethal air, $\mathrm{CO}_{2} 4 ; \mathrm{O}_{2}$ 14.3.

$\mathrm{CO}_{2}$ tension $=30.0$.

We see here that the lethal tension of carbonic acid is, for rats, a little higher than for birds.

That is, furthermore, a general fact in mammals, as will be proved presently by the experiments made on dogs, which experiments will give in addition the explanation of the apparent irregularities in the value of the lethal tension. I did not think I should dwell on these differences from species to species; only one, which I mentioned before, ${ }^{1}$ deserves to be recalled here, as I shall recall elsewhere the general conclusion. This difference is that batrachians and reptiles find carbonic acid much more dangerous than do warm-blooded animals. Here are some experiments to support this important proposition. Some were made by using superoxygenated air at normal pressure: 
Experiment DXCVIII. February 13. Collared adder, placed in a bell of 875 cc., with air with $77 \%$ of oxygen.

Dies February 21.

The air contains $13.5 \%$ of carbonic acid, and $61 \%$ of oxygen.

Experiment DXCIX. March 16. Frog placed in a bell of $400 \mathrm{cc}$, with pure oxygen.

Dies March 23. The temperature was from $6^{\circ}$ to $7^{\circ}$.

The air contains: $\mathrm{O}_{2} 81, \mathrm{CO}_{2} 17$.

Experiment DC. March 16. Frog placed in a bell of the same dimension, in the same air as the preceding.

Dies March 25.

The air contains: $\mathrm{O}_{2} 84, \mathrm{CO}_{2} 13.7$.

For others, to the superoxygenated air there was added in advance a certain proportion of carbonic acid.

Experiment DCI. August 3. Gray lizard, placed at $4: 15$ in a bell containing $570 \mathrm{cc}$. of an atmosphere with $78.9 \%$ of oxygen, the rest being nitrogen.

August 4. Yawns a great deal, is very uneasy; the distress keeps increasing, and the animal dies August 6, about 2 o'clock (70 hrs.).

The temperature varied from $23^{\circ}$ to $29^{\circ}$.

There is $15.7 \%$ of $\mathrm{CO}_{2}$ in the bell.

Experiment DCII. August 3. Gray lizard, placed at 5:15 in a bell containing $550 \mathrm{cc}$. of an atmosphere with $90 \%$ of oxygen and $10 \%$ of $\mathrm{CO}_{2}$.

August 4. Still somewhat sensitive at 4 o'clock in the evening; found dead at 9 o'clock (about 28 hours).

The temperature varied from $23^{\circ}$ to $29^{\circ}$.

The air contains $16 \%$ of $\mathrm{CO}$.

Experiment DCIII. August 3. Frog placed at 5:45 under a bell of $550 \mathrm{cc}$. containing $90 \%$ of oxygen and $10 \%$ of $\mathrm{CO}_{2}$.

August 4. 10 o'clock in the morning, seems to be hardly breathing. Dies at 2 o'clock (lived 20 hours). The temperature of the laboratory varied from $23^{\circ}$ to $29^{\circ}$.

There is $17 \%$ of $\mathrm{CO}_{2}$ in the bell.

For others the experiment was made in compressed air.

Experiment DCIV. July 28. Temperature $22^{\circ}$. Two frogs are placed at 3 o'clock in the small Seltzer water receiver, and subjected to a pressure of 5 atmospheres.

Nothing special during the two or three days following.

August 1. 1 o'clock. Are evidently very sick.

Die about 3 o'clock.

The air contains $3.2 \%$ of $\mathrm{CO}_{2}$; the tension therefore is $3.2 \times 5=16$.

And so, by one or another of these multiple methods, we see that the lethal tension of carbonic acid for reptiles varies between 13.5 
and 17, that it is from 24 to 28 for sparrows, and that it reaches and passes 30 for mammals.

2. The Lethal Concentration of Carbonic Acid in the Blood.

In the experiments the report of which follows, I tried first to determine the lethal concentration of carbonic acid, not in the exterior medium, but in the blood; next, to ascertain the relations which exist between the increasing amount of this gas in the air in which the animal is confined, and the quantity in the blood.

Evidently these experiments could be made only on dogs and I could not try in practice to keep them in closed vessels in compressed air. I therefore had to use the method of respiration in superoxygenated air at normal pressure.

The set-up of the apparatus was very simple. The animal, which was securely fastened, was forced to breathe either through a tightly closed muzzle or directly through the trachea into a very large rubber bag slightly inflated with oxygen. A small opening permitted us to draw air samples at various intervals, taking great precautions that the sample might represent the average composition of the air in the bag.

Let us now consider the report of these experiments:

Experiment DCV. February 14. Dog weighing 6.5 kilos: sick, its pneumogastric having been cut 4 days before.

3 o'clock. Placed a tube in the trachea. Caused to breathe into the rubber bag in which air is introduced. After 10 minutes, I draw $70 \mathrm{cc}$. of blood from the femoral artery .... A

Removed to free air.

$3: 35$. Caused to breathe into the bag, which then contains a mixture with $94 \%$ of oxygen. After 15 minutes, drew $70 \mathrm{cc}$. of blood . . B

5:15. The animal draws deep breaths. Drew $44 \mathrm{cc}$. of blood .... C

9 o'clock. The eye is hardly sensitive; 15 to 16 respirations, in groups of three, like those of tortoises; rectal temperature $27^{\circ}$.

The gas of the bag contains $\mathrm{CO}_{2} 28 ; \mathrm{O}_{2} 60 ; \mathrm{CO}_{2}+\mathrm{O}_{2}=88$; there has very evidently been absorbed a quantity of oxygen corresponding to $6 \%$.

I draw $37 \mathrm{cc}$. of blood, which comes with difficulty . . . D

I let the animal breathe in the open air.

A (air) contains per 100 cc. of blood $\mathrm{O}_{2}, 16 ; \mathrm{CO}_{2} 29.5$

$\mathrm{B}$ (oxygen) contains per $100 \mathrm{cc}$. of blood $\mathrm{O}_{2} 18.4 ; \mathrm{CO}_{2} 20.6$

$\mathrm{C}$ contains per $100 \mathrm{cc}$. of blood $\mathrm{O}_{2} 17.5 ; \mathrm{CO}=50.1$

D $\left(\mathrm{CO}_{2}: 28 ; \mathrm{O}: 60\right.$. $)$ contains per $100 \mathrm{cc}$. of blood $\mathrm{O}_{2} 17.9 ; \mathrm{CO}_{2} 68.4$

At 10 o'clock, the animal is still breathing in the same way, and at the same temperature.

Found dead the next day.

Experiment DCVI. February 16. Very sturdy dog, weighing 15 kilos. 
Tube in the trachea; carotid artery exposed.

2: 40 . Caused to breathe into a bag containing about 30 liters of air; at the end of 3 minutes, I draw $50 \mathrm{cc}$. of blood . . . A A

Allowed to breathe free air.

2:50. Again adjusted to the rubber bag, which contains 35 liters of a mixture with about $90 \%$ oxygen. At 3 o'clock, drew 50 cc. of blood evidently redder.... B

4:05. Respiration becomes deeper; took air from the bag, which contains $21.4 \%$ of $\mathrm{CO}_{2}$; drew 50 cc. of very red blood . . . . C

4:35. Rectal temperature $35^{\circ}$.

$5: 25$. Rectal temperature $33^{\circ}$; at $5: 30$, took $50 \mathrm{cc}$. of blood .... D

$5: 45$. Took from the right heart, through the right jugular, $30 \mathrm{cc}$. of very red blood ....E

5:50. Drew air from the bag, which contains $\mathrm{CO}_{3} 37 . .3 ; \mathrm{O}_{3} 48.8$.

A little air probably entered the heart, for the dog is seized by trembling, convulsions, rigor; it is unfastened.

$6: 15$. Rectal temperature $34^{\circ}$.

At 9 o'clock in the evening, is quite recovered; survives.

A (air) contains per 100 cc. of blood $\mathrm{O}_{2} 21.0$; $\mathrm{CO}=43.5$

$\mathrm{B}$ (oxygen) contains per $100 \mathrm{cc}$. of blood $\mathrm{O}: 22.4 ; \mathrm{CO}_{2} 43.9$

$\mathrm{C}\left(\mathrm{O}_{2}\right.$ for $1 \mathrm{hr}$. 15 min.: $\left.\mathrm{CO}_{2} 21.4\right)$ contains per $100 \mathrm{cc}$. of blood $\mathrm{O}=22.0 ; \mathrm{CO}_{2} 89.0$

D $\left(\mathrm{O}_{2}\right.$ for 2 hrs. 35 min.: $\left.\mathrm{CO}_{2} 35\right)$ contains per 100 cc. of blood $\mathrm{O}_{2} 19.9 ; \mathrm{CO}_{2} 87.2$

$\mathrm{E}$ (venous blood, $\mathrm{CO}_{2} 37.3 ; \mathrm{O}_{2} 48.8$ ) contains per 100 cc. of blood $\mathrm{O}_{2} 16.5 ; \mathrm{CO}_{2} 82.3$.

Experiment DCVII. March 1. Large dog; muzzle.

While it is breathing in the open air with extraordinary rapidity, I draw 70 cc. of blood from the femoral artery . . . A A

And from the vein, $40 \mathrm{cc}$. . . . A'

$3: 45$. Caused to breathe into a bag full of oxygen.

$3: 50$. Venous blood from the femoral. $40 \mathrm{cc} . . .$. B'

3:55. Gas from the bag.... x

3:58. Arterial blood, 40 cc. . . . B

$5: 25$. 30 or 40 calm respirations per minute; rectal temperature $37^{\circ}$; took 40 cc. of arterial blood .... C

The air of the bag contains $\mathrm{CO}_{2} 32.8 ; \mathrm{O}_{2} 53.3 \ldots \mathrm{y}$

At 6 o'clock, the animal is very sick; we inject carbonic acid carefully into the bag through a small orifice, taking pains by agitation of the bag to obtain a mixture as perfect as possible.

About 7 o'clock, it becomes evident that the animal is about to die; we stop injecting the acid; rectal temperature $36^{\circ}$. The animal breathes several times more. During the last respirations, I draw with difficulty $47 \mathrm{cc}$. of very dark blood from the right heart .... D'

Drew next, with just as much difficulty, from the left carotid 40 cc. of very red blood .... D

Immediately after, took gas from the bag . . . z z

I immediately place a tube in the trachea and collect under water the air from the lungs, opening the thorax. It contains per 100: $\mathrm{CO}$ = $60.8 ; \mathrm{O}_{2} 18.8$. 
Summary of the Experiment

$\begin{array}{rr}\mathrm{O}_{3} & \mathrm{CO}_{2} \\ 24.8 & 19.5 \\ 10.0 & 29.0 \\ 23.4 & 33.6 \\ 11.9 & 31.3 \\ & 66.7 \\ 17.5 & 79.5 \\ 4.4 & 73.3\end{array}$

A (free air; respirations very rapid; arterial blood) $24.8 \quad 19.5$

$\begin{array}{llll}A^{\prime} \text { (free air; respiration very rapid; venous blood) } & 10.0 & 29.0\end{array}$

B (air x: $\mathrm{O} 281.8 ; \mathrm{CO}_{2} 3.8$; arterial blood) $\quad 23.4 \quad 33.6$

B' (air x: $\mathrm{O}_{2} 81.8 ; \mathrm{CO}_{2} 3.8$; venous blood) $\quad 11.9 \quad 31.3$

$\mathrm{C}$ (air y: $\mathrm{O}_{2} 53.3 ; \mathrm{CO}=32.8$; arterial blood) 66.7

$\begin{array}{llrr}\text { D (air z: } \mathrm{O}_{2} 37.6 ; \mathrm{CO}_{2} 51.5 \text {; arterial blood) } & 17.5 & 79.5 \\ \mathrm{D}^{\prime} \text { (air z: } \mathrm{O}_{2} 37.6 ; \mathrm{CO}_{2} 51.5 \text {; venous blood) } & 4.4 & 73.3\end{array}$

Experiment DCVIII. March 4. Dog weighing 3.950 kilos.

Placed under a glass bell of 31 liters; brought the pressure to 17 $\mathrm{cm}$.; is very uneasy, sits up anxiously: oxygen admitted. I then take the pressure to $8 \mathrm{~cm}$.: same symptoms, and oxygen admitted up to normal pressure.

The cock is closed at $2: 45$; the air contains $81 \%$ of oxygen.

4:05. Animal uneasy, breathing with difficulty, sitting up in the bell, air sample taken .... a

5:30. The animal has just fallen on its side; air sample taken $\ldots \mathrm{b}$

6:10. Lying down, does not heed raps on the bell, seems insensible; 16 enormous respirations, very painful; took air sample . . . c

9:30. Found dead; there has been absorption considerable enough for the pressure to have diminished from 4 to $5 \mathrm{~cm}$. in the bell; air sample taken .... d

So, in summary:

Uneasy, with air $a: \mathrm{O}_{3} 64.9 ; \mathrm{CO}_{2} 15.7$.

Falls, with air $b: \mathrm{O}_{2} 60.5 ; \mathrm{CO}_{2} 20.2$.

Insensible, with air $c$ : $\mathrm{O}_{2} 53.8 ; \mathrm{CO}_{2} 27.0$.

Dead, with air d: $\mathrm{O}_{2} 46.3 ; \mathrm{CO}_{2} 34.1$.

Taking into account the diminution of pressure in the bell, we easily calculate that there was about 1300 cc. of oxygen absorbed without reappearing in the gaseous state as carbonic acid.

Experiment DCIX. March 8. Medium-sized dog; cannula in the trachea; femoral artery exposed.

3:30. Caused to breathe in the bag containing air; respiration calm; drew $50 \mathrm{cc}$. of blood from the femoral artery .... A

3:53. Caused to breathe in the bag containing about $90 \%$ oxygen. Shows almost complete apnea: merely a few slight respiratory movements. At 4:10, drew $50 \mathrm{cc}$. of very red blood ... . B

$5: 20$. Forced respirations, very difficult; took air sample from the bag; it contains $\mathrm{CO}_{2} 9 ; \mathrm{O}=80.8$. Drew $40 \mathrm{cc}$. of red blood .... C

$6: 15$. Rectal temperature $33^{\circ}$; respirations very uneasy; eye sensitive.

The air of the bag contains $\mathrm{CO}_{2} 18 ; \mathrm{O}_{2} 70$; drew 40 cc. of red blood $\ldots . \mathrm{D}$

Blood A (air) contains per 100 cc. of blood: $\mathrm{O}_{2} 18.9 ; \mathrm{CO}_{2} 36.5$

Blood $\mathrm{B}$ (oxygen) contains per $100 \mathrm{cc}$. of blood: $\mathrm{O}_{2} 23.0 ; \mathrm{CO}_{2} 42.8$

Blood $\mathrm{C}\left(\mathrm{O}=80.8 ; \mathrm{CO}_{2} 9\right)$ contains per 100 cc. of blood: $\mathrm{O}_{2} 24.7$; $\mathrm{CO}_{2} 60.8$

Blood D $\left(\mathrm{O}_{2} 70 ; \mathrm{CO}_{2}, 18\right)$ contains per $100 \mathrm{cc}$. of blood: $\mathrm{O}=17.6$; $\mathrm{CO}_{2} 71.6$ 
Experiment DCX. March 12. Dog weighing 9 kilos. Tube in the trachea.

Femoral artery exposed.

$2: 20$. Breathes air from the rubber bag, from two to three minutes; respirations very calm; drew $45 \mathrm{cc}$. of arterial blood . . . A and $35 \mathrm{cc}$. of venous blood from the lower vena cava . . . . A'

2:55. Caused to breathe mixture with about $90 \%$ of oxygen.

3:10. Drew $45 \mathrm{cc}$. of arterial blood redder than A .... B

Drew 35 cc. of blood from the lower vena cava . . . B B'

3:20. Air from the bag: $\mathrm{O}=81.7 ; \mathrm{CO}_{2} 7.9$.

5: 45 . 16 respirations, very uneasy; 100 weak heart beats; eye lacks sensitivity; rectal temperature $30^{\circ}$; took venous blood from the lower vena cava at the level of the kidneys .... . C'

6:35. The air of the bag contains $\mathrm{CO}_{2} 32.5 ; \mathrm{O}_{2} 55$.

6: 45 . 12 respirations; pulse 87 ; rectal temperature $28.5^{\circ}$; took 45 cc. of very red arterial blood.... D

Next drew from the right heart 35 cc. of blood . . . . D'

$\begin{array}{llll}\text { Was not dead at } 7: 30 \text {; rectal temperature } 28^{\circ} & \mathrm{O}_{2} & \mathrm{CO}_{2}\end{array}$

Blood A (air, arterial blood) _...

Blood A' (air, venous blood)

Blood $\mathrm{B}$ (about $83 \%$ of $\mathrm{O}_{2}$ and $6 \%$ of $\mathrm{CO}_{3}$, arterial blood)

Blood B' (about $83 \%$ of $\mathrm{O}_{2}$ and $6 \%$ of $\mathrm{CO}$, venous blood)

Blood C' (about $60 \%$ of $\mathrm{O}_{2}$, venous blood) ______ $6.7 \quad 73.1$

Blood D (about $\mathrm{O}_{2} 53 \%$; $\mathrm{CO}=33 \%$, arterial blood) _-_18.0 93.8

Blood D' (about $\mathrm{O}_{2} 53 \%$; $\mathrm{CO}=33 \%$, blood from the right heart)

$12.3 \quad 101.4$

The next day, the animal having died during the night, the stomach is much distended by gases which contain $50 \%$ of $\mathrm{CO}_{2}$ and $5 \%$ of oxygen.

The air of the bag contained $\mathrm{O}_{2} 50.6 ; \mathrm{CO}_{2} 34.8$; that of the lungs: O. 23.5; $\mathrm{CO}=57.7$.

I take $45 \mathrm{cc}$. of urine from the bladder, and put it into the pump for the extraction of gases, in which there is already a little sulphuric acid diluted and thoroughly cleared of gas. I thus find that $100 \mathrm{cc}$. of urine contains $106 \mathrm{cc}$. of carbonic acid.

Experiment DCXI. April 17. Dog weighing $9 \mathrm{kilos}$; tube in the trachea.

11:05. Caused to breathe into the bag containing 28 liters of oxygen.

No apnea visible.

11:20. Rectal temperature $37.5^{\circ}$.

3:05. Eye insensitive; respiratory rate 10 ; pulse 64 , rectal temperature $30^{\circ}$.

3:45. Pulse 51, 6 respirations; $29^{\circ}$.

4: 05 . Pulse 48,1 respiration every 2 minutes.

4: 15. Blood drawn from the right heart, $50 \mathrm{cc}$, fairly red . . . . A

4:40. Pulse 45; respirations every 2 or 3 minutes; temperature $27.8^{\circ}$ 
4:50. The heart is still beating; no respiration for about $10 \mathrm{~min}$ utes.

Drew 50 cc. of blood from the left heart, not very red ... . B

5 o'clock. The heart has not been beating for several minutes; drew 50 cc. of very dark blood from the right heart ... . C

5:15. The air of the bag contains $\mathrm{CO}_{2} 45.4 ; \mathrm{O}_{2} 39$; this composition could not have changed perceptibly since death, by endosmosis, for at $6: 45$, I find in it $44.6 \%$ of carbonic acid.

A. (right heart; breathing oxygen for 5 hrs. 10 min.) contains $\mathrm{O}_{2}$ 16.6; $\mathrm{CO}_{2} 101.4$.

B. (left heart; $\mathrm{O}_{2} 39 ; \mathrm{CO}_{2} 45.4$ ) contains $\mathrm{O}_{2} 10.8 ; \mathrm{CO}_{2} 116.6$.

C. (right heart; $\mathrm{O}_{2} 39 ; \mathrm{CO}_{2} 45.4$ ) contains $\mathrm{O}=0.7 ; \mathrm{CO}_{2} 120.4$.

Experiment DCXII. March 15. Temperature $13^{\circ}$. Young bitch, weighing 8.5 kilos.

Vaginal temperature $39^{\circ}$.

$2: 25$. Caused to breathe through the trachea into the bag containing 40 liters of air with $83 \%$ of oxygen.

Respirations extremely rapid.

$2: 30$. Took $25 \mathrm{cc}$. of arterial blood from the carotid; pulse then was 100 ; the blood is extremely red .... A

2:55. 72 deeper respirations; vaginal temperature $36.1^{\circ}$.

$3: 05$. Took air from the bag ....

$3: 07$. 60 respirations, quite deep; temperature $35^{\circ}$; took $25 \mathrm{cc}$. of arterial blood.... B

4:04. 56 respirations; temperature $31^{\circ}$; air from the bag .... y

4:06. 25 cc. of blood, very red .... C

4: 20. Respirations 44 ; pulse 51 ; temperature $30^{\circ}$.

4:50. Respirations 28; pulse 32 ; urine.

5:15. Respirations 20 ; pulse 24 ; temperature $27^{\circ}$.

$5: 25$. Respirations 16 ; pulse 16 ; temperature $26.5^{\circ}$; one eye insensible; still a little sensitivity in the other.

5:32. Took $15 \mathrm{cc}$. of carotid blood, very red ... D

5:38. Temperature $25^{\circ}$; respiration in the bag stopped, sample of the air taken .... z

After a few minutes, the animal, which still lacks eye sensitivity, is seized by rigor in the legs and neck, with a certain uneasiness in the limbs; it is unfastened. It then makes slow and languid movements like those of a marmot waking up.

6:20. Animal calm; respirations 24 ; pulse 32 ; temperature $25^{\circ}$. I draw $25 \mathrm{cc}$. of very red blood, then I take out the tracheal tube . . . E

The next day, the animal is perfectly recovered; its vaginal temperature has risen to $40^{\circ}$. Survives.

Summary of the experiment:

Blood A ( $83 \%$ of oxygen)

O CO Temp.

Blood B (air $x$ : $\mathrm{O}=71.6 ; \mathrm{CO}_{2} 13.3$ )

Blood C (air $y$ : $\mathrm{O}_{2}, 61$; $\mathrm{CO}_{2}, 21.5$ ) 
Experiment DCXIII. March 19. Temperature $18^{\circ}$. Terrier bitch weighing 9 kilos.

$2: 25$. Tube placed in trachea; vaginal temperature $38^{\circ}$.

$2: 32$. Caused to breathe into a bag containing 40 liters of air with $89.4 \%$ of oxygen.

Respirations extremely rapid.

2:43. Drew from the carotid $25 \mathrm{cc}$. of moderately red blood ... . A

100 respirations, pulse 108 , temperature $37.5^{\circ}$.

$3: 10$. Took sample of air from the bag . . . a a

3:13. Drew 25 cc. of blood .... B

$3: 20$. Respiration 36 ; pulse 76 ; temperature $37^{\circ}$.

$3: 38$. Respiration 36 ; pulse 72 , irregular; temperature $36.8^{\circ}$, urine; sample of air from the bag ... . b

3:48. Temperature $35.9^{\circ}$.

4 o'clock. Respiration 36; a cardiometer placed in the carotid oscillates from $11.5 \mathrm{~cm}$. to $19 \mathrm{~cm}$.

$4: 10$. Temperature $35.2^{\circ}$; took sample of air from the bag . . . c

4:18. 25 cc. of blood .... D

$4: 30$. Temperature $34.5^{\circ}$; legs insensible, eye still sensitive; respiration 56 ; pulse 72 .

4:59. Temperature $33.5^{\circ}$; sample of air from the bag ....d

5:05. Absolutely without sensation except in the eye.

$5: 20$. Respiration 68 ; pulse 80 ; temperature $32.8^{\circ}$; air from the bag ....e

5:35. Temperature $32.2^{\circ}$.

5:45. Air ... . f

5:48. Respiration 52, somewhat irregular; pulse 58, very weak; temperature $32^{\circ} ; 30$ cc. of blood . . . G

The cornea becomes insensible; the conjunctiva still retains some sensitivity.

6 o'clock. Respiration 44; pulse 44; temperature $31.2^{\circ}$.

$6: 10,25 \mathrm{cc}$. of blood .... H

The bag is removed, after a sample of air for analysis has been taken ... g

After a few respirations in the open air, the animal displays rigor, which lasts only a short time. When placed on the floor, it twists slowly, without apparent consciousness.

I remove the tracheal tube.

About 6:30, consciousness returns very clearly. At 7 o'clock, when stimulated, stands up, and tries to walk.

$\begin{array}{lllll}\text { The next day, quite recovered; survives. } & \mathrm{O}_{2} & \mathrm{CO}_{2} & \text { Temp. }\end{array}$ Blood A (Air with $89.4 \%$ of oxygen) $\ldots 25.5 \quad 28.9 \quad 38^{\circ}$

Blood B (Air $a ; \mathrm{O}, 78.4 ; \mathrm{CO}, 8.7$ ) $23.7 \quad 52.6 \quad 37^{\circ}$ Air b; O 71.2; CO. $14.8 \ldots 36.8^{\circ}$

Blood D (Air c; O $66.0 ; \mathrm{CO}_{2}$ 19.4)

(Air $d ; \mathrm{O}_{2}$ 58.4; $\mathrm{CO}_{2} 27.3$ ) $-33.5^{\circ}$

(Air e; $\mathrm{O}_{2}$ 53.3; $\mathrm{CO} 232.1$ ) $32.8^{\circ}$

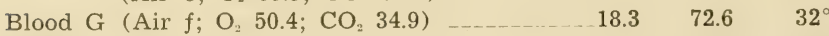

Blood $\mathrm{H}$ (Air $g$; $\mathrm{O}, 47.0 ; \mathrm{CO}_{2} 38.1$ ) $\ldots 17.2 \quad 82.8 \quad 31.2^{\circ}$ 
Experiment DCXIV. Dog weighing 7.7 kilos. Temperature $16^{\circ}$.

$10: 30$. Placed a tube in the trachea. At 10:45, its rectal temperature is $38.2^{\circ}$.

11:35. Caused to breathe in the bag containing 40 liters of air . . a

11: 43. Took $28 \mathrm{cc}$. of carotid blood . . . . A

12:45. Respiration 60 , uneven; pulse 120 ; temperature $38.1^{\circ}$; took air .... b

1:50. Took air ....c

Respiration 40, uneven; pulse 96; the animal is almost insensible.

2:25. Respiration 36 ; pulse 96 ; temperature $31^{\circ}$; eye not very sensitive.

2:55. Respiration 30 ; pulse 66 , double; temperature $29.8^{\circ}$; took air .... d

3:23. Took air ....e

$3: 25$. Respiration 28 ; pulse 60 ; temperature $28.8^{\circ}$; took 26 cc. of blood .... B

3:45. Respiration 28 ; pulse 52 ; temperature $28.2^{\circ}$; carotid pressure oscillating from 12 to $14 \mathrm{~cm}$; eye still slightly sensitive.

4:05. Respiration 20; pulse 44 ; temperature $27.8^{\circ}$; eye still somewhat sensitive; took air.... f

4:37. Eye lacks sensitivity; respiration 20; pulse 43 ; temperature $27^{\circ}$; took air ....g

5:05. Respiration 22 ; pulse 48 ; temperature $26^{\circ}$; took air . . . h

$5: 21$. Temperature $25.2^{\circ}$.

5:35. Respiration 4 ; pulse 40 , very weak; temperature $25^{\circ}$; took air .... i

5:50. Temperature $24.5^{\circ}$.

5:55. Respiration 3 ; pulse 36 ; temperature $24^{\circ}$; took blood from the left heart with the cannula; very red . . . C

$6: 15$. Respiration 2 ; pulse 36 ; temperature $23.5^{\circ}$; took air ... j

The respirations become more and more rare, then cease some minutes before the heart. The latter ceases at $6: 35$; temperature $23^{\circ}$.

$6: 45$. I take blood from the left heart; it is very dark . . . D

Also took air from the bag .....k

The sciatic nerve still causes the muscles to contract at $7: 25$.

The table below gives the results of the experiment:

\begin{tabular}{|c|c|c|c|c|c|c|c|c|c|c|c|}
\hline & 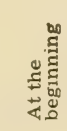 & 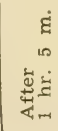 & 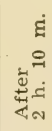 & 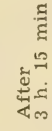 & 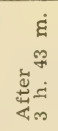 & 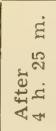 & 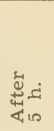 & 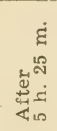 & 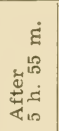 & 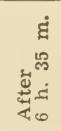 & g \\
\hline & a & b & c & d & e & f & g & $\mathrm{l}$ & i & $\mathrm{j}$ & $\mathrm{k}$ \\
\hline e bag & 70.5 & 8.6 & 47.9 & 42.7 & 39.7 & 37.1 & 34.8 & 34.9 & 34.2 & 33.7 & \\
\hline $\begin{array}{l}\mathrm{CO}_{2} \\
\mathrm{O}_{2} \text { of arterial }\end{array}$ & 52 & & 3 & 6 & $\begin{array}{l}30.4 \\
\mathrm{~B}\end{array}$ & 32.5 & 33 & 33 & 34.2 & 35.4 & $\begin{array}{l}35 \\
D\end{array}$ \\
\hline blood & $6 \overline{1.8}$ & & & & $\begin{array}{l}18.7 \\
90.5\end{array}$ & & & & $\begin{array}{r}18 \\
103\end{array}$ & 2 & $\begin{array}{l}0.0 \\
6.7\end{array}$ \\
\hline & $38.2^{\circ}$ & 38.1 & & 29.8 & 28.8 & 27.8 & 2 & 26 & 25 & | 23.5 & 23 \\
\hline 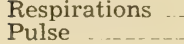 & - & & 40 & & & & & & 4 & 2 & 0 \\
\hline & & & & & & & & & & & \\
\hline
\end{tabular}


Experiment DCXV. March 26. Temperature $14^{\circ}$. Mastiff, very sturdy, weighing 16 kilos.

At 11 o'clock, placed a wide tube in the trachea: the animal struggles, breathes with very great rapidity, then falls, after a series of unusual hasty respirations, into a state of complete apnea which lasts a minute.

11:25. Caused to breathe into a bag containing 60 liters of superoxygenated air .... a

Immediately shows a slight apnea which lasts 15 seconds; temperature $37.6^{\circ}$.

11: 40 . Took $25 \mathrm{cc}$. of very red blood ..... A

11:57. 21 deep respirations; pulse 152 ; temperature $37.3^{\circ}$.

12:30. The animal has been struggling for a quarter of an hour; took air ... b

12: 35 . Temperature $35.8^{\circ}$; urine; took very red blood . . . . B

12:45. Respiration 43; pulse 100 ; temperature $35^{\circ}$.

12:50. Arterial pressure varies between $13 \mathrm{~cm}$. and $15 \mathrm{~cm}$.

1 o'clock. Respiration 40; pulse 92 ; temperature $33.8^{\circ}$.

$1: 34$. Respiration 38 ; pulse 88 ; temperature $32.2^{\circ}$; took air . . . . c

1:40. Arterial pressure varies from $14 \mathrm{~cm}$. to $16 \mathrm{~cm}$.

2 :05. Respiration 36 ; pulse 72 ; temperature $31.2^{\circ}$; took blood . . C

The animal is unfastened; the ends of his toes can be squeezed and his skin cut, without causing the slightest sign of pain, the slightest movement, the slightest change in respiratory rhythm. However, the eye is sensitive.

2:30. Respiration 28; Pulse 60 ; temperature $30.8^{\circ}$; took sample of air ....d

3 o'clock. Respiration 24; pulse 56 ; temperature $30^{\circ}$.

$3: 15$. Eye lacks sensitivity; took sample of air . . . e

3 : 18 . Respiration 20 ; pulse 48 ; temperature $29.5^{\circ}$; drew 25 cc. of carotid blood, very red .... D

$3: 30$. Arterial pressure varies from $12 \mathrm{~cm}$. to $14 \mathrm{~cm}$. with occasional extremes of 11 and $15 \mathrm{~cm}$.

4 o'clock. Respiration 16 ; pulse 32 ; temperature $28.5^{\circ}$; took sample of air .... f

$4: 10$. Took $25 \mathrm{cc}$. of very red blood ... . E

$4: 30$. Respiration 8 ; pulse 28 ; temperature $28^{\circ}$.

4:45. Respiration 8 ; pulse 28 ; temperature $28^{\circ}$; pressure of 8 to $10 \mathrm{~cm}$; took sample of air ....g

$5: 15$. The animal has just stopped breathing; its last respiratory movements were recorded by the pneumograph (See Fig. 78); temperature $27^{\circ}$; the heart is still beating a little; however, blood has to be drawn by a cannula .... F

Took air from the bag .... $h$

$6: 30$. There is still a little muscular contraction after very strong stimulation of the sciatic; nothing at 7 o'clock; duration of about 1 hour and 20 minutes.

At 11:45 and 3:45, I took arterial blood and boiled it with sulfate of soda and charcoal to test for sugar; there were only traces of it.

The summarizing table follows. 


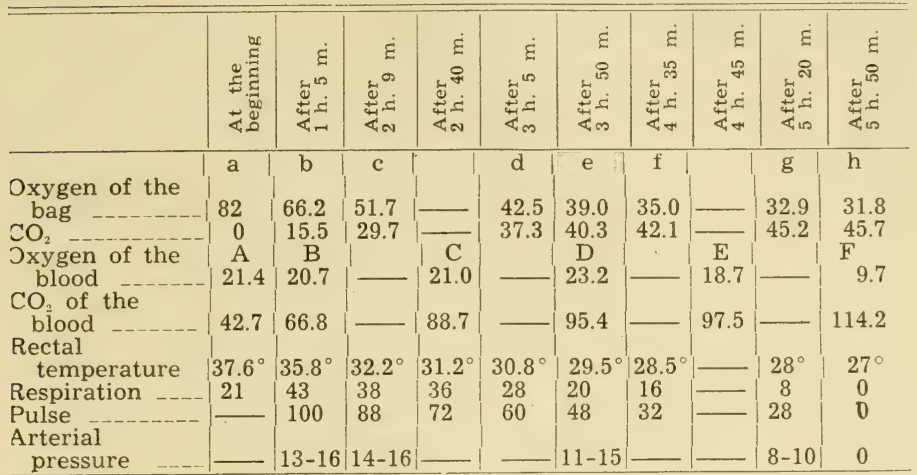

Experiment DCXVI. March 28. Dog weighing 11.5 kilos.

2:58. I cause the dog to breathe through a muzzle in a bag in which there has been left the air remaining from the dog of the preceding experiment. This air still contains $40 \%$ of carbonic acid.

The dog then has a respiratory rate of 20 ; pulse 132 ; I have just taken $25 \mathrm{cc}$. of blood from its carotid, before adjusting the bag . . . . A

3 o'clock. Respiration 33; pulse 108; then suddenly the respiration is speeded up remarkably, and rises to 168 .

3:03. Appears insensible; the skin of its leg is cut and its toes are squeezed without any sign of sensibility.

$3: 05$. The pressure in the carotid varies between 19 and $23 \mathrm{~cm}$; I take $25 \mathrm{cc}$. of carotid blood. ..... B

3:06. Respiration 24, very deep; the diaphragm not acting , the hollow of the stomach is flattened at each inspiration; pulse 180 .

$3: 12$. Legs absolutely lacking sensitivity; the eye is sensitive; the pupils contract in the light; but squeezing the toes causes no change either in the state of the pupils or the arterial pressure.

$3: 17$. Respiration 22; pulse 126; arterial pressure from 15 to 20 $\mathrm{cm}$; temperature $39^{\circ}$.

$3: 25$. Respiration 24 ; pulse 104 ; temperature $39^{\circ}$; eye almost lacking sensitivity.

$3: 26$. I remove the bag and allow the animal to breathe the free air.

3:28. Respiration 44; deep; pulse 165 .

$3: 30$. Sensitivity in the legs restored.

Put down on the floor, cannot stand up, and shows signs of rigor.

3:50. Begins to stand up, tries to walk, but shows a peculiar type of movement, turning towards the left, with its hind part on the floor.

The head is turned, the left ear lowered, the left pupil dilated; nystagmus of both eyes.

These phenomena last about ten minutes, gradually lessening; then the dog recovers completely. 
Blood A (at the beginning) contained 19.1 of oxygen and 44.8 of $\mathrm{CO}_{2}$. Blood B (insensibility) ... contained 18.0 of oxygen and 81.2 of $\mathrm{CO}_{2}$. The air of the bag, after the experiment, contained per 100: $\mathrm{CO}_{2} 43.6 ; \mathrm{O}_{2} 23.1$.

Experiment DCXVII. December 22. Bitch weighing 12.5 kilos.

At $4: 50$, the animal is forced to breathe through a muzzle into a bag containing a mixture of $\mathrm{CO}_{2} 20 \%$, oxygen $60 \%$, nitrogen $20 \%$.

Before the experiment, the animal had a respiratory rate of 20 , pulse 80 ; the arterial pressure oscillated from 16 to $18 \mathrm{~cm}$; its temperature was $38.5^{\circ}$. I took $20 \mathrm{cc}$. of blood from its carotid. . . . . A

At the beginning of respiration in the bag, the animal took a few very deep breaths, but soon became calm.

5 o'clock. Quite sensitive everywhere; 44 deep respirations; the pressure is 18 to $20 \mathrm{~cm}$.

5:30. Sensitivity when the paws are pinched is somewhat blunted; respirations 36 ; pulse 64 ; pressure from 14 to $17 \mathrm{~cm}$.

5:40. I take $20 \mathrm{cc}$. of arterial blood. . . . B

5:48. Sensitivity much dulled, even when the sciatic nerve is stimulated; eye sensitive.

6 o'clock. Respirations 28; pulse 80 ; temperature $36^{\circ}$.

The insensibility is making progress.

$6: 30$. Respirations 36 ; pulse 100 ; temperature $34.5^{\circ}$.

Completely insensible to the piniching of the paws and the ears and the electrical stimulation of the sciatic nerve. The eye is perhaps a little sensitive yet.

The arterial pressure oscillates between 11 and $17 \mathrm{~cm}$; I draw air from the bag and $25 \mathrm{cc}$. of arterial blood. . . . . C

$6: 37$. I unfasten the animal, remove the muzzle, and place the animal on the floor. It is almost immediately seized by a great attack of tonic, then of clonic convulsions, much like those of phenol.

These convulsions diminish little by little. 25 minutes later, the animal begins to stand up, but it is weak and tottering.

$7: 20$. Temperature $35^{\circ}$. The animal is stronger and more sensitive.

The next day it is quite well.

Blood A (outside air) contained. . . . . . . . $\mathrm{O}_{2} 22.5 ; \mathrm{CO}_{2} 39.5$

Blood $\mathrm{B}$ (beginning of insensibility). . . . . . $\mathrm{O}_{2} 22.5 ; \mathrm{CO}_{2} 68.2$

Blood C (complete insensibility; air $\mathrm{CO}_{2} 34.4 ; \mathrm{O}_{2} 43.8$ ) $\mathrm{O}_{2} 21.6$; $\mathrm{CO}_{2} \mathbf{7 7 . 0}$

Experiment DCXVIII. December 26. Dog; rubber muzzle.

Respirations 20; pulse 88; arterial pressure from 18 to $19 \mathrm{~cm}$; temperature $39.5^{\circ}$.

At 5:07, caused to breathe into a bag containing a mixture of $52.8 \%$ of $\mathrm{CO}_{2} ; 36.7 \%$ of oxygen; and $11.5 \%$ of nitrogen.

Almost immediately is seized by struggling with convulsive trembling, which soon ceases.

Anesthesia is complete 2 to 3 minutes afterwards; I then take 25 cc. of arterial blood.... A

5:15. Removed the bag; immediately the respirations become deeper and more frequent.

5: 18. Sensitivity has reappeared; I take 25 cc. of blood ... . B 
Placed on the floor, the animal totters and seems drunk; temperature $39^{\circ}$; but it has no convulsive movements. It has wholly recovered after 15 or 20 minutes.

Blood A (insensibility) contained …… O 23.7; $\mathrm{CO} 98.4$ Blood B (sensitivity restored) contained ____. $\mathrm{O}_{2} 20.8 ; \mathrm{CO}_{2} 31.7$

The air of the bag, at the end of the experiment, contained only $52.2 \%$ of $\mathrm{CO}_{2}$ and $38.5 \%$ of oxygen.

Experiment DCXIX. December 28. Dog.

Respiratory rate 48 , pulse 80 ; the carotid pressure varies from 15 $\mathrm{cm}$. to $19 \mathrm{~cm}$.; rectal temperature $39^{\circ}$. I take $25 \mathrm{cc}$. of arterial blood... A

At $3: 30$, caused to breathe through a muzzle into a bag containing air with $40.9 \%$ of carbonic acid, with $45.6 \%$ of oxygen.

The inspirations become deeper; but there is no struggling. At $3: 33$, pinching the sciatic nerve gives no reaction as to sensitivity; the arterial pressure is from $18 \mathrm{~cm}$. to $21 \mathrm{~cm}$., there are 44 respirations, pulse 152. I take $25 \mathrm{cc}$. of arterial blood .... B

3:35. Muzzle removed. Almost immediately convulsive struggling occurs. Sensitivity returns at $3: 40$, and I take $25 \mathrm{cc}$. more of carotid blood ..... C

The pressure is then from $14 \mathrm{~cm}$. to $16 \mathrm{~cm}$., and the temperature is $39^{\circ}$. No delayed symptom.

Blood A (free air) _...... contained 21.8 of oxygen and 44.6 of $\mathrm{CO}_{2}$ Blood B (insensibility complete) contained 23.2 of oxygen and 78.6 of $\mathrm{CO}_{3}$

Blood C (sensitivity restored) contained 22.1 of oxygen and 51.5 of $\mathrm{CO}_{2}$

The preceding experiments show first that, in the cases whei] they ended in death, it occurred when the respiratory medium contained $35.4 \%$ of $\mathrm{CO}_{2}$ (Experiment DCXIV), or $39 \%$ (Experiment DCXI), or $45.7 \%$ (Experiment DCXV). These numbers differ from each other considerably, as is evident.

On the other hand, some animals survived when the air which they were breathing already contained $34.8 \%$ of $\mathrm{CO}_{2}$ (Experiment DCX) $37.3 \%$ (Experiment DCVI), and even $38 \%$ (Experiment DCXIII)

Without dwelling for the moment upon these peculiar variations, let us consider what happens to the carbonic acid contained in the blood.

In the fatal cases, the proportion of $\mathrm{CO}_{2}$ contained in 100 volumes of arterial blood rose to 106.7 (Experiment DCXIV), 114.2 (Experiment DCXV) and 116.6 (Experiment DCXI); in the last case, the venous blood contained 120.4 of $\mathrm{CO}_{2}$.

On the contrary, in the experiments when death did not occur in spite of the large proportion of carbonic acid in the air, there was in the arterial blood only 82.8 of $\mathrm{CO}_{2}$ (Experiment DCXIII), 
87.2 (Experiment DCVI), and 93.8 (Experiment DCX); yet, in the last case the animal died during the night.

And therefore, as one might have thought a priori, it is not so much the tension of the carbonic acid in the outer air as its tension in the blood that causes death. And besides, the first acts only in causing the second.

This explains why animals which at the very outset were made to breathe a superoxygenated air containing $40 \%$ of carbonic acid (Experiments DCXVI and DCXIX), or even 52.8\% (Experiment DCXVIII), did not die immediately. They had to have time to store up in their arterial blood a sufficient quantity of $\mathrm{CO}_{2}$, and this process was carried out in two different ways: 1) by hindering the escape of the carbonic acid of the venous blood as it passed through the lungs; 2) by absorbing the excess carbonic acid contained in the inspired air; this absorption, moreover, is proved by Experiment DCXVIII, in which the respirable mixture, after 11 minutes of the experiment, contained less carbonic acid than before, and more oxygen.

3. The Accumulation of Carbonic Acid in the Tissues.

But the question is still more complex. It is not only in the blood that the carbonic acid must be stored up progressively, the tension of which in the respired air hinders its regular excretion. The carbonic acid of the blood comes from the tissues; in the normal state, a certain equilibrium of tension is established between the proportion of this gas which remains in these tissues, and that which remains in the blood, after the elimination due to a regular respiration. If some cause maintains an excess of carbonic acid in the blood, an excess of it must remain in the tissues. The whole organism then must be completely impregnated with this gas, which is highly soluble.

To inform myself about this delicate point, I resorted to the following experimental procedure. A determined weight of the tissues of the experimental animal, which had been cut into small pieces, was placed in a measured flask, of about triple capacity. The flask was then quite filled with a rather strong solution of potash or caustic soda; a similar solution was kept as control in another flask quite full and well corked; I let the whole thing stand for twenty-four hours, shaking it quite often, and I considered that in this length of time, the alkali had taken up all the carbonic acid which the tissues might contain.

I then took a certain quantity of the liquid, and introduced it 
into the receiver of the mercury pump, in which a solution of sulphuric acid had previously been placed and purified of its gases. The carbonic acid, immediately removed by the sulphuric acid, was easily extracted and collected, and a very simple caiculation informed me how much carbonic acid was contained in 100 grams of the experimental tissues.

I also subjected to the same treatment the alkali solution which had been kept as control, because it still contained a certain quantity of carbonic acid, which, of course, had to be subtracted.

This very simple method, for which I claim no accuracy in the decimals, seems to me to give sufficiently exact results; it has the great advantage of not requiring complicated equipment, and of enabling me to complete a large number of comparative experiments easily.

Experiment DCXX. March 5. Dog of Experiment DCVIII, which died the day before in a bell filled with oxygen.

$80 \mathrm{gm}$. of muscles, $80 \mathrm{gm}$. of liver, $70 \mathrm{gm}$. of brain, $35 \mathrm{gm}$. of kidneys are placed in flasks of suitable size, which were then filled with a potash solution.

The next day, the liquids subjected to analysis, as has just been explained, show that:

100 grams of muscles contained $42 \mathrm{cc}$. of carbonic acid.

100 grams of brain contained 26 cc- of carbonic acid.

100 grams of kidney contained 62 cc. of carbonic acid.

100 grams of liver contained $64 \mathrm{cc}$. of carbonic acid.

Experiment DCXXI. March 21. 7 o'clock: muscles of the dog of Experiment DCXIV, which had died at 6:45; $100 \mathrm{gm}$. are placed in a flask with $477 \mathrm{cc}$. of a potash solution.

March 23, at 2 o'clock, analysis shows that these $100 \mathrm{gm}$. contained 66 cc. of $\mathrm{CO}$.

Now the tissues of an animal killed by true asphyxia, that is, by lack of oxygen without increase of carbonic acid, contain a much smaller proportion of this gas.

Example:

Experiment DCXXII. April 4. 7 o'clock in the evening. Muscles of the dog in Experiment CLXXXVIII, which died at 6:45, exhaustting the oxygen of a bag full of air, with a solution of potash. $100 \mathrm{gm}$. are placed in $430 \mathrm{cc}$. of a solution of potash.

April 5, at 9 o'clock, these $100 \mathrm{gm}$. have released $13.2 \mathrm{cc}$. of $\mathrm{CO}_{2}$.

Even when animals have died simply in confined air, and when the carbonic acid has not been removed as it was formed, we find that their tissues contain very little carbonic acid. I think I should 
report here the experiments which prove this assertion, from which I shall draw conclusions of another sort when I discuss asphyxia:

Experiment DCXXIII. March 11. Dog died at 2:20 in a bell fllled with air at a pressure of $43 \mathrm{~cm}$.

At 4 o'clock, $80 \mathrm{gm}$. of muscle and $30 \mathrm{gm}$. of kidney are placed in potash solutions.

March 13. We find, by the procedure described above, that $100 \mathrm{gm}$. of muscle contain $12 \mathrm{cc}$. of $\mathrm{CO}_{z} ; 100 \mathrm{gm}$. of kidney contain $35 \mathrm{cc}$.

Experiment DCXXIV. March 5. 7 o'clock. Dog, which died at 6:15 (Experiment DCXXXVIII), asphyxiated in compressed air.

$100 \mathrm{gm}$. of muscle immersed in $900 \mathrm{cc}$. of potash solution.

March 6, 10 o'clock in the morning. These $100 \mathrm{gm}$. contained 22 cc. of $\mathrm{CO}_{2}$.

Experiment DCXXV. March 7, 5:30. A. Dog which had died at 5 o'clock (Experiment DCXXXIX), asphyxiated in compressed air.

B. Dog killed the day before at 5 o'clock by sectioning of the medulla.

$100 \mathrm{gm}$. of muscles of each animal are immersed in $500 \mathrm{cc}$. of potash solution.

March 8, 3 o'clock. We find that the $100 \mathrm{gm}$. of A contained 23 cc. of $\mathrm{CO}_{2}$, and those of $\mathrm{B} 19 \mathrm{cc}$.

Experiment DCXXVI. March 10, 6 o'clock. Dog which was killed by asphyxia at 5:20 (Experiment DCXL).

$100 \mathrm{gm}$. of muscle placed in $585 \mathrm{cc}$. of potash solution.

March 11, 5 o'clock. 24.8 cc. of carbonic acid given off.

In other experiments, in which I analyzed the whole body of sparrows which had died under various circumstances, I obtained results which were quite similar:

Experiment DCXXVII. April 24. Sparrow which had died during the night at 10 atmospheres of air.

The next day, the entire body (13 gm.), with the skin removed, is placed in the potash solution (110 cc.).

We find thus that $100 \mathrm{gm}$. of such an animal would have set free 40 cc. of carbonic acid.

The following experiment is very noteworthy in this connection:

Experiment DCXXVIII. March 18. Sparrows which died under the following circumstances:

A died at 6 atmospheres of air (lethal air: $\mathrm{O}_{2} 16.6 ; \mathrm{CO}_{2} 3.1$ )

$\mathrm{B}$ died at $34 \mathrm{~cm}$. in superoxygenated air (lethal air: $\mathrm{O}_{2} 12.9 ; \mathrm{CO}_{2} 52.4$ )

$\mathrm{C}$ died in the air (lethal air: $\mathrm{O}_{2} 4 ; \mathrm{CO}_{2} 14.6$ )

$\mathrm{D}$ died in the air, at $38 \mathrm{~cm}$. (lethal air: $\mathrm{O}_{2} 8.2 ; \mathrm{CO}_{2} 11.6$ )

These sparrows are immediately skinned, I cut off their heads, feet, and the ends of their wings; the bodies, cut in pieces, weigh from 20 to $22 \mathrm{gm}$. I place them in similar solutions in similar flasks. 
The next day we find that the whole bodies furnished, if proportioned to $100 \mathrm{gm}$.:
A (killed by carbonic acid) 33 cc. of $\mathrm{CO}_{2}$
B (killed by carbonic acid) 36 cc. of $\mathrm{CO}_{2}$
C (died of asphyxia, at normal pressure) 17 cc. of $\mathrm{CO}_{2}$
D (died of simple lack of oyxgen, at $1 / 2$ atmosphere -0 cc. of $\mathrm{CO}_{2}$

We now understand the phenomenon in its entirety and its simplicity. When an animal breathes in a confined medium in which it will not lack oxygen, the increasing tension of the carbonic acio which it excretes maintains in its arterial blood a proportion of this same gas, which also increases. Since a similar equilibrium is established between the blood and the tissues, in which the true source of the carbonic acid exists, this gas is gradually stored up in the whole organism. From this fact arise general disturbances, the symptoms of which we shall presently discuss in detail.

Under these conditions, the blood is finally burdened with an enormous quantity of carbonic acid; we have found as high as 116.6 volumes of it per 100 volumes of arterial blood and 120.4 per 100 volumes of venous blood. This last proportion is approaching saturation. This saturation, which must vary from one blood to another, is, in fact, approximately determined by the following experiments, rather rough no doubt, but which can give us a general idea sufficient for our purpose.

Experiment DCXXIX. February 22. Temperature of the laboratory 14. Defibrinated dog blood.

I place $100 \mathrm{cc}$. of it in two test tubes inverted over mercury, and then add to each one $200 \mathrm{cc}$. of carbonic acid. Energetic repeated shaking; immediate and considerable absorption; much foam. Left the two test tubes in the ambient temperature.

The next day, shaken again. 3 hours afterwards, made the analysis by means of the gas pump.

The extraction and analysis give the following results (gaseous volumes reduced as usual to $0^{\circ}$ ):

One of the bloods contained $\mathrm{CO}_{2} 123 \mathrm{cc}$; $\mathrm{O}_{2} 16.6$.

The other blood contained $\mathrm{CO}_{2} 132 \mathrm{cc}$; $\mathrm{O}$, 11.0 .

Experiment DCXXX. March 10. Defibrinated dog blood. Temperature of the laboratory $15^{\circ}$. Pressure $764 \mathrm{~mm}$.

100 cc. are placed at the bottom of two flasks, through which passes a current of carbonic acid for 24 hours. One of the flasks is immersed in water at $41^{\circ}$.

We find thus that

The blood at $15^{\circ}$ contains $177.6 \mathrm{cc}$. of $\mathrm{CO}_{*}$.

The blood at $40^{\circ}$ contains $138.4 \mathrm{cc}$. of $\mathrm{CO}_{2}$. 
After blood comes urine, which, as Experiment DCX showed, may contain as much as 106 volumes of $\mathrm{CO}_{2}$ per $100^{\circ}$ volumes of liquid.

Finally, the tissues in analysis show that their $\mathrm{CO}_{2}$ content is proportionate to the amount of blood they contain; Experiment DCXX is quite characteristic in this regard; the kidneys and the liver, which are very vascular organs, contained per 100 volumes 62 and 64 volumes of $\mathrm{CO}_{2}$; the muscles had 42 , the brain only 26 .

The combined experiments made on the muscles of dogs or the entire bodies of sparrows seem to show that from the bodies of animals killed by carbonic acid one can extract about $40 \%$ of its volume of this gas; on the other hand, they give us the idea that in the normal state there exists there only about $10 \%$ to $15 \%$. It would then be about $25 \%$ to $30 \%$ of the total volume of the animal which would represent the quantity of carbonic acid formed and not exhaled during the stay of the animal in closed vessels. Now Experiment DCVIII shows us definitely that a dog weighing 3.950 kilos removed from the superoxygenated medium in which it died about $1300 \mathrm{cc}$. of oxygen, which must have been transformed into carbonic acid and remained in its blood and tissues.

These results, we see, agree very well, but we must not attribute to them extreme accuracy: from a third to a half of the volume of the body seems to be the quantity of carbonic acid retained in the tissues by an animal before dying from the action of this gas.

This explains why, as I saw in the early experiments, the details of which it would be useless to report here, if a dog is caused to breathe oxygen contained in a bag of small dimensions, the animal absorbs all the gas from the bag and then dies from simple lack of air. All the oxygen of the bag has remained in the tissues in the form of carbonic acid.

4. Symptoms and Mechanism of Poisoning by Carbonic Acid.

Now that this important point is established, we should study the symptoms and mechanism of this poisoning by gradual absorption of carbonic acid in all the tissues.

Let us first consider the progressive course of the change in the superoxygenated air which the animal is breathing. The graphs of Figure 75, which express the results of Experiment DCXV, show us very clearly what is taking place.

On the horizontal axis are marked in hours the time elapsed 
since the beginning of the experiment; on the vertical axis, the percentage of the gases contained in the bag.

We see very clearly that the consumption of oxygen and the production of carbonic acid are not proportional to the time elapsed.

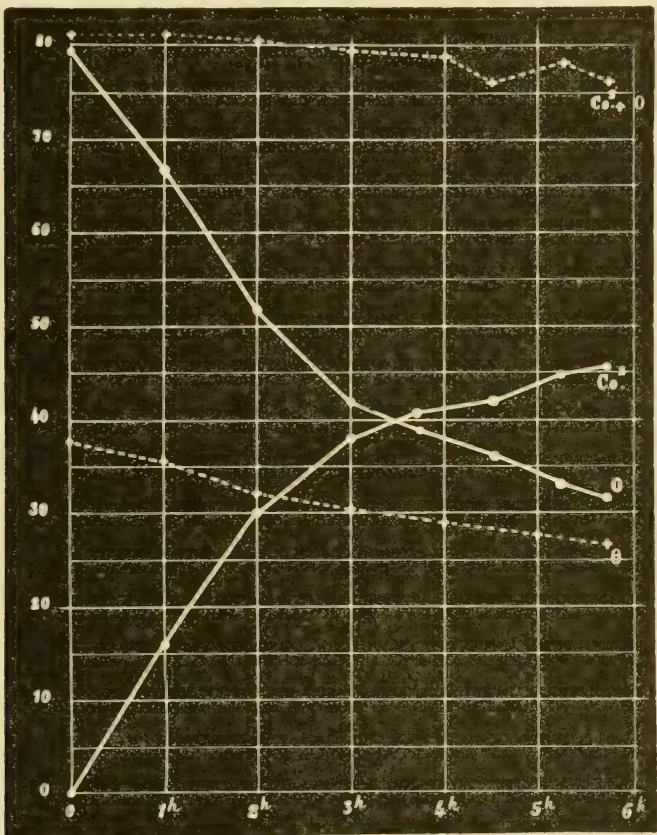

Fig. 75-Death by carbonic acid; changes in the air of the bag. (Exp. DCXV.)

The longer the experiment lasts, the more the value of these phenomena diminishes. The intersection of the graphs with the coordinate lines shows that there were, in percentages:

In the 1st hour 15.8 of oxygen consumed, and 15.5 of $\mathrm{CO}_{2}$ excreted In the 2nd hour 14.5 of oxygen consumed, and 14.2 of $\mathrm{CO}_{2}$ excreted In the 3rd hour 9.2 of oxygen consumed, and 7.6 of $\mathrm{CO}_{2}$ excreted In the 4 th hour 4.5 of oxygen consumed, and 4.0 of $\mathrm{CO}_{2}$ excreted In the 5 th hour 4.0 of oxygen consumed, and 2.7 of $\mathrm{CO}_{2}$ excreted 
In the last

$50 \mathrm{~min}$.

2.2 of oxygen consumed, and

1.7 of $\mathrm{CO}_{2}$ excreted

As a total,

in $5 \mathrm{~h} .50 \mathrm{~m} . \quad 50.2$

Experiment DCXIV gives similar results: there were, in fact:

In the 1st hour 11.9 of oxygen consumed and 9.2 of $\mathrm{CO}_{2}$ excreted In the 2nd hour 9.0 of oxygen consumed and 8.8 of $\mathrm{CO}_{2}$ excreted In the 3rd hour 5.9 of oxygen consumed and 4.6 of $\mathrm{CO}_{2}$ excreted In the 4 th hour 5.2 of oxygen consumed and 3.3 of $\mathrm{CO}_{2}$ excreted In the 5th hour 3.7 of oxygen consumed and 2.8 of $\mathrm{CO}_{2}$ excreted In the 6th hour 0.8 of oxygen consumed and 0.4 of $\mathrm{CO}_{2}$ excreted In the 7th hour 1.5 of oxygen consumed and 1.1 of $\mathrm{CO}_{2}$ excreted As a total,

in $7 \mathrm{hrs}$.

37.0 of oxygen consumed and 30.2 of $\mathrm{CO}_{2}$ excreted

So the consumption of oxygen diminishes progressively: and so, in spite of the high proportion of oxygen contained in the arterial blood, the chemical phenomena of oxidation slacken. It is not surprising, therefore, to see that the temperature of the animai drops progressively until, at the moment of death, it reaches the values of $27.8^{\circ}$ (Exp. DCXI), $27^{\circ}$ (Exp. DCXV) (line $\Theta$ of Fig. 75), and even $23^{\circ}$ (Exp. DCXIV). In this connection I mention Experiment DCX in which the temperature dropped from $39^{\circ}$ to $25^{\circ}$, and in which, however, the animal, when returned to the free air, survived without symptoms. I shall refer later to the importance of this drop in temperature, as a result of the decrease of the inner combustions.

Let us now examine the gases of the blood at different moments in the experiments. Let us take again, for example, Experiment. DCXV, the most complete we have performed. The summarizing table" and lines $\mathrm{Ox}$ and $\mathrm{CO}^{*}$ of Figure 76 show these results clearly.

We see first that in spite of the increasing proportion of carbonic acid, both in the respired air and in the blood, the proportion of oxygen was not much modified during the first four hours of the experiment; not until then did it decrease progressively, although death cannot be attributed to it, since at the last heart-beats, when the respiration had ceased, there still remained 9.7 volumes of oxygen in 100 volumes of arterial blood.

As to the carbonic acid, I have already mentioned the enormous proportion which it reached at the moment of death. But the course of its storing up in the arterial blood is not regularly progressive. 


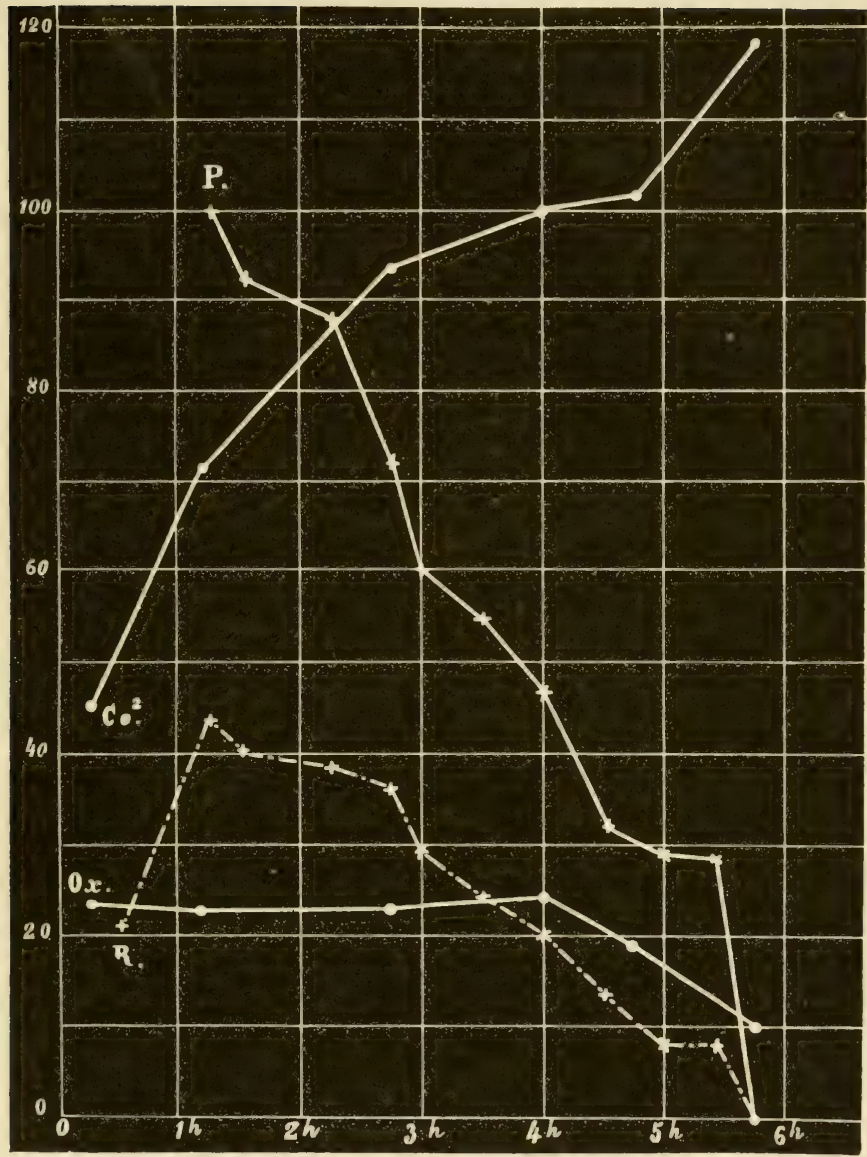

Fig. 76-Death by carbonic acid; modifications in the composition of the gases of the blood, the respiration, and the circulation. (Exp. DCXV.)

We draw from the table following Experiment DCXV and from the line $\mathrm{CO}^{2}$ the following figures:

In the 1st hour, the blood gained 20.0 volumes of $\mathrm{CO}_{2}$ In the 2 nd hour, the blood gained 16.8 volumes of $\mathrm{CO}_{2}$ 
In the 3rd hour, the blood gained 11.0 volumes of $\mathrm{CO}_{2}$ In the 4th hour, the blood gained 5.0 volumes of $\mathrm{CO}_{2}$ In the 5 th hour, the blood gained 5.5 volumes of $\mathrm{CO}_{2}$ In the last

50 minutes, the blood gained 13.2 volumes of $\mathrm{CO}_{2}$

And so, except during the last hour, the $\mathrm{CO}_{2}$ content of the blood increased less and less quickly, whereas the animal was being poisoned. And that is easily understood, since we have seen that the absorption of oxygen was growing slower in the same way, so that the production of carbonic acid in the tissues was less and less active and its discharge into the blood less and less considerable.

But in the last hour the blood suddenly acquires a considerable quantity of $\mathrm{CO}_{2}$ (See Fig. 76, line $\mathrm{CO}^{2}$ ). A glance at the lines $\mathrm{P}$ and $R$ of the same figure, which express the number of the heartbeats and of the respirations, explains this singular fact perfectly; at the moment, in fact, the heart slowed down considerably, and the respiratory movements, reduced to 10 and 8 per minute, ceased for an instant: the blood must have lost less $\mathrm{CO}_{2}$ in passing through the lungs and have gained more in passing through the tissues. Furthermore, the oxygen of the blood was consumed on the spot and must have furnished a certain quantity of carbonic acid.

Since the carbonic acid content of the blood has as its cause the increasing tension of this gas in the confined air which the animal was breathing, it was interesting to determine the ratio between these two variable values. This is easily done by comparing the lines $\mathrm{CO}_{2}$ (which have the same coordinates) of the two figures 75 and 76 , which express the two columns $\mathrm{CO}_{2}$ of the bag and $\mathrm{CO}_{2}$ of the blood in the table summarizing Experiment DCXV.

We thus find first that when the air of the bag contained $10 \%$ of $\mathrm{CO}_{2}, 100$ cc. of arterial blood contained 55 volumes of the same gas, and we are led, by similar comparisons, to draw up the following table:

With 0 of $\mathrm{CO}_{2}$ in the air, there was 40 of it in the blood.

With 10 of $\mathrm{CO}_{2}$ in the air, there was 55 of it in the blood. Difference 15 .

With 20 of $\mathrm{CO}_{2}$ in the air, there was 70 of it in the blood. Difference 15 .

With 30 of $\mathrm{CO}$, in the air, there was 82 of it in the blood. Difference 12 . 
With 40 of $\mathrm{CO}_{2}$ in the air, there was 95 of it in the blood. Difference 13 .

With 45 of $\mathrm{CO}_{2}$ in the air, there was 114 of it in the blood. Difference 19 .

We see that increases in the arterial blood which do not differ much correspond to equal increases in the respirable air; this result conforms to the laws of physics. But we should not attribute to it too great an exactness, because important changes in the

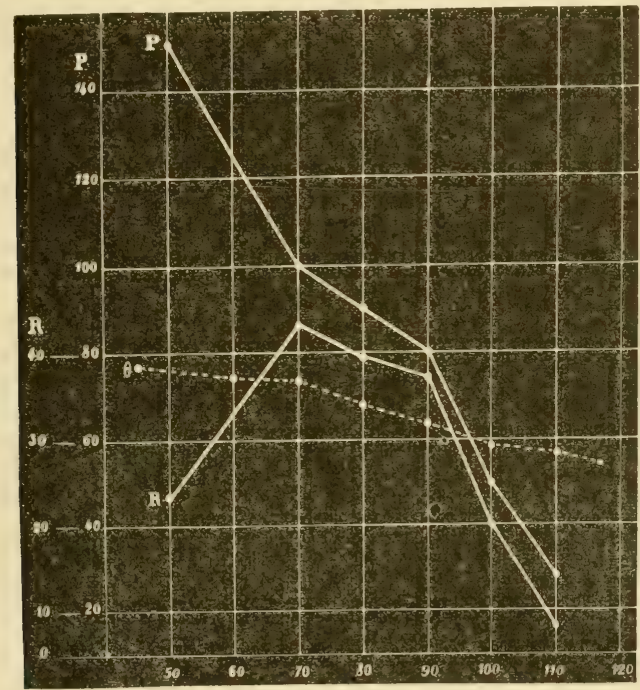

Fig. 77-Death by carbonic acid; relation of the respiration and the circulation to the carbonic acid content of the blood. (Exp. DCXV.)

respiratory rhythm may modify considerably the quantity of carbonic acid contained in the arterial blood.

Let us now drop these chemical considerations and discuss the changes which occurred in the various functions.

The number of heartbeats decreases progressively; the tables summarizing Experiments DCXIV and DCXV show that clearly, and line $\mathrm{P}$ of Figure 76 still more clearly, at least for Experiment DCXV. If we draw up graphs with the results of this experiment, taking for abscissae, not the time elapsed since the beginning of 
the experiment, as in Figure 76, but the quantity of carbonic acid contained in the blood (Fig. 77), we see that this decrease in the number of heartbeats follows quite regularly the increase in the carbonic acid of the blood.

The detailed account of the different experiments shows that the heartbeats persist after the respiratory movements have ceased; in Experiment DCVI, the heart continued to beat for about ten minutes.

On the other hand, we see that the blood pressure in the arteries is modified only very slowly by the accumulation of carbonic acid in the blood and the tissues. At the very beginning it seems increased a little (Exp. DCXV and DCXVI); but it is still from 12 to $14 \mathrm{~cm}$. at a time when there is more than 90 volumes of carbonic acid in the blood (Exp. DCXIV), and from 11 to 15 when there is 95 (Exp. DCXV), and even from 8 to 10 when there are only 8 respirations to the minute, when the temperature has fallen to $28^{\circ}$, and when the arterial blood contains more than its own volume of carbonic acid (Exp. DCXV).

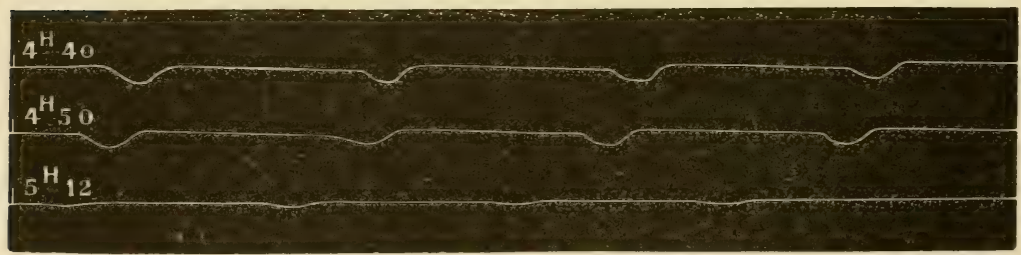

Fig. 78-Death by carbonic acid; last respiratory movements. (Exp. DCXV.)

So, in progressive poisoning by carbonic acid, the heart is the ultimum moriens (last to die), and its beating is the last sign of life which one can observe in the dying animal.

The number of respiratory movements decreases equally; at the beginning of the experiment it often increases, but when the carbonic acid of the blood reaches a proportion above 90 volumes, the slackening assumes considerable intensity. For Experiment DCXV, these phenomena are easy to study in the summarizing table and in the lines $\mathrm{R}$ of Figures 76 and 77 . In Experiment DCXIV, during the last hour of life, there were only 2 to 4 respirations per minute; at the very end, there was only one every two or three minutes, and in Experiment DCVI, one every three or four minutes. At the end, their depth decreased like their number, 
and the tracing in Figure 78 which was made by the pneumograph (Exp. DCXV), shows that the cessation of the respiratory movements took place without a last sigh: this in itself as I proved elsewhere ${ }^{3}$, indicates that carbonic acid is not a heart poison.

During the whole duration of this progressive poisoning, the animals remain perfectly calm. At the beginning, only a few struggles, which soon are quieted. If the animal is unfastened when the arterial blood contains 60 or 70 volumes of $\mathrm{CO}_{2}$, it makes no attempt to escape. Later, it becomes insensible to stimuli, to pinching, even to electrical stimulation of the sensory nerves: finally the eye itself becomes insensible.

This curious anesthesia deserves our attention for a few minutes.

Let us say first that insensibility to pinching occurs long before the animal is threatened by death. In Experiment DCVI, the eye was insensible two hours before death, when there were still 10 respirations, and 64 heart beats, the temperature having fallen to 30 degrees; in Experiment DCXIV, the paws became insensible more than four hours before death, and the eye two hours (respirations 20; pulse 43 ; temperature $27^{\circ}$ ) ; finally in Experiment DCXV, absolute insensibility of the paws was observed more than three hours before death, and the eye became insensible two hours before (respirations 20; pulse 48; temperature $29.5^{\circ}$ ).

This insensibility is very complete; stimulation of the sciatic nerve by pinching or electric currents causes no general movement, no change in the respiratory rhythm (Exp. DCXV), in the arterial pressure or the state of the pupils (Exp. DCXVI), even when they still contract under the direct influence of light. The eye, as I have just said, keeps its sensitivity for a long time yet, and this sensitivity disappears last in the conjunctiva (Exp. DCXIII).

Now when the eye has become absolutely insensible, the animal is by no means in danger. If it is taken from the altered medium and brought into the air, it always recovers (Exp. DCXII, DCXIII, DCXVI, DCXVII, DCXVIII, DCXIX), generally after displaying strange symptoms, to which I shall call attention presently.

If we investigate the proportion of carbonic acid in the air and the arterial blood at which insensibility of the feet or of the eye occurred, this is the average we obtain: insensibility of the feet appeared when the air contained about $28 \%$ of carbonic acid, and insensibility of the eye when the proportion rose to $35 \%$; for the blood, the extremes are much wider, since they vary from 72.3 (Exp. DCXII) to 95.4 (Exp. DCXV). 
This complete anesthesia of the limbs, when the eye is still sensitive, when the heart still beats frequently and strongly, and when the animal is still so far from serious danger, naturally inspired the idea of a possible surgical application.

But an important difficulty appeared. In the experiments which I have just reported, the animal itself forms the carbonic acid which it stores up in its blood and tissues; that requires a very long time. In Experiment DCXIII, insensibility of the paws was observed only after two hours; it took more than three hours in Experiments DCXIV and DCXV. Nothing would be less practical than this long preparation, which would be a long torture. On the other hand, and this is still more important from another point of view, in these long experiments the temperature had dropped several degrees at the time when insensibility of the paws appeared, and that might have serious consequences for the patients.

I then asked myself whether I could obtain results similar to the preceding ones by making the animals breathe a more or less rich mixture of carbonic acid and oxygen early in the experiment. I did this in Experiments DCXVI, DCXVII, DCXVIII, and DCXIX.

When the mixture to be breathed contained $20 \%$ of carbonic acid (Exp. DCXVII), insensibility appeared only after $1 \frac{1}{2}$ hours, at which time the temperature had dropped $4^{\circ}$, the respirations numbered 36, and the pulse rate was 100 ; the arterial blood then contained 77 volumes of $\mathrm{CO}_{2}$. But with $40 \%$ of $\mathrm{CO}_{2}$ (Exp. DCXVI, DCXIX) insensibility occurred after 3 or 5 minutes, of course without a change in the temperature, the heart having singular strength, (19 to $23 \mathrm{~cm}$., Exp. DCXVI; 18 to $20 \mathrm{~cm}$., Exp. DCXIX) greater than in the normal state: the arterial blood contained 78.6 volumes (Exp. DCXIX) or 81.2 volumes (Exp. DCXVI) of carbonic acid.

Finally, with a mixture containing $52.8 \%$ of $\mathrm{CO}_{2}$, insensibility was almost instantaneous, and the arterial blood was laden with 98.4 volumes of $\mathrm{CO}_{2}$ (Exp. DCXVIII).

These last results show that the surgical use of carbonic acid, in a proportion of about $40 \%$, the rest of the gas being nearly pure oxygen, might give good results, and would not at all affect arterial pressure, as do the compounds of carbon and hydrogen and the chloro-carbon compounds of hydrogen.

But this proportion of carbonic acid in the respirable medium must not be much exceeded. I showed in $1864^{4}$ that if two newborn rats were placed, one in carbonic acid, the other in nitrogen, the heart of the latter continues to beat more than a quarter of an 
hour, whereas the heart of the former stops in 2 or 3 minutes. But these conditions are quite different from those of my present experiments. Here we are dealing with carbonic acid slowly formed by the organism itself, and not with a flood of acid reaching the blood of the left heart suddenly.

There is one last point left to study. When the animal is brought back to free air, even though its blood and its tissues are laden with an enormous proportion of carbonic acid, it recovers. And so the dogs in Experiments DCVI, DCXII, DCXIII, survived, although their arterial blood contained 73.3, 82.8, and 87.2 volumes of $\mathrm{CO}_{2}$, and the body temperature had dropped to $25^{\circ}$ (Exp. DCXII).

They recover gradually; their respiration accelerates, as does the heart; their temperature rises, and strength returns with sensitivity, which reappears in 10 or 15 minutes.

But very strange nervous symptoms always appear at this time; these are rigors with a few clonic convulsions, or slow and languid movements, like those of a hibernating animal which is warmed and which is awakening. That lasts a few minutes, during the phase in which insensibility still persists.

One might think that these phenomena are due in part to the considerable loss in temperature of the experimental animals. That is not the case, for in Experiments DCXVI and DCXIX, in which insensibility was obtained early by respiration of supercarbonated air, and in which there was no loss of temperature, the same symptoms appeared.

They are therefore related to the elimination of excess carbonic acid; the return to its normal state of the anesthetized spinal cord is shown by disconnected stimuli which for some minutes cause convulsive symptoms.

We know that, according to M. Brown-Séquard, carbonic acid is a poison which causes convulsions; the violent symptoms which mark the end of asphyxias and quick hemorrhages are explained, according to him, by the action of the carbonic acid accumulation in the tissues. Long ago I replied to this theory, which, I hope will not return for discussion today. But here, by a singular coincidence, these convulsions, which the carbonic acid was accused of producing, are absolutely the sign of its elimination.

I do not think that these convulsive symptoms of the return to sensibility constitute a serious obstacle to the use of carbonic acid by surgeons. They are surely much less terrifying than the violent struggles which so often mark the beginning of the action of chloro- 
form, and which have mistakenly been named the "period of excitation." And besides we might very probably avoid them by lessening the speed of the elimination of the carbonic acid.

But while I call attention of the surgeons to this anesthetic, which has often been considered but which has never been studied with sufficient care, I am far from believing that the preceding researches are precise and detailed enough to authorize immediate application: an experimental table upon which a dog is fastened is one thing, and the bed of a patient is another.

While trying to give myself a precise idea of the inner action of carbonic acid, I reach the following considerations:

The excretion of the carbonic acid which is constantly being formed in the interior of the tissues is a necessary condition on account of the continued metabolic exchanges which give rise to it. Here, as in so many other chemical phenomena, the product of the reaction must be eliminated constantly so that this reaction may maintain its maximum activity. When, through respiration in closed vessels, under conditions specified above, the carbonic acid is stored up in the tissues, it delays all the oxidations there, as is proved by the rapid drop in the temperature. As for the nervous system, if it seems affected first, that is because it is the first to show the general effects which disturb the whole organism; and because the spinal cord fails in its reflex functions of sensitivity and respiration, just as it is the first to show the organic disturbances which occur when we bleed, diminish or increase the $\mathrm{O}_{2}$ of the blood, chill, or overheat an animal.

But when the carbonic acid is artificially brought from outside, and when it is inhaled in a gaseous mixture, it is not the whole organism which is affected as in the first case. The carbonic acid, absorbed by the arterial blood in passing through the lungs, is immediately carried by it to the nervous center, the metabolic changes of which are therefore suddenly disturbed, delayed, and altered: hence the anesthesia. Finally, when the proportion is great enough in the respiratory mixture, the cardiac ganglia themselves are immediately affected in their metabolism and the heart stops, paralyzed.

5. Action of Carbonic Acid upon the Lower Living Beings.

The universality of action of carbonic acid upon all tissues is shown very clearly when we experiment upon lower animals. Long ago, for example, I showed in my courses that frogs or new-born mammals die sooner in carbonic acid than in carbon monoxide. 
And that is easily understood, I said: carbon monoxide acts like a simple hemorrhage or an asphyxia in nitrogen, by suppressing the oxygen of the blood, whereas carbonic acid poisons the tissues themselves. Only if the experiment is stopped before the animals are quite dead, the frog with the $\mathrm{CO}_{2}$ recovers quite quickly, but the one with the $\mathrm{CO}$ dies, on the contrary, since it is definitely deprived of its red corpuscles.

It seemed to me interesting to try to determine the proportion of carbonic acid dissolved in the water, which would be incompatible with the life of fishes. Here are the details of the experiment:

Experiment DCXXXI. May 22. At 12:15. Golden carp of the same size are immersed in flasks with stoppers, full of a well aerated water to which have been added growing proportions of water saturated with carbonic acid so that

A contained pure water (which holds in solution 4.4 volumes of $\mathrm{CO}_{2}$ per 100 volumes of liquid)

$\mathrm{B}$ contained water with $11 \%$ of $\mathrm{CO}_{2}$

C contained water with $18 \%$ of $\mathrm{CO}_{2}$

D contained water with $30 \%$ of $\mathrm{CO}_{2}$

$\mathrm{E}$ contained water with $45 \%$ of $\mathrm{CO}_{2}$.

At $12: 35$, fish $\mathrm{E}$ was breathing very feebly, whereas $\mathrm{B}$ was breathing more strongly than A.

$12: 45$. $\mathrm{E}$ is on its side, very sick; $\mathrm{D}$ is evidently sick too.

1:05. $\mathrm{E}$ is dead; D, very sick; C and $\mathrm{B}$ are breathing with difficulty; D dies about 10 o'clock in the evening.

The next day, A, B, and $\mathrm{C}$ are still alive.

The proportion of free $\mathrm{CO}_{2}$ which is rapidly fatal is therefore in the neighborhood of $30 \%$. That is much above the quantities which exist in all waters not charged with saline elements.

Carbonic acid manifests its action not only on animals, but also on plants.

In a medium with high $\mathrm{CO}_{2}$ content, green plants die rapidly, when we prevent the light from permitting them to decompose the dangerous gas rapidly. ${ }^{5}$

Germination is delayed and checked, when the proportion of the gas is sufficient; the seeds themselves may be killed by it. As an example of these facts, I quote the two experiments following:

Experiment DCXXXII. April 8. Sowed, under a large bell of 11 liters, a few seeds of barley and of cress upon well moistened paper. The bell is filled with a mixture containing: $\mathrm{O}_{2} 16 ; \mathrm{CO}_{2} 20 ; \mathrm{N} 64$.

May 2. Nothing has developed; the air of the bell contains: $\mathrm{O}_{2}$ 12.9; $\mathrm{CO}_{2}$ 29. I leave the seeds in the open air; on May 7 , some shoots appear, and on May 20 all has sprouted well; the barley already measures $12 \mathrm{~cm}$. 
Experiment DCXXXIII. March 30. A. 20 barley seeds are sowed on wet paper, under a bell of 11 liters containing $50 \%$ of carbonic acid and 50 of ordinary air.

B. As controls, other seeds are sowed under a bell of 2.5 liters full of ordinary air.

April 3. Evident germination in B.

April 9. The shoots in B are 3 to $4 \mathrm{~cm}$. high; nothing in A. On the seeds in $\mathrm{B}$ abundant mold has appeared; there is nothing in $\mathrm{A}$.

April 22. There are fine shoots in $\mathrm{B}$, and its air contains $\mathrm{CO}_{2} 4.4$; $\mathrm{O}_{2}$ 13.6. No shoots in $\mathrm{A}$, the air of which still contains 9.3 of oxygen.

A, when left in the open air, does not sprout.

And so, with $20 \%$ to $30 \%$ of carbonic acid, there is merely suspension of germination; but with $50 \%$, the seeds are killed. And what is true of seeds of barley is true of molds, as we see in the very experiment which has just been reported.

It is not surprising then to see that putrefaction itself is greatly delayed and even checked in an atmosphere laden with carbonic acid.

That is what happened in the following experiments:

Experiment $D C X X X I V$. December 14. Fragments of muscles placed in bells filled:

A, with air;

$\mathrm{B}$, with almost pure carbonic acid.

January 8. A is foul, in full decay, covered with mold; B has no odor and no mold is apparent.

Experiment $D C X X X V$. January 14. Fragments of muscles placed in bells filled:

A, with air;

$\mathrm{B}$, with a mixture $\left(\mathrm{O}, 14.4 ; \mathrm{N} 54.6 ; \mathrm{CO}_{2} 31 \%\right)$.

January 17. The air of A now contains only 18.1 of oxygen, with 3 of $\mathrm{CO}_{2}$; it smells bad.

The air of $\mathrm{B}$ has not changed its composition and has no odor.

Experiment DCXXXVI. July 29. A thin slice of beef weighing 100 gm. is hung in the glass apparatus, under a pressure of 6 atmospheres, 5 of which are carbonic acid.

August 10. Decompression.

The meat has no odor; its color is rather dull. I cook it; it has no putrid odor or taste; but its flavor is disagreeable, insipid, sweetish, like that of meat kept in compressed oxygen.

Finally, the muscular contractility is rapidly destroyed by carbonic acid and very probably the same thing would be true of the other vital characteristics. 
Experiment DCXXXVII. June 4. Two feet of the same frog are hung each at the top of a test tube:

$\mathrm{A}$ in air;

$\mathrm{B}$ in almost pure carbonic acid.

June 5. A, nerve not excitable; muscle very contractile;

$\mathrm{B}$, no muscular contractility.

6. Summary and Conclusions.

We have now reached the end of this long study. It is summarized in the following propositions:

A. When an animal breathes in a closed vessel, either in compressed air, or in a superoxygenated air, at normal pressure, so that it never lacks oxygen, the increasing tension of $\mathrm{CO}_{2}$ in the air maintains an increasing proportion of the same gas in the blood, so that the carbonic acid produced within the tissues remains in these tissues.

B. From this accumulation there results a progressive slackening of the intra-organic oxidations, and consequently, a considerable lowering of the body temperature.

C. The central nervous system, in this general effect upon the organism, is the first to show that it is attacked, by the loss of the reflex transmissions, first in the limbs, then in the eye, finally in the respiratory center, from which death results.

D. No struggle, no convulsive movement precedes death.

The heart, though slackening its beats, retains its full strength for a very long time, and remains the ultimum moriens (last to die).

These two facts definitely disprove the theories which make of carbonic acid either a poison which causes convulsions or a poison of the heart.

E. The anesthesia produced by carbonic acid apparently deserves to attract the attention of surgeons again; it is complete at the moment when the life of the animal is far from being in danger.

F. Plant life, germination, the development of molds, and putrefaction are slowed, suspended, and definitely checked by carbonic acid at a sufficient tension.

G. Therefore, carbonic acid is a universal poison, which kills animals and plants, large or microscopic; which kills the anatomical elements, isolated or grouped in tissues. And that is not at all surprising because it is the product of universal excretion of all living cells; its presence hinders excretion, and consequently by interposing a terminal obstacle stops the whole series of the constituent chemical transformations of life, which begin with the absorption of oxygen and end with the discharge of carbonic acid. 


\section{Subchapter II}

\section{ASPHYXIA}

The researches of which I have given an account in the preceding chapters have naturally led me to the study of asphyxia in closed vessels, in ordinary air, at normal pressure. Here, at the moment of death, are very low oxygen tension and fairly high $\mathrm{CO}_{2}$ tension; to which of the two influences is death due? Do both have an effect?

I have already treated this question in my "Lessons on Respiration" (page 525), and basing my belief exclusively on the chemical composition of the lethal air, I had arrived at the following conclusions:

A. For warm-blooded animals, death occurs from lack of oxygen;

B. For cold-blooded animals, from poisoning by carbonic acid.

I was brought to consider this question from another point of view, upon observing the modifications undergone by the gases of the blood, and comparing them on one hand with those reported in Chapter II, Subchapter IV, and oi. the other hand, with those which are the result of carbonic acid poisoning.

The experiments were made by the same method as in the chapters mentioned: respiration with a hermetically closed muzzle, or by the trachea, in a bag containing a certain quantity of air.

The report of a few experiments follows:

Experiment DCXXXVIII. March 5. Spaniel weighing 12 kilos.

$5: 35$. Drew $40 \mathrm{cc}$. of blood from the carotid .... A

$5: 37$. Caused to breathe through a muzzle in a rubber bag containing about 20 liters of air.

5:52. The animal, which has struggled a great deal, and which has lost air around the sides of the muzzle, is very sick.

Took air from the bag .... a

5:55. Drew $33 \mathrm{cc}$. of very dark blood from the carotid .... B

$6: 15$. The animal dies, without convulsions or rigor. With difficulty I draw from the left heart blood which is beginning to coagulate.... C

Air from the bag.... b

Blood $\mathrm{A}$ (in the open air) contained $\mathrm{O}, 15.9 ; \mathrm{CO}_{2} 44.8$

Blood B (air a: O. 4.8; $\mathrm{CO}: 12.1$ ) contained $\mathrm{O}: 2.4 ; \mathrm{CO}=44.5$.

Blood C (lethal air $b: \mathrm{O}: 3 ; \mathrm{CO}, 15.8$ ) contained $\mathrm{O}=0.8 ; \mathrm{CO} .39 .9$

Experiment DCXXXIX. March 7. Spaniel weighing 13 kilos.

I expose the carotid and the trachea.

3 o'clock. Respirations 45 ; pulse 90 ; rectal temperature $38.5^{\circ}$. 
3:05. Drew $33 \mathrm{cc}$. of blood from the carotid, moderately red ... A $3: 15$. Placed a tube in the trachea.

The respirations become extraordinarily rapid.

$3: 20$. Respirations 124 ; temperature $38.5^{\circ}$; drew $33 \mathrm{cc}$. of blood from the carotid, redder than A .... B

$3: 22$. Placed the trachea in communication with a rubber bag containing 60 liters of air.

Much struggling; respirations very frequent.

3: 43. Temperature $38^{\circ}$.

4 o'clock. Respirations 84 ; pulse 96 ; took air and 33 cc. of blood, not so red as A .... C and $a$

4:05. Very deep respirations, 56 per minute; pulse 96 .

4: 15 . Temperature $36.5^{\circ}$.

4:35. Respirations 28; pulse 52 , very irregular.

Temperature $36^{\circ}$. Air from the bag .... b

Cornea sensitive; drew 25 cc. of very dark blood . . . . D

4:40. Cornea without sensitivity; pupils dilated; respirations 16 ; pulse too weak to be felt; temperature $35.5^{\circ}$.

The respirations become slower and slower, and the last takes place at $4: 46$; there is no convulsion.

4:48. The heart still pumps a little blood into the carotid, and with a cannula I succeed in extracting $40 \mathrm{cc}$. of very dark blood from the left heart .....E

Then I take a sample of air from the bag . . . . c

$4: 55$. I collect under water the gases of the lungs .... d

The urine, treated with sulphuric acid in the pump, gives about 15 volumes per 100 of $\mathrm{CO}_{2}$.

Blood A (free air, respiration by natural channel) $\mathrm{O}_{2} 19.8 ; \mathrm{CO}_{2} 40.1$ Blood $\mathrm{B}$ (free air, respiration very rapid, by the trachea) $\mathrm{O}_{2} 21.5$; $\mathrm{CO}_{2} 18.3$

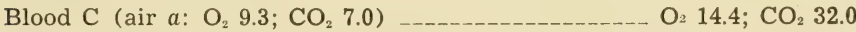

Blood D (air b: $\mathrm{O}_{2} 1.8 ; \mathrm{CO}_{2} 12.0$ ) _..._. $\mathrm{O}_{2} 2.1 ; \mathrm{CO}_{2} 54.3$

Blood E (lethal air $c$ : $\mathrm{O}_{2} 1.5 ; \mathrm{CO}_{2} 12.6$ ) _..._. $\mathrm{O}_{2} 1.2 ; \mathrm{CO}_{2} 42.5$

The air from the lungs $d$ contained; $\mathrm{O}_{2} 0 ; \mathrm{CO}_{2} 14.6$.

Experiment DCXL. March 10. Brach-hound, weighing 16 kilos.

Rectal temperature $39.5^{\circ}$.

$3: 15$. Placed a tube in the trachea; breathes calmly.

$3: 20$. Caused to breathe in the bag, which contains 137 liters of air.

3:23. Respiration calm; drew 33 cc. of blood from the carotid, moderately red .... A

3:49. Deep respirations, 58 ; took air from the bag .... a

3:50. Drew $25 \mathrm{cc}$. of blood, not so red as A . . . B

4:05. Deep respirations, agitated, 48; temperature $37.8^{\circ}$.

$4: 12$. Violent struggling; temperature $37.5^{\circ}$,

4:15. Air from the bag .... b

4:16. Respirations ample, 52 ; drew 25 cc. of blood, considerably less red ..... C

4:38. Air from the bag.... 
4:40. Respirations, 48 ; temperature $35.5^{\circ}$; drew 25 cc. of dark blood .... D

5 o'clock. Respirations fairly deep, 40; pulse 36 ; temperature $35^{\circ}$.

5:03. Air from the bag .... d

5:07. Drew $25 \mathrm{cc}$. of very dark blood .... E

5:08. The eye, till then sensitive, becomes insensible; the pupil dilates.

5:10. Respirations 6 ; pulse 30 .

5:15. Urine; the respirations become slower and slower and weaker and weaker; the heart also is failing.

$5: 20$. Died without convulsions. Took air from the bag ....e

Took blood from the left heart .... F

The urine contains $18 \mathrm{cc}$. of $\mathrm{CO}_{2}$ per $100 \mathrm{cc}$. of liquid.

The sciatic nerve remains excitable by electricity until $6: 40$, that is, for 1 hour 20 minutes.

Blood A (free air) contained $\mathrm{O}_{2} 21.8 ; \mathrm{CO}_{2} 42.9$

Blood B (air $a$ : $\mathrm{O}_{2} 12.5 ; \mathrm{CO}_{2} 6.8$ ) $\mathrm{O}_{2} 21.0 ; \mathrm{CO}_{2} 48.2$

Blood C (air b: $\mathrm{O}_{2} 7.6 ; \mathrm{CO}_{2} 9.8$ ) $\mathrm{O}_{2} 15.4 ; \mathrm{CO}_{2} 57.8$

Blood D (air c: $\mathrm{O}_{2} 4.0 ; \mathrm{CO}_{2} 10.3$ ) $\mathrm{O}_{2} 6.9 ; \mathrm{CO}_{2} 58.3$ Blood $\mathrm{E}$ (air d: $\mathrm{O}_{2} 2.8 ; \mathrm{CO}_{2} 14.7$ ) $\mathrm{O}_{2} 1.0 ; \mathrm{CO}_{2} 52.4$ Blood $\mathrm{F}$ (lethal air $e: \mathrm{O}_{2} 1.9 ; \mathrm{CO}_{2}$ 14.7) $\mathrm{O}_{2}-; \mathrm{CO}=50.2$

Experiment DCXLI. March 28. Dog weighing 11.5 kilos; rectal temperature $39^{\circ}$.

$4: 10$. Took $25 \mathrm{cc}$. of blood from the carotid, moderately red . . . A

I immediately cause it to breathe through the muzzle in the bag which contains about 100 liters of air.

Respirations 28.

4:40. Respirations 36 ; pulse 92 ; temperature $37.5^{\circ}$; took air from the bag .... a

4:41. Drew $25 \mathrm{cc}$. of blood not so red as A .... B

5:10. Respirations 36 ; pulse 100 ; temperature $36^{\circ}$; took air from the bag....b

5:11. Drew 25 cc. of very dark blood .... C

Feet still sensitive.

5:15. Suddenly stops breathing, without convulsive struggling.

$5: 20$. Drew $45 \mathrm{cc}$. of very dark blood from the left heart .... D Took air from the bag.....

The sciatic nerve is excitable until $6: 30$, that is, for 1 hour, 10 minutes.

Blood A (respiration in free air) contained $\mathrm{O}_{2}$ 15.7; $\mathrm{CO}_{2} 36.5$

Blood B (air $a: \mathrm{O}_{2} 19.2 ; \mathrm{CO}_{2} 1.9$ ) contained $\mathrm{O}_{2} 12.8 ; \mathrm{CO}_{2} 49.3$

Blood C (air b: analysis lost) _._._._._. contained $\mathrm{O}_{2} 2.5 ; \mathrm{CO}_{2} 53.8$ Blood D (lethal air $c: \mathrm{O}_{2} 4.3 ; \mathrm{CO}_{2} 13.1$ ) _-_contained $\mathrm{O}_{2} 0.5 ; \mathrm{CO}_{2} 53.6$

Experiment DCXLII. April 2. Young terrier, weighing 7.5 kilos; tube in the trachea.

6 o'clock. Caused to breathe in the bag containing about 40 liters of air.

6:01. Drew $20 \mathrm{cc}$. of very red blood; the animal remains quiet while the blood is being drawn .... A 
6:05. Respirations 136 ; pulse 120 ; temperature $36.5^{\circ}$.

$6: 30$. Respirations 50 ; pulse 106 ; temperature $35.8^{\circ}$; took air from the bag .... a

6:31. Drew 20 cc. of dark blood .... B

The animal struggles; respirations deep and irregular; eyes and feet sensitive.

$6: 45$. Respirations 52 ; pulse 76 ; temperature $34.2^{\circ}$; took air . . . b

$6: 58$. Respirations 9 ; pulse 14 ; temperature $33.8^{\circ}$; eye lacks sensitivity; took air.....

And very dark blood ..... C

7:06. Respiration has stopped; we count 60 more heartbeats, very weak; the intestines move in the abdomen; the heart stops beating at $7: 09$.

Took air from the bag .....d

Blood A (respiration in the open air) _-_contained $\mathrm{O}_{2} 14.6 ; \mathrm{CO}_{2} 46.7$

Blood B (air $a: \mathrm{O}_{2} 7.4 ; \mathrm{CO} 29.1$ ) _..... contained $\mathrm{O}_{2} 9.1 ; \mathrm{CO}_{2} 52.3$

Blood C (air $c: \mathrm{O}_{2} 2.6 ; \mathrm{CO}_{2} 13.3$ ) _..._. contained $\mathrm{O}_{2} 0.8 ; \mathrm{CO}_{2} 51.8$

The lethal air $d$ contains: $\mathrm{O}_{2} 2.4 ; \mathrm{CO}_{2} 12.9$.

[Analysis of air $b$ not given. Translator]

I shall not dwell upon the symptoms shown by the animals the history of which I have just reported: slowing down of the respiration and of the circulation, final insensibility, dilation of the pupil, progressive fall of temperature, these are well-known phenomena. Besides, I have spoken of these symptoms in the chapter in which I discussed asphyxia in closed vessels, the carbonic acid being eliminated.

I shall merely state that the final phenomena, that is, the insensibility of the eye and the dilation of the pupil, occur at the time when there are only about 1 to 2 volumes per 100 of oxygen in the arterial blood (Exp. DCXXXIX and DCXL). The animal, therefore, is then in great danger of death, since the quantity of oxygen found in this same blood after death varied from 0.5 to 1.2 .

Let us now give our attention to the progressive changes in the confined air in which my animals were breathing. The graphs of Figure 79 express the results of Experiment DCLX, the most complete of those which we reported.

On the axis of the x's are measured the periods elapsed since the beginning of the experiment; on the axis of the y's, the existing proportions of oxygen, and $\mathrm{CO}_{2}$, and the sum $\mathrm{O}_{2}+\mathrm{CO}_{2}$ of these two values, the variations of which sum present here, as we shail see, a true interest.

We see that the oxygen consumption kept decreasing in proportion as the asphyxia progressed; in the first hour, it was $13.3 \%$; in the second and last, only $5.7 \%$. Similarly, in the first hour, $9.8 \%$ of carbonic acid was produced, and only $4.9 \%$ in the second. 
These data are identical with those on which I dwelt in Subchapter IV of Chapter II.

I can say the same relating to the final composition of the lethal air. The variations were, for the oxygen, from 4.3 (Exp. DCXLII) to 1.5 (Exp. DCXXXIX), and for carbonic acid, from 12.6 (Exp. DCXXXIX) to 15.8 (Exp. DCXXXVIII)

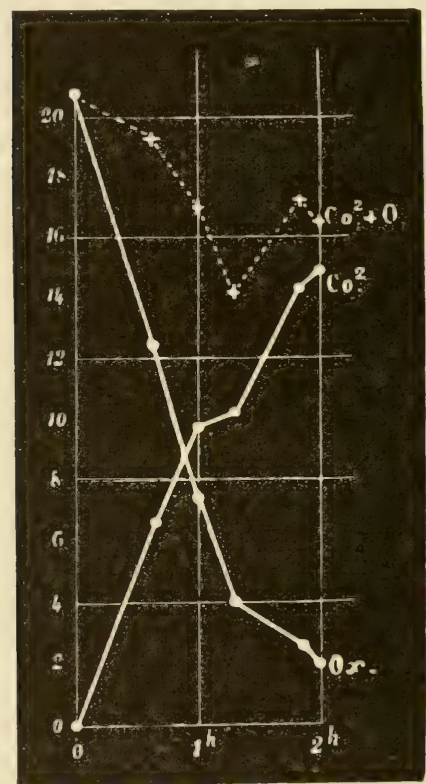

Fig. 79-Death by asphyxia in a in a closed vessel; gases of the air. (Exp. DCXL.)

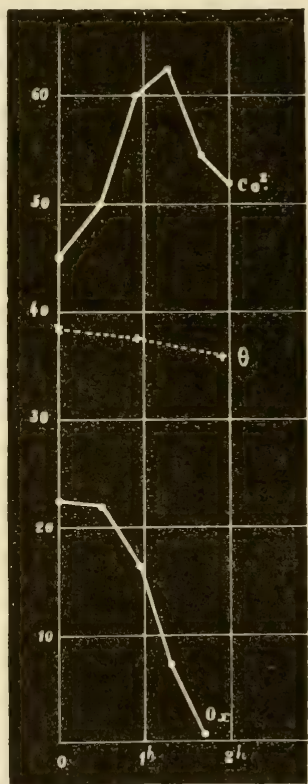

Fig. 80-Death by asphyxia in closed vessels; gases of the blood. (Exp. DCXXXIV.)

Let us now take up the gases of the blood. Here too the accompanying graph (Fig. 80) (the volume of the gases was not reduced to zero) shows the facts very clearly (Exp. DCXXXIV).

As we know, the oxygen continues to diminish in the arterial blood. But it does not diminish in a manner regularly proportional to the time; in the first hour, in fact, we see that the proportion of oxygen dropped only 6.6 volumes, whereas it fell more than 14 in the second hour. 
This agrees with what our former studies taught us. The greater absorption of the exterior oxygen at the beginning results in a relative persistence of the oxygen content of the arterial blood.

If now we construct a graph (Fig. 81), taking for the abscissae the quantities of oxygen contained in the outer air at the various moments of asphyxia, and plotting on the ordinates the quantities of oxygen contained in 100 volumes of arterial blood, we reach a result which is absolutely like line Ox (dotted line) of Figure 39, furnished by asphyxia without carbonic acid. The carbonic acid then seems to have had no effect.

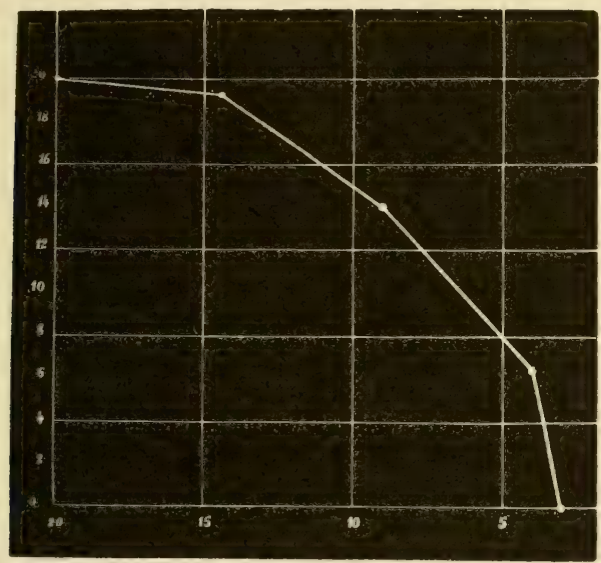

Fig. 81-Relation between the oxygen content of the air and that of the blood.

And as to the carbonic acid, its proportion at first increases in the blood, as we might have expected, since it increases in the air which the animal breathes. But suddenly it decreases, and the curve (Fig. 80) presents a point of retrogression corresponding to 1 hour 20 minutes; and so, in the last moments of life, there is in the blood less $\mathrm{CO}_{2}$ than there was a few instants before. When I observed this fact for the first time, I thought that acid had been absorbed by the tissues at the moment when the heart beats very slowly. But if we compare the line of the $\mathrm{CO}_{2}$ of the blood (Fig. 79) with that of the $\mathrm{CO}_{2}+\mathrm{O}_{2}$ of the air (Fig. 80), we see a similar point of retrogression which shows that, at the precise moment 
when $\mathrm{CO}_{2}$ diminishes in the blood, it increases considerably in the expired air, that, in a word, it leaves the animal. In all my analyses I have found this fact, unknown until now: a glance at the summarizing tables is enough to convince anyone.

We must not then continue to say, as was too easily admitted a priori, that in asphyxia in closed vessels the quantity of $\mathrm{CO}_{2}$ contained in the blood keeps increasing until death; quite to the contrary, it always diminishes in the last moments of life.

Furthermore, when the volume of air in which the animal is asphyxiated is small, the carbonic acid diminishes in the arterial blood from the beginning, in spite of its increase in the air. This is shown by Experiment DCXXXVII, for example, in which although a large dog was given only 20 liters of air, the carbonic acid content of its blood fell from 44.8 to 39.9 .

But when the carbonic acid is prevented from reaching the outer air, as is the case with animals that are strangled or drowned, it increases in the blood, but in a very small proportion.

Examples:

Experiment DCXLIII. April. Dog weighing 15.8 kilos. Drew 33 cc. of arterial blood from the carotid . . . A

Placed a tube in the trachea, and immediately afterwards, a stopper in the tube. Struggling, dead in 4 minutes.

A cannula was inserted into the left heart; at the moment when the heart stopped, $33 \mathrm{cc}$. of very dark blood was drawn . . . B

A contains per $100, \mathrm{CO}_{2} 33.9$.

B contains per $100, \mathrm{CO}_{2} 40.8$.

This answers most decisively the question which we asked ourselves at the beginning of this chapter: Does the carbonic acid produced during asphyxia play any part in causing death?

All that we had learned showed us already that its role in all cases must be decidedly limited. In order that carbonic acid may bring on death in dogs, its proportion in the air must be more than $30 \%$; now in the confined air in which the animal is asphyxiated, it never rises above 17 to 18 . On the other hand, the dis. turbances of circulation, locomotion, calorification, etc., and the variations of the oxygen of the air and the oxygen of the blood are the same in the cases in which the carbonic acid was eliminated from the confined air in which the animal is breathing (Chapter III, Subchapter II) and in ordinary asphyxia.

But the experiments which we have just reported show that the increase of carbonic acid in the arterial blood of asphyxiated animals, when it exists, never reaches a figure much higher than 
that found sometimes in the blood of animals breathing free air; the maximum was 53.6 (Exp. DCXLI), and the visible symptoms of poisoning by carbonic acid do not appear before the blood contains 70 to 80 volumes of this gas. Finally, the question cannot even be asked in cases where carbonic acid, far from increasing, diminished in the blood and the tissues.

This is the time to recall Experiments DCXXIV, DCXXV, DCXXVI, reported in the matter of poisoning by carbonic acid, in reference to the quantity of this gas dissolved in the tissues. They show, in fact, that in the animals of Experiments DCXXXVIII, DCXXXIX, and DCXL, the tissues contained only a small quantity of carbonic acid, hardly, if any, greater than is found there normally. Finally, the urine of asphyxiated dogs released, in presence of an acid, only 15 to 20 volumes of $\mathrm{CO}_{2}$ (Exp. DCXXXIX, DCXL), that is, the quantity found on the average in dogs given a mixed diet.

All this collection of facts shows decisively, then, that carbonic acid plays no part in the death of dogs, which are drowned, strangled, or asphyxiated in a very small quantity of air, and that this part is negligible when asphyxia takes place in larger spaces. Perhaps it would be unwise to apply this last conclusion to animals in which, as in sparrows, the lethal tension of carbonic acid in the air is only from $22 \%$ to $26 \%$; here again, however, Experiment DCXXVIII $\mathrm{C}$ shows that carbonic acid has no great importance.

However, its decrease in the tissues when the asphyxia took place in air freed of carbonic acid or in expanded air (Experiments DCXXVIII D and DCXXIII) may perhaps explain the few differences we noted between asphyxia in closed vessels and asphyxia by decompression, mentioning particularly rigor mortis.

\section{Subchapter III}

\section{OBSERVATIONS ON THE GASES OF THE BLOOD}

The numerous analyses of the gases of the blood which I have reported in this book deserve to occupy us some moments, even disregarding considerations relating to barometric pressure.

I shall say at the very beginning that the high temperature to which I raise the blood in the gas pump permitted me to extract the gases of the blood much more rapidly and much more completely than my predecessors could manage to do. Of course, at 
$40^{\circ}$, under a vacuum, one finally obtains almost all the oxygen and all the $\mathrm{CO}_{2}$ contained in the blood; but it takes a long time, the successive pump strokes bring only small quantities of gas, there comes at the same time water vapor in which the carbonic acid is dissolved again at the time of the condensation, and finally, a more serious matter, a small quantity of oxygen may be consumed during the operation. On the contrary, at the temperature of boiling water, all the gases are immediately extracted by the vacuum, and it has sometimes happened that I extracted all of them with a single stroke of the pump.

Nitrogen. According to the researches of Fernet, 100 volumes of blood, at $15^{\circ}$, can dissolve 1.4 volumes of nitrogen. I have often found figures a little higher than this, which signifies nothing, because some bubbles of air may have been left in the whole apparatus; but I have also found some a little lower, and this is more interesting. Setting aside possible causes of error, we find in this the suggestion that the blood, as it passes through the lungs, is not sufficiently agitated with the air to become saturated with the gases which it is capable of dissolving.

This becomes a certainty when we consider the results of the experiments on the gases of the blood of animals placed in compressed air. In fact, nitrogen is very far from following Dalton's law, because at 10 atmospheres, for example, I found as a maximum only 11.4 volumes (Exp. CLXXXIII).

I shall return in a moment to this important observation.

Oxygen. The proportions of oxygen which we have found in the same volume of blood, in animals of the same species and in equally good health, have varied within limits of astonishing extent.

I am presenting here a table as much for carbonic acid as for oxygen, using, of course, only experiments made on animals breathing ordinary air at normal pressure. I placed in parentheses and. I do not include in the average of the analyses those in which the animals were sick or breathed under abnormal conditions: the necessary specifications are given in the column of observations.

And so, eliminating extraordinary circumstances, the extremes were for oxygen 24.0 (Exp. DCLXVI) and 14.4 (Exp. CCLXXX). There are 8 analyses giving from 14 to 15,9 giving from 16 to 18 , 29 giving from 18 to 20,25 giving from 20 to 22 , and 9 from 22 to 24 ; the general average was 19.4. But we see that I was right to take often in the course of this book as an average the proportion of 20 volumes per 100 . 
Experiments

CLIV
CLV
CLVI
CLVI bis
CLVI ter
CLVII
CLVIII
CLVIII bis
CLIX
CLIX bis
CLX
CLX bis
CLXI
CLXI bis
CLXIII
CLXIV
CLXV
CLXVI
CLXVII
CLXVII

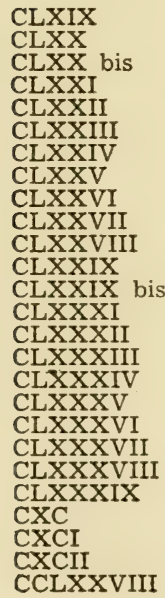

CCLXXIX

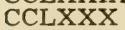

CCLXXXI

CCLXXXII

CCLXXXIII

CCLXXXIV

CCLXXXV

CCLXXXVI

CCLXXXVII

CCLXXXVIII

CCLXXXVIII bis
Table XX

(17.7)

19.7

21.4

21.2

21.5

19.7

(24.6)

(18.2)

18.6

19.4

(11.7)

(12.4)

15.1

20.3

18.8

21.5

21.6

18.3

19.8

(26.4)

20.6

21.9

21.1

19.4

20.1

22.6

(13.3)

17.4

(16.9)

(14.8)

19.2

20.8

20.8

19.2

19.4

18.3

18.4

22.8

20.2

19.0

18.2

21.5

21.6

22.2

18.0

15.5

17.0

14.4

16.9

18.1

19.8

(12.1)

15.1

15.8

17.2

16.0

(23.4)

45.0

39.5

38.6 (32.7) 39.7

41.9

36.3

39.0

39.7

33.8

35.0

35.3

37.1

47.7

50.1

37.1

.18 .0

50.8

47.3

45.0

(29.4)

49.0

39.0

41.0

33.0
$\mathrm{CO}$ Observations

- Exhausted by suppuration

40.1 Same animal

36.7 Curare

(31.2) Medulla sectioned, at rest

(28.8) Medulla sectioned, struggling

37.0 Quiet

35.2 Struggling

(33.6) Animal in state of traumatism

40.8 Normal respiration

(24.0) Trachea; exaggerated respiration

(32.8) After the decompression

(29.1) After the decompression

(22.7) After the decompression

Very rapid respiration

34.7 Before the decompression

35.2 After the decompression

48.4 After the decompression

41.1 After the decompression

(34.9) Sick, same as CLXXI

45.7 After the decompression

(22.1) After the decompression

46.1 Before the decompression

40.5 After the decompression

(22.9) Respiration by tracheal tube, exaggerated

(24.9) Respiration by tube, exaggerated

(20.9) Respiration by tube, exaggerated

(29.6) Respiration by tube, exaggerated

40.8 Natural channels

43.0 Tube in the trachea

(22.3) Tube in the trachea

41.5 Natural channels

(15.2) Trachea 
Table XX-Concluded

\begin{tabular}{|c|c|c|}
\hline Experiments & $\mathrm{O}_{2}$ & Observations \\
\hline CLXXXIX & 16.0 & 44.5 \\
\hline $\mathrm{CCXC}$ & 18.7 & 44.0 \\
\hline CCXCV & 17.0 & 38.5 \\
\hline $\begin{array}{l}\text { CCXCVI } \\
\text { CCCII }\end{array}$ & $\left(\begin{array}{c}19.0 \\
7.3\end{array}\right)$ & $\begin{array}{l}42.0 \\
(33.0) \text { Little dog weighing } 1640 \mathrm{gm} .\end{array}$ \\
\hline DCV & $(16.0)$ & (29.5) Sick with traumatism \\
\hline DCVI & 21.0 & 43.5 \\
\hline DCVII & (24.8) & (19.5) Breathing by natural channels \\
\hline DCVIII & 18.9 & 36.5 out win extraoramary rapiaity \\
\hline DCIX & 22.0 & 46.7 \\
\hline DCXVI & 19.1 & 44.8 \\
\hline DCXVII & 22.5 & 39.5 \\
\hline DCXIX & 21.8 & 44.6 \\
\hline DCXXXVIII & 15.9 & $\begin{array}{l}44.8 \\
40.1 \text { Natural channels }\end{array}$ \\
\hline $\begin{array}{l}\text { DCXXXIX } \\
\text { DCXXXIX bis }\end{array}$ & $\begin{array}{l}19.8 \\
(21.5)\end{array}$ & (18.3) Trachea; exaggerated respiration \\
\hline DCXL & 21.8 & 42.9 \\
\hline $\begin{array}{l}\text { DCXLI } \\
\text { DCXLII }\end{array}$ & $\begin{array}{c}15.7 \\
(14.6)\end{array}$ & $\begin{array}{l}36.5 \\
46.7 \text { Young animal }\end{array}$ \\
\hline DCXLIII & 19.0 & 33.9 - \\
\hline DCXLIV & $(9.4)$ & (27.6) Little dog weighing $1850 \mathrm{gm}$. \\
\hline $\begin{array}{l}\text { DCXLV } \\
\text { DCXLYI }\end{array}$ & 15.5 & $\begin{array}{l}37.2 \\
389\end{array}$ \\
\hline $\begin{array}{l}\text { DCXLVI } \\
\text { DCXLVII }\end{array}$ & $\begin{array}{l}22.5 \\
20.2\end{array}$ & $\begin{array}{l}38.9 \text { Fasting } \text { Same animal } \\
36.6 \text { Digesting Same }\end{array}$ \\
\hline DCXLVIII & 17.9 & 33.0 \\
\hline DCXLIX & & 34.6 \\
\hline DCL & $(15.0)$ & 34.9 Animal of DCXLIX, sick. \\
\hline DCLI & 20.9 & 39.1 \\
\hline $\begin{array}{l}\text { DCLII } \\
\text { DCLIII }\end{array}$ & 21.2 & 40.3 \\
\hline DCLIV & $(16.8)$ & (35.3) Animal of Exp. CLXXII, sick \\
\hline DCLV & 18.0 & (250) Vorw ronid resningtion throurb \\
\hline DCLVI & & $\begin{array}{c}\text { (25.0) Very rapid respiration through } \\
\text { tracheal tube }\end{array}$ \\
\hline DCLVII & 20.8 & 33.3 \\
\hline $\begin{array}{l}\text { DCLVIII } \\
\text { DCLIX }\end{array}$ & 19.6 & $\begin{array}{l}39.4 \\
36.6\end{array}$ \\
\hline DCLXI & 22.1 & $\begin{array}{l}50.0 \\
36.1\end{array}$ \\
\hline DCLXII & 19.3 & 38.7 \\
\hline $\begin{array}{l}\text { DCLXIII } \\
\text { DCLXIV }\end{array}$ & 22.6 & $\begin{array}{l}42.4 \\
40.4\end{array}$ \\
\hline DCLXV & 16 & 36.1 \\
\hline DCLXVI & & \\
\hline Average & 19.4 & 40.4 \\
\hline
\end{tabular}

These variations may be due either to the presence of a lessened quantity of hemoglobin in the same volume of blood (even if there should be the same number of corpuscles), or to a lessened saturation of this hemoglobin in the conditions in which the animal is breathing, or finally to an inner difference in the nature of the hemoglobin and its lessened capacity for absorbing oxygen.

But here, the thought suggested a moment ago by the study of nitrogen appears with much more importance. Almost never, in 
the usual conditions of respiration, is the arterial blood saturated with oxygen, nor does it contain all the oxygen that it can absorb by agitation with air. Nothing is more variable than this difference between the amount of oxygen which the arterial blood does contain and that which it can eontain.

There are therefore individuals in whom a certain increase in the rapidity and amplitude of the respiratory movements can increase considerably the oxygen of the blood, and others, on the contrary, who can get almost no advantage from it. These two classes will, therefore, not be in identical conditions, from the point of view, for example, of diminution of pressure. Inversely, there are individuals who, being more saturated already, will be far more able than others to bear a certain slowing down of respiration, without having the proportion of the oxygen of their blood fall to too low a figure.

In a general way, the oxygen content of the blood is shown by the red coloration, and the redder a blood is, the more oxygen it contains. But that is absolutely true only of the same blood. My analyses have very often shown me, on the contrary, that certain light red bloods were poor in oxygen, compared to other bloods with a dark shade.

That is because the redness shows only the oxygen content of the hemoglobin (oxy-hemoglobic combination). If we imagine two bloods containing the same quantity of oxygen, the one which is very rich in hemoglobin will be considerably less red than the other. I have indeed after a copious bleeding found a blood redder than or as red as before, although with a considerably lower oxygen content; only the tint was lighter, because the blood was less laden with corpuscles.

This occurs in young animals. Experiments CCCII and DCXLV showed us in puppies a light red blood which contained only 9.4 and even 7.3 volumes of oxygen. This explains the low resistance of young animals ( $\mathrm{I}$ am not speaking of new-born animals, of course) to asphyxia, chilling, etc. They are, in the highest degree, anoxyhemic.

My analyses show also that in sick animals the quantity of oxygen contained in the arterial blood is very small. Indeed, it dropped, for example, to 13.3 in the dog of Experiment CLXXIV, an animal which was suffering from a festering wound resulting from bleedings, and which, when healthy, had given 19.4 (Exp. CLXXI).

It seems to me extremely probable that in certain cases of sickness, the lessened quantity of oxygen contained in the blood must 
result, not only from a lessened quantity of corpuscles or even of hemoglobin, but from an alteration in the latter, which becomes less fitted to absorb oxygen. This is a very important subject for research, the study of which, at my suggestion, Dr. Légerot ${ }^{6}$ has begun.

At any rate, setting aside very young animals and sick ones, it is certain that great differences exist between different animals of the same species in regard to the oxygen content of their blood.

On the other hand, in the same animal, considerable changes in the circulatory and respiratory rhythms may greatly change this oxygen content. I have already noted these facts in the chapter which deals with the discussion of my method of analyzing the gases of the blood. Experiments CLVI, CCLXXXVIII, and DCXXXIX, listed in the preceding table, are quite characteristic from this point of view.

Carbonic Acid. Carbonic acid has been extracted from the blood in proportions even more variable than those of oxygen. The extremes, eliminating exceptional data, have been 50.8 (Exp. CLXXXVIII) and 33 (Exp. CCLXXXI). There were 36 analyses giving from 30 to 40,32 giving from 40 to 50,3 above 50 , and the general average was 40.4 .

The acceleration of the respiration, especially when it is carried on directly by the trachea, lessens the quantity of $\mathrm{CO}_{2}$ in the blood in a proportion that is often enormous. I have already men. tioned these facts in dealing with the experimental criticism and the degree of accuracy which may be attributed to the analyses of the gases of the blood. The data given by our experiments are reproduced in the table above: these are Experiments CLXI bis, CCLXXVIII, CCLXXXII, CCLXXXIII, CCLXXXVII bis, DCVII, DCXXXIX bis, DCLVI. I call attention particularly to Experiment CCLXXXVIII, in which the quantity of $\mathrm{CO}_{2}$ fell from 41.5 to 15.2 by tracheal respiration; and Experiment DCVII, in which an exaggerated respiration, through natural channels however, brought this gas to 19.5 .

So the diminution of the carbonic acid of the blood through exaggerated respiration under normal pressure may reach almost the same degree as in animals subjected to the lowest atmospheric pressures, since Table $\mathrm{X}$ gives as averages 29.3 at the pressure of $34 \mathrm{~cm}$., 23.2 at that of $25 \mathrm{~cm}$., and even 12.4 at that of $17 \mathrm{~cm}$.

If we refer to the circumstances of the extraction of the gases by the pump, we shall see that the ease of this extraction depends, as one might have expected, on the quantity of them which exists 
in the blood. In this reference I made a fairly large number of experiments to see in what proportions oxygen and carbonic acid escape from the blood, when the pressure is gradually lowered.

The experiment was set up in the following manner: after a partial vacuum had been made in the barometric pump, I placed in it the blood to be analyzed; then I extracted, by successive strokes of the pump, a part at the same time of the air which remained and the gases which had escaped from the blood; I continued thus until nothing more came out. The gases extracted by each of the successive strokes of the pump were then subjected to just as many analyses. Here are the results of one of these analyses by stages:

Experiment DCLX. January 23. $100 \mathrm{cc}$. of blood taken from the brachial artery of a large shepherd dog.

The gas pump was brought to $16.5 \mathrm{~cm}$. of actual pressure; I introduce the blood, agitate it for a moment, and with the first stroke of the pump extract $92 \mathrm{cc}$. of gas .... A

At a second extraction, I secure $85 \mathrm{cc}$. of gases .... B

At the 3rd (pressure $12.5 \mathrm{~cm}$.) $61 \mathrm{cc}$. of gases .... C

At the 4th (pressure $5 \mathrm{~cm}$.) $25 \mathrm{cc}$. of gases .... D

At the 5 th (up to a vacuum) 2.5 cc. of gases ... E

The hot bath was boiling; I then placed in the receiver a little sulphuric acid diluted with boiled distilled water. 1 cc. more of $\mathrm{CO}_{2}$ was extracted.

The analyses show that:

Gas A contained neither $\mathrm{O}_{2}$ nor $\mathrm{CO}_{2}$, coming from the blood.

Gas, $\mathrm{B}$ contained $\mathrm{O}_{2} 1.9 \mathrm{cc}$. and $\mathrm{CO}_{2} 1.9 \mathrm{cc}$.

Gas $\mathrm{C}$ contained $\mathrm{O}_{2} 13.9 \mathrm{cc}$. and $\mathrm{CO}_{2} 17.8 \mathrm{cc}$.

Gas D contained $\mathrm{O}: 4.6 \mathrm{cc}$. and $\mathrm{CO}_{2} 12.0 \mathrm{cc}$.

Gas $\mathrm{E}$ contained $\mathrm{O}_{2} 0.4 \mathrm{cc}$. and $\mathrm{CO}_{2} 1.6 \mathrm{cc}$.

The total contained $\mathrm{O}_{2} 20.8 \mathrm{cc}$. and $\mathrm{CO}_{2} 33.3 \mathrm{cc}$.

The ratio $\frac{\mathrm{CO}}{\mathrm{O}_{2}}$ between the carbonic acid and the oxygen was then successively: in $\mathrm{B}, 1$; in $\mathrm{C}, 1.3$; in $\mathrm{D}, 2.6$; in $\mathrm{E}, 4$. The total ratio being 6 , it results that during the first phase of the experiment, there escaped from the blood proportionately more oxygen than carbonic acid; the contrary took place in the second phase.

Other similar experiments give the same evidence, and it would be useless to give the details of them. Furthermore, when I placed the blood in a perfect vacuum and analyzed separately the gases obtained by successive strokes of the pump, I always got a similar result. Experiments made on animals subjected to low pressures did the same (See Table X, Col. 4, 5).

And so, from whatever side we approach the problem, we see 
that under the influence of decreased pressure, the blood first loses, proportionately, its oxygen more quickly than its carbonic acid; then equilibrium is established; then the carbonic acid escapes in larger proportion; and finally, the pump brings only carbonic acid.

The same thing is true even when it is a question of blood in which the proportion of carbonic acid is much higher than the average. The experiments on carbonic acid poisoning give us numerous examples.

In Experiment DCXIV, in Blood $\mathrm{C}$ which contained $\mathrm{CO}_{2} 103.6$ and $\mathrm{O}_{2}, 18.2$, the ratio $\frac{\mathrm{CO}_{2}}{\mathrm{O}_{2}}$ being 5.7 , the first strokes of the pump brought a gas in which the ratio $\frac{\mathrm{CO}_{2}}{\mathrm{O}_{2}}$ was 5.2 , whereas the last strokes gave the ratio 6.0. Similarly, in Experiment DCXV, for Blood $\mathrm{E}\left(\mathrm{CO}_{2} 97.5 ; \mathrm{O}_{2}\right.$ 13.7), the ratio $\frac{\mathrm{CO}_{2}}{\mathrm{O}_{2}}$ being 5.2 , we had for the first tubeful of gas the ratio 4.7, and for the second, the ratio 9 . The vacuum of the gas pump, used as I specified, combined with the temperature of boiling water, removes almost all the carbonic acid contained in the blood. The later addition of a strong acid sets free only minimal quantities, sometimes none at all: the experiment which I have just reported gives a satisfactory example of that.

We know how much the opinions of physiologists and chemists have varied in regard to the carbonic acid which can be extracted by the pump (acid which is "free", "dissolved", "ausgepumpen" of the Germans) and that which resists a vacuum aided by heat (acid which is "combined", "bound", "gebunden"). Earlier authors thought the latter very abundant (Lothar Meyer estimated it at 28.58 as against 6.17 of the free acid); but the analyses of Schöffer, Setschenow, Pflüger, etc., have successively reduced the proportion to what we have observed ourselves.

In blood artificially saturated with carbonic acid, this gas is in three forms: simply dissolved, weakly combined (bicarbonates and phosphocarbonates), or strongly combined (carbonates). But in what form does it exist in normal blood, both arterial and venous?

In these natural conditions is there simply dissolved carbonic acid? M. Fernet (loc. cit., page 209), had concluded from his experiments that in saturated liquid, that is, containing $156.1 \mathrm{cc}$. of 
$\mathrm{CO}_{2}$ per $100 \mathrm{cc}$. of blood (beef blood at $16^{\circ}$ ), the largest part (96.4 cc.) of this acid is dissolved in the blood, since it follows Dalton's Law in its relation to the barometric pressure, and since the rest (59.7 cc.) is combined in the form of bicarbonate or phosphocarbonate, because it escapes this law.

Now our analyses have shown us that in arterial blood only very rarely are there 50 volumes of $\mathrm{CO}_{2}$. We may say then that regularly the arterial blood contains only $\mathrm{CO}_{2}$ in combination, both weak and strong. On the contrary, in the blood of the right heart we have found, on the average, higher proportions of $\mathrm{CO}_{2}$; this blood then seems to contain in addition $\mathrm{CO}_{2}$ simply dissolved.

This leads us then to think that respiration, so far as carbonic acid is concerned, consists chiefly and perhaps exclusively of an exhalation of the excess of carbonic acid simply dissolved, the part combined in the state of bicarbonate or phosphocarbonate being only slightly or not at all modified. In perfect respiration, at its regular rhythm, no dissolved acid should remain in the arterial blood.

With the purpose of gaining light upon this point, which is important for the general theory of respiration, I began experiments with the following method. I draw from an animal arterial blood, the carbonic acid tension of which I determine immediately by means of a vacuum and heat. Then for two hours, by means of the water motor (See Fig. 42), I agitate another sample of the same blood in a flask full of pure carbonic acid: a rubber bladder, also full of $\mathrm{CO}_{2}$ and communicating with the flask, prevents absorption from lessening the gaseous tension. After this time, another analysis. I then subtract from the number found the quantity of $\mathrm{CO}_{2}$ which the blood would be capable of dissolving at the actual temperature (the observations of M. Fernet permitted me to use Bunsen's tables for the coefficients of solubility), and the remainder should show whether there is still dissolved $\mathrm{CO}_{2}$ in the arterial blood. For greater clarity, let us take an example: let us suppose that the arterial blood has given 40 volumes of $\mathrm{CO}_{2}$, and that after agitation at $16^{\circ}$ it contains 138 ; the coefficient of solubility being 96.4, we see that the salts of the blood required for saturation $138-96.4=41.6$; therefore, in the blood they were not at the maximum of carbonization, because for that they lacked 1.6 volumes of $\mathrm{CO}_{2}$.

Here are some experiments made by this simple method. The first two include in addition the analysis of the gas of the blood of the right heart: 
Experiment DCLXI. July 4. Dog.

Drew $25 \mathrm{cc}$. of blood from the femoral artery.

It contains $\mathrm{O}_{2} 22.1 ; \mathrm{CO}_{2} 36.1$. Simultaneously $25 \mathrm{cc}$. of blood from the right heart. It contains $\mathrm{O}_{2} 5.5 ; \mathrm{CO}_{2} 56.4$.

100 cc. of blood are shaken for 24 hours with pure $\mathrm{CO}_{2}$ (temperature $20^{\circ}$ ).

They then contain 127.4 of $\mathrm{CO}_{2}$.

Coefficient of solubility at $20^{\circ}: 91.5$. Then, $127.4-91.5=35.9$. Therefore, the salts of the arterial blood are exactly saturated. As for the venous blood, it contains 20.5 volumes of dissolved $\mathrm{CO}_{2}$, saturation being perfect.

Experiment DCLXII. July 9. Dog, digesting, weighing 8 kilos (it dies during the night as a consequence of the hemorrhage).

Drew from the femoral artery $25 \mathrm{cc}$. of blood, which contains O. 19.3 and $\mathrm{CO}_{2} 38.7$ (at $0^{\circ}$ and $760 \mathrm{~mm}$.).

Drew at the same time from the right heart 50 cc. containing $\mathrm{CO}_{2}$ 49.0. Then $350 \mathrm{cc}$. of arterial blood are taken and shaken all night with pure $\mathrm{CO}_{2}$.

The next day (temperature $20^{\circ}$ ), this blood contains 172.1 volumes of $\mathrm{CO}_{2}$.

The coefficient of solubility of $\mathrm{CO}_{2}$ at $20^{\circ}$ was $91.5 ; 172.1-91.5=$ 80.6. It results that the arterial blood lacked 41.9 of being chemically saturated with $\mathrm{CO}_{2}$, and that the venous blood itself lacked $31.6 \mathrm{cc}$.

Experiment DCLXIII. June 26. Large dog; I draw from the carotid 25 cc. of blood, which contains $\mathrm{O}_{2} 22.6 ; \mathrm{CO}_{2} 42.4$.

Agitation for 18 hours with pure $\mathrm{CO}_{2}$. Contains then (temperature $23^{\circ}$ ) 146.8 volumes of $\mathrm{CO}$.

Coefficient of solubility at $23^{\circ}$, about $87 ; 146.8-87=59.8$. Therefore, for saturation, the bases of the arterial blood lack about 17.4 volumes.

Experiment DCLXIV. July 11. Dog, fasting, weighing 10 kilos. Drew $25 \mathrm{cc}$. of blood from the femoral artery; it contains $\mathrm{O}=20.0$; $\mathrm{CO}_{2} 40.4$.

$100 \mathrm{cc}$. of the same blood are shaken with twice its volume of pure $\mathrm{CO}_{2}$. The next day (temperature $22^{\circ}$ ), analysis shows that the blood contains 155.9 volumes.

Coefficient of solubility at $22^{\circ}: 90.1$. Therefore there are lacking for saturation 25.4 volumes of $\mathrm{CO}_{2}$.

Experiment DCLXV. July 18. Dog, fasting, weighing 13 kilos.

Experiment similarly conducted; arterial blood $\mathrm{O}_{2} \quad 16.7 ; \mathrm{CO}=36.1$. After agitation (40 hours) in $\mathrm{CO}_{2}$ contains 147.6 (temperature $20^{\circ}$ ). Coefficient of solubility at $20^{\circ}: 91.5$. Therefore, lack for saturation of 20 volumes of $\mathrm{CO}$.

Experiment DCLXVI. July 22. Dog, fasting, weighing $11 \mathrm{kilos}$.

Arterial blood: $\mathrm{O}_{2} 24.0 ; \mathrm{CO}_{2} 50.3$.

July 26. After agitation: $\mathrm{CO}=167.0$ (temperature $22^{\circ}$ ).

Coefficient of solubility at $22^{\circ}$, about 88.5 . Therefore, lack for saturation of about 28.2 volumes of $\mathrm{CO}_{2}$. 
Experiment DCLXVII. August 20. Dog, fasting.

Arterial blood: $\mathrm{CO}_{2}$ 54.0.

After agitation for 5 hours with pure carbonic acid, the blood contains 166 volumes of $\mathrm{CO}$, at $22^{\circ}$.

The coefficient of solubility being 90.1 , we see that the bases lacked 22 volumes of $\mathrm{CO}_{2}$ for saturation.

Experiment DCLXVIII. July 24. Old horse, exhausted, paralyzed in the hind quarters; one of the sympathetic nerves in the neck has just been cut.

Drew carotid blood on the side of the sympathetic that was cut. It contains $\mathrm{O}_{2} 11.8 ; \mathrm{CO}_{2} 44.8$.

At the same time took venous blood from a branch of the jugular; it contains $\mathrm{O}=11.8 ; \mathrm{CO}_{2} 54.0$.

Before sectioning, the venous blood had given $\mathrm{CO}_{2} 50.1$. Shaken for 24 hours, with pure $\mathrm{CO}_{2}$ contains (temperature $19^{\circ}$ ) 178.2 volumes of $\mathrm{CO}_{2}$. It has taken on a very strange dark color, which I have never seen.

Coefficient of solubility at $19^{\circ}: 92.5$. Therefore, there is lacking for complete saturation of the bases of the arterial blood 40.9 volumes of $\mathrm{CO}_{2}$, and for that of the venous blood before any nervous section, 31.7.

We see that in none of our experiments did the arterial blood contain carbonic acid that was simply dissolved; only once were the alkaline bases exactly saturated (Exp. DCLXI). Furthermore, the venous blood itself, in Experiments DCLXII and DCLXVI, contained only carbonic acid in combination; but in Experiment DCLXI, there were 20.5 volumes of dissolved $\mathrm{CO}_{2}$.

Perhaps, before drawing definite conclusions, we should make a larger number of experiments; however, for the arterial blood, the agreement of our analyses is perfect, and I think we can consider that it is proved that all the dissolved carbonic acid (when it exists in the venous blood) escapes in passing through the lungs, and that the supercarbonated alkaline salts are, moreover, dissociated there from a part of their acid, hardly exceeding one third.

But this last limit may be exceeded, and a larger proportion of combined carbonic acid may escape through respiration and no longer be found in the arterial blood. This happens particularly at the time of exaggerated respirations through a tube placed in the trachea; it happens in curare poisoning, when artificial respiration is given, even with precautions; it happens after or during the convulsions due to compressed oxygen (see particularly from this point of view Experiment CCLXXXVI, in which the proportion of $\mathrm{CO}_{2}$ dropped to 9.9 volumes in the arterial blood); it happens, finally, through respiration in rarefied air. The alkalinity. of the 
blood must increase considerably in these circumstances, which could not fail, if the circumstances continued for some time, to exercise a considerable influence on the state of health of the experimental animal; we shall return to this last point when in the third part of this work we study the conditions of life of dwellers in high places.

1 Lecons sur la physiologie cumparée de la respiration, page 521.

2 In these lines, as in those of Figure 75 , the volume of the gas was not reduced to $0^{\circ}$.

Lecons sur la respiration, p. 431

Bull. de la Société philomatique, 1864, p. 13.

und Wachstum der Pflanzen. (Zitzb. der k. Akad, Einfluss der Kohlensaüre auf das Ergrünen und Wachstum der Pflanzen. (Zitzh. der k. Akad, der Wissensch., LXVIII Bd. Wien. 1873. Thêses de Paris, 1875. 


\section{Part Three}

\section{RECENT DATA, SUMMARY AND CONCLUSIONS}





\section{Chapter I \\ DECREASED PRESSURE}

Subchapter I

\section{OBSERVATIONS, THEORIES, AND RECENT DISCUSSIONS}

The principal results of the experiments reported in the second part of this book, and the theory drawn from them in regard to the influence of high elevations were submitted to the judgment of the public several years ago. ${ }^{1}$ The idea that symptoms produced by a sojourn in rarefied air, particularly mountain sickness, are caused solely by the lessening of the oxygen tension in the air, and are in fact only a form of asphyxia, has aroused much criticism, generally not very instructive, which it would be tedious to reproduce here.

Among those who took it upon themselves to oppose my conclusions, some seem not to have an exact knowledge of them, and particularly not to have read the experiments on which they are based. For instance, M. Bouchut ${ }^{2}$ wrote the following lines in 1875:

One might question whether it is really the diminution of the oxygen of the blood that causes mountain sickness, and not rather a carbonhemia due to the accumulation of carbonic acid in the blood, which dulls the organs and disturbs their functions; but that makes no difference in the fact itself, which is incontestable. In my opinion, and according to my experiments, the nervous phenomena of asphyxia are all due to the dulling action of the carbonic acid retained in the blood. In fact, I have demonstrated that all animals that die asphyxiated for want of oxygen have previously a more or less pronounced anesthesia, and I am surprised that aeronauts have not announced this fact, since it is so easy to verify it on a mammal placed beneath the receiver of an air pump. 
I have read many strange articles on this subject. I shall quote only one, however, because it had the honor of insertion in the Official Journal, ${ }^{3}$ and because it can serve as a model in this common art of hiding ignorance behind pompous scientific terms:

To have a satisfactory explanation of mountain sickness, we must use modern knowledge of human physiology and physics. The cause of these phenomena was at first thought to be the increasing rarefaction of the air as one ascends.

The diminution of density of atmospheric strata does indeed produce an acceleration of pulse and respiration; but these symptoms remain isolated and are often unnoticed by aeronauts at heights much greater than those at which mountain sickness appears. Increase in frequency and depth of respirations compensates for the rarefaction of the air. Furthermore, oxygen in this case, though it is less abundant, appears to be better fixed and dissolved in the blood, a fact which lessens by so much the inconveniences of its rareness.

However this may be, ascent into the upper regions of the air, if it has a certain effect, possesses it only in a secondary way as if to make more noticeable and more speedy the effect of the increased labor which walking requires; for it is in the increase of mechanical labor that we find the real reason for mountain sickness.

To maintain animal warmth and life, man in repose requires a determined quantity of heat, furnished by hydrogen and carbon. According to modern theories, all mechanical labor is the result or the transformation of an equivalent quantity of heat supplied by inner combustion.

This heat, transformed into labor, does not raise the temperature of the body; but it cannot be produced without giving the usual residues, which are, we know, carbonic acid and water vapor. The increase in labor caused by exhausting ascents consumes in the blood the materials of heat production, and produces an excess of carbonic acid, of which the system rids itself by speeding up respiration. Even this outlet is often insufficient; and hence the phenomena which we have described, and which are all the more marked because the traveller is in a cold region; and hence too the speed with which they disappear when the traveller rests, and requires from his breathing only the heat necessary for his existence.

The excess of carbonic acid is removed and everything becomes normal.

There are some who have protested in the name of the ancient theories, and have revived the unfortunately classic ideas about the decrease of the weight supported by the body, hemorrhages by suction, and the peripheral cupping-glass. I reported earlier the strange discussion begun in the Academy of Medicine, and the opinion of M. Colin on the role played by expanded intestinal gases. Dr. Chabert, ${ }^{4}$ in a recent thesis, after reporting and adopting 
our theory, cannot refrain-though not without remorse-from sacrificing also to the ancient gods, the false gods:

The acceleration of respiration and circulation really has as its principal cause the more pressing need of oxygen .... But certain secondary causes also favor this acceleration. Among others, we admit, as a possible aid towards this result, the greater tension of liquids and gases of the blood, an increase in tension which is generally considered to appear in lofty regions, and is due to the diminution of surrounding pressure. It would give the blood greater fluidity, while the diminution of atmospheric pressure would permit the capillaries to dilate, they say, and consequently give the blood freer passage. But has not the influence of the latter cause been somewhat exaggerated? Should not the intense cold of the regions where air is rarefied amply counterbalance this effect, already doubtful, on the peripheral circulation? The cold, in fact, produces a state of stasis of the blood in the capillaries on which its influence can manifest itself, that is, on those which lowering of pressure might influence. Now, this effect of cold should lessen greatly the action (perhaps still problematical) of atmospheric decompression in this case; and to support our opinion we see in the observations that we have reported that this peripheral circulation is far from being speeded up as much as is said. M. Glaisher complains that his hands grew blue; in another ascent, he was forced to pour brandy over the hands of his companion, Coxwell, which had become black and numb, and we have seen the same thing take place on other occasions. (P. 28.)

These old hypotheses ought not to stop us now; a word or two will be enough presently to summarize definite disproof.

But we are far from treating with the same scorn the interesting theory developed by M. Dufour. We have seen, in the historical part of this book, that in 1874 this scientist, without yet knowing of our experiments, had expressed the opinion that mountain sickness is due to the exhaustion, through exaggerated muscular contractions, of the ternary materials of the blood and the tissues, materials necessary for the production of heat and work. The reply to this theory appears of itself and we have expressed it in a few words (page 340). The discussion which took place in the bosom of the Medical Society of Switzerland having informed M. Dufour of the results of my experiments, he somewhat modified his point of view, and finally decided that one must distinguish between "height sickness" and "fatigue sickness," the combination of these two factors producing "mountain sickness." Here are his own words: ${ }^{5}$

A. Height Sickness. The blood loses its oxygen supply according to rules established by M. Bert for some animals. And so, if one can apply to man the results obtained in animals, at 4200 meters the blood 
would already have lost a fifth of the oxygen which it ought to contain, at 6400 meters almost a half, and so on.

It is clear that this constitutes a pathological state, which comes from the simple fact that one breathes at too low a pressure, or in an air containing too little oxygen. Height sickness is the only harm experienced by aeronauts, if we do not take into account the influence of the cold.

B. Fatigue sickness. This is the consequence of muscular labor. If labor is repeated or violent, as after the rapid ascent of a long flight of stairs, fatigue sickness will be an asphyxia for lack of oxygen and excess of carbonic acid in the blood. If the muscular labor is long and not compensated by food, the organism will suffer from inanition.

Asphyxia by muscular labor will hardly be produced on the plains, if the labor is not too rapid; it will be easily produced on the heights, according to the findings of M. Bert. But prolonged labor, whatever it be, will always finally produce pathological symptoms. These must be very hard to determine exactly; it is probable, however, that it is to fatigue sickness that most of the pathological symptoms observed in the mountains are due.

Mountain sickness then would be a combined effect of height sickness and fatigue sickness, or rather a fatigue sickness appearing more quickly on account of the altitude. The more mountain sickness appears at a low level, the more it depends on the factor of inanition on which I have laid stress; the more it appears at a high level, the more important the role which $\mathrm{M}$. Bert's anoxyhemia plays.

Mountain sickness appears to us therefore as a complex phenomenon depending on altitude, fatigue (the latter in its turn depending on labor and food) and the mental impressions which MM. Javelle and Forel (Bulletin, March and June) have proved by interesting examples. (P. 263.)

The conclusion of this is:

That it is impossible for M. Bert to study mountain sickness under the pneumatic bell. Why? Because he experiences only the influence of rarefaction, that is, height sickness pure and simple. (P. 264.)

We make no change in our reply. Does the fatigue to which mountain climbers are subjected have as its imminent cause the exhaustion of carbon compounds of the muscles and blood, as M. Dufour says? That hypothesis is probable, though not proved and certainly incomplete. Much has been written and many experiments have been made on muscular and nervous fatigue, and the question is still full of obscurities. But after all, it does not matter much whether this fatigue following excessive walking and continuous efforts of climbing is the result of excursions on hills 500 or 600 meters high, or in mountains over 4000 meters high. Now the manifestations will be quite different in the two cases; and the very name mountain sickness is highly characteristic. It appears 
only at a certain level, and that where the oxygen lack of the blood has reached a sufficient degree, and we shall make this expression exact in a moment. If aeronauts are not attacked until long after mountain climbers, it is not because their reserve of ternary materials is intact, for they have only to make some efforts and they ton become sick, it is because their muscles in repose do not demand of the impoverished arterial blood a quantity of oxygen which it would be unable to furnish them. Does that mean that the different causes of fatigue play no part in the conditions of the appearance of mountain sickness? I have already replied to that question; but it is doubtful that it is a matter of the using up of the ternary materials, since a sleepless night, an indigestion, some indisposition or other have the same unpleasant consequences. A tired man presents the best conditions for the development of mountain sickness; but it does not recognize fatigue as its cause, since if fatigue operates alone, mountain sickness never appears.

M. Forel, whose works were discussed in our first part, wholly adopted my ideas in his third Mémoire. ${ }^{6}$ I reproduce here the interesting account of an excursion made by this physicist into a grotto in which the air was very poor in oxygen, an account which we must compare with that of M. F. Leblanc and also, because of a remarkable coincidence of symptoms, with my experiment CCLIV.

On June 23, 1864, I made an exploratory tour of the Grotte-desFées of St-Maurice, a very profound cavern, which, among other peculiarities, has an atmosphere very poor in oxygen; here is the result of one of the analyses which Professor Bischoff made on air collected 1000 meters from the entrance of the cavern.

$\begin{array}{lc}\text { Nitrogen } & 82.66 \\ \text { Oxygen } & 1.99\end{array}$

If I calculate the oxygen tension in this air, I see that it is $14.7 \%$, the normal tension on the seashore being 20.9. This number corresponds to the air tension at an altitude of more than 2000 meters.

After a stay of several hours in this cavern, studying my physiological state, I observed: acceleration of pulse, acceleration of respiratory rate, and mental disturbances which I described then in the following terms: When I wanted to count my pulse, I was obliged to try seven times; I was often mistaken, I skipped numbers, I counted twice in succession the same group of ten, or I counted a group of ten beginning at the end.

The almost complete similarity of symptoms of mental disturbances observed by $\mathbf{M}$. Bert and myself, at such a great interval and under such different outer conditions, seemed to me worthy of being noted. (P. 88.) 
M. Forel sees, as we do, the cause of the weakness of muscular contractions during mountain sickness, in the exhaustion of the oxygen of the muscle, and not in the consumption of the carbon compound reserves of the organism, and he expresses himself excellently on this subject:

We can reproduce the special fatigue of mountain sickness on the plain by running rapidly up a very steep slope, a hundred stair steps; for example, l'Escalier-du-Marché, at Lausanne, often served me for this experiment. Getting near the top, one stops out of breath, fincapable of taking a step, a prey to violent palpitations, asphyxiated, worn out, but especially incapable of taking a step, or raising the leg. One is suffering from mountain sickness in all its perfection. Now in this case, the work performed is not very considerable; it is far from exhausting the reserve of combustible materials of the organism. But this work is done very rapidly; this expenditure of strength is completed in a few minutes; it exhausts the reserve of oxygen, and even though the air is not rarefied as it is on a high mountain, we are asphyxiated. (P. 92.)

The memoir from which we have borrowed this contains the very interesting accounts of ascents made by $\mathbf{M}$. Forel at the Gorner-Graat (July 4, 1873; 3136 meters), and at the Sattel Tolle, on Monte Rosa (July 7, 1873; 4300 meters). It is a strange thing, but one which will not surprise our readers too much, that our traveller suffered very definitely from mountain sickness in the first ascent, and was only slightly indisposed during the second, in which, however, he mounted much higher.

Here, in fact, is what he says of his journey to the Gorner-Graat:

5:45. In my bed at Zermatt, temperature $36.75^{\circ}$.

11:45. Arrival at the hotel of the Riffel: $38.62^{\circ}$.

1:45. After lunch, $37.70^{\circ}$.

Excursion to the Gorner-Graat. Very slow walk to the col of the Riffel (2780 meters). I am much affected by mountain sickness. Difficulty in breathing. Flatulence. Nausea. Headache. Sleepy. Very weak pulse. Respiratory rate 24 , very deep. Pulse 93.

I make a sphygmographic record. (Fig. 82.)

Heart impulse very weak, very slow, dicrotism. Wretched pulse. Siesta for a half-hour.

On the way to the Gorner-Graat, pulse 144. I drink some drops of cherry water and the uneasiness disappears.

4:20. Arrived at summit of the Gorner-Graat (3136 meters). $38.36^{\circ}$.

Pulse 126, respiratory rate 30 . (P. 109.)

On the contrary, the ascent of the Sattel Tolle was hardly painful at all: 
1:20. 2509 meters. Awoke at the hotel of the Riffel; temperature $37.10^{\circ}$.

4:30. 2850 meters. Temperature $38.14^{\circ}$; pulse 80 ; respiratory rate 34.

6:00. 3300 meters. Above this point, I begin to suffer from respiratory inconvenience and headache, my head seems encircled in a ring. Our ascent is very slow partly because of this oppression, partly

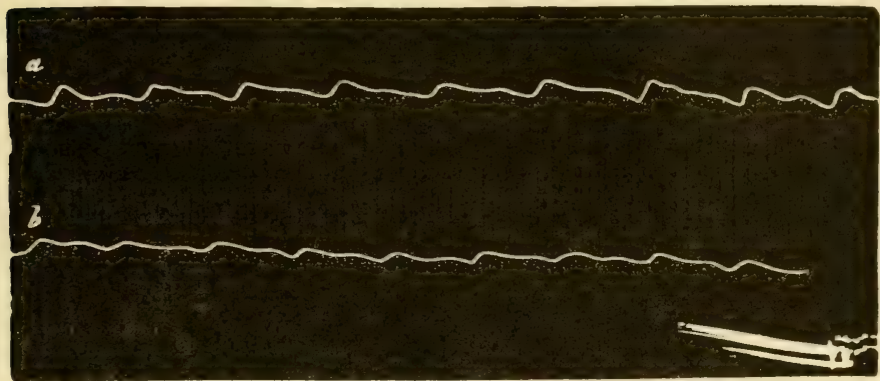

Fig. 82-Pulse at the Riffel Pass $(2780 \mathrm{~m}$.), during mountain sickness (ascent of July 4).

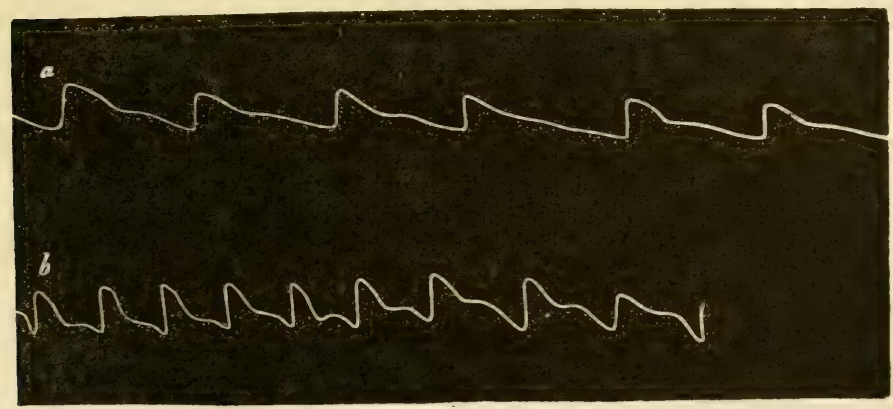

Fig. 83 -Pulse at the Sattel-Tolle $(4300 \mathrm{~m}$.): on arrival $(a)$; after a halfhour of relative rest (b) (ascent of July 7).

because of the horrid state of the snow into which we sink at every step up to the knees.

$6: 35$. Respiratory distress increases; temperature $38.44^{\circ}$; pulse 100 ; respiratory rate 32 .

7:45. 3700 meters. During the climb; temperature $38.25^{\circ}$; pulse 102; respiratory rate 42 .

8.07: 3800 meters. Nausea; third lunch; pulse 80 ; respiratory rate 24 ; dyspnea. 
We begin the ascent of the Botzer Tolle, which we make at one stretch, except for a halt of a few minutes half way up. As we climb I see disappearing one after the other most of the symptoms of mountain sickness from which I had been suffering.

9:50. 4300 meters. At the Sattel Tolle, halt; temperature $38.59^{\circ}$; pulse 80 ; respiratory rate 38 .

10:00. The same; pulse 70 .

10:35. Pulse, 104 to 120; fourth lunch.

10:50. Great irregularity of pulse which is at 86 ; that of my guides is 102 and 108, irregular.

Descent.

3:00. Arrived at the Riffel.

4:00. Temperature $37.87^{\circ}$; pulse 93 ; respiratory rate 28 .

$3: 45$ in the morning at Zermatt (1620 meters) in my bed; temperature $37.32^{\circ}$. (P. 102.)

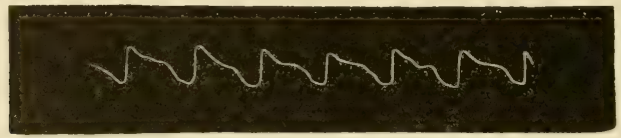

Fig. 84-Pulse at the Riffel $(2569 \mathrm{~m}$.), rest on the return trip (ascent of July 7 ).

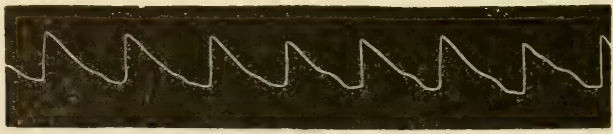

Fig. 85-Pulse at Morges (380 m.), absolute repose (July 10).

I add here, for the sake of comparison, a sphymographic record taken by M. Forel on his return to Morges (380 meters) July 10.

M. Forel attributes the differences between the sufferings of the two ascents to becoming accustomed to the mountains, to the training due to the three days stay at the Riffel (2500 meters):

Each year (he says) I suffered more in my first ascent of the summer than in following expeditions. So, in 1865, I was very much affected by mountain sickness on the col of the Géant at 3400 meters. It was my first ascent; but six days after, trained as I was by successive passages of the cols of the Geant, of Joux, of Ranzola, of Ollen and of Turlo, I made the passage of Weissthor, 3610 meters, without suffering at all from the altitude. (P. 108.)

We ourselves made similar reflections (see page 324 ). The disappearance of symptoms during the ascent of the Botzer Tolle is a very interesting fact; $M$. Forel explains it in a very original manner: 
In preparing for my expedition, I had taken care to get information from everyone familiar with Monte Rosa as to the point where the greatest suffering from mountain sickness is experienced. It is well known that each mountain has its special locality in reference to this; it is not generally on the summit, which is very airy and windy, or on the dangerous or interesting ridges that the sickness is most felt; it is particularly on snowy slopes, hollowed out, well protected against the winds, and tiresome; as example I shall mention the corridor of Mont Blanc. All the reports made to me were unanimous; it was on the Botzer Tolle, before reaching the Sattel, that all the travellers, and even the guides often, were affected. On the ridge of the summit, on the contrary, no one has the slightest idea of suffering from mountain sickness. I prepared therefore to study carefully this Botzer Tolle. I had its beginning indicated by the guides, and forced myself from that point to climb rapidly and without stopping, so as to heighten by fatigue the symptoms from which I was suffering before approaching it. But-strange thing-I saw these symptoms disappear one after the other; as soon as I directed my attention especially to one of them, I felt it lessening. Fatigue, lassitude, depression, headache, left me one after the other, and I made this tiresome passage in perfectly good condition, to the amazement of my guides, who had seen me painfully affected in regions much less dangerous to other travellers. Attention, scientific interest then had for me in this case the same curative effect that danger possesses; no one suffers from mountain sickness in dangerous passages.

This effect on mountain sickness of the morale and of particular attention ought to be pointed out, and deserves to have much more consideration than it has received until now in the study of this malady. I merely indicate it here. (P. 110.)

The temperature of the body, we see by the figures given above, was maintained at its original degree, or even rose above it, during muscular efforts; at any rate, no decrease has been observed. But we must mention the fact that, precisely during the attack of mountain sickness, that is, at the interesting moment, the temperature was not taken. M. Forel, who mentions this omission himself, gives "this negligence as a proof of the physical and mental distress which he was feeling then." (Page 109.)

Two English travellers, having read the work of Dr. Forel, published the notes which they had previously taken on the variations of their buccal temperature during mountain ascents.

M. Thorpe ${ }^{8}$ reached negative results. His ascent consisted of climbing from Catana to Zaffarana: the buccal temperature showed itself invariably $98.4 \mathrm{~F}$.; the pulse rose from 78 to 83 .

M. Tempest Anderson, ${ }^{9}$ on the contrary, said that he had observed a considerable drop in the buccal temperature during the very act of ascent; he asserts that he guarded against all causes of 
error and had previously trained himself in thermometric readings; the thermometer remained five minutes under the tongue. Here is the summary of his observations, made in the hills of Yorkshire:

Table of M. Tempest Anderson.

Time Height Temp. F. (Eng. feet)

In bed 900 $97.7^{\circ}$

Before starting, being cold $9: 40$

After a mile walk on the plain, and a rapid ascent of 1000 feet, tired, hot, sweating, and before stopping $11: 20$

1900 $96.4^{\circ}$

Seated, after 10 minutes, neither hot nor cold $11: 30$

1900 $98.2^{\circ}$

Rapid ascent to the summit, which I reach sweating, unable to breathe 12:00

2414 $97.6^{\circ}$

Seated, having eaten a little, and finding the wind cold $99.3^{\circ}$

Rapid descent of 1000 feet, hot, without stopping

1400 $98.0^{\circ}$

Crossed the valley to climb Grageth; after an ascent of 500 feet, hot, sweating, and without stopping

$\begin{array}{rrr}2: 17 & 1900 & 96.4^{\circ} \\ 2: 24 & 1900 & 97.6^{\circ} \\ 2: 33 & 1900 & 98.6^{\circ} \\ 2: 52 & 2250 & 98.2^{\circ} \\ 3: 12 & 2250 & 98.4^{\circ} \\ 3: 55 & 1200 & 98.0^{\circ} \\ 4: 05 & 1200 & 98.0^{\circ} \\ 9: 50 & 500 & 97.9^{\circ}\end{array}$

Seated

Seated, cold

At the top of Grageth, walking slowly --

Seated, cold

After descending rapidly 1000 feet

Seated

At the inn of the "George and Dragon" -9.50
So the minimum temperature of 96.4 was observed during the

At the inn of the "George and Dragon" -9.50
So the minimum temperature of 96.4 was observed during the

At the inn of the "George and Dragon" -9.50
So the minimum temperature of 96.4 was observed during the ascent, sweating freely, with a sensation of heat.

I agree with Dr. Marcet, that it is the fact of the ascent and not the altitude in itself that influences the temperature.

A single theory can, according to M. Anderson, include apparently contradictory cases, like those of M. Marcet and M. Forel. The human machine, he says, has not the same output in all men. The quantity of heat necessary for the work of the ascent can in certain individuals be developed through greater activity in combustion; it may be that others are incapable of this increase of oxidation:

In the first class one would place M. Forel; in the other, that of persons with weak powers of combustion, I place myself in the honorable company of Doctors Marcet and Lortet. 
Table XXI

\begin{tabular}{|c|c|c|c|c|c|c|c|c|c|c|}
\hline \multirow{2}{*}{$\begin{array}{c}\text { Elevation } \\
\text { meters }\end{array}$} & \multirow[t]{2}{*}{ Time } & \multirow{2}{*}{$\begin{array}{l}\text { Temp. } \\
\text { of air }\end{array}$} & Calberla & Age 26 & Peter & Bohren & Age & 54 Peter & Miiller. & 32 \\
\hline & & & lemp. & ruise & lemp. & Pulse & R. & 'Temp. & Pulse & R. \\
\hline 1638 & $12: 30$ & & $37.0^{\circ}$ & 80 & & 76 & 16 & & 80 & 18 \\
\hline 2 & 3 & $+2.0^{\circ}$ & & 104 & $36.8^{\circ}$ & 100 & 28 & $37.4^{\circ}$ & 108 & 28 \\
\hline 81 & $4: 5$ & $-1.4^{\circ}$ & $37.4^{\circ}$ & 100 & & 96 & 30 & & 108 & 28 \\
\hline 3302 & $5: 55$ & $-1.6^{\circ}$ & & 112 & $37.0^{\circ}$ & 104 & 30 & $37.2^{\circ}$ & 104 & 30 \\
\hline 3521 & $6:$ & $+1.8^{\circ}$ & $37.2^{\circ}$ & 108 & & 108 & 30 & & 112 & 32 \\
\hline 3780 & 8: & $+2.0^{\circ}$ & - & 108 & $36.8^{\circ}$ & 112 & 26 & $37.0^{\circ}$ & 112 & 30 \\
\hline 3817 & $8: 5$ & $+4.5^{\circ}$ & $37.4^{\circ}$ & 112 & & 108 & 26 & & 112 & 28 \\
\hline 4008 & $9: 3$ & $+4.8^{\circ}$ & & 124 & $36.8^{\circ}$ & 116 & 32 & $37.5^{\circ}$ & 120 & 30 \\
\hline 4358 & $10: 4$ & $+3.6^{\circ}$ & $37.5^{\circ}$ & 132 & & 116 & 30 & & 120 & 28 \\
\hline $11: 00$ & (halt) & $+4.1^{\circ}$ & — & 92 & $36.4^{\circ}$ & 88 & 20 & $37.0^{\circ}$ & 100 & 22 \\
\hline 4462 & $11: 50$ & $+0.2^{\circ}$ & $37.2^{\circ}$ & 112 & & 112 & 28 & & & 30 \\
\hline 4553 & $12: 06$ & $-0.4^{\circ}$ & & 136 & $36.8^{\circ}$ & 120 & 30 & $37.2^{\circ}$ & 124 & 34 \\
\hline 4695 (Summit) & $12: 55$ & $+3.8^{\circ}$ & $37.4^{\circ}$ & 124 & $37.2^{\circ}$ & 120 & 28 & $37.2^{\circ}$ & 124 & 34 \\
\hline 4663 (after rest) & ) $2: 00$ & $+4.8^{\circ}$ & $36.8^{\circ}$ & 88 & $36.8^{\circ}$ & 80 & 18 & $36.8^{\circ}$ & 96 & 20 \\
\hline 4374 & $3: 55$ & $+4.6^{\circ}$ & & 124 & $37.0^{\circ}$ & 96 & 24 & $37.2^{\circ}$ & 116 & \\
\hline & & $+5.2^{\circ}$ & 37. & 140 & & 128 & 32 & & 128 & 6 \\
\hline 1 & $9:$ & & $36.8^{\circ}$ & 92 & $36.9^{\circ}$ & 88 & 18 & $37.2^{\circ}$ & 92 & 8 \\
\hline
\end{tabular}

A German traveller, Calberla, published observations of the same sort ${ }^{10}$ taken on Monte Rosa. The table above (Table XXI) summarizes the observations made on himself and two guides; the temperatures were taken in the rectum, even while walking.

The variations in respiratory and pulse rate agree with all that was already known. As for the temperatures, we see that they varied, for Calberla and P. Müller, from $36.8^{\circ}$ to $37.5^{\circ}$; for P. Bohren, from $36.4^{\circ}$ to $37.2^{\circ}$. During the ascent, the temperature kept rising; the minimum observed was during a halt, at 4371 meters, or after the rest on the summit of Monte Rosa, the temperature of the air being $+4.8^{\circ}$.

Professor L. Thomas, in a note joined to the Mémoire of Calberla, says that he had measured his temperature under the tongue for several years at Roccia Melone (3550 meters), at Levanna (3750 meters), at the Grand Pelvoux (3954 meters), without ever having observed a lowering of temperature from the ascent.

But we must note that all these observations leave out entirely the question of what would happen if the observers had really suffered from the altitude; one point then still remains obscure, to which I call the attention of scientific travellers: does the temperature decrease from the act of ascent during a really pronounced attack of mountain sickness? But I must insist again on the precautions to be taken in the use of the buccal thermometer: at least two minutes of application under the tongue are necessary, according to the observations of M. Thorpe. And even so, the causes of error are such that it is best to take the temperature in the rectum, using maximum thermometers.

I shall quote also, as a document interesting for our subject, some extracts from a letter which I received from Dr. Ward, who 
was attached as physician to the railroad construction over the Andes, from Callao to Oroya:

Almost all the men who worked on the tunnel, except natives born on the mountain, suffered more or less severely from the decrease of pressure; however almost all became accustomed to this influence quite rapidly, that is, after one or two weeks. Animals suffered as did the men.

The natives are short, stocky men, with an immense lung capacity, as is proved by the following measurements, taken on the bare skin, on the level of the nipples.

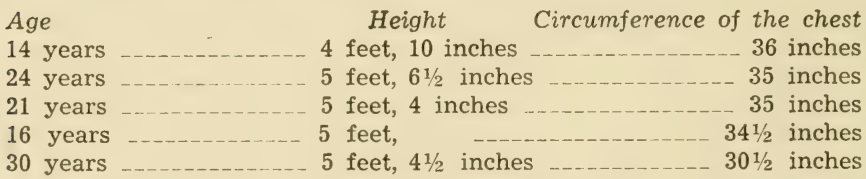

These men eat dry wheat, coca, coarse sugar, potatoes, with little or more often no meat. With a handful of grain and coca, they can work a whole day without giving any sign of fatigue.

M. Malinowski, engineer at Lima, sending me the letter from Dr. Ward, adds:

A North-American, assistant engineer, having made a visit to the tunnel one day, was attacked there by the sorroche very violently. He was hurried to a place about 1000 meters lower in elevation, but he soon died.

Dr. Vacher ${ }^{11}$ has published an interesting study on the medical stations of Davos (1650 meters), in the Grisons, and of Mont Dore (1050 meters) in Auvergne. He observes, as many of his predecessors have done, the immunity to consumption of the population of these elevated regions, and studies the question of the treatment of this dreadful disease by the height cure. For our present topic, we shall quote only the following observations:

1. At Davos, the heart rate is noticeably higher than on the plain; at Paris, my pulse rate is 69 ; at Davos, 78 . It is to this phenomenon that the unsuitable name of "altitude fever" is given .... It continues during the whole stay in this station, which distinguishes it from the phenomena of excitation produced by mineral waters.

2. The functions of the lung are equally modified in this rarefied medium, where a considerable amelioration of respiratory movements is observed. Dr. Spengler asserts that in the atmosphere of Davos the lung makes up for the deficiency of oxygen by deeper and slower inspirations than in normal conditions of pressure. It is quite true that at the altitude of 1650 meters there is a considerable lack of oxygen in the air, but observation proves that it is not by deeper or 
more prolonged inspirations that the lung makes up for this deficit, but by more frequent respiratory movements. At Davos, where I observed myself carefully for several days, I noted 18.2 respiratory movements per minute, while at Paris I have only 16.6. (P. 12.)

As first sign of improvement in the thoracic symptoms of consumption, we observe at Davos an increase of respiratory capacity, measured by aid of the spirometer, an instrument used at present in this station (P. 13.)

On March 22, 1874, Crocé-Spinelli and Sivel made their first flight at great height, in which, encouraged by the result of trials made in our cylinders, they took along bags of oxygen, so as to overcome the effects of the decompression by breathing this gas. The Polar Star, in which they made the ascension, a balloon of 2800 cubic meters, took them in two hours to a height of 7300 meters. I quote here the part of their account ${ }^{12}$ which applies to our subject:

We felt in our flight impressions similar to those which we had experienced in the decompression bells of M. Bert, in which several days before the ascension we were taken down to a pressure of 304 millimeters. However, in the basket, in which we reached 300 millimeters, the discomfort was much keener than in the bell, which should be attributed to the harder work done, to the great drop in temperature, and to the duration of our stay in the upper strata. While in the basket we underwent cold of -22 to -24 degrees, we had a constant temperature of +13 during the decompression on earth; furthermore, the sojourn in the bell lasted only an hour, which is almost the duration of that part of lofty ascensions which is above 7000 meters, whereas we remained in the air 2 hours and 40 minutes, and one hour and 45 minutes above 5000 meters. Moreover, in the bell, the pure oxygen which we were breathing caused dizzy spells like those of drunkenness, whereas on the contrary we were very comfortable with the two mixtures, one of $40 \%$ oxygen and $60 \%$ nitrogen, and the other of $70 \%$ oxygen and $30 \%$ nitrogen, which M. Bert had furnished us for our ascent.

We began to breathe the $40 \%$ mixture at 3600 meters, and continued to 6000 meters; we resorted to that of $70 \%$ for the great heights, because the less rich was insufficient, particularly for $\mathbf{M}$. Crocé-Spinelli. In the most rarefied regions, we both had to leave in our mouths the rubber tubes connected with the gas bags. We breathed thus from time to time, taking care to grip between our teeth the elastic tube when we felt better. When M. Sivel threw out ballast, which prevented him from breathing gas, the 15 kilogram bags seemed to him to weigh 100 .

For M. Crocé-Spinelli, of lymphatico-nervous temperament, the effects were quite different than for M. Sivel, a very vigorous man, of sanguine temperament. When the former was no longer breathing oxygen, he was obliged to sit down on a bag of ballast and make his observations, motionless in that position. During the absorption of 
oxygen, he felt revived, and after about ten inhalations, he could rise, chat gaily, look at the ground attentively, and make delicate observations. His mind was keen and his memory excellent. To look into the spectroscope he had to breathe this gas, rightly called vital; the lines, at first confused, then became very clear.

The oxygen also produced in M. Crocé-Spinelli an effect whose explanation is easy, after what has just been said. To react against the combined effects of cold and rarefaction, he tried to eat. The result was not favorable at first; but when he had the idea of breathing oxygen at the same time, he felt his appetite return and his digestion working smoothly. As for his pulse, it was 140 beats before absorption and 120 immediately after, between the elevations of 6560 and 7400 meters. His pulse on the ground is 80 , on the average.

Neither of us had the bleeding from the nose, lips, and ears of which Gay-Lussac ${ }^{13}$ had complained, although our faces were very red and the mucous membrane almost black. At times, as in the bell, we felt heat in our faces and pricklings in our heads. At times, our foreheads seemed clamped in a vice, and there was a sensation of a solid bar of small size pressing hard above the eyebrow. An inhalation of oxygen dispelled most of these painful sensations.

The descent was made almost without ballast and without oxygen; the provision, of which M. Crocé-Spinelli had absorbed almost two thirds, was exhausted. About 4000 meters, when the temperature had risen to $-7^{\circ}$, M. Sivel was seized with a very strong tremor and extreme discomfort. His face was contracted, and his mouth was opened in a kind of rictus. His companion, though less vigorous, at the time felt only a very keen cold produced by the rapid passage through the air. While at $-22^{\circ}$, we both felt only a rather slight sensation of cold, because the air was calm; we were shivering in the rapid descent. Besides there was certainly another cause of the discomfort of M. Sivel; perhaps he had worked too hard. This discomfort disappeared at 2500 meters.

We had companions in the basket; we took along carrier pigeons, which had been lent us by M. Van Roosbecke. Four pigeons, chosen among the best carriers, were in a cage, with the feather prepared which was to receive the dispatch. They seemed very uncomfortable at lofty elevations; they leaned on their bellies and had their eyelids closed.

The first pigeon was thrown out at 5000 meters, half an hour after the start. At first it flapped its wings, and tried for some time to get up on its cage, then, seeing that its efforts were in vain, it descended with its wings spread out, describing circles of 200 to 300 meters in diameter, with a terrifying speed of about 40 to 50 meters per second. That is the only one that returned with its dispatch, and it took more than 30 hours to get to its destination. The second, thrown out after the start, at about 5200 meters, behaved in the same way. However, it had the strength to fly up on its cage.

We call special attention to the favorable effects of inhalations of oxygen. Return of strength and appetite, decrease of headache, restoration of clear vision, calmness, presence of mind, all the phe- 
nomena already observed in the cylinders of my laboratory were reproduced with a certainty that, under the dramatic circumstances, was very striking and inspired in the two aeronauts a reckless confidence, which proved fatal to them.

April 15, 1875, they began another ascent to great heights, taking with them M. Gaston Tissandier. To the ring of the balloon were fastened three gas bags filled with a mixture of $72 \%$ of oxygen. These gas bags, I can say today, were quite insufficient in capacity. I was then absent from Paris, and warned by a letter from CrocéSpinelli of their coming expedition, a letter in which he specified the quantity of oxygen which they were going to take with them (it was to be, I think, 150 liters), I warned him of its insufficiency. "In the lofty elevations where this artificial respiration will be indispensable to you," I said to him, "for three men you should count on a consumption of at least 20 liters per minute; see how soon your supply will be exhausted!" My letter arrived too late, it seems; the day of the ascension was set, and they drew from my observations only this conclusion which was so fatal, that they should wait for absolute necessity to make use of the gas bags. We know what happened; when the aeronauts, feeling asphyxia overcome them, tried to seize the life-giving tubes, their arms were paralyzed.

M. Gaston Tissandier, the only survivor of the Zenith catastrophe, wrote ${ }^{14}$ a powerful account of it from which I shall borrow freely:

Thursday, April 15, 1875, at 11:35 in the morning, the balloon Zenith rose from the ground at the gas works of La Villette. CrocéSpinelli, Sivel, and I had taken our places in the basket. Three gas bags filled with a mixture of air with $70 \%$ of oxygen were fastened to the ring. At the lower end of each of them, a rubber tube passed through a wash-bottle filled with an aromatic liquid. This apparatus, in the upper regions of the atmosphere, was to furnish to the travellers the oxygen necessary to maintain life. An aspirator bottle filled with petrol, which the low temperature cannot solidify, was hung outside the basket; it was to be suspended vertically at a height of 3000 meters to force air into the potash tubes intended for the determinations of the carbonic acid.... of hope!

We start, we rise in the midst of a flood of light, emblem of joy,

Three hours after the departure, Sivel and Crocé-Spinelli were inanimate in the basket! At 8000 meters altitude, asphyxia had struck with death these disciples of science and truth!

It is for their travelling companion, who miraculously escaped death, to close his heart to grief for a moment, to drive away sad memories and gloomy visions, so that he can report the data gathered 
during the expedition, and tell what he knows of the death of his unfortunate and glorious friends ....

At 4300 meters, we begin to breathe oxygen, not because we feel as yet the need of resorting to the gaseous mixture, but merely because we wish to convince ourselves that our apparatuses, so well arranged by $\mathbf{M}$. Limousin, according to the proportions specified by $\mathbf{M}$. Bert, are functioning properly.

I should say that my dear and regretted Crocé-Spinelli had insisted energetically that I should take part in the high elevation ascension that he was at first to make with Sivel alone. M. HervéMangon, president of the Society of Aerial Navigation, and M. Hureau de Villeneuve, secretary general, did not approve this project, simply because they feared, I hasten to add, that Sivel would be deprived of the necessary amount of ballast, since my presence would cause its amount to be lessened. However these gentlemen yielded to the insistence of Crocé-Spinelli. Who could have resisted the charm of his captivating speech and his gaze? "My friend Tissandier", said Crocé to me a few days before the first ascension of the Zenith, "don't worry, you shall go with us. I won't leave you behind", he added, embracing me. "It takes three to make a high elevation ascension to verify the results. And who knows? Something might happen. Six arms are better than four! Besides, you must breathe oxygen in the upper strata to bear witness with us that it is both effective and necessary."

Crocé-Spinelli had an ardent love for the truth, and was so frank and loyal that he could not permit anyone to doubt his statements. At the height of 7000 meters, at 1:20, I breathed the mixture of air and oxygen, and felt my whole being, already oppressed, revive under the action of this cordial; at 7000 meters, I wrote in my notebook the following lines: I breathe oxygen. Excellent effect.

At this height, Sivel, who had unusual strength and a sanguine temperament, began to close his eyes at times, to grow drowsy, and to become a little pale. But this valiant soul did not long abandon itself to weakness: he drew himself up with an expression of firmness; he had me empty the liquid contained in my aspirator after my experiment, and he threw out ballast to reach loftier heights. The year before, Sivel had reached 7300 meters with Crocé-Spinelli. This year he wanted to mount to 8000 meters, and when Sivel used his will-power, it took very great obstacles to hinder his designs.

Croce-Spinelli had for some time been consulting the spectroscope. He seemed to be beaming with joy, and had already cried: "There is complete absence of the lines of water vapor." Then, after having uttered these words, he continued his observations with such ardor that he begged me to write in my notebook the result of his thermometer and barometer readings.

During this rapid ascent, in the midst of numerous occupations, it was difficult for us to give to physiological observations the attention they required. We were saving our strength in this regard for the time when we should have entered the upper regions, without suspecting the fatal outcome which was to paralyze our efforts. It was possible for us, however, to obtain the following results, which we take from the notebooks: 


\begin{tabular}{|c|c|c|c|}
\hline Time & Altitude & & \\
\hline $12: 48$ & 4602 meters & ${ }^{\circ}$ & - Tissandier, pulse 110 \\
\hline $12: 55$ & 5210 meters & & - Crocé, buccal temperature $37.50^{\circ}$. \\
\hline $1: 03$ & 5300 meters & & . Crocé, pulse 120. \\
\hline $1: 0$ & 5300 meters & . & $\begin{array}{l}\text { Tissandier, number of inspirations } \\
\text { determined by Crocé, } 26 \text {. }\end{array}$ \\
\hline $\begin{array}{l}1: 0 \\
1: 0\end{array}$ & $\begin{array}{l}5300 \mathrm{me} \\
5300 \mathrm{me}\end{array}$ & & $\begin{array}{l}\text { - Sivel, pulse } 155 \text {. } \\
\text { - Sivel, buccal temperature } 37.90^{\circ} \text {. }\end{array}$ \\
\hline
\end{tabular}

Here is the average of the observations which had been taken previously on the ground for several days in succession:

$\begin{array}{lccc} & \text { Pulse } & \text { Respiratory Rate Buccal Temperature } \\ \text { Crocé-Spinelli } & 74 \text { to } 85 & 24 & 37.3^{\circ} \\ \text { Sivel } & 76 \text { to } 86 & \text { unknown } & 37.5^{\circ} \\ \text { Tissandier } & 19 \text { to } 23 & 37.4^{\circ}\end{array}$

I come to the fatal hour when we were about to be seized by the terrible influence of the atmospheric decompression. At 7000 meters we are all standing in the basket; Sivel, numbed for a moment, has revived; Crocé-Spinelli is motionless in front of me. "Look", he says to me, "how beautiful these cirrus clouds are!" The sublime spectacle before our eyes was indeed beautiful. Cirrus clouds, in different forms, some long, others rounded, formed a circle of silvery white around us. And leaning out of the basket one could see, as if at the bottom of a well, whose walls were formed by the cirrus clouds and the vapor below, the surface of the earth which appeared in the abysses of the atmosphere. The sky, far from being dark or black, was a clear and limpid blue; the glowing sun burned our faces. However the cold had already begun to be felt, and we had already wrapped ourselves up. Numbness had seized me; my hands were cold, icy. I wanted to put on my fur gloves; but without my realizing it, the action of taking them from my pocket demanded an effort which I could no longer make.

At this height of 7000 meters, however, I was writing in my notebook almost mechanically; I copy verbatim the following lines, which were written without my having a clear memory of them at present; they are nearly illegible, written by a hand which the cold caused to tremble strangely:

"My hands are icy. I am well. We are well. Vapor on the horizon with little rounded cirrus clouds. We are rising. Crocé is panting. We breathe oxygen. Sivel closes his eyes. Crocé also closes his eyes. I empty the aspirator. Temp. $-10^{\circ} .1: 20 . \mathrm{H}=320 \mathrm{~mm}$. Sivel is drowsy . . 1:25. Temp. $-11^{\circ}, \mathrm{H}=300 \mathrm{~mm}$. Sivel throws out ballast. Sivel throws out ballast." The last words are hardly legible.

Sivel, in fact, who had remained for some instants thoughtful and motionless, sometimes closing his eyes, had no doubt just remembered that he wanted to pass above the limits where the Zenith was then soaring. He drew himself up, his energetic face lighted up suddenly with unusual animation; he turned towards me and said to me: "What is the pressure?" - " 30 centimeters (about 7450 meters altitude)". "We have plenty of ballast, shall I throw some out?" - I answered, "Do as you please". - He turns to Crocé and asks him the 
same question. Crocé nods his head with a very energetic sign of affirmation.

There were in the basket at least five bags of ballast; there were about as many more hung outside on cords. The latter, I should add, were not entirely filled; Sivel had certainly ascertained their weight, but it is impossible for us to make an estimate of it.

Sivel seized his knife and cut three cords successively; the three bags emptied and we rose rapidly. The last very clear memory which remains to me of the ascent goes back to a moment a little before this. Crocé-Spinelli was seated, holding in his hand the wash-bottle of the oxygen; his head was slightly bent and he seemed oppressed. I still had the strength to strike with my finger the aneroid barometer to help the movement of its needle; Sivel had just raised his hand to-

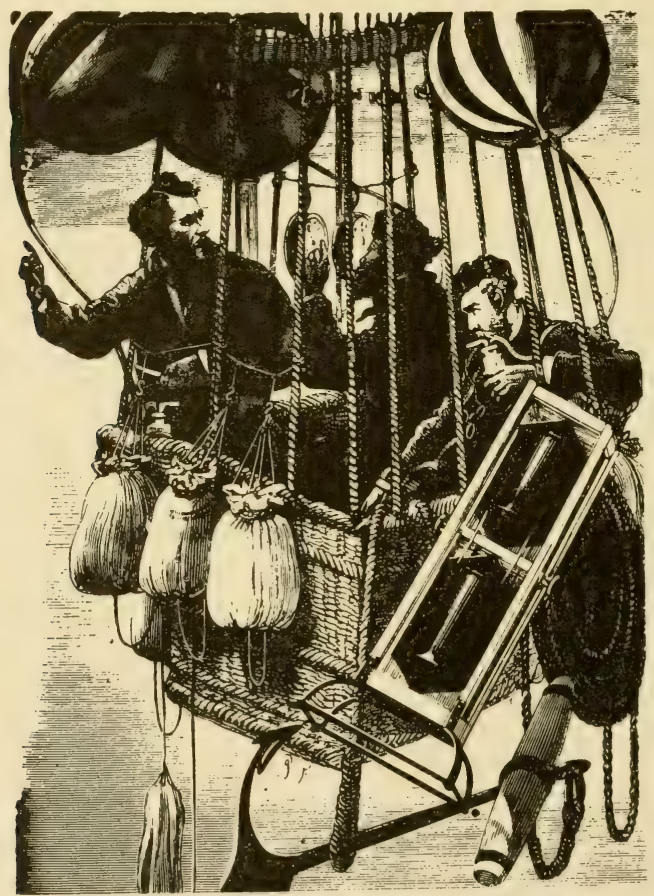

Fig. 86-The basket of the Zenith at a high altitude.

Sivel

cuts the cords which hold to the basket the ballast bags full of sand.
G. Tissandier observes the barometers.
Crocé-Spinelli after making the spectroscopic observations, is about to breathe oxygen. 
wards heaven as if to point out the upper regions of the atmosphere. Fig 86 reproduces as exactly as possible the appearance of the basket of the Zenith at this solemn moment.

But soon I was keeping absolutely motionless, without suspecting that perhaps I had already lost use of my movements. Towards 7500 meters, the numbness one experiences is extraordinary. The body and the mind weaken little by little, gradually, unconsciously, without one's knowledge. One does not suffer at all; on the contrary. One experiences inner joy, as if it were an effect of the inundating flood of light. One becomes indifferent; one no longer thinks of the perilous situation or of the danger; one risès and is happy to rise. Vertigo of lofty regions is not a vain word. But as far as I can judge by my personal impressions, this vertigo appears at the last moment; it immediately precedes annihilation, sudden, unexpected, irresistible.

When Sivel had cut the three bags of ballast, at the altitude of 7450 meters, that is, at the pressure of $300 \mathrm{~mm}$. (that is the last figure I wrote in my notebook), I think I remember that he sat down on the bottom of the basket, and took almost the same position as CrocéSpinelli. As for me, I was leaning in the angle of the basket, where I succeeded in standing only by the help of this support. I soon felt so weak that I could not even turn my head to look at my companions.

Soon I wanted to seize the oxygen tube, but could not raise my arm. My mind, however, was still very lucid. I was still looking at the barometer; my eyes were fixed on the needle which soon reached the pressure number of 290 , then 280 , beyond which it passed.

I wanted to cry out, "We are at 8000 meters!" But my tongue was paralyzed. Suddenly I closed my eyes and fell inert, entirely losing consciousness. It was about $1: 30$.

At 2:08, I awoke for a moment. The balloon was descending rapidly. I succeeded in cutting a bag of ballast to check the speed, and in writing in my notebook the following lines, which I copy:

"We are descending; temperature $-8^{\circ}$; I am throwing out ballast, $\mathrm{H}=315 \mathrm{~mm}$. We are descending. Sivel and Crocé still unconscious at the bottom of the basket. Descending very rapidly."

Hardly had I written these lines when a sort of trembling seized me and I fell inanimate again. The wind was blowing violently upward, and indicated a very rapid descent. Some moments after, I felt myself shaken by the arm, and recognized Crocé, who had revived. "Throw out some ballast", he said to me, "we are descending." But I could hardly open my eyes, and did not see whether Sivel had awakened.

I remember that Crocé had unfastened the aspirator which he threw overboard, and that he threw out ballast, wraps, etc. All that is an extremely confused memory which soon ended, for I fell back into my inertia still more completely than before, and it seems to me that I went into an eternal sleep.

What happened? It is certain that the balloon freed of ballast, impermeable as it was and very warm, mounted once more into the upper strata.

At about $3: 30$, I opened my eyes again, I felt numb, weak, but my mind was active. The balloon was descending with terrifying 
speed; the basket was swinging violently and describing great oscillations. I dragged myself on my knees and pulled both Sivel and Crocé by the arm. "Sivel! Crocé!", I cried, "wake up!"

My two companions were crouched in the basket, their heads hidden under their travelling rugs. I assembled my strength and tried to raise them. Sivel's face was black, his eyes dull, his mouth open and full of blood. Crocé's eyes were half shut and his mouth bloody.

To tell in detail what happened then is impossible. I felt a terrible wind rushing upward. We were still at an altitude of 6000 meters. There were in the basket two bags of ballast which I threw out. Soon the earth drew near, I wanted my knife to cut the rope of the anchor: impossible to find it. I was frantic, I kept crying: "Sivel! Sivel!"

Luckily, I succeeded in finding my knife and unfastening the anchor at the right moment. The shock as we struck the ground was extremely violent. The balloon seemed to be flattened and I thought that it was going to remain where it was, but the wind was strong and carried it away. The anchor did not hold and the basket slid flat over the fields; the bodies of my unhappy friends were jostled this way and that, and at every moment I thought that they would fall out. However I got hold of the valve cord, and the balloon soon emptied, then ripped against a tree. It was four o'clock.

As I set foot on the ground, I was seized by a feverish excitement, and fainted, growing livid. I thought I was going to join my friends in the other world.

However I recovered little by little. I went to my unhappy companions, who were already cold and rigid. I had their bodies sheltered in a neighboring barn. Sobs choked me!

The descent of the Zenith took place in the plains near Ciron (Indre), 250 kilometers from Paris in a direct line. . . .

After having reviewed the story of the ascension of the Zenith, I come to two important points which have keenly occupied the attention of scientists and the public.

What is the maximum altitude reached by the Zenith?

What is the cause of the death of Croce-Spinelli and Sivel?

The first question is settled today by the opening of the barometric tubes (as evidence) contrived by M. Janssen, and used before by Sivel and Crocé-Spinelli in their ascent to 7300 meters (March 22,1874 ).

One tube had broken, others had met with accidents or worked badly, but there were two which had functioned properly, and which furnished us with results that checked. They tend to show that the lowest pressure was 264 to 262 millimeters, which sets the maximum height at 8540 to 8601 meters (correction made for pressure at the ground level).

As at the moment of my unconsciousness, at 8000 meters, the needle of the barometer was passing rapidly over the pressure number of 28 (8002 meters) and indicating thus an ascent of great speed, I am convinced that we reached this altitude of 8600 meters in the first ascent. After the first descent, Crocé-Spinelli and very certainly Sivel were still alive; they were struck by death when the balloon 
reached for a second time the high levels which it had just left, but which it was not to pass beyond, its weight and volume certainly not permitting it to mount higher.

I do not think it doubtful that the death of these unfortunate men is the consequence of the atmospheric decompression; it is possible to endure for a very short time the action of this decompression; it is difficult to undergo its effect time after time during nearly two almost consecutive hours. Our sojourn in the upper strata was, in fact, much longer than that of any preceding ascension to the higher elevations. I will add that the air, which was particularly dry, possibly had a dangerous effect.

It will be asked now what was the cause of my own safety. I probably owe my life to my peculiar temperament, essentially lymphatic, perhaps to my complete unconsciousness, a sort of pause of the respiratory functions. I was fasting at the moment of our start, and I thought at first that this circumstance was peculiar to me, but I have since had proof that if Sivel had eaten, Crocé, like me, had almost no food in his stomach.

The decompression is considerable at the height of 8600 meters, since the mercury column of the barometer is at only about $26 \mathrm{~cm}$.

I am convinced that Crocé-Spinelli and Sivel would still be living, in spite of their prolonged sojourn in the higher strata, if they had been able to breathe oxygen. Like me, they must have suddenly lost power of movement. The tubes conducting the vital air must have slipped from their paralyzed hands! But these noble victims have opened new horizons to scientific investigation; these soldiers of science in death have pointed out the dangers of the way, so that their successors may know how to foresee and avoid them.

M. G. Tissandier has tried to represent by the accompanying diagram (Fig. 87) the course of the balloon, which, as we see, described in space a sort of gigantic M, 8600 meters high. The dotted part of the curve represents the second phase of the ascension; probably it is very like the real graph. It is during this part of the voyage that Crocé-Spinelli and Sivel lost their lives, in the midst of these icy deserts of the high atmospheric levels!

I think it worth while to reproduce here some extracts from an account drawn up by M. Limousin, a distinguished pharmacist, ${ }^{15}$ who had been commissioned to furnish the oxygen necessary for filling the gas bags:

In order to prevent the probable rupture of the goldbeater's skin as a result of the expansion of the gas at a high altitude, only 100 liters of the mixture (oxygen 65; air, 35) were put in each gas bag, whose capacity was about 200 liters.

To neutralize as much as possible the detestable smell which the greased goldbeater's skin gave the gaseous mixture, I put in for each balloonist very small wash bottles provided with a curved tube furnished with rubber so that they could be held in the mouth like a 
pipe, leaving the hands free to put down observations in a notebook. With this arrangement, the gas, passing through water flavored with benzoin, reached the lungs fresh and perfumed.

Unfortunately, all these precautions were, if not useless, at least of very little use. Because of the speed of their upward flight and

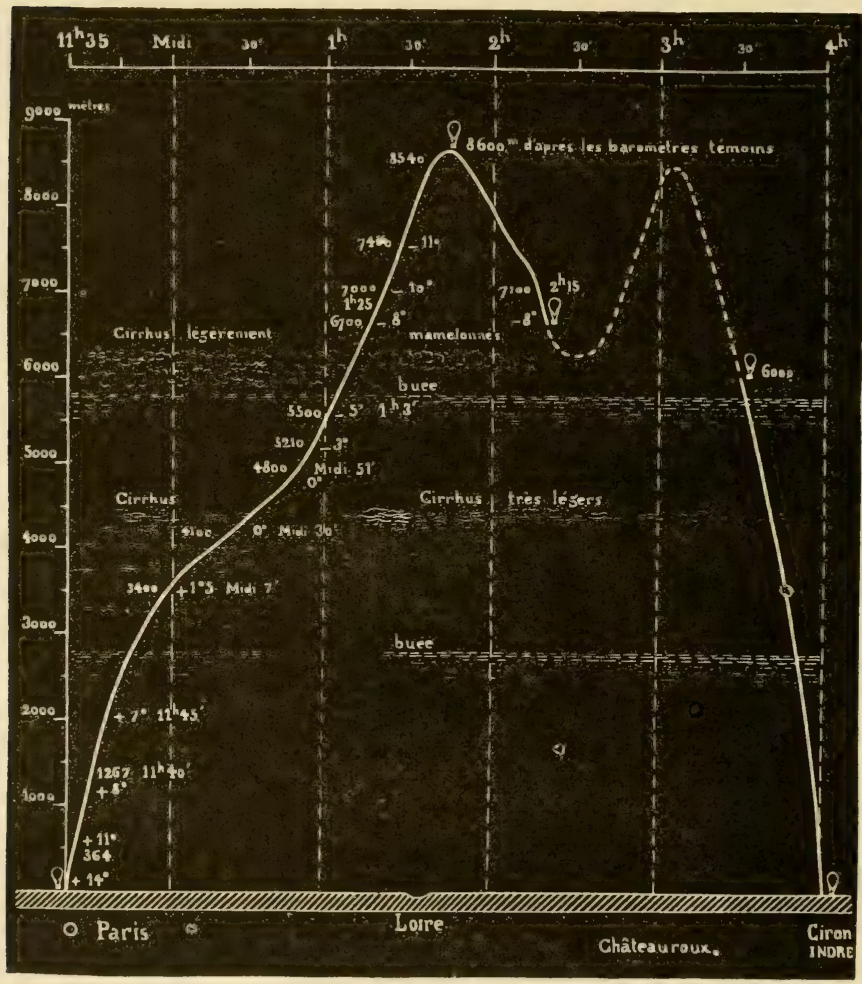

Fig. 87-Diagram of the high altitude ascent of April 15, 1875.

the sudden collapse of the aeronauts, the inhalations could not be made at the moment when they were most indispensable.

M. Gaston Tissandier, who at first had experienced its good effects, could not , at one moment, find enough energy to raise his hand to reach the inhalation tube. On his return, he assured me that at the time of descent of the balloon, which took place, as we know, at Ciron, near Le Blanc, in Indre, the gas bags were fastened below the 
basket, still containing the larger part of the oxygen that had been put into them.

And so we see that the only means that could have averted the terrible catastrophe which ended this ascension could not be used ....

Commissioned by the Society of Aerial Navigation to aid the artist who was to make the busts of the two unhappy aeronauts, we had the coffins opened, on their arrival at the Gare d'Orléans, on Sunday, April 18, at 11:45 in the evening, and $I$ was struck by the state of preservation of the features and the faces.

I could almost have done without the disinfectants with which I was furnished to facilitate the measuring of the faces. . . .

Sivel had preserved his virile and energetic face; he showed no sign of hemorrhage in mouth or nose; his face, slightly swollen, was not cyanosed.

Crocé-Spinelli had his nostrils and mouth filled with blood which we had to remove by repeated washing. On his forehead, his nose, and his right cheek were blackish patches produced by the ecchymoses resulting from bruises caused by the oscillations of the basket. Nevertheless, in spite of the blood which covered them, the lips did not have the bluish tint characteristic of asphyxia, and the left side of his face had almost preserved its normal color.

The catastrophe of the Zenith profoundly moved our country; everyone remembers the solemn funeral rites of the victims, the tributes of political and scientific bodies, the open subscription for the benefit of the families of Crocé and Sivel, a subscription which produced nearly 100,000 francs. May 23, in a great meeting, where for the last time the eloquent voice of Pastor Athanase Coquerel, Jr., was heard, I could say ${ }^{16}$ in all truth:

A month and a half has passed since the catastrophe of the Zenith, and in our country, unjustly accused of frivolity and forgetfulness, the emotion which it aroused is not yet calmed.

This is a remarkable fact upon which we should dwell. Every day the newspapers bring us accounts of terrible disasters, floods, explosions, fires, shipwrecks, which cost the lives of scores, of hundreds of men; it seems that our emotions should be stirred by these and that the loss of two men should hardly affect them. Nay, more! Our country, our heroic and unhappy country, has hardly completed a period of sorrows and sacrifices, in which it mourned not only those who died in her defense, but also those who, still alive, are now torn from her; and yet we learn the death of two men, of only two men, and all France trembles and mourns.

That is because everything in this double death is strange and sublime. Certainly Sivel and Crocé-Spinelli are not the first aeronauts whose loss science has had to deplore; their names are the last of a list at the head of which shine the names of two other scientists, Pilattre du Rozier and Romain, who were dashed to pieces on the beach of Boulogne in 1785. But the death which had struck these two aeronauts was a well-known death, foreseen, common in a way; a 
death of which everyone had thought, that everyone had feared from the day when the contrivance of Montgolfier appeared in the air; that was death by falling. Thus they died. But here, for the first time, we saw two men die in the very bosom of the air, and die while ascending. They felt death coming, a death unknown till then; their oppressed breasts warned them of danger; they took counsel: "Must we descend?" Ah! The consultation was not long. "We have ballast, we can make still more useful observations up there; excelsior, higher! And then they say that an Englishman could live and make observations above 8000 meters: the flag we carry must float higher yet!" They leap up, and death seizes them, without a struggle, without suffering, as a prey fallen to it in these icy regions where an

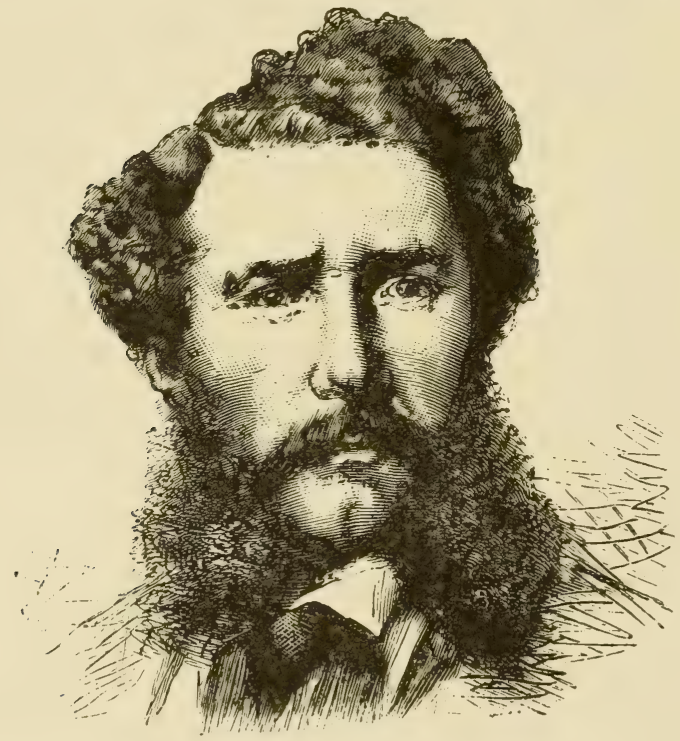

Fig. 88-Sivel.

eternal silence reigns. Yes, our unhappy friends have had this strange privilege, this fatal honor, of being the first to die in what we call the heavens.

And by a painful jest of fate, they died at the moment when science was furnishing them the means to triumph over the danger to which they fell victims.

It was a scientific purpose of great theoretical importance, ${ }^{17}$ of immense practical consequences, that our two friends were pursuing. To determine the direction, the strength, the thickness of the aerial 
strata in movement; to measure the variations of temperature, electricity, humidity, the chemical composition of the air, at different heights; to analyze the constituent elements of the stars, by rising above the sort of screen which the lower strata of the atmosphere form: such were the principal problems which they had set themselves. The utility of ascensions to great heights has been denied: that is denying evidence. Everything leads us to believe that the balloon, by its power of ascension, can carry the observer beyond the extreme limits where the highest clouds float. Now what source of prosperity for humanity could be compared to the unfailing prediction of weather? How can we hope to reach that goal without knowing thoroughly this region where rain, snow, and hail are formed,

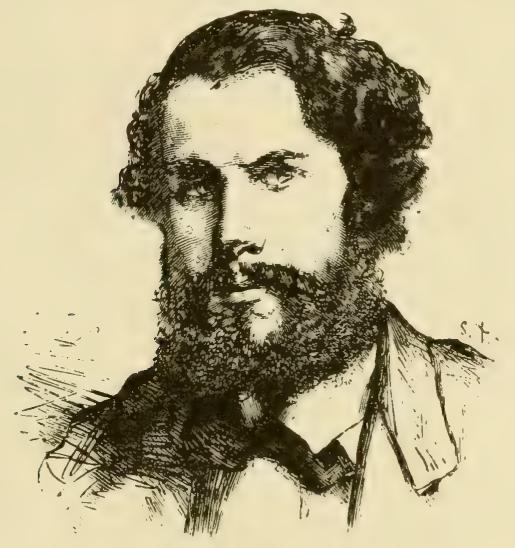

Fig. 89-Crocé-Spinelli.

and where the winds and storms are engendered? And how can we know this region without ascension to a great height, which permits us to reach its domain and, if I may speak thus, to dissect the atmosphere?

I owed these explanations to the Society of Aerial Navigation; I owed them to the memory of our unhappy friends. Furthermore, no one was deceived. Everyone understood that these were men of science, who died doing useful scientific research, and that is the second reason which explains the emotion aroused by their death.

There is a third, more thrilling, more poignant perhaps. Let us go back in thought five years, to the terrible winter. Paris is enclosed in a circle of iron; all communications are cut off; on land, unsurmountable obstacles; nets bar the river. But the air is left, this new route opened by a Frenchman, Montgolfier, on which a Frenchman was the first to venture, Pilattre du Rozier; brave men-M. G. Tissandier was among them-rose into the air, braving a thousand 
dangers, without speaking of the enemy's bullets, spreading in the provinces the news which mitigated the anguish of separation, bearing with them the energetic emotion, the unconquerable resolution of the great city to do its duty to the end. So, I dare say, and who will contradict me-when the news spreac that two men had died in a balloon, Paris recalled these hours of pain and hope, France trembled, and all hearts throbbed as they used to throb when someone told us that a balloon had landed, that someone had seen a balloon in the air.

And so this double death, which seemed as if it were impressed with a strange and mournful poetry, as if lighted up by the halo of science, awoke again memories of the purest patriotism. Is not that enough to explain why it has aroused in all France a feeling so keen, so universal, so lasting?

The emotion of men of science was especially manifested on the one hand by notes and memoirs attempting to explain the death of the two aeronauts, on the other by inventions intended to prevent henceforth such terrible catastrophes. I am forced to state that nothing said or imagined on this subject deserves to be reproduced here. From the theoretical point of view, they are only new editions of old ideas, already condemned, whose strange series we have already listed in our history; for this particular case there has been added the toxic effect of illuminating gas escaping in floods from the balloon, which had been too rapidly dilated, and poisoning the aeronauts. The protecting inventions are worth just as much as the theories which inspired their authors. Most of them speak of divers' suits, glass cages, closed baskets, with confined or compressed air, artificial atmospheres, sources of oxygen, etc.; but nothing which was proposed so seriously is as good as the charming mystification of the "Journey to the -Moon" and M. Jules Verne will excuse me for not discussing it here.

Dr. Stoliczka, a geologist well known for important works on the mountains of India, had in 1864 crossed many passes above 5000 meters in the Himalayas; he had had there "a horrible experience" 18 of fatigues and mountain sickness, and had regained health very slowly. In June, 1874, he left with an English mission commanded by Lieutenant Colonel Gordon, and died suddenly June 19, at the age of 34 , three days after having crossed Karakorum. The details of his death given by the letters of Lieut. Col. Gordon and Capt. Trutter ${ }^{19}$ seem to indicate that the fatal effect of rarefied air played an important part in the death of: the unfortunate geologist.

I give here the letter of Capt Trutter, the most interesting and the most complete: 
June 16, the day when we crossed the Karakorum pass, he complained of a pain in the back of his head; but since he always suffered more or less from headaches as long as he was on lofty elevations, I thought that his pain meant nothing more; the pain continued the 17th, the day when we were crossing the deserts of Dipsang, where the level is still very high. Yesterday, the 18th, he started early to investigate some rocks at Bruchsé, and halfway along he met us for lunch. He seemed very tired and complained about his head. When we reached here about noon, he threw himself on a bed, and soon began to breathe with difficulty and to cough a great deal, and he vomited. His head and hands were very hot and his pulse was quick and hard. He complained a great deal of pains in his neck and the back of his head. By my advice, he put a mustard plaster on his neck and another on his chest without feeling any great relief. In the evening the cough became very severe, and the local doctor prepared a mixture to soothe the irritation which caused the cough; it continued just the same all night. In the morning it disappeared, but the patient, who was very weak, hardly seemed conscious. Since the evening before he had said nothing, and replied only by a few syllables to the questions asked him, without seeming to understand very well what was said to him. This morning I asked him twice if he felt any pain, to which he answered no.

The local doctor seemed to think that he had an attack of acute bronchitis and pneumonia. But after what Capt. Biddulph and I had seen of the sickness that attacked him last October, at Kizil-Jilga, on the Kashgar road, the symptoms of which we recognized, it was clear to us that the disease was the same as the first time, that is, a spinal meningitis. By the doctor's advice, a plaster was placed on his right side. He remained till noon in a state of half-consciousness, and several times took chicken broth and brandy with his medicine.

He appeared neither better nor worse; his respiratory rate was usually 50 to the minute, irregular, and often alternately deep and difficult, or short and easy. The respiration was accompanied by sonorous noises, which resembled the noise at the seaside or the crackling of distant firing. Later, in the morning, it seemed to me that the noise had become harsher. However, the breathing became a little easier, and about 1:30 he signed that he wanted to be placed in his chair. He was carried there and I gave him a little port, but he seemed so weak and exhausted that I called Biddulph who, finding the patient very low, went to get the colonel. When he was placed in his bed, he tried at once to sit up; I held him from behind to support him till the colonel should arrive; the noise of the death rattle ceased-but he was still breathing deeply, his respiratory movements became slower and slower, as did his pulse; finally he breathed his last, dying so peacefully that it was impossible to fix exactly the moment when he passed away. He had no agony, died apparently without pain, and after his death an expression of rest and peace was on his face.

From the moment when he came here until he died, he hardly said a word, and all conversation became impossible; however, when 
he looked at me, I thought I could see that he was conscious of his critical condition.

He had told me a few weeks before that a second attack of meningitis would bring certain death, since it is rare that one survives the first attack. . . . I cannot help believing that the elevation had a good deal to do with the aggravation of the symptoms; he had been exposed to the same cold in the Pamir expedition, and yet, the elevation being less, he had experienced no harm.

I think that Capt. Trutter is right. I do not think that Dr. Stoliczka succumbed to the influence of the rarefied air alone; under the influence of an intense cold, he was probably attacked by spinal meningitis complicated with broncho-pneumonia; but the immediate prostration and death in two days should be attributed to a complication unknown at ordinary levels. I certainly believe that a lessening in the extent or the soundness of the alveolar membrane, which at sea level would have brought only a slight ailment, must have brought death by asphyxia in regions where oxygen absorption was already reduced to a minimum. We shall return to these data in the following subchapter.

An anatomist of high rank, who has just published a considerable work on the respiratory apparatus of birds, tried, among very interesting observations on the operation of this apparatus, to explain the singular immunity which birds of lofty flight enjoy with reference to the effects of rarefied air. In the opinion of M. Campana, ${ }^{20}$ it is all explained by the super-activity given to the respiratory phenomena by the muscular acts of flight; so, he says, alluding to the experiments in which I saw hawks hardly less susceptible to decompression than the other birds:

I should unhesitatingly admit that these same condors, or better yet, condors taken from a menagerie, might very well be subject to all these functional disturbances, if, instead of rising freely in flight, they shared in a passive manner in the ascent of a balloon, kept captive and motionless in a cage, in the bottom of the basket. For all the greater reason, if one subjected them to decompression in closed vessels. (P. 336.)

This survival without distress at heights which, for condors, reaches 7000 meters, results from two causes, according to $\mathrm{M}$. Campana: let us examine them with the care that his important work deserves. These two causes are expressed in the following formula:

In mammals, mountain sickness, balloon sickness, is explained by the impossibility of a thoracic expansion regularly continued and sufficient, due to the weakness of the muscles which move the thorax; 
and also by the immediate exposure of a pulmonary parenchyma retractile at a considerably weakened outer atmospheric pressure, and by the annulment of the compensating function of the glottis. (P. 341.)

First, according to M. Campana, the movements of the wings would put in play part of the aerial sacs (brachial prolongations of the anterior-superior receptacle) situated between the motor muscles of the wing sacs which remain motionless except in flight; they would dilate at the elevation of the wing (that is, according to the observations of M. Marey, at the moment of the tracheal inspiration), and would empty themselves of air at its lowering. The result would be a considerably more rapid circulation of air through the lungs, a more perfect ventilation, which would have as a consequence that:

In the same conditions where mountain sickness appears in mammals, birds in flight escape the two causes of anoxyhemia which attack mammals, if not absolutely and indefinitely, at least to a much greater degree. (P. 341.)

I consider the observations of M. Campana about the development of air cells in the wings during the act of flight as perfectly correct. But I think he has greatly exaggerated the importance of this observation; first, the increase in volume acquired in this way is not very great, considering that of the other gaseous reservoirs which act at the same time, that is, the extra-thoracic sacs. In the second place, if I saw these aids of the respiratory act developing only during flight at great heights, I should admit that they might then offer a certain utility: but they act equally at all heights, provided that the bird is flying; and even if I believe that they help thus to produce the increase of strength necessary for work in the air and to establish the equilibrium of the organism in a dynamic state, I do not understand how they can add, when the low pressure becomes dangerous, a supplement of ventilation and consequently of oxygenation which had not been already furnished in the lower levels. Finally, even admitting that ventilation is made perfect, we have seen that that is of little importance, because it is the capacity of the blood for oxygen which constitutes the real danger, since it has diminished with the height. The perfection of the ventilation can play only a very small role, since it can only raise the quantity of oxygen contained in the arterial blood in circulation to the amount which this blood would be capable of absorbing if it was suitably saturated. This increase is not to be scorned in mammals, and we shall dwell upon this point in the following subchapter. But we ought hardly speak 
of it in birds, because, according to the recent research of $M$. Jolyet, ${ }^{21}$ their arterial blood is always nearly saturated with oxygen; that, let us say in passing, is a fact of the greatest interest, since it shows that in birds, contrary to the situation in mammals, the conditions for the mixture of blood and air are perfect in the respiratory apparatus.

The second reason indicated by M. Campana to explain the resistance of birds of lofty flight is:

That they possess the means of removing the pulmonary parenchyma and up to a certain point the middle receptacles themselves from the absolute dependence upon the barometric pressure which the lungs of mammals endure necessarily during the inspiration. (P. 342.)

In other words, during the inspiration as during the expiration, the lungs, in consequence of the energetic injection carried on alternately by the extra- and intra-thoracic receptacles, "are crammed with air under a pressure greater than that of the outer air." (P. 343.)

And so, the respiratory apparatus is removed up to a certain point from the barometric pressure, which makes possible the ascent into the higher levels of the atmosphere, and a fortiori the soaring flight in the bosom of an icy and asphyxiating air.

I do not wish to report or discuss the details of the very complicated mechanism by which M. Campana explains this compression of the air in the interior of the lungs; in short, it amounts to an injection of air too great for the section of the delivery openings in the meshes of the pulmonary parenchyma. But I cannot admit that such great importance should be attributed to this slight excess of pressure, or that we should consider it as offsetting the enormous decompression to which the bird will be exposed; these intra-pulmonary modifications can be reckoned in millimeters of mercury, whereas the outer decompression is measured by tens of centimeters.

To my notion the question rests, and the immunity of condors and vultures remains unexplained to me. Even if a study of the effect of decompression in closed vessels should show us one of these birds resisting much more than did our hawk, we should be embarrassed by a sort of contradiction, but we should still have no explanation. I shall return to these data in the next subchapter when I speak of dwellers in high places, who seem to present a similar immunity, like the yaks of the Himalaya and the llamas of the Andes. 
I shall end this review of works published since the publication of the principal results obtained in my research by a short analysis of the new book of M. Jourdanet. ${ }^{22}$ This important work, whose appearance I announced and some passages of which I quoted in the first part of my present work, is divided into five parts. In the first (vol. I, p. 3-84), entitled "Preliminary Barometric Studies", I shall only mention here, without being able to dwell on it, the curious chapter on the modifications of barometric pressure in the geological ages, and their influence on living beings. The second (p. 85-367), "Climates of Altitudes", contains, besides a masterly description of lofty, inhabited regions of the globe and important statistics about Mexico, a summary of my own experiments, and the study of the influence exerted by decompression on travellers (mountain sickness) and on the inhabitants of lofty regions. In the third part (vol. II, p. 3-154) "Pathological Constitution of Altitudes", M. Jourdanet develops and supports by very interesting medical observations his remarkable discovery of the depressing influence of great heights, of the anemic state (anoxyhemic) of the dwellers in high places when they are attacked by some disease. The fourth part (p. 155-204) deals with "Mountain Climates". M. Jourdanet explains in the following terms the meaning he attributes to this word, opposed to that of the climate of altitudes:

I call altitude climates those which a sufficient elevation, combined with the distance to the Equator, characterizes by the certain signs of a respiratory alteration, as a consequence of the diminution of the density of the surrounding air.

Below this physiological limit, since the barometric decompression does not act in a way harmful in itself, and may on the contrary produce effects beneficial to health, I apply the term mountain climates to the conditions prevailing at moderate heights and on the lower elevations of the soil in mountainous countries. (Preface, p. 2.)

In this fourth part are found data and particularly statistics of such a sort as to cause sceptical reflexions on the vivifying air and the fortifying effect of the mountains. Finally, in the fifth part (p. 205-292), under the title of "Natural and Artificial Barometric Transitions", the brief sojourn in mountainous places is very cleverly contrasted with the effect of a prolonged abode; very interesting observations are made there, besides, on the therapeutic use of rarefied air.

We see that only the second part of this important work deals with ground on which we ourselves are quartered. In this book, 
when I analyzed the previous works of M. Jourdanet, I have given his remarkable observations the place which they deserve; I cannot, without repeating myself, return to them here. As to the hygienic and medical considerations which my learned colleague has treated with such length and interest, I can only refer the reader to this book, which contains so many curious observations and new ideas, so many proofs of profound and persistent learning, if I may use the word "persistent", and guided by a theoretical idea which is fortunate and fertile. He will wonder at the extent of the general conclusions relative to the constitution of human races, to the history of civilizations, and to philosophical politics, which M. Jourdanet drew from this first observation, that, during a surgical operation in Mexico, the blood which escaped from the arteries did not present its usual reddish hue (vol. I, p. 171). But I cannot continue longer here.

\section{Subchapter II}

\section{SUMMARY AND PRACTICAL APPLICATIONS}

We have given, in our second part, with a superabundance which may perhaps have appeared excessive, the proofs of this truth that diminution in the barometric pressure acts on living beings only by diminishing the tension of the oxygen which they breathe, and if things are carried to the extreme, by asphyxiating them for lack of oxygen. Also that there exists a parallelism to the smallest details between two animals, one of which is subjected in normal air to a progressive diminution of pressure to the point of death, while the other breathes, also to the point of death, under normal pressure, an air that grows weaker and weaker in oxygen. Both will die after having presented the same symptoms; and at different moments of the experiment, at death even, one can observe in both the same proportion between the oxygen tension in the outer air and its proportion in their blood.

All the old theories about the mechanical action of decompression should have disappeared entirely, and it really should be enough to show their folly to recall the experiment in which I went down to the fatal pressure of $248 \mathrm{~mm}$. without the least inconvenience, under the single condition of restoring the oxygen tension to its normal degree by breathing an artificial superoxygenated air. 
The question then appears to have been reduced to a remarkable simplicity; but though the cause of the phenomena observed can thus be expressed in a word, its consequences are so diverse that they deserve to be studied in the different conditions in which the diminution of pressure can act.

\section{Aeronauts.}

Let us begin with the simplest case, and let us consider first the aeronaut, who, without making any effort, is lifted in the upward course of his balloon.

As he rises and the pressure diminishes, his blood loses its oxygen, as my experiments have shown: a very slight weakening at first, whose existence, nevertheless, my analyses have permitted me to prove as soon as the pressure is not more than 56 centimeters. Even then, the oxygen loss cannot have a very definite immediate effect; the difference is like those one observes between individuals who are in equally good health, like those which changes in respiratory rhythm or the different states of activity or of rest, of digestion or abstinence bring in the same individual. The aeronaut cannot feel it.

If he rises higher, the loss of oxygen increases: at 2000 meters it was on the average $13 \%$; at 3000 , it becomes $21 \%$; at $6500,43 \%$; at 8600 meters ( 26 centimeters pressure), the height at which CrocéSpinelli and Sivel died, they must have lost half of the oxygen of their arterial blood. My animals at 17 centimeters pressure had lost $65 \%$; their arterial blood then contained only 7 volumes instead of 20 per 100 volumes of blood, less than ordinary venous blood coming from a contracted muscle. This is the blood which, in the arteries, was given the task of nourishing and animating the muscles, the spinal cord, the sense organs, the brain! In considering these facts, we recall the celebrated experiment of Bichat, on dark blood injected into the vessels of the nervous centers.

We know that, in a general way, the effects of the rarefaction of the air began to be felt quite plainly about the height of 4000 meters, corresponding to a pressure of $46 \mathrm{~cm}$. It is also at about this pressure that in our bells our animals ceased to move about and showed signs of discomfort. Now the graph of Figure 31 shows that at about this moment the proportion of oxygen in the blood diminishes more rapidly; there is a remarkable agreement here.

This decrease in the quantity of oxygen contained in the blood is the prime factor. From it are derived all the symptoms of decompression. Its cause, we have seen, is double: first, the proportion of 
oxygen which the blood can absorb grows proportionately less as the pressure lowers (See Part II, chapter II, subchapter V); in the second place, if we suppose that the respiratory rhythm has not changed, the quantity of oxygen which circulates in the lungs during a given time diminishes in the same proportion as the pressure. Now under normal pressure, the arterial blood, we have seen, is never completely saturated with oxygen, the agitation of the blood and the air not taking place with sufficient energy in the lungs.

The deviation must increase greatly when not only the coefficient of the oxygen absorption but also the intra-pulmonary circulation diminishes. Indeed, at a half-atmosphere, for example, to keep the conditions of intra-pulmonary mixing as they were at sea level, everything must be doubled: the respiratory movements must be double in amplitude and frequency; the heart beats must be double in strength and number. That is evidently impossible.

However, there is a tendency in this direction, as the accounts of all the aeronauts give witness, as I have observed in the animals and experienced myself in my apparatuses; at low pressures the respiration quickens, the heart beats are stronger and more rapid, and equilibrium can be nearly reestablished. We have seen, in fact, that if the pulmonary ventilation increases, the arterial blood may gain 3 or 4 volumes of oxygen per 100 volumes of blood.

But this can be only momentary, and such gymnastics cannot long continue without danger of emphysema and cardiac maladies; and so this increase does not last, and when the balloon becomes stationary, this dangerous acceleration does not continue in the aeronauts: the oxygen then decreases fatally in their blood.

Furthermore, when the pressure diminishes still more, the respiratory and circulatory acceleration not being able even for an instant to compensate for the insufficiency of the intra-pulmonary agitation of the air and the blood, the muscles of respiration, like those of the heart, lose their energy and grow weary, since they are receiving a blood that is insufficiently oxygenated, and yet are compelled to carry on continuous labor. The respirations, always numerous during activity, are shallow, so that the quantity of air inspired in a given time is hardly the same in volume as at normal pressure; in rest, they fall back to their ordinary number, while remaining very shallow, and it even seems, according to the remark of de Saussure, that one sometimes forgets to breathe. The heart movements give similar results; their frequency increases, it is true, but the cardiac tension drops considerably; in one of the 
sphygmographic graphs of $M$. Lortet, taken just as he arrived at the summit of Mont Blanc, it is hard to find indication of the pulse.

And so the organism, conquered in its struggle to compensate for the diminished density of the oxygen in the air by agitation of the air and the blood, returns to the regular routine of its movements, which the poverty of the blood soon weakens. At this time, the seriousness of the phenomena begins to increase rapidly; the blood's insufficient capacity for oxygen is complicated by a greater and greater imperfection in the intra-pulmonary ventilation and circulation caused by the insufficiency of the oxygen absorbed. That is why, as we have seen, the arterial blood of animals under decompression contains even less oxygen than it might absorb at that given pressure.

This rapid decrease in the oxygen content of the blood causes a profound disturbance in metabolism and consequently in the functioning of the organs. We have seen that in animals placed under bells with rarefied air, when the decompression is great enough, the quantity of carbonic acid exhaled and of urea excreted diminishes considerably; the temperature drops also, even when that of the outer air is average. The same thing must certainly happen to aeronauts, when they reach very great heights, where, in addition, the air is generally very cold. I recall that I showed experimentally that in cold air, resistance to decompression is less than at ordinary temperatures.

But under decompressions lower than those which we had to use to show experimentally, that is, roughly, the diminution of the inner workings of metabolism, it is revealed to the observer by the functioning of the organs. But here, as is always the case when we have to do with a cause capable of affecting the whole organism, it is. the nervous system which reacts first, which is the first to complain, if I may use this expression. The sensation of fatigue, the weakening of the sense perceptions, the cerebral symptoms, vertigo, sleepiness, hallucinations, buzzing in the ears, dizziness, pricklings, reactions of the pneumogastric and sympathetic nerves, nausea, palpitation, dilation of the arterioles are the signs of insufficient oxygenation of central and peripheral nervous organs. After the nervous system comes the muscular system, which betrays weakness, is seized by convulsive contractions, and by shudders, in which the nervous system also certainly has its part. Finally, in the last stages, come paralysis, syncope, or to speak more exactly, loss of consciousness, and finally death without a last sigh 
and without convulsions, if the diminution of pressure has not been brought too suddenly to its fatal degree.

The symptoms of decompression disappear very quickly when the balloon descends from the higher altitudes; very quickly also, as I have often seen in my experiments, the normal proportion of oxygen reappears in the blood. There is an unfailing connection here.

No less striking is the correlation between the data observed in balloon ascensions and those in the only two known cases in which men have been subjected to air with low oxygen content, without the interference of carbonic acid. The first was observed, as I have already said, by M. F. Leblanc in the pyrites mines of Huelgoat in Brittany. In a gallery in which the air contained only $9.8 \%$ of oxygen, and which he entered without transition, he had attacks of vertigo and fainting. Now that oxygen tension nearly corresponds to that of the air at a height of 6000 meters, where certainly balloon sickness would violently attack anyone who exposed himself to it suddenly. The second, observed by M. Forel, is particularly noteworthy because of the similarity of the mental symptoms which he experienced in air with a low oxygen content and those from which I myself suffered under a decompression corresponding to the height of Mont Blanc.

The moment at which aeronauts feel and the experimental animals manifest serious disturbances varies, as we have seen, not only with the species, but with individuals in the same species.

The analysis of the gases of arterial blood shows us inequalities quite of the same order, which certainly are the immediate cause of these differences. At a pressure of $36 \mathrm{~cm}$., one of my dogs (Experiment CLXXI, number 10 of Table X) had lost $55.6 \%$ of the oxygen of his blood, another (Experiment CLXXIV, number 11) having lost only 36.1 (Table $\mathrm{X}$, column 14); they had, however, reached about the same figure (8.5 and 8.9, column 8). Another of my dogs showed (Experiment CLXX, numbers 2 and 5) a very remarkable resistance: at $56 \mathrm{~cm}$. he lost only $3.2 \%$ of his oxygen; at $46 \mathrm{~cm}$., only 5.5 , keeping the high proportion of 20.3 .

A careful inspection of Table $\mathrm{X}$ shows many interesting inequalities in this point; but we cannot find the reasons for these inequalities. Neither the vigor of the animals nor the original oxygen content of their blood can serve in themselves as an explanation. Nevertheless, by considering the general results of the analyses of the blood gases, one can account fairly well for these phenomena. 
In the first place, we know that, between two animals of the same species, adult and in good health, the oxygen content of the arterial blood is very variable; the variations, in our analyses, have been (See Table XX) from 14.4 to 22.8 volumes of oxygen per 100 volumes of blood; it seems evident then, a priori, that two animals presenting this difference will not behave in the same way in regard to decompression, and that the first will be more rapidly affected than the second.

In the second place, if we imagine two animals identical in the oxygen content of their arterial blood, it may be that they are not identical in the maximum capacity of their blood for oxygen; one may be already nearly saturated, the other still far from his point of saturation. The latter then, by speeding up his respiratory and circulatory movements, can go further towards saturation and consequently resist decompression better. But that is not all; since he has the same quantity of oxygen, although not saturated, his blood contains in an equal volume more hemoglobin than that of the first, and this hemoglobin is less oxygenated. Now everything shows that the oxy-hemoglobin is hard to dissociate, either in the pump, or by the tissues, in proportion to its distance from its saturation point. Our animal, for this reason too, will lose in decompression less oxygen than the one which nevertheless had the same quantity in the blood.

We can go further yet: two animals of the same weight and identical in the oxygen content and degree of saturation of their arterial blood may differ considerably in the quantity of blood contained in their vessels. And if this is so, it is clear that if, in a given time, they consume the same quantity of oxygen within their organisms, the blood of the one which has the least will give up to the tissues the greater proportion of oxygen; in other words, there will be a greater difference from the point of view of oxygen content between his venous blood and his arterial blood than in the animal with the greater quantity of blood. In our experiments we have observed differences of this sort; we have seen, for example, a certain dog have in his venous blood 9.2 volumes of oxygen less than in the arterial blood (Exp. CXC); another (Exp. CXCII) has only 3.3. If we suppose all other conditions identical, and if we subject these two animals to a considerable diminution of pressure, it is clear that the first will be painfully affected long before the other, because his venous blood has a much smaller reserve of oxygen.

Now we reach the very foundation of the question. Let us con- 
sider an individual whose arterial blood contains 20 volumes of oxygen, per 100 volumes, and whose venous blood contains 12, an individual who consequently for the needs of his organic combustions consumes 8 volumes of oxygen borrowed from his arterial blood. Let us now suppose him subjected in a balloon to the effect of diminished pressure. The oxygen of his arterial blood will decrease progressively as we have seen, and naturally the same thing will be true of his venous blood. But he will pass through two successive phases which we should study carefully. In the first, the impoverished arterial blood, in spite of the compensatory efforts attempted by the respiratory apparatus, will drop to $18,16,14$ volumes of oxygen; that is when-if we take as a basis of our calculations the graph of Figure 31 -the pressure has been lowered to $62,48,40 \mathrm{~cm}$., corresponding approximately to elevations of $1600,3600,5100$ meters. If there is no change in the intensity of his intra-organic combustions, our aeronaut will still need the 8 volumes of oxygen which he consumed at normal pressure, and his venous blood will contain 10, 8, 6 volumes of oxygen. These figures represent degrees of saturation of the hemoglobin which are easily dissociated for the needs of organic combustions; the quantity of oxygen necessary for the inner phenomena of metabolism will have been found, and nothing will be changed in the general equilibrium of our aeronaut. Of course, his tissues will be bathed in a blood relatively low in oxygen; but as they can extract from it what they need, although with a little more difficulty than in the normal state, nutritional disturbances with their functional consequences will be only slight.

But the balloon is still rising and reaches successively 5700 meters (37 cm.), 6600 meters $(33 \mathrm{~cm}$.), 8600 meters $(26 \mathrm{~cm}$.); the oxygen of the arterial blood drops to $13,12,10$ volumes. Then it becomes more and more difficult to find the 8 volumes of oxygen necessary for the regular maintenance of the organism, for the venous blood must fall to $5,4,2$ volumes, and the oxy-hemoglobir. shows itself more and more rebellious to reduction. In fact, experimentation has shown that this reduction does not take place; the graphs of Figure 40 are very characteristic and show that the oxygen consumption lessens in the organism, the difference diminishing between the graphs, till then parallel, which represent the oxygen content of the arterial blood and that of the venous blood at different pressures. Then, simultaneously, we see diminishing in growing proportion the quantity of oxygen consumed from the air, the carbonic acid expelled, and the urea excreted; then too the 
temperature begins to drop. Then, consequently, there appear, with an equally growing intensity, serious physiological disturbances, due to the insufficiency of the quantity of vital force set at liberty; the respiratory muscles, the heart, which till then had struggled to carry on the metabolism, fall exhausted, so to speak; the whole muscular system, the venous system, which can hardly find in the impoverished blood the oxygen strictly necessary for their static maintenance, can carry on no energetic or lasting work. And, by the usual series of sympathies, of organic harmonies, that which was effect becomes cause in its turn: the chilled tissues become less fitted for combustion: the sluggish and weakened heart no longer pumps the nourishing liquid with the same abundance, and the unhappy aeronaut, dragged on in this sort of vicious spiral, rapidly descends the slope which leads to death.

So, in summary, two phases: phase of struggle, phase of defeat, with a passage trom one to the other whose duration will vary according to many circumstances, which we shall rapidly review. We can divide them into two classes: some are inherent, others outside the person under observation.

Among the inherent circumstances, we have already mentioned as favorable the abundant blood supply of the organism, the large oxygen content of the blood, the great capacity of the blood for oxygen, and the smallest relative consumption of oxygen in the blood as it passes through the tissues. There are others also, and important ones, which we do not understand as clearly at first, and which depend on the chemical state of the tissues themselves. Another possibility is, when the quantity of oxygen brought is very small, a tissue in which rest has permitted an accumulation of materials that are easily oxidizable, or a tissue drained of these materials by previous functioning that was too energetic. In the first, everything will be ready for a maximum utilization of the oxygen brought, and consequently for a maximum output of vital force; in the second, on the contrary, beside the phenomena of discharge of vital force and of combustion, the organic equilibrium, lowered to its very limit, will require reductions, the storing up of vital force which will lessen by so much the total available for outlay in heat and work. In addition, the digestion, which gives the organism materials easy to oxidize, must establish a condition favorable to the preservation of a state compatible with strength and health. Finally, to end what pertains to the inherent circumstances, we shall mention the disastrous effects of muscular or intellectual efforts, which, requiring for their accomplishment 
a sudden consumption of oxygen, take from this blood, which is already so poor, the insufficient supply intended for the nourishment of the tissues, and reduce these tissues to poverty and impotency; but this discussion belongs rather in the study of the symptoms of mountain travellers.

First among extrinsic and unfavorable circumstances we must mention the cold. Aeronauts have encountered extremely low temperatures. Now, since the immortal works of Lavoisier, everyone knows what super-activity in oxidations can be required for the maintenance of a constant temperature. It is clear that in the difficult conditions in which the source of oxygen, that is, the arterial blood, is involved, the moment when the organism is threatened can be hastened by the action of an intense cold. But the patient must already, or nearly, have reached the phase of organic depression, without which the compensating action of the same physiological means which permit us, at ground level, to resist cold, would be able to work effectively in the upper strata. A second dangerous circumstance is too great rapidity in the ascent. However confused our ideas still are in regard to the effects of habit, it is quite certain that modifications in our conditions of life have much more painful consequences when they are sudden than when they are brought on somewhat slowly; this fact is very clear in the case of diminution of pressure, and we have often seen in our experiments an animal suddenly overwhelmed by a decompression to which we could have brought him easily if we had made the transitions prudently; besides, this animal, if it is not killed immediately, recovers more or less completely under the same decompression which had almost been fatal to him.

Up to now we have spoken only of the oxygen of the blood. Can it be that the other gases, whose proportion diminishes equally, play some part in the symptoms of decompression? Carbonic acid, whose diminution in the blood advances even more rapidly than that of oxygen (See Fig. 31), does not seem to me important in the case of aeronauts, who remain for so short a time under the influence of decompression; we shall return to that point when we speak of mountain dwellers. As for nitrogen, it enters into the question only from the mechanical point of view. We have shown the formidable part it plays in sudden decompressions from several atmospheres on; but it seems to me impossible to attribute the slightest unpleasant influence to its release during even the most rapid balloon ascension: Coxwell and Glaisher took 50 minutes to arrive at an altitude of 8838 meters; Crocé-Spinelli, 
Sivel, and Tissandier in two hours reached the height of 8600 meters, the decrease in pressure being about three quarters of an atmosphere. Now we have seen that even the slightest symptoms of sudden decompression never appear for an almost instantaneous decompression from one atmosphere; beyond, for decompressions from several atmospheres, twenty minutes per atmosphere give protection from symptoms; we are far from the conditions presented by aeronauts.

We now understand perfectly the phenomena the aeronaut will present as he rises in his balloon. At lower heights, a slight acceleration of the pulse and the respiration attempting to compensate for the diminution of oxygen which the blood begins to undergo, an acceleration which seems to have some of the consequences of fever, as it has some of its symptoms. At this time, in fact, observers have noted a certain intellectual excitement, with a feeling of well-being, of lightness, of strength, which I do not think should be ascribed solely to the excitement of the trip, or to the splendid spectacles offered to the admiration of the aeronaut by the clouds lighted from above by the sun. I think that the increased activity of the circulation, subjecting the organs and particularly the nervous centers to a more rapid irrigation, takes from them more completely the waste products of metabolism and by this sort of washing puts them in conditions most favorable for their functioning. On the other hand, not only the carbonic acid, but all the gaseous impurities which our blood absorbs at ground level, particularly in the air of large cities, escape in an already considerable proportion, and our organs, so sensitive to the influence of these noxious matters still mostly unknown, must experience advantages easier to divine than to define precisely.

But the balloon continues its upward course: it reaches and passes 5000 meters. The oxygen diminishes in the blood in considerable proportion, although enough is left for the necessary consumption. The enthusiasm, the feverish excitement experienced about 2000 meters have nearly disappeared; the heart beats rapidly; movements become rather painful, the cold is felt. Higher yet, rest becomes indispensable; the impoverished blood can no longer provide the increase of oxygen required for muscular contractions; so the least effort causes panting, palpitations; the sturdy Sivel can hardly lift a bag of sand weighing 20 pounds to the level of the basket; drowsiness overcomes the passengers; they have vertigo, buzzing in the ears, dizziness; the sky appears almost black, partly because of the weakness of vision. Finally, higher 
yet, if, in the midst of a sort of muscular, sensorial, and intellectual inertia of which they are victims, they wish to make even a slight movement, to raise an arm like Glaisher and Tissandier, they suddenly perceive that paralysis has struck them unawares, and almost immediately, since the brain to which a weakened heart sends a blood insufficiently oxygenated ceases its duty, there comes a loss of consciousness which, if the balloon does not descend, may lead rapidly to death.

Prophylaxis. The analysis which we have just made shows the usefulness of a certain number of precautions which common sense had already suggested. Aeronauts planning very lofty ascensions ought as much as possible in the preceding days to avoid excess of muscular, nervous, and intellectual fatigue. Although in good health ordinarily, especially from the point of view of respiratory and circulatory organs, they must guard against attacks of bronchitis, which hinder the respiration. Before starting, they should take a meal of substantial food and take with them some cheering victuals to eat frequently on the way.

They should try to arrange everything in the basket so as to avoid making great muscular efforts; the bags of ballast, for example, should be emptied by cutting a cord, and not lifted from the bottom to the edge of the basket. A comfortable arrangement will not be simply luxury, it will save the consumption of oxygen.

Let us add that rugs, bottles of hot water or, better, hot oil, should be taken along to keep away the cold, which also consumes oxygen.

Prudence would dictate that they slacken the ascent when they reach the upper strata, so as not to be subjected to over-sudden changes. Unfortunately that is almost never possible in practice, for if the course of the balloon is slackened, the gas contained in it will grow cold on contact with the icy layers of the air, and the balloon will lose part of its ascensional power. Now there is never too much for such expeditions, and as much ballast as possible must be kept for the accidents of the descent, in which the balloon, almost empty, behaves almost like a simple parachute.

Such are the precautions whose utility was observed before my work. But today, though still useful, they are far less important than the respiration of superoxygenated air. Thanks to this, and to this alone, all the dangers of decompression can be braved with impunity. I have verified this experimentally upon myself, as you have seen, 
To be completely safe it is necessary only to breathe an air whose oxygen content rises proportionately as the pressure falls; so that the oxygen tension may always remain the same, or at least always be equal to, if not higher than, that which exists in the air at normal pressure. In balloon ascensions, nothing is simpler to carry out, since space is not wanting.

Therefore there should be fastened to the ring of the balloon two bags of goldbeater's skin, one of which, filled with a mixture containing $70 \%$ of oxygen, will serve for heights from 5000 to 7000

meters: oxygen tension at 6000 meters $=70 \times \frac{35}{76}=$ about 32 . The other, as pure as possible (95\% in practice), will serve for the greater heights: at 9000 meters, the oxygen tension of the mixture will be about $95 \times \frac{24}{76}=30$, that is, it will be double that of ordinary air at 2700 meters. The size of the bags should be calculated to provide 10 liters per man and per minute of stay in dangerous regions; so, in the fatal and glorious voyage of the Zenith, to avoid all danger and gain advantage from the whole ascent, they should have taken 1300 liters of the first mixture and 1800 liters of the second, ${ }^{23}$ that is, about 3 cubic meters in bags of a 9 meter capacity, because of the extreme expansion of the gas at these heights. But this quantity, I must say, would have been absolutely the maximum.

I cannot recommend too strongly that at 5000 or 6000 meters a direct and compulsory connection be made between the oxygen bags and the mouths of the aeronauts, by means of a mouthpiece like those of the Galibert or Denayrouze apparatuses. If such a precaution had been taken for the Zenith, there would have been no disaster to deplore; simply recall the touching account of M. G. Tissandier: "I wanted to seize the oxygen tube, but I could not raise my arm." If he had had the tube in his mouth, they would all have been saved!

\section{Mountain travellers.}

The conditions in which mountain travellers are placed differ from those of aeronauts in two important points: A. the muscular efforts required by the act of ascent; $B$. the relative slowness of the ascent and the duration of the stay in lofty places. 
A. Muscular effort. The muscular contractions and the production of work necessary to raise the weight of the body require an active consumption of oxygen, for which, at ordinary levels, the acceleration of the respiration would suffice. But when the quantity of oxygen in the blood is considerably lowered, the new expenditure cannot be met without serious disturbances.

And so it is not surprising to see mountain sickness appear at levels considerably lower than balloon sickness; it is generally quite pronounced at 4000 meters ( $46 \mathrm{~cm}$. pressure); almost everyone experiences it at the top of Mont Blanc (4800 meters; $41 \mathrm{~cm}$.). Most of the travellers in the Andes and the Himalayas feel most acute suffering when they pass above the height of 5500 meters (38 cm.), as did the brothers Schlagintweit when on Ibi-Gamin they reached 6880 meters $(32 \mathrm{~cm}$.) ; and yet these brave travellers were already acclimated by a long stay in lofty regions.

The data furnished in my experiments by the birds which, on account of their restlessness, were threatened by death in a decompression which hardly affected their more quiet neighbor; the impossibility of moving at a certain stage of decompression, and in travellers, the extreme lassitude, the necessity of stopping at almost every step, the amelioration which follows rest, especially horizontal rest, all these things are entirely explained by the knowledge we have of the scanty oxygen supply of the blood at great elevations.

Our analyses of the gases of the blood permit us to reject $a$ posteriori, as we have already done a priori, the theory of M. Gavarret on the poisoning of mountain climbers by the excess carbonic acid which they have produced. We have seen, in fact, even in the animals which have been insecurely fastened on their board or table, and which contract their muscles strongly in constant movements, that, far from increasing, the carbonic acid always diminishes.

Let us examine now more closely the question of oxygen consumption, and let us compare our mountain traveller to the aeronaut of whom we spoke before: let us suppose, for the sake of convenience, that it is the same individual, having at normal pressure 20 volumes of oxygen in 100 volumes of arterial blood and 12 volumes in venous blood. Imagine him transported to 3600 meters and at rest; his arterial blood will contain 16 volumes, his venous blood 8 volumes, supposing that there is no change in the intensity of the metabolic processes and that no functional trouble has developed. But now he contracts his muscles, walks, and continues 
to ascend by a series of efforts requiring a consumption of oxygen. Since the research of Claude Bernard, corroborated by that of Ludwig and Sczelkow, we know that there is a difference of about 12 volumes per cent of oxygen between the arterial blood entering a muscle and the venous blood leaving it during the contraction, a difference that amounts to only 8 volumes while the muscle is at rest. If then we suppose that all the consumption of the oxygen of the traveller's blood is due to muscular metabolism which is increased in the proportion of 8 to 12 , the venous blood should contain only $12: 8=8: x=$ about 5 volumes of oxygen; at 5100 meters, the oxygen content of the venous blood should fall from 6 to 4 , as the muscles pass from the state of repose to the state of general contraction; at 6600 meters, it would be reduced to 1.3 ; and all we said above about the difficulty of dissociating the weakly oxygenated combinations of the hemoglobin, shows the dangerous consequences of this exhaustion which our calculations show must take place. Either the exhaustion will be complete, and then the blood which returns to the right heart will be entirely stripped of oxygen and the respiratory exchanges will restore to the arterial blood only a quantity of oxygen that is still less than what was there after the period of rest; or the exhaustion will be hindered by chemical difficulties, and then the muscle, not being able to find a sufficient quantity of oxygen, will stop in its contraction. For one or the other reason, the traveller, after a few steps, is forced to stop immediately, under pain of asphyxia: so he stops, and the venous blood which leaves the muscles in repose, still containing a considerable quantity of oxygen, can go into the lungs to take up what the physico-chemical law of dissociation permits it to take into the expanded gaseous medium. When the percentage has risen sufficiently, a new effort is possible, followed soon by another halt. This has happened to all travellers in lofty regions, as the data reported in the historical part of this book prove superabundantly.

Of course the calculations which we have just made give exaggerated results in this sense, that the body is not all muscles, and that not all the muscles contract at once in the act of ascent. But on the other hand, we have spoken only of static muscular contraction, without taking account of work to be done. Now it is probable, without our being able to consider this allegation as demonstrated today, that a muscle which produces work while it contracts consumes more oxygen than a muscle which contracts statically. 
If, in fact, the consumption of oxygen was the same in both cases, the heat of the muscle should be less when there is work produced; now, Heidenhain has shown that on the contrary it increases, which demands a greater consumption of oxygen. We are therefore justified in believing that the elevation of the weight of the body in the act of ascent increases still more the amount of oxygen taken from the venous blood by the muscles contracting and consequently increases the distress of the organism.

This explains the well-known fact that in lofty regions, while walking on a level is easily endured, the ascent of the smallest hills brings on serious disturbances.

What we have just said of the mountain traveller, and what we said before of the aeronaut, permits us to handle the question of the chilling of the body during the act of ascent. The theory of Lortet and Marcet states that, in conditions of decompression where the temperature remains constant in a state of repose, it drops when the ascent, which requires enormous mechanical labor, produces it at the expense of the heat developed by the organic oxidations. I shall say first that in my opinion there is no transformation of heat into mechanical force in the organism; everything seems to me to show that when forces of tension are set free under the form of vital force in consequence of oxidative processes, heat, electricity, and work are produced at the same time, in proportions which vary of course, but whose variations are initial and do not depend on subsequent transformations. We must then ask ourselves whether it may be, not that heat is transformed into mechanical energy, but that the forces of tension, as they develop, give out less heat in order to meet the requirements of mechanical labor. When the question is put in this way, we must confess that up to now the observations which bear out this theory can be challenged, since the buccal thermometer cannot give accurate results while walking is continued. M. Forel, in a recent work, and M. Calberla, who took the rectal temperature, have always observed an increase of temperature during the act of ascent. And yet, I am persuaded that in higher regions, the statement of M. Lortet would be verified. In our experiments we have seen motionless animals grow cold as a result of the diminution of pressure; I am persuaded that if, at that moment, we had exacted of their exhausted organism a production of mechanical work, their temperature would have dropped still more, because, having already passed the limit of equilibrium and having shown themselves unable to oxidize their organism sufficiently to keep it in the ranks 
of animals with constant temperatures, they would not have been able to release the necessary increase of tension strength, and consequently they would have had to deduct from the production of heat the vital force necessary to execute this work. Now it is possible that even at the limit, when the temperature still remains normal during rest, there is a slight drop in it at the moment of the new expenditure required by the vertical propulsion of the body. I cannot stress too strongly the interest which would be presented by thermometric researches carried on, with all necessary precautions, and during the act of ascent, upon persons already suffering severely from mountain sickness; but perhaps our European mountains are not high enough to permit us to observe a drop of temperature, even in these conditions.

It has been thoroughly demonstrated, at any rate, that chilling of the body is not the cause of mountain sickness, which occurs without modification of the inner temperature.

I do not mean, as I have observed in speaking of aeronauts, that exterior cold plays no part in the matter of mountain sickness. On the contrary, its importance is great because it increases the oxygen requirements of the organism which is struggling to preserve its equilibrium. Indeed it is evidently this necessity of struggling against cold, a new cause for the consumption of oxygen, a new cause for the impoverishment of the blood, which explains why, in our icy Alps, mountain sickness strikes most travellers at heights which are quite harmless in the Cordilleras; here, the limit of perpetual snows is 4800 meters; there, only 2700. Provision must be made for warming the body at the same time as for the muscular efforts of the ascent.

B. Duration of the Ascent. The duration of mountain journeys, much longer than that of balloon ascensions, is a favorable condition, as we said when speaking of the ascensions. The traveller, compelled to mount the slopes slowly, avoids the harmful effect of sudden modifications in the oxygen content of the blood; he can hardly in a day's march mount more than 3000 meters, and then, if he has not reached the summit, he must rest, pass the night, in a word, become accustomed to the state of anoxemia he has reached. This is so true that in the first part of this book we could have explained a part of the peculiarities of mountain sickness in the different regions of the globe by the form of the mountain mass, or the more or less isolated situation of the peak to be climbed.

We have also shown how a better use of muscular strength, due to the habit of exercise in the mountains, explained the much 
greater resistance to the sickness presented by travellers after a few preliminary ascents: the expenditure of strength is thus reduced to its minimum.

For all these questions, for the influence of fatigue, of cold, etc., we refer to the summary already presented of data that have long been known (pp. 315-328). Now that we know that everything is explained by the diminution of the oxygen of the blood, we understand how a useless excess of muscular contractions can more rapidly bring the anoxemia to its asphyxiating degree, and cause the sickness.

As to bad or insufficient nutrition, it is clear that if the oxidable materials are not furnished in suitable quantity, the difficulties of the organism, in the expanded air, in maintaining the necessary combustions, will be increased by so much. But there is nothing there, except the intensity, which is peculiar to lofty places; the expenditure upon which M. Dufour has justly insisted will take place to the same degree in every ascent, whether it is below 1000 meters or above 4000 , and yet the subsequent phenomena will be very different.

As to a more precise analysis of the causes and the value of acclimatization, it seems to me that it will be better placed in the following section, when I speak of the dwellers in high places.

Prophylaxis. To take precautions against the cold, to eat suitably, to reduce muscular efforts to their minimum, to train oneself by preliminary ascents and by a prolonged stay in lofty regions, to spend the night before the main ascent as high as possible, not to hurry on steep slopes, to break the ascent by frequent halts, to eat little and often, such are the general precautions suggested by all we have said.

The use of oxygen, that sovereign protector against the dangers of rarefied air, here presents much greater difficulties than for balloon ascensions. It is impossible, of course, to carry bags of oxygen containing several cubic meters up a mountain. Only two means present themselves: to enclose in solid receivers the necessary provision of oxygen, compressed to several atmospheres; or to prepare the necessary oxygen extemporaneously on the spot, from time to time.

To study the possibility of the first means, I applied to $M$. Denayrouze, who put at my disposal an apparatus composed of two cylinders of sheet steel one millimeter thick, capable of enduring a pressure of 40 atmospheres, which one could carry on his back like a tourist's pack: the two cylinders combined being only $36 \mathrm{~cm}$. high 
and $26 \mathrm{~cm}$. wide, and weighing with the Denayrouze regulator only 13 kilograms. The volume of the cylinders being 11 liters, one would have at 30 atmospheres, a pressure which presents no dangers, 330 liters of oxygen, ${ }^{24}$ which one would evidently have to take as pure as possible, that is, in practice, at 95\%. But since the respiration of pure oxygen is not at all necessary, I had a tube made in the form of a $\mathrm{Y}$, which serves to mix in proper proportions the oxygen of the receiver with the outer air; one of the branches, which opens out, is free; the other, which communicates with the cylinders, has a graduated bolt, by means of which its caliber is narrowed more or less, according to specifications calculated in advance, so as to maintain the oxygen tension at a sufficient degree.

Supposing that one breathes, on the average, air with $45 \%$ of oxygen, the volume available would become 660 liters, which could suffice for the continuous respiration of a man for more than one hour. But in practice it would not be necessary to breathe superoxygenated air constantly. On Mont Blanc, the mountain in Europe where these symptoms are at the maximum, this provision would be enough for the most susceptible of travellers, and on the average could guard two or three travellers from what is sometimes so painful in mountain sickness; they would only have to come from time to time, in difficult places, to breathe some whiffs of this gaseous cordial, to drink some gulps of oxygen, according to the picturesque expression of Sivel. But we see that the use of this means would be rather difficult and inconvenient in very lofty regions, where superoxygenated breathing should be almost continuous, and even, we must confess, dangerous, if a violent fall of the man carrying it should break the apparatus.

It certainly would be much better to be able to produce oxygen from time to time, at necessary halts, to meet the needs, instead of storing it up in little bags. But I do not now know any chemical reaction which can be managed easily without the transportation of fragile or heavy instruments, or, in a word, in conditions practical for ordinary ascents. But scientific expeditions of long duration, like those which sojourned for weeks in the lofty regions of Thibet, Ladak, and Pamir, could and even should carry with them the equipment necessary to procure oxygen under given circumstances. It is rare, no doubt, that anyone dies exclusively from the effects of rarefied air, although we have mentioned examples of this kind of death; but its fearful influence increases rapidly the dangers of all the maladies which jeopardize the oxidation of the blood. I am 
convinced that if Dr. Stoliczka could have breathed oxygen from time to time, he would not have perished thus in two days.

Whatever the difficulties of practical realization, it is certain that, by the respiration of super-oxygenated air, the summit of Mount Everest, the loftiest mountain of the globe (8840 meters), is no longer theoretically inaccessible to man, since I myself without impediment have reached the pressure of 248 millimeters, which corresponds exactly with that of this prodigious height. Now at this level Glaisher fell inanimate in the bottom of his basket, and Crocé-Spinelli and Sivel died 200 meters lower.

3. Dwellers in High Places.

We have seen in the first part of this book that human habitations are found at the level of 4500 meters in South America and the Himalayas; on the summit of Pichincha (4860 meters) humming-birds are numerous; the lapwing "seems at home" at 5500 meters on the high plateaux of Little Thibet. These are extreme limits. Lower, between 2000 and 3000 meters, millions of men live grouped in cities and nations, in conditions where dwellers on the seashore almost always feel painful, sometimes unendurable, effects, when they are suddenly transported there. Finally, on hills of about 1000 meters, not only are there large populations, but the dwellers on the seashore usually feel-at least for a time-more active, more nimble, and stronger there than in their native haunts.

Let us examine successively these different points.

Slight heights.-We place their upper limit at about 2000 meters. The impression which they produce upon the traveller who comes to stay there for several weeks or months is, as we have just said, generally favorable. Let us refer to what we said of the aeronaut carried by his balloon to a corresponding level; the same observations will apply to our traveller. There should be first a tendency to a decrease of the blood oxygen, a decrease for which the acceleration of the respiration and the circulation will probably provide sufficient compensation. These accelerations are real, as the observations of M. Jaccoud (p. 297) and M. Vacher (p. 960-1) prove. The respiration even becomes more ample, "so as to set to work certain indolent regions of the lungs which ordinarily take only a very small part in the inspirational expansion; these regions are the upper parts of the organs." According to Dr. Armieux (p. 298-9), the result is a considerable increase of the thoracic capacity, whose circumference gains an average of 2 to 3 centimeters. Now this increased amplitude of respiratory movements is of great impor- 
tance; not only does it introduce a greater quantity of air into the lungs in a given time, but this air is distributed better and more usefully in the respiratory tree. M. Gréhant ${ }^{25}$ shows that, although the coefficient of ventilation is 0.060 for inspirations of $300 \mathrm{cc}$., it becomes 0.159 for inspirations of $600 \mathrm{cc}$., that is, much more than double for double inspirations. So, he says, and this is not the least interesting among the results of his fine studies: "Thirty-six inspirations of $300 \mathrm{cc}$. made in one minute (10.8 liters) will not renew the gases of the lungs as well as 18 inspirations of a halfliter each (9 liters) p. 537)." That is a consideration which we have not taken into account till now.

The circulatory apparatus also comes to the rescue. M. Mer$\bmod ($ p. 330) found that his pulse rate rose from 62 to 66 , then to 68 , living successively at $300,600,1100$ meters of altitude. Now, as we have said, the greater rapidity of the irrigation of the tissues by the blood should on one hand compensate for the slight deficit of oxygen, and on the other, diminish, by a sort of washing, the proportion of organic wastes retained in the tissues.

Finally, the foreign volatile substances should disappear from the blood, and the carbonic acid lessen there; this decrease is slight, of course, since at 1500 meters $(63 \mathrm{~cm}$.) it should be about 3 volumes out of 40 (See Figure 31 ), supposing that all other conditions are equal; but no one can state that it is absolutely unimportant, and we may think that it is, on the contrary, favorable to the energy of the vital faculties. First, such a diminution takes place in the venous blood (See Figure 40), and consequently in the tissues on which, as I have shown, this acid acts as an anesthetic. We know, furthermore, that the functioning of the muscular and nervous systems results in the formation of lactic acid, and that the accumulation of this acid is very dangerous to the soundness of the organic functions. Now we have seen that the arterial blood almost never contains any dissolved $\mathrm{CO}_{2}$, and that almost always, on the contrary, its bases are not absolutely saturated with carbonic acid. If then the alkalinity of the blood increases, the effects of the formation of lactic acid can more easily be compensated for, and a feeling of better health may be the consequence.

Let us add that these changes in abode, generally planned for reasons of health or pleasure, take the traveller from customary bad conditions of life, subject him to baths of air, to exercise, to more strengthening diet, make digestion easier, compel him to rest his nerves, and stir his blood with the sight of the splendors of nature, 
all these circumstances being procured most satisfactorily by sojourn in the mountains.

Great heights. But let us suppose our traveller transferred suddenly from the seashore not to Chamounix (1020 meters; $67 \mathrm{~cm}$.) or to Davos (1650 meters; $62 \mathrm{~cm}$.), but to La Paz (3720 meters; 48 $\mathrm{cm}$.), or especially to Cerro de Pasco (4350 meters; $44 \mathrm{~cm}$.). If he had, according to our usual hypothesis, 20 volumes of oxygen in his arterial blood and 12 in his venous blood, and nothing else was changed in him, he would have no more than about 16 or 14 volumes in the arterial blood, with 8 or 6 in the venous blood. We have seen in the first part that, without the slightest doubt, at Cerro de Pasco, especially if the action of the cold intervenes, he will be attacked by the soroche (mountain sickness), whose severity will be increased when he tries to walk, climb, or, like d'Orbigny, waltz. The calculations which we made in the preceding section in regard to mountain travellers, will give us a sufficient account of these symptoms.

But very likely he will seem to become habituated progressively to this state of affairs, especially at La Paz; after some time, he will no longer feel the soroche when he is in a state of repose, and will experience its disastrous effects only if he indulges in violent exercise. He may even escape these entirely; he is, or seems to be, as they say, acclimated. Is something changed in him then?

We might ask first whether, by a harmonious compensation of which general natural history gives us many examples, either by a modification in the nature or the quantity of hemoglobin, or by an increase in the number of the red corpuscles, his blood had become qualified to absorb more oxygen under the same volume, and thus to return to the usual standard of the seashore. The dark color of the blood observed formerly by Dr. Jourdanet during surgical operations would not be a positive objection to this hypothesis, since we have seen that the red color of the blood depends not on the quantity of oxygen it contains, but on the proportion between this quantity and that of the hemoglobin. But it is very certain that such a change, if it takes place, requires a very long time; it is even probable that it can come about only through inherited dispositions, and can come to complete development only at the end of successive generations, so that it would explain the acclimatization, not of the individual, but of the race. But even in this case it is far from being proved; let us add that it would be desirable and very easy ${ }^{26}$ to test by direct experiment the hypothesis which I propose without having any great confidence in it. 
But after all, acclimatization, at least apparent, not only of natives but also of temporary residents, is a certainty, when the elevation does not exceed certain limits. How does it happen? To say that they have become accustomed to these new conditions explains nothing, although ordinarily we are compelled to use this vague expression to designate everyday observations. How does it happen that a certain day of average temperature seems to us warm in winter, chilly in summer? That a certain room with closed shutters is dark at first, whereas its slightest details are lighted up after a few minutes? In the particular case we are discussing, we understand very well that, on the one hand, organs accustomed to being irrigated by an arterial blood with $20 \%$ of oxygen, accustomed to live by borrowing from this blood 8 volumes of oxygen easy to dissociate, complain and revolt when the arterial blood brings them only 16 volumes, from which it becomes harder to extract the 8 volumes necessary for inner consumption, and that, on the other hand, at the end of a few days or weeks of more or less painful transition, they progressively alter their first impression, exert themselves, and are more able to manage the somewhat more difficult dissociation to which they are forced. But all this, to tell the truth, is only a paraphrase of the expression "habit," and explains little; we need to know what this inner modification of the tissues consists of, and today we are unable to get the least idea of it.

What is really certain is that this traveller, now a dweller in lofty altitudes, does not even try to struggle against the decrease of oxygen in his arterial blood by speeding up his respirations excessively, as was at first supposed. The observations of Dr. Jourdanet are conclusive (p. 265). And that is easily understood. First the gymnastics which one must perform to ventilate his lungs with the same weight of air at $48 \mathrm{~cm}$. as at $76 \mathrm{~cm}$. evidently cannot be kept up, even for a few minutes. In the second place, they would hardly be effective, since our experiments have shown (See Figure 43, graphs B and C) that at this pressure saturation of the blood by perfect agitation cannot add more than a volume and a half of oxygen, and besides, at normal pressure, there is usually the same average difference between the oxygen content of the arteria! blood and its maximum capacity. However a slight increase of this sort would not be useless, and it could be produced either by an acceleration or by a greater amplitude of the respiratory movements. The first phenomenon does not take place, according to M. Jourdanet; the study of the second would present great difficul- 
ties; one would have to place a gas meter on the course of the inspired or expired air, observe the respiration for a very long time to eliminate occasional modifications, and make observations either on the same person alternately on the seashore and at a great altitude, which would be the best but the hardest, or in a very great number of persons to get averages.

If we suppose, as is probable, that the pulmonary ventilation has changed little or not at all, and if, on the other hand, the organic consumption has remained at the same degree, the result will evidently be that the percentage in volume of carbonic acid in the expired air will have increased in inverse proportion to the pressure. At a half-atmosphere, in this hypothesis, it will have doubled; at two-thirds of an atmosphere $(50 \mathrm{~cm}$. pressure, 3300 meters, nearly the height of Cuzco) it will have increased by a third, and the $4.3 \%$ average on the sea level have become 6.5 ; at Mexico $(58 \mathrm{~cm}$.), where Coindet made his unfortunately unprofitable experiments (p. 266 and 277), it should be $58: 76=4.3: \mathrm{x}=5.6$. These are data which it would be easy to study on the spot; a flask of 200 cubic centimeters in which one would make a score of expirations, so as to renew the air in it completely, could, if provided with a closely fitting heated rubber stopper, serve for distant analyses; I would make this suggestion to travellers sojourning in lofty regions, or even to mere mountain climbers.

But very probably the proportion for acclimated individuals will be less than the calculation requires; in other words, very probably the intensity of the respiratory combustions will have decreased. And this probably constitutes what is called acclimatization in lofty regions; I imagine that its cause is simply a lower consumption of oxygen in a given time, an economy in the combustions, which within certain limits does not hinder the completeness of organic functions. I realize that I am leaving the solid ground of direct experimental results to undertake a hazardous journey in the unsteady realm of hypotheses; but what does it matter, if the hypothesis leads us, not to imprudent conclusions, but to new and fruitful researches? In this, as in so many other matters, nothing ventured, nothing gained.

Let us see then.

Now I am persuaded that at normal pressure, we consume much more oxygen in a given time than is necessary to maintain our temperature at its normal and constant level, and to meet the demands of forces required for muscular and nervous acts. Let us examine the figures as the present state of science furnishes them, 
but making reservations ${ }^{57}$ about the exactness of the values which we are obliged to use; at least they give us an approximation.

Let us suppose that a man weighing 60 kilograms produces in 24 hours 2800 kilogram calories,, 8 and let us consider first the expenditure of heat which he would need to maintain at the normal level (on the average, $38^{\circ}$ ) the mass of his body in an air whose temperature is $19^{\circ}$.

If we assume that this man admits to his lungs in 24 hours 12 kiloliters of air, whose temperature will be raised from $19^{\circ}$, we shall find, since the calorific capacity of the air is 0.26 , that there will have been expended thus in calories $12 \times 19 \times 0.26=59.29$ calories. The pulmonary evaporation of 500 grams of water (probably a maximum quantity) will necessitate a loss of 292 calories (the heat of vaporization being 0.582 ).

The heating of drink and food, the excretion of urine and the faeces causes a loss of heat which Helmholtz estimates at $2.6 \%$ of the total loss, here some 65 calories.

Here then is a known expenditure, which I admit is necessary, of $59+292+65=416$ calories. There remain about 2500 calories lost; 1 , by cutaneous radiation and the contact with the air; 2 , by cutaneous evaporation: this is on the average estimated at 1 kiloliter, consuming thus 582 calories. Are these losses justified, in the circumstances in which we are placed, by the physical necessities of maintaining at the temperature of $38^{\circ}$ a body weighing 60 kilograms, having about $13,000 \mathrm{sq}$. cm. of surface, with a caloric capacity about equal to that of water, and surrounded by air at $19^{\circ}$ ? That is what I should like to be able to settle here. Unfortunately, scientific data at present do not permit us to settle this problem, ${ }^{29}$ and we should have to undertake special researches on this point.

A priori, I cannot help believing that it is needless to lose by simple cutaneous evaporation a kilogram of water per day, and consequently 582 calories; this expenditure can be justified only by an excess of heat produced, which radiation and contact cannot throw off. How can we understand that heat is produced with the sole purpose of losing it afterwards? This excess appears much greater when we consider the human body producing work; the unutilized heat becomes so great that an abundant sweat must remove it by evaporation. Now it may very well be that mountain dwellers have a better regulated machine, which, instead of devoting to work only $18 \%$ to $20 \%$ of the force expended, is considerably more efficient, and consequently, for the same dynamic expenditure, requires a smaller absorption of oxygen and of food. 
We see that very probably, in the habitual conditions of our life, we commit excesses of oxygenation as well as of nourishment, two kinds of excess, which are correlative. And just as peasants, who eat much less than we do, by utilizing all that they absorb, produce in heat and work a useful result equal, if not superior, to that of city dwellers; just as a Basque mountaineer furnished with a piece of bread and a few onions makes expeditions which require of the member of the Alpine Club who accompanies him the absorption of a pound of meat, so it may be that the dwellers in high places finally lessen the consumption of oxygen in their organism, while keeping at their disposal the same quantity of vital force, either for the equilibrium of temperature, or the production of work. Thus we could explain the acclimatization of individuals, of generations, of races.

But we should consider not only the acts of nutrition, but aiso the stimulation, perhaps less, which an insufficiently oxygenated blood causes in the muscles, the nerves, and the nervous centers. We have no measure of these factors, but it is probable that it is a serious matter for these delicate organs, aside from questions of oxidation, to receive an arterial blood containing 20 or only 16 volumes of oxygen, and we certainly may think that in the latter condition, they will tend to be less active on the average.

The consideration of the changes in the carbonic acid content of the blood, which we have somewhat neglected up to now, should, it seems, take us longer, now that we are dealing with a long sojourn. In the cities of an altitude of about 4000 meters, to which in imagination we have transported our traveller, the carbonic acid will have diminished by 6 to 7 volumes, assuming that 40 volumes are the average at sea level. The blood and consequently the tissues will therefore become quite alkaline, and this modification must have consequences whose importance we guess, without being able today to determine their nature.

In fact, according to the observations of $M$. Jourdanet, the dwellers in high places, even the native Europeans, are almost all anemic, ${ }^{30}$ in spite of the appearance of health. Diseases, whatever they may be, especially those which attack the respiratory organs, hamper the absorption of oxygen, and bring out this sort of latent anemia, due, not to the lessening of the number of corpuscles, but to the lessening of their oxygenation, an anoxemia, adopting the happy expression of my learned colleague and friend. Bloodletting, to which one might resort in memory of medical practice at 
low levels, is harmful, and tonics, on the contrary, are really beneficial.

First among these tonics we should place respiration of an air slightly superoxygenated or an air compressed so as to restore normal tension. I am convinced that establishments like those of Junod, or Pravaz, or Tabarié would render great services at Mexico, La Paz, Cuzco, and Cerro de Pasco, especially to new-comers and invalids.

But I shall stop now without drawing any conclusion. It has been enough to show in what physiological conditions the dwellers in high places must be, and how they can accustom themselves to these serious disturbances. As to the reality and the soundness of this acclimatization in individuals, from generation to generation, and the apparent immunity of certain human races or animal species, these are questions whose importance I understand fully, but which devolve upon the hygienist or the naturalist, and whose solution, besides, cannot be found in laboratory experiments. It is upon experimental ground, which is familiar to me and on which I am sure of my steps, that I shall obstinately remain.

\section{Animal and Plant Life at High Elevations.}

The native or imported animals which inhabit the lofty regions of the Cordilleras and the Himalayas present the same problem as the human beings of whom we have just spoken. With both men and animals, the native born, species or races, have infinitely more resistance than those who came to compete with them. The Indian yaks, the American llamas can serve as beasts of burden without suffering where mules and horses often die from the decompression.

Birds can rise still higher than mammals, the condor particularly, which mounts in flight to 7000 meters, and soars for hours at the heights at which the motionless aeronaut begins to feel serious discomforts, and which the brothers Schlagintweit reached on the mountain sides only at the cost of keen suffering due to the rarefied air. Now in my decompression bells, birds showed themselves more susceptible than mammals, and the birds of prey on which we experimented were sick almost as soon as the sparrows. How can we account for this double contradiction in incontestable data?

We have seen that the proposed explanations could not satisfy us, and I confess that I have no other to propose. To attempt one I should first need to master experimental data which are absolutely unknown to me. First, I should have to try in closed vessels the effects of decompression on condors, not menagerie birds, perhaps 
acclimated to the high barometric pressure of our country, but on vigorous condors caught in their usual habitat: conditions difficult to realize. I should also have to know the oxygen content of their blood, and especially, as you can easily ascertain, since I have indicated it above, its oxygen capacity. The amount of blood they contain would also be interesting information. Nothing would be more interesting, after all, than to try to establish their respiratory and nutritional equation by air analyses, by weighing food, and by calorimetric measurements.

Perhaps, after all this had been observed, it would be possible to account for the strange resistance which they present to the effect of rarefied air, even while they are performing the considerable work of ascent by flight.

In finishing this chapter, I shall recall the fact that plants, for the same reason as animals, are affected by the lessened tension of the oxygen which they respire in lofty regions. This element ha.s till now been neglected by botanists, rightly preoccupied with the study of the geographical distribution on the mountains, of the influence of temperature, of the intensity of the solar rays, and of the hygrometric conditions. Usually they do not speak of it, or they deny its importance. For example, M. Radau, ${ }^{31}$ mentioning the fact that certain mountain plants cannot live in our country with temperatures like those of their native land, says expressly: "Atmospheric pressure has probably nothing to do with data of this sort." But my experiments show that vegetation, and germination perhaps even more, are markedly delayed in rarefied air.

They also bring to light a certain inequality of resistance among different vegetable types, the cruciferae seeming less susceptible than the grasses. Finally, and this is an interesting coincidence, we have seen that the phenomena of vegetable life stop precisely at the pressure of $7 \mathrm{~cm}$. of mercury, which is fatal to all animals. It is then at this low oxygen tension (2.5) that organic oxidations in all living beings become so sluggish that they can no longer maintain vital equilibrium.

\section{Medical Applications.}

I make haste to declare that I only suggest this point, which is outside the scope of my studies. Dr. Jourdanet first had the idea of using artificially rarefied air in the treatment of different diseases, notably anemia and consumption (tuberculosis of the lungs). I refer the reader to his books for the study of the results obtained. Both before and after him, residence at lofty heights has been and 
is recommended especially to consumptives; this mode of treatment dates, in the Andes, from the Spanish conquest, and according to Tschudi, doctors abuse it so that "often the invalids lose their lives in the Cordilleras." In Europe, only recently has sojourn in lofty regions and particularly the Engadine been advised; but already it is very fashionable, which proves that it is useful to many society people and probably to invalids too.

I shall only call the attention of the doctors to the advantage which might perhaps be derived in certain cases (fevers or inflammations) from a decompression low enough to take from the blood a considerable part of its oxygen, and even perhaps lower the temperature of the body. It seems to me that this would be an "alterative" medication of great power; but I will stop now, admitting my incompetence in these difficult matters.

1 Here is the list of my notes on this subject, with the dates of their publications:

A.-Recherches expérimentales sur l'infuence que les changements dans la pression baro. métrique exercent sur les phénomènes de la vie. - Comptes-rendus de l'Académie des sciences. Note 1.-Mort dans l'air confiné; diminution de pression. (Session of July 17, 1871.)

Note 2.-Mort dans l'air confiné; augmentation de pression. (Session of August 21, 1871.) 18i2.)

Note 3.-Mort par l'acide carbonique; action torique de l'oxygène. (Session of February 26.

Note 4.-Les modifications dans la pression barométrique n'agissent qu'en modifiant la tension de l'oxygène. (Session of July 1, 18i.).

Note 5.-Les gaz du sang sous diminution de pression. (Session of July 8, 1872.)

Note 6.-La décompression brusque. (Session of August 19, 1872.)

Note 7.-Les gaz du sang sous augmentation de pression. (Session of August 20, 18i2.)

Note 8.-L'empoisonnement par l'oxygène : dose, symptomes; analyse physiologique. (Session of February 17, 1873.)

Note 9.-La décompression brusque : analyse, prophylarie. (Session of March 3, 1873.)

Note 10.-Action toxique de l'acide carbonique. (Session of May 19, 1873.)

Note 11:-Action des z'ariations de pression sur la végétation. (Session of June 16, 1873.) $25,1873$.

Note 12.-Action toxique de l'oxygène : ralentissement des oxydations. (Session of August

Note 13,-Expériences personnelles sur la dépression. (Session of March 30, 1874.)

B.-De la quantite d'oxygène que peut absorber le sang aux diverses pressions barométriques. Proceedings of the session of March 22, 18.5. 28,1875 .

C.-Infuence de l'air comprimé sur les fermentations. Proceedings of the session of June

D.-De l' emploi de l'oxygène à haute tension comme procédé d' incestigation physiologique. Proceedings of the session of May 21, 1877 .

2 Journal officiel of May 22, 1875, p. 3624.

3 Journal officiel of June 14, 1876. p. 4165 .

- Des accidents qu'on observe dans les hautes ascensions aérostatiques. Théses de Paris, 1875.

s Encore un mot sur le mal des montagnes. Bull. de la Soc. méd. de la Suisse romande, 18it, p. 261-264.

${ }^{6}$ Expériences sur la température du corps humain dans l'acte de l'asccnsion sur les mon. tagnes. Third series. Geneva and Bâle, 1874. (Extract from the Bull. de la Soc. méd. de la Sisse romande.)

${ }^{7}$ In a copper mine in the Duchy of Cornwall, the mine of Carn-Brea, P. Moyle found a still lower proportion of oxygen (14.51). Two men were working in it; but he says nothing about physiological disturbances. Ann. de phys. et de chimie, Third series. Vol. III, p. 318-331, 1841.

${ }^{8}$ On the Temperature of the Human Body during Mountain Climbing. Nature, Vol. XII, p. 165,1875 .

Temperature of the Body in Mountain Climbing. Nature, Vol. XII, p. 186, 1875.

10 Ueber das Verhalten der Körpertemperatur bei Bergbesteigungen. Arch. der Heilkunde, XVI, p. 276-281, 1875.

${ }^{11}$ Le mont Lore; Davos. Etude medicale et climatologique. Paris, 187.5.

${ }_{12}$ Comptes rendus de l'Académic des sciences, Vol. LXYVIII, p. 946 and $1060 ; 1574$.

${ }_{13} \mathrm{M}$. Crocé-Spinelli here is mistaken in his refertnce. Gay-Lussac did not suffer from liemorrhage at all. (See in Part I, page 180.)

${ }_{14} \mathrm{La}$ Nature, number of May 1, 1875: third year, first semester, p. 337-344.

15 Les inhalations d'oxygène et l'ascension du Zénith. Répertoire de pharmacie. April, 18i5.

16 L'Aéronaute, July, 1875.

17 This passage is a reply to the statement of M. Faye, that ascensions above 7000 meters were of no practical importance to science. (Comptes rendus de l'Acad. des sciences, Vol. IXXX, ए. $1037,1875$.

1s Obituary. The Geological Magazine, 18it, p. 383. 
${ }^{19}$ Nachrichten uber die letsten Tage der a'erstorbenen $D$. F. Stolicaka. Verhandl. der $K$. $K$. geologischen Reichsanstalt, 1874, p. 2i9-285.

${ }_{20}$ Recherches d'anatomie, de physiologie et d'organogénie pour la détermination des lois de la genèse et de lévolution des espèces animales. First memoir. Physiologie de la respiration chez les oiseaux. Paris, 1875

${ }_{21}$ Contribution a l'étude de la pliysiologie comparée du sang des vertébrés ovipares. Comptes rendus de la Société de biologie, Vol. XXVI, p. 2i8, 18it.

22 Influence de la pression de l'air sur la vie de lhomme. 2 vol. Paris, 1875.

${ }^{23}$ I take these figures from the diagram in Figure 87 ; supposing that the first descent took place regularly, the stay between 500 meters and 7000 meters would have lasted 45 minutes and the stay above 7000 meters about an hour.

${ }^{24}$ By reducing the apparatus to a single cylinder, which each traveller would carry, one could have 230 liters of capacity at a pressure of 30 atmospheres, with a weight of 8 kilograms; by mass. ing three cylinders, carried by a special guide serving several travellers, one would have a capacity of 510 liters with a weight of 17 kilograms. $523-555,1864$

${ }^{25}$ Recherches physiques sur la respiration de l'homme. Journal de Robin, Vol. I, pages

${ }_{26}$ The analysis on the spot of the gases of the arterial blood of thoroughly acclimated animals or the wild animals of high regions (yaks, llamas, especially condors) cannot be made for a long time. But, since the work of M. Jolyet (Comptes rendus de la Société de biologie, 1874) has shown that the capacity of the blood to absorb oxygen does not change after putrefaction, nothing would be easier than to collect the venous blood of a healthy and vigorous man (a.r acclimated European or an Indian) or of an animal, defibrinate it, and send it in a well-corked flask: it would then be sufficient to shake it vigorously in the air to judge its capacity of absorption during life. Fifty cubic centimeters are enough for each analysis.

${ }_{27}$ In this reference see the judicious remarks of $\mathbf{M}$. Gavarret: De la chaleur produite dans les etres vivants, Paris, 1855 , p. 277. After 20 years, they are still applicable to present science.

${ }_{28}$ Lavoisier had found, per kilogram and per hour, a production of 22.9 calories. Barral an average of 23 calories, which would make, for 60 kilograms and 24 hours, 3300 calories. M. Béclari estimates 2500 . (Traité élémentaire de physiologie humaine, section 166. )

2 Péclet worked with this problem in its most general form. (See his Traité de la chalcur consideré dans ses applications. Third Edition, Vol. III, p. 418-453. Paris, 1861.) Two causes cooperate in taking from the body under experiment the heat which must be restored to it: radia. tion and contact with the air. Péclet has found that, within the limits of temperature with which we are dealing, the amount of the cooling by radiation in an hour and for a square meter of surface is expressed by the formula $\mathrm{kt}(1+0.0056 \mathrm{t})$ and that of the loss of air in contact by $k^{\prime} t$ $(1+0.0075 \mathrm{t}), \mathrm{t}$ designating the excess of the initial temperature of the body over that of the ambient medium. Now the coefficient $k$ varies considerably according to the nature of the radiating surface, since it amounts to 0.26 for polished yellow copper and 4.01 for soot: we cannot guess what it is for human skin and for clothing.

On the other hand, the coefficient. $k$ ' depends on the form and size of the body; we can. according to Péclet, by likening the human body to a cylinder 1.70 meters high and 0.12 meters in diameter (surface 12,832 square centimeters) get from it the approximate formula.

$$
\mathrm{k}^{\prime}=\left(0.726+\frac{0.0345}{\sqrt{ } 12}\right) \quad\left(2.43+\frac{0.8758}{V 170}\right)
$$

This amount too would be "only a somewhat inaccurate estimate."

We see that the elements necessary for solving the problem that we have set ourselves are absolutely wanting. To determine the value of the coefficients $k$ and $k$ ', we should resort to direct experimentation, based on the principles indicated by Péclet. It could be done by covering with human skin, freshly removed and kept moist, a hollow cylinder of metal, of about the form and dimensions of the body, filling this cylinder with water at $38^{\circ}$, with an agitating system and thermometers intended to stir the water thoroughly, and following then the decrease of the temperature.

We would thus get the amount of heat necessary to maintain our temperature at its normal degree during repose, in a vertical position and a state of nudity (let us note that we could by this same method study the influence of different kinds of clothing). If the number obtained was considerably less than 2500 calories, we would conclude that our hypothesis is probable.

${ }_{30}$ To support the statement of M. Jourdanet about the real dangers of continued residence in high altitudes, a subject which I am only skimming over, referring to his fine book for a com. plete study, I shall quote the following assertion of Reissacher (Chemische Briefe, Vol. II, p. 48). which I borrow from George von Liebig, p. 450 (Deutch. Archiv. $f$. Klin. Med. f., 1971):

"According' to statements of the managers of the mines of Böckstein, at the top of the Goldberg, in the Rauris (2433 meters, pressure 56 centimeters), miners are unable to work after the age of 40 , and at Rathausberg. on the Böckstein (from 1996 meters, pressure $59 \mathrm{~cm}$. to 2166 meters, pressure $54 \mathrm{~cm}$.), they are past work at $50 .$. . Dogs and cats cannot live on the Goldberg: they succumb to paralysis of the extremities and respiratory disturbances."

${ }^{31}$ Les derniers progrés de la science.-Paris, lefis. D. In8. 


\section{Chapter II \\ INCREASED PRESSURE}

\section{Subchapter I \\ OBSERVATIONS, THEORIES, AND RECENT DISCUSSIONS}

\section{High Pressures.}

The study of high barometric pressures has not been the subject of any recent work. The results of my experiments on the action of oxygen at high tension were accepted without dispute, I might even say without criticism, by physiologists. Similarly, for the effects of sudden decompression and their explanation demonstrated by my researches, no new fact, either in industry or in science, has been produced which can be reported here. I shall except only a very interesting work of M. Guichard, ${ }^{1}$ an engineer with great experience in the use of compressed air and personally very skilled in the use of the diving-suit.

The article of M. Guichard is composed of two kinds of observations. The most numerous relate to the stay in poisonous gases $\left(\mathrm{CO}, \mathrm{CO}_{2}, \mathrm{C}_{2} \mathrm{H}_{4}, \mathrm{SO}_{2}\right.$, etc.); these, in spite of their great practical interest, and the dramatic details of one of them (Observation VIII), have no connection with the subject of our research. In the others, it is a question of respiration in compressed air; I quote two, interesting for various reasons:

Observation XIV. Seven divers were successively seized by epistaxis under a pressure of a column of water of 9 meters. To show the use of a new apparatus for artificial respiration, I descended into a vast masonry basin containing very clear water at a depth of 9 meters. The ascent and descent were executed without any time pre- 
caution, considering the low maximum pressure to be undergone and my practice in enduring it.

I next sent down with more precaution, successively, seven miners, Sardinians by birth, who ordinarily worked at extracting lead ore. Their constitutions were rather weak. They had been exposed for several years to swamp fevers prevalent in the country all summer. These men had a poor diet, eating vegetables and fruits almost exclusively; they slept in the open air six months out of the year. They were in general indolent and did a poor day's work.

These details will perhaps explain why they were all seized by more or less abuhdant nosebleed after having endured four to five minutes, some of them ten, an atmospheric pressure corresponding to 9 meters of water, the total depth of the basin into which they descended. The fact is that without exception they ascended with blood issuing from the nose and in some of them, from the ears.

In general, symptoms of this sort appear only at great depths, 35 or 40 meters, especially when the decompression is too rapid.

Observation XVI. Beginning of asphyxia in a closed vessel under three meters of water. I descended equipped with an apparatus into a little circular basin 3 meters deep and 4 meters in diameter. The water was very muddy, and in spite of the shallowness, vision was almost completely obscured; it was impossible to distinguish anything on the outside. Inexperienced helpers managed the air compression apparatus.

I had lost my bearings during my first steps on the bottom of the basin and the signal cord, which was not secured on the outside, could not help me find the spot where the ladder was which would have permitted me to return. And under these circumstances air suddenly failed me. At least I could use only a reserve provided in the receiver which enclosed me. The total capacity of this reserve of pure air was about 30 liters. Taking on the average 12 inspirations of 75 centiliters per minute, after three minutes I began to breathe an air that had already been breathed. To escape immediate asphyxia, at the beginning I took care to separate from the apparatus the lead weights which held me on the bottom, so that I could rise to the surface. I succeeded easily in detaching one of these weights, but the second was still held by a cord when all effort became impossible to me. I was perspiring abundantly. I had a sensation of intense heat in my head which diminished towards my lower limbs, which seemed cold; my feet prickled.

I breathed very quickly and as if I had not been able to empty my lungs by expiration. This peculiar impression of a conviction that I could not expel the air in my lungs was very distinct. I note it very particularly. Far from suffering from not being able to breathe, I had a feeling that I could not exhale. The sensation appeared to me about like what one would experience if one were buried up to the neck and one's head were in a steam bath at high temperature.

My ears rang and luminous circles appeared before my eyes.

Air returned to me then, and the symptoms disappeared. I recovered in a few minutes, fastened on my weights, and staid ten minutes longer in the water so as not to ascend until I was quite normal. 
I got off with a rather violent headache, which had disappeared the next day. I had stayed about three to four minutes in a closed space containing 30 liters of air. I had a fast, full pulse for the two hours following the experience. Salivation was difficult. I had a few slight chills and stiffness. I slept well- at night.

In the historical part (p. 388) I reported with suitable discretion an account of symptoms observed in the execution of important projects by a large French company. I can speak more clearly today, since the doctor of this company has published a very interesting article on these data. ${ }^{2}$ It dealt with the construction of a bridge over the Limfjord in Denmark; Doctor Heiberg, of Aalborg, reports that the total pressure rose to 4.5 atmospheres; the workmen remained from 2 to 5 hours in the work chamber.

The workmen, after having remained in the bell under compressed air, and having descended into the chamber under this same pressure, which at the end of the excavation reaches $3 \frac{1 / 2}{2}$ atmospheres, (in addition to the atmospheric pressure) all experience the same symptoms; a loud buzzing in the ears, fatiguing respiration, while the pulse beats more slowly, 60 to 70 per minute, a pressure on the eardrum which generally disappears with the movements of swallowing, the nose being closed, a practice which the men always carry out to relieve themselves. Except for the symptoms mentioned above, the men are in good shape while they are working; danger therefore should not be attributed to the pressure of the compressed air. Sometimes the men are inconvenienced by different gases which rise from the bottom of the fjord; once there even occurred an explosion of these gases which burned three workmen severely; but, in general, the stay in the compressed air causes no danger. On the other hand, things are quite different when the men leave and the decompression is carried on too quickly.

The remarkable symptoms of the illness which results are as follows: terrible pains in all parts of the body, accompanied by unendurable pricklings of the skin, great oppression at the heart, harder beats, quicker pulse, 110-130, great heaviness in the head, drowsiness, complete paralysis in the lower parts, the bladder and the rectum, development of emphysemas in several parts of the body, generally on the breast, under the armpits and on the arms, pain at pressure on the spine in the lumbar region.

These symptoms generally appear as soon as the workmen have come out, but sometimes after a delay of several hours. A workman who had come out in good condition was suddenly stricken as he reached home and died immediately.

In some workmen the symptoms disappear at the end of several days; in others, the paralysis persists and often becomes incurable. I have treated two men in whom the paralysis of the bladder and the rectum grew better; sensitivity and motion returned, but the gait remained uncertain. Both of them had to be sent home as unable to continue working. 
Dr. Heiberg then gives interesting details of the autopsy of two workmen whom he had seen die and of the symptoms appearing in the patients he observed. I have already (p. 389) given a very brief summary of the results of one of these autopsies, that of Kiva, but here we are given more detailed information:

Kiva Ferdinando, thirty years old, was attacked, as he left the work chamber, by pains in his limbs, with complete paralysis of the bladder, the rectum, and the lower limbs; he half fainted, cyanosed, his respiration is rattling, there are sounds of moist râle in the lungs, the pulse is weak and rapid. He is taken to the hospital July 26, 1875; his condition does not change, the paralysis remains in the same place, he is continually delirious, then the collapse comes and death occurs July 30 during the night. In the autopsy the lungs are found to be full of blood, with a secretion from the bronchial tubes mingled with blood and a frothy lymph. The spinal cord was quite soft over an extent of several inches in the lower dorsal and upper lumbar region. The softening had very definite limits, without a trace of blood, inflammation, or exudation. In the brain, heart, kidneys, and spleen, nothing abnormal; but my attention was not yet directed to the development of air in the veins, because at that time it was unknown to me.

The other case, which also ended in death, could not be observed while the patient was alive. The workman was returning home seeming well. On the way he felt ill and fell dead as if struck by lightning. The next day the autopsy was performed; the body was already stiff; a deep cyanosis was observed on the body, particularly on the breast, under the armpits, and on the left arm, where a very distinct emphysematous condition could be felt; when an incision was made at these places there issued a bloody lymph with a considerable mixture of air; the spleen, which was very emphysematous, crackled all over its surface at pressure, and when an incision was made, there issued blood mixed with a great deal of air; no air bubbles in the aorta, the jugular vein, the iliac and crural arteries. The kidneys and the liver are in normal condition, the urinary bladder empty, a development of air in the epiploon, the brain not full of blood, very distinct and large bubbles of air in the basilar artery, in the sinus, and in the veins of the upper surface of the brain; among these air bubbles, very small, almost liquid spots of blood. The stomach was much lengthened and contained a certain quantity of vegetable food. No investigation of the spinal cord was made because careful examination of the veins required much time for making the ligatures.

Although these two autopsies are very imperfect, and leave much to be desired, it seems to me that they agree completely. In the first case, in which the symptoms of the disease had developed for several days, and in which bubbles had met and concentrated in the spinal cord, a complete softening occurred entirely in agreement with the experiments of P. Bert. In the second case, in which death was instantaneous before the bubbles had advanced so far, there were 
bubbles of air in the veins of the brain, with emphysemas in several places, both in the interior and on the exterior, and quite agreeing with what P. Bert had observed and reported as being the physiological effect of passing from a high pressure to the atmospheric pressure. The last autopsy seems also to show that three quarters of an hour is too short a time to avoid dangers, when the pressure is $3 \frac{11}{2}$ atmospheres. However it is not impossible that the hearty meal of vegetables which was in the stomach had something to do with the accident.

I treated in the hospital fourteen patients, one of whom died and two were sent home as incapable of resuming work. Eleven cases were less severe; they were cured after several days; in all, the characteristic symptoms were observed in a greater or less degree, particularly severe pains in the limbs, cardiac pressure, painful respiration, cyanosis, pain on pressure along the vertebral column in the lumbo-dorsal region, dragging gait, difficulty in urination; in two cases, complete paralysis of the bladder, rectum, and lower parts, with asthenia. I did not notice the development of emphysemas under the skin; but the workmen state that they exist. I was present at the moment when the workmen left the bell, and I did not observe this symptom; but I should add that none of the workmen whom I examined in this way fell ill.

Since the two cases in which the paralysis improved, but the conditions of the patients remained such that they could not resume their work and had to be sent home, one to Prague and the other to Milan, were very similar, I shall describe one.

Eger Mayer François, 34 years old, strongly built, was taken io the hospital July 23, 1875; he had fallen ill immediately after his exit from the bell; ordinary pains, complete paralysis in the lower parts, bladder and rectum, much pain on pressure on the lumbodorsal regions. Cupping-glasses, induced electric currents, lukewarm baths, and shower-baths were used. After August 1, he could urinate, the paralysis of the rectum continued, there was a little catarrh of the bladder, but the urine was normal. August 18, he could stand erect and walk with crutches, and then with two sticks. His condition improved perceptibly, he took steam baths, nux vomica, and continued the electricity; at last the paralysis of the rectum improved also; he took longer walks, but his gait remained unsteady. November 2, he was sent to Prague, and recently I learned that he had died after quite a long stay in the hospital.

The condition of the second patient was almost the same, only the paralysis of the bladder lasted longer; after a stay of several months in the hospital he could take long walks. But as he could not resume work he had to be sent back to Milan.

The Company of Fives-Lille, which was carrying out this work, having consulted me in regard to these disturbing symptoms, I gave advice as follows: (1) to make the decompression still slower; (2) to set up heating apparatus to spare the workmen the unendurable pains and dangers of a chill in the decompression chamber. 
I had the satisfaction of receiving the following note shortly after from one of the executives of the company:

We have transmitted to our Aalbert Works the information you gave us about the precautions to be taken for men working at high pressures.

We have exceeded the depth of 32 meters below the level of the water, and the symptoms disappeared when the time in the exit lock was increased.

\section{Low Pressures. Medical Apparatuses.}

The effect of low pressures has given rise to only a small number of articles in recent years. But two of them are of considerable importance from the theoretical point of view.

M. J. Pravaz, August 9, 1875, sustained a thesis before the Faculty of Science of Lyons on the effects of an increase of atmospheric pressure, in which he considers successively the circulation, the respiration, and the nutrition.

In regard to the first of these functions he notes, like all former observers, a certain slowing of the pulse during a stay in compressed air, and he explains it: (1) by the increase in the temperature of the body, acting secondarily upon the heart; (2) by the increase of the arterial tension. The latter is supposed to be caused by the direct obstacle to the course of the blood occasioned by the compressed air acting to "drive back from the peripheral parts the blood of the capillaries and veins (p. 23)." We see that M. Pravaz accepts the theory of superficial crushing in compressed air; he considers as proof the strange experience of Vivenot which we reporteci above and rated at its true value. We do not think it worth while to repeat the refutation of these errors.

The respiration, he says, becomes both less frequent and more ample, at least in the neighborhood of a half-atmosphere of compression; beyond (M. Pravaz goes only to two atmospheres), there is a movement in the opposite direction. The explanation of these data is the one which Ch. Pravaz (p. 447) had already given, whose opinions his son adopts on all points. The variations in the amplitude have been measured by the aid of the anapnograph of MM. Bergeon and Kastus: if the extent of respiratory movement at normal pressure is expressed by 100 , it becomes 106 at a pressure of $19 \mathrm{~cm}$., 118 at $38 \mathrm{~cm}$., 109 at $76 \mathrm{~cm}$. But M. Pravaz did not seek to study the relation between the frequency and the amplitude, so as to determine the variations in the output, in the pulmonary ventila- 
tion, or, in other words, in the quantity of air which passes through the lungs in a given time.

The most original part of the thesis is that which relates to the study of the variations in the production of urea. M. Pravaz has made five experiments on this subject:

In the first, he measures the urea voided during 24 hours first at normal pressure, then under increased pressures from $10 \mathrm{~cm}$. to $76 \mathrm{~cm}$.: the urea decreased (average: from $29.6450 \mathrm{gm}$. to 28.4448 gm.).

The second was performed in the same way, with the added precaution of submitting to a fixed and regular diet: increase of urea (average: from $29.1685 \mathrm{gm}$. to $31.4947 \mathrm{gm}$.).

The third, like the second in method, gave a decrease (average: from $27.2401 \mathrm{gm}$. to $26.2224 \mathrm{gm}$.).

In the fourth, the method was changed. The diet was the same (this diet, which seems to me very low in carbon and a little exaggerated in nitrogen, was composed of $250 \mathrm{gm}$. of bread, $200 \mathrm{gm}$. of lean meat, $100 \mathrm{gm}$. of dry cheese), but the urine was collected only in the morning, fasting, for three hours, either in open air, or under pressure. Here, an increase in compressed air (average: from $3.2019 \mathrm{gm}$. to $3.4965 \mathrm{gm}$.).

Finally, in the fifth, performed like the preceding one, the excretion of urea was studied from hour to hour during the stay in compressed air; the averages are: in open air $0.9492 \mathrm{gm}$; during the first hour of compression $1.0758 \mathrm{gm}$; d during the second 1.0651 gm.; during the third $1.0363 \mathrm{gm}$; in the following hour, at normal pressure $0.7178 \mathrm{gm}$.

M. Pravaz concludes from these data:

1). That the excretion of urea increases under the influence of compressed air;

2). That this increase is at its maximum at the beginning of the compression;

3). That it is greater at low pressures (at about $20 \mathrm{~cm}$.) than at high pressures (from $30 \mathrm{~cm}$. to $76 \mathrm{~cm}$.).

4). That after the decompression there is a decrease in the production of urea.

The experiments on the exhalation of carbonic acid, relating only to the percentage of this gas in the expired air, and not to the quantity given off in a given time, could give no really interesting result.

Finally, M. Pravaz thinks he can conclude from his observations on the temperature, that it follows exactly the same course as the 
production of urea: the greatest deviations are, in the rectum, of $0.34^{\circ}$.

I refer to the original article for the reading of the explanations which M. Pravaz gives of the variations in the nutritive phenomena which he thinks he has observed. Personally, I consider that a single experiment does not permit one to draw conclusions, and that one should suspend judgment on the question of whether the combustions really increase only during the first moments of the stay in compressed air. As for the observations which embrace the 24 hour period, the first should be eliminated, since the diet was not regulated. For the two following, no precautions were taken in regard to muscular work: "exercise," says M. Pravaz himself, "was necessarily variable from one day to another, and gave rise to changes in the production of urea, which might introduce into the problem an undeterminable unknown" (p. 43); one should therefore take no account of it. Finally, the fourth presents irregularities which seem to take away all value from the averages he strikes; during three hours fasting, the quantities of urea obtained were:

\begin{tabular}{|c|c|c|}
\hline irst day. & Normal pressure & 3.0075 \\
\hline econd day & $10 \mathrm{~cm}$. compression & 3.1933 \\
\hline day & $19 \mathrm{~cm}$. compression & 3.6990 \\
\hline h day & $38 \mathrm{~cm}$. con & 3.568 \\
\hline & $57 \mathrm{~cm} . \mathrm{con}$ & 3.27 \\
\hline & compressior & 3.7 \\
\hline ever & il pressure & 3.39 \\
\hline
\end{tabular}

We see, besides, that the maximum of production coincided with the highest pressure, which does not agree with the opinion of the author.

Without dwelling any longer on this critical analysis, I quote the general conclusion of M. Pravaz:

If we examine from a general point of view the effects of increase of atmospheric pressure on the animal economy, we are led to distinguish in the action which compressed air exerts two elements: the pressure element and the superoxygenation element.

From the pressure or mechanical element rise principally the modifications produced in the rhythm and amplitude of the respiration.

The modifications experienced by the circulation and the nutrition are the result of the conflict carried on between the superoxygenation element and the pressure element, the first tending, by the superactivity it gives to the chemical phenomena going on in the tissues, to increase the production of urea and carbonic acid, from which come 
the rise in temperature and consecutively the speeding up of the heart beats noticed the first instants of a stay in a denser atmosphere; the second tending, on the contrary, by the modifications it causes in the physical conditions of the flow of the blood and by the increase of the arterial tension resulting, to play a role of moderator by lessening, through the consecutive slowing down of the circulation, the speed of the organic combustions and the production of heat by reason of the stay in compressed air and the rise in pressure. (P. 65.)

Georges Liebig, whose works we have already analyzed (p. 437 and 481), recently published an important memoir, ${ }^{3}$ in which he gave as his special purpose the study of the excretion of carbonic acid at normal pressure (on the average $720 \mathrm{~mm}$.) and in compressed air (on the average $1040 \mathrm{~mm}$.). The person on whom the experiment was carried on was a man 39 years old, weighing 59 kilos, with a lung capacity of 3.9 liters; his mode of life was very regular, and the author gives its details (p. 504); the experiments were always carried on at the same hour. The patient, seated, with a sort of mask over his mouth and nose, breathed for 15 minutes a quantity of air measured by a gas meter; the apparatus used, the description of which we cannot give here, is that of Professor Jolly. ${ }^{4}$ Analyses gave at the same time the volume of air which had passed through the lungs during the length of the experiment (15 minutes), the quantity of carbonic acid produced, the quantity of oxygen which remained in the expired air, from which one derived the quantity of oxygen absorbed, the nitrogen being considered invariable.

I reproduce the summarizing table (Table XXII) of his 37 experiments.

It is upon this important series of analyses that G. Liebig bases a discussion which is not always very clear, and whose principal points we shall try to select.

In the first place, he arranges his experiments in several series, which permits him to compare several averages; these series are established according to the figures in Column 4, that is, according to the quantity of air which has circulated in the lungs for fifteen minutes. At normal pressure, for instance, the first series includes the experiments in which the pulmonary circulation varied from 121 to 130 liters. The numbers of Column 2 of Table XXIII indicate the limits for each of the series; in the other columns are listed the averages which correspond to them.

If we consider first the chemical side of the question, we see that in the general average (Table XXII), as in each individual average of the series of equal rank (Table XXIII), the consump- 
Table XXII

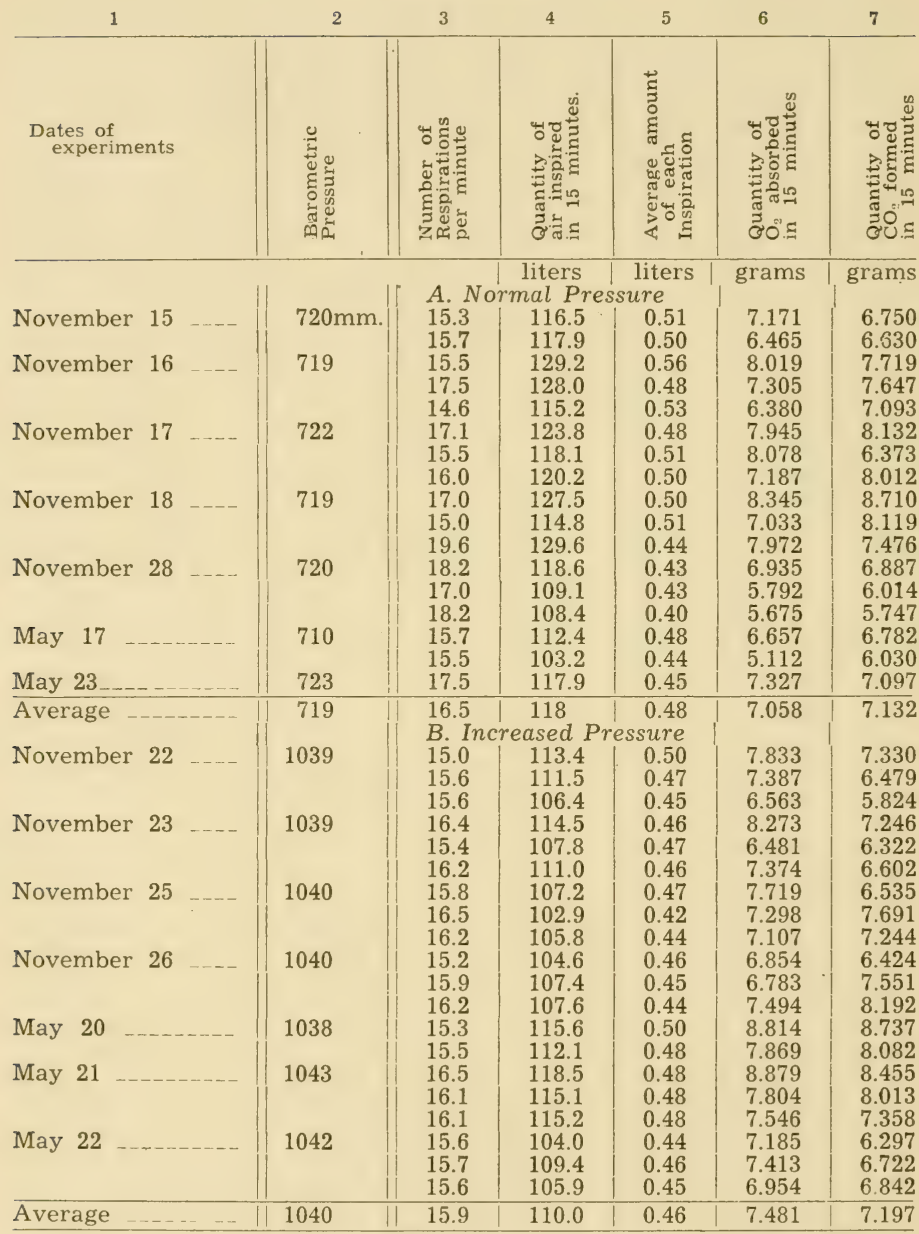

tion of oxygen (Column 6) appeared greater in compressed air than under normal pressure. The general average gives $7.058 \mathrm{gm}$. under normal pressure, and $7.481 \mathrm{gm}$. in compressed air, with extreme deviations going, in the first case, from $5.112 \mathrm{gm}$. to 8.345 
gm., and in the second case, from $6.481 \mathrm{gm}$. to $8.879 \mathrm{gm}$. The difference is much smaller and less constant for carbonic acid (Column 7), if one considers only the averages; however, the examination of the maxima and minima corroborates the idea of a greater formation of carbonic acid in compressed air: at ordinary pressure, indeed, the variations were from $5.747 \mathrm{gm}$. to 8.710 gm., and under pressure from $5.824 \mathrm{gm}$. to $8.737 \mathrm{gm}$.

Table XXIII.

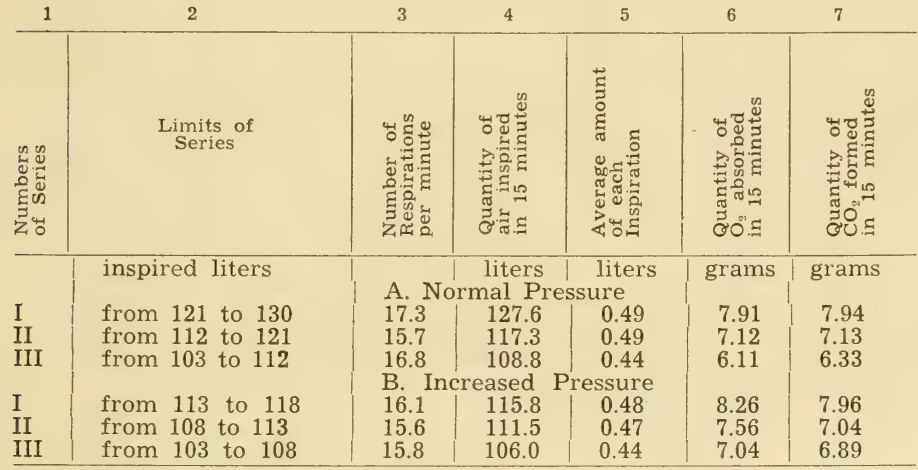

The numbers relating to pulmonary ventilation (Column 4) are also very interesting. First, evidently, there passes through the lungs, in a given time, less air, in volume, under increased pressure than at normal pressure; the general average gives 110 and 118 , with deviations, in the first case, from 102.9 to 118.5 , and in the second, from 103.2 to 129.6 . The number of respiratory movements is also decreased in compressed air; on the average it falls from 16.5 to 15.9 per minute. It results from these two modifications that the respiratory amplitude hardly changes, since it varies on the average only from 0.48 liters (normal pressure) to 0.46 liters (compressed air). Let us add that an attentive inspection of the respiratory movements, holding a watch with a second-hand, would have permitted $\mathrm{G}$. Liebig to note that the respiratory rhythm itself changes in compressed air, the inspiration becoming shorter and the expiration longer: the ratio of duration between these two phases in one of his observations would have passed from $2: 3$ to $1: 2$. He therefore agrees with what Vivenot had said (See Figure 9), and contradicts Panum. 
All these results, which are in harmony with the data already known, are explained, according to G. Liebig, by the mechanical action of the increased pressure:

The mechanical effects of pressure can be explained by the following comparison. Let us suppose a flask covered by an elastic membrane; if one extracts the air from this flask by means of a tube penetrating the interior, he will observe that the membrane is bent inward. The greater the outer pressure, the deeper will be the depression (in the membrane), and vice versa, since its own elasticity acts in a direction opposite to that of the air pressure.

During the inspiration, when the walls of the chest expand, and the diaphragm contracts, a vacuum tends to form around the lungs, and the greater the outer pressure of the air in relation to the elasticity of the lungs, the more easily will this vacuum be filled. The expiration will become more difficult, because the outer pressure of the air offers resistance to the contraction of the lungs.

Panum and Vivenot have shown that the walls of the chest and the diaphragm take in compressed air a state of equilibrium different from the ordinary state, with an enlargement of the thorax. These walls then present a tension from within outwards which opposes the inverse tension of the lungs; both of the two forces are in a determined equilibrium with the third active force, namely, the pressure of the air. If this force is increased or diminished, a change in the equilibrium of the system will be produced. (Page 516.)

Dr. Leonid Simonoff, ${ }^{5}$ director of the aerotherapeutic establishment of St. Petersburg, very recently published an important book on barometric compression, from the medical point of view. The physiological part contains a very interesting summary of previous knowledge, and also an account of a certain number of personal experiences on the variations of weight in patients subjected to aerotherapeutic treatment.

In the course of the year 1873 , Dr. Katschenowsky made observations in my medical service on himself and other persons... . The result is as follows: With quantities of food such that in ordinary air there would be an equilibrium between the ingesta and the excreta, the weight of the body diminishes successively under the influence of a daily sojourn of two hours in compressed air. (Page 79.)

But, M. Simonoff observes, the appetite constantly increases; now if one satisfies it, instead of regulating the diet as Katschenowsky did, the weight of the body increases. Out of 53 persons whom he examined, 32 weighed more after the treatment (on the average, $1077 \mathrm{gm}$. per individual); two had not changed; 19 had lost weight (an average of $786 \mathrm{gm}$. each) (pages 81-92). We must note that all these subjects were invalids, and that the increase of the weight of the body and the appetite seemed to be only an indirect effect of 
the improvement due to treatments. For real proof, one would have to experiment on individuals in good health.

\section{Subchapter II}

\section{SUMMARY AND PRACTICAL APPLICATIONS}

\section{High Pressures.}

The discovery of the toxic action of oxygen at high tension certainly constitutes the most interesting and most unexpected part of this long work. Experiments made on animals and plants, on beings dwelling in the air, as well as those dwelling in the water, on beings of complicated structure, as well as on microscopic monocellular animalculae, and on anatomical elements separated from the body, have shown in the clearest way that above a certain oxygen tension of the ambient atmosphere life becomes impossible, and that death may come with remarkable rapidity.

In warm-blooded animals, the violent convulsive phenomena which we have described (p. 741) appear at once above 20 atmospheres of air; very speedy death takes place above 25 atmospheres; but painful effects are clearly felt at 6 atmospheres, as we have seen by an indirect method (p. 713).

We have given abundant proof that they are the consequence not of the barometric pressure as a physico-mechanical agent, but of the increase in the tension of the ambient oxygen. I refer you for all these data to Chapter IV, subchapter I, where they were studied in detail. I have given there not only the description of the symptoms of poisoning by oxygen, specifications of the lethal dose of exterior oxygen, expressed in tensions, but also that of the oxygen content of the blood which corresponds to the different stages of the exterior phenomena: death occurs quickly when the proportion of this gas has increased by a third in the arterial blood. I also showed there the apparently paradoxical result that under the influence of greater oxygenation of the blood, the tissues oxidize less, the organic combustions lose energy, the production of carbonic acid, the excretion of urea, the intra-sanguine metabolism of sugar are impeded, and that consequently the temperature drops.

These data cease to seem odd when linked with those given in Chapter VI. All the anatomical elements, it is shown there, undergo the formidable effects of compressed oxygen (p. 839); the microscopic organisms which cause true fermentations, are killed by 
this agent; ${ }^{6}$ putrefaction is stopped, and the consumption of oxygen which accompanies it lessens so much that it can be reduced to zero. Now the anatomical elements, in the presence of excessive oxygen, behave like free elementary beings, and when they die, cease to consume the oxygen necessary for the maintenance of their vital acts.

Let us follow this a little further. And first, we have seen for plants as for animals that the pressure of 5 or 6 atmospheres of air (oxygen tension 100 to 120) brings symptoms serious enough for laboratory experiments, which are carried on in a short space of time, to indicate them very clearly. So respiration of pure oxygen at normal pressure (tension 100) cannot be long endured by warm-blooded animals. At about 10 or 12 atmospheres symptoms appear that are quickly fatal, and at about 20 atmospheres, the characteristic convulsions of oxygen poisoning. Now at 6 atmospheres the oxygen of the arterial blood has increased by only 3 volumes; at 12 atmospheres, it has passed on the average from 20 to 25 volumes; at 20 atmospheres, from 20 to 29 (See Fig. 36 ); when it passes from 20 to 35 (example: Experiment CCLXXXVII, 27 atmospheres) death occurs in a few minutes. On the other hand, we have several times stressed this fact, that the arterial blood, in the normal acts of respiration, is almost never saturated with oxygen. When the trachea is opened and there follows, as often happens, a much exaggerated respiration, or when blood is agitated in a flask of air, it gains 3 or 4 volumes on the average.

So the pressure of about 6 atmospheres of air results in introducing into the arterial blood almost the quantity of oxygen which would be necessary to saturate it under normal pressure. And, we have seen, this pressure begins to be harmful to higher organisms. The saturation of the blood would, then, be a harmful condition, and by a happy arrangement, when it is reached, the apnea which ensues prevents it at once from persisting.

From this degree of pressure on, the hemoglobin is saturated with oxygen, and the oxygen which is added to the blood following a progression which approaches Dalton's Law, is only dissolved oxygen, equally divided between the corpuscles and the plasma; and it even dissolves also in the tissues to the same degree, if the stay in compressed air lasts a sufficient time. Now it is a fact of the highest interest that in the presence of this free oxygen that is simply dissolved, the inner oxidations slow up, then stop. It seems that for oxidation the tissues need borrowed oxygen, taken 
from the oxy-hemoglobin, so that in the presence of dissolved oxygen brought by compression, either the tissues become unable to carry out this dissociation, or the corpuscles can no longer give up their oxygen, and remain condemned to perpetual saturation. I know nothing in physiological chemistry more curious than this effect of the presence of dissolved oxygen, having as its result not the activation but the checking of a combination. Whatever are the possible explanations, it is certain that the organic oxidations no longer take place when the blood corpuscle, laden nevertheless with the maximum of oxygen, is surrounded by this sort of atmosphere of free oxygen, dissolved in the plasma, dissolved in the tissues.

We have seen, I remind you again, that this cessation of the oxidizing activity of the tissues takes place in the presence of an excess of oxygen, not only in red-blooded animals, but in all living beings. Now this cessation of vital phenomena is not merely momentary, like that caused in lower beings by the diminution of pressure, but is a real death, a definite death; which shows that very evidently we have to do here not with a simple suspension but with a deviation of the vital phenomena. A seed kept in a vacuum germinates when oxygen is admitted; a dog with the convulsions of asphyxia is restored when given air. But the seed kept under compression will no longer germinate; the dog brought from compressed oxygen to normal pressure may, after twenty-four hours of continuous convulsions, die without having improved. (Experiment CCLXXVIII.) It seems that under the influence of compressed oxygen there is formed in the anatomical elements some toxic product which cannot always be eliminated, and then kills even when its cause has disappeared. To go further than this hypothesis would seem to be imprudent in the present state of knowledge.

The researches of M. Pasteur have shown that microscopic living beings can be divided into groups, one needing for life contact with the air, free oxygen (aerobic), the other (anaerobic) fearing air, on the contrary, and borrowing the oxygen which they consume from organic materials which they separate for this purpose. Now what we have just said shows that anatomical elements grouped in tissues are essentially anaerobic. In the upper animals, where it has been possible to carry the analysis of phenomena to great lengths, we know that they secure their oxygen from the oxyhemoglobin; but when the latter is saturated, the oxygen appears simply dissolved in the plasma and the tissues, the animals become 
ill and die if the experiment lasts long enough, or if the amount of free oxygen is large enough, exactly as do the vibrios of the butyric fermentation $^{7}$ in the presence of atmospheric air. The red corpuscle alone seems an exception, for it appears quite essentially aerobic; but I am inclined to think that that is only an illusion, for this corpuscle itself, when its constituent stroma, its globuline, contains free oxygen after the saturation of its oxygen-loving pigment (hematocrystalline), dies like the other anatomical elements (p. 842). So, in the regular state of things, as we have seen, the hemoglobin is never saturated with oxygen. We must note, furthermore, that the aerobic micro-organisms, like the bacteria, also die under the influence of compressed oxygen; we can then form the hypothesis that they have in them, like the red corpuscle, some material eager for oxygen whose oxygenated combination feeds their own constituent substance. In this hypothesis, all living beings and all their parts taken separately would be anaerobic. At any rate, the parallelism is perfectly established between the red corpuscles and the bacteria on one hand and the anatomical elements and the vibrios on the other. But however different they appear to be, divided here two by two, they are all alike in the death which strikes them rapidly in the presence of a sufficient amount of dissolved oxygen.

Before leaving this subject, let us call attention once more to this new application of the general rule, that when a poison strikes the whole organism, it is the nervous system which reacts first. The dog in compressed air first has convulsions; and these, disturbing the mechanisms whose harmony is necessary for the maintenance of life, kill him before the other anatomical elements are fatally attacked; but for the latter it is only a question of time. His blood is still capable of recalling to life another bloodless dog; but if it is agitated for some hours under oxygen pressure, it will kill the healthy animal into which it is injected, far from being able to save the dying bloodless dog. In the same way, the tail of a rat which has been killed by oxygen can be grafted perfectly; but a longer exposure to compressed oxygen will kill its elements and the graft will be absorbed without suppuration.

\section{Low Pressures.}

Under this title, as I did in Subchapter II of Chapter IV, I in. clude pressures between one and five atmospheres of air, in which the oxygen tension varies between that of air (20.9) and the 100 of pure oxygen. With these tensions, as I have just remarked, 
the arterial blood is not completely saturated with oxygen, although its oxygen content is greater and greater in proportion as we rise above normal pressure.

It is very important for the doctor and the hygienist to study these low pressures, because they are the ones used in therapeutics on the one hand, and in industry on the other. But from my point of view, what seemed most interesting was to find out at what pressure the maximum of intra-organic oxidation took place. We have seen, on the one hand, that from the lowest pressures up to one atmosphere, and on the other hand, beginning with five or six atmospheres and above, these oxidations continue to lessen: where would be the top of the curve which represented these phenomena?

Now my direct analysis of the quantity of carbonic acid exhaled, of oxygen absorbed, and of urea secreted in a given time, and my indirect researches on the rapidity of putrefactions tend to show that it is in the neighborhood of three atmospheres, about the oxygen tension of 60 that the maximum we are seeking is found. The recent experiments of $\mathrm{G}$. Liebig give the same evidence.

But I am the first to recognize that nothing is more difficult than such experiments, and that conclusions are always dangerous. In regard to the production of urea, for example, either we must keep the subject on a very regular diet, and then the excess of oxidation, if there is one, working on the materials of the organism itself, will cease to appear upon exhausting them; or we must increase the amount of food, and then the increase of urea produced will no longer have any possible measure, because we do not know the equivalent in urea of the different foods: upon this last point I have begun researches which are still incomplete. But in spite of all these causes of error, I am struck by the agreement of the analyses of Vivenot, Panum, G. Liebig, and J. Pravaz with mine, and also by the unanimous testimony of doctors and engineers on the increase of the appetite of patients or workmen subjected to compressed air. My conclusions then seem to me at least very probable.

It would follow, if we consider the higher animals, that organic oxidations will increase in intensity as we approach the saturation of the hemoglobin. We can imagine that the maximum point will be where the oxidation takes place most easily, where the last molecules of oxygen are hesitant, so to speak, hardly retained by the hemoglobin, ready to leave it to combine with the tissues; beyond this point, as we saw above, the oxidations lessen.

But on the other hand, the behavior and the speed of develop- 
ment of the lower animals, frog tadpoles, the larvae of insects, kept for a long time under tensions of compressed oxygen between 21 and 100 , show very clearly that even if there is an increase in nutritive processes, there is no better general condition; far from it. Beginning even with 80 , the fatal effect of the oxygen is evidently felt. The same thing is even more true for germinations, which never take place better than under normal pressure.

When I had studied this point, I could not help being interested in the modifications caused by compressed air in circulation and respiration, modifications so often analyzed by doctors. Following many other observers, I noted the decrease in the number of pulsations and the increase in the maximum pulmonary capacity: I found that the quantity of air (in volume) which passes through the lungs during a given time does not change noticeably in compressed air: this point had not been directly investigated before me; I should say that, according to G. Liebig, it would decrease a little (in the ratio of 118 to 100 ).

The most interesting fact which this part of my researches furnished me is the proof that the greater capacity of the lungs is due to the mechanical action of the compression upon the intestinal gases (p. 768). It has another result of lessening the variations of the intrathoracic air pressure during the acts of inspiration and expiration. Finally, I was the first to measure directly the arterial pressure under compression, and to show that it is considerably increased by the mechanical action of the pressure.

Up to now I have been rather severe against the explanations which emphasized the mechanical side of the pressure and have dwelt upon these new observations. But, as I have often said, from this point of view, the pressure can act only on the gaseous reservoirs; it does so for the intestine, which is like a closed bladder, whose volume diminishes following Mariotte's Law, the lung having to follow the diaphragm which drops more; it does so for the thorax, which would be crushed if the tracheal opening did not exist, and which would not be affected at all if this opening were, as it is not, sufficiently wide.

But the relative intensity of this action of the pressure continues to diminish with the amount of the compression; and that is easily understood, for if the intestine loses, in passing from one to two atmospheres, half of its volume, it diminishes only a fourth more in passing from two to four. Furthermore, the increase of the thoracic capacity can represent only a part of the reduction of the volume of the intestine, because the walls of the abdomen fill up 
a proportion which must increase with the pressure, since the diaphragm in its descent meets stronger and stronger obstacles.

\section{Sudden Decompression.}

I think I explained in Chapter VII all that relates to this question, which is relatively simple enough, because it is purely of physical nature. I have shown that all the symptoms, from the slightest to those which bring on sudden death, are the consequence of the liberation of bubbles of nitrogen in the blood and even in the tissues when the compression has lasted long enough.

These few lines are enough to summarize this part of our study, to which we shall return in the following section.

4. Practical Applications. Therapeutics and Hygiene.

A. Therapeutics. I shall refrain, observing in this instance the same prudence as when it was a question of rarefied air, from explaining and judging the applications made since the time of Junod, Pravaz, and Tabarié of slightly compressed air in the treatment of different diseases. However I can affirm, along with so many others, the utility of this treatment in certain forms of asthma and in anemia. But I prefer, after having mentioned these two diseases, to say that the stay in apparatuses for compressed air seems to me to act upon them in a different way: for asthma, I think it is the mechanical action of which I have already spoken which is of benefit; for anemia, I think that it is the chemical action, the more perfect saturation of the hemoglobin.

The interest of this distinction lies in the fact that in cases where chemical action should be sought, and they are very probably those in which it will be a matter of changing the nutritive processes, the stay in the compression cylinders can be satisfactorily replaced by the respiration of superoxygenated air: a great advantage, you will understand, in therapeutic practice, for the costly apparatuses for compressed air can never be operated outside large cities and watering-places, whereas nothing is easier than to procure oxygen at home.

But one must be skilful in the use of oxygen inhalations. Since the day when Priestley disputed with two mice "the honor of having been the first to breathe dephlogisticated air" up to the present epoch, many attempts have been made to introduce respirations of oxygen into the realm of therapeutics. ${ }^{9}$ The enthusiasm of the authors at the end of the last century and the beginning of this one for the curative virtue of the vital air, was tempered by only 
one fear: the irritating action of oxygen on the tissue of the lungs, and especially the ravenous activity it would give to vital oxidations. Brizé-Fradin ${ }^{10}$ expresses himself warmly on this point:

Vital air or pure oxygen would soon wear life out instead of maintaining it ... The torch of life, burning fiercely, would soon be extinguished .... Fever would soon carry off anyone who used vital air immoderately.

It is impossible to breathe oxygen alone for more than two minutes; the pulse beats are then quicker, more frequent; a sensation of unendurable discomfort is felt. (P. 133).

It is hardly necessary to say that the violence of the sensations and of the symptoms experienced is purely imaginary, unless the oxygen was badly prepared.

After having been completely forgotten, oxygen has been gaining favor for several years. But I think that its application has been bad, and that, if it is possible to hope for any advantage from its use, the method must be entirely changed.

As a matter of fact, patients are given almost pure oxygen to breathe, and since it is not possible to have a great quantity of it, a few liters are administered (generally 30 as a maximum in France), which are absorbed in 5 or 6 minutes at the most. This mode of procedure has two disadvantages: first, one cannot hope for any lasting action from a slight increase in the oxygen of the blood for ten minutes at the most; in the second place, as they try to use oxygen as pure as possible, it is possible that they seek the goal they wish to reach by going beyond the maximum of oxygenation that is really useful to oxidation. And so, this method, which, it seems to me, should not be retained in most cases, amounts to a violent shock of short duration, perhaps producing an effect opposite to that which is desired.

Henceforth I should like to see it used only in threatening cases of asphyxia, ${ }^{11}$ poisoning by carbon monoxide ${ }^{1:-}$ or sewer gas, where the time for action is short. Only air with about $60 \%$ of oxygen should be used, and the inhalations should be continued for at least an hour.

Attacks of asthma might also be favorably affected by these inhalations, but much less, no doubt, than by compressed air, in which mechanical action is added to chemical action.

But if is a matter of combatting a slow disease, like anemia, my advice is to try to have the patient breathe, every day for about two hours, a mixture with only $25 \%$ or $30 \%$ of oxygen, which would correspond to a compression of 20 to 35 centimeters. 
For this time, there would be needed at the most a total quantity of one cubic meter of gaseous mixture, containing from 50 to 100 liters of added oxygen; little balloons of goldbeater's skin, with perfumed washbottles, would do in practice, and the necessary manipulations would soon become familiar to the patients. I am deeply convinced that such a medication would give as good results as the use of compressed air.

I think that we have been a little too timid in the therapeutic use of compressed air. Never, indeed, has any medical apparatus gone beyond 2 atmospheres, total pressure; rarely has even this pressure been reached. I think it could be carried without any inconvenience to 3 atmospheres; as a matter of fact, the maximum of intra-organic oxidations is at about this level, and if compressed air acts favorably on patients by increasing the oxidations, we can go that far logically.

Pravaz, we have seen, made some attempts towards the surgical use of compressed air. I am surprised that he did not think of recommending it in the case of strangulated hernias when the intestine contains much gas which prevents reduction; at 2 atmospheres, the volume of these gases would be diminished one-half, at 3 atmospheres by two-thirds, which would make an important difference. The taxis would, of course, be resumed in the apparatus itself.

Finally, in certain stifling cases of tympanites, if one subjected the patient to compressed air, the danger of suffocation would cease immediately. Perhaps it would appear again if no medication could check the disease; but it is worth trying. In all cases, the patients should be kept in the cylinders until completely cured.

What would result from the medical use of very high pressures, 3 atmospheres and more? The lessening of the combustions would make this treatment an antiphlogistic, certainly; but would not some other element enter into the matter? It is probable that the attempt will not be made for a long time, at least by hospital doctors. Those who care for caisson workmen and divers, we have seen, have already had the opportunity to observe that oxygen at high tension exercises a favorable action on inflammatory symptoms.

B. Hygiene. Laborers who work on bridge piling and divers in suits have not yet reached the degree at which the respiration of compressed air becomes evidently dangerous, according to our experiments: the strongest pressure yet attained was 4.25 atmospheres at Douchy and 4.45 at St. Louis, U. S. A. And yet certain 
symptoms of anemia can be attributed to these high pressures. But the symptoms of decompression complicate matters so that it is impossible to make any statement.

But if the necessities of industry bring the use of pressure above 5 atmospheres, we can expect to see appearing in the workmen symptoms the severity of which will increase rapidly; at 10 atmospheres, I do not doubt that death will be frequent, and of course I am speaking here only of the period of compression.

If the importance of this work is enough to justify great expense, and such a case might present itself, for example, for pearl fishers, or divers for sponges and especially coral, or men in divers' suits engaged in salvaging valuable articles, the difficulty may be managed: since the increase in the tension of the ambient oxygen constitutes the danger, this tension must be lessened so that it varies always somewhere between the normal amount of 21 and that of 60 , which seems harmless. To reach it, the caissons would have to be filled, not with ordinary air, but with air of low oxygen content. The apparatus with which M. Tessie du Motay prepares oxygen could be used here; one could get from it, in fact, nitrogen containing only very little oxygen. By mingling this nitrogen with ordinary air in suitable proportions, one could easily secure the desired proportions: at 8 atmospheres, for instance, to bring the oxygen tension to 40 , one would require air containing only $5 \%$ of oxygen. Hydrogen could also be used, and we know that M. Giffard prepares it today at very moderate prices.

But if we imagine these serious difficulties overcome, we shall find ourselves facing the dangers of decompression, greatly aggravated by the enormous proportion of nitrogen which will be dissolved in the blood. Accidents are frequent now, as we have seen, even with ordinary air. But in the case of compression with ordinary air, the only type which we have dealt with as yet, our researches have brought us very important and very practical conclusions.

As soon as the pressure employed has reached 2 atmospheres in total pressure, close watch should be kept; there is as yet no true danger, but already local pains appear, and besides, it is wise to accustom the workmen to precautions early. The great precaution is slowness in decompression.

I think that between 2 and 3 atmospheres, a half-hour should be given to the decompression, to be perfectly safe; from 3 to 4 atmospheres, one hour, and the slowness of the decompression will have to be assured by the degree of opening possible in the equi- 
librium cock. But now appears the serious disadvantage, the danger even, of the chilling that accompanies the expansion of the air, with the condensation of moisture which is the result of it. To ward it off, one must not only give the workman warm and dry clothing, but also place in the decompression chamber heating cylinders, with double hollow walls, through which pass jets of steam, and which the workman can clasp, and against which he can lean. I think that very simple and inexpensive arrangements could settle the problem.

Besides, two chambers of decompression might be arranged, both of them heated, so that one would pass, for example, from a chamber of 3 atmospheres to one of 2 , to stay there for a quarter of an hour at the most and then go into the outside air; these double "locks" would delay the service less.

The longer the workmen remain in the caissons, the more slowly they should undergo decompression, for they must not only allow time for the nitrogen of the blood to escape, but also allow the nitrogen of the tissues time to pass into the blood. And as this last point is the most difficult to obtain, the workmen must not be given too long shifts of work, and must not be allowed to enter the caissons more than once a day.

As for divers in suits, as they cannot be warmed, it would perhaps be difficult to bring about the decompression for them slowly by means of some mechanical and graduated windlass. But nevertheless, when they return from great depths, 30 meters for example, it is absolutely necessary either to bring them up on some seat which allows them to be kept a good quarter of an hour halfway up, or compel them to wait for a sufficient time in some shallow place, when there is one within their working radius.

If, then, in spite of these different precautions, an accident occurs, what is to be done? My researches have already answered for us (Chapter VII, Subchapter IV). If auscultation indicates some gaseous gurgling in the region of the heart, immediately make the patient inhale oxygen as pure as possible, which should always be at hand in a rubber balloon, or better, compressed in quantity in some steel reservoir. Then, when the gases have disappeared from the heart, and death no longer seems imminent, subject the patient immediately to a pressure greater than that from which he came, then make the decompression very slowly. Furthermore. when the pressure reaches 4 atmospheres, they should inhale oxygen, especially divers, immediately after return to open air, without awaiting the appearance of any symptom. When the decompres- 
sion shows its effects by paraplegia, recompression must be carried on at once, without losing time in inhaling oxygen, especially when the symptom did not appear until some time after the return to the open air, for in this case we have to do, not with a general obstruction of the pulmonary circulation, but with some bubble of gas lodged in the vessels of the medulla, whose volume must be reduced at once so that the blood may drive it out.

Workmen employed in compressed air may suffer other discomforts which, though less serious, should not be completely disregarded. Sudden expansion of the intestinal gases and the froth formed in the liquids of the digestive tract may have consequences which are annoying for the digestion and contribute to these disturbances of the appetite which have often been noticed.

Moreover, the air in which they stay is anything but wholesome. In the caissons of the bridge of Kehl, M. Bucquoy found $2.37 \%$ of carbonic acid (p. 373), and when the pressure rose to $31 / 2$ atmospheres, the workmen were, as we have proved, in the same condition as if, at normal pressure, they had breathed air containing $2.37 \times 3.5=8.3 \%$ of $\mathrm{CO}_{2}$; and surely, such an atmosphere would not be without danger. In the same way, other gases, the carbon monoxide of incomplete combustions, the gases produced by the explosions sometimes used in mines, or those which rise from the ground, act in the double ratio of their percentage and the manometric pressure; we have seen (p. 717) how quickly a few drops of ether cause anesthesia in compressed air. We see that energetic ventilation is absolutely necessary, and this point has not been sufficiently emphasized, because the multiplying effects of pressure on the action of toxic gases were not known.

5. Conclusions from the Point of View of General Natural History.

While speaking of diminished pressure, we have shown briefly the part it plays in the general conditions of life on the earth and in the geographical distribution of animals or plants.

The study of present nature shows us nothing comparable from the standpoint of increased pressure, at least if we consider airbreathing living beings: the few regions which are a little below sea level (valleys of the Dead Sea and the Caspian) can hardly be called populated. But the case is quite different, or at least it seems so, for the beings which live in the waters of the sea at depths which reach 4000 and 5000 meters.

First, if we consider in their habitat the creatures of the greatest 
depths, including the celebrated Bathybius, which, after playing such an important part in the new philosophies of nature, seems to have been relegated to mineral matter, ${ }^{13}$ it is clear that they undergo no immediate and mechanical effect from the enormous pressure to which they are constantly subjected and with which they are perfectly in equilibrium. Circumstances would be different if an animal accustomed to live at 2000 meters were submerged to 4000 meters, for example; the excess of pressure would cause a lessening of the volume of its body, which very probably would have a harmful effect on its organism. Conversely, an animal brought from a depth of 4000 meters to the surface will expand considerably (about 15 thousands of its original volume), and this sort of distention of the tissues is largely responsible for the death of animals caught in deep-sea dragging. ${ }^{14}$

The mechanical influence of compression or decompression acts in a very effective and very energetic way upon animals equipped with air bladders, especially when they are closed, as in sea fish. In this case, as M. A. Moreau ${ }^{15}$ has satisfactorily demonstrated, any sudden variation of pressure which, acting on the volume of their bladder, can modify their average density enough to bring them a few meters above or below their place of equilibrium, will, in the first case, lift them to the surface, their bladder dilating to the bursting point; in the second case, will make them sink indefinitely in the depths of the ocean, their bladder contracting and the density of their own body increasing in the same ratio as that of the water. Let us note that since the natural variations of barometric pressure do not exceed two centimeters of mercury (26 $\mathrm{cm}$. of water) per day, and the extreme variations are only 5 centimeters $(65 \mathrm{~cm}$. of water) at the most, the fish are not seriously affected. Furthermore, as the remarkable experiments of M. Moreau have shown, they can in time compensate for this influence, either by secreting oxygen in their swimming bladder, or on the contrary by absorbing the oxygen which it contains, and thus vary at the same time its volume and their density.

We have seen that aquatic animals are killed by oxygen when compression introduces a sufficient quantity of it into the water (p. 777). But this dangerous effect can evidently take place only if the compression acts first on the air and then forces into the water oxygen in growing proportion, following Dalton's Law; but the pressure exerted by the column of water itself upon its deep parts does not at all modify the real tension of the oxygen. Furthermore, direct analyses of the ocean water taken from great 
depths have shown that it contained less oxygen than surface water. According to Lant Carpenter, ${ }^{16}$ the water of the ocean would contain, on the average, no matter what the depth, 2.8 volumes of gas per 100 volumes of water; this gas would be constituted as follows:

Oxygen

Nitrogen

$\mathrm{CO}_{2}$
On the surface

25.00

54.21

20.84

100.00
On the bottom

19.53

52.60

27.87

And so, less oxygen and a little less nitrogen. From this there appear two conclusions:

First, a stay in the depths does not subject the animals to any danger coming from decreased oxygen tension. In the second place, sudden decompression should produce no harmful effect upon the animals of the depths because they will not have an excess of nitrogen dissolved in their tissues; and the truth of this is borne out by the fact that no free gases have ever been found in the tissues of a fish or an invertebrate brought up by the drag.

Circumstances would be greatly changed if some source of air should suddenly gush up from the bottom of the sea. It would need to come from only 100 meters, if it were chemically pure, to kill rapidly all the beings it met on its way.

If we consider, for air-breathing animals as well as aquatic animals, not the present epoch, but geological ages, we have every reason to think that barometric pressure must have played an important part in the appearance and the modification of life on the surface of the globe. In the first ages of our planet, indeed, the oxygen tension must have been much greater than today for two reasons: the atmosphere was higher and its oxygen content greater, since the rocks were not yet cooled and oxidized to so great a depth. The epochs which follow us will no doubt see the air enter further and further into the depths of the ground and the oxygen diminish in it in growing proportion. So it is permissible to imagine that there was a time when present beings could not have lived on the ground because of too great oxygen tension, and that a time will come when they can no longer live on account of its too weak tension. To go beyond this first plausible hypothesis would be to adventure into the pure realm of fancy; we shall leave to others this attractive and easy occupation. 
Perhaps, however, I shall be pardoned for noting that while the three enemies of life as we know it today were, in the first geological ages, heat, oxygen tension, and carbonic acid tension, the beings which are the most resistant to this triple and fatal influence belong to the group of vibrios. It is also they which remain active longest in rarefied air. Probably it is in them that life first appeared, and it is in them that it will end on the surface of our planet.

1 Obseriations sur le séjour dans $l$ air comprimé et dans différents gaz délètères. Journal de Robin, Vol. I, p. 452-476, 1875.

3 Sygdomsformer hos Arbejderne z'ed Fastbroanlaegett over Limfjorden Ugeskrift for Lacger. K jobenhavn, Nov. 25,1876 , p. $377-386$.

${ }^{3}$ Ueber die Sauerstoffaufnalme in die Lungen bei getöhnlichem und erhohtem Luftdruck. Pfiuger's Archiv., Bd. X, p. 479.536, 1875.

4 See Pflüger's Archis', Bd. IX, taf. VII, a: 1874.

5 Aerotherapie. Giessen, $18 \div 6$.

6 The recent researches of M. Pasteur and myself on the virulent agent of carbuncled diseases (charbon or anthrax) seem to indicate an exception to this general rule. The reproductive corpuscles of certain vibrios which, as I have shown, retain their vitality for several months in dilute alcohol, really resist oxygen tensions which kill the vibrios themselves. But we should know whether it is not simply a question of amount in the tension, or of the duration of the experiment. I am investigating this question. to which $T$ cannot yet give an answer. (See the Comptes rendus de l'Academic des sciences. Sessions of May 21, July 9, July 30, 18i7.)

7 See Pasteur, Etudes sur la bière, p. 293. Paris, 1876. 125.

8 Priestly, Experiments and Obscriations on . Air, etc. Translated by Gibelin, Vol. II, p.

9 For the history of the question see Demarquay: Essai de pneumatologie médicale; Paris. 1866. See also the interesting pamphlet of Dr. Andrew Smith: Orygen Gas as a Remedy in Disease: New York, 1870.

${ }_{10}^{10}$ La chimie pneumatique appliquée anx traquan sous l'eau. Paris, 1808. Aug. 15, 1868, observ. I and III) and Limousin, Note sur le traitement de $l$ asphyxie par le gas oxygène; Bull. des trazaux de la Soc. de méd. pratique de Paris, $18 i 1$.

12 See Linas and Limousin, Asphyxie par le charbon; traitement et guérison par l'oxygène. Societe de therapeutique; July $17,1868$. page 1090

${ }_{13}$ See C. Vogt, L' origine de l homme. Reruc scientifique, number of May 12, 1877.

${ }_{14}^{10}$ See Wyville Thomson, Les abimes de la mer. Translated by Lortet. Paris, 1875, page 27.

15 Recherches expérimentales sur les fonctious de la i'essie natatoire. Biblioth. de l'Ecole des hautes études, Vol. XV, 1876.

${ }_{18}$ In W. Thompson, Les abimes, etc. Appendix. 


\section{Chapter III \\ GENERAL CONCLUSIONS}

The data given in the second part of this work, and the theories which are deduced from them, and which are summarized in the third part, can be condensed in the following conclusions, if we omit the chapters dealing with poisoning by carbonic acid, asphyxia, blood gases, and other matters a little outside the subject of this book:

A. The diminution of barometric pressure acts upon living beings only by lowering the oxygen tension in the air they breathe. and in the blood which supplies their tissues (anoxemia of M. Jourdanet), and by exposing them thus to the dangers of asphyxia.

B. The increase in barometric pressure acts only by increasing the oxygen tension in the air and in the blood.

Up to about three atmospheres, this increase in tension results in somewhat more active intra-organic oxidations.

Beyond five atmospheres, the oxidations diminish in intensity, probably change in character, and, when the pressure rises sufficiently, stop completely.

The result is that all living beings, air-breathing or aquatic, animal or vegetable, complex or monocellular, that all anatomical elements, isolated (blood corpuscles, etc.) or grouped in tissues, perish more or less rapidly in air that is sufficiently compressed. The only exception to this generalization is the spores of certain microscopic organisms. For the higher animals, death is preceded by tonic and clonic convulsions of extreme violence.

In the vertebrates, the sudden symptoms due to too great oxygen tension begin to appear only at the moment when the oxygen goes into solution on coming in contact with the tissues, since the hemoglobin is saturated with it. We can say then that the anatomical elements are anaerobes. 
C. Diastases, poisons, and true viruses resist the action of oxygen at high tension.

D. The harmful effects of lowered pressure can be effectively prevented by breathing an air sufficiently rich in oxygen to maintain the tension of this gas at its normal value (20.9).

Those of increased pressure will be prevented by using air sufficiently low in oxygen to secure the same result.

E. In a general way, the benign or harmful gases (oxygen, carbonic acid, etc.) act on living beings only according to their tension in the surrounding atmosphere, a tension which is measured by multiplying their percentage by the barometric pressure; the increase of one of these factors can be compensated for by the decrease of the other.

F. When animals possess reservoirs of air either completely closed (the swimming bladder of acanthopterygian fish, etc.), or in communication with the air only during decompression (swimming bladder of Cyprinidae, intestines of air-breathing vertebrates, etc.), or in communication with the air during compression as well as decompression but by orifices that are too narrow (lungs of airbreathing vertebrates, etc.), the increase or decrease of pressure may have physico-mechanical effects.

G. Sudden decompression beginning with several atmospheres has an effect (except for a few cases included in F) only by allowing to return to the free state the nitrogen which had become dissolved in the blood and the tissues under the influence of this pressure.

$\mathrm{H}$. The organisms at present existing in a natural state on the surface of the earth are acclimated to the degree of oxygen tension in which they live: any decrease, any increase seems to be harmful to them when they are in a state of health.

Therapeutics can advantageously use these modifications in different pathological conditions.

I. The barometric pressure and the percentage of oxygen have not always been the same on our globe. The tension of this gas has probably been diminishing and no doubt will continue to diminish. That is a factor which has not yet been taken into account in biogenic speculation.

Their power of reaction against these different modifications leads us to suppose that microscopic organisms must have appeared first and that they will disappear last, when life becomes extinct through insufficiency of oxygen tension. 
$\mathrm{K}$. It is inexact to teach, as is ordinarily done, that plants must have appeared on earth before animals, in order to purify the air of the large quantity of $\mathrm{CO}_{2}$ which it contained. In fact, germination, even that of molds, does not take place in air that contains enough $\mathrm{CO}_{2}$ to be fatal to warm-blooded animals.

It is just as inexact, as I remarked long ago, to explain the earlier appearance of reptiles with reference to warm-blooded animals by the impurity of air containing too much $\mathrm{CO}_{2}$; reptiles, in fact, fear this gas even more than birds, and especially more than mammals. 


\section{APPENDIX I}

Table indicating very approximately the ratio between the altitude and the height of the barometric column (the calculated altitudes are taken from the book of M. Jourdanet, Vol. II, p. 331).

\begin{tabular}{|c|c|c|}
\hline $\begin{array}{l}\text { Barometric column } \\
\text { in centimeters. } \\
\quad 76\end{array}$ & $\begin{array}{l}\text { Altitude } \\
\text { in meters } \\
0\end{array}$ & \\
\hline 75 & 105 & Orthez (105 m.); Reims (109 m.) \\
\hline 74 & 212 & Dijon $(217 \mathrm{~m}$.$) ; Tulle (222 \mathrm{~m})$. \\
\hline 73 & 321 & Tarbes (302 m.); Epinal (317 m.); Privas (334 m.) \\
\hline 72 & 430 & Brioude $(424 \mathrm{~m}$.$) ; Gibraltar (438 m.)$ \\
\hline 71 & 542 & Bagnères (556 m.); Toledo (563 m.) \\
\hline 70 & 655 & Le Puy (625 m.); Grenada (681 m.) \\
\hline 69 & 769 & Gap $(729 \mathrm{~m})$. \\
\hline 68 & 886 & Burgos $(875 \mathrm{~m})$. \\
\hline 67 & 1004 & The Escorial (995 m.); Chamounix (1020 m.) \\
\hline 66 & 1123 & Barcelonnette $(1130 \mathrm{~m})$. \\
\hline 65 & 1245 & Cormayeur $(1218 \mathrm{~m}$.); the Ballon d'Alsace $(1250 \mathrm{~m})$. \\
\hline 64 & 1368 & Ispahan (1340 m.) \\
\hline 63 & 1494 & The Puy de Dóme (1476 m.) \\
\hline 62 & 1621 & Porté, the.highest village in the Pyrenees (1625 m.) \\
\hline 61 & 1751 & Mount Ossa (1755 m.) \\
\hline 60 & 1882 & The Peak of Sancy (1897 m.); Erzeroum (1860 m.) \\
\hline 59 & 2016 & The Simplon Pass $(2020 \mathrm{~m})$. \\
\hline 58 & 2152 & The Petit Saint-Bernard Pass $(2160 \mathrm{~m})$. \\
\hline 57 & 2291 & Mexico City (2290 m.) \\
\hline 56 & 2432 & $\begin{array}{l}\text { The monastery of the Grand Saint-Bernard ( } 2470 \\
\text { m.); Mount Parnassus }(2470 \mathrm{~m} .)\end{array}$ \\
\hline 55 & 2575 & Santa-Fé de Bogota $(2560 \mathrm{~m})$. \\
\hline 54 & 2721 & $\begin{array}{l}\text { The pass of Mount Viso }(2700 \mathrm{~m} .) \text {; Mount Cinto } \\
\text { (Corsica) }(2710 \mathrm{~m} .)\end{array}$ \\
\hline 53 & 2874 & Quinto $(2910 \mathrm{~m})$. \\
\hline 52 & 3022 & $\begin{array}{l}\text { Endschetkab in Abyssinia }(2960 \text { m. }) \text {; Mount } \\
\text { Olympus }(2975 \mathrm{~m} .)\end{array}$ \\
\hline 51 & 3176 & The Simplon $(3200 \mathrm{~m}$.) \\
\hline 50 & 3334 & Etna $(3310 \mathrm{~m}$.$) ; Mount Perdu ( (3350 \mathrm{~m})$. \\
\hline 49 & 3495 & $\begin{array}{l}\left.\text { The Peak of Nethou ( } 3405^{\circ} \mathrm{m} .\right) \text {; Cuzco }(3470 \mathrm{~m} .) \text {; } \\
\text { Leh }(3505 \mathrm{~m} .)\end{array}$ \\
\hline 48 & 3659 & $\begin{array}{l}\text { Mont-Cenis }(3620 \mathrm{~m} .) \text {; the Peak of Teneriffe } \\
(3715 \mathrm{~m}) \text {. La Paz }(3720 \mathrm{~m} .)\end{array}$ \\
\hline
\end{tabular}




\begin{tabular}{|c|c|c|}
\hline $\begin{array}{l}\text { Barometric column } \\
\text { in centimeters. } \\
\qquad 47\end{array}$ & $\begin{array}{l}\text { Nltitude } \\
\text { in meters } \\
3827\end{array}$ & Mount Argaeus $(3840 \mathrm{~m})$. \\
\hline 46 & 3998 & Lake Titicaca (3915 m.) \\
\hline 45 & 4173 & The Jungfrau (4170 m.); Potosi (4165 m.) \\
\hline 44 & 4352 & $\begin{array}{l}\text { Cerro de Pasco }(4350 \mathrm{~m} .) \text {; the village of Chưshul } \\
(4390 \mathrm{~m} .)\end{array}$ \\
\hline 43 & 4535 & $\begin{array}{l}\text { Mischabel }(4550 \mathrm{~m} .) \text {; the monastery of Hanle } \\
(4610 \mathrm{~m} .)\end{array}$ \\
\hline 42 & 4723 & $\begin{array}{l}\text { Mont Blanc ( } 4810 \mathrm{~m} .) \text {; the tunnel of Oroya ( } 4760 \\
\mathrm{~m} .) \text {; the post-house of Rumihuani ( } 4740 \mathrm{mi} .)\end{array}$ \\
\hline 41 & 4914 & $\begin{array}{l}\text { Pichincha }(4860 \mathrm{~m} .) \text {; the village of Thok-Djalank } \\
(4980 \mathrm{~m} .)\end{array}$ \\
\hline 40 & 5111 & $\begin{array}{l}\text { Kasbek }(5030 \mathrm{~m} .) \text {; the Grand Ararat }(5155 \mathrm{~m} .) \text {; the } \\
\text { mines of Villacota }(5042 \mathrm{~m} .)\end{array}$ \\
\hline 39 & 5313 & Popocatepetl (5420 m.) \\
\hline 38 & 5520 & Elbruz ( $5620 \mathrm{~m}$.$) ; the pass of Karakorum (5650 m.)$ \\
\hline 37 & 5732 & The pass of Parang $(5835 \mathrm{~m}$.) \\
\hline 36 & 5950 & Cotopaxi (5945 m.) \\
\hline 35 & 6174 & Kilimandjaro (6110 m.); Misti (6100 m.) \\
\hline 34 & 6405 & Chimborazo (6420 m.) \\
\hline 33 & 6643 & Cerro de Potosi $(6620 \mathrm{~m})$. \\
\hline 32 & 6888 & Aconcagua $(6835 \mathrm{~m})$. \\
\hline 31 & 7141 & Doukia (7070 m.) ; Robertson's balloon (7170 m.) \\
\hline 30 & 7402 & Chamalari $(7300 \mathrm{~m}$.$) ; Illimani (7310 \mathrm{~m})$. \\
\hline 29 & 7674 & Sorate $(7560 \mathrm{~m})$. \\
\hline 28 & 7951 & Barathor $(7950 \mathrm{~m})$. \\
\hline 27 & 8241 & Dawalaghiri (8185 m.) \\
\hline 26.2 & 8600 & $\begin{array}{l}\text { Crocé-Spinelli, Sivel, and Tissandier, in their bal- } \\
\text { loon. }\end{array}$ \\
\hline 24.8 & 8840 & $\begin{array}{l}\text { Mount Everest ( } 8840 \mathrm{~m} .) \text {; Glaisher's balloon ( } 8838 \\
\text { m.); myself, in my apparatus (See Exp. CCLVII). }\end{array}$ \\
\hline
\end{tabular}




\section{APPENDIX II}

Analysis of the recent work of Dr. Mermod

Just as I was about to authorize the printing of the last page, I received from Dr. Mermod, of whom I have spoken before, a work which is too interesting to be passed over in silence.

M. Mermod has compared the respiratory and circulatory phenomena observed in himself during sojourns of several months at Sainte-Croix (1100 m.), Lausanne (614 m.), Erlangen (343 m.), and Strassburg (142 m.).

After reviewing his former observations on the acceleration of the pulse, he noted (in this point contradicting what was said by preceding authors, see pages 297 and 960) that the frequency of the respiratory movements remained the same at Sainte-Croix and at Strassburg, the obvious conclusion from which is that the ratio between the number of respirations and that of the heart beats decreased as the result of residence at a higher altitude. The body temperature remained unchanged.

But the most important part of M. Mermod's work is that in which he compares the exhalation of carbonic acid in the two extremes of altitude.

The averages of the results which he obtained can be summarized in the following table:

$\begin{array}{cc}\text { Strassburg } & \text { Sainte-Croix } \\ \text { (Alt. 142m.; temp. 12.65 } & \text { (Alt. } 1100 \mathrm{~m} \text {; } \text { iemp. } \\ \text { pressure } 745 \mathrm{~mm} . \text { ) } & 12.68^{\circ} \text {; pres. } 669 \mathrm{~mm} \text {.) }\end{array}$

Number of respirations per minute

11.24

Volume of gas expired per minute ___ 5.85 liters

6.27 liters

This volume reduced to $0^{\circ}$ and $760 \mathrm{~mm}$. 5.48 liters

5.27 liters

Volume of each expiration

$524 \mathrm{cc}$.

This volume reduced to $0^{\circ}$ and $760 \mathrm{~mm} .491 \mathrm{cc}$.

Weight of $\mathrm{CO}_{2}$ expired per minute

Percentage of $\mathrm{CO}_{2}$ in expired air

5.507

$557 \mathrm{cc}$.

$469 \mathrm{cc}$.

$0.402 \mathrm{gm}$.

6.098 
From these figures we draw the following conclusions:

1. The volume of air circulating in the lungs during a given time and that which is brought in by a single inspiration are greater at Sainte-Croix than at Strassburg; but their weight is smaller;

2. The quantity of carbonic acid exhaled in a given time and its proportion in the expired air are greater at Sainte-Croix than at Strassburg.

I have no criticisms to make of the experimental and analytical methods used by M. Mermod, and I consider his results accurate under the conditions in which he obtained them.

But perhaps it would be premature to consider the preceding conclusions general, even for the variations of altitude at which he made the observations.

The author does not give us sufficient information about the conditions and the time of his researches; he merely says that he worked at Strassburg during the winter, and at Sainte-Croix during the autumn. But was it in the same year or in different years? In the latter case, his constitution might have undergone changes which would explain the differences in the experimental results; moreover, M. Mermod does not even speak of the weight of his body. It is probable, besides, that the routine of his life, aside from his diet about which he gives a few details, was not the same on the mountain as in the city, and that might have a certain effect upon the production of carbonic acid in a given time.

With even greater reason it seems unwarranted to apply the preceding results, as M. Mermod has a tendency to do, to a residence in very lofty regions, where the bis or the soroche is prevalent. There, the sickly condition of travellers and even natives is in marked contrast to the feeling of well-being which almost everyone experiences at the low altitudes at which our author made his observations. We refer the reader to what we said previously (page 998 et seq.) about the comparison of low altitudes (below 2000 meters) with great altitudes, from the standpoint of the effects of prolonged residence.

I am very anxious that M. Mermod should complete his interesting experiments by closing the circle, that is, by repeating his analyses beginning with Sainte-Croix, the place where he worked before Strassburg; if he gets the same numbers, he will have removed all objections, as far as low levels are concerned. It would, finally, be extremely important to make observations following 
the same methods at La Paz (3720 meters) or Cerro de Pasco (4350 meters).

In conclusion, I shall mention briefly a question of priority raised by M. Mermod. According to him, his preceptor, the eminent chemist Hoppe-Seypler, discovered the cause of death by sudden decompression and the fundamental reason for mountain sickness sixteen years before I did.

In regard to the latter he quotes a notable page from the memoir which I myself quoted (p. 248), a page with which I agree entirely today. But this passage shows only the keen mind of its author; it is a pure hypothesis which Hoppe's own experiments contradict, and which he renounces in explaining the death of animals subjected to rarefied air. As for his share in the explanation of the death of animals decompressed suddenly from several atmospheres, I have specified that on page 455 of this book.

But I shall not dwell on these questions of priority which never have more than a very slight interest. 


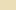




\section{INDEX}

\section{A}

Acclimatization, to decreased pressure balloons, 191, 192

Boyle's experiment, 201

in lofty places,

animals, $61,234,1005$

men $54,292,293,295,960,1000$; Europeans, $263,323,924,960,1000-1004$ : native races, $321,322,960$

Achard, experiments on compressed air, 443

Acosta, description of mountain sickness, 24

explanation of mountain sickness, 195

Aeronauts, physiology of, 981-991 correlation of physiological effects with altitude, 986-990

suggested precautions for, 990-991

Age factor in decompression symptoms, 366

Alcock, Rutherford, ascent of Fujiyama, 163

Alcohol, distaste for, in mountain sickness, $216,242,251$

effect in balloon sickness, 176, 178

effect in mountain sickness, $34,61,65$ $76,95,99,104,105,116,117,132$

external use at high altitudes, 163, 189

Alps, ascents in, 77-120

early crossings, 5

individual peaks, 7

Altitude, variations in, in mountain sickness, $316-318$

Ancients, fear of mountains, 4

precaution against mountain sickness, 196

Anderson, Tempest, buccal temperature during ascent, 957-958

Andes, see Cordillera

Andreoli, ascension with Brioschi, 181 ascension with Zambeccari, 178

Anemia, of altitudes.

Jourdanet, 259-260, 1004-1005

Anesthesia, from carbon dioxide, 921-924

d'Angeville, Mlle., ascent of Mont Blanc. 96

Animals, acclimatization of, at high altitudes, $61,234,1005$

affected by altitude, $24,28,33,135,145$. $153,209,960$. See also Camels, Cats, Cattle, Dogs, Hens, Horses, Llamas. Mules, Yaks

in early experiments, 197, 198, 199, 200 441,443

Anoxemia, theory of Jourdanet on mountain sickness, 255-261,349-351

Anthrax, experiments on bacilli, 847-848

d'Aoust, Virlet, fatigue theory of mountain sickness, 308-311

Apparatus, bellows for artificial respiration, 591

compression chamber 756 for determining lethal concentration of carbon dioxide in blood, 899

for elimination of carbon dioxide in aix in closed vessels, 575

for extracting blood gases, 581-584

for extracting blood under diminished pressure, 594-596

for extracting blood under increased pressure, 615-617

for measuring carbon dioxide production while breathing superoxygenated air, 765-767

for oxygen absorption by defibrinated blood at high pressures, 654

for oxygen absorption by defibrinated blood at low pressures, 643-644

for oxygen provision in mountain climbing, 996-997, 1008 footnote 24

for pressures above one atmosphere, 552-555

for pressures below one atmosphere. $507-512$

for study of intra-pulmonary pressure, 771-773

for study of putrefaction under constant oxygen tension, 814

for use of oxygen in decompression. 695-696

gas meter, 758

mercury pump; 509

mercury reservoir, 588

rebreathing apparatus for dog, 629-630

Aquatic animals, tolerance of high pressures, 1032-1033

Ararat, ascents of, 125, 126, 127

d'Arcet, Doubt of rarefaction of air on mountains, 213

d'Arlandes, Marquis, ascension with Pilatre du Rozler, 171

Armieux, Dr., report on chest expansion at moderate altitudes, 298-300

Arterial blood, oxygen content of; comparison of carotid and femoral, 587

Asphyxia, 928-935

cause of death at normal pressure, 928 cause of death under decreased pressure, 540,579

comparison with decompression, 689-693 under 3 meters of water, 1010

Atkins, ascent of Mont Blanc, 95

Auldjo, ascent of Mont Blanc, 91

\section{B}

Babington and Cuthbert, dangers of decompression, 466 symptoms in caissons of bridge piers, 371-372

Bacon. Francis, explanation of mountain sickness, 196

Barella, symptoms of miners in compressed air, 384-386 
Barral, meteorological balloon ascension. 185

Barry, Dr. Martin, ascent of Mont Blanc, 95

discussed in Biblioth que universelle of Geneva, 230

Bauer, Dr., report of Eads Bridge patients, $387-388$

Baysellance, report of caisson explosion 382-383

Beale, Boyle's suggestions to, 203

Beaufoy, balloon ascension, 182

Beaufoy, Col, ascent of Mont Blanc, 84

Béclard, physiological effects of altitude. 382

Bembo, ascent of Etna, 69

Bernard, Claude, effect of capacity of vessel on duration of life, 532 effect of illness on oxygen consumption. 529

experiments of, 560

lethal tension of carbon dioxide, 558

methods in toxicology, 839

sugar in liver in asphyxia, 689

theory of asphyxia, 506

Bertin, Eugene, therapeutic use of compressed air, 454-455

Biot, ascension with Gay-Lussac, 179

Birds, effect of diminished pressure on $176,180,190,200,211,963,976$

comment on van Musschenbroeck on, 199

living at high altitudes, 57, 62, 159

used in Bert's experiments,

greenfinch (Loxia chloris, Lin.), 570 693

green grosbeak (Fringilla chloris, Lin.), 696

gull (Larus ridibundus, Lin.), 686

hawk (Falco tinnunculus, Lin.), 542 686

linnet, (Fringilla cannabina), 556-557, 565

owl (Strix psilodactyla, Lin.), 540-541

sparrow (Fringilla domestica and Frin-

gilla montana, Lin.), 513-538, 555-557,

$559-563,565-567,570-573,685-686,694$ $696,697-699,706-707,710-713,717-718$ $737,745,856,859-860$

starling, 674

yellowhammer (Emberiza citrinella, 556

Bixio, balloon ascension with Barral, 185

Blanchard, ascension from Ghent, 173 ascension with five balloons, 175 controversy with de Lalande, 174

Blanchard, Mme., ascension from Turin, 182

Blavier, ascent of the Peak of Teneriffe, 75

physiological effects of compressed air, 361

Blindness, from decompression, 365, 385 , 389,492

Blood, color of, as indicative of oxygen content, 939

in compressed air, $364,365,366,367,375$. $542,458,461,491$

in Mexico, 980, 1000

in puppies, 939

experiments on, carbon dioxide accumu-

lation in, 913

carbon dioxide content of, 941

dissolved carbon dioxide of, 944-945

gases of, $646-657,858$

putrefaction in, $817-818$

exposed to high oxygen tension in transfusion, 842

Blood gases,

apparatus for extraction of, 581-584

discussion of, 935-946

early experiments on.

Boyle, 201

E. Darwin, 207

John Davy, 224

effect of diminished pressure on, 615

escape of, in mountain sickness, 342-343
Gavarret, 279

Guilbert, 254

in sudden decompression, 882-883

under diminished pressure, 460, 486, 858

Boyle, 201

Hoppe, 247

experimental procedure for extraction of, $584-585,935$

in asphyxia, 932-935

physiological factors modifying propor-

tion of, 590

agitation, 592-594

former bleedings, 590

respiratory rate, $591-594$

under increased pressure,

carbon dioxide, 625-627

nitrogen, 627-628

oxygen, $622-625$

Body temperature

in exercise, 289

in mountain climbing, 957, 959

Lortet, 114, 284-287, 339

Body weight, changes due to compressed air, 473,491

Bollaert, ascent of Tata Jachura, 36

Boorendo, Pass of, 136, 138

Borelli, ascent of Etna, 70

invention of "diver's bladder" 390

theory of effect of compressed air, 441

theory of effort as cause of mountain sickness, 208

Veratti's quotation of, 204

Bouchard, Bert's refutation of his hypo-

thesis of hemorrhages, 881

hemorrhages and congestions in decompression, 484-485

pathogeny of hemorrhages, 282

Bouchut, cause of mountain sickness, 949

Bouguer, experiences on Pichincha, 27

fatigue as cause of mountain sickness, 208

theory refuted by de Saussure, 216

Bouhy, symptoms of laborers in compressed air, 368

Bourrit, Canon, ascent of Buet, 78

ascent of Mont Blanc, 88

comparison between air of Alps and that of Cordilleras, 213

Boussingault, ascent of Chimborazo, 40

snow as factor in mountain sickness, 227

Boyle, Robert, account of symptoms of mountain sickness on Ararat, 125

on the Peak of Teneriffe, 74

in the Pyrenees, 120

researches with pneumatic pump, 199-

202; on blood, 201, 858

suggestions for experiments, 203

Brachet, cause of panting in mountain sickness, 235

Braddel, ascent of Mount Ophir in Malacca. 163

Brand, Lieut., passage of Cumbre, 35

Bravais, ascent of Mont Blanc, 100

Bridge foundations, use of compressed air in construction of, $368-384,386-390$

Brizé-Fradin, disadvantages of diving-bell 356

sensations in diving-bell, 443-445

Brooke, ascent of Tabalau Indu in Borneo. 163

Brown-Séquard, theory of effect of carbon dioxide, 674, 923

Brunel, use of Triger method in bridge construction, 370

Bubbles, escape from organic liquids,

blood, 201

other organic liquids, 201

as cause of symptoms, 202

Buccal thermometer, criticism of, 287-288, 959

de Buch, Léopold, ascents of Peak of Teneriffe, 75

Bucquoy, confirmation of theory by Bert's experiments, 881

physiological effects in caissons, 373-375 
theory of symptoms of compression and decompression, 457-460

Buksh, the "Munschi" Faiz, in Pamis, 157

Burdach, effect of atmospheric pressure on circulation, 225

Burkhardt, susceptibility of horses and mules to mountain sickness, 60

Burmeister, symptoms of Puna, 52

Burnes, Al, on pass of Hindu-Koush, 144

Burton, in Kamerun mountains, 161 origin of mountain sickness, 296

Butterflies, at high altitudes, 158

Byron, Commander, ascent of Mauna Kea (Hawaii), 164

Caffe, study of compressed air, 465-466

Caisson, construction of compressed air, 368-369

Calberla, rectal temperature in ascent, 959

Caldcleugh, experiences in crossing the Andes, 34

de Calvi, Marchal, effect of atmospheric pressure, 240

Camels, effect of altitude on, 153, 154, 322

Campana, immunity of certain birds to effects of rarefaction, 976-978

Carbon dioxide, accumulation in tissues, 910-914

action upon living beings, 896-927

anesthesia by, 921-924

cause of mountain sickness, 949-950 emanations of, 238

excess in blood in mountain sickness, $274-275,286,346-347$

in asphyxia, $934-935$

lethal concentration in blood, $899-910$

lethal tension in ambient air, 558, 563$564,574,578,896-899$

differences in animal species, 897-899 of blood, 940-946

of blood under increased pressure, 625627

poisoning by, 914-924

production on Mexican plateaux, 263

production under normal and increased pressure, 1017-1019

role of, in death in confined air, 524, 578 saturation point in blood, 913

summary of effects of, 927

Castel, effect of decrease of atmospheric pressure, 235

de Castelnau, effects of soroche on animals, 47

Cats, effect of altitude on, 40, 46, 233, 322 . 1008 footnote 30

experiments on temperature compared to oxygen consumption, 219

resistance of kittens to diminished pressure, $200,545-546,687$

Cattle, effect of altitude on, 29, 47, 54 . 154,322

Caucasus, individual peaks, 10

Cavaroz, hematosis on the Mexican plateaux, 269-270

Cézanne, physiological effects of compressed air in industry, 370

Chabert, Dr., causes of mountain sickness, 951

Charles, invention of hydrogen balloon. 171

symptoms in ears in ascension, 172

Chauveau, research on vaccine, 846

Cheetam, on pass of Lunga-Lacha, 152

Chemical fixation of oxygen of blood Longet, 250

Gavarret, 250

Chest capacity, increase at higher altitude, Baréges (1270 meters), 298 Cordilleras (2500-5000 meters), 301 Mexico, 302

Chodzko, ascent of Ararat, 127

Chomel, ascent of Mont Blanc, 106
Cigna, J. Fr., experiments on sparrows under diminished pressure, 205

Cimento, Academy del, experiments on animals (1667), 197, 441

Circulation, in compressed air. amplitude of pulse, 396

capillary circulation, $397,445,491$

congestions, 451

pulse rate, 374,396

pulse rate in decompression, 366

Clark, Dr., ascent of Mont Blanc, 91

Clifford-Albutt, body temperature in mountain climbing, 289

Clissold, F., ascent of Mont Blanc, 90

theory of mountain sickness, 223

Cloquet, Hipp., mechanical explanation of mountain sickness, 223

mountain sickness at the Grand SaintBernard, 94

Closed vessels, death in,

early experiments on, 204, 205

Coca, prophylactic power of, 305

Coindet, report of carbonic acid production on the Mexican plateaux, 277 controversy with Jourdanet, 261-269

Cold, effect in balloon ascensions, 988 factor in mountain sickness, 326, 327 "physiological", study by Martins, 252

Cold-blooded animals, early experiments on, 200, 201

in Bert's experiments,

adder, 898

carp, 854,925

eels, $752-753,777,889-890$,

frog eggs, 776,777

frogs, 550,716, 717, 768, 898

lizard, 751,898

sticklebacks, 855

tadpoles, 753, 777, 778

susceptibility to carbon dioxide, $897-898$

Coleman, ascent of Mount Baker and Mount Rainier, 69

Colin, intestinal gases in rarefied air, 950

Colladon, Dr., descent in diving-bell, 356357

Comaschi, balloon ascension at Turin, 185

Compressed air ( 1 to 2 atm.), effects of

circulation, $413,415,416,417,423,433,436$ theories about, $449,452,475,478,480$

gaseous exchanges, theories about, 447

$448,450,452,455,458,468,471,479,481$

heat production, $415,433,434$

innervation, 432,477

nutrition, $414,415,417,433$

theories about, 473,477

pulmonary capacity, 418, 432, 435

respiration, $413,416,417,418,420,432$ 435,436

thoeries about, 447, 457, 475, 478, 482

secretions, $414,416,417,455,473$

Compressed air ( 1 to 5 atm.), effects of,

circulation, $764,773-775$

intra pulmonary pressure, 771-773

nutrition, 764

prolonged stay in, 775-779

pulmonary capacity, 768-771, 1026

respiration, 763-764

Compressed air, explanation of effects of. chemical, 498

physico-mechanical, 494

Compressed air, use in industry, 247

in bridge foundations, 368-384

in diving-bells, 252

in mines, 361-368

measures for preventing dangers in use of, 1030-1031

relief of symptoms resulting from use of, $1031-1032$

Compression, sudden, effect of, 852-853

Compression, symptoms due to, see Circulation; Ears, pains in; Innervation:

Nutrition: Respiration: Secretions; Voice

Comte, explosion of compressed air, 367

Condor, causes of its immunity to decompression, 976-978, 1005-1006 
height of flight, 31, 57, 542, 1005

Congestion in comprsesed air, theories about, 452

Contractility, muscular, effect of carbon dioxide at high tension on, 926-927

Cordillera, individual peaks and topography of, 12

Cordier, ascent of Maladetta, 121

ascent of Peak of Teneriffe, 75

Courtois, thesis on symptoms of mountain sickness, 218

Coxo-femoral articulation, relaxing of, 254 , 343-344

Beclard, 282

- Jourdanet, 257-258

Lombard, 244, 252

Meyer-Ahrens, 243

Coxwell, as balloon engineer for Glaisher, 186-191

Craveri, ascent of Popocatepetl, 63

Crocé-Spinelli, ballon ascension in Polar Star, 961-962

ascension organized by Society of Aerial Navigation, 192-193

experiment in decompression chamber. 700-703

fatal ascension in Zenith, 963-969

funeral eulogy, 971-974

Crozet, ascent of Mont Blanc, 106

Cumbre, the puna on, $33,34,35,36$

Cunningham, electricity as cause of mountain sickness, 225

Cupping-glasses, comparison to rarefied air. 217 ,

of Dr. Junod, 229

Curare, used for paralyzing, 591, 593, 769

Cuthbert, see Babington

\section{D}

Darwin, Charles, passage of the Andes, 43

Darwin, Erasmus, experiment on blood under diminished pressure, 207

Davaine, Dr., research on anthrax, 847

Davy, John, experiments on gases of the blood, 224

Deafness, improvement under compression, 359

result of decompression, 364, 365, 378, 492

Death, from decompression, $364,365,371$, $378,395,405$

theories about, 455

Decimals, futility of, $389,513,522,589$

Decken, Baron de, attempted ascents of Kilimandjaro, 162

Decompression, comparison with asphyxia, 689-693

explanations of effects of, 500

explosive,

in accidents, $367,371,382,383,359,868$

effects of $882-883,886$

speed of, $360,362,367,372,377,378,383$,

$384,386,387,389,394,460,487,493,494$,

895, 1013, 1030

sudden, effects of, $878-889$

from one atm., $853-858$

from several atm.. 859

in stages, 874-878

without interruption, 859-874

ill health as factor in resistance to, 880 prevention of

by oxygen inhalations, 884

by slowness of decompression, 890 relief of,

inhalation of oxygen, 891

recompression, 890

variations in individuals, 889

variations in species, $878-880$

symptoms due to, see Blindness, Deaf-

ness, Death, Duration of, "Fleas",

Muscular pains, Paralysis, Respiratory difficulties. Time of appearance

Delon, ascent of Etna. 70

Demavend, ascents of, 128
Demeunier, ascent of Etna 70

Denayrouze, diving apparatus, 392 symptoms of divers, 395

Denial of existence of mountain sickness. $119,308,310$

Desor, ascent of the Jungfrau, 96

Devices suggested to prevent effects of high altitudes, 974

Deville, Charles Sainte-Claire, ascent of Peak of Teneriffe, 76

Diminished pressure in therapeutic apparatuses,

Gondret, 220

Junod, Dr., 228

Diving-bells, 355-358

Diving suits, $390-410$

Dobereiner, experiments on germination, 781

Dogs, effect of altitude on, $37,40,46,61$, $96,154,233,322$

Dollfus, A., journey to Popocatepet1, 60

Dolomieu, ascent of Etna, 70

Dortheren, ascent of Mont Blanc, 88

Douglas, David, ascents in Hawaii, 164

Dralet, conditions in lofty places, 219 summary of data in Pyrenees, 120

Drew, Fr., discussion of mountain sickness, 295

geography of Jumnoo and Cashmere, 160

Drowsiness, in compressed air, 492

Dufour, factors producing mountain sickness, 951-953

muscular exhaustion as cause of mountain sickness, 289

Dumas, Dr. Aug., explanation of symptoms of mountain sickness, 275

Duration of symptoms due to decompression, $364,372,373,380,382,386,387,389$ $404,407,493$

Durier, ascent of Mont Blanc, 114 importance of training in ascents, 293

Duval, Dr., digestive symptoms in mountain sickness, 251

Dwellers in high places, 998-1005

physiological effects on, great heights, 1000-1005 moderate heights, 998-999

Dwellings at high altitudes, 19, 45, 141, 154, 308

\section{$\mathbf{E}$}

Eads, report on Mississippi Bridge laborers, 386-387

Ears, pains in, from compression, 356, 357. $359,362,363,370,371,373,489-490$ means of preventing, $357,363,490$

Edens, ascent of Peak of Teneriffe, 74

Eggs, experiments on putrefaction of, 819820

Elbrouz, ascents of, 124, 125

Electricity as cause of mountain sickness, $221,225,245,337$

Elliotson, effect of rarefied air on dogs, 61

Elsässer, respiration in compressed air, 435 theory of effects of compressed air, 478

Emulsin, experiments on, 839

Engelhardt, ascent of Kasbek with Parrot, 123

Estor and Saint-Pierre, extraction of oxygen of blood, 585-587

Etna, early ascents, 4 later ascents, 69-73

Exhalations as cause of mountain sickness, 238,336

Exhilaration in compressed air, 357, 417. 492

Experimental procedure,

for determining amount of dissolved carbon dioxide ni blood, 943

for determining blood gases in oxygen poisoning. 719

for determining accumulation of carbon dioxide in tissues, $910-911$ 
for determining oxygen capacity of blood under high pressures, 654

for determining oxygen capacity of blood under low pressures, 644-645

for determining oxygen capacity of gasfree blood, 649-651

for extraction of blood under diminished pressure, 596-600

for extraction of blood under increased pressure, 617-618

for extraction of blood gases, 584-585, 941 accuracy of method, 587-589, 594

for low pressures, 644-645

for mercury pump, 510-512

for pressures below one atmosphere, 508509

for rebreathing experiments, 630

for very low pressures with superoxygenated air, 536

for studying effects of increased pressure, $757-760$

in experiments on putrefaction, 810-811

Experiments of Bert

at various pressures

at normal pressure, 513

air with reduced oxygen content, $630-633$

blood gases, 586

low temperature, 533-535

venous blood, 636-638

less than one atmosphere, 514-522, 529.

$540-542,543$

blood gases, 600-605, 613-614

capacity of blood for oxygen, 646-651.

high temperatures, 652-653

superoxygenated air, 537-538, 560-563

more than one atmosphere

blood gases, 618-620

capacity of blood for oxygen, 655,657

low oxygen content, $57 \theta$

ordinary air, 555-557; at low temperature, 559-560; under very high pressures, 565-567, with carbon dioxide eliminated, 575

superoxygenated air, 571-573

on lower forms

anatomical elements, $840-842$

ferments, 800-839

fruit, dry rot, 843-844; ripening, 844845

plants, germination, 782-786, 789-791,

792-796; vegetation, 787, 797

scorpion's venom, 845-846

viruses: anthrax, 847-848; glanders, 847 vaccine, $846-847$

with various purposes

air injections into blood, 888-889

asphyxia, 928-934

carbon dioxide accumulation in tissues. 911-913

carbon dioxide content of blood, 941

dissolved carbon dioxide of blood. 944945

effects of carbon dioxide on lower organisms, 925-927

lethal concentration of carbon dioxide in blood, 899-909

lethal tension of carbon dioxide, 897-898

relieving symptoms of decompression, 890-894

sudden decomposition from 1 atmosphere, 854-856

sudden decompression from several atmospheres, 859-874

Experiments, early, with compressed air. 441,446

with diminished pressure, 197

Explanations of mountain sickness, see Anoxemia: Blood gases, escape of; Carbon dioxide excess in blood; Cold; Coxofemoral articulation, relaxing of; Electricity; Exhalations; Fatigue; Intestinal gases, expansion of; Oxygen lack in air Weight of air sustained by body, decrease of

\section{$\mathbf{F}$}

Fatigue as cause of mountain sickness $325,340,284,952$, (Bouguer) 208, (Dufour) 291, (Hudson) 283, (Lepileur) 236, (Martins) 231

Fatigue on mountains, explanation of, (von Humboldt) 228

Favre, principles of Junod method (hemospasie), 230

Fazello, ascent of Etna, 70

Fellowes, ascent of Mont Blanc, 91

Fermentations, experiments on, under high oxygen tension, $800-839$

diastatic fermentations, 834-839

emulsin, 839

inversive fermnet of yeast, 838

myrosin, 838

pepsin, $837-838$

saliva and diastase, $835-837$

true fermentations, $800-834$

brewers yeast, 826

coagulation of milk, $820-823$

molds, 831-834

putrefaction, $800-816$; blood, 817-818:

eggs, $819-820$; meat, $800-816$

urine, $823-825$

wine, $827-881$

Fernet, on blood gases,

carbon dioxide in solution in saturated blood, 942

experiments on blood gases, 249 ; his conclusions, 611,641 ; discussion of experiments, 611, 641; validity of conclusions, 653

nitrogen content of blood, 936

Ferrara, ascent of Etna, 71

Feuillée, Père, ascent of Peak of Teneriffe, 74

Fileteo, ascent of Etna, 69

Fish, early experiments on, by Academy del Cimento, 197; by Boyle, 200; by French Academy of Sciences, 199

"Fleas" (puces), 373, 377, 381, 398, 461, 464, 487

explanation of, 886

Flechner, oxygen content of mountain air, 234

Flemeing, causes of mountain sickness, 281

Focke, mention of sorocho, 55

Fodere, explanation of hemorrhages in rarefied air, 217

Foley, Dr., effects of insufficient hematosis, 270

physiological phenomena in compressed air, 375-378

suggestion for therapeutic use of compressed air, 464-465

theory of caisson disease, 462-464

Food, as factor in prevention of balloon sickness, 990

as factor in prevention of mountain sickness, $325,290,291,292,293,335,996$

Forbes, expeditions on Alps, 98

de Forbin, Count, ascent of Etna, 72

Forel, ascent of Monte Rosa, 954-957

criticism of buccal thermometer, 287 effects of low oxygen tension, 953-954 increase of temperature while walking, 287,289

Forneret, ascent of Mont Blanc, 88

François, Dr., physiological and pathological effects in caissons, 372-373

Frankland, ascent of Mont Blanc with Tyndall, 107

Fraser, discussion of effect of odor of flowers in mountain sickness, 221 effects of mountain sickness in Himalayas, 132

Fremont, Col., expedition to the Rocky Mountains, 68

Freshfield, Douglas, ascents of Kasbek and Elbrouz, 124

Freud, pulmonary capacity in compressed air, 435 
Frezier, explanation of mountain sickness, 26

Fruit, experiments on, dry rot, 843-844; ripening of, $844-845$

Fujivama, ascents of, 163

de Franqueville, ascent of Nethou, 122

\section{G}

Gal, Dr. Alphonse, pathogeny of caisson disease, 486-487

physiological observations on divers, 395-405

Gallard, Dr., report of deaths in caisson explosion, 383-384

Gamard, ascent of the Jungfrau, 118

Gardiner, ascent of Elbrouz, 125

Garnerin, Jacques, ascension from Moscow, 177

use of parachute, 177

Gas analysis, method used by Bert, 512

Gavarret, article Atmosphere in Dictionnaire Encyclopédique, 279

effect of air pressure on hematosis, 250

effect of excess carbon dioxide in blood. 274

hemorrhages in decompression, 482

Gay, Claude, soroche in the Cordillera, 45

Gay-Lussac, altitude reached, 174

ascension with Biot, 179

symptoms noted in later ascension, 180

Gérard, Alexandre, journeys in Himalayas, $134-138,154,221-223$

Gillis, Lieut., symptoms of mountain sickness, 49

Giraud-Teulon, refutation of mechanical explanation of mountain sickness, 245

Glaisher, comment on report of Andreoli, 182

series of ascensions with Coxwell, 186191

suggestion of artificial aid to respiration, 191

summary of physiological symptoms in ascension, 190

Glanders, experiments on, 847

Glas, G., ascent of Peak of Teneriffe, 74

Glennie, Lieut, W., attack of soroche, 61

Godwin-Austen, Capt., in Himalayas, 155

Gondret, explanation of symptoms of mountain sickness, 220

Gosse, anatomy of Peruvian Indians, 302 questionnaire on mountain sickness, 303 de Gourbillon, ascent of Etna, 72

de la Gournerie, compressed air in boat. 361

Govan, Dr., electricity as cause of mountain sickness, 221

Grafts, animal, effect of oxygen at high tension on, 841

Grandidier, E., discussion of soroche, 51

Grene, balloon ascensions, 183

balloon engineer for Welsh, 186

inaccuracies of statement, 184

Gros, Baron, ascent of Popocatepetl, 61

Grove, Craufurd, symptoms on the Alps, 117

Gubbins, ascent of Fujiyama, 163

Guérard, A., weight supported in compressed air, 453

Guéricke, Otto von, invention of pneumatic pump, 196

Guichard, respiration in compressed air. 1009-1011

Guilbert, Dr. Charles, description of soroche in $\mathrm{La} \mathrm{Paz}, 53$

explanation of mountain sickness, 254

Guinea pigs, experiments on temperature and oxygen consumption, 219

Gunnison, Capt., ascent of Mount Creek. Col., 68
H

Haigh, Samuel, symptoms of mountain sickness on Cumbre. 33

Hallé and Nysten, physiological effects of compressed air, 445

theory of hemorrhages in rarefied air, 217

theory of respiration in rarefied air, 217

Haller, effects of compressed air, 443 effects of rarefied (mountain) air, 210-211

Halley, Dr., improvements in diving-bell. 355,390

Hamel, Dr., ascent of Mont Blanc, 89 descent in diving-bell. 356

plans for experiments on Mont Blanc. 223

Hamilton, ascent of Argaeus, 127

Hardwicke, Capt. Thomas, in Little Thibet, 131

Hardy, ascent of Finsteraarhorn, 116

Hawaii, ascents in, 164-165

Hawes, ascent of Mont Blanc, 91

Hayward, in Little Thibet, 156

Hearing in compressed air 357,492

Heart beats, persistence of, in carbon dioxide poisoning, 920

Heiberg, Dr., symptoms of caisson-workers. 1011-1013

Hematosis in compressed air, 458

Hemorrhages, causes of, 281-282

in compressed air, 356

from decompression, 370-373, 387, 398

theories about, 457, 464, 482, 484

in mountain sickness, 331

Henderson, observations in Himalayas, 157159

symptoms from poisonous artemisia, 295

Hens, effect of high altitude on, 40

Hermel, Dr., case of caisson disease, 379380

explanation of symptoms, 460-462

de Herrera, 26

Hervey, Mistress, adventures in Himalayas, 147-152

poisonous plant as cause of mountain sickness, 294

Hervier and Saint-Lager, carbon dioxide formation in compressed air, 446-447

Heusinger, effect of diminished pressure at high altitudes, 245

Hill, symptoms and cause of mountain sickness, 233

Himalayas, ascents of, 129-160 individual peaks of, 10

Hines, ascent of Mount Hood, Oregon, 69

Hiouen-Thsang, on Hindou-Kouch and Pamir, 129

Hobard, ascension from Lynchburg, Va.. 185

Hodgson, Capt., plant exhalations in mountain sickness, 223

Hoffmeister, in Thibet, 145

Hooker, Dalton, symptoms of mountain sickness, 146

Hoppe, Felix, experiments on death in rarefied air, 247

ascribes death to free blood gases, 248 theory applied to sudden decompression. 455-456

Horses, effect of high altitude on, 32, 36 . $40,43,46,47,52,60,132,134,144,153,154$. $156,159,173,234,272-273,322$

Houel, ascent of Etna, 70

Huc, Pàre, passage of Bourhan-Bota, 144 symptoms of mountain sickness ascribed to carbon dioxide, 238

Hudson, precautions against mountain sickness, 283

Hugi, ascent of Finsteraarhorn, 94

Human beings, experiments on.

Himself, 669, 697-699, 703-704, 706-707. 760-763

Regnard, 763

Sivel and Croce-Spinelli, 700-703 
von Humboldt, ascents of Chimborazo and Antisana, 29; of Peak of Teneriffe, 75 explanation of fatigue on mountains, 228 Hume, A. O., birds in Himalayas, 159 Hunt, Dr. J., attraction of North Pole, 296

Huyghens and Papin, theory of death of animals in vacuum, 202

\section{I}

III health, factor in mountain sickness, 326 factor in resistance to sudden decompression, 880

Innervation, changes in compressed air, 492

Insects at high altitudes, bee, 179; butterflies, 158

Insects, experimental, fly pupae, 776; midge larvae, 778; mosquito larvae, 778; poplar beetle, 552; silkworm cocoons, 684-685. 752,776 ; various species, 751

in early experiments, 201

Insomnia, factor in mountain sickness, 325

Intestinal gases, expansion of, in balloon sickness, 307

in mountain sickness, 343,950

Itier, ascent of Peak of Teneriffe, 76

\section{J}

Jaccoud, Dr., physiological effects of moderate altitude, 296-298

Jacquemont, experiences in Himalayas, 139-142

Javelle, psychological factors in mountain sickness, 292

Jeffreys, ascent of Fujiyama, 163

Joanne, symptoms of mountain sickness. 118

Johnson, Capt., ascent of Tazigand, 139

Jourdanet, Dr., anatomy of Mexican Indians, 302

Anemia of Altitudes, 259-260

Barometric disoxygenation of the blood," 261

controversy with Coindet, 261-269

Effects of Barometric Pressure on Human Life, 979-980

effects of rarefied air in Mexico, 255-259 oxygen content of blood in Mexico, 642 theory of anoxemia, 349-351

Junod, Dr., barometric apparatus for general treatment, 228

cupping-glasses, 230

Magendie's report on work of Junod, 229

therapeutic effects in compressed air. 413-414

\section{K}

Kamerun Mountains, 161

Karakorum, Pass of, 129, 145, 155, 156, 975

Kasbek, ascents of, 123,124

Kaufmann, effects of altitude on physiological functions, 276

Kennedy, ascent of the Dent Blanche, 117

Kilimandjaro, ascents of, 161, 162

Kini-Ballu, ascent of, 162

Kupffer, ascent of Elbrouz, 124

\section{L}

Laborde, ascent of Mont Blanc, 78

La Condamine, experimences on Pichincha, 27, 174, 175

weight of air on body, 210

Ladak, $130,137,148,149$

de Lalande, ascension with Blanchard, 175 criticism of Blanchard. 175

Lange, Dr. G., physiological effects of compressed air, 417

respiration and circulation in compressed air, $475-478$
Laverrière, ascent of Popocatepetl, 63

Leblanc, Felix, oxygen percentage in air of mines, 692-693

Legallois, researches on animal heat, 218

Le Guillou, mountain sickness on Peak of Teneriffe, 76

Lepileur, ascents of Mont Blanc, 100 causes of mountain sickness, 236 summary of Auldjo's ascent of Mont Blanc, 91 symptoms of mountain sickness, 98

Leullier-Duché, Louis, use of balloon ascensions in therapeutics, 172

von Liebig, George, carbon dioxide production in respiration, 481-482, 1017-1019 mechanical action of increased pressure, 1020

pulmonary ventilation under normal and increased pressure, 1019

respiration in compressed air, 437

Light, action of, in mountain sickness, 242. 245

Liguistin, mountain sickness in horses in Mexico, 271-273

Limited mountains; Etna, 73; Peak of Teneriffe, 77

Limousin, Dr, case of caisson disease, 381-382

Llamas, effect of altitude on, 323

Lloyd, mountain sickness, 50

Loevenstern, ascent of Mauna Loa, Hawaii, 164

Lombard, decrease of weight sustained in rarefied air, 243

oxygen content of rarefied air, 251

Longet, effect of air pressure on hematosis, 250,642

Lortet, functional disturbances in mountain climbing, 111

cold as cause of mountain sickness, 284 683-684

report of ascent of Mont Blanc, 109

Low, in Borneo, 162

Lowe, mountain sickness, 44

de Luc, experiences on Buet, 212

Lungs, retraction under decreased pressure, 204-205, 345

de Lusy, Count, ascent of Mont Blanc, 88

\section{M}

Magendie, report on work of Junod, 229 Magnus, experiment on blood gases, 641

Maissiat, effect of compressed air on intestinal gases, 446

influence of expended intestinal gases, 234

Malezieux, reports on Eads and Brooklyn bridges, 388

Mammals used in Bert's experiments, 542 cats, $543-545,662,773,856,861-863,875$ dogs, $546,586,590,591-594,600-605,613-$ $614,618-620,630-633,636-638,661-662$ $672,679-680,682-683,720-733,737,748-$ 749, 769-770, 773-774, 854, 856, 863-870. $876,877, \quad 888-889, \quad 890-894,899-909,928-$ 931,934

guinea pigs, 547-549, 664-665, 874

hedgehog, 550

rabbits, 546-547, 662-664, 737, 861, 875

rats, $675-677,681-682,706-707,718,745$

$746,750,768,856,861,897$

Manasarowar, Lake, 130, 131, 134, 135, 141

Mann, in Kamerun Mountains, 161

Marc, therapeutic effect of compressed air, 437-438

Marcet, Dr. W. ascent on Mont Blanc with Lortet, 109

cold as cause of mountain sickness, 286

Markham, attacked by soroche, 52

Martins, Ch., ascent of Mont Blanc, 100 disbelief in mountain sickness, 231 physiological cold, 252-254, 348

Mathieu and Urbain, oxygen content of blood of various arteries, 587 
Mayer, physiological effects in compressed air, 437

Meat, experiments on, putrefaction, 800 816

Mechanical explanation, of death in vacuum, 202 of decompression, 980

Mercury pump, description of, 509 inventor of, 511 operation of, 511-512, 582-585

de Méricourt, Leroy, article Altitudes in medical encyclopedia, 273

article Hygiene of sponge fishers, 393-394 paralysis after decompression, 482-484

Mermod, Dr., moderate altitudes, pulse rate at, 330

respiratory and pulse rate at, 1041-1042

Meyer, ascent of Mont Blanc, 92

Meyer-Ahrens, Dr., memoir on symptoms of decompression, 241-243

Meyers, symptoms of sorocho, 42

Miers, symptoms of puna on Cumbre, 34

Milk, experiments on, 820-823

Milliet, Dr., physical action of compressed air, 453-454

physiological effects of compressed air. 416

Minerals as alleged cause of mountain sickness, $26,33,36,37,42,48,49,51,55$, $58,209,227,232,233$

Mines, compressed air in, 361-368, 384-386

Mirza, The, in Pamir, 156

Missionaries, in Central Asia, 129

Molds, experiments on; bread, 831-832 cooked starch, 832-833; fruits, 833-834

Molinatti, ascent of Monte Rosa, 93

Mont Blanc, ascents of, 78-96

Monte Rosa, ascents of, 93-94

de Montserrat, journey to Popocatepet1, 60

Moorcroft, journey through the Himalayas, 131

Mossbach, mention of sorocho, 55

Mountain sickness, see Animals affected by altitude; Conditions of appearance of: Denial of existence of: Explanations of; Names given to; Prevention of; Psychological factors in; Remedies for: Symptoms of

Mountain sickness, variations in effects of, $318-328$ questionnaire on, 303-305

Mountain systems, Asia, 10; Europe, 5

Mountain travellers, 991-998; muscular effort, 992-995: rate of ascent, 995-996

de Moussy, Dr. Martin, symptoms of puna, 52

Mulahacen, ascent of, 123

Mules, effect of high altitude on, 26, 32, 36 , $37,40,43,47,51,53,54,55,60,88,118$, $226,234,322$

von Muller, ascent of Orizaba, 66

Murray, Mrs. Elizabeth, report of ascent of Peak of Teneriffe, 76

Muscular pains from decompression, 360 . $361,363,364-366,377,398$

theories about, $456,457,462$

Muscular swellings due to decompression, 492; theory about, 485

van Musschenbroeck, experiments on animals in compressed air, 441-442

explanation of effect of vacuum, 198

quoted by Veratti, 204

Myrosin, experiments on, 838

\section{N}

Nail, Dr., deaths from labor in caissons, 378

Names given to mountain sickness, 328

Néergaard, ascent of Maladetta, 121

Nitrogen of blood, 936

effect in sudden decompression, 881-890, 895,1027

under increased pressure, 627-628
Nutrition, changes in compressed air, 363 , $372,455,491-492$

Nysten, effect of free gases in blood, 882 injection of air into blood, 888 see also Halle and Nysten

Obesity, as factor in mountain sickness, $52,233,291,326$

Oliver, Capt., in Himalayas, 152

Olympus, conditions on summit of, 196

d'Orbigny, anatomy of Peruvian Indians, 301

description of mountain sickness, 37

Orizaba, ascents of, 66,67

Ormsby, ascent of Grivola, 119

Oxide of carbon, for inflating balloon, 184

Oxygen, capacity of blood for, 641-657

at decreased pressures, 643-654; at $38^{\circ}$ and $40^{\circ} \mathrm{C}$., 652-653

at increased pressures, 655; at 40 C. 657

toxic action of, at high tension, 565-570, $574,578,709-754,1021-1024$

use of, in balloon flights, 961-967, 969$970, \quad 990-991$

in decompression, 694-708, 891-894

in mountain climbing, 996-998

Oxygen content, of blood, 936-940; variations in, 940, 984-986

of various arteries, 587

under decreased pressure, 305, 981-984

under increased pressure, 622-625

of air in mines, 692-693,984, 1007 footnote 7

Oxygen lack, in air as cause of mountain sickness, $214,218,223,227,234,235,242$, $244,245,252-254,337,338$

Oxygen tension, effects of, on plants, 782$788,792-796,798$

importance of, $540,578-580,839,842,849-$ 851,980

in geological ages, 1034

in ocean depths, 1033-1034

resistance to, in various mammals, 549

\section{$\mathbf{P}$}

Pamir, plateau of, 129, 143, 157

Panum, Professor, respiration and circulation in compressed air, $435-437$

respiratory exchanges and rhythm in compressed air, 478-481

Papin, Denis, compressed air in divingbell, 358

(with Huyghens) death of animals in vacuum, 202

Parachute, first use in a balloon, 177 made wrong-side out, 184

Paralysis, from decompression, 373, 380 . $381,385,386,389,394,395,399,400,404$. $406,408,482,1011$

from sudden decompression, 883-885

Parrot, Dr., ascent of Ararat, 126

ascent of Kasbek, 123

ascent of Mont Blanc, 92

pulse rate in Pyrenees, 122

Pasteur, classification of fermentations, 799 Pasteurization, 830 research on microscopic organisms, 1023 verification of his experiments, 812

Payerne, cause of weariness at high altitudes, 240

submarine hydrostat, 357

Pepsin, experiments on, 837-838

Perspiration, increase of, in compressed air, 360,376

Petard, Dr., in ascent organized by Society of Aerial Navigation, 192

Physical constitution, as factor in mountain sickness, $319-320$ 
Piachaud, Dr., ascent of Mont Blanc, 108 causes of symptoms of mountain sickness, 284

Pissis, A., letter on effects of altitude, 56

Pitschner, ascent of Mont Blanc, 107

Plants, at low oxygen tension, 1006

as alleged cause of mountain sickness, $135,152,153,221,222,223$

artemisia, 295; flowers, 134; moss, 148 152. 294; onion, 295; primroses, polyanthus, heather, 132; rhubarb, 129

Pneumatic pump, early experiments with. 197

invention of, 196

Poeppig, Ed., denial of effect of decreased pressure, 226

symptoms of puna at Cerro de Pasco, 38

Poiseuille, effect of pressure changes on circulation, 445-446

Pol and Watelle, symptoms of laborers in compressed air, 362-367; cause of, 450-453

Polar Star, ascension of, 961-962

Polo. Marco, on plateau of Pamir, 128

Popocatepeti, ascent by Laverrière, 63 by Scientific Committee of Mexican Expedition, 65 ; by Virlet d'Aoust, 309; various ascents, 61

Pravaz, Dr. Ch., discussion of compressed air, use in surgery, 1029; use in therapeutics, 239, 415; underlying causes of benefist from, $447-450$

Pravaz, J., effects of moderate increased pressure, 1014-1017

Prevention of mountain sickness, 996-998

Priestley, first to breathe oxygen, 1027 theory of mountain sickness, 214

Przevalski, Capt., denial of Père Huc's theory of mountain sickness, 238

Psychological factors in mountain sickness. distraction of attention, 43, 142, 150, 288$289,292,957$

fear, 92

Pulmonary tuberculosis, "height cure" for. 960,1006

on Pacific coast (Andes), 255

"Pundits," The, in Himalayas, 155

Putrefaction, experiments on, $800-820$ effect of high oxygen tension on, 926

Pyrenees, ascents in, 120-123 individual peaks, 9

\section{R}

Rabbits, experiments on, diminished pressure, 198; temperature and oxygen consumption, 219

Radde, ascent in Armenia, 127; ascent of Elbrouz, 124

Rameau, Professor, see Bucquoy

Ramond, ascent of Mont Perdu, 121

Rebmann, reference to Kilimandjaro, 161 Recompression, to relieve symptoms of decompression, 894-895, 1032

Rectal temperature, in mountain ascent, 959

Regnauld, report of caisson explosion, 371

Remedies of natives for mountain sickness, $34,47,49,55$; apricots, 145,157 : dry fruit, 156,157 ; garlic, $34,47,49,50$. 55; plums, 157

Rémy, J., ascent of Pichincha and Chimborazo, 58

Research, Bert's plan of, 505-506, rejection of unnecessary refinements in, 512

Respiration, in carbon dioxide poisoning, 920-921

in compressed air, 360,490

amplitude, 395

capacity, 372, 374, 376, 395

rate, $372,388,395,396$

rhythm, 396, 454

in rarefied air

in the Engadine, 297

in Thibet, 295 on Mexican plateaux, 261-262, 265, 269

Vivenot's experimerits, 280-281

Respiratory difficulties from decompression, 363, 366

Rey, Dr., explanation of mountain sickness, 231

Riche, ascent of Peak of Teneriffe, 75

Riedesel, ascent of Etna, 70

Risler and Schutzenberger, release of oxygen of blood, 658

Robert, balloon ascension with Charles, 171

Robertson, ascension from Hamburg, 175 second ascension, 179

comments on report of Biot and GayLussac, 180

details of symptoms in Hamburg ascension, 183

Robertson; Capt., ascent of Sumeru-Parbut, 147

Robertson, Eugène, ascension from Mexico. 183

ascension from New York, 183

Rocky Mountains, individual peaks, 14

Rostan, blood gases in symptoms of decompression, 225

Roulin, observations on pulse rate on mountains, 224

du Rozier, Pilatre, first aeronaut, 171

Russell, Count Henry, discussion of mountain sickness, 119

Russell-Killough, Count, effect of snow in mountain sickness, 294

reports of ascents of Néthou, 122

\section{S}

de Saint-Cricq, attack of soroche, 49

Saint-Lager, see Hervier

Saint-Pierre, see Estor and Saint-Pierre

Saliva, experiments on, 835-837

Sampadarios, Dr., pathological observations on divers, $405-410$

Sandahl, Dr., physiological effects of compressed air, 416

theory of effects, $466-467$

de Saussure, ascent of Buet, 79; of Mont Blanc, 80; of Mont Cenis, 85

discussion of cause of mountain sickness. 213

exceptional symptoms of mountain sickness, 251

experiment on oxygen content of snow. 227

observation of variations of magnetic power, 179

physiological observations on the Col du Géant, 86

refutation of theory of Bouguer, 216

theory of fatigue in mountain sickness. 347

de Sayve, A., ascent of Etna, 72

Schlagintweit brothers, summary of their highest ascents, 154-155

Schmidtmeyer, on Pass of Cumbre, 35

Schutzenberger, see Risler

Scorpion's venom, experiments on, 845-846

Scoutetten effect of altitude on physiological functions, 276

Secretions, changes in, in compressed air $360,397,455,491,1011$

Seeds, Bert's experiments on, at high carbon dioxide tension, 925-926

at high oxygen tension, 784-785, 793-796 at low oxygen tension, 784,792

germination under decreased pressure, $782-783,786$

germination under increased pressure 443, 789-791

Beale's experiment on lettuce seeds, 203

Boyle's suggestion of experiment, 203

Semenof, mountain sickness in Celestial Mountains, 153

Sensitive plants, as a "reagent," 781

effect of pressure on, 
d e c r e a s ed, experiments, 787-788, Boyle's suggestion of experiment, 203 increased, 797

Sensitivity, loss of, from decompression. $372,402,406$

"Sheep" (moutons), 377; explanation of. 886

Sherwill, Capt, ascent of Mont Blanc, 91

Shifts, length of, in compressed air, 362 $372,377,386,388,389,394,487,493$

Sievers, ascent in Armenia, 127

Silkworm cocoons, Bert's experiments on $684-685,752,776$; Boyle's suggestion of experiment on, 203

Simonoff, Dr. Leonid, medical effects of compressed air, 1020

Simons, balloon ascension with the "Flying Man," 193

Sivel, balloon ascension in Polar Star, 961962

effects of rarefied air on, 673

experience in decompression chamber 700-703

fatal ascension in Zenith, 963-969

funeral eulogy of, 971-974

in ascension organized by Society of Aerial Navigation, 192-193

Sjogrun, ascent of Kasbek, 124

Smell, sense of, weakened in compressed air, 375,492

Smith, Dr. Archibald, notes on mountain sickness in Peru, 44

symptoms and causes of mountain sickness, 233

Smyth, mountain sickness, 44

Snow, as cause of mountain sickness, 226 , 294,338

line of perpetual snow in relation to mountain sickness, 318

Soldan, Mateo Paz, description of soroche. 53

Spalding, improvements in diving-bell, 355

Spallanzani, ascent of Etna, 71

Speer, nature and causes of mountain sickness, 241

Spitaler, ascent of Venediger, 97

Stoliczka, Dr., fatal attack on Karakorum, 974-976

Strobel, Pellegrino, free from effects of soroche, 55

Studer, Gottlieb, ascent of the Jungfrau, 97

Steubel, ascent of Cotopaxi, 59

Sturmius, invention of diving-bell, 355

Submarines, early types of, $357-358$

Symptoms, due to decompression, 540, 983 cerebral disturbances, 363-366, 372-373, $377,379,381,402,406,492$; theories about $457,465,466$

circulation, 669-672

digestion, 672-673

lower pressure limit of appearance of. 685

means of averting, 694-708

nervous and muscular effects, 673-675

nutrition 675-685; body temperature, 683-684; development, 684-685; respiratory exchanges, 675-678; sugar in liver. blood, and urine, 681; urinary excretion, 678-681

post mortem; rigor mortis, 688; shown at autopsy, $687-688$

respiration, 666-669

Symptoms, of mountain sickness, 241-242 circulation, 329-331

digestion, 328

innervation, $332-333$

locomotion and exertion, 331-332 secretions, 329

Symptoms, of oxygen poisoning blood sugar, 749

convulsions, $740-743$

diminution of oxidations, 743

excretion of urea, 748-749

pulmonary exchanges, $744-748$

\section{T}

Tabarie, Dr., therapeutic effects of compressed air, 415

Tardieu, physiological effects of rarefied air, 270

Taste, sense of, weakened in compressed air, 375,492

Temple, Ed., soroche at Potosi, 36

Teneriffe, Peak of, ascents of, 73-77 mountain sickness on, 196

Testu-Brissy, balloon ascension with horse, 173

Therapeutics, use of diminished pressure in, 220, 228, 1007 use of increased pressure in, 239, 1005

Thomas, Prof. L., effect of ascent on body temperature, 959

Thomson, R. F., ascent of Demavend, 128

Thomson, Taylor, ascent of Demavend, 128

Thomson, Dr. Th., passes of Parang and Karakorum, 145

Thoracic capacity, see chest capacity

Thorpe, buccal temperature in ascent, 957

Time of appearance of symptoms due to decompression, 361-364, 493, 1011

Tissandier, Albert, ascent of Mont Blanc. 115

Tissandier, Gaston, report of ascension of Zenith with Sivel and Crocé-Spinelli, 963-969

Tissues, experiments on,

carbon dioxide accumulation in, 911-913

lethal concentration of carbon dioxide in, 914

putrefaction of, in high carbon dioxide tension, 926-927

Torrente, symptoms and cause of mountain sickness, 33

Torricelli, early experiments of, 197 invention of barometer, 196

de la Touanne, discussion of mountain sickness, 36

Tournefort, ascent of Ararat, 126

Training, effect of lack of, in mountain sickness, 292, 293, 294, 324-325, 327

result of, in mountain climbing, 956, 996

Triger, invention of industrial compressed air apparatus, 358

memoir on caisson accidents, 384

physiological effects of compressed air, 359-360

Trouessart, report on Triger apparatus, 359

von Tschudi, J. J., explanation of weariness of legs in ascent, 232 description of the Veta, 45

Truqui, ascent of Popocatepetl, 63

Tuckett, ascent of Grivola, 116

Turner, Samuel, in Thibet, 130

Tutschek, physiological effects of compressed air, 417

theory of action of compressed air, 467

Tyndall first ascent of Mont Blanc, 106 second ascent, 107 importance of food in ascents, 293

\section{U}

Ulloa, discussion of cause of mountain sickness, 209

symptoms caused by mountain air, 210 symptoms of the Mareo, 28

Urbain, see Mathieu

Urea, production of in compressed air (1 to $5 \mathrm{~atm}$.), 748-749, 764-765

in rarefied air, 983 effect of diet on, 1025

thesis of Pravaz on, 1015-1016

Urination effect of decompression on, 373 , $380,387,389,399,401,406$

Urine, Bert's experiments on, 823-825

carbon dioxide content of, 914

secretion of, in compressed air, 364, 385 . 397 
d'Urville, Dumont, ascent of Peak of Teneriffe, 75

\section{V}

Vaccine virus, Bert's experiments on, 846 Vacher, Dr., effect of moderate altitude on pulse and respiration, 960-961

Valentin, unimportance of changes in pressure, 244

Van Rensselaer, ascent of Mont Blanc, 89

Venom, scorpion's, Bert's experiments on, 845-846

Veratti, experiments of, 204

study of asphyxia in closed vessels, 205

Vibriones, tenacity of life in, 1035

Vierordt, effect of decompression on respiration, 236

Vincent, ascent of Monte Rosa, 93

Viruses, Bert's experiments on, 846-848 Anthrax, 847-848

Glanders, 847

Vaccine, 846-847

Visconti, ascent of Monte Rosa, 117

"Vital force," 444

von Vivenot, Rudolph, research on circulation and respiration

circulation in compressed air, 423-432

experiment on circulation, 474-475

respiration in compressed air, 418-423

respiration in rarefied air, 280

respiratory exchanges in compressed air. 467-474

summary of physiological effects in compressed air, 432-435

Vogt, A., effect of altitude on respiration. 237

Voice, changes in, under increased pressure, $359-361,370,375,387,490$

\section{W}

Wafer, on the Isthmus of Darien, 59

Ward, Dr., acclimatization in high altitudes, 960

Watelle, see Pol

Webb, Capt., experiences in Himalayas, 134

Weddell, ascent of Arequipa, 48

soroche in La Paz, 50

Weight of air sustained by body, decrease of, in rarefied air, 276, 340-342

increase of in compressed air, 453,494

Welsh, J., balloon ascension for scientific purposes, 186

Whistling, in compressed air, 359-362, 375 . 490

in rarefied air, 698-699, 704-707

Wilkes, ascents of Mauna Loa, Hawaii, 164

Williamson, ascent of Mount Hood, Oregon, 69

Wind, effect of, in mountain sickness, 335

Wine, Bert's experiments on, 827-831

Wisse, on Rucu-Pichincha, 57

Women mountain climbers, 75, 88, 96, 115 , 122,147

Wood, Lieut. J., on plateau of Pamir, 143

\section{Y}

Yaks, effect of high altitude on, 134

Yeast, brewers, Bert's experiments on, 826

inversive ferment of, experiments on. 838

\section{$\mathbf{Z}$}

Zambeccari, Count Fr., balloon ascension at Bologna, 178

Zenith, ascension of, 963-971

Zumstein, ascent of Monte Rosa, 93 

VARINE BIOLOGICAL LABOPATORY LIV RARY W000S HDOLE, MAASS. W. B. O. I. 


